\title{
Breast Cancer Research and Treatment
}

CONTENTS VOL. 94, Supplement 1, December 2005

\section{Special issue}

$2^{\text {th }}$ Annual SAN ANTONIO BREAST CANCER SYMPOSIUM -

December 8-11, 2005

Program

Invited Abstracts

S1-S4

Abstracts

General Sessions [\#1-43]

$\mathrm{S} 5-\mathrm{S} 21$

Poster Discussion Sessions [\#101-410]

S22-S38

Poster Session I [\#1001-1121]

S39-S82

Poster Session II [\#2001-2113]

S83-S123

Poster Session III [\#3001-3113]

$\mathrm{S} 124-\mathrm{S} 164$

Poster Session IV [\#4001-4113]

S165-S204

Poster Session V [\#5001-5114]

S205-S247

Poster Session VI [\#6001-6111]

S248-S287

Author index for abstracts

S288-S301

\section{Available}

online 
Photocopying. In the U.S.A.: This journal is registered at the Copyright Clearance Center, Inc., 222 Rosewood Drive, Danvers, MA 01923, U.S.A.

Authorization to photocopy items for internal or personal use, or the internal or personal use of specific clients, is granted by Springer for users registered with the Copyright Clearance Center (CCC). The "services" for users can be found on the internet at: www.copyright.com

For those organizations that have been granted a photocopy licence, a system of payment has been arranged. Authorization does not extend to other kinds of copying, such as that for general distribution, for advertising or promotional purposes, for creating new collective works, or for resale.

In the rest of the world: Permission to photocopy must be obtained from the copyright owner. Please apply to Springer, P.O. Box 17, 3300 AA Dordrecht, The Netherlands.

Breast Cancer Research and Treatment is published monthly plus 1 additional issue in January, March, May, July, September and November (Volumes 89-94, 3 issues each, 2005).

Periodicals postage paid at Rahway, N.J. USPS No. 663-130.

U.S. Mailing Agent: Mercury Airfreight International Ltd., 365 Blair Road, Avenel, NJ 07001.

Published by Springer, P.O. Box 17, 3300 AA Dordrecht, The Netherlands, and 101 Philip Drive, Norwell, MA 02061, U.S.A. Postmaster: Please send all address corrections to: Breast Cancer Research and Treatment c/o Mercury Airfreight International Ltd., 365 Blair Road, Avenel, NJ 07001, U.S.A. 


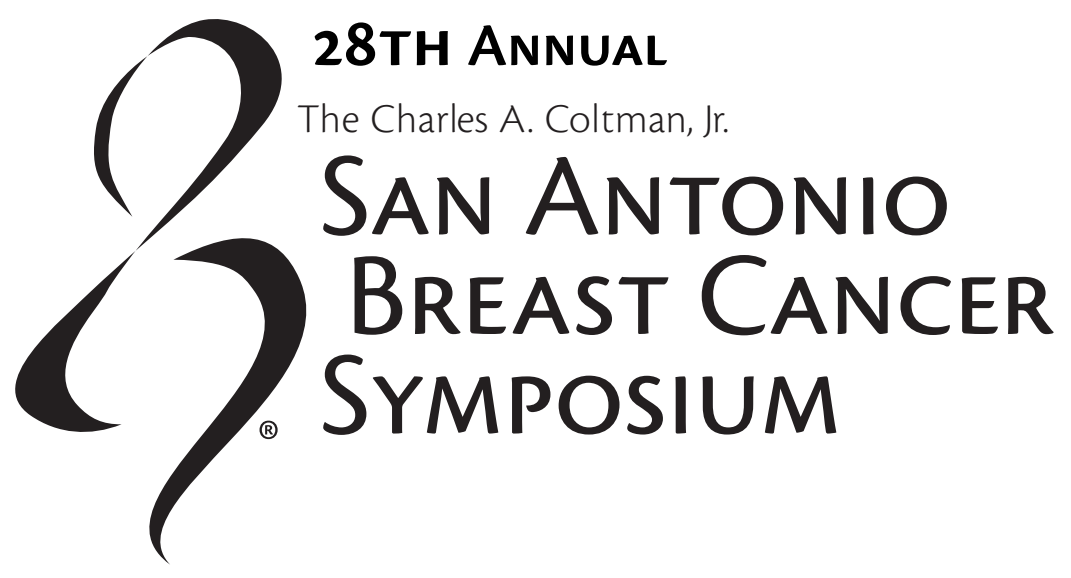

DeCEMBER 8-11 2005

Henry B. Gonzalez Convention Center

200 E. Market Street, San Antonio, Tx 78205

\section{SPONSORS}

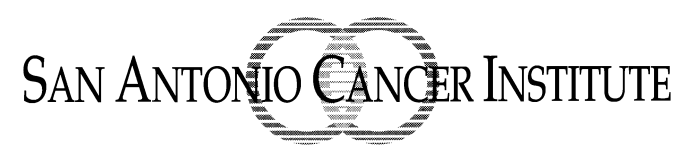

and

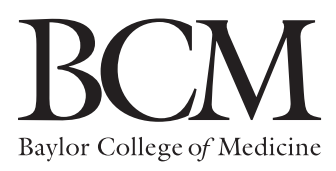

an $\mathrm{NCl}$-designated Clinical Cancer Center

a partnership of

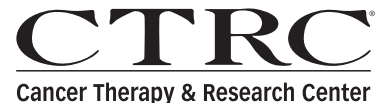

\&




Industry And Agency Support (at press time)

Angel Plus

AstraZeneca

Eli Lilly and Company

Genentech, Inc.

Pfizer Oncology

Roche

Sanofi-Aventis Pharmaceutical

\section{ANGel}

Abraxis Oncology

Bristol-Myers Squibb

Genomic Health, Inc.

GlaxoSmithKline

Novartis

Major Supporter Plus

Amgen

Veridex, LLC

\section{MAJOR SUPPORTER}

Ortho Biotech Products, LP

Sysmex

Xoft, Inc.

\section{CONTRIBUTORS}

Abbott Molecular

Allos Therapeutics, Inc.

Bayer Pharmaceutical Corp./Onyx Pharmaceutical, Inc. Biomedical Systems

Cancer Consultants, Inc. Carl Zeiss Surgical

Ciphergen Biosystems, Inc.

Clarient, Inc.

Clinical Care Options

Cytyc Surgical Products DakoCytomation

DOBI Medical International, Inc.

Genaissance Pharmaceuticals

Genzyme

GTx, Inc.

HistoRx, Inc.

Infrared Sciences Corp.

Medical Tactile, Inc.

Merck Human Health

Merck Research Laboratories

MGI Pharma, Inc.

Molecular Profiling Institute

Myriad Genetic Laboratories, Inc.

National Comprehensive Cancer Care Network (NCCN)

PSI Pharma Support International

Quest Diagnostics

RadPharm

RITA Medical Systems

Sanarus Medical, Inc. Senorx

Sicel Technologies

Sopherion Therapeutics

Tripath Imaging, Inc. US Labs
Ventana Medical Systems, Inc.

Vision BioSystems

\section{DONORS}

Adjuvant, Inc.

AlphaMed Press

American Diagnostica, Inc.

American Society of Clinical Oncology (ASCO)

Aurora Imaging Technology, Inc.

Bio Imagene

Cambridge University Press

Care Wise Medical Products CIRG/TORI

Elsevier (Saunders, Mosby, Churchill)

Faxitron X-Ray Corporation

IMPAC Medical Systems, Inc.

Impedimed, Inc.

Intarcia

Jones and Barlett Publishers

Lippincott Williams \& Wilkins

Men Against Breast Cancer

Oncology Group

Oncology Nursing Society

Physicians' Education Resource/Cancer Information Group PMT/PERMARK

Taylor \& Francis Group

University of Florida Jacksonville Healthcare, Inc.

Varian BrachyTherapy

Conference Grants

American Cancer Society, Texas Division

\section{Future Symposium \\ Meeting Dates}

\author{
29th Annual SABCS \\ December 14-17, 2006 \\ (Thursday-Sunday) \\ 30th Annual SABCS \\ December 13-16, 2007 \\ (Thursday-Sunday) \\ 31st Annual SABCS \\ December 11-14, 2008 \\ (Thursday-Sunday) \\ 32nd Annual SABCS \\ December 10-13, 2009 \\ (Thursday-Sunday)
}


28TH ANNUAL

SAN AnTONio

BREAST CANCER

SYMPOSIUM

\section{Program Schedule}

Room Locations

Exhibit Halls A, B, C \& D,

Ballrooms A \& B: Street Level

Bridge Hall: Street Level

\section{WeDnesdaY, DeCEMBER 7, 2005}

Pre-registered attendees can obtain materials. Those who

have not yet registered may do so.

\section{THURSDAY, DECEMBER 8}

9:00-9:15

WELCOME - Exhibit Hall D

Opening Remarks

C. Kent Osborne, MD

Charles A. Coltman, Jr., MD

9:15-9:45

PLENARY LECTURE 1 - Exhibit Hall D

Treatment guidelines for breast cancer adjuvant therapy: take home messages for clinical practice Martine J. Piccart-Gebhart, MD, PhD

Jules Bordet Institute

Brussels, BELGIUM

\section{9:45-11:00 GENERAL SESSION 1 - Exhibit Hall D}

1. Phase III randomized trial comparing doxorubicin and cyclophosphamide followed by docetaxel

$(\mathrm{AC} \rightarrow \mathrm{T})$ with doxorubicin and cyclophosphamide followed by docetaxel and trastuzumab $(\mathrm{AC} \rightarrow \mathrm{TH})$ with docetaxel, carboplatin and trastuzumab (TCH) in HER2 positive early breast cancer patients: BCIRG 006 study.

Slamon D, Eiermann W, Robert N, Pienkowski T, Martin M, Pawlicki M, Chan M, Smylie M, Liu M, Falkson C, Pinter T, Fornander T, Shiftan T, Valero V, Mackey J, Tabah-Fisch I, Buyse $M$, Lindsay MA, Riva A, Bee $V$, Pegram $M$, Press $M$, Crown J. UCLA, Los Angeles, CA; GBG, Munchen, Germany; US Oncology, Dallas, TX; Maria Sklodowska-Curie (MSC) Centre, Warsaw, Poland; GEICAM, Madrid, Spain; MSC Institute, Krakow, Poland; Mount Hospital, Perth, Australia; Cross Cancer Institute, Edmonton, Canada; Sun Yat-Sen Cancer Center, Taipei, Taiwan; University of Alabama, Birmingham, AL; Petz Aladar County, Gyor, Hungary; OnkologyKliniken, Stockholm, Sweden; Sharp Healthcare, San Diego, CA; MD Anderson Cancer Center, Houston, TX; Sanofi-Aventis, Paris, France; IDDI, Brussels, Belgium; CIRG, Paris, France; USC, Los Angeles, CA; ICORG, Dublin, Ireland.
A randomized phase III trial of paclitaxel versus paclitaxel plus bevacizumab as first-line therapy for locally recurrent or metastatic breast cancer: a trial coordinated by the Eastern Cooperative Oncology Group (E2100).

Miller KD, Wang M, Gralow J, Dickler M, Cobleigh MA, Perez EA, Shenkier TN, Davidson NE. Indiana University Cancer Center, Indianapolis, IN; Dana Farber Cancer Institute; Pudget Sound Oncology Consortium; Memorial Sloan Kettering Cancer Center; Rush University Medical Center; Mayo Clinic; Vancouver Cancer Center; Johns Hopkins Oncology Center.

4. Metronomic chemotherapy with and without bevacizumab for advanced breast cancer: a randomized phase II study.

Burstein HJ, Spigel D, Kindsvogel K, Parker LM, Bunnell CA Partridge AH, Come SE, Ryan PD, Gelman R, Winer EP. Dana-Farber / Harvard Cancer Center, Boston, MA; Sarah Cannon Cancer Center, Nashville, TN.

10:45 46. Trastuzumab sensitivity of breast cancer with coamplification of HER2 and CMYC suggests proapoptotic function of dysregulated $\mathrm{cMYC}$ in vivo. Kim C, Bryant J, Horne Z, Geyer CE, Wickerham DL, Wolmark N, Paik S. NSABP Operations and Biostatistical Center, Pittsburgh, PA.

11:00-12:30 MINI-SYMPOSIUM 1 - Exhibit Hall D

NANOTECHNOLOGY: NEW STRATEGIES FOR BREAST CANCER IMAGING AND TREATMENT

C. Kent Osborne, MD, Moderator

Baylor College of Medicine,

Houston, TX

11:00 Introduction

11:00 Nanotechnology in terms of biomedical applications in cancer and opportunities for funding Mauro Ferrari, PhD

Ohio State University

Columbus, $\mathrm{OH}$

11:30 Diagnostic and therapeutic applications of nanotechnology

Jennifer West, PhD

Rice University

Houston, TX

12:00 New carbon nanostructures for imaging and therapy of breast cancer

Lon J. Wilson, PhD

Rice University

Houston, TX

12:30-1:30 LUNCH [Ticket Required] - Exhibit Hall A

1:30-3:30

GENERAL SESSION 2 - Exhibit Hall D

5. Meta- and pooled analysis of the prognostic value of bone marrow micrometastasis on disease outcome in 4,703 breast cancer patients: final results after 10 years of follow-up.

Braun S, Vogl FD, Pantel K, Collaborative Group Bone Marrow Micrometastasis. Innsbruck Medical University, Insbruck; City Hospital, Meran; Inst. Tumorbiology, Epppendorf University, Hamburg, Germany. 
7. Radiotherapy in breast-conserving treatment for ductal carcinoma in situ (DCIS): ten-year results of European organization for research and treatment of cancer (EORTC) randomized trial 10853.

Bijker N, Meijnen PH, Bogaerts J, Peterse JL, on Behalf of the EORTC Breast Cancer Group \& Radiotherapy Group. The Netherlands Cancer Institute, Amsterdam, Netherlands; EORTC, Brussels, Belgium.

8. Breast conservation without radiotherapy in low risk breast cancer patients - results of 2 prospective clinical trials of the Austrian Breast and Colorectal Cancer Study Group involving 1,518 postmenopausal patients with endocrine responsive breast cancer. Gnant MFX, Poetter R, Kwasny W, Tausch C, Handl-Zeller E, Pakesch B, Schmid M, Hausmaninger H, Stierer M, Kubista E, Sedlmayer F, Draxler W, Luschin-Ebengreuth G, Jakesz R, Austrian Breast and Colorectal Cancer Study Group. Medical Universities of Vienna, Graz, Salzburg, and Innsbruck, Vienna, Austria. pathway preserves and enhances the expression of the estrogen receptor (ER) in HER- 2/neu (HER2) overexpressing human breast tumors and xenografts. Rimawi MF, Mohsin SK, Gutierrez MC, Arpino G, Massarweh SA, Chang JC, Osborne CK, Schiff R. Baylor College of Medicine, Houston, TX; King Hussein Cancer Center, Amman, Jordan

10. PC-cell derived growth factor (PCDGF/GP88, progranulin) stimulates Her-2 phosphorylation and confers herceptin resistance to Her- 2 overexpressing breast cancer cells.

Kim W, Serrero G. University of Maryland School of Pharmacy, Baltimore, MD; A\&G Pharmaceutical Inc., Columbia, MD; University of Maryland, Baltimore, MD.

11. Trastuzumab (H: Herceptin $\left.{ }^{\circledR}\right)$ following adjuvant chemotherapy (CT) significantly improves diseasefree survival (DFS) in early breast cancer (BC) with HER2 overexpression: the HERA Trial.

The HERA Study Team.

3:15 12. Surgical biopsy to diagnose breast cancer adversely affects outcomes of breast cancer care: finding from the National Comprehensive Cancer Network.

Edge SB, Ottesen RA, Lepisto EM, Niland JC, Theriault RL, Bookman MA, Weeks JC. Roswell Park Cancer Institute, Buffalo, NY; City of Hope National Medical Center, Duarte, CA; National Comprehensive Cancer Network, Jenkintown, PA; MD Anderson Cancer Center, Houston, TX; Fox Chase Cancer Center, Philadelphia, PA; Dana Farber Cancer Institute, Boston, MA FOR SCIENTIFIC DISTINCTION LECTURES Exhibit Hall D

4:40-6:40

POSTER SESSION 1 \& RECEPTION Exhibit Hall B

(\#1001-1121)

Detection / Diagnosis: Axillary and Sentinel Nodes

1001 Novel molecular diagnostic method for rapid evaluation of lymph node metastasis in breast cancer. Matsuura N, Tsujimoto M, Nakabayashi K, Daitho M, Ding J, Sonoda R, Kajita M, Otomo Y. Osaka University Graduate School of Medicine and Health Science, Suita, Osaka, Japan; Osaka Police Hospital, Osaka, Japan; Sysmex Corporation, Kobe, Hyogo, Japan.

1002 The combination of frozen section and enhanced polymer one-step staining immunohistochemistry for the intraoprative diagnosis of sentinel nodes of breast cancer.

Wang YS, Yu JM, Liu YB, Wang L, Zhao T, Li JY. Shandong Cancer Hospital, Shandong University, Jinan, Shandong, China.

1003 Comparative study of lymphedema with axillary node dissection and axillary sampling with radiotherapy in women undergoing breast conservation surgery for breast cancer.

Mathew J, Barthelmes L, Neminathan S, Crawford D. Ysbyty Gwynedd, Bangor, Gwynedd, United Kingdom.

1004 Timing of sentinel node biopsy for patients undergoing mastectomy with immediate reconstruction.

McGuire KP, Rosenberg A, Copit S. Thomas Jefferson University, Philidelphia, PA

1005 Does a negative lymphoscintigram predict for sentinel lymph node positivity.

Soran A, Balkan M, Falk J, Keenan D, Bonaventura M, Johnson R. Magee-Womens Hospital of the University of Pittsburgh Medical Center, Pittsburgh, PA.

1006 Sonographic evaluation of axillary lymph nodes using realtime sonoelastography.

Wojcinski S, Maltaris T, Dupont J, Ertan AK, Schmidt W. University of Saarland, Homburg/Saar, Germany.

Analysis of sentinel lymph node biopsy in breast cancer patients after neoadjuvant chemotherapy. Jinno H, Ikeda T, Kitajima M, Fujii H, Mukai M. Keio University School of Medicine, Shinjuku, Tokyo, Japan.

1008 Sentinel lymph node biopsy for breast cancer patients with clinically negative axillary lymph nodes after neoadjuvant chemotherapy.

Kinoshita T, Fukutomi T, Akashi-Tanaka S, Terada K, Takasugi M, Shimizu C, Ando M, Katsumata N, Fujiwara Y. National Cancer Center Hospital, Tokyo, Japan.

1009 The incidence of axillary nodal metastases in older women with small non-high grade breast tumours. Querci della Rovere G, Bonomi R, Ashley S, Benson JR. The Royal Marsden Hospital, Sutton, Surrey, United Kingdom; Addenbrookes Hospital, Cambridge, Cambridgeshire, United Kingdom.

1010 A standardized surgical technique for mastoscopic axillary lymph node dissection. Chengyu L, Yongqiao Z, Hua L, Xiaoxin J, Chen G, Jing L, Jian Z. Affiliated Beijing Fuxing Hospital, Capital University of Medical Science, Beijing, China. 
Intra-operative sentinel lymh node assessment of 193 patients with invasive breast carcinoma: does sentinel lymph node intraoperative examination reduce the complementary axillary lymph node dissection ? Loussouarn D, Dupre PF, Sagan C, Dravet F, Toquet C, Pioud R, Francois T, Curtet C, Classe JM. CHU Laennec, Nantes Saint Herblain, France; CRLCC R Gauducheau, Nantes Saint Herblain, France.

Detection / Diagnosis: Biopsy Techniques

1012 Optical assessment of axillary lymph nodes in breast carcinoma.

Smith J, Kendall C, Christie-Brown J, Sammon A, Barr H, Stone N. Gloucestershire Hospitals NHS Trust, Gloucester, Gloucestershire, United Kingdom.

1013

Clip migration after 11G vacuum-assisted breast biopsy: retrospective review of 447 clips and implication in breast surgery.

Chaveron C, Bachelle F, Ceugnart J, Giard S, Baranzelli MC, Belkaccmi Y, Bonneterre J. Centre Oscar Lambret, Lille, France.

1014 Optical biopsy: breast cancer diagnoses at the speed of light.

Chicken DW, Clarke BR, Johnson KS, Lee AC, Briggs G, Pickard CDO, Falzon M, Novelli M, Bigio IJ, Bown SG, Keshtgar MRS. University College London, London, United Kingdom; Boston University, Boston, MA.

Detection / Diagnosis: Marrow and Blood Micrometastases

1015

Serum EGFR and HER-2 expression in primary and metastatic breast cancer patients.

Asgeirsson KS, Allen C, Hitch A, Chapman C, Cheung KL, Robertson JFR. University of Nottingham, Nottingham, United Kingdom.

1016

Persistence of isolated tumor cells (ITC) in bone marrow (BM) of breast cancer patients predicts increased risk for relapse - results of pooled European data.

Janni W, Wiedswang G, Borgen E, Braun S, Rack B, Schindlbeck C, Sommer H, Pantel K, Heinrigs M, Gerber B Nesland JM, Scholz C, Friese K, Jeschke U, Naume B. LMU, Munich, Germany; Medizinische Universtitaet, Innsbruck, Austria; Insitut fuer Tumorbiologie, UKE, Hamburg, Germany; Radium Hospitalet, Oslo, Norway; University of Rostock, Rostock, Germany; Ullevaal University Hospital, Oslo, Norway.

1017 Molecular profiling of disseminated tumor cells in peripheral blood of breast cancer patients.

Kaul S, Fersis N, Rom J, Zieglschmid V, Hollmann C, Boecher O, Schneeweiss A, Sohn C. University of Heidelberg, Heidelberg, Baden-Wuerttemberg, Germany; AdnaGen AG, Hannover-Langenhagen, Niedersachsen, Germany.

1018 Monitoring circulating breast cancer cells by quantitative real time RT-PCR.

Palomares MR, Schuster GT, Thomas A, Koehler KM, Gralow JR, Sabath DE. City of Hope National Medical Center, Duarte, CA; Seattle Cancer Care Alliance, Seattle, WA; University of Washington School of Medicine, Seattle, WA.

Peri-operative assessment of circulating tumor cells in blood, disseminated tumor cells in bone marrow, and tissue gene signatures in patients with primary breast cancer.

Frazier TG, Flynn M, Sieling BA, Herman M, Rao CS, Gross S, Miller MC, Doyle GV, Terstappen LW. Bryn Mawr Hospital, Bryn Mawr, PA; Immunicon, Huntingdon Valley, PA.
Detection of circulating tumor cells in peripheral blood and bone marrow by quantitative RT-PCR assay for cytokeratin-7 mRNA in breast cancer patients. Kataoka A, Masuda T, Ohno S, Inoue H, Yamaguchi H, Uchida Y, Mimori K, Mori M. National Kyushu Cancer Center, Fukuoka, Japan; Saiseikai Yahata General Hospital, Kitakyushu, Fukuoka, Japan; Medical Institute of Bioregulation, Kyushu University, Beppu, Oita, Japan.

1021

Detection and monitoring of circulating tumor cells (CTCs) by CK-19 mRNA in breast cancer patients treated with neoadjuvant chemotherapy: a marker of early recurrence.

Harris LN, Solomon N, Roberts L, Ngo T, Abi Raad R, Gioioso C, Kuter I, Smith B, Iglehart JD, Friedman P, Taghian A. Dana Farber Cancer Institute, Boston, MA; Abbott Laboratories, Abbott Park, IL; Massachusetts General Hospital, Boston, MA.

1022 Isolation and gene expression profiling of bone marrow disseminated tumor cells from women with locally advanced breast cancer.

Aft RL, Ylagan L, Fleming T, Weilbaecher K, Naughton M, Watson M. Washington University, St. Louis, MO.

Prognosis and Prediction: Predictive Factors

1023

Prospective central assessment of HER-2 status by FISH is not a predictive factor for pathologic complete response ( $p C R$ ) in $\mathbf{6 4 8}$ breast cancer patients treated preoperatively with an anthracycline / taxane based regimen in the multicenter GeparTrio Trial.

Loibl S, Blohmer JU, Raab G, Steffen J, Kaufmann M, Löhr A, Gerber B, Heinrich G, Eidtmann H, Hilfrich J, Jackisch C, Costa SD, Huober J, Bühler H, von Minckwitz G. J.W.GoetheUniversity, Frankfurt, Germany; St. Gertrauden Hospital, Berlin, Germany; Marienhospital, Stuttgart, Germany; German Breast Group, Neu-Isenburg, Germany; HorstSchmidt Kliniken, Wiesbaden, Germany; University Womens Hopsital, Rostock, Germany; Gynäkologische Schwerpunktpraxis, Fürstenwalde, Germany; University Womens Hopsital, Kiel, Germany; Henriettenstift, Hannover, Germany; University Hospital, Marburg, Germany; University Womens Hospital, Magdeburg, Germany; University Womens Hopsital, Tübingen, Germany; RuhrUniversity, Bochum, Germany.

1024 Estrogen receptor genotypes predict the response of serum cholesterol to tamoxifen treatment. Ntukidem NI, Schott A, Skaar T, Jin Y, Li L, Lemler S, Nguyen A, Hayden J, Desta Z, Flockhart DA, Hayes DF. Indiana University, Indianapolis, IN; University of Michigan, Ann Arbor, MI.

1027 Inhibin A and B as predictive markers for chemotherapy-induced premature ovarian failure (POF) among premenopausal women with early stage breast cancer (ESBC).

Anders CK, Snyder SA, Barrier RC, Demark-Wahnefried W, Welch RA, Marcom PK, Shaw HS, Chui SY, Blackwell KL. Duke University, Durham, NC.

1028 TWIST2 gene expression predicts for chemosensitivity in patients from two randomized trials of adjuvant FAC/FEC.

Tomasic G, Scott V, Conforti R, Michiels S, Andre F, Ahomadegbe JC, Koscielny S, Spielmann M, Saghatchian d'Assignies M, Garbay JR, Feunteun J, Lazar V, Vassal G, Tursz T, Arriagada R, Delaloge S. Institut Gustave Roussy, Villejuif, France. 
Molecular determinants of aromatase inhibitor sensitivity in primary breast cancer.

Mackay A, Urruticoechea A, Dexter T, Iravani M, Fenwick K, Young O, Miller WR, Evans DB, Dixon M, Ashworth A, Dowsett M. The Breakthrough Toby Robins Breast Cancer Research Centre, London; Royal Marsden Hospital, London; Western General Hospital, Edinburgh, United Kingdom; Novartis Pharma AG, Basel, Switzerland.

Simultaneous and quantitative detection of multiple biomarkers in human breast cancers using semiconductor multicolor quantum dots. Yezhelyev M, Morris C, Gao X, Marcus A, O'Regan RM. Winship Cancer Institute, Emory University, Atlanta, GA

Role of hypoxia-inducible factor 1 in predicting treatment efficacy in primary chemo-endocrine therapy in human breast cancer.

Fox SB, Bottini A, Generali D, Bonardi S, Wigfield S, Brizzi MP, Campo L, Milani M, Allevi G, Berruti A, Dogliotti L, Harris AL. Institute of Molecular Medicine, University of Oxford, John Radcliffe Hospital, Oxford, UK; Azienda Istituti Ospitalieri, Cremona, Italy; University of Turin, Orbassano, Torino, Italy.

Elevated plasma TIMP-1 level predicts decreased response and survival in metastatic breast cancer. Lipton A, Ali SM, Leitzel K, Demers L, Evans DB, Hamer P, Brown-Shimer S, Pierce K, Carney W. Penn State/Hershey Medical Center, Hershey, PA; Lebanon VA Medical Center, Lebanon, PA; Novartis Pharma AG, Basel, Switzerland; Oncogene Science/Bayer HealthCare, Cambridge, MA

High tumor tissue levels of tissue inhibitor of metalloproteinases- 1 are associated with resistance to chemotherapy in patients with metastatic breast cancer.

Wurtz SO, Schrohl AS, Meijer-van Gelder ME, Romer MU, Sorensen NM, Holten-Andersen MN, Christensen IJ, Look MP, Mouridsen HT, Lademann U, Brunner N, Foekens JA. The Royal Veterinary and Agricultural University, Frederiksberg C, Denmark; Josephine Nefkens Institute, Erasmus MC, Rotterdam, Netherlands; Hvidovre Hospital, Hvidovre, Denmark; Rigshospitalet, Copenhagen, Denmark.

Can diffuse optical spectroscopy predict the final pathological response of neoadjuvant chemotherapy?: a retrospective pilot study. Cerussi AE, Shah N, Hsiang D, Mehta RS, Tromberg BJ. Beckman Laser Institute, University of California, Irvine, Irvine, CA; University of California Medical Center, Orange, CA.

HIGH expression of the microtubule-associated protein, tau, strongly predicts improved progression free and overall survival in patients with metastatic HER-2-negative breast cancers treated with docetaxel and vinorelbine plus filgrastim.

Gown AM, Treaba DO, Goldstein LC, Porter PL, Gralow JR, Livingston RB, Tam S, Yeh I-T, Hayes DF, Barlow W, Lew D. PhenoPath Laboratories and IMPRIS, Seattle, WA; Seattle Cancer Care Alliance, Seattle, WA; University of Texas Health Sciences Center, San Antonio, TX; University of Michigan, Ann Arbor, Ml; Cancer Research and Biostatistics, Seattle, WA; Fred Hutchinson Cancer Research Center, Seattle, WA.
Immunohistochemical detection of ER in breast cancer using the new rabbit monoclonal anti-ER antibody SP1 better predicts survival and response to tamoxifen than the mouse monoclonal antibody 1D5: a tissue microarray study of $\mathbf{4 6 2 0}$ cases.

Treaba DO, Gown AM, Goldstein LC, Nielsen TO, Cheang MCU. PhenoPath Laboratories and IMPRIS, Seattle, WA; University of British Columbia, Vancouver, BC, Canada.

INFLUENCE of hormone receptor status on axillary lymph node (ALN) pathologic complete response ( $P C R$ ) rates in patients with cytologically confirmed ALN metastases prior to primary chemotherapy for breast cancer.

Hennessy BT, Kau SW, Sahin A, Broglio K, Hortobagyi GN, Valero V. MD Anderson Cancer Center, Houston, TX.

1038

MR spectroscopy of breast cancer tissue used for tumor classification and lymph node prediction. Lundgren S, Sitter B, Bathen T, Jensen LR, Axelson D,

Halgunset J, Fjøsne HE, Gribbestad IS. St. Olavs University Hospital, Trondheim, Norway; NTNU, Trondheim, Norway; MRI Consulting, Kingston, ON, Canada.

1039

Incidence of monosomy of chromsome 17: a potential pitfall in assessing HER-2 gene amplifiaction.

Bloom KJ. CLARiENT Inc and University of Southern California, Los Angeles, CA.

1040 Is there a regimen-specific gene signature predicting for pathological complete response after neoadjuvant chemotherapy in hormone-negative breast cancer patients? A microarray substudy of 101 patients included in EORTC 10994/BIG 00-01 Trial. Bonnefoi $\mathrm{H}$, Farmer P, Delorenzi M, Becette V, Piccart $M$, Campone M, Tubiana-Hulin M, Mauriac L, Jassem J, Petit T, Rouanet P, Blot E, Bergh J, Cameron D, Bogaerts J, Iggo R. European Organization on Research and Treatment of Cancer (EORTC); Swiss Institute for Bioinformatics (SIB); Swedish Breast Cancer Group (SweBCG); Anglo-Celtic Cooperative Oncology Group (ACCOG); Swiss Group for Clinical Cancer Research (SAKK); Swiss Institute for Experimental Cancer Research (ISREC).

1041 Identification pharmacogenomic markers for predicting paclitaxel-related toxicity in breast cancer patients treated with neoadjuvant chemotherapy. Fujiwara Y, Shimizu C, Shimoyama T, Takeda M, Nishio K, Ando M, Katsumata N, Kouno T. National Cancer Center Hospital, Tokyo, Japan; National Cancer Center Research Institute, Tokyo, Japan.

Predictors of early ipsilateral breast tumor recurrence following breast conservation therapy.

Gendler LS, Azarbayejani A, Klein LA, Horowitz E, Jin Z, Joseph KA, El-Tamer MB, Schnabel FR. Columbia University Medical Center, New York, NY; Columbia UniversityMailman School of Public Health, New York, NY.

Analysis of thymidylate synthase, methylenetetrahydrofolate reductase and IVS14+1 dihydropyrimidine deshydrogenase gene polymorphisms in advanced breast cancer patients receiving capecitabine as monotherapy. Largillier R, Formento JL, Nebbia JF, Etienne-Grimaldi MC, Ginot A, Francoual M, Renee N, Ferrero JM, Foa C, Namer M, Milano G. Centre Antoine Lacassagne, Nice, France. 
Src as a novel molecular biomarker for response to neoadjuvant chemotherapy with sequential doxorubicin and docetaxel in high-risk breast cancer. Minton SE, Munster PN, Cox C, Lacevic M, Lee J-H, Beam CA, Muro-Cacho CA, Diaz N, Jove R. University of South Florida College of Medicine, H. Lee Moffitt Cancer Center \& Research Institute, Tampa, FL.

Topoisomerase II-alpha gene amplification as a predictor of responsiveness to anthracyclinecontaining chemotherapy in the Cancer International Research Group 006 clinical trial of trastuzumab (herceptin) in the adjuvant setting.

Press MF, Bernstein L, Sauter G, Zhou JY, Eiermann W, Pienkowski T, Crown J, Robert N, Bee V, Taupin H, Villalobos I, Seelig S, Pegram M, Slamon DJ. University of Southern California, Los Angeles, CA; University Medical Center Hamburg-Eppendorf, Hamburg, Germany; GBG, Munchen, Germany; Maria Sklodowska-Curie (MSC) Centre, Warsaw, Poland; ICORG, Dublin, Ireland; US Oncology, Dallas, TX; CIRG, Paris, France; Abbott-Vysis, Inc., Downers Grove, IL; U.C.L.A., Los Angeles, CA.

1046 Evaluation of thymidine phosphorylase (TP) in primary breast cancer treated with docetaxel (D) and capecitabine (C).

Schott AF, Thomas DG, Griffith KA, Smerage JB, Hayes DF. University of Michigan, Ann Arbor, MI.

Methods to optimize tissue collection and assay performance from 16-gauge core biopsies in the I-SPY Trial.

Buxton MB, Bondi SM, Au A, Crothers J, Carey LA, DeMichele A, Dorsey KC, Dressler L, Harden AT, Gray JW, Haqq CM, Madhavan S, Perou C, Petricoin EF, I-SPY Clinical Investigators, Hylton NM, Esserman LJ. University of California, San Francisco, San Francisco, CA; The University of North Carolina at Chapel Hill, Chapel Hill, NC; University of Pennsylvania, Philadelphia, PA; National Cancer Institute, Rockville, MD; US Food and Drug Administration, Rockville, MD.

Predictive markers for 5-FU resistance in metastatic breast cancer.

Christensen AJ, Jensen LB, Balslev E, Nielsen KV, Poulsen TS, Nielsen DL, Moller S, Mouridsen H, Ejlertsen B.

Rigshospitalet, Copenhagen, Denmark; DakoCytomation, Glostrup, Denmark.

1049 Clinical characteristics and molecular markers predicting the development and outcome of breast cancer brain metastases.

Melisko ME, Chew K, Baehner F, Moore D, Sneed PK, Rugo HS. University of California San Francisco, San Francisco, CA.

Recurrence in ductal carcinoma in situ (DCIS) after complete microsurgical local excision is predicted by a high proliferation index and HER2/c-erbB2 status. Wilson GR, Rimouche S, Barnes N, Knox F, Swindell R, Bundred NJ. South Manchester Acute Hospitals Trust, Manchester, United Kingdom.

1051 Identification and multicentric validation of a metagene-based molecular predictor.

Bertucci F, Borie N, Treilleux I, Deraco S, Martinec A, Debono S, Jacquemier J, Fert V, Maraninchi D, Geneve J, Hermitte F, Bachelot T, Viens P, Birnbaum D. Institut PaoliCalmettes, Marseille, France; IPSOGEN, Marseille, France; Centre Leon Berard, Lyon, France; Federation Francaise des Centres de Lutte Contre le Cancer, Paris, France.
Predictivity of serum HER-2/NEU and EGFR concentrations for clinical outcome to the monocloncal anti-HER/2-neu antibody trastuzumab plus combination chemotherapy in metastatic breast cancer.

Lueftner DI, Henschke P, Amin R, Geppert R, Wernecke KD, Possinger K. Charité Campus Mitte, Berlin, Germany; Institut für Medizinische Biometrie, Charité Campus Mitte, Berlin, Germany.

1053 Validity of DNA-methylation marker PITX2 to predict risk of recurrence in lymph node-negative hormone receptor-positive breast cancer patients: a transfer study.

Markert-Hahn C, Jaeger S, Dessauer A, Gehrke R, Krause F, Vogel-Ziebolz S, Schwope I, Hartmann O, Lesche R, Nimmrich I, Maier S, Harbeck N, Mueller V, Ross JS, Gruetzmann R, Kristiansen G, Margossian A, Hartmann A, Golouh R, Paradiso A. Oncology, Penzberg, Germany; Roche Diagnostics GmbH, Mannheim, Germany; Epigenomics AG, Berlin, Germany; Technical University of Munich, Munich, Germany; University Hospital Hamburg Eppendorf, Hamburg, Germany; Albany Medical College, Albany; Technical University of Dresden, Dresden, Germany; Charité, Berlin, Germany; Halitus Instituto Médico, Buenos Aires, Argentina; University Hospital Regensburg, Regensburg, Germany; Institute of Oncology, Ljubljana, Slovenia; National Cancer Institute, Bari, Italy.

Effect of systemic therapy following surgery on outcome in patients diagnosed with an ipsilateral breast tumor recurrence.

Naik R, Gold E, Chuang E, Moore A, Osborne M, Simmons R, Swistel A, Tousimis E, Mazumdar M, Bryant K, Vahdat L. Weill Medical College (WMC) of Cornell University, New York, NY.

Identification of prediction marker for drug response in gene expression analysis combined with the pharmacodynamic profile in breast cancer patients treated with neoadjuvant chemotherapy.

Shimizu C, Shimoyama T, Takeda M, Nishio K, Hasegawa T, Ando M, Katsumata N, Fujiwara Y. National Cancer Center Hospital, Tokyo, Marshall Islands; National Cancer Center Hospital, Tokyo, Japan; National Cancer Center Research Institute, Tokyo, Japan.

1056 Association of MRI morphological phenotype with early and final responses in AC followed by taxane + carboplatin + /- trastuzumab regimen.

Su MY, Yu H, Mehta RS, Schubbert T, Hsiang D, Carpenter PM, Nalcioglu O. UC, Irvine, CA; UCIMC, Orange, CA.

Elevated serum MCP-1 level is associated with favorable clinical prognostic factors and immune response and can be induced by a HER2/neu (E75) vaccine in breast cancer patients.

Dehqanzada ZA, Storrer CE, Foley RJ, Harris KA, Jama YH, Shriver CD, Ponniah S, Peoples GE. Walter Reed Army Medical Center, Washington, DC; USUHS, Bethesda, MD.

The role of the angiogenic marker, endoglin, as a predictor of response to neoadjuvant chemotherapy in primary breast cancer.

Beresford MJ, Ah-See M, Daley F, Richman P, Harris A, Makris A. Mount Vernon Cancer Centre, Northwood, Middlesex, United Kingdom; Weatherall Institute of Molecular Medicine, John Radcliffe Hospital, Oxford, Oxfordshire, United Kingdom. 
Early predictive value of positron emission tomography with [18F]-fluorodeoxyglucose for the pathologic complete response of primary tumor in breast cancer patients treated by neoadjuvant chemotherapy.

Berriolo-Riedinger A, Coudert B, Riedinger JM, Touzery C, Toubeau M, Arnould L, Boichot C, Causeret S, Brunotte F, Fumoleau P. Centre G.F.Leclerc, Dijon, France, Metropolitan.

Predicting distant metastasis after local recurrence (failure) in women treated by breast conserving treatment.

Tchou J, Greshock J, Rebbeck T, Weber BL, Solin L. Abramson Cancer Center, University of Pennsylvania, Philadelphia, PA.

Gene expression profiles in white blood cells of patients with breast cancer - correlation with detectability of tumor by mammographic screening. Yang Y, Heckman C, Shriver CD, Becker T, Liebman MN, Brzeski H. Windber Research Institute, Windber, PA; Walter Reed Army Medical Center, Washington, DC

Expression levels of estrogen receptor (ER) gene and three ER-related genes in metastatic ER-positive breast cancer compared with response to endocrine therapy.

Lai S, Valero V, Booster D, Fiterman DJ, Pusztai L, Symmans WF. UT M.D. Anderson Cancer Center, Houston, TX.

Treatment: Chemotherapy - New Drugs and Formulations

E7389, A Novel Anti-Tubulin, is Safe and Effective in Patients with Refractory Breast Cancer.

Silberman SL, O'Shaughnessy J, Vahdat L, Fabian C, Forero L, Rivera R, Chandrawansa K, Heiskala M, Shapiro G, Meneses N, Fields SZ. Eisai Medical Research, Inc, Ridgefield Park, NJ; Baylor Sammons Cancer Ctr, Dallas, TX; Weill Cornell Breast Ctr, New York, NY; Univ Kansas Cancer Ctr, Kansas City, KS; Harrington Cancer Ctr, Amarillo, TX; US Oncology, Dallas, TX.

A multicenter phase II study of preoperative epirubicin, cyclophosphamide (EC) followed by paclitaxel $(P)$ plus trastuzumab $(T)$ in Her2 positive primary breast cancer.

Untch M, Stoeckl D, Konecny G, Kreienberg R, Thommsen C, Camara O, Moebus V, Kuehn T, DuBois A, Lueck H), Gitsch G, Fasching P. Klinikum Grosshadern, University of Munich, Munich, Germany; University of California, Los Angeles, CA; University Hospital, Ulm, Germany; University Hospital Halle - Wittenberg, Halle, Germany; University Hospital Jena, Jena, Germany; Staedtische Kliniken Frankfurt Hoechst, Frankfurt, Germany; Kreiskrankenhaus Gifhorn, Gifhorn, Germany; Horst - Schmidt - Kliniken, Wiesbaden, Germany; University Hospital, Erlangen, Erlangen, Germany; University Hospital Freiburg, Freiburg, Germany; University Hospital Erlangen, Erlangen, Germany.

1065 Efficacy and tolerability of gefitinib in oestrogen receptor negative and tamoxifen resistant oestrogen receptor positive locally advanced or metastatic breast cancer.

Agrawal A, Gutteridge E, Cheung KL, Hyman-Taylor P, Robertson JFR. City Hospital, Nottingham, Nottinghamshire, United Kingdom; Astra-Zeneca, Macclesfield, United Kingdom.
Phase II study of SU11248, a multitargeted tyrosine kinase inhibitor (TKI) in patients (pts) with previously treated metastatic breast cancer (MBC). Miller KD, Burstein HJ, Elias AD, Rugo HS, Cobleigh MA, Wolff AC, Eisenberg PD, Collier M, Adams BJ, Baum CM. Indiana University Cancer Center; Dana Farber Cancer Institute; University of Colorado Health Sciences Center; University of California San Francisco; Rush University Medical Center; Sidney Kimmel Cancer Center at Johns Hopkins University; California Cancer Care, Inc; Pfizer, Inc.

A phase I/II study of AG-013736, an oral antiangiogenesis agent, in combination with docetaxel in patients (pts) with metastatic breast cancer (MBC). Rugo HS, Stopeck A, Badorf A, Pithavala YK, Steinfeldt HM. University of California, San Francisco, San Francisco, CA; University of Arizona, Tucson, Tucson, AZ; Pfizer Inc, La Jolla, CA.

1068

Treatment of postmenopausal women with locally advanced or metastatic breast cancer with letrozole alone or in combination with temsirolimus: a randomized, 3-arm, phase 2 study.

Baselga J, Roché H, Fumoleau P, Campone M, Colomer R, Cortes-Funes H, Gil M, Chan S, Boni J, Kong S, Cincotta M Moore L. Hospital Vall D'Hebron, Barcelona, Spain; Institut Claudius Regaud, Toulouse, France; Centre René

Gauducheau, Saint Herblain, France; Institut Catala D' Oncologia, Girona, Spain; Hospital Universitario 12 de Octubre, Madrid, Spain; Institut Catala D' Oncologia, Barcelona, Spain; Nottingham City Hospital, Nottingham, United Kingdom; Wyeth Research, Collegeville, PA; Wyeth Research, Cambridge, MA

1069 Phase III randomized trial comparing docetaxel in combination with doxorubicin and cyclophosphamide (TAC) versus doxorubicin and cyclophosphamide followed by docetaxel $(A C \rightarrow T)$ in Her-2/neu negative early breast cancer patients with positive axillary lymph nodes: Interim analysis of the BCIRG 005 study.

Eiermann W, Pienkowski T, Crown J, Chap L, Pawlicki M, Martin M, Saleh M, Sehdev S, Provencher L, Von Minckwitz G, Semiglazov V, Slamon D, Tabah-Fisch I, Buyse M, Riva A, Taupin H, Sauter G, Mackey J. GBG, Munchen, Germany; Maria Sklodowska-Curie (MSC) Centre, Warsaw, Poland; ICORG, Dublin, Ireland; UCLA, Los Angeles, CA; MSC Institute, Krakow, Poland; GEICAM, Madrid, Spain University of Alabama, Birmingham, AL; William Osler Health Centre, Brampton, Canada; CHA - Hopital Du Saint Sacrement, Quebec, Canada; N.N. Petrov Research Institute, St. Petersburg, Russian Federation; Sanofi-Aventis, Paris, France; IDDI, Brussels, Belgium; CIRG, Paris, France; Univ Med Center, Hamburg, Germany; Cross Cancer Institute, Edmonton, Canada.

1070 A phase $2 b$ multicenter evaluation of the safety and efficacy of TOCOSOL ${ }^{\circledast}$ paclitaxel (TOC- P) as initial treatment of patients with metastatic breast cancer (MBC).

Bogdanova N, Tjulandin S, Ognerubov N, Semiglazov V, Afanasjev B, Makhson A, Krasnozhon D, Manikhas G, Vtoraya O, Mitashok I, Astakhov V, Byakhov M, Luciano G, Moore E, Pratt J, Bolton MG. The 1074 TOCOSOL Paclitaxel Working Group, Russian Federation; Sonus Pharmaceuticals, Bothell, WA. 
Biomarker results from a phase II randomized study of lapatinib (GW572016) as first-line treatment for patients with ErbB2 FISH-amplified advanced or metastatic breast cancer.

Gomez HL, Chavez MA, Doval DC, Nag S, Chow LW, Ang PC, Ahmad NM, Berger M, Newstat B, Stein S, Sledge GW. Instituto Especializado de Enfermedades Neoplasica, Lima, Peru; Hospital Alberto Sabogal, Lima, Peru; Rajiv Gandhi Cancer Institute and Research Centre, New Delhi, India; Jehangir Hospital and Medica Centre, Pune, India; Queen Mary Hospital, Hong Kong; National Cancer Centre, Singapore; Hospital University, Bharu, Kalatan, Malaysia; GlaxoSmithKline, Collegeville, PA; Indiana University, Indianapolis.

1072 ZK-EPO, a novel synthetic epothilone B analog, significantly inhibits tumor growth in both nonresistant and resistant breast cancer models. Klar U, Buchmann B, Schwede W, Skuballa W, Lichtner RB, Hoffman J. Schering AG, Berlin, Germany.

1073 A phase I, open-label study of the safety, tolerability and pharmacokinetics of lapatinib (GW572016) in combination with trastuzumab.

Storniolo AM, Burris III HA, Overmoyer B, Silverman P, Pegram MD, Jones SF, Peacock NW, Loftiss J, Koch KM, Paul E, Ho PTC. Indiana University Cancer Center, Indianpolis, IN; Sarah Cannon Cancer Center, Nashville, TN; Ireland Cancer Center, Cleveland, OH; UCLA Center for the Health Sciences, Los Angeles, CA; GSK, RTP, NC.

Long term survival with no apparent toxicity observed with a novel cisplatin-incorporated polymeric micelle, NC-6004, in the MCF-7 breast cancer model.

Alami N, Banerjee K, Page V, Hayashi T, Igarashi E, LeylandJones B. McGill University, Montreal, QC, Canada; NanoCarrier Co., Ltd., Chiba, Japan.

1075 Combination of a prenylation inhibitor and either classical chemotherapy or a M-TOR inhibitor: potential clinical implications.

Budman DR, Calabro A. North Shore University Hospital, New York University, Manhasset, NY

1076 Effects of the potent telomerase template antagonist GRN163L in breast cancer.

Herbert B, Hochreiter A, Pongracz K, Gryaznov SM. Indiana University School of Medicine, Indianapolis, IN; Indiana University Cancer Center, Indianapolis, IN; Geron Corporation, Menlo Park, CA.

1077 Anticancer influence of a methioninase containing fusion protein targeted to the urokinase receptor on breast cancer cells.

Pento JT, Zang XP, Palwai NR, Harrison RH. University of Oklahoma HSC, Oklahoma City, OK; University of Oklahoma, Norman, OK.

The use of p53-mediated alteration of microtubule dynamics to sensitize breast cancer to vinca alkaloids. Toppmeyer DL, Nayak M, Chang J-M, Huzzy L, Shah N, Hait WN. The Cancer Institute of New Jersey, UMDNJ-Robert Wood Johnson Medical School, New Brunswick, NJ.
Unexpected hepatic toxicity after primary treatment with gefitinib and docetaxel in patients with locally advanced breast cancer.

Bines J, Branco LGP, Gomes CA, Costa F, Barrios CH, Martins RG. Instituto Nacional de Cancer, Rio de Janeiro, RJ, Brazil; PUC, Porto Alegre, RGS, Brazil; Washington University, Seattle, WA.

1081 A phase I/II study of capecitabine (X) combined with oral vinorelbine $(\mathrm{N})$ as first- or second-line chemotherapy in patients (pts) with locally advanced breast cancer (MBC).

Delcambre C, Veyret C, Levy C, Switsers O, Allouache D, Raban N, Grellard JM, Leconte A, Delozier T. Centre Francois Baclesse, Caen, France; Centre Henri Becquerel, Rouen, France; Centre Hospitalier Universitaire, Poitiers, France.

1082

Selective inhibition of ADAM metalloproteases as a novel approach for modulation ErbB pathways in cancer.

Douglass EC, Liu X, Caulder E, Liu C, Hansbury M, Zhou BB, Yao W, Li Y, Vaddi K, Newton R, Scherle P, Friedman S, Fridman J. Incyte Corporation, Wilmington, DE.

Phase I/II trial and pharmacokinetic/pharmacodynamic analysis exploring a synergistic interaction between the histone deacetylase inhibitor, valproic acid and the anthracycline, epirubicin.

Munster PN, Minton SE, Marchion DC, Carter WB, Bicaku E, Lush III R, Sullivan DM, Daud AI. H. Lee Moffitt Cancer Center, Tampa, FL.

Multicenter phase 2 study of XRP6258 in taxaneresistant metastatic breast cancer (MBC) patients (pts).

Pivot X, Koralewski P, Hidalgo JL, Chan A, Viens P, Schwartsmann G, Brunel E, Ramazeilles C, Assadourian S, Lotz JP. CHU Jean-Minjoz, Besancon, France; Oddzial Chemioterapii, Krakow, Poland; C.O.I.R, Mendoza, Argentina; Mount Medical Centre, Perth, Australia; Institut Paoli Calmettes, Marseille, France; Federal Univ, Porto Alegre, Brazil; Sanofi Aventis, Antony, France; Hopital Tenon, Paris, France.

1085 Bortezomib and capecitabine in patients with metastatic breast cancer previously treated with taxanes and/or anthracyclines.

Schmid P, Schippinger W, Kiewe P, Lange W, Preiss J, Niederle N, Brossart P, Freier W, Van de Velde H, Possinger K. Charite Campus Mitte, Berlin, Germany; Universitaetsklinikum, Graz, Austria; Charite Campus Benjamin Franklin, Berlin, Germany; Johanniter-Krankenhaus Rheinhausen, Duisburg, Germany; Caritasklinik St. Theresia, Saarbrücken, Germany; Klinikum Leverkusen, Leverkusen, Germany; Universitaetsklinikum Tuebingen, Germany; Practice for Oncology and Hematology, Hildesheim, Germany; Johnson \& Johnson Pharmaceutical Research \& Development, Beerse, Belgium against an endocrine insensitive, p53 mutant MDAMB-231 xenograft preclinical model.

Appleyard MV, O'Neill MA, Murray KE, Spruce BA, Thompson AM. University of Dundee, Dundee, United Kingdom

A phase I trial of scutellaria barbata (BZL101) for metastatic breast cancer.

Tagliaferri M, Cohen I, Vogel C, Perez A, Tan-Chiu E, Franco S, Melisko M, Campbell M, Rugo H, Tripathy D. Bionovo, Inc., Emeryville, CA; Cancer Research Network, Plantation, FL; University of California, San Francisco, San Francisco, CA; Memorial Cancer Institute, Hollywood, FL; University of Texas, Southwestern, Dallas, TX 
A phase II study of KOS-862 (epothilone D) in anthracycline and taxane pretreated metastatic breast cancer: updated results.

Buzdar A, Silverman P, Kaufman PA, Waintraub S, Doyle T, Kroener J, Robinson P, Perez E, Zhang X, DeMario M. MD Anderson Cancer Center, Houston, TX; Univ. Hosp. Cleveland, Ireland Cancer Ctr, Cleveland, $\mathrm{OH}$; DartmouthHitchcock Medical Ctr, Lebanon, $\mathrm{NH}$; Hackensack Univ Medical Ctr, Hackensack, N); Henry Ford Health Systems, Detroit, Ml; Scripps Clinic, La Jolla, CA; Fox Chase Cancer Ctr, Philadelphia, PA; Hoffmann-La Roche Inc., Nutley, NJ.

A phase I/II study of oral capecitabine (X) and vinorelbine (V) as second- or -third line chemotherapy in anthracycline/taxane pretreated patients (pts) with metastatic breast cancer (MBC). Kellokumpu-Lehtinen P, Sjöström J, Sunela K, Lehtinen I, Joensuu H. Tampere University Hospital, Tampere, Finland; Helsinki University Central Hospital, Helsinki, Finland; University of Tampere, Tampere, Finland.

Phase II, open label study of SB-715992 (Ispinesib) in subjects with advanced or metastatic breast cancer. Miller K, Ng C, Ang P, Brufsky AM, Lee SC, Dees EC, Piccart $M$, Verrill M, Wardley A, Loftiss J, Bal J, Yeoh S, Hodge J, Williams D, Dar M, Ho PTC. IU Cancer Ctr, Indianpolis, IN; Univ Malaya Medical Ctr, Kuala Lumpur, Malaysia; National Cancer Ctr, Singapore; UPMC, Pittsburgh, PA; Nat Univ Hosp, Singapore; UNC, Chapel Hill, NC; Institut Jules Bordet, Brussels, Belgium; Newcastle General Hosp, Newcastleupon-Tyne, United Kingdom; Christie Hosp, Manchester, United Kingdom; GSK, RTP, NC, with Cytokinetics Inc., S San Francisco, CA

Phase I study of irinotecan followed by capecitabine in patients with advanced breast carcinoma.

O'Connor T, Rustum Y, Levine E, Kepner J, Creaven P. Roswell Park Cancer Institute, Buffalo, NY.

1091 Plasma kinetics and uptake of a cholesterol-rich microemulsion (LDE) associated to a derivative paclitaxel by neoplastic breast tissue.

Rodrigues DG, Pires LA, Hegg R, Graziani SR, Maranhão RC. Heart Institute - USP, SP, São Paulo, Brazil; USP, SP, São Paulo, Brazil.

1092 Preliminary results of phase I trial of carboplatin (CP) in combination with $\mathrm{ABI-007}$ administered weekly or every 3 weeks in patients (pts) with solid tumors. Stinchcombe TE, Dees EC, Walko CM, Lindley C, Collichio FA, Carey LA, Turner JE, Mu H, Socinski MA. University of North Carolina, Chapel Hill, NC; Abraxis Oncology, Los Angeles, CA.

1093 The conjugation of doxaliform to alpha(v) beta3 $(\alpha v \beta 3)$-targeting peptides provides a potential therapeutic alternative for the management of $\alpha v \beta 3$ overexpressing breast carcinomas.

Vellon L, Menendez JA, Burkhart DJ, Kalet BT, Koch TH, Lupu R. Evanston Northwestern Healthcare Research Institute, Evanston, IL; Northwestern University Feinberg School of Medicine, Chicago, IL; University of Colorado, Boulder, CO. (SU11248) in Caucasian and Japanese populations. Bello CL, Houk B, Sarapa N, Smeraglia J, Huang X, Klamerus KJ. Pfizer Global R\&D, La Jolla, CA.

Trastuzumab (T) and KOS-953 (17-AAG) is feasible and active in patients (pts) with metastatic breast cancer: preliminary results of a phase $1 / 2$ study.

Modi S, Stopeck A, Gordon MS, Solit D, Bagatelle R, Flores S, Cohen J, Block H, Cropp GF, Rosen N, Johnson RG, Hannah AL, Hudis C. Cancer Center, New York, NY; Arizona Cancer Center, Tucson/Scottsdale, AZ; Kosan Biosciences Inc., Hayward, CA.

Tumor and Cell Biology: Angiogenesis

1096 c-jun activation is associated with angiogenesis in invasive breast cancer.

Vleugel MM, Greijer AE, Bos R, van der Wall E, van Diest PJ. University Medical Center Utrecht, Utrecht, Netherlands; VU University Medical Center, Amsterdam, Netherlands.

1097 Lymphangiogenesis and human breast cancer. Cunnick GH, Jiang WG, Douglas-Jones A, Watkins G, Gomez KF, Mokbel K, Mansel RE. University of Wales College of Medicine, Cardiff, Wales, United Kingdom; St. George's Hospital, Tooting, London, United Kingdom.

A histomorphological study of tumor lymphangiogenesis in inflammatory and noninflammatory breast cancer.

Van der Auwera I, Van den Eynden GG, Van Laere SJ, Colpaert CG, van Dam P, Van Marck EA, Vermeulen PB, Dirix LY. Laboratory of Pathology University of Antwerp/University Hospital Antwerp, Edegem; Oncology Centre, General Hospital St-Augustinus, Wilrijk, Antwerp, Belgium.

1099 Vascular endothelial growth inhibitor (VEGI), an antiangiogenic factor, in human breast cancer. Parr C, Gan C, Harrison G, Jiang WG. Wales College of Medicine, Cardiff University, Cardiff, United Kingdom.

1100 Tamoxifen increases matrix metalloproteinase 2 and 9 activities and endostatin levels in breast cancer tumors in vivo.

Nilsson UW, Dabrosin C. University Hospital, Linköping, Sweden.

1101 Lack of correlation between microvessel density \& pericyte coverage index within breast cancer biopsies \& functional dynamic contrast-enhanced MRI-derived vascular parameters.

Ah-See MW, Padhani AR, Taylor NJ, Harris AL, Burcombe RJ, Fox SB, Richman PI, Daley FM, Stirling J), Leach MO, Bentzen SM, Makris A. Mount Vernon Hospital, Northwood, Middlesex, United Kingdom; John Radcliffe Hospital, Oxford, Headington, United Kingdom; Royal Marsden Hospital, Sutton, Surrey, United Kingdom.

1102 Role and prognostic relevance of hypoxia inducible factor $1 \alpha$ and its downstream targets in fibroepithelial tumours of the breast. .

Kuijper A, van der Groep P, van der Wall E, van Diest PJ. University Medical Center Utrecht, Utrecht, Netherlands.

1103 Analysis of angiogenesis genes from paraffinembedded breast tumor and lymph nodes. Schneider BP, Skaar TC, Badve S, Sledge GW, Li L, Flockhart DA. Indiana University, Indianapolis, IN.

Tumor and Cell Biology: Carcinogenesis

1104 MEK5-ERK5 signaling promotes estrogenindependent tumorigenesis of breast carcinoma cells. Xiong W. Tulane University, New Orleans, LA. 

(807C_1648G, "wildtype") is associated with decreased breast cancer risk.

Langsenlehner U, Eder T, Weitzer W, Samonigg H, Krippl P. Medical University Graz, Graz, Styria, Austria.

Tumor and Cell Biology: Genetics

1106 Invasive lobular carcinoma and the high grade variant pleomorphic lobular carcinoma: molecular characterization.

Simpson P, Reis-Filho J, Mackay A, Jones C, Dexter T, Hardisson D, Sarrio D, Weber B, Ashworth A, Schmitt F, Palacios J, Lakhani S. University of Queensland, QIMR, RB\&W's Hospital, Brisbane, Australia; ICR, London, United Kingdom; IPATIMUP, Oporto, Portugal; CNIO/La Paz Hospital, Madrid, Spain; University of Pennsylvania.

1107 Classic lobular breast carcinoma: comprehensive molecular genetic analysis.

Reis-Filho JS, Simpson PT, Lambros M, Jones C, Sarrio D, Savage K, Dexter T, Mackay A, Iravani M, Fenwick K, Weber B, Hardisson D, Schmitt F, Palacios J, Ashworth A, Lakhani SR. ICR, London, United Kingdom; IPATIMUP, Oporto, Portugal; University of Queensland, Brisbane, Australia; ICR, Sutton, United Kingdom; CNIO and La Paz Hospital, Madrid, Spain; University of Pennsylvania.

1108 Is aberrant hypermethylation an early event in breast cancer?

Sullivan RF, Kim SJ, Zapparoli GV, Kachel CA, Chiriboga L, Skinner KA. New York University Cancer Institute, New York, NY.

1109 SNP microarray analysis of genomic alterations in infiltrating ductal carcinoma and infiltrating lobular carcinoma.

Ton CC, Loo LW, Grove DI, Neal CL, Hsu L, Porter PL. Fred Hutchinson Cancer Research Center, Seattle, WA.

1110 Comparison between matched pairs of primary breast cancer and distant metastasis using array CGH.

Gahir J, Reis-Filho JS, Iravani M, Dexter T, Fenwick K, Davidson B, Mackay A, Ebbs S, Ashworth A. ICR, London, United Kingdom; Mayday Hospital, Croydon, United Kingdom; Norwegian Radium Hospital, Montebello, Norway.

1111 C-MYC expression correlates with atypia and malignancy in early breast lesions associated with microcalcifications detected by routine mammography.

Mazzini RC, Kemp C, Logullo AF, Elias S, Oshima CT, Takano DM, Dobo C, Junior JA. Universidade Federal de Sao Paulo, Sao Paulo, SP, Brazil.

1112 Breast cancer metastasis-free survival and its association to a common hereditary gene polymorphism of cyclin D1.

Hofmann G, Langsenlehner U, Renner W, Greimel A, Samonigg H, Krippl P. Medical University of Graz, Graz, Austria; Clinical Institute of Medical and Laboratory Diagnostics, Medical University of Graz, Graz, Austria.

Tumor and Cell Biology: Stages of Cancer Development

1113 Apocrine metaplasia and the development of ERnegative breast cancer.

Lee S, Weiss H, Tsimelzon A, Mao S, Wu Y, Mohsin SK Medina D, Haagensen DE, Allred DC. Baylor College of Medicine, Houston, TX; Traditional Practice Alliance, Sacramento, CA.
Molecular alterations in columnar cell lesions of the breast.

Dabbs DJ, Peng Y, Carter G, Swalsky P, Finkelstein S. MageeWomens Hospital, Pittsburgh, PA.

Late Acceptances

1115 The evaluation of the breast imaging in clinical complete response patients after primary chemotherapy.

Sakemura N, Akashi-Tanaka S, Eriko I, Takasugi M, Terada K, Shien T, Kinoshita T, Miyakawa K, Kohno T, Shimizu C, Ando M, Katsumata N, Fujiwara Y, Fukutomi T. Department of Breast Surgery, Department of Diagnostic Radiology, Department of Breast and Medical Oncology, National Cancer Center Hospital, Tokyo, Japan.

An electronic data registry for evaluating fulvestrant treatment in patients with advanced breast cancer. Wade JL, Esparaz, BT, Lower EE. Decatur Memorial Hospital, Decatur, IL; University of Cincinnati, Cincinnati, $\mathrm{OH}$.

1117 A phase II and biologic correlative study investigating anastrozole (A) in combination with geftinib (G) in post menopausal patients with estrogen receptor positive (ER) metastatic breast carcinoma (MBC) who have previously failed hormonal therapy. Mita M, de Bono JS, Mita A, Patnaik A, Ricart A, Berg K, Takimoto C, Rowinsky EK, Tolcher A, Beeram M. Institute for Drug Development, University of Texas Health Science Center San Antonio, TX

Oncologist-patient discussion of adjuvant hormonal therapy: results of a linguistic study focusing on patient adherence/persistence.

Davidson B, Vogel V, Wickerham L. MBS/Vox, Wayne, N]; University of Pittsburgh School of Medicine, Pittsburgh, PA; NSABP, Pittsburgh, PA

Novel DJ compounds cause reduction in human breast tumors.

Parker-Johnson KA, Anderson D, Knowles B, Minnard E, Johnson DE. Dillard University, New Orleans, LA; West lefferson Hospital, New Orleans, LA.

1120 Supraclavicular failure in patients with 1 to 3 positive axillary lymph nodes treated with breast conserving surgery and breast irradiation, with or without supraclavicular node irradiation.

Kiel KD, Reddy SG. Northwestern Memorial Hospital, Chicago, IL.

Cyclopamine inhibits breast cancer cell growth via hedgehog network-dependent and independent mechanisms unrelated to cholesterol trafficking. Zhang X, Harrington N, Moraes R, Lewis MT. Baylor College of Medicine, Houston, TX

7:00-9:00

\section{KOMEN FOUNDATION'S BRINKER AWARD FOR SCIENTIFIC DISTINCTION DINNER - Marriott Rivercenter}

The Susan G. Komen Breast Cancer Foundation and the 28th Annual San Antonio Breast Cancer Symposium cordially invite you to join us in the Marriott Rivercenter ballroom for dinner and presentation of the Brinker International Awards for Breast Cancer Research. [Ticket Required] 
FrIDAY, DeCEMBER 9 BREAKFAST - Exhibit Hall B

(\#2001-2113)

Detection and Diagnosis: Circulating Markers

2001 Urinary metalloproteinases: a novel non-invasive methodology for breast cancer risk assessment. Pories SE, Lamb CC, Roy R, Lotz MM, Zurakowski D, Raza S, Wewer U, Scheib RG, Schumer S, Exarhopoulos A, Isakovich N, Louis GW, Anand A, Lenahan C, Kilroy S, HirshfieldBartek J, Borges V, Yee BH, Moses MA. Harvard Medical School: Beth Israel Deaconess Medical Center, Children's Hospital, Mount Auburn Hospital, Brigham and Women's Hospital, Dana Farber Harvard Cancer Center, Boston, MA.

Circulating tumor marker discovery using proteolytic peptide profiling and isotope-coded affinity tags. Esteva F), Zhang B, Hawke D, Zhao H, Baggerly K, Koomen J, Hortobagyi GN, Kobayashi R. UT M. D. Anderson Cancer Center, Houston, TX; Proteomics Facility.

The relationship between circulating concentrations of Her-2, C-reactive protein and survival in patients with primary operable breast cancer.

Henley NC, Macmillan DC, Doran C, Burns HJG, George WD, Bartlett JM, Cooke TG. University of Glasgow, Glasgow, United Kingdom; Greater Glasgow NHS Board, Glasgow, United Kingdom.

2004 Evaluation of immunoassay and RT-PCR methods for detection of the NMPG6 complex for diagnosis of breast cancer.

Stoerker J, Lueftner D, Szaro R, Fagan G, Domurad M. Matritech, Inc., Newton, MA; Charite Hospital, Berlin, Germany.

2005 Increased levels of the circulating growth factor GP88 in the serum of breast cancer patients.

Serrero G, Tkaczuk KH, Golubeva O, Jones L, Tait N, Feldman FS, Dai H. A\&G Pharmaceutical Inc., Columbia, MD; University of Maryland, Baltimore, MD.

2006

Circulating tumor cells in adjuvant breast cancer patients.

Almokadem S, Leitzel K, Harvey HA, Bannon E, Ali SM, Miller MC, Repollet M, Terstapenn LWWM, Doyle GV, Frazier T, Lipton A. Pennsylvania State College of Medicine/ Hershey Medical Center, Hershey, PA; Immunicon Corporation, Huntington Valley, PA; Bryn Mawr Hospital, Bryn Mawr, PA.

Detection and Diagnosis: Detection

Methylated genes in ductal lavage fluid from women with known breast cancer undergoing mastectomy. Fackler MJ, Malone K, Schilling E, Swift-Scanlon T, Nayar R, Sukumar S, Khan SA. Feinberg School of Medicien of Northwestern University, Chicago, IL; Feinberg School of Medicine of Northwestern University, Chicago, IL; Johns Hopkins University School of Medicine, Baltimore, MD.
Glycan array identifies specific signatures of antiglycan autoantibodies in sera of breast cancer patients: diagnostic, prognostic and therapeutic opportunities.

Huflejt ME, Blixt O, Vuskovic M, Xu H, Shaw LE, Reuben JM, Kuerer HM, Cristofanilli M. Glycomedical Research Institute, La Jolla, CA; The Scripps Research Institute, Consortium for Functional Glycomics, La Jolla, CA; San Diego State University, San Diego, CA; UT M.D. Anderson Cancer Center, Houston, TX.

2009 Serum profiling predictive of invasive breast cancer. Mansfield BC, Shriver CD, Yip PF, Coleman TA, Hitt BA, Hooke JA, Liebman M, Somiari S, Flynn J. Correlogic Systems Inc., Bethesda, MD; Walter Reed Army Medical Center, Washington, DC; Windber Research Institute, Windber, PA; Landstuhl Regional Medical Center, Landstuhl, Germany.

Patient detected breast cancer not seen on mammography.

Kaplan HG, Malmgren JA, Atwood MK. Swedish Cancer Institute, Swedish Medical Center, Seattle, WA; HealthSTAT Consulting, Inc., Seattle, WA; University of Washington, Seattle, WA

2011 Serum proteome of breast cancer: a group of proteins related to the invasive stage.

Ru Q, Zhu L, Silberman J, Jacobs N, Shriver D. Windber Research Institute, Windber, PA; Breast Cancer Care Center, Walter Reed Army Medical Center, Washington, DC.

Ductal epithelial impedance spectroscopy; a new approach to breast cancer diagnosis.

Davies RJ, Davisson TH. Hackensack Univ. Medical Center, Hackensack, NJ.

New biomarkers in the detection of breast cancer in nipple aspirate flui (NAF), using surface enhanced laser/ desorption ionisation coupled with time-offlight mass spectrometry (SELDI-TOF/ MS) in combination with artificial intelligence methods. Dua RS, Noble JL, Locke I, Coulton GR, Eeles R, Isacke CM, Gui GPH. Royal Marsden Hospital, London, United Kingdom; Breakthrough Breast Cancer Research Centre, Institute of Cancer Research, London, United Kingdom; St George's University of London, London, United Kingdom.

Concurrence of contralateral breast cancers for estrogen and progesterone receptor status and mode of detection.

Martin CV, Sahasrabudhe N, Bundred NJ, Barr L, Byrne G, Baildam AD. South Manchester University Hospital, Manchester, United Kingdom.

2015 Variation in protein expression patterns of nipple aspirate fluid comparing women with breast cancer and healthy women using time-of-flight mass spectrometry.

Noble JL, Dua RS, Locke I, Coulton GR, Eeles R, Isacke CM, Gui GPH. Royal Marsden Hospital, London, United

Kingdom; Breakthrough Breast Cancer Research Centre, Institute of Cancer Research, London, United Kingdom; St George's University of London, London, United Kingdom.
Comparison of FLT-(18F) and FDG-(18F) to visualize cancer spread while staging locally advanced breast cancer with $\mathrm{PET} / \mathrm{CT}$ : preliminary data.

Grahek D, Gligorov J, Beerblock K, Selle F, Segura C, Chopier J, Salem C, Antoine M, Barranger E, Montravers F, Gutman F, Kerrou K, De Beco V, Marsault C, Lotz JP, Uzan S, Talbot JN. Hôpital Tenon; Hôpital Tenon, Paris, France. 
Combined mammography and breast ultrasound are required for a good accuracy of BI-RADS 4/5 results findings of a breast imaging reference center.

Fasching PA, Wenkel E, Bani MR, Bautz W, Papadopoulos T, Beckmann MW, Schulz-Wendtland R. University Hospital Erlangen, Erlangen, Bavaria, Germany; Institute of Diagnostic Radiology, University Hospital Erlangen, Erlangen, Bavaria, Germany; Institute of Pathology, University Hospital Erlangen, Erlangen, Bavaria, Germany.

Detection and Diagnosis: Diagnostic Pathology

Improving the Case Definition of Inflammatory Breast Cancer

Levine PH, Cartin BJ, Lowe JA, Siegel DA, Young HA.

2019

Concordance of HER2 and hormone receptor expression in primary and recurrent breast cancer. Perez EA, Wirk B, Geiger X, Hillman D. Mayo Clinic, Jacksonville, FL.

Proliferating macrophages appear to be uniquely associated with large, palpable DCIS and high grade invasive cancers.

Esserman LJ, Kumar AS, Au A, Baehner F, Chen D, Chen Y, Chan L, Chew K, McGrath M. UCSF, San Francisco, CA.

Mammaglobin identification by immunohistochemistry and reverse transcriptase polymerase chain reaction to increase detection of breast cancer metastases.

Ferguson DJ, Thorne A, Jeffrey M, Yiangou C, Perry PM. Portsmouth Hospitals NHS Trust, Portsmouth, Hampshire United Kingdom; Institute of Biomedical and Biomolecular Sciences, University of Portsmouth, Portsmouth, Hampshire, United Kingdom.

2022 Reliability of core biopsy in pre-operative diagnosis of papillary lesions of the breast.

Swamy R, Loane J, Thomas JS. Western General Hospital, Edinburgh, Scotland, United Kingdom.

Are so-called "intracystic" papillary carcinomas of the breast in situ or invasive lesions?

Collins LC, Carlo VP, Hwang H, Barry TS, Yaziji H, Gown AM Schnitt SJ. Beth Israel Deaconess Medical Center and Harvard Medical School, Boston, MA; Phenopath Laboratories, Seattle, WA.

A nomogram to predict for malignant diagnosis of solid lesions in a one-stop breast unit.

Delaloge S, Rouzier R, Balleyguier C, Andre F, Vanel D, Mathieu MC, Garbay JR, Derneville AM, Marsiglia H, Spielmann M, Vielh P. Institut Gustave Roussy, Villejuif, France; Centre Hospitalier Intercommunal de Creteil, Creteil, France.

2025 Genomic alterations as a pathological aid to classifying ductal carcinoma in situ. Ellsworth RE, Ellsworth DL, Love B, Hoffman LR, Deyarmin B, Hooke JA, Shriver CD. Windber Research Institute, Windber, PA; Walter Reed Army Medical Center, Washington, DC.

Peptide breast cancer biomarkers detectable through blood tests.

Zhu L, Ru Q, Silberman J, Jacobs N, Shriver CD. Windber Research Institute, Windber, PA; Breast Cancer Care Center, Walter Reed Army Medical Center, Washington, DC.
Intra-operative touch preparation cytology; does it have a role in re-excision lumpectomy? Valdes EK, Boolbol SK, Cohen JM, Feldman SM. Beth Israel Medical Center, New York, NY.
Treatment: Antibody-based Regimens
2028

2029

2030

2031

2032

2033

2034
Response in gene expression profile to bevacizumab treatment in patients with inflammatory and locally advanced breast cancer.

Yang SX, Simon RM, Wedam SB, Modrusan Z, Smith V, de Sauvage F, Swain M. National Cancer Institute, Bethesda, MD; Genetech, Inc., South San Fancisco, CA.

Cost-benefit estimates of adjuvant (Adj) trastuzumab (herceptin, $\mathbf{H}$ ) for early breast cancer (BrCa). Ragaz J, Spinelli JJ. McGill University Health Center, Montreal, QC, Canada; British Columbia Cancer Agency, Vancouver, BC, Canada.

A phase II trial of letrozole in combination with bevacizumab, an anti-VEGF antibody, in patients with hormone receptor-positive metastatic breast cancer. Traina TA, Dickler MN, Caravelli JF, Yeh BM, Brogi E, Panageas K, Flores SA, Norton L, Park J, Hudis C, Rugo H. Memorial Sloan-Kettering Cancer Center, New York, NY; University of California, San Francisco, San Francisco, CA.

031 A phase II trial of trastuzumab $(H)$ plus capecitabine $(X)$ as first-line treatment in patients (pts) with HER2-positive metastatic breast cancer (MBC). Xu L, Song S, Zhu J, Luo R, Li L, Jiao S, Pan H, Tao M, Su Y, Liu D. Cancer Hospital Fudan University, Shanghai, China; PLA Hospital 307, Beijing, China; Ruijin Hospital Shanghai No.2 Medical University, Shanghai, China; Nanfang Hospital First Military Medical University, Guangzhou, China; Heilongjiang Provincial Cancer Hospital, Haerbin, China; PLA Hospital 301, Beijing, China; Shao Yifu Hospital Zhejiang University, Hangzhou, China; No.1 Hospital Suzhou University, Suzhou, China; Jiangsu Provincial People's Hospital, Nanjing, China; General Hospital Beijing Military Area, Beijing, China.

Weekly paclitaxel $(P C T) \pm$ trastuzumab $(T)$ as firstline therapy of patients (pts) with HER-2/NEU positive metastatic breast cancer $(M B C)$ : final results of a multicenter randomized phase Ilb trial. Gasparini G. San Filippo Neri Hospital, Rome, Italy.

Capecitabine and trastuzumab: a phase II study in HER2-overexpressing metastatic breast cancer (MBC) patients pretreated with anthracyclines and/or taxanes.

Schaller G, Bangemann N, Gonsch T, Weber J, Kleine-Tebbe A, Conrad B, Klare P, Hindenburg HJ, Ruhmland B, Lakner V, Hinke A. Breast Care Institute, Berlin, Germany; WiSP Research Institute, Langenfeld, Germany; Participating Centers, Germany.

Phase I and pharmacokinetics (PK) of combined erbB1 and erbB2 blockade with OSI-774 (Erlotinib; E) and trastuzumab $(T)$ in combination with weekly paclitaxel $(P)$ in patients (pts) with advanced solid tumors.

Beeram M, De Bono JS, Patnaik A, Mita A, Chu SC, Mita MM, O'Rourke P, Takimoto CH, Tolcher AW, Rowinsky EK. Univ of Texas Health Science Center at San Antonio, San Antonio, TX; Institute for Drug Development/ CTRC, San Antonio, TX.

A phase I-Il study of trastuzumab, gefitinib, and docetaxel as first line chemotherapy in patients with HER-2 overexpressing stage IV breast carcinoma. Somlo G, Koczywas M, Luu T, McNamara M, Russell C, Morgan R, Arnold K, Frankel P. City of Hope Cancer Center, Duarte, CA; University of Southern California, Los Angeles, CA. 
Effect of trastuzumab treatment as first-line on metastatic breast cancer: final results of the French HERMINE cohort after 2-year follow-up ( $n=221)$. Namer M, Antoine EC, Le Deley MC, Vincent Salomon A, Pau D, Remblier C, Vasseur B, Extra JM. Centre Azureen de Cancerologie, Nougins, France; Clinique Hartmann, Neuillysur-Seine, France; Institut Gustave Roussy, Villejuif, France; Institut Curie, Paris, France; Roche, Neuilly-sur-Seine, France.

Treatment: Adjuvant Therapy

Improved breast cancer specific survival (BCSS): the impact of adjuvant systemic therapy.

Olivotto IA, Coldman AJ, Speers C, Phillips N, Goldrick A, Gelmon KA. BC Cancer Agency, Victoria and Vancouver, BC, Canada.

Exploratory analysis from NCCTG N9831: do clinical and laboratory characteristics predict cardiac toxicity of trastuzumab when administered as a component of adjuvant therapy?

Perez EA, Suman VJ, Davidson NE, Kaufman PA, Martino S, Dakhil SR, Ingle JN, Rodeheffer RJ, Gersh BJ, Jaffe AS. NCCTG, Rochester, MN; ECOG, Philadelphia, PA; CALGB, Chicago, IL; SWOG, San Antonio, TX.

2039 Final analysis of a planned comparison of menopausa symptoms in 1618 patients receiving either exemestane (E) or tamoxifen $(T)$ in a blinded adjuvant hormonal study.

Asmar L, Cantrell J, Vukelja SJ, Pippen J, O'Shaughnessy J, Blum JL, Brooks R, Mull S, llegbodu D, Jones S. US Oncology Research, Inc., Houston, TX.

Impact of letrozole on quality of life in postmenopausal women with early breast cancer: does age matter?

Barghout V, Abetz L, Thomas S, Arbuckle R. Novartis Pharmaceuticals, Florham Park, N); Mapi Values, Macclesfield, Cheshire, United Kingdom.

2041 Preliminary cardiac safety results of dose-dense (DD) doxorubicin and cyclophosphamide (AC) followed by paclitaxel $(T)$ with trastuzumab $(H)$ in HER2/neu overexpressed/Amplified breast cancer (BCA).

Dang C, Smith K, Lake D, Fornier M, D'Andrea G, Seidman A, Sklarin N, Troso-Sandoval T, Sugarman S, Gilewski T, Robson M, Drullinsky P, Moynahan M, George R, VanPoznak C, Panageas K, Smith M, Norton L, Hudis C. Memorial Sloan-Kettering Cancer Center, New York, NY.

NCIC CTG MA17: disease free survival according to estrogen receptor and progesterone receptor status of the primary tumor.

Goss PE, Ingle JN, Tu D. Massachusetts General Hospital Cancer Center, Boston, MA; Mayo Clinic, Rochester, MN; Cancer Research Institute, Queen's University, Kingston, ON, Canada.

2043 Bone mineral density loss in premenopausal women given adjuvant chemotherapy for early breast cancer is independant of effects on ovarian function. Cameron DA, Douglas S, Creiger J, Anderson RA. Western General Hospital, Edinburgh, Scotland, United Kingdom; University of Edinburgh, Edinburgh, Scotland, United Kingdom.
Health-related quality-of-life and psychological distress of breast cancer patients after surgery during phase III randomized trial comparing further tamoxifen with switching to anastrozole after adjuvant tamoxifen for 1 to 4 years: N-SAS BC 03 . Ohsumi S, Shimozuma K, Ohashi Y, Nishiuchi H, Aihara T, Takatsuka Y. National Hospital Organization Shikoku Cancer Center, Matsuyama, Ehime, Japan; University of Marketing and Distribution Sciences, Kobe, Hyogo, Japan; University of Tokyo, Tokyo, Japan; Kansai Rosai Hospital, Amagasaki, Hyogo, Japan

Leuprorelinacetate 3 month-depot versus CMF as adjuvant treatment in receptor- and node-positive premenopausal patients with breast cancer: long term results of the TABLE-Study.

Schmid P, Possinger K, Kassjanenko I, Vassiljev L, Meurer J, Tschaika M, Maubach L, Wallwiener D, Kahlert S, Untch M. Universitaetsmedizin Charité Campus Mitte, Berlin, Germany; Institute for Experimental Oncology, Kiew, Ukraine; Institute for Medical Radiology, Charkov, Ukraine; Omnicare CR, Cologne, Germany; Pharma East, Berlin, Germany; Takeda Pharma, Aachen, Germany; University, Tuebingen, Germany; University, Munich, Germany.

The effects of atamestane and toremifene alone or combined on bone, serum lipids and uterus, comparing them to letrozole in the ovariectomized rat.

Goss PE, Qi S, Hu H, Cheung AM, Lang W, Blanchett DG, Langecker PJ. Massachusetts General Hospital Cancer Center, Boston, MA; Toronto General Hospital, Toronto, ON, Canada; Intarcia Therapeutics, Inc., Emeryville, CA.

Letrozole did not worsen quality of life relative to placebo in post-menopausal women with early breast cancer: results from the US subjects of the MA-17 study.

Abetz L, Barghout V, Thomas S, Arbuckle R. Mapi Values, Bollington, Macclesfield, United Kingdom; Novartis Pharmaceuticals, Florham Park, NJ.

Impact of Oncotype $\mathrm{DX}^{\mathrm{m}}$ on decision making in breast cancer clinical practice.

Oratz R, Paul D, Cohn A, Sedlacek S. NYU School of Medicine, New York, NY; Rocky Mountain Cancer Centers, Denver, CO.

Economic evaluation of switching to exemestane at 2.5 years versus continuing tamoxifen as adjuvant therapy in early breast cancer: a Canadian perspective.

Risebrough NA, Verma S, Trudeau M, Charbonneau C, Mittmann N. Sunnybrook and Women's College Health Sciences Centre, Toronto, ON, Canada; Ottawa Regional Cancer Centre, Ottawa, ON, Canada; Toronto Sunnybrook Regional Cancer Centre, Toronto, ON, Canada; Pfizer Canmada Inc., Kirkland, PQ, Canada; University of Toronto, Toronto, ON, Canada.

Menostasis subsequent to individually dose-tailored fluorouracil-epirubicin-cyclophosfamide chemotherapy for early breast cancer. Andersson M, Gunnarsdottir K, Møller S, Blomqvist C, Bergh J, Edlund P, Ahlgren J, Mouridsen HT. Rigshospitalet University Hospital, Copenhagen, Denmark; Danish Breast Cancer Cooperative Group, Copenhagen, Denmark; Uppsala Hospital, Uppsala, Sweden; Karolinska Hospital, Stockholm, Sweden 
Initial results from the LEAP Study: the first direct comparison of safety parameters between aromatase inhibitors (Als) in healthy postmenopausal women. McCloskey E, Eastell R, Hannon RA, Lakner G, Miyamoto A Clack G. University of Sheffield, United Kingdom; MÁV Hospital, Hungary; AstraZeneca Pharmaceuticals; AstraZeneca Pharmaceuticals, United Kingdom.

LH-RH analogues, tailored adjuvant chemotherapy and total estrogenic block in patients with estrogen receptor positive (ER+) tumors, preserve ovarian function and improve the clinical outcome of young women with early breast cancer. Recchia F, Saggio G, Cesta A, Candeloro G, Amiconi G, Di Blasio A, Rea S. Civilian Hospital, Avezzano, AQ, Italy; University of L'Aquila, L'Aquila, AQ, Italy.

Cost-effectiveness of letrozole versus tamoxifen as initial adjuvant therapy in hormone-receptor positive postmenopausal women with early breast cancer from a US perspective.

Delea TE, Karnon J, Thomas SK, Barghout V, Papo NL, Johnston SRD. PAI, Brookline, MA; University of Sheffield, Sheffield, United Kingdom; Novartis Pharmaceuticals Corp., Florham Park, Nj; Novartis Pharmaceuticals UK Ltd., Camberley, United Kingdom; Royal Marsden Hospital, London, United Kingdom.

Breast cancer navigator program: clinical trial access, recruitment and enrollment at a large county hospital.

Donnell SK, Leitch AM, Gray E, Aravind R, McKindles D, Tripathy D. UT Southwstrn Med Ctr; UT Southwstrn Med Ctr, Dallas, TX.

Gynecologic interventions during adjuvant therapy with anastrozole or tamoxifen: results from the ATAC trial.

Duffy SR, Distler W, on Behalf of the ATAC Trialists' group. St James's University Hospital, Leeds, United Kingdom; Universitätsklinikum Carl Gustav Carus, Dresden, Germany.

Side effects in treatment with FEC (5-fluorouracil, epirubicin and cyklophosphamide) in standard doses compared to tailored doses, based on hematological toxicity, for primary breast cancer. Results from the Scandinavian Breast Group 2000-1 Study.

Edlund P, Gunnarsdottir K, Anderson H, Moller S, Andersson M, Mouridsen H, Bergh J, Ahlgren J, Blomqvist C. Gavle County Hospital, Gavle, Sweden; Uppsala University, Uppsala, Sweden; Rigshospitalet, Copenhagen, Denmark; DBCG-Secretariat, Copenhagen, Denmark; Karolinska Inst.\& Hospital, Stockholm, Sweden; Lund University, Lund, Sweden.

Cost-effectiveness analysis of letrozole versus tamoxifen as initial adjuvant therapy in hormonereceptor positive postmenopausal women with early breast cancer: the UK perspective.

Karnon J, Delea TE, Barghout V, Thomas SK, Papo NL, Johnston SRD. University of Sheffield, Sheffield, United Kingdom; Policy Analysis Inc., Brookline, MA; Novartis Pharmaceuticals Corp., Florham Park, NJ; Novartis Pharmaceuticals UK Ltd, Camberley, United Kingdom; Royal Marsden Hospital, London, United Kingdom.
Positive cooperative effects of gefitinib, chemotherapeutics and a breast cancer resistant protein inhibitor on cell growth in a fulvestrantresistant estrogen receptor alpha negative MCF-7 cell model.

Liu H, Welchel AK, Cheng D, Osipo C, Jordan VC. Northwestern University, Chicago, IL; Fox Chase Cancer Center, Philadelphia, PA.

Upregulation of HER-2/neu is independent of the menopausal status of primary breast cancer patients: plasma results from a prospectively randomized trial comparing dose-intense chemotherapy with G-CSF support to 3-weekly chemotherapy for adjuvant therapy of nodal-positive (1-3 LN) breast cancer. Lueftner D, Schildhauer S, Eggemann H, Geppert R, Wernecke K, Possinger K, Elling D. Charité Campus Mitte, Berlin, Germany; Oskar-Ziethen-Krankenhaus, Berlin, Germany; Institut für Medizinische Biometrie, Charité Campus Mitte, Berlin, Germany.

Predictors and temporal trends of adjuvant endocrine therapy use in breast cancer.

Svahn TH, Niland JC, Hughes ME, Ottesen RA, Theriault RL, Edge SB, Schott AF, Bookman MA, Weeks JC, Carlson RW. Stanford University, Stanford, CA; City of Hope, Duarte, CA; Dana-Farber Cancer Institute, Boston, MA; M.D. Anderson Cancer Center, Houston, TX; Roswell Park Cancer Institute, Buffalo, NY; University of Michigan, Ann Arbor, Ml; Fox Chase Cancer Center, Philadelphia, PA.

Fatigue and metabolic changes in patients with early breast cancer $(E B C)$ receiving anthracycline-based adjuvant chemotherapy, a longitudinal prospective study.

Meulemans A, Fontaine C, De Meirleir L, Torosian K, Gerlo E, Von Kemp K, Goyens P, De Waele A, Kaufman L, De Greve J. AZ-VUB; ; AZ-Vrije Universiteit Brussels, Jette, Brussels, Belgium.

Chemotherapy-induced amenorrhea (CIA) in patients treated with adjuvant CEF/CMF or EC/docetaxel: analysis from a phase III randomized EC/Doc Trial. Samuelkutty S, Gluz O, Mohrmann S, Hille S, Zwiefel K, Schuett G, Nitz U. University of Duesseldorf, Duesseldorf, Germany.

The development of a prediction tool for chemotherapy-induced anemia in breast cancer patients receiving adjuvant chemotherapy. Dranitsaris $G$, Clemons $M$, Verma S, Vincent $M$. Toronto Sunnybrook Regional Cancer Centre, Toronto, ON, Canada; London Regional Cancer Centre, London, ON, Canada.

Long-term follow-up of sequential dose-dense chemotherapy with epirubicin (E), paclitaxel $(T)$ and cyclophosphamide (C) (ETC) in breast cancer patients with 4-9 positive nodes: final results of a phase I/II study.

Moebus V, Hauser N, Kurbacher C, Lueck H), Thomssen C, Nitz U, Kreienberg R, Untch M. Staedtisches Klinikum, Frankfurt/M., Germany; University of Ulm, Ulm, Germany; Onkologische Praxis, Koeln, Germany; Medizinische Hochschule, Hannover, Germany; University of Halle, Halle, Germany; University of Duesseldorf, Duesseldorf, Germany; University of Grosshadern, Muenchen, Germany. 
A feasibility study of docetaxel in combination with anthracycline and cyclophosphamide or docetaxe followed by anthracycline plus cyclophosphamide in adjuvant therapy for operable breast cancer with positive axillary lymph nodes: CHN TAX 619.

Shen ZZ, Liu GY, Shao ZM, Wang SM, Zhang B, Jiang ZF, He PQ. Cancer Hospital, Fudan University, Shanghai, China; No.2 Affiliated Hospital of Sun Yat-Sen Medical Univesity, Guangzhou, Guangdong, China; Liaoning Province Cancer Hospital, Shenyang, Liaoning, China; Beijing 307 Hospital, Beijing, China; Shanghai No.6 Hospital, Shanghai, China.

Does switching to letrozole improve hot flushes, mood and quality of life in tamoxifen intolerant patients?

Thomas RJ, Marshall C), Williams M, Walker LG. Bedford \& Addenbrookes Cambridge University NHS Trust, Bedford, United Kingdom; University of Hull, Cranfield University, United Kingdom.

Five years use of aromatase inhibitors (Ais) in the clinical practice. Results from the NORA Study. Cazzaniga ME, Mustacchi G, Pronzato P, Di Costanzo F, De Matteis A, Porcu L. Treviglio Hospital, Treviglio, BG, Italy; University of Trieste, Trieste, TS, Italy; La Spezia Hospital, Le Spezia, SP, Italy; Careggi Hospital, Firenze, FL, Italy; Pascale Institute, Napoli, NA, Italy; Mario Negri Hospital, Milano, MI, Italy.

Prolonged dose-dense (DD) epirubicin and cyclophosphamide (EC) followed by paclitaxel ( $T$ ) in breast cancer (BCA) is feasible.

Dang C, Smith K, Lake D, Fornier M, D'Andrea G, Seidman A, Sklarin N, Troso-Sandoval T, Sugarman S, Gilewski T, Robson M, Drullinsky P, Moynahan M, George R, VanPoznak C, Panageas K, Smith M, Norton L, Hudis C. Memorial Sloan-Kettering Cancer Center, New York, NY.

Epirubicin, paclitaxel and CMF as adjuvant treatment in node positive patients with operable breast cancer. Safety analysis of a randomized phase III study comparing two dose-dense sequential regimens. Fountzilas G, Gogas H, Papadimitriou CH, Kalofonos HP, Tsavdaridis D, Christodoulou CH, Briasoulis E, Bafaloukos D, Karina M, Markopoulos CH, Pectasides D, Karapanagiotis K, Papakostas P, Aravantinos G, Kosmidis P, Stathopoulos GP, Dimopoulos AM. Data Office, Athens, Greece.

Adjuvant dose-dense ( 3 FEC 100 followed by 3 docetaxel every 2 weeks) regimen is not feasible. Results of the FNCLCC-PACS 06 Study.

Fumoleau P, Brain E, Delozier T, Asselain B, Serin D, Roché H, Spielmann $M$, Genève J, Jimenez $M$, Bonnetain F. Centre GF Leclerc, Dijon, France; Centre R Huguenin, St-Cloud, France; Centre F Baclesse, Caen, France; Inst. Curie, Paris, France; Inst. Ste-Catherine, Avignon, France; Inst. C Régaud, Toulouse, France; Inst. G Roussy, Villejuif, France; FNCLCC, Paris, France.

2072 Benchmarking the quality of adjuvant systemic therapy for breast cancer using multicenter data systems and practice guidelines: strengths and limitations.

James TA, Watroba N, Kulkarni S, Francavilla B, Edge SB. RoswellPark Cancer Institute; University at Buffalo, Buffalo, NY.
2073 Pilot study of dose dense doxorubicin + cyclophosphamide followed by $\mathrm{ABI}-007$ in patients with early stage breast cancer.

Robert N, Ambro S, Krekow L, Stokoe C, Bhar P, Hawkins MJ, O'Shaughnessy J. U.S. Oncology Research Network, Houston, TX; American BioScience, Inc., Santa Monica, CA

Late adriamycin-related cardiotoxicity of dose-dense and -intense sequential doxorubicin (A), paclitaxel (T) and cyclophosphamide (C) as adjuvant therapy for high risk breast cancer.

Abu-Khalaf $M$, Juneja V, Chung G, DiGiovanna M, Wackers F, Lee F, Burtness B. Yale University School of Medicine, New Haven, CT.

2075 A prospective assessment of variables contributing to reduced relative dose intensity in patients with earlystage breast cancer receiving adjuvant chemotherapy. Shayne M, Culakova E, Wolff D, Poniewierski M, Lyman GH, Dale DC, Crawford J. University of Rochester, Rochester, NY; University of Washington School of Medicine, Seattle, WA; Duke University Medical Center, Durham, NC.

2076. Initial phase II results from 3 dose dense docetaxel pilots in early stage breast cancer.

Yardley DA, Spigel DR, Barton JH, Peacock NW, Shipley DL, Raefsky E, Burris HA. Sarah Cannon Research Institute/Tennessee Oncology, Nashville, TN.

Treatment: Surgery

2077 Intra-operative tissue characterization probe as a potential tool for surgical margin assessment. Karni T, El-Ram R, Pappo I, Sandbank J, Lavon O, Maklakovski M, Evron E, Kent V, Konichezky M, Morgenstern S, Cohen G, Yarden O, Lelcuk S. Breast Care Institute, Assaf Harofeh Medical Center, Zerifin, Israel; Beilinson Medical Center, Petah Tikva, Israel; Dune Medical Devices, Caesarea, Israel; Tel Aviv University, Tel Aviv, Israel.

2078

A novel method for reconstruction of immediate partial mastectomy defects. Spiegel AJ, Khan FN. Baylor College of Medicine, Houston,

Measuring quality in breast reconstruction Liverpool scoring system.

Sridharan U, Holcombe C. Linda McCartney Centre, Royal Liverpool\&Broadgreen University Hospital, Liverpool, Cheshire, United Kingdom

2080 Early removal of post-mastectomy drains is not beneficial: results from a halted randomized controlled trial.

Barton A, Dabbs K, Blitz M, Callahan D, Yakimets W, Adams D. Misericordia Hospital, Edmonton, $\mathrm{AB}$, Canada; University of Alberta Hospital, Edmonton, AB, Canada.

Early results of nipple-areola-sparing subcutaneous mastectomy (NASSM) with complete resection of the retroareolar ductal system (RDS).

Paepke S, Schmidt R, Paepke D, Euler U, Schwarz-Boeger U, Plattner B, Niemeyer M, Humbert A, Schmalfeldt B, Kiechle $M$, Jacobs VR. Technical University of Munich, Klinikum Rechts der Isar, Germany. 
Optimal timing of surgical intervention for the primary tumor in stage IV breast cancer patients improves outcome.

Rao R, Feng L, Kuerer HM, Singletary SE, Hunt KK, Feig BW, Ross MI, Ames FC, Babiera G. University of Texas-MD

Anderson Cancer Center, Houston, TX

2083 A new latissimus dorsi muscle flap technique in oncoplastic surgery -the Bayreuth modification.

Euler U, Tulusan AH, Paepke S, Plattner B, Jacobs VR, Kiechle M. Technical University of Munich, Munich, Germany; Women's Hospital Bayreuth, Bayreuth, Germany.

Oncoplastic technics for breast conservative surgery with ablation of nipple-areolar complex for central breast cancers.

Faure C, Escalon J, Meunier A, Perol D, Delay E. Centre Léon Bérard, Lyon, France.

2085 Evaluation of local recurrence following surgical treatment of screen-detected breast cancer in Wales diagnosed between 1989 and 2003.

Monypenny IJ, Osborn G. Breast Test Wales, Cardiff, Wales, United Kingdom.

2086

The use of intrapleural analgesia following mastectomy and immediate lattisimus dorsi myocutaneous flap breast reconstructions. Chong YM, Long M, Shah D, Sharma AK. St George's Hospital and Medical School, London, United Kingdom.

Tumor Cell Biology: Gene Therapy

2087 Combination therapy of Ad-mda7 and herceptin synergistically increases apoptosis in Her2/neu over expressing breast cancer cells.

Bocangel D, Mhashilkar A, Zheng M, McKinsey T, Liu Y, Menander K, Hunt K, Chada S. Introgen Therapeutics Inc Houston, TX; UTMD Anderson Cancer Center, Houston, TX.

Tumor Cell Biology: Molecular Biology

Reverse phase protein array in breast cancer classification.

Hennessy BT, Lu Y, Tibes R, Gonzalez-Angulo AM, Hortobagyi GN, Valero V, Mills GB. MD Anderson Cancer Center, Houston, TX.

Ras-mediated post-transcriptional regulation of connexin43 expression: interplay between mRNA 3' and ' 5 ' untranslated regions.

Kandouz M, Zhao J, Batist G. Lady Davis Institute - Jewish General Hospital, McGill University, Montreal, QC, Canada.

Constitutively active type I insulin-like growth factor receptor signaling induces transformation and epithelial-mesenchymal transition in mammary epithelial cells.

Kim HJ, Cui X, Britton O, Lee AV. Baylor College of

Medicine, Houston, TX

2091 Involvement of NF-kappaB in inflammatory breast cancer through the induction of epithelial to mesenchymal transition.

Van Laere S), Van der Auwera I, Van den Eynden GG, Benoy IH, Elst H, Van Dam P, Van Marck EA, Dirix LY, Vermeulen PB. Lab Pathology University of Antwerp and Oncology Center, General Hospital Sint-Augustinus, Wilrijk, Antwerp, Belgium.
Transcriptional analysis of factors affecting estrogen regulation in fine needle aspirates.

Schilling EM, Ivancic DZ, Bhandare DJ, Zaichuk T, Khan SA. Northwestern University, Chicago, IL.

Regulation of steroid sulfatase gene expression in breast cancer.

Zaichuk T, Bhandare D, Ivancic D, Khan SA. Northwestern University, Chicago, IL.

2094 Regulation of bcl-2 by the BP1 homeotic protein in breast cancer cells.

Stevenson H, Fu S, Berg PE. George Washington University Medical Center, Washington, DC.

2095 p53 codom 72 polymorphism and the correlation with breast cancer.

Higo PES, Gebrim LH, Vieira JO, Silva IDCG. Federal

University of Sao Paulo, Sao Paulo, Brazil.

2096 Occludin is aberrantly expressed in human breast cancer.

Martin TA, Jiang WG. Wales College of Medicine, Cardiff, United Kingdom.

\section{Tumor Cell Biology: Tumor Biology}

2097

GRB-7 promotes HER-2/Neu mediated signaling and tumor formation in breast cancer cells.

Luoh S-W, Bai T. Portland VA Medical Center, Portland, OR; Oregon Health \& Science University, Portland, OR

Clinical and pathological characterization of basallike breast cancer.

Osborne CR, Kannan L, Ashfaq R, Ariyibi J, Frawley WH, Tripathy D. University of Texas Southwestern Medical Center, Dallas, TX

Influence of pico-tesla range electromagnetic fields on mammary carcinoma protein expression profiles.

Coyne CP, Siyambalapitiyage Dona WSC, Hagood G, Bell E, Lawrence M. College of Veterinary Medicine, Mississippi State University, Mississippi State, MS.

2100 Protein acetylation and hormone-independent breast cancer.

Cui Y, Parra I, Chen Y, Niu A, Fuqua SAW. Baylor College of Medicine, Houston, TX.

2101 Diet and global DNA methylation in breast cancer. Germano PBMR, Silva AG, Madeira M, Correa IC, Pitas AMCS, Bolsoni EMM, Reis LC, Souza FG, Andreoni S, Simony RF, D'Almeida V, Gebrim LH, Correa M, Jasiulionis MG. Universidade Federal de São Paulo, São Paulo, Brazil.

2102 Molecular pathogenesis of breast cancer in women of African ancestry.

Ikpatt OF, Dignam J, Khramtsov A, Xu J, Dangou J, Perou C, Ndoma-Egba R, Malami S, Adelusola O, Falusi A, Olopade Ol. University of Chicago, Chicago, IL; Pasteur Institute, Dakar, Senegal; University of North Carolina at Chapel Hill, Chapel Hill, NC; University of Calabar, Calabar, CRS, Nigeria; Obafemi Awolowo University Hospital, Ile Ife, Osun, Nigeria Usman Danfodio Teaching Hospital, Sokoto, Nigeria; Institute of Medical Research and Training, Ibadan, Oyo, Nigeria. 

potential therapeutic target.

Rizzo P, Miao H, Siziopikou K, Song LL, Bashir A, Koenerner F, Chaturvedi V, Chin JZ, Zhao H, Selvaggi S, Tonetti DA, Nickoloff JB, Miele L. Oncology Institute, Loyola University Chicago, Maywood, IL; University of Illinois at Chicago, Chicago, IL; Rush University Chicago, Chicago, IL; University of Wisconsin, Madison, Wl; Brigham and Women's Hospital, Boston, MA.

Activated c-Src in ductal carcinoma in situ (DCIS) correlates with high tumour grade, high proliferation and HER2 expression.

Wilson GR, Barnes N, Knox F, Cramer A, Swindell R, Kawakatsu H, Dive C, Bundred NJ. South Manchester Acute Hospitals Trust, Manchester, United Kingdom; Paterson Institute for Cancer Research, Chrisite Hospital, Manchester, United Kingdom; University of California, San Francisco, CA

The pure prolactin receptor (PrIR) antagonist $\Delta 1-9$ G129R-hPrl reduces breast cancer clonogenicity and enhances doxorubicin cytotoxicity in vitro.

Howell S), Anderson E, Kalirai H, Clarke RB. University of Manchester, Christie Hospital NHS Trust, Manchester, United Kingdom.

2106 The potential of $\underline{M R I}$ relaxation times to predict biological aggressiveness of breast cancer. Kimijima I, Yoshida S, Sato A, Tamura R. Kita-Fukushima Medical Center, Date, Japan; Kita-Fukushima Medical Center, Date, Kenya.

Chinese herb lycium barbarum inhibits growth of hormone responsive human breast cancer cells by down-regulating $\mathrm{C} 16 \alpha$-hydroxylation pathway of estradiol metabolism.

Telang NT, Li G, Sepkovic DW, Bradlow HL, Wong GYC. Strang Cancer Research Laboratory, New York, NY; Hackensack University Med. Center, UMDNJ, Hackensack, NJ.

2109 Haemangiogenesis and lymphangiogenesis in the primary tumor and in lymph node metastases of breast cancer: a comparative histomorphometrical study.

Van den Eynden GG, Van der Auwera I, Dirix LY, Vermeulen PB, Van Marck EA. Lab Pathology University of Antwerp/University Hospital Antwerp, Edegem; Oncology Center, General Hospital St-Augustinus, Wilrijk, Wilrijk, Antwerp, Belgium.

Phenotypic characterization of inflammatory breast cancers on tissue microarrays: a study of 109 cases with $\mathbf{2 5}$ proteins.

Charafe-Jauffret E, Tarpin C, Esterni B, Bertucci F, Xerri L, Birnbaum D, Jacquemier J, Viens P. Institut Paoli Calmettes, Marseille, France.

PIK3CA mutations in breast cancer: an attractive target for small molecule inhibitors and a potential biomarker for chemoresistance.

Margeli M, Ramirez J, Taron M, Rosell R, Cirauqui B, Mendez P, Castella E, Barnadas A, Sanchez-Ronco M, Santarpia M. Catalan Inst of Oncol, H Germans Trias i Pujol, Badalona, Barcelona, Spain; H de Sant Pau, Barcelona, Spain; A University of Madrid, Madrid, Spain; H Germans Trias i Pujol, Badalona, Barcelona, Spain
Nectin-3: a putative tumour suppressor in human breast cancer.

Martin TA, Harrison GM, Watkins G, Lane J, Jiang WC. Wales College of Medicine, Cardiff, United Kingdom.

2113 Microarray analysis of breast tumor tissue from African American and Ugandan women show that high risk biological features are similar.

Bhatia V, Wabinga H, Baehner F, Mbidde EK, Luce JL. UCSF San Francisco, CA; Uganda Cancer Institute, Makerere University, Kampala, Uganda.

\section{9:00-9:30 PLENARY LECTURE 2 - Exhibit Hall D}

Emerging ethical issues in cancer genetic testing Kenneth Offit, MD

Memorial Sloan-Kettering Cancer Center

New York, NY

9:30-11:15

GENERAL SESSION 3 - Exhibit Hall D

47. Genetically engineered human breast tumors in mice.

Wu M, Boynton G, Cooper A, Breault L, Vincent S, Richardson A, Depinho RA, Robinson M, Kuperwasser C. AVEO Pharmaceuticals, Inc., Cambridge, MA; Tufts University School of Medicine, Boston, MA; Brigham and Women's Hospital, Boston, MA; Dana-Farber Cancer Institute, Boston, MA; Harvard Medical School, Boston, MA

9:45 13. The benefits of sequencing adjuvant tamoxifen and anastrozole in postmenopausal women with hormone-responsive early breast cancer: 5 yearanalysis of ABCSG Trial 8.

Jakesz R, Gnant M, Greil R, Tausch C, Samonigg H, Kwasny W, Kubista E, Stierer M, Luschin G, Mittlboeck M. Vienna Medical School, Austria.

10:00 14. Optimal duration of adjuvant tamoxifen (TAM) in early breast cancer (EBC): ten year results of a randomized trial (TAM-01) of the FNCLCC Breast Group.

Delozier T, Spielmann M, Janvier M, Fourquet A, Veyret C, Weber B, Mauriac L, Petit T, Kerbrat P. Centre Francois Baclesse, Caen, France; Institut Gustave Roussy, Villejuif, France; Centre Rene Huguenin, Saint Cloud, France; Institut Curie, Paris, France; Centre Henri Becquerel, Rouen, France; Centre Alexis Vautrin, Nancy, France; Institut Bergonie, Bordeaux, France; Centre Paul Strauss, Strasbourg, France; Centre Eugene Marquis, Rennes, France.

10:15 16. Updated analysis of NCIC CTG MA.17 (letrozole vs. placebo to letrozole vs placebo) post unblinding. Goss PE, Ingle JN, Palmer MJ, Shepherd LE, Tu D. Massachusetts General Hospital Cancer Center, Boston, MA; Mayo Clinic, Rochester, MN; Cancer Research Institute, Queen's University, Kingston, ON, Canada.

17. Analysis of duration of letrozole extended adjuvant therapy as measured by hazard ratios of disease recurrence over time for patients on NCIC CTG MA.17.

Ingle JN, Goss PE, Tu D. Mayo Clinic, Rochester, MN Massachusetts General Hospital Cancer Center, Boston, MA; Cancer Research Institute, Queen's University, Kingston, ON, Canada. 
18. Switching from adjuvant tamoxifen to anastrozole in postmenopausal women with hormone-responsive early breast cancer: a meta-analysis of the ARNO 95 Trial, ABCSG Trial 8, and the ITA Trial.

Jonat W, Gnant M, Boccardo F, Kaufmann M, Rubagotti A, Jakesz R. University of Frankfurt, Germany; Vienna Medical School, Austria; National Cancer Research Institute \& University of Genoa, Italy.

19. The influence of hormone replacement therapy (HRT) on tamoxifen induced vasomotor symptoms. Sestak I, Kealy R, Edwards R, Cuzick J. Centre for Epidemiology, Mathematics \& Statistics, London, United Kingdom.

11:15-12:00

WILLIAM L. MCGUIRE MEMORIAL LECTURE Exhibit Hall D

Sponsored by GlaxoSmithKline.

Update on HER-2 directed therapy

Dennis J. Slamon, MD, PhD

University of California, Los Angeles

Los Angeles, CA

12:00-1:00

LUNCH [Ticket Required] - Exhibit Hall A

1:00-2:00

CASE DISCUSSION 1 - Ballroom A

2:00-3:30

$$
\text { GENERAL SESSION } 4 \text { - Exhibit Hall D }
$$

20. Continued technical results of NSABP B-32: Does a positive sentinel node biopsy require an axillary dissection?

Julian TB, Anderson S, Brown A, Krag D, Harlow S, Bear H, Ashikaga T, Weaver D, Miller B, Jalovec L, Frazier T, Noyes RD, Robidoux A, Scarth H, Mammolito D, McCready D, Mamounas E, Costantino J, Wolmark N. NSABP Investigators \& NSABP Operations \& Biostatistical Center, Pittsburgh, PA; University of Vermont, Burlington, VT.

21. Significance of sentinel lymph node micrometastasis on survival for patients with invasive breast cancer.

Cox C, Vrcel V, Riker A, White L, Allred N, Ramos D, Myers M, Dupont E, King J, Cantor A, Diaz N. H. Lee Moffitt Cancer Center, Tampa, FL.

22. Prospective study of axillary radiation without axillary dissection for breast cancer patients with a positive sentinel node.

Gadd M, Harris J, Taghian A, Hughes K, O'Neill A, Powell S, Christian R, Lesnikoski B, Kaelin C, Rhei E, Iglehart J, Habin K, Oberg J, Younger J, Winer E, Smith B. Massachusetts General Hospital, Boston, MA; Brigham and Women's Hospital, Boston, MA; Dana-Farber Cancer Institute, Boston, MA

2:45 23. The incidence of venous thromboembolism in breast cancer patients.

Chew HK, Wun T, Harvey D, Zhou H, White RH. University of California Davis, Sacramento, CA; University of California Davis, Davis, CA.

3:00 44. Central review of ER, PgR and HER-2 in BIG 1-98 evaluating letrozole vs. tamoxifen as adjuvant endocrine therapy for postmenopausal women with receptor-positive breast cancer.

Viale G, Regan M, Dell'Orto P, Del Curto B, Braye S, Orosz Z, Brown R, Olszewski WP, Knox F, Oehlschlegel C, Thürlimann B. The BIG 1-98 Collaborative International Breast Cancer Study Group, Bern, Switzerland.

\author{
3:15 45. TBD \\ 3:30-5:00 \\ MINI-SYMPOSIUM 2 - \\ Exhibit Hall D \\ HOMING IN ON BREAST CANCER METASTASIS \\ Suzanne Fuqua, PhD, Co-Moderator \\ Baylor College of Medicine \\ Houston, TX \\ and \\ Adrian Lee, PhD, Co-Moderator \\ Baylor College of Medicine \\ Houston, TX \\ 3:30 Introduction \\ 3:30 Breast cancer metastasis genes and functions \\ Joan Massague, PhD \\ Memorial Sloan-Kettering Cancer Center \\ New York, NY \\ 4:00 Identification and testing of a gene expression \\ signature for invasion and metastasis in mammary \\ tumors \\ John S. Condeelis, PhD \\ Albert Einstein College of Medicine \\ Bronx, NY \\ 4:30 Detection of circulating breast cancer cells: Are these \\ the cells that really matter? \\ Daniel F. Hayes, MD \\ University of Michigan \\ Ann Arbor, MI. \\ Supported by an educational grant from Sanofi-Aventis.
}

5:00-7:00 POSTER DISCUSSION 1 - Ballroom A

Familial Breast Cancer 101-110

101

Clinicopathological characteristics of young onset breast cancer: initial results from a prospective cohort study.

Simmonds PD, Eccles DM, Gerty S. Southampton General

Hospital, Southampton, United Kingdom.

102 protein modeling, loss of heterozygosity, ethnicity, and clinical correlations.

Karchin R, Beattie M, McLennen J, Toland A, Sali A.

University of California, San Francisco, CA.

Radiation exposure and breast cancer risk for BRCA mutation carriers.

Goldfrank DJ, Chuai S, Ramon y Cajal T, Lee JB, Alonso MC, Diez O, Baiget M, Kauff ND, Offit K, Bernstein JL, Robson ME. Memorial Sloan-Kettering Cancer Center, New York, NY; Hospital Sant Pau, Barcelona, Spain.

Prevalence, spectra and founder effects of $B R C A 1$ and $B R C A 2$ germline mutations in Pakistani breast and/or ovarian cancer families.

Rashid MU, Zaidi A, Torres D, Sultan F, Naqvi B, Shakoori AR, Farooq H, Amin A, Hamann U. German Cancer Research Center, Heidelberg, Germany; Shaukat Khanum Memorial Cancer Hospital and Research Center, Lahore, Pakistan; University of the Punjab, Lahore, Pakistan; Lombardi Cancer Center, Georgetown University, Washington, DC. 

Singapore patients with young onset or familial history of breast or ovarian cancer: identification and characterization of a novel $\mathbf{1 0 . 1} \mathbf{~ k b p}$ deletion. Lim YK, Ali AB, lau PT, Sng JH. Faculty of Medicine, National University of Singapore, Singapore; National University Hospital, Singapore.

Incidence and histology of ductal carcinoma in situ in BRCA1/2 mutation carriers.

Kankipati S, Clark D, Shum M, El-Khoury M, Grana G. The Cancer Institute of New Jersey at Cooper University Hospital, Camden, NJ.

Long-term survival (OS) and prognostic factors of BRCA1-associated versus sporadic breast cancer (BC), results of an extended series.

Brekelmans CTM, Seynaeve C, Menke-Pluymers M, TilanusLinthorst MMA, Bartels CCM, Crepin CMG, Blom JC, Van den Ouweland AMW, Meijers-Heijboer H, Klijn JGM.

Erasmus MC - Daniel den Hoed Cancer Center, Rotterdam, Netherlands; Eramus MC, Rotterdam, Netherlands.

BRCA genetic testing and race: the UNC experience. Susswein LR, Skrzynia C, Lewis CL, Graham II ML, Evans JP. University of North Carolina at Chapel Hill, Chapel Hill, NC; Waverly Hematology Oncology, Cary, NC.

A screening approach to detect hereditary cancer risk in under-served women.

Lee R, Crawford B, Beattie MS, Komoromy M, McLennan J, Luce J, Strachowski L, Ziegler J. University of California, San Francisco, San Francisco, CA; San Francisco General Hospital, San Francisco, CA.

110

Risk reduction choices of women with deleterious BRCA1 and BRCA2 mutations at a single institution. Uyei A, Erlichman J, Lu K, Meric-Bernstam F, Strong L, Arun B. UT MD Anderson Cancer Center, Houston, TX; UTMADCC; UTMDACC.

\section{5:00-7:00 POSTER DISCUSSION 2 - Ballroom B}

Breast Cancer Cell Biology 201-212

201 A single mammary stem cell can reconstitute a functional mammary gland.

Shackleton M, Vaillant F, Simpson KJ, Singl J, Smyth GK, Wu L, Visvader JE, Lindeman G). The Walter \& Eliza Hall Institute of Medical Research, Parkville, VIC, Australia; British

Columbia Cancer Agency, Vancouver, Canada.

Identification of multipotent breast stem/progenitor cells in mammospheres derived from human normal breast parenchyma and breast cancer tissue.

Lee JE, Kim JB, Han W, Hwang SE, Lee KM, Bae JY, Shin HJ, Kim S, Kim SW, Kim SW, Noh DY. Seoul National University College of Medicine, Seoul, Korea; Cancer Research Institute, Seoul National University College of Medicine, Seoul, Korea; Clinical Research Institute, Seoul National University Hospital, Seoul, Korea.

203 In vitro propagation and characterization of tumorigenic breast cancer cells with stem/progenitor cell properties.

Daidone MG, Ponti D, Sozzi G, Capelli C, Gariboldi M, Reid JF, Pierotti MA. Istituto Nazionale Tumori, Milan, Italy; IFOM Foundation, Milan, Italy.
Identification of cell-of-origin breast tumour subtypes in inflammatory breast cancer by gene expression profiling.

Van Laere SJ, Van der Auwera I, Van den Eynden GG, Vandenberghe $M$, Benoy $\mathrm{HH}$, Elst H), Van Dam P, Van Marck EA, Dirix LY, Vermeulen PB. Lab Pathology University of Antwerp and Oncology Center, General Hospital SintAugustinus, Wilrijk, Antwerp, Belgium.

Integrated molecular profiling of human breast cell types and breast cancer cell lines using expression microarrays and array $\mathrm{CGH}$.

Iravani M, Fenwick K, Grigoriadis A, Reis-Filho J, Valgeirsson H, Dexter T, Gahir J, Weber B, O'Hare M, Ashworth A, Mackay A. The Breakthrough Toby Robins Breast Cancer Research Centre, London, United Kingdom; Ludwig Insitute for Cancer Research, London, United Kingdom.

Inhibitors of Hsp90 induce the degradation of HER2 and inhibit the growth of HER2-dependent breast tumors.

Solit DB, Basso A, Smith-Jones P, Modi S, Norton L, Larson S, Neckers L, Scher H, Hudis C, Rosen N. Memorial SloanKettering Cancer Center, New York, NY; National Cancer Institute, Rockville, MD.

Real-time dual-color imaging of trafficking, cellular dynamics, and viability of breast cancer cells in the portal vein.

Tsuji K, Yamauchi K, Yang M, Jiang P, Bouvet M, Al-Zaid M, Endo H, Kanai Y, Yamashita K, Moossa AR, Hoffman RM. AntiCancer, Inc., San Diego, CA; University of California, San Diego, San Diego, CA; Kyorin University, Tokyo, Japan.

208 Breast cancer stromal fibroblast cells: in vitro characterization of activity, invasiveness and the effect of transforming growth factor beta 1 (TGF-B1). Casey TM, Eneman J, Crocker A, White J, Tessitore J, Stanley M, Harlow S, Bunn J, Weaver D, Muss H, Plaut K. University of Vermont, Burlington, VT.

Spontaneous fusion of mouse stroma with transformed estrogen receptor-positive epithelium in a solid tumor model of human breast cancer. Jacobsen BM, Harrell JC, Borges V, Garcia MV, Horwitz KB. Univiersity of Colorado Health Sciences Center, Aurora, CO.

210 Genetically modified HER2-specific $T$ cells recognize low and high HER2 expressing breast cancer cell lines. Ahmed N, Ratnayake M, Pule M, Rooney CM, Heslop HE, Gottschalk S. Baylor College of Medicine, Houston, TX.

211 Resistance to erbB targeted therapy in breast cancer Bacus S, Hortobagyi G, Spector N. Molecular Diagnostics, Westmont, IL; MD Anderson Cancer Center and GlaxoWellcome, Research Triangle Park, NC.

212 Mammary cancers in mice expressing mutated Rad51. Shulemovich E, Tornos C, Jasin M, Moynahan ME. Memorial Sloan-Kettering Cancer Center, New York, NY.

5:00-7:00

POSTER SESSION 3 \& RECEPTION Exhibit Hall B

(\#3001-3113)

Prognosis and Prediction: Prognostic Factors

3001 Risk of early relapse in post-menopausal women with early stage, estrogen receptor positive $(E R+)$ breast cancer on tamoxifen.

McArthur HL, Olivotto I, Gelmon KA, Speers CH, Chia S, Ellard S, Kennecke HF. British Columbia Cancer Agency, Vancouver/Victoria/Kelowna, BC, Canada. 
Outcome and prognostic factors among patients with node-negative invasive breast carcinoma that is one centimeter or less in size (stage 1; T1a,b NO MO): the University of Texas M. D. Anderson Cancer Center experience.

Hanrahan EO, Gonzalez-Angulo AM, Broglio K, MericBernstam F, Cristofanilli M, Buccholz TA, Hortobagyi GN, Valero V. M.D. Anderson Cancer Center, Houston, TX

A novel prognostic immunohistochemical biomarker panel for estrogen receptor expressing breast cancer. Ross DT, Ring BZ, Seitz RS, Beck R, Shasteen WJ, Tarr SM Cheang MC, Yoder BJ, Budd GT, Nielsen TO, Hicks DG, Estopinal NC. Applied Genomics Inc., Sunnyvale, CA; Applied Genomics Inc., Huntsville, AL; Cleveland Clinic Foundation, Cleveland, $\mathrm{OH}$; University of British Columbia, Vancouver, BC, Canada; Comprehensive Cancer Center of Huntsville, Huntsville, AL.

3004

Statistical and pathway analysis of multiple prognostic gene signatures in lymph node negative (LNN) primary breast cancer.

Wang Y, Klijn J, Yu J, Zhang Y, Sieuwerts A, Berns E, Atkins D, Foekens J. A Johnson \& Johnson Company, San Diego, CA; Erasmus MC / Daniel den Hoed Cancer Center, 3000 DR, Rotterdam, Netherlands.

Basal-like breast carcinomas: clinical outcome with chemotherapy.

Banerjee SN, Reis-Filho JS, Ashley S, Steele D, Ashworth A, Lakhani S, Smith IE. Royal Marsden Hospital, London, United Kingdom; Institute of Cancer Research, London, United Kingdom; Life and Health Sciences Research Institute, University of Minho, Braga, Portugal; School of Medicine, The University of Queensland, Mayne Medical School, Herston, Queensland, Australia.

A prospective risk model for neutropenic complications in early-stage breast cancer patients receiving adjuvant chemotherapy.

Lyman GH, Kuderer NM, Shayne M, Dale DC, Wolff D, Culakova E, Poniewierski MS, Crawford J, for the ANC Study Group. University of Rochester School of Medicine and Dentistry, Rochester, NY; University of Washington School of Medicine, Seattle, WA; Duke University Medical Center, Durham, NC.

The percentage of positive/dissected nodes is a useful prognostic indicator of postmastectomy recurrence and mortality.

Truong PT, Olivotto IA, Lee IC, Kader HA, Speers CH, Berthelet E. Vancouver Island Centre, British Columbia Cancer Agency, Victoria, BC, Canada.

The prognostic impact of the axillary lymph node ratio in patients with micrometastatic node-positive breast cancer.

Truong PT, Cserni G, Woodward W, Janni W, Tai P, Vlastos G, Vinh-Hung V, the International Nodal Ratio Working Group. British Columbia Cancer Agency, Vancouver Island Centre, Victoria, BC, Canada; Bács-Kiskun County Hospital, Kecskemét, Hungary; University of Texas, M. D. Anderson Cancer Center, Houston, TX; Ludwig-MaximiliansUniversität, München, Germany; University of Saskatchewan, Regina, SK, Canada; Geneva University Hospitals, Geneva, Switzerland; AZ-VUB, Jette, Belgium.
Ki-67/MIB-1 as prognostic marker in women with early breast cancer: a meta-analysis of published studies involving 10.958 patients.

Azambuja E, Cardoso F, Castro Jr G, Colozza M, Larsimont D, Sotiriou C, Piccart MJ, Paesmans M. Jules Bordet Institute, Brussels, Belgium; Azienda Ospedaliera San Sisto, Perugia, Italy.

3010 Clinicopathologic significance of the basal-like subtype in breast cancer: comparison with hormone receptor and Her2/neu expressing phenotypes. Kim MJ, Ro JY, Gong GY. Asan Medical Center; Cornell University, Methodist Hospital.

Prognostic value of pathologic complete response after primary chemotherapy in patients with hormone receptor-positive breast cancer. Guarneri V, Broglio KR, Kau S, Cristofanilli M, Buzdar AU, Valero V, Buchholz TA, Meric F, Middleton L, Hortobagyi GN, Gonzalez-Angulo AM. The University of Texas M.D. Anderson Cancer Center, Houston, TX.

3012 Breast cancer characteristics and 10 year survival in young women.

Kaplan HG, Malmgren JA, Atwood MK. Swedish Cancer Institute, Swedish Medical Center, Seattle, WA; HealthSTAT Consulting, Inc., Seattle, WA; University of Washington, Seattle, WA

Prognostic significance of CDKs profiling in breast cancer.

Kim SJ, Nakayama S, Miyoshi Y, Taguchi T, Tamaki Y, Matsushima T, Torikoshi Y, Tanaka S, Yoshida T, Ishihara $\mathrm{H}$ Noguchi S. Graduate School of Medicine, Osaka University, Suita, Osaka, Japan; Sysmex Corporation, Kobe, Hyogo, Japan.

3014 The survival analysis of immunohistochemically defined basal and luminal subtype of breast cancer. Lee JB, Kim AR, Son GS, Bae JW, Koo BH. Korea University College of Medicine, Seoul, Republic of Korea.

Normalization of urinary $\mathrm{N}$-telopeptide levels by zoledronic acid correlates with improved survival in patients with bone metastases from breast cancer. Lipton A, Hei YJ, Coleman RE, Major P, Smith M, Cook RJ. Milton S. Hershey Medical Center, Hershey, PA; Novartis Oncology, East Hanover, NJ; University of Sheffield, Sheffield, England, United Kingdom; Hamilton Regional Cancer Centre, Hamilton, ON, Canada; Massachusetts General Hospital, Boston, MA; University of Waterloo, Waterloo, ON, Canada.

Predicting relapse in estrogen receptor (ER) positive breast cancer (luminal) subgroups treated with adjuvant tamoxifen.

Loi SM, Desmedt C, Haibe-Kains B, Lallemand F, Gillett C, Tutt A, Ryder K, Ellis P, Harris A, Smeds J, Bergh J, Cardoso F, Piccart MJ, Sotiriou C. Jules Bordet Institute, Brussels, Belgium; Guy's Hospital, London, United Kingdom; Weatherall Institute of Molecular Medicine, University of Oxford, John Radcliffe Hospital, Oxford, United Kingdom; CCK Cancer Centrum Karolinska, Karolinska Institutet and Hospital, Stockholm, Sweden.

3017 Leptin receptor isoforms (OBR-L and OBR-S) expression in breast cancer and relation with clinical outcome.

Revillion F, Charlier M, Lhotellier V, Hornez L, Giard S, Baranzelli MC, Djiane J, Peyrat JP. Centre Oscar Lambret, Lille, France; Institut National de la Recherche Agronomique, Jouy-en-Josas, France. 
Using AQUA ${ }^{\mathrm{rm}}$ and tissue microarrays for discovery of a minimal set of multiplexed markers to subclassify breast cancer.

Dolled-Filhart MP, Cregger M, Camp RL, Rimm DL. Yale

University School of Medicine, New Haven, CT.

Predicting prognosis in early stage primary breast cancer using a five biomarker panel and image assisted immunohistochemistry (IHC) scoring. Ross JS, Boguniewicz AB, Ross MS, Whitehead CM, Morel D, He Q, Sheehan CE. Albany Medical College, Albany, NY; Tripath Oncology, Inc, Durham, NC.

Breast cancer phenotype associated with a propensity for central nervous system (CNS) metastases.

Tham YL, Sexton K, Kramer R, Hilsenbeck S, Elledge R. Baylor College of Medicine, Houston, TX.

Lymph node ratio as a prognostic factor in metastatic breast cancer.

Ueno NT, Cserni G, Wallace AM, Janni W, Royce M, Nieto $Y$, Vinh-hung $\vee$, International Nodal Ratio Working Group. INRWG, Houston, TX; INRWG, Kecskemét, Hungary; INRWG, Albuquerque, NM; INRWG, München, Germany; INRWG, Pamplona, Spain; INRWG, Brussels, Belgium.

3022 Prognostic value of UPA and PAI-1 mRNA expression in primary breast cancer.

Verjat T, Lamy PJ, Grenier J, Servanton AC, Paye M, Krause Marcy I Etoile, France; Centre Regional de Lutte Contre le Cancer Val d Aurelle, Montpellier, France; Centre Leon Berard, Lyon, France.

Breast cancer of the lower inner quadrant is associated with an increased mortality risk among women with early stage disease.

Sarp S, Fioretta G, Verkooijen HM, Wespi Y, Schubert H, Bouchardy C, Vlastos G. Institute for Social and Preventive Medicine, Geneva, Switzerland; Association of Physicians of the Canton of Geneva, Geneva, Switzerland; Geneva University Hospital, Geneva, Switzerland.

3024 Risk factor analysis of early metastatic relapse for post-menopausal patients treated with tamoxifen. Debled M, MacGrogan G, Brouste V, Mathoulin-Pélissier S, Durand M, Mauriac L. Institut Bergonié, Regional Cancer Center, Bordeaux, France.

Four genes by RT-PCR predicts distant relapse for women given adjuvant tamoxifen.

Desmedt C, Loi SM, Haibe-Kains B, Soree A, Lallemand F, Durbecq V, Larsimont D, Tutt A, Ellis P, Gillett C, Ryder K, Harris A, Cardoso F, Martiat PH, Piccart MJ, Sotiriou C. Jules Bordet Institute, Brussels, Belgium; Guy's Hospital, London, United Kingdom; Weatherall Institute of Molecular Medicine, University of Oxford, John Radcliffe Hospital, Oxford, United Kingdom.

-kit expression in high-risk breast cancer treated A, Bachelot T, Puisieux A, Mougin B, Leissner P. BioMerieux,

Genomic alterations identified by array comparative genomic hybridization as prognostic markers in tamoxifen treated estrogen receptor positive breast cancer.

Han W, Han MR, Kang JJ, Bae JY, Lee JE, Shin H), Hwang KT, Hwang SE, Noh DY. Seoul National University College of Medicine, Seoul, Korea; Cancer Research Institute, Seou National University College of Medicine, Seoul, Korea; Macrogen Inc., Seoul, Korea.

Prognostic value of $\mathrm{Ki}-\mathrm{G7}$ in lymph node-negative breast cancer and the usefulness of a combination of $\mathrm{Ki}-\mathbf{6 7}$ and the St. Gallen classification.

Jung SY, Han W, Park IA, Shin HJ, Lee JE, Hwang KT, Hwang SE, Noh DY. Seoul National University College of Medicine, Seoul, Korea.

valuation of TGF- $\alpha$ expression and prevalence of EGFR and HER2 kinase domain mutations in breast cancer.

Konecny GE, Finn F, Seshagiri S, DeForge L, Untch M, Wang HJ, Kahlert S, Slamon DJ, Pegram MD. UCLA, Los Angeles,

CA; Genentech Inc., South San Francisco; Ludwig

Maximilians University, Munich, Germany.

Detection and prognostic significance of HER2 mRNA-positive cells in the peripheral blood of patients with operable breast cancer. Mavroudis D, Perraki M, Apostolaki S, Politaki E, Xenidis N, Manousakis E, Georgoulias V. University General Hospital, Heraklion, Crete, Greece; School of Medicine, University of Crete, Heraklion, Crete, Greece.

HER-2/neu is associated with axillary nodal invasion in breast cancers expressing both hormone receptors. Neven P, Huang HJ, Drijkoningen M, Amant F, Leunen K, Berteloot P, Wildiers H, Van Limbergen E, Paridaens R, Christiaens MR, Vergote I. UZ-Leuven, Leuven, Belgium.

$3032 \quad \beta 1$ integrin expression is prognostic for overall and disease-free survival in breast cancer. Yao ES, Lee B, Chen YY, Moore DH, Chew K, Park CC. University of California, San Francisco, CA.

CSF1 expression signature identifies a subset of breast carcinomas and influences outcome.

West RB, Horlings H, Nuyten DSA, Subramanian S, Zhu SX Miller M, Rubin BP, Nielsen TO, Gilks CB, Huntsman DG Tibshirani R, van de Vijver M, van de Rijn M. Stanford University Medical Center, Stanford, CA; Netherlands Cancer Institute, Amsterdam, Netherlands; Vancouver General Hospital, Vancouver, BC, Canada.

Confirmation of an ER negative PR positive phenotype by quantitative PCR.

Bloom KJ. CLARiENT Inc and University of Southern California, Los Angeles, CA. with high-dose (HD) or conventional dose-dense chemotherapy: results of multivariate analysis from the WSG-AM-01 phase III trial.

Diallo R, Ting E, Gluz O, Mohrmann S, Schuett G, Rody A Geddert H, Schaefer KL, Gabbert HE, Nitz U, Poremba C. Institute of Pathology, Heinrich-Heine-University of Duesseldorf, Duesseldorf, Germany; University Hospital of Duesseldorf, Duesseldorf, Germany; University Hospital of Frankfurt, Frankfurt, Germany.
Disease free survival (DFS) of breast cancer patients with invasive mucinous/tubular (M/T) carcinomas vs invasive ductal/lobular $(D / L)$ carcinomas relative to the grade of the tumor.

Chalchal HI, Derakhshan M, Kazmi N, Cheshenckuk S, Tonita J, Salim M. Allan Blair Cancer Centre, Regina, SK, Canada.

Identifying univariable and multivariable correlates of HER2 amplification.

Crowe JP, Rybicki LA, Patrick RJ, Budd GT, Tubbs R, Hicks D. Cleveland Clinic Foundation, Cleveland, $\mathrm{OH}$. 
Hepsin expression is inversely correlated with patient prognosis in human breast cancer.

Parr C, Watkins G, Jiang WG. Wales College of Medicine,

Cardiff University, Cardiff, United Kingdom.

The androgen receptor gene polymorphisms in human breast cancer: short CAG repeats are associated with lymph node involvement.

Betancor E, Rodriguez FG, Gonzalez A, Cabrera A, Sanchez $M$, Vega V, Murias A, Bohn U, Limeres M, Pestano J, DiazChico BN, Diaz-Chico JC. ICIC - Instituto Canario de Investigacion del Cancer, Las Palmas de Gran Canaria, Canary Islands, Spain; Hospital Materno-Insular and Hospital Dr Negrin, Servicio Canario de Salud, Las Palmas de Gran Canaria, Canary Islands, Spain; University of Las Palmas de GC, Las Palmas de Gran Canaria, Canary Islands, Spain.

The distribution of EGFR mRNA expression in 247 breast carcinomas and its relationship to ER MRNA expression.

Bloom KJ. CLARIENT Inc and University of Southern California, Los Angeles, CA.

CX chemokine receptor 4 (CXCR4) membrane staining is an independent prognostic factor in primary breast cancer.

Blot E, Laberge-Le-Couteulx S, Jamali H, Guillemet C, Duval C, Hellot MF, Pille JY, Picquenot JM, Veyret C. Centre Henri Becquerel, Rouen, France; Faculté de Médecine-Pharmacie, Rouen, France.

$3041 \quad$ Plakoglobin ( $\gamma$-catenin) is a prognostic marker in breast cancer.

Buehler H, Mahnke E, Duvnjak B, Schaller G. Medical Center Marienhospital Herne, Ruhr-Universitaet, Bochum,

Germany; Martin-Luther Hospital, Berlin, Germany; RuhrUniversitaet, Bochum, Germany.

3042 C-KIT expression in ductal carcinoma in situ of the breast: co-expression with HER-2/neu.

Diallo R, Rody A, Schaefer KL, Geddert H, Shroyer KR, Gabbert HE, Kaufmann M, Jackisch C, Poremba C. Institute of Pathology, University of Duesseldorf, Duesseldorf, Germany; University Hospital of Frankfurt, Frankfurt, Germany; University of Colorado at Denver and Health Sciences Center, Denver, CO; University Hospital of Marburg, Marburg, Germany.

3043 Sprouty 4 expression is decreased in node-negative breast cancer and intimately related to expression of cell cycle proteins.

Faratian D, Halliday G, Kerr GR, Thomas JS, Cameron DA, Harrison DJ. University of Edinburgh, Edinburgh, Scotland, United Kingdom; Weastern General Hospital, Edinburgh, Scotland, United Kingdom.

p53 protein accumulation and presence of visceral metastasis are independent prognostic factors for survival in patients with metastatic inflammatory breast carcinoma.

Sezgin C, Gokmen E. Ege University School of Medicine, Bornova, Izmir, Turkey.
Pretreatment plasma leptin and leptin receptor levels in metastatic breast cancer.

Leitzel K, Demers L, Ali SM, Evans DB, Lipton A. Penn State/Hershey Medical Center, Hershey, PA; Lebanon VA Medical Center, Lebanon, PA; Novartis Pharma AG, Basel, Switzerland.

Identification of a mechanistically-defined panel of mRNA markers associated with long-term prognosis of node-negative breast cancer.

Macina RA, Ghosh S, Doval DC, Patole K, Sridhar T, Saxena R, Segal MR, McNeil M, Vartanian S. diaDexus, Inc, South San Francisco, CA; Triesta Sciences, Bangalore, India; Rajiv Gandhi Cancer Institute and Research Center, New Delhi, India; University of California, San Francisco, CA.

Cyclin E2 mRNA expression and metastasis-free survival in untreated node-negative breast cancer patients.

Schmidt M, Glawatz C, Gehrmann MC, Puhl A, von Toerne C, Steiner E, Boehm D, Koelbl H. University of Mainz, Medical School, Mainz, Germany; Bayer HealthCare AG, Levekusen, Germany; Bayer Technology Services, Leverkusen, Germany.

3049 Survivin is a predictor of poor outcome in breast cancer.

Hinnis A, Walker RA. University of Leicester, Leicester, United Kingdom.

3050 Prognostic value of p53 specific mutations in low-risk HER-2/neu negative primary breast cancers. Wu L, Robin HS, Gallarda JL, Eberhardt JS, Muller WD, Sadeghi S, Clark RC. Roche Molecular Systems, Pleasanton, CA; Sharp Memorial Hospital, San Diego, CA; DecisionQ, Washington, DC.

3051 Prognostic and predictive value of CK-19 mRNApositive cells detected by real time RT-PCR in the peripheral blood of patients with axillary lymph node-negative breast cancer receiving adjuvant chemotherapy.

Xenidis N, Perraki M, Pallis A, Kalmanti L, Stathopoulou A, Lianidou E, Mavroudis D, Georgoulias V. University General Hospital of Heraklion, Heraklion, Greece; School of Medicine, University of Crete, Heraklion, Greece; University of Athens, Athens, Greece.

3052 Prognostic factors predicting survival of metastatic breast cancer patients: analysis of $\mathbf{5 9 1}$ patients. Kim SI, Jung SY, Sohn JH, Keum KC, Park BW, Lee KS. Yonsei University Medical College; Yonsei University Medical College, Seoul, Korea.

3053 Expression of leptin and leptin receptor in breast cancer are associated with aggressive histology, distant recurrence and survival.

Kulkarni SA, Saxena S, Bundy R, Groth J, Watroba N, Edge SE, Ambrosone CA, Geradts J. Roswell Park Cancer Institute/SUNY Buffalo, Buffalo, NY.

3054 Comparison of outcomes of hormone receptor (HR) negative, and HER2 negative (triple negative, TN) to HER2 + breast cancer (BC) patients (pts): impact of HER2 status.

Man MC, Moore D, Chen YY, Rugo HS. University of California San Francisco; University of California San Francisco, San Francisco, CA. 
Expression of estrogen receptor and $\mathrm{Ki}-\mathbf{6 7}$ as prognostic factors for locoregional recurrence after breast conserving surgery.

Shin HJ, Han W, Park IA, Hwang KT, Hwang SE, Lee JE, Noh DY. Seoul National University College of Medicine, Seoul, Korea.

Clinicopathologic characteristics and prognostic factors in $\mathbf{4 2 0}$ metastatic breast cancer patients with central nervous system metastases.

Altundag K, Bondy ML, Kau SW, Broglio K, Rivera E. The University of Texas M.D. Anderson Cancer Center, Houston, TX.

Epidemiology, Advocacy, and Education: Epidemiology

3057 Patterns of care in patients included in the TEAM (tamoxifen and exemestane adjuvant multicentre) trial. Differences among the participating countries. van de Velde C), Jones SE, Seynaeve C, Namer M, Kieback DG, Rea DW, Dirix D, Markopoulos C, Hozumi Y, van Nes JG, Klein Kranenburg WM, Putter H. Leiden University Medical Centre, Leiden, Netherlands; US Oncology, Inc., Dallas, TX; Erasmus Medical Centre, Rotterdam, Netherlands; Centre Antoine Lacassagne, Nice, France; University Hospital Maastricht, Maastricht, Netherlands; Institute of Cancer Studies, The University of Birmingham, Birmingham, United Kingdom; St Augustinus Hospital, Wilrijk, Belgium; Euroclinic of Athens, Athens, Greece; Jichi Medical School, Tochigi, Japan.

Benchmarking patterns of utilization among breast cancer patients.

Schafer JM, Lee M-P, Stout KL, Nydam JE, Swisher JM, Siambekos MT, Suvari WC. Sg2, Evanston, IL.

Comorbidity risk model for patients with breast cancer.

Braithwaite D, Ozanne E, Moore D, Belkora J, Esserman L. University of California, San Francisco, San Francisco, CA; Institute for Technology Assessment, Massachusetts General Hospital, Boston, MA.

3060 Decreasing incidence of Paget's disease of the breast among American women.

Chen C-Y, Sun L-M, Anderson BO. University of Washington, Seattle, WA; Fred Hutchinson Cancer Research Center, Seattle, WA.

3061 Breast cancer characteristics at diagnosis among Arab-American women compared to European- and African-American women in the Detroit SEER registry.

Hensley Alford S, Schwartz K, Soliman A, Gruber S, Douglas JA, Johnson CC, Merajver SD. University of Michigan, Ann Arbor, Ml; Karmanos Cancer Institute, Wayne State University, Detroit, Ml; Henry Ford Health System, Detroit, MI.

3062 Pregnancy after breast cancer in Western Australian women.

Ives $A D$, Saunders $C M$, Semmens JB. The Iniversity of Western Australia, Perth, Western Australia, Australia; The University of Western Australia, Perth, Western Australia, Australia.

General population rates of selected conditions and events recorded in breast cancer hormonal therapy trials.

Kulig K, Erensen JG, Zhou Z. Pfizer Inc., New York, NY.
Comparing improvements in survival for older and younger breast cancer patients.

Bhatia P, Hilsenebeck SG, Dunn JK, Klos K, Chenault C,

Morrison A. Baylor College of Medicine, Houston, TX;

University of Texas Health Science Center, Houston, TX.

3065

Variation in breast disease co-occurrence frequencies between pre- and post-menopausal women.

Maskery S, Zhang Y, Hu H, Hooke J, Shriver CD, Liebman M. Windber Research Institute, Windber, PA; Walter Reed Army Medical Center, Washington, DC

Distinct breast cancer incidence and survival patterns according to histopathology: analysis of the $\mathrm{NCl}$ 's SEER database.

Anderson WF, Jatoi I. National Cancer Institute, Bethesda, MD; National Naval Medical Center and Uniformed Services University, Bethesda, MD.

3067 Incidence and risk factors for lymphedema after axillary lymphadenectomy for breast cancer. Bergmann A, Mattos IE, Koifman RJ, Ribeiro MJP. National School of Public Health, Rio de Janeiro, Brazil; National Cancer Institute, Rio de Janeiro, Brazil.

Trends in breast cancer incidence in Scotland: the influence of screening and deprivation.

Brown SBF, Hole DJ, Cooke TG. Glasgow Royal Infirmary, Glasgow, United Kingdom; University of Glasgow, Glasgow, United Kingdom.

registHER: treatments and clinical outcomes from a prospective observational cohort study of patients with HER2-positive metastatic breast cancer. Brufsky A, Rugo H, Tripathy D, Kaufman P, Mayer M, Paik S, Ulcickas-Yood M, Yardley D, Tan-Chiu E. University of Pittsburgh Cancer Center, Pittsburgh, PA; UCSF Comprehensive Cancer Center, San Francisco, CA; University of Texas Southwestern Medical Center, Dallas, TX; Dartmouth-Hitchcock Medical Center, Lebanon, NH; Patient Advocate, New York, NY; National Surgical Adjuvant Breast Bowel Project, Pittsburgh, PA; EpiSource, LLC and Yale University School of Medicine, New Haven, CT; Sarah Cannon Cancer Center, Nashville, TN; Cancer Research Network, Plantation, FL.

3070

Do changes in ER status explain improvements in survival? Henley NC, Hole DJ, Leake RE, Cooke TC. University of Glasgow, Glasgow, United Kingdom; University of Glasgow, United Kingdom.

3071 The incidence and outcomes of gestational breast cancer in Western Australian women.

Ives AD, Saunders CM, Semmens JB. The University of Western Australia, Perth, Western Australia, Australia; The Iniversity of Western Australia, Perth, Western Australia, Australia.

A systematic review and descriptive analysis of inflammatory breast cancer clinical trials. Kim TY, Lau J, Erban J. Tufts-New England Medical Center, Boston, MA; Institute for Clinical Research and Health Policy Studies, Tufts-New England Medical Center, Boston, MA. 
Breast cancer in young women age $<\mathbf{3 6}$ years: a retrospective analysis of prognostic factors in $\mathbf{9 0 8}$ patients in $\mathbf{8}$ french instituitions. GETNA Group. Pouillart P, Gligorov J, Guilhaume M, Spielmann M, Luporsi E, Rivera S, Penault-Llorca F, Aimard L, Savignoni A, Asselain B, Namer M. Institut Curie, Paris, France; Tenon Hospital, Paris, France; Institut Gustave Roussy, Villejuif, France; Alexis Vautrin, Nancy, France; Geoges Francois LeClerc, Dijon, France; Jean Perrin, Clermont Ferrand, France; Hospital Ambroise Pare, Marseille, France; Antoine LaCassagne, Nice, France.

A survey of breast cancer screening activity and beliefs among Arab women in the Detroit metropolitan area.

Schwartz KL, Shah B, Kakish M, Bartoces MG, Monsur J, Fakhouri M. Wayne State University, Detroit, Ml; Arab American and Chaldean Council, Lathrup Village, MI.

3075.

Relationship between educational level and breast cancer.

Sun W, Zhang Y, Hooke J, Brzeski H, Shriver CD, Liebman $\mathrm{MN}, \mathrm{Hu} \mathrm{H}$. Windber Research Institute, Windber, PA; Walter Reed Army Medical Center, Washington, DC

Epidemiology, Advocacy, and Education: Advocacy and Education

Dying with breast cancer - an audit. Clemons $M$, Simmons C, Sue J, Fralick J, Fralick M, Blair A, Fitzgerald B, Zalany L, Beaudoin G, Marcus T. Sunnybrook and Women's College Health Science Centre, Toronto, ON, Canada.

Patient satisfaction in breasst cancer care - results from the patient satisfaction and quality in oncological care study (PASQOC ${ }^{\circledR} 2004$ ). Kleeberg UR, Behrens MS, Heiden I. Hamburg Cancer Society, Hamburg, Germany; GlaxoSmithKline GmbH \& Co. KG, Munich, Germany; Picker Institute Deutschland, Hamburg, Germany.

3078 Efficacy of internet-based education for patients with post breast therapy pain syndrome and lymphedema. Wascher RA, Rosenbaum E, Andrews A, Manuel F, Shapiro R, Dollbaum CM. Cancer Research Center, University of Hawaii, Honolulu, HI; Stanford Hospitals and Clinics, Palo Alto, CA; Union Memorial Hospital, Baltimore, MD; University of California at San Francisco, San Francisco, CA.

3079 Neoadjuvant vs. adjuvant chemotherapy: young women's experiences, attitudes and information needs after diagnosis.

Berlin LM, Westphal LM, Rugo HS. Young Moms with Breast Cancer, San Jose, CA; Stanford University, Stanford, CA; University of California at San Francisco, San Francisco, CA.

3080 Does inequality of access affect whether patients have breast reconstruction after mastectomy? A survey of breast care nurses in the South West region of the UK.

Scarrott S, Cassidy-Gray M, Thomas A, Mansoor I, Titcomb D, Bristol JB, Chan HY. Cheltenham General Hospital, Cheltenham, Gloucestershire, United Kingdom.

$3081 \quad$ Alamo breast cancer foundation patient advocate program.

Eastman D.
Knowledge and practice of breast-self examination in underserved population (Goiania - Brazil).

Freitas Junior R, Koifman S, Santos NRM, Nunes MOA, Melo AFB. Goias Federal University, Goiania, GO, Brazil; Oswaldo Cruz Foundation, Rio de Janeiro, RJ, Brazil; Hospital das Clinicas, Goias Federal University, Goiania, GO, Brazil.

3083

Assessing the needs of women with advanced (metastatic) breast cancer.

Mayer M, Grober SE, Caplan ES. Living beyond Breast Cancer, Ardmore, PA.

Creating a DNA bank for pharmacogenomic epidemiology: the Friends for Life study.

Lemler S, Rufenbarger C, Skaar T, Murphy V, RushTaylor A Garvey J, Thompson B, Christmon D, Coleman N,

Rosenberg L, Schneider B, on Behalf of the Friends for Life Volunteers. Indiana University, Indianapolis, IN; Catherine Peachey Fund.

$3085 \quad$ Mucositis - an evolving problem.

Dollbaum CM, Andrews A, Wascher RA, Rosenbaum E, Ignoffo RJ. University of California at San Francisco, San Francisco, CA; Stanford Hospitals and Clinics, Palo Alto, CA; Cancer Research Center, University of Hawaii, Honolulu, HI.

3086 Emerging solutions: moving from informed consent to informed choice, an advocate collaborative model. Devine P, Brady C. Cancer Information \& Support Network, Pleasanton, CA.

Epidemiology, Advocacy, and Education: Racial Aspects

3087 Differential gene expression in normal breast tissue from African American and Caucasian women. Field LA, Love BJ, Kane J, Deyarmin B, Hooke JA, Ellsworth RE, Shriver CD. Windber Research Institute, Windber, PA; Walter Reed Army Medical Center, Washington, DC.

Racial disparities in the utilization of adjuvant chemotherapy and radiation therapy in elderly patients with early stage breast cancer: a populationbased study.

Hershman DL, McBride RB, Wang X, Grann VR, Jacobson JS, Neugut Al. Mailman School of Public Health, Columbia University, New York, NY; College of Physicians and Surgeons, Columbia University, New York, NY.

3089 Delays and receipt of adjuvant chemotherapy and radiation therapy in breast cancer patients: $a$ population-based study. Hershman DL, Wang X, McBride RB, Jacobson JS, Grann VR, Neugut Al. Mailman School of Public Health, Columbia University, New York, NY; College of Physicians and Surgeons, Columbia University, New York, NY.

Impact of ethnicity on conditional survival of breast cancer patients: analysis from the SEER database. Wang SJ, Luh JY, Fuller CD, Thomas, Jr CR. University of Texas Health Science Center, San Antonio, TX.

Low socio-economic status African-American, Hispanic \& white women with breast cancer demonstrate similar hormone receptor status, tumor grade \& survival.

Dookeran KA, Wang Y, Ferrer K, Sekosan M, Gao X, De La Torre R, Diaz de Leon L, Lukaszcyk B, Roman G, Muthyala N, Rogowski WA, Zaren HA. University of Illinois at Chicago, Chicago, IL; Stroger Hospital of Cook County, Chicago, IL. 
Racial/ethnic differences in delay in obtaining medical care for breast symptoms.

Friedman LC, Kalidas M, Elledge R, Chang J, DuLay MF,

Romero C, Liscum KR. Baylor College of Medicine, Houston, TX; Baylor College of Medicine-The Methodist Hospital Breast Care Center, Houston, TX.

Factors affecting breast cancer screening practices among African American women in Western New York.

Hurd TC, Chapman IR, Kelly M, Wall B, Rodgers T, Womack SD. University of Texas Health Sciences Center, San Antonio, TX; Roswell Park Cancer Institute, Buffalo, NY; State University of New York at Buffalo, Buffalo, NY.

Racial differences do not predict response to induction chemotherapy.

Maloney N, Schneider H, Elkins D, Goffman T, Laronga C. Eastern Virginia Medical School, Norfolk, VA.

Eligibility to the study of tamoxifen and raloxifene (STAR) by ethnicity in New Mexico (NM).

Vargas Y, Parsons A, Heurtin-Roberts S, Verschraegen C,

Moser R, McCaskill-Stevens W. NCI/NIH, Bethesda, MD;

UNM, Albuquerque, NM.

3096 Breast cancer treatment and survival in African Americans and Caucasians.

Simon M, Banerjee M, Schwartz K, May HC, Noone AM, Vigneau F. University of Michigan, Ann Arbor, Ml; Karmanos Cancer Institute, Wayne State University, Detroit, MI.

Understanding racial differences in outcome from metastatic breast cancer (MBC): a pooled analysis of Cancer and Leukemia Group B (CALGB) 9342 and 9840.

Polite BN, Cirrincione C, Fleming GF, Berry DA, Seidman AD, Muss H, Norton L, Hudis C, Winer EP. University of Chicago Medical Center, Chicago, IL; Duke University Medical Center, Durham, NC; Memorial Sloan-Kettering Cancer Center, New York, NY; University of Vermont, Burlington, VT; Dana-Farber Cancer Institute, Boston, MA.

3098 Does screening underserved/minority women for breast cancer under the age of $\mathbf{5 0}$ make a difference? Shum M, Robles E, Kankipati S, El-Khoury M, Bodofsky E, Grana G. The Cancer Institute of New Jersey at Cooper University Hospital, Camden, NJ.

Hormone replacement therapy (HRT) may not increase the incidence of breast cancer in Japan.

Saeki T, Takashima S, Takeuchi M, Sano M, Honjo H, Sonoo H, Ochiai K, Komoike Y. Saitama Medical School, Irumagun, Saitama, Japan; Shikoku Cancer Center, Matsuyama, Ehime, Japan.

Cyclophosphamide and 5-fluorouracil: an alternative neoadjuvant chemotherapy for patients with stage II breast cancer in underdeveloped countries. Vigil CE, Vigil KJ, Valdivia S, Velarde R, Vigil Sr CE. Henry Ford Hospital, Detroit, Ml; Instituto de Enfermedades Neoplasicas, Lima, Peru.

3101 A comparison of clinicopathological features and molecular markers in British and Nigerian women with breast cancer.

Gukas ID, Jennings BA, Mandong BM, Girling A, Igun G, Prime W, Leinster S). University of East Anglia; Norfolk and Norwich University Hospital Trust, Norwich, United Kingdom; Jos University Teaching Hospital, Jos, Nigeria; Univeristy of Liverpool, Liverpool, United Kingdom.

\section{Tumor Cell Biology: Drug Resistance}

The SNP309 HDM2 polymorphism is associated with chemoresistance and poor survival in breast cancers harboring mutations in the TP53 gene.

Staalesen V, Knappskog S, Geisler S, Baumbusch L, BørresenDale AL, Lillehaug JR, Lønning PE. University of Bergen, Bergen, Norway; Haukeland University Hospital, Bergen, Norway; The Norwegian Radiumhospital, Oslo, Norway.

Activation of nuclear factor (NF)-kB is linked to resistance to neoadjuvant chemotherapy in breast cancer patients.

Montagut C, Tusquets I, Domingo-Domenech J, Corominas JM, Ferrer B, Bellosillo B, Fernandez PL, Rovira A, Suarez M, Albanell J. Hospital del Mar - IMAS, Barcelona, Spain; Hospital Clinic, Barcelona, Spain.

3104 Altered prostaglandin-signalling in hormone resistant breast cancer by microarray and real time PCR validation.

Scott DJ, Cummings M, Parkes AT, Poola I, Speirs V. Institute of Molecular Medicine, Epidemiology and Cancer Research, University of Leeds, Leeds, W Yorks, United Kingdom; Howard University, Washington, DC.

Gene expression profile of ATP binding cassette (ABC) transporter in breast cancer patient in relation to the response to neoadjuvant chemotherapy. Park S, Shimizu C, Shimoyama T, Takeda M, Hasegawa T, Nishio K, Ando M, Katsumata N, Kouno T, Fujiwara Y. National Cancer Center Hospital, Tsukiji, Chuo-ku, Tokyo, Japan; National Cancer Center Research Institute, Tsukiji, Chuo-ku, Tokyo, Japan.

Elevated c-met expression accompanies endocrine resistance in MCF7 breast cancer cells and promotes in vitro cell migration and invasion. Hiscox S, Harper M, Jiang WG, McClelland R, Nicholson RI. Cardiff University, Cardiff, United Kingdom; Cardiff University Medical School, Cardiff, United Kingdom

3107 A novel role for the ASK/JNK pathway in mediating Akt-induced endocrine therapy resistance. Nielsen A, Silva JM, Friedrichs WE, Beeram M, deGraffenried LA. UT Health Science Center at San Antonio, San Antonio, $\mathrm{TX}$

Zinc-dependant stimulation of Src, EGFR and IGFR signalling pathways in tamoxifen-resistant breast cancer and the role of zinc transporters. Taylor KM, Vichova P, Hiscox S, Nicholson RI. Cardiff University, Cardiff, UK, United Kingdom.

Overexpression of c-Myc confers anti-estrogen resistance in breast cancer cells. McNeil CM, Sergio CM, Butt AJ, Musgrove EA, Sutherland RL. Garvan Institute of Medical Research, Darlinghurst, NSW, Australia.

3110 Expression patterns of 5-fluorouracil metabolismrelated genes in breast cancer using focused DNA array.

Shimada K, Kuroki S, Ohshima A, Takeda T, Shirahane K, Koga K, Tanaka M. National Hospital Organization, Kokura Hospital, Kitakyushu, Fukuoka, Japan; Graduate School of Medical Sciences, Kyushu University, Fukuoka, Japan. 
Tamoxifen failure in breast cancer: use of gene expression array and immunohistochemistry tissue micro arrays to define a molecular signature of tamoxifen resistance.

Bray SE, Robertson K, Vendrell J, Nguyen C, Purdie CA Thomson G, Thompson AM, Cohen P. University of Dundee, Dundee, United Kingdom; University of

Montpellier, Montpellier, France; University of Aix-Marseille II, Marseille, France.

Therapeutic modulation of anti-estrogen resistance through histone deacetylase inhibition.

Beeram M, Russell DH, Friedrichs WE, Silva JM,

deGraffenried LA. UT Health Science Center at San

Antonio, San Antonio, TX

3113 SERM-resistant breast cancer is cross-resistant to tibolone.

Osipo C, Meeke K, Cheng D, Betrucci A, Weichel A, Kloosterboer HJ, Jordan VC. Feinberg School of Medicine Northwestern University, Chicago, IL; Fox Chase Cancer

Center, Philadelphia, PA; Organon, Netherlands.

\section{SATURDAY, DECEMBER 10}

7:00-9:00

\section{POSTER SESSION 4 \& CONTINENTAL} BREAKFAST - Exhibit Hall B

(\#4001-4113)

Risk and Prevention: Familial Breast Cancer / Genetic Testing

4001 Genetic counseling and testing for hereditary breast cancer in underserved women.

Beattie MS, Lee RF, Crawford B, Komaromy M, McLennan J, Luce J, Ziegler J. University of California, San Francisco, San Francisco, CA

4002

German populations with infrequent CHEK2*1100delC and minor associations with earlyonset and familial breast cancer.

Hamann U, Rashid MU, Jakubowska A, Justenhoven C, Harth V, Pesch B, Baisch C, Pierl CB, Bruening T, Ko Y, Benner A, Wichmann HE, Brauch H, the GENICA Network. German Cancer Research Center, Heidelberg, Germany; Pomeranian Medical University, Szczecin, Poland; Dr. Margarete FischerBosch-Institute of Clinical Pharmacology, Stuttgart, Germany; Berufsgenossenschaftliches Forschungsinstitut für Arbeitsmedizin, Ruhr University Bochum, Bochum, Germany; Johanniter Krankenhaus, Bonn, Germany; GSFNational Research Centre for Environment and Health, Institute of Epidemiology, Neuherberg, Germany.

Actively approaching breast cancer patients for genetic counseling during adjuvant radiotherapy: does it harm?

Warlam-Rodenhuis CC, Schlich-Bakker KJ, van Echtelt J, Ausems MG, ten Kroode HF. University Medical Center Utrecht, Utrecht, Netherlands.

Genetic testing for $B R C A 1$ and $B R C A 2$ mutations in the Hispanic population.

Erlichman J, Valero V, Lu K, Rivera E, Strong L, Arun B. UT MD Anderson Cancer Center, Houston.

4005 Determinants in the uptake of genetic testing for BRCA1/2 mutations.

Fowler ES, Neese ER, Schwartzberg LS. Baptist Centers for Cancer Care, Memphis, TN; The West Clinic, Memphis, TN.
Breast cancer risk management choices by women with inherited breast cancer predisposition: a preliminary analysis.

Kurian AW, Hartman AR, Mills MA, Jaffee M, Chun NM, Garber JE, Ford JM, Plevritis SK. Stanford University Schoo of Medicine, Stanford, CA; Dana-Farber Cancer Institute, Boston, MA.

4007 Characteristics of pre-menopausal invasive breast cancer and age-associated risk of breast cancer in BRCA1 and BRCA2 mutation carriers compared with non-carriers (BRCA0).

McLennan JL, Crawford BC, Stewart N, Mak J, Lee R, Braithwaite D, Esserman L, Ziegler J. UCSF Comprehensive Cancer Center, San Francisco, CA

Patients' perceived breast cancer risk and psychological distress: can oncologist-based counseling achieve durable improvements? Mertens WC, Katz D, Quinlan M, Barham R, Carr C, MakariJudson G. Baystate Regional Cancer Program, Springfield MA.

Risk-reducing strategies in breast cancer: a decision analysis.

Chagpar AB, Studts JL, Abell T, Ruberg J, Fleming M, McMasters KM. University of Louisville, Louisville, KY; Ouray Research Consulting, Ouray, CO.

$B R C A 1$ and $B R C A 2$ mutations in a South American population.

Reyes JM, Jara L, Bustamante E, Seccia L, Rodriguez J, Bustamante M, Martinez V, Catenaccio A, Lay-Son G, Blanco R, Gonzalez-Hormazabal P. Instituto Oncologico, Clinica Las Condes, Las Condes, Santiago, Chile; Institute of Biomedical Sciences, School of Medicine, Universidad de Chile, Santiago, Chile; Corporracion Nacional del Cancer Santiago, Chile.

4011 A strong family history of breast cancer increases the use of systemic treatment among patients with earlyonset breast cancer: results from a population-based study.

Verkooijen HM, Chappuis PO, Rapiti E, Vlastos G, Fioretta G, Sarp S, Sappino AP, Schubert H, Bouchardy C. Institute for Social and Preventive Medicine, Geneva, Switzerland; Geneva University Hospital, Geneva, Switzerland.

Risk and Prevention: Prevention

4012 Preliminary results of a randomized phase Ilb doubleblind $2 \times 2$ trial of low-dose tamoxifen and fenretinide for breast cancer prevention.

Bonanni B, Guerrieri-Gonzaga A, Robertson C, Serrano D, Cazzaniga M, Mora S, Gulisano M, Johansson H, Galimberti V, Intra M, Latronico A, Franchi D, Pelosi G, Decensi A. European Institute of Oncology, Milan, Italy; Strathclyde University, Glasgow, United Kingdom; Ospedale San Bortolo, Vicenza, Italy.

Celecoxib downregulats estrogen receptor expression in breast tissue of women at increased risk for developing breast cancer.

Arun B, Valero V, Hornbeak J, Gong Y, Broglio K, Logan C, Browne D, Hortobagyi G, Sneige N. The University of Texas MD Anderson Cancer Center, Houston, TX; BMO, Houston, TX; Houston, TX; NCl, Bethesda, MD 
Chemopreventive efficacy of new RXR specific retinoids against mammary cancers and correlations with short-term biomarkers.

Christov K, Muccio D, Brouillette W, Atigadda R, Desphande A, Bland K, Beenken S, Grubbs C, Lubet R. University of Illinois at Chicago, Chicago, IL; University of Alabama at Birmingham, Birmingham, AL; National Cancer Institute, Bethesda, MD.

Reproducibility of ductal lavage findings in high-risk women.

Bhandare DJ, Nayar R, Masood S, Bryk M, Cohn R, Hou N, Rademaker A, Khan SA. Northwestern University Feinberg School of Medicine, Chicago, IL; University of Florida

College of Medicine, Jacksonville, FL.

Bone turnover by osteocalcin and risks of breast cancer and fracture: a prospective study.

Cummings SR, Blackwell T. California Pacific Medical Center Research Institute, San Francisco, CA; University of

California, San Francisco, San Francisco, CA

Chemopreventive effects of the EGFr inhibitor Iressa in the methylnitrosourea (MNU) - induced model of mammary carcinogenesis.

Grubbs C, Christov K, You M, Wang Y, Steele V, Juliana M, Lubet R. University of Alabama at Birmingham, Birmingham, AL; University of Illinois at Chicago, Chicago, IL; Washington University, St. Louis, MO; National Cancer Institute, Bethesda, MD.

Breast endoscopy in the evaluation of individuals in a high-risk breast cancer clinic.

Ley M, Frank D, Davis J, Degan J, Lacovara J, Waer A, Kim C. University of Arizona, Arizona Cancer Center, Tucson, AZ; ; University of Arizona.

4019 Chemopreventive effects of the statins, lipitor (Atorvastatin) and lovastatin, in the methylnitrosourea (MNU) induced model of mammary carcinogenesis.

Lubet R, Grubbs C, Steele V, Eto I, Juliana M, Kopelovich L. National Cancer Institute, Bethesda, MD; University of Alabama at Birmingham, Birmingham, AL.

Curcumin induces cell cycle arrest and apoptosis in an in vitro model for hormonally non-responsive ductal carcinoma in situ.

Crawford CV, Thakur S, Kim D, Osborne MP, Katdare M. Weill Medical College of Cornell University, New York, NY; Strang Cancer Prevention Center, New York, NY.

Effect of estrogen deprivation on proliferation marker Ki-67 and minichromosome maintenance protein-2 (Mcm-2) in normal postmenopausal breast tissue: potential biomarkers for chemoprevention. Kendall AH, Williams $G H$, Stoeber K, Salter J, Dowsett $M$. Royal Marsden Hospital, London, United Kingdom; Wolfson Institute for Biomedical Research, University College London, London, United Kingdom

Association of RAR $\beta 2$, ER, BRCA and p16 promoter methylation with cytologic atypia in random periareolar fine needle aspiration (RPFNA) breast tissue of asymptomatic women at high risk for breast cancer.

Seo PH, Bean GR, Baker Jr. JC, Scott JV, Rasheed K, Yee LD, Troch MM, Case N, Bowie ML, Marcom PK, Kimler BF, Zalles CM, Sloane R, Fabian C), Seewaldt VL. Duke University Medical Center, Durham, NC; Ohio State University Medical Center, Columbus, $\mathrm{OH}$; University of Kansas Medical Center, Kansas City, KS.
Effect of raloxifene on invasive breast cancer incidence in postmenopausal women stratified by body mass index $\left(<25\right.$ and $\left.\geq \mathbf{2 5} \mathbf{~ k g} / \mathrm{m}^{2}\right)$.

Cauley J, Disch D, Dowsett S, Mershon J. University of Pittsburgh, Pittsburgh, PA; Eli Lilly and Company, Indianapolis, IN

Identification of genes modulated by LGD1069, a rexinoid that prevents mammary tumorigenesis. Li Y, Kim H, Uray I, Bissonnette R, Lamph W, Johnson K, Brown P. Baylor College of Medicine, Houston, TX; Ligand Pharmaceuticals, Inc, San Diego, CA; National Cancer Institute, National Institutes of Health, Bethesda, MD.

Activation of ATM and p53 in mammary gland epithelial cells as a possible breast cancer prevention model.

Loehberg CR, Thompson T, Kastan MB, Conneely OM, Medina D, O'Malley BW. Baylor College of Medicine, Houston, TX; St. Jude Children's Research Hospital, Memphis, TN

Induction of apoptosis in the absence of p53: implications for chemoprevention for ER-negative breast cancer.

Lee MH, Ganai S, Barnard Z, Mason HS, Arenas RB. Pioneer Valley Life Sciences Institute, Springfield, MA; Baystate Medical Center, Springfield, MA; University of Massachusetts, Amherst, MA.

Expression of prostaglandin $E_{2}$ receptor, $E_{1}$, in breast cancer.

Morimiya A, Mehrotra S, Konger R, Badve S. Indiana University, Indianapolis, IN.

Counceling and care combined with breast self examination training as motivation strategy for breast cancer awareness and participation in breast cancer screening programs.

Artmann A, Heyne M, Ruessmann B, Hammes A, Kiechle M, Harbeck N. Technical University of Munich, Klinikum Rechts der Isar, Germany.

4029 Anticarcinogenic effects of citrus auraptene on rat breast cancer.

Kleiner HE, Campbell CT, Prince M, Robertson TA, Krishnan P, Li BD, Chu QD. Louisiana State University Health Sciences Center, Shreveport, LA.

A case-control study evaluating the association of purposeful physical activity, body fat distribution and steroid hormones on pre-menopausal breast cancer risk.

Kumar NB, Riccardi D, Cantor A, Dalton K, Allen K. H. Lee Moffitt Cancer Center \& Research Inst, Tampa, FL.

4031 The controversy of annual mammographic screening (AMS) for $\mathbf{4 0}$ to $69 y$-o women of Brazilian cohort of 10.000 underserved women.

Caleffi M, Duarte Filho D, Skoniesky G, Bedin Jr A, Zignani JM, Antunes LP, Dias EC, Ashton-Prolla P, Weber B, Kivitz P, Graudenz MS, Pohlmann PR. Hospital Moinhos de Vento, Porto Alegre, RS, Brazil. 
Improved survival, Quality Of Life (QOL), and quality-adjusted survival (QAS) in breast cancer patients treated with efaproxiral (EFAPROXYN"') + whole brain radiation therapy (WBRT) for brain metastases.

Scott C, Suh J, Stea B, Nabid A, Hackman J. CBS Squared; Cleveland Clinic Hospital; $U$ of AZ Health Sciences Center Centre Hospitalier U de Sherbrooke; Allos Therapeutics.

4033 Decision-making process for early-stage breast cancer is surgeon driven.

Nkoy FL, Rees W, Sause W, Hammond E, Pinto K, Rowe K. Intermountain Health Care (IHC), SLC, UT

4034 Adjuvant chemotherapy in stage II node positive male breast cancer.

Walshe JM, Vatas U, Berman AW, Steinberg SM, Llppman ME, Anderson WF, Swain SM. Cancer Therapeutics Branch; Biostatistics and Data Management Section, National Cancer Institute, NIH, Bethesda, MD; Univ of Michigan, Ann Arbor, Ml; Division of Cancer Epidemiology \& Genetics, National Cancer Institute, NIH, Bethesda, MD.

Treatment: Radiation Therapy

4035 Long-term risk of cardiovascular disease in 10-year survivors of breast cancer.

Hooning MJ, Botma A, Aleman BM, Klijn JG, van Leeuwen FE. Netherlands Cancer Institute, Amsterdam, Netherlands; Erasmus MC, Daniel den Hoed Cancer Center, Rotterdam, Netherlands.

Stroke rates and risk factors in patients treated with radiation therapy for early stage breast cancer. Jagsi R, Griffith KA, Koelling T, Roberts R, Pierce LJ. University of Michigan, Ann Arbor, Ml; Massachusetts General Hospital (Visiting Researcher, $U$ of Michigan), Boston, MA.

4037 Inverse-planned, dynamic, multi-field, intensity modulated radiation therapy (IMRT) for left sided breast cancer: comparison to best standard technique.

Olivotto IA, Beckham W, Popescu C, Patenaude V, Wai ES, Cao F. Vancouver Island Centre, BC Cancer Agency, Victoria, BC, Canada.

One year analysis of cosmesis and treatment efficacy by the American Society of Breast Surgeons (ASBS) MammoSite breast brachytherapy registry trial in patients treated with accelerated partial breast irradiation (APBI).

Vicini FA, Beitsch P, Quiet CA, Keleher A, Garcia D, Snider H, Gittleman M, Zannis V, Kuerer H, Whitacre E, Whitworth P, Fine R, Haffty B. William Beaumont Hospital, Royal Oak, Ml; Dallas Breast Center, Dallas, TX; Arizona Oncology, Phoenix, AZ; Western PA Hospital, Pittsburgh, PA; St.Louis Cancer and Breast CTR, St. Loius, MO; Baptist Medical Center, Montgomery, AL; Sacred Heart Hospital, Allentown, PA; MDACC, Houston, TX; The Breast Ctr of Southern Arizona, Tuscon, AZ; The Breast Ctr, Marietta, GA; Yale, New Haven, CT.

Radiation therapy and cardiac toxicity in breast cancer patients 65 years and older: a populationbased study.

Doyle J), Neugut AI, McBride RB, Jacobson JS, Grann VR, Hershman DL. Mailman School of Public Health, Columbia University, New York, NY; College of Physicians and Surgeons, Columbia University, New York, NY.

4042 Accelerated partial breast irradiation compared to whole breast radiotherapy: the potential for reduced contralateral breast dose and heart dose.

Ben-David MA, Marsh RB, Moran JM, Balter JM, Hayman JA, Griffith KA, Pierce LJ. University of Michigan Medical School, Ann Arbor, Ml; University of Michigan, Ann Arbor, MI

4043 A phase I dose escalation trial of gemcitabine with radiotherapy for breast cancer in the treatment of chest wall recurrences.

Lin A, Hayman JA, Schipper MJ, Schott AF, Shewach DS, Pierce LJ. University of Michigan, Ann Arbor, MI.

Targeted intraoperative radiotherapy (TARGIT) as a boost yields very low recurrence rates.

Vaidya JS, Baum M, Tobias JS, Wenz F, Massarut S, Hilaris BS, Houghton J, Murphy O, Saunders C, Corica T, Harrisson E, Keshtgar M, Douek M, Sainsbury R, Kraus-Tiefenbacher U, Melchart F, Joseph D. University of Dundee and Ninewells Hospital, Dundee, United Kingdom; University College London, United Kingdom; University of Mannheim, Mannheim, Germany; CRO, Aviano, Italy; Our Lady of Mercy New York Medical College; Sir Charles Gairdner Hospital, Perth, Australia.

4045 Breast magnetic resonance imaging (MRI) enhancement beyond the tumor margin: implications for radiation therapy.

Rembert JL, Klifa C, Lu Y, Gibbs J, Hylton N, Park C. University of California, San Francisco, San Francisco, CA.

Risk of internal mammary recurrence after mastectomy in absence of internal mammary chain radiation therapy. A retrospective study. Lerouge D, Levy C, Ollivier JM, Switsers O, Vie B, Delozier T. Centre Francois Baclesse, Caen, France.

Frequency of asymptomatic brain metastases in Her-2 positive breast cancer patients.

Niwinska A, Tacikowska M, Pienkowski T, Lemanska I, BauerKosinska B, Glogowska I, Rudnicka H. Memorial Cancer Center and Institute, Warsaw, Poland.

Over expression of apoptotic markers - p53 and bcl-xl is associated with axillary recurrence following radiotherapy in breast cancer patients.

Jameel JK, Garimella V, Long E, Beavis A, Drew PJ, Cawkwell L. Postgraduate Medical Institute, University of Hull, Castle Hill Hospital, Cottingham, East Yorkshire, United Kingdom; Hull \& East Yorkshire Hospitals NHS Trust, Hull, East Yorkshire, United Kingdom. 
Improved survival after radiotherapy for brain metastases in patients with HER2 positive breast tumors.

Maur M, Frassoldati A, Piacentini F, Ramundo D, Sabbatini R, Giovannelli S, Ficarra G, Bertolini F, Falchi AM, Conte PF. University of Modena and Reggio Emilia, Modena, Italy.

Efficacy of accelerated partial breast irradiation (APBI) as a neoadjuvant treatment for patients with breast cancer: a pilot study.

Sato K, Uematsu M, Saito T, Hiraide H. National Defense Medical College, Namiki, Tokorozawa, Saitama, Japan; Keio University School of Medicine, Shinanomachi, Shinjuku-ku, Tokyo, Japan; Saitama Red Cross Hospital, Kami-ochiai, Chuo-ku, Saitama, Japan.

Mammosite brachytherapy: predictive factors for complications and cosmesis.

McLaughlin M, Isreal P, Fine R, Corgan K, Robbins A, Hughes L, Haile K, Vanipalli J, Pope K. North Georgia Radiation Therapy, Marietta, GA; Wellstar Kennestone Hospital, Marietta, GA.

Tumor Cell Biology: Oncogenes and Tumor Suppressors

Fatty acid synthase (FAS)-catalyzed endogenous fatty acid metabolism regulates Her-2/neu (erbB-2) oncogene expression via malonyl-coenzyme-adependent expression of the Ets protein polyomavirus enhancer activator 3 (PEA3), a transcriptional repressor of Her-2/neu promoter activity in cancer cells.

Menendez JA, Papadimitropoulou A, Vellon L, Colomer R, Lupu R. Evanston Northwestern Healthcare, Evanston, IL; Northwestern University Feinberg School of Medicine, Chicago, IL; Institut Catala Oncologia, Hospital Universitari Dr. Josep Trueta, Girona, Catalonia, Spain.

\section{Epigenetic alteration of a protein tyrosine} phosphatase and its role in tamoxifen-resistance in breast cancer.

Ramaswamy B, Motiwala T, Kutay H, Majumder S, Shapiro $\mathrm{CL}$, Jacob ST. Ohio State University, Columbus, $\mathrm{OH}$.

EPLIN, epithelial protein lost in neoplasm, is aberrantly expressed in human breast cancer and is related to clinical outcomes.

Jiang WG, Martin TA, Douglas-Jones A, Mansel RE. School of Medicine, Wales College of Medicine, Cardiff University, Cardiff, Wales, United Kingdom; Cardiff University, Cardiff, Wales, United Kingdom.

4055 BRCA1 promoter methylation confers sensitivity to cisplatin in vitro.

Nanda R, Dignam JJ, Collins C, Xu J, Dolan ME, Olopade OI. University of Chicago, Chicago, IL.

4056 ER status and age-at-diagnosis determine frequency and structural severity of breast cancer p 53 mutations.

Fedele V, Roydasgupta R, Tommasi S, Paradiso A, Albertson D, Benz C. University of California, San Francisco, CA;

National Cancer Institute-Bari, Bari, Italy; Buck Institute for Age Research, Novato, CA.

4057 The human $\mathrm{p} 53$ gene encodes nine $\mathrm{p} 53$ protein isoforms that can modulate p 53 tumour suppressor activity.

Bourdon JCR, Murray-Zmijewski F, McDowell H, Thompson A, Lane DP. University of Dundee, Dundee, Scotland, United Kingdom. mda-7: a remedy for oncogene addiction in breast cancer?

Chada S, Mhashilkar A, Liu Y, Bocangel D, Zheng M,

Ramesh R, Meyn R, Hunt K. Introgen Therapeutics Inc., Houston, TX; UTMD Anderson Cancer Center, Houston, TX.

4059 Brg1, a chromatin remodeling gene, is suppressed in ER-negative breast cancer in human.

Pan M. Kaiser Permanente Medical Center, Santa Clara, CA.

4060 Notch ligands and receptors are co-expressed at high levels in a subset of breast tumors with poor prognosis pathological features.

Reedijk M, Odorcic S, Chang L, Zhang H, Egan SE. The Hospital for Sick Children, Toronto, ON, Canada; Princess Margaret Hospital, The University Health Network, Toronto, ON, Canada.

4061 Pattern of expression of genes linked to epigenetic silencing in human breast cancer.

Munot K, Bell SM, Horgan K, Lane S, Quirke P, Speirs V. Institute of Molecular Medicine Epidemiology and Cancer Research, University of Leeds, Leeds, W Yorks, United Kingdom.

Tumor Cell Biology: Metastasis / Invasion

4062 Genomic alterations in axillary lymph node metastases are associated with clinical outcomes in patients with breast cancer.

Becker TE, Ellsworth RE, Ellsworth DL, Deyarmin B, Hooke JA, Shriver CD. Walter Reed Army Medical Center, Washington, DC; Windber Research Institute, Windber, PA.

4063 Manipulation of expression of MMP-14 and its impact on the invasivess and progression of breast cancer cells.

Jiang WG, Davies G, Martin TA, Parr C, Mason MD, Mansel RE. School of Medicine, Wales College of Medicine, Cardiff University, Cardiff, Wales, United Kingdom.

4064 Osteopontin expression increases lymphatic metastasis of breast cancer: experimental and clinical studies.

Vantyghem SA, Allan AL, George R, Lee MW, Hodgson N, Engel C), Holliday R, Girvan D, Scott L, Al-Katib W, Stitt L, Yeatman TJ, Chambers AF, Tuck AB. London Regional Cancer Program, London, ON, Canada; London Health Sciences Centre, London, ON, Canada; H. Lee Moffitt Cancer Center and Research Institute University of South Florida, Tampa, FL.

4066 Tumour-associated tenascin-C isoforms promote breast cancer cell invasion and proliferation. Alcock RA, Holliday DL, Shaw JA, Walker RA, Pringle JH, Jones JL. University of Leicester, Leicester, United Kingdom; Institute of Cancer, Cancer Research UK Clincial Centre, Charterhouse Square, London, United Kingdom.

The CxCR4 mRNA and/or protein expression in breast cancer tissue does not always correlate with cancer metastasis.

Koyama Y, Valera V, Kaneko K, Kanbayashi C, Hatakeyama K. Niigata University Graduate School of Medical \& Dental Sciences, Niigata, Japan. human breast cancer cells and its impact on cance invasion.

Lane J, Martin TA, Jiang WG. Wales College of Medicine, Cardiff University, Cardiff, Wales, United Kingdom. 
The use of DNA microarray to determine potential pathways of tumor cell metastasis.

Moulder SL, Enkemann S, Dupont E, Riker A, Furman B, Carter WB, Hoover S, Cox C, Eschrich SA, Yeatman T, Diaz N. H.Lee Moffitt Cancer Center and Research Institute, Tampa, FL.

The role of angiotensin II in integrin mediated breast cancer cell metastasis.

Puddefoot JR, Udeozo U, Vinson GP. Quen Mary, University of London, London, United Kingdom.

Gene profile of fibroblasts from involved and uninvolved lymph nodes from breast cancer patients and influence of malignant cancer cells on their gene expression.

Santos RPC, Rozenchan PB, Katayama MLH, Brentani HP, Carraro DM, Patrao DFC, Mota LDC, Bastos EP, Lyra EC,

Goes JCGS, Brentani MM, Koike Folgueira MAA. Faculdade de Medicina da Universidade de Sao Paulo, Sao Paulo,

Brazil; Instituto Ludwig de Pesquisa Sobre o Cancer, Sao

Paulo, Brazil; Instituto Brasileiro de Controle do Cancer, Sao Paulo, Brazil.

4072 Enhanced growth of KGF-transfected human breast cancer cells in a mouse xenograft model. Zang XP, Howard EW, Jupe ER, Manjeshwar S, Pento JT. University of Oklahoma HSC, Oklahoma City, OK.

Increased expression of CD44 in visceral metastases of breast cancer.

Cabioglu N, Sahin AA, Guray M, Islam R, Morandi P, MericBernstam F, Hortobagyi GN, Cristofanilli M. MD Anderson Cancer Center, Houston, TX.

4074 Women with breast cancer heterozyous for CC chemokine receptor $5 \Delta 32(\Delta 32 / \mathrm{WT})$ may have a greater tendency for metastatic pleural effusion than those with wild type CCR5 (WT/WT).

Kaplan MH, Dosik MH, Lu R, Wang XP. North Shore University Hospital, Manhasset, NY; Stony Brook University, Stony Brook, NY.

4075 Identification of estrogen regulated metastasisassociated genes using hormone-responsive bone metastases models.

Simons LA, Thurn KE, Satcher RL, Levenson AS.

Northwestern University Feinberg School of Medicine, Chicago, IL.

4076 Expression of secretory leukocyte protease inhibitor in human breast carcinoma.

Yoshida S, Sugino T, Yasuda M, Hiroya S, Ohtake T, Takenoshita S, Suzuki T. Fukushima University School of Medicine, Fukushima-shi, Fukushima-ken, Japan.

Tumor Cell Biology: Growth Factors / Inhibitors

Epidermal growth factor induces the IGF signaling protein insulin receptor substrate- 2 via the JNK/AP-1 pathway and NF-kB transcription factor in breast cancer cells.

Cui x, Kim H, Kuiatse I, Lee AV. Baylor College of Medicine, Houston, TX.

Autophophorylation of the hepatocyte growth factor receptor, cMET in human breast cancer.

Jiang WG, Davies G, Watkins G, Mason MD, Mansel RE. School of Medicine, Wales College of Medicine, Cardiff University, Cardiff, Wales, United Kingdom.

Results of BCIRG 103: a presurgical study to evaluate molecular alterations that occur in human breast cancer tissue after short-term exposure to gefitinib. Finn RS, Wilson CA, Dering J, Ginther C, Cook AM, Glaspy P, Venkatesen N, Raab G, Pawlicki M, Gerber B, Pinter T, Eiermann W, von Minckwitz G, Mackey J, Reese D, Kiger C, French T, Barrett I, Chang KM, South M, Slamon DJ. Geffen School of Medicine at UCLA, Los Angeles, CA; Frauenklink von Roten Kreuz, Munich, Germany; Maria Sklodowska-

Curie Memorial Cancer Institute, Krakow, Poland; Frauenklink der LMU, Munich, Germany; Petz Aladar County Hospital, Gyor, Hungary; Frauenklinik von Roten Kreuz, Munich, Germany; JW Goethe-UniversitatsFrauenklinik, Frankfurt, Germany; Cross Cancer Institute, Edmonton, Canada; TORI, Los Angeles; CIRG, Edmonton, Canada; AstraZeneca, Manchester, United Kingdom.

Gefitinib has a low clinical benefit rate in advanced breast cancer patients.

Francis P, Green M, Gebski V, Harvey V, Karapetis C, Chan A, Snyder R, Forbes J. Australian New Zealand Breast Cancer Trials Group (ANZ BCTG), Newcastle, NSW, Australia.

Mammary specific overexpression of insulin receptor substrate-1 (IRS-1) or IRS-2 in mice results in tumorgenesis and metastasis.

Dearth RK, Cui X, Kim HJ, Lazard Z, Lawrence N, Kuiatse I, Britton O, Mohsin S, Hadsell DL, Lee AV. Baylor College of Medicine, Houston, TX; Children's Nutrition Research Center, Houston, TX.

The ROCK Inhibitor Y-27632 supresses the effect of HGF in human breast cancer cells.

Lane J, Martin TA, Jiang WG. Wales College of Medicine, Cardiff University, Heath Park, Cardiff, United Kingdom.

4083 Human epidermal growth factor receptor 1 (EGFR) expression was not associated with gene amplification but intimately associated with HER2 gene amplification and protein expression in tissue microarray of clinical breast cancers. Park K, Kim H, Lim S, Kwak K, Han S. Inje University Sanggye Paik Hospital, Seoul, Korea.

Combination approach using RAD001 plus or minus tamoxifen or letrozole. A preclinical model of the treatment of endocrine-resistant breast tumours. Farmer I, Evans DB, Lane HA, Lykkesfeldt AE, Dowsett M, Martin L-A. Breakthrough Breast Cancer Research Centre, London, United Kingdom; Novartis Pharma AG, Basel, Switzerland; Institute of Cancer Biology, Danish Cancer Society, Copenhagen, Denmark.

The effect of silencing the insulin-like growth factor receptor on tamoxifen sensitive and tamoxifen resistant breast cancer cells.

McVittie C), Khalaf S, Ogunkolade BW, Bustin SA, Jenkins PJ, Carpenter R. St Bartholomew's Hospital, London, United Kingdom; Bart's and the London, London, United Kingdom.

Does HER2 positive breast cancer have a prelediction to metastasise to the brain?

Paterson C, Mclntyre A, Canney PA. Beatson Oncology Centre, Western Infirmary, Glasgow, United Kingdom.

Inhibition of PCDGF/GP88 expression by SiRNA restores tamoxifen responsiveness in tamoxifen resistant breast cancer cells.

Tian C, Serrero G. A\&G Pharmaceutical Inc., Columbia, MD. 
The intrinsic effects of IGFBP-3 on the survival of human breast epithelial cells involve the sphingolipid 'rheostat'.

Perks CM, Holly JM, Carter JV, Winters ZE. University of Bristol, Bristol, South-West, United Kingdom.

EGFR is necessary but not sufficient for YB-1mediated EGF independence.

Pang B, Wu R, Chen YQ, Berquin IM. Wake Forest University Health Sciences, Winston-Salem, NC.

4090 Estrogen receptor alpha modulates TGF-beta signaling independent from its activation status. Buck MB, Laukemann S, Peusser T, Knabbe C. Institute of Clinical Pharmacology, Stuttgart, Germany; Robert Bosch Hospital, Stuttgart, Germany.

4091 Long term culture of MCF-7 breast cancer cells with small interfering RNA to the insulin-like growth factor receptor causes decreased cell proliferation. McVittie C), Khalaf S, Ogunkolade BW, Bustin SA, Jenkins PJ, Carpenter R. St Bartholomew's Hospital, London, United Kingdom; Barts and the London, London, United Kingdom.

$4092 \quad$ Blockade of p38 and JNK kinases inhibits the growth of normal and malignant breast cells.

Krisko T I, DuPre E N, Kim H, Brown P H. Baylor College of Medicine, Houston, TX.

Tumor Cell Biology: Imunology / Immunotherapy

Anti-idiotype antibody vaccine therapy for HER2/Neu overexpressing breast cancer.

Nahleh ZA, Mohanty K, Pal S, Mallick P, Saha A, Chatterjee SK, Jazieh A, Foon KA, Bhattacharya-Chatterjee $M$. University of Cincinnati, Cincinnati, $\mathrm{OH}$; University of Pittsburg, Pittsburg, PA.

Enhanced HER2/neu specific T-cell immunity in vitro by HER2/neu li-key modified "agonist" class II peptides in breast cancer patients.

Murray J, Kawano K, Efferson C, Babiera G, Meric-Bernstam F, Ibrahim N, Kallinteris NL, Humphreys RE, Von Hofe E. M.D. Anderson Cancer Center, Houston, TX; Antigen Express, Inc., Worchester, MA.

4095 CpG DNA augments dendritic cell-based therapy of breast cancer.

Baar J, Cai Q, Kublo L. University of Pittsburgh Cancer Institute, Pittsburgh, PA.

Cellular immunotherapy in late stage breast cancer patients with reactivated autologous memory T-cells derived from bone marrow.

Schuetz F, Ehlert K, Schneeweiss A, Schirrmacher V, Diel IJ, Sohn C, Beckhove P. University of Heidelberg, Medical School, Heidelberg, Germany; German Cancer Research Center, Heidelberg, Germany.

4097 Whole cell autologous/allogeneic vaccine induces an immune response to specific antigens in breast cancer patients.

Head JF, Fort KA, Hsu K, Elliott RL. Mastology Research Institute, Elliott-Elliott-Head Breast Cancer Research and Treatment Center, Baton Rouge, LA.

$4098 \quad$ Evaluation of foxp3 expression in sentinel nodes in breast cancer patients.

Matsuura K, Yamaguchi Y, Osaki A, Ueno H, Ohara M,

Arihiro K. Research Institute for Radiation Biology and Medicine, Hiroshima University, Hiroshima, Japan; Hiroshima University, Hiroshima, Japan.
Synthetic peptide vaccine candidates and their matching profile with the proteome.

Mittelman A, Ashok BT, Kanduc D, Tiwari RK. New York

Medical College, Valhalla, NY; University of Bari, Bari, Italy.

\section{Tumor Cell Biology: Antiestrogens}

4100

An important role for AIB1 phosphorylation in mediating growth factor signaling dependent estrogen agonist activity of tamoxifen in breast cancer cells.

Shou J, Choudhury P, Chamness G, Osborne K, Schiff R. Baylor College of Medicine, Houston, TX.

4101 Gene expression changes during acquired resistance to letrozole; a preclinical model of post-menopausal breast cancer.

Macpherson NA, Moore S, Brodie A, Thiantanawat A, Jelovac D, Nelson CC. BC Cancer Agency, Victoria, BC, Canada; Vancouver General Hospital, Vancouver, BC, Canada; University of Maryland, Baltimore, MD.

4102 Raloxifene effectively inhibits the growth of tamoxifen resistant T47D:A18/PKC $\alpha$ tumor. Zhang Y, Zhao H, Tonetti DA. University of Illinois at Chicago, Chicago, IL.

4103 The phytoestrogen resveratrol acts opposite of estrogen to inhibit migration and differentially signal to the actin cytoskeleton of metastatic breast cancer cells.

Azios N, Krishnamoorthy L, Harris M, Cubano L, Dharmawardhane S. University of Texas at Austin, Austin, TX; Universidad Central del Caribe, Bayamon, Puerto Rico.

4104 Comparison of effects of 4-hydroxy-tamoxifen and trilostane on oestrogen-regulated gene expression in MCF-7 cells: up-regulation of oestrogen receptor beta.

Barker S, Malouitre SD, Glover HR, Puddefoot JR, Vinson GP. Queen Mary, University of London, London, United Kingdom.

4105 Glyceollins (I-III), novel anti-estrogenic phytochemicals isolated from soy.

Zimmermann MC, Salvo VA, Boue SM, Fonseca JP, Elliot S, Dugan CM, Zhu Y, Corbitt C, Collins-Burow BM, Weldon

CB, Curiel TJ, Shih BY, Carter-Wientjes C, Wood C, Clarkson TB, Erhardt P, McLachlan JA, Cleveland TE, Beckman BS, Burow ME. Tulane University, New Orleans, LA; Tulane Cancer Center, New Orleans, LA; The Center for Bioenvironmental Research, New Orleans, LA; Tulane University Health Science Center, New Orleans, LA; Southern Regional Research Center, USDA, New Orleans, LA; University of Louisville, Louisville, KY; Wake Forest University School of Medicine, Winston-Salem, NC; University of Toledo, Medical College of Ohio, Toledo, $\mathrm{OH}$.

Tumor Cell Biology: Endocrinology

4106

Down regulation of $\mathrm{p} 42 / 44$ MAPK and $\mathrm{PAKT}$ in response to neo-adjuvant tamoxifen or anastrozole (IMPACT) in ER positive breast cancer. Salter J, A'Hern R, Smith IE, Dowsett M. Royal Marsden Hospital, London, United Kingdom.

4107 Macrophage colony-stimulating factor (CSF-1) overexpression leads to mammary tumorigenesis: induction of CSF-1 receptor, c-fms, by steroid hormones.

Kirma NB, Liu Y, Nair HB, Tekmal RR. University of Texas Health Science Center at San Antonio, San Antonio, TX. 
Lipid profile and homocysteine levels in postmenopausal women with early breast cancer at low risk treated for two years with exemestane: follow-up results of a randomized, placebo-controlled study.

Lønning PE, Geisler J, Krag L, Ottestad L, Risberg T, Hagen Al, Schlichting E, DiSalle E, Polli A, Paolini J. Haukeland University Hospital, Bergen, Norway; Central Hospital of Rogaland, Stavanger, Norway; The Norwegian Radiumhospital, Oslo, Norway; University Hospital of Northern Norway, Tromsø, Norway; St. Olavs Hospital, Trondheim, Norway; Ullevål University Hospital, Oslo, Norway; Pharmacia Italia S.p.A. / Pfizer Group, Milan, Nerviano, Italy.

4109 Aromtase X HER-2/Neu double transgenic mice: effect of local estrogen on mammary development and carcinogenesis.

Tekmal RR, Perla RP, Nair HB, Liu Y-G, Kirma NB. University of Texas Health Science Center at San Antonio, San Antonio, TX.

4110 Total body aromatization is strongly correlated to plasma leptin levels in postmenopausal breast cancer patients.

Geisler J, Haynes B, Ekse D, Dowsett M, Lønning PE. Haukeland University Hospital, Bergen, Norway; Royal Marsden Hospital, London, United Kingdom.

\section{Effects of aromatase inhibitors on human osteoblast} cells: a possible androgenic bone protective effects induced by exemestane.

Miki Y, Suzuki T, Igarashi K, Kanno J, Sasano H. Tohoku University Graduate School of Medicine, Sendai, Japan; National Institute of Health Sciences, Biological Safety Research Center, Tokyo, Japan.

4112 Effect of nomegestrol acetate on aromatase activity in MCF-7aro breast cancer cells.

Chetrite G, Shields-Botella J, Postruznik D, Pasqualini JR. Institut de Puériculture et de Périnatalogie, Paris, France; Laboratoires Merck-Théramex, Monaco, Monaco.

Estradiol is an anti-aromatase agent in human breast cancer cells.

Pasqualini JR, Chetrite G. Institut de Puériculture et de Périnatalogie, Paris, France.

\section{PLENARY LECTURE 3 - Exhibit Hall D}

Proteomics in situ: Direct analysis of tissues in biological and clinical research

Richard M. Caprioli, PhD

Vanderbilt University

Nashville, TN

\section{9:30-11:30 GENERAL SESSION 5 - Exhibit Hall D}

9:30 24. Genetic alterations associated with early hyperplastic precursors of breast cancer. Lee S, Tsimelzon A, Wu Y, Mao S, Mohsin SK, Medina D, Allred DC. Baylor College of Medicine/The Methodist Hospital, Houston, TX; Baylor College of Medicine, Houston, TX.

9:45 25. Ductal carcinoma in situ (DCIS) mammosphere formation; effect of epidermal growth factor (EGF) and notch signalling pathways on self renewal capacity. Farnie G, Brennan K, Clarke RB, Bundred NJ. University of Manchester; University Hospital of South Manchester, United Kingdom
26. Cell of origin determines histological type, tumorigenicity and metastatic behavior of breast tumors.

Ince TA, Weinberg RA. Whitehead Institute for Biomedical Research; Harvard Medical School; Brigham \& Women's Hospital, Boston, MA

10:15 27. Magnitude and laterality of breast cancer risk according to histologic type of atypical hyperplasia: results from the Nurses' Health study.

Collins LC, Baer HJ, Tamimi RM, Connolly JL, Colditz GA Schnitt S). Beth Israel Deaconess Medical Center and Harvard Medical School; Brigham and Women's Hospital; Harvard School of Public Health; Harvard Center for Cancer Prevention, Boston, MA

10:30 28. Multi-center validation of the 76-gene prognostic signature in lymph node negative (LNN) primary breast cancer.

Foekens JA, Atkins D, Sweep CGJ, Harbeck N, Paradiso A, Cufer T, Eppenberger S, Daxenbichler G, Kotzsch M, Sieuwerts AM, Talantov D, Timmermans M, Span PN, Tjan-Heijnen VCG, Specht K, Mangia A, Wight E, Angerer J, Zito AF, Hoefler H, Berns EMJ, Golouh R, Barreton G, Schittulli F, Schmitt M, Beex LVA, Klijn JGM, Wang Y. Erasmus MC, Rotterdam, Netherlands; Veridex LLC, a Johnson \& Johnson Company, San Diego, CA; Radboud University Nijmegen Medical Centre, Nijmegen, Netherlands; Frauenklinik und Institut für Allgemeine Pathologie und Pathologische Anatomie, Technische Universität, München, Germany; National Cancer Institut, Bari, Italy; Institute of Oncology, Ljubljana, Slovenia; Universitätshospital Basel, Basel, Switzerland; Medical University, Innsbruck, Austria; Institut für Pathologie, Technische Universität, Dresden, Germany.

29. Association between the 21-gene recurrence score assay (RS) and risk of locoregional failure in nodenegative, ER-positive breast cancer: results from NSABP B-14 and NSABP B-20.

Mamounas E, Tang G, Bryant J, Paik S, Shak S, Costantino J, Watson D, Wickerham DL, Wolmark N. NSABP, Pittsburgh, PA; Aultman Health Foundation, Canton, $\mathrm{OH}$; Genomic Health, Inc., Redwood City, CA; Allegheny General Hospital, Pittsburgh, PA.

11:00 30. A functional luteinizing hormone (LH) receptor polymorphism predicts adverse outcome in premenopausal breast cancer patients. Piersma D, Themmen APN, Verhoef-Post M, Look MP, Klijn JGM, Foekens JA, Uitterlinden AG, Pols HAP, Berns EMJJ. Erasmus MC-Daniel den Hoed Cancer Center, Rotterdam, Netherlands; Erasmus MC, Rotterdam, Netherlands.

31. Phenotypes for endocrine resistance can be identified by RNA microarray of sequential biopsies and are more variable than those predicting for tumour response.

Miller WR, Krause A, Evans DB, Renshaw L, Murray J, Larionov A, Anderson TJ, White S, Hampton G, Walker JR, Ho S, Dixon MJ. University of Edinburgh, Edinburgh, Scotland, United Kingdom; Novartis Pharma AG, Basel, Switzerland; Novartis Institutes for BioMedical Research, Basel, Switzerland; Novartis Genomic Institute, San Diego, CA.

\section{1:30-12:00 PLENARY LECTURE 4 - Exhibit Hall D}

Lifestyle approaches to breast cancer risk reduction: insights and opportunities

Leslie Bernstein, PhD

USC/Norris Comprehensive Cancer Center

Los Angeles, CA 
12:00-1:00

LUNCH [Ticket Required] - Exhibit Hall A

1:00-2:00

CASE DISCUSSION 2 -Ballroom A

2:00-3:30

GENERAL SESSION 6 - Exhibit Hall D

$2: 00$

32. A reliable new model of estrogen dependent human breast cancer lymph node metastasis Harrell JC, Sartorius CA, Horwitz KB. University of Colorado Health Sciences Center, Aurora, CO.

33. Estrogen receptor alpha antagonizes $\mathrm{p} 53$ function by direct interaction-a novel cellular mechanism with a clinical correlate.

Das GM, Liu W, Konduri SD, Nayak BK, Bansal S, Rajasekaran SA, Abraham BK, Brauch H, Fritz P, Srivastava P, Rajasekaran AK Roswell Park Cancer Institute, Buffalo, NY; University of Texas Health Science Center at San Antonio, San Antonio, TX; University of California at Los Angeles, Los Angeles, CA; Dr. Margarete Fischer-Bosch-Institute of Clinical Pharmacology, Auerbachstr 112, Stuttgart, Germany.

34. An estrogen receptor-negative breast cancer subset with over expression of hormone responsive genes.

Doane AS, Danso MA, Lal P, Donaton M, Zhang L, Hudis C, Gerald WL. Memorial Sloan-Kettering Cancer Center, New York, NY.

35. Estrogen receptor-beta has favorable independent prognostic value for estrogen receptor-alpha negative breast cancer patients receiving adjuvant tamoxifen. Gruvberger-Saal SK, Bendahl P-O, Saal LH, Laakso M, Eden P, Peterson C, Malmstrom P, Isola J, Borg A, Ferno M. Lund University, Lund, Sweden; Institute for Cancer Genetics, Columbia University, New York, NY; Institute of Medical Technology, University of Tampere, Tampere, Finland.

36. Statin-using breast cancer patients are less likely to have ER-negative tumors.

Kumar AS, Minami CA, Shim V, Moore DH, O'Neal KC, Esserman L). University of California San Francisco, San Francisco, CA; Kaiser Permanente - Oakland Medical Center, Oakland, CA.

3:15 37. Better characterization of estrogen receptor (ER) positive luminal subtypes using genomic grade. Sotiriou C, Wirapati P, Loi S, Desmedt C, Durbecq V, Harris A, Bergh J, Smeds J, Haibe-Kains B, Larsimont D, Cardoso F, Buyse M, Delorenzi M, Piccart M. Jules Bordet Institute, Free University of Brussels, Brussels, Belgium; Swiss Institute of Bioinformatics, Swiss Institute of Experimental Cancer Research, Epalinges, Switzerland; The Weatherall Institute of Molecular Medicine, University of Oxford, Oxford, United Kingdom; Karolinska Institute, Stockholm, Sweden; International Drug Development Institute, Brussels, Belgium.

3:30-5:00 MINI-SYMPOSIUM 3 Exhibit Hall D

THE ORIGINS OF ESTROGEN RECEPTOR (ER) STATUS IN BREAST CANCER

D. Craig Allred, PhD, Co-Moderator

Baylor College of Medicine, Houston, TX

and

Jenny Chang, MD, Co-Moderator

Baylor College of Medicine, Houston, TX
3:30 Introduction

3:30 The origins of ER positive and ER negative breast cancer

Robert B. Clarke, PhD

University of Manchester

Manchester, UNITED KINGDOM

4:00 Developmental and therapeutic implications of the molecular portraits of breast tumors

Charles M. Perou, PhD

University of North Carolina

Chapel Hill, NC

4:30 How epidemiologic risk factors differ according to receptor status of breast cancer

Graham Colditz, MD, PhD

Harvard School of Public Health

Boston, MA

5:00-7:00 POSTER DISCUSSION 3 - Ballroom A

Expression Profiles in Prognosis and Prediction 301-312

301 Multi-centre independent validation of a gene prognostic signature for patients with node-negative breast cancer $(B C)$ - final results.

Cardoso F, Piccart MJ, Viale G, Van 't Veer L, Saghatchiand'Assignies M, Glas A, Ellis P, Harris A, Bergh J, Lidereau R, Rutgers E, Delorenzi M, Bogaerts J, Therasse P, Lazar V, Amakrane M, Sotiriou C, Loi S, Buyse M. On Behalf of the TRANSBIG Consortium.

302 Breast tumours with intermediate histological grade can be reclassified into prognostically distinct groups by gene expression profiling.

Sotiriou C, Wirapati P, Loi S, Viale G, Harris A, Bergh J, Smeds J, Farmer P, Praz V, Haibe-Kains B, Lallemand F, Desmedt C, Durbecq V, Larsimont D, Cardoso F, Buyse M, Delorenzi M, Piccart M. Jules Bordet Institute, Free University of Brussels, Brussels, Belgium; Swiss Institute of Experimental Cancer Research, Epalinges, Switzerland; The Weatherall Institute of Molecular Medicine, University of Oxford, Oxford, United Kingdom; Karolinska Institute, Stockholm, Sweden; International Drug Development Institute, Brussels, Belgium; European Institute of Oncology, University of Milan, Milan, Italy.

303 A miniPathway for tamoxifen therapy resistance. Jansen M, Foekens J, Ritstier K, van Staveren I, Meijer-van Gelder M, Sieuwerts A, Portengen H, Dorssers L, Klijn J, Berns E. Erasmus MC - Daniel den Hoed Cancer Center, Rotterdam, Netherlands; Erasmus MC, Rotterdam, Netherlands.

Gene expression profiles as predictors of response to neoadjuvant taxotere and adriamycin/cytoxan: a prospective randomized multicenter trial in breast cancer.

Chang JC, Hilsenbeck SG, Yee D, Ostler P, Tsimelzon A, Harrison M, Gutierrez MC, Elledge RM, O'Connell P, Osborne CK, Makris A. Baylor College of Medicine, Houston, TX; University of Minnesota; Mount Vernon Hospital, London, United Kingdom; Virginia Commonwealth University. 
Predicting response to ixabepilone: genomics study in patients receiving single agent ixabepilone as neoadjuvant treatment for breast cancer (BC).

Baselga J, Gianni L, Llombart A, Manikhas G, Kubista E, Steger G, Lee H, Ronczka A, Xu L, Clark E, Galbraith S. Vall d'Hebron, Barcelona, Spain; Istituto Nazionale Per Lo Studio E La Cura Dei Tumori, Milan, Italy; Instituto Valenciano De Oncologia, Valencia, Spain; Municipal Oncology Outpatient Clinic, St Petersburg, Russian Federation; Medical University Vienna, Vienna, Austria; Bristol-Myers Squibb

Pharmaceutical Research Institute, Princeton, NJ.

Affymetrix gene chip profile predicts pathologic complete response to preoperative paclitaxel/FAC chemotherapy in breast cancer.

Pusztai L, Hess KR, Gold DL, Anderson K, Ross JS, Valero V, Hortobagyi GN, Symmans WF. U.T. M.D. Anderson Cancer Center, Houston, TX; Albany Medical Center, Albany, NY.

Transcriptional profiling can predict the achievement of a pathologic complete response ( $P C R$ ) after preoperative chemotherapy (PST) with gemcitabine (G), epirubicin (E) and docetaxel (Doc) in primary breast cancer (PBC) with high accuracy. Schneeweiss A, Thuerigen $O$, Toedt $G$, Warnat P, Hahn M, Schuetz F, Lauschner I, Benner A, Brors B, Sinn H-P, Sohn C, Lichter P. University, Heidelberg, Germany; German Cancer Research Center, Heidelberg, Germany.

Measurements of estrogen receptor and reporter genes from microarrays determine receptor status and time to recurrence following adjuvant tamoxifen therapy.

Symmans WF, Sotiriou C, Anderson SK, Hatzis C, Valero V, Booser DJ, Larsimont D, Desmedt C, Gold DL, Sneige N, Cristofanilli M, Arun B, Gong Y, Ross JS, Hess K, Piccart MJ, Harris AL, Hortobagyi GN, Pusztai L. M.D. Anderson Cancer Center, Houston, TX; Institut Jules Bordet, Brussels, Belgium; Nuvera Biosciences, Inc., Woburn, MA; Albany Medical College, Albany, NY; Oxford University, Oxford, United Kingdom.

Feasibility of gene expression profiling in community hospitals; preliminary results of a pilot study in $\mathbf{N}_{\mathbf{0}}$ breast cancer patients.

Bueno de Mesquita JM, Van De Vijver MJ, Peterse JL, Rutgers EJTh, Van 't Veer LJ, Van Harten WH, Van Dam FSAM, Karsenberg KF, Douma K, Van Tinteren H, Floore AN, Glas AM, Rodenhuis S, Linn SC. The Netherlands Cancer Institute-Antoni van Leeuwenhoek Hospital, Amsterdam, Netherlands; Agendia, Amsterdam, Netherlands.

Measurement of gene expression using tissue microarray cores of paraffin embedded breast cancer tissue.

Baker J, Salter J, Liu M-L, Hackett JR, Cronin M, Shak S, Dowsett M. Genomic Health, Inc., Redwood City, CA; Royal Marsden Hospital, London, United Kingdom.
Validation of HOXB13, IL17BR and CHDH as predictors of clinical outcome of adjuvant tamoxifen monotherapy in breast cancer.

Erlander MG, Ma XJ, Hilsenbeck SG, Sgroi DC, Osborne CK Allred DC. Arcturus BioScience, Inc., Mountain View, CA; Baylor College of Medicine, Houston, TX; Massachusetts General Hospital, Harvard Medical School, Boston, MA.
A two-gene expression ratio of HOXB13 and IL-17BR for prediction of recurrence and survival in women receiving adjuvant tamoxifen.

Goetz MP, Suman VJ, Ingle JN, Nibbe AM, Visscher DW, Reynolds C, Lingle WL, Erlander MG, Ma XJ, Sgroi DC, Perez EA, Couch FJ. Mayo Clinic College of Medicine, Rochester, MN; Arcturus Bioscience, Mountain View, CA; Harvard Medical School, Boston, MA; Mayo Clinic College of Medicine, Jacksonville, FL.

5:00-7:00 POSTER DISCUSSION 4 - Ballroom B

Breast and Nodal Surgery 401-410

Axillary recurrence after negative SLN biopsy. Ly QP, White L, Dupont E, Cox C, Reintgen D, Dessureault S. Moffitt Cancer Center, Tampa, FL.

Low local-regional failure rates in selected breast cancer patients with tumor-positive sentinel nodes who do not undergo completion axillary dissection. Hwang RF, Gonzalez-Angulo AM, Yi M, Buchholz TA, Meric-Bernstam F, Ames FC, Kuerer HM, Ross MI, Singletary SE, Babiera GV, Feig BW, Hunt KK. UT-M.D. Anderson Cancer Center, Houston, TX.

Additional axillary metastases and stage migration in patients with micrometastases or submicrometastases in sentinel lymph nodes. van Rijk MC, Peterse JL, Nieweg OE, Rutgers EJ, Oldenburg HS, Kroon BB. The Netherlands Cancer Institute/ Antoni van Leeuwenhoek Hospital, Amsterdam, Netherlands.

Predicting negative axillary lymph node dissection in patients with positive sentinel lymph node biopsy: can a subset of patients be spared axillary dissection? Rescigno J, Taylor LA, Aziz MS, Axelrod DM, Bernik S, Vallejo CE, Riegel AC, Troob SH, Klein P. St. Vincents Comprehensive Cancer Center, New York, NY; New York Medical College, Valhalla, NY; New York University, New York, NY.

A prospective evaluation of a new technique using aponeurosis padding without vacuum drainage to reduce morbidity in patients undergoing axillary node dissection for localized breast cancer (LBC). Garbay J-R, Thoury A, Moinon E, Picone O, Rey A, Di Palma M. Institut Gustave Roussy, Villejuif, Paris, France; Hopital Bichat, Paris, France.

406 Optimizing the total skin-sparing mastectomy. Kumar AS, Wijayanayagam A, Foster RD, Mathes S, Kind G, Wolverton D, Au A, Esserman LJ. University of California San Francisco, San Francisco, CA

The effectiveness of per-operative use of human surgical sealant - 'Quixil' in reducing the post operative seroma formation in breast cancer patients. Vijayaganesh T, Jones BG, Khaira H, Brown JH, Jewkes A. Good Hope Hospital NHS Trust, Birmingham, West Midlands, United Kingdom.

Intraoperative digital specimen mammography: improving efficiency without loss of accuracy. Kaufman CS, Bachman BA, Jacobson L, Kaufman BE. Bellingham Breast Center, Bellingham, WA; University of Washington, Seattle, WA. 
The impact of radiotherapy on capsule formation and aesthetic outcome after immediate breast reconstruction using biodimensional anatomic expander implants.

Gui GPH, Behranwala K, Dua RS, Ward A, A'Hern R. Royal Marsden NHS Foundation Trust, London, United Kingdom.

Early stage breast cancer in young women: does selection of surgical treatment impact overall survival?

de Silva SS, Wilson IB, Erban JK. Tufts-NEMC, Boston, MA.

5:00-7:00

$$
\text { POSTER SESSION } 5 \text { \& RECEPTION - }
$$$$
\text { Exhibit Hall B }
$$

(\#5001-5114)

Detection and Diagnosis: Mammography / Imaging

$5001 \quad$ MRI surveillance downstages invasive cancer (IC) to DCIS in women at high risk for hereditary breast cancer.

Warner E, Causer PA, Hill KA, Ramsay E, Jong RA, Wong JW, Wright FC, Detzler G, Glazier J, Murray C, Muldoon J, Messner SJ, Eisen A, Rosen B, Verity L, Chung A, Yaffe MJ, Narod SA, Plewes DB. Sunnybrook \& Women's College Health Sciences Centre, Toronto, ON, Canada; University of Toronto, Toronto, ON, Canada; Sunnybrook \& Women's College Health Sciences Centre, Canada; Sunnybrook \& Women's College Health Sciences Center, Canada; Sunnybrook \& Women's College Health Sciences Centre.

5002

Clinical guidelines for early detection of tumor response to neoadjuvant chemotherapy for breast cancer using contrast-enhanced MRI.

Loo CE, Schlief AT, vd Vijver MJ, Muller SH, Rodenhuis S, Gilhuijs KG. The Netherlands Cancer Institute, Amsterdam, Plesmanlaan, Netherlands.

$5003 \quad$ Correlating breast cancer grade and hypoxia status with MRI features.

Ah-See M, Makris A, Taylor NJ, Stirling JJ, Daley FM, Richman P, Harris A, d'Arcy J, Collins D, Padhani AR. Mount Vernon Cancer Centre, Northwood, Middlesex, United Kingdom; Weatherall Institute, John Radcliffe Hospital, Oxford, Oxfordshire, United Kingdom.

5004 Observer variability in dynamic contrast-enhanced MRI when used for prediction of response to neoadjuvant chemotherapy in primary breast cancer. Beresford MJ, Makris A, Taylor NJ, Stirling JJ, Ah-See M, d'Arcy JA, Collins D, Padhani AR. Mount Vernon Hospital, Northwood, Middlesex, United Kingdom.

5005 Mammographic breast density as a predictor for local recurrence after breast conserving surgery and radiotherapy.

Park C, Rembert J, Chew K, Moore D, Kerlikowske K. University of California, San Francisco, CA.

Effect of 4-hydroxytamoxifen gel treatment on breast density and safety in premenopausal women.

Harvey JA, McTiernan A, LeNestour E. UVA Health System, Charlottesville, VA; Fred Hutchinson Cancer Research Ctr,

Seattle, WA; Besins International, Paris, France.

Baseline radiological staging in primary breast cancer: impact of an educational intervention on adherence to published guidelines.

McWhirter E, Yogendran G, Fralick J, Sue J, Fralick M, Wright F, Dranitsaris G, Clemons M. Sunnybrook and Women's Health Sciences Centre, Toronto, ON, Canada
5008 Discomfort and pain during mammography.

Freitas Junior R, Fiori WF, Ramos FJF, Godinho E, Rahal RMS, Oliveira JG. Hospital Araujo Jorge, Goias Anticancer Association, Goiania, GO, Brazil; Clinica ARO, Goiania, GO, Brazil; Goias Federal University, Goiania, GO, Brazil.

5009 Estrogen receptor alpha gene polymorphisms and mammographic density in postmenopausal women without hormonal therapy.

Kemp C, Ramos EHM, Silva IDCG, Chambo D, Nogueira de Souza NC. EPM-UNIFESP, São Paulo, SP, Brazil.

Significant improvement in the diagnosis of breast lesion by means of real-time elastographie.

Thomas A, Fischer T, Kristiansen G, Lichtenegger W, Kuemmel S. University of Berlin, Charité, CCM, Berlin, Germany; Institut of Pathology, University of Berlin, Charité, CCM, Berlin, Germany.

5011 Menstrual-cycle dependence of breast parenchyma elasticity determined by realtime sonoelastography: finding the optimal time for examination. Wojcinski S, di Liberto A, Cassel M, Ertan AK, Schmidt W. University of Saarland, Homburg, Germany.

5012 Clinicopathological and radiological characteristics of screening ultrasound-detected breast cancers with negative mammography findings.

Hwang SE, Han WS, Cho N, Park IA, Hwang KT, Lee JE, Shin HJ, Kim SW, Moon WK, Noh DY. Seoul National University Hospital, Seoul, Korea.

5013 Is ultrasound useful in the management of patients with ductal carcinoma in situ?

Zager JS, Al-Refaie WB, Hunt KK, Khakpour N, Kuerer HM, Lin E, Yen T, Stephens T, Feig BW, Ames FC, Singletary SE, Ross MI, Babiera GV. MD Anderson Cancer Center, Houston, TX.

5014 Preoperative FDG-PET/CT can change the tumour stage in locally advanced breast cancer. Segaert I, Neven P, Ceyssens S, Amant F, Berteloot P, Leunen K, Smeets A, Wildiers H, Paridaens R, Vergote I, Christiaens MR. UZ-Leuven, Leuven, Belgium

5015 Evaluation of 18-FDG PET in initinal staging of the axilla in breast cancer.

Jeong J, Lee S, Yoon S, Lee I, Ryu Y, Jung W, Lee H. Ongdong Severance Hospital, Yonsei University College of Medicine, Seoul, Republic of Korea

5016 Cone beam breast CT - a feasibility study with surgical mastectomy specimens.

Yang WT, Shaw CC, Chen L, Altunbas C, Wang T, Lai C), Cheenu K, Tu SJ, Liu X, Whitman G). The University of Texas M. D. Anderson Cancer Center, Houston, TX.

5017 A chart review of method of detection of contralateral breast cancers in two different age cohorts of patients.

Robinson AG, Speers C, Olivotto I, Chia S. British Columbia Cancer Agency, Vancouver, BC, Canada.

Detection and Diagnosis: Screening

Local recurrence rates in screen detected breast cancers from 1996-1997.

MacNeill FA. East of England Screening Quality Assurance Reference Centre, Cambridge, United Kingdom. 
An analysis of breast cancer recurrences for screen detected and symptomatic breast cancers diagnosed in the West Midlands in 1996 and 1997.

Lawrence G, Pritchard MG, Kearins O, Casey M. West Midlands Cancer Intelligence Unit, Birmingham, United Kingdom; Royal Wolverhampton Hospital NHS Trust, Wolverhampton, United Kingdom.

Mammographic breast density, dense area and breast area by phase in the menstrual cycle.

Buist DSM, Aiello EJ, Miglioretti D, Mahoney L, White E. Group Health Cooperative, Seattle, WA; University of Washington, Seattle, WA.

Association of travel distance to mammography and breast cancer tumor size at diagnosis.

Schroen AT, Lohr ME. University of Virginia, Charlottesville, VA.

5022 Resource and service implications of a screening clinic for women at increased breast cancer risk from a family history.

Gui GPH, Kadayaprath G, Darhouse N, Ward A, A'Hern R, Self J, Eeles R. Royal Marsden NHS Foundation Trust, London, United Kingdom; Institute of Cancer Genetics, Institute of Cancer Research, London, United Kingdom.

Diffuse optical spectroscopy: a novel laser-based approach for breast cancer diagnosis and screening in young women.

Shah NS, Cerussi AE, Hsiang D, Yu H, Su M, Nalcioglu O, Tromberg BJ. Beckman Laser Institute, University of California, Irvine, Irvine, CA; University of California, Irvine Medical Center, Orange, CA; University of California, Irvine, Irvine, CA.

Role of fine needle aspiration cytology as an adjunct to core biopsy in the diagnosis of screen-detected breast carcinoma.

Lieske B, Ravichandran D, Wright D. Bedfordshire and Hertfordshire Breast Screening Unit and Luton \& Dunstable Breast Unit, Luton, Bedfordshire, United Kingdom.

5025 Molecular profiling of human breast cancer with serum mass spectrum data.

Zhang Y, Zhu L, Ru Q, Brzeski H, Liebman MN, Hooke J, Shriver CD. Windber Research Institute, Windber, PA; Walter Reed Army Medcical Center, Washington, DC.

Treatment: Chemotherapy - Support

A phase II, randomized, placebo-controlled trial of the safety and efficacy of dexmethylphenidate (dMPH) as a treatment for fatigue and "chemobrain" in adult cancer patients.

Fleishman S, Lower E, Zeldis J, Faleck H, Manning D. Beth Israel Cancer Center, New York, NY; University of Cincinnati Medical Center, Cincinnati, $\mathrm{OH}$; Celgene Corporation, Summit, NJ.

Anemia is a common and neglected complication of adjuvant chemotherapy for early stage breast cancer. Goldrick AJ, Olivotto IA, Alexander C, Speers CH, Barnett J, Allan S. British Columbia Cancer Agency, Victoria and Vancouver, BC, Canada.

5028 Greater area under the hemoglobin change curve is associated with improved outcomes in breast cancer patients receiving epoetin alfa for chemotherapyrelated anemia.

Lefebvre P, Duh MS, McKenzie RS, Piech CT. Groupe d'Analyse, Ltée, Montréal, QC, Canada; Analysis Group, Inc., Boston, MA; Ortho Biotech Clinical Affairs, LLC, Bridgewater, NJ.
Acute and delayed chemotherapy-induced nausea and vomiting and its impact on quality of life in patients with breast cancer in community practice settings.

Cunningham RS, Hu HX, Chen Y-T. The Cancer Institute of New Jercey, New Brunswick, NJ; Merck \& Co., Inc, West Point, PA.

A randomised controlled trial to assess the efficacy of Maharishi Amrit Kalash - an ayurvedic herbal compound in ameliorating toxicity of cancer chemotherapy in women with breast cancer. Srivastava A, Seenu V, Saxena A, Dixit S, Parshad R, Taranikanti V, Misra MC. All India Institute of Medical Sciences, New Delhi, Delhi, India.

First and subsequent cycle pegfilgrastim results in low rates of neutropenic events in patients receiving myelosuppressive chemotherapy.

Rader ME, Breyer W, Luedke S, Truscinski D, Ding B, Dansey R, Ozer H. Nyack Hospital, Nyack, NY; Cancer Center, Provo, UT; Cancer \& Breast Institute, St Louis, MO; Amgen Inc., Thousand Oaks, CA; U of Oklahoma, Cancer Center, Oklahoma City, OK.

Synchronicity: evaluating darbepoetin alfa administered at $\mathbf{3 0 0}$ mcg every three weeks to treat chemotherapy-induced anemia in breast cancer patients.

Silberstein P, Boccia R, Liu D, Tchekmedyian S, Holladay C, Tomita D, Rossi G, Otterson GA. Creighton University, Omaha, NE; Center for Cancer and Blood Disorders, Bethesda, MD; New York Medical College, Valhalla, NY; Pacific Shores Medical Group, Huntington Beach, CA; Charleston Cancer Center, Charleston, SC; Amgen Inc, Thousand Oaks, CA; Ohio State University, Columbus, $\mathrm{OH}$.

Darbepoetin alfa administered once every three weeks is effective for treating chemotherapy-induced anemia.

Canon J-L, Bodoky G, Mateos MV, Bastit L, Ferreira I, Amado R, Vansteenkiste J. Centre Hospitalier Notre Dame et Reine Fabiola, Charleroi, Belgium; Szt. Laszlo Hospital, Budapest, Hungary; University of Salamanca Hospital Clinic, Salamanca, Spain; Centre Frederic Joliot, Rouen, France; Amgen Inc., Thousand Oaks, CA; University Hospital Gasthuisberg, Leuven, Netherlands.

Comparison of outcomes in patients receiving standard community care while enrolled on a nationwide registry with those enrolled in a prospective nationwide community-based clinical trial.

Lyman GH, Rader M, Wolff D, Culakova E, Ding B, Dansey R, Ozer H. University of Rochester, School of Medicine, Rochester, NY; Nyack Hospital, Nyack, NY; Amgen Inc., Thousand Oaks, CA; University of Oklahoma, Oklahoma City, OK.

Darbepoetin alfa administered once every three weeks either synchronously or asynchronously with every-three-week chemotherapy improves anemia in breast cancer patients.

Glaspy J, Henry D, Patel R, Tchekmedyian NS, Berg R, Hendricks L, Rossi G. UCLA School of Medicine, Los Angeles, CA; Joan Karnell Cancer Center, Philadelphia, PA; Comprehensive Blood and Cancer Center, Bakersfield, CA; Pacific Shores Medical Group, Long Beach, CA; Amgen Inc., Thousand Oaks, CA. 
Treatment: Cost-Effectiveness

Cost-utility evaluation of adjuvant hormonal options in postmenopausal women with breast cancer: tamoxifen vs. anastrazole vs. tamoxifen then exemestane.

Skedgel C, Rayson D, Dewar R, Younis T. Dalhousie University, Halifax, NS, Canada; Queen Elizabeth Health Sciences Centre, Halifax, NS, Canada; Cancer Care Nova Scotia, Halifax, NS, Canada.

Cost-effectiveness of switching to exemestane following two-to-three years of therapy with tamoxifen in postmenopausal women with primary breast cancer.

Thompson D, Taylor DCA, Montoya EL, Winer E, Weinstein MC. INNOVUS Research, Inc., Medford, MA; Harvard School of Public Health, Boston, MA; Dana Farber Cancer Institute, Boston, MA

Cost-effectiveness of adjuvant chemotherapy for node + breast cancer: modeling the downstream effects of adjuvant TAC vs FAC: docetaxel (T), adriamycin (A), cyclophosphamide (C) compared to 5-fluorouracil (F) A C

Au H), Golmohammadi K, Chia S, Verma S, Younis T, Chin C, Jacobs P. Cross Cancer Institute, Edmonton, AB, Canada; Institute of Health Economics, Edmonton, $A B$, Canada; Vancouver Cancer Centre, Vancouver, BC, Canada; Ottawa Hospital Integrated Cancer Care Program, Ottawa, ON, Canada; QEll Health Sciences Centre, Halifax, NS, Canada; Aventis Pharma Inc., Montreal, QC, Canada; University of Alberta, Edmonton, AB, Canada.

5039 Economic evaluation of sequential capecitabine (X) and taxanes vs. the combinations in patients (pts) with advanced/metastatic breast cancer (MBC): a Mexican Oncology Study Group (MOSG) Trial. Reynoso N, Torrecillas L, Soto C, Reyes S, Perez-Michel L, Ramirez M, Cervantes G, Benitez H, Delgadillo F, Talavera J. Centro de Investigacion en Ciencias Medicas UAEM, Toluca, Mexico; ISSSTE Centro Medico 20 de Noviembre, Mexico City, Mexico; IMSS, Mexicali, Mexico; IMSS, San Luis Potosi, Mexico; IMSS, Cd. Obregon, Mexico; IMSS, Chihuahua, Mexico; IMSS, Guadalajara, Mexico; ISSSTE, Guadalajara, Mexico; IMSS Siglo XXI, Mexico City, Mexico.

5040 Clinical and cost-effectiveness implications of the adjuvant transtuzumab in HER2 + breast cancer trials. Hillner BE. Virginia Commonwealth Univ., Richmond, VA.

5041 Cost-evaluation of second generation adjuvant chemotherapy options in breast cancer. Al-Shehri A, Skedgel C, Rayson D, Sellon M, Younis T. Queen Elizabeth II Health Sciences Centre, Halifax, NS, Canada.

Predictive value of health economic models: similarity in lifetime results using three-year versus five-year observations from the ATAC Trial. Verma S, Rocchi A. The Ottawa Hospital Regional Cancer Centre, Ottawa, ON, Canada; Axia Research, Hamilton, ON, Canada.

Physician-based active cost management of gynecological-oncological therapies reducing pharmaceutical costs by $\mathbf{- 8 3 . 4 \%}$ in two years without leaving standard of care.

Jacobs VR, Thoedtmann J, Euler U, Niemeyer M, Paepke S, Fischer T, Harbeck N, Kiechle M. Technical University Munich, Munich, Germany.
Cost-effectiveness of nanoparticle albumin-bound paclitaxel versus docetaxel in the treatment of metastatic breast cancer.

Gradishar W, Vishalpura T, Franklin M, Bramley T. Northwestern University Feinberg School of Medicine, Chicago, IL; Applied Health Outcomes, Palm Harbor, FL.

Treatment: Neo-adjuvant Chemotherapy

5045 Microarray-based comparative genomic hybridisation (aCGH) analysis of breast cancer patients receiving neoadjuvant chemotherapy: analysis of tumour subtypes and chemotherapy-related molecular genetic changes.

Pierga J-Y, Reis-Filho JS, Cleator SJ, Dexter T, MacKay A, Jones R, Ashworth A, Smith IE, Powles T, Dowsett M Breakthrough Breast Cancer Research Centre, The Institute of Cancer Research, London, United Kingdom; Royal Marsden Hospital, London, United Kingdom; Institut Curie, Paris, France.

Predictive gene signatures for response to neoadjuvant TAC-chemotherapy from expression profiling.

Rody A, Karn T, Munnes M, von Minckwitz G, Loibl S, Gaetje R, Solbach C, Holtrich U, Kaufmann M. J.W.GoetheUniversity, Frankfurt, Germany; Bayer Healthcare AG, Leverkusen, Germany; German Breast Group, Neu-Isenburg, Germany.

5047 Preoperative doxorubicin / cyclophosphamide followed by docetaxel (AC-Doc) versus dose-dense doxorubicin and docetaxel (Adoc) as preoperative treatment in operable breast cancer: first analysis of the event-free survival of the GeparDuo-Study. Raab G, Kaufmann M, Schuette M, Hilfrich J, Blohmer JU, Gerber B, Costa SD, Eidtmann H, Eiermann W, Lampe D, Jackisch C, du Bois A, von Minckwitz G. Marien Hosp, Stuttgart, Germany; Univ. Hosp., Frankfurt, Germany; Bethesda Hosp., Essen, Germany; Henriettenstift, Hannover, Germany; St. Gertrauden Hosp., Berlin, Germany; Univ. Hosp., Rostock, Germany; Univ. Hosp., Magdeburg, Germany; Univ. Hosp., Kiel, Germany; Rot-Kreuz Hosp., Munich, Germany; Hosp., Weissenfels, Germany; Univ. Hosp., Marburg, Germany; Horst-Schmidt-Kliniken, Wiesbaden, Germany; German Breast Group, Neu-Isenburg, Germany.

5048

Operable breast cancer: preliminary results of a phase II, double blind, placebo controlled, randomized trial of preoperative chemotherapy $+/$ gefitinib with biomarkers evaluation.

Guarneri V, Frassoldati A, Ficarra G, Giovannelli S, Borghi F, Puglisi F, Mansutti M, Andreetta C, Banna G, Masci G, Santoro A, Boni C, Bisagni G, Michelotti A, Crispino S, Conte PF. Modena University Hospital, Modena, Italy; Modena University Hospital, Modena; Udine University Hospital; Istituto Clinico Humanitas, Rozzano; Arcispedale Santa Maria Nuova, Reggio Emilia; S Chiara University Hospital, Pisa; USL7, Siena.

5049 Prospective data of additional patients treated with neoadjuvant therapy with paclitaxel followed by FEC chemotherapy with trastuzumab in HER-2 positive operable breast cancer, and an update of initial study population.

Buzdar AU, Valero V, Ibrahim N, Francis D, Theriault RL, Green M, Hunt K, Sahin A, Buchholz T, Hortobagyi GN. The University of Texas M.D. Anderson Cancer Center, Houston, TX 

docetaxel, carboplatin and trastuzumab in HER2positive, locally advanced breast cancer on behalf of the GETN(A) Group.

Coudert B, Largillier R, Chollet P, Camponne M, Coeffic D, Priou F, Gligorov J, Martin X, Trillet Lenoir V, Weber B, Arnould L, Bleuse JP, Vasseur B, Serin D, Namer M. CAC GF Leclerc, Dijon, France; CAC A Lacassagne, Nice, France; CAC J Perrin, Clermont Ferrand, France; CAC R Gauducheau, Nantes, France; Clinique du Mail, Grenoble, France; $\mathrm{CH}$ Les Oudairies, La Roche sur Yon, France; Hopital Tenon, Paris, France; Clinique Ste Marie, Chalon sur Saone, France; Institut St Catherine, Avignon, France; Sanofi Aventis, Paris, France; Roche, Neuilly, France; CHU Lyon Sud, Lyon, France; CAC A Vautrin, Nancy, France. /primary systemic therapy (PST) with dose-dense sequential epirubicin (E)/ paclitaxel (P) chemotherapy versus standard dose therapy regimen in patients with breast cancer (bc), multicentre study of the AGO, Germany): subgroup analysis of inflammatory bc.

Ditsch N, Bauerfeind I, Kahlert St, Lenhard MS, Himsl I, Untch M. Ludwig-Maximilians. University, Grosshadern, Munich, Bavaria, Germany.

Mature results from a randomized phase III trial of docetaxel/capecitabine (TX) vs. doxorubicin/ cyclophosphamide (AC) as primary chemotherapy for patients (pts) with stage II/III breast cancer (BC). Lee KS, Lee ES, Kwon YM, Nam BH, Kwon HS, Chung KW, Kang HS, Kim EA, Kim SW, Ro J. National Cancer Center, Goyang, Republic of Korea.

$5053 \quad$ Evaluation of the effect of neoadjuvant chemotherapy on tumour microvessel density (MVD), pericyte coverage index $(\mathrm{PCI})$ \& vascular endothelial growth factor (VEGF) in primary breast cancer. Ah-See MW, Harris AL, Burcombe RJ, Fox SB, Richman PI, Daley FM, Padhani AR, Bentzen SM, Makris A. Mount Vernon Hospital, Northwood, Middlesex, United Kingdom; John Radcliffe Hospital, Oxford, Headington, United Kingdom.

$5054 \quad$ Frequent pathologic complete responses seen with neoadjuvant q4week carboplatin and weekly paclitaxel \pm weekly trastuzumab in resectable and locally advanced breast cancer: a Brown University Oncology Group (BrUOG) Study.

Fenton MA, Ries LM, Strenger R, Dizon DS, Legare RD, Joseph PJ, Theall KP, Graves TA, Gass JS, Sikov WM, Brown University Oncology Group. Rhode Island Hospital, Providence, Rl; Women and Infants Hospital of Rhode Island, Providence, Rl; The Miriam Hospital, Providence, Rl; Memorial Hospital of Rhode Island, Pawtucket, RI.

A phase II randomized study to compare the neoadjuvant administration of docetaxel and vinorelbine or docetaxel followed by adriamycin and cytoxan with all chemotherapy administered in a dose dense fashion to women with stage II and stage III breast cancer. Limentani SA, Brufsky AM, Rubin P, Lambert-Falls R, Carroll M. Blumenthal Cancer Ctr, Charlotte, NC; Magee Women's Hospital, Pittsburgh, PA; Moses Cone Reg Cancer Ctr, Greensboro, NC; S Carolina Onc Assoc, Columbia, SC.

High pathological complete remission rates with paclitaxel and carboplatin \pm trastuzumab $(\mathrm{TC} \pm \mathrm{H})$ following dose dense doxorubicin and cyclophosphamide (AC) supported by GM-CSF in breast cancer-a phase II study.

Mehta RS, Schubbert T, Hsiang D, Butler J, Baick C, Su M-Y University of California, Irvine, Orange, CA.

5057 Semi-quantitative gene expression profiling for therapy prediction in a breast cancer neoadjuvant therapy study applying docetaxel/epirubicin/cyclophosphamide.

Schlotter CM, Vogt U, Tidow N, Kemming D, Bosse U, Bonk $\mathrm{U}$, Ergoenc $\mathrm{Y}$, Adiguezel $\mathrm{H}$, Egbert $\mathrm{M}$, Brandt $\mathrm{BH}$. Clinical Centre, Ibbenbueren; European Laboratory Association, Ibbenbueren; GeneSys Lab, Muenster; Institute of Tumor Biology, University Medical Center, Hamburg; Institute of Pathology, Osnabrueck; Institute of Pathology, Bremen; St. Anna Hospital, Herne; Institute of Tumor Biology, University Medical Centre, Hamburg.

Multicenter study of nonpegylated liposomal doxorubicin and docetaxel as neoadjuvant treatment in patients with stage II - III breast cancer. Modolell A, Mayordomo J, Garcia JM, Machengs I, Alvarez I, Palombo H, Yubero A, Murillo L, Belon J, Andres R, Burillo M, Lambea J, Centelles M, Tres A. I Corachan, Barcelona; $H$ Clinico, Zaragoza; P Miramar, Palma; H Sagrado Corazon, Barcelona; H S Jorge, Huesca; Cl Remedio, Barcelona; $\mathrm{H}$ Obispo Polanco, Teruel; H R Sofia, Tudela; H Virgen de las Nieves, Granada, Spain.

5059 Dose-dense taxotere $(T)$ and adriamycin/cyclophosphamide (AC) as neoadyuvant treatment in locally advanced breast cancer (LABC). García-Mata J, Calvo L, García-Palomo A, Mel JR, Almanza MC, Ramos M, de Paz L. H. Santa María Nai, Ourense, Spain; H. Juan Canalejo, A Coruña, Spain; H. de León, León, Spain; H. Xeral Calde, Lugo, Spain; Clínica Povisa, Vigo, Spain; Centro Oncológico, A Coruña, Spain; H. Arquitecto Marcide, Ferrol, Spain

5060 Neoadjuvant capecitabine chemoradiation (X-RT) for patients (pts) with locally advanced breast cancer (LABC) failing anthracycline-based neoadjuvant therapy: findings from a prospective phase II trial. Gaui M, Amorim G, Pereira G, Moreira D, Djahjah C, Spector N. Instituto Nacional do Cancer, Rio de Janeiro, Brazil.

5061 The farnesyl transferase (FTase) inhibitor (FTI) tipifarnib inhibits FTase in vivo and enhances the efficacy of neoadjuvant dose-dense doxorubicincyclophosphamide (AC) in patients with locally advanced breast cancer (LABC).

Moulder SL, Sparano JA, Kazi A, Wright J, Munster PN, Vahdat L, Minton S, Hershman D, Diaz N, Malafa M, Riker A, Lee D, Pellegrino C, Li T, Negassa A, Sebti S. H. Lee Moffitt Cancer Center and Research Institute, Tampa, FL; New York Phase II Consortium (N01-CM-57018), New York, NY

Neoadjuvant dose dense chemotherapy (NDDC) with sequential doxorubicin/cyclophosphamide (AC) followed by taxane yields high pathologic complete response (pCR) rate in stage II/III breast cancer. Schwartzberg LS, Kanter LR, Huang R, Tauer KW, Somer BR. The West Clinic, Memphis, TN; Accelerated Community Oncology Research Network, Memphis, TN. 
Response to primary chemotherapy in breast carcinoma depends on histological tumor type: a study on $\mathbf{8 6 0}$ patients from one institution.

Tubiana-Hulin MJ, Stevens DM, Guinebretiere JMR, Bouita L, Lasry S, Cohen-Solal C, Cherel P, Rouesse J. Centre Rene

Quality of life during three-weekly versus weekly neoadjuvant docetaxel: a randomised trial.

Walker LG, Eremin JM, Vassanasiri W, Walker MB, El-Sheemy M, Jibril JA, Valerio D, Cowley G, Clarke D, Kamal M, Thorpe G, Beer J, Wiseman J, Eremin O. Oncology Health Centres and Institute of Rehabilitation, University of Hull, Kingston upon Hull, United Kingdom; Lincoln County Hospital, Lincoln, United Kingdom.

The changes of histologic and biologic markers induced by neoadjuvant chemotherapy in locally advanced breast cancer.

Choi UJ, Lee KM. Wonkwang University School of Medicine, Iksan, Jeongbuk, Korea.

Doxorubicin and cyclophosphamide followed by weekly docetaxel (AC-T) as neoadjuvant chemotherapy in operable breast cancer patients: GEICAM 2002-03 Study.

Estévez LG, Adrover E, Barnadas A, Cuevas JM, Seguí MA. On Behalf of the Spanish Breast Cancer Research Group (GEICAM), San Sebastián de los Reyes, Madrid, Spain.

Dynamic infrared imaging - a real-time, non-invasive tool for monitoring tumor response to neoadjuvant therapy for breast cancer.

Fanning S, Andresen S, Silverman P, Hicks D, Budd GT, Moore H, Crowe J, Weng DE. Cleveland Clinic Foundation, Cleveland, $\mathrm{OH}$; Case Western Reserve University, Cleveland, $\mathrm{OH}$.

Recurrence rates after dynamic contrast enhancedmagnetic resonance image guided planning for breast conserving surgery following neoadjuvant chemotherapy for breast cancer.

Garimella V, Qutob O, Iwuagwu O, Mahapatra TK, McManus P, Fox JN, Long ED, Lowry M, Chaturvedi A, Turnbull LW, Drew PJ. University of Hull, Hull, East Yorkshire, United Kingdom; Hull and East Yorkshire Hospitals NHS Trust, Hull, East Yorkshire, United Kingdom; Hull and East Yorkshire NHS Trust, Hull, East Yorkshire, United Kingdom.

Impact of pre-operative three different regimens on breast- conservation surgery (BCS) and pathological complete response rates ( $P C R$ ) in locally advanced breast cancer (LABC) in Pakistani patients.

Lal AM, Alidina AG, Khan SM, Valimohd AT, Vaziri IA. AKU, Khi, Sind, Pakistan. Huguenin, Saint Cloud, France.

Neoadjuvant chemotherapy for invasive lobular carcinomas of the breast: a poorer response rate but not a worse prognosis than invasive ductal carcinoma.

Vincent-Salomon A, Pierga J-Y, Gautier C, Sigal-Zafrani B, Freneaux P, Lae M, Rosty C, Asselain B, Salmon R, SastreGarau X. Institut Curie, Paris, France.

5072

Neoadjuvant, biweekly, dose-dense chemotherapy with epirubicin and cyclophoshamid followed by docetaxel in primary breast cancer.

Cramer EM, Moers C, Zarghooni V, Bosse K, Mallmann P, Warm M. Faculty of Medicine, University of Cologne, Cologne, Germany.

5073 Neoadjuvant dose dense chemotherapy alternating gemcitabine (G) + docetaxel (D) and vinorelbine (V) + epirubicin (E) in locally advanced non inflammatory breast carcinoma (LABC): a phase II study.

Levy E, Jenabian A, Scotte F, Lecuru F, Lefrere-Belda MA, Hoffman H, Eme D, Rideller K, Medioni J, Andrieu JM. Georges Pompidou European Hospital, Paris, France.

5074 Sequential FEC100 and taxotere as a neoadjuvant treatment for operable breast cancer.

Servent V, Baranzelli MC, Deschildre L, Chauvet MP, Giard S, Belkacemi Y, Fournier C, Bonneterre J. Centre Oscar Lambret, Lille, France.

5075 Monitoring early treatment response of breast cance to neoadjuvant chemotherapy using MR spectroscopy.

Su MY, Baik HM, Yu H, Mehta RS, Nalcioglu O. University of California, Irvine, CA; UCIMC, Orange, CA.

Treatment: Endocrine Therapy

Skeletal effect of exemestane in the Intergroup Exemestane Study (IES) - 2 year bone mineral density (BMD) and bone biomarker data.

Coleman RE, Banks LM, Girgis SI, Vrdoljak E, Fox J, Porter LS, Snowdon CF, Hall E, Bliss JM, Coombes RC. Yorkshire Cancer Research Centre, Weston Park Hospital, Sheffield, United Kingdom; Imperial College, London, United Kingdom; Clinical Hospital Split, Split, Croatia; Castle Hill Hospital, Cottingham, United Kingdom; Institute of Cancer Research, Sutton, United Kingdom; On Behalf of the Intergroup Exemestane Study (IES).

5078 Inhibition of steroid sulfatase by 667 COUMATE (STX64): a new treatment paradigm for breast cancer. Stanway S, Purohit A, Woo LW, Wilson R, Sufi S, Dobbs N, Vigushin D, Stanczyk FZ, Potter BV, Reed MJ, Coombes RC. Imperial College, London, United Kingdom; University of Bath, Bath, United Kingdom; Belfast City Hospital Tower, Belfast, United Kingdom; Cancer Research UK, London, United Kingdom; USC Keck School of Medicine, Womens and Childrens Hospital, Los Angeles, CA.

Pérez-Manga G, Méndez M, Palomero MI, Quibén R, Belón J. Hospital Gregorio Marañón, Madrid, Spain; Hospital de Móstoles, Madrid, Spain; Hospital Virgen de las Nieves, Granada, Spain
Rosiglitazone sensitizes breast cancer cells to early apoptosis and synergizes with roscovitine to inhibit cellular proliferation.

Mody M, Dharker N, McCaffrey TA, Yang Z, Pumfery AM, Glickman TS, Pinzone J). The George Washington University, Washington, DC. 
Molecular changes in response to pre-operative endocrine therapy.

Richer JK, Harvell DME, Spoelstra NS, Singh M, Elias AD,

Horwitz KB. University of Colorado Health Sciences Center,

Aurora, $\mathrm{CO}$.

5081 Synergistic interaction between recombinant human insulin-like growth factor-binding protein 3 (rhIGFBP-3) and letrozole in estrogen positive breast cancer.

Alami N, Banerjee K, Page V, Brossard M, Shiry L, Brodie A, Leyland-Jones B. McGill University, Montreal, QC, Canada; Insmed Inc., Richmond, VA; University of Maryland, Baltimore, MD.

5082 A role for aromatase inhibition in the treatment of estrogen receptor- $\alpha$ negative breast carcinoma. Brandy KP, Maier KG, Lemke SM, O'Donnell RW, Landas SK, Gatto LA, Kort KC. SUNY Upstate Medical University, Syracuse, NY; SUNY Geneseo, Geneseo, NY; SUNY Cortland, Cortland, NY.

Inhibition of ER $\alpha$ and PI3K/Akt pathways improve sensitivity of long term estrogen deprived breast cancer cells to antiestrogens.

Sabnis G), Jelovac D, Long BJ, Brodie AM. University of Maryland, Baltimore, Baltimore, MD.

Randomized pre-operative study of $750 \mathrm{mg}$ of fulvestrant and $20 \mathrm{mg}$ tamoxifen in premenopausal women with estrogen receptor-positive breast cancer. Young O, Renshaw L, White S, Macaskill EJ, Cameron D, Thomas J, Faratian D, Dixon JM. Western General Hospital, Edinburgh, Scotland, United Kingdom.

Regulation of aromatase expression in the breast by LRH-1: a new potential target for breast cancer therapy.

Simpson ER, McDonnell DP, Kovacic A, Clyne CD, Safi R. Prince Henry's Institute of Medical Research, Clayton, Victoria, Australia; Duke University Medical Center, Durham, NC.

\section{Relationship between CYP2D6 and SULT1A1} genotypes and serum concentrations of tamoxifen and its metabolites during steady state treatment in breast cancer patients.

Gjerde J, Hauglid M, Breilid H, Lundgren S, Varhaug JE, Kisanga ER, Mellgren G, Steen VM, Lien EA. Haukeland University Hospital, Norway; Institute of Medicine, University of Bergen, Norway; University of Bergen; St. Olavs Hospital Trondheim University Hospital; Haukeland University Hospital.

5087 A randomised, blinded, phase II study of tipifarnib $\left(\right.$ Zarnestra $^{\circ}$ ) combined with letrozole in the treatment of advanced breast cancer after antiestrogen therapy.

Johnston SRD, Semiglazov V, Manikhas G, Spaeth D, Romieu G, Dodwell D, Wardley A, Neven P, Bessems A, Ma Y-W, Howes AJ, on Behalf of the R115777 INT-22 Investigators. Royal Marsden Hospital, London, United Kingdom; Petrov Research Institute of Oncology, St Petersburg, Russian Federation; City Oncology Dispensary, St Petersburg, Russian Federation; Centre Alexis Vautrin, Nancy, France; Centre Val D'Aurelle, Montpellier, France; Cookridge Hospital, Leeds, United Kingdom; Christie Hospital, Manchester, United Kingdom; Universitair Ziekenhuis Gasthuisberg, Leuven, Belgium; Johnson \& Johnson PRD, Raritan, NJ.
Changes in estrogen binding to ER during endocrine therapy measured by serial [F-18]-fluoroestradiol positron emission tomography (FES PET).

Linden HM, Link JM, Stekhova S, Livingston RB, Gralow JR, Ellis GK, Schubert EK, Peterson LM, Krohn KA, Mankoff DA. University of Washington/Seattle Cancer Care Alliance, Seattle, WA; University of Washington, Seattle, WA.

Modeling for cost-effective strategies in adjuvant hormonal therapy for postmenopausal women with breast cancer: upfront aromatase inhibitors vs sequential tamoxifen-aromatase inhibitors.

Younis T, Rayson D, Dewar R, Skedgel C. Queen Elizabeth II Health Sciences Centre, Halifax, NS, Canada.

Metabolism of the aromatase inhibitor drug letrozole by the human hepatic cytochrome P450 enzyme system.

Desta Z, Ward BA, Flockhart DA. Indiana University School of Medicine, Indianapolis, IN

5091 A phase l, open-label, non-randomized, dose-finding safety, tolerance, and pharmacokinetic study of TAS108 administered orally in postmenopausal female patients with breast carcinoma following standard endocrine therapies.

Noguchi S, Saeki T, Aogi K, Inaji H, Tabei T, Ikeda T. Osaka University Medical School, Suita, Osaka, Japan; National Shikoku Cancer Center Hospital, Matsuyama, Ehime, Japan; Osaka Medical Center for Cancer and Cardiovascular Diseases, Higashinari-ku, Osaka, Japan; Saitama Cancer Center Hospital, Kitaadachi-gun, Saitama, Japan; Keio University School of Medicine, Shinjyuku-ku, Tokyo, Japan.

Similar time to response between fulvestrant and anastrozole: comparison from two phase III trials. Pippen J. Baylor Sammons Cancer Center \& US Oncology Research, Dallas.

5093 Ovarian histopathology in premenopausal patients with breast cancer receiving gonadotropin-releasing hormone(GnRH) agonist and/or cytotoxic chemotherapy.

Sato N, Sano M, Kaneko K, Kanbayashi C, Honmma K. Niigata Cancer Center Hospital, Niigata, Japan.

Side effect profile of anastrozole compared with tamoxifen in Japanese women: findings from N-SAS BC03 Trial.

Aihara T, Nishiuchi H, Takatsuka Y, Ohashi Y. Kansai Rosai Hospital, Amagasaki, Hyogo, Japan; University of Tokyo, Bunkyoku, Hongo, Tokyo, Japan.

Celecoxib anti-aromatase neoadjuvant (CAAN) Trial for locally advanced breast cancer.

Chow LWC, Toi M. University of Hong Kong Medical Centre, Hong Kong, Hksar, Hong Kong; Tokyo Metropolitan Komagome Hospital, Tokyo, Japan.

Female sexual dysfunction and changes in hormonal levels in patients with early breast cancer on antiestrogen therapy.

Amsterdam AD, Wheler J, Hudis C, Krychman ML. Memorial Sloan-Kettering Cancer Center, New York, NY. Primary hormone therapy in locally advanced breast cancer.

Buhari SA, Cheung Kl, Robertson JFK. Nottingham Breast Institute, Nottingham City Hospital, Nottingham, United Kingdom 
Tipifarnib with tamoxifen as a rescue for tamoxifen acquired clinical resistance for metastatic ER and/or PgR positive breast cancer after releapse under tamoxifen. Preliminary results.

Dalenc F, Lacroix-Tikri M, Mourey L, Debled M, Gladieff L, Tilkin AF, Faye JC, Seronie-Vivien S, Roché H. Claudius Regaud Institute, Toulouse, France; Bergonié Institute, Bordeaux, France.

5099 Tolerance for adjuvant letrozole in daily practice. Fontaine C, Vandenbossche K, Dewaele A, Verfaillie G, Collen K, Neyns B, Schallier D, Vermeij J, Bourgain C, De Grève J. AZ-VUB, Brussels, Belgium.

$5100 \quad$ Aromatase inhibitors (Als) are unlikely to improve overall survival in postmenopausal women with stage I breast cancer.

Diab S. Rocky Mountain Cancer Centers, Aurora, CO; The Women's Breast Center-Aurora Medical Center.

Tumor Cell Biology: Estrogen and Progestin Receptors

5101 Standardization of estrogen and progesterone receptor assay values.

Chapman JW, Jasani B, Ibrahim M, Miller K, Murray D, Hewlett B, Daidone MG, Allred C, Hammond E, Li D, Sweep F, O'Malley FP, Kelly J, Goss P. National Cancer Institute of Canada, Kingston, ON, Canada; UK-NEQAS, United Kingdom; University of Toronto, Canada; Milan, Italy; Baylor Breast Center, TX; Intermountain Health Care and University of Utah; Radboud University Nijmegen Medical Center, Netherlands; BC Cancer Agency, Canada; Harvard University.

5102 Inhibition of MAPK restores anti-estrogen response in vitro and $E R \alpha$ expression in breast tumors. Bayliss JM, Hilger AM, Murthy S, Diehl KM, El-Ashry D. University of Michigan, Ann Arbor, MI.

5103 Estrogen-induced suppression of gene expression: mechanisms of down-regulation.

Cuba VL, DeNardo DG, Hilsenbeck SG, Brown PH. Baylor

College of Medicine, Houston, TX.

5104 Loss of estrogen receptor (ER) expression in MCF-7 cells following long-term exposure to fulvestrant. Giles M, Fiegl H, Widschwendter M, Gee J, Wakeling A, Nicholson R. Cardiff University, United Kingdom; University Hospital, Austria; AstraZeneca Pharmaceuticals, United Kingdom.

5105 Scaffold attachment factor B1 (SAFB1) - an estrogen receptor $\alpha$ corepressor.

Meyer R, Dobrzycka KM, Ivanova M, Jiang J, Kang K, Oesterreich S. Baylor College of Medicine, Houston, TX.

Thyroid hormone may induce breast cancer progression via interactions with the estrogen receptor.

Thor A, Liu B, Ordonez-Ercan D, Edgerton S. OUHSC, Oklahoma City, OK.

5107 Day of surgery affects estrogen receptor test results in women with breast cancer.

Nkoy FL, Hammond E, Rees W, Sause W, Pinto K, Rowe K. Intermountain Health Care (IHC), Salt Lake City, UT. estrogen-mediated repression of genes.

Zubairy S, Wilscher E, Oesterreich S. Baylor College of Medicine, Houston, TX. 
SUNDAY, DECEMBER 11

7:00-9:00

POSTER SESSION 6 \& CONTINENTAL BREAKFAST - Exhibit Hall B

(\#6001-6111)

Risk and Prevention: Diet and Nutrition

6001 Method of cooking and risk of breast cancer in the Philippines.

Kotsopoulos J, Liede A, De Leon Matsuda ML, Sun P, Narod SA. Sunnybrook and Women's College Hospital, Toronto, ON, Canada; University of Toronto, Toronto, ON, Canada; College of Medicine and Philippine General Hospital, University of the Philippines, Manila, Philippines.

Risk and Prevention: Risk Factors

6002 A single gene biomarker identifies undifferentiated breast cancers associated with short duration of breastfeeding.

Symmans WF, Fiterman DJ, Anderson SK, Ayers M, Rouzier R, Dunmire V, Stec J, Valero V, Sneige N, Albarracin C, Wu Y, Ross JS, Wagner P, Theriault RL, Arun B, Kuerer H, Hess K, Zhang W, Hortobagyi GN, Pusztai L. M.D. Anderson Cancer Center, Houston, TX; Millennium Pharmaceuticals, Inc, Cambridge, MA; Albany Medical College, Albany, NY.

6003 Past exogenous hormone use and current endogenous sex hormone status in postmenopausal women in the EPIC-Norfolk population cohort. Chan MF, Khaw KT, on Behalf of EPIC-Norfolk Collaborators, University of Cambridge. Institute of Public Health, University of Cambridge.

6004 Antidepressants and breast cancer risk: casual link or no cause for concern?

Masry P, George R, Jackman M, Thain D, Walker R, Warner J, Wintonic A, Melinyshyn S, Sunderland C. Queen's University, Kingston, ON, Canada; Hotel Dieu Hospital, Kingston, ON, Canada.

6005 Pilot study of changes in mammographic density in women treated with letrozole or placebo on NCIC CTC MA17.

Vachon CM, Ingle JN, Scott CG, Olson JE, Goss PE. Mayo Clinic College of Medicine, Mayo Clinic, Rochester, MN; Harvard Medical School, Boston, MA.

6006 Influence of family history on breast cancer risk in women with biopsy-confirmed benign breast disease: results from the Nurses' Health study.

Collins LC, Baer HJ, Tamimi RM, Connolly JL, Colditz GA, Schnitt SJ. Beth Israel Deaconess Medical Center and Harvard Medical School; Brigham and Women's Hospital; Harvard School of Public Health; Harvard Center for Cancer Prevention, Boston, MA.

Ultra-sensitive GC/Tandem mass spectrometry assay for estradiol measurements in post-menopausal women.

Santen RJ, Demers LM, Ohorodnik SK, Settlege JA, Langecker P, Wang S. University of Virginia, Charlottesville, VA; Penn State, Hershey, PA; Taylor Technologies, Princeton, Nj; Intarcia Therapeutics, Emeryville, CA. laterality of breast cancer. Olsson HL, Luts L, Anderson H. University Hospital, Lund, Sweden.

The relationship between serum cholesterol level and axillary lymph node statu in breast cancer patients. Utkan G, Onur H, Akbulut H, Yalcin B, Buyukcelik A, Tek I, Doruk H, Dogan M, Demirkazik A, Icli F. Ankara University School of Medicine, Ankara, Turkey.

6010 Association of manganese superoxide dismutase (MnSOD) gene polymorphism and breast cancer in males and females.

Bica CG, Silva LLM, Toscani NV, Da Cruz IBM, Graudenz MS. FFFCMPA, Porto Alegre, Rio Grande do Sul, Brazil.

6011 Ductal carcinoma in situ and risk factors for breast cancer: can we target individuals for surveillance? Saettler ER, George R, Thain D, Walker R, Warner J, Wintonic A, Melinyshyn S, Sunderland C. Queen's University, Kingston, ON, Canada; Hotel Dieu Hospital, Kingston, ON, Canada.

6012 Morphological and immunohistochemical aspects of the breast tissue in postmenopausal women before and after hormone replacement therapy.

Elias S, Dardes RC, Baracat EC, Logullo AF, Kemp C. Federal University of São Paulo, São Paulo, Brazil.

6013 Transfer of lipids to HDL in patients with breast cancer.

Grazianni SR, Hegg R, Morikawa A, Puk CG, Vinagre CG, Maranhao RC. Heart Institute-USP, Sao Paulo, Brazil; University of Sao Paulo, Sao Paulo, Brazil.

6014 Risk factors in breast cancer, a myth - an Indian experience.

Pant CS, Tandon A. Col Pant's Imaging Centre, New Delhi, Delhi, India.

6015 The effect of the oral contraceptive pill on prognosis and survival in women with breast cancer. Clarke E, Haji A, Kalimuddin S, Hajduga V, Bates T. William Harvey Hospital, Ashford, Kent, United Kingdom.

Prognosis and Prediction: Prognostic Factors - Methods

6016 Prediction of axillary sentinel node status: study of a large single institution series of breast cancer patients.

Zurrida S. European Institute of Oncology, Milan, Italy.

6017 Telomere DNA content and allelic imbalance predict disease-free survival and define field cancerization in histologically normal tissue adjacent to breast tumors.

Heaphy CM, Bisoffi M, Fordyce CA, Haaland-Pullus CM, Hines WC, Joste NE, Mangalik A, Griffith JK. University of New Mexico, Albuquerque, NM; University of California at San Francisco, San Francisco, CA.

6018 Validation of reference genes for relative real time PCR to study hormone-dependent gene expression in breast cancer biopsies.

Larionov AA, Dixon JM, Krause A, Evans DB, Miller WR. WGH, Edinburgh, United Kingdom; Novartis Pharma AG, Basel, Switzerland. 
Molecular risk estimation and adjuvant chemotherapy in node-negative breast cancer patients - a status report of the prospective clinical trial NNBC 3-Europe.

Herbst F, Paepke D, Gauger K, Gaskill N, Sweep F, Meisner C, Schmitt M, Jaenicke F, Thomssen C, Harbeck N. Universitaetsklinikum Hamburg-Eppendorf, Hamburg, Germany; Technische Universitaet Muenchen, Muenchen, Germany; University Hospital Nijmegen, Nijmegen, Netherlands; Institute fuer Medizinische Datenverarbeitung, Universitaet Tuebingen, Tuebingen, Germany; MartinLuther-Universitaet Halle, Halle, Germany.

Repeatability and sources of uncertainty in relative real time PCR gene expression measurements in breast cancer biopsies.

Larionov AA, Dixon JM, White S, Anderson TJ, Miller WR. WGH, Edinburgh, United Kingdom.

6021 Identification of predictive biomarker panels by computational modeling of treatment responses in breast cancer patients.

Samadzadeh LK, Lett SG, Stella G, Nagle RB, Grogan TM, Beresford PJ, Pestano GA. Ventana Medical Systems Inc., Tucson, AZ; The BioAnalytics Group Inc., Princeton, NJ; University of Arizona Cancer Center, Tucson, AZ.

A new rabbit monoclonal antibody (4B5) for the immunohistochemical (IHC) determination of the HER2 status in breast cancer: comparison with CB11, fluorescence in situ hybridization (FISH) and interobserver variability.

Hicks DG, Prescott N, Tarr S, Pettay J, Laniauskas S, Swain E, Grogan T, Roche P, Powell W, Tubbs R, Hartke M. Cleveland Clinic Foundation, Cleveland, $\mathrm{OH}$; Ventana Medical Systems Inc., Tucson, AZ.

$\mathbf{6 0 2 3}$ Improvements of breast cancer cure fractions in surveillance, epidemiology, and end results (SEER) estimated using CanSurv software.

Lee S-J, Royce ME, Wallace AM, Chapman JW, Tai P. University of New Mexico Cancer Research and Treatment Center, Albuquerque, NM; National Cancer Institute of Canada-Clinical Trials Group, Queen's University, Kingston, ON, Canada; University of Saskatchewan, Allan Blair Cancer Center, Regina, SK, Canada.

$\mathbf{6 0 2 4}$ Factors predicting the axillary lymph node status in women with an ER-positive breast cancer are agedependent.

Neven P, Huang HJ, Drijkoningen M, Amant F, Leunen K, Berteloot P, Wildiers $H$, Van Limbergen E, Paridaens R, Christiaens MR, Vergote I. University Hospitals Leuven, Leuven, Belgium; Chang Gung Memorial Hospital, Taoyuan, Taiwan.

6025 Lymph node ratio (LNR) is better survival predictor than conventional nodal categories: a surveillance, epidemiology, and end results (SEER) database analysis for node-positive breast cancer (BC). Royce ME, Lee S-J, Wallace AM, Woodward WA, Ueno NT, Vinh-Hung $V$, the International Nodal Ratio Working Group. University of New Mexico Cancer Research and Treatment Center, Albuquerque, NM; U.T. M.D. Anderson Cancer Center, Houston, TX; U.T. M. D. Anderson Cancer Center, Houston, TX; AZ-VUB, Jette, Belgium; Spain, Belgium, USA.
6026

Flourescence in situ hybridization (FISH) as the primary methodology for the assessment of HER2 status in adenocarcinoma of the breast: a single institution experience.

Tubbs R, Hicks DG, Downs-Kelly E, Pettay J, Hartke M, Myles J, Budd GT, Crowe JP. Cleveland Clinic Foundation, Cleveland, $\mathrm{OH}$.

6027 Newly established ELISA suitable for evaluation of HER2 antibodies in sera of patients with primary or advanced breast cancer, or benign or premalignant breast lesions.

Willems A, Harbeck N, Henrichs C, Kiechle M, Peschel C, Bernhard H, Schmitt $M$. Technical University of Munich, Klinikum Rechts der Isar, Germany.

Automation of preanalytical components and image quantification of direct dual label fluorescence in situ hybridization (FISH) for HER2 gene amplification. Tubbs R, Pettay J, Swain E, Roche P, Powell W, Hicks D, Grogan T. Cleveland Clinic \& the Cleveland Clinic Lerner College of Medicine, Cleveland, OH; Ventana Medical Systems International, Tucson, AZ.

6029 Blood oxygenation level dependent (BOLD) contrast MRI for early evaluation of breast cancer chemotherapy.

Jiang L, McColl R, Weatherall P, Tripathy D, Mason RP. UT Southwestern Medical Center at Dallas, Dallas, TX.

Treatment: Bone Metastases

6030 Multicenter, phase IV randomized study to assess efficacy of continuous versus alternate administration of pamidronate to breast cancer patients with symptomatic bone metastasis: GEICAM/2000-01 Trial.

Ruiz-Borrego M, Lluch A, Martín M, Calvo L, Bayo J, Ramos $M$, Adrover E, Franquesa R, Rodríguez-Lescure A, Barnadas A. On Behalf of the Spanish Breast Cancer Research Group (GEICAM), San Sebastián de los Reyes, Madrid, Spain.

6031 Accurate tumor response assessment in bone-only metastatic breast cancer by comprehensive imaging and by new response criteria.

Hamaoka T, Costelloe CM, Madewell JE, Islam R, Rondon G, Ayers GD, Champlin RE, Berry DA, Hortobagyi GN, Ueno

NT. St Luke's International Hospital, Tokyo, Japan; University of Texas M. D. Anderson Cancer Center, Houston, TX.

$\mathbf{6 0 3 2}$ Efficacy and safety of systemic samarium 153 therapy in metastatic breast cancer patients with widespread bone metastases.

Lacko A, Pajak K, Kolodziejczyk A, Zebrowski J, Garncarek A, Filipczyk-Cisarz E. Wroclaw Medical University, Wroclaw, Poland; Lower Silesian Oncology Center, Wroclaw, Poland; IV Military Hospital, Wroclaw, Poland.

6033 Non-inferiority of oral ibandronate to intravenous zoledronic acid for reducing markers of bone turnover in metastatic breast cancer patients. Lichinitser MR, Coleman RE, Tjulandin SA, Bergström B, Body JJ. RAMS, Moscow, Russian Federation; Cancer Research Centre, Weston Park Hospital, Sheffield, United Kingdom; Hoffmann-La Roche Inc., Nutley, NJ; Institut Jules Bordet, Université Libre de Bruxelles, Brussels, Belgium. 
Intravenous ibandronate 15-minute infusion followed by daily oral ibandronate for metastatic bone disease: bone marker data.

Bergström B, Lichinitser MR, Andreeva N, Budde M, Body JJ. Hoffman-La Roche Inc., Nutley, NJ; NN Blokhin Russian

Cancer Research Center, Moscow, Russian Federation; Semashko Central Clinical Hospital, Moscow, Russian Federation; F. Hoffmann La-Roche AG, Basel, Switzerland; Institut Jules Bordet, Université Libre de Bruxelles, Brussels, Belgium.

6035 Safety of oral ibandronate and intravenous zoledronic acid in breast cancer patients with metastatic bone disease.

Body J), Lichinitser MR, Tjulandin SA, Coleman RE, Bergström B. Institut Jules Bordet, Université Libre de Bruxelles, Brussels, Belgium; NN Blokhin Russian Cancer Research Center, Moscow, Russian Federation; Cancer Research Centre, Weston Park Hospital, Sheffield, United Kingdom; Hoffman-La Roche, Inc., Nutley, NJ.

6036 Fractures negatively affect survival in patients with bone metastases from breast cancer.

Hei YJ, Saad F, Coleman RE, Chen YM. Novartis Oncology, East Hanover, NJ; Hôpital Notre-Dame, Montreal, QC, Canada; Weston Park Hospital, Cancer Research Centre, Sheffield, United Kingdom.

6037 Efficacy and safety of intravenous ibandronate $6 \mathrm{mg}$ infused over 15 minutes: results from a 2-year study of breast cancer patients with metastatic bone disease.

Heras P, Hatzopoulos A, Mitsibounas D. General Hospital of Nafplio, Nafplio, Greece; Hellenic Medical Society for the Study of Psychosomatic Disorders, Athens, Greece.

6038

Changes in tumor metabolism and local bone turnover in patients treated for bone-dominant metastatic breast cancer measured by fluorodeoxyglucose (FDG) and fluoride positron emission tomography (PET).

Gralow JR, Brenner W, Linden HM, Livingston RB, Ellis GK, Schubert EK, Peterson LM, Muzi M, Mankoff DA. University of Washington/Seattle Cancer Care Alliance, Seattle, WA; University of Washington, Seattle, WA; University Medical Center Hamburg-Eppendorf, Hamburg, Germany.

Treatment: DCIS modalities, treatments and long term outcome. Analysis of 183 cases.

Cutuli B, Levi C, Lemanski C, Brunaud C, Giard S, Quetin P, Cohen-Solal Le-Nir C, De Lafontan B, Meunier A, Fay R. Polyclinique de Courlancy, Reims, France; French Cancer Centers Breast Group, Paris, France; Centre d'Investigation Clinique, Toul, France.

Role of sentinel lymph node biopsy in screen detected ductal carcinoma in situ: analysis of $\mathbf{5 8 7}$ cases.

Goyal A, Douglas-Jones A, Stevens G, Monypenny I, Sweetland H, Mansel R. Cardiff University, Cardiff; Breast Test Wales, Cardiff, United Kingdom.

Effects of letrozole and anastrozole on ductal carcinoma in situ (DCIS): results from a randomised trial.

Faratian D, White S, Murray J, Renshaw L, Young O, Macaskill EJ, Evans DB, Cameron D, Miller WR, Dixon JM. Western General Hospital, Edinburgh, Scotland, United Kingdom; Novartis Pharma AG, Basel, Switzerland.
Changes in DCIS features and treatment over a 20 year period. Analysis of $\mathbf{2 5 1 2}$ patients.

Cutuli B, Lemanski C, Cohen-Solal Le-Nir C, Fourquet A, De Lafontan B, Fay R, Jourdan R. Polyclinique de Courlancy, Reims, France; Centre Val d'Aurelle, Montpellier, France; Centre Rene Huguenin, Saint Cloud, France; Institut Curie, Paris, France; Centre Claudius Regaud, Toulouse, France; Centre d'Investigation Clinique, Toul, France; Astra Zeneca, Rueil, France.

Treatment: Hormone Replacement Therapy

LIBERATE Trial: a safety study of tibolone in breast cancer surgery patients - design and baseline data. Foidart JM, Bundred NJ, Kenemans P, Kubista E, von Schoultz B, Sismondi P, Vassilopoulou-Sellin R. Univ of Liege, Liege, Belgium; Univ of Manchester, Manchester, United Kingdom; Free Univ, Amsterdam, Netherlands; Medical Univ, Vienna, Austria; Karolinska Inst, Stockholm, Sweden; Univ of Turin, Turin, Italy; Anderson Cancer Center, Univ of Texas, Houston.

$\mathbf{6 0 4 4}$ Vaginal estrogens appear to be contraindicated in postmenopausal women on adjuvant aromatase inhibitors.

Kendall AH, Dowsett M, Folkerd EJ, Smith IE. Royal Marsden Hospital, London, United Kingdom.

6045 Menopausal hormone therapy after breast cancer why are the results so different? von Schoultz E. Karolinska Institute, Stockholm, Sweden.

6046 The effects of natural progesterone and medroxyprogesterone acetate on risk markers for breast cancer in the normal postmenopausal breast. Wood CE, Register TC, Lees C), Cline JM. Wake Forest University School of Medicine, Winston-Salem, NC.

6047 Role of hormonal replacement therapy(HRT) on clinical characteristics tumors histo-pronostic factors and survival of patients with breast cancer. Czernichow C, This P, Asselain B, Savignoni A, Salmon RJ. Institut Curie, Paris, France

6048 Tibolone and its metabolites inhibit invasion of human mammary carcinoma cells in vitro. Depypere HT, Bracke ME, Vanhoecke BW, Kloosterboer HJ. State Universty, De Pintelaan 185, Ghent, East Flanders, Belgium; Organon, Oss, Netherlands.

6049 Hormone replacement therapy in women with breast cancer. A survey of patient's attitudes. Turner LE, Bundred NJ. South Manchester University Hospital, Manchester, United Kingdom.

Treatment: Male Breast Cancer

6050 The sentinel lymph node biopsy in male breast cancer: the European Institute of Oncology experience.

Chagas ERM, Gentilini O, Intra M, Silva L, Luini A. European Institute of Oncology, Milan, Italy.

\section{Treatment: Other Therapies}

6051 Selective inhibition of ADAM metalloproteases blocks
Her-2 extracellular domain (ECD) cleavage and
potentiates trastuzumab in blocking the growth of
Her-2 overexpressing breast cancer cells.
Liu X, Wang Q, Yang G, Covington M, Marando C, Fridman
J, Caulder E, Zhuo J, Li Y, Yao W, Vaddi K, Newton R,
Friedman S, Scherle P. Incyte Corporation, Wilmington, DE. 

antiestrogenic activity in the breast: implications for treating benign breast pain and reducing cancer risk. Mansel RE, O'Connell K. University of Wales College of Medicine, Cardiff, Wales, United Kingdom; Columbia Univ Medical Ctr, New York, NY.

The effects of relaxation guided imagery on natural killer (NK) cell and cytokine IL-2 induced NK cytotoxicity in breast cancer patients.

Lengacher CA, Bennett M, Gonzalez L, Cox C, Cantor A Djeu J, Carter WB, Buck H, Yang CY. University of South Florida, Tampa, FL; H. Lee Moffitt Cancer Center \& Research Institute, Tampa, FL; Indiana State University, Terre Haute, IN.

\section{Treatment: Patient Management}

6054

Decision criteria for adjuvant chemotherapy or hormonal therapy in node negative breast cancer: results of a french oncologist survey.

Cowen D, Gligorov J, Pignon T, Padovani L. Hôpital Timone,

Marseille, France; Hôpital Tenon, Paris, France.
Premature menopause following chemotherapy for early stage breast cancer: long-term results from IBCSG trials $\mathbf{V}$ and VI.

Gelber S, Partridge A, Gelber RD, Castiglione-Gertsch M, Goldhirsch A, Winer E. DFCl, Boston, MA; University of Bern, Bern, Switzerland; European Institute of Oncology, Milan, Italy.

The evaluation of the clinical effectiveness of telemedicine in breast cancer multidisciplinary decision making: TELEMAM, a cluster randomised trial.

Kunkler $I H$, Fielding RG, Brebner J, Prescott RJ, Maclean JR, Chetty U, Bowman A, Neades G, Lee R, Smith M, Dixon JM, Swann S, Macnab M, Cairns J, Gardner T, Lee M. Edinburgh University, Edinburgh, United Kingdom.

Fatigue, weight gain, lethargy and amenorrhea in breast cancer patients on chemotherapy: is subclinical hypothyroidism the culprit? Kumar NB, Allen K, Riccardi D, Bercu B, Cantor A, Minton S, Balducci L, Jacobsen P. H. Lee Moffitt Cancer Center \& Research Inst, Tampa, FL; University of South Florida, Tampa, FL.

The Toyota production system applied to breast cancer care.

Wechter DG, Dubuque DP, Jacobs AD. Virginia Mason Medical Center, Seattle, WA; The Cancer Institute, Virginia Mason Medical Center, Seattle, WA.

6059 Correlation between preference for adjuvant therapy prior to surgery and actual choice of therapy. Fama T, Wood ME, Muss HB. University of Vermont, Burlington, VT.

One year outcomes of an early identification and intervention model to reduce upper extremity morbidity related to breast cancer treatment. Gergich NL, Pfalzer LA, McGarvey CL, Augustine EA, Springer B, Gerber LH, Soballe PW. National Naval Medical Center, Bethesda, MD; National Institutes of Health, Bethesda, MD; University of Michigan- Flint Campus, Flint, Ml; Walter Reed Army Medical Center, Washington, DC.
Longitudinal patterns of weight gain after breast cancer diagnosis: observations beyond the first year. Makari-Judson G, Judson CH, Barham RB, Mertens WC. Baystate Medical Center, Springfield, MA.

Meta-analysis examining the efficacy of serotonin selective reuptake inhibitors in the treatment of women with hot flashes.

Mukherjee SD, Al-Sagheir A, Levine M. Juravinski Cancer Centre, Hamilton, ON, Canada

Time to progression as a surrogate endpoint of clinical benefit in the taxanes and aromatase inhibitors decade: "El Álamo" project.

De la Haba J, Aranda E, Lluch A, Llombart A, Martín M, Alba E, Munárriz B, Balil A, Ramos M, Martínez del Prado P. On Behalf of the Spanish Breast Cancer Research Group (GEICAM), San Sebastián de los Reyes, Madrid, Spain.

The effect of a pilot exercise intervention on bone remodeling and body composition in breast cancer survivors.

Knobf MT, Insogna K, Fennie K, Thompson AS, DiPietro L. Yale University, New Haven, CT.

Acute and delayed nausea still a considerable problem in adjuvant breast cancer chemotherapy. Malmström A, Norberg B, Börjeson S, Hursti T, Sundqvist $M$, Peterson $C$, Andersson B, Jungå A-S, Ljung U. Linköping University Hospital, Sweden; Jönköping County Hospital, Sweden; Linköping University, Sweden; Uppsala University, Sweden; Kalmar County Hospital, Sweden.

Breast cancer and HIV.

Hurley J, DeCesare T, Gomez-Fernandez C, Powell J. Jackson Memorial Hostpital, Miami, FL; University of

Miami/Sylvester Cancer Center, Maimi, FL.

The impact of paclitaxel on menstrual function. Oktay K, Libertella N, Oktem O, Beck L, Cil A. Weill Medical College of Cornell University, New York, NY; Fertile Hope, New York, NY.

6068 Attitudes and management approaches of physicians who care for women with DCIS.

Partridge AH, Winer JP, Sampson E, Blood E, Dees C, Emmons K, Winer EP. Dana-Farber Cancer Institute, Boston, MA; Brigham and Women's Hospital, Boston, MA; University of North Carolina, Chapel Hill, NC.

6069 When less is more? Follow up strategies for patients with breast cancer.

Sheiner J, Fitzgerald B, Blair A, Callaghan W, Clemons M. Toronto Sunnybrook Regional Cancer Centre, Toronto, ON, Canada

6070 The adherence of practice guidelines in the assessment of bone health in women with chemotherapy-induced amenorrhea.

Tham YL, Sexton K, Kramer R, Weiss H, Grollman J, Minnix J, Friedman LC. Baylor College of Medicine, Houston, TX.

Treatment: Psychosocial Aspects

6071 A prospective longitudinal study of the impact of adjuvant chemotherapy for breast cancer (BC) on older patients' functional status and quality of life. Hurria A, Hurria A, Panageas K, Zuckerman E, Fornier M, D'Andrea G, Dang C, Moasser M, Robson M, Seidman A, Currie V, Vanpoznak C, Theodoulou M, Norton L, Atienza M, Hudis C. Memorial Sloan-Kettering Cancer Center, New York, NY; Suny Upstate, Syracuse, NY; University of California San Francisco, San Francisco, CA. 

longitudinal results from a cohort study. Partridge AH, Adloff K, Blood E, Dees C, Kaelin C, Weeks ), Emmons K, Winer EP. Dana-Farber Cancer Institute, Boston, MA; Brigham and Women's Hospital, Boston, MA; University of North Carolina, Chapel Hill, NC.

Post-decision regret following breast reconstruction among women with breast cancer.

Sherman KA, Sheehan JC, Lam T, Boyages J, Zibdeh S. Macquarie University, Sydney, New South Wales, Australia; New South Wales Breast Cancer Institute, Westmead, NSW, Australia.

Memory impairments with anastrozole versus tamoxifen therapy in women with early stage breast cancer.

Bender CM, Sereika SM, Ryan CM, Casillo FE, Vogel VG, Berga SL, Cohen SM, Rastogi P, Brufsky AM. University of Pittsburgh, Pittsburgh, PA; Emory University, Atlanta, GA.

Distress in a nationwide cohort study of Danish women treated for locoregional invasive breast cancer. Prevalence and associations with histopathological variables, type of treatment and social relations.

Christensen S, Zachariae R, Jensen AB, Møller S, Ravnsbæk J, Væth M, Maase HVD. Aarhus University Hospital, Aarhus, Denmark; Rigshospitalet, Copenhagen, Denmark; Aarhus University, Aarhus, Denmark.

Pre-surgical screening for emotional distress and psychiatric co-morbidity among women with newly diagnosed early stage breast cancer.

Moore CP, Kearing S, Collins ED, Hegel MT, Ahles TA, Gillock KL, Riggs RL, Clay KF. Dartmouth Hitchcock Medical Center; Dartmouth Medical School.

Oncology rehabilitation improves patient physical function and emotional health.

Smith KY, Rodgers RG. Cancer Association of Anderson, Anderson, SC; AnMed Health, Anderson, SC.

6078 Determinants of presentation delay in locally advanced breast cancer.

Kerr-Cresswell DM, Fitzgerald B, Fergus K, Gould J, Clemons MJ. Toronto Sunnybrook Regional Cancer Center, Toronto, ON, Canada.

The role of fatigue in mediating "chemo fog" in breast cancer patients.

Awad N, Collins B, Dent S, MacKenzie J, Bielajew C, Stewart A. University of Ottawa, Ottawa, ON, Canada; Ottawa Hospital, Ottawa, ON, Canada; Ottawa Hospital Regional Cancer Centre, Ottawa, ON, Canada.

6080 What do patients bring to the consultation? Professional and social support in breast cancer: the role of childhood abuse.

Clark LK, Holcombe C, Hill J, Krespi R, Fisher J, Downey H, Salmon P. The University of Liverpool, Liverpool, Merseyside, United Kingdom; Royal Liverpool University Hospital, Liverpool, Merseyside, United Kingdom; Royal Liverpool Childrens Hospital (Alder Hey), Liverpool, Merseyside, United Kingdom. adrenal (HPA) axis function as potential diagnostic markers in the assessment of depression in patients with advanced breast cancer.

Jehn CF, Kuehnhardt D, Bartholomae A, Pfeiffer S, Schmid P, Possinger K, Flath BC. Charite Berlin Mitte, Berlin, Germany.

Using the Brief Symptom Inventory-18 to screen patients referred to high-breast cancer risk assessment clinic: patient factors associated with "caseness" before and after counseling. Katz D, Makari-Judson G, Barham R, Carr C, Quinlan M, Mertens WC. Baystate Regional Cancer Program, Springfield, MA.

6083

Pre-chemotherapy assessment of cognitive function using functional magnetic brain imaging in women with breast cancer.

Cimprich B, Hayes DF, Therrien B, Reuter-Lorenz P, Noll D, Normolle D, Welsh R, Clark PM, Vincent C, Nelson J. University of Michigan, Ann Arbor, Ml; School of Medicine; Biomedical Engineering.

\section{Treatment: Chemotherapy - General}

A quantitative study of tumor response and progression-free survival as surrogate endpoints for overall survival in first-line treatment of metastatic breast cancer.

Burzykowski T, Piccart MJ, Sledge G, Carmichael J, Luck HJ, Mackey JR, Nabholtz JM, Paridaens R, Biganzoli L, Jassem J, Blohmer JU, Bontenbal M, Bonneterre J, Chan S, Atalay G, Therasse P, Buyse M. Limburgs Universitair Centrum, Diepenbeek, Belgium; Institut Jules Bordet, Brussels, Belgium; IDDI, Brussels, Belgium.

6085 Chemotherapy and cardiotoxicity in older breast cancer patients: a polulation-based study. Doyle J), Neugut Al, Jacobson J), Grann VR, Hershman DL. Mailman School of Public Health, Columbia University, New York, NY; College of Physicians and Surgeons, Columbia University, New York, NY.

Effects of taxanes alone or in combination with anthracyclines on tumor response, progression-free survival and overall survival in first-line chemotherapy of patients with metastatic breast cancer: an analysis of 4,256 patients randomized in 12 trials.

Piccart M), Burzykowski T, Sledge G, Carmichael J, Luck HJ, Mackey JR, Nabholtz JM, Paridaens R, Biganzoli L, Jassem J, Blohmer JU, Bontenbal M, Bonneterre J, Chan S, Atalay G, Therasse P, Buyse M. Institut Jules Bordet, Brussels, Belgium; Limburgs Univsersitair Centrum, Diepenbeek, Belgium; IDDI, Brussels, Belgium.

A phase III randomized trial of doxorubicin $(A)$ and docetaxel $(D)$ versus doxorubicin and paclitaxel $(P)$ in metastatic breast cancer - preliminary results of the Erasme 3 study.

Cassier PA, Chabaud S, Freyer G, Peaud PY, Tigaud JD, Cure $\mathrm{H}$, Orfeuvre H, Salles B, Martin C, Jacquin JP, Agostini C, Bachelot T. Centre Leon Berard, Lyon, France; Centre Hospitalier Lyon Sud, Lyon, France; Centre Hospitalier, Valence, France; Hopital Edouard Herriot, Lyon, France; Centre Jean Perrin, Clermont-Ferrand, France; Centre Hospitalier, Bourg-en-Bresse, France; Centre Hospitalier, Chalon-sur-Saone, France; Centre Hospitalier, Annecy, France; Clinique de la Digonniere, St Etienne, France; Centre Hospitalier, Chambery, France. 
Timing of initiation of adjuvant chemotherapy for early breast cancer does not influence disease-free survival. A Spanish Breast Cancer Research Group (GEICAM) analysis.

Jara C, Ruiz A, Martín M, Antón A, Munárriz B, Plazaola A Cerrato L, Martínez del Prado P, Alba E, FernándezAramburo A. On Behalf of the Spanish Breast Cancer Research Group (GEICAM), San Sebastián de los Reyes, Madrid, Spain.

A multicenter phase III trial comparing docetaxel plus epirubicin versus docetaxel plus capecitabine as first line treatment in patients with locally advanced and metastatic breast cancer. Preliminary report.

Mavroudis D, Boukovinas I, Ardavanis A, Syrigos K, Kouroussis $\mathrm{CH}$, Kakolyris S, Malamos N, Athanasiadis A Varthalitis I, Potamianou A, Georgoulias V. Hellenic Oncology Research Group, Heraklion, Greece.

6090

Pegylated liposomal doxorubicin in previously treated patients with metastatic breast cancer- a large multicenter phase II trial.

Al-Batran SE, Bischoff J, von Minckwitz G, Atmaca A, Kleeberg U, Meuthen I, Morack G, Lerbs W, Hecker D, Jager E. Krankenhaus Nordwest, Frankfurt, Germany; Klinik Bad Trissl, Oberaudorf, Gabon; Universitaets-Frauenklinik, Frankfurt, Finland; Heamatologisch-Onkologische Praxis Altona, Hamburg, Germany; Krankenhaus Holweide, Köln, Germany; Klinikum Berlin-Buch, Berlin, Germany; Essex Pharma, Munich, Germany; Essex Pharma, Munich, Switzerland.

6091 Results of a phase II trial of combination therapy with oral capecitabine and weekly paclitaxel for metastatic breast cancer: preliminary results in taxane pretreated women.

Blum JL, Dees EC, Asmar L, Vukelja S, McMahon R, Amare M, Gill D, llegbodu D, Boehm KA, O'Shaughnessy J. US Oncology Research, Inc., Houston, TX; Baylor-Charles A. Sammons Cancer Center, Dallas, TX; Texas Oncology, P.A., Dallas, TX; The University of North Carolina at Chapel Hill, Chapel Hill, NC.

6092 Phase II trial of gemcitabine plus carboplatin (plus trastuzumab in HER2 + patients) in metastatic breast cancer patients.

Loesch DM, Asmar L, Mclntyre KJ, Doane LL, McKittrick RJ, Monticelli MA, Paul D, Vukelja SJ, Zhan F, Boehm KA, O'Shaughnessy J. US Oncology Research, Inc., Houston, TX; Central Indiana Cancer Centers, Indianapolis, IN; Texas Oncology, P.A., Dallas, TX; Kansas City Cancer Centers, Overland Park, KS; Kansas City Cancer Centers, Kansas City, KS; Williamette Valley Cancer Center, Springfield, OR; Rocky Mountain Cancer Centers, Denver, CO; Tyler Cancer Center, Tyler, TX; Baylor-Charles A. Sammons Cancer Center, Dallas, TX

The impact of educational attainment on initial doses of breast cancer adjuvant chemotherapy.

Griggs J), Sorbero MS, Culakova E, Lyman GH. University of Rochester, Rochester, NY; RAND Corporation, Pittsburgh, PA.
CHAT - an open-label, randomized phase II study of trastuzumab plus docetaxel with or without capecitabine in patients with advanced and/or metastatic, HER2-positive breast cancer: second interim safety analysis.

Wardley A, Antón-Torres A, Otero Reyes D, Jassem J, Toache LMZ, Alcedo JC, Bell R. Christie Hospital, Manchester,

United Kingdom; Hospital Universitario Miguel Servet, Zaragoza, Spain; Hospital CIMA, San Jose, Costa Rica; Akademia Medyczna, Gdansk, Poland; Hospital Rosevelt, Guatemala, Guatemala; Instituto Oncológico Nacional, Panama, Panama; Andrew Love Cancer Centre, Geelong, Victoria, Australia.

6095 Who profits most from a guideline basedTreatment for advanced breast cancer?

Dieing A, Possinger K, Schmid P, Regierer AC, Schulz CO, Wolters R, Wischnewsky MB. Charité, Camöus Mitte, Humboldt University, Berlin, Germany; University of Bremen, Bremen, Germany.

Tumor Cell Biology: Antigens and Markers

Characterization of anti-fatty acid synthase expression in normal breast and breast cancer. Jensen KC, Montgomery K, West RB, van de Rijn JM. Stanford University Medical Center, Stanford, CA.

6097 DD-M111/ hAG-2 is highly expressed in ductal and lobular breast cancer.

Naar EM, Macina RA, Vartanian S, Simon I, Liu SH, Shroyer KR. University of Colorado Health Sciences Center, Aurora, CO; diaDexus Inc., South San Francisco, CA

Increased tartrate-resistant acid phosphatase (Trap) expression in breast cancer, patients' sera and cell

lines.

Honig A, Rieger L, Kapp M, Krockenberger M, Dietl J, Kammerer U. University of Wuerzburg, Wuerzburg, Germany.

6100

The loss of 14-3-3 sigma $(\sigma)$ protein expression in invasive adenocarcinoma of the breast is associated with promoter hypermethylation and a more favorable clinical outcome.

Yang B, Yoder BJ, Roma AA, Wang L, Tarr S, Laniauskas S, Tso E, Choueiri T, Budd GT, Crowe JP, Hicks DG. Cleveland Clinic Foundation, Cleveland, $\mathrm{OH}$.

\section{Tumor Cell Biology: Apoptosis}

6101 Growth regulation is altered in cancer-containing breasts.

Walker RA, Rodrigues CM, Gordon-Weeks A, Luckett JC, Jones JL. University of Leicester, Leicester, United Kingdom; Queen Marys School of Medicine and Dentistry, London, United Kingdom.

Tumour necrosis factor-a converting enzyme (TACE) promotes apoptosis in breast cancers by cleaving HER4.

Kirkegaard T, Naresh A, Tovey SM, Dunne B, Jones FE, Bartlett JMS. Endocrine Cancer Group, Glasgow Royal Infirmary, Glasgow, United Kingdom; Glasgow Royal Infirmary, Glasgow, United Kingdom; Tulane University Health Sciences Center, New Orleans, LA. 

disrupting BRCA1 phosphorylation in breast cancer cells exposed to ionizing radiation.

Arciero CA, Chen X, Godwin AK. Fox Chase Cancer Center, Philadelphia, PA.

6104 Therapeutic potential of antisense $B c l-2$ as a chemosensitizer for patients with breast cancer. Kim R, Emi M, Tanabe K. Research Institute for Radiation Biology and Medicine, Hiroshima University, Hiroshima, Japan.

Bystander activity of Ad-mda7: human MDA-7 protein kills breast cancer cells via an IL-20 receptordependent pathway.

Zheng M, Bocangel D, Menander K, Hunt K, Chada S. Introgen Therapeutics Inc., Houston, TX; UTMD Anderson Cancer Center, Houston, TX.

Tumor Cell Biology: Cell Biology

The tumour-suppressor function of breast myoepithelial cells is mediated in part through regulation of S100A9.

Mulligan KT, Wang H, Shaw JA, Hart IR, Jones JL. Institute of Cancer, Cancer Research UK Clinical Centre, Charterhouse Square, London, United Kingdom; University of Leicester, Leicester, United Kingdom.

6107 Evidence that PI3K/Akt pathway is involved in the short non genomic autocrine loop between $17-\beta$ estradiol and aromatase activity.

Catalano S, Barone I, Giordano C, Rizza P, Gu G, Mastroianni F, Bonofiglio D, Ando' S. Faculty of Pharmacy, Rende, CS, Italy.

(18)F flurothymidine (FLT) for imaging of tumor cell proliferation; an in vitro-study for monitoring chemo-endocrine treatment in breast cancer cells. Fersis N, Jusufoska A, Gargya B, Rupp C, Wallwiener D, Dittmann H. University of Heidelberg, Heidelberg, Germany; University of Tuebingen, Tuebingen, Germany.

The role of the JNK signaling pathway in breast cancer cell lines.

Xue Y, Jordan CV. Fox Chase Cancer Center, Philadelphia, PA.

6110 The selectivity of Ras signaling in tumor formation. Cheng C-M, Onken B, Philips M, Chang EC. Baylor College of Medicine, Houston, TX; New York University School of Medicine, New York, NY.

6111 Non-transformed basal (cytokeratin $5 / 14$ postitive) breast cells migrate in matrigel by collective cell migration.

Clare SE, Kolanko P, Blosser R, Xiao H, Badve S, Herbert B. Indiana University School of Medicine, Indianapolis, IN.

9:00-9:30 PLENARY LECTURE 5 - Exhibit Hall D

Tomosynthesis - A new tool for breast cancer detection

Elizabeth A. Rafferty, MD

Massachusetts General Hospital

Boston, MA
$9: 30-11: 00$

38. Comparison of docetaxel/doxorubicin/ cyclophosphamide (TAC) versus vinorelbine/ capecitabine (NX) in patients non-responding to 2 cycles of neoadjuvant TAC chemotherapy - first results of the phase III GEPARTRIO-Study by the German Breast Group.

von Minckwitz G, Blohmer JU, Loehr A, Raab G, Eidtmann H, Hilfrich J, Gerber B, Huober J, Costa SD, Jackisch C, Loibl S, Schickling O, Zuna I, Kaufmann M. German Breast Group, Neu-Isenburg; St. Gertrauden Hosp., Berlin; HSK, Wiesbaden Marien Hosp., Stuttgart; Univ. Hosp., Kiel; Henrietten Stift, Hannover; Univ. Hosp., Rostock; Univ. Hosp., Tuebingen; Univ. Hosp., Magdeburg; Univ. Hosp., Marburg; SKM, Wiesbaden, Germany; Univ. Hosp., Frankfurt, Germany.

39. Multicenter, randomized phase III study of adjuvant chemotherapy for node positive breast cancer comparing 6 cycles of $\mathrm{FE}_{90} \mathrm{C}$ versus 4 cycles of $\mathrm{FE}_{90} \mathrm{C}$ followed by 8 weekly paclitaxel administrations: interim efficacy analysis of GEICAM 9906 Trial.

Martín M, Rodríguez-Lescure A, Ruiz A, Alba E, Calvo L, Ruiz-Borrego M, Munárriz B, López-Vega JM, Rodríguez CA, Crespo C. On Behalf of the Spanish Breast Cancer Research Group (GEICAM), San Sebastián de los Reyes, Madrid, Spain.

10:00 40. Final analysis: TC (docetaxel/cyclophosphamide, 4 cycles) has a superior disease-free survival compared to standard AC (doxorubicin/cyclophosphamide) in 1016 women with early stage breast cancer.

Jones SE, Savin MA, Holmes FA, O'Shaughnessy JA, Blum JL, Vukelja S), George TK, McIntyre KJ, Pippen JE, Sandbach J, Kirby RL, Bordelon JH, Hyman WJ, Negron AG, Khandelwal P, Richards DA, Anthony S, Nugent JE, Mennel RG, Banerji M, Edelman G, Ruxer RL, Amare M, Kampe CE, Koutrelakos N, Meyer WG, Asmar L. US Oncology Research, Inc., Houston, TX.

10:15 41. Five year follow-up of INT C9741: dose-dense (DD) chemotherapy (CRx) is safe and effective.

Hudis C, Citron M, Berry D, Cirrincione C, Gradishar W, Davidson N, Martino S, Livingston R, Ingle J, Perez E, Abrams J, Schilsky R, Ellis M, Muss H, Norton L, Winer E. MSKCC, NY, NY; ProHealth Care Assoc, Lake Success, NY; MD Anderson, Houston, TX; CALGB Stat Office \& Data Ops, Durham, NC; Northwestern U, Chicago, IL; Kimmel Comp $\mathrm{Ca} C$ tr at Johns Hopkins, Baltimore, MD; JWCI, Santa Monica, CA; U of Wash, Seattle, WA; Mayo, Rochester, MN; Mayo, Jacksonville, FL; NCl, Bethesda, MD; CALGB Central Office, Chicago, IL; Wash U., St. Louis, MO; U of Vt, Burlington, $\mathrm{VT} ; \mathrm{DFCl}$, Boston, MA.

10:30 42. IL-8 is involved in the development and growth of osteolytic bone lesions.

Margulies AG, Akel NS, Perrin D, Carver A, Bendre MS, Gaddy D, Suva LI. University of Arkansas for Medical Sciences, Little Rock, AR.

10:45 43. Effects of oral clodronate (BONEFOS ${ }^{\circ}$ ) therapy on bone turnover and skeletal metastases in women with primary breast cancer.

McCloskey EV, Paterson AHG, Powles TJ. Northern General Hospital, Sheffield, United Kingdom; Tom Baker Cancer Centre, Calgary, AB, Canada; Parkside Hospital, Wimbledon, United Kingdom. 
11:00-12:30 MINI-SYMPOSIUM 4 - Exhibit Hall D

PERSONALIZED MEDICINE - INHERITED POLYMORPHISMS IN RISK AND TREATMENT OF

\section{BREAST CANCER}

Steffi Oesterreich, PhD, Co-Moderator

Baylor College of Medicine, Houston, TX

$$
\text { and }
$$

Daniel F. Hayes, MD, Co-Moderator

University of Michigan, Ann Arbor, MI

11:00 Introduction

11:00 Effects of genetic variability on breast cancer risk and prognosis

Christine B. Ambrosone, PhD

Roswell Park Cancer Institute

Buffalo, NY

11:30 Searching for low-penetrance breast cancer susceptibility alleles in East Anglia

Alison M. Dunning, PhD, MSC

CR-UK Dept. Of Oncology,

Strangeways Research Laboratory

Cambridge, UNITED KINGDOM

12:00 Pharmacogenomics in the endocrine treatment of

\section{breast cancer}

David A. Flockhart, MD, PhD

Indiana University School of Medicine

Indianapolis, IN

Supported by an educational grant from Roche

12:30 ADJOURNMENT,

28th Annual San Antonio

Breast Cancer Symposium 
ML1

Update on HER-2 directed therapy.

Slamon D.

Data Not Provided

\section{P1}

Treatment guidelines for systemic adjuvant therapy of breast cancer: strengths and weaknesses.

Piccart-Gebhart MJ. Jules Bordet Institute, Brussels, Belgium

The rapidly expanding knowledge base generated by an increasingly more efficient clinical trials process reinforces the need for periodic "clinical practice guidelines", which are an important tool to facilitate evidence-based research. These guidelines are prepared by experts whose delicate task is to digest the evidence provided by the clinical trials - which may indicate a weak or a strong average treatment effect for a patient population - and to translate this evidence into implications for individual patient care.

Guidelines are thought to enhance the quality of care by reducing under-treatment, over-treatment and wrong treatment. At least one study has shown an adverse impact on overall mortality if treatment guidelines are not followed (Hebert-Croteau $\mathrm{N}$ et al., JCO 2004; 22: 3685-93).

Guidelines that have "authority" in the adjuvant treatment of breast cancer are the NIH and NCCN guidelines (in the US mainly) and those developed in St. Gallen. In addition, many countries develop their own national guidelines, which are more likely to take into account cultural and socio-economic factors.

The recently updated St. Gallen Guidelines will be the main focus of this lecture. They will be compared to the NCCN Guidelines, and adjuvant systemic treatment options will be discussed from the perspective of the author's own biases.

As the result of a major shift in thinking, risk of relapse is no longer the major determinant in the new St. Gallen algorithm for clinical decision making: it comes second after determining a patient's "endocrine-responsiveness".

The rationale for this paradigm shift is at least three-fold: 1) there is growing evidence of much larger benefits from chemotherapy (CT) in endocrine non-responsive disease; 2) substantial additional progress has been made lately in adjuvant endocrine therapy with the use of aromatase inhibitors, reducing the magnitude of additional benefit brought by $\mathrm{CT}$ in endocrine-responsive disease; and 3) gene-expression profiling studies nicely show that the estrogen receptor status is the major discriminator of expression subtypes and are likely to improve prediction of response to treatment in the near future.

The St.Gallen risk classification has also undergone fine-tuning: node positive disease is no longer synonymous with "high risk", with the 1-3 positive node group joining the intermediate risk category in case of a negative HER-2 status. Positive HER-2 status, in contrast, is sufficient to upgrade a node negative patient to the intermediate risk category.

The threshold to recommend adjuvant chemotherapy is lowest in the non-endocrine responsive group and highest in the endocrine responsive category.

The author will "jump in the water" and present slightly modified algorithms for the specific use of "stronger" CT regimens and/or aromatase inhibitors. An algorithm for trastuzumab prescription alone or in combination with CT will also be proposed.

\section{P2}

\section{Emerging ethical issues in cancer genetic testing.}

Offit K. Memorial Sloan-Kettering Cancer Center, New York, NY

During the decade following the discovery of genes associated with predisposition to common adult cancers, genetic testing has become part of the clinical practice of preventive oncology. At the same time, ethical and legal issues have emerged as challenges to the responsible translation of these advances to the practice of molecular medicine. Among these challenges include: 1) conflicting directives regarding the physician's "duty to warn" relatives of inherited genetic risk; 2) implications of genetic testing on reproductive choices; 3 ) concerns regarding testing of children; and 4) concerns regarding social stigmatization and possible discrimination based on results of genetic testing. Each of these issues will be examined with special emphasis on the relationship to breast cancer genetic testing. It will be concluded that the potential benefits of genetic testing for hereditary breast and ovarian cancer outweigh the documented harms and liabilities, however, significant and important ethical issues remain. Further discussion of these issues is required if scientific advances in cancer genetics are to be most effectively translated to the care of breast cancer patients and their families.

\section{P3}

In situ proteomics in cancer tissues using mass spectrometry.

Caprioli RM. Vanderbilt University, Nashville, TN

A detailed understanding of protein expression in breast cancer will require the use of new tools and methodologies with which to probe molecular changes underlying this disease. One new approach utilizes Imaging Mass Spectrometry and brings new and extraordinarily powerful capabilities to the laboratory in allowing either direct molecular profiling or molecular imaging of a tumor tissue sample. MS offers a unique high-accuracy molecular specificity for such in situ that is essential to the discovery of molecular events in these tissues and also the spatial distribution of peptides and proteins within the section. Applications range from lowresolution profiling experiments where typically 5-10 spots on the tissues are analyzed to high resolution images where many thousands of spots, or pixels, are analyzed in an ordered array. Each spot on the sample irradiated by the laser is approximately 30-50 microns in diameter and typically covers the $\mathrm{m} / \mathrm{z}$ range $1000-100,000$. Individual $\mathrm{m} / \mathrm{z}$ values from each mass spectrum in the data array can then be plotted to produce selected molecular images. Sections obtained from any tissue type can be imaged to locate tissue specific peptides and proteins in $\mathrm{X}, \mathrm{Y}$ coordinates along with relative intensity. Tumors present in breast as well as lung, brain, colon, and other organs have been profiled and imaged, comparing new proteins differentially expressed in the various tumor grades and in the corresponding normal tissue. Major differences in protein expression have been found in tumor subtypes. This will be illustrated with studies of breast tumor biopsies and also those for human glioblastomas. In the latter, MS patterns have also been correlated with patient outcomes. Laser capture microdissection has been employed to isolate individual types of cells from heterogeneous cell populations in tissues and these isolated cells profiled for proteins by MALDI MS. Imaging MS has also been applied to drug targeting and metabolic studies with analysis of specific tissues after systemic drug administration. Whole animal sagittal sections have been imaged to measure molecular changes in proteins in multiple organs and correlating this with drug concentrations in these same organs.

\section{P4}

Identification and testing of a gene expression signature for invasion and metastasis in mammary tumors. Condeelis JS. Albert Einstein College of Medicine, Bronx, NY

Cell motility has been implicated in the spread of cancer cells and is an essential step in metastasis. Chemotaxis to blood vessels is involved in the escape of cancer cells from primary mammary tumors. The recent convergence of technologies for expression profiling and intravital imaging has revealed the identities of the genes involved in the survival, motility and chemotaxis of cancer cells inside living tumors, the invasion signature. The invasion signature indicates that the invasive cancer cells are a population that is neither proliferating nor apoptotic but highly chemotactic. Of particular relevance to the chemotactic behavior of invasive 


\section{S2 Abstracts - Invited Speakers}

cancer cells is the finding that the genes coding for pathways leading to the minimum motility machine, i.e., the cofilin, capping protein and Arp2/3 pathways, that regulate -actin polymerization at the leading edge, and the directionality of cell protrusion, are coordinately up-regulated. Key genes in the invasion signature have been studied for their ability to alter metastatic outcome and these results confirm the importance of the invasion signature in predicting metastasis. The invasion signature predicts that invasive tumor cells, upon escaping the primary tumor, are non-dividing and resistant to chemotherapy, predictions that have been confirmed in vitro. Finally, the invasion signature provides several new target opportunities for preventing metastasis from otherwise silent metastatic tumors.

\section{P5}

Tomosynthesis: a new tool for breast cancer detection. Rafferty EA, Kopans DB, Wu T, Moore RH. Massachusetts General Hospital, Boston, MA

Mammography is the only imaging test to date that has been shown to decrease mortality from breast cancer, however mammography is an imperfect tool; as many as $20 \%$ of women presenting with a breast cancer will have had a negative mammogram within the year. A major factor contributing to this limitation of mammography is the "structured noise" that is created by the overlap of normal breast structures which are superimposed on each other in the acquisition of a two-dimensional mammographic projection. These overlapping structures and the resultant "structured noise" can obscure a lesion, rendering it mammographically occult, an effect which becomes more pronounced as the breast density increases. Breast tomosynthesis is an imaging technique developed on a conventional digital mammography platform. The moving $x$-ray tube acquires angled images of the breast at radiation doses comparable to conventional mammography and the images are synthesized to display a threedimensional mammographic study of the breast.

The principle advantage of breast tomosynthesis over conventional mammography is the elimination of structured noise. Through the removal of structured noise, tomosynthesis allows for greater visibility of suspicious mammographic lesions. Pilot studies confirm equal or superior visualization of masses and architectural distortion in $89 \%$ of cases and equal or superior visualization of malignant calcifications in $88 \%$ of cases. Conventional two-view mammography also has a significant false positive rate; as many as $25 \%$ of women recalled from screening mammography are ultimately shown to have no abnormality at all. This situation results from overlapping structures ("structured noise") mimicking abnormality where none exists. Our initial work suggests that approximately $80 \%$ of these callbacks can be avoided by screening with tomosynthesis. Additionally, through the removal of structured noise, marginal analysis of breast lesions is facilitated. It is principally through assessment of a lesion's margins that radiologists assign probability of malignancy. Tomosynthesis allows lesions to be visualized in isolation from surrounding structures thus enabling more accurate marginal analysis and consequently more accurate prediction of the benign or malignant nature of a lesion. Furthermore, the acquisition of the data as a three dimensional volume also permits precise lesion localization within the breast; knowledge critical for intervention. One of the distinct advantages offered by tomosynthesis is that it extends the capabilities of conventional mammography, an imaging modality which is affordable, available, well-studied and wellunderstood. The simultaneous increase in the cancer detection rate coupled with a decrease in the callback rate (simultaneously increasing sensitivity and specificity) at a radiation exposure comparable to conventional digital mammography represents a clear advance in breast cancer screening.

\section{MS1-1}

New carbon nanostructures for imaging and therapy of breast cancer.

Wilson LJ. Rice University, Houston, TX,

Paramagnetic gadolinium $\left(\mathrm{Gd}^{3+}\right)$-containing carbon nanostructures derived from fullerenes $\left(\mathrm{C}_{60}\right)$ and single-walled carbon nanotubes are being pursued as a new paradigm in magnetic resonance imaging (MRI) contrast agent (CA) design. These new materials demonstrate dramatic fundamental advantages over current clinical MRI CAs $\left(\mathrm{Gd}^{3+}\right.$ chelate compounds) by offering the potential for early-stage detection and therapy of breast cancer and other malignancies. Our recent work with the derivatized $\mathrm{Gd}^{3+} @ \mathrm{C}_{60^{-}}$ based nanomaterials, $\mathrm{Gd}^{3+} @ \mathrm{C}_{60}\left[\mathrm{C}(\mathrm{COOH})_{2}\right]_{10}$ and $\mathrm{Gd}^{3+} @ \mathrm{C}_{60}(\mathrm{OH})_{\mathrm{x}}$, have shown them to exhibit exceptionally large proton relaxivities approaching $100 \mathrm{mM}^{-1} \mathrm{~s}^{-1}$ or approximately 20x larger than current clinical agents. Water-proton relaxivities have been measured in aqueous solution at variable temperatures $(278-355 \mathrm{~K})$ and as a function of magnetic field ( $5 \times 10^{-4}-9.4 \mathrm{~T}$; NMRD profiles $)$ to investigate the proton relaxation mechanism of these unusual nanoscale materials. ${ }^{1}$ The proton relaxivities also display a remarkable $\mathrm{pH}$-dependency, increasing with decreasing $\mathrm{pH}(\mathrm{pH}$ : 3-12). Water-soluble fullerene materials, such as these $\mathrm{Gd}^{3+} @ \mathrm{C}_{60^{-}}$ derived CAs, readily cross cell membranes, suggesting an application for the gadofullerenes as the first intracellular, as well as $\mathrm{pH}$ responsive, MRI CAs. Most recently, we have also prepared the first carbon nanotube-based MRI CAs. ${ }^{2}$ These CAs are derived from ultra-short $(20-50 \mathrm{~nm})$ carbon nanotubes (US-tubes) which have been internally loaded with superparamagnetic clusters of $\mathrm{Gd}^{3+}$ ions to yield $\mathrm{Gd}^{3+}{ }_{n} @$ US-tube species with relaxivities 50-100x greater than current clinical agents. These new magnetic nanostructures are especially exciting since they offer the potential for targeted, MRI-guided cancer therapy by hyperthermia. References

1) E. Toth, et al., J. Am. Chem. Soc. 2005, 127, 799-805.

2) B. Sitharaman, et al., Chem. Commun. 2005, 3915-2917.

\section{MS1-2}

Gold nanoshells as a new treatment strategy for breast Cancer.

West $J$.

Data Not Provided

\section{MS1-3}

Nanotechnology in terms of biomedical applications in cancer and opportunities for funding.

Ferrari $M$.

Data Not Provided

\section{MS2-1}

Detection of circulating breast cancer cells: are these the cells that really matter?

Hayes D.

Data Not Provided

\section{MS2-2}

Identification and testing of a gene expression signature for invasion and metastasis in mammary tumors.

Condeelis JS. Albert Einstein College of Medicine, Bronx, NY

Cell motility has been implicated in the spread of cancer cells and is an essential step in metastasis. Chemotaxis to blood vessels is involved in the escape of cancer cells from primary mammary tumors. The recent convergence of technologies for expression profiling and intravital imaging has revealed the identities of the genes involved in the survival, motility and chemotaxis of cancer cells inside living tumors, the invasion signature. The invasion signature indicates that the invasive cancer cells are a population 
that is neither proliferating nor apoptotic but highly chemotactic Of particular relevance to the chemotactic behavior of invasive cancer cells is the finding that the genes coding for pathways leading to the minimum motility machine, i.e., the cofilin, capping protein and Arp $2 / 3$ pathways, that regulate -actin polymerization at the leading edge, and the directionality of cell protrusion, are coordinately up-regulated. Key genes in the invasion signature have been studied for their ability to alter metastatic outcome and these results confirm the importance of the invasion signature in predicting metastasis. The invasion signature predicts that invasive tumor cells, upon escaping the primary tumor, are non-dividing and resistant to chemotherapy, predictions that have been confirmed in vitro. Finally, the invasion signature provides several new target opportunities for preventing metastasis from otherwise silent metastatic tumors.

\section{MS2-3}

\section{Breast cancer metastasis genes and functions.} Massague J. Memorial Sloan-Kettering Cancer Center, New York, $N Y$

Reasoning that each organ site places different demands on circulating breast cancer cells for the development of metastatic lesions, we sought to identify genes whose expression in breast cancer confers organ-specific metastatic functions. The bone and the lung are frequent sites of breast cancer metastasis, and metastases at these sites differ in terms of their evolution, treatment, morbidity and mortality. By means of in vivo selection in the mouse, aided by bioluminescence technology, we isolated from a single patient breast cancer cells that are highly metastatic either to the bone or the lung. Using transcriptomic analysis, we identified gene sets whose expression is closely correlated with these organ-specific metastatic activities. Most of these genes encode extracellular proteins and many are of previously unknown relevance to cancer metastasis. By overexpression of these candidate metastasis genes in poorly metastatic cells, as well as by RNAi-mediated knockdown in highly metastatic cells, we functionally verified their ability to mediate breast cancer metastasis either to the bone or the lung. Clustering analysis of transcriptomic datasets from a cohort of primary tumors obtained from patients at MSKCC, we demonstrated that a subset of these metastasis genes is frequently expressed in primary tumors with high risk of relapsing to the lung as the principal site of metastasis. The lung met gene-expression signature as well as a 18-gene subset of this signature can predict risk of lung metastasis better than other markers in use (estrogen receptor, HER2, basal cell markers, poor prognosis signature). Evidence of clinical relevance was also obtained for the bone metastasis gene set. Thus, these sets of genes appear to mark, mediate and predict the propensity of breast tumors to metastasize selectively to lung or bone. Some of these genes serve metastagenicity functions whereas others confer metastatic virulence. The ability to diminish the rate of metastasis by RNAimediated depletion of some of these genes, including EREG, MMP1, MMP2, and COX2, shows their potential as targets of combined anti-metastasis therapy. We are also defining the role of the TGF $\mathrm{b} / \mathrm{Smad}$ pathway in the activation of metastasis genes. These findings shed new light into the biology of cancer metastasis and its clinical implications.

\section{MS3-1}

\section{Developmental and therapeutic implications of molecular} profiles of ER-positive and ER-negative breast cancers. Perou CM. University of North Carolina, Chapel Hill, NC

Many studies have shown that breast cancer is not a single disease, but rather, several diseases. Gene expression profiling of Invasive Breast Carcinomas (IBC) has shown that there are at least 4 Intrinsic subtypes (Luminal A, Luminal B, Basal-like, and HER2+/ ER-). The Luminal A and B subtypes are ER+, and the Basal-like and HER2+/ER- subtypes are ER-negative and PR-negative. These subtypes were identified using IBC, and thus, two questions remain:
First, can these subtypes be identified in early breast lesions? Second, what are the cellular origins of each subtype?

We evaluated the gene expression profiles of a set of 25 Ductal Carcinoma In Situ (DCIS) samples and found that Luminal/ER+, HER2+/ER- and Basal-like DCIS lesions exist; thus, the Intrinsic subtypes are present in the DCIS stage. Additional studies are underway to determine if within a single sample, Basal-like and Luminal/ER+ DCIS lesions co-exist, and if ER+ Atypical Ductal Hyperplasias might co-exist with Basal-like or HER2+/ER- DCIS lesions.

Clues to the cellular origins of the subtypes can be seen in the patterns that define these groups, which categorize the tumors into those with Luminal/Alveolar features (Luminal A, Luminal B and HER2+/ER-) and those with Basal/Myoepithelial features (Basal-like). The Basal-like tumors are the only subtype that express Basal/Myoepithelial keratins (5, 6A, 6B, 14 and 17), while the Luminal/Alveolar subtypes express keratins 8 and 18; we have also determined that half of the Basal-like tumors coexpress Basal/Myoepithelial and Luminal keratins. IHC studies of Basal-like tumors show that they do not express CD10, p63 or SMA, and therefore, are not likely derived from Myoepithelial cells. Basal-like tumors are all rapidly growing, express some stem cell markers including a Sca-1 like protein (LY6D) and c-KIT, and show expression of Wnt-Catenin pathway genes.

Analyses of the Luminal/Alveolar patterns show that the Luminal A and B tumors express ER, ER-regulated genes (XBP1, PR and RERG), Androgen Receptor (AR), GATA3 and many GATA3regulated genes (CK8, CK18 and FOXA1). This expression signature is lower in Luminal B tumors, and the data suggests they have a worse prognosis and are less hormone responsive. Part of this expression signature is also present in HER2+/ER- tumors (CK8, CK18, AR), while another part is not (ER, GATA3, and their regulated genes).

Our hypothesis is that a tumor's subtype is maintained during progression from DCIS to IBC, and that tumors do not change subtype. Second, the subtypes are derived either from cells that represent discrete stages of epithelial cell development or from stem cells that develop and arrest at specific stages of development. The Basal-like tumors may represent a "transient amplifying" cell that is a committed progenitor with bi-potent potential, while the Luminal A tumors represent a well differentiated Luminal/ Alveolar cell. The Luminal B and HER2+/ER- tumors may be derived from developmental steps between the committed progenitor and mature Luminal/Alveolar cell.

\section{MS3-2}

\section{How epidemiologic risk factors differ according to receptor} status of breast cancer.

Colditz GA, Rosner BA. Harvard Medical School, Boston, MA

Drawing on the prospective Nurses' Health Study we have evaluated risk factors for breast cancer classified according to receptor status. During 22 years of follow-up from 1980 to 2002 we confirmed 2783 incident cases of breast cancer with ER and PR status reported. Of these cases 1728 were ER+PR+, 518 were ER-PR-, 440 were $\mathrm{ER}+\mathrm{PR}-$, and 97 were ER-PR+. We fit a log-incidence model of breast cancer and used polytomous logistic regression to compare coefficients for breast cancer risk factors. To evaluate differences in odds ratios for ER and PR we evaluated ER status controlling for PR status and vice versa. We observed significant heterogeneity among the four ER/PR categories of breast cancer for some risk factors as previously reported based on 2096 incident cases (JNCI 2004;96:218-28).

The one-time adverse effect of first pregnancy was present for $\mathrm{ER}+/ \mathrm{PR}$ - and for ER-PR- but not for ER+PR+ and ER-PR+ tumors. There was statistically significant heterogeneity for the adverse association of first pregnancy with breast cancer incidence. Further evaluation of risk factors according to ER and PR status showed that PR status was statistically significantly related to breast cancer incidence after controlling for ER status $(p=0.03)$. 


\section{S4 Abstracts - Invited Speakers}

Parity, on the other hand showed a strong inverse association with incidence of $\mathrm{ER}+\mathrm{PR}+$ and $\mathrm{ER}+\mathrm{PR}$ - tumors, but not with ERtumors. The difference in relative risk of tumors based on receptor status was not statistically significant, however.

Duration of use of oral estrogen alone and of estrogen plus progestin both increased risk of breast cancer. The difference in relative risk according to receptor status was significant for PR controlling for

ER status for both formulations of postmenopausal hormones.

No differences in the breast cancer associations according to receptor status were observed for family history and benign breast disease.

These discordant results point to different etiologies for cancer classified according to receptor status. These data from the largest epidemiologic study of risk factors for breast cancer according to receptor status will be review in the context of results from other epidemiologic studies to highlight conclusions regarding etiologic pathways and future breast cancer risk prediction.

\section{MS3-3}

Tomosynthesis: A new tool for breast cancer detection.

Rafferty EA, Kopans DB, Wu T, Moore RH. Massachusetts General Hospital, Boston, MA

Mammography is the only imaging test to date that has been shown to decrease mortality from breast cancer, however mammography is an imperfect tool; as many as $20 \%$ of women presenting with a breast cancer will have had a negative mammogram within the year. A major factor contributing to this limitation of mammography is the "structured noise" that is created by the overlap of normal breast structures which are superimposed on each other in the acquisition of a two-dimensional mammographic projection. These overlapping structures and the resultant "structured noise" can obscure a lesion, rendering it mammographically occult, an effect which becomes more pronounced as the breast density increases. Breast tomosynthesis is an imaging technique developed on a conventional digital mammography platform. The moving $x$-ray tube acquires angled images of the breast at radiation doses comparable to conventional mammography and the images are synthesized to display a threedimensional mammographic study of the breast.

The principle advantage of breast tomosynthesis over conventional mammography is the elimination of structured noise. Through the removal of structured noise, tomosynthesis allows for greater visibility of suspicious mammographic lesions. Pilot studies confirm equal or superior visualization of masses and architectural distortion in $89 \%$ of cases and equal or superior visualization of malignant calcifications in $88 \%$ of cases. Conventional two-view mammography also has a significant false positive rate; as many as $25 \%$ of women recalled from screening mammography are ultimately shown to have no abnormality at all. This situation results from overlapping structures ("structured noise") mimicking abnormality where none exists. Our initial work suggests that approximately $80 \%$ of these callbacks can be avoided by screening with tomosynthesis. Additionally, through the removal of structured noise, marginal analysis of breast lesions is facilitated. It is principally through assessment of a lesion's margins that radiologists assign probability of malignancy. Tomosynthesis allows lesions to be visualized in isolation from surrounding structures thus enabling more accurate marginal analysis and consequently more accurate prediction of the benign or malignant nature of a lesion. Furthermore, the acquisition of the data as a three dimensional volume also permits precise lesion localization within the breast; knowledge critical for intervention. One of the distinct advantages offered by tomosynthesis is that it extends the capabilities of conventional mammography, an imaging modality which is affordable, available, well-studied and wellunderstood. The simultaneous increase in the cancer detection rate coupled with a decrease in the callback rate (simultaneously increasing sensitivity and specificity) at a radiation exposure comparable to conventional digital mammography represents a clear advance in breast cancer screening.

\section{MS4-1}

Pharmacogenomics in the endocrine treatment of breast cancer.

Flockhart D.

Data Not Provided

\section{MS4-2}

Effects of genetic variability on breast cancer risk and prognosis.

Ambrosone $C$

Data Not Provided

\section{MS4-3}

Searching for low-penetrance breast cancer susceptibility alleles in East Anglia.

Dunning AM, for the SEARCH Breast Cancer Study Team. CR-UK University of Cambridge, Cambridge, United Kingdom

Much of the familial clustering of breast cancer is due to the combined effects of genetic variants. However the number of such alleles, their frequencies and the magnitudes of the risks they confer are, as yet, unknown. For the past few years we have been using candidate gene based association studies, with an increasing emphasis on using high-throughput systems, to find low-penetrance breast cancer susceptibility alleles in a large East Anglian population-based case-control study. Most recently we have been attempting complete exclusion from associations of all variants in each candidate gene using a SNP-tagging approach. To this end we have studied 500 SNPs in 95 genes using a 2 stage study design in which a first set of 2300 cases and controls is analysed, and any SNP with a significance value of $\mathrm{P}<0.05$ is then tested in a second, similar-sized case/control set. We have detected some alleles conferring mild risks but no SNP has, to date, given a level of statistical significance (P- value for difference in genotype distribution) of $<10^{-3}$. Many of our potential associations will be false positives - the consequence of multiple testing. To exclude these, we still require confirmation of our findings in other large studies, which we are working to assemble through international collaboration.

In an attempt to hasten the discovery process, we have initiated (with collaborators in the UK and Perlegen Science Inc) a genomewide scan. Here we will use a 3-stage design. In the first stage we are evaluating 266,000 SNPs in 800 breast cancer cases and controls. The cases are 'enriched' for genetic effects by choosing those with a family history but without mutations in the BRCA1 / 2 genes. In the second stage, the most significant $5 \%$ of SNPs from Stage 1 will be evaluated in 4600 cases and controls. A final stage of evaluation for positives from Stage 2 will again require confirmation in very large case/control sets $(n>10,000)$ from international collaboration. 
1

Phase III randomized trial comparing doxorubicin and cyclophosphamide followed by docetaxel (AC®T) with doxorubicin and cyclophosphamide followed by docetaxel and trastuzumab (AC®TH) with docetaxel, carboplatin and trastuzumab (TCH) in HER2 positive early breast cancer patients: BCIRG 006 study.

Slamon D, Eiermann W, Robert N, Pienkowski T, Martin M, Pawlicki M, Chan A, Smylie M, Liu M, Falkson C, Pinter T, Fornander T, Shiftan T, Valero V, Von Minckwitz G, Mackey J, Tabah-Fisch I, Buyse M, Lindsay MA, Riva A, Bee V, Pegram M, Press M, Crown $J$, on behalf of the BCIRG 006 Investigators. UCLA, Los Angeles, CA; GBG, Munchen, Frankfurt, Germany; US Oncology, Houston, TX; Maria Sklodowska-Curie (MSC) Centre, Warsaw, Poland; GEICAM, Madrid, Spain; MSC Institute, Krakow, Poland; Mount Hospital, Perth Australia; Cross Cancer Institute, Edmonton, Canada; Sun Yat-Sen Cancer Center, Taipei, Taiwan; University of Alabama, Birmingham, AL; Petz Aladar Korhaz, Gyor, Hungary; Karolinska University Hospital, Stockholm, Sweden; Sharp Healthcare, San Diego, CA; MDACC Houston, TX; SanofiAventis, Paris, France; IDDI, Brussels, Belgium; CIRG, Paris, France ${ }^{4}$; USC, LA, CA; ICORG, Dublin, Ireland.

Background: This study evaluates the benefit of two trastuzumabbased $(\mathrm{H})$ regimens in HER2 amplified breast cancer with the intent of integrating $\mathrm{H}$ to maximize efficacy and minimize known cardiotoxicity.

Material and Methods: HER2 amplified (centralized FISH) patients with axillary lymph node (LN) positive or high risk LN negative were randomized to either AC $(60 / 600 \mathrm{mg} / \mathrm{m} 2 \mathrm{q} 3 \mathrm{wk} \times 4)$ followed by $\mathrm{T}(100 \mathrm{mg} / \mathrm{m} 2 \mathrm{q} 3 \mathrm{wk} \mathrm{x} 4)$ or two H-containing regimens; $\mathrm{AC}$ followed by $\mathrm{T}$ with $\mathrm{H} \times 1$ year (q1wk during chemo/q3wk during FUP) or TCarbo (75 mg/m2 / AUC6 q3wk x 6) with $\mathrm{H} \times 1$ year. Patients were prospectively stratified by positive LN $(0,1-$ 3 vs $4+$ ) and hormone receptor (HR) status. Patients with HR+ tumors received hormonal therapy for 5 yrs after chemotherapy. The primary endpoint was disease-free survival (DFS) with $80 \%$ power (0.05 significance level) to detect an absolute difference of 7\%. Secondary endpoints included OS, safety, including cardiotoxicity (symptomatic events -CHF, gr3/4 ischemia/ infarction, gr3/4 arrhythmia- and asymptomatic LVEF decline). We report the results of the first planned, protocol-mandated interim analysis conducted after 322 events (breast cancer relapse, second primary malignancy or death).

Results: A total of 3222 pts (1073 in AC-T, 1074 in AC-TH and 1075 in TCH) were recruited between Apr 2001 and Mar 2004. At a median follow-up of 23 months, the two H-containing arms have both met the DFS endpt: hazard ratio of 0.49 with AC-TH, p-value $=0.00000048$ and 0.61 with $\mathrm{TCH}$, p-value $=0.00015$ (as compared to AC-T). At this time, there is no statistically significant difference btw the two H-containing arms perhaps due to the small number of events currently separating them. Symptomatic cardiac events: AC-T: $1.2 \%$ vs AC-TH: $2.3 \%$, p-value $=0.046$; ACT vs TCH: $1.2 \%, \mathrm{p}$ value $=1.00$. Absolute LVEF decline $>15 \%$ and below lower limit of normal occurred in $0.6 \%$ pts in AC-T, $2.4 \%$ in $\mathrm{AC}-\mathrm{TH}$ and $0.4 \%$ in $\mathrm{TCH}$ arms respectively (AC-T vs AC-TH ( $\mathrm{p}=0.001)$; AC-T vs TCH $(\mathrm{p}=0.54)$.

Discussion: Result of this trial confirms the benefit of $\mathrm{H}$ when combined with docetaxel (AC-TH) or with docetaxel and carboplatin $(\mathrm{TCH})$ without an anthracycline. There are fewer severe cardiac adverse events when $\mathrm{H}$ is administered without prior A. Longer follow-up is needed in order to confirm whether non-A-based adjuvant $\mathrm{H}$ regimens will have efficacy comparable to A-based regimens.
2

Trastuzumab in combination with docetaxel or vinorelbine as adjuvant treatment of breast cancer: the FinHer Trial. Joensuu H, Kellokumpu-Lehtinen P-L, Bono P, Alanko T, Kataja $V$, Asola R, Utriainen T, Kokko R, Blanco G, Isola J. Helsinki University Central Hospital, Helsinki, Finland

Background: Trastuzumab (T) is effective as adjuvant treatment of HER2-positive early breast cancer (BC).We investigated the safety and efficacy of $\mathrm{T}$ given for only nine weeks concomitantly with presumably synergistic chemotherapy agents in the treatment of early BC.

Patients and methods: Women $(n=1,010)$ with either axillary node positive $(\mathrm{pN}+) \mathrm{BC}$ or with node negative $(\mathrm{pN} 0)$ cancer with tumor $>20 \mathrm{~mm}$ and $\mathrm{PgR}$ - were randomly allocated to receive either three 3 -weekly cycles of docetaxel $\left(100 \mathrm{mg} / \mathrm{m}^{2}\right)$ or eight weekly cycles of vinorelbine $\left(25 \mathrm{mg} / \mathrm{m}^{2}\right)$ as adjuvant therapy. Single-agent docetaxel/vinorelbine was followed in both arms by three 3-weekly cycles of cyclophosphamide, epirubicin and 5fluorouracil $\left(\mathrm{C}_{600} \mathrm{E}_{60} \mathrm{~F}_{600}\right.$, and tamoxifen was given for five years for ER or PgR positive disease. Patients whose tumor showed erbB2 amplification in chromogen in situ hybridization (CISH, $\mathrm{n}=232,23 \%$ ) had a second randomization to receive nine weekly cycles of $\mathrm{T}(2 \mathrm{mg} / \mathrm{kg}$, first dose $4 \mathrm{mg} / \mathrm{kg})$ concomitantly with either docetaxel or vinorelbine, or to no T. CISH analysis for presence of $\operatorname{erbB} 2$ amplification was done prior to randomization in one of two laboratories using the same protocol. Cardiac left ventricular ejection fractions (LVEFs) were measured at baseline, after completion of chemotherapy, and 12 and 36 months after study entry. The median follow-up is 38 months. One patient with overt distant metastases at study entry was excluded from survival analyses.

Results: BC recurrence (distant or locoregional recurrence, or contralateral $\mathrm{BC}$ ) was less frequent among patients treated with docetaxel/CEF than among those treated with vinorelbine/CEF (39/502 vs. $68 / 507$, HR $0.58, \log$-rank test $\mathrm{P}=0.0036$ ). Distant cancer recurrence was also less frequent among patients who received docetaxel ( 32 vs. 56 events, HR $0.58, \log$-rank test $\mathrm{P}$ for DDFS 0.0087). Adjuvant 9 -week T was effective in preventing any $\mathrm{BC}$ recurrence $(11 / 115$ vs. $26 / 116, \mathrm{HR} 0.46, \mathrm{P}$ for recurrencefree survival 0.0078). Three-year distant disease-free survival of patients who received $\mathrm{T}$ was $93 \%$ and that of patients who did not receive $\mathrm{T} 76 \%$ ( $\mathrm{P}=0.0078,11 / 115$ vs. $26 / 116$ events, HR 0.43 ). There was a trend towards superior overall survival of patients treated with $\mathrm{T}(6 / 115$ deaths vs. $14 / 116, \mathrm{HR} 0.43, \mathrm{P}=0.08)$. $\mathrm{T}$ was well tolerated, and the LVEFs were maintained during the $3-\mathrm{yr}$ follow-up.

Conclusions: Single-agent docetaxel/CEF was more effective than vinorelbine/CEF as adjuvant treatment of $\mathrm{BC}$. $\mathrm{T}$ given concomitantly with docetaxel or vinorelbine for 9 weeks was well tolerated, and was not associated with a decrease of LVEFs making monitoring of the LVEFs unnecessary for most patients. Short duration administration of $\mathrm{T}$ is highly effective in preventing recurrence of $\mathrm{BC}$ with erbB2 amplification when given concomitantly with potentially synergistic chemotherapy, and may be better tolerated than one-year use of $\mathrm{T}$. 
3

A randomized phase III trial of paclitaxel versus paclitaxel plus bevacizumab as first-line therapy for locally recurrent or metastatic breast cancer: a trial coordinated by the Eastern Cooperative Oncology Group (E2100).

Miller KD, Wang M, Gralow J, Dickler M, Cobleigh MA, Perez EA, Shenkier TN, Davidson NE. Indiana University Cancer Center, Indianapolis, IN; Dana Farber Cancer Institute; Pudget Sound Oncology Consortium; Memorial Sloan Kettering Cancer Center; Rush University Medical Center; Mayo Clinic; Vancouver Cancer Center; Johns Hopkins Oncology Center

Purpose: This randomized phase III trial compared the efficacy and safety of paclitaxel (P) with or without bevacizumab (B), a monoclonal antibody to vascular endothelial growth factor (VEGF), as initial chemotherapy in patients with metastatic breast cancer (MBC). Methods: Patients were randomly assigned to receive $\mathrm{P}$ $\left(90 \mathrm{mg} / \mathrm{m}^{2}\right)$ Days 1,8 , and 15 every 4 weeks alone or in combination with $\mathrm{B}(10 \mathrm{mg} / \mathrm{kg})$ Days 1 and 8 . The primary endpoint was progression-free survival (PFS); response was assessed by RECIST criteria every 3 cycles. The study provided $85 \%$ power to detect a $33 \%$ improvement in PFS assuming a one-sided type one error $=2.5 \%$. Results: From December 2001 to May 2004 , 722 patients were enrolled. Treatment arms were well balanced for median age, disease-free interval, ER status, sites of disease, and exposure to adjuvant chemotherapy. Hypertension requiring treatment $(13.5 \%$ vs. $0 ; p<0.0001)$, Grade $3 / 4$ proteinuria $(2.5 \%$ vs. $0 ; p=0.0004)$ and Grade $3 / 4$ neuropathy $(20.2 \%$ vs. $14.2 \%$; $p=0.01$ ) were more frequent in patients receiving $\mathrm{P}+\mathrm{B}$. Thromboembolic events and serious bleeding episodes were infrequent and similar $(<1.5 \%)$ in both groups. Combination therapy significantly increased the response rates in all patients $(28.2 \%$ vs. $14.2 \% ; p<0.0001)$ and in the subset of patients with measurable disease $(34.3 \%$ vs. $16.4 \% ; p<0.0001)$. With 355 events in the current analysis, P+B significantly prolongs PFS (10.97 mos. vs. 6.11 mos.; HR $=0.498, p<0.001)$. Though the data is immature, early follow-up suggests that $\mathrm{P}+\mathrm{B}$ improves overall survival $(\mathrm{HR}=0.674, p=0.01)$. Conclusions: $\mathrm{P}+\mathrm{B}$ significantly prolongs disease-free survival compared to $\mathrm{P}$ as initial chemotherapy for MBC with minimal increase in toxicity. Updated analysis of overall survival, quality of life and potential surrogates of response will be presented.

\section{4}

Metronomic chemotherapy with and without bevacizumab for advanced breast cancer: a randomized phase II study. Burstein HJ, Spigel D, Kindsvogel K, Parker LM, Bunnell CA, Partridge AH, Come SE, Ryan PD, Gelman R, Winer EP. DanaFarber / Harvard Cancer Center, Boston, MA; Sarah Cannon Cancer Center, Nashville, TN

Background: Low-dose, repetitive "metronomic" chemotherapy can inhibit tumor growth in animal models and in patients with advanced cancer. Laboratory studies suggest that pairing metronomic chemotherapy with a dedicated anti-angiogenesis therapy may be particularly effective. We sought to evaluate this concept in a randomized, phase II clinical trial.

Patients and Methods: Eligible patients have stage IV breast cancer with measurable disease by RECIST criteria, $0-1$ prior chemotherapy regimens in the metastatic setting, no prior oral cyclophosphamide chemotherapy, ECOG PS 0-1, and LVEF > $45 \%$. Patients with bleeding or clotting diatheses, brain metastases, or large effusions are ineligible. Patients with visceral metastases were required to have prior anthracycline exposure in the adjuvant or metastatic setting. Patients were randomized to metronomic chemotherapy alone (cyclophosphamide $50 \mathrm{mg}$ PO QD and methotrexate $2.5 \mathrm{mg}$ PO BID x 2 days each week), or to the same treatment plus bevacizumab ( $10 \mathrm{mg} / \mathrm{kg}$ IV q 14 days). The primary study endpoint is response rate; secondary endpoints include progression-free survial, toxicity, and correlative measures of angiogenesis.
Results: To date, 42 patients have enrolled on the study. A protocolspecified stopping rule called for discontinuation of accrual to a treatment arm if 4 or fewer patients had objective response among the first 18 patients in each arm. Based on this planned interim analysis, accrual to the metronomic chemotherapy alone arm has stopped, while accrual of an additional 13 patients to the combination arm continues. Final clinical data from all patients including response and toxicity analyses will be available. Conclusion: Metronomic chemotherapy in combination with bevacizumab has clinical activity in advanced breast cancer.

\section{6}

Trastuzumab sensitivity of breast cancer with coamplification of HER2 and cMYC suggests pro-apoptotic function of dysregulated $\mathrm{cMYC}$ in vivo.

Kim C, Bryant J, Horne Z, Geyer CE, Wickerham DL, Wolmark N, Paik S. NSABP Operations and Biostatistical Center, Pittsburgh, $P A$

Background: Addition of trastuzumab to adjuvant chemotherapy reduces 4 year relapse risk of patients diagnosed with HER2 amplified/overexpressing tumors by $53 \%$. To further improve outcome, addition of other targeted therapies to trastuzumab regimen is being considered. However, toxicity and high cost demands careful selection of patients who may best benefit from such an approach. Predictive markers for response to trastuzumab are needed. In an effort to identify amplified genes in breast cancer that correlate with poor prognosis in patients treated with standard adjuvant chemotherapy, we have screened for the presence of gene amplification at 27 gene loci (amplicons that are associated with increased mRNA expression) in 1900 cases of node positive breast cancer enrolled in NSABP trial B-28, using fluorescence in situ hybridization (FISH). In multivariate analysis, 3 amplicons (HER2, cMYC, HTPAP) were associated with poor prognosis independent of other known prognosticators. While coamplification of HER2 and HTPAP was rare, a significant number of cases had co-amplification of HER2 and cMYC with worse outcome than when each one was amplified alone. This has prompted us to examine the significance of cMYC amplification in HER2 amplified breast cancer treated with trastuzumab. Our a priori hypothesis was that patients with cMYC amplified tumors would derive less benefit from trastuzumab due to independent signaling through cMYC.

Patients, materials, and methods: In NSABP B-31, 1736 patients with follow-up were randomized to receive adjuvant chemotherapy of 4 cycles of doxorubicin plus cyclophosphamide followed by 4 cycles of paclitaxel with or without trastuzumab, which was given for total of one year beginning with the first cycle of paclitaxel. cMYC FISH results were available from 1549 cases. cMYC was amplified in 432 cases $(30 \%)$. We examined Recurrence Free Survival as a primary clinical end point.

Results: Numbers of events and hazard ratios (HR) for recurrence and death are shown below $(\mathrm{C}=$ chemotherapy, $\mathrm{C}+\mathrm{T}=$ chemotherapy and trastuzumab):

\begin{tabular}{ll} 
& $\begin{array}{c}\text { cMyc not amplified } \\
(\mathrm{N}=1078)\end{array}$ \\
Recurrences & $82 / 540(\mathrm{C})$ vs. \\
& $55 / 538(\mathrm{C}+\mathrm{T})$ \\
HR for Recurrence 0.63 \\
Deaths $\quad 28 / 540(\mathrm{C})$ vs. \\
\multicolumn{3}{c}{$29 / 538(\mathrm{C}+\mathrm{T})$} \\
HR for death & 0.99
\end{tabular}

$\begin{array}{ll}\begin{array}{l}\text { cMyc amplified } \\ (\mathrm{N}=471)\end{array} & \begin{array}{l}\text { Interaction } \\ \text { p-value }\end{array} \\ 51 / 234(\mathrm{C}) \text { vs. } & \\ 13 / 237(\mathrm{C}+\mathrm{T}) & \\ 0.24 & \mathbf{0 . 0 0 7} \\ 23 / 234(\mathrm{C}) \text { vs. } & \\ 8 / 237(\mathrm{C}+\mathrm{T}) & \\ 0.36 & \mathbf{0 . 0 3 7}\end{array}$

Conclusion: While patients with co-amplification of cMYC and HER2 had worse outcome when treated with chemotherapy alone, addition of trastuzumab reversed this trend, achieving 4 year recurrence free survival of over $90 \%$. Although these data contradict our a priori hypothesis, they are consistent with preclinical models that suggest that the pro-apoptotic function of dysregulated cMYC needs to be counterbalanced by an anti- 
apoptotic signal by another activated oncogene in order for such cells to develop into cancer. Amplified HER2 may provide such anti-apoptotic signaling that is reduced by treatment with trastuzumab, resulting in triggering of apoptosis. These data suggest that indirect targeting of dysregulated cMYC may be possible if co-operating oncogenes providing anti-apoptotic signals are identified.

\section{5}

Meta- and pooled analysis of the prognostic value of bone marrow micrometastasis on disease outcome in 4,703 breast cancer patients: final results after $\mathbf{1 0}$ years of follow-up. Vogl FD, Braun S, Pantel K, Collaborative Group Bone Marrow Micrometastasis. Innsbruck Medical University, Insbruck; City Hospital, Meran; Inst. Tumorbiology, Epppendorf University, Hamburg

Background: Available prognostic data on outcome of breast cancer patients with bone marrow micrometastasis (BMM) is limited due to small sample sizes of individual studies. Statistically powerful studies are needed to provide the evidence for implementation of $\mathrm{BMM}$ in clinical decision making.

Methods: Individual patient data of 9 studies, involving 4,703 patients with stage I-III breast cancer, were combined to analyze long-term clinical outcome. Meta-analysis was conducted to summarize the results of included studies. Using the pooled data, piecewise proportional hazards regression models were estimated for the complete set of patients and in subgroup analysis.

Results: The prevalence of BMM was $30.6 \%$, and was significantly associated with larger tumor size, higher grade, lymph node metastasis and endocrine non-responsiveness (each $\mathrm{P}<0.001$ ). Meta-analytic hazard ratios indicated a more than 2-fold increased risk of either dying or relapse for overall (OS), cancer-specific (CCS), disease-free (DFS) and distant disease-free survival (DDFS). Assessment of statistical heterogeneity in the pooled data set revealed significant inter-study variation of hazards ratio estimates (Q-test, $\mathrm{P}=0.007$ for $\mathrm{OS} ; \mathrm{P}<0.001$ for DFS). According to sensitivity analysis, however, there was no bias for the pooled survival estimates. Residual heterogeneity was removed by stratifying by center. Multivariable regression analysis including established prognostic factors revealed that BMM was an independent prognostic variable for all investigated endpoints This effect was strongest during the first years following primary breast cancer diagnosis: adjusted hazards ratios were 1.81 (95\% CI, 1.51-2.16) for OS, 1.93 (1.58-2.36) for CCS, $1.85(1.59-2.14)$ for DFS, and $2.03(1.72-2.39)$ for DDFS. On univariate analysis, survival of patients with BMM in subgroups with either endocrine therapy or chemotherapy alone was significantly reduced (each $\mathrm{P}<0.001$ ). Among patients with $\mathrm{pT} 1 \mathrm{~N} 0$ disease, who received no systemic adjuvant treatment, patients with BMM had significantly reduced OS $(\mathrm{P}=0.001), \mathrm{CSS}(\mathrm{P}<0.001)$, DDFS $(\mathrm{P}=0.007)$, and DFS $(\mathrm{P}=0.01)$.

Conclusions: This combined analysis provides conclusive level-I evidence that presence of bone marrow micrometastasis is a significant indicator of poor prognosis in breast cancer patients.

\section{6}

Prognostic and predictive value of circulating tumor cells in metastatic breast cancer patients treated with endocrine or chemotherapy.

Ellis MJ, Miller MC, Cristofanilli M, Budd GT, Stopeck A, Hayes DF, Doyle GV, Matera J, Terstappen LWMM. Washington University, St Louis, MO; Immunicon Corporation, Huntingdon Valley, PA; MD Anderson Cancer Center, Houston, TX; Cleveland Clinic Foundation, Cleveland, OH; Arizona Cancer Center, Tuscon, AZ; University of Michigan Comprehensive Cancer Center, Ann Arbor, MI

Background: Elevated ( $\geq 5$ ) circulating tumor cells (CTC) / 7.5mL of whole blood in patients with measurable metastatic breast cancer
(MBC) are associated with poor clinical outcomes (Cristofanilli, et al; NEJM, 2004). This report expands this original dataset to include patients with bone dominant (non-measurable) disease and identifies the optimal timing of CTC assessment for different therapies. Methods: CTCs were enumerated in patients with MBC prior to commencing a new therapy, and at 3-5, 6-8, 9-14 and 1520 weeks after initiation of therapy. CTC counts were correlated with progression free and overall survival (OS), with the time to progression and/or death calculated from the time of each followup blood draw. Results: Of the total 223 patients, $46(21 \%)$ had non measurable while $177(79 \%)$ had measurable disease. The patients were separated by treatment type, i.e. chemotherapy, combination therapy and endocrine therapy. The incidence of CTCs / $7.5 \mathrm{~mL}$ of blood and the median survival of patients with $<5$ vs. 5 CTCs are provided in the table below. Conclusions: In measurable and non-measurable metastatic breast cancer, CTCs provide an early, reliable indication of disease progression and survival for patients irrespective of therapy. Patients on endocrine therapy (more indolent disease) survived longer than those on chemotherapy. However, the magnitude of the difference in OS between the groups is similar. It was also observed that follow-up assessment of patients on endocrine therapy by CTCs should be delayed several weeks as anti-tumor activity of endocrine therapies seems to lag behind those of chemotherapy.

CTCs and Survival in Metastatic Breast Cancer Chemo Therapy Only

\begin{tabular}{|c|c|c|c|c|c|c|c|}
\hline & $\mathrm{n}$ & $\begin{array}{l}\geq 5 \text { CTC } \\
\%\end{array}$ & $\begin{array}{l}<5 \text { CTC } \\
\text { months }\end{array}$ & $\begin{array}{l}\geq 5 \mathrm{CTC} \\
\text { months }\end{array}$ & $\begin{array}{l}\% \dagger 1 \mathrm{y} \\
<5 \text { CTC }\end{array}$ & $\begin{array}{l}\% \dagger 1 \mathrm{y} \\
\geq 5 \mathrm{CTC}\end{array}$ & $\begin{array}{l}\text { logrank } \\
\text { p-value }\end{array}$ \\
\hline baseline & 104 & 57 & 18.0 & 7.4 & 29 & 64 & 0.0004 \\
\hline 3-5 wks & 75 & 44 & 15.5 & 6.3 & 26 & 67 & 0.0022 \\
\hline $6-8 \mathrm{wks}$ & 65 & 29 & 14.2 & 5.4 & 30 & 79 & 0.0025 \\
\hline $9-14$ wks & 70 & 21 & 15.1 & 5.8 & 24 & 73 & 0.0002 \\
\hline $15-20 \mathrm{wks}$ & 43 & 19 & 17.5 & 4.6 & 14 & 62 & 0.0093 \\
\hline \multicolumn{8}{|c|}{ Combination Therapy } \\
\hline baseline & 51 & 47 & 20.6 & 13.9 & 11 & 50 & 0.0721 \\
\hline 3-5 wks & 41 & 22 & $>25$ & 2.7 & 12 & 89 & $<0.0001$ \\
\hline $6-8 \mathrm{wks}$ & 30 & 7 & $>25$ & 2.0 & 14 & 100 & 0.0003 \\
\hline $9-14$ wks & 35 & 14 & $>25$ & 1.2 & 7 & 80 & $<0.0001$ \\
\hline $15-20 \mathrm{wks}$ & 26 & 4 & $>25$ & 0.7 & 8 & 100 & $<0.0001$ \\
\hline \multicolumn{8}{|c|}{ Endocrine Therapy Only } \\
\hline baseline & 68 & 34 & 26.9 & $>25$ & 9 & 17 & 0.3817 \\
\hline 3-5 wks & 48 & 27 & 25.9 & 16.4 & 9 & 23 & 0.0429 \\
\hline 6-8 wks & 34 & 35 & $>25$ & 15.0 & 0 & 33 & 0.0038 \\
\hline $9-14$ wks & 58 & 26 & $>25$ & 17.8 & 5 & 27 & 0.0031 \\
\hline $15-20 \mathrm{wks}$ & 37 & 32 & $>25$ & 22.9 & 0 & 17 & 0.0268 \\
\hline
\end{tabular}

\section{7}

Radiotherapy in breast-conserving treatment for ductal carcinoma in situ (DCIS): ten-year results of European organization for research and treatment of cancer (EORTC) randomized trial 10853.

Bijker N, Meijnen PH, Bogaerts J, Peterse JL, on Behalf of the EORTC Breast Cancer Group \& Radiotherapy Group. The Netherlands Cancer Institute, Amsterdam, Netherlands; EORTC, Brussels, Belgium

Background: DCIS is present in up to $30 \%$ of screen detected breast cancer patients. Controversy regarding the most optimal local therapy for women diagnosed with these non-invasive lesions still exists. We present the 10-year results of the EORTC 10853 study investigating the role of radiotherapy after local excision of DCIS

Patients and Methods: After complete excision of the lesion, women with DCIS were randomly assigned to receive either no further treatment or radiotherapy, to a dose of 50 Gray in five weeks to the whole breast. Between 1986 and 1996, 1010 women with clinically or mammographically (71\%) detected DCIS, measuring $\leq 5 \mathrm{~cm}$ were entered in the trial. The median follow-up was 10.2 years.

Results: The 10-year local relapse-free rate was $75 \%$ in the group treated with local excision alone compared with $85 \%$ in the women treated by local excision plus radiotherapy (logrank $\mathrm{p}<0.0001, \mathrm{HR}=0.55(95 \% \mathrm{CI} 0.41-0.73))$. The risks of DCIS and invasive local recurrence were both reduced with $42 \% \quad(p=0.009$ 
and $\mathrm{p}=0.006$, respectively). The risk of contralateral breast cancer was similar in both groups. There was no difference in the development of distant metastases and death between the treatment groups. Twenty-two patients $(2 \%)$ developed distant metastases as a result of an invasive local recurrence. At multivariate analysis, factors significantly associated with an increased risk of local recurrence were, young age $(\leq 40$ years, HR $=1.95$ (95\%CI 1.16 $3.30)$ ), symptomatic detection $(\mathrm{HR}=1.53$ (95\% CI 1.09-2.16)), intermediately or poorly-differentiated DCIS (as opposed to welldifferentiated DCIS, HR=1.77 (95\%CI 1.13-2.78) and $\mathrm{HR}=1.37$ (95\%CI 0.78-2.39) respectively), solid or cribriform growth pattern (as opposed to clinging/micropapillary subtypes, HR=2.21 $(95 \% \mathrm{CI}$ 1.31-3.71) and $\mathrm{HR}=2.28$ (95\%CI 1.23-4.24) respectively), doubtful margins $(\mathrm{HR}=1.82(95 \% \mathrm{CI} 1.30-2.54))$, and treatment by local excision alone $(\mathrm{HR}=1.74(95 \% \mathrm{CI} 1.28-2.42))$. Some groups were at high risk of recurrence: women of 40 years of age or younger and treated with excision plus radiotherapy had a $27 \%$ local recurrence rate. When excision margins were doubtful, $23 \%$ of the patients developed a local recurrence after treatment with radiotherapy. DCIS with a clinging or micropapillary growth pattern had the lowest recurrence rate of $6 \%$ after radiotherapy.

Conclusions: With long-term follow-up, radiotherapy after local excision for DCIS continued to reduce the number of ipsilateral breast tumor recurrences, with a $45 \%$ reduction at 10 years. Treatment with radiotherapy reduced the risk of local recurrence in all clinical and pathological subgroups of patients. Women who appear at high risk for local recurrence are those of 40 years of age or younger, and those with lesions that cannot be excised with tumor-free margins.

8

Breast conservation without radiotherapy in low risk breast cancer patients - results of 2 prospective clinical trials of the Austrian Breast and Colorectal Cancer Study Group involving 1,518 postmenopausal patients with endocrine responsive breast cancer.

Gnant MFX, Poetter R, Kwasny W, Tausch C, Handl-Zeller E, Pakesch B, Schmid M, Hausmaninger H, Stierer M, Kubista E, Sedlmayer F, Draxler W, Luschin-Ebengreuth G, Jakesz R, Austrian Breast and Colorectal Cancer Study Group. Medical Universities of Vienna, Graz, Salzburg, and Innsbruck, Vienna, Austria

Background: In postmenopausal women with favourable prognosis endocrine responsive $(\mathrm{HR}+)$ early breast cancer $(\mathrm{BC})$ treated by breast conservation plus adjuvant endocrine treatment it remains unclear whether whole breast irradiation is necessary with regard to local control, disease-free and overall survival. In two consecutive prospective clinical trials, the Austrian Breast and Colorectal Cancer Study Group tried to define a sub-group of patients with lowest locoregional risk and the subsequent chance to avoid adjuvant radiotherapy (RT).

Methods: Within the prospective clinical trial ABCSG-06 (randomized 2,020 $\mathrm{HR}+$ postmenopausal BC patients, Schmid M et al, JCO 2003), a low-risk sub-group was prospectively defined as follows: tumor size $<3 \mathrm{~cm}$, node negative disease, received tamoxifen \pm aminoglutethimide $(\mathrm{n}=713)$. For 698 patients of this subgroup (97.9\%), complete data and follow-up is available, ABCSG$6 \mathrm{~B}$. Furthermore, 875 postmenopusal women of the ABCSG-08 trial $(\mathrm{n}=3,935 ; 5 \mathrm{yrs}$ of Tam vs. 2 yrs Tam +3 yrs Anastrozole, Jakesz R et al, SABCS 2004) were randomly assigned to receive whole breast irradiation (group I, $n=410$ ) or not (group II, $n=416$ ) (ABCSG-8A). Favourable early BC was again specified as tumour size $<3 \mathrm{~cm}, \mathrm{~N} 0, \mathrm{ER}+$ and/or $\mathrm{PgR}+$, and breast conserving surgery. RT was performed after lumpectomy with two tangential opposed breast fields with 50 Gy and 2 Gy per fraction in 5 weeks. Primary endpoint was locoregional relapse (LR). Further endpoints were controlateral BC, DDFS, DFS, and OS.

Results: Median FU was 121 months for ABCSG-6B and 48 months for ABCSG-8A. In ABCSG-6B, with more than 10 years of FU, LR was $3.58 \%$. For patients receiving RT, LR was $3.26 \%$, for those treated without radiotherapy LR was $5.17 \%, \mathrm{p}=\mathrm{n} . \mathrm{s}$. In the randomized ABCSG-8A trial, overall LR was $1,71 \%$, with $0.24 \%$ $(n=1 / 413)$ in group I receiving RT and $3.19 \%(n=13 / 407)$ in group II, $\mathrm{p}<0.0008$. In terms of OS, there was no significant difference in neither trial.

Conclusion: Breast conserving therapy can be performed without adjuvant RT in a selected group of lowest risk breast cancer patients with very low long-term locoregional relapse rates. In a prospective randomized comparison, however, even in this favourable patient sub-group and with extremely low overall LR rates, there remains a significant reduction of locoregional relapse risk for those who received RT after breast conserving surgery. In fact, the risk of LR can be nearly diminished by proper multimodality treatment. These data from 2 large clinical trials may assist patients and physicians in their clinical decision-making.

\section{9}

Inhibiting the growth factor receptor (GFR) pathway preserves and enhances the expression of the estrogen receptor (ER) in HER-2/neu (HER2) over-expressing human breast tumors and xenografts.

Rimawi MF, Mohsin SK, Gutierrez MC, Arpino G, Massarweh SA, Chang JC, Osborne CK, Schiff R. Baylor College of Medicine, Houston, TX; King Hussein Cancer Center, Amman, Jordan

Background and Purpose: Data from the clinic and our xenograft model suggest that ER expression in breast cancer cells may be influenced by endocrine therapy and GFR targeted therapy. We hypothesized that the expression of ER and HER2 is a dynamic interrelated process and that inhibiting the GFR pathway may lead to enhancement and emergence of ER expression and function. Further understanding of these expression patterns will provide insight into the clinical management of breast cancer.

Methods: Patient core biopsies and xenograft samples on tissue arrays were assessed by immunohistochemistry for ER, progesterone receptor (PR) and HER2 expression.Clinical samples were obtained from a neoadjuvant trastuzumab trial in 35 patients with HER2 over-expressing tumors (Mohsin et al.; J Clin Oncol. 2005 23:2460). MCF7/HER2 over-expressing xenografts were established in nude mice with exogenous estrogen. Mice were then randomized and treated for different periods of time with continued estrogen or estrogen deprivation (ED), each alone or with a potent anti-HER2 regimen composed of gefitinib, trastuzumab and pertuzumab (GTP). Additionally, a set of tumors treated with ED until resistance developed were randomized to continued ED with or without treatment with GTP, or reintroduction of estrogen. Results: 7/35 (20\%) HER2 over-expressing human tumors were ER positive. Of those, 3 tumors $(43 \%)$ had an increase in ER and/ or PR expression after receiving trastuzumab therapy. In addition, one initially ER negative tumor converted to ER positive after treatment. Likewise, in our xenograft model, treatment with GTP reduced in half the ER loss observed with ED. Furthermore, GTP treatment led to a significant increase in expression of ER $(>2.5$ fold) as well as PR ( $>1.5$ fold) in the presence of estrogen. The enhanced PR expression suggests increased classical pathway signaling of ER. We have previously shown that resistance to ED in this model is associated with increased HER2 levels and a complete loss of ER expression. Reintroducing estrogen led to only minimal ER re-expression but considerably higher reexpression of PR. Anti-HER2 therapy in these ED resistant tumors resulted in re-expression of substantial levels of ER in $50 \%$ of the tumors. Notably, this re-expression of ER correlated with response to anti-HER2 treatment, implying its predictive value.

Conclusions: Anti-HER2 therapy leads to enhanced expression of ER and PR in our xenograft model and in human tumors. Upregulation of the GFR pathway leads to ER loss observed upon resistance to ED in our model. This ER loss can be reversed with anti-HER2 therapy. The re-expression of ER may restore sensitivity to endocrine therapy suggesting its important predictive and therapeutic implications which warrant further study. 
10

PC-cell derived growth factor (PCDGF/GP88, progranulin) stimulates Her-2 phosphorylation and confers herceptin resistance to Her-2 overexpressing breast cancer cells.

Kim W, Serrero G. University of Maryland School of Pharmacy, Baltimore, MD; A\&G Pharmaceutical Inc., Columbia, MD; University of Maryland, Baltimore, $M D$

Her-2 overexpression is observed in approximately $25 \%$ of breast carcinomas, and is correlated with poor prognosis and aggressive tumors. To date, the most popular form of treatment for breast cancer patients overexpressing Her2/erbB2 is the use of an antiHer2 antibody known as Herceptin. However, Herceptin is only effective in about $25-30 \%$ of the patients administered this drug. We show here that the expression of the autocrine growth factor PC Cell Derived Growth Factor (PCDGF/GP88, progranulin) in Her2 overexpressing breast cancer cell lines leads to Herceptin resistance. PCDGF/GP88 is an $88 \mathrm{kDa}$ protein that is the largest member of the epithelin-granulin family of polypeptides characterized by a unique cysteine rich motif. PCDGF/GP88 plays a critical role in breast tumorigenesis. Its expression increases in breast cancer cells in a positive correlation with their tumorigenesis. Inhibition of PCDGF/GP88 action or expression blocked the proliferation of human breast carcinoma cells, as well as leading to a $98 \%$ reduction in tumor incidence and growth rate in vivo. Pathological studies of paraffin embedded breast cancer biopsies have shown that PCDGF/GP88 is expressed in $80 \%$ of infiltrating ductal carcinoma and correlated with parameters of poor prognosis such as tumor grade, p53 expression and Ki67 proliferation index. In contrast, PCDGF/GP88 expression was independent of Her2. However, about $20 \%$ of Her-2 overexpressing breast cancer biopsies also displayed a high GP88expression. Based on this observation, we investigated the effect of PCDGF/GP88 in Her-2 overexpressing cell lines. Using several Her-2 overexpressing human breast adenocarcinoma cell lines such as SKBR3, BT-474 and ErbB2-MCF-7 cells, we show that PCDGF/GP88 stimulated erbB2/Her2 phosphorylation in a time- and dose-dependent manner. In addition, PCDGF/GP88 activates erbB2, c-Src and ultimately c-myc by utilizing ERK1/2 and Akt pathways, both of which are involved in mitogenic signaling pathways. We demonstrate that overexpression of PCDGF/GP88 blocked the inhibitory effect of Herceptin on the cell proliferation, soft agar colony formation and MAP kinase activation of Her-2 overexpressing cells. Our findings provide a novel paradigm for the acquisition of Herceptin resistance in Her-2 overexpressing breast cancers.

\section{1}

Trastuzumab (H: Herceptin $\left.{ }^{\circledR}\right)$ following adjuvant chemotherapy (CT) significantly improves disease-free survival (DFS) in early breast cancer (BC) with HER2 overexpression: the HERA Trial. the HERA Study Team.

Background: The Breast International Group (BIG), in collaboration with Roche, conducted an international, multi-center, randomized, 3 -arm trial to compare 1 year of 3 weekly $\mathrm{H}(8 \mathrm{mg} /$ $\mathrm{kg}$ iv day $1 ; 6 \mathrm{mg} / \mathrm{kg}$ iv q 3 weeks thereafter) with observation and 2 years of 3 weekly $\mathrm{H}$ with observation in patients with HER2 overexpressing, node-negative $(\mathrm{T}$ size $>1 \mathrm{~cm})$ or node-positive $\mathrm{BC}$ who had completed at least 4 cycles of an acceptable (neo)adjuvant chemotherapy (CT) regimen. Adjuvant endocrine therapy (mostly tamoxifen) also followed CT for patients with hormone receptor positive disease. Prior to randomization, eligibility criteria included central confirmation of HER2 overexpression (3+) or amplification (FISH+) and a baseline LVEF (echo or MUGA) $>55 \%$ following CT.

Methods: 5090 patients were enrolled from 12/2001 to 4/2005 by 478 institutions from Europe, Canada, South Africa, Israel, the Asia Pacific Region, Japan, and Latin America: median age $=49$ yrs, node negative $=32 \%$, hormone receptor negative $=49 \%$, prior anthracyclines $(\mathrm{A})=68 \%$, prior $\mathrm{A}$ and taxanes $=25 \%$.

Results: At a median follow-up of 1 year, 475 events were observed in the database and triggered the first and only interim analysis. The Independent Data Monitoring Committee (IDMC) recommended release of the results for the 1 year $\mathrm{H}$ arm (1694 pts; 127 events) versus observation (1693 pts; 220 events), which were presented at ASCO 2005 (see table below). The 2 year $\mathrm{H}$ arm also improved DFS compared with observation $(\mathrm{p}<0.0001)$. Htreated patients had a higher incidence of NYHA class III-IV CHF (cardiologist confirmed) with LVEF drop at least $10 \mathrm{EF}$ points from baseline to below 50\%: $9(0.5 \%)$ with $\mathrm{H}$ v. 0 without $\mathrm{H}$. Cardiac deaths were rare: 0 with $\mathrm{H}$ v. 1 without $\mathrm{H}$.

Discussion:One year H significantly improves outcome compared with observation. The trial continues to assess 2 years $\mathrm{v} 1$ year of $\mathrm{H}$, and monitor late side effects. Updated results and information on cardiac AEs will be presented. HERA Study Results - ASCO, May 16, 2005

\begin{tabular}{lllll}
\multicolumn{1}{c}{} & DFS* & RFS & DDFS** & OS \\
HR & 0.54 & 0.50 & 0.51 & 0.76 \\
$95 \%$ CI & $0.43-0.67$ & $0.40-0.63$ & $0.40-0.66$ & $0.47-1.23$ \\
p-value & $<0.0001$ & $<0.0001$ & $<0.0001$ & 0.26 \\
events & 127 v. 220 & 113 v. 209 & 98 v. 179 & 29 v. 37 \\
2-year $\%$ & $85.8 \%$ v. $77.4 \%$ & $87.2 \%$ v. $78.6 \%$ & $89.7 \%$ v. $81.8 \%$ & $96.0 \%$ v. $95.1 \%$ \\
*includes local, regional, distant recurrences, contralateral BC, 2 red malignancies, death
\end{tabular}

*includes local, regional, distant recurrences, contralateral BC, 2nd malignancies, death without prior event. ** includes distant recurrences, contralateral BC, 2nd malignancies.

\section{2}

Surgical biopsy to diagnose breast cancer adversely affects outcomes of breast cancer care: finding from the National Comprehensive Cancer Network.

Edge SB, Ottesen RA, Lepisto EM, Niland JC, Theriault RL, Bookman MA, Weeks JC. Roswell Park Cancer Institute, Buffalo, NY; City of Hope National Medical Center, Duarte, CA; National Comprehensive Cancer Network, Jenkintown, PA; MD Anderson Cancer Center, Houston, TX; Fox Chase Cancer Center, Philadelphia, PA; Dana Farber Cancer Institute, Boston, MA

Objective: The choice between needle and surgical biopsy as the initial diagnostic method for evaluation may affect the quality of subsequent breast cancer care. We examined the frequency of reexcision (more than one surgery on the breast parenchyma) and the total number of open surgical operations (breast + axilla) based on the type of initial breast biopsy and the time to complete cancer surgery with re-excision vs. none.

Methods: The type of initial biopsy for Stage 0, I and II breast cancer at 8 cancer centers was classified as needle or surgical for patients seen between July 1997 and June 2002. Needle biopsy included any type of core biopsy or FNA with or without image localization. Surgical biopsy included any open surgical procedure. Endpoints included re-excision, the total number of trips to surgery, and elapsed time to complete surgery.

Results: Among 6,282 women, the initial biopsy was needle in $57 \%$ and surgical in $43 \%$. The table shows the proportion of requiring re-excision and the mean number of surgical procedures by type of initial biopsy. Using multivariable logistic regression and controlling for age, cancer stage, image localization, and institution, re-excision was significantly associated with type of initial biopsy $(\mathrm{p}<0.0001)$. Multivariable mean score response modeling adjusted for the same covariates, demonstrated that on average women whose initial biopsy was surgical had 0.83 more surgeries than women with initial needle biopsy $(\mathrm{p}<0.0001)$. The mean time to complete surgery was 30 days without re-excision and 48 days with re-excision.

Conclusions: Surgical biopsy for breast cancer adversely affects quality of care, increasing the need for repeated surgery and the time to complete surgery. These data support the measurement of the proportion of women who receive needle biopsy for diagnosis as a measure of the quality of care for breast cancer. 
Re-Excision and Total Number of Operations by Type of Initial Biopsy

$\begin{array}{lll}\text { Type of Initial Biopsy } & \text { Needle Biopsy } & \text { Surgical Biopsy } \\ \text { Percent with greater than one operation } & & \\ \text { on breast parenchyma (re-excision) } & 23 \% & 92 \% \\ \text { Mean number total operations (breast + axilla) } & 1.32 & 2.15\end{array}$

\section{7}

Genetically engineered human breast tumors in mice.

Wu M, Boynton G, Cooper A, Breault L, Vincent S, Richardson A, Depinho RA, Robinson M, Kuperwasser C. AVEO Pharmaceuticals, Inc., Cambridge, MA; Tufts University School of Medicine, Boston, MA; Brigham and Women's Hospital, Boston, MA; Dana-Farber Cancer Institute, Boston, MA; Harvard Medical School, Boston, $M A$

It has been demonstrated that tumorigenesis varies in a species-, tissue-, and context-dependent manner. To define the genetic elements and stromal changes that promote human breast cancer, we developed an in vivo human breast tumor model system through tissue reconstitution in mice. Using this model system, we have demonstrated that, unlike mouse cancer models, overexpression of dominant oncogenes in combination with knockdown of $p 53$ in human breast epithelial cells only led to the development of pre-neoplastic lesions. Development of invasive human breast adenocarcinomas in vivo requires the concomitant expression of dominant oncogenes and the SV40 early region. In addition, the development of these tumors was also dependent on specialized stromal fibroblasts, as tumors rarely developed in the absence of this microenvironment. Furthermore, in contrast to in vitro transformation, in vivo breast cancer development did not require the transduction of $h T E R T$ in primary human mammary epithelial cells (HMECs). This model system will be invaluable for further elucidating the mechanisms involved in human breast tumor progression and for the development of new therapies against breast cancer.

\section{3}

The benefits of sequencing adjuvant tamoxifen and anastrozole in postmenopausal women with hormoneresponsive early breast cancer: 5 year-analysis of ABCSG Trial 8.

Jakesz R, Gnant M, Greil R, Tausch C, Samonigg H, Kwasny W, Kubista E, Stierer M, Luschin G, Mittlboeck M. Vienna Medical School, Austria

Background: The aromatase inhibitor (AI) anastrozole has been proven to be more effective than tamoxifen as adjuvant monotherapy for postmenopausal women with hormone-sensitive early breast cancer (EBC). There is also strong evidence to suggest that switching from tamoxifen to an AI after 2-3 years' adjuvant therapy improves outcomes for patients compared with completing 5 years' tamoxifen. This evidence includes data from the combined analysis of ABCSG Trial 8 and ARNO 95 where the hazard ratio (HR) for event-free survival with anastrozole versus tamoxifen was $0.60(95 \% \mathrm{CI} 0.44,0.81 ; \mathrm{p}=0.0009)$ at a median follow-up of 28 months (SABCS 2004). However, unlike other switching trials, ABCSG Trial 8 randomized newly diagnosed patients, rather than randomizing at the point of switch, and the data for the full 5-year adjuvant period have now been analyzed. We therefore present here the results from the first tamoxifen-AI sequencing trial, which compares using 5 years of tamoxifen with 2 years of tamoxifen, followed by 3 years of anastrozole.

Methods: Eligible patients were postmenopausal women with histologically verified G1 or G2, locally radically treated invasive or minimally invasive hormone receptor-positive breast cancer. Patients were randomized to receive 5 years of tamoxifen therapy or 2 years' tamoxifen followed by anastrozole for 3 years. The primary endpoint was event-free survival (EFS), including locoregional, contralateral, or distant metastatic recurrences. Secondary endpoints included safety and overall survival.

Results: 3700 patients were eligible for the analysis at the data cutoff of March 31, 2005. After a median follow-up of 30 months,
158 events (local or metastatic recurrence, or contralateral breast cancer) have been reported. The HR for EFS with tamoxifen followed by anastrozole versus tamoxifen was 0.68 (95\% CI 0.49 , $0.91 ; \mathrm{p}=0.02$ ). This HR represents a $32 \%$ reduction in the risk of disease recurrence for patients receiving tamoxifen followed by anastrozole versus those receiving tamoxifen alone.

Conclusions: These data demonstrate that for postmenopausal women newly diagnosed with EBC, a sequencing strategy of 2 years of tamoxifen followed by 3 years of anastrozole is superior to treatment with 5 years of tamoxifen.

\section{4}

Optimal duration of adjuvant tamoxifen (TAM) in early breast cancer (EBC): ten year results of a randomized trial (TAM-01) of the FNCLCC Breast Group.

Delozier T, Spielmann M, Janvier M, Fourquet A, Veyret C, Weber B, Mauriac L, Petit T, Kerbrat P. Centre Francois Baclesse, Caen, France; Institut Gustave Roussy, Villejuif, France; Centre Rene Huguenin, Saint Cloud, France; Institut Curie, Paris, France; Centre Henri Becquerel, Rouen, France; Centre Alexis Vautrin, Nancy, France; Institut Bergonie, Bordeaux, France; Centre Paul Strauss, Strasbourg, France; Centre Eugene Marquis, Rennes, France

Background: Although adjuvant hormonal treatment has been proved to reduce recurrence and mortality in early breast cancer, the optimum duration of therapy is still controversial

Aim: In 1986, a multicentric randomized trial was initiated to assess the efficacy and tolerance of long term adjuvant TAM. A short duration of adjuvant TAM was compared to lifelong adjuvant TAM.

Material and method: were eligible patients with $\mathrm{EBC}$ receiving adjuvant TAM since 2-3 years, disease-free since primary treatment, aged 75 years or younger. From 9/1986 to 5/1995, 3,793 patients were randomized; $1,882(49.6 \%)$ patients stopped TAM (short) while 1,911 (50.4\%) patients continued TAM (long) at the same dose as previously prescribed until recurrence or death. The trial protocol was amended in February 1997, limiting tamoxifen treatment to ten years after randomization, thus giving a comparison between 2-3 years treatment and 12-13 years treatment. Preliminary results have been published previously. Data from 2,826 patients was updated in 12/2004. The median follow up time was 120 months. Mean TAM duration was 29 and 127 months respectively in the short and long duration group. Results: Overall, 453 and 397 patients respectively have relapsed in the short and long duration group, leading to a 5-year diseasefree survival (DFS) rate of $77 \%$ and $82 \%$, and a 10 -year DFS rate of $67 \%$ and $72 \%(p=0.0022)$. In contrast, overall survival (OS) does not differ between the two arms $(\mathrm{p}=0.16)$. The hazard ratio analysis shows that the reduction in breast cancer recurrence is transient ; The annual reduction in the odds of recurrence decreased rapidly after 5 years of tamoxifen. After 5 years of tamoxifen the annual rate of relapse is the same in both groups. We conclude that there is no benefit in prolonging TAM over 5 years.

Complete data of the whole population will be presented.

\section{5}

\section{Withdrawn by Author.}

\section{6}

Updated analysis of NCIC CTG MA.17 (letrozole vs. placebo to letrozole vs placebo) post unblinding. Goss PE, Ingle JN, Palmer MJ, Shepherd LE, Tu D. Massachusetts General Hospital Cancer Center, Boston, MA; Mayo Clinic, Rochester, MN; Cancer Research Institute, Queen's University, Kingston, ON, Canada

Background and Rationale: In MA.17, 5187 postmenopausal women were originally randomized to receive letrozole (LET) or placebo (PLAC) after 5 years of tamoxifen. The hazard ratio 
(HR) for disease-free survival (DFS) was 0.58 (0.450.76, $\mathrm{p}=0.00004$ ) after a median follow-up of 30 months. The trial was unblinded in October 2003 after the first interim analysis. Women randomized to PLAC were offered LET at the time of unblinding. We present a comparison of efficacy endpoints in the following three groups: randomized originally to LET (LET), to PLAC but crossed over to LET (PLAC-LET), or stayed on PLAC (PLAC). Design and Methods: LET and PLAC-LET have been compared to PLAC, based on the hazard ratio and adjusting for baseline patient and disease variables including, among others, tumor size, nodal status and prior adjuvant chemotherapy.

Results: Information about their follow-up treatment after unblinding was available on 2247 women originally assigned to PLAC and who were free of recurrence and alive at the time of unblinding. Among them, 1601 crossed over from PLAC to LET. Age, nodal status, endocrine symptomatology and being in the USA as compared to Canada predicted for switching to LET (Luk C et al., ASCO 2005). The total number of breast cancer events in the three groups since the original randomization is at present 342 with 211 deaths and median follow-up of 49 months. The adjusted HR of DFS between LET and PLAC as well as PLAC LET vs PLAC will be presented together with updated analyses of toxicities, new diagnoses of osteoporosis and clinical fractures, and cardiac events.

Conclusion: MA.17 was unblinded at the first preplanned interim analysis because of a strong treatment effect of LET. Among the clinical questions left unanswered is the optimal duration of LET, long term toxicities and whether starting LET after a prolonged period off tamoxifen is of benefit. This analysis will address these questions. To further answer the question of duration we have also begun enrolling on MA17R, a re-randomization of all participants completing LET on MA.17 to a further 5 years of treatment.

\section{7}

Analysis of duration of letrozole extended adjuvant therapy as measured by hazard ratios of disease recurrence over time for patients on NCIC CTG MA.17.

Ingle JN, Goss PE, Tu D. Mayo Clinic, Rochester, MN; Massachusetts General Hospital Cancer Center, Boston, MA; Cancer Research Institute, Queen's University, Kingston, ON, Canada

Background: MA.17 randomized 5187 postmenopausal women with early stage breast cancer after 5 years of tamoxifen to 5 years of letrozole $(\mathrm{L})$ or placebo $(\mathrm{P})$. After 30 months median follow-up (range 1.5-61.4 months), disease-free survival (DFS) was superior in the overall study population for L (HR 0.58 with $95 \%$ CI $0.45-0.76 ; p=0.00004)$. The following analysis was conducted to examine the relationship in the extended adjuvant setting between duration of letrozole therapy and hazard for recurrence.

Materials and Methods: A nonparametric kernel method was used to estimate the hazard rates and hazard ratio, as a measure of treatment effect, at various time points. A Cox model with a timedependent covariate was used to test the trend of the hazard ratio over time.

$\begin{array}{lllll}\begin{array}{l}\text { Months After } \\ \text { Randomization }\end{array} & \begin{array}{l}\text { Number at } \\ \text { risk (L/P) }\end{array} & \begin{array}{l}\text { Hazard } \\ \text { rate }(\mathrm{L})\end{array} & \begin{array}{l}\text { Hazard } \\ \text { Rate }(\mathrm{P})\end{array} & \begin{array}{l}\text { Hazard } \\ \text { Ratio(L vs P)* }\end{array} \\ 12 & 2425 / 2409 & 0.00093 & 0.00180 & 0.52(0.40-0.64) \\ 24 & 1555 / 1530 & 0.00105 & 0.00236 & 0.45(0.33-0.56) \\ 36 & 768 / 723 & 0.00090 & 0.00261 & 0.35(0.21-0.48) \\ 48 & 244 / 231 & 0.00059 & 0.00306 & 0.19(0.04,0.34)\end{array}$

Hazard ratios less than one indicate values in favor of letrozole $\quad 0.19(0.04,0.34)$

Results: For placebo patients, there was an increasing risk of disease recurrence over time after discontinuing prior tamoxifen. For letrozole patients, the risk of recurrence appeared to peak at around two years of treatment and decrease thereafter. The hazard ratio (letrozole/placebo) for recurrence showed a statistically significant $(\mathrm{p}=0.02)$ trend to a decrease over time indicating a greater benefit of letrozole over time.

Conclusions: This analysis of the hazard ratios for disease recurrence over time between the letrozole and placebo arms of MA.17 indicates that, at least out to 4 years, the longer patients are exposed to letrozole, the greater the benefit. The increasing $\mathrm{HR}$ in the placebo group is of note and emphasizes the residual risk of recurrence that exists in women completing 5 years of tamoxifen To further address the issue of duration of letrozole therapy, a rerandomization of all participants completing letrozole on MA.17 to a further 5 years of treatment is underway.

\section{8}

Switching from adjuvant tamoxifen to anastrozole in postmenopausal women with hormone-responsive early breast cancer: a meta-analysis of the ARNO 95 Trial, ABCSG Trial 8, and the ITA Trial.

Jonat W, Gnant M, Boccardo F, Kaufmann M, Rubagotti A, Jakesz R. University of Frankfurt, Germany; Vienna Medical School, Austria; National Cancer Research Institute \& University of Genoa, Italy

Background: The results of the combined analysis of ABCSG Trial 8 and the ARNO 95 trial have shown that switching postmenopausal patients with hormone-sensitive early breast cancer from tamoxifen to anastrozole after 2 years' adjuvant therapy results in a significant improvement in event-free survival compared with continuing therapy with tamoxifen. Results from the original and recently updated analyses of the ITA trial, in node-positive women only, also demonstrated the significant clinical benefits of switching to anastrozole after 2-3 years of adjuvant tamoxifen. We intend to report a meta-analysis of the latest data from these three trials. The purpose of the metaanalysis is to investigate whether the benefits in event-free survival seen in the individual trials translate into benefits in long-term outcomes, including improved overall survival, and thereby gain further insight into the value of the switching approach.

Methods: ABCSG Trial 8, the ARNO 95 trial and the ITA trial all investigate whether switching postmenopausal women with hormone-sensitive early breast cancer to anastrozole after 2-3 years of tamoxifen treatment is more effective than continuing on tamoxifen. The designs of the three trials are broadly similar, allowing a meta-analysis of the trials to be performed.For each therapy arm, the distribution of the event-free survival and overall survival times will be estimated using the Kaplan-Meier method, and Kaplan-Meier curves will be prepared.

Results: Over 3500 eligible patients across the three trials will be included in the meta-analysis, 2262 from ABCSG Trial 8, 962 from ARNO 95 and 448 from ITA. The data for the efficacy endpoints will be presented, with a focus on the long-term endpoints, particularly overall survival.

Conclusions: We expect the results of the meta-analysis to demonstrate that the benefits in event-free survival seen in the switching arms of the individual trials translate into overall benefits in long-term endpoints, and thereby confirm that postmenopausal women currently receiving adjuvant tamoxifen should be switched to anastrozole upon completion of 2-3 years' treatment.

\section{9}

The influence of hormone replacement therapy (HRT) on tamoxifen induced vasomotor symptoms.

Sestak I, Kealy R, Edwards R, Cuzick J. Centre for Epidemiology, Mathematics \& Statistics, London, United Kingdom

Background: Tamoxifen is an effective drug, both for preventing and treating breast cancer, but its role in prevention is limited by its side effect profile, particularly related to endometrial problems and thrombotic events. Non-life threatening side effects such as vasomotor symptoms also have an important influence in its use for prevention. In the IBIS-I study, 7,154 women at increased risk of breast cancer were either randomised to tamoxifen $20 \mathrm{mg} /$ day or placebo for 5 years.

Methods: Women in the IBIS-I study gave detailed information of any vasomotor symptoms at each 6 monthly follow-up visit. 


\section{S12 Abstracts - General Sessions}

Vasomotor symptoms were evaluated according to follow-up time, severity and use of hormone replacement therapy.

Results: After a median follow-up of 84 months, 2,537 (70.9\%) women in the tamoxifen group and $2,041(57.1 \%)$ in the placebo group reported hot flushes of any severity $(\mathrm{OR}=1.80,95 \% \mathrm{CI}$ 1.63-1.99). The majority of newly developed hot flushes were reported in the first two follow-up months, indicating that vasomotor symptoms are early side effects of tamoxifen. Women in both treatment arms reported mainly mild to moderate hot flushes, whereas the rate of severe hot flushes was smaller, but more related to tamoxifen usage $(12.2 \%$ vs. $6.6 \%, \mathrm{OR}=1.97,95 \%$ CI 1.66-2.33). The risk of having hot flushes was lower in women over $55(\mathrm{OR}=0.62,95 \% \mathrm{CI} 0.41-0.94)$ and in women with a greater time of menopause $(\mathrm{OR}=0.52,95 \%$ CI $0.31-0.88)$. For women on tamoxifen, the risk of having hot flushes was associated with the use of HRT at entry $(75.4 \%$ baseline HRT vs. $68.7 \%$ never HRT, OR=1.39, 95\% CI 1.16-1.66). Baseline HRT use did not have a significant effect on the occurrence of hot flushes within the first 6 follow-up months for tamoxifen patients $(60.8 \%$ HRT vs. $49.2 \%$ no HRT, $\mathrm{p}=0.1$, table 1$)$ whereas for placebo patients a difference was seen $(22.9 \%$ HRT vs. $34.3 \%$ no HRT, $\mathrm{p}=0.03$ ). For those who were still reporting hot flushes on tamoxifen at month 12, use of HRT didn't show an effect in reducing their incidence, whereas in the placebo group HRT use did lead to significantly fewer hot flushes $(20.4 \%$ HRT vs. $39.0 \%$ no HRT, $\mathrm{p}=0.0003$ ).

Conclusions: Overall, HRT use at entry and HRT use during the trial only prevented women in the placebo group from developing hot flushes. Commencing the use of HRT to reduce vasomotor symptoms did not lead to a reduction in hot flushes for women taking tamoxifen. Other ways need to be found to reduce tamoxifen induced vasomotor symptoms.

Hot flushes (\%) of any severity according to HRT use and treatment in women who are taking HRT entry

\begin{tabular}{lllllll} 
& \multicolumn{3}{c}{ HRT use during period } & & \multicolumn{3}{c}{ No HRT use during period } \\
Time period & Placebo & Tamoxifen & P-value & Placebo & Tamoxifen & P-value \\
0-6 months & 22.9 & 60.8 & $<0.0001$ & 34.3 & 49.2 & 0.09 \\
6-12 months & 20.4 & 47.9 & $<0.0001$ & 39.0 & 51.4 & 0.59
\end{tabular}

\section{0}

Continued technical results of NSABP B-32: Does a positive sentinel node biopsy require an axillary dissection?

Julian TB, Anderson S, Brown A, Krag D, Harlow S, Bear H, Ashikaga T, Weaver D, Miller B, Jalovec L, Frazier T, Noyes RD, Robidoux A, Scarth H, Mammolito D, McCready D, Mamounas $E$, Costantino $J$, Wolmark N. NSABP Investigators \& NSABP Operations \& Biostatistical Center, Pittsburgh, PA; University of Vermont, Burlington, VT

Background: The standard approach following a positive sentinel node (SN) biopsy is to perform an axillary dissection (AD). However a majority of clinically node negative patients are at low risk for positive non-sentinel axillary nodes. Factors affecting the need for an axillary dissection following a positive SN biopsy are evaluated in NSABP B-32.

Materials and Methods: After stratification, women with operable invasive breast cancer and clinically negative nodes were randomized to Sentinel Node Resection (SNR) with immediate conventional Axillary Disection (AD) [Group 1] or to SNR without AD [Group 2]. Group 2 patients with positive SNs underwent AD. A multivariate analysis of SN positive patients for whom both a $\mathrm{SNR}$ and an $\mathrm{AD}$ had been performed was used to assess the need for axillary dissection following sentinel node biopsy. Their nodes were classified as either SNs or non-sentinel nodes (NSNs), defined as all axillary dissection nodes plus any intramammary or other nodes that were not resected as SNs.

Results: Between May 1999 and February 2004, 5,611 patients were entered into NSABP Protocol B-32. 2,807 were assigned to Group 1 and 2,804 were assigned to Group 2. There was a combined total of 1,361 SN positive patients with AD from Group 1 and 2 . Data from 1,355 patients were available for multivariate analysis.
The percentage of patients with at least one positive NSN was found to be significantly higher in Group 2 than Group 1 (41.9\% vs. $35.5 \%$, respectively, $\mathrm{p}=0.0081$ ). The percentage of patients with at least one positive NSN was significantly increased with an increase in clinical tumor size $(p=0.0004)$, with an increase in the number of positive SNs $(\mathrm{p}<0.001)$, and with an increase in the number of total NSNs removed $(\mathrm{p}<0.0001)$. The percentage of patients with at least one positive NSN significantly decreased when the tumor was not in the upper outer quadrant $(\mathrm{p}=0.02)$, as the number of hot spots identified increased $(\mathrm{p}=0.0024)$, and as the number of SNs removed increased $(\mathrm{p}<0.0001)$. Age at study entry, type of biopsy performed, histologic grade and ER and PR status were not significant multivariate predictors of patients with positive NSNs.

A predictive model for the probability of having at least one positive NSN following positive SN biopsy will be presented. Discussion: These results support the need for an axillary dissection in most patients following the identification of positive sentinel nodes to assess staging and prognosis and aid in treatment planning.

\section{1}

Significance of sentinel lymph node micrometastasis on survival for patients with invasive breast cancer.

Cox $C$, Vrcel V, Riker A, White L, Allred $N$, Ramos D, Myers $M$, Dupont E, King J, Cantor A, Diaz N. H. Lee Moffitt Cancer Center, Tampa, FL

OBJECTIVE: The overall objective of this study was to test the impact of micrometastatic carcinoma detected by sentinel lymph node (SLN) biopsy on survival in invasive breast cancer patients. To do so, we compared survival outcomes in such patients with a negative SLN biopsy and the outcomes of those with micrometastatic disease in a SLN.

METHODS: The charts of 2145 invasive breast cancer patients with pathology reports of SLN with either micrometastatic or no metastatic disease were reviewed. The SLN H\&E and immunostained (cytokeratin) slides of patients with the diagnosis of micrometastatic carcinoma were analyzed and reclassified according to the $6^{\text {th }}$ edition of the AJCC Cancer Staging Manual. Tumor deposits $>0.2 \mathrm{~mm}$ but not $>2 \mathrm{~mm}$ were classified as N1mi. Patients with SLNs with isolated tumor cells not $>0.2 \mathrm{~mm}$ were classified as NO(i+). SLNs with no epithelial cells on either H\&E or immunostaining were classified as NO(i-). Kaplan Meier graphs of overall survival (OS) and disease free survival (DFS) were done. RESULTS: Of the 2145 patients reviewed, 1854 (87\%) were N0(i-), 291(13\%) of our patients had single cells and/or small cell clusters or micrometastatic disease. $138(6 \%)$ were reclassified as $\mathrm{N} 1 \mathrm{mi}$ and $153(7 \%)$ as NO(i+). OS and DFS of the patients with N1mi SLN differed significantly from patients with NO(i-) SLN $(\mathrm{p}=0.005$ and 0.016 respectively; Figures 1 and 2)

CONCLUSIONS: The detection of micrometastatic carcinoma in the SLNs of invasive breast cancer patients, as presently defined by the AJCC, is a significant indicator of survival. Subset analysis of NO(i+) patients will be presented. Results of the ACOSOG Z0010 trial may validate the latter results and clarify the clinical significance of $\mathrm{NO}(\mathrm{i}+)$ detected by SLN biopsy. 

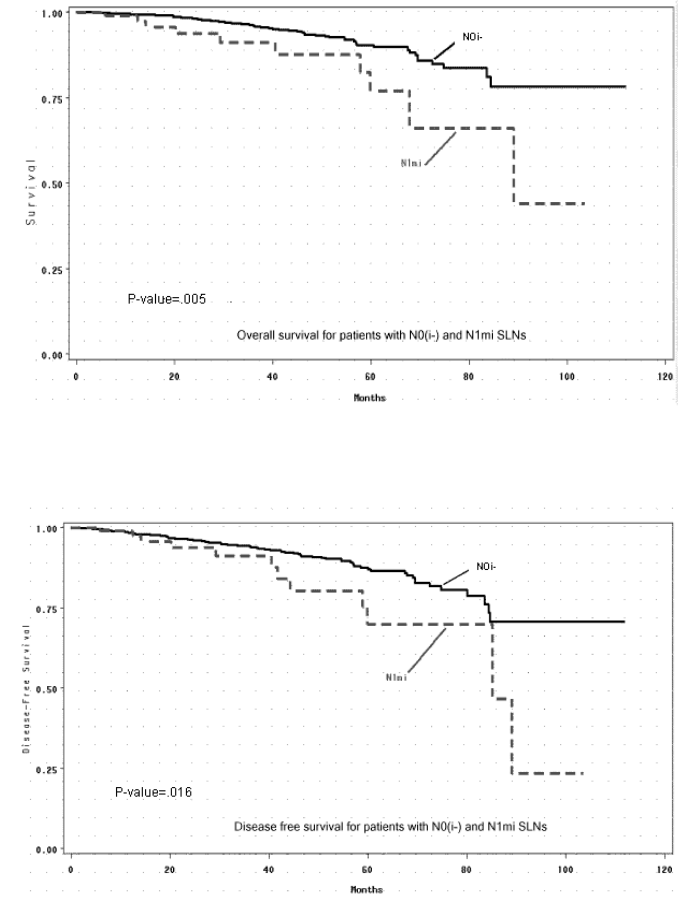

\section{2}

Prospective study of axillary radiation without axillary dissection for breast cancer patients with a positive sentinel node.

Gadd M, Harris J, Taghian A, Hughes K, O'Neill A, Powell S, Christian R, Lesnikoski B, Kaelin C, Rhei E, Iglehart J, Habin K, Oberg J, Younger J, Winer E, Smith B. Massachusetts General Hospital, Boston, MA; Brigham and Women's Hospital, Boston, MA; Dana-Farber Cancer Institute, Boston, MA

Background: Sentinel node biopsy (SNB) provides reliable pathologic staging of the axilla. A negative SNB now requires no further axillary treatment, but completion dissection is standard for SNB+ patients. Approximately $50 \%$ of patients will have no additional positive nodes at axillary dissection, but will have a 15$25 \%$ risk of lymphedema or chronic pain as a result of more extensive axillary surgery. Earlier series of clinically node negative breast cancer patients have shown axillary radiation (RT) as effective as dissection in preventing recurrence, but with lower rates of lymphedema and other complications. As systemic therapy decisions are now less dependant on the number of positive axillary nodes, we proposed axillary RT instead of dissection in SNB+ patients as an approach to lower morbidity but maintain good local control.

Materials and Methods: 560 clinical T1-2, N0 patients, planned for breast-conservation prospectively underwent SNB from 1/00$2 / 04$. They received axillary RT without dissection if SNB+. RT was delivered as a $3^{\text {rd }}$ field ( $49 \mathrm{~Gy}$ in 27 fractions). SNB+ was defined as any metastatic deposit by H\& E. At 6 month intervals, arm circumference and grip strength were measured, and quality of life questionnaires were completed.

Results: 73 patients underwent breast conservation and received axillary RT with median follow-up of 32 months. All patients received systemic therapy. One axillary recurrence (1/73) was noted 17 months after RT and the patient remains NED 2.5 years after salvage dissection. One patient reported transient arm edema at 6 months but remains free of arm edema at 4 years. Additional benefits included minimal arm pain or numbness, better range of motion, and less time out of work.

Conclusion: Early follow-up demonstrates extremely low rates of arm symptoms after SNB plus axillary RT and a low rate of early axillary failure. These early data support further study of axillary RT instead of dissection in SNB+ breast cancer patients.

\section{3}

The incidence of venous thromboembolism in breast cancer patients.

Chew HK, Wun T, Harvey D, Zhou H, White RH. University of California Davis, Sacramento, CA; University of California Davis, Davis, $C A$

Background: Among patients with newly diagnosed breast cancer, the incidence of venous thromboembolism (VTE) and risk factors associated with VTE have not been described in detail.

Objectives: To determine the incidence of VTE, risk factors associated with VTE and the effect of VTE on death among breast cancer patients.

Methods: The California Cancer Registry was merged with the California Patient Discharge Data Set, and the number of VTE events determined among cases diagnosed between 1993-95 and 1997-1999 with at least 2 years follow up.

Results: Among 108,255 cases (99\% women, mean age $62 \pm 16$ years), $61 \%(66,475)$ were diagnosed with localized disease, $31 \%$ $(32,990)$ with regional disease, $4 \%$ (4499) with metastatic disease, and $4 \%$ (4291) with unknown stage. Histological subtypes included adenocarcinoma $(82 \%)$, lobular $(8 \%)$, carcinoma not otherwise specified $(4 \%)$, mucinous $(3 \%)$, tubular $(1.5 \%)$, medullary $(1 \%)$, and papillary $(<1 \%)$. The cumulative incidence of VTE was 975 cases $(0.9 \%)$ after 1 year, and 1,306 cases $(1.2 \%)$ after 2 years. Expressed as events $/ 100$ patient-years, the incidence rate was 0.9 and 0.7 during year- 1 and year-2, respectively. The cumulative incidence of upper extremity VTE was $<0.5 \%$ at 3,6 , and 12 months after breast cancer diagnosis. In a multivariate model, significant predictors of VTE in year 1 were: Asian race $(\mathrm{HR}=0.3$, CI:0.2-0.5), advancing age (HR $=1.9$ if $>75$ years versus $<45$ years, CI; 1.9-4.8), stage (HR $=2.2, \mathrm{CI}: 1.9-2.5$ for regional and $\mathrm{HR}=6.5$, CI:5.3-7.9 for metastatic, versus localized disease), and breast-related surgery within 61 days of diagnosis $(\mathrm{HR}=0.6, \mathrm{CI}$ : 0.5-0.7). Histological subtype was not a significant predictor of VTE. In risk-adjusted Cox models stratified by SEER stage, VTE was a strong predictor for death within 1 year for all stages: HR = 6.0 (CI:3.4-10) for localized, HR = 2.1 (CI:1.3-3.9) for regional, and $\mathrm{HR}=1.5$ (CI:1.3-1.8) for metastatic disease.

Discussion: In this large population-based study, approximately $1 \%$ of patients with breast cancer developed VTE within 1 year. Metastatic disease was the strongest predictor of VTE. Interestingly, cases undergoing breast cancer-related surgery had a significantly lower risk of VTE. For all cancer stages, diagnosis of VTE was associated with a higher risk of death within 1 year.

\section{4}

Central review of ER, PgR and HER-2 in BIG 1-98 evaluating letrozole vs. tamoxifen as adjuvant endocrine therapy for postmenopausal women with receptor-positive breast cancer.

Viale G, Regan M, Dell'Orto P, Del Curto B, Braye S, Orosz Z, Brown R, Olszewski WP, Knox F, Oehlschlegel C, Thürlimann $B$. The BIG 1-98 Collaborative International Breast Cancer Study Group, Bern, Switzerland

Background: The BIG 1-98 trial, a large international Phase III study, evaluated letrozole $(n=4003)$ vs. tamoxifen $(n=4007)$ as initial adjuvant endocrine therapy for postmenopausal women with receptor-positive breast cancer. Results of the primary core analysis were presented in St. Gallen and ASCO in 2005 and showed that letrozole significantly improved DFS as compared with tamoxifen (HR=0.81, 95\% CI 0.71-0.93). In subgroup analysis of 


\section{S14 Abstracts - General Sessions}

the BIG 1-98 trial according to locally-assessed progesteronereceptor $(\mathrm{PgR})$ status, the magnitude of benefit of letrozole vs. tamoxifen on disease-free survival (DFS) did not vary. This contrasts to the ATAC trial where the magnitude of the effect of anastrozole vs. tamoxifen was greater in estrogen-receptorpositive/progesterone-receptor-negative (ER+/PgR-) tumors than in $\mathrm{ER}+/ \mathrm{PgR}+$ tumors. A central review of tumor tissue is being performed for BIG 1-98.

Methods: As of May 2005, over 3000 tumor blocks have been collected for the 8010 patients in this analysis. The IBCSG Central Pathology Laboratory is evaluating the tumors for ER and PgR content by immunohistochemistry (IHC), and for HER-2 immunoreactivity by IHC and by FISH for IHC $1+$ or $2+$ tumors. Results: In the original study, local assessment showed that $97.9 \%$ of the 8010 patients had ER+ tumors, and $63.1 \%, 20.4 \%, 14.4 \%$, and $1.8 \%$ were classified ER+/PgR+, ER+/PgR-, ER+/PgR? (PgR? $=\mathrm{PgR}$ unknown), and ER-/PgR+ respectively. DFS was improved with letrozole among $\mathrm{ER}+/ \mathrm{PgR}+(\mathrm{HR}=0.84,95 \% \mathrm{CI} 0.69-1.03)$, among $\mathrm{ER}+/ \mathrm{PgR}-(\mathrm{HR}=0.83,95 \% \mathrm{CI} 0.62-1.10)$ and among $\mathrm{ER}+/$ PgR? (HR=0.72, 95\% CI 0.53-0.98) cohorts. DFS will be reanalyzed according to centrally-assessed ER and PgR status, and explored according to quantitative values of receptor levels (\% staining cells) using subpopulation treatment effect pattern plot (STEPP) methodology. The role of HER-2 overexpression will also be evaluated.

Discussion: The availability of centrally-assessed ER, PgR and HER-2 by IHC in this large population of postmenopausal women with ER+ breast cancer will provide a reliable evaluation of the role of PgR and HER-2 as predictive factors of response to letrozole vs. tamoxifen as initial adjuvant endocrine therapy.

\section{4}

Genetic alterations associated with early hyperplastic precursors of breast cancer.

Lee S, Tsimelzon A, Wu Y, Mao S, Mohsin SK, Medina D, Allred DC. Baylor College of Medicine/The Methodist Hospital, Houston, TX; Baylor College of Medicine, Houston, TX

Background/Purpose: Enlargement of normal terminal duct lobular units (TDLUs) by hyperplastic columnar epithelial cells is a very common alteration in the adult female human breast. These hyperplastic enlarged lobular units (HELUs), known by many synonyms (e.g. columnar alteration of lobules), may further progress into several types of benign and premalignant lesions, including atypical ductal hyperplasia. In this sense, HELUs can be viewed as the earliest histologically identifiable potential precursor of breast cancer and the biological alterations responsible for their development are reasonable targets for efficient prevention therapy. The purpose of this study was to evaluate and compare gene expression profiles between TDLUs and HELUs to gain insight into the causes of very early multi-potential hyperplasia. Design/Methods: RNA was extracted (Ambion Optimum) from epithelial cells harvested by laser-capture microdissection from histological slides containing matched pairs of adjacent TDLUs and HELUs prepared from 7 formalin-fixed paraffin-embedded clinical samples of breast tissue ( $n=14$ total samples). The RNA was amplified two rounds (Arcturus Paradise) and evaluated for the expression of essentially the entire human genome (Affymetrix U133-Human X3P microarrays). Results were evaluated with dChip, BRB-ArrayTools, and Array Analyzer software. Results: In preliminary supervised comparisons, 218 genes showed $>3$-fold differences in expression in HELUs compared to TDLUs (range 3 -to- 21 fold; average 4.6 fold; $\mathrm{p}<.01$ ), including prominent relative increases in AREG, EREG, ESR1, PTHLH, RBP1, and IGF1R, and prominent relative decreases in EGF, EGFR, PDGFC, and IGF1. Other preliminary analyses showed highly significant $(p<.005)$ differential activation of at least 16 intersecting biological pathways, including signal transduction through EGFR and HER2, anti-apoptosis through IGF-1R signaling, cell migration/adhesion through thrombin and PI3K activation, and increased MTA3 signaling through ER. Plans are to extend the study to 10 matched pairs of TDLUs and HELUs and to validate some of the most interesting genes by qRT-PCR and immunohistochemistry in the arrayed samples as well as in a larger set of independent samples. Conclusions: HELUs are a very common alteration of normal TDLUs and the earliest histologically identifiable potential precursor of breast cancer. They show highly significant differences in the expression of many genes which may be involved in their development, especially involving the HER family of surface membrane receptors and their ligands and, thus, may be amenable to prevention strategies targeting these and other molecules.

\section{5}

Ductal carcinoma in situ (DCIS) mammosphere formation; effect of epidermal growth factor (EGF) and notch signalling pathways on self renewal capacity.

Farnie G, Brennan K, Clarke RB, Bundred NJ. University of Manchester; University Hospital of South Manchester

The cancer stem cell hypothesis suggests that targeting stem cells in cancer will improve current therapeutic strategies. In vitro culture of mammospheres (MS), analogous to neurospheres which enrich for brain stem cells, has been used to study the factors that affect stem cell self-renewal in DCIS. Patients $(n=19)$ undergoing mastectomy for DCIS provided written informed consent to sample DCIS tissue.

Single cell suspensions of enzymatically digested DCIS samples were seeded at 10,000 cells/ml either in non-adherent plates or matrigel. DCIS MS formation was assessed by counting the number of mammospheres formed $(>60 \mathrm{~mm})$ after 3 days in non-adherent suspension culture $(n=15)$.

DCIS MS in non-adherent suspension culture contained both myo (cytokeratin 14) and luminal (cytokeratin 18) epithelial cells, expressed ErbB2 (similar to the original DCIS) and Ki67, a proliferation marker. Dissociated DCIS MS recapitulated DCIS in matrigel forming solid ductal structures expressing both luminal and myo-epithelial cells. High Grade $(85 \%$ estrogen receptor positive, $100 \%$ erbB2 positive) MS forming ability was significantly greater than low grade $(100 \%$ estrogen receptor positive, $60 \%$ erbB2 positive) MS ( $\mathrm{p}=0.02$ ). Low grade MS formation significantly increased after addition of EGF $(\mathrm{p}=0.002)$ and although both low and high grade DCIS MS formation were decreased after gefitinib in the presence of EGF $(\mathrm{p}<0.01)$, only high grade MS formation decreased in the presence of gefitinib when no EGF was present in the media $(p=0.001$, see table). Therefore suggesting that high grade DCIS MS have an autocrine feed back loop which is signalling via the EGF receptor.

DCIS $-\mathrm{EGF}-\mathrm{EGF}+$ +EGF + EGF +

$\begin{array}{llll} & & \text { gefitinib } 1 \mu \mathrm{M} & \text { gefitinib } 1 \mu \mathrm{M}\end{array}$ $\begin{array}{lllll}\text { Low Grade }(\mathrm{n}=5) & 0.9 \pm 0.05 \% \%^{\mathrm{a}, \mathrm{c}} & 0.83 \pm 0.04 \% & 1.28 \pm 0.12 \% \mathrm{~b}, \mathrm{c} & 0.86 \pm 0.09 \% \\ \text { High } & \end{array}$ $\begin{array}{lllll}\text { High Grade }(\mathrm{n}=7) & 1.39 \pm 0.15 \%^{\mathrm{a}, \mathrm{e}} & 0.27 \pm 0.12 \%^{\mathrm{e}} & 1.88 \pm 0.19 \% & 0.9 \pm 0.11 \% \\ \text { Table showing percentage DCIS MS formation }(\mathrm{a}, \mathrm{b} \& \mathrm{~d} \mathrm{p} \leq 0.02, \mathrm{c} \& \text { e } \mathrm{p} \leq 0.002)\end{array}$

Activated Notch Intra-Cellular Domain (NICD) was increased in 11 DCIS samples (but not normal breast) when measured by Western blotting, DCIS MS also expressed NICD and BMI-1 (a downstream target of Notch). Notch inhibition using both $\gamma$-secretase inhibitor $(10 \mu \mathrm{M})$ and a Notch 4 receptor blocking antibody reduced DCIS MS formation $(0.18 \pm 0.02, \mathrm{p}<0.0005)$.

These data indicate that the Notch and EGFR signalling pathways are critical to DCIS mammosphere growth. Combinations of inhibitors of these pathways are likely to have therapeutic value in DCIS as adjuvant therapy.

Funded by the Breast Cancer Campaign, grant number 2001:201.

\section{6}

Cell of origin determines histological type, tumorigenicity and metastatic behavior of breast tumors.

Ince TA, Weinberg RA. Whitehead Institute for Biomedical Research; Harvard Medical School; Brigham \& Women's Hospital, Boston, MA

Background: The multi-step genetic progression model of cancer postulates that mutations that accumulate in a tumor account for 
its biology. This "mutation-centric" view does not fully take into account the contribution of traits tumors inherit from their "cell of origin" (normal cells without any genetic alterations). We investigated the contribution of cell-of-origin to tumor phenotype by comparing tumors derived from tow different normal human breast epithelial cell populations.

Materials and Methods: Breast epithelial cells were grown in two different media; the conventional medium MEGM, and a novel defined medium (WIT) that we have developed. MEGM and WIT select for and maintain mutually exclusive populations of primary breast epithelial cell types that were transformed in parallel by introduction of hTERT, SV40 ER and H-Ras in retroviral expression vectors.

Results: the tumorigenic derivatives of the two different breast epithelial cells (HMLER and BPLER) were injected into mice for comparison of tumor type and behavior. While HMLER cells formed keratinizing squamous cell carcinomas, BPLER cells formed adenocarcinomas. Suprisingly, there was orders of magnitude difference in tumorigenicity e.g.; while injection of only 102 BPLER cells was adequate for tumor formation, HMLER cells required injection of at least 106 cells. Moreover, HMLER tumors were non-metastatic; in contrast, $80 \%$ of BPLER tumors metastasized to lungs.

Discussion: Since HMLER and BPLER tumors are identical with respect to the genes driving the neoplastic process, we conclude that the observed differences in tumor morphology, tumorigenicity and metastatic behavior must arise from differences that were inherent to the normal cells-of-origin of these tumors. If further experiments confirm these results it would dramatically alter our view of tumor progression and establish tumor cell-of-origin as a central prognostic and therapeutic factor in management of cancer.

\section{7}

Magnitude and laterality of breast cancer risk according to histologic type of atypical hyperplasia: results from the Nurses' Health study.

Collins LC, Baer HJ, Tamimi RM, Connolly JL, Colditz GA, Schnitt SJ. Beth Israel Deaconess Medical Center and Harvard Medical School; Brigham and Women's Hospital; Harvard School of Public Health; Harvard Center for Cancer Prevention, Boston, MA

Background: Prior clinical and epidemiologic studies have demonstrated that women with a benign breast biopsy showing atypical hyperplasia $(\mathrm{AH})$ are at increased risk for the development of breast cancer. However, the details of the relationship between histologic type of $\mathrm{AH}$ (i.e., atypical ductal hyperplasia [ADH] vs atypical lobular hyperplasia [ALH]) and the magnitude and laterality of breast cancer risk are less well-defined.

Methods: We conducted a case-control study of benign breast disease (BBD) and breast cancer risk nested within the Nurses Health Study. Cases were women with biopsy-confirmed BBD who subsequently developed breast cancer. Controls were women with biopsy-confirmed BBD who were free from breast cancer; they were matched to cases on year of birth and year of benign biopsy. Slides from 1848 breast biopsies originally diagnosed as benign (353 cases; 1495 controls) were reviewed and categorized as showing either non-proliferative lesions, proliferative lesions without atypia, or $\mathrm{AH}$. Those showing $\mathrm{AH}$ were further categorized as $\mathrm{ADH}$ or ALH using the criteria of Page, et al. Unconditional logistic regression models were used to estimate odds ratios (ORs) and $95 \%$ confidence intervals (CIs) for breast cancer risk according to histologic subtype of BBD.

Results: Compared with women with non-proliferative lesions, the OR for breast cancer among all women with $\mathrm{AH}$ was 4.30 (95\% CI, 2.96-6.23). However, the magnitude of the breast cancer risk differed according to histologic type of $\mathrm{AH}$. The OR for the subsequent development of breast cancer among women with ALH (33 cases; 38 controls) was 6.03 (95\% CI 3.50-10.41) whereas the OR for those with ADH (42 cases; 99 controls) was 3.24 (95\% CI 2.07-5.08), and this difference approached statistical significance $(p=0.08)$. Among the small subset of women whose benign biopsies showed both ADH and ALH, the OR for breast cancer was 6.96 (95\% CI 2.98-16.27). Overall, 60.6\% of the breast cancers that developed in women with $\mathrm{AH}$ were in the ipsilateral breast. While the risk of ipsilateral breast cancer was higher among women with ALH than those with ADH $(64.3 \%$ vs $53.1 \%)$, this difference was not statistically significant $(\mathrm{p}=0.38)$.

Conclusions: All women with $\mathrm{AH}$ in a benign breast biopsy are at a substantially increased risk for the development of breast cancer, but the risk appears to be greater among those with ALH than among those with ADH. Although the risk of cancer in the ipsilateral breast was slightly higher among women with ALH than $\mathrm{ADH}$, this difference was not significant. Therefore, for the purposes of clinical managment both ALH and ADH are best regarded as markers of a generalized (bilateral) increase in breast cancer risk.

\section{8}

Multi-center validation of the 76-gene prognostic signature in lymph node negative (LNN) primary breast cancer.

Foekens JA, Atkins D, Sweep CGJ, Harbeck N, Paradiso A, Cufer $T$, Eppenberger $S$, Daxenbichler $G$, Kotzsch M, Sieuwerts AM, Talantov D, Timmermans M, Span PN, Tjan-Heijnen VCG, Specht $K$, Mangia A, Wight E, Angerer J, Zito AF, Hoefler H, Berns EMJ, Golouh R, Barreton G, Schittulli F, Schmitt M, Beex LVA, Klijn JGM, Wang Y. Erasmus MC, Rotterdam, Netherlands; Veridex LLC, a Johnson \& Johnson Company, San Diego, CA; Radboud University Nijmegen Medical Centre, Nijmegen, Netherlands; Frauenklinik und Institut für Allgemeine Pathologie und Pathologische Anatomie, Technische Universität, München, Germany; National Cancer Institut, Bari, Italy; Institute of Oncology, Ljubljana, Slovenia; Universitätshospital Basel, Basel, Switzerland; Medical University, Innsbruck, Austria; Institut für Pathologie, Technische Universität, Dresden, Germany

Background: In our earlier genome-wide measurements of gene expression we have identified by a single-center study a 76-gene signature that sub-classifies tumors and may provide better means of risk assessment on an individual basis for lymph node-negative (LNN) breast cancer patients (The Lancet 365:671-679, 2005). The aim of the present study was to validate this gene signature in independent and more diverse populations of LNN patients obtained from multiple institutions.

Material and Methods: Using custom-designed Affymetrix VDX2 GeneChips we analyzed the expression of the previously identified 76 genes by assessment of total RNA of frozen tumour tissue specimens obtained from 180 LNN patients who had not received any adjuvant systemic treatment and from $55 \mathrm{ER}+$, LNN patients who had received tamoxifen. As clinical endpoints for prognostic value, distant metastasis-free survival (DMFS) was used. Results: In both of these completely independent validation sets, the 76-gene signature proved to be highly informative in identifying patients who eventually will develop distant metastasis within 5 years. In the 180 untreated patients from 4 institutions, the 76-gene signature gave a hazard ratio of 7.41 [95\% CI 2.63$20 \cdot 9$ ], even when corrected for traditional prognostic factors in multivariate analysis $(11.36[2.67-48 \cdot 4])$. The sensitivity for DMFS was $90 \%$ and the specificity $50 \%$. In the $55 \mathrm{ER}+$, tamoxifentreated patients from 7 institutions, a subset of a larger ongoing study, the 76-gene signature gave a hazard ratio of 6.15 [95\% CI 0.78-48.7], when corrected for traditional prognostic factors in multivariate analysis $(6 \cdot 31[0 \cdot 77-51 \cdot 7])$. The sensitivity for DMFS was $86 \%$ and the specificity $40 \%$.

Discussion: Our data provide a strong methodological and clinical multi-center validation of the pre-defined prognostic 76-gene signature in both untreated and tamoxifen-treated LNN breast cancer patients with similar prognostic power as in our original single-center study. 
29

Association between the 21-gene recurrence score assay (RS) and risk of locoregional failure in node-negative, ER-positive breast cancer: results from NSABP B-14 and NSABP B-20.

Mamounas E, Tang G, Bryant J, Paik S, Shak S, Costantino J, Watson D, Wickerham DL, Wolmark N. NSABP, Pittsburgh, PA; Aultman Health Foundation, Canton, OH; Genomic Health, Inc., Redwood City, CA; Allegheny General Hospital, Pittsburgh, PA

Background: RS has been validated to quantify risk of distant recurrence in tamoxifen-treated patients with $\mathrm{N}-$, ER+ breast cancer. In this report we investigate the association between RS and risk for loco-regional recurrence in N-, ER+ breast cancer patients treated in two NSABP protocols (NSABP B-14 and NSABP B-20).

Subjects and Methods: Details on patient eligibility, methods of RNA extraction, the RT-PCR methodology used and the genes included in the RS have been previously published in detail (Paik, NEJM 2004). The primary endpoint for this analysis was time to first local or regional recurrence (LRR). Occurrence of distant metastasis, 2nd primary cancer and death before LRR were censored in the analysis. For the correlation between RS and LRR in tamoxifen-treated patients, such patients from B-14 and B-20 were combined in one group. The correlation between RS and LRR was also evaluated in the placebo-treated patients from NSABP B14 and in the tamoxifen plus chemotherapy treated patients from NSABP B-20.

Results: The present analyses include a total of 895 tamoxifentreated patients (668 from B-14 and 227 from B-20), 355 placebotreated patients (from B-14) and 424 chemotherapy and tamoxifen-treated patients (from B-20). LRR in tamoxifen-treated patients was significantly associated with RS (see Table, $\mathrm{p}<0.00001$ ). There were also similar associations in placebo-treated patients from B-14 $(\mathrm{p}=0.022)$ and in tamoxifen plus chemotherapy-treated patients from $B-20(p=0.028)$.

\begin{tabular}{|c|c|c|c|c|c|}
\hline Treatment & RS Group & $\begin{array}{l}\text { 10-year Event Rate } \\
\text { (KM) }\end{array}$ & $95 \% \mathrm{Cl}$ & $\begin{array}{c}\text { Log-Rank } \\
\text { P-value }\end{array}$ & EventTotal \\
\hline \multirow[t]{3}{*}{ Placebo } & Low Risk & $10.8 \%$ & $\begin{array}{l}(5.8 \%, 15.8 \% \\
\end{array}$ & 0.022 & \multirow{2}{*}{$\begin{array}{l}19 / 171 \\
15 / 85\end{array}$} \\
\hline & $\begin{array}{l}\text { Intermediate } \\
\text { Risk }\end{array}$ & $20.0 \%$ & $(9.9 \%, 30.0 \%)$ & & \\
\hline & High Risk & $18.4 \%$ & $(9.5 \%, 27.4 \%)$ & & $19 / 99$ \\
\hline \multirow[t]{3}{*}{ Tamoxifen } & Low Risk & $4.3 \%$ & $(2.3 \% \%, 6.3 \%)$ & $<0.00001$ & \multirow{2}{*}{$\begin{array}{l}24 / 473 \\
16 / 194\end{array}$} \\
\hline & $\begin{array}{c}\text { Intermediate } \\
\text { Risk }\end{array}$ & $7.2 \%$ & $(3.4 \%, 11.0 \%)$ & & \\
\hline & High Risk & $15.8 \%$ & $(10.4 \%, 21.2 \%)$ & & $33 / 228$ \\
\hline \multirow[t]{3}{*}{ Chemo+TAM } & Low Risk & $1.6 \%$ & $(0 \%, 3.5 \%)$ & 0.028 & \multirow{2}{*}{$4 / 218$} \\
\hline & $\begin{array}{l}\text { Intermediate } \\
\text { Risk }\end{array}$ & $2.7 \%$ & $(0 \%, 6.4 \%)$ & & \\
\hline & High Risk & $7.8 \%$ & $(2.6 \%, 13.0 \%)$ & & $8 / 117$ \\
\hline
\end{tabular}

In multivariate analysis, RS was a significant predictor of LRR in tamoxifen-treated patients independent of age, clinical tumor size and tumor grade.

Conclusion: Similar to the association between RS and risk for distant recurrence, the present analyses demonstrate that such an association also exists between RS and risk for LRR. This information may have clinical implications relative to locoregional therapy decisions and follow up requirements for patients with node-negative, ER-positive breast cancer.
30

A functional luteinizing hormone (LH) receptor polymorphism predicts adverse outcome in premenopausal breast cancer patients.

Piersma D, Themmen APN, Verhoef-Post M, Look MP, Klijn JGM, Foekens JA, Uitterlinden AG, Pols HAP, Berns EMJJ. Erasmus MC-Daniel den Hoed Cancer Center, Rotterdam, Netherlands; Erasmus MC, Rotterdam, Netherlands

Background: In addition to indirect epidemiological evidence, multiple studies in animals indicate a carcinogenic role of estrogens in breast cancer. The pituitary gonadotropins Luteinizing Hormone (LH) and Follicle Stimulating Hormone are important regulators of estrogen production in premenopausal women. Considering the role of LH in estrogen production and potential effect of estrogens on mammary cells, LH-RH, LH and LH Receptor (LHR) gene variants may have functional consequences in breast cancer development and/or its progression. We report the impact of polymorphisms in these genes on function and on disease outcome in breast cancer patients.

Methods: The associations between a LH-RH gene polymorphism and the polymorphic Leu-Gln insertion (insLQ) in the signal peptide encoded by exon 1 of the LHR gene with clinicopathological features and (disease free) survival was studied in a large cohort of 751 breast cancer patients with complete followup. Functional analyses were carried out using transfection studies. All statistical tests were two-sided.

Results: The mechanism of the effect of insLQ on LHR function involves increased receptor sensitivity and higher plasma membrane expression (insLQ-LHR has 1.4 higher Bmax; $\mathrm{p}=0.0006$ ), rendering the insLQ-LHR allele more active.

The frequency of the insLQ-LHR allele in breast cancer patients (0.28) was not different from non-patient cohorts $(0.29, \mathrm{n}=5399$ controls). Hetero- or homozygous presence of the insLQ allele in the LHR was identified as an independent adverse prognostic factor for relapse, especially in premenopausal and obese women. This was not significant in postmenopausal patients.

We found an association between the insLQ-LHR and tumor size and shorter overall survival and disease-free survival (DFS). The prognostic value of the insLQ allele was tested in the multivariate model for DFS, including classical prognostic factors: age, menopausal status, nodal stuatus, tumor size, differentiation grade and receptor status. Although larger tumors were significantly more often observed in the insLQ carriers versus the non-carriers, the presence of insLQ independently predicts DFS $(\mathrm{p}=0.003)$ in a multivariate analysis.

The adverse effect on DFS was particularly observed in premenopausal women (HR 1.52; 1.11-2.08: $\mathrm{p}=0.009)$ and especially in obese premenopausal women (HR 2.56; CI 1.036.37; $\mathrm{p}=0.04)$. Interestingly, when insLQ-LHR was combined with the LH-RH gene status, the DFS of premenopausal women was reduced by another $50 \%$.

Conclusion: The insLQ polymorphism increases LHR activity, thereby shortening breast cancer disease-free survival, probably by increasing estrogen exposure in female carriers. Prospective studies will reveal the value of different genotypic subgroups as a determinant for patient-tailored treatment with drugs that interfere with the LH-LHR system. 


\section{1}

Phenotypes for endocrine resistance can be identified by RNA microarray of sequential biopsies and are more variable than those predicting for tumour response.

Miller WR, Krause A, Evans DB, Renshaw L, Murray J, Larionov A, Anderson TJ, White S, Hampton G, Walker JR, Ho S, Dixon MJ. University of Edinburgh, Edinburgh, Scotland, United Kingdom; Novartis Pharma AG, Basel, Switzerland; Novartis Institutes for BioMedical Research, Basel, Switzerland; Novartis Genomic Institute, San Diego

Background: Optimal management of breast cancer by endocrine therapy requires identification of markers predicting for response/ resistance so that treatment may target responsive tumours. This study uses RNA microarrays combined with neoadjuvant treatment to identify molecular phenotypes predicting for tumour hormone sensitivity and resistance.

Materials and Methods: 52 postmenopausal women with large primary ER-rich breast cancers were treated neoadjuvantly with letrozole $(2.5 \mathrm{mg}$ daily) for 3 months; clinical response was determined by serial ultrasound measurements of the primary tumour. RNA from tumour biopsies taken before and after 14 days treatment was hybridized on Affymetrix U133A chips. Informative probe sets were categorized according to response by logistic regression and Wilcoxon test followed by Random Forests analyses. Results: $37(71 \%)$ tumours were classified as clinical responders ( $>50 \%$ reduction in volume at 3 months). Microarray analysis of pre- and 14-day biopsies identified 291 covariates (84 baseline, 72 14-day and 135 change) that were highly predictive of response status. Probe set ontology related to genes involved in protein synthesis/degradation, transcription, signal transduction and cell proliferation/apoptosis. Blinded hierarchical clustering separated responding and non-responding tumours entirely, apart from a single case. A dissimilarity matrix demonstrated responding tumours formed a homogeneous group whereas non-responding tumours showed heterogeneous profiles which were distinct from responding tumours.

Discussion: Molecular profiling of baseline and early changes with treatment predict for subsequent clinical response to endocrine treatment. Signatures for response offer reassurance of successful therapy, whereas those for resistance are indicative of the need for other therapy. The diverse phenotypes associated with resistance suggest the presence of multiple pathways capable of bypassing therapeutic restraints.

\section{2}

A reliable new model of estrogen dependent human breast cancer lymph node metastasis.

Harrell JC, Sartorius CA, Horwitz KB. University of Colorado Health Sciences Center, Aurora, CO

Background: Breast cancer metastases kill 40,000 American women yearly. The principal sites to which breast cancers first spread are the axillary lymph nodes (LN). Importantly, 70-80\% of primary breast cancers are estrogen (ER) and progesterone (PR) receptor positive and more than $80 \%$ of these LN metastases retain ER or PR. To date, no reliable models exist to study spread of ER+ breast cancers into $\mathrm{LN}$ and the influence of hormones on this process

Methods: $\mathrm{ER}+\mathrm{PR}+\mathrm{MCF} 7$ cells, and ER+, PR- or PR+ T47D cells were tagged with new, ultra bright fluors - ZsGreen or DsRedexpress - by retroviral transduction, then flow sorted for the brightest $10 \%$ of the population and expanded in culture. Ovariectomized nude mice were injected into the abdominal (\#4) mammary glands with one-million fluorescent human breast cancer cells in $100 \%$ matrigel. Mice were untreated (-E) or estradiol supplemented (+E). Tumor growth was monitored weekly for 12 weeks and tumor cell dissemination was monitored by whole body fluorescent imaging, and by microscopy at necropsy. PR and ER were measured in primary and disseminated tumors by immunohistochemistry.
Results: Tumor growth of all cell lines is absolutely E dependent. Tumor fluorescence is stable and superficial LN metastases can be monitored in living mice without use of anesthetics. At necropsy, stably fluorescent metastatic cells can be seen microscopically in $\mathrm{LN}$ and occasionally in distant organs. Metastases are ER+. They are also PR+ if the primary tumor was PR+. LN dissemination rates correlate with primary tumor size; $\sim 70 \%$ of tumors $>50 \mathrm{~mm}^{2}$ in size spread to LN. Fluorescent tumor cell boluses are observed in lymphatics, often accompanied by extensive lymphangiogenesis. Discussion: We have developed a reliable model of ER+/PR+ breast cancer LN metastasis that allows study of hormone regulation of this process within the tumor, the lymphatics and LN. The model also allows direct monitoring of treatments aimed at blocking tumor LN metastases.

\section{3}

Estrogen receptor alpha antagonizes p53 function by direct interaction-a novel cellular mechanism with a clinical correlate.

Das GM, Liu W, Konduri SD, Nayak BK, Bansal S, Rajasekaran SA, Abraham BK, Brauch H, Fritz P, Srivastava P, Rajasekaran AK. Roswell Park Cancer Institute, Buffalo, NY; University of Texas Health Science Center at San Antonio, San Antonio, TX; University of California at Los Angeles, Los Angeles, CA; Dr. Margarete Fischer-Bosch-Institute of Clinical Pharmacology, Auerbachstr 112, Stuttgart, Germany

Background: Estrogen receptor-alpha (ERalpha) promotes cell proliferation in breast tumors whereas tumor suppressor protein p53 impedes cell cycle progression. Whether there is a direct link between these two opposing pathways has remained unclear. Here we report that in human breast cancer cells, ERalpha binds directly to p53 and negatively regulates its function.

Material and Methods: Multiple experimental methods such as electophoretic mobility shift assay (EMSA), immunoprecipitation, and chromatin immunoprecipitation (ChIP) assay were used to demonstrate that $\mathrm{p} 53$ and ERalpha co-exist in a complex in vitro and in vivo in MCF-7 cells. Further, GST pull-down assays were used to analyze direct binding of ERalpha with p53. Immunoflourescence followed by confocal microscopy was used tom show nuclear colocalization of these two proteins. We used quantitative real-time PCR assays on endogenous transcripts and protein to show that ERalpha knock down enhances p53-dependent p21 (CDKN1A) expression. Effect of ERalpha on p53-mediated transcription was analyzed by Luciferase-based transfection assays. Flow cytometric analysis and BrdU incorporation assays revealed that knocking down ERalpha and p53 elicits opposite effects on cell cycle progressionof breast cancer cells. ER and p53 expression in patient samples were analyzed by immunohystochemistry.

Results: ERalpha binds directly to p53 and negatively regulates its function. Knocking down ERalpha and p53 elicits opposite effects on p53-dependent gene expression and cell cycle progression. Genomic damage by ionizing radiation and antiestrogens disrupted the ERa-p53 interaction, whereas 17b-estradiol (E2) increased it. Consistent with these cellular and molecular observations, our retrospective study on patients with a clinical follow-up of up to 176 months shows that presence of wild type p53 in ER-positive breast tumors is associated with better response to tamoxifen therapy.

Discussion: The results demonstrate a new role for ERalpha in breast oncogenesis and suggest that suppressing p53 function is an important component in the pro-proliferative role of ERa. Our study revealing a novel mechanism by which ERalpha inactivates a major tumor suppressor pathway has significant clinical implications and translational potential. 
34

An estrogen receptor-negative breast cancer subset with over expression of hormone responsive genes.

Doane AS, Danso MA, Lal P, Donaton M, Zhang L, Hudis C, Gerald WL. Memorial Sloan-Kettering Cancer Center, New York, NY

Background: Little is known of the underlying biology of ER(-)/ $\mathrm{PR}(-)$ breast cancer (BC) and few targeted therapies are available. Clinical heterogeneity of ER(-)/PR(-) tumors suggests that genomewide molecular characterization may provide insight into their biology, reveal distinct subsets and identify new therapeutic targets. Methods: We performed genome-wide expression analysis of 99 primary BC samples and $8 \mathrm{BC}$ cell lines using Affymetrix HGU133 oligonucleotide microarrays. Unsupervised and supervised analyses were used to investigate gene expression profiles. Predictive models were developed using a supervised k-nearest neighbor technique. Findings were further evaluated by immunohistochemistry, in situ hybridization, and in vitro cell line experiments.

Results: Unsupervised hierarchical clustering revealed distinct subtypes of primary BC largely correlated with ER status. However, a subset of samples negative for ER clustered with the ER positive tumors. Analysis of this subset of ER(-)/PR(-) tumors revealed over expression of genes known to be either direct targets of ER, responsive to estrogen, or differentially expressed in $\mathrm{ER}(+) \mathrm{BC}$. Differentially expressed genes included PDEF, FOXA1, XBP1, CYB5, TFF3, NAT1, APOD, ALCAM and AR $(\mathrm{p}<0.0001)$, and suggested ER-independent mechanisms for activation of steroid hormone responsive genes. An expression signature of 179 genes for this group of $\operatorname{ER}(-) / \operatorname{PR}(-)$ BC with hormone responsive features was used to build a classification model that performed well in leave-one-out cross-validation. The predictor was applied to an independent set of 77 ER(-)/PR(-) primary tumors, and identified subsets in similar proportion as the original analysis. Unsupervised hierarchical clustering of the validation set yielded groups of samples corresponding to our class prediction assignments. The classification system also identified the cell line MB-453 as an in vitro model for this subtype of ER (-) BC. This cell line was not estrogen dependent but had a proliferative response to androgen in an AR dependent manner. Expression profiles for MB-453 generated after administration of androgens or AR antagonists were distinguished by marked changes involving the 179-gene expression signature suggesting androgen and AR regulation. IHC and ISH were used to validate RNA analysis, and to provide a means for clinical identification of this subgroup.

Conclusion: A subset of ER(-)/PR(-) BC has a molecular signature that suggests a functional or persistent hormonal response pathway. Examination of an in vitro model for this subtype suggests AR dependent mechanisms of pathway activation. Clinical investigation of antiandrogen therapy to target this subset of BC may be warranted.

\section{5}

Estrogen receptor-beta has favorable independent prognostic value for estrogen receptor-alpha negative breast cancer patients receiving adjuvant tamoxifen.

Gruvberger-Saal SK, Bendahl P-O, Saal LH, Laakso M, Eden P, Peterson C, Malmstrom P, Isola J, Borg A, Ferno M. Lund University, Lund, Sweden; Institute for Cancer Genetics, Columbia University, New York, NY; Institute of Medical Technology, University of Tampere, Tampere, Finland

BACKGROUND

While estrogen receptor (ER) $\alpha$ is important for breast cancer initiation and progression, and is a marker used to direct endocrine therapy, ER $\beta$ biology and its relation to endocrine therapy response is not clear.

\section{METHODS}

ER $\beta$ was semi-quantified by immunohistochemistry in 353 stage II primary breast tumors from patients treated with two years adjuvant tamoxifen with a median clinical follow-up of 5.7 years for non-recurring patients. Gene expression profiles of a representative subset of 88 of these breast tumors were generated using 27,648-element cDNA microarrays.

\section{RESULTS}

Seventy-four percent of tumors were positive for ER $\beta ; 20 \%$ were strongly positive $(E R \beta++)$. In contrast to $E R \alpha$, the level of ER $\beta$ protein did not correlate to any other clinicopathological variables. ER $\beta$ expression was significantly associated with increased distant disease-free survival among all cases $(P=0.01)$, and in particular within $\mathrm{ER} \alpha$ negative patients $(P=0.003)$, but not in the $\operatorname{ER} \alpha$ positive subgroup $(P=0.49)$; this differential effect was significant $(P=0.04$, interaction in Cox regression analysis). ER $\beta$ was significantly associated with increased overall survival in the $\operatorname{ER} \alpha$ negative group $(P=0.04)$. Lack of ER $\beta$ was a strong marker for poor prognosis (HR 14, 95\% CI 1.8-106, $P=0.01$ ) compared to $\mathrm{ER} \beta++$ within the ER $\alpha$ negative subgroup even after adjustment for other markers (menopausal status, tumor size, node status, $\mathrm{ER} \alpha$ status, ERBB2 amplification). An ER $\beta$ gene expression profile was identified only within $\mathrm{ER} \alpha$ negative tumors and was markedly different from the $\mathrm{ER} \alpha$ gene expression signature.

\section{CONCLUSIONS}

$\mathrm{ER} \beta$ is an independent marker for favorable prognosis after adjuvant tamoxifen treatment in $\mathrm{ER} \alpha$ negative breast cancer patients and motivates investigating the use of tamoxifen to treat $\mathrm{ER} \alpha$ negative ER $\beta$ positive patients. This may be highly clinically significant, as it can be estimated from our data that in the United States alone, approximately 10,000 patients will be diagnosed in 2005 with $\mathrm{ER} \alpha$ negative $\mathrm{ER} \beta$ positive breast carcinoma.

\section{6}

Statin-using breast cancer patients are less likely to have ER-negative tumors

Kumar AS, Minami CA, Shim V, Moore DH, O'Neal KC, Esserman LJ. University of California San Francisco, San Francisco, CA; Kaiser Permanente - Oakland Medical Center, Oakland, CA

Background: HMG CoA reductase inhibitors (statins), drugs used to reduce cholesterol, have emerged as agents capable of affecting potentially critical breast cancer pathways: cell proliferation and estrogen synthesis. Statins, particularly lipophilic statins, are shown in vitro to inhibit proliferation of estrogen receptor negative (ER-) breast cancer cells more effectively than ER-positive breast cancer cells and in a dose-dependent manner. There is increasing epidemiologic evidence to suggest overall breast cancer risk reduction among statin users. To date, no clinical study has investigated the relationship of breast cancer ER status and statin use.

Materials and Methods: To test whether prior use of statins among female breast cancer patients resulted in a reduced number of ER-negative tumors compared to statin non-users, we performed a retrospective cohort analysis of 2141 patients in the Kaiser Permanente Northern California (KPNC) Cancer Registry who were listed as incident cases of breast malignancy (DCIS or primary breast cancer) in 2003, whose ER status was known and who had been KPNC members prior to June 2001. Prior use of lipophilic statin (lovastatin, simvastatin, atorvastatin) and exogenous hormone $(\mathrm{E}, \mathrm{P}$ or $\mathrm{E}+\mathrm{P})$ replacement were determined by listings in the Kaiser electronic pharmacy records since 1993.

Results: Ages ranged from 15 to 96 (mean 62 years). Statin users $(\mathrm{n}=387,18 \%)$ median age was 69 (range 40 to 93$) .1164(54 \%)$ had exogenous hormone exposure prior to diagnosis; median age was 61 (range 28 to 92). $206(9.6 \%)$ patients used both statins and hormones. Contrary to studies showing higher association of ERpositive tumors with exogenous hormone use, this study showed no significant relationship. Of breast cancer patients who used statins prior to their diagnosis, the chance of having an ERnegative breast cancer was $35 \%$ less for statin-users, compared to 
non-users $(\mathrm{p}=0.008), 25 \%$ less after adjusting for age $(\mathrm{p}=0.09)$. Statin use $>1$ year significantly reduced age-adjusted proportion of ER- tumors by $36 \%(\mathrm{p}=0.02)$ compared to statin non-use or use for $<1$ year.

\begin{tabular}{|c|c|c|c|c|c|}
\hline $\begin{array}{l}\text { Statin Use } \\
\text { prior to } \mathrm{dx}\end{array}$ & $\mathrm{n}$ & $\%$ ER-tumors & $\begin{array}{l}\text { Age-adjusted } \\
\text { Odds Ratio } \\
\text { of having } \\
\text { ER- tumor }\end{array}$ & $\mathrm{p}$ value & $\begin{array}{l}95 \% \\
\text { confidence } \\
\text { interval }\end{array}$ \\
\hline None & 1754 & $19.2 \%$ & 1.00 & & \\
\hline$<1$ ye & 84 & $20.2 \%$ & 1.20 & 0.52 & $0.69-2.07$ \\
\hline$>1$ year & 303 & $11.5 \%$ & 0.63 & 0.02 & $0.44-0.93$ \\
\hline
\end{tabular}

Discussion: The relationship between lipophilic statin use and reduced risk for developing ER-negative breast cancer is consistent with preclinical data and warrants further clinical investigation. Our analysis did not address whether overall cancers were reduced by statin use, though other studies have. Statin use may confound analyses of breast cancer risk assessment from hormone replacement therapy, and this interaction deserves further study. Given that we have effective chemoprevention agents targeting ER-positive breast cancer (tamoxifen, aromatase inhibitors), statins may represent a promising approach for prevention of ERnegative breast cancer.

\section{7}

Better characterization of estrogen receptor (ER) positive luminal subtypes using genomic grade.

Sotiriou C, Wirapati P, Loi S, Desmedt C, Durbecq V, Harris A, Bergh J, Smeds J, Haibe-Kains B, Larsimont D, Cardoso F, Buyse M, Delorenzi M, Piccart M. Jules Bordet Institute, Free University of Brussels, Brussels, Belgium; Swiss Institute of Bioinformatics, Swiss Institute of Experimental Cancer Research, Epalinges, Switzerland; The Weatherall Institute of Molecular Medicine, University of Oxford, Oxford, United Kingdom; Karolinska Institute, Stockholm, Sweden; International Drug Development Institute, Brussels, Belgium

Background: Several microarray studies have shown that breast tumours can be grouped in at least 4 to 5 individual subtypes namely basal-like, erbB2-like and luminal-like A, B, C or 1, 2, 3. However, although the basal and the erbB2 subtypes are repeatedly recognized as distinct entities, the definition of luminal subtypes has been far from consistent between published series. Refinement of their molecular definition is therefore needed. In this study we sought to better characterize luminal subtypes by applying gene expression grade index (GGI) as previously defined by our group (Sotiriou et al. Proc Am Soc Clin Oncol, 2005), and to correlate them with clinical outcome. Material and Methods: GGI was defined based on the 128 most significant genes identified by gene expression profiling (GEP) in our training set of 64 ERpositive histological grade $(\mathrm{HG}) 1$ or 3 breast tumours. ER-positive tumours were then classified as genomic grade (GG) 1 (GG1, low grade) or GG3 (high grade) based on their GGI values in our unpublished dataset including a series of 154 untreated and 175 tamoxifen-treated breast cancer patients. We also used as external validation sets several previously published datasets from Sorlie et al. 2001, van de Vijver, M. J. et al. 2002, Sotiriou et al. 2003, and Wang et al. 2005. Results: Almost all ER-positive tumours previously defined as luminal-like A or 1 subtype, which had the best clinical outcome, showed low GGI values (low grade). In contrast, luminal $\mathrm{B} / \mathrm{C}$ or $2 / 3$ ER-positive tumours showed high GGI values (high grade) similar to those of basal-like and erbB2like subtypes which are predominantly ER-negative. In other words, GGI divided ER-positive tumours into two distinct subgroups namely GG1 and GG3 having statistically distinct clinical outcome in either untreated (HR: 3.93, 95\% CI 2.28-6.76, p<0.0001) or tamoxifen-treated (HR: 3.1, 95\% CI 1.64-5.52, p=0.0002) populations. Consistent results were found in each external validation dataset that we have analysed despite differences in clinical populations and microarray platforms. Conclusion: GG better identifies luminal subtypes in a highly reproducible manner and the GG-defined subtypes show a statistically distinct clinical outcome. We believe that a better characterization of the ER- positive luminal subtypes has the potential to improve tailoring of breast cancer management.

\section{8}

Comparison of docetaxel/doxorubicin/cyclophosphamide (TAC) versus vinorelbine/capecitabine $(\mathrm{NX})$ in patients non-responding to 2 cycles of neoadjuvant TAC chemotherapy - first results of the phase III GEPARTRIOStudy by the German Breast Group.

von Minckwitz G, Blohmer JU, Loehr A, Raab G, Eidtmann H, Hilfrich J, Gerber B, Huober J, Costa SD, Jackisch C, Loibl S, Schickling O, Zuna I, Kaufmann M. German Breast Group, NeuIsenburg; St. Gertrauden Hosp., Berlin; HSK, Wiesbaden; Marien Hosp., Stuttgart; Univ. Hosp., Kiel; Henrietten Stift, Hannover; Univ. Hosp., Rostock; Univ. Hosp., Tuebingen; Univ. Hosp., Magdeburg; Univ. Hosp., Marburg; SKM, Wiesbaden, Germany; Univ. Hosp., Frankfurt, Germany

Background: Primary breast cancer patients $(\mathrm{P})$ with no response to 2 cycles of neoadjuvant TAC $(75 \mathrm{mg} / \mathrm{m} / 50 \mathrm{mg} / \mathrm{m} / 500 \mathrm{mg} / \mathrm{m} 2$ day 1, q21, supported with primary prophylaxis with (pegylated) G-CSF and secondary prophylaxis with epoetin) experience a low pathologic complete remission (pCR) rate after further 4 cycles TAC (von Minckwitz et al, Ann Oncol 2005). We compared continuation of TAC with a non-cross resistant combination of Vinorelbine $25 \mathrm{mg} / \mathrm{m} 2$ day $1+8$ plus Capecitabine $2000 \mathrm{mg} / \mathrm{m} 2$ day 1 14, q21(NX).

Patients and methods: $P$ with operable $(T>=2 \mathrm{~cm}$ by palpation) or locally advanced (T4 or N3, M0) breast cancer were treated with 2 cycles TAC. If tumor reduction was $<50 \%$ according to breast ultrasound, $\mathrm{P}$ were randomized to receive either 4 additional TAC or 4 NX cylces. Endpoints were sonographic response before surgery (primary), pCR-rate (no invasive and no non-invasive residuals), breast conservation rate, safety and compliance.

Results: More than 2050 P with a median clinical tumor size was 4.0 (1.0 to 30.0$) \mathrm{cm}$ were recruited into the GEPARTRIO trial between $07 / 02$ and June 15th 05 and approx. 620 non-responding patients were randomized. Safety and blinded efficacy interim analysis was performed on 300 patients (154 TAC, 146 NX, operable $82.2 \%$, locally advanced $17.8 \%$ ). Sonographic partial or complete response before surgery was $67.7 \%$; breast conservation in $59.2 \%$ and pCR in $5.2 \%$. Main toxicities (grade I-IV \% TAC vs $\% \mathrm{NX}$ ) were: anemia (92 vs 86 ), thrombopenia (37 vs 29), neutropenia (72 vs 81 ), febrile neutropenia (10 vs 6), infection (30 vs 23 ), vomiting ( 40 vs 23 ), diarrhea (44 vs 32 ), stomatitis (67 vs 45 ), edema (42 vs 37 ), asthenia ( 89 vs 85 ), hand-footsyndrome ( 23 vs 46 ), allergic (18 vs 21 ), nail (42 vs 25 ), dyspnea (35 vs 28 ), sensory neuropathy (49 vs 57 ). Treatment was discontinued in $28 \mathrm{P}(9.3 \%)$ due to toxicity (11 P, 4 vs 7 ), on patients/investigators request (12 $\mathrm{P}, 4$ vs 8 ) and tumor progression (5 P, 4 vs 1 ).

Conclusions: Both chemotherapy regimens were well tolerated; $\mathrm{NX}$ (without G-CSF) is associated with a better toxicity profile as compared to TAC (with G-CSF). Continuation of treatment in patients without early response to TAC can achieve sonographic responses in $2 / 3 \mathrm{rd}$ of these patients with a clinically relevant chance for breast conservation. Results on the efficacy endpoints will be presented. 
39

Multicenter, randomized phase III study of adjuvant chemotherapy for node positive breast cancer comparing 6 cycles of $\mathrm{FE}_{90} \mathrm{C}$ versus 4 cycles of $\mathrm{FE}_{90} \mathrm{C}$ followed by 8 weekly paclitaxel administrations: interim efficacy analysis of GEICAM 9906 Trial.

Martín M, Rodríguez-Lescure A, Ruiz A, Alba E, Calvo L, RuizBorrego M, Munárriz B, López-Vega JM, Rodríguez CA, Crespo C. On Behalf of the Spanish Breast Cancer Research Group (GEICAM), San Sebastián de los Reyes, Madrid, Spain

Objective: to evaluate efficacy and toxicity of sequential administration of $\mathrm{FE}_{90} \mathrm{C}$ followed by weekly paclitaxel $(\mathrm{T})$ as adjuvant chemotherapy (CT) of node positive, operable breast cancer patients (pt). Methods: pt aged 18-70, presenting Karnofsky $\geq 90$, adequate bone marrow, renal and hepatic function, were stratified [menopausal status, affected lymph nodes (1-3 vs. 24 )], and randomized to $6 \mathrm{FE}_{90} \mathrm{C}$ cycles (cy) (Fluorouracil/ Epirubicin/Cyclophosphamide 600/90/600 mg/m² day 1 every 3 weeks) (control group, Arm A) or $4 \mathrm{cy}$ of the same schedule followed by 8 weekly doses of T $100 \mathrm{mg} / \mathrm{m}^{2}$ (experimental group, Arm B). Radiotherapy was mandatory after conservative surgery, and recommended in pt with $>4$ axillary lymph nodes and tumors $>5 \mathrm{~cm}$. Tamoxifen was given for 5 years to all hormone receptor (HR) positive pt. Intention to treat interim efficacy analysis was planned at 202 events, and performed at a median follow-up of 47 months. Analysis was conducted using a log-rank test, stratified by menopausal and nodal status. Study complied with GCP/ICH with $100 \%$ source data verification. Results: 1.248 pt were recruited; $634 \mathrm{pt}$ in arm A and 614 in arm B. Main pt characteristics were well balanced between arms: median age 50 years, conservative surgery $40 \%$, both HR negative $17 \%$, HR positive-either ER or PgR- $77 \%$, grade III $34 \%, 1-3$ involved nodes $62 \%$. Median number of $\mathrm{FE}_{90} \mathrm{C}$ cy (A vs $\mathrm{B}$ ) were 6 (range 1-6) vs 4 (range 1-4). Median number of $\mathrm{T}$ administrations in arm $\mathrm{B}$ were 8 (range 1-8). Relative dose-intensities (RDI) of F (99.0 vs $99.1 \%$ ), E ( 98.8 vs $98.8 \%)$ and C (99.1 vs $99.1 \%)$ were similar in both arms during the first 4 cycles. Median RDI of T was $99.5 \%$. Toxicity (data presented at ASCO 2004; abstract \#596): $\mathrm{FE}_{90} \mathrm{C}$ administration: febrile neutropenia (FN) rate was statistically higher in arm A (9.3 vs $5.1 \% \mathrm{pt} ; \mathrm{p}=0.004)$. Statistical differences were observed in $(\% \mathrm{pt}$, Arm A vs Arm B): G3/4 neutropenia (30 vs $20.5 \%$ ), G3 leukopenia (10.6 vs $7.4 \%)$ and $\mathrm{G} 3$ mucositis (5.4 vs $3 \%)$. T administration: G3/4 neutropenia/ leukopenia occurred in $12.1 \%$ of pt. G2 neuropathy (sensory) and asthenia were present in $21.3 \%$ and $23.4 \%$ of pt, respectively. Efficacy: as of 12 May 2005, $229 \mathrm{pt}$ have experienced at least 1 event. There is a significant improvement in DFS for arm B $(86,9 \%)$ vs. A $(79,2 \%)$ (36\% risk reduction of recurrence; $p=0.0009)$. No statistical differences between arms in overall survival have been reached yet $(94.5$ vs. $91.8 \%$, arms B and A respectively, $\mathrm{p}=0.1375 ; 26 \%$ risk reduction of death). Conclusion: 4 cy of $\mathrm{FE}_{90} \mathrm{C}$ followed by 8 weekly T100 administrations improves DFS of node positive operable breast cancer pt. compared to $6 \mathrm{cy}$ of $\mathrm{FE}_{90} \mathrm{C}$. Main toxicities reported with this scheme are moderate neuropathy and mild asthenia.
40

Final analysis: TC (docetaxel/cyclophosphamide, 4 cycles) has a superior disease-free survival compared to standard AC (doxorubicin/cyclophosphamide) in 1016 women with early stage breast cancer.

Jones SE, Savin MA, Holmes FA, O'Shaughnessy JA, Blum JL, Vukelja SJ, George TK, McIntyre KJ, Pippen JE, Sandbach J, Kirby RL, Bordelon JH, Hyman WJ, Negron AG, Khandelwal P, Richards DA, Anthony S, Nugent JE, Mennel RG, Banerji M, Edelman G, Ruxer RL, Amare M, Kampe CE, Koutrelakos $N$, Meyer WG, Asmar L. US Oncology Research, Inc., Houston, TX

Introduction: Studies of combined docetaxel and cyclophosphamide (TC) showed promise in metastatic breast cancer without cardiac toxicity. Accordingly, in 1997, we designed a trial to test the efficacy of the nonanthracycline-based regimen of TC compared to standard AC in the adjuvant setting. Patients were eligible if they had Stage I, II, or operable Stage III invasive breast cancer; had complete surgical excision of the primary tumor; were $>18$ years old; had adequate renal, hepatic, and hematologic functions; and had Karnofsky PS $\geq 80 \%$. Exclusion criteria included other significant malignancies or illness or neoadjuvant chemotherapy.

Patients and Methods: Between June 1997 and December 1999, 1016 patients were randomized to 4 cycles of either standard-dose AC $\left(60 / 600 \mathrm{mg} / \mathrm{m}^{2}\right)[\mathrm{n}=510]$, or TC $\left(75 / 600 \mathrm{mg} / \mathrm{m}^{2}\right)[\mathrm{n}=506]$, administered intravenously every 3 weeks as adjuvant treatment. All chemotherapy was administered before radiation therapy (XRT), if XRT was indicated. Tamoxifen was administered to all patients with hormone receptor-positive breast cancer after chemotherapy.

Results: $85 \%$ of patients were Caucasian, and both treatment groups (TC and AC) were well-balanced with respect to major prognostic features. Overall, $71 \%$ of cancers were hormone receptor-positive. Nodal status included: negative (48\%), 1 - 3 positive $(41 \%)$, and 4 or more positive $(11 \%)$. Patients were followed through April 2005, and 165 events occurred, which prompted this statistical analysis. At 5 years, the DFS is significantly better for TC compared to AC (see Table).

$\begin{array}{llll} & 506 \mathrm{TC}(95 \% \mathrm{CI}) & 510 \mathrm{AC}(95 \% \mathrm{Cl}) & \\ \text { Relapses } & 68 & 87 & \\ \text { \%DFS at 5 Years } & 86 \%(84 \%-88 \%) & 81 \%(79 \%-83 \%) & (\mathrm{P}=0.027) \\ \text { Deaths } & 50 & 66 \\ \text { \%OS at 5 Years } & 89 \%(88 \%-91 \%) & 88 \%(86 \%-89 \%) & (\mathrm{P}=0.188)\end{array}$
\%OS at 5 Years $\quad 89 \%(88 \%-91 \%) \quad 88 \%(86 \%-89 \%) \quad(\mathrm{P}=0.188)$ Overall survival (OS) between treatments is not yet statistically significant, but there is a trend in favor of TC. Toxicity has been previously reported (Proc ASCO 2001, abstract \#128), and in general, TC was a more tolerable regimen.

Conclusions: TC is a better-tolerated adjuvant regimen, which produced a longer DFS compared to standard AC for lower-risk early breast cancer.

Supported by Sanofi-Aventis, Inc. New York, NY

\section{1}

Five year follow-up of INT C9741: dose-dense (DD) chemotherapy $(\mathrm{CRx})$ is safe and effective.

Hudis C, Citron M, Berry D, Cirrincione C, Gradishar W, Davidson $N$, Martino S, Livingston R, Ingle J, Perez E, Abrams J, Schilsky R, Ellis M, Muss H, Norton L, Winer E. MSKCC, NY, NY; ProHealth Care Assoc, Lake Success, NY; MD Anderson, Houston, TX; CALGB Stat Office \& Data Ops, Durham, NC; Northwestern U, Chicago, IL; Kimmel Comp Ca Ctr at Johns Hopkins, Baltimore, MD; JWCI, Santa Monica, CA; U of Wash, Seattle, WA; Mayo, Rochester, MN: Mayo, Jacksonville, FL; NCI, Bethesda, MD; CALGB Central Office, Chicago, IL; Wash U., St. Louis, MO; U of Vt, Burlington, VT; DFCI, Boston, MA

Based on INT-0148/C9344 and the Norton-Simon hypothesis, we compared efficacy and safety for $\mathrm{DD}(\mathrm{q} 2 \mathrm{wk}) \mathrm{CRx}$ with doxorubicin (A), paclitaxel (P), and cyclophosphamide () to standard (q 3 wk) therapy and, via factorial design, concurrent (conc) with sequential (seq) AC. Doses were the same on all arms: $\mathrm{A}=60, \mathrm{P}=175, \mathrm{C}=600$ 
all $\mathrm{mg} / \mathrm{m} 2 \times 4.2005$ pts enrolled and 1972 were treated and evaluable. At the only protocol-stipulated analysis, the med follow up (f/u) was 36 mos (range 0.2-60) DD CRx improved the primary endpoint of DFS (RR $0.74, p=0.01$ ) and secondary endpoint of OS (RR 0.69, p=0.013). There were no differences between conc or seq CRx. A subsequent unplanned subset analysis demonstrated greatest benefit among pts with hormone receptor (ER) negative (-) disease. (Berry et al, SABCS 2004). This report is a formal update at a med f/u $=69 \operatorname{mos}($ range $0.2-87$ ). Q2 wk CRx significantly improved DFS with a similar trend for OS. The benefits of $\mathrm{q} 2$ wk CRx, as demonstrated by reduced hazards of recurrence, remain most striking in the first 3 years of $\mathrm{f} / \mathrm{u}$, and in the ER (-) subset. Benefits cannot be excluded in later years of f/u nor in ER (+) disease in part because tamoxifen extended to 5 years beyond CRx. Long-term toxicity is essentially unchanged with 7 cases $(0.7 \%)$ of AML/MDS in each of the $\mathrm{q} 3$ and $\mathrm{q} 2 \mathrm{wk}$ groups and 1$3 \%$ delayed cardiac toxicity among all 4 regimens combined. Conclusion: DD CRx with $\mathrm{A}, \mathrm{P}$, and $\mathrm{C}$ is more effective than $\mathrm{q} 3$ wk CRx with no increased risk of long-term toxicities. Table 1

Number Of First Failures By Site:

Local

Distant

Local \& distant synchronously

Death wh relaps: 'or

Death w/o relapse: "other' cause

Death w/o relapse: unknown cause 6

Table 2

Number Of DFS And OS Events By Schedule And Receptor Status DFS Q3 Q2 Hazard Ratio

$\begin{array}{llllll}\text { ER Status } & \mathrm{n} \text { pts } & \mathrm{n} \text { failures } & \mathrm{n} \text { pts } & \mathrm{n} \text { failures } & \text { HR (q2 vs q3) } \\ \text { Negative } & 327 & 122 & 335 & 98 & 0.75\end{array}$

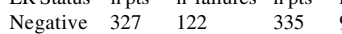

\begin{tabular}{lllll} 
Negative & 327 & 122 & 335 & 98 \\
Positive & 639 & 130 & 636 & 113 \\
\hline & 984 & 260 & 988 & 215
\end{tabular}

$\begin{array}{lllll}\text { Positive } & 639 & 130 & 636 & 113\end{array}$

0.75
0.86

Seq Q2
26
68
2
1
7
6

$\begin{array}{lll}\text { Conc Q3 } & \text { Conc Q2 } & \text { To } \\ 27 & 20 & 102 \\ 80 & 64 & 292 \\ 3 & 6 & 15 \\ 3 & 1 & 7 \\ 6 & 9 & 30 \\ 12 & 5 & 29\end{array}$ 105 75

OS ER Status $\mathrm{npts} n$ deaths $\mathrm{npts} n$ deaths Negative $327-100-335-81$ Positive $639-80-038074$

$\begin{array}{lllll}\text { Total } & 984 & 185 & 936 & 74 \\ & & & & \end{array}$

\subsection{7}

0.92

0.85

95\% $\quad \mathrm{p}$-Value $\begin{array}{ll}95 \% \mathrm{Cl} & (2 \text {-sided }) \\ 0.57-0.97 & 0.031\end{array}$ $0.67-1.11 \quad 0.26$ $0.67-0.96 \quad 0.018$

\section{2}

IL-8 is involved in the development and growth of osteolytic bone lesions.

Margulies AG, Akel NS, Perrin D, Carver A, Bendre MS, Gaddy D Suva LJ. University of Arkansas for Medical Sciences, Little Rock, AR

Background: Bone is one of the most common sites for breast cancer metastasis. Skeletal metastases indicate a dramatic change in the prognosis for the patient and significantly increase the morbidity associated with breast cancer. Still, relatively little is known about the molecular mechanisms that control bone metastasis We have shown that elevated levels of the chemokine IL-8 correlate with increased bone metastasis and that IL- 8 is able to directly stimulate osteoclast formation in vitro, suggesting a role for IL-8 in tumor osteolysis. Thus, we hypothesized that the chemokine IL-8 may be involved in the induction of osteolysis by breast cancer cells resident in bone.

Materials and Methods: Human breast cancer cells were injected in the tibia of nude mice. The mice were treated with either a monoclonal antibody directed against IL- 8 or no treatment every alternate day for 28 days following tumor cell inoculation. Mice were sacrificed and the injected and contralateral tibiae evaluated. Results: All injected mice receiving no treatment developed bone tumors (12/12). In the IL-8 antibody treated group (3/12) demonstrated tumor. Small tumor foci with no demonstrable osteolysis were observed in (2/12) mice and an additional (1/12) mouse developed osteolytic tumor. The total area of osteolytic lesions and tumor burden was significantly lower in mice treated with IL-8 antibody compared with mice receiving no treatment. Interestingly, in those untreated animals with small tumors, circulating levels of IL-8 and TRAP5b were not elevated, suggesting that the osteolysis in these animals was indeed local, possibly reflecting the early stage of tumor development. Immunohistochemical evaluation of the tumors growing in bone is ongoing to determine the expression of IL- 8 by the tumors in vivo.

Discussion: These data suggest that IL- 8 has a role in the initiation and growth of osteolytic bone lesions. The efficacy of anti IL- 8 antibody provides a strong rationale for the utility of anti-IL- 8 therapy in the inhibition of tumor growth in bone, and suggests a novel therapeutic opportunity for the treatment, and perhaps prevention of bone metastasis.

\section{3}

Effects of oral clodronate (BONEFOS $®)$ therapy on bone turnover and skeletal metastases in women with primary breast cancer.

McCloskey EV, Paterson AHG, Powles TJ. Northern General Hospital, Sheffield, United Kingdom; Tom Baker Cancer Centre, Calgary, AB, Canada; Parkside Hospital, Wimbledon, United Kingdom

BACKGROUND: Breast cancer treatments that suppress ovarian function, such as hormone therapy and chemotherapy, accelerate bone turnover and the loss of bone mass.

METHODS: In a randomized, double-blind, placebo-controlled study, 2 years of oral clodronate (a bisphosphonate) therapy significantly reduced the occurrence of bone metastases within the first 5 years and improved overall survival in women with operable primary breast cancer. In a predefined sub-group of 555 patients, we have examined the relationship between bone turnover response and incident bone metastases.

RESULTS: At entry to the study, serum PINP (amino-terminal propeptide of type I collagen, a marker of bone turnover) was identical in both treatment groups. Median values were slightly, but not statistically significantly, higher in postmenopausal women than in premenopausal women $(37.0$ vs $34.5 \mathrm{mg} / \mathrm{L}, P=0.07)$. During 2 years of therapy with clodronate, serum PINP values showed a median decrease of $26 \%$ while in the placebo group there was a median increase of $5 \%(P<0.0001$ between groups). PINP levels in the clodronate group returned to baseline within one year of stopping therapy. Using percentage changes between baseline and 1 year, women were classified into responsive $(>20 \%$ decrease in PINP), unchanged, or progressive ( $>20 \%$ increase in PINP) bone turnover groups. The percentage of women showing a response was significantly higher (55\% vs $31 \%$ ) during clodronate therapy, while the number showing progression was significantly lower $(23 \%$ vs $41 \%)(P<0.0001$ both comparisons). Within the clodronate group, the incidence of bone metastases was significantly lower in women with a response to therapy $(4.8 \%)$ than in those with progressive bone turnover $(17 \%, P=0.016)$.

Median baseline PINP values were identical in women who subsequently developed incident bone metastases $(n=56)$ and those who remained bone metastasis-free $(n=499)(35.0 \mathrm{mg} / \mathrm{L}$ both groups). At 1 year, however, serum PINP values were significantly higher in women who subsequently developed bone metastases than in those remaining metastasis-free (median 40.0 vs. $30.0 \mathrm{mg} /$ $\mathrm{L} P=0.003$ ). Similar results were obtained if the analysis was based on percentage changes from baseline at 1 year (median PINP \% change $+16.2 \%$ vs. $-12.0 \%, P=0.013)$ or if women with known incident bone metastases at 1 year were excluded $(P=0.024)$.

CONCLUSIONS: Adding clodronate to standard adjuvant therapy in primary breast cancer is associated with reduced bone turnover and protection of the skeleton from metastases. Serum PINP holds potential as a marker of response to therapy and possibly early detection of skeletal metastases. The time course of metastases reduction mirrors that observed for effects on bone turnover so that the optimum duration of treatment with clodronate remains to be determined. 
101

Clinicopathological characteristics of young onset breast cancer: initial results from a prospective cohort study. Simmonds PD, Eccles DM, Gerty S. Southampton General Hospital, Southampton, United Kingdom

The POSH study is a prospective cohort study that will recruit 2000 women aged 40 years or younger in the UK with newly diagnosed breast cancer. The aim of the study is to prospectively examine the influence of genotype on outcomes in this patient group. Information regarding clinical presentation, family history, pathological tumour characteristics, treatment and annual clinical follow up data are being collected from each patient. DNA, PBLs and serum samples are also being stored. Over 1200 patients have been recruited and this is an initial analysis of the clinicopathological characteristics of the patients for whom data is currently available.

The median age at diagnosis is 36 years (range $22-40$ ). The majority presented with symptomatic breast disease, however in $1.4 \%(10 / 736)$ an abnormality was detected by some form of screening and $3.3 \%(26 / 792)$ presented with metastatic disease. $35 \%$ of patients have a family history that meets the current UK guideline threshold for BRCA1/2 testing via clinical genetics services (10\% definitely carry or are highly likely to carry BRCA1 or BRCA2 gene mutations).

The pathological characteristics of the tumours from the first 750 patients recruited are tabulated below:

$\begin{array}{lll}\text { Histological type* } & \text { Number } & \% \\ \text { ductal } & 659 & 87.9 \\ \text { lobular } & 52 & 6.9 \\ \text { medullary } & 8 & 1.1 \\ \text { atypical medullary } & 7 & 0.9 \\ \text { other } & 44 & 5.9 \\ \begin{array}{l}\text { Associated DCIS } \\ \text { present } \\ \text { absent } \\ \text { Tumour size }\end{array} & 495 & 66 \\ \text { T1 } & 255 & 34 \\ \text { T2 } & & \\ \text { T3 } & 336 & 44.8 \\ \text { Unknown } & 297 & 39.6 \\ \text { Tumour location } & 71 & 9.5 \\ \text { unifocal } & 46 & 6.1 \\ \text { multifocal } & & \\ \text { unknown } & 435 & 58 \\ \text { Tumour grade } & 171 & 22.8 \\ \text { G1 } & 144 & 19.2 \\ \text { G2 } & & \\ \text { G3 } & 37 & 4.9 \\ \text { unknown } & 238 & 31.7 \\ \text { Nodal status } & 422 & 56.3 \\ \text { N0 } & 53 & 7.1 \\ \text { N+ } & & \\ \text { unknown } & 325 & 43.3 \\ \text { Lymphovascular invasion present } \\ \text { present }\end{array}$

* some mixed tumours contain more than one histological subtype

For patients who presented with early stage disease nearly half $[48.7 \%,(380 / 781)]$ underwent mastectomy, 2.6\% (20/781) have had no surgery and the remainder underwent breast conserving surgery $[48.2 \%,(381 / 781)]$. Most patients received adjuvant $[79.5 \%(511 / 643)]$ or neoadjuvant $[12.9 \% \quad(83 / 643)]$ chemotherapy. Tamoxifen was the most common adjuvant hormonal therapy $[61.9 \%,(398 / 643)]$, but $17 \%(109 / 643)$ received an LHRH agonist, $3.6 \%$ (23/643) underwent adjuvant oophorectomy and $1.6 \%(10 / 643)$ received an aromatase inhibitor in conjunction with ovarian suppression. Adjuvant radiotherapy was administered to $82.7 \%(527 / 637)$ of patients.

Of the 26 patients presenting with metastatic disease 5 have died (12 - 23 months post diagnosis) and 21 remain alive with a median follow up of 13 months (2-59 months).

More complete data from the first 1000 patients recruited should be available for the conference. The longer term aim is to undertake central pathological review as well as to perform genotyping and construct tissue microarrays to explore differences between hereditary and sporadic breast cancer.

\section{2}

Variants of undetermined significance in BRCA2: protein modeling, loss of heterozygosity, ethnicity, and clinical correlations.

Karchin R, Beattie M, McLennen J, Toland A, Sali A. University of California, San Francisco, CA

Background: In the US, approximately $5 \%$ of Caucasians, and $20 \%-30 \%$ of non-Caucasians undergoing genetic testing for BRCA1/ 2 receive the ambiguous test result, "Variant of Undetermined Significance" (VUS). In UCSF's Cancer Risk Program (CRP), the majority of VUS results occur in BRCA2. To better identify these VUS as neutral/low clinical significance or pathogenic/high clinical significance, we propose combining clinical and molecular data, including a novel protein model of BRCA2

Methods: The C-terminal domain of human BRCA2 protein was modeled, based on x-ray crystal structures from mouse and rat. We evaluated evolutionary conservation in this area using a new sequence alignment of 18 BRCA2 orthologs. We next identified patients with missense VUS in this region and analyzed their clinical data, including ethnicity and pedigree data. For patients with available tumors, loss of heterozygosity $(\mathrm{LOH})$ studies were performed. Each VUS was classified as neutral or pathogenic, according to 13 features of protein sequence, structure, and conservation, with a supervised machine learning method (support vector machine or SVM). The SVM was trained on 1457 diseaseassociated missense mutations (OMIM) and 2504 polymorphism (dbSNP), covering 1842 proteins. The SVM classifications are $80 \%$ accurate on the training set when tested with a three-fold cross-validation protocol.

Results: 87 VUS were identified in UCSF's CRP, 28 in $B R C A$ and 59 in $B R C A 2.9$ of these VUS found in the C-terminal domain of BRCA2 were studied in more detail. 


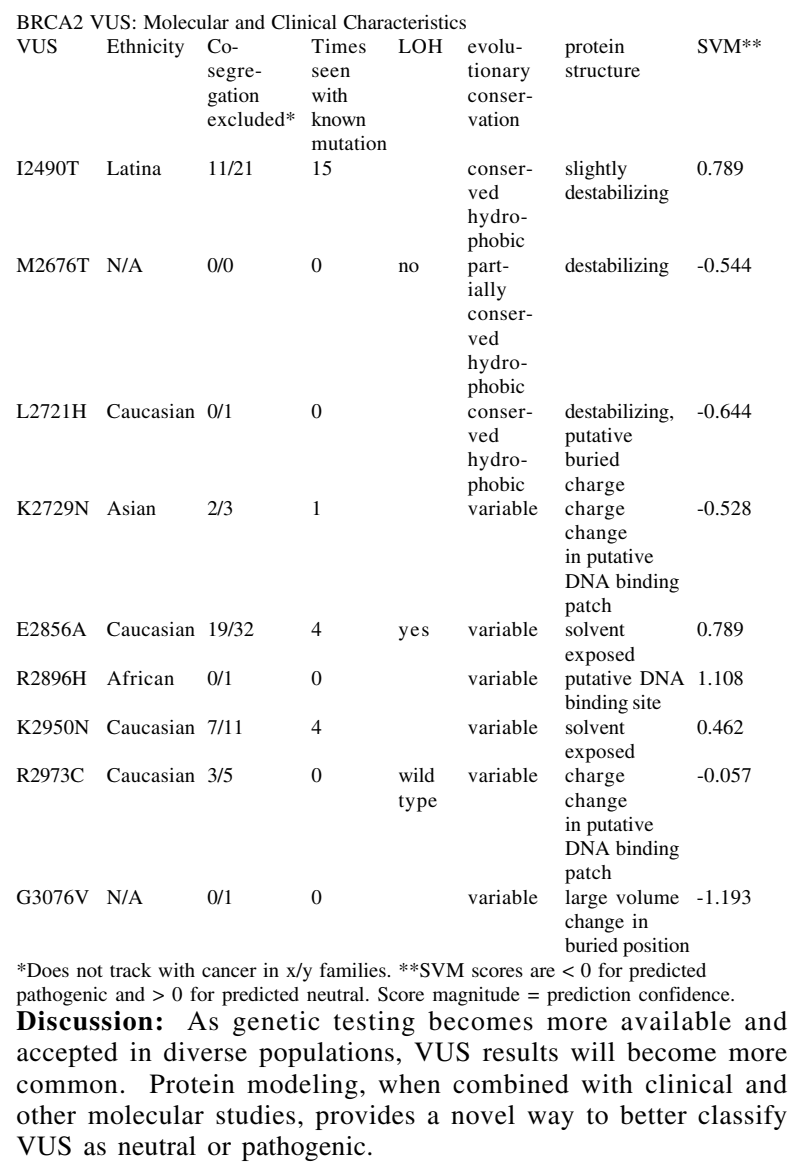

103

Radiation exposure and breast cancer risk for BRCA mutation carriers.

Goldfrank DJ, Chuai S, Ramon y Cajal T, Lee JB, Alonso MC, Diez O, Baiget M, Kauff ND, Offit K, Bernstein JL, Robson ME. Memorial Sloan-Kettering Cancer Center, New York, NY; Hospital Sant Pau, Barcelona, Spain

Background: Women who carry BRCA1 and BRCA2 mutations are at significantly increased risk for breast cancer. Carriers are counseled to undergo careful breast surveillance including annual mammograms starting by age 25 . One important environmental cause of DNA damage is exposure to ionizing radiation. The molecular functions of the BRCA1 and BRCA2 genes are not fully understood, but their protein products function in common biochemical pathways involved in signaling the presence of and/ or repairing of certain forms of DNA damage. This raises a concern that women who are either BRCA1 or BRCA2 mutation carriers may be predisposed to radiation-induced breast carcinogenesis due to deficient repair capacity. To evaluate this possibility, we analyzed the association between early mammogram exposure and breast cancer risk in women with mutations.

Materials and methods: The subjects of this study were 121 BRCA1 and 92 BRCA2 mutation carriers participating in IRBapproved studies of hereditary breast cancer predisposition at Memorial Sloan-Kettering Cancer Center (MSKCC) and Hospital Sant Pau (HSP) in Barcelona, Spain between 1995 and 2005. At the time of enrollment on study, subjects completed baseline questionnaires describing history of mammogram exposure and other radiation exposure. Subjects were classified as being affected or unaffected by breast cancer at the time of questionnaire completion, and associations between mammogram exposure and cancer status were assessed using multivariable unconditional logistic regression.

Results: Of the 213 mutation carriers, 85 women were affected and 128 unaffected. On average, affected women reported a slightly greater total lifetime number of mammograms (mean 9.97 vs. 9.87, $\mathrm{P}=\mathrm{NS}$ ), but unaffected women reported more mammograms before questionnaire than affected women did before cancer diagnosis (mean 8.56 vs. $5.85, \mathrm{P}=0.01$ ). In unadjusted analyses, total reported number of mammograms did not differ significantly between affected and unaffected women either as a whole (OR $1.06,95 \%$ C.I. $0.87-1.31$ ), or when stratified by gene (BRCA1: OR 1.16, 95\% C.I. 0.89-1.51; BRCA2: OR 0.95, 95\% C.I. 0.68$1.30)$.

Discussion: The present study does not support the hypothesis that exposure to low level radiation from mammograms is associated with an increased breast cancer risk among women with BRCA mutations, and it does not support the removal of mammography from surveillance programs for women at hereditary risk.

\section{4}

Prevalence, spectra and founder effects of $B R C A 1$ and $B R C A 2$ germline mutations in Pakistani breast and/or ovarian cancer families.

Rashid MU, Zaidi A, Torres D, Sultan F, Naqvi B, Shakoori AR, Farooq H, Amin A, Hamann U. German Cancer Research Center, Heidelberg, Germany; Shaukat Khanum Memorial Cancer Hospital and Research Center, Lahore, Pakistan; University of the Punjab, Lahore, Pakistan; Lombardi Cancer Center, Georgetown University, Washington, $D C$

Introduction: Germline mutations in the $B R C A 1$ and $B R C A 2$ genes are responsible for different proportions of hereditary breast and/or ovarian cancer. The spectrum of mutations within these genes shows considerable ethnic and geographic variation. Pakistan has the highest rate of breast cancer (excluding Jews in Israel) and ovarian cancer in Asia. Little information exists about the significance of $B R C A 1 / 2$ mutations in hereditary breast and/or ovarian cancer in this region. This is the first familial study that aims to identify the impact of these mutations in the Pakistani population.

Material and Methods: From June 2001 to November 2004, 176 families deemed to have high risk based on presentation of breast cancer at $\leq 30$ years or ovarian cancer $\leq 45$ years of age or breast/ovarian cancer in $\geq 2$ relatives, at least one diagnosed $\leq 50$ years of age were identified at the SKMCH \& RC. Comprehensive mutation screening of the BRCA1/2 genes was performed using protein-truncation test, single-strand conformational polymorphism analysis, and denaturing high-pressure liquid chromatography analysis followed by DNA sequencing of detected variants.

Results: Thirty deleterious germline mutations were identified in the 176 (30/176, 17.0\%) families evaluated: 23 in BRCA1 (23/30, $76.7 \%)$ and 7 in $B R C A 2(7 / 30,23.3 \%)$. Twenty-two mutations were distinct including 12 frame shift mutations, 8 nonsense mutations, 2 splice-site mutations and 1 missense mutation. Eleven mutations $(11 / 30,36.7 \%)$ were unique to the Pakistani population; six in $B R C A 1(6 / 15,40.0 \%)$ and five in BRCA2 $(5 / 7,71.4 \%)$. These novel mutations were not found in 50 healthy controls suggesting a causative role. Four distinct BRCAl mutations were identified in multiple unrelated patients. Haplotype analysis of all mutation carriers using 3 intragenic BRCA1 markers suggested founder effects. Among the families with $\geq 3$ female breast cancer, or two ovarian cancer, or breast and ovarian cancer diagnoses the mutation frequency for BRCA1 was $28.6 \%, 33.3 \%$ and $42.9 \%$, respectively. For $B R C A 2$, the highest mutation frequency of $14.2 \%$ was found in families with $\geq 3$ female breast cancer cases. Lower frequency was found in families with one female breast cancer diagnosed $\leq 30$ years of age; $8.3 \%$ for $B R C A 1$ and $3.6 \%$ for $B R C A 2$. BRCA1 mutation frequency of $9.0 \%$ was found in families with 
one case of ovarian cancer diagnosed $\leq 45$ years of age. Conclusion: $B R C A 1$ and $B R C A 2$ germline mutations may have significant impact on hereditary breast/ovarian cancer risk in the Pakistani population. The identification of unique founder mutations may facilitate carrier detection in Pakistani breast and/ or ovarian cancer families.

\section{5}

Screening for $B R C A$ genomic rearrangements in Singapore patients with young onset or familial history of breast or ovarian cancer: identification and characterization of a novel $10.1 \mathrm{kbp}$ deletion.

Lim YK, Ali AB, Iau PT, Sng JH. Faculty of Medicine, National University of Singapore, Singapore; National University Hospital, Singapore

Background: Large genomic rearrangements account for about $10 \%$ to $15 \%$ of BRCA1 gene mutations. Up to $40 B R C A$ rearrangements have been described to date, all of which have been reported in Caucasian populations of predominantly Western European descent. Most of these rearrangements have been characterized and found to include either deletions or duplications of one or more exons in BRCA1. At present, no data exists on the presence of $B R C A$ genomic rearrangement in any Asian population. This study aims to investigate the presence of $B R C A$ rearrangements among Singapore patients with early onset or familial history of breast or ovarian cancer.

Methods: Multiplex ligation-dependent probe amplification (MLPA) was used to screen patients presenting with early onset or familial breast/ovarian cancer for $B R C A$ genomic rearrangements. Results: Using MLPA, we have screened 100 Singapore patients previously tested negative for deleterious $B R C A$ mutations by the conventional polymerase chain reaction (PCR)-based mutation detection methods, single-strand conformation polymorphism (SSCP) and protein truncation test (PTT). The data from our analyses will be presented, including the detection of a novel $B R C A 1$ rearrangement in a large breast and ovarian cancer family. Characterization of this rearrangement by long range PCR and direct sequencing showed an exon 13-15 deletion (10.1 kbp in size), presumed to be the result of an $A l u$-mediated recombination event.

Conclusion: This study presents the first genomic rearrangement to be described in an Asian population. Given the increasing number of rearrangements reported in recent years and their contribution to the $B R C A$ mutation spectrum, the suitability of including rearrangement analysis within the $B R C A 1$ mutation screening protocols in Asian populations will be discussed.

\section{6}

Incidence and histology of ductal carcinoma in situ in BRCA1/2 mutation carriers.

Kankipati S, Clark D, Shum M, El-Khoury M, Grana G. The Cancer Institute of New Jersey at Cooper University Hospital, Camden, NJ

Background: It is well known that about $10 \%$ of all cases of invasive breast cancer are hereditary and the majority of these are due to mutations in the BRCA1/2 genes, however it is unclear if ductal carcinoma in situ (DCIS) is a part of the hereditary spectrum. It has been postulated that BRCA mutation carriers may lack a preinvasive phase and instead present as invasive disease. Demonstration of the existence of a preinvasive phase in carriers is of considerable practical importance to women with these mutations and to their families. We pursued this study in order to determine the prevalence of DCIS in BRCA1/2 mutation carriers and to examine the pathobiology of these tumors.

Methods: We did a retrospective chart review of patients who tested positive for a BRCA1/2 mutation at Cooper University Hospital. We then reviewed their pathology looking for a diagnosis of DCIS alone or in combination with invasive breast cancer.
Results: Out of the 38 mutation carriers identified through the study, 45 breast cancers were found. Six women had bilateral cancers and one had a late reoccurrence in the same breast. Out of 45 cancers, $11(24 \%)$ had pure DCIS $(100 \%)$ with no invasive component. Another 8 cancers $(17 \%)$ had a component of DCIS ranging from $10-90 \%$ of the tumor, while the rest of the cancers were invasive disease. Nearly all DCIS (18/19) had comedo necrosis, and a majority were high grade. Comedocarcinoma is often more aggressive and is associated with a higher probability of microinvasion.

Conclusion: It appears that DCIS is prevalent in patients carrying BRCA mutations. In our sample population, $42 \%$ of cancers had at least some component of DCIS. Nearly all patients with DCIS had high grade histology with comedo necrosis. This supports the hypothesis that BRCA mutation carriers have aggressive phases in both initiation and promotion of breast cancer, and that preinvasive breast cancer should be a factor when assessing patients for hereditary risk. Our findings suggest that DCIS, especially when coupled with high-grade features, should be included in BRCA risk assessment models, and that these women are appropriate candidates for genetic counseling and testing.

\section{7}

Long-term survival (OS) and prognostic factors of BRCA1associated versus sporadic breast cancer $(\mathrm{BC})$, results of an extended series.

Brekelmans CTM, Seynaeve C, Menke-Pluymers M, TilanusLinthorst MMA, Bartels CCM, Crepin CMG, Blom JC, Van den Ouweland AMW, Meijers-Heijboer H, Klijn JGM. Erasmus MC Daniel den Hoed Cancer Center, Rotterdam, Netherlands; Eramus MC, Rotterdam, Netherlands

\section{Background}

Data on OS in BRCA1-associated as compared to sporadic BC are inconsistent, partly because mostly small sample sizes and heterogeneous patient populations have been studied. The impact of the classical tumor and treatment features on prognosis has previously not been addressed in BRCA1-associated BC separately. Methods

From the Rotterdam Family Cancer Clinic registration, we selected 223 patients (pts) with primary, invasive BC diagnosed between 1980 and December 2001 from families with an identified BRCA1mutation. To correct for ascertainment bias, we considered BRCA1associated patients in 1) index pts with a $\mathrm{BC}$ diagnosis more than 2 yrs before the DNA diagnosis $(n=53)$, and 2) other BRCA1-pts $(\mathrm{n}=170)$. The index patients were excluded from the multivariate analyses. All BRCA1-associated pts were matched for age at and year of diagnosis to sporadic $\mathrm{BC}$ pts, in a 2:1 ratio. The occurrence of ipsi- (IBTR) and contralateral BC (CBC), distant disease-free (DDFS), BC-specific and OS were compared between BRCA1associated and sporadic BC. By Cox proportional regression modelling, the prognostic impact of tumor and treatment factors, including a bilateral (salpingo-)oophorectomy $(\mathrm{B}(\mathrm{S}) \mathrm{O})$, was investigated separately in BRCA1-associated and sporadic BC. Results

Median follow-up was $5.1 \mathrm{yrs}$, median age at diagnosis $39 \mathrm{yrs}$ BRCA1-associated BCs were significantly more frequently differentiation-grade 3, negative regarding ER- and PR-status, node-negative, and of a non-ductal (mainly medullary) celltype. The 5-yr incidence of CBC was increased $(0.18 \%$ vs. $0.04 \%$; $\mathrm{p}=0.001)$, but not of IBTR $(0.16 \%$ vs. $0.12 \%$; $=0.24)$. DDFS and $\mathrm{BC}$ specific survival were not significantly different $\left(\mathrm{HR}_{\text {mult }} 0.88\right.$, $\mathrm{p}=0.54$; and $\mathrm{HR}_{\mathrm{mut}} 1.24, \mathrm{p}=0.26$, respectively). After exclusion of non-ductal $\mathrm{BCs}$, a trend towards a worse survival was found for BRCA1-associated BC ( $\left.\mathrm{HR}_{\text {mult }} 1.50, \mathrm{p}=0.07\right)$. Significant prognostic factors for BRCA1-associated survival were tumour size and nodal status ( $\geq 4$ pos. lymph nodes). Further, survival was nonsignificantly improved by systemic treatment: HR for hormonal treatment $0.19(\mathrm{p}=0.17)$, for chemotherapy $0.39(\mathrm{p}=0.12)$; and after a BSO (HR 0.41, $\mathrm{p}=0.23$ ). 
Conclusions

BRCA1-associated BC is characterized by specific tumor features and an increased incidence of CBC. However, BC-specific survival was not significantly different between BRCA1- and sporadic BC, despite more node-negative disease. The prognostic impact of tumour size and nodal status $(\geq 4+)$ on the outcome in BRCA1associated BC implicates that the use of these factors as a proxy for ultimate mortality, and therefore in the consideration of possible additional preventive mastectomy, appears to be valid.

\section{8}

BRCA genetic testing and race: the UNC experience.

Susswein LR, Skrzynia C, Lewis CL, Graham II ML, Evans JP. University of North Carolina at Chapel Hill, Chapel Hill, NC; Waverly Hematology Oncology, Cary, NC

Background: Many studies suggest that African-Americans (AAs) are less likely than Whites to pursue BRCA genetic testing. Researchers have hypothesized that this decreased interest among AA is related to an unfamiliarity with breast cancer genetics, greater worry related to historic medical abuses, spiritual and religious differences, greater guilt about at-risk relatives, or an inability to pay for testing.

One potential flaw in studies of race and genetic testing is the possibility of ascertainment bias. AAs are less likely to be referred for genetic counseling. In addition, the cost of BRCA testing can be prohibitive to patients of lower socio-economic status. Furthermore, clinicians may be less likely to offer testing to AAs if they feel the patients will decline testing.

The UNC Cancer Genetics Clinic is in a unique position to approach and offer BRCA testing to patients without the confounding issue of ascertainment bias. First, the UNC cancer genetics team evaluates every newly diagnosed patient in the Multidisciplinary Breast Cancer Clinic. Thus, any patient with potential genetic issues is ascertained by genetics team regardless of race or SES. Second, we at UNC are able to offer BRCA1/2 genetic testing at no charge to patients who cannot obtain insurance coverage. Thus, cost does not play a factor in a patient's decision regarding BRCA testing.

Objective: We sought to quantify the UNC experience and compare the uptake of BRCA testing by the African-American vs. White patients

Results: Since 1998, we have offered BRCA testing to 810 patients. Of this group, slightly fewer AAs (43\%) chose to pursue testing compared with $58 \%$ of Whites $(p=.0041)$. However, when we isolate the 439 women with a recent breast cancer diagnosis, there is no statistically significant difference $(\mathrm{p}=0.08)$ in uptake between AAs (50\%) and Whites (61\%).

Conclusions: For our entire patient population, our clinic's experience is similar to much of the literature: AAs are less likely to pursue BRCA genetic testing when offered. However, among our newly-diagnosed population, our data reveal no significant difference between AAs' and Whites' uptake. Since we see a higher uptake among AAs in the acute vs. non-acute setting, it may be that when AAs see testing as integral to their own immediate health, they are more apt to pursue it.

In spite of a lower uptake, substantial numbers of AAs are still interested in testing. AA individuals at risk for carrying a BRCA mutation should be approached about their genetic risk as often as Whites.

\section{9}

A screening approach to detect hereditary cancer risk in under-served women.

Lee R, Crawford B, Beattie MS, Komoromy M, McLennan J, Luce J, Strachowski L, Ziegler J. University of California, San Francisco, San Francisco, CA; San Francisco General Hospital, San Francisco, $C A$

Genetic counselling and testing for BRCA1/2 mutations is largely unavailable to underserved women in the USA. In 2002, the UCSF
Cancer Risk Program (CRP) began an outreach program at San Francisco General Hospital (SFGH) to provide these services, free of charge, to patients. Follow-up preventive services are also available to patients who test positive at SFGH free of charge. Several methods were used to recruit women into this program, one of which was a one-page questionnaire to assess familial risk of breast cancer. This report analyzes the results from our use of this questionnaire.

Methods: Over the last 3 years, women receiving mammography at SFGH are invited to fill out a one page questionnaire regarding their family history. This questionnaire is available in 4 languages (English, Chinese, Spanish, and Russian). The questionnaire queries both maternal and paternal family history of breast, ovarian, or other cancers in first and second-degree relatives as well as age of cancer onset. The questionnaires were evaluated by genetic counsellors and divided into low and high risk groups based on published criteria. Primary care physicians of women with high heritable risk were contacted and offered a referral to the SFGH program.

Results: 7290 questionnaires were evaluated, $46 \%$ of which were in English. 447 patients $(6 \%)$ were judged to represent a high risk of heritable cancer (at least $10 \%$ prior probability of carrying a $B R C A$ mutation). Of this high risk group, primary care providers were contacted 192 times to convey this risk and to offer referral to the SFGH program. 103 patient referrals resulted from this. An additional 27 patients who consented to direct contact without PCP involvement were also referred. If family history had only included maternal first degree relatives with breast cancer, 247 patients would have been designated as high risk. So, the remaining 200 high risk patients were determined by paternal and second degree relatives. Of the 19 patients who have tested positive for BRCA1/2 mutations at SFGH, $6(32 \%)$ were detected only by this screening questionnaire administered during mammography.

Discussion: Family history questionnaire administration during mammography is a feasible way to identify women at high risk of hereditary cancer in an underserved population. The percentage of "high risk" patients $(6 \%)$ is similar to studies in populations of higher socio-economic status. Family history that does not include paternal history or second degree relatives misses a significant number of "high risk" patients. This screening questionnaire identified a substantial proportion (nearly 1/3) of BRCA carriers that would not have otherwise been referred to the program.

\section{0}

Risk reduction choices of women with deleterious BRCA1 and BRCA2 mutations at a single institution.

Uyei A, Erlichman J, Lu K, Meric-Bernstam F, Strong L, Arun B. UT MD Anderson Cancer Center, Houston, TX; UTMADCC; UTMDACC

Background: $5-10 \%$ of all breast cancers are inherited. Since genetic testing for the $B R C A 1$ and $B R C A 2$ genes became available, many individuals underwent testing to identify genetic susceptibility to breast $(\mathrm{BrCa})$ and ovarian cancer (OvCa). Identification of these individuals sets a platform to discuss risk reduction options There are several factors that influence risk reductive decisions in individuals. The aim of this study is to characterize women with BRCA $1 / 2$ mutations and review their risk-reductive choices.

Methods: The U. T. MD Anderson Clinical Cancer Genetics database was reviewed for women who underwent genetic testing and tested positive for a deleterious mutation from 1996-present. Information regarding the number of women who underwent BRCA1/2 genetic testing, results and choices individuals made for risk reduction were collected.

Results: Since 1996, 513 women have been tested for the BRCA1/ 2 mutations. 112 women $(22 \%)$ were found to carry either a BRCA1 $(n=63)$ or BRCA2 $(n=49)$ mutation. Factors used in deciding who would be eligible for genetic testing included: Known mutation in the family, strong family history of breast and/or ovarian cancer, personal history of $\mathrm{BrCa}$ at a young age (under 
40 ), and a personal history of OvCa. In the BRCA1 mutation carrier population, 19 women had 1 primary $\mathrm{BrCa}, 6$ had 2 primary BrCas, and 5 had $\mathrm{BrCa}$ and OvCa. 11 women had $\mathrm{OvCa}$ without a history of $\mathrm{BrCa} .15$ women had no personal history of $\mathrm{BrCa}$. In the BRCA2 mutation carriers, 23 women had 1 primary $\mathrm{BrCa}$, 4 had 2 primary $\mathrm{BrCa}$, and 1 patient had $\mathrm{BrCa}$ and $\mathrm{OvCa} .6$ women had $\mathrm{OvCa}$ and 14 women have no personal history of $\mathrm{BrCa}$. After discussion of risk reduction options, of the 29 BRCA1 or BRCA2 mutation carriers without a personal history of cancer, 5 $(17 \%)$ chose to have prophylactic bilateral mastectomies, $7(24 \%)$ bilateral prophylactic bilateral oophorectomy, and only $2(7 \%)$ chose to take tamoxifen. In contrast, of the 42 women who were diagnosed with 1 primary $\mathrm{BrCa}, 22(52 \%)$ underwent bilateral mastectomies and $23(52 \%)$ prophylactic bilateral oophorectomy. Of the 10 women who were diagnosed with 2 primary BrCas, 8 $(80 \%)$ underwent bilateral mastectomies and bilateral oophorectomy.

Conclustion: $22 \%$ of the women who were tested for BRCA1/2 mutations were found to be mutation carriers. Among these individuals with a mutation, the acceptance for tamoxifen as prevention was low. More women tend to opt for surgical risk reductive management options. This trend was especially observed in women with a prior diagnosis of cancer. There are several factors, which influence the choice of risk reduction options in women with known BRCA1 and BRCA 2 mutations. Identification of these factors in prospective studies will certainly aid in risk management discussions among high risk individuals and health care providers.

\section{1}

A single mammary stem cell can reconstitute a functional mammary gland.

Shackleton M, Vaillant F, Simpson KJ, Singl J, Smyth GK, Wu L, Visvader JE, Lindeman GJ. The Walter \& Eliza Hall Institute of Medical Research, Parkville, VIC, Australia; British Columbia Cancer Agency, Vancouver, Canada

Background: The mammary gland can be functionally regenerated in mice by serial transplantation of epithelial fragments, providing evidence for the existence of self-renewing, multipotential mammary stem cells (MaSCs). Recently the concept has emerged that MaSCs play a central role in breast tumorigenesis. However, the identity and purification of MaSC has proved elusive due to the lack of defined markers.

Methods and Results: Using specific cell surface markers and flow cytometry, we have identified a distinct subpopulation that is enriched for MaSCs, demonstrated by transplantation into cleared mammary fat pads at limiting dilution. Remarkably, a single mammary epithelial cell from this population, carrying the lac Z transgene, was found to generate a complete mammary gland in vivo. These cells contributed to both the luminal and myoepithelial lineages in transplanted virgin mammary glands, and extensive lobuloalveolar units were generated during pregnancy. Serial transplantation of the clonal outgrowths also yielded complete mammary glands, confirming that the cells were capable of selfrenewal.

Discussion: These data establish that single cells from the enriched population have multipotential and self-renewing capacity, a hallmark of stem cells. It will be of interest to determine whether the stem cell/progenitor population is a target for transformation in mammary tumorigenesis models, in support of a potential role for breast stem cells in human breast cancer.

\section{2}

Identification of multipotent breast stem/progenitor cells in mammospheres derived from human normal breast parenchyma and breast cancer tissue.

Lee JE, Kim JB, Han W, Hwang SE, Lee KM, Bae JY, Shin HJ, Kim S, Kim SW, Kim SW, Noh DY. Seoul National University College of Medicine, Seoul, Korea: Cancer Research Institute, Seoul National University College of Medicine, Seoul, Korea; Clinical Research Institute, Seoul National University Hospital, Seoul, Korea

There have been several reports of identification of multipotent stem/progenitor cells in various types of somatic stem cells such as neural, hematopoietic and skin stem cells. However there has been no published report about multipotent human breast stem cells yet. We cultured human breast stem cells using mammospheres obtained from the human normal breast parenchyma and breast cancer tissue. Mammospheres were cultured and passaged in floating condition under the medium consist of DMEM:F12 = 3:1, supplemented with B27, basic fibroblast growth factor, human recombinant epidermal growth factor and leukemia inhibitory factor at $37^{\circ} \mathrm{C}$ in a humidified atmosphere containing $5 \%$ of $\mathrm{CO}_{2}$. The number of live cells was counted in Neubauer counting chamber with $0.4 \%$ trypan blue dye in every passage. After the seventh passage, the number of viable cells was maintained almost constantly as $1 \%$ relative to the total number of the initial live cells from tissue. After the tenth passage, we harvested and the mammospheres and cultured them onto cover slips coated with type IV collagen in medium composed of DMEM:F12=1:1, EGF insulin, hydrocortison, transferrin, 17- $\beta$ estradiol with 5\% FBS for 3 days. We could identify the cytokeratin 14 and 18 coexpressing cells with immunocytochemistry under confocal microscope. When we cultured these mammospheres in the 3D culture in collagen mixture, they also formed mammary epithelial branching morphogenesis. Then we tested if human breast stem cells in mammospheres have the ability to differentiation neuronal and mesenchymal cells. When we cultured the tenth passaged mammospheres on cover slips coated with type IV collagen in medium with 3\% FBS without growth factor/cytokine for three days, we found nestin and fibronectin expressing cells under confocal microscope. A small number of nestin and glial fibrillary acidic protein co-expressing cells were also found. These results suggest that human mammary stem cells may generate both neuronal and mesodermal differentiated cells.

\section{3}

In vitro propagation and characterization of tumorigenic breast cancer cells with stem/progenitor cell properties.

Daidone MG, Ponti D, Sozzi G, Capelli C, Gariboldi M, Reid JF, Pierotti MA. Istituto Nazionale Tumori, Milan, Italy; IFOM Foundation, Milan, Italy

Background: Breast cancer-initiating cells (BC-Ics) have been prospectively identified in breast carcinoma as $\mathrm{CD} 44^{+} / \mathrm{CD} 24^{- \text {Ilow }}$ stem-like cells, which exclusively retain tumorigenic activity (AlHajj M. et al., PNAS 2003;100:3983-8). We recently provided evidence that cells isolated from human breast cancers and propagated in vitro as non-adherent mammospheres (according to Dontu G. et al., Genes and Dev 2003:17:1253-70) display stem/ progenitor cell properties (Ponti D. et al., Cancer Res, July 2005 , in press). Mammosphere cultures encompassed undifferentiated, self-renewing $\mathrm{CD} 44^{+} / \mathrm{CD} 24^{-}$cells capable to differentiate along distinct mammary epithelial lineages, tumorigenic in mice when injected at low concentration $\left(10^{3}\right.$ cells $)$, and overexpressing neoangiogenic (Vascular Endothelial Growth Factor A [secreted isoform 165] and C) and cytoprotective factors such as survivin. In addition, cells isolated from mammospheres expressed the putative stem cell marker Oct- 4 and exhibited telomerase activity. Methods: To investigate whether a gene expression pattern could be recognized in BC-Ics, we compared the gene expression profiles of breast cancer cells isolated from nonadherent mammospheres 
obtained from 3 breast cancer lesions (B3R, B16 and BP1) and from the established breast carcinoma cell line MCF-7 (MCF-S) with the gene expression profile of the MCF-7 parental cell line using Affymetrix technology. In addition, cytogenetic analysis was performed on MCF-S and MCF-7 cell lines: spectral karyotyping was performed on metaphase cells and karyotypes were described in accordance with ISCN guidelines.

Results: Unsupervised hierarchical clustering grouped BC-Ics according to the sphere forming efficiency. Triplicate samples of each individual BC-IC line clustered together. On the other hand, the MCF-7 cell line replicates clustered separately with respect to BC-Ics. Cytogenetic analysis revealed a more complex and heterogeneous pattern of chromosome aberrations in the MCF-7 parental cell line compared to the MCF-S cell line with stem/ progenitor cell properties. However, MCF-S and MCF-7 cells shared similar alterations in chromosomes 1, 2, 3, 19 and 20.

Conclusion: In this study we demonstrated that breast tumorigenic cells with stem/progenitor cell properties propagated in vitro as non-adherent tumor spheres showed overlapping transcriptional profiles which, in the case of BC-Ics derived from an established breast carcinoma cell line, are distinct from those exhibited by the parental cell line. Conversely, the lower number of structural chromosomal aberrations detected in MCF-S than in MCF-7 cells is in keeping with the hypothesis of a protective mechanism favoring the survival of cells with self-renewal properties. Long-term cultures of BC-ICs represent a suitable in vitro model to develop novel diagnostic and therapeutic approaches.

\section{4}

Identification of cell-of-origin breast tumour subtypes in inflammatory breast cancer by gene expression profiling. Van Laere SJ, Van der Auwera I, Van den Eynden GG, Vandenberghe M, Benoy IH, Elst HJ, Van Dam P, Van Marck EA, Dirix LY, Vermeulen PB. Lab Pathology University of Antwerp and Oncology Center, General Hospital Sint-Augustinus, Wilrijk, Antwerp, Belgium

Inflammatory Breast Cancer (IBC) is an aggressive form of locally advanced breast cancer. Most patients have lymph node involvement at the time of diagnosis and $1 / 3$ of the patients have distant metastases. In a previous study, we demonstrated that IBC is a distinct form of breast cancer in comparison with non-IBC (Van Laere et al, Breast Cancer Res Treat, 2005). The aim of this study was to investigate the presence of the different cell-oforigin subtypes in our data set of 16 IBC and 18 non-IBC specimen. Therefore, we selected an "intrinsic gene set" of 144 genes, present on our cDNA chips and common to the "intrinsic gene set" defined by Sorlie et al (PNAS, 2003). This set of genes was tested for performance in the Norway/Stanford data set by unsupervised hierarchical clustering. $84 \%$ Of the samples belonging to this set clustered in the same manner as described in the original manuscript. Expression centroids were then calculated for the core members of each of the 5 subclasses in the Norway/Stanford data set and used to classify our own specimens. We found a higher amount of basal-like and ErbB2-overexpressing tumours and a lower amount of luminal A, luminal B or normal-like tumours in IBC as compared to non-IBC (ErbB2+/Basal: IBC:8, non-IBC:3; LumA/LumB/Norm: IBC:8, non-IBC:15; Pearson Chi-Square, $\mathrm{p}=0.036$ ). Our findings were in good agreement with protein expression data for Estrogen Receptor (ER+; ErbB2+/Basal: 2/11, LumA/LumB/Norm: 12/23, $\mathrm{p}=0.063)$ and Cytokeratin 5/6 (CK5/6+; basal: 6/7, non-basal: 4/ 13, $\mathrm{p}=0.057)$. The classification was confirmed by using an alternative unsupervised hierarchical clustering method. The robustness of this classification was confirmed by unsupervised hierarchical clustering using an alternative gene set of 141 genes related to the cell-of-origin subtypes. Compared to the data published by Bertucci et al (Cancer Research, 2005), we found a higher amount of basal and Her2 overexpressing tumours and a lower amount of luminal A, luminal B or normal-like tumours in
IBC as compared to non-IBC (Her2/Basal: IBC:8, non-IBC:3; LumA/LumB/Norm: IBC:8, non-IBC:15; Pearson Chi-Square, $\mathrm{p}=0.036$ ). Furthermore, we found a significant difference in the amount of ER+ IBC specimen in the combined LumA/LumB/ Norm cluster as compared to the corresponding cluster reported by Bertucci et al (respectively 4/8, 19/19, Fisher's Exact Test; $\mathrm{p}=0.004)$. The presence of the same molecular cell-of-origin subtypes in IBC as in non-IBC does not exclude the specific molecular nature of IBC. The molecular mechanisms involved in the biology of IBC are translated in gene sets, different from the ones used to define cell-of-origin subtypes. Therefore we suggest that IBC and non-IBC have to be regarded as separate entities with important diagnostic and therapeutic consequences.

\section{5}

Integrated molecular profiling of human breast cell types and breast cancer cell lines using expression microarrays and array CGH.

Iravani M, Fenwick $K$, Grigoriadis A, Reis-Filho J, Valgeirsson $H$, Dexter T, Gahir J, Weber B, O'Hare M, Ashworth A, Mackay A. The Breakthrough Toby Robins Breast Cancer Research Centre, London, United Kingdom; Ludwig Insitute for Cancer Research, London, United Kingdom

AIM: To identify changes which drive tumorigenesis and phenotypic differentiation by integrating expression profiling and array $\mathrm{CGH}$ in a wide panel of cell lines representing different breast cancer phenotypes.

METHODS: We have profiled a panel of 26 sporadic breast cancer cell lines, purified primary populations of normal breast luminal epithelial cells, myoepithelial cells, endothelial cells, fibroblasts and their immortalized counterparts. Expression microarrays were performed on $17 \mathrm{~K}$ Breakthrough arrays and array $\mathrm{CGH}$ was performed on $1 \mathrm{MB}$-spaced BAC arrays and using tiling path $\mathrm{CGH}$ arrays constructed from the $32 \mathrm{~K}$ BAC re-array collection.

RESULTS: Unsupervised hierarchical clustering of expression microarray results clearly separated ER positive cell lines from normal breast epithelial cells (luminal and myoepithelial), mesenchymal cells (endothelial and fibroblast) and a number of cell lines with a more normal epithelial phenotype.

Clustering of breast cancer cell lines based solely upon array CGH produced a completely different unsupervised classification based upon the major amplifications/deletions.

Tiling path array $\mathrm{CGH}$ was able to finely map the major amplicons in a number of lines including separate focused amplification of CCND1 and PAK1 on chr 11q13 in and differing losses on chr16q (CDH1).

Chromosomal amplifications and deletions were confirmed by fluorescent in situ hybridization including 3p14 gain in MCF-7 and $734 \mathrm{~b}$ and 7q11(EGFR) in MDA-MB-468 cells. Differential expression of a number of luminal and basal markers were confirmed by RT-PCR and by fluorescent immunocytochemistry.

The overlay of expression microarray and array CGH identified a number of important amplicon drivers including amongst others; erbB2/17q12, FGFR1/8q11.2 and STK6/20q13.

Expression profiling identified MCF-7, T47D and 734b as lines best representing an ER positive luminal phenotype (although clearly different and distinct from normal luminal epithelial cells) based largely on the expression of genes in the ER cluster (GATA3, PDZK1, TFF1 and ARHGEF17). ER negative lines most closely resembling the phenotype of basal-like breast cancers were identified as HMT3552, MDA-MB157 and MDA-MB468 based on the expression of a small number of basal genes (KRT5/14/17, S100A2, TRIM29).

Functional analyses of a small number of luminal and basal genes (including LCN2 and S100A7) was performed by combining RNAi trasnfection and microarray profiling in different cell lines.

CONCLUSIONS: The combination of purified normal cells and sporadic breast cancer cell lines with this type of molecular profiling helps to define model cell systems, events which drive tumorigenesis 
and targets for therapeutic intervention in different sub types of breast cancer.

\section{6}

Inhibitors of Hsp90 induce the degradation of HER2 and inhibit the growth of HER2-dependent breast tumors.

Solit DB, Basso A, Smith-Jones P, Modi S, Norton L, Larson S, Neckers L, Scher H, Hudis C, Rosen N. Memorial Sloan-Kettering Cancer Center, New York, NY; National Cancer Institute, Rockville, $M D$

Activation of HER2 by gene amplification occurs in $20-30 \%$ of human breast cancers. The anti-HER2 antibody Herceptin has antitumor activity in these patients when administered as a single agent and sensitizes tumors to taxanes and other cytotoxics. Although Herceptin is quite useful clinically, all patients with Stage 4 disease eventually develop resistance. It is not clear whether these tumors are still driven by HER2, but if so, alternative strategies for HER2 inhibition may be useful. The Hsp90 chaperone protein is required for the conformational maturation of "client" proteins many of which contribute to tumor initiation and progression. A family of natural products, including geldanamycin, bind to the ATP/ADP site in Hsp90 and inhibit its function. This causes the proteasomal degradation of its client proteins including HER2. Exposure of cells to low nM concentrations of 17-AAG, a geldanamycin derivative now being tested in the clinic, causes the rapid degradation of HER2, loss of phosphorylation of HER3, inhibition of PI3Kinase/AKT kinase signaling and concomitant loss in D-cyclin expression. This leads to growth arrest and sensitization of the cell to proapoptotic stimuli. 17-AAG potently degrades HER2 in tumors in vivo at non-toxic dosesand the pharmacodynamics of the drug can be assessed by dynamic PETimaging of loss of HER2 expression. 17-AAG has significant antitumor activity in HER2-driven xenograft and transgenic models and sensitizes these tumors to taxanes and enhances the activity of Herceptin. Thus, Hsp90 function can be inhibited in vivo by $17-\mathrm{AAG}$, with selective toxicity to tumor cells. These data form the basis for a clinical trial of this agent in advanced carcinoma of the breast.

\section{7}

Real-time dual-color imaging of trafficking, cellular dynamics, and viability of breast cancer cells in the portal vein.

Tsuji K, Yamauchi K, Yang M, Jiang P, Bouvet M, Al-Zaid M, Endo H, Kanai Y, Yamashita K, Moossa AR, Hoffman RM. AntiCancer, Inc., San Diego, CA; University of California, San Diego, San Diego, CA; Kyorin University, Tokyo, Japan

In the present study, we imaged trafficking, cellular dynamics, and viability of cancer cells after their injection into the portal vein (PV) of mice. We have genetically engineered dual-color fluorescent cells that express green fluorescent protein (GFP) linked to histone $\mathrm{H} 2 \mathrm{~B}$ in the nucleus and retroviral red fluorescent protein (RFP) in the cytoplasm. These dual-color fluorescent cells enable the visualization of cellular dynamics in vitro as well as in vivo. We observed cell trafficking in the PV in real time. Mouse mammary tumor MMT cells and HCT-116 human colon cancer cells labeled with GFP in the nucleus and RFP in the cytoplasm were injected in the PV of nude mice. The cells were continuously observed intravitally in the liver at the single-cell level in real time, using the Olympus OV100 Whole Mouse Imaging System. HCT-116 cells arrived at the peripheral glisson and impacted into sinusoids rapidly after injection. Most injected cells remained in sinusoids near peripheral portal veins. Only a small fraction of the cancer cells invaded the lobular area. Clasmocytosis (destruction of the cytoplasm) of the cancer cells occurred within 6 hours. The number of apoptotic cells rapidly increased within the portal vein within 12 hours of injection. Apoptosis was readily visualized in the dualcolor cells by their altered nuclear morphology. The data suggest frequent death of single HCT-116 cells in the PV. In contrast, dual-color MMT cells injected into the PV mostly survived in the liver of nude mice after 24 hours after injection. Surviving MMT cells showed invasive figures with cytoplasmic protrusions. The cells grew aggressively and formed colonies in the liver. This model should be useful for further understanding of the in vivo cell biology of cancer cells trafficking in the PV, a critical route for metastasis to the liver.

\section{8}

Breast cancer stromal fibroblast cells: in vitro characterization of activity, invasiveness and the effect of transforming growth factor beta 1 (TGF-B1).

Casey TM, Eneman J, Crocker A, White J, Tessitore J, Stanley M, Harlow S, Bunn J, Weaver D, Muss H, Plaut K. University of Vermont, Burlington, VT

Cancerous invasion is associated with a stromal reaction that contains: activated fibroblasts (myofibroblasts), remodeled ECM and angiogenesis. The clinical significance of these changes is not known. However, we hypothesize that it facilitates tumor invasion by providing scaffolding for tumor growth and invasion. Further, since TGF-B1 activates breast fibroblasts into myofibroblasts in vitro and induces a stromal reaction in mice, we hypothesize that TGF-B remodels the ECM creating an environment that promotes breast cancer (BC) invasion and metastasis. Our objective was to determine if fibroblasts isolated from $\mathrm{BC}$ patients are different from fibroblasts from reduction mammoplasty (RM) patients, and the differential effects of TGF-B1 on these cultures.

Tissue obtained at surgery for invasive BC $(n=29)$ or RM $(n=10)$ was used to isolate primary fibroblast cells by differential centrifugation. Experiments were performed between passages 310 and TGF-B 1 concentration was 0 or $2.5 \mathrm{ng} / \mathrm{ml}$. Cells were phenotypically characterized with positive vimentin and negative cytokeratin immunostaining. Myofibroblast activation was measured by counting cells immunostained for smooth muscle (sm)- $\alpha$-actin in cultures +/- TGF-B1. For RNA isolation, cultures were grown to confluence and media was changed to +/-TGF-B1. After $24 \mathrm{~h}$, conditioned media (CM) from cells was collected for invasion assays and cells were homogenized in TRiZol for RNA isolation. RT-Q-PCR was used to measure expression of c-myc, fibronectin, laminin, collagen IV, uPA, MMP-3 and sm- $\alpha$-actin. Boyden invasion chambers were plated with MDA-MB-231 cells in $0.1 \%$ BSA $(100,000$ cells/insert $), \mathrm{CM}$ from cells treated $+/$ TGF-B was added to bottom chamber, and incubated at $37 \mathrm{C}$ for 24 $\mathrm{h}$, The number of invaded cells were counted.

A greater percent of myofibroblasts were activated in cultures from BC patients and this effect was enhanced by TGF-B 1 treatment. Invasion rate of MDA-MB-231 cells was greater in chambers prepared with $\mathrm{CM}$ from fibroblast cultures derived from $\mathrm{BC}$ patients than from RM patients. Interestingly, although TGF$\mathrm{B} 1$ in control wells acted as a chemoattractant, $\mathrm{CM}$ from primary stromal cells decreased invasion relative to $\mathrm{CM}$ from non-TGF-B treated cultures. Thus, fibroblasts isolated from patients with $\mathrm{BC}$ are measurably different from RM patients indicating that the stroma may be an important player in mediating the carcinogenic response.

\section{9}

Spontaneous fusion of mouse stroma with transformed estrogen receptor-positive epithelium in a solid tumor model of human breast cancer.

Jacobsen BM, Harrell JC, Borges V, Garcia MV, Horwitz KB. Univiersity of Colorado Health Sciences Center, Aurora, CO

Background: Stromal influences on breast epithelium are commonly described, but little is known about the ability of tumor epithelium to modify the stroma that surrounds it.

Materials and Methods: Metastatic cells from the pleural effusion of a patient with ER+ breast cancer were cultured for 
several weeks, then grown in vivo into solid tumors in the mammary gland of ovariectomized nude mice supplemented with estradiol for 8 weeks. Tumors were isolated and paraffin embedded or returned to culture and expanded into cell lines. One cell line (BJ3Z) was karyotyped. Solid xenograft tumor sections, the BJ3Z cells, and a human tumor control were assayed by dual-colored FISH using SpectrumRed human and SpectrumGreen mouse Cot-1 DNA, and counterstained with DAPI. Immunocytochemistry for smooth muscle actin (SMA) and human specific CK7 was performed on the BJ3Z cells.

Results: Eighty-three (83) metaphase spreads were scored in BJ3Z cells. Seventy percent $(70 \%)$ had polyploid $(72-83 ; \sim 4 n)$ mouse karyotypes. However distinct human chromosomes (chr) were detected among the mouse chr in $30 \%$ of cells. Human chr 3 , $8, \operatorname{der}(?) \mathrm{t}(11 ; 14), 15,17,18,19,20,21, \operatorname{der}(\mathrm{X}) \mathrm{t}(\mathrm{X} ; 7)$ were found to be recurrent abnormalities in the "hybrid" cells. Among these, $8 \%$ carried mouse/human translocations. Two hundred (200) consecutive interphase nuclei were scored in BJ3Z cells, which showed an even higher proportion (64\%) of hybrid cells. Sections of the solid tumor were then analyzed by dual fluorescence microscopy and hybrid mouse/human nuclei were detected. BJ3Z cells stained positive for SMA and negative for human CK7 suggesting they are of mouse stromal origin.

Discussion: We conclude that formation of the synkaryons occurred in the solid tumor in vivo prior to culture, as a result of fusions between normal mouse mammary stromal cells and human malignant epithelial cells. While most studies have demonstrated stromal effects on the epithelium, we show here that epithelium can modify stroma. This has interesting implications for breast cancer biology.

\section{0}

Genetically modified HER2-specific $T$ cells recognize low and high HER2 expressing breast cancer cell lines.

Ahmed N, Ratnayake M, Pule M, Rooney CM, Heslop HE, Gottschalk S. Baylor College of Medicine, Houston, TX

Background: Only patients with breast cancers expressing high levels of HER2 benefit from anti-HER2 monoclonal antibodies such as trastuzumab. In the present study we investigated in vitro, if chimeric T-cell receptors (TCR), which combine the antigenspecificity of monoclonal antibodies with the effector function of $\mathrm{T}$ cells can overcome this limitation.

Material and Methods: $\mathrm{T}$ cells from healthy donors were transduced with retroviral vectors containing the HER2-specific chimeric TCR gene with a CD28-?zeta] signaling domain $(\mathrm{H}$ CD28-[zeta]). The specificity of the genetically modified T cells was determined by their ability 1) to kill breast cancer cell lines in cytoxicity assays, and 2) to proliferate and secrete cytokines (IFN- $\gamma$ and IL-2) after stimulation with breast cancer cell lines The following panel of cell lines was used: autologous PHA blasts, MDA-MB-468 (both HER2 negative), MCF-7 (HER2 low), Her218 and SKBR-3 (both HER2 high).

Results: H-CD28-[zeta] expressing T cells killed low and high HER2 positive breast cancer cell lines in cytotoxicity assays, where as HER2 negative T cells were not killed. Stimulation of T cells with low and high positive HER 2 positive breast cancer cell lines resulted in T-cell proliferation and secretion of IFN- $\gamma$ and IL-2 in a HER2 dependent manner.

Discussion: We demonstrate that MCF-7 cells activate $\mathrm{H}-\mathrm{CD} 28$ [zeta] expressing $\mathrm{T}$ cells, induce $\mathrm{T}$-cell proliferation, and the production of IL-2, an important T-cell growth factor. These results indicate that $\mathrm{T}$ cells expressing chimeric TCRs might extend the application of HER2 targeted therapies to HER2 low expressing malignancies.

\section{1}

Resistance to erbB targeted therapy in breast cancer.

Bacus S, Hortobagyi G, Spector N. Molecular Diagnostics, Westmont, IL; MD Anderson Cancer Center and GlaxoWellcome, Research Triangle Park, NC

\section{Background:}

ErbB receptors are associated with aggressive cancers and are therapeutic targets for drugs, such as antibodies or small molecules that block receptor activity and downstream pathways. Nuclear receptors, such as estrogen receptor (ER) and progesterone receptor (PR), are also targeted for anti-hormone therapies. There is an inverse correlation between ErbB receptors expression and ER and PR. Patients with increased expression levels of ErbB1 and ErbB2 anti-hormone therapies are less effective. The estrogen receptors pathway also upregulates the anti-apoptotic factor Bcl2. This study was directed at understanding the transregulation of these pathways and their association to resistance to erbB targeted therapy.

Methods:

cDNA was extracted and studied for gene expression from cells treated with a dual inhibitor to ErbB1and ErbB2. The breast cancer cell line that overexpresses ErbB2 was transfected with either ER or Bcl-2 cDNAs. The cells were treated with Herceptin or a dual EGFR/ErbB2 inhibitor. Cells were analyzed by microarray Western Blot analysis or by immunohistochemistry before and after treatment for markers such as EGFR, ErbB2, IGF-1R, TGF $\alpha$ Bcl-2, ER, PR, Cyclin D1, Survivin, FOXO 3, as well as phosphorylated forms of Erk, Akt and S6. In addition, breast cancer biopsies from patients treated with small molecule inhibitors to erbB receptors or antibodies were analyzed before and after treatments for the same markers.

Results:

Expression of ER, PR and Bcl-2 were associated with resistance to ErbB targeted therapies in cells and in patients. Anti-hormone therapies overcame this resistance. The effect of inhibition on ErbB receptors activity was associated with changes in calcium channels that resulted in upregulating the estrogen and $\mathrm{Bcl}-2$ pathways.

Conclusions:

The nuclear hormone receptor pathway and the ErbB oncogenic receptor pathway interact with each other to affect the response to ErbB targeted therapies. This study elucidates the patients' optimal sub-population, most likely to respond to ErbB targeted therapy as a single agent. In addition, strategies combining the selectivity of inhibitors to ErbB receptors together with antihormone therapies, hold promise in treating breast cancers.

\section{2}

Mammary cancers in mice expressing mutated Rad51.

Shulemovich E, Tornos C, Jasin M, Moynahan ME. Memorial Sloan-Kettering Cancer Center, New York, NY

The BRCA1 and BRCA2 hereditary breast cancer genes are involved in the repair of DNA double strand breaks by homology-directed repair (HDR). Although loss of BRCA1 and BRCA2 predispose to breast cancer, the breast tumors that arise from deficiencies in these proteins are separable by molecular analysis of gene expression patterns and genomic imbalances strongly suggesting different pathways to tumorigenesis. To further examine the role of defective HDR in mammary tumorigenesis we have mutated Rad51, the central repair protein in the HDR pathway. Rad51 forms a nucleoprotein filament with DNA at the site of the DNA double strand break, directs the homology search and promotes ATP-dependent strand exchange activities. Although coding region mutations in Rad51 are not observed in human tumors, aberrant expression and defective repair have been observed in tumor specimens and tumor derived cell lines. Like Brca1 and Brca2, knock out mouse models for Rad51 die early in embryogenesis. Expression of Rad51 mutant transgenes that disrupt ATP binding 
(Rad51 K133A) or ATP hydrolysis ( $\operatorname{Rad} 51 \mathrm{~K} 133 \mathrm{R})$ were previously shown to reduce HDR in cultured mammalian cells. To examine the effect of defective Rad51-mediated HDR on mammary tumorigenesis, mice that harbor the mutant Rad51 transgene were mated to doxycycline-regulatable MMTV-rtTA mice (Gunther et al., gift of L. Chodosh) to direct expression in mammary epithelial tissue following doxycycline administration. Incorporation of a luciferase reporter gene within the transgene construct allows imaging of the animals to assess for transgene expression, primary tumors and metastases. Development of the mammary gland is grossly intact and the bitransgenic animals successfully nurse their pups. Female mice were followed for tumor incidence. In a small cohort of doxycycline fed parous bi-transgenic mice mammary tumors occurred with complete penetrance, no mammary tumors occurred in the control single transgenic littermates. The mammary tumors that developed in the parous mice were of varied histology - including adenocarcinoma with secretory and squamous features and sarcoma. There was invasion into the surrounding chest wall muscles and soft tissue. Multifocal abnormalities of other mammary glands were also observed. Cohorts of virgin mice are being followed for mammary cancer incidence, but thus far the incidence is low in virgin animals with occasional tumors observed at long latency. Given that spontaneous chromosome abnormalities are a hallmark of cells defective for homology-directed repair, karyotypic analysis of tumor derived cells and array $\mathrm{CGH}$ are ongoing to assess for genomic instability.

\section{1}

Multi-centre independent validation of a gene prognostic signature for patients with node-negative breast cancer (BC) - final results.

Cardoso F, Piccart MJ, Viale G, Van ' $t$ Veer L, Saghatchiand'Assignies M, Glas A, Ellis P, Harris A, Bergh J, Lidereau R, Rutgers E, Delorenzi M, Bogaerts J, Therasse P, Lazar V, Amakrane $M$, Sotiriou C, Loi S, Buyse M. On Behalf of the TRANSBIG Consortium

Background: MINDACT will be the first clinical trial to prospectively evaluate the role of a genomic tool, the Amsterdam 70-gene prognostic signature, in BC management. Before its launch we ran an external independent validation of the signature. This was done on frozen archival tumour material from node negative $(\mathrm{N}-)$ pts aged $<61$, diagnosed $\leq 1998$ and receiving only locoregional therapy at 5 non-Dutch cancer centres. After initial results presented at SABCS 2004 (Piccart et al), final results with independent audit and central pathology review are given. Materials \& methods: Hazard ratios (HRs) were calculated to compare event rates in high vs low risk groups [events: time to distant metastases (TTDM), disease-free survival (DFS), overall survival (OS)]. Clinical risk groups were defined according to StGallen criteria (StG), Nottingham Prognostic Index (NPI), and Adjuvant! Online (AO) and determined by an independent statistician. Gene profiling (Agilent) was done at NKI "blinded" to clinical data. The microarray risk classification was reproduced in Lausanne, and central pathology review, for ER $(\mathrm{N}=218)$ and grade $(\mathrm{N}=237)$, was done in Milan. Centres were visited by two auditors for source data verification. Genomic low risk (GLR) group defined as 5 year distant metastasis free survival (DDFS) $>90 \%$. Clinical low risk (CLR) group defined as pts with 10-year survival probability $>88 \%$ if ER+, and $>92 \%$ if ER-. Results: This analysis refers to 302 validation pts ( 24 excluded by auditors). Median FU was 13.6 years, and 92 events occurred. The gene signature outperformed the three clinical tools in predicting a) TTDM: HR 2.32 (95\% CI 1.35-4.00) without adjustment for clinical risk, and to 2.15 (95\% CI 1.25-3.71), 2.32 (95\% CI 1.29-3.82) and 2.13 (95\% CI 1.19-3.82) when adjusted for StG, NPI and AO; b) $\underline{\text { OS}}$ : HR 2.79 (95\% CI 1.60-4.87) without adjustment, and 2.69 (95\% CI 1.57-4.99), 3.03 (95\% CI 1.65-5.59) and $2.66(95 \% \mathrm{CI}$ 1.46-4.84) when adjusted; and c) DFS: HR 1.50 (95\% CI 1.042.16) without adjustment, and 1.41 (95\% CI $0.97-2.06), 1.42$
(95\% CI 0.97-2.08) and 1.36 (95\% CI 0.91-2.03) when adjusted For pts with genomic high risk (GHR) the 10-year survival was 0.69 in both CLR and clinical high risk (CHR), while for pts at GLR the 10-year survival was 0.89 and 0.88 , respectively.Conclusions: 1) The 70-gene signature is a strong prognostic factor for TTDM, DFS and OS in untreated N- BC pts 2) The signature remains significant for TTDM and OS after adjustment for all known clinico-pathological prognostic factors. 3) Its prognostic value is almost completely independent from the definition of clinical risk. 4) Results provide level-3 evidence for clinical value of this new genomic tool. 5) Level-1 evidence will be provided by the MINDACT that will start in the fall of 2005.

\section{2}

Breast tumours with intermediate histological grade can be reclassified into prognostically distinct groups by gene expression profiling.

Sotiriou $C$, Wirapati $P$, Loi $S$, Viale $G$, Harris A, Bergh J, Smeds J, Farmer P, Praz V, Haibe-Kains B, Lallemand F, Desmedt C, Durbecq V, Larsimont D, Cardoso F, Buyse M, Delorenzi M, Piccart M. Jules Bordet Institute, Free University of Brussels, Brussels, Belgium; Swiss Institute of Experimental Cancer Research, Epalinges, Switzerland; The Weatherall Institute of Molecular Medicine, University of Oxford, Oxford, United Kingdom Karolinska Institute, Stockholm, Sweden; International Drug Development Institute, Brussels, Belgium; European Institute of Oncology, University of Milan, Milan, Italy

Background: Histological grade (HG) in breast cancer provides important prognostic information. Low and high grade (HG1 and HG3, respectively) tumours are known to have good and poor prognosis. However, intermediate grade (HG2) tumours present a difficulty in clinical decision making, because their survival profile is not different from that of the total (non-graded) population and their proportion is large (40\%-50\%). The aim of this study was to determine whether the prognostic value of grade could be refined by using gene expression profiling. Methods: Gene expression profiles (GEP) from Affymetrix U133A Genechips were contrasted between HG 1 (low grade) and 3 (high grade) tumours using a training set of 64 estrogen receptor (ER)-positive breast cancer samples. A score called the "gene-expression grade index" (GGI) based on the 128 most significant genes was defined and tested on a independent validation dataset of 129 tumour samples. A multiple independent external validation was also performed using three publicly available datasets from van de Vijver, M. J. et al. 2002, Sorlie et al. 2001 and Sotiriou et al. 2003 using different populations and microarray platforms (total=474 tumour samples). Results: HG 1 and 3 tumours were associated with distinct GEP and GGI values. The GGI clearly splits HG 2 (intermediate grade) tumours into high-risk (gene-expression grade GG 3) and low-risk (GG 1) groups with significantly different clinical outcomes (HR: 3.49, 95\% CI 2.14-5.69, $\mathrm{p}<0.0001$ ), similar to that of $\mathrm{HG} 3$ and 1 , respectively (HR: 3.48 , 95\% CI 2.26-5.36, $\mathrm{p}<0.0001)$. Replacing $\mathrm{HG}$ with genomic grade $(\mathrm{GG})$ in the Nottingham Prognostic Index significantly improved prognostic classification. Similar results were found when we applied GG to the 3 external independent datasets. We are currently validating our findings in the TransBig series of 302 tumour samples from 5 different European institutions from which grading was determined based on central pathology review in Milan. Conclusions: Geneexpression-based grading can significantly improve current grading systems for the prognostic assessment of breast cancer. Reproduction of these findings across multiple independent datasets and across different platforms suggests our findings are robust. Refined grading based on gene expression measurements can have important clinical implications for breast cancer management in the near future. 


\section{3}

A miniPathway for tamoxifen therapy resistance.

Jansen M, Foekens J, Ritstier K, van Staveren I, Meijer-van Gelder $M$, Sieuwerts A, Portengen H, Dorssers L, Klijn J, Berns E. Erasmus MC - Daniel den Hoed Cancer Center, Rotterdam, Netherlands; Erasmus MC, Rotterdam, Netherlands

Background: Our previously performed microarray analysis on primary breast cancer specimens identified Seven in Absentia Homolog 2 (= SIAH2) and Enhancer of Zeste Homolog 1 (= EZH1) to be differentially expressed in patients with advanced disease with a favourable and poor disease outcome, respectively, after first-line tamoxifen therapy. Interestingly EZH2, a homolog of EZH1, was shown to be a prognostic marker in breast and prostate cancer. Like SIAH2, EZH2 has been reported to bind to the proto-oncogene VAV1.

Patients and Methods: EZH1, SIAH2 and VAV1 and their homologs EZH2, SIAH1 and VAV3 were analysed with a quantitative RT-PCR assay in 253 estrogen receptor (=ER) positive primary breast carcinomas from patients with recurrent disease treated with first-line tamoxifen. Frozen primary tumor specimens were obtained from 54 patients with an objective response, 110 patients with stable disease and 99 patients with progressive disease after therapy. Expression levels of the genes were compared with housekeeper genes and correlated as continuous parameters with type of response and progression-free-survival using logistic and Cox regression analyses. In multivariable analysis, each gene was compared with the basic model of traditional predictive factors (i.e. menopausal status, disease-free interval, dominant site of relapse, $\log$ ER and $\log$ PR). All statistical tests were two-sided. Results: In uni- and multivariable analysis only EZH2, SIAH2 and VAV3 expression levels correlated significantly with antihormone therapy failure both in type of response and progressionfree-survival. When analysed in multivariable analyses, odds ratios for response are $0.65(\mathrm{P}=0.014), 1.69(\mathrm{P}=0.003)$ and 1.41 $(\mathrm{P}=0.029)$, for $\mathrm{EZH} 2, \mathrm{SIAH} 2$, and VAV3 respectively. With respect to progression-free-survival, hazard ratios are $1.25(\mathrm{P}=0.008)$, $0.75(\mathrm{P}<0.001)$, and $0.86(\mathrm{P}=0.044)$, respectively. Furthermore, SIAH2 and VAV3 expression levels correlated with each other and with ER level; EZH2 expression only anticorrelated with ER level. A stepdown multivariable regression analysis showed the EZH2:SIAH2 expression ratio to be superior to the basic model in predicting type of response (odds ratio $=0.56(\mathrm{P}<0.001)$ ) and progression-free-survival (hazard ratio $=1.35(\mathrm{P}<0.001)$ ). We propose a functional link between EZH2 and SIAH2 via VAV3 and ongoing studies, including RNA interference and expression vectors, are evaluating this "miniPathway" in relation with hormone therapy resistance in a panel of human breast cancer cell lines.

Conclusions: Upregulation of EZH2 and downregulation of VAV3 and SIAH2 correlate with tamoxifen therapy resistance. Data indicate that EZH2, SIAH2, and VAV3 may interact. Finally, EZH2 and SIAH2 seem to be involved in therapy resistance via different mechanisms, i.e. via an estrogen receptor dependent (SIAH2) and independent pathway (EZH2).

\section{4}

Gene expression profiles as predictors of response to neoadjuvant taxotere and adriamycin/cytoxan: a prospective randomized multicenter trial in breast cancer.

Chang JC, Hilsenbeck SG, Yee D, Ostler P, Tsimelzon A, Harrison M, Gutierrez MC, Elledge RM, O'Connell P, Osborne CK, Makris A. Baylor College of Medicine, Houston, TX; University of Minnesota; Mount Vernon Hospital, London, United Kingdom; Virginia Commonwealth University

Introduction: Previously, we had identified a 92-gene expression pattern that predicted response to neoadjuvant Taxotere in primary breast cancers. In this prospective, randomized, multicenter trial we set out to validate this profile, and to compare it with the molecular patterns for response to AC. We report here the clinical and early gene expression validation results of this study.
Methods: Patients were randomized to either 4 cycles of Taxotere $100 \mathrm{mg} / \mathrm{m}^{2}(\mathrm{~T})$, or 4 cycles of Adriamycin $60 \mathrm{mg} / \mathrm{m}^{2}$ plus Cytoxan $600 \mathrm{mg} / \mathrm{m}^{2}$ (AC), prior to surgery and clinical responses to these agents recorded. Core biopsies were obtained before chemotherapy and stored at $-80^{\circ} \mathrm{C}$ for subsequent gene expression array analysis. Double-stranded cDNA was synthesized using an oligo-dT primer containing a T7 RNA polymerase promoter, followed by in vitro transcription with biotinylated ribonucleotides. The labeled cRNA was hybridized to Affymetrix U133A chips, which comprise $\sim 22,200$ genes, to determine gene expression patterns.

Results: We have completed recruitment of 120 patients. Of these, 113 have completed the neoadjuvant phase and 105 have had surgery. Results on the 113 women (57 T-treated, 56 ACtreated), with median age of 48 yrs (range 30-72) are presented below. The pathological complete response was $9.4 \%$ vs. $7.7 \%$ in $\mathrm{T}$ and $\mathrm{AC}$, respectively. Clinical response rates $(\mathrm{CR}+\mathrm{PR})$ were also similar in both arms, $65 \%$ vs. $57 \%$ respectively. Higher grade 3 and 4 toxicities were observed with T, febrile neutropenia (23\% vs. $12 \%)$ and GI toxicity (13\% vs. $5 \%$ ), but these were not statistically significant. Gene expression results of the first 12 patients on $\mathrm{T}$ have been analyzed, and the 92-gene expression pattern correctly classified 7/8 clinically resistant cancers, and $2 /$ 4 sensitive cancers.

Conclusions: In this randomized prospective study, response rates to neoadjuvant $\mathrm{T}$ and $\mathrm{AC}$ were similar, with acceptable toxicity in both arms. We will present the validation results of gene expression patterns for $\mathrm{T}$, as well as the $\mathrm{AC}$ response patterns of all the patients enrolled in this multicenter prospective study. Gene expression array analysis of pretreatment biopsy specimens may allow selection of the most effective treatments for individual patients.

\section{5}

Predicting response to ixabepilone: genomics study in patients receiving single agent ixabepilone as neoadjuvant treatment for breast cancer (BC).

Baselga J, Gianni L, Llombart A, Manikhas G, Kubista E, Steger $G$, Lee H, Ronczka A, Xu L, Clark E, Galbraith S. Vall d'Hebron, Barcelona, Spain; Istituto Nazionale Per Lo Studio E La Cura Dei Tumori, Milan, Italy; Instituto Valenciano De Oncologia, Valencia, Spain; Municipal Oncology Outpatient Clinic, St Petersburg, Russian Federation; Medical University Vienna, Vienna, Austria; Bristol-Myers Squibb Pharmaceutical Research Institute, Princeton, NJ

Ixabepilone is a semi-synthetic analog of epothilone in Phase III trials in metastatic BC. This study was designed to discover candidate gene expression profiles to predict complete pathological response (pCR) to ixabepilone as neoadjuvant therapy for $\mathrm{BC}$.

Methods: Women with invasive stage IIA-IIIB BC with tumors $\geq 3 \mathrm{~cm}$ received $40 \mathrm{mg} / \mathrm{m}^{2}$ ixabepilone over 3-hours on Day 1 for up to four 21-day cycles, followed by surgery. Pathological response was assessed using the Sataloff criteria. Core needle biopsies were obtained pre-therapy for analysis of mRNA expression using Affymetrix HG-U133 2.0 arrays. Adjuvant chemotherapy with an anthracycline combination regimen, radiotherapy and tamoxifen were administered as indicated. 56 patients were randomly divided into a training $(n=34)$ and a validation set $(n=22)$. Penalized logistic regression with recursive feature elimination was used to select and to train the model to predict pCR. The model with the least cross-validation error and the fewest number of genes based on the training set was chosen to test on the validation set.

Results: A total of 164 patients were enrolled. Gene expression and clinical data are currently available for 56 and 96 patients respectively and will be updated on all 164 patients at the meeting. Median age was 56 yrs (range 27-79), 99\% were ECOG 0. TNM status T2/T3/T4 was $57 \% / 23 \% / 16 \%$, Grade $1 / 2 / 3 /$ unk was $11 \%$ / $40 \% / 24 \% / 25 \%$ and ER status of $+/$-/unk was $51 \% / 46 \% / 3 \%$. Grade $3 / 4$ neutropenia occurred in $14 \% / 5 \%$. Grade 2 toxicities for arthralgia/myalgia, neuropathy and mucositis were $23 \%, 12 \%$ and 
$4 \%$, grade 3 toxicities were $2 \%, 1 \%$ and $3 \%$ respectively. The pCR rate in the breast was $19 \%$. In the 56 patients with gene expression data available the pCR rate was $20 \%$ (21\% in the training set and $18 \%$ in the validation set).

A six gene model was selected using the training set. The prediction error for pCR in the validation set was $28 \%$, sensitivity $50 \%$, specificity $94 \%$, positive predictive value (PPV) $66 \%$ and negative predictive value (NPV) $89 \%$.

Conclusion: Based on this early analysis, ixabepilone has manageable toxicity, and a pCR rate which compares favorably to reported studies of single agent chemotherapy. Using a 6 gene predictive model, a PPV of $66 \%$ and NPV of $89 \%$ for pCR was obtained (i.e. of those who were marker positive vs negative the pCR rate was $66 \%$ vs $11 \%$ respectively). Such a predictive model could be used in future trials to select those patients likely to benefit from ixabepilone, and exclude those who are unlikely to respond to ixabepilone.

\section{6}

Affymetrix gene chip profile predicts pathologic complete response to preoperative paclitaxel/FAC chemotherapy in breast cancer.

Pusztai L, Hess KR, Gold DL, Anderson K, Ross JS, Valero V, Hortobagyi GN, Symmans WF. U.T. M.D. Anderson Cancer Center, Houston, TX; Albany Medical Center, Albany, NY

Purpose: Our goal was to develop gene expression based predictors of pathologic complete response (pCR) to preoperative chemotherapy using Affymetrix Gene Chips and define an optimal predictor for prospective validation. Patients: Eighty-two patients with stage I-III breast cancer were included. Fine needle aspirations were collected before starting chemotherapy with sequential paclitaxel and 5-fluorouracil, doxorubicin, cyclophosphamide. Gene expression profiling was performed with Affymetrix U133 A chips. We developed multi-gene predictors of pCR using supervised learning algorithms and used complete cross-validation to estimate how well the classifiers would perform on independent cases. Results: The overall pCR rate was $26 \%$. We identified 56 differentially expressed probe sets (49 genes) between cases with pCR versus residual disease at a false discovery rate of $1 \%$. We examined the performance of 546 distinct classifiers (set of genes + prediction algorithm). The vast majority of these classifiers yielded fully cross-validated performance estimates that were within 2 standard deviations of each other. We selected a 30-probe set (26-gene) DLDA classifier for independent validation in an ongoing randomized trial. This classifier yielded cross-validated estimates of $81 \% \pm 5 \%(\mathrm{SD})$ for overall accuracy and $92 \% \pm 3 \%$ for area under the ROC curve $(73 \%$ and $78 \%$, respectively when adjusted for gene selection). Conclusion: Multiple overlapping gene sets and several different prediction algorithms can yield predictors that show similar performance in full cross validation. The estimated predictive accuracy of these tests is within a clinically useful range.

\section{7}

Transcriptional profiling can predict the achievement of a pathologic complete response (pCR) after preoperative chemotherapy (PST) with gemcitabine (G), epirubicin (E) and docetaxel (Doc) in primary breast cancer (PBC) with high accuracy.

Schneeweiss A, Thuerigen O, Toedt G, Warnat P, Hahn M, Schuetz $F$, Lauschner I, Benner A, Brors B, Sinn H-P, Sohn C, Lichter P. University, Heidelberg, Germany; German Cancer Research Center, Heidelberg, Germany

Objectives: To evaluate the utility of a multigene predictor of pCR to PST for PBC, and to identify and validate a gene expression signature predicting pCR to PST with G, E and Doc administered either as triple therapy (6xGEDoc $800 \mathrm{mg} / \mathrm{m}^{2}$ day (d) $1+8 / 90 \mathrm{mg}$ / $\left.\mathrm{m}^{2} \mathrm{~d} 1 / 75 \mathrm{mg} / \mathrm{m}^{2} \mathrm{~d} 1 \mathrm{q} \mathrm{d} 21\right)$ or sequentially $\left(5 x \mathrm{GE} 1250 \mathrm{mg} / \mathrm{m}^{2} \mathrm{~d} 1 /\right.$ $100 \mathrm{mg} / \mathrm{m}^{2}$ d1 q d $14 \rightarrow 4 x$ Doc $80 \mathrm{mg} / \mathrm{m}^{2}$ d 1 q d14).

Patients and Methods: 98 patients (pts) with T2-4 N0-2 M0 PBC underwent pretreatment core needle biopsy to collect snap frozen tissue for microarray analysis. Small amounts of breast tumor RNA were amplified with a newly developed amplification protocol. Comprehensive RNA expression profiles were generated using DNA microarrays carrying 21.329 unique gene specific 70mer oligonucleotide probes. Analysis was started with a training data set of 50 pts who received $5 \times \mathrm{xGE} \rightarrow 4 \mathrm{xDoc}$ (pCR $\mathrm{n}=15$; non-pCR $\mathrm{n}=35$ ). Results were validated on an independent data set of 48 pts who received $6 x$ GEDoc $(\mathrm{pCR} n=9$; non-pCR $\mathrm{n}=39$ ).

Results: The Support Vector Machine algorithm was applied in combination with a recursive feature elimination approach for building a predictive model based on the training data set. Cross validation of predictive models based on differently sized sets of genes was performed showing that the number of genes can be reduced to 512 without decreasing the performance of the model. The most significant pathways included in the final set of 512 genes were regulators of BRCA1 and Ras signaling. By applying this classifier to the independent test set of 48 pts prediction of pCR was achieved with a sensitivity of $78 \%$ and a specificity of $90 \%$ for an overall accuracy of $88 \%$ (95\% confidence interval, $75-95)$. The positive and negative predictive value was $64 \%$ and $95 \%$, respectively. Overall accuracy and predictive value of the signature in predicting a pCR was superior to those data of the conventional parameters ductal invasive histology, tumor grade 3 , achievement of a partial remission after 6 weeks of PST or absence of hormone receptors. A multivariate logistic regression analysis showed that only gene expression signature and her2 overexpression $\left(3+\right.$ by HercepTest $\left.{ }^{\mathrm{TM}}\right)$ were independent predictors for the achievement of a pCR.

Conclusions: Our results show that transcriptional profiling can identify a gene expression signature in T2-4 N0-2 M0 PBC that may serve as a clinically useful independent predictor of $\mathrm{pCR}$ to PST containing G, E and Doc. Thus, a highly efficient selection of pts benefiting from these drugs could be achieved.

\section{8}

Measurements of estrogen receptor and reporter genes from microarrays determine receptor status and time to recurrence following adjuvant tamoxifen therapy.

Symmans WF, Sotiriou C, Anderson SK, Hatzis C, Valero V, Booser DJ, Larsimont D, Desmedt C, Gold DL, Sneige N, Cristofanilli M, Arun B, Gong Y, Ross JS, Hess K, Piccart MJ, Harris AL, Hortobagyi GN, Pusztai L. M.D. Anderson Cancer Center, Houston, TX; Institut Jules Bordet, Brussels, Belgium; Nuvera Biosciences, Inc., Woburn, MA; Albany Medical College, Albany, NY; Oxford University, Oxford, United Kingdom

Purpose: To determine the accuracy and clinical relevance of gene expression levels for estrogen receptor (ER) and co-expressed ER reporter genes in breast cancer.

Materials and Methods: Gene expression profiles of newly diagnosed breast cancer were obtained from 82 fine needle aspiration (FNA) samples and 136 frozen tissue samples in two different laboratories using Affymetrix U133A GeneChip technology. Immunohistochemistry (IHC) and/or enzyme immunoassay (EIA) were used to define ER status. All expression data were normalized using a single digital standard (dCHIP software). ER gene expression (ER mRNA), EIA, a 200-gene ER reporter index (defined from an independent public dataset), and the product of ER mRNA and reporter index (RI) were all dichotomized at their median, and IHC by Allred score $(<=6$ vs $>=7$ ). These were each included in Cox proportional hazards models with tumor size ( $\mathrm{T} 1 \mathrm{vs}>=\mathrm{T} 2$ ), nodal status, grade, and age (dichotomized at median) to evaluate distant relapse-free survival (DRFS) in 96 of the patients with ER-positive breast cancer who received only adjuvant tamoxifen therapy.

Results: ER mRNA level (probe ESR1 205225_) >= 500 (arbitrary units) defined ER-positive status (IHC $>=10 \%$ ) in FNAs and 
tissues (overall accuracy 96\%, 95\%). ER mRNA correlated with IHC (Allred score) and EIA $(\mathrm{R}=0.85,0.58)$. Lower ER mRNA predicted worse DRFS (HR 2.00, p = 0.02), especially when combined with RI (HR 2.30, p=0.006), but EIA and IHC were not significant. Tumor size was also independently significant (HR $2.78, \mathrm{p}=0.002$ ). In tumors $>2 \mathrm{~cm}$, higher ER mRNA with higher RI predicted $100 \%$ DRFS at 5 years, higher ER mRNA with lower RI predicted $80 \%$ DRFS, and lower ER mRNA predicted $50-60 \%$ DRFS.

Discussion: Expression values of ER mRNA and an ER reporter index from Affymetrix GeneChips accurately determine ER status, are comparable in FNA and tissue samples from two independent laboratories, and predict DRFS in women who receive adjuvant tamoxifen.

\section{9}

Feasibility of gene expression profiling in community hospitals; preliminary results of a pilot study in $\mathbf{N}_{0}$ breast cancer patients.

Bueno de Mesquita JM, Van De Vijver MJ, Peterse JL, Rutgers EJTh, Van ' $t$ Veer LJ, Van Harten WH, Van Dam FSAM, Karsenberg KF, Douma K, Van Tinteren H, Floore AN, Glas AM, Rodenhuis S, Linn SC. The Netherlands Cancer Institute-Antoni van Leeuwenhoek Hospital, Amsterdam, Netherlands; Agendia, Amsterdam, Netherlands

Background: Recently we have identified a gene expression profile of 70 genes using microarray analysis (70-gene MA test), which was a more powerful prognostic factor for freedom of distant metastases than current clinicopathological features in node negative breast cancer patients up to 55 years of age (van ' $t$ Veer et al., Nature 2002; Van de Vijver et al., New Engl J Med 2002). To assess whether this 70-gene MA test can be implemented in daily clinical practice we aimed to answer the following three questions: I. Is it feasible to collect fresh tumor samples in order to make this test available in $\mathrm{pN}_{0}$ breast cancer patients in community hospitals? II. What is the proportion of a "poor prognosis" versus a "good prognosis" in current node negative patients? III. What is the concordance between the 70-gene MA risk profile and the metastasis risk as assessed with current Dutch guidelines based on clinicopathological factors (such as age, pT, tumor grade, hormonal receptor-status)?

Patients \& Methods: Women younger than 61 years presenting with cT1-2N0M0 unifocal breast cancer were eligible to participate and entered onto this prospective study after informed consent. Fresh tumor tissue samples were collected within one hour after surgery and sent in RNAlater® to our hospital. A 70-gene MA test was performed in node negative patients with a representative tumor tissue sample; $\mathrm{pN}+$ patients were excluded. According to current Dutch guidelines (used for guiding adjuvant systemic treatment) for node negative patients, high risk is defined as age $\leq 35$ years, pT any size and grade $2-3$ or pT $>1 \mathrm{~cm}$ and grade 1 , or age $>35$ years, pT1-2 $\mathrm{cm}$ and grade $3, \mathrm{pT} 2-3 \mathrm{~cm}$ and grade $2-3$ or pT $>3 \mathrm{~cm}$ and any grade; all others are defined as low risk.

Results: Thus far, 214 patients were included (average age 50 years) and 11670 -gene MA tests were performed. Ninety-eight $(46 \%)$ patients were excluded postoperatively because of $\mathrm{pN}+$ $(51 / 214 ; 24 \%)$ or inadequate tumor samples $(47 / 214 ; 22 \%)$. For $54(47 \%)$ patients a poor prognosis 70 -gene MA-risk profile was found; for $62(53 \%)$ a good prognosis profile. In 37\% (43/116) of the patients the 70 -gene risk profile was discordant with risk assessment based on clinicopathological factors according to the Dutch guidelines.

Conclusion: These first results show that the implementation of the 70-gene MA test in community hospitals is feasible. Furthermore, the 70-gene MA risk profile is discordant in a substantial proportion of lymph node negative breast cancer patients compared with metastasis risk assessed with conventional clinicopathological factors according to Dutch guidelines.

\section{0}

Measurement of gene expression using tissue microarray cores of paraffin embedded breast cancer tissue.

Baker J, Salter J, Liu M-L, Hackett JR, Cronin M, Shak S, Dowsett M. Genomic Health, Inc., Redwood City, CA; Royal Marsden Hospital, London, United Kingdom

Introduction. High throughput RT-PCR technology can be used to profile gene expression in fixed paraffin-embedded (FPE) tumor specimens and predict distant recurrence (Paik et al. NEJM [2004]). However, in many studies, limited amounts of FPE tissue are available, for example as $600 \mu \mathrm{m}$ cores in the form of tissue microarrays (TMA). We conducted a feasibility study to determine first, whether the standard 21 gene Oncotype DX assay can be obtained with such limited FPE tissue, and second, whether RNA amplification prior to RT-PCR can be successfully performed to maximize the number of additional genes that can be correlated with prognosis and treatment benefit.

Methods. Single cores $(600 \mu \mathrm{m}$ diameter, $\sim 0.2 \mathrm{~mm}$ long) were taken from 8 tumor blocks prepared from excisions of invasive breast cancer from patients in the IMPACT trial. RNA was extracted and total RNA content was determined using the RiboGreen fluorescence method. The standard Oncotype DX 21 gene assay was performed on $375 \mathrm{ng}$ of unamplified RNA. In addition, $50 \mathrm{ng}$ of RNA was amplified, and then analyzed by the Oncotype DX assay. The RT-PCR results using unamplified and amplified RNA were compared.

Results. Sufficient total RNA ( $>375 \mathrm{ng}$ ) was obtained in all 8 specimens (mean RNA yield $1066 \mathrm{ng}$, range 510 - $3276 \mathrm{ng}$ ) to run the standard Oncotype DX assay without pre-amplifying RNA. Gene expression profiles in all 8 specimens for the 21 gene Oncotype DX assay on unamplified RNA had strong signals and met all criteria for successful RT-PCR. As has been observed in all other breast cancer studies, the range of expression of genes is very large (e.g., 1000-fold range in quantitative expression of ER). Profiles for 3 of the samples were typical of ER negative tumors and profiles for 5 of the samples were typical of ER positive tumors. RNA amplification yielded a 100-200 fold increase in total RNA. Overall, profiles and Recurrence Scores obtained using amplified RNA were similar to those obtained with unamplified RNA. Amplified RNA can be used for screening studies, but further work will be required to provide high fidelity. We are currently assessing the phenotype of these samples by conventional means to correlate with the quantitative RT-PCR expression results. Conclusion: Gene expression profiling from very small FPE specimens taken for TMA construction is feasible using RT-PCR.

\section{1}

Validation of HOXB13, IL17BR and CHDH as predictors of clinical outcome of adjuvant tamoxifen monotherapy in breast cancer.

Erlander MG, Ma XJ, Hilsenbeck SG, Sgroi DC, Osborne CK, Allred DC. Arcturus Bioscience, Inc., Mountain View, CA; The Breast Center, Baylor College of Medicine, Houston, TX; Massachusetts General Hospital, Harvard Medical School, Boston, $M A$

Background: We previously showed that microarray-based expression levels of HOXB13, IL17BR, and CHDH, and the HOXB13:IL17BR composite index, in particular, strongly predicted clinical outcome in a case-controlled, retrospective 60patient cohort of breast cancer patients, all treated with tamoxifen monotherapy (Ma XJ et al. Cancer Cell, 2004). The predictive utility of the HOXB13:IL17BR index was initially confirmed in an independent cohort of 20 patients. These three genes have not been previously associated with breast cancer and estrogen signaling. Further validation of these potential new biomarkers in larger clinical cohorts is therefore needed.

Materials and Methods: Expression of HOXB13, IL17BR, $\mathrm{CHDH}, \mathrm{ERa}$ and PR and 4 reference genes (ACTB, HMBS, SDHA, 
UBC) were analyzed by TaqMan real-time PCR in tissue sections of formalin-fixed paraffin-embedded breast cancer biopsies from 1002 breast cancer patients. PCR data and clinical variables (tamoxifen therapy, nodal status, ER/PR status, tumor size, Sphase fraction) were analyzed for association with disease-free survival (DFS) in both univariate and multivariate Cox regression models

Results: PCR data from $852(85 \%)$ patients were obtained. Higher levels of HOXB13 and lower levels of IL17BR and CHDH expression correlated significantly with shorter DFS $(p<0.01)$ in the entire cohort. In particular, the HOXB13:IL17BR index (computed as a difference of standardized log transformed values) was significantly associated with DFS in node-negative patients but not in node-positive patients. In addition, breast cancer from node-positive patients had significantly higher HOXB13:IL17BR index values than that from node-negative patients. Finally, in multivariate analysis including age, PR, tumor size, S-phase fraction and aneuploidy, HOXB13:IL17BR index remained a significant predictor $(p<0.001)$ in ER-positive, node-negative patients. Conclusion: This retrospective tumor bank study demonstrated that the HOXB13:IL17BR index is a strong independent prognostic factor in breast cancer in both untreated and tamoxifen-treated patients. In addition, HOXB13:IL17BR index significantly correlated with nodal status, suggesting that HOXB13 and IL17BR might be associated with metastasis potential in breast cancer. This and earlier studies together demonstrate potential clinical utility of these novel biomarkers in predicting clinical outcome for patients with ER-positive, node-negative breast cancer patients.

\section{2}

A two-gene expression ratio of HOXB13 and IL-17BR for prediction of recurrence and survival in women receiving adjuvant tamoxifen.

Goetz MP, Suman VJ, Ingle JN, Nibbe AM, Visscher DW, Reynolds $C$, Lingle WL, Erlander MG, Ma XJ, Sgroi DC, Perez EA, Couch FJ. Mayo Clinic College of Medicine, Rochester, MN; Arcturus Bioscience, Mountain View, CA; Harvard Medical School, Boston, MA; Mayo Clinic College of Medicine, Jacksonville, FL

Background: The homeobox 13 (HOXB13) gene is a marker of invasion and metastasis. The HOXB13 to interleukin-17 B receptor (IL-17BR) expression ratio was recently discovered to predict relapse and survival in patients (pts) treated with tamoxifen as adjuvant therapy for estrogen receptor (ER) positive breast cancer (Ma XJ, et al. 2004; Cancer Cell)

Methods: We sought to validate these findings by determining whether the HOXB13 to IL-17BR ratio was predictive of relapse and survival in a cohort of women with early stage ER positive breast cancer enrolled onto a North Central Cancer Treatment Group adjuvant trial (NCCTG 89-30-52) in which pts received 5 years of adjuvant tamoxifen monotherapy.

Results: Tumor blocks were obtained from 211 of 256 eligible pts and quantitative RT-PCR profiles for HOXB13 and IL-17BR were obtained from $206(98 \%)$. The median length of follow-up was 11.0 years (range: 5.7-13.6 yrs). The optimal cut-point for the two gene $\log _{2}$ (expression ratio) that best discriminated clinical outcome (recurrence and survival) was at the $58^{\text {th }}$ percentile of the observed HOXB13 to IL-17BR expression ratio distribution (1.85 ), but differed as a function of nodal status [lymph node (LN) negative tumors $\left(59^{\text {th }}\right.$ percentile; -1.34$)$ versus $L N$ positive $\left(90^{\text {th }}\right.$ percentile; 4.4)]. Overall, pts with a HOXB13 to IL-17BR ratio > $-1.849(n=84)$ had significantly worse relapse free survival (RFS), disease free survival (DFS), and overall survival (OS), independent of standard prognostic markers [ER, PR, HER-2, tumor grade, tumor size and LN status], than pts with ratios $<-1.849(\mathrm{n}=122)$. However, the HOXB13 to IL-17BR ratio performed best in the node negative cohort $(n=130)$ and consistently predicted survival in the univariate $(\mathrm{p}<0.0001)$, multivariate (HR 2.4, 95\% CI 1.19$4.84, \mathrm{p}=.014$ ), and multivariate cross validation analyses (HR
$2.01 ; 95 \%$ CI $1.02-3.99 ; \mathrm{p}=0.045)$. There were no events (recurrence or death) observed in the LN negative pts with HOXB13 to IL-17BR ratio $<-1.34$ during the first 2 years of follow-up.

Conclusion: The HOXB13 to IL-17BR ratio is predictive of relapse and death in node negative, ER positive tamoxifen treated breast cancer and may account for the early peak in the hazard rate for relapse seen following the initiation of adjuvant tamoxifen. Women identified to be at high risk of recurrence by means of this marker may benefit from upfront aromatase inhibitors and/or chemotherapy.

\section{1}

Axillary recurrence after negative SLN biopsy.

Ly $Q P$, White L, Dupont E, Cox C, Reintgen D, Dessureault $S$. Moffitt Cancer Center, Tampa, FL

Background: Lymphatic mapping and sentinel lymph node (SLN) biopsy have replaced axillary lymph node dissection (ALND) as the definitive nodal staging procedure for breast cancer because SLN biopsy has been proven to cause less morbidity and be more cost effective than complete ALND. Short-term follow-up has shown that lymphatic mapping and SLN have a low false negative, but there is not yet any published data showing long-term outcome with large sample size.

Materials \& Methods: This is a retrospective review of a prospective database on 1680 breast cancer patients who were treated at Moffitt Cancer Center with complete ALND (before SLN), both SLN and ALND (during the SLN trial in 1994), and SLN alone.

Prior to April 1994, 607 breast cancer patients were treated with ALND and were found to have negative nodes (first control group). Between April 1994 and August 2000, 1702 consecutive patients with clinically node-negative breast cancer were mapped at the MCC. Lymphatic mapping was successful in identifying the SLN in 1638 patients $(96.2 \%) .551$ patients $(33.7 \%)$ were found to have metastatic disease either by hematoxylin and eosin stains or by cytokeratin immunohistochemistry. 1086 patients $(66.3 \%)$ had negative sentinel lymph node biopsies. The first 120 patients in this group all underwent ALND (second control group). Two patients in this group were found to have metastatic disease in the nodal basin (False Negative Rate $=2 \%$ ).

The subsequent 965 patients who had a negative SLN without further nodal dissection have been observed (study group). All patients were followed either at MCC or by their local physicians who correspond with MCC with updates on the patients' disease status.

Lymphatic mapping was performed using $\mathrm{Tc}^{99 \mathrm{~m}}$-labelled sulfur colloid and isosulfan blue dye. A SLN was defined as any blue node and/or any hot node with ex vivo radioactivity counts $>10$ times an excised non-SLN or in situ radioactivity count $>3$ times the background counts.

Results: Mean follow-up is 63.3 months; median follow-up is 68.1 months (range: 0.3 - 101 months). Over 8 years of follow-up, there have been 74 deaths, 55 total recurrences, 23 ipsilateral breast recurrences, 2 contralateral breast cancers, 28 distant metastases, and 2 ipsilateral axillary recurrences in our study group $(n=965)$. In the control group $(n=727)$, over 18 years of followup (mean: 7 years), there were 126 deaths, 80 total recurrences, 52 ipsilateral breast recurrences, 2 contralateral breast cancers, 20 distant metastases, and 2 ipsilateral axillary recurrences. The recurrence rate and overall survival are not different than that of historical controls who had a complete ALND and a negative node status.

Conclusion: Our data confirm that SLN biopsy is an effective and safe alternative to ALND for the detection of nodal metastases in patients with invasive breast cancer and should be used as the standard tool for nodal staging as well as treatment for these patients. 


\section{2}

Low local-regional failure rates in selected breast cancer patients with tumor-positive sentinel nodes who do not undergo completion axillary dissection.

Hwang RF, Gonzalez-Angulo AM, Yi M, Buchholz TA, MericBernstam F, Ames FC, Kuerer HM, Ross MI, Singletary SE, Babiera GV, Feig BW, Hunt KK. UT-M.D. Anderson Cancer Center, Houston, $T X$

Background: Recently, clinicians have elected to avoid completion axillary dissection in selected breast cancer patients with tumorpositive sentinel lymph nodes (SLN). The purpose of the current study was to examine the long-term safety of such an approach in this selected group of patients.

Methods: The records of all patients with invasive breast cancer who underwent SLN biopsy at our institution between 1993 and December 2004 were reviewed. 3366 patients underwent a SLN biopsy and 750 had a positive SLN. 196 patients (195 female, 1 male) with a positive SLN did not undergo completion axillary dissection (CLND) based on clinician and patient preference. SLNs were considered positive if tumor cells were identified by hematoxylin and eosin (H\&E) staining or by cytokeratin on immunohistochemistry (IHC). Clinicopathologic variables, treatment patterns and long-term local-regional, distant recurrence and survival were analyzed.

Results: The majority of the tumors were infiltrating ductal carcinomas (74\%), ER positive (82\%), PR positive (69.9\%), HER$2 /$ neu negative $(78.6 \%)$ and negative for lymphovascular invasion $(58.7 \%)$. Primary tumors were predominantly $\mathrm{T} 1$ or $\mathrm{T} 2(72.4 \%$ and $23.0 \%$, respectively) with the remainder $\mathrm{T} 3$ and $\mathrm{T} 4(3.6 \%$ and $1.0 \%$, respectively). The mean number of SLNs removed was 3.7 (range, 1-14), and the mean number of positive SLNs was 1.2 (range, 1-6). The majority of the SLNs were positive by H\&E $(64.3 \%$ ), while $35.7 \%$ of SLNs were positive by IHC only. Extracapsular extension was present in $6.6 \%$ of the positive SLNs. Most patients underwent breast conserving surgery (54.6\%) and radiation therapy was utilized in $61.7 \%$ of patients. Chemotherapy was utilized in a neoadjuvant setting in $14.3 \%$ and as adjuvant treatment in $55.6 \%$ of patients. Endocrine therapy was the sole adjuvant treatment in $17.3 \%$ of patients. With a median followup of 29.5 months (range, 1.3-62.3 months), two patients have died of unrelated causes. Of the remaining 194 patients, none have developed axillary recurrence, 1 patient has developed supraclavicular nodal recurrence and three have developed metastatic disease to the lung (2) or bone (1). The median time to recurrence was 27.0 months (range, 11.4-40.1 months). Conclusion: In selected patients with tumor-positive SLN, longterm follow-up at our institution suggests that the local-regional failure rate is low without CLND. Multi-center prospective studies will be valuable to corroborate these results and to determine which patients are at risk for nonsentinel lymph node involvement and higher rates of axillary recurrence.

\section{3}

Additional axillary metastases and stage migration in patients with micrometastases or submicrometastases in sentinel lymph nodes.

van Rijk MC, Peterse JL, Nieweg OE, Rutgers EJ, Oldenburg HS, Kroon BB. The Netherlands Cancer Institutel Antoni van Leeuwenhoek Hospital, Amsterdam, Netherlands

Background: Axillary lymph node dissection (ALND) is standard of care in breast cancer patients with a tumor-positive sentinel node. Due to step-sectioning and immunohistochemical staining, micrometastases (between 0.2 and $2 \mathrm{~mm}$ ) and submicrometastases (less than $0.2 \mathrm{~mm}$, isolated tumor cells) are increasingly found in sentinel nodes. The clinical relevance of these metastases is still unknown and the need for ALDN in the patients concerned is subject of debate. The aim of this study was to investigate the incidence of micro- and submicrometastases in the sentinel node, the incidence and size of additional metastasis in the ALND specimen, and the implications for staging.

Patients and Methods: Between 1999-2004, 2150 breast cancer patients received treatment for breast cancer at out institute and had undergone sentinel lymph node biopsy. All sentinel nodes were formalin-fixated, bisected, paraffin-embedded and cut at a minimum of three levels at 50 to $150-\mu \mathrm{m}$ intervals. Pathological evaluation included haematoxylin-eosin and immunohistochemical staining.

Results: 650 patients $(30 \%)$ had a tumor-positive axillary sentinel node, 148 of them (23\%) had micrometastases and $106(16 \%)$ had submicrometastases.

A total of 106 of the 148 patients with micrometastases underwent ALND and additional metastases were found in 20 patients $(19 \%)$. Sixteen of these patients $(15 \%)$ had macrometastases and were upstaged from $\mathrm{pN} 1 \mathrm{mi}$ to $\mathrm{pN} 1 \mathrm{a}$ or $\mathrm{pN} 2 \mathrm{a}$. Four patients had additional micrometastases.

Fifty-four of the 106 patients with submicrometastases underwent lymph node dissection. Two (4\%) had additional macrometastases and were upstaged from $\mathrm{pN} 0$ to $\mathrm{pN} 1 \mathrm{a}$, and another two had additional micrometastases.

Conclusion: In $39 \%$ of the patients with a positive sentinel node the nodal involvement consisted of micro- or submicrometastases. Additional metastases were found in $19 \%$ and $7 \%$ respectively, and upstaging occurred in $15 \%$ and $4 \%$ respectively. Based on these findings, we recommend additional treatment of the axilla in patients with micrometastases but to refrain from ALND in patients with submicrometastases in their sentinel node. Pathological work-up should focus on the detection of macro- and micrometastases, and not on the detection of submicrometastases.

\section{4}

Predicting negative axillary lymph node dissection in patients with positive sentinel lymph node biopsy: can a subset of patients be spared axillary dissection?

Rescigno J, Taylor LA, Aziz MS, Axelrod DM, Bernik S, Vallejo CE, Riegel AC, Troob SH, Klein P. St. Vincents Comprehensive Cancer Center, New York, NY; New York Medical College, Valhalla, NY; New York University, New York, NY

Background: Factors predictive of absence of disease at axillary lymph node dissection (ALND) may allow selected patients (pts) with positive sentinel lymph node (SLN) biopsy to avoid ALND or axillary irradiation.

Patients and Methods: From 8/02 to 8/04, 77 pts (76 women and 1 man) at a single institution had positive SLN biopsy and underwent ALND (6-35 non-SLN dissected-median 16). Four pts with only clusters in SLN were excluded (all 4 had T1a/T1b tumors and negative ALND). Clinicopathologic factors associated with non-SLN involvement were determined by Pearson chi-square test and binary logistic regression. Odds ratios (OR) were determined for significant variables $(\mathrm{p}<0.05$, two-sided) derived from univariate and multivariate analyses.

Results: The mean number of SLN (+/- 95\% CI) was $3.2(2.8$ 3.7). The mean number of lymph nodes removed at the time of SLN biopsy (SLN and palpable non-SLN) was 4.5 (3.8-5.2). NonSLN (palpable non-SLN and/or nodes from completion ALND) were involved in $39 \%$ of patients, and completion ALND nodes were involved in $31 \%$ of patients. In univariate analysis, the following factors were significant for non-SLN involvement: proportion of SLN involved as a continuous variable: $\mathrm{OR}=1.2$ per $10 \%, \mathrm{p}=0.02)$, SLN extracapsular extension (ECE) (58 \% vs. 29 $\%, \mathrm{OR}=3.3, \mathrm{p}=0.02$ ), primary tumor perineural invasion $(\mathrm{PNI})$ ( $58 \%$ vs. $30 \%, \mathrm{OR}=3.2, \mathrm{p}=0.02)$; primary tumor multicentricity ( $83 \%$ vs. $35 \%, \mathrm{OR}=9.2, \mathrm{p}=0.02$ ); number of SLN positive: $2+$ vs. one $(56 \%$ vs. $31 \%, \mathrm{OR}=2.9, \mathrm{p}=0.03)$, grade $2 / 3$ vs. grade $1(43 \%$ vs. $0 \%, \mathrm{OR}=1.8, \mathrm{p}=0.03$ ), and size of $\mathrm{SLN}$ involvement: macro vs. micro ( $36 \%$ vs. $12 \%, \mathrm{OR}=4.2, \mathrm{p}=0.03)$. In multivariate analysis, proportion of involved SLN (OR=1.2 per $10 \%, \mathrm{p}=0.02)$, 
ECE $(\mathrm{OR}=3.1, \mathrm{p}=0.04)$, and PNI $(\mathrm{OR}=3.1, \mathrm{p}=0.04)$ were independently associated with non-SLN involvement. Based on this analysis, a subgroup of pts with a low risk of completion ALND involvement was defined: pts with involvement of fewer than half of nodes retrieved at the time of SLN biopsy, without PNI, and without SLN ECE accounted for $29 \%$ of pts in this series. These pts had a $4.5 \%$ risk of ALND involvement, in contrast to pts with one or more of these adverse factors, who had a $42 \%$ risk of ALND involvement.

Conclusion: A subgroup of pts could be identified that had less than 5\% risk of completion ALND involvement, potentially sparing nearly one-third of women with positive SLN the morbidity of ALND or axillary radiotherapy. Independent validation of this model is required prior to clinical implementation.

\section{5}

A prospective evaluation of a new technique using aponeurosis padding without vacuum drainage to reduce morbidity in patients undergoing axillary node dissection for localized breast cancer (LBC).

Garbay J-R, Thoury A, Moinon E, Picone O, Rey A, Di Palma M. Institut Gustave Roussy, Villejuif, Paris, France; Hopital Bichat, Paris, France

Objective:

Despite the use of sentinel node biopsy, many patients with LBC require axillary lymphadenectomy. Axillary aponeurosis padding appeared to be a valuable alternative technique as it avoids vacuum drainage and its risks. After reporting our first experience with muscular padding (1), we report here the results with axillary aponeurosis padding.

Patients and Methods:

Aponeurosis padding was prospectively performed in patients with LBC. Level I and II axillary lymphadenectomy was performed through a horizontal skin incision close to the hairline. The aponeurosis was incised at the same level and dissection started underneath. Padding consisted of suturing the edges of the axillary aponeurosis to the underlying muscle with 3 separate stitches, without drainage. A surgeon, a pain clinician and a physiotherapist, respectively evaluated surgical complications (i.e. infection, seroma,. .), pain after surgery and at 6 weeks, mobility of the shoulder and arm.

Results:

From 01/ 2004 to 03/ 2005, 114 patients were treated. The mean number of excised nodes was 14 (5-36). The mean hospital stay was 2 days. There was no clinical seroma in $91 \%$ of the patients and aspiration was required in only $4 \%$. There was no pain at 6 weeks in $71 \%$ of the patients. This compares very favourably with a previous cohort of patients operated on by the same team using vacuum drainage: mean hospital stay was 4 days, incidence of seroma and upper arm mobility were similar, and pain at 6 weeks was present for almost $50 \%$ of the patients.

Discussion and conclusion:

Aponeurosis padding without drainage is easy to learn and effectively reduces morbidity after axillary node dissection in patients with LBC. A longer follow-up is required but this new technique appears to be very promising.

[1] Garbay JR, Picone O, Fourchotte V, Cavalcanti A, Thoury A. Axillary lymphadenectomy with muscular padding, without drainage. Gyn Obst Fertil 2004; 32: 1039-1046.

\section{6}

Optimizing the total skin-sparing mastectomy.

Kumar AS, Wijayanayagam A, Foster RD, Mathes $S$, Kind $G$, Wolverton D, Au A, Esserman LJ. University of California San Francisco, San Francisco, $C A$

Background: Removal of the nipple during mastectomy is the current standard of care. The concern of occult tumor present in the nipple-areola complex (NAC) along with maintence of NAC viability has deterred surgeons from leaving behind the nippleareolaskin. We report the outcomes of a variety of techniques in performing the total skin-sparing (TSS) mastectomy in which sub-nipple ductal tissue is dissected away, sparing the entire skinenvelope of the breast.

Methods: Sixty-three mastectomies with attempted preservation of the NAC were performed in 43 women from October 2001 to May 2005. Preoperative magnetic resonance imaging (MRI) confirmed absence of disease within $2 \mathrm{~cm}$ of the nipple. Pathologic evaluation was undertaken by serially sectioning the nipple tissue from all 63 specimens. Preservation of the breast skin envelope was attempted with free grafting of the nipple-areola skin, or TSS mastectomy was performed using one of four types of incisions: nipple crossing incision, inframmary incision, mastopexy incision or radial incision. Immediate reconstruction was performed using implants with or without tissue expanders, latissimus dorsi flap, TRAM flap or DIEP flap.

Results: Of the 63 mastectomies performed with preservation of the nipple-areola skin $29(46 \%)$ were performed for prophylaxis, $13(21 \%)$ for DCIS and $21(33 \%)$ for invasive carcinoma. Two of 63 specimens were found to have DCIS in nipple tissues, and the affected nipples were subsequently removed. Although follow up is limited, no patients have exhibited cancer recurrence to date. Of the many techniques used, radial incisions were the most robust and resulted in $97 \%$ survival of nipple and areola skin (see table). Conclusion: Patients having mastectomy for breast cancer prophylaxis, ductal carcinoma in situ or invasive carcinoma may be offered total skin sparing mastectomy. Pre-operative MRI can facilitate appropriate patient selection and is used to ensure there is no evidence of carcinoma in the nipple-areola complex. Serial sectioning of the nipple tissue as a separate specimen further ensures there is no evidence of malignancy in the nipple tissue. Total skin-sparing mastectomy is a technically challenging and time-intensive procedure. It is, however, feasible yielding good cosmesis. Particularly in the setting of prophylactic surgery for mutation carriers, total skin-sparing mastectomy is an option that may increase the willingness of women to consider this riskreducing intervention.

Nipple/Areola Skin Survival by Incision Type

Type of Incision $\mathrm{n} \quad$ Survival Partial Survival Lo

Inframammary

Crossing NAC

Mastopexy

Radial

$3(50 \%)$

$3(100 \%)$

$2(18 \%)$

$7(88 \%)$

$34(97 \%)$

$52(83 \%)$

$1(17 \%)$
0
$7(6$
0
0
5

$1(17 \%)$

$7(64 \%)$

$5(8 \%)$

$2(33 \%)$

0

$2(18 \%)$

$1(13 \%)$

$1(3 \%)$

$6(9 \%)$

\section{7}

The effectiveness of per-operative use of human surgical sealant - 'Quixil' in reducing the post operative seroma formation in breast cancer patients.

Vijayaganesh T, Jones BG, Khaira H, Brown JH, Jewkes A. Good Hope Hospital NHS Trust, Birmingham, West Midlands, United Kingdom

Background: The Breast Unit at Good Hope Hospital has conducted a Prospective Randomised Controlled Trial to investigate the role of the first ever human fibrin glue 'Quixil' in reducing the incidence of seroma formation in post operative breast cancer patients.

Material and Methods: 100 consecutive patients, who consented to take part in the study, undergoing mastectomy or wide local excision and axillary node clearance for invasive breast cancer, were divided randomly into two groups. The one group of 50 patients had 'Quixil' sprayed on their wound just before closure. Patients in the other group did not receive the spray. Patients were blinded in this study as were the Breast Care Nurses who collected the data.

The following data was collected: the amount of seroma fluid collected in the immediate post operative period, the amount of seroma fluid collected in the out patient department when they presented with symptomatic seroma, the number of days of post 
operative inpatient stay and the number of outpatient clinic visits with symptomatic seroma formation.

Results: Mann-Whitney U-test analysis showed highly statistically significant differences between the two groups (nonQuixil vs Quixil): In-patient seroma drainage $(755 \mathrm{ml}$ vs $200 \mathrm{ml}$ : $\mathrm{p}<0.0000005)$ In-patient stay (5 days vs 4 days: $\mathrm{p}<0.0005)$ Out-patient seroma aspirate $(925 \mathrm{ml}$ vs $195 \mathrm{ml}$ : p< 0.00005) Out-patient visit with symptomatic seroma (5 visits vs 2 visits: $\mathrm{p}<0.000005$ )

Discussion: The results clearly show the use of Quixil reduces post-operative seroma formation and subsequent out-patient attendance with symptomatic seroma.

\section{8}

Intraoperative digital specimen mammography: improving efficiency without loss of accuracy.

Kaufman CS, Bachman BA, Jacobson L, Kaufman BE. Bellingham Breast Center, Bellingham, WA; University of Washington, Seattle, WA

Introduction: Since the majority of newly diagnosed breast cancers are non-palpable, image guided surgery is a daily occurrence. A specimen mammogram of the targeted lesion is obtained to confirm the lesion has been adequately removed and to check for clear margins by imaging criteria. A major difficulty experienced with standard specimen mammography is the delay in surgery waiting for the specimen to travel from the operating room to the radiology suite, followed by film processing and ending with a communication from the radiologist to the surgeon. In many centers, this process commonly takes 20-30 minutes. A new method to obtain digital specimen mammograms in the operating room is available for surgeons to obtain intraoperatively and expedite the process. To compare these two methods, we obtained both intraoperative digital specimen mammography as well as standard $\mathrm{x}$-ray film specimen mammography on 100 consecutive image guided lumpectomies.

Methods:A consecutive series of 100 image guided lumpectomies were performed, primarily for breast cancer. Each patient had an immediate intraoperative digital specimen mammogram (IDSM) obtained (Faxitron ${ }^{\circledR}$ MX-20 digital system). After this set of films, the specimen was sent to the usual x-ray unit to obtain standard specimen mammography films. Surgical decisions were based on incorporating both types of imaging, although most decisions were made immediately using the intraoperative device. Data accumulated included 1) the ability of either method of specimen imaging to identify the target lesion, and 2) the time required for intraoperative versus standard imaging. Patients were only charged for one set of films.

Results: Intraoperative digital specimen mammography (IDSM) was equally as accurate as standard $\mathrm{x}$-ray film specimen mammography. There was no significant difference between 1) the frequency of identification of the target lesion, 2) lack of identification of any lesion, 3) frequency of involved margins using imaging criteria. However, there was a marked difference in 1) the speed at which the digital mammogram was ready to be read, 2) the ability of the surgeon to obtain multiple views of the specimen to identify close margins by imaging criteria, 3) time for surgical "open to close" and overall operating room time.

Conclusions: Intraoperative digital specimen mammography (IDSM) is equally as accurate as standard specimen mammography obtained in the $\mathrm{x}$-ray department. Use of intraoperative digital specimen mammography (IDSM) saved significant operative time over sending films to the $\mathrm{x}$-ray department. Using this new technology allows surgeons to obtain immediate feedback which translates into shorter more efficient operations.

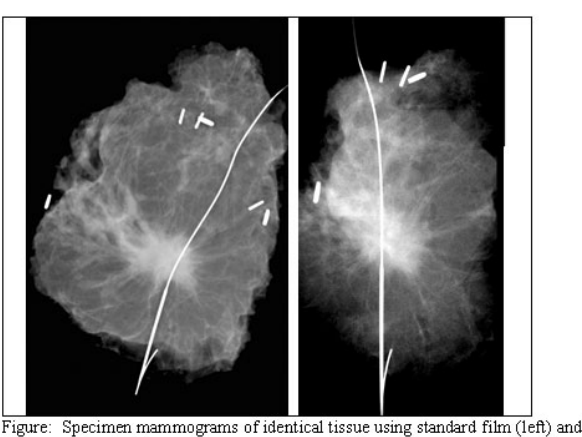

Intraoperative digital specimen mammogram (right)

\section{9}

The impact of radiotherapy on capsule formation and aesthetic outcome after immediate breast reconstruction using biodimensional anatomic expander implants.

Gui GPH, Behranwala K, Dua RS, Ward A, A'Hern R. Royal Marsden NHS Foundation Trust, London, United Kingdom

Introduction: Capsular contracture occurs more frequently in association with radiation fields that may affect surgical outcome after immediate breast reconstruction (IBR). The aim of this study was to investigate the impact of radiotherapy (RT) after IBR using a single implant type.

Methods: Data were collected prospectively on 136 patients. 64 women had submuscularimplant alone and 72 had an implant assisted latissimus dorsi myocutaneous flap $(n=72)$ using a McGhan 150 biodimensional permanent expander implant.

Results: The mean patient age was 45 (range 20-77) years and the median follow-up was 4 (range 1-5) years. 44 patients received RT, 15 at the time of initial cancer treatment associated with breast conservation (mastectomy was performed at recurrence) while 29 had post-mastectomy radiotherapy after IBR. On univariate analysis, RT was the only variable related to capsule formation $(\mathrm{p}<0.001)$. Capsule formation occurred in $13 / 92$ $(14.1 \%)$ patients with no RT and in $17 / 44(38.6 \%)$ patients with RT. Multivariate analysis hazard ratios $(95 \%$ confidence interval) of pre-reconstruction RT and post-reconstruction RT were 1.54 $(0.36-6.56)$ and $4.81(2.05-11.26)$ respectively, $\mathrm{p}<0.001$. Significant differences in geometric measurements of symmetry were identified in patients with capsules. Photographic assessments were worse in the capsule group: mean photo score $8(95 \% \mathrm{CI} 8$, $8.5)$ compared to the no capsule group 6.5 (95\% CI 5, 7.5)), $\mathrm{p}<0.001$.

Conclusion: Capsule formation is three times more likely in association with RT. Despite this, patients often accept the aesthetic outcome and IBR with a biodimensional device is a viable option in selected cases.

\section{0}

Early stage breast cancer in young women: does selection of surgical treatment impact overall survival? de Silva SS, Wilson IB, Erban JK. Tufts-NEMC, Boston, MA

Equivalent survival following either mastectomy or breast conservation therapy (BCT) for early stage breast cancer has been established in several randomized controlled trials done in women between 40 to 60 years of age. Young age, defined as age 35 years or less, is an adverse prognostic factor for breast cancer recurrence, especially in those receiving BCT. Whether BCT is an equivalent treatment option for young women with breast cancer remains to be determined. In the present study, the California Cancer Registry (CCR) and Surveillance, Epidemiology and End Results (SEER) data were examined to determine if selection of 


\section{S38 Abstracts - Poster Discussion Sessions}

surgical treatment, either BCT or mastectomy, impacted overall survival in women 35 years of age or less who were diagnosed with early stage breast cancer. In addition, these young women were compared to older cohorts in terms of overall survival.

Methods: Data collected between January 1, 1988 and December 31, 1998 identified 129,702 with stage I or II breast cancer; 3538 were women age 35 and below. Women were divided into 5 age groups $(\leq 35,36-50,51-65,66-80$ and $>80$ years). The demographic and tumor characteristics of the study population were compared across age groups using Chi-square analysis. Demographic and clinical covariates found to be significant in univariate Cox proportional hazards analyses $(\mathrm{p}<.05)$ were entered into a multivariate model which predicted the treatment effect on survival controlling for these covariates.

Results: Compared to older cohorts, women 35 years of age or less were more likely to be non-White Hispanic or Black $(23.2 \%$ or $10.1 \%$ vs. $9.9 \%$ or $4.7 \%, \mathrm{p}<0.0001)$. They also presented at a later stage of diagnosis (Stage II: $67.3 \%$ vs. $46.9 \%, \mathrm{p}<0.0001$ ), with larger tumors $(2-5 \mathrm{~cm}: 44.6 \%$ vs. $31.2 \%, \mathrm{p}<0.0001)$, more lymph nodes positive $(42.6 \%$ vs. $26.8 \%, \mathrm{p}<0.0001)$ and with hormone receptor negative tumors (ER-/PR-: $39.3 \%$ vs. $17.9 \%$, $\mathrm{p}<0.0001)$. In the covariate adjusted model, for women age 35 years or less, receipt of mastectomy predicted higher mortality than receipt of BCT (M: HR=1.29,95\% CI [1.13-1.48]). In addition, young women in either surgical category fared worse than women age 36 to 50 (BCT: HR=0.66 95\% CI [0.58-0.75] M: $\mathrm{HR}=1.0495 \% \mathrm{CI}[1.02-1.28])$.

Conclusions: In this study, after adjustment for usual prognostic factors, women age 35 years or less who were treated with mastectomy had worse overall survival than those treated with BCT. Analysis of factors that may have accounted for such a result, such as the role of radiation therapy, will be explored in future analyses. Breast cancer in young women does have some unique features, such as larger tumor size, increased positive lymph node status and negative hormone receptor status, than older cohorts, suggesting more aggressive disease. However, these factors do not appear to explain the inferior result following mastectomy. Prospective trials are needed in this age group to determine how best to treat this special patient population. 


\section{1}

Novel molecular diagnostic method for rapid evaluation of lymph node metastasis in breast cancer.

Matsuura N, Tsujimoto M, Nakabayashi K, Daitho M, Ding J, Sonoda R, Kajita M, Otomo Y. Osaka University Graduate School of Medicine and Health Science, Suita, Osaka, Japan; Osaka Police Hospital, Osaka, Japan; Sysmex Corporation, Kobe, Hyogo, Japan

Background: Intraoperative accurate evaluation of lymph node status is essential for appropriate lymph node dissection for curative operation of breast cancer. Histopathological diagnosis to frozen section is usually used for this evaluation. However a number of shortcomings have been pointed out for intraoperative histological examination, including lower sensitivity and dependency on pathologists' capabilities. The molecular analysis using RT-PCR (reverse-transcriptase polymerase chain reaction) has higher sensitivity and more objectivity, but clinical application for rapid examination during operation would be difficult since it needs several hours.

Methods: To overcome these problems, we develop a new intraoperative molecular diagnostic method, one-step nucleic acid amplification (OSNA) to measure cytokeratin (CK) 19 mRNA expressions quantitatively. This assay consists of the sample preparation and rapid gene amplification by RT-LAMP (reversetranscriptase loop-mediated isothermal amplification) and it takes within $30 \mathrm{~min}$ for the whole process. In order to test availability of OSNA for rapid diagnostic method to lymph node metastasis, 2 studies were performed. Retrospective study; Frozen 106 LNs of 36 patients were analyzed for CK19 mRNA expression levels to determine cutoff value. Prospective study; Fresh 120 LNs of 37 patients were analyzed to evaluate intraoperative performance of OSNA assay in comparison with histopathological and immunohistochemical studies.

Results: Retrospective study; Histological negative LNs had less than $3 \times 10^{2}$ copies of CK19 mRNA per reaction, while histological positive LNs had over $1.0 \times 10^{3}$ copies per reaction. From these results, the cutoff value of CK19 mRNA copy number was determined as 500 copies per reaction in OSNA assay. By using this cutoff value, OSNA assay had $98.1 \%$ (104/106) concordance with histopathological evaluation for serial sections at $2.0 \mathrm{~mm}$ intervals; the sensitivity was $100 \%(22 / 22)$, and the specificity was $97.6 \%(82 / 84)$. Prospective study; there was $96.6 \%(112 /$ 116) concordance between the results of OSNA assay and intraoperative histopathological analysis evaluated at $2.0 \mathrm{~mm}$ intervals; the sensitivity was $92.3 \%$ (24/26), and the specificity was $97.8 \%$ (88/90). Two false negative LNs contained micrometastasis.

Conclusions: CK19 was an excellent molecular marker for evaluation of LN metastasis. In addition, since CK19 mRNA expression levels by OSNA assay were highly correlated with histopathological analysis for many sections, examination of CK19 mRNA by OSNA assay will be useful diagnostic tool for rapid analysis of LN metastasis in breast cancer.

\section{2}

The combination of frozen section and enhanced polymer one-step staining immunohistochemistry for the intraoprative diagnosis of sentinel nodes of breast cancer. Wang YS, Yu JM, Liu YB, Wang L, Zhao T, Li JY. Shandong Cancer Hospital, Shandong University, Jinan, Shandong, China

Backgroud: Though sentinel nodes (SN) biopsy has been accepted as a standard treatment for patients with node negative breat cancer, the application of frozen section method (FS) to evaluate SN intraoperatively is still debated for its accuracy. With increasing interest in reducing patient morbidity and controlling overall cost, it is apparent that FS and other rapid, accurate methods should be used to spare patients added morbidity from a second procedure and help control cost. Enhanced Polymer One-step Staining immunohistochemistry (EPOS) is a rapid, accurate method for the detection of metastatic breast cancer in frozen sections of lymph nodes. The accuracy of intraoperative diagnosis of SN might be improved with the combination of FS and EPOS.

Materials and Methods: 926 SNs from 243 consecutive patients undergoing SN biopsy were evaluated by FS intraoperatively. Among them, 461 SNs from 125 cases were evaluated with the combination of FS and EPOS. Monoclonal anti-cytokeratin MNF116 (code No.U7022) was used for EPOS. The average time for EPOS in our study is 24 minutes. All SNs were additionally studid with Hematoxylin \& Eosin (HE) stains on the paraffin sections and served as gold standard of diagnosis.

Results: Diagnositic results of FS are shown in Table1. The diagnostic accuracy of FS for SNs as calculated with SNs number is as following: sensitivity $93.9 \%$, specificity $100 \%$, false negative rate $6.1 \%$, false positive rate 0 , accurate rate $99.1 \%$. The diagnostic accuracy of FS as calculated with patients number is as following: sensitivity $94.9 \%$, specificity $100 \%$, false negative rate $5.1 \%$, false positive rate 0 , accurate rate $99.2 \%$.

Table 1. Diagnostic results of FS for SNs

\begin{tabular}{lllllll} 
& \# SN & & \multicolumn{3}{c}{ \# Case } & \\
& HE (+) & HE (-) & Total & HE (+) & HE (-) & Total \\
FS (+) & 123 & 0 & 123 & 74 & 0 & 74 \\
FS (-) & 8 & 795 & 803 & 4 & 165 & 169 \\
Total & 131 & 795 & 926 & 78 & 165 & 243
\end{tabular}

Diagnostic results of FS combined with EPOS are shown in Table 2. The diagnostic accuracy of FS plus EPOS for SNs as calculated with SNs number is as following: sensitivity $98.4 \%$, specificity $100 \%$, false negative rate $1.6 \%$, false positive rate 0 , accurate rate $99.8 \%$. The diagnostic accuracy of FS plus EPOS as calculated with patients number is as following: sensitivity $97.7 \%$, specificity $100 \%$, false negative rate $2.3 \%$, false positive rate 0 , accurate rate $99.2 \%$.

Table 2. Diagnostic results of FS combined with EPOS for SNs

\begin{tabular}{lllllll} 
& \# SN & & \multicolumn{7}{c}{ \# Case } \\
& HE $(+)$ & HE $(-)$ & Total & HE $(+)$ & HE $(-)$ & Total \\
FS \& EPOS (+) & 63 & 0 & 63 & 42 & 0 & 42 \\
FS \& EPOS (-) & 1 & 397 & 398 & 1 & 82 & 83 \\
Total & 64 & 397 & 461 & 43 & 82 & 125
\end{tabular}

Conclusion: The FS is an accurate and cost effective method for SN evaluation with a short learning curve. With the combination of EPOS, it could decrease the false negative rate to a very low level, and satisfy the clinical demand for intraoperative diagnosis of SNs. Patients could be spared potential morbidity from a second procedure and result in significant cost savings to the individual patient and lower average overall cost for all patients undergoing this procedure.

\section{3}

Comparative study of lymphedema with axillary node dissection and axillary sampling with radiotherapy in women undergoing breast conservation surgery for breast cancer.

Mathew J, Barthelmes L, Neminathan S, Crawford D. Ysbyty Gwynedd, Bangor, Gwynedd, United Kingdom

\section{Introduction}

It has been suggested that combining axillary surgery and radiotherapy could increase the incidence and severity of lymphedema. The aim of our study was to assess and compare the incidence of lymphedema in two groups of patients undergoing breast conservation surgery; one undergoing axillary sampling, and radiotherapy to patients with positive axillary nodes and the other undergoing axillary clearance.

\section{Methods}

It is a retrospective review of records of two groups of patients who had breast conservation therapy; one with axillary sampling between Jan 1994 and Dec 1998 (Group 1) and the other having axillary clearance between Jan 2000 and Dec 2002 (Group 2). Group 1 patients with positive nodes went on to receive radiotherapy. The diagnosis of lymphedema was based on a difference of $2 \mathrm{~cm}$ or more in arm circumference at a corresponding point between affected and non effected limbs. Minimum period of 2 years follow-up were there for both groups. 


\section{Results}

312 patients were included in group 1 and 194 in group 2. There were no significant differences between the clinicopathological features between the two groups (Mean age- Group1 (59 years) and group 2 (58 years), Screen detected cancers- Group 1 (36.2\%) and Group $2(30.4 \%)$, Tumours less than 3cm- Group $1(97.1 \%)$ and Group $2(96.9 \%)) .26 \%$ of the patients in group 1 had lymph node metastasis compared to $20 \%$ in group 2 .

Only $2.2 \%$ of the patients in group 1 developed lymphedema compared to $12.3 \%$ in group 2 with a significant statistical difference between the two groups with a $\mathrm{P}$ value of $<0.001$. In the node positive patients in group 1 who had sampling and radiotherapy, the incidence of lymphedema was $6.2 \%$ and it was lower than the node positive patients in group 2 who had axillary clearance, although the differences were not statistically significant with a $P$ value of $<0.17$

\section{Conclusion}

The incidence of lymphedema in node positive patients receiving radiotherapy in axillary sampling groups were low compared to node positive patients undergoing axillary clearance. With the increased acceptance of sentinel node biopsy as a staging procedure, the effectiveness of radiotherapy as an alternative to full axillary dissection in patients with positive nodes remains to be investigated in randomised clinical trials.

\section{4}

Timing of sentinel node biopsy for patients undergoing mastectomy with immediate reconstruction.

McGuire KP, Rosenberg A, Copit S. Thomas Jefferson University, Philidelphia, PA

Background: Sentinel lymph node biopsy(SLNB) is a common procedure intrinsic to staging early breast cancer and rapidly replacing axillary lymph node dissection (ALND) as standard of care. Although many patients will have negative SLNB, reoperation after reconstruction for ALND for patients with positive nodes is associated with increased risk of complications. Thus, SLNB should be a separate procedure prior to mastectomy. The purpose of this study was to evaluate the results of patients undergoing SLNB and mastectomy with various types of immediate reconstruction to assess the need for a delay between SLNB and reconstruction based upon the type of reconstruction performed.

Methods: Records of all patients at one institution undergoing SLN and mastectomy with immediate reconstruction between 1999 and 2004 were reviewed. These were evaluated for tumor type, stage, age, node status and reconstruction type.

Results: From 1999-2004, 3865 patients with breast cancer were seen at TJUH. 1076 patients underwent mastectomy, of those $505(46.9 \%)$ underwent immediate reconstruction, $147(29.1 \%)$ latissimus flaps, $160(31.7 \%)$ TRAM flaps, and 198(39.2\%) tissue expanders. 207 (41\%) received SLN prior to definitive surgery, 298(59\%) received SLNB at the time of surgery. Of those, 122(24.2\%) had a positive SLN and underwent ALND (with or without radiation), whereas $383(75.8 \%$ ) had a negative SLNB and received no further axillary surgery.

Conclusions: We believe that only patients undergoing latissimus flap reconstruction need a delay between SLNB and their definitive procedure as this is the only reconstruction that rearranges the anatomy of the axilla, so that subsequent completion dissection would jeopardize the reconstruction/flap. Reconstructions using a tissue expander or implant only, or a pedicled TRAM flap can be done at the same time as the SLNB as they do not disrupt the axilla.

\section{5}

Does a negative lymphoscintigram predict for sentinel lymph node positivity.

Soran A, Balkan M, Falk J, Keenan D, Bonaventura M, Johnson R. Magee-Womens Hospital of the University of Pittsburgh Medical Center, Pittsburgh, PA

Background: Sentinel lymph node mapping (SLNM) has become standard of care in most large breast centers and dual tracer (blue dye + TC-99m labeled filtered sulfur colloid) mapping has been reported to improve both detection and false negative rates. Lymphoscintigraphy (LSG) pre-operatively has been abandoned in many centers because of the high sensitivity of intra-op detection by hand-held gamma probes, making a positive LSG unnecessary. We wanted to investigate the hypothesis that non-visualization on LSG predicts a subset of patients at higher risk of being node positive.

Methods: We retrospectively reviewed the records of 1500 patients (mean age $=55$; range, $28-88$ years) who underwent dual tracer SLNM for breast cancer at MWH between 1999 and 2004. LSG were reported as negative (no uptake in ipsilateral axilla) or positive. SLNB was followed by ALND only in node positive patients. Average tumor size was $1.9 \pm 0.6 \mathrm{~cm}$. Multicentricity was reported $10.4 \%$ of the pathologic specimens. Tumor location was recorded as upper outer quadrant in $31 \%$ of cases and $33.2 \%$ location were recorded as overlapping. Average BMI was 26.8 (range; $15-60) \mathrm{kg} / \mathrm{m}^{2}$ in LSG positive group, and it was 29.1 (range; $17-41) \mathrm{kg} / \mathrm{m}^{2}$ in LSG negative group $(\mathrm{P}<0.00001)$

Results: 1366 of 1500 patients $(91 \%)$ had axillary SLN(s) identified on LSG imaging. In 133/134 (99.3\%) patients with a negative LSG an SLN(s) was identified intra-operatively either by blue dye or hand-held gamma detection. The SLN was positive in 38 patients (28.4\%) of 134 patients who had negative preoperative LSG image. One patient had positive final axillary LN pathology who had both negative LSG and negative SLNM reports (False negative rate for both technique together is $1 / 38=2.6 \%$ ).

Conclusion: Dual tracer SLN mapping is technically successful in a high percentage of cases. Failure to demonstrate axillary uptake of tracer appears to be related technical factors and patient related factors (BMI). The equivalent rate of SLN positivity in patients with positive or negative LSG would appear to reject the hypothesis that failure to visualize a node on LSG is due to tumor related factors.

$\begin{array}{llll} & \text { LSG }(+)(\mathrm{n}=1366) & \text { LSG }(-)(\mathrm{n}=134) & \mathrm{P} \\ \text { Age (mean; min-max) years } & 55(23-88) & 59(31-82) & 0.00001 \\ \text { BMI (mean; min-max) kg/m2 } & 26.8(15-60) & 29.1(17-41) & 0.00001 \\ \text { Tumor site (UOQ) } & 417(30.5 \%) & 48(35.8 \%) & 0.2 \\ \text { Tumor size (cm) } & 1.69 & 1.55 & 0.14 \\ \text { SLN detection \% } & 1361(99.6 \%) & 133(99.2 \%) & 0.5 \\ \text { SLN removed (mean) } & 2.72 & 2.125 & 0.0005 \\ \text { SLN positivity } & 397(29.1 \%) & 38(28.4 \%) & 0.7\end{array}$

\section{6}

Sonographic evaluation of axillary lymph nodes using realtime sonoelastography.

Wojcinski S, Maltaris T, Dupont J, Ertan AK, Schmidt W. University of Saarland, Homburg/Saar, Germany

Background: The purpose of this study was to determine the utility of realtime sonoelastography in the evaluation of axillary lymph nodes (LNs). Realtime elasticity imaging is a new technique that enables a highly accurate estimation of the tissue elasticity distribution. Like colour Doppler examinations, sonoelastography can be performed with conventional ultrasound probes. The examination results are represented in colour over the conventional B-mode image.

Materials and Methods: Axillary sonography was performed on 156 patients (age $22-85$, median 51) with a total of $202 \mathrm{LNs}$ examined ( $\max 2$ per patient). After routine diagnosis including history taking, clinical examination, conventional sonography and mammography, eligible patients were recruited and B-mode sonography and realtime sonoelastography of axillary LNs were 
performed using the sonoelastography module that can be integrated into the platform of the HITACHI EUB-8500 system. Each image was acquired using the HITACHI EUP-L54M probe $(50 \mathrm{~mm}, 13 \mathrm{MHz}) .27$ patients had suspicious breast lesions that were identified as invasive carcinomas on biopsy, and underwent axillary dissection. 15 of these patients had a metastases in the previously examined $\mathrm{LN}$ and formed study group 1 . The 12 patients without metastases formed group 2. 129 patients were found healthy and formed group 3 . In each patient the elasticity of LN cortex and medulla were analyzed and correlated with B-mode features and histopathological findings.

Results: Regarding B-mode sonography 6 LNs were found suspicious preoperatively in group 1 . The 9 LNs not suspicious showed only focal micrometastases in the cortex. In group 2 there was only one case of a false positive result. The most sensitive feature to predict metastases was cortical thickening with an average cortex of $3.2 \mathrm{~mm}$ in positive LNs (group 1) and $1.6 \mathrm{~mm}$ in negative LNs (groups 2 and 3) respectively ( $\mathrm{p}=0.003$ ). Regarding sonoelastography, LNs generally displayed a relatively soft medulla and a harder cortex. There was no difference in the elasticity of the medulla comparing positive (group 1) and negative LNs (groups 2 and 3), but the metastatic LNs presented a significantly harder cortex $(p=0.015)$. This relatively hard cortex could also be demonstrated in the subgroup of LNs with micrometastases which were not suspicious in B-mode sonography, although this difference was statistically not significant.

Discussion: Ultrasound is known to be an accurate imaging method for the diagnosis of axillary LN metastases, although micrometastases are so far not detectable. Realtime sonoelastography is a promising technique that also permits the evaluation of axillary LNs. Normal LNs show a repeating pattern of elasticity distribution regarding the cortex and the medulla. Metastatic LNs, even if only micrometastases are present, display a harder cortex in sonoelastography. Therefore the complementary use of realtime sonoelastography in combination with B-mode sonography might improve the accuracy of preoperative assessment of axillary LN status.

\section{7}

Analysis of sentinel lymph node biopsy in breast cancer patients after neoadjuvant chemotherapy.

Jinno H, Ikeda T, Kitajima M, Fujii H, Mukai M. Keio University School of Medicine, Shinjuku, Tokyo, Japan

Background: Sentinel lymph node biopsy (SLNB) is a potential alternative procedure to conventional axillary lymph node dissection (ALND) in clinically node-negative breast cancer patients. Neoadjuvant chemotherapy (NAC) is a standard of care for patients with locally advanced breast cancer and indications of NAC have been widespread to operable breast cancer patients to facilitate breast conserving surgery. However, the feasibility and accuracy of SLNB in breast cancer patients who received NAC is still controversial.

Patients and Methods: Thirty-four patients with stage II or III breast cancer who were treated with NAC from January 2002 to December 2004 were included in the study. Consecutive 122 patients who had SLNB without NAC during the same period were used as a control group. All patients underwent SLNB followed by completion ALND. Sentinel lymph node was detected using a combined method of injecting isosulfun blue dye and small-sized technetium-99m-labeled tin colloid (particle size: 200-400 $\mathrm{nm}$ in diameter) peritumorally and subcutaneously. All dissected lymph nodes were evaluated by means of $\mathrm{H} \& \mathrm{E}$ and immunohistochemical staining.

Results: Sentinel lymph nodes were successfully identified in 31/ 34 patients $(91.2 \%)$ treated with NAC and $112 / 113$ patients $(99.1 \%)$ without NAC $(\mathrm{p}=0.01)$. Metastases in the sentinel lymph nodes were found in $10 / 31$ patients $(32.3 \%)$ with NAC and $32 / 112$ patients $(28.6 \%)$ without NAC. There were 5 false negative cases (false negative rate: $33.3 \%$ ) in the NAC group and 2 false negative cases (false negative rate: $5.9 \%)$ in the control group $(\mathrm{p}=0.01)$. Accuracy of SLNB in the NAC group was also significantly inferior to the control group $(83.9 \%$ vs. $98.2 \%, \mathrm{p}<0.01)$. The presence of clinically positive axillary lymph nodes before chemotherapy did not predict false negative SLNB.

Conclusion: These data suggest that NAC might be considered a contraindication to SLNB even in patients with clinically negative axillary lymph nodes before NAC.

\section{8}

Sentinel lymph node biopsy for breast cancer patients with clinically negative axillary lymph nodes after neoadjuvant chemotherapy.

Kinoshita T, Fukutomi T, Akashi-Tanaka S, Terada K, Takasugi M, Shimizu C, Ando M, Katsumata N, Fujiwara Y. National Cancer Center Hospital, Tokyo, Japan

Background: Within this study, the feasibility and accuracy of sentinel lymph node (SLN) biopsy for breast cancer patients with clinically negative axilary lymph nodes after neoadjuvant chemotherapy (NAC) has been investigated under the administration of a radiocolloid imaging agent injected intradermally over a tumor. Also, conditions which may affect SLN biopsy detection and false-negative rates with respect to clinical tumor response and clinical nodal status before NAC were also analyzed. Limited studies with smaller number of patients exist in the use of SLN biopsy after NAC. We assesed the feasibility of SLN biopsy after NAC.

Methods: Seventy-seven patients with Stage II and III breast cancer previously treated with NAC were enrolled in this study. All patients were with clinically node negative after NAC. The patients then underwent SLN biopsy, which involved a combination of intradermal radiocolloid injection over the tumor of radiocolloid and a subareolar injection of blue dye. This was followed by standard level I/II axillary lymph node dissection(ALND). The histopathologic examination of SLNs and dissected axillary lymph nodes were performed and nodal status was compared.

Results: The SLN could be identified in $72 / 77$ patients (identification rate $93.5 \%$ ). In $69 / 72$ patients $(95.8 \%)$ the SLN accurately predicted the axillary status. Three patients had a falsenegative SLN biopsy, resulting in a false-negative rate of $11.1 \%$ (3/ 27). The SLN identification rate tended to be higher, although not statistically significant, among patients who had clinically negative axillary lymph nodes before NAC (97.6\%; 41 of 42$)$, in comparison to patients who had a positive axillary lymph nodes before NAC $(88.6 \% ; 31$ of 35$)$.

Conclusion: SLN identification rate and false-negative rate were similar to those in non-neoadjuvant studies. The SLN accurately predicted metastatic disease in the axilla of patients with any tumor response after NAC and any clinical nodal status before NAC. The diagnostic technique of subdural injection of radiocolloid may provide treatment guidance for patients after NAC.

\section{9}

The incidence of axillary nodal metastases in older women with small non-high grade breast tumours.

Querci della Rovere G, Bonomi R, Ashley S, Benson JR. The Royal Marsden Hospital, Sutton, Surrey, United Kingdom; Addenbrookes Hospital, Cambridge, Cambridgeshire, United Kingdom

Background: With an increasing proportion of node negative patients, a selective policy for managing the axilla may be more appropriate. Axillary sampling and sentinel node biopsy are alternative methods for staging the axilla, but observation alone may be an acceptable approach for a selected subgroup of patients with small tumours of favourable histological grade and a low probability of nodal involvement $(5-10 \%)$.

Material and Methods: A retrospective analysis was undertaken examining the incidence of nodal metastases (H\&E staining) in a 


\section{S42 Abstracts - Poster Session I}

group of 355 consecutive patients who underwent mastectomy or breast conserving surgery for early breast cancer. All patients had either grade I $(\leq 20 \mathrm{~mm})$ or grade II $(\leq 20 \mathrm{~mm})$ oestrogen receptor positive tumours without lymphovascular invasion.

Results: The overall incidence of positive nodes in this good prognostic group of patients was very low $(13 \%$ - 95\% CI $9.5-$ 16.5). Furthermore, when nodal involvement occurred the total number of positive nodes was 3 or fewer and most commonly only a single node was positive. When the analysis was confined to grade I tumours $(<20 \mathrm{~mm})$ and grade II tumours $(<10 \mathrm{~mm})$ the overall incidence of nodal metastases was $10 \%(25 / 251)$. Only $2.7 \%$ of grade I tumours $(\leq 10 \mathrm{~mm})$ had nodal involvement compared with $11.6 \%$ of grade II tumours of similar size.

Discussion: These results support the conclusion that axillary surgery (staging/therapeutic) can be safely omitted in a selected subgroup of patients for whom the probability of nodal metastases is of similar magnitude to the false negative rates reported for the sentinel node biopsy technique $(5-10 \%)$. Furthermore, the majority of this subgroup will have micrometastases confined to the sentinel node which are of uncertain clinical significance and may not mandate completion axillary dissection nor be an indication for systemic therapy.

The incidence of nodal metastases according to tumour size and grade

Tumour Patient Number Node positive Number of positive nodes

size/grade $355 \quad 46$

$(1-10 \mathrm{~mm}) \quad(20.5 \%)$

Grade I 109

$(11-20 \mathrm{~mm}) \quad(30.8 \%)$

$(1-10 \mathrm{~mm})(19.4 \%)$

Grade II 104

$(11-15) \quad(29.3 \%)$

$$
\begin{aligned}
& 46 \\
& (13 \%) \\
& 2 \\
& (2.7 \%) \\
& 15 \\
& (13.8 \%) \\
& 8 \\
& (11.6 \%) \\
& 21 \\
& (20.2 \%)
\end{aligned}
$$$$
\begin{aligned}
& 1 \\
& 2 \\
& (2.7 \\
& 8 \\
& (7.3 \%) \\
& 3 \\
& (4.3 \%) \\
& 14 \\
& (13.5)
\end{aligned}
$$$$
\begin{array}{lll}
2 & 3 & 4 \\
0 & 0 & 0 \\
3 & 3 & 1 \\
(2.8 \%) & (2.8 \%) & (0.9 \%) \\
1 & 2 & 2 \\
(1.4 \%) & (2.9 \%) & (2.9 \%) \\
3 & 1 & 3 \\
(2.9 \%) & (1.0 \%) & (2.9 \%)
\end{array}
$$

\section{0}

A standardized surgical technique for mastoscopic axillary lymph node dissection.

Chengyu L, Yongqiao Z, Hua L, Xiaoxin J, Chen G, Jing L, Jian Z. Affiliated Beijing Fuxing Hospital, Capital University of Medical Science, Beijing, China

Objective To standardize the surgical technique on mastoscopic axillary lymph node dissection(MALND). Methods Mastoscopic lymph node dissection was performed consistently by a group of surgeon in 316 cases of breast cancer. Result The mean operation time was 46.7 minutes with minimal bleeding, and the median lymph nodes dissected from each operation were 17.0. There was neither operative complication in any case nor trocar implantation or tumor diffusion occurring during the mean follow-up time of 15.1 months. Conclusion. Mastoscopic lymph node dissection is distinctive and practicable in operative anatomy, and it is safe and convenient. The location of critical anatomy such as interocostobrachial nerve, lateral thoracic artery, medial thoracic nerve and thoracicoepigastric vein should be clearly identified to avoid damage to them, so that the great advantage of mastoscopic lymph node dissection can be achieved.

[Key words] Breast neoplasm Axillary lymph node dissection Endoscopy

\section{1}

Intra-operative sentinel lymh node assessment of 193 patients with invasive breast carcinoma: does sentinel lymph node intraoperative examination reduce the complementary axillary lymph node dissection?

Loussouarn D, Dupre PF, Sagan C, Dravet F, Toquet $C$, Pioud $R$, Francois T, Curtet C, Classe JM. CHU Laennec, Nantes Saint Herblain, France; CRLCC R Gauducheau, Nantes Saint Herblain, France

Background: Guidelines usually advise to complete axillary lymph node dissection when sentinel lymph node (SLN) is involved. The intra-operative assessment of axillary sentinel lymph node allows a one-step procedure for patients who present sentinel lymph node involvement. The aim of this study is to determine the sensitivity of the SLN intra-operative imprint cytology procedure. Method: 193 patients with invasive breast cancer who underwent sentinel lymph node biopsy (SLNB) on a 40 months period were included. Each sentinel lymph node (SLN) was examined intraoperatively: each SLN was perpendicularly sectioned along the long axis at $2 \mathrm{~mm}$ intervals. Cytological imprint was effectued on each cut surface. In case of SLN involvement a complementary axillary lymph node dissection was provide in a one step. SLN was entirely submitted in blocks. Each blocks was sectioned at 6 levels ( $4 \mu \mathrm{m}$ serial sections at $150 \mu \mathrm{m}$ intervals). Slices were then analysed by Hematoxylin-eosin-safron (HES) and cytokeratin 7 immunohistochemistery (IHC) when the SLN is negative.

Results: Medium age was 57 (37-84), 60 patients were T0(31\%), 106 patients were T1 $(55 \%), 27$ patients were T2 $(14 \%)$. The medium size of invasive breast cancer was $14.6 \mathrm{~mm}$. Histological sub type: 158 ductal carcinoma (82\%), 20 lobular carcinoma (10\%). The histological grade was grade I for 64 patients (33\%), grade II for 103 patients $(53.5 \%)$, grade III for 26 patients (13.5\%). 178 patients expressed oestrogen receptor $(92 \%)$ and 154 patients expressed progesterone receptor $(78 \%)$

The detection rate was $100 \%$ using blue patent ${ }^{\circledR}$ and radiocolloide. The average number of SLN detected was 2.8. Cytological imprint was examined for each SLN.

30 patients $(15 \%)$ had SLN involvement and underwent immediate axillary lymph node dissection. For 163 patients $(85 \%)$, the intraoperative SLN examination was negative. Among these patients, $46(28 \%)$ had secondary axillary lymph node dissection: effectively, after SLN definitive histopathological procedure, 17 of 46 patients (10\%) had macrometastasis ; 24 of 46 patients $(15 \%)$ had micrometastatis. 5 patients had secondary surgical intervention despite non metastatic SLN: 4 patients presented a multifocal invasive carcinoma and 1 patient presented a positive non SLN. Global sensitivity for our intra-operative SLN assessment was $42 \%$ and the negative predictive value $75 \%$.For macrometastasis, the sensitivity increased up to $64 \%$ and the negative predictive value was $89 \%$.

Conclusion: SLN intra operative examination is feasible and effective for macrometastasis diagnostic. SLN intra-operative examination allows a one step surgical procedure for $15 \%$ of our patients.

\section{2}

Optical assessment of axillary lymph nodes in breast carcinoma.

Smith J, Kendall C, Christie-Brown J, Sammon A, Barr H, Stone N. Gloucestershire Hospitals NHS Trust, Gloucester, Gloucestershire, United Kingdom

\section{Objective}

Raman spectroscopy is an optical technique with a track record in the assessment of human pathology including breast carcinoma. The technique has the ability to compare and quantify aspects of tissue biochemistry without tissue processing.

The objective of this study is to apply laboratory-based Raman spectroscopy in the optical biopsy of axillary lymph nodes which are positive and negative for metastatic breast carcinoma.

Method

$7 \mu \mathrm{m}$ sections of snap-frozen fresh axillary lymph node were assessed using a bench-top Raman spectrometer. Haematoxylin and eosin slides were produced from the adjacent parallel lymph node section for pathology reporting. Colour-weighted principal component analysis was used to construct images of each lymph node section. Guided by images, spectra from areas of homogeneous positive and negative lymph node from 43 patients were included in a diagnostic model. Principal component analysis and linear discriminant analysis were applied in model processing. Preliminary "leave one spectrum out" cross-validation allowed correction of coding errors. 
Results

In this corrected model, Raman spectroscopy is $90 \%$ sensitive and $92 \%$ specific for the correct classification of spectra from metastasis positive lymph nodes. More than $50 \%$ of spectra were correctly predicted for 42 out of 43 lymph nodes, with an average of $93 \%$ correctly predicted (range $45 \%$ to $100 \%$ ).

Mean spectra from positive and negative groups in the model show that areas of homogeneous metastatic breast carcinoma have increased DNA and tyrosine contributions, and reduced collagen contributions when compared to regions of homogeneous negative lymph node. Lipid contributions are present in both positive and negative lymph nodes. In addition, there is some evidence that carotenoid contributions are increased in regions of homogeneous negative lymph node.

Conclusions

Laboratory-based Raman spectroscopy may be effectively applied in the biochemical assessment of axillary lymph nodes. The technique has potential as an optical biopsy tool in the diagnosis of lymph node metastases in breast carcinoma.

\section{3}

Clip migration after 11G vacuum-assisted breast biopsy: retrospective review of 447 clips and implication in breast surgery.

Chaveron C, Bachelle F, Ceugnart J, Giard S, Baranzelli MC, Belkaccmi Y, Bonneterre J. Centre Oscar Lambret, Lille, France

Purpose: To assess clip migration after vacuum-assisted biopsy with lateral approach and explain mechanisms of migration. We suggest options to localize biopsy site if surgery is required.

Material and Methods: We performed a retrospective review of 601 consecutive vacuum breast biopsies with 11 gauge. 447 clips (Micromark II Ethicon) have been deployed when complete removal of the lesion was suggested on stereotactic control. Postbiopsy mammograms in two orthogonal planes were performed to determine the adequacy of clip placement and the location of the clip. We compared pre and postbiopsy mammograms and measured the distance between clip an biopsy site with a direct method of measurement.

Results: The distance from clip to lesion site was more than $20 \mathrm{~mm}$ on at least one post-biopsy mammogram in $60(13.4 \%)$ of 447 lesions that underwent clip placement. Clip migrations are mainly attributed to an accordion effect along the axis of compression; in theory, this effect decreases with lateral approach of probe. Other mechanisms can explain: delayed accordion effect, bleeding during or after procedure, breast movement. A few options are suggested: sonographically research of postbiopsy scar, sonographically clip placement a few days after biopsy.

Conclusion: Clip migration after vacuum-assisted breast biopsy does exist and is a practical concern. It can affect localization for future surgery when it is over than $20 \mathrm{~mm}$. For surgical cases, repeat craniocaudal and $90^{\circ}$ mediolateral mammograms should be obtained routinely on the day of pre-operative localization. We try to identify the percutaneous biopsy site in the excised specimen and to correlate histologic findings in the surgical specimen with those at vacuum-assisted biopsy to determine if the correct tissue was removed at surgery.

\section{4}

Optical biopsy: breast cancer diagnoses at the speed of light.

Chicken DW, Clarke BR, Johnson KS, Lee AC, Briggs G, Pickard CDO, Falzon M, Novelli M, Bigio IJ, Bown SG, Keshtgar MRS. University College London, London, United Kingdom; Boston University, Boston, MA

Background: Elastic scattering spectroscopy (ESS) is an optical technique which utilizes the difference in light scattering properties between benign and malignant tissue to make diagnoses. The development of computer algorithms for analysis of the spectra allows near instantaneous diagnoses, using portable inexpensive hardware. We are conducting an ongoing translational research programme developing roles for ESS in breast cancer diagnosis and treatment. To date we have applied the optical biopsy system (OBS) to in-vivo diagnosis of breast cancer at the time of core biopsy, resection margin assessment after wide local excision and the intraoperative detection of sentinel node metastases. Current work is on the development of a scanning device for intensive ESS sampling of tissue and consequent image generation, the diagnosis of pathology at ductoscopy and the detection of ploidy as a prognostic marker, and we will be presenting early results of this work in progress at the congress.

Methods: The ESS optical biopsy system consists of a laptop computer which activates a xenon lamp to fire pulses of white light through an optical fibre in contact with the tissue under examination. After calibration with Spectralon ${ }^{\circledR}$, elastically scattered light is detected by a second optical fibre, which transmits the scattered light to a spectrometer and outputs measurements back to the computer. Spectral analysis is performed by a process of normalization, principle component analysis and linear discriminant analysis. Diagnoses are made by applying the discriminant algorithm developed on a training set of spectra with matched histopathology to independent test spectra. Accuracy of diagnosis is calculated using standard statistical formulae.

\section{Results:}

Differentiate tumour from surrounding tissue: Sensitivity $96 \%$ specificity $98 \%$

Differentiate benign from malignant at core biopsy: Sensitivity $69 \%$ Specificity $84 \%$

Detection of sentinel node metastases: Sensitivity $60 \%$ specificity $94 \%$

Detection of sentinel node total metastases: Sensitivity $85 \%$ specificity $87 \%$

Conclusions \& Current Work: The OBS using ESS is able to differentiate benign from malignant tissue with a high degree of accuracy. Multiple potential applications for this technology exist in breast cancer diagnosis and treatment. Further work enhancing optical sampling of tissue is likely to improve diagnostic accuracy. The major advantages are the potential for instant diagnoses without the need for interpretation and using affordable and portable equipment.

Acknowledgement: Research funding from the US Department of Defence Breast Cancer Imaging Research Programme

\section{5}

Serum EGFR and HER-2 expression in primary and metastatic breast cancer patients.

Asgeirsson KS, Allen C, Hitch A, Chapman C, Cheung KL, Robertson JFR. University of Nottingham, Nottingham, United Kingdom

Background: Breast tissue expression of the ERBB protooncogene family has been extensively studied. Recently, it has been shown that the expression of EGFR (c-erbB-1) and HER-2 (c-erbB-2) can be detected in the serum of breast cancer patients. The clinical relevance of EGFR especially is not clear. Materials and Methods: Analysing our departments database, patients with paired serum samples (at time of primary and metastatic diagnosis) were identified. EGFR and HER-2 microtiter immunoassays (kindly provided by Bayer Healthcare) were performed on 57 patients with paired serum samples, in 100 consecutive unselected primary breast cancer patients and 49 normal individuals. Results: EGFR serum levels (normal range $45-78 \mathrm{ng} / \mathrm{mL}$ ) were significantly higher in normal individuals (mean 75.9, range 43.2-114.2) compared to primary breast cancer patients (mean 60.7, range 21.3-94.1) $(\mathrm{P}<0.001)$. In the paired serum samples, EGFR levels decreased significantly between the time of primary (mean 66.0, range 29.1142.7 ) and metastatic diagnosis (mean 47.6, range 10.9-194.2) $(\mathrm{P}<0.001)$. When serum levels were compiled into normal vs. overexpression groups according to reference ranges, EGFR 


\section{S44 Abstracts - Poster Session I}

overexpression was seen in 18/57 $(31.6 \%)$ at diagnosis of primary breast cancer and in $12 / 57(21 \%)$ at metastasis. In 6 patients $(11 \%)$, a change therefore occurred from overexpression to normal expression. In contrast, no significant difference was seen in HER2 serum levels (normal range $<15 \mathrm{ng} / \mathrm{mL}$ ) in normal individuals (mean 12.5, range 7.8-20.9) and primary breast cancer patients (mean 14.0, range 6.9-122.2) $(\mathrm{P}=0.398)$. However, in the paired serum samples, HER-2 levels increased significantly between the time of primary (mean 15.9 , median 12.2 , range $5.7-85.0$ ) and metastasis (mean 145.3, median 17.7, range 6.33337.4) $(\mathrm{P}=0.041)$. HER-2 overexpression was seen in $16 / 57(28 \%)$ at primary breast cancer diagnosis and in $31 / 57(54 \%)$ at metastasis. In 18 patients (32\%), HER-2 expression changed from normal to overexpression. Despite these changes, the majority of patients remained in the same group expression (i.e. normal or overexpression) at primary and at metastasis, for both EGFR and HER-2 $(\mathrm{p}<0.001$ and $\mathrm{p}=0.017$ respectively). Discussion: Both EGFR and HER-2 serum expression levels change significantly between time of primary diagnosis and metastasis, albeit in converse directions. We have demonstrated a significant decrease in EGFR serum expression in the same patients between diagnosis of primary disease and metastasis. Furthermore, normal individuals have significantly higher levels than primary breast cancer patients. In contrast, HER-2 serum expression increased in patients with distant metastases. These results suggest that relying on protooncogene expression in the primary tumour may not be truly reflective of their expression at time of metastatic diagnosis.

\section{6}

Persistence of isolated tumor cells (ITC) in bone marrow (BM) of breast cancer patients predicts increased risk for relapse - results of pooled European data.

Janni W, Wiedswang $G$, Borgen $E$, Braun $S$, Rack B, Schindlbeck $C$, Sommer H, Pantel K, Heinrigs M, Gerber B, Nesland JM, Scholz C, Friese K, Jeschke U, Naume B. LMU, Munich, Germany; Medizinische Universtitaet, Innsbruck, Austria; Insitut fuer Tumorbiologie, UKE, Hamburg, Germany; Radium Hospitalet, Oslo, Norway; University of Rostock, Rostock, Germany; Ullevaal University Hospital, Oslo, Norway

Background:

The prognostic significance of DTC in the BM of breast cancer patients at the time of primary diagnosis has recently been confirmed by a large pooled analysis (Braun S, NEJM, in print). If the persistence of DTC after adjuvant therapy confers a similar risk for relapse, there might be an indication for secondary adjuvant treatment.

Methods:

We analyzed BM aspirates of 584 patients from academic breast cancer units in Oslo $(n=356)$ and Munich $(n=228)$ during recurrence-free follow-up at a median interval of 38.6 months (standard deviation [std] 18.9 mon) after primary diagnosis of breast cancer pT1-4, pN0-3 pM0. Carcinoma cells were detected using a standardized immunoassay with the monoclonal antibodies A45-B/B3 (Munich) or AE1 and AE3 (Oslo), directed against cytokeratin $(\mathrm{CK})$. Patients were followed for a median of 62.7 months (std 23.1 mon) after primary diagnosis.

Results:

Persistent DTC in the BM were detected in $14.0 \%$ of the patients $(\mathrm{n}=82)$. The Kaplan-Meier estimate for mean relapse-free survival was 159.0 mon $(153.2-164.795 \% \mathrm{CI})$ in patients with negative and 91.5 mon $(74.4-108.6,95 \% \mathrm{CI}, \mathrm{p}<.0001, \log$ rank test) in patients with positive BM status. Patients without evidence of persistent DTC had a significantly longer overall survival (165.5 $[156.7-174.4])$, than patients with positive BM status (104.0 mon [91.5 - 116.5], $\mathrm{p}<.0001)$. In multivariate Cox regression analysis, allowing for bone marrow status, tumor size and nodal status, DTC was an independent significant predictor for reduced breast cancer specific survival (RR 5.1, p<.0001). Conclusion:
Evidence of persistent DTC in breast cancer patients indicates an increased risk for subsequent relapse, and may serve for monitoring in future clinical trials. Such trials might investigate the benefit of individualized secondary adjuvant treatment or extended adjuvant therapy of patients with DTC.

Breast Cancer Specific Survival

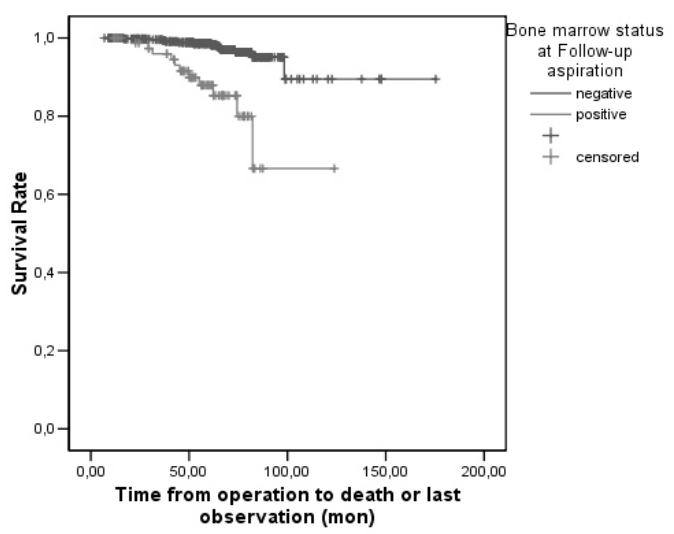

1017

Molecular profiling of disseminated tumor cells in peripheral blood of breast cancer patients.

Kaul S, Fersis N, Rom J, Zieglschmid V, Hollmann C, Boecher $O$, Schneeweiss A, Sohn C. University of Heidelberg, Heidelberg, Baden-Wuerttemberg, Germany; AdnaGen AG, HannoverLangenhagen, Niedersachsen, Germany

Backgroud: The purpose of this study was the detection and analysis of disseminated tumor cells (DTC) in blood of breast cancer patients by expression profiling using a DTC detection assay.

Materials and Methods: Patients with primary breast cancer $(n=89)$ and patients with metastatic breast cancer $(n=156)$ were enrolled in a multicenter clinical performance study. $5 \mathrm{ml}$ blood were used for DTC analysis. The DTC assay consists of immunomagnetic tumor cell selection targeting EpCAM and MUC1. Isolated tumor cells were lysed and mRNA was isolated using oligo-dT-magnetic beads. Breast carcinoma-associated transcripts GA733-2 (EpCAM), MUC-1 and HER-2 were analysed by multiplex RT-PCR. Claudin7, cytokeratin 19 (CK19), mammaglobin 1 (MBGB1) and survivin (BIRK5) were analysed by nested RT-PCR. All PCR products were analysed by capillary electrophoresis with the Agilent Bioanalyzer 2100. Specificity of the RT-PCR was confirmed by examination of blood of healthy donors.

Results: Sensitivity for every single transcript was assessed to be 2 tumor cells per $5 \mathrm{ml}$ blood. In patients with primary breast cancer $(n=89)$ we achieved an overall detection rate of $20 \%$. In patients suffering from metastatic disease $(n=156) 59 \%$ were positive. Tumor-associated transcripts were heterogeneously expressed. Expression rates for MUC-1, GA733-2, and HER-2 analysed by multiplex RT-PCR were $73 \%, 49 \%$ and $45 \%$, respectively. Claudin 7, MGB1 and survivin were detected by nested RT-PCR at a frequency of $62 \%, 21 \%$ and $23 \%$, respectively. The specificity of the DTC detection assay was $>97 \%(n=223)$.

Discussion: We have established a cDNA collection of peripheral blood samples from patients with breast cancer using a new immunomagnetic tumor cell enrichment method. Recently microarray strategies confirmed established and identified new informative molecular markers for the detection of DTC. We 
describe the application of a panel of 7 genes highly overexpressed in metastatic breast cancer for the identification of tumor cells in peripheral blood. Survivin as a unique member of the inhibitor of the apotosis protein family as well as HER-2 and MGB1 identified in disseminated breast cancer cells may serve as a prognostic indicator of tumor progression and could represent valid targets for new therapeutic interventions.

\section{8}

\section{Monitoring circulating breast cancer cells by quantitative real time RT-PCR.}

Palomares MR, Schuster GT, Thomas A, Koehler KM, Gralow JR, Sabath DE. City of Hope National Medical Center, Duarte, CA; Seattle Cancer Care Alliance, Seattle, WA; University of Washington School of Medicine, Seattle, WA

Background: Development of a highly sensitive quantitative method to detect circulating breast cancer cells allows noninvasive monitoring of breast cancer response to treatment and early detection of recurrence. PCR methods are generally more sensitive than microscopic methods and have the additional advantage of high-throughput technology. We designed a quantitative real-time RT-PCR (qPCR) assay using cytokeratin-19 (K19) mRNA as a marker for breast cancer cells, and have tested the assay on serial blood collections in 70 patients followed over a median of 6.6 months.

Methods: Seventy female breast cancer patients seen at the Seattle Cancer Care Alliance (SCCA) consented to participation in a serial blood collection protocol. K19 mRNA was quantified using a 5' to 3' exonuclease (Taqman) qPCR assay. Synthetic K19 standard mRNA was prepared by cloning the K19 gene into pBlueScript plasmid vector and expressing RNA using T3 polymerase. The dynamic range of the assay was determined to be 0.01 to $1000 \mathrm{fg}$ of K19 mRNA. High and low controls were included with each assay to assess inter-assay reliability, and reverse transcriptasefree controls were used to exclude nonspecific genomic DNA amplification. $\beta_{2}$-microglobulin was used to verify RNA integrity. Results: Baseline K19 mRNA levels were detectable in 10 of 18 $(55.6 \%)$ patients with metastatic breast cancer and 3 of $52(5.8 \%)$ patients with stage I-III breast cancer $\left(p<0.001, \chi^{2}\right.$ test). Furthermore, mean baseline K19 mRNA levels were significantly higher in the metastatic patients than the patients without metastases: 0.4 vs $0.0058 \mathrm{fg}$, respectively $(\mathrm{p}<0.01$, two-sided $\mathrm{t}-$ test). Upon follow-up, K19 mRNA trends were noted to correlate with tumor burden in the metastatic patients $(n=62$ evaluable time points in 18 subjects, $\mathrm{p}=0.001, \chi^{2}$ for trend). A rising K19 mRNA level was associated with an 8-fold increased likelihood of tumor progression, which was statistically significant (OR $8.23,95 \%$ CI $2.5-27.1, \mathrm{p}=0.001)$. All 3 of the nonmetastatic patients with detectable K19 mRNA at baseline had undetectable levels 6 months later, and they all remain without clinical evidence of disease. Conclusion: Preliminary results suggest clinical correlation between serial K19 mRNA levels determined by qPCR and disease course in metastatic breast cancer patients. Analysis of more subjects with longer follow-up is needed to determine its clinical utility; however, initial results appear promising. Follow-up is ongoing at SCCA, and accrual will start soon at the City of Hope National Medical Center.

\section{9}

Peri-operative assessment of circulating tumor cells in blood, disseminated tumor cells in bone marrow, and tissue gene signatures in patients with primary breast cancer. Frazier TG, Flynn M, Sieling BA, Herman M, Rao CS, Gross S, Miller MC, Doyle GV, Terstappen LW. Bryn Mawr Hospital, Bryn Mawr, PA; Immunicon, Huntingdon Valley, PA

Background: $\sim 30 \%$ of the 200,000 women diagnosed annually with breast cancer will recur. Without a validated assay to identify these patients, all become candidates for adjuvant therapy. Both
Real-time RT-PCR analysis of primary tissue and detection of disseminated tumor cells (DTC) in bone marrow by immunohistochemistry (IHC) purportedly aid in identifying these patients. The primary objective of this study was to demonstrate that the automated CellSearch ${ }^{\mathrm{TM}}$ system used to detect 'circulating' tumor cells (CTC) in blood could also be used to quantify DTCs in marrow. Incidence of CTCs, DTCs and gene signatures in matched specimens were also compared. Methods: $30 \mathrm{ml}$ blood and $3 \mathrm{ml}$ bone marrow specimens were collected in CellSave preservative peri-operatively from 33 consented primary breast cancer patients stage 0-III. 31 healthy donors were used to determine CTC background in blood while a separate 51 healthy marrow donors served as DTC controls. Both blood and marrow specimens were prepared on the CellTracks Autoprep system. Using the CellSpotter Analyzer, cells expressing EpCAM were enriched and were counted as tumor cells if they were also nucleated, expressed Cytokeratin and lacked CD45. The OncoType Dx Multi-gene RT-PCR assay was used to analyze paraffin treated tissue. Results: $0 / 31$ control blood donors had CTCs while 6/33 (18\%) patients had $\geq 2 \mathrm{CTC} /$ $30 \mathrm{ml}$ blood (Range 2-8, mean 3.2/30ml, 2.4SD) [Fisher's exact pvalue $=0.025$ ]. $4 / 51(8 \%)$ control marrow donors had $\geq 1 \mathrm{DTC} /$ $3 \mathrm{ml}$ marrow (range $1-6$, mean 4DTC/3ml, SD2.4) while $9 / 33$ $(27 \%)$ patients had $\geq 1$ DTC/3ml (range $1-29$, mean $8 \mathrm{DTC} / 3 \mathrm{ml}$, SD11) [Fisher's exact p-value $=0.028$ ]. 2 patients $(1$ DCIS, 1 Stage I) had positive CTC and DTC counts. 2 patients still had DTCs $(26,29 / 3 \mathrm{ml})$ after neoadjuvant therapy. Patients with OncoType Dx recurrence scores 6-15 (low risk) also had no detectable CTCs and/or DTCs. Discussion: The CellSearch system can be used to quantify DTCs. CTCs and DTCs may provide prognostic information complementary to gene expression profiling possibly increasing the accuracy of assessment of risk of recurrence in patients with primary breast cancer. The DTC method is being further validated by comparison to a 'gold standard' IHC bone marrow assay in a multi center international study.

\section{0}

Detection of circulating tumor cells in peripheral blood and bone marrow by quantitative RT-PCR assay for cytokeratin-7 mRNA in breast cancer patients.

Kataoka A, Masuda T, Ohno S, Inoue H, Yamaguchi H, Uchida Y, Mimori K, Mori M. National Kyushu Cancer Center, Fukuoka, Japan; Saiseikai Yahata General Hospital, Kitakyushu, Fukuoka, Japan; Medical Institute of Bioregulation, Kyushu University, Beppu, Oita, Japan

The clinical significance of circulating tumor cells (CTC) remains unknown. We investigated it in peripheral blood (PB) and bone marrow (BM) in operable breast cancer patients. First, we investigated the expression levels of mRNA of 7 representative molecular markers (CEA, cytokeratin-7, cytokeratin-18, cytokeratin-19, cytokeratin-20, mammaglobin and MUC-1) for detecting CTC in 27 cancer and 8 non-epithelial cell lines using quantitative RT-PCR (QRT-PCR) with LightCycler (Roche Diagnostics), and showed that the expression level of cytokeratin7 (CK7) was higher in every cancer cell line than in the nonepithelial cell lines. Next, we studied the clinical significance of CTC in PB and BM by QRT-PCR for CK7 mRNA in 246 operable breast cancer patients (stage I-III, T1-3, N0-1, M0). Paired $1 \mathrm{ml}$ of $\mathrm{PB}$ and $\mathrm{BM}$ samples were obtained from the patients with written informed consent at the surgery. Based on comparison with 17 non-cancer controls, $42(17.1 \%)$ and $120(48.8 \%)$ of the 246 patients were positive for CK7 in PB and BM, respectively. For both $\mathrm{PB}$ and $\mathrm{BM}$, no significant differences in clinicopathological factors such as age, menopausal status, tumor size, lymph node metastasis, lymphatic or vascular involvement, histological grade, ER, and PgR were found between the CK7positive and CK7-negative groups. In 186 cases observed over 36 months after curative surgery, the CK7-positive group in PB had poorer distant disease-free survival (dDFS) than the negative group $(\mathrm{p}<0.01)$. The CK7-positive group in $\mathrm{PB}$ showed poorer dDFS 
than the negative group in 132 lymph node-negative cases ( $\mathrm{p}=0.01$ ), and moreover, in $92 \mathrm{lymph}$ node-negative cases observed over 36 months after surgery, the CK7-positive group in PB showed poorer dDFS than the negative group $(\mathrm{p}<0.0001)$. Multivariate analysis demonstrated that the positive CK7 mRNA in $\mathrm{PB}$ was an independent prognostic factor in lymph node-negative cases. In BM, no significant difference in dDFS was found between the CK7-positive and CK7-negative groups. QRT-PCR for CK7 mRNA could be a useful and universal method for detecting CTC, and the quantitative detection of CK7 in PB would have a prognostic value as a marker of early recurrence in breast cancer patients with surgery. This strategy for detection of CTC would help in the design and monitoring of new therapeutic strategies for prevention of recurrent disease as well as the selection of lowrisk breast cancer patients who do not need systemic therapy. Further study in a larger series with a longer follow-up period is needed to conclude the clinical significance of CTC in PB.

\section{1}

Detection and monitoring of circulating tumor cells (CTCs) by CK-19 mRNA in breast cancer patients treated with neoadjuvant chemotherapy: a marker of early recurrence. Harris LN, Solomon N, Roberts L, Ngo T, Abi Raad R, Gioioso C, Kuter I, Smith B, Iglehart JD, Friedman P, Taghian A. Dana Farber Cancer Institute, Boston, MA; Abbott Laboratories, Abbott Park, IL; Massachusetts General Hospital, Boston, MA

PURPOSE: To evaluate the feasibility of detecting CTCs by CK19 mRNA in breast cancer patients and determine the ability of this marker to predict response to therapy and recurrence.

PATIENTS AND METHODS: Blood samples from Stage II-III patients enrolled on a prospective phase II, randomized trial of neoadjuvant, sequential doxorubicin (4 cycles of $60 \mathrm{mg} / \mathrm{m} 2$ q 2 weeks) > paclitaxel (9 cycles of weekly $80 \mathrm{mg} / \mathrm{m} 2$ ) vs paclitaxel $>$ doxorubicin were taken pre-, during and post-chemotherapy and at 6 month intervals during follow-up. Peripheral blood mononuclear cells were isolated and enriched for epithelial cells by immunomagnetic selection (DynabeadsÒ). The presence of CK19 gene mRNA was determined by quantitative real-time RTPCR using a Beacon's Assay.

RESULTS: A total of 56 patients enrolled and completed the study. CK19 mRNA was undetectable in 29/30 healthy controls. Of patients who have completed neoadjuvant chemotherapy to date, 16/56 (29\%) were positive for CK19 expression at baseline. Of the 9 patients who developed recurrence during 6 monthly followup, 7 had had detectable levels of CTCs (78\%) whereas only 7/44 patients developed CTCs without evidence of recurrence $(\mathrm{p}=0.009)$. Of note, in patients with recurrent disease, CTCs appeared in the peripheral blood from 6 months to 1 year prior to diagnosis of clinically apparent metastases.

CONCLUSIONS: Results of this study suggest that CTCs measured by quantitative RT-PCR for cytokeratin 19 are detectable in a significant proportion of Stage II-III breast cancer patients. Appearance of CTCs in followup appears to be a marker of early recurrence.

\section{2}

Isolation and gene expression profiling of bone marrow disseminated tumor cells from women with locally advanced breast cancer.

Aft RL, Ylagan L, Fleming T, Weilbaecher K, Naughton M, Watson M. Washington University, St. Louis, MO

Background: The presence of bone marrow disseminated tumor cells (BM-DTCs) is an important prognostic biomarker in breast cancer. We have investigated the feasibility of performing immunoselection of BM-DTCs followed by gene expression profiling as a more accurate means of ascertaining the prognostic significance of bone marrow micrometasases.
Patients and Methods: In the context of a neoadjuvant trial of Epirubicin and Taxotere for locally advanced breast cancer, preand post-therapy bone marrow aspirates were collected and subjected to Ficoll density gradient centrifugation to enrich for mononuclear cells. Approximately $2 \times 10^{6}$ cells were analyzed using cytokeratin immunocytochemistry to score for the presence of BM-DTCs. In parallel, for thirteen samples, approximately 110x $10^{7}$ nucleated bone marrow cells were incubated with magnetic beads (Dynal Biotech) coated with antibody to the cell surface antigen, EpCAM (TACSTD1). Total RNA was isolated from the EpCAM-enriched cell population, amplified, and used for cRNA target generation and hybridization to GeneChip ${ }^{\circledR}$ microarrays. Results: Unsupervised cluster analysis of EpCAM captured BMDTCs produced two distinct classes based upon gene expression.. EpCAM transcript expression was detected in all samples. In one expression cluster, 5 of 6 samples corresponded to those that contained 1-7 cytokeratin positive cells per field by immunocytochemical analysis. This included both pre- and posttreatment bone marrow biopsies. In the second expression cluster, 6 of 7 samples corresponded to bone marrow samples without detectable cytokeratin positive cells. In two cases where patientmatched immunoselected BM-DTCs and primary tumors were compared, gene expression patterns were remarkably disparate. Conclusions: This study demonstrates the feasibility of performing gene expression profiling on immunoselected BMDTCs. A signature has been identified that discriminates between cytokeratin positive and negative bone marrow. Current work is addressing the effect of using different target antigens for the immunoselection process, which will ultimately define a combined method and gene expression signature to molecularly stratify BMDTCs and better predict their clinical significance in individual breast cancer patients.

\section{3}

Prospective central assessment of HER-2 status by FISH is not a predictive factor for pathologic complete response (pCR) in 648 breast cancer patients treated preoperatively with an anthracycline / taxane based regimen in the multicenter GeparTrio Trial.

Loibl S, Blohmer JU, Raab G, Steffen J, Kaufmann M, Löhr A, Gerber B, Heinrich G, Eidtmann H, Hilfrich J, Jackisch C, Costa SD, Huober J, Bühler H, von Minckwitz G. J.W.Goethe-University, Frankfurt, Germany; St. Gertrauden Hospital, Berlin, Germany; Marienhospital, Stuttgart, Germany; German Breast Group, NeuIsenburg, Germany; Horst-Schmidt Kliniken, Wiesbaden, Germany; University Womens Hopsital, Rostock, Germany; Gynäkologische Schwerpunktpraxis, Fürstenwalde, Germany; University Womens Hopsital, Kiel, Germany; Henriettenstift, Hannover, Germany; University Hospital, Marburg, Germany; University Womens Hospital, Magdeburg, Germany; University Womens Hopsital, Tübingen, Germany; Ruhr-University, Bochum, Germany

Objective: The predictive value of HER2 for anthracycline/ taxane based treatments in breast cancer is still controversial. Reports about Her-2 being a predictive factor refer mostly to retrospective analysis, derived from metastatic breast cancer patients, or include only a small number of patients (pt).

Methods: More than 2050 participants of the GeparTrio trial with a clinical tumor size of median $4(1-30) \mathrm{cm}$ were treated preoperatively with 2 cycles of Docetaxel, Doxorubicin and Cyclophosphamide (TAC) and were then randomized according to their response to further 4 vs. 6 cycles of TAC (response >= $50 \%$ ) or 4 cycles of TAC vs. 4 cycles of Vinorelbine/Capecitabine (NX) (response $<50 \%$ ). All pt were operated thereafter. The primary endpoint was pCR rate. One secondary endpoint was to assess the value of the Her-2 to predict $\mathrm{pCR}$. The amplification ( $>5$ gene copies) of the HER-2 gene was centrally assessed by FISH on core biopsies on the first $648 \mathrm{pt}$ in the trial. 
Results:464 (71.6\%) tumors showed no gene amplification for Her-2, whereas in $184(28.4 \%)$ a HER-2 gene amplification could be detected. More than 10 gene copies were detectable in 93 $(14.4 \%)$ and $>20$ gene copies in $38(5.9 \%)$ of these tumors. pCR rate was $19.2 \%$ in the Her- 2 negative and $24.5 \%$ in Her- 2 positive pt $(\mathrm{p}=0.17)$. No correlation was found for the number of gene copies and pCR rate (5-10: 24.4\%, 11-20: $22.9 \%, 20+: 27.3 \%)$. In the multivariate analysis grading $(\mathrm{p}<0.001)$, estrogen receptor status $(\mathrm{ER})(\mathrm{p}<0.001)$, progesterone receptor status $(\mathrm{PR})(\mathrm{p}<0.001)$ and response after 2 cycles of TAC $(\mathrm{p}<0.001)$ were significant predictive factors for pCR, but not HER-2 status.

Discussion: In this first prospective analysis of a multicenter, neoadjuvant breast cancer trial HER-2 centrally assessed by FISH was not predictive for the pathologic response to TAC/NX. Response after 2 cycles of TAC, grade, ER, and PR, but not HER2 were significant predictors in a univariate and multivariate model. Central FISH examination was therefore abandoned for further study participants.

\section{4}

Estrogen receptor genotypes predict the response of serum cholesterol to tamoxifen treatment.

Ntukidem NI, Schott A, Skaar T, Jin Y, Li L, Lemler S, Nguyen A Hayden J, Desta Z, Flockhart DA, Hayes DF. Indiana University, Indianapolis, IN; University of Michigan, Ann Arbor, MI

Background and Aim: Breast cancer responses and non-tumoral effects during tamoxifen treatment are variable. Some of this variability may be caused by inherited germ line single nucleotide polymorphism (SNPs) in candidate genes, including estrogen receptor alpha $(E R-\alpha)$ and beta $(E R-\beta)$. We tested the hypothesis that different serum lipid profile changes among breast cancer patients treated with adjuvant tamoxifen are associated with candidate SNPs in ER- $\alpha$ and ER- $\beta$ genes.

Methods: ER- $\alpha$ and ER- $\beta$ genotypes were correlated with fasting serum lipid profile in 185 breast cancer patients who were prospectively followed before and after four months of adjuvant tamoxifen $(20 \mathrm{mg} /$ day $)$. Serum lipid analysis was performed in standard clinical laboratories using validated methods and LDL cholesterol was calculated using the Friedwald Equation. Standard Restriction Fragment Length Polymorphism methods were used to identify the IVS1-401 (PvuII) and IVS1-354 (XbaI) polymorphisms in ER- $\alpha$, while TaqMan(r) assays were used to genotype ER- $\beta$ for single nucleotide polymorphisms IDs rs 1256049 (ESR2-01) and rs4134646 (ESR2-02).

Results: Tamoxifen therapy significantly lowered total cholesterol (-14.1 vs. $-24.2 \mathrm{mg} / \mathrm{dl})$ and LDL cholesterol (-20.5 vs. $-26.9 \mathrm{mg} /$ dl) compared to baseline in both pre- and postmenopausal women. A non-significant trend in cholesterol lowering was observed for postmenopausal compared to pre- and perimenopausal women $(\mathrm{P}=0.06$ for postmenopausal vs. premenopausal). Women who carry the ER- $\alpha$ PvuII CC allele had a 2-fold greater decrease in total cholesterol when compared to women with CT/TT alleles $(\mathrm{P}=0.01)$. No association between LDL cholesterol changes and ER- $\alpha$ genotype was observed. In multivariate analysis, grouping the subjects according to their combined ER- $\alpha$ and ER- $\beta$ genotypes, we found that the subgroup with ER- $\alpha$ PvuII CC and any ESR2-02 allele combination had the greatest reduction in total cholesterol concentration when compared to ER- $\alpha$ CT/TT and any ESR2-02 $(\mathrm{P}=0.0032)$. No statistically significant association was observed between any genotype and LDL, HDL or triglyceride levels. Conclusion: ER- $\alpha$ genotype may predict the response of serum total cholesterol to tamoxifen treatment in breast cancer patients. If validated, genotypic analysis could be used to select women who would not benefit from the favorable lipid lowering effects of tamoxifen.

\section{5}

Withdrawn by Author
1026

\section{Withdrawn by Author}

\section{7}

Inhibin A and B as predictive markers for chemotherapyinduced premature ovarian failure (POF) among premenopausal women with early stage breast cancer (ESBC).

Anders CK, Snyder SA, Barrier RC, Demark-Wahnefried W, Welch RA, Marcom PK, Shaw HS, Chui SY, Blackwell KL. Duke University, Durham, NC

Background: Inhibin, a dimer composed of alpha (A) and beta (B) subunits, is a product of female ovarian granulosa cells. Expression correlates with ovarian cell activity and levels decrease in women approaching menopause. This study looks at Inhibin A and $\mathrm{B}$, estradiol, $\mathrm{LH}$, and $\mathrm{FSH}$ pre- and post-chemo in women receiving adjuvant chemo and correlates them with POF.

Material and Methods: Pre-, immediate post- and 6 months post-anthracycline/taxane-based chemo, serum is being collected from premenopausal women as part of an ongoing study to examine Inhibin levels (INHIBIN; Anders, PI). In addition, serum was collected pre- and 6 months post-chemo from premenopausal women with ESBC who had completed anthracycline-based adjuvant chemo and an exercise intervention (STRENGTH; Demark-Wahnefried, PI). Menstrual histories and QoL questionnaires were collected from both groups. Serum was analyzed using ELISA in duplicate for the following: Inhibin A, Inhibin B, $\mathrm{FSH}, \mathrm{LH}$, and estradiol. POF was defined as failure to resume menses by 6 months post-chemo.

Results: 45 patients from the STRENGTH study (mean age $=42.6$, range 31-51) and 18 patients from the INHIBIN study (mean age $=41.3$, range $26-51$ ) had sequential serum samples analyzed. Post-chemo, 28/63 (44.4\%) had not resumed menses. There was no difference in age among those with or without POF. Among all 45 patients from the STRENGTH study, there was a significant decrease in median Inhibin A $(\mathrm{p}<.0001)$ from pre- to post-chemo. This trend was also observed in INHIBIN patients. There was a significant correlation between Inhibin A and $\mathrm{LH}\left(\mathrm{r}^{2}=.28, \mathrm{p}=.05\right)$ and Inhibin A and estradiol $\left(\mathrm{r}^{2}=.43, \mathrm{p}=.01\right)$. Among patients with amenorrhea, the median decrease in Inhibin A from pre- to 6 months post-chemo was $22.32 \mathrm{pg} / \mathrm{mL}(\mathrm{IQR}=10.54-36.20)$ in the STRENGTH study; $39.80 \mathrm{pg} / \mathrm{mL}$ (IQR=27.37-54.70) from preto post-chemo in the INHIBIN study. This compares to median decrease of $17.57 \mathrm{pg} / \mathrm{mL}(\mathrm{IQR}=0-29.16)$ and $10.33 \mathrm{pg} / \mathrm{mL}(\mathrm{IQR}=-$ 4.85-65.18) respectively for patients who resumed menses. In the INHIBIN study, pre-chemo Inhibin A was lower for patients with amenorrhea $($ median $=62.0 \mathrm{pg} / \mathrm{mL} ; \mathrm{IQR}=36.43-75.8)$ compared to those who resumed menses (median $=83.4 \mathrm{pg} / \mathrm{mL}$; IQR=56.297.7). No such difference in Inhibin B was observed between groups. Discussion: Predictive markers of POF will be invaluable to premenopausal women and their clinicians as they face therapy for ESBC. These data will be expanded and updated, along with QoL parameters, as part of an ongoing study to determine markers of POF. Thus far, our results indicate that changes in serum markers, in particular Inhibin A, from pre- to post-chemo could serve as very important predictors for POF.

\section{8}

TWIST2 gene expression predicts for chemo-sensitivity in patients from two randomized trials of adjuvant FAC/ FEC.

Tomasic G, Scott V, Conforti R, Michiels S, Andre F, Ahomadegbe $J C$, Koscielny S, Spielmann M, Saghatchian d'Assignies M, Garbay JR, Feunteun J, Lazar V, Vassal G, Tursz T, Arriagada R, Delaloge S. Institut Gustave Roussy, Villejuif, France

Background: Adjuvant FAC/FEC for breast cancer (BC) patients has long demonstrated its ability to avoid relapses and BC-related 
deaths. Factors that may influence the sensitivity/resistance to this regimen in the adjuvant setting, and therefore potentially guide therapeutic decision, remain though to be determined. In the late eighties, we conducted two large adjuvant randomized trials, which compared the administration of six cycles of adjuvant FAC/ FEC to observation (premenopausal study, N=311) or the same adjuvant CT followed by tamoxifen to tamoxifen alone (postmenopausal study, $\mathrm{N}=835$ ). These trials demonstrated a DFS benefit favoring the CT arm (Arriagada et al, Acta Oncologica 2005). We examined frozen tumor samples from patients included in these studies with the aim to investigate the predictive effect of a set of candidate genes on the impact of chemotherapy on diseasefree survival.

Materials and Methods: A case-control method was applied among patients from the two pooled trials. Cases were defined by the occurrence of either local or distant relapse. Controls were defined as patients without any events, and matched to cases according to: CT (yes/no), tamoxifen (yes/no), HR status, Tumor grade $(1 / 2 / 3)$ and tumor size $(<3 />3 \mathrm{~cm})$. A set of 40 candidate genes were selected from the very recent literature on $\mathrm{BC}$ prediction profiles (including the NSABP 21-gene set) and on sensitivity to the drugs used. mRNA were extracted from frozen samples and gene quantification was assessed using a real time quantitative RT PCR method. Normalization of gene expression levels was performed using the average level of four reference RNAs: $18 \mathrm{~S}$, RPLO, 28S and PPIA. For each gene, a conditional logistic regression was applied to test for interaction between its expression and response to chemotherapy. A two-sided exact test was applied. Results: 46 matched case-control pairs were selected (of whom 22 had received and 24 not received CT). Median follow-up was 9 years (7-14). Cases and controls were well matched for the target characteristics. A sole gene differentially predicted for sensitivity to adjuvant FAC, TWIST2 $(\mathrm{P}=0.01)$. TWIST2 is a transcription factor implicated in p53-mediated response to genotoxic damages. A large tissue array has been built which includes the tumor samples of all patients $(\mathrm{N}=820)$ from our institution who entered both randomized trials. Immunohistochemistry confirmation of the gene expression data is ongoing on this tissue array and will be presented at the meeting.

Discussion: TWIST2 appears as a new potentially useful candidate gene for independent prediction of tumor sensitivity to adjuvant FAC/FEC. This hypothesis deserves ongoing confirmation in larger sample.

\section{9}

Molecular determinants of aromatase inhibitor sensitivity in primary breast cancer.

Mackay A, Dixon JM, Urruticoechea A, Dexter T, Iravani M, Fenwick K, Young O, White S, Miller WR, Evans DB, Ashworth A, Dowsett M. The Breakthrough Toby Robins Breast Cancer Research Centre, London, UK; Edinburgh Breast Unit, Western General Hospital, Edinburgh, UK; Royal Marsden Hospital, London, UK; Novartis Pharma AG, Basel, Switzerland

Aim: To identify the determinants of biological response of breast tumors to the aromatase inhibitors, letrozole and anastrozole. Methods: 34 postmenopausal patients with primary breast cancer (ER Allred score 2-8) were randomized to presurgical treatment for 2 weeks with letrozole $(n=16)$ or anastrozole $(n=18)$. Biopsies were taken before treatment and at surgery. RNA from each biopsy was subjected to microarray gene expression profiling on Breakthrough $17 \mathrm{~K}$ cDNA microarrays. Changes in proliferation were assessed by Ki67 immunohistochemistry.

Results: Unsupervised clustering resulted in pretreatment and posttreatment biopsies clustering together in 18 out of 34 cases indicative of significant change with treatment in the expression of a large number of genes in the remainder. Paired SAM statistical analysis identified 1484 genes up-regulated and 1310 genes downregulated by $\mathrm{AI}$ treatment below a local false discovery rate of $1 \%$. The most consistently down-regulated genes included PDZK1,
CCND1 and TFF1. The most consistently up-regulated genes included STARD10, FAS and MAN1A1.

A global index of estrogen sensitivity was defined by the number of genes changing by at least 2-fold between each pair of biopsies. This index positively correlated with expression levels of ER, TFF1 and change in the proliferation marker Ki67 and inversely with high level overexpression of HER2.

In a supervised clustering analysis genes chosen by a weighted Kolmogorov Smirnov test separated the biopsies into pre- and post-treatment arms, both correctly classifying 29 out of 34 cases. This analysis identified a cluster of genes containing cyclin D1, TFF3 and other classically E-regulated genes as being clearly downregulated in all tumors treated with AIs. Another cluster of genes associated with cell cycle progression was identified which were dramatically changed only in the tumors showing a clear biological response to estrogen withdrawal. Preliminary analysis identified tumors showing a poor biological response with a cross validated overall error rate of $14 \%$ using only 18 pretreatment genes.

Conclusions: This is a novel approach for determining in vivo estrogen-responsive genes, which may eventually be used in guiding the therapeutic use of aromatase inhibitors in breast cancer. The gene clusters separating pre- and post-treatment biopsies identify better indices of biological response than the commonly used Ki67. The predictor of biological response needs full validation but appears to identify major index genes of estrogen dependence.

\section{0}

Simultaneous and quantitative detection of multiple biomarkers in human breast cancers using semiconductor multicolor quantum dots.

Yezhelyev M, Morris C, Gao X, Marcus A, O'Regan RM. Winship Cancer Institute, Emory University, Atlanta, GA; Emory University, Atlanta, GA

The benefit of targeted therapies, such as endocrine agents and trastuzumab, depends not only on the presence of, but the quantity of targeted protein present. Conventional methods do not allow for simultaneous detection and quantification of cellular proteins on single tissue specimens. Fluorescent nanoparticles, such as semiconductor quantum dots (QDs) exhibit novel optical and electronic properties, and can be engineered to emit over a wide spectrum. These QDs can be conjugated to antibodies, and together with wavelength-resolved spectroscopy can be used to detect and quantify cellular proteins. Methods: We directly conjugated QDs, emitting at 3 separate wavelengths, to primary antibodies for ER, $\mathrm{PR}$ and HER2/neu. These conjugated QDs were used to detect and quantify the 3 receptors in breast cancer cell lines and frozen breast tumors, and results were compared to conventional methods. Results: Multicolored QDs conjugated directly to primary antibodies simultaneously detected and quantified the expression of ER, PR and HER2/neu in single specimens of cancer cell lines and human tissue clinical specimens. There was good agreement between the expression of the proteins using conjugated QDs and conventional methods (immunohistochemical staining and immuno blotting). Coupled with hyper-spectral imaging and wavelengthresolved spectroscopy, multiplexed QD probes were used to quantify a panel of up to 8 different colors at the single-cell level. Conclusions: The use of conjugated QDs offers the possibility of detecting and accurately quantifying multiple cellular proteins simultaneously on single tissue specimens, allowing correlation of traditional histopathology and molecular signatures for intact cancer cells and tissue specimens. These results raise new possibilities for nanotechnology applications in molecular pathology and clinical oncology, particularly in linking multiplexed cancer biomarkers with clinical outcome, and allowing the possibility of individualized therapy. 


\section{1}

Role of hypoxia-inducible factor 1 in predicting treatment efficacy in primary chemo-endocrine therapy in human breast cancer.

Fox SB, Bottini A, Generali D, Bonardi S, Wigfield S, Brizzi MP, Campo L, Milani M, Allevi G, Berruti A, Dogliotti L, Harris $A L$. Institute of Molecular Medicine, University of Oxford, John Radcliffe Hospital, Oxford, UK; Azienda Istituti Ospitalieri, Cremona, Italy; University of Turin, Orbassano, Torino, Italy

Purpose: Hypoxia-induced factor (HIF) family includes a number of the key mediators in response to cellular oxygen deprivation. These factors are able to enhance mechanisms that are important in conferring an aggressive phenotype such as cancer cells ability to migrate and survive in distant organs. HIF1 activation results in activation of many genes regulating tumour processes that contribute to resistance to radiotherapy and cytotoxic therapy. The aim of the present study was to evaluate the role of hypoxia inducible factor $1 \alpha(\mathrm{HIF} 1 \alpha)$ expression in predicting the response to chemo-endocrine therapy and disease free survival (DFS) in breast cancer patients enrolled in a single institution trial of primary anthracycline and tamoxifen therapy. We also evaluated the correlation between HIF1 expression and common patho-biological markers

Patients and Methods: HIF1 $\alpha$ expression was assessed in 187 patients with T2-4 N0-1 breast cancer enrolled in a randomized trial comparing single agent epirubicin (i.v. $60 \mathrm{mg} / \mathrm{m} 2,1-2-21$ for 4 cycles $)$ versus epirubicin + tamoxifen $(30 \mathrm{mg})$ as primary systemic treatment. All patients received post-operatively 4 cycles CMF regimen (600-40-600 mg/m2, 1-8-28). ER+ve patients had 5 years of tamoxifen $(20 \mathrm{mg})$.

Results: HIF $1 \alpha$ expression at baseline conditions showed an inverse relationship with bcl2 $(\mathrm{P}=.05)$ and a positive association with c-erb2 ( $\mathrm{P}=.005)$. According to the HIF1 $\alpha$ expression, overall response progressively decreased with the increase of HIF $1 \alpha$ expression score $(\mathrm{p}<0.04)$. HIF $1 \alpha$ expression was associated with a poor DFS $(\mathrm{p}=0.02)$ while overall survival was not affected. Stratifying patients according to ER status, HIFla was a significant predictor of poor DFS in ER+ve patients but not in ER-ve ones. Conclusions: HIF1a confirms to be a marker of aggressiveness in breast cancer patients and it is a predictive marker of chemotherapy failure particularly in patients with ER+ tumor. These results indicate that HIF1a can be used to discriminate patients who are more likely to be resistant to endocrine therapy. HIF1a positive tumors can achieve advantages by the association of conventional chemotherapy with treatments able to increase oxygen delivery to the tumor bed.

Supported in part by the "Associazione Patologia Oncologica Mammaria (APOM)", by a grant from the Consiglio Nazionale delle Ricerche (CNR) Rome, Italy, by Cancer Research UK (CRUK).

\section{2}

Elevated plasma TIMP-1 level predicts decreased response and survival in metastatic breast cancer.

Lipton A, Ali SM, Leitzel K, Demers L, Evans DB, Hamer P, Brown-Shimer S, Pierce K, Carney W. Penn State/Hershey Medical Center, Hershey, PA; Lebanon VA Medical Center, Lebanon, PA; Novartis Pharma AG, Basel, Switzerland; Oncogene Science/Bayer HealthCare, Cambridge, MA

Background: Tissue inhibitors of metalloproteinase (TIMPs) are known to have at least two different functions. They inhibit the catalytic activity of MMPs and they are also able to act as growth factors. Increased TIMP-1 has been associated with an unfavorable prognosis in some tumor types, such as lymphomas, colorectal, gastric, head and neck, and lung cancer.

Materials and Methods: Pretreatment EDTA plasma TIMPwas assayed from 251 patients enrolled in a phase III $2^{\text {nd }}-$ line hormone therapy trial and 50 post-menopausal control females using the TIMP-1 ELISA from Oncogene Science/Bayer HealthCare, Cambridge, MA

Results: The plasma TIMP-1 levels from the post-menopausal control group $(\mathrm{n}=50)$ had a mean + standard deviation of $201+86$ $\mathrm{ng} / \mathrm{ml}$ (range $49-455 \mathrm{ng} / \mathrm{ml}$ ). The upper limit of normal was defined at the mean +2 SD of the control group $(373 \mathrm{ng} / \mathrm{ml})$. Patient pretreatment plasma TIMP-1 ranged from $70-982 \mathrm{ng} / \mathrm{ml}$. Plasma TIMP-1 was elevated above the mean +2 SD of the control group $(373 \mathrm{ng} / \mathrm{ml})$ in 19 patients $(7.6 \%)$. In univariate analysis, patients with elevated vs. normal plasma TIMP-1 had a reduced clinical benefit rate (CBR) (16\% vs. $42 \%, \mathrm{p}=0.03)$. Time to progression (TTP) (HR 3.0, p <0.0001) and overall survival (HR 4.5, p $=0.0001$ ) were also significantly shorter in patients with elevated TIMP-1 levels. TTP and overall survival were also significantly shorter in patients with higher TIMP-1 plasma levels when analyzed as a continuous variable. Patients with elevated vs. normal serum HER-2/neu levels had higher plasma TIMP-1 levels (mean- 306 vs. $187 \mathrm{ng} / \mathrm{ml}, \mathrm{p}<0.0001)$. In multivariate analysis, elevated plasma TIMP-1 level remained a prognostic factor for reduced overall survival $(\mathrm{p}<0.0001)$, as did elevated serum HER-2/neu $(\mathrm{p}<0.0001)$ andvisceral metastases $(\mathrm{p}=0.003)$.

Conclusion: Elevated pretreatment plasma TIMP-1 levels predicted decreased response to $2^{\text {nd }}$-line hormone therapy and reduced survival.

\section{3}

High tumor tissue levels of tissue inhibitor of metalloproteinases- 1 are associated with resistance to chemotherapy in patients with metastatic breast cancer. Wurtz SO, Schrohl AS, Meijer-van Gelder ME, Romer MU, Sorensen NM, Holten-Andersen MN, Christensen IJ, Look MP, Mouridsen HT, Lademann U, Brunner N, Foekens JA. The Royal Veterinary and Agricultural University, Frederiksberg C, Denmark; Josephine Nefkens Institute, Erasmus MC, Rotterdam, Netherlands; Hvidovre Hospital, Hvidovre, Denmark; Rigshospitalet, Copenhagen, Denmark

Background: Only about $50 \%$ of patients receiving cytotoxic chemotherapy for metastatic breast cancer do benefit from the treatment. Today, no validated markers exist for the prediction of chemotherapy sensitivity/resistance in this patient group. Tissue Inhibitor of Metalloproteinases 1 (TIMP-1) has been shown to protect against apoptosis, including chemotherapy-induced apoptotic cell death and may as such represent a marker of chemoresistance.

Aim: The purpose of the present study was to test the hypothesis that tumors expressing high levels of TIMP-1 are protected against apoptosis-inducing agents and thus less sensitive to chemotherapeutic drugs that work through induction of apoptosis. Materials and Methods: To test this hypothesis, we have established fibrosarcoma cell lines from wild-type and TIMP-1 gene-deficient mice and exposed these cell lines to chemotherapy. In addition, we investigated the association between primary tumour expression levels of TIMP-1 protein (ELISA) and objective response to apoptosis-inducing chemotherapy in 174 patients with metastatic breast cancer.

Results: Fibrosarcoma cell lines devoid of TIMP-1 expression were significantly more sensitive to chemotherapy. When primary tumor tissue levels of TIMP-1 were analysed as a continuous logtransformed variable, increasing tumour tissue TIMP-1 levels were significantly associated with a poor response to CMF and anthracycline-based chemotherapy (OR=0.54, CI $0.33-0.87$, $\mathrm{p}=0.01$ ). In a multivariate model TIMP-1 was significantly associated with response to treatment $[\mathrm{OR}=0.57, \mathrm{CI}=0.33-0.95$, $\mathrm{p}=0.03$ ), while none of the other included classical patient parameters were significantly associated with response to treatment.

Conclusion: Our in vitro experimental studies suggest that TIMP1 protects against chemotherapy-induced apoptosis. This is supported by the clinical studies in which we demonstrated a 
significant association between tumor tissue levels of TIMP-1 and response to the most frequently used chemotherapeutic drugs, namely $\mathrm{CMF}$ and anthracyclines for patients with metastatic breast cancer. Together, this suggests that TIMP-1 could be useful as a predictive marker in breast cancer.

\section{4}

Can diffuse optical spectroscopy predict the final pathological response of neoadjuvant chemotherapy?: a retrospective pilot study.

Cerussi AE, Shah N, Hsiang D, Mehta RS, Tromberg BJ. Beckman Laser Institute, University of California, Irvine, Irvine, CA; University of California Medical Center, Orange, CA

Background: Diffuse Optical Spectroscopy (DOS) is a noninvasive technique that employs harmless levels of non-ionizing near-infrared light to measure absolute concentrations of tissue deoxy-hemoglobin, oxy-hemoglobin, water, and lipids. These concentrations are related to tissue perfusion, angiogenesis, and cellularity. Previously we have demonstrated that DOS has high sensitivity to these functional components in tumor tissue and in tumor tissue undergoing neoadjuvant chemotherapy (NAC). There is a growing clinical need for a reliable and inexpensive method for measuring tumor response to NAC in order to delineate responders from non-responders. Since the NSABP-18 and -27 trials have indicated the importance of obtaining final pathological response, in this pilot study we tested the hypothesis: Can changes in functional DOS parameters be predictive of the final pathological response to NAC?

Materials and Methods: A DOS instrument non-invasively measured scattering and absorption spectra from 650-1000 nm in the breast tissue of 11 women undergoing a standard neoadjuvant chemotherapy regiment(doxorubicin/cyclophosphamide, 3-4 cycles of 3 weeks each). Measurements taken within one week prior to the initial treatment and within one week post treatment were compared. The pre- and posr-treatement relative changes in DOS-measured parameters were compared with final surgical pathology to assess the predictive value of DOS for pathological outcome. Patients were stratified into responder and non-responder categories based upon changes $(>$ or $<50 \%$ ) in the maximum tumor axis.

Results: The degree of change in several DOS parameters, namely deoxy-hemoglobin and water, correlated significantly with the degree of pathological response. Tumor deoxy-hemoglobin changed only $4(3) \%$ in the non responder group $(\mathrm{N}=4)$ and changed $26(16) \%$ in the responder group $(\mathrm{N}=7)$. Differences between tumor water changes were also were evident (3(1)\% versus $16(14) \%)$ Discussion: DOS measurements in less than one week after initial therapy separated responder from non-responder. The early dynamics of DOS-measured physiology may provide important insight into the progression of therapy. We note that two potential markers for tumor cell death, cellularity (through water) and angiogenesis (through deoxy-hemoglobin) are the best predictors of final pathological response. Future work will focus on the separation of partial from compete responders, as well as investigate other therapy regiments.

\section{5}

HIGH expression of the microtubule-associated protein, tau, strongly predicts improved progression free and overall survival in patients with metastatic HER-2-negative breast cancers treated with docetaxel and vinorelbine plus filgrastim.

Gown AM, Treaba DO, Goldstein LC, Porter PL, Gralow JR, Livingston RB, Tam S, Yeh I-T, Hayes DF, Barlow W, Lew D. PhenoPath Laboratories and IMPRIS, Seattle, WA; Seattle Cancer Care Alliance, Seattle, WA; University of Texas Health Sciences Center, San Antonio, TX; University of Michigan, Ann Arbor, MI; Cancer Research and Biostatistics, Seattle, WA; Fred Hutchinson Cancer Research Center, Seattle, WA

Background: Taxanes such as docetaxel are presumed to target microtubules in tumor cells, and there is preliminary published evidence that tau, a tubulin-associated protein, can stabilize tubulin and alter its sensitivity to taxane-based agents. We tested the hypothesis that the levels of tau expression in breast cancer could predict response to taxane-based chemotherapy regimens, using tissues obtained from the the SWOG S0102 trial, in which patients with HER-2-negative metastatic breast cancer were treated with docetaxel and vinorelbine plus filgrastim. In this regimen, the taxane was given on day one, but the vinca was given on days 8 and 15 of a 21 -day schedule.

Materials and Methods: Blocks from 51 patients in S0102 could be retrieved for this analysis; of the 51, only 37 had tissue sufficient for evaluation. Immunohistochemistry (IHC) using antibodies to tau was performed on a tissue microarray constructed from the S0102 paraffin blocks. IHC signal was evaluated in a semiquantitative method: 0 (negative), 1,2 or 3 , based on the intensity of cytoplasmic immunostaining in the tumor cell cytoplasm. The maximum tau score for the 3 representative cores of each tissue block was employed in the analysis. Progression free survival (PFS) and overall survival (OS) were evaluated using long-rank tests and Cox regression models.

Results: When scored dichotomously (3 vs. 0,1, or 2), patients with scores of 3 , corresponding to high level tau expression, had significantly longer PFS (HR $=0.301, \log$-rank p-value 0.0059$)$, and significantly longer OS $(\mathrm{HR}=0.242 ; \log$-rank p-value $=0.016)$ compared with patients with tau scores of 0,1 or 2 .

Conclusions: Immunohistochemical identification of breast cancer specimens showing high expression levels of tau strongly predicts improved PFS and OS in patients with metastatic HER-2 negative breast cancers treated with docetaxel and vinorelbine plus filgrastim. These results are seemingly in conflict with the recently reported finding of low tau expression predicting increased sensitivity to taxanes in breast cancer (Rouzier R et al., PNAS, 2005). Our results regarding the predictive power of tau may relate to the incorporation of vinorelbine in this regimen, an agent with opposing effects on microtubule formation to those of taxanes.

\section{6}

Immunohistochemical detection of ER in breast cancer using the new rabbit monoclonal anti-ER antibody SP1 better predicts survival and response to tamoxifen than the mouse monoclonal antibody 1D5: a tissue microarray study of 4620 cases.

Treaba DO, Gown AM, Goldstein LC, Nielsen TO, Cheang MCU. PhenoPath Laboratories and IMPRIS, Seattle, WA; University of British Columbia, Vancouver, BC, Canada

Background: Estrogen receptor (ER) expression predicts improved disease-free survival and is widely targeted in breas cancer therapy. In a recent study, we reported the increased sensitivity of the new rabbit monoclonal antibody (SP1) when compared with the anti-ER mouse antibody (1D5), the latter in widest use in the United States. With long-term clinical follow-up and laboratory data available, this study integrates the comparative 
performance of these two anti-ER antibodies with survival and therapeutic response data.

Design: Tissue microarrays were obtained from a series of 4620 patients (median age 60 years) diagnosed with breast cancer and referred to the British Columbia Cancer Agency between 1986 and 1992. Median clinical follow-up was 12.4 years. The $0.6 \mathrm{~mm}$ cores on tissue microarrays were tested by IHC using SP1 (Neomarkers) and 1D5 (DakoCytomation) antibodies, and manually scored for semiquantitative percentage of tumor cell positivity according to the following: Negative $(<1 \%), 1+(1-$ $25 \%), 2+(25-75 \%), 3+(>75 \%)$.

Results: In this population-based TMA study, the positivity for the rabbit monoclonal anti-ER antibody (SP1) was $69.8 \%$ while the positivity for $1 \mathrm{D} 5$ was $63.2 \%$. Both monoclonal antibodies were good prognostic indicators of longer breast cancer specific survival. In the discordant cases, the SP1+/1D5immunophenotype was associated with better survival than the SP1-/1D5+ immunophenotype $(\mathrm{p}=0.029)$. The Cox regression model, including tumor size, nodal status, age at diagnosis, and tumor grade, identified SP1 as a superior independent prognostic factor. Furthermore, in the subgroup of patients treated with only hormonal therapy $(32.6 \%)$ the ER+ patients identified by SP1 had better survival than the ER+ patients identified by 1D5.

Conclusions: The rabbit monoclonal anti-ER antibody SP1 is significantly more sensitive than the mouse monoclonal antibody 1D5. In long term clinical follow-up, SP1 is a better independent prognostic factor and more accurately identifies the group of ER+ patients who will have a better survival with hormonal therapy.

\section{7}

INFLUENCE of hormone receptor status on axillary lymph node (ALN) pathologic complete response (pCR) rates in patients with cytologically confirmed ALN metastases prior to primary chemotherapy for breast cancer.

Hennessy BT, Kau SW, Sahin A, Broglio K, Hortobagyi GN, Valero V. MD Anderson Cancer Center, Houston, TX

\section{INTRODUCTION}

Following primary chemotherapy for cytologically confirmed ALN-positive breast cancer, patients who have subsequent negative ALNs (i.e. ALN pCR) have an excellent prognosis regardless of the presence of a residual primary tumor. Hormone receptornegative breast tumors are known to have significantly higher pCR rates in keeping with greater chemosensitivity. However, the influence of progesterone receptor (PR) status alone on chemosensitivity has not been as well documented, nor has that of hormone receptor status on outcome after primary chemotherapy. METHODS

Patients with cytologically documented ALN metastases at diagnosis treated in 1 of 5 prospective trials of doxorubicin- or taxane-based primary chemotherapy prior to definitive surgery at The University of Texas M.D. Anderson Cancer Center were analyzed, according to the presence or absence of residual carcinoma in ALNs, and according to the hormone receptor status of the tumor. We used the chi-square test or Fisher's exact test, as appropriate to test for associations between hormone receptor status and ALN pCR. Survival was estimated by the Kaplan Meier method.

\section{RESULTS}

Of 925 patients treated in these 5 trials, 403 patients had cytologically confirmed ALN metastases. 89 patients $(22 \%)$ had ALN pCR following primary chemotherapy. $31 \%$ of those with an estrogen receptor (ER)-negative tumor $(28 \%$ in $<50$ years and $35 \%$ in older patients) and $12 \%(11 \%$ in those $<50$ years and $12 \%$ in older patients) of those with an ER-positive tumor achieved an ALN pCR $(\mathrm{p}<0.001)$. In those achieving ALN pCR, ER status was not associated with a statistically significant survival difference. However, in patients with residual ALN carcinoma, those with ER-positive tumors had significantly better overall survival $(84 \%$ vs. $53 \%$ at 5 years $(\mathrm{p}<0.001))$ and relapse-free survival $(68 \%$ vs.
$46 \%$ at 5 years $(\mathrm{p}<0.001))$. ALN pCR rates were: ER-/PR- 30\% vs. ER-PR+ $32 \%$ vs. ER+PR- $20 \%$ vs. $E R+P R+8 \%(\mathrm{p}<0.0001)$. The ALN pCR rate was $28 \%$ among patients with PR- tumors and $13 \%$ among patients with $\mathrm{PR}+$ tumors $(\mathrm{p}=0.001)$. Among patients with ER+ tumors, PR status was significantly associated with ALN $\mathrm{pCR}(\mathrm{p}=0.01)$. Among those with ER-disease, PR status was not significantly associated with ALN pCR rates (30\% PR- vs. 32\% $\mathrm{PR}+)$.

CONCLUSION

Patients with complete histologic eradication of axillary disease by primary chemotherapy have an excellent prognosis irrespective of hormone receptor status. ER-negative tumors are significantly more chemosensitive. ALN pCR rates are similar with one or both hormone receptors negative but are significantly lower in those patients with positive ER and PR. The very low ALN pCR rate in $\mathrm{ER}+\mathrm{PR}+$ breast cancers may mean that chemoresistance caused by ER-positivity is closely related to the ER's mechanism of PR control in these tumors.

\section{8}

MR spectroscopy of breast cancer tissue used for tumor classification and lymph node prediction.

Lundgren S, Sitter B, Bathen T, Jensen LR, Axelson D, Halgunset J, Fjosne HE, Gribbestad IS. St. Olavs University Hospital, Trondheim, Norway; NTNU, Trondheim, Norway; MRI Consulting, Kingston, ON, Canada

Background: Axillary lymph node $(\mathrm{pN})$ status is an important prognostic factor for breast cancer (BC) patients. About $25 \%$ of $\mathrm{pN}$-(negative) patients experience recurrence or metastasis. Additional methods might be important for better treatment strategies. Malignant cells have altered metabolism, and metabolic mapping of tissue biopsies using high-resolution magic angle spinning (HR MAS) MR spectroscopy can give detailed information on the metabolic composition. The aim of this study was to compare MR spectroscopic findings from BC tissue to histological grading of tumor and patient $\mathrm{pN}$ status.

Methods: BC and non-involved adjacent tissue were excised from patients with infiltrating ductal carcinoma (IDC). Intact specimens were analyzed in a $50 \mu \mathrm{L}$ MAS rotor. HR MAS spectra were recorded on a Bruker Avance DRX600 spectrometer at $4{ }^{\circ} \mathrm{C}$. Proton MR spin echo spectra were acquired (total echo time 285 $\mathrm{ms}, 5 \mathrm{kHz}$ spinning rate, and water suppression). A pathologist scored the relative areas of normal and neoplastic elements visually after MR analysis, excluding samples with less than 5\% tumorcontent. The final database consist of 115 samples: 48 noninvolved tissue and 69 IDCs (histological grade I (4), II (33) and III (32)). The 69 tumor samplesconsisted of $37 \mathrm{pN}-$ and $32 \mathrm{pN}+$ patients. The spectral region $2.9-4.8 \mathrm{ppm}$ was selected for principal component analysis (PCA). Two sample sets were used as PCA input: all samples (115) and tumor samples (69). Classification histological grade (I, II and III) and lymphatic spread was performed by a probabilistic neural network (PNN) strategy. The 25 first principal component (PC) scores from PCA of tumor samples were used as input in PNN. Both PCA and PNN were performed with full cross-validation.

Results: The 2D score plot of PC2 and PC 3 from the PCA of all samples show a clear separation of non-involved tissue and tumor samples, but no possibility to differentiate among the three types of grading, and PNN of spectra from tumor samples resulted in true classification of 56 of the 69 samples with respect to grading, whereas two samples were not classified (specificity and sensitivity exceeded $80 \%$ ). A PCA score plot of PC2 and PC3 for tumor samples shows a trend of clustering with respect to $\mathrm{pN}$ status. PNN gave a true classification of 65 of the 69 samples.

Classification results of lymph node status from PNN.

Classification Actual negative Actual positive Total

$\begin{array}{llll}\text { Negative } & 34 & 1 & 35 \\ \text { Positive } & 3 & 31 & 34\end{array}$

$\begin{array}{llll}\text { Positive } & 3 & 31 & 34 \\ \text { Total } & 37 & 32 & 69\end{array}$

Total $\quad 37$ Sensitivity:97\%, Specificity: $92 \%$ 
Conclusion: Metabolic patterns in primary breast tumours differ from $\mathrm{pN}+$ and $\mathrm{pN}$ - patients. HR MAS of $\mathrm{BC}$ biopsies has the potential to predict the axillary lymph node status.

\section{9}

Incidence of monosomy of chromsome 17: a potential pitfall in assessing HER-2 gene amplifiaction.

Bloom KJ. CLARiENT Inc and University of Southern California, Los Angeles, $C A$

The assessment of HER-2 gene amplifcation by fluorescence insitu hybridization is typically performed by determining the ratio of the mean number of HER-2 gene copy signals to the mean number of chromosome 17 centromere (CEP-17) signals. The intent of calculating a ratio is to identify those tumors in which an elevated mean number of HER-2 signals is due to polysomy of chromosome 17 rather than true HER-2 gene amplification. Over the last few years, we have noticed a number of tumors in which the HER-2:CEP-17 ratio was $\geq 2.0$ but the mean HER-2 count was less than 4. Based on the FDA approved guidelines for scoring the PathVysion assay, these tumors would be scored as positive for HER2 gene amplification since the assessment is based on ratio rather than the number of HER-2 genes. The aim of this study was to assess the frequency of reduced CEP-17 signals and the relationship to HER-2:CEP-17 ratios.

Material and Methods: 10280 consecutive breast cancers assessed for HER-2 gene amplification by FISH were reviewed. FISH was performed utilizing the PathVysion kit (Vysis, Downers Grove, IL). Twenty cells were assessed and the number of HER-2 and CEP-17 signals were counted in each cell, up to twenty signals each. The HER-2:CEP17 ratio was calculated by dividing the mean number of HER-2 signals by the mean number of CEP-17 signals.

Results: One hundred and fifty-six (1.5\%) of the 10280 breast cancers assessed demonstrated a HER-2:CEP-17 ratio of $\geq 2.0$ and a mean HER-2 count of less than 4 . In 56 tumors, the maximum number of CEP-17 signals counted in each cell did not exceed one, thus the mean CEP-17 count was 1 . In another 607 tumors, the mean CEP-17 count was less than 1.5.

Discussion: Based on these findings, approximately $1.5 \%$ of breast cancers assessed as demonstrating HER-2 gene amplification using the PathVysion kit and the FDA approved scoring criteria do not demonstrate an increased number of HER-2 genes and thus are not truely amplified. Based on prior studies, tumors with mean HER-2 counts less than 4 do not show significant over-expression of HER-2 protein and thus these patients would be considered to have an IHC- FISH discrepancy.

\section{0}

Is there a regimen-specific gene signature predicting for pathological complete response after neoadjuvant chemotherapy in hormone-negative breast cancer patients? A microarray substudy of 101 patients included in EORTC 10994/BIG 00-01 Trial.

Bonnefoi H, Farmer P, Delorenzi M, Becette V, Piccart M, Campone M, Tubiana-Hulin M, Mauriac L, Jassem J, Petit T, Rouanet P, Blot E, Bergh J, Cameron D, Bogaerts J, Iggo R. European Organization on Research and Treatment of Cancer (EORTC); Swiss Institute for Bioinformatics (SIB); Swedish Breast Cancer Group (SweBCG); Anglo-Celtic Cooperative Oncology Group (ACCOG); Swiss Group for Clinical Cancer Research (SAKK); Swiss Institute for Experimental Cancer Research (ISREC)

Background: The goal of this study was to investigate the presence of a regimen-specific gene signature predicting for a complete pathological response (pCR) following neo-adjuvant chemotherapy. Since hormone-receptor negative (HR-) tumours are more sensitive to chemotherapy, therefore our strategy is to first focus in analysing gene expression data from this subset of patients included in an ongoing large randomized trial (EORTC 10994/BIG 00-01). This trial compares a non-taxane regimen (fluorouracil + epirubicin + cyclophosphamide x 6; arm A) with a taxane regimen (docetaxel x 3 and epirubicin + docetaxel x 3; arm B) in patients with large operable or locally advanced/inflammatory breast cancer and with any hormone-receptor status.

Methods: With the cut-off date of April 1st, 2005, this study was restricted to cases meeting the following criteria: (1) non T4 tumours, (2) HR- tumours, (3) more than $20 \%$ tumour cells on the frozen sample, (4) good quality and yield (at least $200 \mathrm{ng}$ ) of RNA extracted from the frozen sample. Frozen samples were analysed centrally. After T7 amplification, samples were labelled by Enzo kit and hybridized to X3P Affymetrix arrays (61927 probesets). We reported recently the feasibility of microarray analysis in the context of this EORTC 10994 trial (Oncogene 2005). A total of 101 samples were selected for this study: 51 in arm A with 29 (of which 14 pCR) and 22 for the learning and the validation sets respectively, and 50 in arm $\mathrm{B}$.

Results: In patients assigned to arm A, we have built a 65 genes signature predicting for pCR to anthracyclines. This model is currently being tested on the validation set to define its accuracy. The same analysis will be performed on samples from patients assigned to arm B. Results will be presented at the meeting. The comparison of the two gene signatures may allow identifying which genes are purely predictive of response to either treatment A or B.

Discussion: Identifying regimen-specific gene signatures is very attractive and may have essential clinical applications. However it requires solid and repeated confirmations in independent data sets or in prospective trial. Should gene signature fail to show predictive relevance, we will use other genomics or non-genomics methods in an attempt to determine predictive factors of response to chemotherapy.

\section{1}

Identification pharmacogenomic markers for predicting paclitaxel-related toxicity in breast cancer patients treated with neoadjuvant chemotherapy.

Fujiwara Y, Shimizu C, Shimoyama T, Takeda M, Nishio K, Ando M, Katsumata N, Kouno T. National Cancer Center Hospital, Tokyo, Japan; National Cancer Center Research Institute, Tokyo, Japan

Background Palitaxel (TAX) shows efficacy in advanced breast cancer.However, TAX-related toxicity including peripheral neuropathy (PN) limits its therapeutic benefit. Molecular markers estimative and predictive of severe PN may assist clinical management by identifying patients likely to derive harm from TAX.

MethodsWe designed a custom cDNA array containing preclinically-selected 1084 genes that related with cellular response to taxane and that are expressed in lymphoid cells. To identify the gene expression change during TAX treatment, we monitored gene expression profiles of 72 peripheral blood mononuclear cells (PBMC) before and after treatment from breast cancer patients who received TAX as neoadjuvant therapy. PN was evaluated throughout the chemotherapy according to NCI-CTC ver.2.

Results We identified the TAX-relative genes discriminating pretreatment and post-treatment PBMC samples using an odds ratio $(\mathrm{OR})$ and paired t-test $(\mathrm{P}<0.01$ and $\mathrm{OR}>2)$. Separately, we also identified the PN-related genes correlated with PN grading score using chi-square test. Finally we selected overlapping candidate genes for prediction maker for PN. Using a machinelearning classification algorithm based on these candidate genes set, we have built a multi-gene classifier for predicting PN grading score with $85 \%$ accuracy and identified biomarker genes including synapse-associated genes. The regression model using the expression profiles of these synapse-associated genes accurately predicted the degree of neuropathy.

Conclusion This work represents a novel exploratory approach to define molecular marker estimating TAX toxicity in surrogate tissue. 
This study is supported by Health and Labour Science Research Grants, Research on Advanced Medical Technology, H14-Toxico007.

\section{2}

Predictors of early ipsilateral breast tumor recurrence following breast conservation therapy.

Gendler LS, Azarbayejani A, Klein LA, Horowitz E, Jin Z, Joseph KA, El-Tamer MB, Schnabel FR. Columbia University Medical Center, New York, NY; Columbia University-Mailman School of Public Health, New York, NY

Introduction: The overall risk of ipsilateral breast tumor recurrence (IBTR) after breast conservation therapy (BCT) is well established in the medical literature. However, early IBTR presents a special concern, possibly reflecting improper patient selection, residual or persistent disease, or aggressive tumor biology. The purpose of this study was to attempt to identify factors predicting an increased risk of early IBTR for patients treated with BCT for invasive breast cancer.

Methods: A retrospective review was conducted of 2260 patients who underwent BCT for Stage I-III breast cancer between 1990 and 2003 at Columbia University Medical Center. Data was obtained from the institutional Tumor Registry, and patients with exclusively in situ disease were excluded from this study. The study population consisted of a total of 107 patients who developed IBTR. Cases were evaluated for details of their surgical procedure, tumor biology, medical therapy, and radiation therapy. Clinicopathologic factors were studied by univariate and multivariate analyses to analyze for factors predictive of early IBTR.

Results: A total of 47 patients developed IBTR within 2 years of breast cancer diagnosis, and 60 patients were diagnosed with IBTR more than 2 years after diagnosis. A Kaplan-Meier curve demonstrated that the rate of IBTR within 2 years was $2.4 \%(95 \%$ Confidence interval $[\mathrm{CI}] ; 1.7 \%-3.1 \%)$ and the rate of IBTR within 5 years was $6.4 \%(95 \% \mathrm{CI} ; 5 \%-7.8 \%)$. Both univariate and multivariate analyses were performed comparing early $(<2$ years) IBTR versus late ( $>2$ years) IBTR populations. In a univariate analysis, factors predictive for IBTR within 2 years were ER negativity (odds ratio [OR] 2.41, 95\% CI 1.03-5.68), lack or delay of radiation therapy (OR 8.19, 95\% CI 3.27-20.51) and tumor size $>2 \mathrm{~cm}$ (OR 1.42, 95\% CI 1.01-2.00). The multivariate analysis showed similar trends after controlling for other confounding factors. There were 14 patients diagnosed with early IBTR after completing chemotherapy and prior to commencing radiation therapy. Age, tumor type, surgical margins, re-excision rate, lymph node involvement, LVI, PR, extent of intraductal component, and differentiation were not predictive of early $(<2$ years) versus late ( $>2$ years) IBTR.

Conclusion: Patients with IBTR are a heterogeneous population, however, ER negativity, lack or delay of radiation therapy, and tumor size $>2 \mathrm{~cm}$ significantly predict an early IBTR within 2 years. This may have an important implication for selection of patients for breast conservation therapy in the future. Thirteen percent of all IBTR in our study were identified after completing chemotherapy and prior to commencing radiation therapy. This emphasizes the need for pre-radiation therapy breast imaging to exclude the possibility of residual or persistent disease prior to radiation.
1043

Analysis of thymidylate synthase, methylenetetrahydrofolate reductase and IVS14+1 dihydropyrimidine deshydrogenase gene polymorphisms in advanced breast cancer patients receiving capecitabine as monotherapy.

Largillier R, Formento JL, Nebbia JF, Etienne-Grimaldi MC, Ginot A, Francoual M, Renee N, Ferrero JM, Foa C, Namer M, Milano G. Centre Antoine Lacassagne, Nice, France

Background: Pharmacodynamics of fluoropyrimidines may be influenced by thymidylate synthase (TYMS), dihydropyrimidine deshydrogenase $(D P Y D)$ and reduced folate levels. The aim of this prospective study was to analyze the impact of constitutional polymorphisms in the TYMS, DPYD and methylenetetrahydrofolate reductase (MTHFR) genes, on toxicity and clinical response in advanced breast cancer patients treated with capecitabine. Material and Methods: Polymorphisms were analyzed in 105 patients (mean age 61,33-84) with advanced breast cancer treated with capecitabine as monotherapy $\left(28 \% 1^{\text {st }}\right.$ line, $41 \% 2^{\text {nd }}$ line). The mean initial dose was $2020 \mathrm{mg} / \mathrm{m}^{2} / \mathrm{d}(\mathrm{d} 1-$ 14 every 3 weeks, median number of cycles $=7$ ). TYMS polymorphisms $\left(6 \mathrm{bp}\right.$ deletion in $3^{\prime}+28$ bp repeats including the G>C SNP in 5') and IVS14+1G $>$ A $D P Y D$ mutation were analyzed by PCR-RFLP. $677 \mathrm{C}>\mathrm{T}$ and $1298 \mathrm{~A}>\mathrm{C}$ MTHFR polymorphisms were determined by melting curve analyses. Results: Grade 2-3-4 toxicity (WHO criteria, 1st cycle) was $14.4 \%$ nausea-vomiting, $13.4 \%$ hematotoxicity, $9.3 \%$ hand-foot syndrome, $9.3 \%$ diarrhea, $8.2 \%$ mucositis. 3' TYMS genotype (46\% wt/wt, $45 \% \mathrm{del} / \mathrm{wt}, 9 \%$ del/del), 5' TYMS genotype (9\% 3RG/3RG, 35\% 2R/3RG or 3RC/ $3 \mathrm{RG}, 56 \% 2 \mathrm{R} / 2 \mathrm{R}$ or $2 \mathrm{R} / 3 \mathrm{RC}$ or $3 \mathrm{RC} / 3 \mathrm{RC}), 677 \mathrm{C}>\mathrm{T} M T H F R$ genotype $(38 \% \mathrm{C} / \mathrm{C}, 42 \% \mathrm{C} / \mathrm{T}, 20 \% \mathrm{~T} / \mathrm{T}), 1298 \mathrm{~A}>\mathrm{C} M T H F R$ genotype $(56 \% \mathrm{~A} / \mathrm{A}, 34 \% \mathrm{~A} / \mathrm{C}, 10 \% \mathrm{C} / \mathrm{C})$ and the IVS14+1 DPYD genotype (one mut/wt patient) were not correlated to any type of capecitabine-related toxicities. 76 patients progressed under treatment. The median response duration was 5.8 months. Response duration was significantly related to the 5 'TYMS genotype, with 3RG/3RG patients exhibiting the shorter response duration (Logrank: $p=0.037$ ). Other polymorphisms were not related to response duration. Discussion: The 5'TYMS genotype that is theoretically associated with the highest TYMS gene transcription $(3 R G / 3 R G)$ is a promising predicive factor influencing capecitabine pharmacodynamics.

\section{4}

Src as a novel molecular biomarker for response to neoadjuvant chemotherapy with sequential doxorubicin and docetaxel in high-risk breast cancer.

Minton SE, Munster PN, Cox C, Lacevic M, Lee J-H, Beam CA, Muro-Cacho CA, Diaz N, Jove R. University of South Florida College of Medicine, H. Lee Moffitt Cancer Center \& Research Institute, Tampa, FL

Background: Src is a novel protein shown to be important in the oncogenesis of several different cancers. Several breast cancer cell lines possess activated Src tyrosine kinases and activated Stat3. Inhibition of Src leads to suppression of constitutively-active Stat 3 and demonstrated subsequent growth inhibition and apoptosis in breast cancer cell lines. We have previously reported on Stat3 as a predictor of response to therapy. With the early development of Src inhibitors we sought to study the role of Src as a predictor of response to neoadjuvant chemotherapy.

Methods: Women with stage III breast cancer $(\mathrm{N}=45)$ having at least a $5 \mathrm{~cm}$ palpable breast mass were eligible for the neoadjuvant treatment. Treatment consisted of 3 cycles of doxorubicin at 80 $\mathrm{mg} / \mathrm{m}^{2} \mathrm{IV}$ given every 2 weeks in a dose dense fashion followed sequentially by 3 cycles of docetaxel at $100 \mathrm{mg} / \mathrm{m}^{2}$ IV given every 2 weeks. G-CSF was given from days 3 through 10 to maintain the dose density of the chemotherapy. Response to the chemotherapy was measured bidimentionally prior to each chemotherapy 
treatment and upon completion of treatment just prior to definitive surgery. Levels of phospho-Src and phospho-Stat 3 were quantified by immunohistochemistry.

Results: The complete $(27 \%)$ and partial clinical response $(67 \%)$ was $94 \%$. The complete pathologic response in the breast was $27 \%$. Phosph-Src correlated with complete clinical response to the neoadjuvant chemotherapy. Higher levels of phospho-Src were associated with a higher likelihood of complete clinical response $(\mathrm{p}=0.01)$. There was a numerical trend in correlation between phospho-Src and pathologic complete response $(\mathrm{p}=0.08)$.

Discussion: Phospho-Src may be an important molecular biomarker of response to neoadjuvant chemotherapy with doxorubicin and docetaxel in high-risk breast cancer. Furthermore, as a potential new target for therapy, Src inhibitors in combination with chemotherapy should be investigated in the treatment of breast cancer.

\section{5}

Topoisomerase II-alpha gene amplification as a predictor of responsiveness to anthracycline-containing chemotherapy in the Cancer International Research Group 006 clinical trial of trastuzumab (herceptin) in the adjuvant setting.

Press MF, Bernstein L, Sauter G, Zhou JY, Eiermann W, Pienkowski T, Crown J, Robert N, Bee V, Taupin H, Villalobos I, Seelig S, Pegram M, Slamon DJ. University of Southern California, Los Angeles, CA; University Medical Center Hamburg-Eppendorf, Hamburg, Germany; GBG, Munchen, Germany; Maria Sklodowska-Curie (MSC) Centre, Warsaw, Poland; ICORG, Dublin, Ireland; US Oncology, Dallas, TX; CIRG, Paris, France; AbbottVysis, Inc., Downers Grove, IL; U.C.L.A., Los Angeles, CA

Background. Topoisomerase II-alpha (TOP2A) gene amplification, not HER2 amplification, may be the predictive marker for responsiveness to anthracycline-based chemotherapy since approximately $40 \%$ of HER 2 amplified breast cancers are also amplified for TOP2A, a known target for anthracyclines. In this study we test this by evaluating TOP2A gene amplification in breast cancer tissue from women entered in randomized clinical trials of trastuzumab (Herceptin ${ }^{\circledR}$ ) in studies combined with anthracycline-based chemotherapy. The control arm for these studies received anthracycline-based therapy alone.

Methods and Results. We evaluated TOP2A amplification by fluorescence in situ hybridization (FISH) in breast cancer tissue from women entered in the Breast Cancer International Research Group (BCIRG) 006 randomized clinical trial of trastuzumab in the adjuvant setting. The HER 2 gene amplification status was prospectively determined by FISH in one of two centralized laboratories prior to patient randomization. Two of the BCIRG 006 treatment arms were anthracycline containing ( $\mathrm{AC}->\mathrm{T}$ and $\mathrm{AC}->\mathrm{TH}$ ) and accrued 1074 patients in each treatment arm. We assessed the cumulative survival among the subgroups of patients defined by treatment with or without trastuzumab and correlate this with TOP2A status.

Conclusions. TOP2A gene amplification in breast tumors of women with HER2 amplified breast cancer have been reported to respond better to anthracycline-based chemotherapy. Since the loci for TOP2A and HER2 are in close proximity, this could explain and improve outcome (should it exist) in HER2 positive breast cancer patients treated with anthracycline-based regimens.

\section{6}

Evaluation of thymidine phosphorylase (TP) in primary breast cancer treated with docetaxel (D) and capecitabine (C).

Schott AF, Thomas DG, Griffith KA, Smerage JB, Hayes DF. University of Michigan, Ann Arbor, MI

We performed a unique clinical trial to delineate drug metabolism in breast tumors in patients, in order to 1) evaluate a hypothesized mechanism of synergy between chemotherapy agents during neoadjuvant chemotherapy for breast cancer, and 2) explore whether induction of drug metabolism is predictive of response to treatment. These goals were accomplished by performing quantitative evaluation of TP in the tumors of breast cancer patients receiving combination chemotherapy with DC. TP is an enzyme that is required to convert $\mathrm{C}$ into 5-fluorouracil. TP induction by $\mathrm{D}$ is a proposed mechanism for the observed preclinical synergy of DC combination therapy. Although the DC regimen has shown promising efficacy in breast cancer, evaluation of TP in the breast tumors of patients during treatment with this combination has not been reported. The specific aims were to: 1) Evaluate the technical barriers to TP analysis by quantitative immunofluorescence (QIF) on research core biopsies done at baseline and on day 5 of cycle $1 ; 2$ ) Evaluate whether D increases TP protein expression, as measured by QIF; and 3) Provide preliminary evidence of whether induction of TP expression correlates with pathologic complete response (pCR) to DC chemotherapy.

Methods: Eligible patients had Stage I-III breast cancer and a measurable breast mass. Biopsies of the breast tumor were performed using ultrasound guidance at baseline and 5 days after the first dose of D. Chemotherapy consisted of D $36 \mathrm{mg} / \mathrm{m} 2$ days $1,8,15$ and capecitabine $2500 \mathrm{mg} /$ day (later reduced to $2000 \mathrm{mg}$ /day)days 5 21 of a $28 \mathrm{~d}$ cycle, $\mathrm{x} 4$ cycles. At the end of chemotherapy patients had a core biopsy to evaluate for residual disease, and if residual disease was present went on to receive AC $x 4$ cycles q 2 wks. Results: 26 patients were enrolled over 15 months. Grade 3 toxicities included hand-foot syndrome, diarrhea, cellulitis, angina, hyperbilirubinemia, and cytokine release syndrome. Eye tearing and nail changes were clinically significant but did not reach grade 3. Three patients had to stop treatment due to toxicity. Clinical response to DC was $15 / 20$ (75\%); pCR was seen in $2 / 20(10 \%)$. Core biopsy after neoadjuvant chemotherapy was accurate in determining pathologic CR in $21 / 22(95 \%)$, with one false negative. Serial biopsies were obtained on 25/26 patients, and QIF for TP was evaluated in all specimens $(96 \%)$. TP upregulation did not occur on day 5 after D administration, as measured by either IHC or QIF. TP expression had no apparent relationship with pCR.

Conclusions: DC chemotherapy exhibited increased toxicity compared to standard taxane regimens, with a similar pCR rate. The study design was successful in that we were able to perform and analyze $96 \%$ of patients' serial biopsies for the enzyme of interest. Core biopsy after neoadjuvant chemotherapy is highly accurate in predicting pCR and will be used in subsequent neoadjuvant study designs to evaluate $\mathrm{pCR}$ rate to experimental therapies prior to standard chemotherapy.

\section{7}

Methods to optimize tissue collection and assay performance from 16-gauge core biopsies in the I-SPY Trial.

Buxton MB, Bondi SM, Au A, Crothers J, Carey LA, DeMichele A Dorsey KC, Dressler L, Harden AT, Gray JW, Haqq CM, Madhavan $S$, Perou C, Petricoin EF, I-SPY Clinical Investigators, Hylton NM, Esserman LJ. University of California, San Francisco, San Francisco, CA; The University of North Carolina at Chapel Hill, Chapel Hill, NC; University of Pennsylvania, Philadelphia, PA; National Cancer Institute, Rockville, MD; US Food and Drug Administration, Rockville, MD

Background: A multi-center trial (The I-SPY TRIAL) of serial imaging and biopsies for women with $>3 \mathrm{~cm}$ tumors receiving neoadjuvant chemotherapy is ongoing. The primary objective is to identify surrogate markers of response that are predictive of pathologic complete response and survival in Stage III breast cancer. A central component is continual quality control and improvement. We present our efforts to develop a system for prospectively capturing and analyzing sample quality and optimize the quantity and diversity of assays with 16-gauge core biopsies. Methods: Four tissue samples ( 2 frozen and 2 paraffin) are 
collected at 3-4 time points [baseline (T1), 24-96 hours after chemotherapy initiation (T2), inter-regimen, if applicable (T3), and surgery (TS)] by a dedicated team of clinicians at each institution. Frozen cores are cut and distributed to 5 laboratories across the country for $\mathrm{CGH}$, gene chip, gene expression, and proteomic analysis. The paraffin cores are utilized for IHC/FISH assays at 2 institutions. The NCI Center for Bioinformatics has developed a Quality Indicator (QI) portal to assist in monitoring the workflow process along with tissue sufficiency, RNA and DNA quantity, and RNA, DNA, IHC/FISH, and tissue lysate array quality. Results: As of May 2005, 177/244 patients have been accrued, and 920 frozen and 920 paraffin cores collected. We have processed 115 frozen samples from 48 patients $(\mathrm{T} 1=48$ samples, $\mathrm{T} 2=48$ $\mathrm{TS}=19)$, and 363 paraffin samples from 121 patients $(\mathrm{T} 1=121$ samples, $\mathrm{T} 2=115, \mathrm{~T} 3=73, \mathrm{TS}=54)$. Invasive cancer is present in $80 \%(38 / 38), 85 \%(41 / 48)$, and $58 \%(11 / 19)$ of the frozen samples at T1, T2, and TS, respectively. For the paraffin samples, invasive cancer is present in $84 \%(101 / 120)$ of the T1 samples and $82 \%(94 / 115)$ of the T2 samples. For the expression arrays, $85 \%(11 / 13)$ had acceptable quality array results. There is sufficient tissue to conduct other analyses in $80-85 \%$ of the samples.

Conclusion: Systematic collection and processing of the samples andmonitoring and maintaining quality control are critical for a complex biomarker study. Results indicate that the quality of the tissue samples is high $(\geq 80 \%)$. The QI portal, although designed specifically for this trial, it is a model for prospective sample quality assessment and clearly has future applications for studies collecting biologic materials.

\section{8}

Predictive markers for 5-FU resistance in metastatic breast cancer.

Christensen AJ, Jensen LB, Balslev E, Nielsen KV, Poulsen TS, Nielsen DL, Moller S, Mouridsen H, Ejlertsen B. Rigshospitalet, Copenhagen, Denmark; DakoCytomation, Glostrup, Denmark

Background: A clinically utilizable predictive marker for the outcome with 5-FU containing treatment has not been developed. The efficacy of 5-FU is mediated through a functioning thymidylate synthase pathway and ought to be blocked by absence or reduced function of key enzymes in the pathway. We used fluorescence in situ hybridization (FISH) to identify copy number changes in three candidate genes from the thymidylate cycle.

Material and Methods: Two groups of patients were selected from a series of breast cancer patients treated with capecitabine for metastatic disease: one group without clinical benefit (disease progression in less than 3 months) and a second group with clinical benefit (time to progression greater than 6 months). Archival tissue from the primary tumor of 29 patients was collected and analyzed for gene copy number (GCN) changes by FISH technique in the 3 genes (TYMS, DHFR and ECGF1) involved in the primary incorporation of 5-FU into DNA.

Results: The FISH analysis was technically successful for 24 of the 29 tissue samples. All 15 patients with a clinical benefit (TTP $>6$ months) of capecitabine had a normal copy number of the 3 genes in the tumor tissue. Nine patients had no clinical benefit (TTP $<3$ months), and 7 of these 9 patients had deletion of at least one of the 3 genes in the tumor tissue. This distribution is highly significant $(\mathrm{p}<0.002)$.

Distribution of gene status in relation to clincal outcome of 5-FU treatment Normal Gene Copy Abnormal GCN of Total

$\begin{array}{llll} & \text { Number (GCN) } & \text { at least one gene } & \\ \text { Clinical benefit } & 15 & 0 & 15 \\ \text { No clinical benefit } & 2 & 7 & 9 \\ \text { Total } & 17 & 7 & 24\end{array}$

Nine of the patients analyzed previously received 5-FU containing adjuvant treatment. Five of these had a TTP longer than 6 months and a normal GCN.

Discussion: These preliminary data suggests that a 3 gene FISH assay may predict resistance to 5-FU treatment. The resistant genotype was identified in the primary tumor and resistance to 5FU therapy seems to be highly preserved.

\section{9}

Clinical characteristics and molecular markers predicting the development and outcome of breast cancer brain metastases.

Melisko ME, Chew K, Baehner F, Moore D, Sneed PK, Rugo HS. University of California San Francisco, San Francisco, CA

Background: Brain metastases (BM) are an increasingly important problem as patients live longer with metastatic breast cancer. Data suggests that patients with hormone receptor (HR) negative or HER2/neu overexpressing cancers are more likely to develop BM, but other molecular characteristics that are associated with BM are not well understood. Since treatment options are limited, identifying patients at greatest risk of developing BM might allow for better prevention strategies. Understanding molecular markers associated with BM may also offer insight into prognosis and facilitate the development of targeted treatments. Methods: We reviewed the treatment and clinical outcomes of 74 patients with BM who received oncology care at our institution between 1997 and 2005. We retrieved archival tissue from 8 resected BM, from the primary breast tumors of approximately 50 patients who developed BM, and from 50 control patients with metastatic disease who were matched for age and HR status but did not develop BM. Immunohistochemical staining for HER2/neu, epidermal growth factor receptor (EGFR), EGFRvIII, pAKT, cyclin D1, and platelet derived growth factor (PDGF) was performed to determine if these molecular markers differ between resected BM and the primary tumors of patients with or without BM.

Results: The median length of follow-up from initial diagnosis of breast cancer was 74 months. At last follow-up, 19 patients were alive with median time of 24.8 months (range 4.6 to 76.4 months) since the diagnosis of BM. The median survival for the entire group after the diagnosis of BM was 12 months. 58\% of patients had tumors that overexpressed HER-2/neu, and 53\% were HR negative. There was a trend towards shorter time to development of BM for patients with HER-2 positive vs. HER-2 negative disease (mean $41.1 \pm 5.4$ vs. $60.9 \pm 9.7$ months, $\mathrm{p}=0.06$ ). There was no difference in survival after the diagnosis of BM for patients with HER-2 positive vs. HER-2 negative disease (23.6 \pm 3.5 vs. $14.2 \pm 2.0$ months, $\mathrm{p}=0.41, \log$ rank) or for patients with HR positive vs. HR negative cancers $(22.2 \pm 2.6$ months vs. 10.3 \pm 2.5 months, $\mathrm{p}=0.27, \log$ rank). Median survival was prolonged in patients who were treated with stereotactic radiosurgery (SRS) at any time compared to patients who did not undergo SRS (22.2 \pm 3.2 vs. $11 \pm 2.7$ months, $\mathrm{p}=0.025, \log$ rank). Correlation between molecular markers, development of BM, and clinical outcomes is under analysis.

Conclusion: In this series, HER2/neu overexpression did not shorten survival after brain metastases, and treatment with SRS at any time was associated with improved survival. New determinants of risk and prognosis are needed. Results of immunohistochemical studies and correlation with clinical data will be presented.

\section{0}

Recurrence in ductal carcinoma in situ (DCIS) after complete microsurgical local excision is predicted by a high proliferation index and HER2/c-erbB2 status.

Wilson GR, Rimouche S, Barnes N, Knox F, Swindell R, Bundred NJ. South Manchester Acute Hospitals Trust, Manchester, United Kingdom

Background: Factors predicting recurrence following breast conserving surgery (BCS) with clear margins for Ductal Carcinoma In Situ (DCIS) are largely unknown.

Aim: To determine recurrence rates and predictors of recurrence risk in patients who underwent BCS with clear margins $(>1 \mathrm{~mm})$ for pure DCIS.

Method: We reviewed all patients who underwent BCS $(n=305)$ for pure DCIS and then identified 232 patients with clear margins 
to examine factors predicting recurrence. Estrogen receptor status (ER), HER2, HER4 expression and Ki67 levels were measured by immunohistochemistry. A HER2/HER4 score $\geq 2$ was considered positive.

Results: In the group overall $(n=305)$ margin status was a highly significant recurrence predictor $(\mathrm{p}=<0.0001)$. Overall recurrence was $10.7 \%$ (25/232) in DCIS with clear margins (median recurrence time 29.5 months) at 5 years compared to $49 \%$ (24/49) DCIS with involved margins (median recurrence time 22.5 months). Tumour grade, ER status, tumour size and age at diagnosis did not predict recurrence.

Using log rank analysis in the group of women with clear margins after BCS $(n=232)$, high epithelial proliferation (measured by $\mathrm{Ki} 67, \mathrm{p}=0.0057)$ and HER2 positivity $(\mathrm{p}=0.036)$ were associated with increased recurrence. There was a trend towards recurrence in HER4 negative DCIS ( $\mathrm{p}=0.074)$. In the ER positive DCIS group, treatment with Tamoxifen had a $24.5 \%$ lower recurrence rate at 5 years $(\mathrm{p}=0.048)$ compared to no adjuvant treatment.

Patient Characteristics Non-recurrent $(n=198)$ Recurrent $(n=34)$ p value (log rank)

$\begin{array}{llll}\text { HER2 negative }(<2) & 55 \%(30 / 54) & 27 \%(6 / 22) & \\ \text { HER2 positive }(\geq 2) & 45 \%(24 / 54) & 73 \%(16 / 22) & 0.036 \\ \text { Ki67 score }<11 & 55 \%(33 / 60) & 26 \%(6 / 23) & \\ \text { Ki67 score } \geq 11 & 45 \%(27 / 60) & 74 \%(17 / 23) & 0.0057 \\ \text { ER negative \% } & 23 \%(22 / 95) & 34 \%(10 / 29) & \\ \text { ER positive \% } & 77 \%(73 / 95) & 66 \%(19 / 29) & 0.167 \\ \text { Tumour Grade } & & & \\ \text { Low } & 15 / 180 & 1 / 34 & \\ \text { Intermediate } & 49 / 180 & 11 / 34 & \\ \text { High } & 116 / 180 & 22 / 34 & 0.421\end{array}$

Table 1 . Factors predicting recurrence in DCIS after breast conserving surgery with clear margins $(>1 \mathrm{~mm})$. A p value $\leq 0.05$ was considered statistically significant

Conclusion. HER2 positivity and high proliferation predicts recurrence in DCIS after BCS with clear margins. Small molecular inhibitors targeting HER2 may be beneficial in reducing recurrence.

\section{1}

Identification and multicentric validation of a metagenebased molecular predictor.

Bertucci F, Borie N, Treilleux I, Deraco S, Martinec A, Debono $S$, Jacquemier J, Fert V, Maraninchi D, Geneve J, Hermitte F, Bachelot T, Viens P, Birnbaum D. Institut Paoli-Calmettes, Marseille, France; IPSOGEN, Marseille, France; Centre Leon Berard, Lyon, France; Federation Francaise des Centres de Lutte Contre le Cancer, Paris, France

Background: The significant genetic heterogeneity among breast cancer patients is a primary obstacle to effective clinical diagnosis and management. Emerging technologies based on gene expression profiling (GEP) may provide clinically useful information to improve the management of breast cancer. GEP has been used to refine classification of previously undistinguishable tumor subgroups, and predict prognosis and response to anticancer agents. Here we report a multicentric GEP study to identify and validate a metagene-based molecularpredictor in order to improve tumor classification and predict patients most likely to respond to standard chemotherapy.

Material and Methods: 451 patients with early breast cancer treated with adjuvant anthracycline-based chemotherapy were selected from Institut Paoli-Calmettes (IPC), Marseille, Centre Leon Berard (CLB), Lyon and PACS01 clinical trial from Federation Nationale des Centres de Lutte Contre le Cancer (FNCLCC), Paris. RNAs were analyzed on $10 \mathrm{~K}$ nylon cDNA microarrays. Several metagenes for tumor classification were identified based on adjusted t-test analysis and hierarchical clustering on an identification set. A Cox-based method was used to find predictors able to discriminate patients with favorable outcome (no metastasis) after chemotherapy, by combining validated metagenes with clinical factors on an identification set of 159 patients treated with anthracyclines (IPCa). The stability and robustness of these predictors were assessed on three different and independent validation sets (IPCb $n=54$, CLB $n=110$, FNCLCC $\mathrm{n}=128$ ). The best predictor was compared with the Nottingham Prognostic Index (NPI).
Results: A predictor was identified on patients treated with chemotherapy (anthracyclines). This predictor was based on a linear combination involving metagenes and clinical factors, i.e. $\mathrm{A} *($ metagene 1$)+\mathrm{B} *($ metagene 2$)+\mathrm{C}^{*}$ (clinical factors $)$. It classified patients in two groups with different outcome. The robustness of this predictor was then confirmed on the three validation sets of patients. Our predictor compared favorably with the NPI, improving the classification of the low-risk patients. Discussion: Our metagene-based molecular predictor is highly efficient to discriminate patients with favorable outcome under adjuvant anthracycline-based chemotherapy. It uses a validated combination of genes known for their biological relevance, and is valid irrespective of the clinical centre. Additional clinical studies and technical developments are ongoing to translate this new tool into a test designed for routine clinical practice.

\section{2}

Predictivity of serum HER-2/NEU and EGFR concentrations for clinical outcome to the monocloncal anti-HER/2-neu antibody trastuzumab plus combination chemotherapy in metastatic breast cancer.

Lueftner DI, Henschke P, Amin R, Geppert R, Wernecke KD, Possinger K. Charité Campus Mitte, Berlin, Germany; Institut für Medizinische Biometrie, Charité Campus Mitte, Berlin, Germany

Introduction: The role of the shed antigen of HER-2/neu in serum (sHER-2/neu) as prediction and monitoring parameter for the management of trastuzumab therapy was clarified in the last years. The impact of EGFR, an important receptor dimerization partner of HER-2/neu, and its serum antigen (sEGFR) remains unclear. We evaluated sHER-2/neu and sEGFR in metastatic breast cancer patients on trastuzumab plus combination chemotherapies and correlated the baseline- and longitudinal results to clinical outcome.

Patients and methods: sHER-2/neu and sEGFR levels were measured in serial samples from 53 patients with metastatic breast cancer with complete outcome assessment. The initial serum sample was obtained prior to initiation of trastuzumab therapy, followed by at least 3 serial samples. sHER-2/neu levels were measured using the Bayer Immuno $1^{\mathrm{TM}}$ HER-2/neu assay with an upper limit of normal of $15 \mathrm{ng} / \mathrm{mL}$. sEGFR was measured using standardized enzyme-linked immunoassays with a cut-off of $62 \mathrm{ng} / \mathrm{ml}$.

Results: $24.5 \%(13 / 53)$ of the patients had an objective response (CR/PR) to trastuzumab plus combination chemotherapy, clinical benefit (CR/PR/SD) could be obtained in $75.5 \%(40 / 53)$ of the patients. Type of chemotherapy and demographic data had no influence on clinical outcome. We found that $69.8 \%$ of the patients had elevated levels of sHER-2/neu at baseline. $21.6 \%$ of the women had increased sEGFR levels. There was a strong correlation between sHER-2/neu positivity and dominant site of involved organ systems. Patients with visceral metastatatic disease (especially with liver metastases) had statistically significant higher sHER-2/neu levels ( $\mathrm{p}=0.003$ ) but had similar clinical outcome as compared to patient without visceral metastases. There was no difference in the response rate (RR) between sHER-2/neu-negative patients $(20.0 \%)$ and sHER-2/neu-positive patients $(26.3 \% ; \mathrm{p}=0.78)$. However, the progression-free interval (PFI) and the duration of response (DR) were longer for sHER-2/neu-positive patients (mean 35 and 11 weeks, resp.) in comparison to sHER-2/neu-negative patients (mean 29 and 5 weeks, $\mathrm{p}=0.1$ and 0.4 , resp). RR of sEGFR subgroups were not different $(\mathrm{p}=0.37)$, also PFI was equal in both subgroups. $92.3 \%$ of the patients with clinical response to Herceptin had sEGFR levels $<62 \mathrm{ng} / \mathrm{ml}$. Further subgrouping according to sHER2/neu and EGFR levels did not reveal any benefit for any subset of patients.

Conclusions: Our data confirm that sHER-2/neu-positive patients show pronounced benefit from Herceptin-based therapy, especially in patients with visceral disease. SEGFR baseline concentrations don't help to further subspecify metastatic breast 
cancer patients who might benefit from trastuzumab therapy. This fits into data from other solid tumors showing that EGFR determination is not essential even for EGFR-targeted therapies.

\section{3}

Validity of DNA-methylation marker PITX2 to predict risk of recurrence in lymph node-negative hormone receptorpositive breast cancer patients: a transfer study.

Markert-Hahn C, Jaeger S, Dessauer A, Gehrke R, Krause F, Vogel-Ziebolz S, Schwope I, Hartmann O, Lesche R, Nimmrich I, Maier S, Harbeck N, Mueller V, Ross JS, Gruetzmann R, Kristiansen $G$, Margossian A, Hartmann A, Golouh R, Paradiso A. Oncology, Penzberg, Germany; Roche Diagnostics GmbH, Mannheim, Germany; Epigenomics AG, Berlin, Germany; Technical University of Munich, Munich, Germany; University Hospital Hamburg Eppendorf, Hamburg, Germany; Albany Medical College, Albany, Technical University of Dresden, Dresden, Germany; Charité, Berlin, Germany; Halitus Instituto Médico, Buenos Aires, Argentina; University Hospital Regensburg, Regensburg, Germany; Institute of Oncology, Ljubljana, Slovenia; National Cancer Institute, Bari, Italy

We have recently shown that DNA-hypermethylation of PITX2 predicts outcome in steroid receptor positive breast cancer patients treated with adjuvant tamoxifen monotherapy. The marker was identified in two studies using a methylation microarray and fresh frozen samples, and afterwards, confirmed on paraffin-embedded tissues (PET) using quantitative methylation PCR (QM-PCR). For the development of an assay system, reproducibility among different laboratories and different operators is highly important. To assess the robustness of PITX2 as breast cancer risk prediction marker, a transfer study was conducted where the complete assay workflow was transferred from Epigenomics' laboratory to a Roche Molecular Diagnostics' laboratory. Methods for DNA isolation from PET as well as bisulfite treatment were applied withou significant changes. QM-PCR was kept constant regarding the $\mathrm{CpG}$ sites covered by the detection probes but the instrument platform was switched from an ABI 7700 instrument to the Roche COBAS TaqMan 48 platform. Experiments were performed in parallel at Roche and Epigenomics.

The transfer study was performed in three parts to separate technical from clinical issues.

During the first two parts PCR (using clean target DNA mixtures) and workflow efficiency (using breast cancer PET samples withou follow up data) were examined. The concordance of methylation ratios between both laboratories was very good (correlation coefficient was 0.92).

In the third part of the study we assessed a clinical cohort with follow- up data. 447 samples of patients with breast cancer that were hormone receptor positive, lymph node-negative and Tamoxifen treated were examined using the transferred workflow at Roche laboratory. The same samples had been previously analyzed at Epigenomics' laboratory. The methylation values again correlated well between the two laboratories (correlation coefficien was 0.9). Detailed statistical analysis of the results will be presented at the meeting.

This study - conducted by an independent laboratory - further supports that PITX2 is a highly robust and reproducible marke for outcome prediction in breast cancer.

\section{4}

Effect of systemic therapy following surgery on outcome in patients diagnosed with an ipsilateral breast tumor recurrence.

Naik R, Gold E, Chuang E, Moore A, Osborne M, Simmons R, Swistel A, Tousimis E, Mazumdar M, Bryant K, Vahdat L. Weill Medical College (WMC) of Cornell University, New York, NY

Background: Ipsilateral breast tumor recurrence (IBTR) after breast conservation surgery is associated with high rates of local recurrence and systemic metastases. The effect of systemic therapy after surgical salvage therapy for IBTR is unknown.

Methods: A retrospective chart review was performed at WMC. Information on original tumor diagnosis of breast cancer and invasive IBTR was obtained. Tumor size, nodal status, ER/PR and HER-2/neu of each original and recurrent tumor were recorded. Systemic therapy data were collected including type of chemotherapy regimen (non-anthracycline, anthracyclinecontaining, taxane-containing or both) and hormonal therapy (SERM or aromatase inhibitor). Disease-free (DFS) and overall survival (OS) estimates were calculated using Kaplan-Meier methodology, and pair-wise comparisons on therapies were made using log-rank test for categorical variables.

Results: Three-thousand eighty charts of women diagnosed with breast cancer were reviewed, and 129 (4\%) IBTRs were identified. Median time from original diagnosis to IBTR was 5.4 years (yrs) (range 0.5 to $21.1 \mathrm{yrs}$ ). Salvage mastectomy was performed in $83 \%$ and reconservation with lumpectomy in $17 \%$. Median followup was 3.3 yrs.

Variable

No. patients

Chemotherapy

-non-anthracycline

-anthracycline-base

-taxane-based

-anthra+taxane

Hormonal therapy

-SERM

-aromatase inhibitor

Combined (chemo-hormonal)

No further therapy

No further therapy

$\begin{array}{ll}\text { Stage I (no.) } & \text { Stage II \& III (no.) } \\ 71 & 28 \\ 23 & 14 \\ 10 & 5 \\ 9 & 1 \\ 3 & 3 \\ 1 & 5 \\ 36 & 12 \\ 22 & 7 \\ 14 & 5 \\ 8 & 3 \\ 13 & 1 \\ 57(80 \%) / 71(100 \%) & 15(54 \%) / 24(86 \%)\end{array}$

Trends for improvement in DFS were observed with chemotherapy regimens containing an anthracycline $+/-$ taxane. There was no apparent added benefit of hormonal therapy; however, the numbers analyzed are small.

Conclusion: The DFS/OS observed at a median follow-up of 3.3 years is below that of recent Intergroup trials. Aggressive multiagent systemic therapy may be needed to improve outcome for some patients with an invasive IBTR. However, long-term followup is necessary to determine the optimal systemic therapy for these patients.

\section{5}

Identification of prediction marker for drug response in gene expression analysis combined with the pharmacodynamic profile in breast cancer patients treated with neoadjuvant chemotherapy.

Shimizu $C$, Shimoyama $T$, Takeda $M$, Nishio $K$, Hasegawa $T$, Ando M, Katsumata N, Fujiwara Y. National Cancer Center Hospital, Tokyo, Marshall Islands; National Cancer Center Hospital, Tokyo, Japan; National Cancer Center Research Institute, Tokyo, Japan

Background Anthracyclines and taxanes are the key drugs in the treatment of breast cancer. Prediction of sensitivity and toxicities of these drugs remains investigating. We monitored gene expressions in tumor tissue and peripheral blood mononuclear cells (PBMC) of breast cancer patients who received neoadjuvant 5FU/epirubicin/ cyclophosphamide followed by weekly paclitaxel (FEC+T) to analyze the pharmacodynamic activity.

Methods Preclinically, 1084 genes that have known or suspected roles in breast tumorgenesis or pharmacodynamics of these drugs and that are expressed in lymphoid cells were selected. To identify the moleculer profile of tumor tissue and PBMC and their specific changes associated with $\mathrm{FEC}+\mathrm{T}$ treatment, we compared the gene expression profiles of total 178 samples obtained from breast cancer patients before and after treatment. (49: pretreatment tumor biopsy, 18: excised tumor after chemotherapy, 57: pretreatment PBMC, 54: treated PBMC) and generated the expression profiles related to drug sensitivity.

Results Using an odds ratio (OR) and paired t-test $(\mathrm{OR}>2$ and $\mathrm{P}<0.01)$, we selected 31 significant genes that correlated with the pathological response to neoadjuvant chemotherapy from 35 pre- 
treatment tumor biopsy samples as a training-set. This process was validated by bootstrap Q-Q plotting method as ultimate crossvalidation test. Alternatively, we identified the drug-modulated genes of tumor and PBMC as pharmacodynamic markers that significantly changed in expression level after the administration of chemotherapy. We compared pharmacodynamic gene profiles of tumors that showed a partial remission and tumors that did not respond to chemotherapy. In further analysis, we tried to represent the change in the expression profile of the tumor by pharmacodynamic profiles of PBMC and combined the data with 31 significant genes profiles of tumor for the prediction of drug sensitivity. Tumor sampling as test set is on going.Conclusion This study has identified pharmacogenomic surrogate marker of PBMC that may predict tumor response to FEC+T. These markers may increase the accuracy of response prediction by applying to the gene expression profiles of tumor samples.

This study is supported by Health and Labour Science Research Grants, Research on Advanced Medical Technology (H14-Toxico007).

\section{6}

Association of MRI morphological phenotype with early and final responses in $\mathrm{AC}$ followed by taxane + carboplatin +/- trastuzumab regimen.

Su MY, Yu H, Mehta RS, Schubbert T, Hsiang D, Carpenter PM, Nalcioglu O. UC, Irvine, CA; UCIMC, Orange, CA

Introduction: It has been shown that different MRI phenotype in breast cancer may show different response to neoadjuvant chemotherapy with the $\mathrm{AC}$ regimen. We investigated whether the morphological pattern is associated with response to dose-dense AC (given every 2 weeks with growth factor support), followed by Taxane + Carboplatin \pm Trastuzumab regimen $(\mathrm{TCa} \pm \mathrm{H})$. Based on the $3 \mathrm{D}$ morphological pattern of the lesions, they were classified into four types: I- circumscribed mass; II- nodular pattern; IIIdiffuse pattern, and IV- septal pattern. The relationship between the response to $\mathrm{AC}$ and to $\mathrm{TCa} \pm \mathrm{H}$ was also investigated, and the benefit with addition of Herceptin was determined.

Materials and Methods: Forty-one patients (31 to 75 years old) who elected to receive neoadjuvant chemotherapy were included. Each patient received a baseline MRI before treatment, then several follow-ups during the course of treatment, and a final MRI before surgery. The response was assessed based on the RECIST criteria, using the longest dimension determined on the maximum intensity projections (MIPs) generated from subtraction MR images.

Results: The morphological phenotype was not correlated with response to dose-dense AC. The response rates were similar in all 4 types, 14/22 (64\%) for type-I (mass), 7/11 (64\%) for type-II (nodular), $2 / 3(67 \%)$ for type-III (diffuse), and $2 / 4(50 \%)$ for type-IV (septal). All patients showing greater than $15 \%$ reduction after 1 or 2 cycles AC were responders after 4 cycles. Following AC, 14 patients completed TCa treatment and 8/14 were complete responders on final MRI ( 7 were $\mathrm{AC}$ responders, the other unknown). Nine patients completed $\mathrm{TCa}+\mathrm{H}$ treatment after $\mathrm{AC}$, and 8/9 were complete responders on MRI (3 were non-responders to $\mathrm{AC})$.

Discussion: We did not find association between morphological phenotype with response, possibly due to the more aggressive dose-dense setting thus more effective. The early response after 1-2 cycles AC predicts the response after 4 cycles AC. The response to $\mathrm{AC}$ was not associated with response to $\mathrm{TCa}+\mathrm{H}$. Patients who were non-responder to AC could still achieve a complete response to $\mathrm{TCa}+\mathrm{H}$ on MRI. On the contrary, the response to AC might enhance the response to $\mathrm{TCa}$ without $\mathrm{H}$. The addition of Herceptin in Her-2/neu positive patients enhanced the treatment outcome.

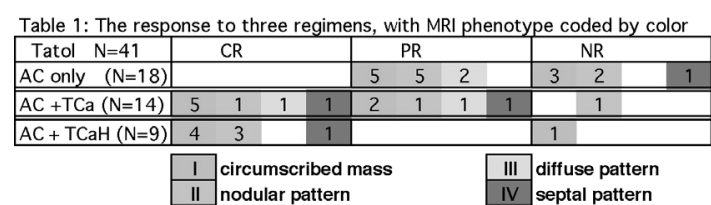

\section{7}

Elevated serum MCP-1 level is associated with favorable clinical prognostic factors and immune response and can be induced by a HER2/neu (E75) vaccine in breast cancer patients.

Dehqanzada ZA, Storrer CE, Foley RJ, Harris KA, Jama YH, Shriver CD, Ponniah S, Peoples GE. Walter Reed Army Medical Center, Washington, DC; USUHS, Bethesda, MD

INTRODUCTION: The role of monocyte chemotactic protein-1 (MCP-1) in breast cancer (BCa) is unclear given its potential to originate from the tumor or immune cells. We have shown that serum MCP-1 levels are increased in $\mathrm{BCa}$ patients compared to controls [131.6 pg/ml vs. $50.3 \mathrm{pg} / \mathrm{ml}$, respectively $(\mathrm{P}=0.001)]$ and in vaccinated patients compared to their pre-vaccination sera [217.0 pg/ml vs. $145.8 \mathrm{pg} / \mathrm{ml}$, respectively $(\mathrm{P}=0.003)]$. To further elucidate the role of $\mathrm{MCP}-1$ in $\mathrm{BCa}$, we investigated serum $\mathrm{MCP}$ 1 amounts in $\mathrm{BCa}$ patients and correlated them with clinicopathologic parameters and immune response to the E75 vaccine. METHODS: The LUMINEX multiplex platform was used to measure the serum MCP-1 levels of $34 \mathrm{BCa}$ patients, pre- and post-vaccination with a HER2/neu (E75) vaccine and GM-CSF Clinical prognostic variables were collected. Vaccine-specific immunologic responses were monitored using HLA-A2:Ig dimer assays measuring \%E75-specific CD8+T-cells. Pre-existing antitumor immunity was defined as $>0.3 \%$.

RESULTS: Serum MCP-1 levels >250pg/mL (MCP-High) correlated with favorable prognostic variables. MCP-High patients, compared to MCP-Low $(<250 \mathrm{pg} / \mathrm{ml})$ patients, demonstrated later onset of disease $(63.9$ vs. 53.8 years, $\mathrm{p}=0.01)$, lower incidence of stage 2 or above disease ( $0 \%$ vs. $55 \%, \mathrm{p}=0.03$ ), fewer nodal metastasis $(0 \%$ vs. $45 \%, \mathrm{p}=0.01)$ and therefore, less chemotherapy $(10 \%$ vs. $76 \%, p=0.002)$. MCP-High patients had increased levels of E75-specific T-cell immunity when compared to the MCPLow group $(69 \%$ vs. $21 \%, p=0.02)$. Interestingly, MCP-Low patients, as compared to the MCP-High group, demonstrated higher inducible levels of MCP-1 (41\% vs. $0 \%, \mathrm{p}=0.001)$ postvaccination. MCP-Low patients with $>50 \%$ post-vaccination serum MCP-1 increase (Response-High) had the worst clinical prognostic variables as compared to Response-Low group $(<50 \%$ increase in serum MCP-1 level post-vaccination). Response-High patients also had more poorly differentiated tumors ( $86 \%$ vs. $33 \%, \mathrm{p}=0.03)$, higher stage 2 or above disease $(86 \%$ vs. $40 \%, \mathrm{p}=$ $0.04)$ and higher percentage of tumors larger than 2 centimeters (71\% vs. $7 \%, \mathrm{p}=0.01)$. Additionally, MCP-Low patients with $>30 \%$ post-vaccination MCP-1 increase also demonstrated significant increases in E75-specific CD8+T-cells (0 vs. $0.32 \%$, $\mathrm{p}=0.03)$.

CONCLUSIONS: We have linked high serum MCP-1 levels in $\mathrm{BCa}$ with favorable prognostic variables and increased E75-specific Tcell immunity. Our results suggest an immune origin for MCP-1 in $\mathrm{BCa}$ that may reflect endogenous anti-tumor reactivity. Most importantly, E75 vaccination induces the largest MCP-1 response in the cohort with unfavorable clinico-pathologic variables. Therefore, low serum MCP-1 levels may help identify patients with worse prognosis and those most likely to benefit from this vaccination strategy. 


\section{8}

The role of the angiogenic marker, endoglin, as a predictor of response to neoadjuvant chemotherapy in primary breast cancer.

Beresford MJ, Ah-See M, Daley F, Richman P, Harris A, Makris A. Mount Vernon Cancer Centre, Northwood, Middlesex, United Kingdom; Weatherall Institute of Molecular Medicine, John Radcliffe Hospital, Oxford, Oxfordshire, United Kingdom

Background: Endoglin (CD105) is a cell membrane gycoprotein which is over-expressed in endothelial cells of tissues undergoing neovascularisation and has been shown to play a role in promoting angiogenesis in breast cancer. Previous studies have shown that although microvessel density as measured by CD34 monoclonal antibodies is reduced after chemotherapy, neither baseline CD34 nor alpha-smooth muscle actin (a marker of mature blood vessels) can predict for response to chemotherapy. This study examines whether a marker of new vessel formation may be of predictive value.

Material and Methods: 32 women (median age 50, range 2970) received 6 cycles of 3-weekly neoadjuvant chemotherapy (5 fluorouracil, epirubicin and cyclophosphamide) for operable breast cancer. Immunohistochemical staining using CD105 was performed on pre-treatment biopsies and post-treatment surgical specimens. Individual $\mathrm{CD} 105$ positive microvessels were counted on 10 random fields at $\times 200$ magnification (or in the case of small biopsies for all fields; range of fields $=4-10$; median 10). Median counts were correlated with clinical and pathological response using the MannWhitney U-test.

Results: 23 of 32 patients ( $72 \%$ ) had a clinical response, 13 $(41 \%)$ had a pathological response. On pre-treatment biopsies, median CD105-positive vessel counts were 4.5 and 5 per field for clinical responders and non-responders respectively (range $0-18.5$ ) showing no correlation with clinical response $(\mathrm{p}=0.44)$. For pathological response assessment there was a significant correlation with non-response, with a median CD105 count of 4 per field for responders and 6 for non-responders (range 0-18.5, $\mathrm{p}=0.04$ ). Postchemotherapy counts were lower in all groups: clinical responders $=2.5$, clinical non-responders $=2.25(\mathrm{p}=0.63)$, pathological responders $=0$, pathological non-responders $=4.5(\mathrm{p}=0.04)$. Discussion: Breast tumour neovascularisation measured by CD105 staining is reduced after neoadjuvant chemotherapy. Assessment of CD105 staining on pre-treatment biopsies can predict for eventual pathologic response with a lower count being more favourable.

\section{9}

Early predictive value of positron emission tomography with $[18 \mathrm{~F}]$-fluorodeoxyglucose for the pathologic complete response of primary tumor in breast cancer patients treated by neoadjuvant chemotherapy.

Berriolo-Riedinger A, Coudert B, Riedinger JM, Touzery C, Toubeau M, Arnould L, Boichot C, Causeret S, Brunotte F, Fumoleau P. Centre G.F.Leclerc, Dijon, France, Metropolitan

Background: To determine the predictive value of early [18F]fluorodeoxyglucose (FDG) positron emission tomography (PET) for the pathologic complete response (pCR) in breast cancer patients treated with neoadjuvant chemotherapy.

Patients and methods: FDG uptake of breast lesions, evaluated by maximal Standard Uptake Value (SUVmax) corrected by body surface area and glycemia, measured after the first course of chemotherapy was compared with the baseline in 19 patients (50 \pm 9 years) with non inflammatory, non metastatic and locally advanced breast cancer. Histopathologic response was determined after completion of chemotherapy (4 or 6 courses) on surgical resection specimens according to the Sataloff classification. Patients were classified in two groups: pCR $(\mathrm{N}=5)$ and non complete response (pNCR) $(\mathrm{N}=14)$.
Results: None of the clinical, pathologic or biologic prognostic factors were predictive of the response (age, T, N, histological grade, ER, PR and HER2). No significant difference of the baseline SUVmax was found between the pCR and pNCR patients (mean = 0.49 vs $\left.0.65 \mathrm{mM} \cdot \mathrm{m}^{2} \cdot \mathrm{kg}^{-1} \cdot \mathrm{L}^{-1}\right)$. On the contrary, the SUVmax decrease was significantly greater in the pCR group $(-82.1 \%$ vs $14.2 \% ; \mathrm{p}=0.006)$. A SUVmax decrease below $50 \%$ of the baseline (threshold calculated by ROC analysis) identified the pCR patients with a sensitivity of $80 \%$, a specificity of $93 \%$, an accuracy of $84 \%$, a Positive Predictive Value of $80 \%$ and a Negative Predictive Value of $93 \%$.

Conclusion: These preliminary results suggest that in breast cancer patients the FDG-PET uptake decrease after the first course of neoadjuvant chemotherapy is an early predictor of the pathologic complete response. Updated results with more patients will be presented at the meeting.

\section{0}

Predicting distant metastasis after local recurrence (failure) in women treated by breast conserving treatment. Tchou J, Greshock J, Rebbeck T, Weber BL, Solin L. Abramson Cancer Center, University of Pennsylvania, Philadelphia, PA

Background: Most local recurrences after breast conserving treatment (BCT) are treated by salvage mastectomy. Local recurrence may be a marker for distant metastasis or a source for secondary dissemination.

Materials and Methods: The charts of 1,687 women with Stage I or II invasive breast cancer treated by BCT between 1977 and 2002 were reviewed. A matched case-control selection was done where cases were defined as women with local recurrence as first event. Controls were women without local recurrence matched to within one year of the initial case diagnosis and matched for at least the same length of follow up. Of the 149 women with local recurrence, 49 also had distant metastasis. Univariate analysis was performed.

Results: Univariate analysis showed the following variables significant in predicting local recurrence: positive margins on primary excision $(\mathrm{p}=0.0407)$, history of prior malignancy $(\mathrm{p}=$ $0.0164)$, tumors detected on physical examination only ( $\mathrm{p}=$ $0.0115)$, and younger age $(\mathrm{p}=0.0002)$. Other variables examined including tumor size, histologic grade, nodal status, and hormone receptor status were not statistically significant $(\mathrm{p}>0.05)$. Distant metastasis was associated with local recurrence $(\mathrm{p}<0.0001)$. The strongest predictors of distant metastasis in women with a local recurrence were those with primary tumors detected on physical examination only $(\mathrm{p}=0.0029)$ and positive margins on primary excision $(\mathrm{p}=0.0478)$.

Discussion: In addition to confirming that young age and positive margins of resection as significant factors predicting local recurrence, we have also shown a significant correlation of local recurrence with distant metastasis in this case-control analysis. Interestingly, women with local recurrence who had primary tumors detected on physical examination only are also more likely to have distant metastasis.

\section{1}

Gene expression profiles in white blood cells of patients with breast cancer - correlation with detectability of tumor by mammographic screening.

Yang Y, Heckman C, Shriver CD, Becker T, Liebman MN, Brzeski $H$. Windber Research Institute, Windber, PA; Walter Reed Army Medical Center, Washington, DC

Introduction: Mammography screening is one of the most effective tools for the early detection of breast cancer. Joensuu et al published results (JAMA Sep 2004) indicating that patients had an improved 10-year disease-free survival if their cancerous tumors were first detected by mammography screening versus clinical- or breast-self exam. We compared gene expression profiles in 
peripheral blood leukocytes of patients with mammographically versus non-mammographically detected breast cancers, in an attempt to identify if any molecular differences might be detected to account for the Joensuu findings.

Material and Methods: All CBCP patients with a diagnosis of breast disease have blood samples drawn into PAXGene (RNA stabilization) tubes. At WRI, RNA from white blood cells was isolated and used for microarray analysis using CodeLink UniSet Human 20K I chips. The clinical diagnoses were examined retrospectively and 23 patients with tumors which fit the criteria used by Joensuu et al (namely, unilateral invasive breast carcinoma, greater than $1 \mathrm{~cm}$ in size and node-negative) were identified. Retrospective examination of mammograms from these patients indicated that 6 had tumors that were detectable by mammography screening (MMG) while 17 were not detectable by this method (NONMMG). The raw signal intensities from the chips were imported into GeneSpring microarray data analysis software (Agilent Technologies) and normalized using global normalization. Differentially expressed genes were identified based on a t-test and used for hierarchical clustering.

Results: We identified 40 genes that showed differential expression $(\mathrm{p}<0.01)$ between MMG and NONMMG samples. Using these 40 genes, we were able to separate all 23 samples into two cluster groups. One cluster was composed of 15 NONMMG samples ( $88 \%$ of all NONMMG samples used in the analysis) while the other group contained all $6 \mathrm{MMG}$ samples and 2 NONMMG samples (12\% of all NONMMG samples used in the analysis).

Discussion: Microarray results relating to expression of 19982 genes in white blood cells from cancer patients enable us to identify genes that were differentially expressed between MMG and NONMMG groups. Hierarchical clustering using these genes was able to separate the samples into two groups with a high degree of accuracy $(91 \%)$. The results point to the potential use of microarrays as a diagnostic tool. We are expanding the sample size for further investigation.

\section{2}

Expression levels of estrogen receptor (ER) gene and three ER-related genes in metastatic ER-positive breast cancer compared with response to endocrine therapy.

Lai S, Valero V, Booster D, Fiterman DJ, Pusztai L, Symmans WF. UT M.D. Anderson Cancer Center, Houston, TX

Background: For stage IV breast cancer, the efficacy of hormonal treatment varies among individuals whose breast cancer cells express estrogen receptor by immunohistochemistry (IHC). Expression of ER gene and ER-related genes may reflect endocrine sensitivity of metastatic disease.

Material and Methods: Frozen tissue was obtained from twenty ER-positive surgically resected metastases. Sixteen patients had received prior endocrine therapy and 15 had received chemotherapy. Gene expression (mRNA) levels of estrogen receptor-alpha (ESR1), GATA3, carbonic anhydrase XII (CA12), and $\mathrm{Bcl}-2$ were measured using real-time reverse-transcription polymerase chain reaction. Expression levels were dichotomized about the median as high or low. Fourteen patients were subsequently treated with endocrine therapy alone, and followed to disease progression.

Results: High Bcl-2 gene expression predicted a significantly improved progression-free survival (Wilcoxon test, $\mathrm{p}=0.01$ ). High expression levels of ESR1, GATA3, and CA12 were not significantly associated with progression-free survival.

Discussion: High Bcl-2 gene expression in ER-positive metastatic breast cancer is associated with longer time to progression during endocrine treatment.

\section{3}

E7389, A Novel Anti-Tubulin, is Safe and Effective in Patients with Refractory Breast Cancer.

Silberman SL, O'Shaughnessy J, Vahdat L, Fabian C, Forero L, Rivera $R$, Chandrawansa $K$, Heiskala $M$, Shapiro $G$, Meneses $N$ Fields SZ. Eisai Medical Research, Inc, Ridgefield Park, NJ; Baylor Sammons Cancer Ctr, Dallas, TX; Weill Cornell Breast Ctr, New York, NY; Univ Kansas Cancer Ctr, Kansas City, KS; Harrington Cancer Ctr, Amarillo, TX; US Oncology, Dallas, TX

Introduction: E7389 is a structurally simplified synthetic analog of Halichondrin B with a novel anti-tubulin activity characterized by sequestration of tubulin into aggregates and prevention of microtubule growth.

Methods: E7389 was evaluated in a Phase II trial as monotherapy for patients with refractory breast cancer ( $\geq 2$ prior chemotherapy regimens, prior anthracycline + taxane, progression within 6 months) as an IV bolus dose of $1.4 \mathrm{mg} / \mathrm{m}^{2}$ on Days $1,8,15$ of a 28 Day cycle as determined in Phase I (Synold, et al Proc ASCO 2005). No premedication was required. The primary endpoint was response rate. Since $\beta$-tubulin isotypes were shown to predict sensitivity of breast cancer cell lines to E7389 (Agoulnik, et al, Proc ASCO 2005), a secondary objective was to explore the relationship of $\beta$-tubulin isotypes and related proteins (e.g. stathmin, microtubule-associated protein 4).

Results: By June 30, 2005, 30 patients were enrolled, and 29 had received treatment, and had completed their $2^{\text {nd }}$ cycle of treatment for which their end of $2^{\text {nd }}$ cycle tumor assessment was available. Median age was 54 yrs (range 36-73), ECOG performance status $0-1, \mathrm{ER}+$ and/or PR+ (18 patients), HER2/neu 3+ (3 patients). All patients had prior anthracycline and taxane therapy, and a median of 4 prior chemotherapies (range 2-12). Prior hormonal therapy and experimental/biologic compounds were reported for $91 \%$ and $27 \%$ of patients, respectively. Safety: The major toxicity related to study drug was myelosuppression: 1 patient had grade 3 febrile neutropenia, and 17 had grade 3 or 4 neutropenia. The other grade 3 toxicities included nausea (1), fatigue (1), dehydration (1), arthralgias (2), dyspnea (2) and peripheral neuropathy (1), this last in a patient who had a pre-existing drug-related neuropathy. Efficacy: There were eight partial responses (PR) using RECIST criteria out of 29 evaluable patients, with six currently confirmed at cycle 4 . For three patients the best response has been stable disease (range 4-7 cycles). Based on disruption of dosing at day 15 for many patients, a Day 1,8 q21 day schedule is currently being evaluated. An update on efficacy, safety and new dosing schedule will be provided, as well as an evaluation of $\beta$-tubulin isotypes as a possible biomarker for sensitivity to E7389.

Conclusions: Based on the safety and efficacy shown to date in this refractory breast cancer population, E7389 may be a useful treatment option for breast cancer patients after multiple prior therapies.

\section{4}

A multicenter phase II study of preoperative epirubicin, cyclophosphamide (EC) followed by paclitaxel (P) plus trastuzumab $(\mathrm{T})$ in Her2 positive primary breast cancer. Untch M, Stoeckl D, Konecny G, Kreienberg R, Thommsen C, Camara O, Moebus V, Kuehn T, DuBois A, Lueck HJ, Gitsch G, Fasching P. Klinikum Grosshadern, University of Munich, Munich, Germany; University of California, Los Angeles, CA; University Hospital, Ulm, Germany; University Hospital Halle - Wittenberg, Halle, Germany; University Hospital Jena, Jena, Germany; Staedtische Kliniken Frankfurt Hoechst, Frankfurt, Germany, Kreiskrankenhaus Gifhorn, Gifhorn, Germany; Horst - Schmidt Kliniken, Wiesbaden, Germany; University Hospital, Erlangen, Erlangen, Germany; University Hospital Freiburg, Freiburg, Germany; University Hospital Erlangen, Erlangen, Germany

Background: Trastuzumab in combination with chemotherapy offers clinical benefit to women with HER2 positive metastatic 
breast cancer $(\mathrm{MBC})$. We conducted a multicenter phase II study of preoperative EC followed by $\mathrm{P}$ plus trastuzumab (T) in HER2 positive patients. The primary clinical endpoints of the analysis were histopathological response (breast and axilla), overall cardiac toxicity, NYHA III / IV events, death caused by a cardiac event. Secondary endpoints are disease - free survival, overall survival, rate of breast conservation, quality of life.

Methods: Two hundred and thirty patients (age $18-65$ ) with breast cancer $>2 \mathrm{~cm}$ or inflammatory disease, HER2 positive (IHC 3+ or FISH positive confirmed by central pathology), received 4 x EC 90/600 mg/m2 q3w followed by 4 X P $175 \mathrm{mg} / \mathrm{m} 2 \mathrm{q} 3 \mathrm{w}$ with T loading dose $8 \mathrm{mg} / \mathrm{kg}$ followed by $6 \mathrm{mg} / \mathrm{kg} \mathrm{q} 3$ weeks, followed by surgery and postoperative $\mathrm{T} \mathrm{q} 3 \mathrm{w} 6 \mathrm{mg} / \mathrm{kg}$ for 9 months. Radiotherapy and endocrine therapy were applied according to standard recommendations.

Results: Analysis of the primary endpoints is carried out for 119 patients: The histopathological complete response is: $37 \%$ (y T0/ is, ypNx). Twenty/ 119 patients (17\%) had only residual DCIS in the breast. Eighty/ 119 patients (73\%) had histologically negative axillary nodes at surgery. For the final presentation in December 2005 histopathological response, cardiac safety and toxicity data will be available for all 230 study patients.

\section{5}

Efficacy and tolerability of gefitinib in oestrogen receptor negative and tamoxifen resistant oestrogen receptor positive locally advanced or metastatic breast cancer.

Agrawal A, Gutteridge E, Cheung KL, Hyman-Taylor P, Robertson JFR. City Hospital, Nottingham, Nottinghamshire, United Kingdom; Astra-Zeneca, Macclesfield, United Kingdom

Background: Gefitinib (Iressa ${ }^{\mathrm{TM}}$ ) was developed as an EGFR tyrosine kinase inhibitor to block signalling through the EGFR pathway, which becomes dysregulated in many types of cancer. EGFR is highly expressed in many oestrogen receptor (ER) negative breast cancers. The possibility that gefitinib may also have efficacy in some ER positive hormone responsive phenotypes was raised by in-vitro and in-vivo data showing that there is a significant increase in EGFR expression and cross-talk between EGFR and the ER pathways in tumours which have developed acquired tamoxifen resistance.

Materials and Methods: The study required recruitment of 54 patients stratified into two arms: 27 patients have been recruited to the ER negative arm and 26 thus far to the ER positive tamoxifen resistant arm. To date 4/53 remain on trial, all of whom are ER positive. Gefitinib was orally administered at a dose of $500 \mathrm{mg} /$ day with an option of dose reduction to $250 \mathrm{mg}$ if patients had severe side effects.

Results: WHO status was $0(n=27), 1(n=23)$ or $2(n=3)$. The cancers were grade $2(n=15)$, grade $3(n=29)$ or grade unknown $(n=9)$. Sites of initial disease were loco-regional disease $(n=21)$, bone metastasis $(n=17)$, liver metastasis $(n=9)$, lung or pleural metastasis $(\mathrm{n}=6)$.

Out of the 53 patients, 6 were withdrawn at an early stage; 4 because of side effects and 2 due to patient request. 1 patient died of bronchopneumonia while on treatment. The clinical efficacy is demonstrated in the table below:

Clinical efficacy of Gefitinib

\begin{tabular}{|c|c|c|c|c|c|c|c|}
\hline & & & & & & & \\
\hline & & M & $\mathrm{CB}$ & & & Survi & \\
\hline & $\begin{array}{l}\text { Age } \\
\text { (years) }\end{array}$ & $\begin{array}{l}\text { DFI } \\
\text { (months) }\end{array}$ & (\%) & $\begin{array}{l}\text { TTP } \\
\text { (months) }\end{array}$ & $\begin{array}{l}\text { DOR } \\
\text { (months) }\end{array}$ & (months)* & $\begin{array}{l}\text { Iressa } \\
\text { Survival } \\
\text { (months) }\end{array}$ \\
\hline $\begin{array}{l}\text { All } \\
(\mathrm{n}=53)\end{array}$ & 61.7 & 43.5 & $\begin{array}{l}36.9 \\
(\mathrm{n}=17)\end{array}$ & $\begin{array}{l}4.8 \\
(0.5-14)\end{array}$ & $\begin{array}{l}5.9+ \\
(0.5-37.5)\end{array}$ & 15.9 & \\
\hline ER pos. & 63.5 & 54.0 & $\begin{array}{l}54.5 \\
(\mathrm{n}=12)\end{array}$ & $\begin{array}{l}6.4 \\
(1-14)\end{array}$ & $\begin{array}{l}8.3+ \\
(1-375)\end{array}$ & 19.6 & 13.9 \\
\hline $\begin{array}{l}\text { ER neg. } \\
(\mathrm{n}=27)\end{array}$ & 60.0 & 33.3 & $\begin{array}{l}20.8 \\
(\mathrm{n}=5)\end{array}$ & $\begin{array}{l}3.6 \\
(0.5-13.5)\end{array}$ & $\begin{array}{l}3.6 \\
(0.5-13.5)\end{array}$ & 12.5 & 9.0 \\
\hline
\end{tabular}

DFI=Disease Free Interval $\mathrm{CB}=\mathrm{Clinical}$ Benefit $(\mathrm{CB}=\mathrm{CR}+\mathrm{PR}+\mathrm{SD}>24$ weeks by

UICC);TTP=Time to progression;DOR=Duration of response. $*=$ Survival from the date of entry into trial

The predominant side effects were skin dryness, skin rash, diarrhoea, nausea/vomiting, lethargy and alopecia in that order; majority being CTC Grades I and II. As a result of these side effects, 17 patients had a dose reduction to $250 \mathrm{mg}$. At the time of the analysis, 4 patients had been withdrawn due to side effects including 3 who did not benefit from dose reduction.

Conclusions: Gefitinib has significant activity in tamoxifen resistant ER positive breast cancer - supporting previous in-vitro and in-vivo data. Clinical benefit in ER negative disease was lower - a result which neither confirms nor excludes that gefitinib may have significant activity in this population of patients. The majority of patients experienced side-effects at $500 \mathrm{mg}$ which decreased when patients had dose reduction to $250 \mathrm{mg}$.

\section{6}

Phase II study of SU11248, a multitargeted tyrosine kinase inhibitor (TKI) in patients (pts) with previously treated metastatic breast cancer (MBC).

Miller KD, Burstein HJ, Elias AD, Rugo HS, Cobleigh MA, Wolff AC, Eisenberg PD, Collier M, Adams BJ, Baum CM. Indiana University Cancer Center; Dana Farber Cancer Institute; University of Colorado Health Sciences Center; University of California San Francisco; Rush University Medical Center; Sidney Kimmel Cancer Center at Johns Hopkins University; California Cancer Care, Inc; Pfizer, Inc

Background: Autocrine and paracrine signaling involving VEGFR and PDGFR stimulate angiogenesis and proliferation of BC. SU11248 is an oral multitargeted TKI with antitumor and antiangiogenic activity, inhibiting VEGFR, PDGFR, KIT, and FLT3 TKs. This study investigated the efficacy and safety of SU11248 monotherapy in pts with previously treated MBC. Methods: Eligible pts had received prior anthracycline (A) and taxane (T) therapy and had resistant disease, defined as progression while on or within 12 months of last $\mathrm{A}$ or $\mathrm{T}$ treatment as adjuvant and/or MBC therapy; measurable disease was required. Pts were treated with SU11248, $50 \mathrm{mg}$ daily x 28 days followed by a 14-day break; 6 weeks defined one cycle. The primary endpoint was ORR defined by RECIST; disease status was assessed every two cycles. A total sample size of 63 was required to identify a clinically meaningful ORR $\geq 15 \%$ based on Simon's Minimax two-stage design. Results: 64 pts were enrolled. Median age was 51 (36-71). 56\% of pts were ER+; $16 \%$ were HER2+. The majority of pts $(82 \%)$ had visceral disease. 52 pts had prior adjuvant chemotherapy (A: 90\%, T: $56 \%$ ); 62 pts were previously treated for MBC (A: $26 \%$, T: $69 \%$ ). In addition, most pts had received other chemotherapies in the MBC setting (66\% capecitabine, $23 \%$ vinorelbine, $16 \%$ platinum, $15 \%$ gemcitabine). Detailed toxicity data are available for $41 \mathrm{pts}$. No grade 4 toxicities have been reported. The most frequently reported grade $2 / 3$ non-hematologic toxicities were fatigue $(\mathrm{G} 2$ : $32 \%$, G3: $5 \%$ ), diarrhea (G2: $20 \%$, G3: $7 \%$ ), anorexia (G2: 17\%), hypertension (G2: 10\%, G3: 5\%), mouth pain $(\mathrm{G} 2: 12 \%)$, and hand-foot syndrome (G2: $5 \%, \mathrm{G} 3: 7 \%)$. Grade 3 neutropenia was reported by $39 \%$ of pts, but there were no neutropenic fevers. Grade 3 thrombocytopenia and anemia were less common (15\% and $2 \%$, respectively). $7 / 41(17 \%)$ pts required dose-reduction for toxicity; an additional 13/41 (31\%) required dose-interruption. Preliminary efficacy data are available for 51 pts. $7(14 \%)$ pts have had a PR; 1 pt had prolonged ( $\geq 6$-month) SD for 11 months. Conclusion: SU11248 has significant single-agent activity in pts with refractory MBC. Toxicity, albeit manageable, frequently necessitated dose adjustment. Updated clinical results and correlative studies will be presented. Future studies should focus on less heavily pretreated pts as well as exploring alternate dosing schedules and combination regimens. 
1067

A phase I/II study of AG-013736, an oral anti-angiogenesis agent, in combination with docetaxel in patients (pts) with metastatic breast cancer (MBC).

Rugo HS, Stopeck A, Badorf A, Pithavala YK, Steinfeldt HM. University of California, San Francisco, San Francisco, CA; University of Arizona, Tucson, Tucson, AZ; Pfizer Inc, La Jolla, $C A$

Background: AG-013736 is an oral small molecule with potent inhibitory effects against the VEGF and PDGF receptor tyrosine kinases with broad preclinical activity in xenograft models of solid tumors. A phase I study in solid tumors identified $5 \mathrm{mg}$ BID as the therapeutic dose; a phase II study in renal cell cancer showed significant efficacy from single agent therapy with a response rate (RR) of 46\% (Rini et al, ASCO 2005). We studied the safety, PK and preliminary efficacy of AG-013736 (AG) in combination with docetaxel (DOC) as first-line therapy for MBC.

Methods: A randomized, placebo controlled, phase II study was preceded by a phase I component. All pts received DOC IV q 3 wks at $80 \mathrm{mg} / \mathrm{m}^{2}$. In the phase I study, AG PO $5 \mathrm{mg}$ BID was given beginning C1D3. Pts with PR or SD had the opportunity to continue single agent AG after stopping DOC. Eligible pts have measurable disease, no prior chemo for MBC, ECOG 0-2, no uncontrolled brain mets. Full PK profiles were collected on C1D1 (DOC alone), C1D21 (steady state, AG alone), and C2D1 (DOC + AG). In the phase II trial, pts are randomized to AG or placebo plus DOC beginning C1D1.

Results: 6 pts were treated (rx) on the phase I portion of this trial. PK: Plasma profiles and PK parameters $(n=4)$ of DOC were similar in the presence and absence of AG-013736 (mean AUC ${ }_{\infty}$ 4829 and $5089 \mathrm{ng} . \mathrm{h} / \mathrm{mL}$ respectively). The PK of AG in plasma were likewise similar in the presence and absence of DOC (mean AUC 823 and $786 \mathrm{ng} . \mathrm{h} / \mathrm{mL}$ respectively). Toxicity: The primary toxicity was hematologic with gr $3 / 4$ NTP in 3 pts, FN in $1 \mathrm{pt}$, and gr $3 / 4$ anemia in 3 pts. Gr 2 HTN was observed in 4 pts, 1 pt stopped rx due to gr 3 stomatitis. Efficacy: 2 pts had PR, 3 SD and 1 PD by RECIST criteria. Pts with PR or SD received a median of 6 cycles of DOC, and 14 wks of single agent AG post DOC (2-36). Duration of single agent AG post DOC with SD was 21 and 36 wks, and with PR 6 and 14 wks. Median time on study was 9 mos (4-16).

Conclusion: This combination is safe and appears to be effective treatment for $\mathrm{MBC}$, with prolonged SD/PR on AG alone post DOC/AG. The phase II randomized trial is ongoing and has currently enrolled 57 pts. Preliminary efficacy and toxicity data will be presented.

\section{8}

Treatment of postmenopausal women with locally advanced or metastatic breast cancer with letrozole alone or in combination with temsirolimus: a randomized, 3 -arm, phase 2 study.

Baselga J, Roché H, Fumoleau P, Campone M, Colomer R, CortesFunes H, Gil M, Chan S, Boni J, Kong S, Cincotta M, Moore L. Hospital Vall D'Hebron, Barcelona, Spain; Institut Claudius Regaud, Toulouse, France; Centre René Gauducheau, Saint Herblain, France; Institut Catala D' Oncologia, Girona, Spain; Hospital Universitario 12 de Octubre, Madrid, Spain; Institut Catala D' Oncologia, Barcelona, Spain; Nottingham City Hospital, Nottingham, United Kingdom; Wyeth Research, Collegeville, PA; Wyeth Research, Cambridge, MA

Background: Temsirolimus (TEMSR) is a specific inhibitor of mTOR, a protein critical for tumor growth and cell survival. We update previously reported results for patients (pts) with locally advanced or metastatic breast cancer on treatment with letrozole (LET) alone or in combination with oral TEMSR (Carpenter et al. Proc ASCO 23:19S, 2005). Methods: Pts were randomized 1:1:1 into 1 of 3 cohorts (all pts received $2.5 \mathrm{mg}$ LET daily): 1) TEMSR $10 \mathrm{mg}$ daily schedule, 2) TEMSR $30 \mathrm{mg}$ intermittent schedule (daily for 5 days every 2 weeks), or 3) LET alone. Each cycle was approximately 2 weeks. Results: Preliminary data as of 7 April 2005 are presented for the 92 pts enrolled (daily: 33; intermittent: 30; LET alone: 29 ). The 3 most frequently occurring grade 1-4 toxicities, regardless of causality, were 1) $10 \mathrm{mg}$ daily: peripheral edema (46\% pts), asthenia (42\%), and diarrhea (36\%); 2) $30 \mathrm{mg}$ intermittent: asthenia $(60 \%)$, diarrhea $(43 \%)$, and mucositis $(43 \%)$; 3) LET alone: asthenia $(55 \%)$, arthralgia (31\%), and nausea (31\%). Grade 3-4 toxicities, regardless of causality, that occurred in $>2$ pts were 1) $10 \mathrm{mg}$ daily: hyperglycemia (4 pts); 2) $30 \mathrm{mg}$ intermittent: hyperglycemia (6 pts) and asthenia (3 pts); 3) LET alone: none. Patients in the 3 cohorts were evaluated for tumor response and progression-free survival (PFS, Table). Patients in the 30-mg intermittent cohort had a longer median PFS, a higher estimated rate of PFS at 16 mos, and less disease progression and death than patients in the other 2 cohorts. After cycles 1, 3, 5, and 7, estradiol concentrations in the blood of patients in the 3 cohorts were similar. Discussion: Preliminary data suggest that theTEMSR + LET schedules were tolerable and that PFS may be longer for pts treated with $30 \mathrm{mg}$ TEMSR intermittent $+2.5 \mathrm{mg}$ LET daily than for those treated with LET alone. A phase 3, randomized, double-blind study is ongoing to evaluate 2 cohorts, $30 \mathrm{mg}$ TEMSR daily for 5 days every 2 weeks $+2.5 \mathrm{mg}$ LET daily vs. placebo daily for 5 days every 2 weeks + $2.5 \mathrm{mg}$ LET daily.

Evaluation of Breast Cancer Patients Receiving Letrozole Alone or in Combination With Temsirolimus

Characteristic

Objective response rate ${ }^{1}$

Median PFS, mos

Estimated PFS rate, $16 \mathrm{mos}$

Patients who progressed or died, $\%$

Patients who progressed

${ }^{1}[(\mathrm{CR}+\mathrm{PR}) / \mathrm{n}]$ x 100 ; modified RECIST criteria.

$\begin{array}{lll}10 \mathrm{mg} \text { TEMSR } & 30 \mathrm{mg} \text { TEMSR } & \text { LET Alone } \\ 33 \% & 40 \% & 45 \% \\ 11.5 & 13.2 & 11.6 \\ 39 \% & 45 \% & 27 \% \\ 48 \% & 37 \% & 62 \% \\ 24 \% & 10 \% & 24 \%\end{array}$

\section{9}

Phase III randomized trial comparing docetaxel in combination with doxorubicin and cyclophosphamide (TAC) versus doxorubicin and cyclophosphamide followed by docetaxel (AC®T) in Her-2/neu negative early breast cancer patients with positive axillary lymph nodes: Interim analysis of the BCIRG 005 study.

Eiermann W, Pienkowski T, Crown J, Chap L, Pawlicki M, Martin $M$, Chan A, Saleh M, Sehdev S, Provencher L, Von Minckwitz $G$, Semiglazov V, Slamon D, Tabah-Fisch I, Buyse M, Riva A, Taupin $H$, Sauter G, Mackey J, on behalf of the BCIRG 005 Investigators. GBG, Munchen and Frankfurt, Germany; Maria SklodowskaCurie (MSC) centre, Warsaw, Poland; ICORG, Dublin, Ireland; UCLA, Los Angeles, CA; MSC Institute, Krakow, Poland; GEICAM, Madrid, Spain; Mount Hospital, Perth Australia; Georgia Cancer Specialists, Atlanta, GA; William Osler Health Centre, Brampton, Canada; CHA-Hôpital Du Saint Sacrement, Quebec, Canada; N.N. Petrov Research Institute, St. Petersburg, Russia: SanofiAventis, Paris, France; IDDI, Brussels, Belgium; CIRG, Paris, France; University Medical Center, Hamburg, Germany; Cross Cancer Institute, Edmonton, Canada.

Background: The relative benefits of adjuvant breast cancer chemotherapy with docetaxel in combination with anthracycline, or given sequentially after an anthracycline-based regimen, are unknown.

Material and Methods: We randomized patients (pts) with axillary lymph node positive, HER-2 negative breast cancer to either TAC $\left(75 / 50 / 500 \mathrm{mg} / \mathrm{m}^{2} \mathrm{q} 3 \mathrm{wk} \times 6\right.$ cycles $)$ or AC $(60 / 600$ $\mathrm{mg} / \mathrm{m}^{2} \mathrm{q} 3 \mathrm{wk} \times \mathrm{x} 4$ cycles $)$ followed by $\mathrm{T}\left(100 \mathrm{mg} / \mathrm{m}^{2} \mathrm{q} 3 \mathrm{wk} \times 4\right.$ cycles). Pts were prospectively stratified by number of positive nodes (1-3 vs. 4+) and hormone receptor status. Pts with ER and or PR positive (HR+) tumors received hormonal therapy for $5 \mathrm{yrs}$ after chemotherapy. The primary endpoint was disease-free survival (DFS) with $80 \%$ power (0.05 significance level) to detect an absolute difference of $5 \%$. Secondary endpoints included overall survival and safety. 
Results: A total of 3298 pts (1649 per arm) were recruited between Aug. 2000 and Feb. 2003. Baseline characteristics were well balanced: age $<50$ yrs $47 \%, 1-3$ nodes $61 \%, \mathrm{HR}+82 \%, \mathrm{~T}>2 \mathrm{~cm}$ $58 \%$. The planned 6 cycles of TAC were given to $93.5 \%$ of pts and 8 cycles of AC-T to $90.5 \%$. Febrile neutropenia (17.9\% vs. $8.5 \%$ ) was more frequent with TAC, while grade $3 / 4$ neutropenic infections were equivalent $(8.7 \%$ with TAC vs. $8.0 \%)$. Primary prophylaxis with G-CSF was given beginning cycle 1 in $16.4 \%$ of pts receiving TAC and $3.5 \%$ of pts on AC-T. One septic death occurred in the TAC arm. Grade 3/4 non-hematological toxicity rates were fatigue $(5.2 \%$ vs. $6.3 \%)$, nausea $(4.5 \%$ vs. $4.1 \%)$, vomiting $(4.2 \%$ vs. $4.1 \%)$, diarrhea $(2.9 \%$ vs. $3.1 \%)$, stomatitis ( $2.6 \%$ vs. $3.0 \%)$, peripheral edema (1.3\% vs. $2.6 \%)$, sensoryneuropathy $(0.6 \%$ vs. $2.0 \%)$ and $\mathrm{CHF}(0.1 \%$ vs. $0.4 \%)$ in the TAC and AC-T arms, respectively. Other grade 3/4 docetaxel-specific toxicities (nail and skin) were observed in less than $0.5 \%$ in both arms. At the protocol-specified event-driven interim analysis, median follow-up was 30 months and 392 DFS events were observed. However, the IDMC has chosen not to release efficacy data at this time.

Discussion: The safety profile of the two common docetaxelbased adjuvant chemotherapy regimens is comparable with the exception of a higher incidence of febrile neutropenia with TAC. Additional follow-up is required to evaluate the relative efficacy of combination vs. sequential docetaxel-containing chemotherapy in the adjuvant treatment of women with node positive, HER-2breast cancer.

\section{0}

A phase $2 \mathrm{~b}$ multicenter evaluation of the safety and efficacy of TOCOSOL ${ }^{\circledR}$ paclitaxel (TOC- P) as initial treatment of patients with metastatic breast cancer (MBC).

Bogdanova N, Tjulandin S, Ognerubov N, Semiglazov V, Afanasjev B, Makhson A, Krasnozhon D, Manikhas G, Vtoraya O, Mitashok I, Astakhov V, Byakhov M, Luciano G, Moore E, Pratt J, Bolton MG. The 1074 TOCOSOL Paclitaxel Working Group, Russian Federation; Sonus Pharmaceuticals, Bothell, WA

TOC-P is a novel Cremophor ${ }^{\circledR}$-free vitamin E-based paclitaxel formulation that does not need reconstitution or dilution, is given over 15 minutes i.v. push, may result in reduced incidence and severity of infusion reactions and better patient tolerance (in particular, less neuropathy), thus enabling higher single doses and/ or a higher cumulative paclitaxel dose, and, potentially, improved anti-tumor efficacy. Pre-medication with steroids is not required. 47 patients (pts) with previously untreated MBC were assigned to receive weekly TOC-P $120 \mathrm{mg} / \mathrm{m}^{2}$ until PD or intolerable toxicity. Median age: $57(21-74)$. ECOG PS $0=26$ pts, PS $1=21$ pts. Chemotherapy naïve: 19 pts; prior adjuvant chemotherapy: 28 pts; prior anthracycline: 18 pts. ER+: 12 pts, ER-: 4 pts, ER status ND: 31 pts. Prior hormone therapy: 14 pts. Pts were required to have measurable disease by RECIST, thus defining a population with a high tumor burden; visceral metastases: 43 pts, $\geq 3$ sites of disease: 21 pts. One pt was ineligible and is not included in the efficacy analysis. Safety and Efficacy data for the first 16 weeks of treatment are available for 47 and 44 pts respectively. The mean dose delivered was $95 \mathrm{mg} / \mathrm{m}^{2} /$ week. 27 pts remain on therapy after an average 17 weeks; 20 pts have discontinued: $P D=11$, toxicity $=7$, withdrawal not due to toxicity $=2$. Investigator reported RR: 22 pts $(48 \%)$ confirmed PR (confirmatory CT 4 weeks after OR determination); an additional 4 pts (9\%) have unconfirmed PR; 8 pts have SD at $16 \mathrm{wks} ; 9$ have PD. The median TTP has not yet been reached. The most frequent toxicity reported was neutropenia $(87 \%)$. Grade $3 / 4$ neutropenia: $66 \%$ of pts, $60 \%$ of pts required a dose reduction by wk 4 . Dose re-escalation was permitted. The time to return to full dose was $1 \mathrm{wk}$ in $>70 \%$ of pts. Grade 3 neuropathy: 11\% (no grade 4). Arthralgias and myalgias: $34 \%$ (2\% grade 3 , no grade 4$) .24$ pts $(51 \%)$ had an adverse event related to infusion (event occurred within 30 minutes of end of dose). One grade 4 event (sacral pain) was reported and resulted in discontinuation of study drug after 3 occurrences. In all other pts, infusion reactions were easily managed and did not result in discontinuation of therapy. Final data will be presented. TOCOSOL paclitaxel is an active agent in the treatment of MBC. The recommended dose for Phase 3 study is $100 \mathrm{mg} / \mathrm{m}^{2}$ weekly.

\section{1}

Biomarker results from a phase II randomized study of lapatinib (GW572016) as first-line treatment for patients with ErbB2 FISH-amplified advanced or metastatic breast cancer.

Gomez HL, Chavez MA, Doval DC, Nag S, Chow LW, Ang PC, Ahmad NM, Berger M, Newstat B, Stein S, Sledge GW. Instituto Especializado de Enfermedades Neoplasica, Lima, Peru; Hospital Alberto Sabogal, Lima, Peru; Rajiv Gandhi Cancer Institute and Research Centre, New Delhi, India; Jehangir Hospital and Medica Centre, Pune, India; Queen Mary Hospital, Hong Kong; National Cancer Centre, Singapore; Hospital University, Bharu, Kalatan, Malaysia; GlaxoSmithKline, Collegeville, PA; Indiana University, Indianapolis

Background: Lapatinib is a selective, reversible, oral small molecule inhibitor of both ErbB1 (EGFR) and ErbB2 (HER-2/ neu) kinase activity. The primary objective of this study was to evaluate the response rate of two lapatinib dosing regimens as first-line treatment for patients (pts) with metastatic breast cancer (MBC) and documented ErbB2 amplification by FISH. Several studies have concluded that elevated pretreatment serum HER-2/ neu levels are associated with favorable response to Herceptinbased therapies and that pts who respond to treatment have declines in extracellular domain (ECD). We report the results of the analysis of ECD ErbB1 and ErbB2 and its correlation with response to lapatinib. Material and methods: Eligible pts had advanced or MBC that amplified the ErbB2 gene and measurable disease (RECIST). Pts were randomized (1:1, open label) to lapatinib $1500 \mathrm{mg}$ as a single daily dose (QD) or lapatinib 500mg twice daily (BID). Response was defined by RECIST criteria. Final enrollment of 130 pts is planned; an interim analysis was performed after 40 pts reached 12 weeks of treatment. Tumor tissues were obtained from each pt at the time of most recent biopsy. Sequential quantitation of ECD for both ErbB1 and ErbB2 were obtained at baseline, every 4 weeks and at the time pt stopped therapy. Results: An interim analysis was performed on the first $40 \mathrm{pts}$ randomized to treatment $(n=19$ on $500 \mathrm{mg}$ BID and $n=21$ on $1500 \mathrm{mg}$ QD). No unexpected toxicity was reported, and there were no grade $3 / 4$ treatment-related adverse events. Efficacy by dose schedule appeared comparable. By investigator review, confirmed PR was demonstrated in 12 pts $(30 \%)$ pts and by independent review, 14 pts $(35 \%)$ : stable disease for at least 8 weeks, was 13 pts $(32.5 \%)$ by investigator and $14(35 \%)$ by independent review. For the initial 40 pts, baseline ErbB1 or ErbB2 ECD levels were not significantly different between responders $(\mathrm{PR})$ and non-responders (SD+PD). However, 22\% $(6 / 27)$ of non-responders had ErbB2 ECD levels $>100 \mathrm{ng} / \mathrm{ml}$ compared to $36 \%(4 / 11)$ of responders. An analysis of sequential ECD levels will be performed. Conclusion: Lapatinib appears well tolerated and shows evidence of activity as first-line treatment for women with ErbB2-amplified advanced breast cancer. Analysis of serum biomarkers ErbB1/ErbB2 ECD and further analysis of molecular phenotypes in tumor tissue is being performed to identify factors predictive of response to lapatinib. 
1072

ZK-EPO, a novel synthetic epothilone B analog, significantly inhibits tumor growth in both non-resistant and resistant breast cancer models.

Klar U, Buchmann B, Schwede W, Skuballa W, Lichtner RB, Hoffman J. Schering AG, Berlin, Germany

Background: ZK-EPO, the first fully synthetic third-generation compound in clinical trials of a novel class of natural products, the epothilones, exhibits marked preclinical antiproliferative effects. Preclinical data indicate that ZK-EPO has higher efficacy compared with taxanes in a number of in vitro and in vivo non-resistant and resistant tumor models. ZK-EPO is not recognized by efflux pumps and so possesses the potential to overcome resistance.

Methods: In vitro, human breast tumor cell lines (non-resistant: MCF7 and MaTu; resistant: MCF7/ADR, NCI/ADR, and MaTu/ ADR) were treated with ZK-EPO, paclitaxel or other tubulinbinding drugs to determine their respective $\mathrm{IC}_{50}$ values, cellular uptake and distribution. In vivo, effects of ZK-EPO at different concentrations were compared with paclitaxel in non-resistant (MaTu and MX-1) and resistant (MaTu/ADR and NCI/ADR) human breast tumor models. Efficacy was assessed by measuring the tumor area during treatment and calculating the treated/control ratios $(\mathrm{T} / \mathrm{C})$.

Results: In vitro, ZK-EPO was significantly more active in all human breast tumor cell lines examined compared with paclitaxel. Short-term (4 hours) exposure to ZK-EPO produced a significant inhibition of proliferation in NCI/ADR cells that overexpressed P-glycoprotein, a finding not observed after treatment with paclitaxel or the epothilone BMS-247550. Exposure (3 days) with ZK-EPO inhibited proliferation of the resistant NCI/ADR breast tumor cells more effectively than paclitaxel and other first- or second-generation epothilones, including epothilone D, BMS-247550 and BMS-310705. Radiolabelling studies indicated that unlike paclitaxel, ZK-EPO preferentially localized to the nuclei of cells, with $71 \%$ of ZK-EPO vs $34 \%$ of paclitaxel being found in the nuclei of MaTu/ADR cells. In vivo, ZK-EPO exhibited favorable tolerability and was highly effective, producing markedly superior inhibition of tumor growth compared with paclitaxel especially in human breast tumor xenograft models expressing resistancies (MaTu/ADR, NCI/ADR).

Conclusions: ZK-EPO exhibited significant in vitro and in vivo activity in all of the human breast tumor models examined. ZKEPO also showed significant in vitro activity when compared with paclitaxel and other epothilones (epothilone D, BMS-247550, and BMS-310705) and demonstrated excellent activity in nonresistant and resistant human breast tumor models. In addition, because ZK-EPO is not recognized by cellular efflux pumps, early use of this agent may delay or prevent the development of resistance.

\section{3}

A phase I, open-label study of the safety, tolerability and pharmacokinetics of lapatinib (GW572016) in combination with trastuzumab.

Storniolo AM, Burris III HA, Overmoyer B, Silverman P, Pegram MD, Jones SF, Peacock NW, Loftiss J, Koch KM, Paul E, Ho PTC. Indiana University Cancer Center, Indianpolis, IN; Sarah Cannon Cancer Center, Nashville, TN; Ireland Cancer Center, Cleveland, OH; UCLA Center for the Health Sciences, Los Angeles, CA; GSK, $R T P, N C$

ErbB1 and ErbB2 receptor expression in tumors predicts a poor outcome. Lapatinib is a potent oral ErbB1/ErbB2 receptor tyrosine kinase inhibitor. A novel approach to the treatment of breast cancer is the combination of trastuzumab and lapatinib, which may enhance cytostatic action by inactivation of ErbB2 through two different molecular mechanisms. In vitro data indicate synergistic activity of lapatinib in combination with trastuzumab in ErbB2 positive breast cancer cells.
Patients (pts) with advanced or metastatic breast cancer that overexpressed the ErbB2 protein $2+$ or $3+$, confirmed by either IHC and/or FISH were enrolled. Escalating dose levels of lapatinib $(750-1500 \mathrm{mg} / \mathrm{d})$ were administered once daily in combination with weekly, standard dose of trastuzumab ( $4 \mathrm{mg} / \mathrm{kg}$ loading dose followed by weekly $2 \mathrm{mg} / \mathrm{kg}$ infusions). Three pts were treated at each dose level, with expansion to 6 in the event of dose-limiting toxicity. Limited and full pharmacokinetic samples were obtained. Assessments of clinical response per RECIST criteria were performed at week 8 and then every 8 weeks. Cardiac safety assessments include collecting left ventricular ejection fraction (LVEF) by MUGA or ECHO, and 12-lead ECG at week 4, 8 and then every 8 weeks.

54 pts were treated, 27 in the dose escalation phase (cohort $750-$ 3; cohort 1000 - 11; cohort 125010 , cohort $1500-3$ ) and 27 in the PK phase (cohort 1000). Median age was 53 years (range 3080 ). A median of 4 treatment periods ( 1 treatment period $=4$ weeks) were administered (range 1-15). G1-2 diarrhea, anorexia, fatigue and rash were the common toxicities. One incidence each of dose-limiting G3 fatigue and G3 nausea was reported separately at the $1500 \mathrm{mg} / \mathrm{d}$ dose level. No symptomatic declines in LVEF were reported at any dose level. In the dose escalation phase there was $1 \mathrm{CR}, 5$ PRs and 4 SDs $>6$ months. In the PK phase there were 2 PRs and 4 SD $>6$ months. The median number of prior chemotherapy regimens, in the responding pts, was 3 (range 1-4) and prior trastuzumab (monotherapy or in combination) was 4 (range 1-7).

The combination of lapatinib and trastuzumab showed significant clinical activity in this heavily pretreated population. The proposed phase II/III dose for this combination is $1000 \mathrm{mg}$ lapatinib and standard doses of weekly trastuzumab. The clinical data support the synergism of lapatinib and trastuzumab noted in preclinical studies with ErbB2 overexpressing breast cancer cells. Additional randomized studies are planned with lapatinib and trastuzumab.

\section{4}

Long term survival with no apparent toxicity observed with a novel cisplatin-incorporated polymeric micelle, $\mathrm{NC}-6004$, in the MCF-7 breast cancer model.

Alami N, Banerjee K, Page V, Hayashi T, Igarashi E, LeylandJones B. McGill University, Montreal, QC, Canada; NanoCarrier Co., Ltd., Chiba, Japan

Background: Cis-dichlorodiammineplatinum (II) (cisplatin) is among the most effective and widely used anti-neoplastic agents. However, its clinical use is restricted due to severe side effects such as acute nephrotoxicity. A new class of polymeric micelles incorporating cisplatin, NC-6004, via the polymer-metal complex formation between cisplatin and poly-(ethylene glycol)-poly (glutamic acid) block copolymers has been originated by Kataoka et al. (1). NC-6004 had a size of $\sim 30 \mathrm{~nm}$ with remarkably narrow distribution, a key factor to achieve homogeneous delivery.Previous pre-clinical studies showed that NC-6004 specifically accumulated in solid tumours and induced significant anti-tumor activity without significant body weight loss in C-26 colon tumour model. This study was designed to evaluate the antitumor activity of NC6004 against the MCF-7 breast cancer xenograft model and compare this against cisplatin, carboplatin, oxaliplatin and JM216. Material and Methods: CD-1 nude mice bearing subcutaneous MCF-7 tumors were treated with NC-6004 (2 \& $4 \mathrm{mg} / \mathrm{kg}$, i.v., q2dx5), cisplatin (4 mg/kg, i.v., q2dx5), carboplatin (120 mg/kg, i.p. bolus on day 1), oxaliplatin $(10 \mathrm{mg} / \mathrm{kg}$, i.p. bolus on day 1$)$ and JM216 (40 mg/kg, p.o. daily x 5).

Results: NC-6004 showed significant antitumor activity at both $2 \& 4 \mathrm{mg} / \mathrm{kg}$, compared with control $(P<0.01)$, and induced a tumor growth inhibition (TGI) of 85 and $81 \%$ at day 42 , respectively. NC-6004 at $2 \& 4 \mathrm{mg} / \mathrm{kg}$ caused $3 / 15$ and $5 / 15$ tumor regression, respectively and $1 / 15$ and $2 / 15$ complete tumor suppression, respectively, with no body weight loss or death for the entire duration of the study (day 49). Moreover, NC-6004 
caused no increase of blood urea nitrogen (BUN) at both 2 and 4 $\mathrm{mg} / \mathrm{kg}$. Carboplatin induced a TGI of $70 \%$ on day 36 , but no tumor suppression or regression. Oxaliplatin caused a TGI of $60 \%$ (day 28), with 2/16 tumor regressions. 4/7 toxicity-related deaths were observed in the carboplatin- and oxaliplatin-treated mice.Cisplatin induced a TGI of $55 \%$ on day $21(P<0.05)$, resulted in $1 / 15$ complete tumor suppression and $2 / 15$ tumor regressions and induced 4/8 toxicity-related deaths. JM216 induced a TGI of $55 \%$ (day 21) and high toxicity (8/8) as also demonstrated by body weight loss $(15 \%)$ and $27 \%$ increase of BUN, as compared with day 0 . Cisplatin also induced a $25 \%$ increase of BUN at the end of the treatment, whereas carboplatin and oxaliplatin showed no increase of these levels.

Discussion: In reviewing the literature to date, we have not observed an agent achieving this long term survival in the MCF-7 model. While all the agents exhibited comparable TGI at day 21 $(49-55 \%)$, NC-6004 treatment (both at $2 \& 4 \mathrm{mg} / \mathrm{kg}$ ) was the only agent which produced long term survival (TGI of $85 \& 81 \%$, respectively, at day 42) without any apparent toxicity. These preclinical data strongly support the clinical development of NC6004 for the treatment of breast cancer.

\section{5}

Combination of a prenylation inhibitor and either classical chemotherapy or a M-TOR inhibitor: potential clinical implications.

Budman DR, Calabro A. North Shore University Hospital, New York University, Manhasset, $N Y$

Background: Targeted therapies against RAS with the use of farnesyl transferase inhibitors are being clinically tested and are expected to have potential synergism when used with traditional agents. Statins inhibit both farnesylation and geranylgeranylation leading to inhibition both pathways of mevalonate metabolism. There is also cross talk between the MAP kinase pathway and the AKT pathway which might be amenable to inhibition. Inhibitors of AKT through M-TOR inhibition have shown clinical activity. We have used median effect isobologram analysis with defined cell lines to search for rational synergistic combinations of agents The current study evaluated fluvastatin to block prenylation, zolderonic acid which also blocks prenylation and classical cytotoxics.

Material and Methods: MCF7 (wild type), MCF7/adr (a multiply resistant line), SK-BR-3 (Her2/neu over expression) and BT 474 (p53 mutant) cell lines were used. Carboplatin, 5'DFUR, epirubicin, and rapamycin were obtained from Sigma Aldrich; Herceptin from commercial stock, gemcitabine from Eli Lilly Company, docetaxe from Aventis, vinorelbine from Glaxo SmithKline, fluvastatin and zoledronic acid from Novartis Pharma AG. Previous procedures (Breast Cancer Res Treat 74: 41-46, 2002) were used. Fluvastatin was studied at clinically achievable concentrations. All studies were done in duplicate with 4 wells per point. CI values within one standard deviation of 1 were considered additive.

Results: Fluvastatin displayed global synergy with zoledronic acid. Fluvastatin displayed synergism with epirubicin in 3 of 4 cell lines. Fluvastatin and rapamycin (M-TOR inhibitor) exhibited profound synergy $(\mathrm{CI}<0.3)$.

Discussion: Statins have not been clinically tested in breast cancer patients in combination with either classical cytotoxic agents or inhibitors (M-TOR inhibitor) of the AKT pathway. Their effect with zoledronic acid has not been previously noted. The present study suggests innovative combinations which may be advanced to clinical trials.

\section{6}

Effects of the potent telomerase template antagonist GRN163L in breast cancer.

Herbert B, Hochreiter A, Pongracz K, Gryaznov SM. Indiana University School of Medicine, Indianapolis, IN; Indiana University Cancer Center, Indianapolis, IN; Geron Corporation, Menlo Park, $C A$

Background: Telomerase has been detected in the vast majority of cancer cells, making the enzyme an attractive target for anticancer therapies. GRN163L is a novel lipid modified N3' $\rightarrow$ P5' thio-phosphoramidate (NPS) oligonucleotide with a sequence complementary to the RNA template region of human telomerase (hTR). GRN163L, like other NPS oligonucleotides complementary to template region to hTR, blocks the binding of telomerase to telomeres. The earlier generation NPS oligonucleotides have been shown to be effective inhibitors of telomerase and subsequently, the cancer cell growth in vitro and in vivo. The purpose of our study was to evaluate the effects of GRN163L treatment on a variety of breast cancer cells representing different tumor subtypes and genetic backgrounds.

Materials and Methods: Here we used MDA-MB-231, MDAMB-435, MCF-7, SK-BR-3, 21NT, HCC1937, HCC1937+wtBRCA1, and tumorigenic human mammary epithelial (HME) cells as our panel of breast cancer cell lines. Cells were treated every three days with 1-2.5 $\mu \mathrm{M}$ GRN163L during the course of the long-term experiment in which telomerase activity was inhibited $95-100 \%$. A mismatch control oligo showed no effect on telomerase activity. Cells were monitored every other day for gross toxicity or changes in morphology. With each passage, cell growth was documented and measured as cumulative population doublings. At the same time, aliquots were collected for telomere length analyses, telomerase activity assays, clonal analyses, and anchorage independence/ colony formation assays.

Results: GRN163L was effective in inhibiting telomerase activity in a dose-dependent fashion in all breast cancer cell lines. Telomerase inhibition by GRN163L induced rapid telomere shortening. Interestingly, the optimal endpoints of cell growth inhibition and apoptosis did not correlate with the predicted time based on initial telomere length. Cells that exhibited telomerase inhibition yet continued cell growth also exhibited reduced tumorigenicity.

Conclusions: These results show the cell-type differences in response to the telomerase inhibitor GRN163L in breast tumor cell lines as well as the potential of GRN163L to be an effective novel anti-tumor agent.

\section{7}

Anticancer influence of a methioninase containing fusion protein targeted to the urokinase receptor on breast cancer cells.

Pento JT, Zang XP, Palwai NR, Harrison RH. University of Oklahoma HSC, Oklahoma City, OK; University of Oklahoma, Norman, $O K$

Background: It has been shown that methionine depletion inhibits cancer cell growth and survival. The present study developed a novel fusion protein targeted specifically to breast cancer cells. The fusion protein contains two components: the amino terminal fragment of human urokinase (amino acids 1-49) that binds to the urokinase receptor protein which is over-expressed on the surface of invasive cancer cells, and L-methioninase (398 amino acids) which depletes methionine and arrests the growth of methioninedependent cancers. The present study examined influence of the fusion protein on the proliferation and motility of MCF-7 cancer cells in a culture wounding assay and the growth and metastatic development of these cells in a mouse xenograft model.

Materials and Methods: The fusion proteins were produced by recombinant methods in $E$. coli and purified by chromatography. In the mutated fusion protein the gene for L-methioninase was mutated by changing the Tyr at position 114 to Phe. It was 
determined that the mutated fusion protein lacked methioninase activity. The culture wounding assay measured proliferation and motility of MCF-7 cells. The xenograft experiments were conducted with MCF-7 cells transfected with a Beta-galactosidase reporter to quantify the density and distribution of cancer cells in tumor, lung and liver samples.

Results: It was determined that that treatment with fusion protein over a concentration range of $10^{-8}$ to $10^{-6} \mathrm{M}$ produced a dosedependent inhibition of both the migration and proliferation of MCF-7 cells in the culture. Treatment with L-methioninase alone produced a much smaller but significant inhibitory response, while the methioninase-mutated fusion protein produced no inhibitory effect. The fusion protein was found to be non-cytotoxic to the mice in the xenograft experiments. In the xenograft tumors the total number of cancer cells/gram of tissue was reduced by fusion protein treatment. Further, it was observed that fusion protein treatment eliminated lung micro-metastases in these experiments. Discussion: These results demonstrate that specific targeting of a methioninase containing fusion protein to urokinase receptors on breast cancer cells reduces the proliferation and motility of the breast cancer cells in culture. Further, the results of the mouse xenograft experiments indicate that fusion protein treatment reduces the growth and metastasis of these cancer cells in vivo. In conclusion, specific targeting of methioninase containing fusion proteins to cancer cells may provide a new and effective therapeutic approach for the treatment and/or prevention of breast cancer growth and metastatic progression.

Acknowledgement: This study was supported in part by grants from the Oklahoma Center for the Advancement of Science and Technology (OCAST) and from the Presbyterian Health Foundation

\section{8}

The use of p53-mediated alteration of microtubule dynamics to sensitize breast cancer to vinca alkaloids. Toppmeyer DL, Nayak M, Chang J-M, Huzzy L, Shah N, Hait WN. The Cancer Institute of New Jersey, UMDNJ-Robert Wood Johnson Medical School, New Brunswick, NJ

Background: Molecular determinants of drug sensitivity promise more precise selection of patients (pts) for treatment. p53 transcriptionally represses MAP4, a microtubule-associated protein that promotes micrtotubule polymerization and influences sensitivity to microtubule binding drugs. In preclinical studies, the induction of wild-type p53 by DNA-damaging agents, such as doxorubicin, repressed MAP4, decreased microtubule polymerization, and increased binding of and sensitivity to vinca alkaloids. A Phase I pilot demonstrated the clinical safety and feasibility of this approch. Therefore, we conducted a Phase II study of sequential epirubicin (EPI) and vinorelbine (V) in previously untreated pts with stage IIIB or IV breast cancer to test if DNA damage by EPI represses MAP4 and if V effectiveness can be improved.

Methods: Patients with Stage III and /or IV breast cancer received EPI $\left(100 \mathrm{mg} / \mathrm{m}^{2}\right) \mathrm{D} 1$ followed by V $\left(25 \mathrm{mg} / \mathrm{m}^{2}\right) \mathrm{D} 3$ and D10. Pts with Stage III disease received a maximum of 5 cycles of therapy. To measure the biological response to EPI and V, pts underwent sequential biopsies and peripheral blood sampling on D1 and D3 immediately prior to receiving EPI and V, respectively.

Results: Fourteen pts (4 metastatic/10 locally advanced) received 58 treatment cycles (range 2-5). Six patients with stage IIIB or IIIC disease completed the planned five cycles of EPI/V; five of six patients had cCRs and $1 / 6$ had a pCR. An additional five patients (4/Stage III; 1/Stage IV) had a cPR (3 are still receiving treatment), while three patients (stage IV) who have completed the study had SD.

\begin{tabular}{lcl}
\multicolumn{3}{l}{ Overall Response Rate } \\
RR & $11 / 14$ & $79 \%$ \\
CR & $5 / 14$ & $35 \%$ \\
PR & $6 / 14$ & $43 \%$ \\
SD & $3 / 14$ & $21 \%$
\end{tabular}

Grade 3 and 4 toxicities were primarily hematologic. Toxicities included 9 and 16 episodes of Grade 3 and Grade 4 neutropenia, respectively; 3 episodes of Grade 3 anemia; and 4 episodes of Grade 3 thrombocytopenia. Non-hematologic Grade 3 toxicities included 3 episodes mucositis and 3 episodes of fatigue. To measure the biological response to EPI and V, we analyzed p53 induction and MAP4 repression in 13/14 pts who underwent sequential biopsies and peripheral blood sampling. 48 hours following treatment with EPI, MAP-4 was downregulated in PBMNCs from $11 / 13$ patients. p53 expression in PBMNCs was increased in 7/ 13 , unchanged in $1 / 13$, and decreased in $5 / 13$. Protein expression was determined in 12 sets of paired tumor biopsies (D1 and D3). MAP4 and p53 protein expression was detected in all samples. MAP4 expression was decreased in 10/12 samples. 7/10 samples had decreased MAP4 and increased p53 while 3/10 demonstrated decreased p53. MAP4 was increased in 1/12 samples and unchanged in 1/12 samples. p21 expression, a transactivation target for wtp53, in 9/9 samples assessed, correlated with p53 expression.

Discussion: Accrual to the study is ongoing as the response rate is encouraging and the toxicity profile acceptable with minimal protocol modifications.

\section{9}

A phase I trial of scutellaria barbata (BZL101) for metastatic breast cancer.

Tagliaferri M, Cohen I, Vogel C, Perez A, Tan-Chiu E, Franco S, Melisko M, Campbell M, Rugo H, Tripathy D. Bionovo, Inc., Emeryville, CA; Cancer Research Network, Plantation, FL; University of California, San Francisco, San Francisco, CA; Memorial Cancer Institute, Hollywood, FL; University of Texas, Southwestern, Dallas, TX

Background: BZL101 is an aqueous extract from herba Scutellaria Barbata D. Don of the Lamiaceae family. The extract demonstrates in vitro growth inhibitory effects on four human breast cancer cell lines (SKBR3, MCF7, MDA-MB231, and BT474) and one murine breast cancer cell line (MCNeuA) using the anti-proliferative crystal violet, sulforhodamine or CyQuant assays. ID50 values ranging from $<10 \mu \mathrm{g} / \mathrm{ml}$ to $>1.5 \mathrm{mg} / \mathrm{ml}$. BZL101 does not inhibit the growth of normal human mammary epithelium (HuMEC) and is a mitogen to normal human lymphocytes. In a murine xenograft model, oral and intraperitoneal administration of BZL101 inhibited tumor formation without any observed toxicity. BZL101 arrests breast cancer cells in the G1 phase of the cell cycle and induces apoptosis as measured by a sub-G1 population of cells by flow cytometry. By attenuating mitochondrial membrane potential, BZL101 causes cytochrome $\mathrm{C}$ and apoptosis inducing factor (AIF2) release, inducing caspase-independent DNA cleavage and high molecular grade DNA fragmentation. We therefore conducted an open-label, phase I study of BZL101 for metastatic breast cancer. Methods: Eligible patients had histologically confirmed metastatic breast cancer and measurable disease. Patients could not receive any other chemotherapy, hormone therapy or herbal medicine. Patients received $350 \mathrm{ml}$ (6 gm dry solubles) per day of BZL101 extract until disease progression, toxicity or personal preference to discontinue. The primary endpoints were safety, toxicity and tumor response defined by RECIST. Results: 21 patients were treated. Mean age was 54 years $(30-77)$ and mean number of prior treatments was $3.6(0-10)$. There were no hematologic or grade III or IV non-hematologic adverse events (AEs). The most frequently reported BZL101-related grade I and II AEs included: nausea $(43 \%)$, diarrhea $(20 \%)$, headache $(20 \%)$ flatulence $(14 \%)$, vomiting $(10 \%)$, constipation $(10 \%)$, and fatigue $(10 \%)$. Sixteen patients were evaluable for response. Four of the 16 patients had stable disease (SD) for $>90$ days $(25 \%)$ and $3 / 16$ had SD for $>180$ days $(19 \%)$. Three patients had objective tumor regression, one of which was $1 \mathrm{~mm}$ short of a PR based on RECIST criteria. Conclusions: BZL 101 has a favorable tolerability profile and demonstrates encouraging clinical activity in this heavily pretreated population. 


\section{0}

Unexpected hepatic toxicity after primary treatment with gefitinib and docetaxel in patients with locally advanced breast cancer.

Bines J, Branco LGP, Gomes CA, Costa F, Barrios CH, Martins $R G$. Instituto Nacional de Cancer, Rio de Janeiro, RJ, Brazil; PUC, Porto Alegre, RGS, Brazil; Washington University, Seattle, WA

Introduction: Locally advanced breast cancer is a public health problem in Brazil. More than 50\% of Brazilian women present with stage III/IV disease. Besides improvement in earlier detection, we need better treatment strategies. Preclinical studies suggest synergism between gefitinib (Iressa) and docetaxel (Taxotere) in breast cancer cell lines (Ciardello F. Int J Cancer 2002). We performed a multicenter phase II trial of primary treatment with weekly docetaxel and daily gefitinib in patients with locally advanced breast cancer.

Objectives: (1) Objective clinical response rate (ORR), (2) Pathological response, and (3) Safety profile.

Patients and Methods: Patients with locally advanced breast cancer were eligible. Exclusion criteria included inflammatory breast cancer and positive supraclavicular lymph nodes. Primary treatment for 2 cycles: docetaxel at $36 \mathrm{mg} / \mathrm{m}^{2}$ IV weekly x 6 out of 8 weeks. Gefitinib was given at $250 \mathrm{mg}$ PO daily concurrently with chemotherapy until surgery. Pre-medication: dexamethasone $(8 \mathrm{mg}) 12$ hours and 1 hour prior to docetaxel. Post-medication at the investigator's discretion.

Results: Thirteen patients were enrolled into the study. Eight patients were withdrawn due to transaminases elevations and the trial has therefore been stopped. Median age 48 (23-59), $\mathrm{PS}=0$. Median tumor size $7 \mathrm{~cm}$ (4-20); stage: IIB (1), IIIA (3), IIIB (9); $\mathrm{HR}+(8)$ and $\mathrm{HR}-(5)$.

There has been no grade 3-4 hematologic toxicity. Eleven patients developed an acneiform rash, all grade I and II. Eleven patients had diarrhea, with grade 3 in only 2 of them. Hepatic toxicity was characterized by grade 2, 3 and 4 serum glutamic oxaloacetic transaminase (SGOT)/ serum glutamic pyruvic transaminase (SGPT) elevations in 1,5 and 2 patients, respectively. Transaminases levels returned to normal values within a few weeks of stopping treatment. There were no abnormalities in serum bilirubin and no symptoms associated with these lab changes, except in 1 patient who developed grade 2 asthenia. There was no previous history of excessive alcohol intake, hepatotoxic medications or viral hepatitis.

Conclusion: This is the first report of the combination of weekly docetaxel and daily gefitinib as primary treatment in patients with locally advanced breast cancer. We found a high frequency of hepatic toxicity. This finding led to trial closure. Previous reports of weekly docetaxel alone (Bines J. Proc Am Soc Clin Oncol 2001) and gefitinib and docetaxel every 3 weeks (Ciardello F. Proc Am Soc Clin Oncol 2005) showed no such adverse event. Combination of chemotherapy and biological agents is a growing treatment strategy in cancer. Close monitoring is an essential part of these trials in order to detect unexpected and potentially life threatening side effects. Support from Astra Zeneca and Sanofi Aventis - Brazil.

\section{1}

A phase I/II study of capecitabine $(X)$ combined with oral vinorelbine $(\mathrm{N})$ as first- or second-line chemotherapy in patients (pts) with locally advanced breast cancer (MBC). Delcambre C, Veyret C, Levy C, Switsers O, Allouache D, Raban $N$, Grellard JM, Leconte A, Delozier T. Centre Francois Baclesse, Caen, France; Centre Henri Becquerel, Rouen, France; Centre Hospitalier Universitaire, Poitiers, France

Background: The oral fluoropyrimidine $\mathrm{X}$ is highly effective and well tolerated in pts with MBC. Adding $\mathrm{X}$ to docetaxel improves survival, time to disease progression and response compared with docetaxel alone. When administered intravenously (i.v.) $\mathrm{N}$ is also an effective agent in MBC. The combination of $\mathrm{X}$ and i.v. $\mathrm{N}$ has been shown to be effective in phase I/II studies with response rates of $48-61 \%$ and a good safety profile. The few overlapping toxicities between $\mathrm{X}$ and oral $\mathrm{N}$ make this an attractive new combination. Materials and Methods: To evaluate this all-oral combination, we conducted a multicentre phase I/II study of X plus oral $\mathrm{N}$ in pts with $\mathrm{MBC}$ to determine the maximum tolerated doses (MTD), recommended doses, safety profile and efficacy. Eligibility criteria were stage III/IV BC, age $>18$ years, ECOG PS $<2, \geq 12$ months since the end of adjuvant or neoadjuvant chemotherapy, HER2 negative or unknown and adequate major organ function. Results: We enrolled 61 pts: $75 \%$ received firstline $\mathrm{XN}$ and $25 \%$ received $\mathrm{XN}$ as second-line therapy. Baseline characteristics were: median age 57.2 years (range 39-81); stage III/IV disease $(0 / 100 \%)$; sites of metastases: liver $(\mathrm{n}=31)$, lung $(n=24)$, lymph nodes $(n=24)$, bone $(n=23)$, breast $(n=8)$, skin $(n=4)$, pleural effusion $(n=7) .15$ pts had $>2$ metastatic sites. DLTs determining the MTD were Febrile Neutropenia and grade 3 Mucitis. The recommended doses are: $\mathrm{X} 1250 \mathrm{mg} / \mathrm{m}^{2}$ twice daily and $\mathrm{N} 60$ $\mathrm{mg} / \mathrm{m}^{2} .33 \mathrm{pts}$ received the treatment at the recommended dose. Efficacy findings were: 1 complete response (CR, 2\%), 20 partial responses (PR, 43\%), 16 pts with stable disease (ST, 35\%), 9 pts with progressive disease (PD, 20\%) and 15 not known. Most common adverse events were grade $3 / 4$ neutropenia $(11 \%)$ and grade $2 / 3$ hand-foot syndrome (8\%). Mature results will be presented during the meeting. Conclusion: the all-oral combination of $\mathrm{X}$ and $\mathrm{N}$ is feasible and well tolerated. The recommended doses from this study are: $X 1250 \mathrm{mg} / \mathrm{m}^{2}$ bid d1-d14 and $\mathrm{N} 60 \mathrm{mg} / \mathrm{m}^{2} \mathrm{~d} 1$ and $\mathrm{d} 8 \mathrm{q} 3 \mathrm{w}$. This combination appears highly active and enrolment continues to confirm the response rate and to evaluate disease-free survival.

\section{2}

Selective inhibition of ADAM metalloproteases as a novel approach for modulation ErbB pathways in cancer.

Douglass EC, Liu X, Caulder E, Liu C, Hansbury M, Zhou BB, Yao $W$, Li Y, Vaddi K, Newton R, Scherle P, Friedman S, Fridman $J$. Incyte Corporation, Wilmington, $D E$

The ErbB family of receptor tyrosine kinases and the ligands that bind to them are important regulators of cell proliferation, differentiation and survival. Dysregulation of this pathway, through [epi]genetic alterations, results in enhanced signal transduction and has been observed in numerous cancers. As such, the ErbB pathways represent targets for therapeutic intervention and have resulted in the development of a number of agents that are currently used in the clinic. These include antibodies directed against ErbB1/ EGFR (Erbitux ${ }^{\circledR}$ ) and ErbB-2/Her-2 (Herceptin $\left.{ }^{\circledR}\right)$, as well as small molecule inhibitors of the ErbB1 tyrosine kinase (Iressa ${ }^{\circledR}$, Tarceva $\left.{ }^{\circledR}\right)$. An alternative approach to reduce the mitogenic and survival signals from the ErbB pathways is to identify inhibitors of the proteases responsible for the cleavage and activation of the ligands that bind to and activate the ErbB receptors. This proteolytic processing, termed ectodomain shedding, has emerged as a critical step for the functional activation of ErbB ligands and is mediated by members of the ADAM family of zinc-dependent metalloproteases. Toward this end, we have identified selective, orally bioavailable small molecule inhibitors of ADAM proteases that block shedding of a number of ErbB ligands (e.g. TGF-a, HBEGF, and heregulin) resulting in inhibition of multiple ErbB pathways. The selective ADAM inhibitors INCB7839 and INCB3619, block ErbB ligand shedding with potencies in the nanomolar range in vitro and significantly inhibit tumor growth in vivo, with efficacy equivalent to that achieved with the EGFR kinase inhibitor, gefitinib (Iressa $\left.{ }^{\circledR}\right)$. Tumor specimens from compound treated animals had reduced Ki67 staining, a marker of proliferation, and decreased AKT activity, similar to what was observed following treatment with agents that directly target growth factor receptors. These ADAM inhibitors also improve 
therapeutic responses to both cytotoxic agents (e.g. paclitaxel) and targeted agents (e.g. trastuzumab or the anti-estrogen fulvestrant). Importantly, the compounds showed no toxicities in a two-week rodent safety study nor was there evidence of fibroplasia or tendonitis, the dose-limiting toxicities associated with broadspectrum matrix metalloprotease inhibitors (e.g. Marimastat). Thus, inhibition of proteases responsible for activating ErbB pathways, through ligand and/or receptor cleavage, may offer a potentially novel and well tolerated therapeutic strategy for the treatment of human cancers. Toward testing this therapeutic hypothesis, INCB7839 is currently in clinical trials.

\section{3}

Phase I/II trial and pharmacokinetic/pharmacodynamic analysis exploring a synergistic interaction between the histone deacetylase inhibitor, valproic acid and the anthracycline, epirubicin.

Munster PN, Minton SE, Marchion DC, Carter WB, Bicaku E, Lush III R, Sullivan DM, Daud AI. H. Lee Moffitt Cancer Center, Tampa, FL

Background: In vivo and in vitro studies in breast cancer models show that histone deacetylase inhibitors (HDACi) potentiate anthracycline-induced DNA damage without increasing toxicity. Pre-exposure to an HDACi results in histone acetylation and chromatin decondensation, thereby facilitating the access of anthracyclines to the DNA substrate. Valproic acid (VPA) is a well-known anti-convulsant that also inhibits HDACs. Epirubicin is a widely used anthracycline.

Methods: The toxicity, efficacy, pharmacokinetics (PK) and pharmacodynamics (PD) of a sequence-specific administration of VPA and epirubicin were explored in a Phase I dose escalation study with a dose expansion in breast cancer at the maximally tolerated dose. An intravenous loading dose of VPA was followed by 6 oral doses of VPA given twice daily. Epirubicin was administered on day 3. Cycles were repeated every 21 days. Histone acetylation, chromatin structural proteins and topoisomerase II levels were evaluated in pre-(d1) and post- (day3) treatment tumor samples and peripheral blood mononuclear cells. Dose limiting toxicities were assessed in cycle 1 . Tumor progression and cardiac functions were monitored every 6 weeks.

Results: To date, 25 patients [median age 53 (43-78)] have been treated at six dose levels: VPA $(\mathrm{mg} / \mathrm{kg} / \mathrm{d}) /$ epirubicin $\left(\mathrm{mg} / \mathrm{m}^{2}\right): 15 /$ $75,30 / 75,45 / 75,60 / 75,75 / 75$ and 75/100. Tumor types included: breast (7), melanoma (9), lung (3), cervical (1) and others (5). While VPA was associated with dose-dependent somnolence, ataxia and confusion, it did not exacerbate epirubicin-related myelosuppression, nausea/vomiting or cardiac dysfunction. Despite a median number of 3 prior regimens, a pre-exposure to VPA prior to epirubicin was highly active across different tumor types, including patients with prior anthracycline exposure or in anthracycline-resistant tumors such as melanoma and cervical cancer. Responses evaluable in 23 patients were as follows:(complete/partial response 4/23 (17\%); stable disease $\geq 12$ weeks $11 / 23$ (48\%); progression $8 / 23$ (35\%). A median number of 4 (1-8) treatment cycles were administered. In patients with breast cancer, $2 / 7$ had a confirmed partial response and 3/7 patients had stable disease for $\geq 12$ weeks. VPA PK and histone acetylation showed a linear increase with dose.

Discussion: A sequence-specific combination of VPA and epirubicin appears highly active without exacerbation of epirubicin toxicity. VPA plasma levels exceeded concentrations needed for in-vitro synergy. The noteworthy anti-tumor activity seen in this heavily pretreated patient population should warrant further exploration in patients with breast cancer.

\section{4}

Multicenter phase 2 study of XRP6258 in taxane-resistant metastatic breast cancer (MBC) patients (pts).

Pivot X, Koralewski P, Hidalgo JL, Chan A, Viens P, Schwartsmann $G$, Brunel E, Ramazeilles C, Assadourian S, Lotz JP. CHU JeanMinjoz, Besancon, France; Oddzial Chemioterapii, Krakow, Poland; C.O.I.R, Mendoza, Argentina; Mount Medical Centre, Perth, Australia; Institut Paoli Calmettes, Marseille, France; Federal Univ, Porto Alegre, Brazil; Sanofi Aventis, Antony, France; Hopital Tenon, Paris, France

Background: XRP6258 is a new semisynthetic taxane with a demonstrated broad spectrum of activity in in vivo tumor models, particularly in taxane-resistant models.

Methods: Eligible pts have histologically confirmed MBC resistant to prior taxane containing therapy, measurable disease as per RECIST, and are aged 18-75 years, ECOG PS 0-2. Taxane resistance is defined as progression within 12 months of adjuvant treatment or progression within 4 months of first/second line treatment of metastatic disease or lack of response after more than 3 months of treatment for MBC. XRP6258 was administered as 1-hour intravenous infusion every 3 weeks at $20 \mathrm{mg} / \mathrm{m}^{2}$; in absence of any toxicity $>$ grade (gr) 2 during first cycle (cy), dose could be increased to $25 \mathrm{mg} / \mathrm{m}^{2}$ in subsequent cy. Premedication prior to infusion included single intravenous administration of antihistaminic antiH1. Treatment was administered up to progression, unacceptable toxicities or consent withdrawal. Primary endpoint was overall response rate (ORR).

Results: 71 pts were enrolled and all were treated. Median (range) age: 53 years (35-77), median (range) PS: 1 (0-2). $74.6 \%$ pts had visceral involvement. A total of 345 cy were administered: median 4 (1-25), median relative dose intensity: 0.99 . The most common adverse events per pt were any gr/gr 3-4: fatigue $50.7 \% / 8.5 \%$, nausea $43.7 \% / 1.4 \%$, diarrhea $39.4 \% / 2.8 \%$, anorexia $25.4 \% / 1.4 \%$, myalgia $25.4 \% / 0 \%$, vomiting $23.9 \% / 1.4 \%$, infection without neutropenia $18.3 \% / 2.8 \%$, neurosensory $16.9 \% / 0 \%$. Among these events, no gr 4 was observed except for fatigue $(1.4 \%)$ Hematological toxicities per pt were: gr 3-4 neutropenia $73.2 \%$, neutropenia gr $4>5$ days $26.8 \%$, gr $3-4$ thrombocytopenia $4.2 \%$, neutropenic infection $4.2 \%$, febrile neutropenia $2.8 \%$. One toxic death was reported on day 10 of $\mathrm{Cy} 1$ and 1 death from unknown origin on day 22 of $\mathrm{Cy} 1$. All pts were assessed for efficacy: there were $2 \mathrm{CR}, 8 \mathrm{PR}, 27 \mathrm{SD}, 29 \mathrm{PD}$, and $5 \mathrm{NE}$ as per investigator, giving an ORR of $14.1 \%$ (95\%CI: 7.0-24.4). The median TTP was 2.7 months (95\%CI: 1.45-4.07), and the median OS was 12.3 months (95\% CI: 9.49-15.05).

Conclusions: XRP6258 at the dose of $20 \mathrm{mg} / \mathrm{m}^{2}$ is active and well tolerated in MBC pts resistant to prior taxane containing therapy. These results support further development.

\section{5}

Bortezomib and capecitabine in patients with metastatic breast cancer previously treated with taxanes and/or anthracyclines.

Schmid P, Schippinger W, Kiewe $P$, Lange $W$, Preiss $J$, Niederle $N$ Brossart P, Freier W, Van de Velde H, Possinger K. Charite Campus Mitte, Berlin, Germany; Universitaetsklinikum, Graz, Austria; Charite Campus Benjamin Franklin, Berlin, Germany; JohanniterKrankenhaus Rheinhausen, Duisburg, Germany; Caritasklinik St. Theresia, Saarbrücken, Germany; Klinikum Leverkusen, Leverkusen, Germany; Universitaetsklinikum, Tuebingen, Germany; Practice for Oncology and Hematology, Hildesheim, Germany; Johnson \& Johnson Pharmaceutical Research \& Development, Beerse, Belgium

Background: The ubiquitin-proteasome pathway plays an essential role in intracellular degradation of key regulatory proteins that can affect cell cycle, angiogenesis, adhesion and apoptosis. Bortezomib (VELCADE, PS-341) is a first-in class selective inhibitor of the $26 \mathrm{~S}$ proteasome. The oral fluoropyrimidine 
capecitabine (Xeloda) has shown substantial activity in taxane and/or anthracycline pretreated patients with metastatic breast cancer. This phase I trial was initiated to determine the maximum tolerated doses (MTD), efficacy and tolerability of combined treatment with capecitabine and bortezomib in patients with metastatic breast cancer previously treated with taxanes and/or anthracyclines.

Patients and Methods: A total of 19 patients were treated with bortezomib (1.0-1.3 $\mathrm{mg} / \mathrm{m} 2$; days $1,4,8 \& 15)$ and capecitabine (1500-2500 mg/m2, days 1-14) in 3-weeks intervals. Dose limiting toxicity (DLT) was defined as grade (G) 4 platelets, any $G$ platelets with bleeding, G4 ANC $>4$ days, febrile neutropenia, any $>\mathrm{G} 2$ nonhematologic toxicity except alopecia, nausea or emesis, or any $\geq \mathrm{G} 2$ toxicity persisting over day 35 .

Results: The MTD were bortezomib $1.3 \mathrm{mg} / \mathrm{m} 2$ and capecitabine $2500 \mathrm{mg} / \mathrm{m} 2$. Two DLTs were seen: G3 stomatitis in 1 out of 6 patients at 1.0/2000 and G3 diarrhea in 1 out of 6 patients at 1.3/ 2500. Hematologic and non-hematological toxicities were generally mild to moderate with no G4 toxicities being observed. G3 toxicities were reported for platelets in 5 patients, elevation of transaminases in 2 patients and stomatitis, diarrhea, nausea, asthenia, infection and peripheral neuropathy in 1 patient each. Most common side effects were thrombocytopenia (G1/2 $29 \%$ of cycles, G3 12\%), neutropenia (G1/2 28\%), nausea (G1/2 29\%, G3 2\%), diarrhea (G1/2 24\%, G3 2\%), hand-foot syndrome (G1/2 30\%), peripheral neuropathy (G1/2 26\%, G3 2\%), and asthenia (G1/2 50\%, G3 $2 \%$ ). To date 17 patients are assessable for response. Two patients achieved a partial response $(12 \%)$. Disease stabilization was observed in 5 patients $(29 \%)$.

Conclusion: The recommended phase II doses are bortezomib 1.3 $\mathrm{mg} / \mathrm{m} 2$ and capecitabine $2500 \mathrm{mg} / \mathrm{m} 2$ with stomatitis and diarrhea being DLTs. Data suggest good tolerability and moderate antitumor activity in anthracycline and taxane pretreated patients. A phase II study has been initiated.

\section{6}

High efficacy of the sigma antagonist rimcazole against an endocrine insensitive, p53 mutant MDA-MB-231 xenograft preclinical model.

Appleyard MV, O'Neill MA, Murray KE, Spruce BA, Thompson AM. University of Dundee, Dundee, United Kingdom

Background: Breast cancers which are endocrine insensitive and harbour inactive p53 are often also resistant to chemotherapeutic agents. Sigma receptors, members of the opioid family, present a novel therapeutic target in breast cancer. The sigma receptor antagonist rimcazole, which has previously progressed to phase 3 trials as an antipsychotic drug, inhibits the growth of a wide range of tumour cell lines in vitro. We investigated the efficacy of rimcazole against the hormone insensitive breast cancer cell line MDA-MB-231 (which expresses sigma receptors but contains nonfunctional p53) in a mouse xenograft model.

Methods: Nude mice were injected subcutaneously with MDAMB-231 cells. When tumours were in the range $10-20 \mathrm{~mm}^{3}$ mice were divided into 3 groups: 1 vehicle control (mice were injected with $100 \mu \mathrm{H}_{2} \mathrm{O}$ daily by the intraperitoneal route); 2 rimcazole at the concentration of $10 \mathrm{mg} / \mathrm{kg}$ (given by the intraperitoneal route daily); 3 rimcazole at the concentration of $40 \mathrm{mg} / \mathrm{kg}$ (given by the intraperitoneal daily). Rimcazole was freshly prepared daily and administered for upto 14 days. Animals were inspected daily, sacrificed at predetermined timepoints and material harvested from the xenograft tumours.

Results: Signs of drug toxicity were minimal with no weight-loss in the treated groups. Eleven days after treatment, statistically significant reductions in growth rate compared with the control groups were found: $85 \%$ for rimcazole at $10 \mathrm{mg} / \mathrm{kg}$ and over $100 \%$ for rimcazole at $40 \mathrm{mg} / \mathrm{kg}$ (Student's t-test $\mathrm{p}<0.05, \mathrm{n}=8$ ). The tumour doubling time was 3.85 days in the control group, 27 days in the group treated with rimcazole $10 \mathrm{mg} / \mathrm{kg}$ and tumours treated with rimcazole at $40 \mathrm{mg} / \mathrm{kg}$ had regressed at this time point. This pattern of regression was maintained at least until the end of the experiment, 14 days after treatment.

Discussion: These preclinical data demonstrate the activity of rimcazole against MDA-MB-231 xenograft tumours at doses suitable for clinical use and show potential to provide a rational basis for novel biological therapy in a clinically challenging setting.

\section{7}

A phase II study of KOS-862 (epothilone D) in anthracycline and taxane pretreated metastatic breast cancer: updated results.

Buzdar A, Silverman P, Kaufman PA, Waintraub S, Doyle T, Kroener $J$, Robinson P, Perez E, Zhang X, DeMario M. MD Anderson Cancer Center, Houston, TX; Univ. Hosp. Cleveland, Ireland Cancer Ctr, Cleveland, OH; Dartmouth-Hitchcock Medical Ctr, Lebanon, NH; Hackensack Univ Medical Ctr, Hackensack, NJ; Henry Ford Health Systems, Detroit, MI; Scripps Clinic, La Jolla, CA; Fox Chase Cancer Ctr, Philadelphia, PA; Hoffmann-La Roche Inc., Nutley, $\mathrm{NJ}$

Background: $\operatorname{KOS}-862(\mathrm{~K})$ is Epothilone D produced by recombinant DNA technology. $\mathrm{K}$ has demonstrated activity in multiple breast cancer models, including taxane-resistant cell lines. This phase II trial examines K efficacy and safety in women with metastatic breast cancer (MBC) previously treated with anthracycline $(\mathrm{A})+$ taxane $(\mathrm{T})$ chemotherapy.

Methods: Eligible patients are: $\mathrm{MBC}$ and $\mathrm{A}+\mathrm{T}$ treatment failure (defined as disease progression after both $\mathrm{A}+\mathrm{T}$ (adjuvant or metastatic) or inability to tolerate $\mathrm{A}$ or $\mathrm{T}$ due to toxicity). Additional entry criteria: ECOG $0-1$, baseline neuropathy $<$ grade 1 , and no CNS metastases. $\mathrm{K}$ given as $100 \mathrm{mg} / \mathrm{m}^{2} 90 \mathrm{~min}$ iv infusion wkly x 3 Q4 wks. $\mathrm{H}_{1} / \mathrm{H}_{2}$ antagonists + corticosteroids given $30-60 \mathrm{~min}$ prior to $\mathrm{K}$ as infusion reaction prophylaxis. Blood samples for PK of $\mathrm{K}+$ its major seco-metabolite are taken after $1^{\text {st }}, 3^{\text {rd }}+4^{\text {th }}$ drug administration.

Results: Demographics:37 women (29 evaluable) received K from $2 / 04$ to $4 / 05$. Mean age 52.7 (29-87) yrs. Mean treatment cycles 2.4 (1-6); 7 pts had $\geq 4$ cycles, 3 pts had 6 cycles. Efficacy: 4 pts have had confirmed PR (14\% of evaluable pts), including 2 pts with hepatic metastases who had $>50 \%$ tumor reduction by RECIST. One additional pt with cutaneous-based metastatic disease has had unconfirmed PR. All confirmed PR pts had adjuvant taxane therapy; 3 of 4 also had taxane therapy for metastatic disease. Safety: Data available for 27 pts. Peripheral sensory neuropathy was observed in 21 of 27 pts ( 3 of these grade 3 ). Other grade 3 neurologic toxicities are ataxia and dizziness. Overall, $18.5 \%$ of pts report any grade 3 neurotoxicity. Neurologic toxicities limited to grade $1 / 2$ severity include cognitive disorder/confusion/ disorientation, memory impairment/amnesia, insomnia, hallucinations, and visual changes. Principal non neurologic toxicities are fatigue (including 1 grade 3 ), nausea (including 1 grade 3), diarrhea, flushing, and anorexia. PK $(n=21)$ : KOS-862 $\mathrm{C}_{\max } 3.95 \pm 1.41 \mathrm{ug} / \mathrm{mL}, \mathrm{AUC}_{\mathrm{inf}} 19.8 \pm 12.3 \mathrm{~h} \cdot \mathrm{ug} / \mathrm{mL}, \mathrm{CL} 13.7 \pm$ $10.3 \mathrm{~L} / \mathrm{hr}, \mathrm{Vz} 203 \pm 135 \mathrm{~L}$ and $\mathrm{T}_{1 / 2} 11.4 \pm 5.7 \mathrm{hr}$. Seco-metabolite is $43 \pm 19 \%$ of KOS-862.

Conclusions: Encouraging antitumor activity has been demonstrated for $\mathrm{K}$ (4 confirmed partial responses (RECIST)) in women with $\mathrm{A}+\mathrm{T}$ pretreated $\mathrm{MBC}$. PK data are similar to the phase I trials and suggest moderate interpatient variability. Neurotoxicities are the most common safety-related events, but these have rarely resulted in discontinuation of $\mathrm{K}$ treatments. Accrual continues in the 2 nd Simon stage of this trial (53 evaluable pts total) in order to determine $\mathrm{K}$ activity in this refractory population. 


\section{8}

A phase I/II study of oral capecitabine $(\mathrm{X})$ and vinorelbine (V) as second- or -third line chemotherapy in anthracycline/ taxane pretreated patients (pts) with metastatic breast cancer (MBC).

Kellokumpu-Lehtinen P, Sjöström J, Sunela K, Lehtinen I, Joensuu H. Tampere University Hospital, Tampere, Finland; Helsinki University Central Hospital, Helsinki, Finland; University of Tampere, Tampere, Finland

Background: Approximatelyhalf of patients (pts) have responded to the combination of $\mathrm{X}$ and intravenous $\mathrm{V}$ in phase I-II studies with a good safety profile. Few overlapping toxicities and oral formulations make $\mathrm{X}$ plus oral $\mathrm{V}(\mathrm{X}+\mathrm{V})$ an attractive new combination for treating anthracycline or/and taxane pretreated pts. Methods: To evaluate this all-oral combination, we conducted a phase $\mathrm{I} / \mathrm{II}$ in pts with MBC keeping X dose standard $\left(1000 \mathrm{mg} / \mathrm{m}^{2}\right.$ twice daily on days 2-6 and 8-14) and increasing the dose of $\mathrm{V}$ from $40 \mathrm{mg} / \mathrm{m}^{2}$ to $80 \mathrm{mg} / \mathrm{m}^{2}$ on days 1 and 7 to determine the recommended dose of $\mathrm{V}$, as well as the safety profile and the efficacy of the combination. The eligibility criteria included MBC, age $>18$, ECOG PS $\leq 2$, a prior anthracyline and/or taxane combination for the treatment of $\mathrm{MBC}$ and adequate major organ function. The $\mathrm{V}$ dose escalation was performed between 3 pts cohorts, but the dose of $\mathrm{V}$ could also been increased to next level in the same patient after three cycles if there were no dose limiting toxicities at the used dose level. Results: 21 pts were enrolled. The median age was 52 years (range 32-70); sites involved: bone $18(86 \%)$ liver 10 (48 \%), lung/pleura 5 (24\%), lymph nodes/soft tissue $2(1 \%)$ and 13 pts $(62 \%)$ had $\geq 2$ metastatic sites. The median number of cycles was 8 (range 1-21) and altogether 173 cycles were delivered. The treatment was well tolerated. Grade 12 toxicities were recorded in $28(85 \%)$ of the 35 cycles at $\mathrm{V}$ dose $40 \mathrm{mg} / \mathrm{m}^{2}$, in $27(84 \%)$ of the 32 cycles at $\mathrm{V}$ dose $50 \mathrm{mg} / \mathrm{m}^{2}$, in 48 $(83 \%)$ of the 58 cycles at $\mathrm{V}$ dose $60 \mathrm{mg} / \mathrm{m}^{2}$, in $30(91 \%)$ of the 33 cycles at $\mathrm{V}$ dose $70 \mathrm{mg} / \mathrm{m}^{2}$ and in 13 of the 13 cycles $(100 \%)$ at the $\mathrm{V}$ dose level $80 \mathrm{mg} / \mathrm{m}^{2}$ The respective figures for Grade 3-4 toxicities were $3(9 \%), 1(3 \%), 4(7 \%), 3(9 \%)$ and $1(8 \%)$. The maximum tolerated $\mathrm{V}$ dose could not be determined. However, the most common well-tolerated $\mathrm{V}$ dose in these quite heavily pretreated patients was $60 \mathrm{mg} / \mathrm{m}^{2}$. In one patient the dose was reduced to $30 \mathrm{mg} / \mathrm{m}^{2}$ and in only 2 patients the dose could be escalated up to $80 \mathrm{mg} / \mathrm{m}^{2}$. We observed 2 partial responses $(5$ and $16+$ mo months), 8 stable disease (SD) (SD lasting over 6 months in 5 pts), 9 progressive disease and 2 pts were non evaluable Thus the clinical benefit was in 7/19 evaluable pts (37\%) Conclusion: Oral combination of $\mathrm{X}$ and $\mathrm{V}$ is feasible and well tolerated at the $\mathrm{V}$ doses ranging from $40-80 \mathrm{mg} / \mathrm{m}^{2}$ and the combination is active in anthracycline/taxane pretreated pts.

\section{9}

Phase II, open label study of SB-715992 (Ispinesib) in subjects with advanced or metastatic breast cancer. Miller K, Ng C, Ang P, Brufsky AM, Lee SC, Dees EC, Piccart M, Verrill M, Wardley A, Loftiss J, Bal J, Yeoh S, Hodge J, Williams D, Dar M, Ho PTC. IU Cancer Ctr, Indianpolis, IN; Univ Malaya Medical Ctr, Kuala Lumpur, Malaysia; National Cancer Ctr, Singapore; UPMC, Pittsburgh, PA; Nat Univ Hosp, Singapore; UNC, Chapel Hill, NC; Institut Jules Bordet, Brussels, Belgium; Newcastle General Hosp, Newcastle-upon-Tyne, United Kingdom; Christie Hosp, Manchester, United Kingdom; GSK, RTP, NC, with Cytokinetics Inc., S San Francisco, CA

Kinesin spindle protein (KSP), a novel molecular target for anticancer therapy, is expressed only in dividing cells and is required early in mitosis for establishment of mitotic spindle bipolarity and for cell cycle progression through mitosis. KSP is abundantly expressed in breast cancer tissue relative to normal breast tissue. Ispinesib, a selective inhibitor of KSP, can suppress growth of MX-1, MCF-7 and MDA-MB-468 breast tumor cell lines in vitro, with IC50s ranging from 1 to $10 \mathrm{nM}$. A Ph I study was conducted evaluating dosing once every 21 days. The most common adverse events (AEs) included grade (G) 1-4 neutropenia (nadir Day 8 with resolution within 2-4 days), G1-3 diarrhea, and G1-3 fatigue. A Ph II dose of $18 \mathrm{mg} / \mathrm{m}^{2}$ was selected based on prolonged ( $\geq 5$ days) G4 neutropenia observed as the dose-limiting toxicity.

This two stage study was conducted to assess overall response rate of ispinesib following IV administration of $18 \mathrm{mg} / \mathrm{m}^{2}$ over $1 \mathrm{hr}$ once every 21 days. Thirty evaluable patients (pts) were required to complete Stage 1. Pts with advanced breast cancer, either refractory or relapsed after treatment with both an anthracycline and taxane-based chemotherapy regimen, who had received $\leq 2$ prior chemotherapy regimens were eligible. An evaluable pt was defined as one who met entry criteria, completed at least 2 cycles or withdrew prior to the completion of cycle (C) 2 due to progressive disease (PD). If $\geq 3$ pts achieved a PR or CR, 25 additional pts were to be enrolled in Stage 2. Disease assessments were performed every 2 cycles per RECIST. An independent, blinded reviewer (IBR) verified all baseline and subsequent scans for evidence of measurable disease and response.

Thirty-four pts (34 F, median age 49 yrs) were enrolled. A median of 2 and a total of $77 \mathrm{C}(3 \mathrm{wks}=1 \mathrm{C})$ were completed. Four pts were dose reduced to $15 \mathrm{mg} / \mathrm{m}^{2}$, all at $\mathrm{C} 2$, due to neutropenia. The most common AEs were G4 neutropenia (15 events), G1 infusion site pain (13 events), G1 fatigue (7 events) and G1 anorexia (5 events). Twenty-two pts had PD at the end of C2. Stable disease (SD) (3-6 cycles) was the best response in 7 pts, whereas $1 \mathrm{pt}$ achieved a PR (IBR confirmed from C2 to C6). Two pts remained on study through C6. At present, 4 pts continue on study. Data from Stage 1 is currently being analyzed.

At the dose and schedule evaluated, ispinesib had a manageable tolerability profile in this pt population. SD with a single PR was the best response observed in this preliminary data set.

\section{0}

Phase I study of irinotecan followed by capecitabine in patients with advanced breast carcinoma.

O'Connor T, Rustum Y, Levine E, Kepner J, Creaven P. Roswell Park Cancer Institute, Buffalo, NY

Background: Data from preclinical and pilot studies performed at Roswell Park Cancer Institute suggested that when irinotecan is given with 5-fluorouracil (5-FU), efficacy is affected by the sequence of drug administration. Pre-treatment with irinotecan $24 \mathrm{hrs}$ before 5-FU increases the number of tumor cells in S-phase and antitumor activity in a preclinical system. These data provided the rationale for the evaluation of irinotecan and capecitabine, a 5FU prodrug, sequentially administered in patients with advanced breast cancer.

The main objective of this study was to determine the MTD and identify dose-limiting toxicities of capecitabine and irinotecan. Additionally, the degree of accumulation of cells in S-phase in tumor biopsies obtained at $24 \mathrm{hrs}$ after the first dose of irinotecan was assayed in consenting patients. The MTD of irinotecan was defined as the dose that results in $>50 \%$ increase in recruitment of cells into S-phase in $2 / 3$ patient tumors, quantitated by immunohistochemistry using cyclin A antibody and whenever possible confirmed by Flow Cytometry. The starting dose of irinotecan was $80 \mathrm{mg} / \mathrm{m}^{2}$ given over $90 \mathrm{~min}$ on $\mathrm{d} \mathrm{1,8,22,29}$ and capecitabine $1500 \mathrm{mg} / \mathrm{m}^{2} / \mathrm{d} 2-15$ and $\mathrm{d} 23-36$.

Patients: Eligible patients had metastatic breast cancer with progression on at least 1 prior chemotherapy regimen in the metastatic setting with an expected survival of at least 3 mos and ECOG 0-2. Patients treated with prior capecitabine or irinotecan were eligible. Twelve patients were enrolled and treated; one continues on cycle 3 . The median number of prior chemotherapy regimens was 3 (range 1-7). Sequential tumor biopsies were performed on five patients. Patients continued on study drug until disease progression or significant toxicity. Evaluation for response was performed after one cycle. 
Results: The first three patients treated exhibited modulation in cyclin A index on tumor biopsy as defined by the study, establishing the modulatory dose of irinotecan as $80 \mathrm{mg} / \mathrm{m}^{2}$. Overall, $4 / 5$ biopsies showed modulation. DLTs were assessed during the first cycle of therapy. Two DLTs (grade 3 nausea, vomiting, and dehydration; grade 3 pneumonia, hypoxia, hypotension) were seen at dose level 2 of capecitabine $\left(2000 \mathrm{mg} / \mathrm{m}^{2} /\right.$ day $)$ and the first cohort was expanded. There were no DLTs for patients treated at DL 1. No grade 3-4 toxicities occurred at DL 1. Seven patients were evaluable for response following one cycle of treatment (partial response 1, stable disease 4, progressive disease 2). Of the five inevaluable patients, two experienced DLT, one received $50 \%$ of the planned capecitabine dose, one progressed prior to evaluation, and one withdrew consent.

Conclusions: Irinotecan $80 \mathrm{mg} / \mathrm{m}^{2} \mathrm{~d} \mathrm{1,8,22,29}$ in combination with capecitabine $1500 \mathrm{mg} / \mathrm{m}^{2} / \mathrm{d}$ in divided dose d 2-15 and d 2336 has an acceptable toxicity profile and resulted in modulation of $\mathrm{S}$-phase in $4 / 5$ specimens examined. Further studies of the modulatory effect of irinotecan are planned.

\section{1}

Plasma kinetics and uptake of a cholesterol-rich microemulsion (LDE) associated to a derivative paclitaxel by neoplastic breast tissue.

Rodrigues DG, Pires LA, Hegg R, Graziani SR, Maranhão RC. Heart Institute - USP, SP, São Paulo, Brazil; USP, SP, São Paulo, Brazil

Background: Previously we described the association of paclitaxel to a cholesterol-rich nanoemulsion (LDE) that binds to low-density lipoprotein (LDL) receptors and concentrates in neoplastic tissues. The association of the drug is stable, preserves the anti-proliferative activity of the drug and reduces the toxicity to animals. The present study was designed to determine the plasma kinetics of the association LDE:paclitaxel oleate and to verify whether the complex has the ability to concentrate in malignant breast cancer. Material and Methods: To facilitate the association to LDE, paclitaxel is derivatized with oleic acid. $\left[{ }^{3} \mathrm{H}\right]$ paclitaxel oleate associated to LDE labeled with $\left[{ }^{14} \mathrm{C}\right]$-Cholesteryl oleate was intravenously injected into 3 patients with breast cancer $(60 \pm 7$ yr.) $24 \mathrm{~h}$ before surgery. Blood samples were collected over the 24 $\mathrm{h}$ period to determine the plasma decay curves of the radioactive labels. Radioactivity present in plasma aliquots was quantified in a scintillation solution and the pharmacokinetic parameters were calculated by compartmental analysis. Specimens of tumors and normal breast excised during the surgery were collected for lipid extraction, separation by thin layer chromatography and radioactive counting. The experimental protocol was approved by the Ethics Committee of the hospital and an informed consent was obtained from each participant.

Results: Fractional clearance rate (FCR) of LDE and of the drug were similar $(0.030 \pm 0.026$ e $0.018 \pm 0.018$, respectively, $\mathrm{P}=$ $0.5742)$. The uptake of both $\left[{ }^{14} \mathrm{C}\right]-\mathrm{LDE}$ and $\left[{ }^{3} \mathrm{H}\right]$-paclitaxel oleate by breast malignant tissue was two and three fold greater than that of the normal breast tissue, respectively (LDE uptake $=680 \pm 481$ and $290 \pm 247$ and paclitaxel oleate uptake $=1134 \pm 1549$ c.p.m. $/$ g and $469 \pm 695$, respectively). Paclitaxel oleate has a $T_{1 / 2}=19 \mathrm{~h}$, AUC $=1.4 \mathrm{mg} / \mathrm{h} / \mathrm{L}, \mathrm{VSS}=41.8 \mathrm{~L}$ and $\mathrm{CL}=1.5 \mathrm{~L} / \mathrm{h}$.

Discussion: Our results indicate that most of the drug is retained in the microemulsion particles until its removal from the circulation and internalization by the cells. In addition, we showed that when paclitaxel is associated with LDE, the drug can be concentrated in malignant breast tissues while deviating from the normal tissue. Therefore, LDE can be used to target paclitaxel against malignant breast cells.

\section{2}

Preliminary results of phase I trial of carboplatin $(\mathrm{CP})$ in combination with ABI-007 administered weekly or every 3 weeks in patients (pts) with solid tumors.

Stinchcombe TE, Dees EC, Walko CM, Lindley C, Collichio FA, Carey LA, Turner JE, Mu H, Socinski MA. University of North Carolina, Chapel Hill, NC; Abraxis Oncology, Los Angeles, CA

Background: $\mathrm{CP}$ in combination with paclitaxel produced objective responses in $62 \%$ of 95 women with advanced breast cancer (Loesch et al, JCO 20:3857, 2002). ABI-007 (Abraxane ${ }^{\mathrm{TM}}$ ) is an albumin-bound particle form of paclitaxel that has recently been shown to increase the response rate and time tumor progression to paclitaxel (Gradishar et al, JCO 2005, in press).

Methods: We are currently conducting a Phase I study to determine the recommended Phase II dose (RP2D) of ABI-007 administered either weekly (d1, 8, 15 q 28 days) or on day 1 every 3 weeks in combination with carboplatin AUC 6 on day 1. On the days both drugs were administered, $\mathrm{ABI}-007$ preceded $\mathrm{CP}$ except in cycle 2 . Pharmacokinetics (PK) were performed during cycles 1 and 2 to determine if there was a sequence-dependent interaction between the two drugs. To date 15 pts (4 NSCLC, 4 melanoma, 2 breast, 5 other) have been treated: ABI-007 weekly 6 pts (4 and $2 @ 100$ and $125 \mathrm{mg} / \mathrm{m}^{2}$, respectively) and q3w (3 each at 220, 260, and $300 \mathrm{mg} / \mathrm{m}^{2}$ ).

Results: Toxicities by maximum grade have included $\mathrm{Gr} 4$ neutropenia, Gr 4 thrombocytopenia, Gr 3 febrile neutropenia $\mathrm{Gr}$ 3 anemia, Gr 2 nausea and constipation and Gr 1 neuropathy. The maximum tolerated dose has not yet been determined for either regimen. 4 PRs have occurred in pts with melanoma, SCLC and NSCLC and 1 CR has occurred in a pt with NSCLC.

Conclusion: Trial is currently ongoing. Based on preliminary data the combination appears to be well tolerated and has demostrated activity. PK, toxicity, and response data will be presented.

\section{3}

The conjugation of doxaliform to alpha(v) beta3 $\left(\alpha_{v} \beta_{3}\right)$ targeting peptides provides a potential therapeutic alternative for the management of $\alpha_{v} \beta_{3}$-overexpressing breast carcinomas.

Vellon L, Menendez JA, Burkhart DJ, Kalet BT, Koch TH, Lupu R. Evanston Northwestern Healthcare Research Institute, Evanston, IL; Northwestern University Feinberg School of Medicine, Chicago, IL; University of Colorado, Boulder, CO

Background: Significant limitations for doxorubicin treatment of cancer are drug resistance and chronic cardiotoxicity. One of the alternatives to reduce the side effects of chemotherapeutics like doxorubicin is the selective delivery to cancer cells and/or associated vasculature. Considering its important role in tumor metastasis and angiogenesis, $\alpha_{w} \beta_{3}$ may offer a good molecular target for drug delivery. Here, we have analyzed the effects of a novel conjugate of the prodrug doxaliform, to a cyclic $\alpha_{v} \beta_{3}$-targeting peptide (RGD-fK-d-DOXSF) in highly invasive breast cancer models overexpressing $\alpha_{v} \beta_{3}$ (MDA-MB-231 and Hs578T). Materials and Methods: Breast cancer cell models were maintained in IMEM medium supplemented with 5\% FBS. Cell viability in response to the conjugate RGD-fK-d-DOXSF or doxorubicin was assessed by the MTT assay. DNA content and drug uptake was assessed by flow cytometry. Results: Interestingly, the conjugate RGD-fKd-DOXSF dramatically decreases cell viability of MDA-MB-231 and Hs578T cells. Moreover, flow cytometric analysis showed that RGD-fK-d-DOXSF exerted dramatically altered cell cycle progression of MDA-MB-231 and Hs578T breast cancer cells, inducing $\mathrm{G} 2 / \mathrm{M}$ arrest and apoptosis. Of note, the extent of the effects of RGD-fK-d-DOXSF was related to the levels of $\alpha_{v} \beta_{3}$ expression in the cells (Hs578T>MDA-MB-231), thus proving the specificity of target $\left(\alpha_{v} \beta_{3}\right)$. To additionally control the specificity of the conjugate RGD-fK-d-DOXSF for its integrin target, we pretreated MDA-MB-231 as well as Hs578T cells with 
small peptidomimetic antagonists of $\alpha_{v} \beta_{3}$ in the presence or the absence of rising concentrations of RGD-fK-d-DOXSF or doxorubicin. Interestingly, functional blockade of $\alpha_{v} \beta_{3}$ strongly antagonized the effects of the conjugate RGD-fK-d-DOXSF, indicating that blockade of the RGD-binding site of $\alpha_{\mathrm{v}} \beta_{3}$ impaired the effects of RGD-fK-d-DOXSF. Flow cytometric analysis showed that the cellular uptake of the conjugate is lower than that of doxorubicin in $\alpha_{v} \beta_{3}$-overexpressing breast cancer models; however, the uptake of RGD-fK-d-DOXSF is not significant in the $\alpha_{v} \beta_{3}$ negative MCF-7 cells. Discussion: Collectively, the present data suggest that the conjugate RGD-fK-d-DOXSF is as effective as doxorubicin but would bind the cells at those sites on the membrane where $\alpha_{v} \beta_{3}$ is present, thus being delivered primarily to $\alpha_{v} \beta_{3}$ overexpressing cells. Therefore, the conjugation of doxaliform to $\alpha_{\mathrm{v}} \beta_{3}$-targeting peptides would reduce doxorubicin side effects while serving to the purpose of specifically hit both, tumor cells as well as supporting vasculature in $\alpha_{v} \beta_{3}$-overexpressing breast carcinomas.

\section{4}

Rifampin reduces exposure to sunitinib malate (SU11248) in Caucasian and Japanese populations.

Bello CL, Houk B, Sarapa N, Smeraglia J, Huang X, Klamerus KJ. Pfizer Global R\&D, La Jolla, CA

\section{Background}

Sunitinib malate is an oral multitargeted tyrosine kinase inhibitor that specifically inhibits VEGFR, PDGFR, KIT, RET and FLT3. It has demonstrated single-agent antiangiogenic and antitumor activities in clinical trials in a variety of advanced solid tumors, including gastrointestinal stromal tumor, metastatic renal cell carcinoma and metastatic breast cancer. Sunitinib is metabolized to SU12662, its equipotent metabolite, in a reaction catalyzed by cytochrome P450 (CYP) 3A4. CYP34A also metabolizes SU12662. This suggests that exposure to sunitinib may be reduced when sunitinib is used concomitantly with drugs that induce CYP3A4. Materials and methods

In this open-label, two-way crossover drug-interaction study, sunitinib was coadministered with rifampin, a potent inducer of CYP3A4, in healthy male volunteers. Volunteers were randomized to receive initial treatment with either sunitinib alone (Treatment A) or rifampin and sunitinib together (Treatment B), and then crossed over to the other treatment after a 2-week washout period. Treatment A consisted of a single 50-mg oral dose of sunitinib on day 1. Treatment B consisted of rifampin $600 \mathrm{mg} /$ day orally for 17 days combined with a single $50-\mathrm{mg}$ oral dose of sunitinib on day 8. Blood samples were collected pre-sunitinib dosing and for 17 days following sunitinib administration in both Treatments A and B for determination of sunitinib and SU12662 concentrations. In both treatment arms, doses of sunitinib were administered in the morning after an overnight fast of at least 8 hours. In order to derive preliminary data on inter-ethnic pharmacokinetics, sunitinib was administered to Caucasian $(n=13)$ or Japanese $(n=15)$ males, with and without CYP3A4 induction by rifampin.

\section{Results}

Coadministration of sunitinib and rifampin was associated with 4.8- and 4.7-fold reductions in sunitinib $\mathrm{AUC}_{\text {last }}$ (267 vs. 1285 $\mathrm{h} \cdot \mathrm{ng} / \mathrm{mL})$ and $\mathrm{AUC}_{0-\infty}(278 \mathrm{vs} .1294 \mathrm{~h} \cdot \mathrm{ng} / \mathrm{mL})$ compared with administration of sunitinib alone. Coadministration was also associated with a 2.3-fold reduction in sunitinib $C_{\max }$ (13.0 vs. 29.5 $\mathrm{ng} / \mathrm{mL})$. In terms of the active metabolite SU12662, coadministration of sunitinib and rifampin was associated with a 1.3-fold increase in AUC and a 2.4-fold increase in $\mathrm{C}_{\max }$. The PK results with and without coadministration of rifampin were similar in both ethnic groups.

\section{Conclusions}

Coadministration of sunitinib with drugs that induce CYP3A4 reduces exposure to sunitinib and should be avoided when possible or consideration given to a dose adjustment. The lack of ethnic differences supports the use of a common sunitinib starting dose and schedule in Caucasian and Japanese populations.

\section{5}

Trastuzumab (T) and KOS-953 (17-AAG) is feasible and active in patients (pts) with metastatic breast cancer: preliminary results of a phase $1 / 2$ study.

Modi S, Stopeck A, Gordon MS, Solit D, Bagatelle R, Flores S, Cohen J, Block H, Cropp GF, Rosen N, Johnson RG, Hannah AL, Hudis C. Cancer Center, New York, NY; Arizona Cancer Center Tucson/Scottsdale, AZ; Kosan Biosciences Inc., Hayward, CA

Background: KOS-953 (17-AAG in a novel cremophor-based formulation) binds to and inhibits the activity of Hsp90, resulting in degradation of client proteins. One of the most sensitive client proteins is the HER2 receptor. In vivo, 17-AAG induces rapid degradation of HER2 in a HER2-expressing breast cancer cell line with loss of AKT phosphorylation, cyclin D2 and tumor growth inhibition.

Objectives: $\mathrm{Ph}$ 1: define the recommended dose (RP2D) and toxicity of KOS-953 in combination with standard doses of $\mathrm{T}$ in pts with solid tumors. $\mathrm{Ph} 2$ : determine the objective response rate in pts with HER2+ metastatic breast cancer (MBC) with progression following treatment with T. PK are performed on KOS-953, its active metabolite and T. Leucocytes are purified to investigate changes in intracellular signaling proteins by immunoblot.

Methods:Eligible pts for the $\mathrm{Ph} 1$ portion had advanced solid tumors; for Ph 2: HER2 (+) disease with progression on T with 1 chemotherapy was required. In $\mathrm{Ph} 1$,pts receive standard weekly doses of T followed by KOS-953 in escalating doses via weekly IV infusions over $2 \mathrm{hrs}$. Dose escalation follows $3+3$ rules; the RP2D will produce DLT in no more than $1 / 6$ evaluable pts.

Results: As of 25May05, 16 pts (13 female; 11 with MBC; median age 68 yrs, range 33-87; median KPS 90; prior regimens for metastatic disease 2, range 0-7 were enrolled in 4 dose levels $\left(225,300,375\right.$ and $450 \mathrm{mg} / \mathrm{m}^{2}$ with $4,3,8$ and $1 \mathrm{pt}$ treated per dose level, respectively). DLT was first observed at $375 \mathrm{mg} / \mathrm{m}^{2}$ in 1 out of 8 pts treated, consisting of 2-week dose delay to allow recovery from toxicities of Gr 4 fatigue, Gr 2 nausea and anorexia, and Gr 1 abdominal pain. One other pt was dose reduced at this level due to Gr 1-2 elevations in AST/ALT. Drug-related Gr 3 toxicity was limited to 1 episode of emesis and hypersensitivity. Other Gr 1-2 drug-related toxicity: nausea $(n=8)$, diarrhea $(n=8)$, fatigue $(n=7)$, anorexia $(n=5)$, emesis $(n=4)$, headache $(n=4)$ and maculopapular rash $(\mathrm{n}=4)$. PK of parent drug $\left(225\right.$ and $300 \mathrm{mg} / \mathrm{m}^{2}$ only): $\mathrm{t}^{1} \frac{2}{2} 2.8 \pm 1.6 \mathrm{~h}$; clearance $42.9 \pm 10.9 \mathrm{~L} / \mathrm{hr} ; \mathrm{Vz} 159 \pm 72.3 \mathrm{~L}$. Cmax and AUCtot $\left(300 \mathrm{mg} / \mathrm{m}^{2}\right): 4260 \mathrm{ng} / \mathrm{mL}$ and $15263 \mathrm{ng} /$ $\mathrm{mL} * \mathrm{~h}$. Metabolite reached Tmax $30 \mathrm{~min}$ after end-of-infusion with similar AUC and longer $\mathrm{t}^{1 / 2}$ of $5.6 \mathrm{hr}$. Tumor responses by CT and PET-CT were seen in 3 pts. PD testing shows that AKT and CD4 in leucocytes is decreased, together with reactive induction of Hsp70/72.

Conclusions: Definition of RP2D dose is pending, with escalation to $450 \mathrm{mg} / \mathrm{m}^{2}$ in progress. PK parameters for $17-\mathrm{AAG}$ in this formulation at this dose range are similar to KOS-953 monotherapy and previous formulation. Preliminary signs of activity in pts with $\mathrm{MBC}$, previously treated with $\mathrm{T}$, have been observed. Updated data will be available at the time of the presentation.

\section{6}

c-jun activation is associated with angiogenesis in invasive breast cancer.

Vleugel MM, Greijer AE, Bos $R$, van der Wall E, van Diest PJ. University Medical Center Utrecht, Utrecht, Netherlands; VU University Medical Center, Amsterdam, Netherlands

c-Jun is a component of the transcription factor AP-I, which binds and activates transcription at TRE/AP-I elements. The transcriptional activity of c-Jun is regulated by phosphorylation of c-Jun at Ser63/73. Extracellular signals, including growth factors, transforming oncoproteins and UV irradiation stimulate phosphorlylation of c-Jun at Ser 63/73 and activate c-Jun dependent transcription. Thereby, activated c-Jun potentially plays an 
important role in carcinogenesis and cancer progression. Indeed, c-Jun has recently been implicated in angiogenesis. However, most knowledge on c-Jun has been gathered in model systems and little translational work has been performed. The aim of this study was to evaluate expression patterns of activated c-Jun in breast cancer, in relation to various other important biomarkers and clinicopathological data.

Immunohistochemistry was performed on 103 cases of invasive breast cancer with an antibody recognizing phosphorylated c-Jun at Serine 73.

Activated c-Jun showed a predominantly nuclear expression at the invasive front in $38 \%$ of invasive breast cancer cases in varying percentages (1-20\% of nuclei, mean $4 \%$ ). Furthermore, expression of activated c-Jun was seen in the invasive front in mitotic cells of $40 \%$ of cases, sometimes however also centrally in the tumours. Accompanying DCIS showed similar expression patterns. Occasionally, fibroblasts, endothelial and benign breast cells showed nuclear expression. Activated nuclear c-Jun expression showed positive correlations with expression of hyperphosphorylated $\mathrm{pRb}$, VEGF and with microvessel density. Mitotic c-Jun expression showed positive relations with $\mathrm{pRb}$, and microvessel density. Stromal c-Jun expression showed positive relations with microvessel density. In survival analysis, no significant relation was found with activated c-Jun expression and survival although a trend with poor survival was found for mitotic cells overexpressing activated cJun $(\mathrm{p}=0.09)$.

In conclusion, activated c-Jun is mainly expressed at the invasive front in invasive breast cancer where most proliferation and angiogenesis takes place. Indeed, it is often expressed in mitotic cells, and associated with angiogenesis. As earlier studies have established a functional link between activated c-Jun and angiogenesis, c-Jun/AP-1 targeting may provide new ways to block tumour angiogenesis.

\section{7}

\section{Lymphangiogenesis and human breast cancer.}

Cunnick GH, Jiang WG, Douglas-Jones A, Watkins G, Gomez KF, Mokbel K, Mansel RE. University of Wales College of Medicine, Cardiff, Wales, United Kingdom; St. George's Hospital, Tooting, London, United Kingdom

Aims: To determine whether lymphangiogenesis and lymphatic density correlated with nodal metastasis. Using all known lymphatic markers (LYVE-1, Prox1, Podoplanin, 5-nucleotidase and VEGFR3), lymphangiogenesis was indirectly quantified by measuring mRNA expression of the markers, using quantitative polymerase chain reaction (QPCR) methods. Lymphatic density was semiquantified in tissues using immunohistochemistry (IHC).

Methods: 120 invasive breast cancers and 33 normal breast samples were studied. Tumour details were blinded until the end of the study. The following cell lines were also used: MCF7 and MDMBA-231 (breast cancers), MRC-5 (fibroblasts) and human umbilical vein endothelial cells (HUVECs). Conventional PCR and Real-time QPCR was performed on cDNAs from breast samples and cell lines, using primers specific for each marker - lymphatic markers: LYVE-1, Prox1, Podoplanin, 5-nucleotidase and VEGFR3, and lympangiogenic factors: VEGF-C and VEGF-D. Expression levels were compared between the different lymph node groups and different prognostic categories. IHC was used to identify lymphatics and lymphangiogenic factors, using, anti-LYVE-1, antipodoplanin, VEGFR-2, VEGFR-3, VEGF-C and VEGF-D antibodies, respectively

Results: The six endothelial markers were expressed in HUVECs. VEGF-C and VEGF-D were expressed in the aggressive breast cancer cells, MD-MBA-231. Expression of all lymphatic endothelial markers and growth factors was significantly higher in breast cancer than normal breast tissue (table 1). Expression was higher in tumours which had metastasised to regional lymph nodes than those which had not, although these differences were not significant. Expression in poor prognosis tumours (Nottingham
Prognostic Index) was higher than good prognosis tumours. LYVE1, VEGF-R2 and VEGF-R3 proteins stained strongly in breast tissues. In breast cancer, there was stronger lymphatic staining in peritumour tissues and to a limited degree, intra-tumour lymphatics. Both breast cancer cells and stromal cells stained with VEGF-D and VEGF-C, although much stronger in the latter.

Conclusions: Lymphangiogenesis was higher in cancer compared to normal breast tissue and non-significantly higher in node positive tumours than node negative. Lymphatic density appeared higher in and around tumours than in normal breast tissue. Expression of Markers in Tumour \& Normal Breast. [Mean \pm s.d.(n)]

\begin{tabular}{llll}
\multicolumn{5}{l}{ Expression of Markers in Tumour \& Normal Breast. [Mean \pm s.d.(n)] } \\
& TUMOUR & NORMAL & P-VALUE \\
LYVE-1 & $57.0 \pm 326(93)$ & $0.28 \pm 0.37(23)$ & $<0.0001$ \\
Prox 1 & $5099 \pm 8353(119)$ & $1270 \pm 1555(32)$ & 0.0009 \\
Podoplanin & $13722 \pm 67277(120)$ & $4973 \pm 7115(29)$ & 0.048 \\
5'-Nucleotidase & $4964 \pm 7166(112)$ & $3208 \pm 8761(32)$ & 0.007 \\
VEGFR-3 & $121.8 \pm 223.8(120)$ & $65.6 \pm 197.0(32)$ & 0.010 \\
VEGF-C & $1899 \pm 8596(84)$ & $270 \pm 306(23)$ & 0.026 \\
VEGF-D & $57.3 \pm 113.1(58)$ & $11.7 \pm 12.2(15)$ & 0.016
\end{tabular}

\section{8}

A histomorphological study of tumor lymphangiogenesis in inflammatory and non-inflammatory breast cancer.

Van der Auwera I, Van den Eynden GG, Van Laere SJ, Colpaert $C G$, van Dam P, Van Marck EA, Vermeulen PB, Dirix LY. Laboratory of Pathology University of Antwerp/University Hospital Antwerp, Edegem; Oncology Centre, General Hospital St-Augustinus, Wilrijk, Antwerp, Belgium

At the time of diagnosis, metastatic dissemination of tumor cells via the lymphatic system has occurred in most patients with inflammatory breast cancer (IBC). High mRNA levels of lymphangiogenic factors are found in IBC $^{1}$. Whether the lymphatic spread of breast cancer is dependent on lymphangiogenesis and/or invasion of pre-existing lymph vessels (LVs) remains unclear. Quantification methods of lymphangiogenesis need further optimization and standardization to resolve current controversy. We aimed to identify the most suitable marker to visualize LVs in breast cancer and to obtain quantitative morphological data on lymphangiogenesis in (non)IBC.

Immunohistochemical staining patterns of podoplanin, LYVE-1, prox-1, D2-40, CD31, CD34 and FVIII were compared in 20 serial sections of (non-)IBC. Relative LV area (LVA), LV perimeters (LVP), counts (LVN) and lymphatic endothelial cell proliferation (LECP) were measured in D2-40/Ki-67-stained sections of 10 normal breast tissues, 29 IBCs and 56 non-IBCs. All parameters were assessed in 3 hotspots, both in the tumor parenchyma and at the tumor margin. D2-40 was the most suitable antibody for staining peri- and intratumoral LVs. Respectively $50.5 \%$ and $35.1 \%$ of D2-40 stained LVs were also positive for podoplanin and prox1. Despite its strong expression on peritumoral LVs, LYVE-1 showed weak or no immunoreactivity on intratumoral LVs. D240 and FVIII showed a mutually exclusive vascular expression pattern. D2-40-stained intratumoral LVs were present in $80 \%$ of non-IBCs and $82.8 \%$ of IBCs. In non-IBC, LVs located in the tumor parenchyma were smaller and less numerous than at the tumor margin $(\mathrm{P}<0.0001)$, while in IBC, intra- and peritumoral parameters were not different. None of the peritumoral parameters was different in IBC and non-IBC. LVs located in the tumor parenchyma of IBC covered a larger tumor area and were larger and more numerous than LVs located in the tumor parenchyma of non-IBC: median relative LVAmean was $0.84 \%$ in IBC and $0.33 \%$ in non-IBC $(\mathrm{P}=0.01)$; median LVPmax was $432.64 \mu \mathrm{m}$ in IBC and $344.52 \mu \mathrm{m}$ in non-IBC $(\mathrm{P}=0.04)$; median LVNmax was 9 in IBC and 6 in non-IBC $(\mathrm{P}=0.05)$. LECP at the tumor margin was higher in IBC than in non-IBC: median LECP was $5.74 \%$ in IBC and $1.83 \%$ in non-IBC $(\mathrm{P}=0.005)$

The presence of dividing lymphatic endothelial cells suggests that there is lymphangiogenesis in breast cancer. In addition to lymphangiogenesis, pre-existing LVs are being incorporated in IBC. We propose D2-40/Ki-67 immunohistochemistry to quantify 
LECP as a standard technique for assessing lymphangiogenesis in breast cancer.

${ }^{1}$ Van der Auwera I et al. Increased angiogenesis and lymphangiogenesis in inflammatory versus non-inflammatory breast cancer by real-time RT-PCR gene expression quantification. Clin Cancer Res 10(23):7965-71 (2004)

\section{9}

Vascular endothelial growth inhibitor (VEGI), an antiangiogenic factor, in human breast cancer.

Parr C, Gan C, Harrison G, Jiang WG. Wales College of Medicine, Cardiff University, Cardiff, United Kingdom

Background: Vascular Endothelial Growth Inhibitor (VEGI) is a new anti-angiogenic cytokine that belongs to the tumour necrosis factor (TNF) family. Very little is known about the significance of VEGI in human cancer. This study examined the function of VEGI and analysed VEGI levels in human breast cancer in relation to clinical parameters.

Material and Methods: VEGI expression and distribution was examined using RT-PCR and Western Blotting (on a range of 24 normal and cancer cell lines), immuno-histochemically (patient samples of both normal and breast cancer tissue), and quantitatively using real-time quantitative PCR on a cohort of human breast cancer tissue $(n=95)$ and background breast tissue $(n=34)$. To assess the biological function of VEGI we also employed a ribozyme transgene system to knockout the expression of VEGI in a human breast cancer cell line (MDA-MB-231). The effect of VEGI elimination was assessed through a series of in vitro studies. Results: RT-PCR and IHC staining revealed that VEGI expression was dramatically reduced in the breast cancer tissues compared to the normal breast tissues. In addition, endothelial cells and breast cancer cells of low invasive nature demonstrated the highest levels VEGI expression. Quantitative PCR demonstrated that VEGI expression was significantly decreased $(\mathrm{p}=0.048)$ in patients with an overall poor prognosis $(69.5 \pm 21$ copies $/ \mathrm{ml})$, compared to those with a good prognosis $(102 \pm 14$ copies $/ \mathrm{ml})$. However, no significant correlations were observed in comparison of tumour grade, nodal involvement, and tumour node metastasis Q-PCR values. Importantly, knockout of VEGI expression resulted in a significant increase $(\mathrm{p}=0.008)$ in vessel formation in a breast cancer (MDA-MB-231) and endothelial cell (HECV) co-culture system.

Discussion: This is the first study to examine VEGI in breast cancer. We report that VEGI is an anti-angiogenic factor that may display prognostic value in breast cancer patients, as reduced levels of VEGI correlated with an overall poor prognosis for breast cancer patients.

\section{0}

Tamoxifen increases matrix metalloproteinase 2 and 9 activities and endostatin levels in breast cancer tumors in vivo.

Nilsson UW, Dabrosin C. University Hospital, Linköping, Sweden

The extracellular microenvironment of the local host tissue is of utmost importance throughout cancer progression. Matrix metalloproteinases (MMPs) are a family of endopeptidases involved in the degradation and remodeling of the extracellular matrix. These proteases seem to have dual functions in cancer. In addition to degrading basement membrane and thereby enabling invasion and angiogenesis, MMPs also form anti-angiogenic fragments such as endostatin. Sex steroids play a dominant role in breast carcinogenesis and tumor growth but the mechanisms are not fully explored. In this study we show that estrogen and the anti-estrogen tamoxifen affect MMP activities in breast cancer cells (MCF-7) in vitro. However, in vivo, the activation of MMPs occurs mainly in the extracellular environment under the influence of all cell types present in the tissue. Endostatin is also generated by cleavage of collagen in the extracellular matrix. Hence, a direct measurement of MMP activity, and endostatin direct in tumor tissue in vivo is necessary. Therefore, we used microdialysis to measure the extracellular activity of MMP-2 and MMP-9 in solid MCF-7 tumors in nude mice after treatment with estrogen and tamoxifen. The microdialysis catheter was perfused with an MMP$2 / 9$ specific fluorogenic substrate and the fluorescence in the outgoing dialysate was measured. With this approach we could directly quantify the intratumoral MMP activity in vivo. The microdialysate was also analyzed for extracellular tumor levels of endostatin in situ. We found that the MMP-2/9 activity increased significantly after tamoxifen treatment and that this increase was accompanied by significantly increased levels of endostatin. We conclude that microdialysis used for direct measurements of MMP activities in vivo provides valuable insights into the modulation of the proteolytic environment in situ. Moreover, we suggest that the anti-angiogenic effects of tamoxifen in breast cancer may in part be explained by increased endostatin generation by a sex steroid dependent modulation of MMP2/9 activities.

\section{1}

Lack of correlation between microvessel density \& pericyte coverage index within breast cancer biopsies \& functional dynamic contrast-enhanced MRI-derived vascular parameters.

Ah-See MW, Padhani AR, Taylor NJ, Harris AL, Burcombe RJ, Fox SB, Richman PI, Daley FM, Stirling JJ, Leach MO, Bentzen SM, Makris A. Mount Vernon Hospital, Northwood, Middlesex, United Kingdom; John Radcliffe Hospital, Oxford, Headington, United Kingdom; Royal Marsden Hospital, Sutton, Surrey, United Kingdom

\section{Background:}

Functional dynamic contrast-enhanced MRI (DCE-MRI) provides a method for assessing \& characterising tumour microvasculature In primary breast cancer (PBC), the relationship between DCEMRI vascular parameters \& immunohistochemically-derived measures of tumour angiogenic status remain unclear. Here we assess the relationship between tumour microvessel density (MVD) \& pericyte coverage index (PCI) \& DCE-MRI derived vascular parameters in PBC.

\section{Methods:}

39 patients with biopsy-proven $\mathrm{PBC}$ (median age 47 years, range 29-70) were imaged prior to treatment. DCE-MRI was performed using Gd-DTPA contrast \& parametric images were calculated reflecting microvessel permeability (transfer constant $\left[\mathrm{K}^{\text {trans }}\right]$, leakage space $\left[\mathrm{v}_{\mathrm{e}}\right]$, rate constant $\left[\mathrm{k}_{\mathrm{op}}\right]$, maximum contrast medium uptake [MaxGd]) \& perfusion (relative blood volume [rBV], relative blood flow $[\mathrm{rBF}]$, mean transit time [MTT]). Median values for each kinetic parameter were derived from whole tumour regions of interest. MVD \& PCI were quantified by immunohistochemistry using the panendothelial marker, CD34, \& alpha-smooth muscle actin ( $\alpha$-SMA) in diagnostic biopsy specimens. MVD \& PCI were scored from random fields (median 10; range 4-25) at x200 magnification or, in the case of small samples $(\mathrm{n}=8)$, from al fields (median 6; range 1-14). The association between two parameters was quantified by Spearman's rank correlation.

\section{Results:}

The median (interquartile range) MVD \& PCI values were 75.9/ $\mathrm{mm}^{2}\left(45.8-101.1 / \mathrm{mm}^{2}\right) \& 12.5 \%(5.5-29.5 \%)$ respectively. No correlation was found between the pre-treatment vascular parameter median values as assessed by DCE-MRI \& either tumour MVD (for $\mathrm{K}^{\text {trans }} \mathrm{r}_{\mathrm{s}}=0.11, \mathrm{p}=0.5 ; \mathrm{v}_{\mathrm{e}} \mathrm{r}_{\mathrm{s}}=-0.08, \mathrm{p}=0.6 ; \mathrm{k}_{\mathrm{e} p} \mathrm{r}_{\mathrm{s}}=0.03$, $\mathrm{p}=0.9 ; \operatorname{MaxGad~}_{\mathrm{s}}=-0.17, \mathrm{p}=0.3 ; \mathrm{rBV} \mathrm{r}_{\mathrm{s}}=-0.21, \mathrm{p}=0.2 ; \mathrm{rBF}_{\mathrm{s}}=$ $0.25, \mathrm{p}=0.1$; MTT $\mathrm{r}_{\mathrm{s}}=-0.15, \mathrm{p}=0.4$ ) or PCI (for $\mathrm{K}^{\text {trans }} \mathrm{r}_{\mathrm{s}}=0.08$, $\mathrm{p}=0.6 ; \mathrm{v}_{\mathrm{e}} \mathrm{r}_{\mathrm{s}}=0.24, \mathrm{p}=0.2 ; \mathrm{k}_{\text {op }} \mathrm{r}=-0.01, \mathrm{p}=0.9 ;$ MaxGad $\mathrm{r}_{\mathrm{s}}=0.22$ $\mathrm{p}=0.2 ; \mathrm{rBV} \mathrm{r}_{\mathrm{s}}=-0.10, \mathrm{p}=0.5 ; \mathrm{rBF}_{\mathrm{s}}=-0.06, \mathrm{p}=0.8 ; \mathrm{MTT}_{\mathrm{s}}=-0.04$, $\mathrm{p}=0.4$ ).

\section{Conclusion:}

No significant correlation was seen between tumour MVD or PCI in the pre-treatment breast cancer biopsy specimens \& the median values of the DCE-MRI-derived vascular parameters. Failure to 
demonstrate a correlation may be due to the small patient number within the study or due to a disparity between immunohistochemically-defined visible microvasculature \& "realtime" vascular function.

\section{2}

Role and prognostic relevance of hypoxia inducible factor $1 \alpha$ and its downstream targets in fibroepithelial tumours of the breast. .

Kuijper A, van der Groep P, van der Wall E, van Diest PJ. University Medical Center Utrecht, Utrecht, Netherlands

Hypoxia inducible factor $1 \alpha$ (HIF-1 $\alpha)$ and its downstream targets CAIX and VEGF are key factors in the survival of proliferating tumour cells in a hypoxic microenvironment. The relevance of these factors has been established in several types of cancers. We studied the role and prognostic relevance of HIF-1 and its downstream targets CAIX and VEGF in phyllodes tumours and fibroadenomas of the breast.

To determine expression levels of HIF-1 $\alpha$, CAIX, VEGF and p53, immunohistochemistry was performed on a group of 37 primary phyllodes tumours and 16 fibroadenomas with known clinical follow-up. Tumour microvasculature was visualised by immunohistochemistry for CD31. Proliferation was assessed by Ki67 immunostaining and mitotic counts. Immunoquantification was performed in stroma and epithelium.

Only one fibroadenoma displayed low-level stromal HIF- $1 \alpha$ reactivity in the absence of CAIX expression. Stromal HIF-1 $\alpha$ expression in phyllodes tumours was positively correlated with grade $(\mathrm{p}=0.001)$, proliferation as measured by Ki67 expression $(\mathrm{p}<0.001)$ and mitoses counts $(\mathrm{p}<0.001), \mathrm{p} 53$ accumulation $(\mathrm{p}=0.009)$, and global $(\mathrm{p}=0.003)$ and hot-spot $(\mathrm{p}=0.041)$ microvessel counts, but not to CAIX expression. Interestingly, CAIX and HIF- $1 \alpha$ expression were both frequently found in morphologically normal epithelium of phyllodes tumours. High expression of VEGF was regularly found in both fibroadenomas and phyllodes tumours, with only a positive relation between stromal VEGF and grade in phyllodes tumours $(\mathrm{p}=0.016)$. The distance from the epithelium to the nearest microvessels was higher in phyllodes tumours as compared to fibroadenomas, but microvessel counts as such did not differ between fibroadenomas and phyllodes tumours. In survival analysis, stromal HIF- $1 \alpha$ overexpression $(p=0.032)$ in phyllodes tumours was predictive of disease free survival, but this was not independent from stromal p53 overexpression $(\mathrm{p}<0.001)$.

In conclusion, these results indicate that HIF- $1 \alpha$ may play an important role in the stromal progression of phyllodes tumours and predicts prognosis. In view of the absence of stromal CAIX expression, stromal upregulation of HIF-1 $\alpha$ in phyllodes tumours is most likely caused by hypoxia independent pathways, with p53 inactivation as one of possible causes. In contrast, coexpression of HIF- $1 \alpha$ and CAIX in the epithelium in phyllodes tumours points to epithelial hypoxia, most likely caused by relatively distant blood vessels.

Supported by an unrestricted grant from Aegon Inc.

\section{3}

Analysis of angiogenesis genes from paraffin-embedded breast tumor and lymph nodes.

Schneider BP, Skaar TC, Badve S, Sledge GW, Li L, Flockhart DA. Indiana University, Indianapolis, IN

Background: Angiogenesis is important in tumor growth and metastasis. Germ-line polymorphisms critical to the angiogenesis pathway have been shown to confer prognostic information in multiple tumor types. These genes include vascular endothelial growth factor (VEGF) and endothelial nitric oxide synthase (eNOS).

Methods: We extracted DNA from 53 specimens obtained from 21 patients including a primary breast tumor, and/or a histologically involved lymph node, and/or a histologically normal lymph node. We subsequently genotyped all specimens to evaluate two polymorphisms in the eNOS gene and one polymorphism in the VEGF gene. DNA samples were assayed for genetic polymorphisms using polymerase chain reaction (PCR)-restriction fragment length polymorphism (RFLP) assays. After digestion with the appropriate restriction endonuclease, the resulting fragments were analyzed via generation of chromatographs using the Agilent 2100 Bioanalyzer with the DNA 500 chip.

Results: PCR amplifications were considered sucessful if interpretable chromatographs were generated on the Bioanalyzer following the PCR and restriction digestion. Chromatographs were generated in $145 / 159(91 \%)$ samples. When assessing all polymorphisms by site, chromatographs were generated in $42 / 51$ $(82 \%, 95 \%$ CI, $64.3 \%$ to $89.7 \%)$ samples obtained from the primary tumor and 103/108 (95\%, 95\% CI, $89 \%$ to $98.4 \%)$ from lymph nodes. Chromatographs were generated in 46/53 (87\%) samples from the $\mathrm{T}^{-786} \mathrm{C}$ polymorphism in the 5'-flanking region in the eNOS gene, $49 / 53(92 \%)$ when assessing the Glu ${ }^{298} \mathrm{Asp}$ polymorphism in exon 7 in the eNOS gene and 50/53 samples (94\%) for the $\mathrm{C}^{936} \mathrm{~T}$ polymorphism in the VEGF gene. In total, there was $100 \%$ concordance between analyses from the primary tumor, uninvolved lymph node, and involved lymph node from the same case (95\% CI, 0.97 to 1.00). Also, the likelihood of successfully genotyping from a lymph node source was significantly higher than genotyping from the primary tumor $(\mathrm{p}=0.016)$.

Discussion: We successfully extracted DNA and genotyped several polymorphisms in two genes important in angiogenesis. These genotypes were determined in breast tumors, but also in involved and uninvolved lymph nodes. There was $100 \%$ concordance between the genotypes of germline DNA obtained from uninvolved lymph nodes and those determined in tumor samples, implying that the tumor angiogenic genotype reflects the host genotype.

\section{4}

MEK5-ERK5 signaling promotes estrogen-independent tumorigenesis of breast carcinoma cells.

Xiong W. Tulane University, New Orleans, LA

Background: Expression and activation of the mitogen-activated protein (MAP) kinase family have been described to function in the progression of breast and prostate carcinoma to a hormoneindependent and endocrine therapy resistant phenotype. Using gene expression profiling of human breast carcinoma cells, we have identified a member of the MAPK family - MEK5, whose expression is increased in drug-resistant breast carcinoma cells.

Materials and Methods: To test the role of MEK5-ERK5 pathway in tumorigenesis, we established stably expressing constitutively active (CA)-MEK5 MCF-7 human breast carcinoma cell lines. Using an ERK5 targeting pSUPER-GFP RNA interference (RNAi) system, we developed stable ERK5-RNAi or vector-RNAi expression MCF7-MEK5 cells. Expression levels of estrogen responsive genes were obtained by RT-PCR and Western blot analysis. For the in vivo tumorigenesis assay, MCF-7, MCF7MEK5 and its ERK5-RNAi cells were transplanted into mammary fat pads of immunocompromised athymic female nude mice (nu/ nu) and monitored for the development of tumors.

Results: We found that MCF7-MEK5 cells exhibited greater proliferation, clonogenic survival and apoptotic resistance in vitro. MEK5 expressing breast carcinoma cells possessed an earlier tumor onset and greater tumor growth than vector cells. Of significant interest was the observation that MEK5 cells were capable of tumor formation in the absence of exogenous estrogen, while the ER-positive MCF7-Vec cells were unable to form tumors without $\mathrm{E}_{2}$ stimulation, demonstrating the MEK5's role in progression to a more malignant hormone-independent phenotype. Inhibition of ERK5 expression delayed MCF7-MEK5 tumor onset and suppressed tumor growth in mice. Expression of cyclin $\mathrm{A}_{1}, \mathrm{D}_{1}$, and $\mathrm{E}_{2}$ were responsive to estrogen in MCF-7 and ERK5-RNAi stable cells, whereas in MCF7-MEK5 cells, there was a constitutive 
overexpression of these cyclins that was independent of estrogen stimulation. Ongoing research involves studying protein interactions with C-terminal domain of ERK5 through a yeast two-hybrid system.

Discussion: These results demonstrate that activation/ overexpression of the MEK5-ERK5 pathway converts breast carcinoma cells to a more aggressive and hormone-independent phenotype. Our results with RNAi-mediated suppression of ERK5 and recent evidence demonstrating increased expression and activation of the MEK5-ERK5 pathway in breast and prostate carcinoma cells suggests that this pathway may represent a useful marker whose levels could be utilized as a prognostic indicator of therapeutic response and as a prospective target for therapeutic intervention.

\section{5}

The most common integrin ITGA2 haplotype (807C_1648G, "wildtype") is associated with decreased breast cancer risk. Langsenlehner U, Eder T, Weitzer W, Samonigg H, Krippl P. Medical University Graz, Graz, Styria, Austria

Background: Integrins are cell surface receptors which mediate cell-to-cell and cell-to-extracellular matrix adhesion. Some of them, e.g. $\alpha_{\mathrm{V}} \beta_{3}, \alpha_{\mathrm{IIb}} \beta_{3}$ and $\alpha_{2} \beta_{1}$, have been suggested as key players for cancer development and tumor metastasis. Two polymorphisms in the gene for the $\alpha_{2}$ component, ITGA2 $807 \mathrm{C}>\mathrm{T}$ and $1648 \mathrm{G}>\mathrm{A}$, have been associated with the cell-surface density of integrin $\alpha_{2} \beta_{1}$. The $176 \mathrm{~T}>\mathrm{C}$ polymorphism in the ITGB3 gene, encoding the $\beta_{3}$ subunit of integrins $\alpha_{\mathrm{II}} \beta_{3}$ and $\alpha_{\mathrm{V}} \beta_{3}$, modifies a variety of traits of $\beta_{3}$ expressing cells.

Patients and methods: To analyze the role of ITGA2 and ITGB3 polymorphisms for breast cancer risk and prognosis, we performed a case-control study including 500 female breast cancer patients and 500 healthy female age-matched control subjects. All study participants were of Caucasian origin (Austria, Middle-Europe). Genotypes were determined by 5'-nuclease assays (Applera, Austria). Primer and probe sets were designed and manufactured using Applera's 'Assay-by-Design' custom service. The PCR reaction was performed in a Primus 96 plus thermal cycler (MWG Biotech AG, Germany) using a total volume of $5 \mu$ containing 2.5 $\mu$ l SuperHot-Master-Mix (Bioron GmbH, Germany),

Results: The ITGA2 1648_AA genotype was significantly associated with breast cancer (odds ratio $3.12 ; 95 \%$ confidence interval 1.11 - 8.77). Carriers of the most common ITGA2 haplotype (807C_1648G, "wildtype") were at decreased risk for breast cancer (odds ratio $0.72 ; 95 \%$ confidence interval 0.53 0.98 ). A histological grade of 3 or 4 was found more often in ITGA2 807TT subjects ( $\mathrm{p}=0.039$ compared to $\mathrm{CC}+\mathrm{CT}$ genotypes) and carriers of an ITGA2 1648A allele ( $\mathrm{p}=0.017$ compared to GG genotype). Carriers of the ITGA2 807C_1648G haplotype were less likely to have a histological grade 3 or 4 compared to non-carriers $(\mathrm{p}=0.003)$. The ITGB3 176T $>\mathrm{C}$ polymorphisms was not associated with breast cancer susceptibility. In a Cox-regression analysis, carriers of the homozygous ITGB3 176-CC genotype had a higher risk for metastasis (relative risk $2.2 ; 95 \%$ CI $1.2-4.0 ; \mathrm{p}=0.015$ )

Conclusion: We conclude that functional polymorphisms in integrin genes ITGA2 and ITGB3 influence the development and progression of breast cancer, respectively. The precise mechanism remains to be determined, but likely involves dysregulated signaling pathways.

\section{6}

Invasive lobular carcinoma and the high grade variant pleomorphic lobular carcinoma: molecular characterization.

Simpson P, Reis-Filho J, Mackay A, Jones C, Dexter T, Hardisson $D$, Sarrio D, Weber B, Ashworth A, Schmitt F, Palacios J, Lakhani S. University of Queensland, QIMR, RB\&W's Hospital, Brisbane, Australia; ICR, London, United Kingdom; IPATIMUP, Oporto, Portugal; CNIO/La Paz. Hospital, Madrid, Spain; University of Pennsylvania

Background: Immunohistochemical analysis of E-cadherin has changed the way lobular neoplasia is perceived. It has helped to classify difficult cases of carcinoma in situ with indeterminate features and led to the identification of new variants of lobular carcinoma (LC), including pleomorphic lobular carcinoma (PLC) and pleomorphic lobular carcinoma in situ (PLCIS) which are reported to be associated with a more aggressive clinical behaviour. Although PLC/PLCIS show morphological features of classic lobular neoplasia and lack E-cadherin expression, it is unclear whether these lesions evolve through the same genetic pathway as LC or are high grade ductal neoplasms that have lost E-cadherin. Methods: We have analysed a series of $16 \mathrm{LC}$ and 15 PLC, including a case containing extensive PLCIS. All cases were reviewed by three of the authors and subjected to immunohistochemistry for E-cadherin, oestrogen and progesterone receptors, p53 and HER2/neu. Array-based comparative genomic hybridization $(\mathrm{aCGH})$ was performed using the Breakthrough Breast Cancer Research Centre aCGH platform containing 5620 bacterial artificial chromosome clones arranged at $\sim 1 \mathrm{Mb}$ intervals throughout the genome. Normalized data were smoothed using local polynomial adaptive weights smoothing and the statistical significance for difference in copy number changes between LC and PLC calculated by Fisher's exact test. Confirmation of genetic alterations was by High Resolution CGH and chromogenic in situ hybridization (CISH).

Results: All carcinomas showed typical architectural features of LC and were negative for E-cadherin. By aCGH, both LC and PLC had more gains than losses and PLC had a greater proportion of the genome altered than LC. Recurrent copy number alterations (in $>50 \%$ of cases) included gain at 1q21-q25, 1q32-q44, 5q35, 7q22, 11q13, 12q13, 16p13-p12, 17q24-q25, 19p13, 20q13 and loss at 11q21-q22, 13q21, 16q11-q23, 18q12 and Xq21. Genomic alterations more frequently identified (Fisher's exact, $p<0.05$ ) in PLC included gain of $8 \mathrm{q} 24,9 \mathrm{q} 22,17 \mathrm{q} 11$ and $17 \mathrm{q} 24-\mathrm{q} 25$ and loss of 9p21, 13q21-22 and Xq13-q21. Gain of 9q34 was significantly more common in LC. Amplification of c-myc (8q24) and ERBB2 (17q12) were confirmed in PLC and PLCIS by CISH.

Discussion: The similarity in morphology, immunohistochemistry and molecular profiles between LC and PLC provides evidence for a conserved evolutionary relationship. Both entities appear reliant upon early genetic hits at $1 \mathrm{q}, 16 \mathrm{q}$ and loss of E-cadherin. Additional genetic alterations involving known oncogenes (eg c-myc, HER2/neu) and as yet unconfirmed genes at other designated chromosomal loci are likely to contribute to the higher grade and more aggressive nature of PLC.

\section{7}

Classic lobular breast carcinoma: comprehensive molecular genetic analysis.

Reis-Filho JS, Simpson PT, Lambros M, Jones C, Sarrio D, Savage $K$, Dexter T, Mackay A, Iravani M, Fenwick K, Weber B, Hardisson D, Schmitt F, Palacios J, Ashworth A, Lakhani SR. ICR, London, United Kingdom; IPATIMUP, Oporto, Portugal; University of Queensland, Brisbane, Australia; ICR, Sutton, United Kingdom: CNIO and La Paz Hospital, Madrid, Spain; University of Pennsylvania

Background: Classic lobular carcinomas (CLCs) account for $\sim 15 \%$ of all breast cancers and are morphologically characterised by monomorphic, discohesive cells with mild nuclear atypia that 
infiltrate the stroma as single cells or single cell files. At the genetic level, CLCs almost invariably show recurrent gain of 1q and physical loss of 16q, coupled with lack of E-cadherin (CDH1) expression. However little is known on the role of putative oncogenes and tumour suppressor genes (TSGs) in the biology of these lesions.

Material and Methods: Thirteen cases were subjected to a comprehensive molecular genetic analysis including i) immunohistochemistry for E-cadherin, oestrogen (ER) and progesterone $(\mathrm{PgR})$ receptors, HER2/neu and p53; ii) LOH analysis on 16q21-q22 and 5q21; iii) CDH1 gene mutations; iv) CDH1 gene promoter methylation; v) chromogenic in situ hybridisation (CISH) for cyclin D1 (CCND1); vi) high resolution comparative genomic hybridisation (HR-CGH); and vii) microarray based comparative genomic hybridisation (aCGH) using the Breakthrough Breast Cancer Research Centre aCGH platform, containing 5620 bacterial artificial chromosome clones arranged at $<1 \mathrm{MB}$ intervals throughout the genome.

Results: All cases lacked expression of E-cadherin, p53 and HER2. ER and PgR were positive in $11 / 13$ and $7 / 13$ cases, respectively. $\mathrm{CDH} 1$ gene mutation, $\mathrm{LOH}$ and methylation were observed in 2 $13,8 / 11$ and $6 / 13$ cases, respectively. HR-CGH revealed a mean of 8 chromosomal arms affected per case, with similar frequencies of gains and losses (4 and 3.9/ per case, respectively). The most frequent recurrent changes comprised gains on $1 \mathrm{q}(85 \%), 8 \mathrm{q}(46 \%)$, $8 \mathrm{p}$ and $19 \mathrm{p}$ (both, 23\%) and recurrent losses on $16 \mathrm{q}(85 \%), 11 \mathrm{q}$, $13 \mathrm{q}, 17 \mathrm{q}$ and $18 \mathrm{p}(\mathrm{all}, 31 \%)$. The agreement between aCGH and HR-CGH ranged from $47 \%$ to $100 \%$ (median $=88 \%$ ). In addition to the chromosomal changes identified with HR-CGH, aCGH revealed recurrent gains of $16 \mathrm{p}(61.5 \%)$, small amplicons (in $>30 \%$ of the cases) mapping to $3 \mathrm{q} 27.1,6 \mathrm{p} 21.33-\mathrm{p} 21.1,7 \mathrm{q} 11.23$, 7q22.1, 8p11.2-p12, 9q34.12-q34.3, 11q13.1-q13.3, 12q13.12 $\mathrm{q} 14.1,14 \mathrm{q} 22.2-\mathrm{q} 22.3$ and $17 \mathrm{q} 24.3-\mathrm{q} 25.1$ and small deletions (in $>30 \%$ of the cases) mapping to $8 \mathrm{p} 23.2-\mathrm{p} 23.1,10 \mathrm{q} 21.1-\mathrm{q} 21.2$ $15 \mathrm{q} 14,15 \mathrm{q} 21.3$ and $15 \mathrm{q} 25.1-\mathrm{q} 25.2$. Increased CCND1 (11q13.3) gene copy numbers were confirmed by CISH in all cases harbouring CCND1 gains as defined by aCGH.

Conclusion: CLCs are characterised by lack of E-cadherin, p53 and HER2, recurrent physical loss of $16 \mathrm{q}$ and gain of 1q, CCND1 amplification and a higher genomic complexity than previously appreciated with other methods. Further analysis may allow the identification of new amplicon drivers and TSGs.

\section{8}

Is aberrant hypermethylation an early event in breast cancer?

Sullivan RF, Kim SJ, Zapparoli GV, Kachel CA, Chiriboga L Skinner KA. New York University Cancer Institute, New York, NY Introduction: Tumor suppressor gene (TSG) silencing by DNA methylation is common in cancers. Previous work identified eight TSG promoters that were frequently hypermethylated in invasive breast cancer (IBC): APC, CALCA, cyclinD2, GSTP1, HPP1, MYOD1, RAR 32 , RASSF1. Abnormal TSG methylation has been demonstrated to be an early event in many cancers. We studied the patterns of methylation of these eight TSGs in ductal carcinoma in situ of the breast (DCIS) to determine if DNA hypermethylation was an early event in breast cancer

Methods: DNA was extracted from archival paraffin embedded blocks containing DCIS from 23 patients. The DNA was bisulfite converted and assayed by the MethyLight technique targeting the eight aforementioned TSGs.

Results: All eight genes were methylated with high frequency in DCIS (Table 1). TSG methylation was significantly more frequent in DCIS than in IBC in three of the eight genes studied (MyoD1, RAR 32 , and RASSF1). In the remaining genes, the frequency of methylation was statistically equivalent but slightly higher in DCIS for APC, CALCA, cyclinD2, GSTP1, and slightly lower in DCIS for HPP1. At least 1 of the 8 genes was methylated in $96 \%$ of DCIS samples compared to $86 \%$ of IBC samples, and multiple genes were methylated in $87 \%$ of DCIS samples compared to $74 \%$ of IBC samples. The average number of methylated genes was 4.4 in DCIS samples compared to 3.0 in IBC samples. Table 1: \% of Samples Methylated in DCIS and IBC
Gene

DCIS IBC

p-value
Gene

DCIS

DCIS

p-value

$\begin{array}{ll}\text { APC } & \text { CALCA } \\ 57 & 26 \\ 38 & 20 \\ 0.14 & 0.56 \\ \text { HPP1 } & \text { MYOD1 } \\ 39 & 65 \\ 56 & 38 \\ 0.18 & 0.03\end{array}$

cyclinD2
61
40
0.09
RARß2
78
28

\author{
GSTP1 \\ 22
18 \\ 0.64 \\ RASSF1 \\ 91
58
}

58

Conclusion: TSG methylation is a frequent event in DCIS, demonstrating that DNA hypermethylation is an early event in breast cancer. The finding of higher frequencies of hypermethylation in DCIS than in IBC suggests that this mechanism of TSG silencing may play a more important role in the early phases of malignant transformation than in the later phases of invasion and metastasis. This phenomenon might be exploited for molecular screening for breast cancer or for targeted therapeutics for DCIS.

\section{9}

SNP microarray analysis of genomic alterations in infiltrating ductal carcinoma and infiltrating lobular carcinoma.

Ton CC, Loo LW, Grove DI, Neal CL, Hsu L, Porter PL. Fred Hutchinson Cancer Research Center, Seattle, WA

Background: Approximately $75-80 \%$ of invasive cancers are ductal in origin while $10-15 \%$ are of the invasive lobular type. Significantly, it has been observed that the incidence of ILC has been increasing among post-menopausal women in parts of the U.S. Specifically, post-menopausal women who take combined hormone replacement therapy (HRT) appear to be at an elevated risk of ILC, but not of IDC. It is therefore important to understand the genomic changes (e.g. aneuploidy) which underlie the development of IDC and ILC.

Materials and Methods: DNA from 42 primary archival breast tumors (14 ILC and 28 IDC) were analyzed using the Affymetrix $10 \mathrm{~K}$ SNP array. This method permitted the assessment of both copy number gain/loss and the mapping of areas of allelic imbalance that arose in the development of the individual tumors. Tumors were classified by histologic sub-type, expression of known prognostic tumor proteins, and ploidy. To enrich for the neoplastic cell fraction, tumor samples were stained for cytokeratin and sorted by flow cytometry. DNA from sorted tumor cells and normal blood (normal controls) was extracted, labelled according to manufacturer's instructions and hybridzed to the MAP10K SNP array. The copy number changes between ILC and IDC subtypes were assessed by Student's t-test, and those SNPs for which $\mathrm{p}<0.05$ were grouped for further hierarchical cluster analysis. In addition, regions of loss-of-heterozygosity $(\mathrm{LOH})$ were identified with the Affymetrix GDAS 2.0 software, using patient-matched DNA from blood lymphocytes as constitutive normal reference. As a preliminary analysis, the $\mathrm{LOH}$ fraction (\% LOH/informative) were computed for each chromosomal arm, and used in k-Means analysis. Results and Discussion: The copy number analysis identified 583 SNPs at the $\mathrm{p}<0.05$ threshold, where ILC and IDC mean copy number were significantly different. Cluster analysis of tumors on this subset of SNPs yielded 5 major clusters: one of "pure" ILC and two of IDC, and two intermediate clusters containing both tumor subtypes. This outcome remained robust even when other metrics and modes of linkage were employed. Clustering of the SNPs yielded 11 major groupings. Recognizable within these clusters were SNPs located in proximity to genes mediating, for example, key processes of hormone response, antiestrogen resistance, genome integrity, tumor suppression, cell adhesion and matrix remodeling. K-Means analysis of LOH resolved the ILC/IDC tumor set into 5 distinct groupings as well, in good concordance with the copy number analysis. $\mathrm{LOH}$ subgroups were characterized by specific patterns of allelic loss. In one subset of IDC, for 
example, coordinate $8 \mathrm{p}, 6 \mathrm{q}$ LOH was evident; whereas in another group, co-occurrence of $6 \mathrm{q}, 11 \mathrm{q}, 13$ and 22 was found. These early results indicate that the microarray approach can be successfully used to identify the patterns of genomic lesions which distinguish the IDC/ILC tumor subtypes.

\section{0}

Comparison between matched pairs of primary breast cancer and distant metastasis using array CGH.

Gahir J, Reis-Filho JS, Iravani M, Dexter T, Fenwick K, Davidson B, Mackay A, Ebbs S, Ashworth A. ICR, London, United Kingdom; Mayday Hospital, Croydon, United Kingdom; Norwegian Radium Hospital, Montebello, Norway

Background: Twenty five percent of women with breast cancer die as a result of the disease spreading to distant organs. The process of cancer metastasis consists of a long series of sequential interrelated steps that are believed to be associated with complex stochastic genetic changes.

Aim: The aim of this project is to identify molecular genetic changes that are i) present in primary tumours (PTs) and their paired nodal and distant metastases (MTs) and ii) specific to neoplastic cells in the metastatic deposits.

Patients and Method: 22 patients with known primary breast cancers and who later developed distant and nodal metastases were graded (Bloom-Richardson-Scarff system) and immunohistochemically analysed with antibodies for oestrogen receptor (ER), HER2, epidermal growth factor receptor and cytokeratin 5/6. Tumour samples were microdissected to ensure a purity of $>70 \%$ of neoplastic cells. DNA was extracted, labelled and hybridised to the $5.8 \mathrm{~K}$ Breakthrough Breast Cancer Research Centre array comparative genomic hybridisation (aCGH) platform, which contains 5620 bacterial artificial clones arranged throughout the genome at $<1 \mathrm{Mb}$ intervals. All experiments were carried out in duplicate ('dye-swaps'). After data acquisition, normalisation and 'dye-swap' collation, a running median smoothing was applied to all samples. A categorical analysis was applied to the smoothed ratios after classifying them as gains, losses or no-change.

Results: Of the 22 PTs, $13 \%$ were grade I, $40 \%$ grade II and $47 \%$ grade III. In $80 \%$ of the cases, nuclear grade was identical in paired PTs and MTs. No dedifferentiation from grade I to grade III was observed. The immunohistochemical profile of PTs and MTs was similar in all but one case, where the PT was ER+ whilst the MT was negative. The concordance between the molecular genetic changes identified in PTs and MTs ranged from 0 to 0.91 ( mean $=0.51$, median $=0.58)$. When comparing paired PTs with MTs, medians of $32.0 \%$ (range, $0-53.8 \%$ ), 30.1\% (range, $0-82.3 \%$ ) and $40.8 \%$ (range, $0-83 \%$ ) of all events were observed in PTs only, MTs only and concurrently in both, respectively. Recurrent gains in the PTs comprised 1q, 3q, 4p, 11p, 16p, 20p and 22, whilst 1q, 11p, 20 and 22 were the most frequently observed in the MTs. Recurrent losses included 1p, 11q, 19q, Xp and Xq in the PTs and $13, \mathrm{Xp}$ and $\mathrm{Xq}$ in the MTs. Interestingly, when paired cases where analysed, gains on 1q, 11,16q, 17p, 19, 21 and losses on 4q, $9 p, 13 p, 16 q$ and $17 p$ were more frequently observed in MTs only. Conclusion: Based upon histological, immunohistochemical and molecular genetic features, primary tumours and metastasis are remarkably similar. However, the presence of molecular genetic changes observed only in metastatic deposits suggest the existence of genomic regions specifically associated with the process of metastasis.

\section{1}

C-MYC expression correlates with atypia and malignancy in early breast lesions associated with microcalcifications detected by routine mammography.

Mazzini RC, Kemp C, Logullo AF, Elias S, Oshima CT, Takano DM, Dobo C, Junior JA. Universidade Federal de Sao Paulo, Sao Paulo, SP, Brazil

Introduction: c-myc is a proto-oncogene associated to cell cycle control. Amplification and super-expression of c-myc is involved in early stage of many human malignant tumors. Recently a possible role of c-myc in breast carcinogenesis has been hypothesized in literature.

Objective: To evaluate c-myc expression in biopsies from early detected breast lesions by mammography. To compare c-myc expression to histopathological and clinical variables.

Methods: in a retrospective analysis 98 lesions from 79 female patients diagnosed and treated at Universidade Federal de São Paulo from 1998 to 2004 were elected. All cases were submitted to percutaneous biopsy of breast lesions containing microcalcifications classified as BI-RADS 4 and 5 in routine mammography. Morphology and immunohistochemistry were analyzed by two independent observers. Final diagnosis sub-divided the cases in two groups, non-malignant lesions and malignant lesions. Non-malignant cases were classified as with and without atypia. C-myc expression was evaluated with standard ABC immunohistochemical essay considering nuclear staining as positive. More than $10 \%$ of positive cells were considered as positive.

Results: average age was 52,9 years. From 98 lesions, 29 were malignant $(29,6 \%)$, including infiltrative and in situ ductal carcinoma, and 11 cases atypical ductal hyperplasia $(11,2 \%)$ and remaining 58 cases $(59,2 \%)$ were non-malignant (fibrocystic changes and typical ductal hyperplasia). C-myc was positive in 40 $(40,8 \%)$ lesions and negative in $58(59,2 \%)$. Among the malignant cases, $14(48,3 \%)$ were c-myc negative and $15(51,7 \%)$ positive, whereas between the 11 hyperplasia 4 were negative $(36,4)$ and 7 positive $(63,6 \%)$. From 58 non-malignant lesions, $18(31 \%)$ exhibited c-myc expression and $40(69 \%)$ were negative. We found a close trend to positive association between malignant lesions versus benign lesions without atypia $(p=0,060)$ and a positive association between atypical versus benign without atypia lesions $(p=0,039)$. However, clinical variables (age, menopause and use of hormone therapy) did not correlate to c-myc expression in both groups.

Conclusion: c-myc protein identification was more frequent in malignant than non-malignant early detected breast lesions and is associated to presence of atypia suggesting that alterations in c$m y c$ expression is not an early event in breast carcinogenesis. The role of c-myc expression on detecting potential malignant lesions must be further addressed.

\section{2}

Breast cancer metastasis-free survival and its association to a common hereditary gene polymorphism of cyclin D1. Hofmann G, Langsenlehner U, Renner W, Greimel A, Samonigg H, Krippl P. Medical University of Graz, Graz, Austria; Clinical Institute of Medical and Laboratory Diagnostics, Medical University of Graz, Graz, Austria

Background: Cyclin D1 (CCND1) is a key regulator of the G1 phase of the cell cycle. CCND1 plays an important role in tumor development and progression, as well. A common $870 \mathrm{G}>\mathrm{A}$ polymorphism in the gene for CCND1 has been linked to alternative splicing and cancer susceptibility. Aim of the present study was to evaluate the role of this polymorphism for breast cancer metastazing.

Methods and Patients: A retrospective study was performed including 500 female breast cancer patients. A Cox regression model including CCND1 870A carriage, age at diagnosis, primary presence of regional lymph node metastasis, primary tumor size 
larger than $2 \mathrm{~cm}$, and estrogen and/or progesteron receptor negativity in the primary tumor, was used to estimate the effect of the CCND1 genotype on metastasis-free survival time.

Results: At the time of diagnosis, the patients were between 28 and 84 years of age, with a mean age of $57 \pm 11$ years. Median metastasis-free survival time was 120 months (95\% CI: 106 134). In the subgroup of 302 patients with stage III - IV breast cancer, $250(82.8 \%)$ patients developed metastases in the time between diagnosis and study entry, whereas $52(17.2 \%)$ patients remained free of metastases. The CCND1 870 AA genotype was found more frequently among subjects without metastases $(44.2 \%)$ than among those with metastases $\left(24.8 \%\right.$; chi $^{2}$ test, $\left.\mathrm{p}=0.005\right)$. In a logistic regression model including age at diagnosis and estrogen and/or progesterone receptor negativity in the primary tumor as potential confounders, the 870_AA genotype was still significantly associated with metastasis risk (odds ratio 0.43 , 95\% CI 0.23 $0.83 ; \mathrm{p}=0.010)$.

Conclusion: Our data support the hypothesis that the Cyclin D1 $870 \mathrm{G}>$ A polymorphism is associated with metastasis-free survival time in female patients with breast cancer.

\section{3}

\section{Apocrine metaplasia and the development of ER-negative breast cancer.}

Lee S, Weiss H, Tsimelzon A, Mao S, Wu Y, Mohsin SK, Medina D, Haagensen DE, Allred DC. Baylor College of Medicine, Houston, TX; Traditional Practice Alliance, Sacramento, CA

Normal/benign breast epithelium commonly transforms into cells resembling those in apocrine sweat glands. This transformation, referred to as "apocrine metaplasia" (APOM), is associated with a near-total loss of estrogen receptor (ER) expression. The first substantial loss of ER during breast cancer evolution does not occur until the late stage of ductal carcinoma in situ (DCIS), and it is likely that progression of a subset of ER-negative DCIS accounts for the majority of ER-negative invasive breast cancer. We have noted a continuum of apocrine histological features in DCIS and hypothesized that, similar to normal/benign epithelium, some DCIS may undergo APOM and become ER-negative in the process. Design/Results: In preliminary studies, we performed a blinded assessment of apocrine histological features (scale: $0=$ none; $1=$ mild; 2 = moderate; 3 = extensive), histological grade, and ER expression in a series of 200 consecutive DCIS, and looked for correlations between them. As apocrine features increased, there was a corresponding increase in histological grade $(\mathrm{p}=0.002)$, and a corresponding decrease in ER expression $(p=0.001)$. Among the ER negative cases $(31 \%$ of the total), $38 \%$ showed mild (score $=1)$ and $15 \%$ showed moderate-to-extensive $($ scores $=2 / 3)$ apocrine features. To identify the genetic changes associated with APOM, we evaluated and compared the expression of 47,000 genes (Affymetrix U133 Human X3P microarrays) using RNA from seven paired samples of benign and apocrine epithelium harvested by laser-capture microdissection from formalin-fixed paraffin-embedded breast tissue (14 total samples). The results were evaluated with dChip, BRB-ArrayTools, and Array Analyzer software.In preliminary supervised comparisons, nearly 1,500 genes showed $>3$-fold differences in expression (range 3-to-340 fold; average 10.5 fold; $\mathrm{p}<.01$ ), including an especially large number involved in steroid (androgen/estrogen), prostaglandin, fatty acid, glutathione, and carbohydrate metabolism. Other prominent changes associated with APOM occurred in genes involved in cellular growth/differentiation (e.g. down-regulation of PROM11, AREG, WIF1, IRS2, and EGR1); intercellular attachment/ communication (e.g. increases in CLDN1 and LIMS1 and decreases in TNC and LAM5); and other miscellaneous interesting pathways (e.g. a 30-fold decrease in KIT). Conclusions/Goals: There are extraordinary differences in gene expression between normal/benign and apocrine breast epithelium. The goal of future studies will be to determine the prevalence of these genes in breast cancer, their correlation with ER-status and, most importantly, identify those which are down-regulating ER. The latter could be potentially targeted to allow re-expression of ER and treatment with available hormonal therapies.

\section{4}

Molecular alterations in columnar cell lesions of the breast.

Dabbs DJ, Peng Y, Carter G, Swalsky P, Finkelstein S. MageeWomens Hospital, Pittsburgh, PA

Background: Columnar cell lesions of the breast (CCL) include a morphologic spectrum of simple columnar cell change (CCC), columnar cell hyperplasia $(\mathrm{CCH})$, columnar cell hyperplasia with atypia $(\mathrm{ACCH})$ and DCIS of micropapillary/cribriform type. Invasive carcinomas of low grade type are often seen in association with this spectrum. The biologic significance of these lesions that are commonly found on breast biopsies is unknown. We have previously demonstrated that CCL are almost always positive for estrogen receptor and show increasing proliferation markers with increasing levels of atypia.

Design: Four cases of formalin fixed, paraffin embedded breast tissues, each displaying the entire spectrum of CCC through DCIS and including foci of invasive carcinoma were microdissected at multiple sites to evaluate neoplasia progression. Minute tissue targets were microdissected (4-8/case) from unstained 4 micron thick recut paraffin sections and included non-neoplastic breast and sites of $\mathrm{CCC}, \mathrm{CCH}, \mathrm{ACCH}$, DCIS and invasive carcinoma. Allelic imbalance for a broad panel of microsatellite markers in proximity to known tumor suppressor genes was quantitated using automated PCR/gel electrophoresis. Genomic loci evaluated $1 \mathrm{p}$, $3 p, 5 q, 9 p, 9 q, 10 q, 17 p, 17 q, 19 q, 22 q$. The presence, topographic relationship and time course of mutational damage was correlated with columnar morphologic features.

Results: Detailed allelic imbalance information was obtained from each microdissection tissue target producing a detailed fingerprint of mutational damage in each case. The overall results are as follows:

$\begin{array}{llll}\text { Case } & \text { ACCH } & \text { DCIS } & \text { Carcinoma } \\ 1 & 17 \mathrm{q} & 17 \mathrm{q} & 17 \mathrm{q} \\ 2 & \text { NA } & 9 \mathrm{q}, 10 \mathrm{q}, 17 \mathrm{q} & 9 \mathrm{q}, 10 \mathrm{q}, 17 \mathrm{q} \\ 3 & \text { No mutations } & \text { No mutations } & \text { No mutations } \\ 4 & 9 \mathrm{q}, 17 \mathrm{p} & \text { NA } & 1 \mathrm{p}, 17 \mathrm{p}\end{array}$

Conclusions (1) Low level of allelic imbalance was demonstrable in columnar cell lesions by the microdissection approach. A gradient of progressive mutational change could be delineated in each case manifesting allelic loss damage. (2)Allelic loss damage appeared to preferentially target loci at $9 q, 10 q, 17 p$ and $17 q$. (3) The frequent findings of CCL in breast biopsies, coupled with the low level of mutational damage, suggests that CCL are not obligate precursors to carcinoma.

\section{5}

The evaluation of the breast imaging in clinical complete response patients after primary chemotherapy.

Sakemura N, Akashi-Tanaka S, Eriko I, Takasugi M, Terada $K$, Shien T, Kinoshita T, Miyakawa K, Kohno T, Shimizu C, Ando M Katsumata N, Fujiwara Y, Fukutomi T. Department of Breast Surgery, Department of Diagnostic Radiology, Department of Breast and Medical Oncology, National Cancer Center Hospital, Tokyo, Japan.

Background: Recently, primary chemotherapy has been used not only for locally advanced breast cancer but also for breast conserving treatment for patients with early stage of breast cancer. The achievement of pathological complete response (pCR) is associated with a survival advantage. We sought to investigate whether contrast-enhanced computed tomography (CE-CT) and ultrasonography (US) could be used to predict histopathological response in cases which achieved clinical complete response (cCR) after primary chemotherapy for breast cancer. 
Material and Methods: Between 1999 and December 2004, 279 patients with breast cancer of at least $2 \mathrm{~cm}$ in diameter who were treated with anthracycline and taxane based primary chemotherapy underwent surgery at National Cancer Center Hospital. 61 patients obtained cCR. CE-CT and US were performed at the baseline and before surgery. Lesions were classified into 5 types by early and delay phase enhancement pattern and morphology of tumor; type 1 and 2 were diagnosed as pCR, type 3 to 5 were diagnosed as noninvasive or invasive tumor.

Results: Histopathological diagnosis among the 61 patients, 13 (21.3\%) achieved pCR, 13 (21.3\%) obtained residual noninvasive tumor, while $35(57.4 \%)$ showed residual invasive tumor. Positive predictive value of residual tumor (PPV) in CE-CT diagnosis was $83.6 \%$, and in US was $82.4 \%$, while negative predictive value of residual tumor (NPV) in CE-CT was $66.7 \%$ compared to $40 \%$ in US. Sensitivity of residual tumor in CE-CT diagnosis was $95.8 \%$ and in US was $87.5 \%$; on the other hand, specificity of residual tumor in CE-CT and US were equally $30.8 \%$.

Discussion: CE-CT and US may effort diagnosis of the residual lesions after primary chemotherapy in cases of $\mathrm{cCR}$, however both modalities were not satisfactory for accurate diagnosis of pCR. Further study is necessary for strategy of cCR cases after primary chemotherapy for breast cancer.

\section{6}

An electronic data registry for evaluating fulvestrant treatment in patients with advanced breast cancer.

Wade JL, Esparaz, BT, Lower EE. Decatur Memorial Hospital, Decatur, IL; University of Cincinnati, Cincinnati, $\mathrm{OH}$

Background: Fulvestrant represents an important treatment option for postmenopausal women with hormone-receptor positive advanced breast cancer. Whereas the registration trials focused on women with metastatic breast cancer following antiestrogen therapy, it is unclear how this agent is currently being used in clinical practice. To address this issue, an electronic data registry was developed to provide insight into current fulvestrant usage and to collect clinical outcomes data of patients treated with fulvestrant

Methods: To conduct this observational study, data entry was implemented via MedNet Solutions electronic registry. Participating practices entered data via a secure Web site including baseline patient characteristics, patient follow up, closure of treatment, and efficacy parameters.

Results: Among the 213 patients enrolled from 34 physician practice sites, 189 patients completed fulvestrant treatment and 24 patients remain on treatment. Ninety-four percent of patients (200/213) received previous endocrine therapy that included tamoxifen, anastrozole, exemestane, letrozole, toremifene, or megestrol. 164 patients $(77 \%)$ had prior exposure to tamoxifen, and of these, $51(24 \%)$ had metastatic disease which had progressed on tamoxifen before receiving fulvestrant. In spite of the extensive prior hormonal therapy, of the 213 enrolled patients, $47.9 \%$ of patients $(102 / 213)$ demonstrated clinical benefit (as defined by $\mathrm{CR}+\mathrm{PR}+\mathrm{SD} 324$ weeks)

Discussion: This electronic registry is a useful tool to monitor usage of fulvestrant and obtain valuable outcomes data in clinical practice. While there are limitations to any observational study, it is interesting to note that the clinical benefit observed in this setting is in alignment with the $43.5 \%$ clinical benefit reported in the two Phase III studies. Importantly, considering the majority of patients treated with prior endocrine therapies, these data lend further support to the impressive lack of cross resistance of fulvestrant and underscore its role as an important treatment option in the setting of advanced breast cancer.

\section{7}

A phase II and biologic correlative study investigating anastrozole $(A)$ in combination with geftinib (G) in post menopausal patients with estrogen receptor positive (ER) metastatic breast carcinoma (MBC) who have previously failed hormonal therapy.

Mita M, de Bono JS, Mita A, Patnaik A, Ricart A, Berg K, Takimoto $C$, Rowinsky EK, Tolcher A, Beeram M. Institute for Drug Development, University of Texas Health Science Center San Antonio, TX

Background: Overactive epidermall growth factor receptor (EGFR) signaling may contribute to resistance to hormone therapy in breast cancer. Blockade of EGFR signaling in combination with continued estrogen suppression by aromatase inhibition may result in increased therapeutic potential.

Material and Method: The objectives of this phase II study were to determine the antitumor activity and the safety of the combination and to identify potential pharmacokinetic (PK) interactions and pharmacodynamic (PD) markers. Patients with ER positive MBC who progressed following therapy with an aromatase inhibitor received $\mathrm{G} 250 \mathrm{mg}$ orally (po) daily in combination with A $1 \mathrm{mg}$ po daily on a 28 day cycle. A was started 2 weeks before $G$ to allow PK assessments of $G$ at a steady state plasma concentration of A. If 0 out of the first 18 patients experienced clinical benefit [complete response $(\mathrm{CR})$, partial response (PR) or stable disease (SD) more than 6 months], the enrollment was to be terminated.

Results: Fifteen patients were enrolled to date, median age 63 (range 47-74), and received a total of 40 courses (median 2) Thirteen patients $(86 \%$ ) had a performance status (PS) $0-1,2$ patients had PS 2. The tolerability was satisfactory: no grade 3-4 events were recorded. Grade 1-2 fatigue, acneiform rash, diarrhea, nausea and vomiting were the most common side-effects. No patient experienced clinical benefit as defined by protocol criteria Three patients had SD for 4-6 months. PK and PD data are currently being analyzed.

Discussion: The study showed the safety and tolerability of the combination of $\mathrm{G}$ and A. Enrollment is continuing, however the lack of robust anti-tumor activity will likely result in study termination after the first stage of accrual.

\section{8}

Oncologist-patient discussion of adjuvant hormonal therapy: results of a linguistic study focusing on patient adherence/persistence.

Davidson B, Vogel V, Wickerham L. MBS/Vox, Wayne, NJ; University of Pittsburgh School of Medicine, Pittsburgh, PA; NSABP, Pittsburgh, PA

Background: While studies have proven the benefit of 5+ years of adjuvant hormonal breast cancer therapy, data shows that longterm adherence/ persistence on this therapy is sub-optimal. An observational linguistic study analyzed communication between patients and their oncologists, to determine what areas of communication influenced adherence/persistence.

Methods: Invitation letters were mailed to $800+$ oncologists; 14 met the screening criteria and agreed to participate in this study. A researcher was sent to record patient-oncologist interactions and separate post-visit interviews. Twenty-eight postmenopausal, early-stage breast cancer patients on or initiating hormonal therapy were recorded during their scheduled visits. Time on therapy ranged from initiation discussion to 59 months.

Results: 1. Oncologist-patient discussions on hormonal therapy were good in general, but did not address adherence at all, even for patients initiating therapy. Persistence was discussed, but often in terms of a variable number of likely years on therapy; these discussions of persistence were almost always monologues, and framed in terms of an "emerging study data". 2. Discussions bore a resemblance to discussions of chronic management in preventive 
medicine (e.g., dyslipidemia and hypertension); because of the "routine" nature of these visits, much emotional intensity and urgency to treat were lacking compared to chemotherapy visits. 3. Minimal nurse interactions were observed, which differs from other oncology categories.

Discussion: The lack of discussion of benefits of adherence/ persistence, lack of emotional engagement, and the variable "framing" of time on therapy are seen as potential influences on persistence/adherence on hormonal therapy. Regardless of the causal role of these discussions in poor adherence, it is recommended that oncologists leverage the existing good communication with these patients by increasing the amount and quality of discussions around this topic to increase adherence/persistence.

\section{9}

\section{Novel DJ compounds cause reduction in human breast} tumors.

Parker-Johnson KA, Anderson D, Knowles B, Minnard E, Johnson DE. Dillard University, New Orleans, LA; West Jefferson Hospital, New Orleans, LA

Background: Although there are various FDA approved chemotherapeutic drugs used to treat metastatic breast cancer, some breast cancer cells become refractory to these agents and ultimately allow the heterogeneous tumor population to continue to rapidly proliferate. Therefore, there is always a need to develop novel antineoplastic agents that offer alternative mechanisms that target different cellular pathways in order to treat metastatic breast cancer. Previously, our laboratory synthesized a group of novel isochalcones called DJ Compounds that demonstrated significant in vitro antiproliferative activity against human metastatic breast cancer cell line models: Caucasian- MCF-7, T47D, and African American - HCC-70, HCC-1500, and MDAMB468. These compounds demonstrated significant epidermal growth factor receptor inhibitor (EGF-R) activity. Based on these results, we decided to test selected DJ Compounds in a nude mice model implanted with MCF-7 cells in order to evaluate whether these drugs possessed any significant in vivo antitumor activity. Materials and Methods: The in vitro protocol involved the plating of human metastatic breast cancer cell lines in a 96-well plate $(10,000)$. Cells were allowed to attach overnight. Cells were dosed for 48 hours at concentrations ranging from 1 micromolar to 1 nanomolar. Alamar blue dye exclusion method was used to determine the antiproliferative activity of DJ Compounds. Cell densities were measured with a microplate reader. The in vivo protocol involved the implantation of MCF-7 cells $(10,000,000)$ into the fat pad of athymic nude mice and tumors were allowed to develop over a 14-21 day period. Nude mice were divided into 4 groups: control, $10 \mathrm{mg} / \mathrm{kg}, 30 \mathrm{mg} / \mathrm{kg}$ and $100 \mathrm{mg} / \mathrm{kg}$. All animals were dosed IP daily with DJ56, DJ64, and DJ82. Tumors were measured every seven days with a caliper over a forty-two day period. Tumor volumes are represented by $\mathrm{mm}^{3}$.

Results: The in vitro data indicated that there was a concentrationdependent decrease in the growth of human metastatic breast cancer cell lines MCF-7, T47D, HCC-70, HCC-1500, and MDAMB-468; however, there was no change in percent growth in MDA-MB-231 by any of the tested compounds. In T47D cells, DJ52 was the most potent agent, while DJ82 was the most potent against MCF-7 cells. DJ53 was the most potent agent against HCC-1500, and both DJ52 and DJ53 were equally as potent in HCC-70. The in vivo results indicated that DJ56 $(30 \mathrm{mg} / \mathrm{kg})$ was the most potent agent against MCF-7 tumors by reducing tumor volumes by $80 \%$ over a 42 day period. DJ56 and DJ82 did not prove to significantly reduce tumor volumes over a 42 day period. Discussion: Previously, our laboratory used the in vitro pharmacological screening process to identify potential in vivo drug candidates. The selected DJ compounds show different affinities for various human breast cancer cell lines. We decided to use the three drug candidates: DJ56, DJ64, and DJ82 to test in an available nude mouse model that was implanted with MCF-7 tumorgenic cells. We found that the parent compound, DJ56, was least potent in the in vitro model, however, was the most potent in the in vivo model. DJ56, DJ64, and DJ82 were lethal at 100 $\mathrm{mg} / \mathrm{kg}$. Therefore, we identified a group of common derivatives that enabled us to identify a novel agent that showed significant antitumor activity against an estrogen-dependent human metastatic breast cancer model. However, it showed no significant antitumor activity against estrogen-independent human breast cancer cell model MDA-MB-231. These findings suggest that this group of novel DJ compounds could be potential antineoplastic agents for therapy against estrogen-dependent human metastatic breast cancers.

\section{0}

Supraclavicular failure in patients with 1 to 3 positive axillary lymph nodes treated with breast conserving surgery and breast irradiation, with or without supraclavicular node irradiation.

Kiel KD, Reddy SG. Northwestern Memorial Hospital, Chicago, IL

Background: Supraclavicular nodal failure (SCF) after breast conserving treatment may be early evidence of distant metastases (DM) or may eventually lead to distant DM, for the 5-year survival rates in the salvage of these patients is poor. If SCF leads to metastases with poor prognosis, prophylactic treatment in this area may be important for patients at high risk for failure. Although studies have shown a fewer regional node failures (RNFs) in patients with ${ }^{34}$ positive axillary nodes treated with regional node irradiation (RNI), RNI in patients with 1-3 positive nodes remains controversial. Various guidelines suggest that RNI be considered for selected patients. RNI increases the complexity of radiation treatment and may increase the risk of radiation complications. This study evaluated the need for RNI in patients with 1-3 positive nodes by evaluating the incidence of SCF in patents treated with breast conserving surgery and breast irradiation with or without supraclavicular node fields.

Materials and Methods: 224 patients with 1-3 positive axillary nodes, treated with breast conserving surgery and breast irradiation between August 1985 and May 2002 were identified. All patients underwent tumor excision and Level I/II axillary dissection. The median number of dissected axillary nodes was 14 (range 1-42). The breast was treated to a median dose of $45 \mathrm{~Gy}$ and in $91 \%$ a breast boost was delivered to a median of 16 Gy. 20 patients $(10 \%)$ received supraclavicular node fields to a median dose of $50 \mathrm{~Gy}$ : Either chemotherapy, generally an adriamycin-contained regimen, or hormonal therapy was delivered. The median followup was 57 months (range 0-193). SCF was reported as a recurrence in the ipsilateral supraclavicular lymph nodes with or without local recurrence and distant metastases. Crude rates for SCF were calculated.

Results: Four of $224(1.8 \%)$ patients failed in the ipsilateral supraclavicular lymph nodes. 0 of the 20 patients treated to the supraclavicular nodes failed and 4 of the $204(1.96 \%)$ not treated to the supraclavicular nodes failed. All patients with SCF had adequate axillary dissections. The median tumor size for all patients was $1.9 \mathrm{~cm}$ and, for the 4 patients with SCF, all were grade 3 with a median size of $3 \mathrm{~cm}$. In one patient with SCF, there was extensive mediastinal and contralateral node failure. All patients developed DM concurrently or rapidly after SCF.

Discussion: The low risk of SCF in patients with 1-3 positive nodes treated with breast radiation alone after breast conserving surgery suggests that the addition of RNI is unnecessary in this cohort. SCF appeared to be associated with concurrent or rapid development of distant metastases, suggesting that prophylactic treatment is futile in this low risk group. The complexity of radiation treatment and an increased risk of possible radiationrelated complications can be reduced without planned RNI. 
1121

Cyclopamine inhibits breast cancer cell growth via hedgehog network-dependent and independent mechanisms unrelated to cholesterol trafficking.

Zhang X, Harrington N, Moraes R, Lewis MT. Baylor College of Medicine, Houston, $T X$

The hedgehog signal transduction network is required for normal development of many organs and structures including skin, limbs, lung, eye, and nervous system, as well as the mammary gland. Altered hedgehog signaling is now implicated in the development of approximately $20-25 \%$ of all cancers, especially soft tissue cancers. Genetic evidence in mice coupled with more recent immunolocalization studies suggested that deregulated hedgehog signaling may contribute significantly to neoplastic progression in human breast cancers. If so, hedgehog signaling inhibitors may be useful for breast cancer treatment or prevention. We now find that cyclopamine, a potent inhibitor of hedgehog network signaling, inhibits anchorage-dependent and anchorage-independent growth of two ER-positive tumorigenic cell lines (MCF7 and BT474), and two ER-negative tumorigenic cell lines (MDA-MB231, SK-BR-3), while growth of two non-tumorigenic cell lines, MCF10A and MCF12A, was relatively unaffected. In anchoragedependent growth assays, modest growth inhibition by $10 \mu \mathrm{M}$ cyclopamine could be rescued by competition with $1 \mathrm{ng} / \mathrm{ml}$ recombinant SHH-N ligand. However, strong growth inhibition at $20 \mu \mathrm{M}$ cyclopamine could not be rescued by competition with any concentration of SHH-N tested. Both cyclopamine and tomatidine showed similar effects on cholesterol trafficking in both tumorigenic and non-tumorigenic cells at dosages below those required for strong growth inhibition, thereby excluding trafficking defects as a possible alternative mechanism for growth inhibition at higher doses. Our data suggest that cyclopamine does indeed inhibit hedgehog signaling in breast cancer cell lines, but that significant growth inhibition by cyclopamine may be largely independent of its effect on hedgehog signaling or cholesterol trafficking, thus implicating a possible "second target" for cyclopamine that is critical for tumorigenic, but not nontumorigenic, breast epithelial cell growth. 


\section{1}

Urinary metalloproteinases: a novel non-invasive methodology for breast cancer risk assessment.

Pories SE, Lamb CC, Roy R, Lotz MM, Zurakowski D, Raza S Wewer U, Scheib RG, Schumer S, Exarhopoulos A, Isakovich $N$, Louis GW, Anand A, Lenahan C, Kilroy S, Hirshfield-Bartek J, Borges V, Yee BH, Moses MA. Harvard Medical School: Beth Israel Deaconess Medical Center, Children's Hospital, Mount Auburn Hospital, Brigham and Women's Hospital, Dana Farber Harvard Cancer Center, Boston, MA

Background: Matrix metalloproteinases (MMPs) have been implicated in mechanisms of tumor growth, progression and metastasis, in several experimental cancer models and in human malignancies. We have previously reported that MMPs can be detected in the urine of breast cancer patients and that their presence is an independent predictor of disease status. We have also demonstrated that urinary ADAM 12 (a disintegrin and metalloprotease) significantly increases with disease progression in breast cancer patients. In the current study, we have addressed a key question: Can urinary MMP and ADAM 12 analysis provide valuable clinical information regarding the risk of developing breast cancer?

Material and Methods: To answer this question, we have analyzed urine samples from women with biopsy-proven marker lesions that indicate an increased risk of developing invasive breast cancer. Urine samples were obtained from 151 women: 45 women with Atypical Lobular Hyperplasia (ALH) or Atypical Ductal Hyperplasia (ADH), 25 women with Lobular Carcinoma in Situ (LCIS) and 81 age-matched healthy controls. Thirty microliters of each urine sample was analyzed by substrate gel electrophoresis (zymography) using gelatin as the substrate. MMP identity and ADAM 12 expression was verified by immunoblot analyses using monospecific antibodies. Band intensities were analyzed with UNSCAN-ITTM(Silk Scientific, Orem, UT) software digitizer technology.

Results: We used logistic regression to analyze the utility of ADAM 12 and MMPs for breast cancer risk assessment. This revealed that MMP-9 and ADAM 12 were independent predictors of both LCIS (both $\mathrm{p}<0.001$ ) and ADH-ALH (MMP-9, $\mathrm{p}=0.004$; ADAM 12, $\mathrm{p}<0.001)$. Maximum likelihood estimation was used to obtain probability of LCIS or ADH-ALH for the various possible test results: a positive urinary MMP-9 and ADAM 12 is associated with a probability of LCIS or Atypia of 100\%, negative for MMP9 and positive for ADAM 12, a probability of LCIS or Atypia of 50\%-67\%, positive for MMP-9 and negative for ADAM 12, a probability of LCIS or Atypia of $25-40 \%$, and negative for both MMP-9 and ADAM 12, a probability of LCIS or Atypia of $0 \%$. Discussion: Our results suggest that the detection of urinary MMP 9 and ADAM 12 provides useful clinical information regarding breast cancer risk assessment. Analysis of urinary MMP 9 and ADAM 12 may offer a novel non-invasive approach for identifying women at increased risk of developing breast cancer. (Supported by NIH PO1CA45548 to M.A.M., Harvard Center for Excellence in Women's Health, Global Medical Products, The Fortin Foundation, The Advanced Medical Foundation and AstraZeneca.)

\section{2}

Circulating tumor marker discovery using proteolytic peptide profiling and isotope-coded affinity tags.

Esteva FJ, Zhang B, Hawke D, Zhao H, Baggerly K, Koomen J, Hortobagyi GN, Kobayashi R. UT M. D. Anderson Cancer Center, Houston, TX; Proteomics Facility

Serum protein profiling using mass spectrometry is a promising approach to identify novel circulating breast cancer markers. One of the major problems to uncover lower abundance protein markers in the serum is that they are frequently masked by large, abundant proteins such as albumin and immunoglobulins among others.
Methods: Serum samples from healthy women and breast cancer patients were enriched for potential biomarkers using two different methods. First, immobilized lectins Concanavalin A (Con A) and Wheat Germ Agglutinin (WGA) (Sigma) were used to enrich for glycoproteins. Breast cancer and control pools were derivatized with either heavy or light cleavable-ICAT reagent (Applied Biosystems), combined and separated by SDS-PAGE. The entire gel was excised, digested with trypsin, affinity purified, the handle cleaved off and analyzed by nano-LC-MS/MS (LC-Packings nanoLC and Qstar). Data was analyzed with Pro-ICAT (Applied Biosystems), iTRAQ (Applied Biosystems) and other search tools such as Mascot. Second, we enriched 30 serum samples from healthy women and breast cancer patients using antibody columns (Seppro and Agilent). Each depleted fraction was digested with trypsin and subsequently analyzed by LC-MS. Rather than using bioinformatic analysis as a pattern-matching technique, peptides were targeted based on the disease to control peak intensity ratios measured in the averages of all mass spectra in each group and t-tests of the intensity of each individual peak. A series of preprocessing steps were employed to produce an expansive list of peptides for further investigation and sequencing. Results: Using Con A selection followed by ICAT analysis, 43 serum proteins with a variety of functions were identified. Among those, 6 proteins appeared differently expressed by $>1$ standard deviation of the median. Haptoglobin was up-regulated in serum from breast cancer patients, as previously reported using other methods. Con A and WGA showed different binding specificity for glycoproteins. By applying Con A and WGA sequentially, 71 proteins were identified. Comparison of ICAT with iTRAQ data is ongoing. The Seppro and Agilent antibody columns removed 12 of the most abundant proteins in serum, including albumin, IgG, Fibrinogen, Transferrin, IgA, IgM, a1-Antitrypsin, Haptoglobin, a1-Acid Glycoprotein, a2-Macroglobulin and HDL (Apolipoproteins A-I and A-II). Using LC-MS and bioinformatic analysis we found 12 differentially expressed peaks in the Cancer vs. Healthy groups. Efforts are ongoing to identify targeted peptide ion signals using tandem matrix-assisted laser desorption/ionization mass spectrometry (MALDI-MS/MS). Conclusions: Serum fractionation using specific antibody columns followed by LC-MS and bioinformatic analysis is a feasible approach to peptide profiling in healthy women and breast cancer patients.

\section{3}

The relationship between circulating concentrations of Her-2, C-reactive protein and survival in patients with primary operable breast cancer.

Henley NC, Macmillan DC, Doran C, Burns HJG, George WD, Bartlett JM, Cooke TG. University of Glasgow, Glasgow, United Kingdom; Greater Glasgow NHS Board, Glasgow, United Kingdom

Background: Prediction of recurrence and survival following potentially curative resection of primary operable breast cancer remains problematic. Conventionally, prediction of outcome has been based on pathological examination of the tumour. Recently, a number of circulating factors have been suggested to improve prediction of outcome. The aim of the present study was to examine the prognostic value of serum concentrations of HER-2/neu and C-reactive protein in patients with primary operable breast cancer. Patients and Methods: One hundred and seventy nine patients presenting with invasive primary operable breast cancer to two hospitals (Royal and Western Infirmaries, Glasgow) in the West of Scotland between October 2000- January 2002 were included in the study. Prior to surgery, a blood sample was obtained for the measurement of HER-2/neu and C-reactive protein concentrations. Clinical data including age, tumour size, histological grade, oestrogen receptor status and lymph node status were recorded. Grade, tumour size and lymph node status were combined and expressed as the Nottingham Prognostic Index (NPI). Patients were followed-up until 31 ${ }^{\text {st }}$ December 2004.

Results: The median follow-up was 46 months. During this period, 25 patients died. On univariate analysis, NPI $(\mathrm{p}<0.001)$, oestrogen 
receptor status $(\mathrm{p}=0.009)$, HER-2/neu $(\mathrm{p}<0.001)$, C-reactive protein $(\mathrm{p}=0.019)$ were predictors of overall survival. On multivariate analysis, NPI coded (good/ intermediate/ poor, HR 7.07, 95\% CI 3.21-15.56, p<0.001), HER-2/neu $(<13 />13 \mathrm{ug} / 1$, HR 3.35, 95\% CI 1.42-7.89, $\mathrm{p}=0.006)$ and C-reactive protein $(\leq 10 />10 \mathrm{mg} / 1$, HR 5.67, 95\%CI 2.03-15.79, $\mathrm{p}<0.001)$ remained independent predictors of overall survival.

Discussion: The results of the present study indicate that elevated serum HER-2/neu and C-reactive protein concentrations, predict survival independent of the NPI. Further evaluation of these parameters in the pre-operative assessment of patients with primary operable breast cancer is warranted.

\section{4}

Evaluation of immunoassay and RT-PCR methods for detection of the NMP66 complex for diagnosis of breast cancer.

Stoerker J, Lueftner D, Szaro R, Fagan G, Domurad M. Matritech, Inc., Newton, MA; Charite Hospital, Berlin, Germany

Background: We investigated the performance of two methods of detecting NMP66, a nuclear matrix protein complex, in discriminating between serum from women with and without breast cancer in a cohort of 298 prospectively collected, blinded samples. Materials and Methods: The NMP66 nuclear matrix protein complex has been demonstrated to be present in the sera of breast cancer patients and absent from the sera of women with no evidence of breast disease (Exp. Rev. Mol. Diag. 2:23, 2002). A Signature protein of the complex was first isolated on a nickel affinity surface and identified by time of flight mass spectrometry using a SELDI-TOF instrument (Ciphergen Corp., Inc.). Subsequently, a prototype two-site colorimetric sandwich immunoassay for the identified protein was developed and a qualitative reverse transcriptase-polymerase chain reaction (RT-PCR) assay was constructed using probes specific for unique nucleic acid sequences found within the NMP66 complex (Development of a blood based immunoassay to detect the NMP66 breast cancer associated nuclear matrix protein, 4th European Conference: Perspectives in Breast Cancer, Seville, Spain, 2004). The current investigation evaluated the performance of these methods in discriminating between samples from patients with and without breast cancer.

Pre-biopsy blood samples were prospectively collected from 208 women who had suspicious mammograms and/or palpable breast lesions. Subsequent pathological examination determined that 55 had cancer (15 DCIS, 6 LCIS, 3 invasive lobular, 26 T1, 3 T2, $1 \mathrm{~T} 3,1 \mathrm{~T} 4)$ and 153 had benign breast conditions. Fifteen samples collected from women with metastatic breast cancer and 75 from women who had no evidence of breast disease on two sequential mammograms in two years were added to the cohort. All samples $(\mathrm{N}=298)$ were blinded by a third party and tested using both methods for detection of NMP66.

Results: The qualitative RT-PCR correctly identified over $70 \%$ of the cancer samples, and the colorimetric immunoassay demonstrated good differentiation of noncancer samples, ruling out $80 \%$ of those from patients with benign breast disease or no evidence of disease. There was a $67 \%$ greater likelihood of cancer being present when the test was positive compared to cancer being present when the test was negative among patients who had clinical or biopsy confirmation of breast disease (RR 1.67). This effect was even greater for postmenopausal women, among whom there was a $75 \%$ greater likelihood of cancer being present upon pathological confirmation when the immunoassay result was positive (RR 1.75).

Discussion: These preliminary results suggest that measurement of the NMP66 protein and associated complexes or products could provide utility in diagnosis of patients with a cost-effective blood-based method. Additional investigations and data are being compiled.

\section{5}

Increased levels of the circulating growth factor GP88 in the serum of breast cancer patients.

Serrero G, Tkaczuk KH, Golubeva O, Jones L, Tait N, Feldman FS, Dai H. A\&G Pharmaceutical Inc., Columbia, MD; University of Maryland, Baltimore, MD

The identification of a measurable biomarker that is a therapeutic target of malignant transformation or malignant progression of breast carcinoma (BC) will provide new approaches for the development of novel breast cancer therapies with their companion diagnostics. The $88 \mathrm{kDa}$ autocrine growth factor named PC-Cell Derived Growth Factor (PCDGF) or G88 plays a critical role in breast cancer and may have such potential. GP88 is expressed in human BC tumors in a positive correlation with their tumorigenicity. In estrogen receptor positive $\left(\mathrm{ER}^{+}\right)$cells, $\mathrm{PCDGF} /$ GP88 expression is low and is stimulated by estradiol whereas in ER negative cells, it is constitutively overexpressed. In $\mathrm{ER}^{+}$cells, GP88 mediates estrogen mitogenic activity and its overexpression renders cells estrogen-independent and tamoxifen-resistant. Inhibition of GP88 expression by antisense transfection leads to inhibition of breast tumor incidence and growth in nude mice. GP88 is expressed in $80 \%$ of human invasive ductal carcinomas and correlates with expression of markers of poor prognosis whereas normal tissues and benign breast lesions are negative. The objective of the present pilot clinical study was to investigate whether the level of GP88 was elevated in the serum of breast cancer patients when compared to healthy volunteers. For this purpose, a blood sampling study was conducted to measure the GP88 serum level by quantitative enzyme immunoassay in healthy volunteers (HV) and breast cancer patients (BC pts). One hundred twenty three subjects including $16 \mathrm{HV}$ and $107 \mathrm{BC}$ pts were accrued. The BC patient characteristics were the following: Race: Caucasian51, African American-51, Asian-5, median age, 52.5 (range 2984), stage I - 25, II - 29, III - 12, IV - 41. Circulating GP88 was measurable in the serum of $\mathrm{HV}$ and $\mathrm{BC}$ pts. Comparison between the two groups of subjects indicated that GP88 level was significantly higher in the sera of BC pts. Median level of baseline GP88 was $32.8 \mathrm{ng} / \mathrm{ml}$ (range 23.8-42.8) in $\mathrm{HV}$ and $44.4 \mathrm{ng} / \mathrm{ml}$ (range 23-158.4) in BC pts, $(\mathrm{p}-$ value $=0.004)$. In addition, longitudinal study of stage IV patients provided evidence of increased GP88 level in stage IV patients with a progressive disease. Future studies will investigate the correlation between GP88 level with BC prognostic factors such as stage, tumor size, tumor grade, lymph node status, and expression of ER and HER-2 as well as survival of breast cancer patients.

\section{6}

Circulating tumor cells in adjuvant breast cancer patients. Almokadem S, Leitzel K, Harvey HA, Bannon E, Ali SM, Miller $M C$, Repollet M, Terstapenn LWWM, Doyle GV, Frazier T, Lipton A. Pennsylvania State College of Medicinel Hershey Medical Center, Hershey, PA; Immunicon Corporation, Huntington Valley, PA; Bryn Mawr Hospital, Bryn Mawr, PA

Background: One of the first steps in metastasis is the ability of primary breast cancer cells to detach and invade the circulation. The presence of $>5$ circulating tumor cells (CTCs) in $7.5 \mathrm{~mL}$ of blood from metastatic breast cancer patients predicts shorter progression-free and overall survival (M Christofanilli et al NEJM 351:781-791, 2004). The purpose of our study was to determine if CTCs were present in the blood of patients who had recently completed adjuvant chemotherapy.

Methods: 51 patients were accrued within 12 months of completing adjuvant chemotherapy, none of whom had evidence of recurrence by imaging. Patients characteristics: 17 (33\%) patients were stage I, $26(51 \%)$ stage II, and $8(16 \%)$ stage III. In addition, $8(16 \%)$ patients were Her $2 /$ neu $3+$ by IHC. CTCs were immunomagnetically separated and fluorescently stained using the CellSearch ${ }^{\mathrm{TM}}$ Kit. Cells were classified using the CellSpotter® 
Analyzer as CTCs if they stained positive for DAPI (nuclear dye), and cytokeratin 8, 18 and/or 19, and if they stained negative for the leukocyte-specific antibody CD45.

Results: In a control group of 145 healthy females, $8(5.5 \%)$ had 1 CTC / 7.5mL blood. In 199 patients with benign breast diseases, $14(7.0 \%)$ had $1 \mathrm{CTC} / 7.5 \mathrm{~mL}$, and only $1(0.5 \%)$ had $3 \mathrm{CTCs} / 7.5$ $\mathrm{mL}$ detected in their blood. 8 patients out of 51 patients in the study group $(16 \%)$ had $\geq 1 \mathrm{CTC} / 7.5 \mathrm{~mL}$ (five patients has $1 \mathrm{CTC}$ in one tube, two patients had $2 \mathrm{CTC}$ in one tube, and the eighth patient had one CTC in three tubes). Of the 8 patients with CTCs, 2 were stage I (12\%), 4 stage II (15\%), and 2 stage III $(25 \%)$. Additionally, $2(25 \%)$ were Her $2 /$ neu $3+$ by IHC in the primary tumor. In summary, CTC were detected in $8 / 51(16 \%)$ adjuvant breast cancer patients, $8 / 145(5.5 \%)$ healthy control, and 15/199 $(7.5 \%)$ in benign breast diseases patients. There were statistically significant differences in the proportion of CTCs between these groups (Fisher's exact test $\mathrm{p} \geq 0.0346$ breast cancer vs healthy control; $\mathrm{p} \geq 0.0993$ breast cancer vs benign diseases group; and $\mathrm{p} \geq 0.0404$ breast cancer group vs both control groups)

Conclusions: CTCs were detected in $16 \%$ of breast cancer patients who recently completed adjuvant chemotherapy; this finding was statistically significant in comparison with the healthy control group. Patient accrual and follow-up in this study continues to determine if the presence of elevated CTCs is associated with early recurrence of the disease.

\section{7}

Methylated genes in ductal lavage fluid from women with known breast cancer undergoing mastectomy.

Fackler MJ, Malone K, Schilling E, Swift-Scanlon T, Nayar R, Sukumar S, Khan SA. Feinberg School of Medicien of Northwestern University, Chicago, IL; Feinberg School of Medicine of Northwestern University, Chicago, IL; Johns Hopkins University School of Medicine, Baltimore, $M D$

Background: The imperfect performance of screening mammography, particularly in young women, has led to a new generation of tests. These include ductal lavage (DL), one of the anticipated uses of which is the early detection of breast cancer by cytological analysis of DL samples. We have recently shown that the sensitivity of ductal lavage to detect malignancy in women with known breast cancer undergoing mastectomy was $43 \%$ (Khan SA JNCI 2004). This low sensitivity was partially explained by benign or mildly atypical cytology from cancer containing ducts. We hypothesized that evaluation of gene promoter hypermethylation markers in DL cells would provide improved sensitivity and accuracy over cytology alone. Methods: We used the quantitative multiplex-MSP (QM-MSP) technique (Fackler MJ Cancer Res. 2004) to co-amplify 9 genes (RASSF1A, Twist, Cyclin D2, HIN-1, Retinoic acid receptor- $\beta$ (RAR $\beta$ ), APC1, BRCA1, BRCA2 and p16) in 37 Papanicoloaou stained cytology samples from both cancer $(n=27)$ and non-cancer $(n=3)$ containing breasts sent blinded to the Johns Hopkins labs. We examined the association between cumulative gene promoter methylation, duct histopathology and lavage cytology in matched samples. Sixty samples derived from routine DL of apparently normal high risk women $(n=34)$ were evaluated to establish baseline levels of methyation for each gene in women without cancer. Results: 37 ducts from 30 breasts were evaluated (30 lavaged ducts with matching cytological, histological and methylation data and 7 ducts with methylation and cytology, but no histopathology data). We found significantly higher levels of cumulative methylation in DL cells from women undergoing mastectomy than for normal high risk women (mean 34.6 vs $0.9, \mathrm{p}=.0004$ ). Based on $\sim 90^{\text {th }}$ percentile of control, an upper threshold for normal was established ( $<2.0$ units). By this criterion, 51\% (19 of 37) of the mastectomy group were positive for methylation. All 8 of 8 of samples with malignant or markedly atypical cytology were strongly positive for QM-MSP, (mean 116 units). Among histologically positive ducts QM-MSP identified 63\% (12 of 19) compared to $31.5 \%$ (6 of 19) identified by cytological evaluation alone $(\mathrm{p}=.0017)$. Successful cannulation of cancer bearing ducts was achieved in $63 \%$ (17 of 27) breasts. Among these, abnormalities were detected in $82 \%$ (14 of 17) of breasts by QM-MSP versus 35\% (6 of 17) by cytology only. Conclusions: Compared to cytology, QM-MSP more than doubled the rate of detection of malignancy in DL samples from cancer-containing breasts, and is being tested in other scenarios of breast cancer diagnosis and risk assessment.

\section{8}

Glycan array identifies specific signatures of anti-glycan autoantibodies in sera of breast cancer patients: diagnostic, prognostic and therapeutic opportunities.

Huflejt ME, Blixt O, Vuskovic M, Xu H, Shaw LE, Reuben JM, Kuerer HM, Cristofanilli M. Glycomedical Research Institute, La Jolla, CA; The Scripps Research Institute, Consortium for Functional Glycomics, La Jolla, CA; San Diego State University, San Diego, CA; UT M.D. Anderson Cancer Center, Houston, TX

Background: Malignant transformation and tumor progression are associated with the specific changes in the complex surface carbohydrates, known as Tumor-Associated Carbohydrate Antigens (TACAs). However, very little is known about immune response against these abnormal glycans. A robust glycan array containing many known TACAs and related glycans has been recently developed and validated. We tested the hypothesis that this technology can identify anti-glycan autoantibodies in sera of patients with metastatic (MBC) and primary breast cancers (PBC) and we speculated that specific autoantibody profiles may be associated with early disease status or otherwise have prognostic implications.

Methods: A total of 57 serum samples from MBC (48\%), PBC $(26 \%)$ and healthy donors $(26 \%)$ were analyzed. Glycan array slides were incubated with sera diluted with $\mathrm{PBS} / 3 \% \mathrm{BSA}$, then with biotinylated goat antibody against human $\operatorname{IgG}, \operatorname{IgM}$ and $\operatorname{IgA}$, and with streptavidin-Alexa 488. The intensity of fluorescence in spots corresponding to the antibodies bound to the individual glycans was quantified with ImaGene image analysis software and data were plotted using MS Excel software.

Computational data evaluation: The univariate t-test and multivariate Hotelling's test were used to establish the significance in differences in anti-glycan autoantibody levels between "healthy controls" and breast cancer serum samples. To visualize data clustering, the Fisher-Rao projections, as well as projections based on support vector machines (SVM) were used.

Results and Discussion: Breast cancer is associated with significantly higher levels of several autoantibodies against glycans including $\mathrm{N}$-acetyllactosamines (LacNAc), fucosylated, and Core2 glycans. Autoantibodies against 6-sulfo lactose, sialylated poly LacNAcs and O-linked T-antigen show most significantly increased levels in MBC as compared to PBC and healthy individuals. Our studies demonstrate that the printed glycan array is a sensitive and promising tool for the development of clinical serum-based screening tests for early detection and evaluation of malignancy status in breast cancer. The unique method for defining clusters of circulating anti-glycan autoantibodies may lead to identification of specific TACAs as potential targets for the development of anti-cancer therapeutics.

\section{9}

Serum profiling predictive of invasive breast cancer. Mansfield BC, Shriver CD, Yip PF, Coleman TA, Hitt BA, Hooke $J A$, Liebman M, Somiari S, Flynn J. Correlogic Systems Inc., Bethesda, MD; Walter Reed Army Medical Center, Washington, DC; Windber Research Institute, Windber, PA; Landstuhl Regional Medical Center, Landstuhl, Germany

Background: Serum profiling may detect malignant disease, but no single circulating biomarker exists for breast cancer. Our interest is the identification of multiple markers that, taken together, 
indicate the presence of disease. Using nanospray mass spectrometry we are analyzing the spectral profiles of serum for coordinated changes that may be predictive of disease.

Materials and Methods: We have established an on-going multisite collection protocol for serum collected from women attending the Clinical Breast Care Project. Sera are collected prior to biopsy, processed promptly by a standard protocol, and classified by retrospective tissue biopsy pathology. The collection currently consists of 793 samples, 365 from women diagnosed with cancer and 428 representing normal-benign breast tissue. Conditions represented include: 97 in situ, 268 invasive (stages 1-4), 31 no breast disease; 238 benign non-neoplastic; 130 benign neoplastic; and 29 atypical ductal hyperplasia. Sera are analyzed on an ABI QSTAR time-of-flight mass spectrometer equipped with an Advion Nanomate ${ }^{\circledR}$ System. Spectra obtained are used to build models using the Correlogic Systems Inc. ProteomeQuest ${ }^{\circledR}$ software which combines multi-dimensional lead cluster mapping with a genetic algorithm to identify patterns predictive of disease status. In all experiments we hold out an independent set of spectra files as a blinded validation set, to emulate a clinical setting.

Results: Our initial focus is to model invasive serum profiles against normal-benign conditions. To date we have acquired spectra on 371 invasive and 234 normal-benign sera. A number of multifeature models have been created which demonstrate sensitivities and specificities in the range of $80-90 \%$ on the blinded validation set. One region of the spectrum, about $\mathrm{m} / \mathrm{z} 537$, appears particularly powerful in discriminating between invasive cancer and nonmalignant conditions. However, alone, neither this, nor any other region, is sufficiently informative. When the coordinated changes in the relative levels of multiple features in the serum are combined in models, the serum profiles are highly predictive of disease. One model, combining 10 features yielded $98.5 \%$ specificity and $90.3 \%$ sensitivity on a testing set of 196 non-malignant sera and 103 invasive sera, which dropped to $94.4 \%$ specificity (95\% CI 83.7 $98.6 \%$ ) and $80.5 \%$ sensitivity (95\% CI $64.6-90.6 \%)$ on a truly blinded validation set of 54 non-malignant and 41 invasive sera. Discussion: Profiling the changes in the relative levels of multiple features in the serum, using this technology and algorithm, is reasonably accurate in classifying women with invasive breast cancer from normal and benign conditions prior to undergoing biopsy.

\section{0}

Patient detected breast cancer not seen on mammography. Kaplan HG, Malmgren JA, Atwood MK. Swedish Cancer Institute, Swedish Medical Center, Seattle, WA; HealthSTAT Consulting, Inc., Seattle, WA; University of Washington, Seattle, WA

Background: Most estimates of mammography sensitivity are derived from screening studies using interval cancers as the false negative portion of the equation. An alternative method is to review charts of patient detected breast cancer patients and calculate the number seen on mammography when mammography is done at the time of diagnosis.

Materials and methods: We conducted a cohort study of women age 21-94 diagnosed with primary invasive breast cancer Stage IIV from 1989-1999 tracked by the institutions' breast cancer registry. Patient age, race, method of detection, tumor size, histologic type, biopsy and mammography results at the time of diagnosis were ascertained from chart review and included patient (PtD), clinician or mammography detected method, and seen, not seen, not done $(2.6 \%)$ or unknown $(8.4 \%)$ for mammography. All PtD tumors were confirmed by biopsy $(n=1291)$. The Swedish Two County Program tumor size groupings were used to compare size by seen/not seen on mammography.

Results: $88.9 \%$ of the PtD breast cancer cases had mammograms done post presentation $(n=1148)$. Of these PtD cancers, 26\% were $2.0-2.9 \mathrm{~cm}, 77 \%$ were ductal histologic type, $32 \%$ were 40 49 years of age, $88 \%$ were white, and $34 \%$ were Stage I. $75 \%$ were seen on mammography, and $25 \%$ were not. There was no difference by age, race, or stage between cancers seen and not seen on mammography. Tumor size of breast cancers not seen were more often less than $1.5 \mathrm{~cm}, 36 \%$ vs. $21 \%$, and greater than $5 \mathrm{~cm}, 17 \%$ vs. $13 \%($ Chi square $=35.56, p<.001)($ table $)$. By histological type, $\mathrm{PtD}$ breast cancer not seen on mammography were more often lobular (16\% vs. 9\%) and less often ductal (70\% vs. $80 \%$ ) $($ Chi square $=27.91, \mathrm{p}=.03)$.

Discussion: Our finding of $75 \%$ sensitivity for tumors visible on mammography in biopsy positive patient detected breast cancer is similar to published estimates of mammography sensitivity using interval cancers as false negatives. In PtD breast cancer, younger and older women had the same percentage of tumors not seen on mammography. While mammography is a useful screening tool, it will not diagnose a significant percentage of breast cancers, regardless of size and histologic type. From our findings, complete reliance on mammography for breast cancer detection is not warranted and manual methods should be retained as an integral part of breast health programs.

Supported by the Kaplan Cancer Research Fund

Tumor size in $\mathrm{cm}$ categories by mammography results $(\mathrm{n}=1131)$

Seen Not Seen

$\mathrm{N}$ (column \%) $\quad \mathrm{N}$ (column \%) Chi square

$<1.5 \mathrm{~cm} \quad 176(20.7 \%) \quad 101(35.8 \%)$

$1.5-1.9 \mathrm{~cm} \quad 165(19.4 \%) \quad 42(14.9 \%)$

$\begin{array}{lll}2.0-2.9 \mathrm{~cm} & 238(28.0 \%) & 62(22.0 \%)\end{array}$

$3.0-4.9 \mathrm{~cm} \quad 160(18.8 \%) \quad 30(10.6 \%)$

$47(16.7 \%)$

$\begin{array}{ll}\text { Chi square } & \mathrm{p} \text { value } \\ 35.56 & <.001\end{array}$

$849(75.1 \%)$

$282(24.9 \%)$

\section{1}

Serum proteome of breast cancer: a group of proteins related to the invasive stage.

$R u$ Q, Zhu L, Silberman J, Jacobs N, Shriver D. Windber Research Institute, Windber, PA; Breast Cancer Care Center, Walter Reed Army Medical Center, Washington, DC

Background: Proteomic research and technology has recently undergone dramatic improvements. More and more physicians have realized that proteomics may revolutionize cancer diagnostics and elucidate oncopathologies. The latest proteomic tool, multidimensional protein identification technology (MudPIT), is an effective alternative to two-dimensional gel electrophoresis (2-D gel) because it provides high-throughput analyses, good reproducibility, and effective characterization of small metabolic byproducts.

Methods: One hundred human serum specimens from breast cancer patients (23 invasive, 14 atypical, and 41 benign) and normal control (22) were analyzed via an optimized MudPIT method. Only 10 microliters of raw plasma were needed. Every sample was run three times to test reproducibility and to maximize identification. The Thermo Finnigan ProteomeX workstation was used for MudPIT analyses, and the Thermo Finnigan Bioworks Browser 3.1 SR1 and IPI human protein database version 06.23.04 were used to complete a Turbo Sequest search. Protein data was analyzed with Microsoft Excel.

Results: Five hundred twenty-six proteins were identified from 100 human serum specimens. It was also found that 24 proteins were identified in 78 breast cancer patients, but not in 22 normal samples. This group includes a subset of four proteins that is found in approximately $50 \%$ of invasive samples, but in about $5 \%$ of benign samples. When the four proteins are combined as one target, the detection frequency in invasive samples increases to $87 \%$, while that of benign and normal samples is approximately $11 \%$ (Table 1)

Discussion: Unlike traditional protein chemistry, which investigates specific proteins, protoemics may reveal groups of proteins related to cancer. Preliminary investigations identified a group of four proteins that is highly related to invasive stage breast cancer, and that is not detected in control samples. Results of a large-scale validation will be reported. 


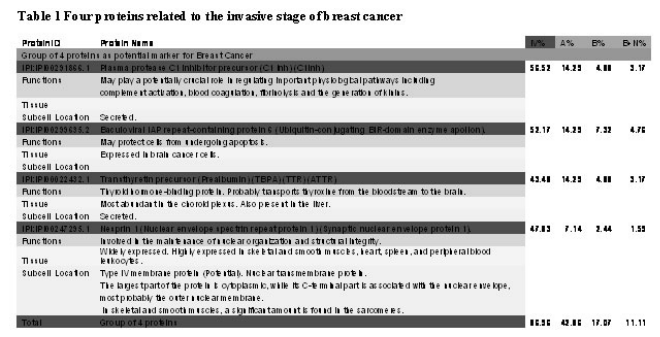

\section{2}

Ductal epithelial impedance spectroscopy; a new approach to breast cancer diagnosis.

Davies RJ, Davisson TH. Hackensack Univ. Medical Center, Hackensack, NJ

Background: Breast cancer develops within the ductal or lobular epithelium of the breast. Functional changes occur in transgenic models of breast cancer, and we have previously demonstrated that a down-regulation of specific ionic conductances occurs in human breast epithelia during breast cancer development. Although electrical impedance scanning, or tomography, have been used to image mass lesions within the breast, epithelial impedance spectroscopy has not been utilized to diagnose cancer in the epithelium, where breast cancer originates. We have therefore developed an "Electronic Biopsy" to non-invasively identify breast cancer in the epithelium.

Patients and Methods: With IRB and patient consent, electrical contact with ductal epithelium was established non-invasively, using a specially designed nipple sensor in 26 women scheduled for breast biopsy. Transepithelial impedance measurements were obtained over a frequency range of $0.1-60 \mathrm{~K} \mathrm{~Hz}$ and processed using a frequency response analyzer and sine-wave correlation technique. Data were analyzed using a t-test, Mann-Whitney test, or ANOVA as appropriate.

Results: In patients with malignant or pre-malignant lesions (MAL, $\mathrm{n}=10$ ), on subsequent biopsy, the transepithelial resistance of the ductal system was $78.4 \pm 38.3 \mathrm{KW}$ (mean \pm SEM) compared with $25.1 \pm 5.3 \mathrm{KW}$ in benign lesions $(\mathrm{BEN}, \mathrm{n}=16),(\mathrm{p}=\mathrm{ns})$ at higher frequencies. At lower frequencies the transepithelial resistance progressively increases to $442.4 \pm 225.5 \mathrm{KW}$ in the MAL group compared with $157.1 \pm 37.1 \mathrm{KW}(\mathrm{p}=0.037)$ in the BEN group. In the 6 patients in the BEN group with ADH or hyperplasia the change in epithelial resistance at low frequencies was intermediate between true benign lesions $(n=10)$ and malignant ones $(\mathrm{p}=0.045)$.

Discussion: This preliminary study demonstrates that changes in ductal epithelial impedance identifies patients with proliferative or malignant breast disease. Although malignant tumors have been reported to have lower impedances than benign ones, the ductal epithelial elements have a higher impedance, which may be related to alterations in secretory or absorptive function of the epithelium during carcinogenesis.

\section{3}

New biomarkers in the detection of breast cancer in nipple aspirate flui (NAF), using surface enhanced laser/ desorption ionisation coupled with time-of-flight mass spectrometry (SELDI-TOF/ MS) in combination with artificial intelligence methods.

Dua RS, Noble JL, Locke I, Coulton GR, Eeles R, Isacke CM, Gui GPH. Royal Marsden Hospital, London, United Kingdom; Breakthrough Breast Cancer Research Centre, Institute of Cancer Research, London, United Kingdom; St George's University of London, London, United Kingdom

Background

The proteomic analysis of nipple aspirate fluid holds great promise in early cancer detection. In order to evaluate the feasibility of this technique, we collected paired samples from women undergoing surgery at the Royal Marsden Hospital, London. SELDI-TOF/MS was used to evaluate the following: (1) the consistency and reproducibility of proteomic data, (2) to define specific phenotypic subgroups within the sample population. Pathologic variables studied included axillary node nodal status, pathologic primary tumour grade, the extent of association with pre-invasive disease, tumour size and hormonal receptor status.

Methods

An ethics protocol was approved by the Royal Marsden Hospital Ethics committee, and all patients undergoing surgery for unilateral breast cancer were recruited, subject to inclusion criteria. Nipple aspiration was performed on both breasts, prior to surgery, using the healthy contralteral breast as an internal control. A pilot study of 50 subjects was performed to evaluate cytologic analysis from the cancer bearing breast, followed by a proteomic comparison of cancer-bearing versus healthy control NAF employing surface enhanced laser desorption coupled with timeof-flight mass spectrometry (SELDI-TOF). Following normalisation of protein concentration and denaturation, samples were applied in duplicate to two different surfaces: a weak cation exchange (CM10) and an immoboilised metal chromatography (IMAC30) surface.

Results

The resulting spectra were normalised, and based on the normalisation co-efficient, outliers excluded. Non-parametric univariate analysis uncovered 5 proteins that successfully discriminated cancer-associated NAF from the healthy controls (7312 Da, 19943 Da, 3103 Da, 4115 Da, $4237 \mathrm{Da}) ; \mathrm{p}<0.05$ peaks of interest were subjected to further analysis using multivariate analyses incorporating (i) decision trees, (ii) artificial neural networks and (iii) genetic algorithms to investigate whether a cancer protein pattern could be derived from these individual components. In the second part of the study, looking at standard pathological variables, a protein at 11,210 daltons discriminated between cancer-associated NAF and pathological nipple discharge $(\mathrm{p}=0.00009)$, and a protein at $7,312 \mathrm{Da}$ was expressed at significantly higher levels in node-positive patients $(\mathrm{p}=0.0028)$ Conclusion

Using SELDI-TOF/ MS in combination with sophisticated artificial intelligence, we have discovered new biomarkers that may hold promise in the diagnosis of breast cancer.

\section{4}

Concurrence of contralateral breast cancers for estrogen and progesterone receptor status and mode of detection.

Martin CV, Sahasrabudhe N, Bundred NJ, Barr L, Byrne G, Baildam AD. South Manchester University Hospital, Manchester, United Kingdom

Background:Mammographic surveillance is performed routinely in the follow-up of primary breast cancer and contralateral tumours are not uncommon, affecting between $5-10 \%$ of patients with breast cancer.The aim of this study was to determine if the mode of detection of the first cancer (screen detected SDBC vs 
symptomatic) predicted the presentation of the contralateral tumour and if there was correlation of prognostic factors between the two cancers.

Materials and Methods:We studied 249 patients diagnosed with contralateral breast cancer between 1975 and 2004 in a single breast unit, for whom reliable data was available. Data was extracted from case notes, supplemented by review of pathological specimens where necessary. Variables compared included mode of presentation of tumour,pathological size,histological type,grade,estrogen/ progesterone receptor status, lymph node status and interval of time between cancers.

Results: The median age of diagnosis of the first cancer was 55 for SDBC and 56 for symptomatic. $1 / 3$ of these were detected by mammographic screening and $2 / 3$ by symptomatic presentation. First tumours detected on mammogram were highly likely to have a screen detected contralateral breast cancer $(p=0.001)$.ER and PR status between first and second tumours correlated regardless of mode of detection $(\mathrm{p}=0.01)$. Grade and Histological type did not correlate. However, $3 / 4$ of Grade $1 \mathrm{CBCs}$ were screen detected and $3 / 4$ of Grade 3 CBC were symptomatic.Screen detected CBC tended to be smaller, with $76 \%$ measuring less than $20 \mathrm{~mm}$ whereas only $43 \%$ of symptomatic cancers were $<20 \mathrm{~mm}$. SDCBCS were mainly lymph node negative $(81 \%)$. The interval between cancers did not differ significantly for SD or symptomatic CBC.

Conclusion:Screen detected primary tumours are likely to have Mammographically detected contralateral breast cancer. SDCBCs are smaller, lower grade and more likely to be lymph node negative than symptomatic CBC. The present study supports the value of repeated mammographic surveillance.

\section{5}

Variation in protein expression patterns of nipple aspirate fluid comparing women with breast cancer and healthy women using time-of-flight mass spectrometry.

Noble JL, Dua RS, Locke I, Coulton GR, Eeles R, Isacke CM, Gui GPH. Royal Marsden Hospital, London, United Kingdom; Breakthrough Breast Cancer Research Centre, Institute of Cancer Research, London, United Kingdom; St George's University of London, London, United Kingdom

Background

The emerging field of proteomics provides a promising approach to biomarker discovery in a variety of cancers. Combined with the intraductal approach, comprising nipple aspiration, ductal lavage and ductoscopy it may prove useful in the early detection, diagnosis and screening of breast cancer. This study examines the feasibility of nipple aspiration to distinguish women with breast cancer from healthy women using surface-enhanced laser desorption/ionisation time-of-flight mass spectrometry (SELDI-TOF/MS).

Materials and Methods

In this pilot study, nipple aspiration fluid was collected from each breast in 10 women newly diagnosed with unilateral breast cancer and 10 healthy women. The fluid was diluted to $1 \mathrm{mg} / \mathrm{ml}$ and applied to two protein arrays (CM10 and IMAC-30). Each array was processed using the Ciphergen SELDI-TOF/MS system. Results

142 distinct peaks were identified. Protein expression from the cancer-bearing breast and the contralateral healthy breast were compared. No difference was found using the CM10 chip and only 4 proteins were overexpressed in the cancer-bearing breast compared to the contralateral breast using the IMAC-30. In contrast, the cancer-bearing breast compared to healthy women revealed 52 peaks which were statistically significantly different between the two groups $(\mathrm{p}<0.05)$. Finally comparing the contralateral healthy breast to healthy women found 36 statistically significant peaks which were overexpressed.

Conclusions

Differences between women with breast cancer and healthy women can be demonstrated using a proteomic approach to nipple aspiration fluid. We are currently recruiting more women to validate our findings in a larger study.

\section{6}

Comparison of FLT-(18F) and FDG-(18F) to visualize cancer spread while staging locally advanced breast cancer with PET/CT: preliminary data. .

Grahek D, Gligorov J, Beerblock K, Selle F, Segura C, Chopier J, Salem $C$, Antoine M, Barranger E, Montravers F, Gutman F, Kerrou K, De Beco V, Marsault C, Lotz JP, Uzan S, Talbot JN. Hôpital Tenon; Hôpital Tenon, Paris, France

Objectives: Fluorothymidine-(18) or FLT is a new radioactive tracer, the uptake of which is related to the proliferation of cells. This study, including patients with locally advanced breast cancer (LABC), aimed to evaluate the visualization of the malignant lesions with FLT positron emission tomography (FLT-PET), in comparison with fluorodeoxyglucose (FDG)-PET, the reference PET tracer in oncology.

Methods: FDG-PET/CT and FLT-PET/CT were performed in 11 patients with LABC before chemotherapy. The tumors were not inflammatory and corresponded to 8 ductal carcinomas and 3 lobular carcinomas. The Ki-67 proliferation marker ranged between 10 and $50 \%$. Axillary lymph nodes were palpable in 4 pts. PET/ $\mathrm{CT}$ acquisitions were performed in prone position 1 hour after injection of FLT-(18F) and 2 hours after injection of FDG-(18F) on a different day. The interpretation was visual and tumor/ background ratio (T/B) and standard uptake value were also calculated.

Results: Mammary tumors were visualized in all patients with both tracers ; the average SUV value was 5 (range: 3-8.2) for FDG and 3.1 (range: 1.5-4.8) for FLT. Fifteen abnormal axillary foci were visualized in 8 patients with both tracers. Regarding axillary foci, the average SUV were respectively 1.8 (range: 0.7-3.6) and 1.7 (range: $0.6-2.6$ ) for FDG and FLT. The average T/B values were respectively 2.8 (range: 1.2-5.5) and 2.2 (range 1.1-3.5) for FDG and FLT. When the T/B value was less than 1.5 (3 cases with FDG and 1 case with FLT) the abnormal axillary foci were hardly visible, and of small size at CT. Such a discrepancy occurred in 4 patients: in 3 patients, clearly visible axillary foci with FLT were not at all obvious with FDG and reverse in 1 patient. A bone focus was only visualized with FDG that corresponded to an osteolytic metastasis.

Conclusion: Even though the uptake of FLT in the malignant lesions was less than the uptake of FDG, all primary lesions was imaged with FLT. All but one abnormal axillary foci seen at FDGPET/CT were also visualized at FLT-PET/CT that also revealed 3 foci not visible with FDG. The lack of FLT uptake in brown fat and muscles could facilitate the visualization of small axillary lesions. Conversely, the high FLT uptake by bone marrow prevented the identification of one bone metastasis. An initial FLT PET/CT examination could be worthwhile not only as a reference for early assessment of response to chemotherapy but also for a better evaluation of the nodal invasion.

\section{7}

Combined mammography and breast ultrasound are required for a good accuracy of BI-RADS 4/5 results findings of a breast imaging reference center.

Fasching PA, Wenkel E, Bani MR, Bautz W, Papadopoulos T, Beckmann MW, Schulz-Wendtland R. University Hospital Erlangen, Erlangen, Bavaria, Germany; Institute of Diagnostic Radiology, University Hospital Erlangen, Erlangen, Bavaria, Germany; Institute of Pathology, University Hospital Erlangen, Erlangen, Bavaria, Germany

Background: The Breast Imaging Reporting and Data System (BIRADS) of the American College of Radiology (ACR) is a diagnostic tool to estimate the risk for the malignancy of breast lesions. The systematic categorisation of morphological findings and malignant risk are thought to minimize inconsistencies of inter- and intraindividual estimations of breast imaging. Aim of our analysis was the evaluation of the accuracy of BI-RADS $4 / 5$ results in a large collective. 
Methods: From 1999 to 2003 all consecutive patients with BIRADS $4 / 5$ results were prospectively documented in a central database. All patients underwent biopsy by an appropriate method. 5636 biopsies were performed due to a BI-RADS 4 or 5 result. Positive predictive values (PPV) were calculated and adjusted for method of biopsy, morphological findings, and diagnostic method (mammography vs. ultrasound).

Results: Patients with a BI-RADS 4 result $(n=3966)$ showed a malignant histology in $15,7 \%$ of cases $(n=623)$. A BI-RADS 5 result showed a malignant histology in $86,6 \%$ (1447 out of 1670 results). Mammography alone would prove $299(14,4 \%)$ carcinomas wrongly negative, ultrasound alone $367(17,7 \%)$ wrongly negative. Best discrimination of BI-RADS 4 vs. BI-RADS 5 results was seen in the group of patients with solid masses $(10 \%$ vs. $92,9 \%)$ and sonografic guided biopsy $(8,9 \%$ vs. $91,6 \%)$. Findings with either architectural distortion or calcification resulted in over $20 \%$ in malignant histologies in BI-RADS 4 diagnoses.

Conclusion: BI-RADS categorisation is helpful to evaluate the accuracy of breast imaging results. The ACR-proposed probability of malignancy could not be achieved. Concerning subgroups of morphological findings the PPV of BI-RADS 4 results was much higher than the recommended threshold. The complementary application of mammography and ultrasound seems to be mandatory. For the prevention of pitfalls special constellations of covariates have to be respected carefully.

\section{8}

\section{Improving the Case Definition of Inflammatory Breast Cancer \\ Levine PH, Cartin BJ, Lowe JA, Siegel DA, Young HA.}

Background: Although inflammatory breast cancer (IBC) is recognized as an aggressive form of breast cancer, controversy surrounding diagnostic criteria for IBC has limited our understanding of its etiology and clinical behavior. The IBC Registry was established to collect standardized information and specimens from IBC patients residing in the US and Canada, with the goal of clarifying the etiology and biology of these tumors. The information that has been gathered on the 163 patients currently in the Registry has now documented the importance of revising the current case definitions and the need to better understand some of the problems associated with epidemiologic studies in the literature.

Material and Methods: Of the 163 patients enrolled in the Registry, most (120) were self-referred through the Internet.

Results: Just over $35 \%$ of the patients were initially diagnosed as having an infection and received antibiotics for up to ten months before the diagnosis of IBC was made. Of 121 patients with mammogram records, 22 had no definitive findings such as a mass or skin thickening, and the tumor was often attributed to dense breasts. Receptor status was variable, with approximately $50 \%$ of cases classified as ER positive, 35\% PR positive, and 35\% HER2/ neu positive. The clinical presentation was wide-ranging; cases were categorized according to the extent of clinical findings and the presence or absence of documented dermal lymphatic invasion. The median disease free interval (DFI) in weeks for all analyzable patients in the Registry who were initially diagnosed after 1998 $(n=96)$ was 60.5 weeks. For those with IBC meeting the American Joint Committee on Cancer (AJCC) criteria for IBC the median DFI was 42.5 weeks $(n=46)$ and for those that did not, the median DFI was 72.0 weeks $(n=40)$. DFI was not recorded for patients with secondary IBC.

Approximately $89 \%(\mathrm{n}=105)$ of patients received neoadjuvant chemotherapy, usually including Adriamycin and Cyclophosphamide and usually followed by mastectomy, the timing of the mastectomy depending on the chemotherapy response. Ninety-four patients (approximately $80 \%$ ) received radiation therapy post-mastectomy. Fifty of the patients reported an excellent initial response to chemotherapy.
Discussion: The 72 week DFI in patients who did not meet the case definition of the AJCC for IBC, while not as short as those meeting the case definition, still indicates the importance of broadening the case definition. The poor survival in patients in SEER and in our Registry with no clinical signs of IBC but only pathological features emphasizes this point.

\section{9}

Concordance of HER2 and hormone receptor expression in primary and recurrent breast cancer.

Wirk B, Geiger X, Hillman D, Perez EA. Mayo Clinic, Jacksonville, FL

Background: Determination of accurate HER2 and hormone receptor status is of primary importance in breast cancer treatment. Concordance of expression of these 2 prognostic and predictive factors between primary and recurrent tumors provide guidance related to the potential need to re-biopsy patients at the time of recurrence, or managing them based on the characteristics of the original tumor. Methods: Retrospective review of all medical records available of patients (pts) with recurrent breast cancer between 1997 and 2003 (160 cases total) at a single institution as to whether expression levels of HER2 by immunohistochemistry (IHC) using HercepTest ${ }^{\mathrm{TM}}$ or fluorescence in situ hybridization (FISH) using Pathvysion ${ }^{\mathrm{TM}}$ as well as ER (estrogen receptor) and PR (progesterone receptor) by nuclear staining differ in the primary tumor and the asynchronous recurrent lesions. Results: Out of 160 cases, 39 pts (ages 41-85 years) had HER2 status available on the primary breast cancer and biopsies of the asynchronous recurrent breast cancer lesions. $8(20.5 \% ; 95 \% \mathrm{CI}$ 7.8-33.2\%) pts had HER2 status conversion (table 1). 7 pts with HER2 status conversion had HER2 status determination by HercepTest and 1 patient had FISH. All pts with HER 2 concordance had HercepTests. 14 (35.9\%; 95\% CI:20.8-51\%) pts had ER/ PR status conversion from the primary breast cancer to the recurrent breast cancer (table 2). Of those pts with HER2 status conversion, the disease free interval (DFI) was 10 to 45 months. Of those with HER2 status concordance, the DFI was 9 months to 12 years. 7 of the 8 pts with HER2 status conversion had locoregional recurrence (with biopsies of the breast [4 pts], axillary lymph node [2 pts], chest wall [1 pt]) and 1 had distant recurrence (biopsy of the bone). 3 of 8 pts with HER2 status conversion had ER and PR status conversion (ie ER+ or PR+ status of the primary breast cancer and ER- PR- status of the asynchronous recurrent breast cancer). 4 of the 8 pts with HER2 status conversions received anthracycline based chemotherapy and tamoxifen; 1 of the 8 pts received tamoxifen alone; 3 of the 8 pts received chemotherapy alone and 6 of the 8 pts received radiation for their primary breast cancer. Conclusions: Changes in HER2 $(20.5 \%)$ and hormone receptor expression $(35.9 \%)$ were found between the primary and asynchronous recurrent breast cancer. Pts with recurrent breast cancer should have new biopsies performed to best determine whether therapy with trastuzumab and/or antiestrogen therapy is indicated. Only 39 of 160 recurrent breast cancers examined between 1997-2003 had biopsies of the recurrent lesions and data regarding the 2004 metastatic breast cancer cases are forthcoming. Table 1.

$\begin{array}{lll}\text { Number of patients } & \text { Primary breast cancer HER2 } & \text { Recurrent breast cancer HER2 } \\ 4 & \text { HER2 2+ IHC } & \text { HER2 0 IHC } \\ 1 & \text { HER2 3+ IHC } & \text { HER2 1+ IHC } \\ 2 & \text { HER2 0 IHC } & \text { HER2 3+ IHC } \\ 1 & \text { HER2 FISH amplification } & \text { HER2 no FISH amplification } \\ \text { Table 2 } & & \\ \text { Number of patients } & \text { Primary breast cancer ER PR } & \text { Recurrent breast cancer ER PR } \\ 7 & \text { ER+ or PR+ } & \text { ER- PR- } \\ 2 & \text { ER- PR- } & \text { ER+ PR+ } \\ 4 & \text { ER+ PR+ } & \text { ER+ PR- } \\ 1 & \text { ER- PR- } & \text { ER- PR+ }\end{array}$


2020

Proliferating macrophages appear to be uniquely associated with large, palpable DCIS and high grade invasive cancers. Esserman LJ, Kumar AS, Au A, Baehner F, Chen D, Chen Y, Chan $L$, Chew K, McGrath M. UCSF, San Francisco, CA

Background: The clinical and pathologic presentation of DCIS is highly variable. Large palpable DCIS, is uncommon but distinct. Clinically, it arises rapidly, and disproportionately, represents a subset of patients with poor outcomes: approximately $3 \%$ of all DCIS cases, but associated with a $3 \%$ mortality rate. These large, high grade lesions may have a different etiology than other DCIS. They represent. In a previous study of DCIS lesions characterized by MRI and immunohistochemistry, we observed that palpable lesions have a distinct MRI appearance, and a high proportion of macrophages. Due to the nature of their rapid progression, we hypothesized that these lesions have a high pathologic inflammatory component. Previous studies of lymphoma identified the presence of a novel macrophage population expressing both macrophages (CD68) and proliferation (PCNA) markers in the most aggressive subset. These macrophages have been termed promacs and in animal model studies were capable of inducing lymphoma. We hypothesized that this aggressive subset of DCIS would contain promacs.

Methods: From a study of 49 prospective cases of DCIS with complete MRI and pathology (IHC) data, we compared high grade lesions to all large palpable DCIS lesions from 1997 to 2005. Cases were double stained for CD68, a cytoplasmic stain and PCNA, a nuclear stain. CD68/PCNA positive cells were counted in 3 high powered fields and the mean recorded. Two pathologists independently evaluated the CD68 /PCNA double stains, without knowledge of lesion palpability. Sixty invasive cancer cases of varying grades were also evaluated. A single, blinded clinician reviewed the case records to determine which patients had palpable lesions.

Results: Eleven large palpable cases were (10/11 were high grade) compared to 15 high grade non-palpable DCIS lesions from the same study. All palpable lesions had a homogenous enhancement pattern on MRI. The total number of macrophages were significantly higher in the palpable lesions, compared to nonpalpable high grade DCIS, mean 44.3 (SD 42.3) vs. 12.7 (SD 13), $\mathrm{p}<0.05$. Only the palpable DCIS had CD68/PCNA double stained macrophages (range 2-27): $11 / 11$ vs. $0 / 15$ in palpable vs. nonpalpable cases, respectively $(\mathrm{p}<0.005)$. Of the 11 patients with palpable DCIS, one was a 35 year-old mutation carrier with positive nodes and two died of metastatic disease shortly after DCIS diagnoses at ages 39 and 48. Promacs were also found in invasive cancer cases at incidences of $20 \%, 26 \%$ and $75 \%$, for grade I, II, and III tumors, respectively, with a significant relationship of promacs and high grade invasive cancers $(\mathrm{p}<0.005)$.

Conclusion: Pathologic macrophages or promacs have been identified as a unique feature in large palpable DCIS, a distinct but rare population and the most aggressive form of DCIS, as well as a common feature of high grade invasive cancer. They may represent an important clue to the etiology of these types of lesions.

\section{1}

Mammaglobin identification by immunohistochemistry and reverse transcriptase polymerase chain reaction to increase detection of breast cancer metastases.

Ferguson DJ, Thorne A, Jeffrey M, Yiangou C, Perry PM. Portsmouth Hospitals NHS Trust, Portsmouth, Hampshire, United Kingdom; Institute of Biomedical and Biomolecular Sciences, University of Portsmouth, Portsmouth, Hampshire, United Kingdom

Background: Lymph nodes status is the most important prognostic factor in breast cancer. However, $1 / 3^{\text {rd }}$ of node negative women show poor survival. These patients may have occult nodal disease, undetected due to insensitivity of the markers used to identify metastases. Mammaglobin (MG) is recognised by Reverse Transcriptase Polymerase Chain Reaction (RT-PCR) and Immunohistochemistry (IHC) as a breast specific tumour marker. Cytokeratin markers are used to aid detection of breast cancer nodal metastases but are not breast specific and may falsely stain normal lymph nodes. The aim of this study was to develop a novel anti-mammaglobin antibody for use in IHC metastasis detection and compare it with standard $\mathrm{H} \& \mathrm{E}$ and cytokeratin lymph node staining (CAM 5.2 (Becton-Dickinson)) along with MG RT-PCR and in the same patients.

Methods: The MG antibody was induced in a host (rabbit) by a novel conjugated mammaglobin peptide (MG-KLH). The sequence of the peptide chosen (identical to that used for RT-PCR) was the most accessible and variable sequence (residues 51-65). ELISA and Western blotting assessed the antibody's sensitivity and specificity, against recombinant MG protein, MG-KLH and an acid protein extract from a MG expressing patient. MG antibody was compared clinically to H\&E histology, CAM 5.2 IHC and nested RT-PCR (30 amplifications giving approximately $2^{28}$ copies of the target DNA sequence) for its sensitivity to detect nodal metastases in 210 lymph nodes sections from 104 patients.

Results: The results show that whole and recombinant MG protein, along with conjugated MG peptide, were specifically detected by the MG antibody (demonstrated by both ELISA and Western blotting). Histologically, MG IHC was positive on all bar one of the node positive cases identified by CAM 5.2, but detected a metastasis in one patient missed by H\&E. 68\% of lymph nodes were MG positive by RT-PCR, $22.8 \%$ more than detected by standard histology $(\mathrm{p}=0.0001)$

Levels of metastas detection

\begin{tabular}{llll}
\multicolumn{2}{l}{ Levels of metastasis detection } & & \\
H\&E nodes & Lymph node & Lymph node & Lymph node \\
& MG RT-PCR & MG IHC & CAM IHC \\
+ve 47 & +ve 69 & +ve 48 & +ve 49 \\
-ve 57 & -ve 32 & -ve 56 & -ve 55
\end{tabular}

Discussion: In conclusion, IHC with a novel anti-MG antibody was able to specifically identify lymph nodal metastases with sensitivity very close to that of CAM 5.2. IHC with this antibody could increase the specificity and sensitivity of detection of nodal metastases in breast cancer patients since it is known to have greater specificity than currently used cytokeratin IHC.MG RTPCR detects a significantly greater number of patients with lymph nodal metastases than H\&E and IHC but the prognostic value of RT-PCR, unlike that of IHC remains unproven.

\section{2}

Reliability of core biopsy in pre-operative diagnosis of papillary lesions of the breast.

Swamy R, Loane J, Thomas JS. Western General Hospital, Edinburgh, Scotland, United Kingdom

Background: Current UK NHS Breast Screening Programme (NHSBSP)screening guidelines recommend that the overwhelming majority of core biopsy-confirmed papillary breast lesions be excised because of concerns about adequacy of sampling these lesions which may be heterogeneous. In contrast, recent literature has promoted the idea that core biopsy is an accurate predictor of subsequent benign excision histology and that conservative management of benign papillary lesions through follow-up alone can be based in part on core biopsy histology. We report our experience of papillary lesions diagnosed on core biopsy from a large breast-screening unit serving SE Scotland.

Materials and Methods: We identified from our archives 43 papillary lesions diagnosed on core biopsy with subsequent excision follow up over a four-year period (2001-2004). H\&E sections were examined at 3 levels. Immunohistochemistry for myoepithelial markers (CK5/6 and P63) was supplemented to assist diagnosis if required. Each of three observers examined independently the core biopsies blinded to the results of the excision biopsies which were later reviewed. Consensus diagnosis was thereafter agreed in cases in which independent opinions differed. The recommendations of the NHSBSP guidelines were used for 
categorisation of core biopsies and were then correlated with their paired excision biopsy sections.

Results: On excision there were 26 papillomas and 17 papillary malignancies. Of the 26 benign lesions core biopsy showed: benign papilloma (12); benign papilloma with usual type hyperplasia (7); and benign papilloma with atypical changes (7). Of the latter 7 cases atypia was focal in the excisions. Two of the benign papillary excision biopsies were associated with an unexpected radial scar in the adjacent tissue not predicted in the preceding core biopsies. Papillary malignancy was identified correctly on core biopsy in every case. A benign core biopsy had been obtained two years previously from the site of a subsequent papillary carcinoma in one case.

Discussion: Our results are similar to those reported by others but in all recent reports numbers are comparatively small. Our findings confirm the focal nature of atypia in some papillary lesions. Although we identified correctly the excision biopsy diagnosis on core biopsy in every case we believe that it is premature to depart from NHSBSP guidelines for the management of papillary lesions. The infrequency of finding benign foci in papillary malignancies and neoplastic foci in otherwise benign papillomas is noted. Entirely benign papillary lesions on core biopsy without worrying radiological features may not need excision.

\section{3}

Are so-called "intracystic" papillary carcinomas of the breast in situ or invasive lesions?

Collins LC, Carlo VP, Hwang H, Barry TS, Yaziji H, Gown AM, Schnitt SJ. Beth Israel Deaconess Medical Center and Harvard Medical School, Boston, MA; Phenopath Laboratories, Seattle, WA

Background: "Intracystic" papillary carcinomas (ICPC) of the breast have traditionally been considered to be variants of ductal carcinoma in situ (DCIS). However, it is not clear if all lesions categorized histologically as ICPC are truly in situ carcinomas, or if some such lesions might represent circumscribed nodules of invasive carcinoma growing in an expansile pattern, with secondary cystic degeneration. The demonstration of a myoepithelial cell (MEC) layer around nests of carcinoma cells is a useful means to distinguish in situ from invasive carcinomas of the breast in problematic cases. Assessment of the presence or absence of a MEC layer at the periphery of the nodules that comprise ICPC could help resolve the issue of whether these lesions are in situ or invasive carcinomas.

Design: We evaluated the presence and distribution of MECs at the periphery of the nodules of 22 ICPC and, for comparison, 15 benign intraductal papillomas (IP) using immunostaining for 5 highly sensitive markers that recognize various MEC components: smooth muscle myosin heavy chain, calponin, p63, CD10 and cytokeratin $5 / 6$

Results: All 22 ICPC studied showed complete absence of MEC at the periphery of the nodules with all 5 markers. In contrast, a continuous layer of MEC was detected around foci of conventional DCIS present adjacent to the nodules of ICPC. Furthermore, all benign IP, including those of sizes comparable to those of ICPC, showed a continuous MEC layer around virtually the entire periphery of the lesion with all 5 MEC markers.

Conclusion: We could not detect a MEC layer at the periphery of the nodules of any of 22 lesions categorized histologically as "intracystic" papillary carcinoma. One possible explanation for this observation is that these are in situ lesions in which the delimiting MEC layer has become markedly attenuated or altered with regard to expression of these antigens, perhaps due to their compression by the expansile growth of these lesions within a cystically dilated duct, though this seems unlikely given that the same phenomenon is not observed in IPs of a similar size. Alternatively, it may be that at least some lesions categorized as "intracystic" papillary carcinomas using conventional histologic criteria actually represent circumscribed nodules of invasive papillary carcinoma rather than in situ lesions. Based on our observations, use of the term "cystic" papillary carcinoma may be more accurate than "intracystic" papillary carcinoma for circumscribed nodules of papillary carcinoma in which a peripheral delimiting layer of MEC is not demonstrable. Regardless of whether these lesions are in situ or invasive carcinomas, available outcome data indicate that they appear to have an excellent prognosis with adequate local therapy.

\section{4}

A nomogram to predict for malignant diagnosis of solid lesions in a one-stop breast unit.

Delaloge S, Rouzier R, Balleyguier C, Andre F, Vanel D, Mathieu MC, Garbay JR, Derneville AM, Marsiglia H, Spielmann M, Vielh P. Institut Gustave Roussy, Villejuif, France; Centre Hospitalier Intercommunal de Creteil, Creteil, France

Background: In western countries, the incidence of breast cancer has considerably increased within the past 20 years, partly due to large programs of mammogram breast screening. Preoperative diagnosis is mandatory in order to avoid unnecessary surgical biopsies. Diagnoses may be obtained either through breast biopsies or breast cytology. Both methods have been associated with variable rates of false negative results. The only strong repeatedly demonstrated predictor of the rates of cancer diagnoses in this setting is the the Birad ACR classification (Mammogram, ultrasound, MRI). In the present study, we aimed at evaluating which additional factors may guide the physician in the therapeutic/ investigational decision.

Methods: Patients referred for newly diagnosed breast abnormalities are seen in our one-stop diagnosis unit. They undergo multiple medical consultations and complementary investigations as necessary, with the aim to reach diagnosis as much as possible within the same day and to propose treatment plan as required. Solid lesions are first investigated by fine-needle aspiration, which is completed by core biopsy as indicated. Fine needle aspiration results are discussed to reach a consensus between the diverse physicians present (surgeons, radiologist, pathologist, oncologist). Data regarding patients and lesions characteristics, as well as results of explorations performed have been prospectively recorded. A multivariate analysis of factors predicting for a cancer diagnosis was performed and a nomogram was constructed using the $\mathrm{R}$ statistical package. It was validated by bootstrapping.

Results: 697 fine-needle aspirations were performed for suspect solid lesions within a 12 month period. Two thirds of them were ultrasound-guided. Median age of the patients was 56 (16-92). Median tumour size was $15 \mathrm{~mm}(2-20) .56 \%$ of the lesions appeared palpable at careful examination. Cytological diagnosis was cancer in $369(53 \%)$, suspect in $59(8.4 \%)$, benign in $247(35 \%)$, and non significant in $22(3 \%)$. Final diagnoses at 9 months median followup are: 423 carcinomas $(61 \%), 262$ benign $(38 \%), 7$ atypical hyperplasia $(1.7 \%)$. $0 \%$ of 14 patients with Birad ACR2, $3.2 \%$ of 152 with ACR $3,43 \%$ of 171 with ACR 4 and $97 \%$ of 353 with ACR5 lesions had breast carcinoma.

In the multivariate analysis, ACR classification, age and palpability were independently associated with diagnosis of malignancy. The nomogram to predict malignancy based on ACR classification, age and palpability had excellent discrimination and calibration (area under the ROC curve $=0.95, \mathrm{p}<0.001$ ).

Conclusion: Our study provides an original nomogram for prediction of the malignant nature of recently discovered solid breast lesions. Further data including epidemiological individual risk evaluation will be presented at the meeting. 
2025

Genomic alterations as a pathological aid to classifying ductal carcinoma in situ.

Ellsworth RE, Ellsworth DL, Love B, Hoffman LR, Deyarmin B, Hooke JA, Shriver CD. Windber Research Institute, Windber, PA; Walter Reed Army Medical Center, Washington, DC

Background: Thanks to improved and more prevalent mammographic screening of eligible populations of women, the diagnosis of ductal carcinoma in situ (DCIS) has increased dramatically in recent years, but. $</$ DEL $>$ treatment options can vary and include margin-negative excision with or without radiation, adjuvant hormonal therapy, and even total mastectomy. Difficulties in developing standardized treatment regimens are attributable to histological variability among lesions and the inability of pathological evidence to accurately predict lesions prone to progression and/or recurrence. To investigate the potential role of genomic profiling of DCIS, we used patterns of allelic imbalance (AI) to develop molecular profiles to supplement pathological information in the classification of in situ ductal carcinomas.

Methods: DNA was isolated from laser microdissected pure DCIS $(n=60)$ representing low $(n=10)$, intermediate $(n=22)$, and highgrade $(\mathrm{n}=28)$ lesions. All samples were genotyped using 52 microsatellite markers representing 26 chromosomal regions commonly deleted in breast cancer, previously developed, described, and verified by our group. Conditional probability testing of the AI data at each chromosomal region was then used to derive molecular classifications for the in situ carcinomas.

Results: Applying Bayes Rule to calculate conditional probabilities, three chromosomal regions were highly informative in differentiating high-grade from low-grade DCIS. Chromosomes $6 \mathrm{q} 25-\mathrm{q} 27,17 \mathrm{p} 13.3$, and $18 \mathrm{q} 21$ showed significantly higher levels of AI $(P<0.05)$ in high-grade compared to low-grade DCIS. Allelic imbalance at any one of these regions correctly classified highgrade lesions $\sim 70 \%$ of the time, but AI at two or more of these regions correctly distinguished high-grade from low-grade lesions $>90 \%$ of the time.

Conclusion: Allelic imbalance at three chromosomal regions is useful in distinguishing high-grade from low-grade DCIS. Alterations of genes located within these regions, in particular IGF2R at 6q25$\mathrm{q} 27$, HIC-1 at $17 \mathrm{p} 13.3$, and DCC at $18 \mathrm{q} 21$, may provide new insights into the biology of progression to invasive carcinoma, and allow for genomic classification of biologically aggressive DCIS. Genomic instability in the three chromosomal regions may provide useful supplemental information to improve the pathological classification of in situ ductal carcinomas and therefore optimize the selection of appropriate treatments.

\section{6}

Peptide breast cancer biomarkers detectable through blood tests.

Zhu L, Ru Q, Silberman J, Jacobs N, Shriver CD. Windber Research Institute, Windber, PA; Breast Cancer Care Center, Walter Reed Army Medical Center, Washington, DC

Background: Proteomics researchers may soon identify diagnostically useful cancer biomarkers. Tools used to this end include two-dimensional liquid chromatography coupled with tandem mass spectrometry (2-D LC-MS/MS), two-dimensional gel electrophoresis coupled with mass spectrometry (2-D gel/MS), and protein chip with surface-enhanced laser desorption and ionization (SELDI) mass spectrometry. 2-D LC-MS/MS techniques have recently been improved such that they provide better reproducibility, higher throughput, and greater mass spectrometry capabilities than 2-D gel/MS or SELDI.

Method: Seventy digested human sera from breast cancer patients (13 atypical, 20 invasive, 22 benign non-neoplastic, and 15 benign neoplastic), and 19 digested human sera from a healthy control group, were separated via 2-D LC and detected via ion-trap tandem mass spectrometry. All experiments were completed using the
ProteomeX Workstation (Thermo Finnigan, San Jose, CA), and raw data was exported to text files using its bundled software. SpotFire ${ }^{\mathrm{TM}} 8.0$ was used to analyze cluster statistics. An approach called the P-MTH Statistical Method was also developed to identify peptides $(\mathrm{P})$ based on their mass values $(\mathrm{M})$, retention times $(\mathrm{T})$, and peak heights $(\mathrm{H})$.

Results: P-MTH was used to identify more than one thousand peptides. A group of 16 of these peptides was found to be a potential breast cancer biomarker. Cluster results showed significant differences between benign and invasive stages (Figure 1).

Discussion: Identifying biomarkers has hitherto been limited by mass spectrometry capabilities. Our approach has allowed us to overcome some of these limitations. Investigating peptide patterns instead of identifying proteins has prevented the risk of search errors, increased the amount of data generated, and improved throughput. 2-D LC-MS/MS yielded 1,026,000 survey scans per sample, a much greater number than is possible with either 2-D gel/MS or SELDI. Generating a large amount of high-quality data has, presumably, increased the likelihood of biomarker discovery. Further validation will be completed on the 16 diagnostically significant peptides.

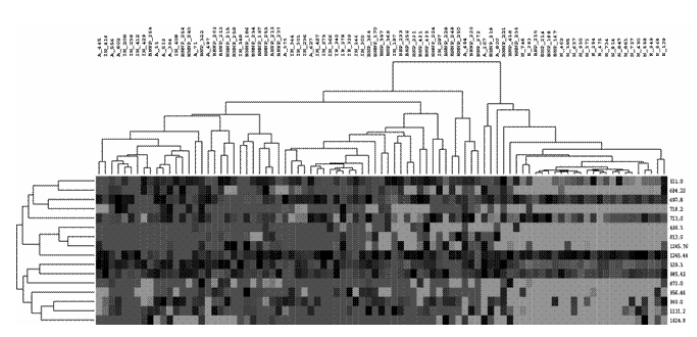

Figure 1 Cluster result of 16 peptide candidates on 89 serum samples

\section{7}

Intra-operative touch preparation cytology; does it have a role in re-excision lumpectomy?

Valdes EK, Boolbol SK, Cohen JM, Feldman SM. Beth Israel Medical Center, New York, NY

Objective: Breast carcinoma is the most frequently diagnosed malignancy in women of the North America. The combination of breast conservation surgery and radiotherapy has become a standard of treatment for the majority of breast cancers. It is critical to obtain clear margins to minimize local recurrence, however avoiding multiple re-excision helps optimize cosmetic results. Intraoperative touch preparation cytology (IOTPC) may decrease the need for multiple re-excisions and thereby improve cosmesis. The literature suggests that IOTPC can be useful in evaluation of margins. Klimberg et al. evaluated IOTPC prospectively in 428 patients undergoing breast biopsy for undiagnosed breast masses. They reported a diagnostic accuracy, sensitivity, specificity, positive predictive value, and negative predictive value of $100 \%$ for IOTPC.

There is no published data in the literature on the role of IOTPC for evaluation of margins in re-excision cases. This report describes our experience with IOTPC for margin assessment for re-excision partial mastectomy at Beth Israel Medical Center (BIMC). The purpose of this study is to determine whether IOTPC is reliable for evaluating margins in patients undergoing re-excision for involved or close margins.

Methods: A prospective study of 28 patients who have undergone re-excision partial mastectomy after breast conservation surgery with the use of IOTPC for margin assessment at BIMC was performed. The specimens were oriented intra-operatively and were submitted fresh for cytologic assessment. The technique consisted of touching the corresponding margin onto the slide and the principle is that cancer cells will stick to the slide while fat 
cells will not. A slide was prepared for each re-excision specimen Air-dried samples were stained using the Diff-Quik method and examined by a cytopathologist.

Results: Twenty-eight patients underwent re-excision lumpectomy for involved or close margins with IOTPC for assessment of 63 margins. Twenty-four patients had invasive ductal carcinoma (IDC) and/ or ductal carcinoma in situ (DCIS), 3 patients had invasive lobular carcinoma (ILC) and the remaining 1 patient had a combination of invasive lobular and ductal carcinoma. There was a correlation between touch preparation cytology and final pathology in 51/63 margins, which accounts for $81 \%$ of the cases Table 1-

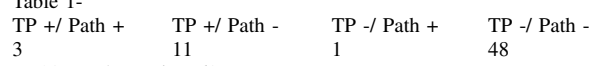

$\mathrm{N}=28$ Total margins $=63$

Conclusion: Intra-operative touch preparation cytology for assessment of margins in patients undergoing re-excision lumpectomy has a sensitivity of $75 \%$, specificity of $81.4 \%$, positive predictive value of $21.4 \%$, and negative predictive value of $98 \%$. This high negative predictive value and a single false negative case are quite significant. Therefore based on our experience IOTPC can be a useful tool for intra-operative assessment of margins for patients undergoing re-excision partial mastectomy.

\section{8}

Response in gene expression profile to bevacizumab treatment in patients with inflammatory and locally advanced breast cancer.

Yang SX, Simon RM, Wedam SB, Modrusan Z, Smith V, de Sauvage F, Swain M. National Cancer Institute, Bethesda, MD; Genetech, Inc., South San Fancisco, CA

Background: Inflammatory breast cancer (IBC) is an aggressive and highly angiogenic disease. Vascular endothelial growth factor (VEGF) is a potent angiogenic molecule that mediates tumor angiogenesis. In a pilot study, bevacizumab, a recombinant humanized monoclonal antibody to VEGF, was used to treat previously untreated patients with IBC and locally advanced breast cancer (LABC).

Material and Methods: Twenty patients with IBC (19 patients) and LABC (1 patient) were treated with bevacizumab at a dose of $15 \mathrm{mg} / \mathrm{kg}$ for one cycle. Gene expression profiles in tumor core biopsies pre- and post-bevacizumab were measured with Agilent 60-mer oligo microarray. Tumor apoptosis and tissue VEGF expression pre- and post-bevacizumab in paraffin-embedded biopsy sections were examined by terminal deoxynucleotidyl transferasemediated dUTP nick-end labeling (TUNEL) assay and by immunohistochemistry (IHC), respectively.

Results: A change signature which include 92 genes was identified by supervised comparison analysis at the individual level $(\mathrm{p}<0.001)$. Many of these encode proteins that regulate or relate to angiogenesis. These included an increase in nidogen 2 , a basement membrane protein with diverse binding properties and endothelial cell-specific molecule1. No significant change in VEGF was found. Various factors involved in inflammation were among the significantly changed genes such as chemokine ligand 2; interleukin 1 receptor, type II; chemokine receptor 1 ; and chemokine ligand 8. Tumor protein p53 inducible protein 3 and tumor necrosis factor alpha-induced protein 2 were increased by bevacizumab. Both are tumor suppressor p53 induced genes which are involved in p53-mediated cell death. A median increase of $128.9 \%$ in tumor apoptosis by TUNEL $(\mathrm{p}=0.0008)$ and a median decrease of $50 \%$ in tissue VEGF by IHC $(\mathrm{p}=0.35)$ were found. Gene ontology (GO) groups represented by response to wounding, inflammatory response and collagen were the significantly changed GO categories identified by $\mathrm{GO}$ analysis $(\mathrm{p}<0.005$; permutation test). Among 103 pathways tested, a pathway in adhesion and diapedesis of lymphocytes was significantly changed after bevacizumab treatment $(\mathrm{p}=0.0047$; permutation test $)$.
Discussion: Our data demonstrate that with bevacizumab treatment there is a significant change in gene expression profile represented by angiogenic, inflammatory and apoptotic genes in patients with IBC and LABC. Also, there is a significant increase in tumor apoptosis. Further work will include validation of the identified genes.

\section{9}

Cost-benefit estimates of adjuvant (Adj) trastuzumab (herceptin, H) for early breast cancer (BrCa).

Ragaz J, Spinelli JJ. McGill University Health Center, Montreal, QC, Canada; British Columbia Cancer Agency, Vancouver, BC, Canada

INTRODUCTION. The $52 \%$ reduction of $\mathrm{BrCa}$ recurrences, and $33 \%$ reduction of $\mathrm{BrCa}$ mortality due to adjuvant $\mathrm{H}$, as seen in NSABP B31-NCCTG N9831 analyses (with comparable results in HERA trial), prompted a rapid guideline change, to include $\mathrm{H}$ in Adj. setting. Dollar cost and logistics dominate the speed of this decision worldwide. This analysis was done using a formula for calculating the overall fiscal impact of new therapies affecting cause-specific events (e.g. Br ca mortality), applicable to Adj. H therapy (th):

Total Cost Impact $=\mathbf{C t h}$ adj $-[\mathrm{Cth}$ rec $+\mathbf{C}$ th mets $]$, where:

Cth $\boldsymbol{a d j}=$ Cost of Adj H (estimates: Can \$50,000.00/1 pt/ year);

Cth rec $=$ Saved cost, of no $H$ th at recurrence if given in adj. setting (estimates: $70 \%$ of all Her2+ve $\mathrm{Br}$ Ca cases); and Cth mets $=$ the cost of avoided metastases (estimates: Can \$70,000.00/ pt), projecting the "best" and the "worst" case scenario (i.e. DFS improvement of $8 \%$ in HERA; or $18 \%$ in NSABP \& NCCTG trials.

RESULTS. 1. Cost of adj H: Can $\$ 12.5$ mil. /1,000 new pts / year $(50,000 \times(.25 \times 1,000) ; 2$. Cost of $\mathrm{H}$ at recurrence: Can $\$ 8.75 \mathrm{mil}$ $(0.7$ [ $50,000 \times(.25 \times 1,000)] ; 3$. Cost of avoided metastases, "best case scenario": Can $\$ 3.15 \mathrm{mil}[70,000 \times(.18 \times 250)]$; and a "worse case" scenario: Can $\$ 1.4$ mil $(70,000 \times(.08 \times 250)$.

Total Cost Impact showed a total cost (deficit) ranging from Can\$ 0.6 mil - Can $\$ 2$ mil/1,000 new BrCa cases / year, for the "best" versus the "worst" case scenario.

CONCLUSIONS:

1. These estimates, applicable to regional, national or international budget projections, indicate that if adj $\mathrm{H}$ is given to Her2/Neu +ve cases, the fiscal impact is acceptable, despite a substantial upfront dollar cost. This is in addition to a significant number of saved lives.

2.These calculations are based on 1 year use of $\mathrm{H}$, and on a premise that administration of $\mathrm{H}$ in adj.setting precludes its use in metastatic disease. If future studies show that prolonged or repeated $\mathrm{H}$ are of benefit, the figures will differ, but the concept remains valid, and methodology can be applied for different scenarios.

3. These estimates are important in costing experimental therapies with curative intent such as adjuvant $\mathrm{H}$, and may substantially accelerate approvals and logistics of their implementation.

\section{0}

A phase II trial of letrozole in combination with bevacizumab, an anti-VEGF antibody, in patients with hormone receptor-positive metastatic breast cancer.

Traina TA, Dickler MN, Caravelli JF, Yeh BM, Brogi E, Panageas $K$, Flores SA, Norton L, Park J, Hudis C, Rugo H. Memorial Sloan-Kettering Cancer Center, New York, NY; University of California, San Francisco, San Francisco, CA

Background: Bevacizumab (B) added to chemotherapy (chemoRx) prolongs PFS and OS in patients (pts) with metastatic breast cancer (MBC) (Miller, ASCO 2005). In DMBA-induced animal models of breast cancer, estrogen $\left(\mathrm{E}_{2}\right)$ induces expression of VEGF that is suppressed by aromatase inhibition (Nakamura, 1996). Because it is possible that $E_{2}$-induced VEGF expression may promote breast cancer growth, combination therapy with an 
aromatase inhibitor (AI) and an antibody to VEGF may be more effective than either agent alone. Hence, we performed a feasibility study testing B with letrozole (L) for the treatment of hormonereceptor positive $\mathrm{MBC}$.

Methods: Eligible pts have MBC and are candidates for AI therapy. Prior non-steroidal AI use without progression is permitted. Premenopausal pts are rendered menopausal prior to start of treatment. Therapy consists of L (2.5 mg daily) and B $(15 \mathrm{mg} / \mathrm{kg}$ IV q3 weeks). The primary endpoint is toxicity. Secondary endpoints include response rate, clinical benefit rate and time to tumor progression. Using a two-stage design, 19 pts were accrued to the first stage. If $<3$ pts experience Grade (Gr) 4 toxicity, then 23 additional pts would be enrolled. If $<5$ of the 42 pts have $\mathrm{Gr} 4$ toxicity, the regimen will be considered feasible. Markers of the ER, HER2 and VEGF pathways will be evaluated in archival tumor tissue. Serial levels of circulating endothelial cells (CECs), epithelial cells (CTCs), plasma VEGF and bFGF are measured.

Results: Nineteen pts have enrolled, completing accrual to the first stage. Data is available on 15 pts: median age 50 yrs (36-67), median ECOG PS 0 (0-1), sites of MBC: bone only 6/15, liver 4/ 15 , chest wall/lymph nodes $6 / 15$. None are HER2 positive. Prior therapy: adjuvant chemoRx 10; adjuvant tamoxifen 6 . Fourteen pts received $\mathrm{L}$ as first-line treatment of $\mathrm{MBC}$, starting a median of 25 wks $(0-215)$ before $B$. One pt received first-line tamoxifen; none had prior chemoRx for MBC. Grade 2 drug related toxicity in pts after a median of 6 cycles (2-12): fatigue 2 , joint pain 2 , headache 2 , hypertension 1 , proteinuria 1 , epistaxis 1 , hot flashes 1. One patient withdrew due to Gr 3 headaches. There were no other Gr 3-5 toxicities. Eleven pts are evaluable for response: 5 pts have stable disease $(\mathrm{SD})>6 \mathrm{mo} ; 4$ pts have SD; 2 pts had progression. CECs and CTCs are measurable in all pts.

Conclusions: Combination letrozole and bevacizumab appears well tolerated. Additional safety and efficacy data is anticipated. Data on CECs and CTCs will be correlated with response. Supported in part by Genentech and Novartis.

\section{1}

A phase II trial of trastuzumab $(\mathrm{H})$ plus capecitabine $(\mathrm{X})$ as first-line treatment in patients (pts) with HER2-positive metastatic breast cancer (MBC).

Xu L, Song S, Zhu J, Luo R, Li L, Jiao S, Pan H, Tao M, Su Y, Liu D. Cancer Hospital Fudan University, Shanghai, China; PLA Hospital 307, Beijing, China; Ruijin Hospital Shanghai No.2 Medical University, Shanghai, China; Nanfang Hospital First Military Medical University, Guangzhou, China; Heilongjiang Provincial Cancer Hospital, Haerbin, China; PLA Hospital 301, Beijing, China; Shao Yifu Hospital Zhejiang University, Hangzhou, China; No.1 Hospital Suzhou University, Suzhou, China; Jiangsu Provincial People's Hospital, Nanjing, China; General Hospital Beijing Military Area, Beijing, China

Background: Breast cancer is one of the most common malignancies in Chinese women. The mortality rate has increased over the past 20 years: in the urban Zhejiang Province, mortality increased from $6.56 / 100,000$ in $1990-1992$ to $8.01 / 100,000$ in 2000-2002. In HER2-positive MBC, adding $H$ to a taxane provides significant clinical benefit, including prolonged survival. $\mathrm{H}$ adds little to the toxicity profile of taxanes alone. $\mathrm{X}$ has consistently high activity and a favorable safety profile. Adding $X$ to docetaxel extends survival in MBC. Preliminary data (Bangemann et al. 2000 ) indicated that the combination of $H$ and $X$ is effective and well tolerated for intensively pretreated HER2-positive MBC (ORR $47 \%$ ). The current study evaluated the combination of $\mathrm{H}$ plus $\mathrm{X}$ as first-line therapy in HER2-positive MBC. Materials and Methods: 48 pts were enrolled between Mar 2003 and Oct 2004 All pts had measurable (WHO criteria), HER2-positive (IHC 3+ or IHC $2+$ /FISH positive) $\mathrm{MBC}$, KPS $\geq 60$, and adequate bone marrow, renal and hepatic functions. No prior chemotherapy for MBC was permitted. Pts received $\mathrm{H}$ as a $4 \mathrm{mg} / \mathrm{kg}$ loading dose followed by $2 \mathrm{mg} / \mathrm{kg}$ i.v. weekly (until disease progression) and $\mathrm{X}$ $1250 \mathrm{mg} / \mathrm{m}^{2}$ twice daily on $\mathrm{d} 1-14 \mathrm{q} 3$ wks (max 6 cycles). Results:
43 pts received at least 9 wks, 38 pts at least 18 wks, 33 pts at least $26 \mathrm{wks}, 11 \mathrm{pts}$ at least $34 \mathrm{wks}$, and $3 \mathrm{pts}$ at least $50 \mathrm{wks}$ of treatment. Baseline characteristics $(n=43)$ : median age 49 years (range 27-74), median KPS 90 (range 60-100). Principal tumor sites were lymph nodes (49\%), lung (33\%), liver (28\%), breast $(14 \%)$, thoracic wall $(9 \%)$, chest $(9 \%)$, other $(5 \%)$. Prior treatment included surgery $(74 \%)$, radiotherapy (19\%), and adjuvant chemotherapy $(65 \%)$, including anthracycline $(42 \%)$, docetaxel (9\%), and paclitaxel (7\%). In the 43 pts evaluable for safety, the most common grade $1 / 2$ adverse events were HFS (23\%), leucopenia (9\%), SGOT abnormality (9\%), and SGPT abnormality $(7 \%)$. Grade 3 HFS occurred in 4 pts $(9 \%)$ and grade 3 leucopenia in 1 pt $(2 \%)$; these events improved/resolved in all pts. In the 43 pts evaluable for efficacy, the ORR is $63 \%(n=27)$, including 8 CRs $(19 \%)$ and 19 PRs $(44 \%) .13$ pts $(30 \%)$ have stable disease. Median progression-free and overall survival have not been reached. Discussion: These results confirm that the combination of $\mathrm{H}$ and $\mathrm{X}$ is highly active and well tolerated as first-line treatment for HER2-positive MBC.

\section{2}

Weekly paclitaxel $(\mathrm{PCT}) \pm$ trastuzumab $(\mathrm{T})$ as first-line therapy of patients (pts) with HER-2/NEU positive metastatic breast cancer (MBC): final results of a multicenter randomized phase IIb trial.

Gasparini G. San Filippo Neri Hospital, Rome, Italy

The aim of the study was to demonstrate whether weekly PCT-T is superior to PCT alone in patients with HER-2/neu positive MBC. Primary end-point was time to progression (TTP); secondary end-points were safety, response rate (RR) and biological correlates (HercepTest (HT) vs FISH and serum HER-2 assay). Inclusion criteria were: untreated MBC with HER-2/neu overexpression $(2+$ or $3+$ by IHC Herceptest, HT), age $\geq 18$ and $\leq 70$ years, adequate organ functions, ECOG PS scale $\leq 2$. The schedules of therapy were: weekly PCT $80 \mathrm{mg} / \mathrm{m} 2$ (arm A) and weekly PCT+T (loading dose of $4 \mathrm{mg} / \mathrm{kg}$, followed by weekly doses of $2 \mathrm{mg} / \mathrm{kg}$ ) ( $(\mathrm{arm} \mathrm{B})$. Overall, 124 pts have been enrolled and 123 are evaluable $(A=60$; $\mathrm{B}=63$ ). Pts characteristics are well balanced: median age $54 \mathrm{yrs}$ in arm $\mathrm{A}$ and 56 yrs in B; postmenopausal pts $68 \%$ in $\mathrm{A}$ and $66 \%$ in $\mathrm{B}$; HT $3+73 \%$ in A and $63 \%$ in B; $\mathrm{ER}+55 \%$ in $\mathrm{A}$ and $41 \%$ in $\mathrm{B}$; $\mathrm{PR}+47 \%$ in $\mathrm{A}$ and $41 \%$ in $\mathrm{B}$, respectively. An identical percentage of pts $(57 \%)$ treated with adjuvant anthracyclines was enrolled in both arms. Tumor involvement in $>2$ sites was seen in $66,7 \%$ (A) and $60 \%(\mathrm{~B})$, visceral disease in $71,7 \%(\mathrm{~A})$ and $66,7 \%(\mathrm{~B})$, respectively. Both the treatments were well tolerated: grade 3 neuropathy was observed in $8,2 \%$ (A) and $4,8 \%$ (B); grade 3 neutropenia in $6,5 \%$ (A) and $12,7 \%$ (B), respectively; no grade 4 toxicity occurred. Overall, 118 pts are evaluable for RR: 58 (A) and 60 (B). The overall RR (56,9\% vs $75 \%)$ and time to progression $(234 \pm 22$ vs $278 \pm 19$ days) were better in arm B. In HT $3+$, TTP was $239 \pm 28$ days (A) vs $284 \pm 19$ days $(\mathrm{B})(\mathrm{p}=0.03)$, respectively; in pts with visceral disease TTP was $188 \pm 18$ days (A) vs $266 \pm 20$ days $(B)(p=0.008)$. The analysis of biological correlations is ongoing. In conclusion, $\mathrm{PCT} \pm \mathrm{T}$ is feasible and active and $\mathrm{T}$ significantly enhances TTP and response rates in the pts with HER2/neu positive MBC with visceral disease or HT 3+.

\section{3}

Capecitabine and trastuzumab: a phase II study in HER2overexpressing metastatic breast cancer (MBC) patients pretreated with anthracyclines and/or taxanes.

Schaller G, Bangemann N, Gonsch T, Weber J, Kleine-Tebbe A, Conrad B, Klare P, Hindenburg HJ, Ruhmland B, Lakner V, Hinke A. Breast Care Institute, Berlin, Germany; WiSP Research Institute, Langenfeld, Germany; Participating Centers, Germany

Background: Systemic treatment in the palliative setting after anthracycline and/or taxane pretreatment is often critical because of reduced drug tolerance and low performance status. Trastuzumab 
(Herceptin; H) and Capecitabine (Xeloda; X) in combination with taxanes have proven significant clinical benefits. Both $\mathrm{H}+\mathrm{X}$ have a mild spectrum of side effects. In-vivo data show that both these targeted drugs have at least additive activity. Therefore, we investigated the combination of $\mathrm{H}+\mathrm{X}$ in a clinical setting. Patients and Methods: Pts received $\mathrm{H} 4 \mathrm{mg} / \mathrm{kg}$ loading dose followed by 2 $\mathrm{mg} / \mathrm{kg}$ weekly and X $1,250 \mathrm{mg} / \mathrm{m} 2$ bi-daily, on days $1-14$ of a $21-$ day cycle, given until disease progression. Eligible pts, aged 18-75 (mean 54), had HER2 IHC $3+$ or IHC2+/FISH+ disease. Results: 27 pts with metastatic disease were enrolled in the study. Metastases were present in visceral organs in 20 pts $(73 \%)$, with liver metastasis in $13(48 \%)$ pts. Prior (neo)adjuvant chemotherapy was received by $24(88 \%)$ pts.; anthracyclines in $20(74 \%)$ and taxanes in 11 $(41 \%)$ of these cases. 10 pts. (37\%) had received palliative chemotherapy. The ORR was 52\% (per protocol; 4 CR, 8 PR) and $44 \%$ (intent-to-treat). The median progression-free survival was 29 weeks, and median overall survival 122 weeks to date. The combination was generally well tolerated. Grade 3/4 anaemia, leucopenia and thrombocytopenia were observed in only $8 \%, 4 \%$ and $4 \%$ of patients, respectively. Grade 3/4 non-haematological toxicities most frequently observed were: general pain $(28 \%)$, fatigue $(20 \%)$, hand-foot syndrome $(16 \%)$, vomiting $(12 \%)$ and nausea $(12 \%)$. Conclusions: These promising data illustrate the efficacy and high tolerability of the combination of $\mathrm{H}$ and $\mathrm{X}$ in patients with HER2-positive and intensively pretreated MBC, with a remarkably high number of long-term survivors. Further investigation is warranted to substantiate these findings.

\section{4}

Phase I and pharmacokinetics (PK) of combined erbB1 and erbB2 blockade with OSI-774 (Erlotinib; E) and trastuzumab $(T)$ in combination with weekly paclitaxel $(P)$ in patients (pts) with advanced solid tumors.

Beeram M, De Bono JS, Patnaik A, Mita A, Chu SC, Mita MM, O'Rourke $P$ Takimoto $C H$, Tolcher AW, Rowinsky EK. Univ of Texas Health Science Center at San Antonio, San Antonio, TX; Institute for Drug Development/ CTRC, San Antonio, TX

Background: Co-expression of erbB1 and erbB2 receptors confers a growth advantage in erbB2 overexpressing (+) cancers Specifically, co-expression alters the normal rapid internalization and inactivation of erbB1, slows dissociation of the erbB1 ligandreceptor complex and degradation of the active receptor. $\mathrm{Co}$ targeting both receptors together may offer a therapeutic advantage over targeting erbB2 alone, especially in T refractory solid tumors. A phase I and PK study was launched to determine the toxicity and recommended dose of continuous daily oral $\mathrm{E}$ in patients with erbB $2+$ cancers along with weekly $\mathrm{P}$ and $\mathrm{T}$, especially since $\mathrm{T}$ improves survival in combination with chemotherapy.

Methods: Eligible pts were treated with escalating doses of $\mathrm{E}$ and weekly T IV ( $2 \mathrm{mg} / \mathrm{kg} / \mathrm{wk}$ ) along with weekly P (starting at $80 \mathrm{mg}$ / $\mathrm{m}^{2}$ ). MUGA scans were performed at baseline and every 2 cycles ( 8 weeks). Two schedules- 3 out of 4 weeks and continuous weekly $\mathrm{P}$ and $\mathrm{T}$ were explored.

Results: To date, 16 pts [Breast (14), Colon (1) and Ovary (1)] have received 54 courses [median 2; range 1-13] in 4 cohorts, with $E$ at doses of $50(n=3), 100(n=9)$ and $150 \mathrm{mg}(n=4)$ PO daily for 28-days and $P$ at doses of $80-90 \mathrm{mg} / \mathrm{m}^{2}$ weekly for 3 out of 4 weeks. Pts were women with median age -54 yrs [range- 37-75] and PS 0 (4), PS 1 (11) and PS 2 (1). 9 pts received prior T therapy. Dose limiting grade (gr) 3 diarrhea and gr 3 dermatitis was seen in $1 \mathrm{pt}$ at $100 \mathrm{mg}$ of $\mathrm{E}$ and $80 \mathrm{mg} / \mathrm{m}^{2}$ of $\mathrm{P}$. Other toxicities included gr 2 diarrhea, skin rash, fatigue, neutropenia and alopecia. Significant asymptomatic drop in LVEF was noted in 1 pt after 3 courses, with rapid recovery upon stopping T. One complete, two partial and 1 minor responses have been seen in pts with breast cancers that have failed prior $\mathrm{T}$ therapy. Two breast cancer pts experienced stable disease lasting 13 and 6 courses, respectively. PK data does not suggest a clinically relevant interaction between the 3 agents. Plasma steady state concentratins of $\mathrm{E}$ were comparable to the steady state concentrations of E observed in population pharmacokinetics.

Conclusions: $\mathrm{E}$ combined with $\mathrm{T}$ and $\mathrm{P}$ provides a well-tolerated, targeted therapy with impressive anti-tumor activity in $\mathrm{T}$ refractory breast carcinoma. Dose escalation continues on the continuous dosing schedule.

\section{5}

A phase I-II study of trastuzumab, gefitinib, and docetaxel as first line chemotherapy in patients with HER-2 overexpressing stage IV breast carcinoma.

Somlo G, Koczywas M, Luu T, McNamara M, Russell C, Morgan $R$, Arnold K, Frankel P. City of Hope Cancer Center, Duarte, CA; University of Southern California, Los Angeles, CA

Background: Combining docetaxel with the HER-2 antibody trastuzumab yields superior outcome in comparison to docetaxel alone in patients with HER-2 overexpressing breast cancer. The outcome of experiments in HER-2 overexpressing breast cancer cells suggests synergistic activity when trastuzumab is combined with gefitinib, a tyrosine kinase inhibitor of EGFR.

Methods: Patients with HER-2 overexpressing breast cancer (defined by $3+$ immunohistochemical staining, or FISH positivity), with measurable, or evaluable disease were enrolled. Prior hormonal therapy, or adjuvant taxane or trastuzumab therapy were allowed if such therapy was prescribed $>6$ months prior to enrollment. A left ventricular ejection fraction of $>45 \%$ and SGOT/SGPT $<2.5$ times the upper limit of normal, and an ECOG performance status of $\leq 2$ were required. Patients were to receive docetaxel $75 \mathrm{~m}^{2}$, trastuzumab $8 \mathrm{mg} / \mathrm{kg}$ loading dose followed by $6 \mathrm{mg} / \mathrm{kg}$ every 3 weeks, and gefitinib $250 \mathrm{mg}$ daily.

Results: The first two patients treated at a docetaxel dose of 75 $\mathrm{mg} / \mathrm{m}^{2}$ developed grade 4 febrile neutrophenia, hence, all subsequent patients received treatment with docetaxel $60 \mathrm{mg} / \mathrm{m}^{2}$. So far 9 patients have been accrued. Patients received a median of 6 courses of therapy (range, $1+$ to 10 ); 2 of these patients just finished their first cycle. Toxicities have been manageable. There were 3 cases of febrile neutropenia (the first 2 after the first cycle at the phase I dose of docetaxel). One patient required reduction of docetaxel to $45 \mathrm{mg} / \mathrm{m}^{2}$ due to liver enzyme abnormalities. Gefitinib was held temporarily in 2 patients due to rash and in one patient due to diarrhea. No cardiac toxicities were noted. There were 4 partial responses, 3 cases of stable disease as best response, and 2 cases are too early to assess. The median time to progression is $6+$ months $(1+$ to $10+)$.

Conclusion: The combination of docetaxel, trastuzumab, and gefitinib is feasible. Response rates are encouraging. Due to recent data generated from studies in lung cancer suggesting a possible interaction between chemotherapy and gefitinib when given concurrently, and in order to further reduce toxicity, the schedule of gefitinib has been modified starting with patient number 9 , to $250 \mathrm{mg}$ on days $2-14$ of the 21 day cycle. Accrual is ongoing and additional data will be presented. Supported by NCI CA33572 and by a grant from AstraZeneca.

\section{6}

Effect of trastuzumab treatment as first-line on metastatic breast cancer: final results of the French HERMINE cohort after 2-year follow-up $(\mathbf{n}=\mathbf{2 2 1})$.

Namer M, Antoine EC, Le Deley MC, Vincent Salomon A, Pau D, Remblier C, Vasseur B, Extra JM. Centre Azureen de Cancerologie, Nougins, France; Clinique Hartmann, Neuilly-sur-Seine, France; Institut Gustave Roussy, Villejuif, France; Institut Curie, Paris, France; Roche, Neuilly-sur-Seine, France

Background: The efficacy and safety of trastuzumab (T) are well documented in clinical trials in HER2+ metastatic breast cancer (MBC). In this presentation, we compared our 2-year follow-up data on overall survival (OS), time to progression (TTP) and cardiac safety with M77001 (T+docetaxel arm) and H0648g 
(T+paclitaxel arm), two pivotal trials. Methods: This longitudinal, observational study assessed a 2-year follow-up of $623 \mathrm{MBC}$ patients (pts) treated with $\mathrm{T}$ and followed by 102 oncologists. Eligible pts started $\mathrm{T}$ in 2002. Data were collected from patient files from Nov 2003 to March 2005 and reviewed by an independent scientific committee. Results: $221 \mathrm{MBC}$ pts were given $\mathrm{T}$ as first-line therapy. Pt characteristics included: median age 54 years, median time from first diagnosis 3.5 years, median disease-free interval 1.6 years, MBC at diagnosis $19 \%$, ductal carcinoma 93\%, HER2+ (IHC 3+) $96 \%$, SBR grade III 65\%, ER+ and/or PR+ 42\%, ER+ and $\mathrm{PR}+23 \%$, ER- and PR- 59\%, past cardiac history 24\%. Prior disease management included surgery $(90 \%)$, radiotherapy $(79 \%)$, chemotherapy (78\%; anthracyclines $86 \%$ ) and hormonal therapy $(34 \%)$. T treatment was used in combination $(98 \%)$ with paclitaxel $(68 \%)$, vinorelbine $(31 \%)$, docetaxel $(26 \%)$ or others. Median T treatment duration was 16.2 months. Comparison of 2-year data between the HERMINE, M77001 $(\mathrm{n}=92)$ and H0648g $(\mathrm{n}=68)$ trials, respectively, showed: median OS 30.4, 31.2 and 24.8; median TTP 10.3, 11.7 and 7.1; adverse events (heart failure) 3\%, 2\% and $8.8 \%$. Conclusion: The final 2 -year results of this large cohort of MBC pts treated by $\mathrm{T}$ as first-line therapy and in reallife conditions are consistent with the cardiac safety and efficacy data from the M77001 and H0648g, two randomized controlled trials.

\section{7}

Improved breast cancer specific survival (BCSS): the impact of adjuvant systemic therapy.

Olivotto IA, Coldman AJ, Speers C, Phillips N, Goldrick A, Gelmon $K A$. BC Cancer Agency, Victoria and Vancouver, BC, Canada

Background: Both Adjuvant Systemic therapy (AST) since 1976, and screening mammography (Scr Mam) since the mid-1980's, have contributed to improved BCSS and reduced breast cancer mortality. The purpose of this study was to determine the relative contributions of AST and Scr Mam to improved BCSS in British Columbia (BC), Canada, since 1975.

Methods: All cases of female breast cancer (invasive or in situ) diagnosed in BC in 1975 (prior to AST or Scr Mam), 1985 (AST common, Scr Mam rare), 1995 (both AST and Scr Mam common) and 2000 (extended indications for AST, Scr Mam common) were identified from the BC Cancer registry. 10-year BCSS was determined through linkage with the Provincial Vital Statistics database. To determine population-based use of AST, a 50\% random sample of all women with a new diagnosis of breast cancer in BC in 1995, had demographic, pathology, stage, treatment and survival data abstracted from BC Cancer Agency (BCCA) records, or from primary physicians, if not referred to the BCCA. To determine the effect on BCSS of AST use in 1995, BCSS estimates with and without AST, as used in 1995, were calculated based on the mortality benefits of chemotherapy and/or tamoxifen from the 1998 Oxford Overview.

Results: 10-year BCSS improved significantly from $60 \%$ in 1975 to $66 \%$ in 1985 ( $\mathrm{p}<0.001)$ and $80 \%$ projected for 1995 ( $\mathrm{p}<0.001)$. 5-year BCSS was similar in 1995 and 2000; both 87\% (see figure).
Figure: Breast Cancer Specific Survival in British Columbia, Canada

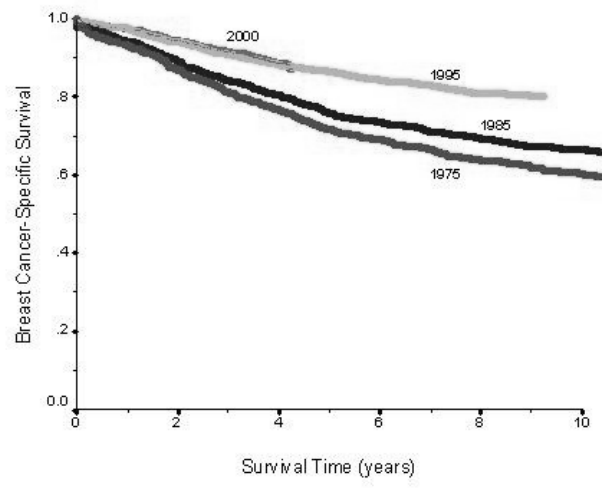

In BC in $1995,13 \%$ of patients had in situ disease alone, $83 \%$ had invasive, non-metastatic disease and $4 \%$ had metastatic disease with 10-year BCSS of $98 \%, 80 \%$ and $0 \%$, respectively. $57 \%$ of patients with invasive, non-metastatic disease received systemic therapy in 1995 as hormonal therapy alone (33\%), chemotherapy alone $(14 \%)$ or both hormonal and chemotherapy $(10 \%)$. For the distribution of patients presenting in 1995, if systemic therapy had not been used, the estimated 10-year BCSS would have been $74.1 \%$ compared to $80.2 \%$ observed.

Conclusion: Absolute 10-year BCSS improved by $20 \%$ for patients diagnosed in 1995 compared to 1975 and has subsequently plateaued. AST contributed $6.1 \%$ of this gain ( $30 \%$ relative). Increasing the proportion of low risk women using AST between 1995 and 2000 has contributed little to short-term, populationbased BCSS. New approaches are required to further improve BCSS.

\section{8}

Exploratory analysis from NCCTG N9831: do clinical and laboratory characteristics predict cardiac toxicity of trastuzumab when administered as a component of adjuvant therapy?

Perez EA, Suman VJ, Davidson NE, Kaufman PA, Martino S, Dakhil SR, Ingle JN, Rodeheffer RJ, Gersh BJ, Jaffe AS. NCCTG, Rochester, MN; ECOG, Philadelphia, PA; CALGB, Chicago, IL; SWOG, San Antonio, TX

Background: The benefits of adding trastuzumab (Herceptin, H) to adjuvant chemotherapy were demonstrated in a joint analysis from Intergroup NCCTG N9831 and NSABP B-31 trials (Romond 2005, Perez 2005). Significant improvements were observed in disease-free survival and overall survival in women with operable HER2 positive breast cancer. Approximately 2-3\% patients (pts) experienced a clinically significant cardiac event during the course of $\mathrm{H}$ treatment in the Intergroup NCCTG N9831 trial (Perez, 2005). This abstract will detail the follow-up and analysis of clinical/ laboratory factors that may be predictive of cardiac toxicity.

Methods: Demographic data included in this analysis are age, baseline left ventricular ejection fraction (LVEF), history of hypertension, use of antihypertensive therapy, therapeutic radiation exposure, site of radiation, and LVEF post anthracycline exposure. A cardiac event was defined as CHF or probable cardiac death. Pts underwent LVEF evaluations at 3 mos (after AC: doxorubicin, cyclophosphamide), at $6 \operatorname{mos}$ (after $\mathrm{T}$ or TH: paclitaxel with or without trastuzumab), 9 and 18-21 mos after study entry. Additional LVEF evaluations were performed if decreases met protocol-specified criteria, for decisions related to use of trastuzumab. A subset of 120 pts were enrolled in a sub-study to evaluate circulating markers of cardiac injury after the $1^{\text {st }}$ or $2^{\text {nd }}$ 
doses of $\mathrm{AC}, \mathrm{T}$ or $\mathrm{TH}$, or $\mathrm{H}$. These markers included troponins, BNP, TNF alpha, CD40, and others.

Results: Accrual to N9831 was completed as of April 29, 2005 with 3505 pts. Analysis of pts who developed a cardiac event, follow up of these pts in terms of symptoms and LVEF, the relationship of demographic factors with significant decreases in LVEF and/or cardiac events, as well as the percentage of pts who had to discontinue $\mathrm{H}$ therapy due to symptomatic and asymptomatic decreases in LVEF will be updated in the Fall of 2005 and available for presentation. Data of relationship of cardiac events with baseline and post AC LVEF are being analyzed, and are to be updated this Fall. Data of the percentage of pts with LVEF below 50\% at the 18-21month follow up for Arms A, B, and C will also be available, as well as data related to circulating cardiac markers.

Conclusions: Adjuvant trastuzumab after anthracycline based chemotherapy leads to a an approximate $2.3-3.3 \%$ rate of significant clinical cardiac events. Most, but not all pts recover cardiac function following treatment for cardiac dysfunction. Additional pt follow up, analysis of circulating markers and SNP polymorphisms are under evaluation. The predictive value of demographic and clinical factors with cardiac events will be presented.

\section{9}

Final analysis of a planned comparison of menopausal symptoms in 1618 patients receiving either exemestane (E) or tamoxifen (T) in a blinded adjuvant hormonal study. Asmar L, Cantrell J, Vukelja SJ, Pippen J, O'Shaughnessy J, Blum JL, Brooks R, Mull S, Ilegbodu D, Jones S. US Oncology Research, Inc., Houston, TX

Background: We assessed 10 menopausal symptoms during the blinded first year of the randomized Phase III TEAM trial in postmenopausal women with early-stage hormone receptorpositive breast cancer treated for 5 years with exemestane (E) or tamoxifen (T).

Methods: This analysis is based on a review of 7287 validated Menopausal Symptoms Questionnaires. Each patient assessed 10 symptoms at baseline and every 3 months as none, mild, moderate, or severe. A "hot flash score" was added on as a bivariate construct to quantify hot flash frequency per day and average intensity. All menopausal symptoms were analyzed statistically by repeated measures ANOVA. Each time period was repeatedly tested against the baseline. Then, an overall $\mathrm{p}$ value was given for each time period. Finally, the proportion of patients experiencing each side effect at the quarterly follow-up was calculated and compared by treatment arm.

Results: The median age of 1618 eligible patients was 64 years (range, $40-90$ ). Completion of the questionnaires ranged from $99 \%$ at baseline to $81 \%$ at 12 months. Most menopausal symptoms were mild or moderate. Baseline symptom assessment in both arms showed difficulty in sleeping and low energy among $60 \%$ and $74 \%$ of patients, respectively. When comparing the proportion of patients with mild to severe symptoms, there were no significant differences between the 2 treatment arms with respect to vaginal bleeding, mood alteration, or low energy. However, patients receiving $\mathrm{T}$ had more vaginal discharge $(\mathrm{p}<0.0001)$, and the following symptoms were more frequent among patients receiving E: vaginal dryness $(\mathrm{p}=0.0004)$, impaired word finding $(\mathrm{p}=0.0057)$, bone/muscle aches $(\mathrm{p}<0.0001)$, decreased libido $(0.03)$, and difficulty sleeping $(\mathrm{p}=0.03)$. In both groups, hot flashes peaked at 3 months and decreased thereafter. At 12 months, patients receiving $\mathrm{T}$ had a higher mean hot flash score $(\mathrm{p}=0.0253)$ with the number of hot flashes/day increasing by $33 \%$ in the $\mathrm{T}$ group and by $7 \%$ in E. Additional results will be presented on the differences at each time period and the proportion of patients experiencing each symptom by intensity.

$\begin{array}{lll}\begin{array}{l}\text { Menopausal Symptoms Analysis } \\ \text { Symptom }\end{array} & \begin{array}{l}\text { P value } \\ <0.0001\end{array} & \text { Worse with } \\ \text { Vaginal discharge } & 0.1697 & \mathrm{~T} \\ \text { Vaginal bleeding } & 0.0004 & \mathrm{E} \\ \text { Vaginal dryness } & 0.9769 & \\ \text { Mood alteration } & 0.0057 & \mathrm{E} \\ \text { Impaired word finding } & <0.0001 & \mathrm{E} \\ \text { Bone/muscle aches } & 0.6924 & \\ \text { Low energy } & 0.0343 & \mathrm{E} \\ \text { Decreased libido } & 0.0346 & \mathrm{E} \\ \text { Difficulty sleeping } & 0.0253 & \mathrm{~T} \\ \text { Hot flashes } & 12 \mathrm{mon}\end{array}$

Conclusion: Following 12 months of therapy, E therapy was associated with significantly fewer hot flashes but with more vaginal dryness, impaired word finding, and bone/muscle aches. Supported by Pfizer, New York, NY

\section{0}

Impact of letrozole on quality of life in post-menopausal women with early breast cancer: does age matter?

Barghout V, Abetz L, Thomas S, Arbuckle R. Novartis Pharmaceuticals, Florham Park, NJ; Mapi Values, Macclesfield, Cheshire, United Kingdom

Introduction: MA-17 was a randomized placebo-controlled trial that compared the efficacy and safety of 5 years of letrozole (Femara $\left.{ }^{\circledR}\right) 2.5 \mathrm{mg} / \mathrm{d}$ versus placebo and related QoL impact on postmenopausal women with early breast cancer, after 5 years of tamoxifen. Due to significant lowering in risk of disease recurrence and distant metastases observed with letrozole, the trial was unblinded early after 2.4 years mean follow-up. Evaluation of QoL impact may vary by age, thus the objectives were to describe QoL scores by treatment group and age $(<65 ;>=65)$ for US and Canada in MA-17. Methods: The generic validated QoL scale (SF-36 Health Survey) and the validated menopause symptom scale (MENQOL) were administered. The SF-36 yielded 2 summary scores providing a global indicator of patients' physical and mental QoL and 8 subscales. Symptom impact associated with estrogen suppression was assessed using 4 domains of the MENQOL. Due to the early unblinding of MA17, differences in SF-36 and MENQOL scores between treatment groups are reported only for the first 3 years of the study $(6,12,24,36$ months), using non-parametric testing. Results: Across all time points and both age groups (younger and older) for US and Canada, no significant differences between letrozole and placebo were observed for SF-36 mental and physical QoL summary scores. In the younger age group, no differences were observed all 8 sub domains of the SF-36 in the US and for 6 out of 8 sub domains in Canada; significant differences in favour of placebo were observed for bodily pain (month 6) and general health (month 24) in Canada. In the older age group, no significant differences were observed across all time points for all of the 8 sub domains of the SF-36 in Canada and in 5 out of the 8 subscales in the US; significant differences favouring placebo were observed for physical functioning, vitality and social functioning (month 6). Across all time points and both age groups for US and Canada, no significant differences were observed for MENQOL psychosocial and physical domains. Significant differences in MENQOL vasomotor symptoms favouring placebo were observed in both countries in the younger age group (Canada: months 12 and 24; USA: months 6 and 12) and for the older age group in the USA (month 24). Significant differences favouring letrozole were observed in the MENQOL sexual scale at months 12 and 24 in the younger group in Canada. All observed significant differences were less than 5 points on a 100 point scale and were not considered clinically relevant based on current methodology. Conclusions: Extended adjuvant treatment with letrozole after standard adjuvant tamoxifen in postmenopausal women provides improved efficacy while not worsening QoL relative to placebo, regardless of women's age 
2041

Preliminary cardiac safety results of dose-dense (DD) doxorubicin and cyclophosphamide (AC) followed by paclitaxel $(T)$ with trastuzumab $(H)$ in HER2/neu overexpressed/Amplified breast cancer (BCA).

Dang $C$, Smith $K$, Lake D, Fornier M, D'Andrea G, Seidman A, Sklarin N, Troso-Sandoval T, Sugarman S, Gilewski T, Robson M, Drullinsky P, Moynahan M, George R, VanPoznak C, Panageas $K$, Smith M, Norton L, Hudis C. Memorial Sloan-Kettering Cancer Center, New York, NY

Background: With the superiority of DD q 2 weekly (w) AC $\rightarrow$ $\mathrm{T}$ over conventionally scheduled AC $\rightarrow \mathrm{T}$ in CALGB 9741(Citron et al, J Clin Oncol 21: 1431-1439, 2003) and the known cardiac safety data of adjuvant $\mathrm{H}$ in NSABP B-31 (Geyer $\mathrm{C}$ et al, SABCS 2003, Romond et al, ASCO 2005), NCCTC N9831 (Perez et al, ASCO 2005), and HERA trial (Piccart-Gebhart et al, ASCO 2005), we are testing DD q $2 \mathrm{w} \mathrm{AC} \rightarrow \mathrm{T}+\mathrm{H}$ x one year as adjuvant treatment (Rx) of patients (pts) with HER2/neu-overexpressed/ amplified BCA to determine cardiac safety. Based on the reported cardiac event $(\mathrm{CE})$ rate of $\leq 4 \%$ in these trials in pts who received conventionally scheduled chemotherapy $+\mathrm{H}$, we planned this trial evaluating $\mathrm{DD}$ q $2 \mathrm{w} \mathrm{AC} \rightarrow \mathrm{T}+\mathrm{H}$. The primary endpoint is cardiac safety, defined as discontinuation of $\mathrm{H}$ due to 1) cardiac death or 2) symptomatic congestive heart failure defined as dyspnea with normal activity or at rest and absolute decline in left ventricular ejection fraction (LVEF) by $>10 \%$ to $<55 \%$ or $>5 \%$ below $55 \%$ by multi-gated radionuclide angiography scan (MUGA).The secondary endpoint is time to recurrence and overall survival. Although the incidence of late cardiac toxicity was low with DD q 2 w AC $\rightarrow$ T in CALGB 9741, LVEF was not monitored post-Rx. In this study, data will be available on the cardiac effects of DD AC as well as that of $\mathrm{H}$ with DD AC $\rightarrow \mathrm{T}$.

Methods: Pts with HER2/Neu IHC 3+ or FISH-amplified BCA were enrolled, regardless of tumor size or nodal status. Rx consisted of AC at $60 / 600 \mathrm{mg} / \mathrm{m}^{2} \times 4 \rightarrow \mathrm{T}$ at $175 \mathrm{mg} / \mathrm{m}^{2} \times 4 \mathrm{q} 2 \mathrm{w}$ with pegfilgrastim $6 \mathrm{mg}$ on day $2+\mathrm{H} \mathrm{x}$ one year $(\mathrm{H} 4 \mathrm{mg} / \mathrm{kg}$ bolus and $2 \mathrm{mg} / \mathrm{kg} \mathrm{q} \mathrm{w}$ during T and $6 \mathrm{mg} / \mathrm{kg} \mathrm{q} 3 \mathrm{w}$ after all chemotherapy is completed). MUGA is obtained at baseline and at months 2, 6, 9, and 18. Pts with baseline LVEF of $\geq 55 \%$ and without cardiac illnesses as specified by the study are eligible. Pts with significant asymptomatic LVEF decline after DD AC based on month 2 MUGA will not receive $\mathrm{H}$, and pts with significant asymptomatic LVEF decline during $\mathrm{H}$ may have $\mathrm{H}$ held permanently, as per protocol. These pts will not be counted to have suffered a true CE and will be followed long-term with more cardiac monitoring.

Results: From January 4, 2005 to May 20, 2005, we enrolled 34 of 70 planned pts. Median age is 52 years (range, 31-79). Median baseline LVEF is $70 \%$ (range, 55-79 \%). As of May 31, 2005, 22 pts have had month 2 MUGA after DD AC and there has been no significant LVEF decline.

Discussion: This is the first report of cardiac safety of DD AC $\rightarrow$ $\mathrm{T}+\mathrm{H}$. Updated results will be available. If this $\mathrm{Rx}$ is feasible, it may change the standard of care in treating HER2/neu overexpressed/amplified BCA pts.

\section{2}

NCIC CTG MA17: disease free survival according to estrogen receptor and progesterone receptor status of the primary tumor.

Goss PE, Ingle JN, Tu D. Massachusetts General Hospital Cancer Center, Boston, MA; Mayo Clinic, Rochester, MN; Cancer Research Institute, Queen's University, Kingston, ON, Canada

Background: Identifying biomarkers to predict response to adjuvant aromatase inhibitor therapy is important. In the ATAC trial (anastrozole vs tamoxifen) benefit of anastrozole over tamoxifen appeared restricted to the ER+ PgR - patients and not in those with ER+ PgR+ tumors. In contrast in the BIG 1-98 trial LET appeared equally superior to tamoxifen in both the ER+PgR+ and ER+PgR- subgroups. MA.17 randomized 5187 postmenopausal women disease free after 5 years of tamoxifen to 5 years of letrozole or placebo. Almost all patients (97.4\%) had estrogen receptor (ER) and/or progesterone receptor ( $\mathrm{PgR}$ ) positive primary tumors. We present here on the outcome of women in MA.17 according to the receptor status of their primary tumors.

Materials and Methods: The ER and PgR values were both known in 4653 patients and retrospective exploratory analyses were conducted to compare time to recurrence in the four receptor sub-groups by ER (+/-) and PgR (+/-) status. ER and PgR positivity was defined as $\geq 10 \mathrm{fmol} / \mathrm{mg}$ protein, or positive by ERICA or PgRICA.

Results: The DFS events according to treatment arm and receptor status are given in the table below. The benefit of letrozole was clearly present in women with $\mathrm{ER}+\mathrm{PgR}+$ tumors and apparently absent in women with $\mathrm{ER}+\mathrm{PgR}-(\mathrm{p}=0.02$ for the comparison of HRs of treatment effect between these two groups). Adjustment for nodal status and prior adjuvant chemotherapy did not affect this result.

$\begin{array}{lllll} & \mathrm{n} & \text { Letrozole (L) events } & \text { Placebo (P) events } & \text { HR* L vs P (95\% CI) } \\ \text { ER+PgR+ } & 3809 & 60(3 \%) & 117(6 \%) & 0.50(0.360 .68) \\ \text { ER+PgR- } & 636 & 19(6 \%) & 17(5 \%) & 1.19(0.622 .29) \\ \text { ER-PgR+ } & 200 & 4(4 \%) & 5(5 \%) & 0.62(0.172 .31) \\ \text { ER-PgR- } & 8 & - & - & -\end{array}$

*Hazard ratios for events in DFS (HR less than one indicates value in favor of letrozole) Conclusions: InMA.17, the effect of LET relative to placebo appears most pronounced in women with the most hormone dependent, ER+ PgR+, tumors. Its apparent lack of benefit in patients with ER+ PgR- suggests that a functional ER is necessary for letrozole to have an effect following 5 years of tamoxifen. These results should be interpreted with caution as this was an unplanned analysis and the receptor levels were measured locally. We plan to centrally measure standard ER and PgR levels and to compare them to quantitative assessment by immunofluorescence.

\section{3}

Bone mineral density loss in premenopausal women given adjuvant chemotherapy for early breast cancer is independant of effects on ovarian function.

Cameron DA, Douglas S, Creiger J, Anderson RA. Western General Hospital, Edinburgh, Scotland, United Kingdom; University of Edinburgh, Edinburgh, Scotland, United Kingdom

Because the treatment of premenopausal breast cancer is known to induce bone loss, and chemotherapy induces ovarian failure, it is often assumed that estrogen deficiency is the main cause of bone loss.

We now have data on the changes in bone mineral density, menstrual diaries and serum estradiol and FSH levels in 56 prospectively recruited pre-menopausal women for the first two years following diagnosis of early breast cancer: median age 41 (range 28.5 to 53). 41 women received adjuvant chemotherapy, of which 33 went on to get hormonal therapy on completion of the chemotherapy, with no patient given hormonal therapy concomitantly with their chemotherapy. 14 women received endocrine therapy alone, of which 9 had goserilin + tamoxifen $(8$ cases) /goserilin+aromatase inhibitor (1 case) (ovarian suppression group), and 5 who had tamoxifen alone. Baseline lumbar spine BMD was significantly greater than the normal population ( $\mathrm{z}$ score $0.28 \pm 0.14$, $($ mean \pm sem $), p=0.047)$, and had fallen from $1.06 \pm 0.02$ to $1.01 \pm 0.02$ (mean $-3.6 \%, \mathrm{p}<0.001)$ at 6 months in the 41 women receiving chemotherapy, and from $1.04 \pm 0.03$ to $0.99 \pm 0.03$ in the ovarian suppression group $(\mathrm{p}<0.01)$. Serum estradiol was unchanged in the chemo group $(298 \pm 24$ to $353 \pm 59 \mathrm{pmol} / 1)$ but was appropriately reduced in the ovarian suppression group ( $335 \pm 57$ to $63 \pm 9$ ). FSH was markedly increased in the chemo group $(10.4 \pm 1.4$ to $42.1 \pm 4.3 \mathrm{IU} / \mathrm{L})$ and fell in the ovarian suppression group $(6.2 \pm 0.5$ to $1.9 \pm 0.5)$. Tamoxifen treatment following chemotherapy resulted in continuing bone loss $(0.97 \pm 0.03$ to $0.95 \pm 0.03$ over 6 months, $\mathrm{p}=0.002)$ irrespective of estradiol concentrations. Tamoxifen therapy alone caused bone 
loss that was significant after 12 months $(0.97 \pm 0.02$ to $0.94 \pm 0.02$, $\mathrm{p}=0.03$ ).

There were no significant differences in the fall in BMD over the first 6 months of treatment according to age, chemotherapy regimen, or by oestrogen level or menstrual function.

During the second 6 months of treatment (ie following chemotherapy), there was a much greater fall in BMD in those women who were amenorrhoeic $(7.0 \%$ vs $2.9 \%, \mathrm{p}<0.001)$, who also had lower E2 than those maintaining ovarian function. Conclusion

These data strongly suggest that the administration of standard adjuvant chemotherapy and/or supportive medication directly reduces bone mineral density in premenopausal women independent of any effects on ovarian function.

Furthermore, the mechanism of this change may be different from that seen with endocrine therapy, as despite evidence of ovarian damage in the chemo group (elevated FSH), estradiol production was not suppressed. This may be a direct effect of the chemotherapeutic drugs on bone turnover, but it is also possible that dexamethasone given as an anti-emetic may contribute to this.

$\begin{array}{lllll}\text { \% BMD fall } & \text { Under 40? } & \text { Anthracycline? } & \begin{array}{l}\text { Oestradiol } \\ <100 \mathrm{pml} / \mathrm{L} ?\end{array} & \begin{array}{l}\text { Continuing } \\ \text { menstruation? }\end{array} \\ \text { Yes } & 3.0 & 3.7 & 3.2 & 3.8 \\ \text { No } & 4.1 & 2.7 & 3.7 & 3.3\end{array}$

\section{4}

Health-related quality-of-life and psychological distress of breast cancer patients after surgery during phase III randomized trial comparing further tamoxifen with switching to anastrozole after adjuvant tamoxifen for 1 to 4 years: N-SAS BC 03.

Ohsumi S, Shimozuma K, Ohashi $Y$, Nishiuchi $H$, Aihara $T$, Takatsuka Y. National Hospital Organization Shikoku Cancer Center, Matsuyama, Ehime, Japan; University of Marketing and Distribution Sciences, Kobe, Hyogo, Japan; University of Tokyo, Tokyo, Japan; Kansai Rosai Hospital, Amagasaki, Hyogo, Japan Backgroud: Although tamoxifen (TAM) has been a standard adjuvant endocrine therapy for postmenopausal women with breast cancer for a long time, aromatase inhibitors (AIs) are regarded as alternatives of TAM now. The results of the randomized controlled trials comparing TAM with AIs in the adjuvant setting have shown better disease free survival in favor of AIs. However, very limited data have been reported regarding heath-related quality of life (HRQOL) outcomes of the patients who changed their adjuvant treatment from several years' TAM to AI. Patients and Methods: Recurrent-free breast cancer patients were serially enrolled in a phase III randomized trial: National Surgical Adjuvant Study of Breast Cancer (N-SAS BC) 03. Primary endpoints of the N-SAS BC 03 trial were disease-free survival and adverse events. HRQOL and psychological distress were included in secondary endpoints. Eligible patients were postmenopausal women who had received definitive surgery for primary breast cancer with positive hormone receptor(s), and had been taking TAM for 1 to 4 years after the surgery. They were randomly assigned to continue TAM or to switch from TAM to anastrozole (ANA) after obtaining written informed consent. They were asked to answer patient-administered instruments to assess HRQOL (FACT-B [breast cancer scale] and FACT-ES [endocrine symptom scale]) and psychological distress (CES-D: Center for Epidemiologic Studies Depression scale) at the randomization (baseline), 3 months, and 1 year after the randomization. HRQOL and psychological distress scores during this period were compared using the general linear model with correlated errors. Results: There was no difference in demographic and medical characteristics between the two treatment groups. The response rate of the questionnaires was more than $90 \%$ at baseline. At baseline 555 patients (276 in TAM group and 279 in ANA group) answered them. The scores of FACT-G, FACT-B, and FACT-ES were significantly better in TAM group than in ANA group $(\mathrm{p}=0.012, \mathrm{p}=0.010$, and $\mathrm{p}=0.015$, respectively). However, any significant differences were found between the two treatment groups for the scores of CED-D, subscales of FACT-G, FACT-B, and FACT-ES. Conclusions: Further TAM treatment after adjuvant TAM for 1 to 4 years may provide breast cancer patients with better HRQOL comparing with switching to ANA.

\section{5}

Leuprorelinacetate 3 month-depot versus CMF as adjuvant treatment in receptor- and node-positive premenopausal patients with breast cancer: long term results of the TABLE-Study.

Schmid P, Possinger K, Kassjanenko I, Vassiljev L, Meurer J, Tschaika M, Maubach L, Wallwiener D, Kahlert S, Untch M. Universitaetsmedizin Charité Campus Mitte, Berlin, Germany; Institute for Experimental Oncology, Kiew, Ukraine; Institute for Medical Radiology, Charkov, Ukraine; Omnicare CR, Cologne, Germany; Pharma East, Berlin, Germany; Takeda Pharma, Aachen, Germany; University, Tuebingen, Germany; University, Munich, Germany

\section{Background:}

Ovarian supression with LHRH-analogues (LHRHa) has been shown to be an effective adjuvant treatment for premenopausal patients with hormone receptor positive $(\mathrm{HR}+)$ breast cancer. We previously reported results of a randomized phase III trial comparing the efficacy and safety of a 2 year treatment with the 3 months-depot LHRHa leuprorelinacetate (LAD 3M) and a 6 months CMFchemotherapy. This paper provides updated results after a median follow-up of 5.8 years.

Patients and Methods: Pre- or perimenopausal patients with $\mathrm{HR}+(96.8 \%)$ or unknown, node-positive, early breast cancer $\left(\mathrm{pT}_{1}\right.$. ${ }_{3}, \mathrm{~N}_{+}, \mathrm{M}_{0}$ ) were randomly assigned to receive 2 years treatment of LAD-3M (11.25 mg as s.c. injection) or 6 courses of i.v. CMF (C $500 \mathrm{mg} / \mathrm{m}^{2}, \mathrm{M} 40 \mathrm{mg} / \mathrm{m}^{2}$, F $600 \mathrm{mg} / \mathrm{m}^{2}$, days $\left.1 \& 8 \mathrm{q} 4 \mathrm{w}\right)$. Primary endpoint was 2-year progression free survival (2yPFS). Secondary endpoints included 5-years PFS, overall survival (OS), tolerability, estradiol (E2) serum levels and menstrual status. Statistical analysis was designed to test for non-inferiority of LAD 3M.

Results: 599 patients were enrolled in the trial. There were no significant differences between the two treatments in $2 y$ PFS (LAD-3M 77.9\%, CMF 71.2\%) and 5y PFS (LAD-3M 53.4\%, CMF $49.8 \%$ ) according to ITT analysis. At a median follow-up of 5.8 years 276 events (LAD-3M 127, CMF 149) have been reported accounting for a mean PFS of 6.0 years for LAD-3M and 5.7 years for CMF, respectively $(\mathrm{p}=0.24)$. To date, 197 patients have died (LAD-3M 83, CMF 114; $<<0.01$ ). During LAD-3M treatment amenorrhea was observed in $\geq 95.7 \%$ of patients. After the end of LAD-3M treatment the amenorrhea rate decreased to $66 \%$ within 6 months and remained between $55 \%$ an $60 \%$ for the following 3 years. In contrast, the amenorrhea rate was $43.9 \%$ at 3 months in the CMF-group but continuously increased to $72.7 \%$ after 5 years. Conclusion: This up-date analysis confirms that the 2 year hormonal treatment with the LAD-3M is an effective adjuvant treatment in premenopausal $\mathrm{HR}+, \mathrm{N}+$ breast cancer patients that is non inferior to CMF chemotherapy. As expected there is a higher rate of menstrual recovery following LAD-3M. The safety profile is in favour of LAD-3M.

\section{6}

The effects of atamestane and toremifene alone or combined on bone, serum lipids and uterus, comparing them to letrozole in the ovariectomized rat.

Goss PE, Qi S, Hu H, Cheung AM, Lang W, Blanchett DG, Langecker PJ. Massachusetts General Hospital Cancer Center, Boston, MA; Toronto General Hospital, Toronto, ON, Canada; Intarcia Therapeutics, Inc., Emeryville, CA

Background: Aromatase inhibitors (AI) and anti-estrogens combined may allow more complete blockade of estrogenic signaling than either compound alone. In contrast to other 


\section{S100 Abstracts - Poster Session II}

combinations, the steroidal AI atamestane (ATA) and the antiestrogen toremifene (TOR) have shown no PK interaction. We evaluated the effects of ATA and TOR alone or combined on bone, serum lipids and uterus in ovariectomized (OVX) rats, and compared them to the non-steroidal AI letrozole (LET).

Methods: ATA $15 \mathrm{mg} / \mathrm{kg}$, b.i.d.; TOR $10 \mathrm{mg} / \mathrm{kg}$, LET $1 \mathrm{mg} / \mathrm{kg}$ and Flutamide (FLT) $10 \mathrm{mg} / \mathrm{kg}$, q.d. were given by oral gavage to OVX rats for 16 weeks, after which uterine weight and histology, lumbar vertebral and femoral bone mineral density (BMD), mechanical testing, histomorphometry, serum cholesterol $(\mathrm{CH})$, low-density lipoprotein (LDL) and triglycerides (TG) were measured.

Results: 1) lumbar spine BMDs were $10.4 \%, 7.3 \%, 14.6 \%$ and $16.8 \%$, higher in OVX animals given ATA, ATA + FLT, TOR, and TOR + ATA, respectively, than in OVX controls $(\mathrm{p}<0.01)$. Similar effects were observed on femoral BMDs. 2) The OVX animals given ATA, ATA + FLT, TOR, and TOR + ATA had a $14.8 \%$, $13.1 \%, 18.3 \%$ and $23.4 \%$ increase, respectively, in three-point bone bending strength compared to OVX controls $(\mathrm{p}<0.01)$. Similar effects were observed on compressive strength of the fifth lumbar vertebra. 3) Trabecular bone volume was significantly higher, and osteoid parameters showed a significant decrease in OVX rats treated with ATA, ATA + FLT, TOR, and TOR + ATA than in OVX controls. 4) ATA had no stimulatory effect on uterine weight compared to OVX controls while OVX rats given TOR and TOR + ATA had an increase by $69 \%$ and $70 \%(\mathrm{p}<0.0001)$ in uterine weight. 5) OVX rats given TOR and TOR+ATA caused $58.8 \%$ and $56.4 \%$ decrease in serum $\mathrm{CH}, 83.5 \%$ and $80.2 \%$ decrease in serum LDL, and $31.2 \%$ and $31.6 \%$ decrease in serum TG, respectively, compared to OVX controls $(\mathrm{p}<0.01)$. 6) OVX rats given LET had $\mathrm{BMD}$, mechanical properties, morphometry, lipid levels and uterine weight similar to OVX controls.

Conclusions: In OVX rats, ATA, distinct from LET, significantly prevents osteoporosis but this effect is not blocked by FLT and appears to be non-androgenic. ATA has no stimulatory effect on uterine weight indicating an absence of an intrinsic estrogenic signal. Thus ATA + TOR are being investigated clinically as an alternative to anastrozole and tamoxifen (ATAC) as a total estrogen blockade. Lower doses of TOR merit further testing in this rat model of end-organ effects.

\section{7}

Letrozole did not worsen quality of life relative to placebo in post-menopausal women with early breast cancer: results from the US subjects of the MA-17 study.

Abetz L, Barghout V, Thomas S, Arbuckle R. Mapi Values, Bollington, Macclesfield, United Kingdom; Novartis Pharmaceuticals, Florham Park, NJ

Introduction: MA-17 was a randomized placebo-controlled trial that compared the efficacy and safety of 5 years of letrozole (Femara $\left.{ }^{\circledR}\right) 2.5 \mathrm{mg} / \mathrm{d}$ versus placebo and related QoL impact on postmenopausal women with early breast cancer, after 5 years of tamoxifen. Due to significant lowering in risk of disease recurrence and distant metastases observed with letrozole, the trial was unblinded early after 2.4 years mean follow-up. Earlier studies have reported that letrozole did not worsen patient's QoL relative to placebo in this population. Evaluation of QoL impact may vary by place of residence, thus this analysis report the QoL results for the US subjects in MA-17. Methods: The generic validated QoL scale (SF-36 Health Survey) and the validated menopause specific scale (MENQOL) were administered. The SF36 yielded 2 summary scores providing a global indicator of patients' physical and mental QoL and 8 subscales. Symptom impact associated with estrogen suppression was assessed using 4 domains of the MENQOL. Due to the early unblinding of MA17, differences in SF-36 and MENQOL change scores between treatment groups are reported for the first 3 years of the study $(6,12,24,36$ months), using non-parametric testing. Results: Across all time points, no significant differences were observed between letrozole and placebo in the overall QoL summary scores (mental and physical) and 5 of 8 sub-domains of SF-36. Small but significant differences in favour of placebo was observed on SF-36 rolephysical, role-emotional subscales at month 12 and vitality subscale at month 12 and 24. Across all time points, no significant differences were observed for MENQOL psychosocial and physical domains. Small but significant differences in favour of placebo were observed for the vasomotor scale at months 6,12 and 24 and a significant difference in favour of letrozole, was observed in the sexual scale at month 24 . All observed significant differences were less than 5 points on a 100 point scale and therefore were not considered clinically relevant based on current methodology. Conclusions: In the US, extended adjuvant treatment with letrozole after standard adjuvant tamoxifen in postmenopausal women provides improved efficacy while not worsening QoL relative to placebo.

\section{8}

\section{Withdawn by Author}

\section{9}

Impact of Oncotype $\mathrm{DX}^{\mathrm{TM}}$ on decision making in breast cancer clinical practice.

Oratz R, Paul D, Cohn A, Sedlacek S. NYU School of Medicine, New York, NY; Rocky Mountain Cancer Centers, Denver, CO

Background: The Oncotype DX Recurrence Score (RS) has been validated to predict the likelihood of distant recurrence as well as response to hormonal therapy (HT) and chemotherapy (CT). This study was designed to determine if the RS influenced treatment decisions in a community based, oncology practice.

Methods: The experience with the RS in the community practice of four oncologists was reviewed. RS was ordered on tumors from 74 patients (pts) with ER (+) stage I or II BC. Demographic information and details of pathology were extracted from medical records. 10-year relapse free survival was calculated using Adjuvant Online. Physician (MD) treatment $(\mathrm{Rx})$ recommendation prior to knowledge of $\mathrm{RS}$ was compared to $\mathrm{MD} \mathrm{Rx}$ recommendation after RS and the Rx actually administered.

Results: RS was obtained in $72 / 74$ pts (97\%). 2 pts (3\%) had insufficient tumor tissue. In 4 pts MD Rx recommendation prior to $\mathrm{RS}$ and/or actual $\mathrm{Rx}$ received were unknown. 68/72 pts were evaluable: 67 female and 1 male. Median age was 54 yrs (range 35 77) and mean tumor size was $1.2 \mathrm{~cm}(\mathrm{SD} 0.6 \mathrm{~cm})$. Tumor grade was $44 \%$ grade $1,35 \%$ grade 2 , and $21 \%$ grade 3 . The distribution of RS was similar to that observed in previous studies. Mean RS was 22 (range 5-68); 32 pts $(47 \%)$ were low risk $(\mathrm{RS}<18), 22$ pts $(32 \%)$ were intermediate risk (RS 18-30), and $14(21 \%)$ pts were high $\operatorname{risk}(\mathrm{RS} \geq 31)$. The correlations of $\mathrm{RS}$ with patient age $\left(\mathrm{R}^{2}=0.04\right)$ and tumor size $\left(\mathrm{R}^{2}=0.07\right)$ were low. The rank correlation of RS with tumor grade $\left(\mathrm{R}^{2}=0.34\right)$ was modest. Although some correlation was seen between the likelihood of distant recurrence based on the $\mathrm{RS}$ and the likelihood of relapse based on Adjuvant Online $\left(\mathrm{R}^{2}=0.43\right)$, there was a highly significant difference $(\mathrm{p}<0.0001)$. Knowledge of the RS altered MD Rx recommendation in 14/68 (21\%) pts and altered actual $\mathrm{Rx}$ administered in $17 / 68(25 \%)$ pts. Prior to knowing RS, MD Rx recommendation was HT in $51 \%$ and combined HT + $\mathrm{CT}$ in $49 \%$. Post RS, MD Rx recommendation was HT in $51 \%$, $\mathrm{CT}$ alone in $6 \%$, and $\mathrm{HT}+\mathrm{CT}$ in $42 \%$ pts. Actual Rx administered was HT in $68 \%$; CT in $4 \%$ and HT + CT in $28 \%$. Of the 14 pts in whom MD Rx recommendations changed, 7 went from CT to HT and 7 went from HT to CT. The decision to switch from CT to HT was generally associated with low RS, while the decision to switch from HT to CT was generally associated with high RS. The odds of the MD Rx recommendation changing from HT to CT was $111 x$ higher if RS was high versus low risk, and from CT to HT was $18 \mathrm{x}$ higher if $\mathrm{RS}$ was low versus high risk.

Conclusion: TheOncotype DX Recurrence Score assay changed systemic adjuvant therapy in $25 \%$ of pts with early stage BC. It is likely that genomic information will play an increasingly important role in clinical decision-making for individual $\mathrm{BC}$ patients. 
2050

Economic evaluation of switching to exemestane at 2.5 years versus continuing tamoxifen as adjuvant therapy in early breast cancer: a Canadian perspective.

Risebrough NA, Verma S, Trudeau M, Charbonneau C, Mittmann $N$. Sunnybrook and Women's College Health Sciences Centre, Toronto, ON, Canada; Ottawa Regional Cancer Centre, Ottawa, ON, Canada; Toronto Sunnybrook Regional Cancer Centre, Toronto, ON, Canada; Pfizer Canmada Inc., Kirkland, PQ, Canada; University of Toronto, Toronto, ON, Canada

Background/Objectives: The superiority of switching to exemestane (E) at 2 to 3 yrs compared to remaining on tamoxifen (T) for 5 yrs has been established by the Intergroup Exemestane Study (IES) trial. E is considerably more expensive than T. We determined the incremental cost per life-year (LY) gained and cost per quality adjusted life-year (QALY) from a Canadian (CDN) government payer perspective.

Methods: A Markov model with a $7.5 \mathrm{yr}$ time horizon was constructed. Event rates for $\mathrm{T}$ and relative risk reduction of breast cancer recurrence with $\mathrm{E}$ in the first $2.5 \mathrm{yrs}$ of the model were determined from supplementary analysis of the IES trial. Local, contralateral $(\mathrm{CN})$ and distant recurrence rates 5 yrs after the completion of $\mathrm{T}$ were extrapolated using constant hazard ratios from Kaplan Meier curves. These transition states were modeled: (1) survival; (2) breast cancer recurrence (local, $\mathrm{CN}$ and distant); (3) other primary cancers; (4) discontinuation due to adverse events and/or drug related adverse events requiring treatment (osteoporosis and fractures). We assumed that all patients with a new osteoporosis diagnosis while on adjuvant therapy continued bisphosphonates for the $5 \mathrm{yrs}$ following adjuvant therapy. In the base case, the difference between the recurrence rate for $\mathrm{E}$ and $\mathrm{T}$ 5 yrs after completing adjuvant therapy was assumed to remain constant. This was conservative as the IES trial suggested additional benefit for exemestane. Probability of disease progression following breast cancer recurrence came from published sources. Costs for drugs, inpatient and outpatient treatment and follow-up were based on CDN government sources and published literature and presented in 2004 CDN dollars. Costs and outcomes accrued beyond 1 year were discounted at $5 \%$.

Results: The total cost of the $\mathrm{T}$ strategy was $\$ 18,991$ compared to $\$ 20,810$ with E. Life years and QALYs increased from 6.37 and 5.64 with $\mathrm{T}$ to 6.43 and 5.73 respectively with $\mathrm{E}$. The incremental medical cost per QALY gained with E vs. T was $\$ 19,124$, while incremental cost gained per LY was $\$ 28,565$. The sensitivity analysis showed results were robust to reasonable changes in probability and quality of life parameters, but were sensitive to distant recurrence costs. If the actual cost of recurrence was twice as high as in the base case analysis (\$14,927 per 6 months), E became a dominant therapy with better clinical outcomes and lower overall treatment cost.

Conclusions: Treatments resulting inincremental cost per QALY below $\$ 20,000 \mathrm{CDN}$ are considered to be cost-effective. In adjuvant breast cancer, treatment with 2.5 years of $\mathrm{E}$ following $2.5 \mathrm{yrs}$ of $\mathrm{T}$ falls within the parameters of cost-effective strategies.

\section{1}

Menostasis subsequent to individually dose-tailored fluorouracil-epirubicin-cyclophosfamide chemotherapy for early breast cancer.

Andersson M, Gunnarsdottir K, Møller S, Blomqvist C, Bergh J, Edlund P, Ahlgren J, Mouridsen HT. Rigshospitalet University Hospital, Copenhagen, Denmark; Danish Breast Cancer Cooperative Group, Copenhagen, Denmark; Uppsala Hospital, Uppsala, Sweden; Karolinska Hospital, Stockholm, Sweden

Background: The influence of age, fluorouracil-epirubicincyclophosphamide (FEC) chemotherapy (CT) dose and leukopenia on the risk of menostasis (M) is not fully elucidated.

Material and methods: In the SBG 2000-1 study, 1019 premenopausal node+ or high-risk node- early breast cancer patients received one cycle of intravenous (IV) FEC $\left(600,60,600 \mathrm{mg} / \mathrm{m}^{2}\right.$ $=$ standard dose, (SD)). Patients with white blood cell (WBC) nadir grade 3 continued to receive cycles $2-7$ in $S D(n=279)$ IV q 3 weeks. Patients with WBC nadir grade 0-2 were randomized to either SD $(n=374)$ or escalated dose (WBC nadir 2: 600,75, 900 $\mathrm{mg} / \mathrm{m}^{2}$; WBC nadir $\left.0-1: 600,90,1200 \mathrm{mg} / \mathrm{m}^{2}\right)(\mathrm{n}=366)$ for cycles 2-7. Patients reported after each CT cycle whether they had had menstruation since last cycle.

Results: The percentage of patients who reported having had menstruation after cycles 1 through 7, respectively, was $61 \%$, $60 \%, 45 \%, 31 \%, 19 \%, 13 \%$ and $9 \%$. Among 556 patients with full information about menstruation, $424(76.3 \%)$ reported no menstruation after both 5., 6. and 7. cycle (which was taken as a surrogate measure for menopause (SM)). SM in relation to a. age: <35 years: $3 / 28$ (11\%), 35-39: 46/103 (45\%), 40-44: 89/119 $(75 \%),>44: 286 / 306(94 \%) \mathrm{p}($ trend $)<0.0001$; b. maximal WBC nadir during CT cycles 1-7: grade 0-1: 23/35 (6\%), grade 2: $1116 /$ $160(73 \%)$, grade $3: 223 / 286(78 \%)$, grade $4: 62 / 75(83 \%)$ $\mathrm{p}($ trend) $=0.02$; c. CT dose: SD (non-randomized) $123 / 156(79 \%)$, SD (randomized) 147/211) 70\% Level +1: 88/109 (81\%), Level $2+66 / 80(83 \%) \mathrm{p}($ trend $)=0.02$ (non-randomized excluded from analysis). $\quad \mathrm{SD}$ (non-randomized) vs SD(randomized): $\mathrm{p}=0.06$.Discussion: This study presents $\mathrm{M}$ data only from during and immediately after administration of CT. It is wellknown that CT-induced $\mathrm{M}$ is sometimes reversible, but the picture is often obscured by treatment with tamoxifen which the majority of the patients received subsequently to CT. The study demonstrates that SM is highly dependent on age, only $11 \%$ of patients $<35 \mathrm{yrs}$ becoming SM. Further, SM is significantly related to CT dose and to hematological toxicity even for patients on the same dose level. This suggests that individual sensitivity to CT-induced toxicity, including SM, is important.

\section{2}

Initial results from the LEAP Study: the first direct comparison of safety parameters between aromatase inhibitors (AIs) in healthy postmenopausal women.

McCloskey E, Eastell R, Hannon RA, Lakner G, Miyamoto A, Clack G. University of Sheffield, United Kingdom; MÁV Hospital, Hungary; AstraZeneca Pharmaceuticals; AstraZeneca Pharmaceuticals, United Kingdom

Background: When considering long-term adjuvant drug use, safety is of prime importance. The Letrozole, Exemestane, and Anastrozole Pharmacodynamics (LEAP)trialassessed pharmacodynamic differences between anastrozole ('Arimidex'), letrozole (both non-steroidal, competitive AIs), and exemestane (a steroidal, non-competitive $\mathrm{AI}$ ), including differential effects on markers of bone turnover and cardiovascular effects, that may lead to differences in their safety profiles with long-term use. ${ }^{1}$ LEAP is an open, randomized, multicenter, Phase I pharmacodynamic study comparing the effects of these three AIs on serum markers of bone formation and resorption, lipid profiles, adrenal function, and safety in healthy postmenopausal women. Material and methods: Healthy volunteersfrom the UK and Hungary were randomized to receive anastrozole ( $1 \mathrm{mg} /$ day $)$, letrozole $(2.5 \mathrm{mg} / \mathrm{day})$, or exemestane $(25 \mathrm{mg} /$ day $)$ orally, once daily for 24 weeks. The primary objective of the LEAP study was to assess changes in bone alkaline phosphatase (ALP), a serum marker of bone formation. Secondary outcome variables included other markers of bone formation and resorption, lipid measurements, and measures of adrenal function (using the lowdose short Synacthen test). Serum samples were taken at baseline and after 2,12, 24, and 36 weeks (12 weeks post-dosing) for analysis of ALP. In addition to bone ALP, markers analyzed included procollagen type-I amino-terminal propeptide, $\beta$-Cterminal crosslinking telopeptide of type-I collagen, parathyroid hormone, total cholesterol, triglycerides, high-density lipoprotein, low-density lipoprotein, cortisol, aldosterone, adrenal androgens, and fasting glucose. Safety assessment included analyses of clinical 


\section{S102 Abstracts - Poster Session II}

chemistry, hematology, urinalysis, symptoms, blood pressure, electrocardiograms, pulse, and physical examination.

Results: 102 healthy volunteers (target 84 evaluable) have been recruited and, at the time of writing, 57 volunteers from 4 centers have completed dosing.

Discussion: Dosing is scheduled to be completed in August 2005; first results will be presented.

Reference

1. Jackson J et al. Expert Opin Drug Saf 2003; 2: 73-86.

'Arimidex' is a trademark of the AstraZeneca group of companies

\section{3}

LH-RH analogues, tailored adjuvant chemotherapy and total estrogenic block in patients with estrogen receptor positive $(E R+)$ tumors, preserve ovarian function and improve the clinical outcome of young women with early breast cancer.

Recchia F, Saggio G, Cesta A, Candeloro G, Amiconi G, Di Blasio A, Rea S. Civilian Hospital, Avezzano, AQ, Italy; University of L'Aquila, L'Aquila, AQ, Italy

Background and rationale: In a previous study (Anticancer Drugs 13:417-24, 2002) we have shown that the addition of a LH$\mathrm{RH}$ analogue to adjuvant therapy of premenopausal patients with early breast cancer protected long-term ovarian function. In this study we observed that the majority of failures occurred in the second year, predominantly in estrogen receptor positive $(E R+)$ patients. The protocol was emended, administration of the analogue was prolonged for 2 years and ER+ patients were treated with an aromatase inhibitor (AI), after the completion of chemotherapy during the treatment with the analogue. Objective of the present study was the retrospective evaluation of 100 consecutive, high risk, premenopausal early breast cancer patients, treated with the above described therapy.

Patients and methods: Following surgical treatment, patients received an LH-RH analogue and an adjuvant chemotherapy, which was tailored to the peculiar biologic features of each tumor. Patients characteristics: median age, 43 years (range 27-50), 52 estrogen receptor positive $(\mathrm{ER}+)$ and 48 ER negative (ER-), 64 stage II disease, and 36 stage III. All patients had their serum estradiol suppressed to values $<40 \mathrm{pg} / \mathrm{ml}$. Chemotherapy administered: 26 cyclophosphamide, methotrexate and 5-fluorouracil; 74 an anthracycline-based regimen and 9 of them, with more than 10 axillary nodes, high-dose chemotherapy with autologous peripheral blood progenitor cell transplantation. CERB-2 positive patients received also a taxane. Eighty patients were irradiated. An aromatase inhibitor (AI) was given to ER+ patients, after chemotherapy, during the therapy with the LH-RH analogue.

Results. After a median follow-up of 75 months, normal menses were resumed by all patients below 40 years and by $56 \%$ of patients above 40 years of age. Three pregnancies were observed: 2 at term and 1 voluntary abortion. Projected recurrence-free survival rates at 5 and 10 years were $84 \%$ and $76 \%$, while projected overall survival rates at 5 and 10 years were $96 \%$ and $91 \%$, respectively. None of 36 patients with ER+ tumors, treated with total estrogenic block recurred.

Conclusion: These data show that in premenopausal patients with early breast cancer, the addition of a LH-RH analogue to adjuvant therapy and temporary total estrogen suppression in $\mathrm{ER}+$ patients, is well tolerated, protects long-term ovarian function and seems to improve the expected clinical outcome.

\section{4}

Cost-effectiveness of letrozole versus tamoxifen as initial adjuvant therapy in hormone-receptor positive postmenopausal women with early breast cancer from a US perspective.

Delea TE, Karnon J, Thomas SK, Barghout V, Papo NL, Johnston SRD. PAI, Brookline, MA; University of Sheffield, Sheffield, United Kingdom; Novartis Pharmaceuticals Corp., Florham Park, NJ; Novartis Pharmaceuticals UK Ltd., Camberley, United Kingdom; Royal Marsden Hospital, London, United Kingdom

Background: In the primary core analysis of the BIG 1-98 study, the aromatase inhibitor letrozole (LET) significantly improved disease free survival (DFS) by $19 \%$ (HR=0.81, 95\% CI $0.70-0.93$, $\mathrm{p}=.003$ ) and DFS excluding $2^{\text {nd }}$ primary cancer and death without recurrence by $28 \%(\mathrm{HR}=0.72,95 \%$ CI $0.61-0.86, \mathrm{p}=.0002)$ compared with tamoxifen (TAM) in postmenopausal women with hormone-receptor positive $(\mathrm{HR}+)$ early breast cancer. The risk of distant metastases was significantly reduced by $27 \%$ (HR 0.73 , 95\% CI 0.60-0.88; $\mathrm{P}=.001)$. Patients receiving LET also experienced nonsignificant improvements in overall survival $(\mathrm{HR}=0.86,95 \% \mathrm{CI} 0.70-1.06, \mathrm{p}=.15)$ and risk of invasive contralateral breast cancer $(\mathrm{HR}=0.61,95 \%$ CI $0.35-1.08, \mathrm{p}=.09)$. LET patients had reduced risks of endometrial cancer and thromboembolic events, but increased risks of hypercholesterolemia, cardiac events, and fractures. This study evaluates the cost-effectiveness of initial adjuvant therapy with LET vs TAM from a US healthcare system perspective based on preliminary analyses of published results of the BIG 1-98 trial. Methods: A Markov model was used to estimate the incremental cost per life-year (LY) and quality-adjusted LY (QALY) saved with 5 years of initial adjuvant therapy with LET versus TAM in postmenopausal women with HR+ early stage breast cancer. Probabilities of recurrence (including contralateral tumor) and treatment side effects (endometrial cancer, thromboembolic events, hip and other fractures, hypercholesterolemia, and MI) for TAM were based on preliminary published results of the BIG 198 trial and other published population-based studies. Corresponding probabilities for LET were calculated by multiplying probabilities for TAM by estimated RRs for LET vs TAM from the BIG 1-98 study. Other probabilities, costs of breast-cancer care and treatment of side effects (2004 US\$), and health-state utilities were obtained from published studies. Costs and QALYs were estimated over the lifetime of a cohort of HR+ postmenopausal women with early breast cancer, aged 61 years at initiation of adjuvant therapy, and discounted at $3 \%$ annually.

Results: Compared with TAM, LET results in an additional 0.27 life years (13.89 vs 13.62) and 0.28 QALYs (13.10 vs 12.82). These benefits are obtained at an additional costs of $\$ 9,026$ $(\$ 63,990$ vs $\$ 54,964)$. Cost effectiveness of LET vs TAM is therefore $\$ 33,430$ per LY saved and $\$ 32,236$ per QALY saved. Conclusion: Initial adjuvant treatment with LET is cost-effective compared with TAM from the US healthcare system perspective and should be considered in postmenopausal women with HR+ early breast cancer.

\section{5}

Breast cancer navigator program: clinical trial access, recruitment and enrollment at a large county hospital.

Donnell SK, Leitch AM, Gray E, Aravind R, McKindles D, Tripathy D. UT Southwstrn Med Ctr; UT Southwstrn Med Ctr, Dallas, TX

Expanding access to clinical trials among women of diverse backgrounds has been a focus of national research policy. Currently, the NIH requires that women and their associated sub-populations be included in Phase III clinical trials to allow for valid analysis of differences in intervention effects. Breast cancer research with a broad representation of age, ethnicity, culture, socioeconomics and geographical location contribute to understanding how these factors impact diagnosis, treatment, disease state and outcomes among diverse populations. 


\section{Abstracts - Poster Session II S103}

Method: A Navigator program was designed to increase access and participation in breast cancer clinical trials in a busy clinical setting with limited resources. The pilot program was implemented at a large county hospital. The hospital-based clinic serves minority women, mostly women of African-American and Hispanic background. Clinical trial candidates were identified at the time of initial diagnosis and new recurrence. Demographic and clinical information was gathered and stored in an institutional database. A systematic approach to screening new and established patients based on criteria for eligible candidates was applied. Clinical trials consisted of neo-adjuvant, adjuvant, and palliative treatment protocols. Physicians and coordinators determined final eligibility, approached candidates, and reported outcomes to the Navigator. Result: The program was implemented in October 2003 with data generated through October 2004. A total of 375 breast cancer patients were screened for eligibility for at least one clinical trial. Of the 375 candidates, 310 were eligible with $35(11.3 \%)$ enrollments to treatment trials. Approximately 156 candidates screened were eligible for three adjuvant trials and 12 patients $(7.7 \%)$ enrolled. Reasons for not enrolling included patient decline, alternative treatment chosen and ineligibility due to co-morbidities, non-English speaking status, and risk for non-compliance. Ethnic distribution was: African-American $45.6 \%$, Hispanic $27.5 \%$, Caucasian $20 \%$ and Asian $4.3 \%$. Median age was 53 with $42 \%$ under the age of 50 and $13 \%$ over the age of 65 .

Conclusion: Integrating a Navigator program results in early identification of clinical trial eligibility among minority and underserved populations of women. The program increases access to clinical trials among women of diverse ages, ethnic and cultural backgrounds. Outcomes to enrollment aid in identifying barriers to clinical trial participation and low enrollment among patient groups. Additional research that incorporates ethnic, cultural and socioeconomic factors into the design and implementation of research protocols is needed.

\section{6}

Gynecologic interventions during adjuvant therapy with anastrozole or tamoxifen: results from the ATAC trial. Duffy SR, Distler W, on Behalf of the ATAC Trialists' group. St James's University Hospital, Leeds, United Kingdom; Universitätsklinikum Carl Gustav Carus, Dresden, Germany

Background: The estrogenic activity of tamoxifen on the endometrium results in double the risk of endometrial cancer after 1-2 years and quadruple the risk of endometrial cancer after 5 years' treatment. Anastrozole, a highly selective third-generation aromatase inhibitor (AI), has efficacy superior to that of tamoxifen in patients with early breast cancer and is also associated with significantly fewer gynecologic adverse events (AEs). Gynecologic AEs often require further investigation and treatment, which, as well as being costly, are distressing for the patient.

Material and Methods: We examined retrospectively the incidence of gynecologic interventions conducted in patients receiving anastrozole or tamoxifen in the main 'Arimidex', Tamoxifen, Alone or in Combination (ATAC) trial database. No statistical analysis of the gynecological interventions was performed.

Results: The incidence of gynecologic AEs in the main ATAC trial was significantly lower for anastrozole compared with tamoxifen (vaginal bleeding: 5.4\% (167/3092) vs. $10.2 \%$ (317/ 3094), p<0.0001; vaginal discharge: $3.5 \%$ (109/3092) vs. $13.2 \%$ (408/3094), p<0.0001; endometrial cancer: $0.2 \%(5 / 2228 *)$ vs. $0.8 \%(17 / 2236 *), p=0.02)$. Overall, patients receiving anastrozole experienced fewer gynecologic interventions compared with those receiving tamoxifen (Table). An almost four-fold reduction in the incidence of both hysteroscopy and hysterectomy was observed in patients receiving anastrozole; the incidence of most other interventions was also lower in this group.

Discussion: The significant difference in the incidence of gynecologic AEs previously reported for anastrozole compared with tamoxifen in the ATAC trial appears to translate to a requirement for fewer gynecologic interventions in patients receiving the AI. Therefore, treatment with anastrozole rather than tamoxifen may avoid the psychologic distress and the associated costs of the investigation/treatment of gynecologic events in many women. These findings offer further support to the use of anastrozole as the preferred primary adjuvant treatment for postmenopausal women with early breast cancer.

Intervention, $\mathrm{n}(\%) \quad$ Anastrozole $(\mathrm{n}=3092) \quad$ Tamoxifen $(\mathrm{n}=3094)$

$\begin{array}{lll}\text { Ultrasound } & 250(8.1) & 266(8.6)\end{array}$

$\begin{array}{lll}\text { Polypectomy* } & 29(1.3) & 70(3.1)\end{array}$

Hysteroscopy* $\quad 41(1.8) \quad 137(6.1)$

Dilatation and curettage* $\quad 29(1.3) \quad 97(4.3)$

Oophorectomy $\quad 33(1.1) \quad 59(1.9)$

Hysterectomy* $\quad 31(1.4) \quad 119(5.3)$

Endometrial biopsy* $\quad 28(1.3) \quad 47(2.1)$

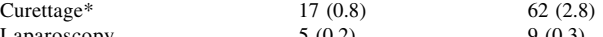

$\begin{array}{lll}\text { Laparoscopy } & 5(0.2) & 9(0.3) \\ \text { Colposcopy } & 5(0.2) & 7(0.2)\end{array}$

$\begin{array}{lll}\text { Colposcopy } & 5(0.2) & 7(0.2) \\ \text { Anterio/posterior repair* } & 1(<0.1) & 10(0.4)\end{array}$

Anterior/posterior repair* $\quad 1(<0.1) \quad 10(0.4)$

Trerage $4(0.1)$

"Percentages calculated based on the number of patients with an intact uterus at baseline (anastrozole $\mathrm{n}=2228$; tamoxifen $\mathrm{n}=2236$ )

\section{7}

Side effects in treatment with FEC (5-fluorouracil, epirubicin and cyklophosphamide) in standard doses compared to tailored doses, based on hematological toxicity, for primary breast cancer. Results from the Scandinavian Breast Group 2000-1 Study.

Edlund P, Gunnarsdottir K, Anderson H, Moller S, Andersson M, Mouridsen H, Bergh J, Ahlgren J, Blomqvist C. Gavle County Hospital, Gavle, Sweden; Uppsala University, Uppsala, Sweden; Rigshospitalet, Copenhagen, Denmark; DBCG-Secretariat, Copenhagen, Denmark; Karolinska Inst.\& Hospital, Stockholm, Sweden; Lund University, Lund, Sweden

Background: The doses of chemotherapy regimens are mostly based on patients' body surface area. There are large inter- individual differences in systemic exposure and tolerance for cytostatics, likely due to pharmacokinetics. Retrospective studies have demonstrated that patients with high-grade leucopenia during adjuvant chemotherapy have a better outcome. The SBG 2000-1 trial will prospectively investigate if patients who get individually dosed adjuvant chemotherapy based on grade of leucopenia have a better outcome than those who get standard doses based on body suface area only. This report evaluates the dose-intensity and toxicity for the included patients. Patients and methods: 1535 lymph node positve or high-risk node negative (T2 and/or ER/ PGR negative) women were registered in the trial.7 FEC courses were given every 3 week to all patients. The first course was given in standard doses to all patients $\left(5-\mathrm{FU} 600 \mathrm{mg} / \mathrm{m}^{2}, \mathrm{E} 60 \mathrm{mg} / \mathrm{m}^{2}, \mathrm{C}\right.$ $600 \mathrm{mg} / \mathrm{m}^{2}$ ). Leucocyte nadir values were measured at day 1012 13 and 15. Patients who achieved leukopenia grade 0-2 were randomized to tailored FEC (T) according to a dose escalation schedule (E $75-90 \mathrm{mg} / \mathrm{m}^{2}$, C $900-1200 \mathrm{mg} / \mathrm{m}^{2}$ ) in order to reach leucopenia grade 3 , or to continue treatment with standard doses (S). Patients who had leucopenia grade 3-4 after the first course were not randomized but received standard doses courses 2-7 (R). The non hematological toxicity was registered according to the NCI/CTC criteria by the patients themselves for each course. Following inclusion, 68 patients withdrew consent and 14 were ineligible due to missing nadir blood samples and 1 because of bilateral cancer. Data for courses 2 and later have not been obtained for 2 patients. Thus the number included in this analysis is 1450 (401 in R, 526 in S and 523 in T). Results: 96,2\% of all patients completed 7 cycles. The median cumulative doses $\left(\mathrm{mg} / \mathrm{m}^{2}\right)$ of $\mathrm{C}$ were 4181 for $\mathrm{R}, 4183$ for $\mathrm{S}$ and 6030 for $\mathrm{T}$ and for $\mathrm{E}, 418,418$ and 512 for R,S and T respectively. The proportion of patients who achieved leucopenia grade 3-4 at any time during courses 2-7 were $88 \%$ for R, $28 \%$ for S and $90 \%$ for T (S vs T, p<0.0001). The proportion of the randomized patients who had grade 3-4 nonhematological toxicity during courses $2-7$ were higher in $T$ vs $S$ 


\section{S104 Abstracts - Poster Session II}

for vomiting $(19 \%$ vs $9.9 \%, \mathrm{p}<0.01)$ and alopecia $(97,5 \%$ vs $94.0 \%, \mathrm{p}=0.01$ ) but not for emesis, mucositis, diarrea and fatigue. Conclusion: Leucopenia grade 3 was achieved by dose adjustment based on leucocyte nadir after course one without adding other severe toxicity. Outcome data will be presented in 2007.

\section{8}

Cost-effectiveness analysis of letrozole versus tamoxifen as initial adjuvant therapy in hormone-receptor positive postmenopausal women with early breast cancer: the UK perspective.

Karnon J, Delea TE, Barghout V, Thomas SK, Papo NL, Johnston SRD. University of Sheffield, Sheffield, United Kingdom; Policy Analysis Inc., Brookline, MA; Novartis Pharmaceuticals Corp., Florham Park, NJ; Novartis Pharmaceuticals UK Ltd, Camberley, United Kingdom; Royal Marsden Hospital, London, United Kingdom

Background: In the primary core analysis of the BIG 1-98 study, the aromatase inhibitor letrozole (LET) significantly improved Disease-Free Survival (DFS) by $19 \%$ (HR 0.81 ; $95 \%$ CI 0.70 , $0.93 ; \mathrm{P}=0.003)$ and DFS excluding $2^{\text {nd }}$ primary cancers and death without recurrence by $28 \%$ (HR $0.72 ; 95 \%$ CI $0.61,0.86$; $\mathrm{P}=0.0002)$ compared with tamoxifen (TAM) in postmenopausal women with hormone receptor positive $(\mathrm{HR}+)$ early breast cancer. The risk of distant metastasis was significantly reduced by $27 \%$ (HR $0.73 ; 95 \%$ CI $0.60,0.88 ; \mathrm{P}=0.001$ ). Patients receiving LET also experienced non-significant improvements in overall survival (HR $0.86 ; 95 \%$ CI $0.70,1.06 ; \mathrm{P}=0.15)$ and risk of invasive contralateral breast cancer (HR $0.61 ; 95 \%$ CI $0.35,1.08 ; \mathrm{P}=0.09$ ). LET patients had reduced risks of endometrial cancer and thromboembolic events, but increased risks of hypercholesterolemia, cardiac events and fractures. This study reports the cost-effectiveness of initial adjuvant therapy with LET vs TAM from the UK NHS perspective based on preliminary analyses of published results of the BIG 1-98 trial.

Methods: A Markov model was used to estimate the incremental cost per Life Year (LY) and per quality-adjusted life year (QALY) saved with five years of initial adjuvant therapy with LET versus TAM in postmenopausal women with $\mathrm{HR}+$ early stage breast cancer. Probabilities of breast cancer events (contralateral tumour; locoregional recurrence; soft tissue; bone; and visceral metastases) and treatment side effects (endometrial cancer, thromboembolic events, hip fractures, other fractures, hypercholesterolemia and MI) for TAM were based on published results of the BIG 1-98 trial and other published population-based studies. Corresponding probabilities for LET were calculated by multiplying probabilities for TAM by estimated RRs for LET vs TAM from the BIG 1-98 study. Other probabilities, costs of breast cancer care and treatment of side effects (2004 UK£), and health-state utilities (QALY weights) were obtained from published studies. Costs and QALYs were estimated over the remaining lifetime of a cohort of HR+ postmenopausal women aged 61 years, discounted at $3.5 \%$ annually. Results: Compared with TAM, LET results in an additional 0.292 LYs (13.337 vs 13.045), and 0.325 QALYs (12.665 vs 12.340). These benefits are obtained at an additional cost of $£ 4,546(£ 9,568$ vs $£ 5,022)$. The cost-effectiveness of LET vs TAM is $£ 15,549$ per LY saved $(95 \%$ CI $£ 11,341-£ 29,406)$ and $£ 14,001$ per QALY saved (95\% CI $£ 10,067-£ 26,068)$.

Conclusion: Adjuvant treatment with LET is cost-effective from a UK NHS perspective compared with TAM and should be considered as a treatment option in women diagnosed with HR+ early breast cancer.

\section{9}

Positive cooperative effects of gefitinib, chemotherapeutics and a breast cancer resistant protein inhibitor on cell growth in a fulvestrant-resistant estrogen receptor alpha negative MCF-7 cell model.

Liu H, Welchel AK, Cheng D, Osipo C, Jordan VC. Northwestern University, Chicago, IL; Fox Chase Cancer Center, Philadelphia, $P A$

To explore mechanisms and potential therapeutics for fulvestrant resistant breast cancer, we have generated a unique fulvestrantresistant $(\mathrm{MCF}-7 / \mathrm{F})$ estrogen receptor alpha (ER) negative human breast cancer cell model. MCF-7/F cells were derived from MCF$7 \mathrm{ER}$ positive cells and irreversibly lost expression of ER (AACR 2004, Abstract \# 5600). In this study, we compared and contrasted gene expression profiles in MCF-7 treated with ethanol, $1 \mathrm{nM}$ estrogen or $1 \mu \mathrm{M}$ fulvestrant for 40 hours and MCF-7/F cells without any treatment using a microarray chip assay with Human Genome U133 Plus 2.0 GeneChip (over 47,000 transcripts with around 53,000 probe sets). In the four groups tested 13,941 probe sets reached significance at level $p<0.05$ by one-way ANOVA test. In $\mathrm{MCF}-7 / \mathrm{F}$ cells 1685 probe sets were differentially overexpressed or underexpressed. The changes in expression of three genes, ER, epithelial growth factor receptor (EGFR) and breast cancer resistant protein (BCRP/MXR/ABCG2), might have effects on treatment of fulvestrant resistant breast cancer. Expression of ER was dramatically decreased and expression of EGFR was significantly upregulated. MCF-7/F cells had crossresistance to 4-hydroxytamoxifen and raloxifene. Gefitinib, an EGFR tyrosine kinase inhibitor, inhibited cell growth in MCF-7/F cells in a concentration dependent manner as shown previously (AACR 2004, Abstract \# 5600). Interestingly, BCRP was highly expressed in MCF-7/F cells. Overexpression of BCRP was further validated with western blot analysis. MCF-7/F cells became less sensitive to the inhibitory effect of mitoxantrone. $\mathrm{EC}_{50}$ for mitoxantrone increased 6.8 fold $(p<0.05)$ in MCF-7/F cells $(0.13$ $\mu \mathrm{M})$ compared to MCF-7 cells $(0.019 \mu \mathrm{M})$. Moreover, inhibition of BCRP with a BCRP specific inhibitor, fumitremorgin C (FTC), resensitized $\mathrm{MCF}-7 / \mathrm{F}$ cells to mitoxantrone. More interestingly, gefitinib, a specific EGFR tyrosine kinase inhibitor, also increased sensitivity to mitoxantrone in MCF-7/F cells. Thus, MCF-7/F cells become less chemosensitive due to BCRP overexpression. The results indicate that fulvestrant resistant breast tumors with overexpression of both EGFR and BCRP might benefit from combination treatment with gefitinib, chemotherapeutic reagents such as mitoxantrone and BCRP inhibitors. Supported by the SPORE CA89018-05

\section{0}

Upregulation of HER-2/neu is independent of the menopausal status of primary breast cancer patients: plasma results from a prospectively randomized trial comparing dose-intense chemotherapy with G-CSF support to 3-weekly chemotherapy for adjuvant therapy of nodal-positive (1-3 LN) breast cancer.

Lueftner D, Schildhauer S, Eggemann H, Geppert R, Wernecke K, Possinger K, Elling D. Charité Campus Mitte, Berlin, Germany; Oskar-Ziethen-Krankenhaus, Berlin, Germany; Institut für Medizinische Biometrie, Charité Campus Mitte, Berlin, Germany

Background: The ASG is completing recruitment into an adjuvant trial in which breast cancer patients (pts) either receive conventional ECP (Arm A; epirubicin (E): $90 \mathrm{mg} / \mathrm{m}^{2}+$ cyclophosphamide (C) $600 \mathrm{mg} / \mathrm{m}^{2} \mathrm{x} 4 \mathrm{q} 3 \mathrm{w}$, followed by paclitaxel (P) $175 \mathrm{mg} / \mathrm{m}^{2} \times 4 \mathrm{q} 3 \mathrm{w}$ ) or dose-dense EP + G-CSF on days 5-13 (Arm B; E: $120 \mathrm{mg} / \mathrm{m}^{2}$ x4 q2w, followed by P: $175 \mathrm{mg} / \mathrm{m}^{2} \mathrm{x} 4 \mathrm{q} 2 \mathrm{w}$ ). Plasma for circulating HER-2/neu, EGFR and CA 27.29 levels is prospectively collected at baseline, at the end of chemotherapy and at relapse. 
Methods: Circulating HER-2/neu is measured using a standardized ELISA assay (Bayer Diagnostics/Oncogene Science, Cambridge, USA). The nonparametric analysis of variance for repeated measurements is used to detect significant influences of treatment arm, menopausal status and time effects, and to determine interactions.

Results: Longitudinal plasma results (baseline and end of chemotherapy) are available from 415 pts of which $53 \%$ are postmenopausal. HER-2/neu concentrations increased from 9.4/ $9.3 \mathrm{ng} / \mathrm{mL}(\mathrm{Arm} \mathrm{A} / \mathrm{B}$ ) at baseline to $11.2 / 11.0 \mathrm{ng} / \mathrm{mL}$ (Arm A/B) at the end of chemotherapy for pre- and postmenopausal pts equally with a significant time effect $(\mathrm{p}<0.00001)$. In contrast to circulating HER-2/neu, CA 27.29 increased to a greater extent over time $(\mathrm{p}<0.00001)$ in the dose-dense Arm B from $21.3 \mathrm{U} / \mathrm{mL}$ to $37.2 \mathrm{U} / \mathrm{mL}$ as compared to Arm A from $20.5 \mathrm{U} / \mathrm{mL}$ to $25 \mathrm{U} /$ $\mathrm{mL}$. At the same time, circulating EGFR levels decreased significantly over time $(\mathrm{p}=0.0012)$ in the dose-dense Arm B only. Conclusions: These are the first results that show that HER-2/ neu levels increase significantly in postmenopausal breast cancer pts. Identical results were published for premenopausal pts only (Lüftner et al., Breast Cancer Res Treat 2003). Circulating EGFR is known to be lower in postmenopausal pts than in premenopausal pts, which could reflect the faster ovarian ablation in the doseintense arm. The pronounced increase of CA 27.29 in Arm B may be explained by cell death of minimal residual disease during intensified chemotherapy

\section{1}

Predictors and temporal trends of adjuvant endocrine therapy use in breast cancer.

Svahn TH, Niland JC, Hughes ME, Ottesen RA, Theriault RL, Edge SB, Schott AF, Bookman MA, Weeks JC, Carlson RW. Stanford University, Stanford, CA; City of Hope, Duarte, CA; Dana-Farber Cancer Institute, Boston, MA; M.D. Anderson Cancer Center, Houston, TX; Roswell Park Cancer Institute, Buffalo, NY; University of Michigan, Ann Arbor, MI; Fox Chase Cancer Center, Philadelphia, PA

Background: Endocrine therapy is one of the most important aspects of adjuvant treatment for patients with hormone receptorpositive breast cancer. Tamoxifen was the primary adjuvant endocrine therapy until the first report of the Arimidex, Tamoxifen Alone or in Combination (ATAC) trial in December of 2001. In December 2001, the National Comprehensive Cancer Network (NCCN) Breast Cancer Treatment Guidelines were modified to allow anastrozole as an alternative to tamoxifen in the adjuvant treatment of postmenopausal patients. This study examines the treatment patterns of adjuvant endocrine therapy at NCCN institutions participating in the Breast Cancer Outcomes Database, identifies temporal relationships in the use of aromatase inhibitors (AI), and examines patient and tumor characteristics associated with the choice of endocrine therapy.

Methods: Data were available on 3,578 postmenopausal patients with hormone receptor-positive stages I, II and III breast cancer treated from July 1997 to September 2004. Analyses included patient and tumor characteristics, endocrine therapy with time trend analysis, and univariate and multivariable logistic regression models.

Results: Median age at diagnosis was 62 (33-94) years. $4 \%$ had pre-existing vascular disease. $63 \%$ of tumors were low or intermediate grade, $67 \%$ lymph node-negative, and 9\% overexpressed HER2. $85 \%$ received adjuvant endocrine therapy: $81 \%$ tamoxifen, $18 \%$ anastrozole, $1 \%$ letrozole or exemestane. Time trend analysis demonstrated an increase in AI use with a concomitant decrease in tamoxifen use following the release of ATAC results $(\mathrm{p}<0.0001)$. In multivariable regression analysis, NCCN institution $(\mathrm{p}<0.0001)$, age at diagnosis $(\mathrm{p}=0.0013)$, history of vascular disease $(\mathrm{p}=0.0004)$, stage $(\mathrm{p}=0.0003)$ and HER2 status $(\mathrm{p}=0.02)$ were independent predictors of AI use over tamoxifen. For the time period 2001-2004, individual NCCN institutional rates of $\mathrm{AI}$ use ranged from 15 to $66 \%$.
Conclusions: The use of AI in place of tamoxifen increased rapidly at NCCN institutions after the first report of ATAC. Patients who were older, had a history of vascular disease, whose tumors overexpressed HER2 or were more advanced stage were more likely to be treated with AI. There was substantial variation between institutions in the early adoption of AI.

\section{2}

Fatigue and metabolic changes in patients with early breast cancer (EBC) receiving anthracycline-based adjuvant chemotherapy, a longitudinal prospective study.

Meulemans A, Fontaine C, De Meirleir L, Torosian K, Gerlo E, Von Kemp K, Goyens P, De Waele A, Kaufman L, De Greve J. AZVUB; ; AZ-Vrije Universiteit Brussels, Jette, Brussels, Belgium

Background: Fatigue is a prevailing distress affecting the quality of life of many cancer patients. Treatment and disease factors contribute to the symptom and much of the focus has been on anemia. Other metabolic factors have not been studied adequately in humans. Limited data are available only in patients with advanced cancer in whom it is difficult to discriminate between treatmentor disease-related factors. We report on a clinical-metabolic study of the effect of adjuvant chemotherapy on fatigue, thereby excluding confounding disease-related factors.

Patients and Methods: After surgery patients were treated with adjuvant CEF chemotherapy for 6 cycles and locoregional radiotherapy. Consenting patients were prospectively and comprehensively followed with the FACT-F subscale; a standardized aerobic forearm exercise test with measurement of venous blood levels of lactate, pyruvate, $\mathrm{pH}$, free carnitine and acylcarnitines, $\mathrm{pO}_{2}, \mathrm{pCO}_{2}$, urinary organic acids and brachial arterial flow (ABF). All measurements were performed at baseline, after 3 and 6 cycles of chemotherapy, and 3 and 6 months of follow-up. The variables were determined at rest, during exercise and in the recovery phase. Results: Twenty seven patients (stage I-III) were included in the study, 16 and 12 patients are currently evaluable after 3 and 6 cycles of chemotherapy respectively. Mean age was 45,5 years (27-67 years). Eight of 16 pts had HR-positive cancer and 4/16 had Her2 amplification. The FACT-F subscale was less than 32 in $2 / 16$ patients at baseline and $4 / 16$ after 3 cycles. The baseline FACT-F was 38,8 , decreased to a mean of 33,9 after 3 cycles $(\mathrm{p}=0.012)$ and stabilized to 32.1 after 6 cycles. Variables that were significantly altered by chemotherapy in the overall population were: decreased $\mathrm{Hb}$ levels $(\mathrm{p}=0.004)$, decreased Hbsat at rest $(p=0.031)$, decreased free carnitine $(p=0.007)$ and increased ABF $(\mathrm{p}=0.017)$. A non-parametric correlation (Spearman test) found a significant correlation of FACT-F only with $\mathrm{pO} 2(\mathrm{p}=0.017)$ and Hbsat $(\mathrm{p}=0.004)$. One patient had a baseline $\mathrm{pO} 2$ extraction deficit and $1 / 16$ patient acquired a $\mathrm{pO} 2$ extraction deficit, indicating mitochondrial dysfunction. In individual patients development of fatigue could be correlated to one or more of the variables tested. Discussion: This is the first prospective study to demonstrate a clinically significant decline in the fatigue subscale under adjuvant anthracycline-based chemotherapy in EBC. Chemotherapy not only induces anemia, but also decreases Hbsat, increases $\mathrm{ABF}$ and decreases free carnitine levels. In individual patients, several factors including anemia, carnitine depletion and mitochondrial dysfunction contribute to chemotherapy induced fatigue.

\section{3}

Chemotherapy-induced amenorrhea (CIA) in patients treated with adjuvant CEF/CMF or EC/docetaxel: analysis from a phase III randomized EC/Doc Trial.

Samuelkutty S, Gluz O, Mohrmann S, Hille S, Zwiefel K, Schuett G, Nitz U. University of Duesseldorf, Duesseldorf, Germany

Background: About 25\% - 30\% of breast cancers occur in premenopausal women. Amenorrhea and infertility correlate with therapy duration and use of specific compounds. For the very young patient they may represent an important factor for selection 


\section{S106 Abstracts - Poster Session II}

of a specific chemotherapy regimen. We compared the effect of a sequential taxane based regimen to standard 6 cycles of $\mathrm{CEF} / \mathrm{CMF}$ on menstrual function.

Methods: We retrospectively sent questionnaires to premenopausal women randomised from $3 / 2000$ to $7 / 2003$ to a phase III trial comparing 6 cycles of $\mathrm{C}_{500} \mathrm{E}_{100} \mathrm{~F}_{500} \mathrm{q} 3 \mathrm{w}$ or $\mathrm{C}_{600} \mathrm{M}_{40} \mathrm{~F}_{600} \mathrm{~d} 1$ and $8 \mathrm{q} 4 \mathrm{w}$ versus 4 cycles $\mathrm{E}_{90} \mathrm{C}_{600} \mathrm{q} 3 \mathrm{w}$ followed by 4 cycles of Docetaxel ${ }_{100}$ q3w. A minimum follow-up of 18 months was required. CIA was defined as permanent cessation of menses during and/or after chemotherapy. Baseline and treatment relevant data were available for all patients.

Results: 209 from 340 eligible patients completed the survey.. In our analysis 106 patients received EC/Doc, 103 received $\mathrm{CEF} /$ $\mathrm{CMF}$ (only a minority of centres choose the CMF regime). Rates of permanent CIA were $64 \%$ in the EC/Doc arm and $61 \%$ in CEF/ CMF arm $(p=0,316) .38$ patients in the taxane containing arm and 36 patients in the CEF/CMF arm were younger than 40 years. In this subgroup $5(5 / 38)$ patients in EC/Doc arm and 21/36 patients in the standard arm had no CIA $(\mathrm{p}<0,001)$ directly after completion of chemotherapy. 3 patients who received EC/Doc and 10 patients who received CEF without CIA subsequently got GnRH analogues. Altogether in this subgroup 17 patients in the EC/Doc arm (45\%) and 8 patients in the $\mathrm{CEF} / \mathrm{CMF}$ arm $(22 \%)$ had permanent CIA ( $\mathrm{p}=0,051)$. Women older than 40 years (135 patients) had a high likelihood of experiencing permanent CIA with both ECDoc $(81 \%)$ and with the CEF/CMF (82\%).

Conclusions: Sequential docetaxel after 4 x EC seems to increase the risk of CIA in patients $<40$ compared to a standard regimen like CEF. This should be carefully considered for family planning, planning of endocrine oncologic therapy and contraception in this age group. The potential survival benefit should be carefully outweighted versus the toxicity profile individually. Impact of dose-intesity will be furtherly evaluated in larger sample sizes.

\section{4}

The development of a prediction tool for chemotherapyinduced anemia in breast cancer patients receiving adjuvant chemotherapy.

Dranitsaris $G$, Clemons $M$, Verma S, Vincent M. Toronto Sunnybrook Regional Cancer Centre, Toronto, ON, Canada; London Regional Cancer Centre, London, ON, Canada

Background: Anemia remains a common complication in breast cancer patients receiving adjuvant chemotherapy. Many oncologists acknowledge that anemia is unpredictable and usually act on a low hemoglobin value once the patient is clinically anemic (i.e. reactively). It is possible that patient care could substantially be improved if the occurrence of severe anemia could be accurately predicted through the use of validated mathematical models. In this study, the development and validation of a prediction model for grade III/IV anemia is described.

Methods: The medical records of 331 patients who had received adjuvant breast cancer chemotherapy were reviewed. Clinical and biochemistry data that could potentially be associated with anemia were collected. The patient sample was then randomly divided into a $2 / 3$ model derivation and $1 / 3$ validation sample. Multivariable logistic regression techniques were applied to develop the initial model. A risk scoring system based on the regression parameters was then created ranging from 0 to 50 . As a final step, a operating characteristic curve (ROC) analysis was undertaken to measure the predictive accuracy of the scoring system when applied to the validation sample.

Results: Precycle hemoglobin, platelets $\leq 200\left(10^{3} / \mathrm{mm}\right)$, cycle number, patient age, type of adjuvant chemotherapy and the use of prophylactic antibiotics were identified as being important predictors for grade III/IV anemia. The ROC analysis on the validation dataset had an area under the curve of $0.88(95 \% \mathrm{CI}$ : $0.86-0.91)$. An overall risk score of $\geq 24$ for a given patient was identified as being the optimal cut off to maximize both the sensitivity $(83.5 \%)$ and specificity $(92.3 \%)$ of the prediction tool.
Patients with a score of $\geq 24$ would be considered at high risk for developing grade III/IV anemia following a particular cycle of chemotherapy.

Discussion: This study outlines the development of an accurate anemia prediction tool for breast cancer patients receiving adjuvant chemotherapy. The application and the planned continued refinement of this prediction tool will be an important source of patient specific risk information for the practicing oncologist and can enhance patient care by utilizing anemia therapies earlier in a proactive manner.

\section{5}

Long-term follow-up of sequential dose-dense chemotherapy with epirubicin $(E)$, paclitaxel $(T)$ and cyclophosphamide (C) (ETC) in breast cancer patients with 4-9 positive nodes: final results of a phase I/II study.

Moebus V, Hauser N, Kurbacher C, Lueck HJ, Thomssen C, Nitz $U$, Kreienberg R, Untch M. Staedtisches Klinikum, Frankfurt/M., Germany; University of Ulm, Ulm, Germany; Onkologische Praxis, Koeln, Germany; Medizinische Hochschule, Hannover, Germany; University of Halle, Halle, Germany; University of Duesseldorf, Duesseldorf, Germany; University of Grosshadern, Muenchen, Germany

Background: Dose-dense chemotherapy has become a new treatment option in breast cancer patients (pts) (INT C9741, ETC-trial). Long-term survival and toxicity data of the two phaseIII trials are pending. We report the final results of the foregoing ETC phase I/II study with a median follow-up of 6,5 years.

Methods: A multicenter phase I/II pilot study was conducted in Germany between $12 / 96$ and 12/98. 102 pts with 4-9 positive lymph nodes were recruited, median age was 50 years. Pts received three courses each of epirubicin $(120-150 \mathrm{mg} / \mathrm{m} 2)$, paclitaxel $(200-250 \mathrm{mg} / \mathrm{m} 2)$ and cyclophosphamide $(2.000-3.000 \mathrm{mg} / \mathrm{m} 2)$ at seven different dose levels. Cycles were given at 2 weeks interval with G-CSF support (5microgram/kg/SC day 3-10).

Results: The median number of positive nodes was $6.90 \%$ of pts received all nine cycles. No cardiac toxicity was reported. Hematological toxicity was highest during treatment with cyclophosphamide and modest during treatment with paclitaxel. Grade III/IV neutropenia occured in $22,6 \%$ of epirubicin cycles, only in $1,7 \%$ of paclitaxel cycles and in $51,8 \%$ of cyclophosphamide cycles. 16 cases $(16,7 \%)$ of febrile neutropenia were reported. Only one patient required platelets transfusion, but $26,4 \%$ of pts required RBC's. Dose-limiting non-hematological toxicity (grade III neurotoxicity) was observed with paclitaxe (250 $\mathrm{mg} / \mathrm{m} 2)$ in $7 / 27$ evaluable pts $(25,9 \%)$. One patient experienced acute myelogenous leukemia. With a median followup of 6,5 years, disease-free survival is $73 \%$ and overall survival is $79 \%$

Conclusions: The final results of the ETC phase I/II trial confirm the acceptable long-term toxicity of this regimen. DFS and OS show very promising data in this high-risk group of pts. The results of the long-term follow-up $(6,5 \mathrm{yrs})$ correspond with the preliminary results of the ETC phase-III trial which was reported 2004. 


\section{6}

A feasibility study of docetaxel in combination with anthracycline and cyclophosphamide or docetaxel followed by anthracycline plus cyclophosphamide in adjuvant therapy for operable breast cancer with positive axillary lymph nodes: CHN TAX 619.

Shen ZZ, Liu GY, Shao ZM, Wang SM, Zhang B, Jiang ZF, He PQ. Cancer Hospital, Fudan University, Shanghai, China; No.2 Affiliated Hospital of Sun Yat-Sen Medical Univesity, Guangzhou, Guangdong, China; Liaoning Province Cancer Hospital, Shenyang, Liaoning, China; Beijing 307 Hospital, Beijing, China, Shanghai No.6 Hospital, Shanghai, China

Background: Anthracycline based regimens followed by a taxane (CALGB-9344 trial and NSABP-B28) or reversed (MD Anderson Adjuvant Trial) has already accepted as adjuvant therapy for node positive breast cancer. Also in this group of patients, data from BCIRG-001 trial had shown that 6 cycles of adjuvant TAC (docetaxel, doxorubicin and cylophosphamide) is superior to standard FAC (5-FU, doxorubicin and cylophosphamide) in terms of both disease free and overall survival, while associated with a higher rate of febrile neutropenia. Then question arose whether it is better to use docetaxel and anthracycline in combination or sequence. Material and Methods:In this national wide study, 860 women with node positive operable breast cancer from 34 centers were designed to randomize to 6 cycles of adjuvant TAC (Taxotere ${ }^{\circledR}$ $75 \mathrm{mg} / \mathrm{m}^{2}$, doxorubicin $50 \mathrm{mg} / \mathrm{m}^{2}$ or epirubicin $60 \mathrm{mg} / \mathrm{m}^{2}$, cyclophosphamide $\left.500 \mathrm{mg} / \mathrm{m}^{2}\right)$, and 4 cycles of $\mathrm{T}\left(100 \mathrm{mg} / \mathrm{m}^{2}\right)$, followed by 4 cycles of AC(doxorubicin $60 \mathrm{mg} / \mathrm{m}^{2}$ or epirubicin $75 \mathrm{mg} / \mathrm{m}^{2}$, cyclophosphamide $600 \mathrm{mg} / \mathrm{m}^{2}$ ). Prophylaxis with GCSF was allowed when febrile neutropenia occurred in the first cycle of the study treatment. The second endpoint of this study is disease free survival. The primary objective is to compare the safety profiles of the two arms. The study started in July 2003 and patient recruitment is still ongoing. Results: Up to May 2005, 470 eligible patients were enrolled in the study. 124 women in TAC arm and 107 in T to AC arm completed there study treatment and were optimal for safety analysis. As was expected, the incidence of febrile neutropenia, on a per-patient basis was $15.6 \%$, and was not different between two arms $(16.1 \%$ in TAC and $15.0 \%$ in $\mathrm{T}$ to AC). No significant difference in other common toxicities was found between two groups (see Table1).Conclusions: Although the efficacy data of this study is too immature to report, the safety profile showed no difference between TAC and T to AC in designed dosages.

Adverse Events in Two Arms

Haematological AE
(NCIC Grade III/IV)

neutropenia

febrile neutropenia

anemia

anemia

Non-haematological AE

(NCIC Gatogical AE

NCIC Grade III/IV)

alopecia

nause

fatigue

myalgia/arthralgia

vomit

diarrhea

fluid retention

mucitis

$\begin{array}{ll}\begin{array}{l}\text { TAC } \\ \text { No. }\end{array} & \% \\ & \\ & \\ 69 & 55.6 \\ 20 & 16.1 \\ 2 & 1.6 \\ 0 & 0 \\ & \\ & \\ 56 & 45.2 \\ 13 & 10.5 \\ 17 & 13.7 \\ 12 & 9.7 \\ 5 & 4.0 \\ 3 & 2.4 \\ 0 & 0 \\ 0 & 0\end{array}$

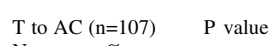

No. $\%$

Palue

51

47.7
15.0
3.7
0.9

0.2260

0.5499

0.5499
0.4632

0.2316

0.8584

0.0750

0.9318

0.0622

0.8428

0.2135

0.2135

\section{7}

Does switching to letrozole improve hot flushes, mood and quality of life in tamoxifen intolerant patients?

Thomas RJ, Marshall CJ, Williams M, Walker LG. Bedford \& Addenbrookes Cambridge University NHS Trust, Bedford, United Kingdom; University of Hull, Cranfield University, United Kingdom

Background: Over a third of patients on adjuvant tamoxifen suffer distressing side effects, particularly hot flushes. The IES,
MA17 and ATAC studies showed no overall difference in quality of life between tamoxifen (T) and aromatase inhibitors (AI). However, a comparison of $\mathrm{T}$ and an $\mathrm{AI}$ in a tamoxifen "intolerant" subgroup has not been reported previously.

Methods: 104 post-menopausal women participated in a longitudinal, open-label, prospective, crossover study. Eligible patients were taking $\mathrm{T}$ and were experiencing significant hot flushes. A one-week hot flushes diary (HFD), The Functional Assessment of Cancer Therapy (Breast with Endocrine Symptom add-ons; FACT-es) and the Mood Rating Scale (MRS) were completed at day 0 , and again following six weeks of letrozole (L). The women were then prescribed $\mathrm{T}$ or $\mathrm{L}$ based on these data and a patient preference questionnaire (PPQ). The primary end point, hot flush score (HFS intensity $\mathrm{x}$ number as assessed by the HFD) at 6 weeks, was powered to detect a difference of 12.5 (alpha [2tailed] $=0.05$ ). A likely $25 \%$ placebo effect was predetermined, based on previous blinded placebo controlled trials. A further arthralgia and PPQ were completed at 3 months.

Findings: The HFS decreased by 53.7\% from 97.0, following 6 wks letrozole, to $52.1 \quad(\mathrm{p}=0.001)$. This was even lower in those who chose letrozole $(\mathrm{p}=0.0001)$. The mean MRS improved from 47.7 to $52.8 \mathrm{~cm}(\mathrm{p}=0.004)$. The total mean FACT-es score improved from 132.7 to $142.1(\mathrm{p}=0.001)$, the endocrine subscale from 50.65 to $56.34(\mathrm{p}=0.01)$ with all other subscales also reaching statistical significance. The arthralgia rate associated with the two treatments at 3 months was mild (T 39\%, L 24\%), moderate (T15\%, L34\%) and severe (T0\%, L7\%); arthralgia influenced a further 5 patients to go back to T at 3 months. So far, $66 \%$ have preferred to remain on $\mathrm{L}, 24 \%$ preferred to go back to $\mathrm{T}$ and $10 \%$ have stopped all therapy. All patients said they appreciated the opportunity to experience both drugs and to choose for themselves. Only 1 of $105(1 \%)$ eligible patients declined trial entry, ensuring this cohort reflected routine oncology practice. $33 \%$ of patients had read negative or positive media reports on AI's before or during the trial, and $8 \%$ (all in the group reporting minimal differences between $\mathrm{L} \& \mathrm{~T}$ ) recorded that this could have influenced their choice, but not their toxicity reporting.

Discussion: It is emphasized that this trial cohort evaluated patients intolerant of adjuvant T. In this group, switching to L was associated with a significant reduction in hot flushes, an improvement in Qol and mood. Although the benefit in hot flushes was over which could have been anticipated by placebo within an open design, a causal effect needs to be confirmed by a blinded, randomised trial of $\mathrm{T}$ and L. Furthermore, it would be interesting to confirm this effect with other AI's. Patients appreciated the opportunity to make a trade off between hot flushes and arthralgia.

\section{8}

Five years use of aromatase inhibitors (Ais) in the clinical practice. Results from the NORA Study.

Cazzaniga ME, Mustacchi G, Pronzato P, Di Costanzo F, De Matteis A, Porcu L. Treviglio Hospital, Treviglio, BG, Italy; University of Trieste, Trieste, TS, Italy; La Spezia Hospital, Le Spezia, SP, Italy; Careggi Hospital, Firenze, FL, Italy; Pascale Institute, Napoli, NA, Italy; Mario Negri Hospital, Milano, MI, Italy

NORA is an observational study aimed at investigating adjuvant strategies in 3500 breast cancer (BC) patients (pts) radically treated with surgery in 77 Oncological Centres.

We analysed the use of AIs during the last 5 years according to tumour stage, age and with respect to the availability of first results of the ATAC trial presented in St Gallen in 2003.

Considering the whole population, $80 \%$ pf the pts has received TAM, both alone or in combination with chemotherapy (CHT). According to ECOG stage, the use of AIs increases with the increase of the stage starting from $6.5 \%$ and $8.1 \%$ in Stage I pts (HT and $\mathrm{CHT}+\mathrm{HT}$, respectively), till to $40 \%$ in Stage IIIA pts. In advanced stages, AIs are mainly chosen as HT alone instead of in combination with CHT $(21.6 \%$ vs $7.7 \%$ in Stage IIA and $21.4 \%$ vs $7.6 \%$ in 


\section{S108 Abstracts - Poster Session II}

Stage IIB). In pts older than 65 years, AIs are mainly administered in combination with CHT in those pts aged 66-75, whereas in pts older than 75 AIs are mostly used as HT alone (18.9\%).

According to the first results of the ATAC trial presented in St Gallen in 2003, the use of AIs as HT alone changed from $9.4 \%$ in the years $2000-2002$ to $18.4 \%$ in the years 2003-2004, whereas the administration of AIs did not significantly changed when used in combination with CHT ( $9 \%$ vs $10.8 \%$ ).

In conclusion, according to ECOG stage, the use of AIs increases with the increase of the stage, but only when hormones are administered alone. According to pts age, we observed an increase in the use of AIs mainly in very old pts ( $>75$ years) and in association with CHT. According to St Gallen 2003 guidelines, we observed as well an increase in the use of AIs, mostly as HT alone.

\section{9}

Prolonged dose-dense (DD) epirubicin and cyclophosphamide (EC) followed by paclitaxel $(\mathrm{T})$ in breast cancer (BCA) is feasible.

Dang $C$, Smith $K$, Lake D, Fornier M, D'Andrea $G$, Seidman A, Sklarin N, Troso-Sandoval T, Sugarman S, Gilewski T, Robson M, Drullinsky P, Moynahan M, George R, VanPoznak C, Panageas $K$, Smith M, Norton L, Hudis C. Memorial Sloan-Kettering Cancer Center, New York, NY

Background: To develop a potentially superior adjuvant chemotherapy regimen $(\mathrm{Rx})$ using a prolonged anthracycline $\rightarrow$ taxane, we conducted a pilot study of DD q 2 weekly (w) EC x $6 \rightarrow$ $\mathrm{T} \times 6$ with pegfilgrastim. A prior DD trial of a prolonged anthracycline-taxane Rx using q 2 w FEC (5-fluorouracil + EC) with filgrastim x $6 \rightarrow \mathrm{q}$ w $\mathrm{T}$ alternating with docetaxel $\times 18$ was not feasible because $9 \%$ patients (pts) experienced chemical pneumonitis during the FEC phase and $12 \%$ developed grade $(\mathrm{G})$ $3 / 4$ pericardial/pleural effusions during the taxane phase (Dang et al, Clin Cancer Res 10:5754-5761, 2004). The chemical pneumonitis was felt to be attributable to an interaction of the FEC combination, q $2 \mathrm{w}$ dosing, and/or filgrastim. Furthermore, studies of DD q $2 \mathrm{w}$ EC (without the F) have not reported pneumonitis.DD T q $2 \mathrm{w}$ is feasible (Citron et al, J Clin Oncol 21: 1431-1439, 2003). Thus, in this study we chose q 2 w EC x $6 \rightarrow \mathrm{T}$ $\mathrm{x} 6$. The primary objective was to determine feasibility of this $\mathrm{Rx}$. Methods: Pts withBCA were enrolled, regardless of tumor size or nodal status, and received $\mathrm{Rx}$ adjuvantly or neoadjuvantly. $\mathrm{Rx}$ consisted of q $2 \mathrm{w}$ EC at $100 / 600 \mathrm{mg} / \mathrm{m}^{2}$ x $6 \rightarrow \mathrm{T}$ at $175 \mathrm{mg} / \mathrm{m}^{2} \mathrm{x}$ 6 with pegfilgrastim $6 \mathrm{mg}$ on day 2 . If pts received $\mathrm{Rx}$ neoadjuvantly, all chemotherapy agents were given before surgery. Results: Between November 24, 2004 and May 9, 2005, 38 pts were enrolled. Median age was 46 years (range 30-72); 33 pts received $\mathrm{Rx}$ adjuvantly and 5 neoadjuvantly. Of these 33 pts, the median tumor size was $2.2 \mathrm{~cm}$ (range, 0.2-8.5 cm); 29/33 (88\%) were node $(+)$ with the median number of + nodes of 6 (range, 1 46 ), and 4/33 (12\%) were node (-). As of May 31, 2005, 24/38 pts have completed the EC phase. Of these 24 pts, one completed only EC x 5 due to $\mathrm{G} 3$ fatigue and proceeded to receive $\mathrm{T}$, and one completed only EC x 4 and withdrew consent for personal reasons. $8 / 38$ pts have completed the $\mathrm{T}$ phase; one completed only $\mathrm{T} \times 4$ due to G 3 nail changes and withdrew consent. As of May 31, 2005, 4/38 (11\%) pts experienced G 3 febrile neutropenia (FN); 3 of these pts had 2 episodes of FN each. All FN events were during the EC phase resulting in protocol-stipulated EC dose reductions in these 4 pts. Of the 24 pts who completed the EC phase, other G 3/4 toxicities were leukopenia (4 pts), neutropenia (4 pts), anemia (1 pt), thrombocytopenia (1 pt), fatigue ( $3 \mathrm{pts})$, and $\mathrm{G} 3$ headache $(1 \mathrm{pt})$. Of the 8 pts who have completed the $\mathrm{T}$ phase, $\mathrm{G}$ $3 / 4$ toxicities were nail changes (1 pt) and sensory neuropathy (1 pt).

Conclusion: Updated assessments will be reported. DD q 2 w EC x $6 \rightarrow \mathrm{T}$ x 6 with pegfilgrastim appears to be feasible and should be compared to other standard Rxs.

\section{0}

Epirubicin, paclitaxel and CMF as adjuvant treatment in node positive patients with operable breast cancer. Safety analysis of a randomized phase III study comparing two dose-dense sequential regimens.

Fountzilas G, Gogas H, Papadimitriou CH, Kalofonos HP. Tsavdaridis D, Christodoulou CH, Briasoulis E, Bafaloukos D, Karina M, Markopoulos CH, Pectasides D, Karapanagiotis K, Papakostas P, Aravantinos G, Kosmidis P, Stathopoulos GP, Dimopoulos AM. Data Office, Athens, Greece

Background: Dose-dense sequential adjuvant chemotherapy (CT) has been proven to be a very effective treatment for high-risk patients with operable breast cancer. However, the optimal doseschedule and sequence of the active drugs have not been clearly defined. The primary endpoint of the present study was to compare the disease-free survival of node-positive breast cancer patients treated with two different dose-dense regimens. By study design, duration of CT and cumulative doses of all drugs were indentical in both groups, even though dose intensities (DIs) of epirubicin (E) and paclitaxel $(\mathrm{P})$ were double in group A.

Patients and Methods: From March 2000 until May 2005 1059 eligible patients entered the study. Patients in group $\mathrm{A}(\mathrm{N}=538)$ were treated with 3 cycles of $E 110 \mathrm{mg} / \mathrm{m}^{2}$, followed dy 3 cycles of P $250 \mathrm{mg} / \mathrm{m}^{2}$ over 3-hours, followed by 3 cycles of intensified CMF $\left(840 \mathrm{mg} / \mathrm{m}^{2} ; 57 \mathrm{mg} / \mathrm{m}^{2} ; 840 \mathrm{mg} / \mathrm{m}^{2}\right)$ (E-T-CMF). All cycles were given every 2 weeks with G-CSF support. Patients randomized to group $\mathrm{B}(\mathrm{N}=521)$ were treated with 4 cycles of $\mathrm{E} 83 \mathrm{mg} / \mathrm{m}^{2}$ and P $187 \mathrm{mg} / \mathrm{m}^{2}$ every 3 weeks, followed by 3 cycles of CMF every 2 weeks, (ET-CMF). Radiation therapy and appropriate hormonal treatment were administered after the completion of chemotherapy.

Results: As of May 2005, 978 (92\%) patients (497 in group A vs 481 in group B) had completed CT and $73(7 \%)$ were still on treatment ( 38 vs 35 ). Eight patients $(1 \%)$ had never started chemotherapy ( 3 vs 5 ). A total of 7,473 (4,211 vs 3,262) cycles were delivered. Median relative DI (RDI) of E was 0.98 in both groups and that of $\mathrm{P} 0.97$ and 0.98 in group $\mathrm{A}$ and $\mathrm{B}$, respectively Median RDI of CMF was 0.97 in both groups. Most frequently seen grade III-IV side effects included neutropenia (25\% vs $23 \%$, $\mathrm{p}=0.5$ ), leukopenia ( $12 \%$ in each group) and febrile neutropenia ( $4 \%$ vs $6 \%, \mathrm{p}=0.2$ ). Severe hypersensitivity reactions (HSR) and peripheral neuropathy were significantly more profound in group $\mathrm{A}$, as expected, due to the higher dose of $\mathrm{P}$. There was one toxic death in group A. Updated results on the safety of both treatments will be presented at the meeting.

Conclusions: Safety analysis of the present study demonstrated that both regimens were well tolerated and planned DIs of all drugs were maintained at satisfactory levels. Toxicity was manageable. Severe neutropenia, HSR and peripheral neuropathy were the most frequently reported side effects.

\section{1}

Adjuvant dose-dense (3 FEC 100 followed by 3 docetaxel every 2 weeks) regimen is not feasible. Results of the FNCLCC-PACS 06 Study.

Fumoleau P, Brain E, Delozier T, Asselain B, Serin D, Roché H, Spielmann M, Genève J, Jimenez $M$, Bonnetain F. Centre GF Leclerc, Dijon, France; Centre R Huguenin, St-Cloud, France; Centre F Baclesse, Caen, France; Inst. Curie, Paris, France; Inst. Ste-Catherine, Avignon, France; Inst. C Régaud, Toulouse, France; Inst. G Roussy, Villejuif, France; FNCLCC, Paris, France

Background : Administration of cytotoxic courses every 2 weeks (q2w) so called dose-dense therapy could be one of the ways to improve efficacy in node positive $(\mathrm{N}+)$ breast cancer. In this setting, our group demonstrated the benefit of 3 FEC 100 followed by 3 docetaxel q3w (FNCLCC-PACS 01 results, SABCS 2004). Prior to initiating a large phase III study, we decided to conduct a randomised phase II trial designed to assess the feasibility of a 
sequential administration of FEC100 and docetaxel in a dosedense regimen in $\mathrm{N}+$ non metastatic breast cancer.

Methods: PACS 06 compares FEC 100 [5-FU $500 \mathrm{mg} / \mathrm{m}^{2}$, epirubicin $100 \mathrm{mg} / \mathrm{m}^{2}$, cyclophosphamide $\left.500 \mathrm{mg} / \mathrm{m}^{2}\right]$ x 3 cycles every 2 weeks followed by docetaxel $100 \mathrm{mg} / \mathrm{m}^{2}$ x 3 cycles every 2 weeks, in association with G-CSF day 3-10, with a 2-week (arm A) versus a 4-week (arm B) interval between FEC and docetaxel. The primary endpoint was to define the rate of patients with any toxicity (DLT) requiring dose reduction or treatment delay by more than one week over the 6 courses. These toxicities were defined as $1 /$ on the planned day of treatment administration: haematological / non-haematological grade $\geq 2$ (except nausea/ vomiting and alopecia), 2/ worst toxicity occurrence at any time: febrile neutropenia, thrombocytopenia grade 4, nonhaematological grade $\geq 3$ (except nausea/vomiting and alopecia) An interim analysis was planned after the enrolment of 30 patients in each arm. If $8(27 \%)$ or more DLT's as defined above reported, the patient recruitment should be stopped in this arm.

Results: As of May, 2005, 74 patients were included (37 in each arm). In arm A, 14 DLT's (38\%) were reported, skin / hand-foot syndrome grade 4: 2 pts, grade 3: $11 \mathrm{pts,} \mathrm{asthenia} \mathrm{grade} \mathrm{3:} 1 \mathrm{pt}$. The skin / hand-foot syndrome grade $3 / 4$ toxicities were all seen during the $\mathrm{q} 2 \mathrm{w}$ docetaxel part of this sequential regimen. In arm B, 3 DLT's $(8 \%)$ were reported as skin / hand-foot syndrome grade 3 seen during docetaxel treatment. Using G-CSF, only 2 haematological toxicities, both grade 4 , were reported in arm B. 23 and 19 patients received at least one cycle of docetaxel in arm $\mathrm{A}$ and $\mathrm{B}$ respectively. Due to the high incidence of severe skin toxicities, the patient recruitment was stopped in the arm A.

Conclusion: FEC 100 x 3 cycles every 2 weeks followed by docetaxel $100 \mathrm{mg} / \mathrm{m}^{2}$ x 3 cycles every 2 weeks, with a 2 -week interval between FEC and docetaxel is not feasible due to an excess of skin / hand-foot syndrome severe toxicities. Updated results will be presented.

This trial was supported by Sanofi-Aventis, Amgen and the National League Against Cancer.

\section{2}

Benchmarking the quality of adjuvant systemic therapy for breast cancer using multicenter data systems and practice guidelines: strengths and limitations.

James TA, Watroba N, Kulkarni S, Francavilla B, Edge SB. RoswellPark Cancer Institute; University at Buffalo, Buffalo, NY

Background: Improving the quality of cancer care has become a national priority. Variation in the quality of breast cancer (BC) care causes unnecessary suffering and death. Measures of quality must be relevant, rigorous, fair, and reliable. Practice guidelines may be a good source for quality measures. The objective of this study was to determine the accuracy of practice guideline quality measures in defining the quality of BC adjuvant systemic therapy (AST) when applied in a rigorous multicenter outcomes database. Methods: All patients treated at Roswell Park Cancer Institute have data entered into the BC Outcomes Database of the National Comprehensive Cancer Network (NCCN). The NCCN performs central analysis of the care as recorded in the database compared with the treatment recommended in the relevant NCCN guideline. Care is reported for each patient as concordant or non-concordant (NC). The medical records of patients with invasive cancer $>1 \mathrm{~cm}$ for who AST was coded as NC were reviewed and each instance of NC care classified as:

a) Error in data entry or in coding the NCCN concordance algorithm

b) Patient declined concordant therapy,

c) Physician advised against concordant therapy, or

d) Major deviation from guidelines.

Results: There were 413 women with tumors $>1 \mathrm{~cm}$. The NCCN database algorithm identified care concordant NCCN guidelines for AST in $85 \%$. Among the 63 coded as NC, the medical record review documented clear justification for $\mathrm{NC}$ care in all but $1 \%$ of cases.
A) Errors in data entry or coding the concordance algorithm - 20 $(5 \%)$. Care was concordant using the corrected data. This left 43 $(10 \%)$ cases with true NC care.

B) Patients declined therapy - $22(5 \%) .7$ declined tamoxifen and 15 declined chemotherapy ( 8 of these received tamoxifen only and 7 no therapy).

C) Physician advised against the guideline concordant care - 16 (4\%). $12 / 16$ women were over age 70 and the physician documented co-existing illness that precluded chemotherapy. 2 women under age 70 had serious co-morbidity precluding chemotherapy, and 2 had thromboembolic disease justifying omission of tamoxifen.

D) Major guideline deviations - $5(1 \%) .2$ women with receptor negative cancer did not receive chemotherapy and were not referred to medical oncology. 2 women with receptor positive cancer did not receive tamoxifen after chemotherapy. One woman had surgery before AST instead of neoadjuvant chemotherapy for Stage IIIB cancer.

Conclusions: Quality measures derived from practice guidelines applied to a multicenter database are useful for broad quality assessment and institutional quality improvement. However, accounting for all factors that justify $\mathrm{NC}$ is difficult in even the most rigorous data collection program. Therefore benchmarkings and comparisons between physicians and institutions based on concordance with guidelines using multi-center data systems must be interpreted with caution.

\section{3}

Pilot study of dose dense doxorubicin + cyclophosphamide followed by ABI-007 in patients with early stage breast cancer.

Robert N, Ambro S, Krekow L, Stokoe C, Bhar P, Hawkins MJ, O'Shaughnessy J. U.S. Oncology Research Network, Houston, TX; American BioScience, Inc., Santa Monica, CA

ABI-007 (Abraxane ${ }^{\mathrm{TM}}$ ) is an albumin-bound particle form of paclitaxel that has recently been shown to increase the response rate and time to tumor progression in women with metastatic breast cancer compared to Cremophor-based paclitaxel (Gradishar, JCO 2005, in press). We are conducting a pilot study to confirm the tolerability of dose dense AC q2wks x 4 cycles followed by dose dense ABI-007 $260 \mathrm{mg} / \mathrm{m} 2$ q2wks x 4 cycles prior to conducting a definitive comparison of AC followed by either ABI007 or Cremophor-based paclitaxel as adjuvant therapy for early stage breast cancer. Pegfilgastrim support was routinely used during AC chemotherapy but was to be used with ABI-007 only if cycles were delayed due to persistent neutropenia. From 3/10/05 to 5/05/ 05 , thirty patients with early stage (T1-3, N1-2, M0) breast cancer were entered onto the study. The accrued patients are now completing doxorubicin + cyclophosphamide (AC) chemotherapy and are starting ABI-007. To date 3 of 4 patients have received their 2nd cycle of ABI-007 without a treatment delay or pegfilgastrim support. Toxicity data for all cycles of AC and ABI007 will be presented for all patients.

\section{4}

Late adriamycin-related cardiotoxicity of dose-dense and intense sequential doxorubicin (A), paclitaxel $(T)$ and cyclophosphamide (C) as adjuvant therapy for high risk breast cancer.

Abu-Khalaf M, Juneja V, Chung G, DiGiovanna M, Wackers F, Lee $F$, Burtness B. Yale University School of Medicine, New Haven, CT

Background: Anthracycline cardiomyopathy has been reported to occur 5 or more years after completion of therapy, even in patients who had no evidence of cardiac dysfunction during therapy or the year thereafter. We wished to evaluate the incidence of late doxorubicin-related cardiotoxicity after dose-dense and -intense sequential doxorubicin (A), paclitaxel (T) and cyclophosphamide (C) as adjuvant therapy for breast cancer with $=4$ involved axillary 


\section{S110 Abstracts - Poster Session II}

nodes. Patients and Methods: Patients were enrolled between March 1994 and April 2001 after definitive breast cancer surgery if $=4$ involved axillary nodes and if distant metastases were not present on CT scan or bone scan. Planned treatment was A $90 \mathrm{mg} /$ $\mathrm{m} 2 \mathrm{q} 14 \mathrm{~d}$ x 3 , T $250 \mathrm{mg} / \mathrm{m} 2$ q $14 \mathrm{~d}$ x 3 , C $3 \mathrm{gm} / \mathrm{m} 2 \mathrm{q} 14 \mathrm{~d}$ x 3 with filgrastim (G) support. Left ventricular ejection fraction (LVEF) was monitored using equilibrium radionuclide angiography (ERNA) at baseline before the initiation of chemotherapy, and after 3 cycles of each chemotherapeutic agent. At this time, we are obtaining ERNA scans on this group of patients to evaluate the long- term cardiotoxicity of this regimen. Results: Eighty five eligible patients were enrolled, and the median delivered dose intensity was $>94 \%$ for all 3 chemotherapeutic agents. Clinical heart failure developed in one patient, and the median change in LVEF between pre- and post-treatment ERNA scan was $(-3.5 \%)$; [range $(-28)-(+14)$ ]. Seven $(8 \%)$ patients had LVEF $<50 \%$ at the end of therapy. One patient required medical therapy for congestive heart failure, but no cardiac-related deathswere noted. Fifteen (22\%) of the 69 surviving patients have consented to late cardiac imaging. At a median follow-up of 7 years, the mean absolute change in LVEF from baseline was $(-5.8 \%)$; [range $(-25)-(+8)$ ], with a decrease of $>10 \%$ occurring in $6(40 \%)$ of the 15 patients. The mean absolute change in LVEF from the end of chemotherapy was $(-0.8 \%)$; [range $(-17)-(+14)$ ], with a decrease $>10 \%$ occurring in only one $(7 \%)$ of the 15 patients. Only one patient had a LVEF $<50 \%$, but without a history of cardiac symptoms. This patient's LVEF decreased $18 \%$ from baseline at the end of chemotherapy, and an additional $7 \%$ (total 25\%) since the completion of chemotherapy at a 5.5 years follow-up. Discussion: Significant decline in cardiac function compared to the post-treatment evaluation is uncommon. Enrollment of intensively treated patients continues.

\section{5}

A prospective assessment of variables contributing to reduced relative dose intensity in patients with early-stage breast cancer receiving adjuvant chemotherapy.

Shayne M, Culakova E, Wolff D, Poniewierski M, Lyman GH, Dale DC, Crawford J. University of Rochester, Rochester, NY; University of Washington School of Medicine, Seattle, WA; Duke University Medical Center, Durham, NC

Background: Clinical outcomes in early stage breast cancer are dependant, in part, on the dose intensity of adjuvant chemotherapy. Retrospective studies have demonstrated that upwards of $56 \%$ of patients receive RDI $<85 \%$. We present here recent results on women treated with adjuvant chemotherapy for ESBC from a nationwide prospective registry study.

Methods: A prospective study of 115 community oncology practices was undertaken between March 2002 and the present. Data through August 2004 on 622 consecutive patients with ESBC receiving the six most common chemotherapy regimens were analyzed.. The primary endpoint of the study was the delivered RDI calculated for each drug and averaged for each regimen. Primary prophylaxis with granulocyte colony stimulating factor (G-CSF) was defined as administration prior to neutropenia in the first cycle of chemotherapy. RDI comparisons between subgroups were based on the Wilcoxon rank-sum test.

Results: The mean age of the study population was 53 years, with $15 \%$ of patients $>65$ years old at diagnosis. The average RDI for all regimens across the first four cycles of treatment was $94.2 \%$, with $14 \%$ of patients receiving $<85 \%$ of standard dose intensity. Two thirds of the reduced RDI was planned from the start of therapy and one third was unplanned. RDI $<85 \%$ was more common in patients with multiple comorbidities $(\mathrm{P}$ trend $=$ $.067)$ and with increasing age $(\mathrm{P}$ trend $=.015)$ primarily due to the greater planned dose reductions. Significant differences in delivered RDI across chemotherapy regimens were observed $(\mathrm{P}=.0022)$. An RDI $<85 \%$ was most frequently observed with docetaxel/ doxorubicin/cyclophosphamide (TAC) $(27 \%)$, yet only $7 \%$ of patients on this regimen received prophylactic G-CSF Alternatively, only $2 \%$ of patients on Q14 day doxorubicin/ cyclophosphamide/paciltaxel (ACT) with G-CSF support received RDI $<85 \%$. While half of the patients received G-CSF at some point during their therapy, only $9 \%$ received primary prophylaxis with G-CSF. The average RDI was significantly higher in patients who received prophylactic G-CSF starting in cycle 1 compared with those who did not $(\mathrm{P}<0.001)$.

Discussion: Compared with previous retrospective reports, this ongoing prospective registry study demonstrates a lower frequency of planned and unplanned reductions in RDI over the first four cycles. The average RDI was significantly higher in patients who received prophylactic G-CSF. Significant reductions in RDI were observed with multiple comorbidities, increasing age and TAC chemotherapy. In addition to supporting dose dense regimens, primary prophylaxis with a CSF may improve the delivery of full dose intensity conventional chemotherapy in women with ESBC.

\section{6}

Initial phase II results from 3 dose dense docetaxel pilots in early stage breast cancer.

Yardley DA, Spigel DR, Barton JH, Peacock NW, Shipley DL, Raefsky E, Burris HA. Sarah Cannon Research Institute/Tennessee Oncology, Nashville, TN

Background: Administration of q2 week taxanes and anthracyclines/ cyclophosphamide has demonstrated feasibility, curtailing the duration of adjuvant breast cancer therapy. Three phase II pilots were performed to identify the optimal dose dense docetaxel (D) $\rightarrow$ doxorubicin/cyclophosphamide (AC) as a planned arm for a phase III adjuvant trial. To avoid the skin toxicity reported for D immediately following anthracyclines, this sequence was chosen.

Material and Methods: From 3/4/04 to 5/4/05, 73 pts with high risk early stage or locally advanced breast cancer were enrolled in 3 sequential dose dense pilot studies evaluating q2 wk D followed by AC with pegfilgrastim (P) support. Chemotherapy doses in pilot $1(\mathrm{P} 1)$ and $2(\mathrm{P} 2)$ were as follows: D $100 \mathrm{mg} / \mathrm{m}^{2} \times 4 \rightarrow \mathrm{AC}$ $\left(60 / 600 \mathrm{mg} / \mathrm{m}^{2}\right) \times 4$ cycles. In pilot $3(\mathrm{P} 3)$, D was decreased to 75 $\mathrm{mg} / \mathrm{m}^{2}$. In P1 only, $\mathrm{P}$ was administered the same day of chemotherapy. Based on reports of increased myelosuppression with day $1 \mathrm{P}, \mathrm{P}$ was subsequently administered on day 2 for P2 \& $\mathrm{P} 3$. Given the G3 arthralgias as well as the lack of myelosuppression noted with $\mathrm{P}$ during dose dense $\mathrm{D}$ in $\mathrm{P} 1, \mathrm{P}$ was reduced to $3 \mathrm{mg}$ only with $\mathrm{D}$ in $\mathrm{P} 2$ \& $\mathrm{P} 3$. Dexamethasone was begun the evening before $\mathrm{D}$ as follows: $\mathrm{P} 1: 8 \mathrm{mg}$ po $\mathrm{q} 12 \times 5, \mathrm{P} 2: 4$ mg po q12 x 3, and P3: $8 \mathrm{mg} \mathrm{q} 12 \times 3$ doses.

Results: 73 pts were enrolled: P1-33, P2-20, \& P3-20 pts. Median age 52 (range 30-78). Tumors: T1-24, T2- 35, T3-11, T4-3 pts. 7 pts were treated neoadjuvantly. P1 \& P2 toxicities are presented Treatment was discontinued in $6 \mathrm{P} 1$ pts (intercurrent illness-2, poor compliance-2, toxicity-2 pts) and in $3 \mathrm{P} 2$ pts due to toxicity. There were no toxic deaths \& 8 pts required $\mathrm{D}$ dose reductions. With q2 wk D, nonhematologic toxicities were remarkable for G3 arthralgias (P1-7 pts) with none noted in P2 corresponding to changes in P dose and schedule. 4 P2 pts demonstrated G3 cutaneous toxicity compared to $1 \mathrm{P} 1 \mathrm{pt}$, perhaps attributable to reduced steroids in P2. G3/4 hyperlacrimation (P1-2, P2-2), G3 nail changes (P1-2, P2-1) and G3 fatigue (P1-2, P2-1) did not differ between $\mathrm{P} 1$ \& P2. With AC, G3/4 fatigue was noted in $6 \mathrm{P} 1$ and $1 \mathrm{P} 2$ pts. $\mathrm{AC}$ associated G3/4 neutropenia was prominent in P1 with G3-11/ G4-18 pts however, day $2 \mathrm{P}$ dosing in $\mathrm{P} 2$ resulted in a nearly 50\% reduction in G3/4 neutropenia (6/12 pts) yet the rate of $\mathrm{FN}$ did not change (P1-3, P2-5pts). With D, only $1 \mathrm{P} 1 \mathrm{pt}$ experienced neutropenia.

Conclusion: In spite of the taxane sequence with q2 week D 100 $\mathrm{mg} / \mathrm{m}^{2} \rightarrow \mathrm{AC}$ in this pilot, cutaneous toxicity was still evident and perhaps exacerbated by reduced steroids in P2. Same day P was not associated with enhanced D mediated myelosuppression however, prominent G3/4 marrow suppression characterized day $1 \mathrm{P}$ 
administration with AC. Despite improved counts evident with day $2 \mathrm{P}$ dosing with $\mathrm{AC}$, this did not translate into a lower incidence of FN. Reduced dose P is feasible with dose dense D, resulting in continued amelioration of docetaxel's myelosuppression as well as G3 arthralgias.

\section{7}

Intra-operative tissue characterization probe as a potential tool for surgical margin assessment.

Karni T, El-Ram R, Pappo I, Sandbank J, Lavon O, Maklakovski $M$, Evron E, Kent V, Konichezky M, Morgenstern S, Cohen G, Yarden O, Lelcuk S. Breast Care Institute, Assaf Harofeh Medical Center, Zerifin, Israel; Beilinson Medical Center, Petah Tikva, Israel; Dune Medical Devices, Caesarea, Israel; Tel Aviv University, Tel Aviv, Israel

Background: The surgical margin status after breast-conserving surgery is considered the strongest predictor for local failure. Therefore, a primary goal of breast surgeons is to obtain adequate negative margins of excision. The capsule-probe study was designed as a study of a novel electromagnetic tissue characterization modality developed by Dune Medical Devices. The study assesses the technology's potential in providing the surgeon with realtime data on tissue status at the surgical margins. The measurements were performed ex-vivo on freshly excised breast tissue.

Methods: Tissue samples were obtained from excised lumpectomy and mastectomy specimens. Each tissue sample was cylindrically shaped, with a volume of $0.1 \mathrm{ml}$. Tissue segments were analyzed using the capsule-probe, followed by a histological evaluation. Tissue samples were categorized into well-defined groups of homogenous composition, cancer and normal. As part of the classification process, tissue samples were randomly divided into two sub-groups. $35 \%$ were used for the learning group and the rest, $65 \%$, were the classification group.

Results: From 57 patients, a total of 231 tissue samples were obtained. From these, $198(86 \%)$ tissue samples qualified for analysis. In all, $134(67 \%)$ tissue samples contained $(75 \%$ of a specific tissue type. The breakdown of these tissue samples according to their grouping was as follows: Malignant breast tissue $34(25 \%)$, Normal breast tissue $100(75 \%)$. Classification performance of the capsule probe was: sensitivity $=0.95(95 \% \mathrm{CI}$ : $0.77-0.99)$ and specificity $=0.94(95 \% \mathrm{CI}: 0.85-0.98)$. Classification ability of mixed content tissue samples exists, however somewhat decreased as composition of the tissue becomes less homogeneous.

Conclusions: Cancer tissue can be detected by the capsule-probe with excellent sensitivity and specificity. The new modality has the potential of providing the necessary accuracy for a real-time margin assessment tool. The interaction volume in this configuration is a crucial element of design and should be further optimized for enhanced surface detection and small malignant cell cluster detection, which are necessary for real-time intra-operative use.

\section{8}

A novel method for reconstruction of immediate partial mastectomy defects.

Spiegel AJ, Khan FN. Baylor College of Medicine, Houston, TX

Background: Breast conservation therapy (BCT) is a viable option for women presenting with early stage breast cancer. Consisting of a lumpectomy, sentinel lymph node biopsy, and radiation therapy, BCT offers comparable survival rates to those obtained with a mastectomy. Unfortunately, although the purported benefit of BCT is to maintain breast cosmesis, $20-50 \%$ of women have significant residual deformity that worsens with time as radiation therapy side effects influence the final shape. In a study of 35 patients, Clough et al. reported that $71 \%$ of patients undergoing $\mathrm{BCT}$ requested reconstruction, with a mean interval of 27 months between BCT and reconstructive surgery. Often, however, due to tumor size or location, post-operative breast distortion can be predicted and immediate partial reconstruction becomes an option. Immediate partial reconstructions with the use of implants and flaps (including the latissimus dorsi and TRAM) have been performed but these methods have significant disadvantages, primarily due to the use of implants in an irradiated field or muscle sacrifice. Newer methods of complete breast reconstruction, including the deep inferior epigastric perforator (DIEP) or superficial inferior epigastric artery (SIEA) flap, eliminate the need for muscle sacrifice and offer superior cosmetic results. This prospective study was undertaken to assess the feasibility and examine the cosmetic outcome of the use of the DIEP and SIEA flap for immediate partial breast reconstruction. Material and Methods: Seven patients over a 2-year period underwent "immediate" partial breast reconstruction after negative margins were confirmed on final pathology approximately 1 week status-post lumpectomy. Two of the seven (29\%) had DIEP flap reconstruction and the remaining five $(71 \%)$ underwent reconstruction with a SIEA flap. Mean follow-up was 12 months status-post completion of radiation therapy.

Results: All seven of the flaps were soft and retained their shape, with no evidence of fat necrosis or necrosis due to radiation therapy. Four flaps displayed some degree of hyperpigmentation, with the more severe skin changes occuring in two flaps that had each received one BOOST treatment.

Discussion: This study indicates that superior cosmetic results are attainable with the use of the DIEP or SIEA flap for immediate partial breast reconstruction. The flaps all remained soft without any change in breast contour. This is in direct contrast to the severe side effects that are often observed in patients who undergo radiation therapy after a complete mastectomy and immediate reconstruction with flap tissue. This is most likely due to the different dosing of radiation that is applied for BCT versus mastectomy patients. These findings suggest that this is a novel reconstructive option for women undergoing BCT.

\section{9}

Measuring quality in breast reconstruction - Liverpool scoring system.

Sridharan $U$, Holcombe C. Linda McCartney Centre, Royal Liverpool\&Broadgreen University Hospital, Liverpool, Cheshire, United Kingdom

Breast Reconstruction is becoming increasingly common after mastectomy and is recognised as a mark of quality Oncological care. It is vital that reconstruction performed is of good quality with minimal complications. Currently there is no standard tool to evaluate the quality of Breast reconstruction. We have developed a scoring system to compare the quality of different reconstruction techniques, different surgeons and centres.

$\underline{\text { Aim: }}$ : The scoring system has been designed to measure the quality of breast reconstruction by measuring four independent quality domains - morbidity, economics, cosmesis and patient satisfaction, which can be combined into a Global score of quality.

Methods: We reviewed 100 patients who had reconstruction done by five surgeons and applied the scoring system.

Morbidity score involves risk factors and complications.

Economics - Measured in terms of operation time, hospital stay \& extra OPD visits

Cosmetic Score - Assessment of photographs by three independent evaluators

Patient assessment by a simple questionnaire

Total score (Global score) combines all 4 scores. 


\section{S112 Abstracts - Poster Session II}

$\begin{array}{lllllll}\begin{array}{l}\text { Results (Mean Score) } \\ \text { Type of } \\ \text { reconstruction } \\ (\mathrm{N}=100)\end{array} & \begin{array}{l}\text { Morbidity } \\ \text { score }\end{array} & \begin{array}{l}\text { Economic } \\ \text { score }\end{array} & \begin{array}{l}\text { Cosmetic } \\ \text { score } \\ (\max 100)\end{array} & \begin{array}{l}\text { Patient } \\ \text { Assessment } \\ (\max 100)\end{array} & \begin{array}{l}\text { Global } \\ \text { Implant } \\ (\max 200)\end{array} \\ & \begin{array}{l}\text { Primary } \\ (28)\end{array} & 5 & -6.82 & 35.39 & 50.57 & 83.96 \\ & \begin{array}{l}\text { Secondary } \\ (11)\end{array} & 5.45 & -4.82 & 41.64 & 56.27 & 98.73 \\ \text { LD } & \begin{array}{l}\text { Primary } \\ (15)\end{array} & 1.80 & -7.20 & 59.93 & 50.93 & 105.00 \\ & \begin{array}{l}\text { Secondary } \\ (9)\end{array} & 5.89 & -9.67 & 45.44 & 64.22 & 105.89 \\ \text { Tram } & \begin{array}{l}\text { Primary } \\ (26)\end{array} & 4.04 & -6.35 & 70.42 & 58.00 & 124.12 \\ & \begin{array}{l}\text { Secondary } \\ (11)\end{array} & 4.36 & -9.64 & 63.82 & 66.55 & 120.55 \\ & & & & & & \end{array}$

Conclusion:

Patient satisfaction does not always correlate with cosmetic outcome.

Patients who had secondary reconstruction are more satisfied. TRAM flap reconstruction is better cosmetically in this series. The scoring system allows comparison between techniques and can be used as a benchmark in the quality of breast reconstruction.

\section{0}

\section{Withdrawn by Author.}

\section{1}

Early results of nipple-areola-sparing subcutaneous mastectomy (NASSM) with complete resection of the retroareolar ductal system (RDS).

Paepke S, Schmidt R, Paepke D, Euler U, Schwarz-Boeger U, Plattner B, Niemeyer M, Humbert A, Schmalfeldt B, Kiechle M, Jacobs VR. Technical University of Munich, Klinikum Rechts der Isar, Germany

\section{Background:}

Skin-sparing or subcutaneous mastectomies (SCM) with immediate reconstruction are being used more frequently to treat many cases of breast cancer.

Skin-sparing tumor resection coupled with immediate reconstruction can optimise cosmesis, but the longterm oncological safety of these procedures is unclear. Nevertheless, little consideration has been given to the feasibility of nipple-areolasparing SCM using intraoperative frozen-section assessment of NAC and complete removal of the retroareolar ductal system (RDS).

\section{Method and Material:}

We modified the technique of subcutaneous mastectomy to achieve a complete resection of RDS. During performing SCM, frozen section analysis of the tissue beneath the nipple-areola-complex was performed, and if there was evidence of neoplastic involvement, the NAC was resected. In case of free margins we remove additionally the retroareolar ductal system also for fresh frozen section to proof the involvement with DCIS or invasive carcinoma. Aim of the feasibility phase of the study was to proof the concept, local recurrence rate (LCR) into the first two years, side effects and cosmesis.

From 06/02 - 04/05 52 NASSM were performed in case of DCIS or invasive breast cancer with immediate reconstruction as expander-, implant-, flap or combining techniques.

\section{Results:}

A secondary NAC-resection was necessary after final histologic report in $2 / 52(3.8 \%)$ cases because of involved RDS. 4 cases had involved margins beneath the NAC but free retroareolar ductal system - reason to recommend radiation therapy of the NAC/ breast. No central local recurrence in the NAC was observed. One patient $(1.9 \%)$ suffered a local recurrence in the lateral interquadrantal area $(9 \mathrm{~mm}, \mathrm{G} 3) 18$ months after the primary local treatment (without radiation).

Side effects: The complete removal of the RDS with impairment of blood supply leeds to a partial necrosis of the NAC, but not more than $20 \%$ of the NAS-area. Discomfort exist because of a prolonged postoperative wound control phase, long duration of re-pigmentation and re-sensibilisation up to 9 months and irreversible depigmentation of the nipple and/or areolar complex, partial loss of sensibility and hypaesthesia.

\section{Discussion:}

Our early experience suggests as any other results, that, using frozen section analysis of NAC during operation, NASSM can be a reasonable option for selected patients who want immediate reconstruction of the breast. The additionally performed complete resection of the RDS is a guarantee for lowering the central local recurrence with only a low rate of side effects and discomfort. Further investigation is necessary for the long-term follow up regarding the local recurrence rate and patient satisfaction.

\section{2}

Optimal timing of surgical intervention for the primary tumor in stage IV breast cancer patients improves outcome. Rao R, Feng L, Kuerer HM, Singletary SE, Hunt KK, Feig BW, Ross MI, Ames FC, Babiera G. University of Texas-MD Anderson Cancer Center, Houston, TX

Background: Several recent studies have demonstrated improved progression-free survival and improved overall survival with extirpation of the primary tumor in breast cancer patients who present with metastatic disease at initial diagnosis. The subset of patients who would most benefit from surgical intervention remains unclear. The current study evaluates the pathological attributes and optimum timing for surgical intervention in patients who presented with stage IV breast cancer and an intact primary tumor. Methods: A retrospective, single-institution review of all breast cancer patients between 1997-2002 presenting with an intact primary breast cancer and synchronous metastatic disease was undertaken. Baseline information collected included: demographics, tumor characteristics (histology, grade, ER/PR, HER-2), site(s) of metastases, type and timing of surgery, use of radiation therapy, and systemic therapy received. All patients initiated treatment within 3 months of their diagnosis of cancer. The timing of surgical intervention was evaluated and patients were divided into 4 groups based on three month intervals from date of diagnosis to the date of surgery. Disease progression and vital status at last follow-up were evaluated. Analysis of metastatic progression-free survival (defined by progression of systemic disease) benefit in relation to timing of surgical intervention was performed. Results: Multivariate analysis revealed that patients having only one site of metastasis, negative surgical margins, and Caucasian race had improved progression-free survival. Further analysis revealed that non-Caucasian patients more often underwent surgical intervention for palliation versus surgery for curative intent, possibly explaining their overall worse outcome. Patients who underwent surgery in the 6-9 month period after diagnosis had superior progressionfree survival. Conclusions: Surgical extirpation of the primary tumor in patients diagnosed with synchronous stage IV disease is associated with improved progression-free survival when performed at 6-9 months after diagnosis. Resection should be planned with the intent of obtaining negative margins.

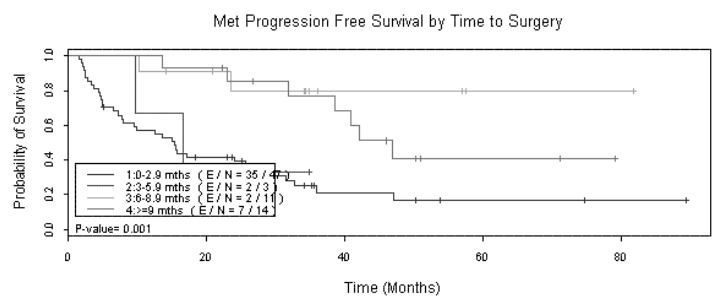


2083

A new latissimus dorsi muscle flap technique in oncoplastic surgery -the Bayreuth modification.

Euler U, Tulusan AH, Paepke S, Plattner B, Jacobs VR, Kiechle M. Technical University of Munich, Munich, Germany; Women's Hospital Bayreuth, Bayreuth, Germany

Objective: Oncoplastic surgery often requires special techniques in order to restitue the parenchymal defects of the breast. One method is the latissimus dorsi muscle flap to fill the defect after tumorectomy or mastectomy. We modified the original latissimus dorsi flap technique in order to avoid the large scar on the back and to reduce surgical complications.

Method: 118 patients (pts) with invasive breast cancer or DCIS and the demand for breast conservation, but primarily not suitable for breast conserving therapy alone, were additionally offered oncoplastic reconstruction with latissimus dorsi flap sometimes combined with breast tissue expander in two German centers. 45 pts presented with extended invasive breast cancer, 26 pts with large DCIS, 12 pts with a local recurrence of the breast and 34 pts received primary systemic chemotherapy before surgery. After tumorectomy the latissimus dorsi flap was prepared by removing the flap from the skin and the chest wall via the axillary cut. According to the size of defect the muscle was prepared and cut on its origin. Only the thoracodorsal vascular bundle remained. The patient was lying on the side, so no change of position of the patient and no additional cut on the back was necessary during the operation. The muscle was placed in the breast where soft tissue was needed to fill the defect in the breast. In 8 cases the oncoplastic surgery was combined with an tissue expander under the muscle. Results: The cosmetic results were very good in $65 \%$, good in $15 \%$ and acceptable in $7 \% .4$ necrosis of the muscular flap required another operation. 2 cases of inflammation of the breast were seen. None of the patient showed a reduced arm motility. So far there were only 2 local recurrences within 2 years.

Conclusion: The Bayreuth modification of the latissimus dorsi muscle flap used in oncoplastic surgery showes very good results without compromising a higher rate of complications or of local recurrences. This new technique avoids a scar on the back which is not only cosmetically highly acceptable but also shortens the time of surgery enormously because no change of position of the patient is necessary.

\section{4}

Oncoplastic technics for breast conservative surgery with ablation of nipple-areolar complex for central breast cancers.

Faure C, Escalon J, Meunier A, Perol D, Delay E. Centre Léon Bérard, Lyon, France

Background: Central breast cancer has long been an indication for mastectomy. Plastic surgical technics adapted to cancer (oncoplastic surgery) have made it possible to offer breast cancer patients conservative surgery with resection of the nipple-areolar complex (NAC). We evaluate carcinologic results and cosmetic outcomes.

Material and Methods: We performed a retrospective study in all patients with retro- or para-areolar $(<2 \mathrm{~cm}$ from areola) central breast cancers undergoing breast-conserving with NAC resection at Leon Berard Center, between 1995 and 2004. Carcinologic results were assessed by calculating local and metastatic recurrences rates. Cosmetic results were evaluated on four criteria: shape, symmetry, volume and deformation of the breast. Each criteria was firstly assessed by the patient then by two surgeons using the same 4-points rating scale, anchored from "excellent results" to "bad results".

Results: 47 patients with central breast cancer were eligible for carcinologic assessment. The mean age of the patients was 59, 8 years (44-84 years). The mean tumour diameter was $17.5 \mathrm{~mm}$ (6$39 \mathrm{~mm}$ ), with negative resection margins in all but one patient. $70 \%$ of the patients had axillary lymph node involvement. $60 \%$ of the patients underwent chemotherapy. Histological involvement of the nipple is present in $53 \%$ of the cases. Nipple involvement at clinical examination (53\%) was confirmed by histology in $64 \%$ of the cases. No local recurrence, neither death was observed at 4 , 5 years median follow-up. One patient had liver metastatic recurrence at 83 months.

Cosmetic results were assessed in 34 patients.NAC surgery was performed using either short, transverse incision $(38 \%$ of the cases), periareolar incision with "round-block" mammaplasty $(59 \%)$ or $\mathrm{T}$ plasty (one patient). Cosmetically, $71 \%$ of the surgeons and $82 \%$ of the patients considered the shape of the breast very good or satisfactory. Breast deformity was found minor or moderate in $73 \%$ of the cases for the patients and $79 \%$ for the surgeons. Symmetry was judged very good or satisfactory by $50 \%$ of the surgeons and $53 \%$ of the patients, though symetrisation was performed in only $11 \%$ (4 patients). Round-block provided better aesthetic results: the shape of the breast was considered very good or satisfactory for $85 \%$ of the surgeons in round-block technics and for $42 \%$ in transverse incision $(\mathrm{P}=0.02)$.

Discussion: Breast-conserving surgery is feasible in selected patients with $\mathrm{T} 1$ or $\mathrm{T} 2$ central breast cancers, with no impact on the risk of local recurrence. NAC resection is essential especially when the patients have clinical signs of nipple involvement. It provides satisfactory cosmetic results, especially with the roundblock technique, possibly associated with nipple reconstruction using the "cat-design" technique developed by our team.

\section{5}

Evaluation of local recurrence following surgical treatment of screen-detected breast cancer in Wales diagnosed between 1989 and 2003.

Monypenny IJ, Osborn G. Breast Test Wales, Cardiff, Wales, United Kingdom

Background: Ascertainment of local recurrence rates after surgical treatment of breast cancer in normal multi-institutional practice is problematic, particularly since early discharge from routine clinical follow up has been recommended by the National Institute for Clinical Excellence in the UK. It remains however one of the best markers of surgical quality assurance.

Methods: Pathology records of all surgical biopsies in Wales with a breast cancer diagnosis have been collected on a database at Breast Test Wales (BTW) since the start of population breast screening in 1989, as are treatment and death data for all breast cancers diagnosed by BTW. Since virtually all local recurrences (LR) will have histological or cytological confirmation, LR rates have been determined from these sources for all cases diagnosed by screening and receiving surgical treatment between 1989 and $2003,97.7 \%$ of whom were treated between 15 surgeons. The LR rate for the $17 \%$ of patients treated by one surgeon was crosschecked against other data sources and $100 \%$ concordance found, validating the methodology. Kaplan-Meier survival analysis was carried out using SPSS, censoring at 31/12/2004 where no recurrence or death event had occurred. Actuarial 10 year local recurrence failure rates (ALR) are reported.

Results: 6228 patients were treated (median follow up 70 months, range 1-190), with 59\% having breast conserving surgery (BCS). Mastectomy LR events were 37/2019 (ALR 3.3\%) for invasive disease and 7/522 (ALR 2.5\%) for ductal carcinoma insitu (DCIS). BCS LR events were 65/2190 (ALR 4.8\%) for invasive disease and $70 / 777$ (ALR 17.0\%) for DCIS, but the latter rose to $18 / 100$ (ALR $31.0 \%$ ) with margin involvement and this was not improved by post-operative radiotherapy. No significant differences were found for operating surgeon or across the 3 screening centres in Wales.

Conclusion: Concentrating treatment of screen-detected breast cancer to a small number of high caseload surgeons has resulted in low 10 year actuarial local recurrence rates for invasive cancers. Treatment of DCIS has changed during the period under study with closer attention being paid to margin clearance and greater use of radiotherapy after BCS. 


\section{S114 Abstracts - Poster Session II}

\section{6}

The use of intrapleural analgesia following mastectomy and immediate lattisimus dorsi myocutaneous flap breast reconstructions.

Chong YM, Long M, Shah D, Sharma AK. St George's Hospital and Medical School, London, United Kingdom

\section{Introduction}

Latissimus-dorsi flap reconstruction following mastectomy can be associated with considerable post-operative pain. We aimed to see if intrapleural analgesia (IPA) was a useful adjunct to standard post-op analgesia techniques.

Methods

Between December 2000 and October 2004, patients undergoing Latissimus-dorsi flap reconstruction following mastectomy were offered IPA. During flap mobilisation, a $16 \mathrm{G}$ epidural catheter was inserted into the $5^{\text {th }}$ intercostal space posteriorly. Intraoperatively, a bolus dose of Bupivocaine was injected at different dosages (15 $30 \mathrm{ml}$ at $0.25-0.50 \%$ concentration) for each patient. Postoperatively, a continuous infusion of $0.10 \%$ Lignocaine was also commenced at different rates $(5-15 \mathrm{ml} / \mathrm{hr})$ for each patient. Casenotes were reviewed for: Objective Pain Scoring (OPS), duration of intrapleural catheter infusion, whether breakthrough analgesia was required, time to mobilization and discharge and complications eg pneumo/haemothorax. OPS was based on: Score 0 - no pain at rest/on movement, Score 1- mild pain on movement, Score 2- moderate pain on movement, Score 3- severe pain on movement, Score 4 -continuous pain at rest/severe pain on movement.

\section{$\underline{\text { Results }}$}

Twenty eight patients were consented to IPA of which 21 cases had complete data. In the recovery room, the mean OPS was 0.8 with $70 \%$ of patients having an OPS of $\leq 1$. During the infusion period, $80 \%$ had a mean OPS of $\leq 1$ while $30 \%$ had an OPS of 0 . 2 cases had high OPS (mean of 1.67 and 1.71 respectively) due to blocked catheter and suboptimal infusion rate. Infusion continued for a mean period of 31.5 hours ( 7 - 70 hours) with 16 cases continuing for 24-48 hours. Patients were given regular oral analgesia while being weaned-off IPA. 10 patients required breakthrough analgesia with highest frequency between $16^{\text {th }}$ and $36^{\text {th }}$ hours post-op. The mean period to mobilisation and hospital discharge was 1.9 days ( 1 to 3 ) and 9.3 days (6 to 14) respectively. There were no reported complications. Within this limited sample, no correlation could be found between dosage of local anaesthetic and analgesia achieved.

\section{Conclusion}

IPA using bolus and infusion of local anesthetics appears to be a safe, well-tolerated and effective adjunct to standard forms of post-operative analgesia. Inadequate analgesia after $16^{\text {th }}$ hour postoperatively may be due to pleural absorption of local anaesthetic or suboptimal infusion rates. Changes to infusion rate should be based on regular pain assessment. The potential of IPA as postoperative analgesia for this procedure should be further evaluated by prospective studies.

Results of Objective Pain Scoring (OPS) During Intrapleural Analgesia After LatissimusDorsi Breast Reconstruction Surgery

Period At recovery 4 hours 8 hours 12hours 16hours 1st morning 2nd morning $\begin{array}{llllllll}\text { post-op } & \text { room } & & & & \text { post-op } & \text { post-op } \\ \text { Range } & 0 \text { to } 2 & 0 \text { to } 2 & 0 \text { to } 3 & 0 \text { to } 2 & 0 \text { to } 2 & 0 \text { to } 2 & 0 \text { to } 1\end{array}$

$\begin{array}{llllllll}\text { Range } & 0 \text { to } 2 & 0 \text { to } 2 & 0 \text { to } 3 & 0 \text { to } 2 & 0 \text { to } 2 & 0 \text { to } 2 & 0 \text { to } 1 \\ \text { Mean OPS } & 0.8 & 0.8 & 0.7 & 0.7 & 0.9 & 1 & 0.6\end{array}$

$\begin{array}{llllllll}\text { Mode } & 0 & 0.8 & 0.7 & 0.7 & 0.9 & 1 & 0.6 \\ & & 0 & 0 & 0 & 1 & 1 & 1\end{array}$

\section{7}

Combination therapy of Ad-mda7 and herceptin synergistically increases apoptosis in Her2/neu over expressing breast cancer cells.

Bocangel D, Mhashilkar A, Zheng M, McKinsey T, Liu Y, Menander K, Hunt K, Chada S. Introgen Therapeutics Inc., Houston, TX; UTMD Anderson Cancer Center, Houston, TX

The melanoma differentiation associated gene-7 (mda-7) is a member of the IL-10 cytokine family and a novel tumor suppressor gene. Adenoviral-mediated $m d a-7$ (Ad-mda7) gene transfer inhibits growth and induces apoptosis in a broad spectrum of cancer cells, but not normal cells. In breast cancer cells, adenoviral-induced mda-7 expression triggers antiproliferative effects by regulating molecules from the beta-catenin and PI3K pathways. The antihuman epidermal growth factor receptor-2 (HER-2) monoclonal antibody, Trastuzumab (Herceptin), increases the sensitivity of HER-2/neu overexpressing breast cancer cells to chemotherapeutic agents and radiotherapy. We evaluated the combination therapy of Ad-mda7 and Herceptin in a panel of HER-2/neu overexpressing cell lines and in established tumors in nude mice. The combination of Ad-mda7 and Herceptin demonstrated enhanced anti-tumor activity in HER-2/neu overexpressing tumor cell lines, increased cell death, induced cell cycle block, and induced apoptosis. The interaction was shown to be synergistic by isobologram analysis. Ad-mda7 does not alter cell surface HER-2/neu levels, but decreases expression of survival signals, such as bcl-2 and Akt.

Combination Ad-mda7+Herceptin treatment results in increased expression of cell surface E-cadherin with concomitant translocation of beta-catenin from the nucleus to the cell membrane. In vivo, the combination of Ad-mda7 and Herceptin showed significantly increased anti-tumor activity $(\mathrm{p}<0.05)$ against HER-2/neu overexpressing tumors compared to either Ad-mda7 or Herceptin alone. This activity correlated with loss of Akt and p-Akt in vivo in tumor xenografts. Thus, Ad-mda7 synergistically enhances the activity of Herceptin in HER-2/neu overexpressing breast cancer cells in vitro and in vivo. These data suggest that the combination of Ad-mda7 with Herceptin may be an effective novel therapy for breast cancer patients whose tumors overexpress HER-2/neu.

\section{8}

Reverse phase protein array in breast cancer classification. Hennessy BT, Lu Y, Tibes R, Gonzalez-Angulo AM, Hortobagyi GN, Valero V, Mills GB. MD Anderson Cancer Center, Houston, TX INTRODUCTION:

Reverse phase protein arrays (RPPA) are a new proteomic technology that allow us to simultaneously, globally and quantitatively study the heterogeneity of protein signaling in breast cancer by quantitatively assaying not only total protein levels but also the activation status of proteins (e.g. phosphorylation).

\section{METHODS:}

We applied RRPA to simultaneously study the activation status of the phosphatidylinositol 3 kinase (PI3K) and mitogen-activated protein kinase (MAPK) pathways and also the presence of other important proteins (cyclins, ER, E cadherin, keratins) in 40 breast cancer cell lines and 21 human breast tumors using validated proteinand phospho-protein specific antibodies.

\section{RESULTS:}

Breast cancer cell lines cluster into distinct molecular subgroups using RPPA. Each molecular subgroup is associated with a different pattern of protein signaling which likely reflects the precursor cell, genetic aberrations or interactions between these events. Cell lines clustered together according to the presence of known molecular abnormalities such as mutations of PI3K. Despite differences in the 2 technologies, clustering of cell lines using RPPA recreates well the clusters determined by transcriptional/ messenger ribonucleic acid (mRNA) profiling. This suggests that although breast tumor clusters determined by mRNA profiling are 
conventionally thought to reflect the cell of origin of the breast cancer (e.g. basal or luminal), these clusters may also have relevance in terms of molecular pathogenesis and protein signaling. Luminal cell lines have low levels of kinase activation ('luminal' protein signature) while PI3K pathway activation is much more prominent in other transcriptional breast cancer cell line groups (e.g. basal, HER2/neu, together constituting the 'kinase' protein signature). PTEN loss is a feature of a subgroup of basal/stromal breast cancer cell lines but not of luminal cell lines. Clustering 21 fresh frozen breast tumors using RPPAs generates preliminary evidence that protein signaling patterns may also have prognostic/predictive information content.

\section{CONCLUSION:}

RPPAs have the potential to explore the activation status of important protein signaling pathways in breast cancer cells and to cluster breast cancers according to similarity in protein signaling. Our data provides preliminary evidence that protein signaling patterns differ between breast cancer cell lines with different genomic abnormalities and contain prognostic and/or predictive information content, and that mRNA profiling reflects not only the cell of origin of the breast tumor but probably also distinct underlying pathogenic abnormalities and protein signaling in breast cancer cell lines.

\section{9}

Ras-mediated post-transcriptional regulation of connexin 43 expression: interplay between mRNA 3' and 5' untranslated regions.

Kandouz M, Zhao J, Batist G. Lady Davis Institute - Jewish General Hospital, McGill University, Montreal, QC, Canada

Background: Gap junction intercellular communication (GJIC) is involved in a multitude of physiological functions including regulation of cell growth, cell differentiation, and the maintenance of tissue homeostasis and is mediated by structures made of connexin proteins. We documented that Connexins are important tumor chemosensitivity modulators in established tumors. Connexin43 $(\mathrm{Cx} 43)$ is an important component of gap junctions. We previously found a loss of Cx43 expression in human breast tumor versus adjacent normal tissue. We therefore hypothesize that restoration of $\mathrm{Cx} 43$ in cancer cells, by virtue of its proven anti-proliferation and differentiation-inducing effects, is a pertinent therapeutic approach. We are exploring the mechanisms involved in loss of Cx43 expression in breast cancer, with a particular focus on post-transcriptional gene regulation processes. The 3'Untranslated Region (3'UTR) and 5'Untranslated Region (5'UTR) are the essential elements of post-transcriptional regulation of gene expression, being involved in mRNA transport, stability or translation.

Results: We analyzed the 3'UTR and 5'UTR-mediated regulation of Cx43 mRNA in normal versus breast cancer cell lines and localized sequences that showed differential regulatory features. The Ras signal transduction pathway plays a critical role in regulating both mRNA translation and cell transformation, through its effect on the initiation factor eIF4E, an essential element in the translational machinery, also involved in tumorigenesis. We used a model of H-Ras-induced transformation in NIH-3T3 and MCF-7 cells, to study the cancer-related post-transcriptional regulation of $\mathrm{Cx} 43$. We found that the Cx43 3'UTR region presents a strong positive regulatory element in the non-transformed NIH3T3neo cells that stimulate the expression of $\mathrm{Cx} 43$. The overexpression of H-Ras not only blocked all 3'UTR-mediated positive effects, but it even showed a negative effect that was only brought to control levels by the presence of the Cx43 5'UTR. We identified a short sequence with the strongest positive regulatory function and it was still subjected to the H-Ras-driven activation block. Acute (Tet On/Off inducible) versus chronic (stable transfection) effects of $\mathrm{H}$-Ras expression on $\mathrm{Cx} 43$ regulation are differentially analyzed.The determinants of H-Ras-mediated posttranscriptional regulation of connexin 43 expression are being elucidatedand a mechanistic view is proposed. We also present an evidence of an original and differential interplay between 3'UTR and 5'UTR regions of the Cx43 mRNA, in normal and transformed contexts.

\section{0}

Constitutively active type $I$ insulin-like growth factor receptor signaling induces transformation and epithelialmesenchymal transition in mammary epithelial cells.

Kim HJ, Cui X, Britton O, Lee AV. Baylor College of Medicine, Houston, $T X$

Previous studies have shown that type I insulin-like growth factor receptor (IGF-IR) mediates breast cancer invasion and metastasis. However, the molecular mechanisms underlying this IGF-IR function still remain to be identified. We have reported a novel animal model that involves transgenic expression of a fusion receptor (CD8-IGF-IR) of IGF-1R beta subunit with CD8alpha extracellular domain that is constitutively activated by homodimerization. Transgenic mice that expressed the activated receptor developed rapid tumor formation as early as 8 weeks of age and showed lung metastasis. To reveal the molecular mechanism of tumor formation and metastasis in this animal model, we stably overexpressed CD8-IGF-IR in MCF10A cells. Overexpression of CD8-IGF-IR in MCF10A cells disrupted well-organized acini formation in three dimensional culture and these CD8-IGF-IR transfectants grew anchorage-independent in soft agar. Compared with control MCF10A cells, these transformed cells displayed increased motility and gained invasion ability in vitro. Interestingly, these cells showed spindle-like morphology in contrast to the cuboidal shape in control cells. Moreover, in these cells, epithelial markers such as E-cadherin, beta-catenin and alphacatenin were dramatically reduced wherease mesenchymal markers like fibronectin and a-smooth muscle actin were increased. Snail transcription factor, a repressor of E-cadherin, was highly induced in these CD8-IGF-1R overexpressing cells. Collectively, these phenotypic and molecular changes suggest that overexpression of CD8-IGF-IR induces epithelial-mesenchymal transition (EMT) in MCF10A. Our studies indicate that aberrant IGF-1R signaling plays an important role in breast cancer invasion and metastasis.

\section{1}

Involvement of NF-kappaB in inflammatory breast cancer through the induction of epithelial to mesenchymal transition.

Van Laere SJ, Van der Auwera I, Van den Eynden GG, Benoy IH, Elst H, Van Dam P, Van Marck EA, Dirix LY, Vermeulen PB. Lab Pathology University of Antwerp and Oncology Center, General Hospital Sint-Augustinus, Wilrijk, Antwerp, Belgium

Inflammatory Breast Cancer (IBC) is an aggressive form of locally advanced breast cancer. Most patients have lymph node involvement at the time of diagnosis and $1 / 3$ of the patients have distant metastases. In a previous study, we demonstrated that IBC is a distinct form of breast cancer in comparison with non-IBC (Van Laere et al, Breast Cancer Res Treat, 2005). Unsupervised hierarchical clustering based on the expression of 756 differentially expressed genes was able to separate IBC from non-IBC. This suggested a distinct molecular phenotype for IBC. Amongst the differentially expressed genes, there was a high number of NFkB target genes and upstream activators of NFkB. The aim of the present study was to further investigate the role of NFkB transcription factors in the molecular pathogenesis of IBC. Therefore, immunohistochemical (IHC) staining of 40 IBC and 54 non-IBC tissue sections was performed for RelA, RelB and p50. In each tissue section, hot spots with nuclear staining were searched for and within these hot spots, a total number of 500 


\section{S116 Abstracts - Poster Session II}

nuclei was counted. For p50, on average $58 \%$ of the tumour cells in IBC stained positively, whereas only $44 \%$ of the tumour cells in non-IBC showed nuclear staining $(p=0.0002)$. We also found significantly more positive nuclei in IBC compared to non-IBC for RelB ( $31 \%$ and $20 \%$ respectively, $p=0.05$ ). Moreover, there was a significant correlation between RelB IHC staining and RelB gene expression data measured by cDNA microarray analysis $(\mathrm{r}=0.375, \mathrm{p}=0.034)$. For RelA nuclear staining, no difference was found between IBC and non-IBC (16\% and $14 \%$ respectively, $\mathrm{p}=0.47$ ). Huber et al (J Clin Invest, 2004) described the importance of NFkB in the induction and maintenance of epithelial-tomesenchymal transition (EMT). Jechlinger et al (Oncogene, 2003) performed expression profiling of epithelial plasticity in tumour progression. The gene list with differentially expressed genes after induction of EMT was analysed using the expression data for the corresponding genes in our dataset. Out of 144 genes, we found 57 genes to be present on our chip. 34/57 Genes were overexpressed in IBC relative to non-IBC, from which 24 genes were shown to be induced after EMT and 23/57 genes were repressed in IBC, relative to non-IBC, from which 16 genes were shown to be repressed after EMT (Pearson Chi-Square, $\mathrm{p}=0.003$ ). These results indicate that EMT is a process more active in IBC as compared to non-IBC. Altogether, our data suggest an important role for NFkB in IBC, possibly through the induction of EMT. This can explain how NFkB contributes to the aggressive and invasive phenotype of IBC. Therefore, IBC has to be regarded as a separate entity in comparison with non-IBC. Confirmation of the NFkB signature by quantitative real-time RT-PCR is ongoing.

\section{2}

Transcriptional analysis of factors affecting estrogen regulation in fine needle aspirates.

Schilling EM, Ivancic DZ, Bhandare DJ, Zaichuk T, Khan SA. Northwestern University, Chicago, IL

Background: Random fine needle aspiration (rFNA) is a method of breast epithelial sampling that is useful for risk assessment and biomarker studies, but the ability to acquire sufficient cells for studies of gene expression is not well established. We have assessed cell number, RNA yield, and the expression of enzymes involved in estrogen metabolism in rFNA samples from ex-vivo mastectomy specimens. Methods: Mastectomy specimens were sampled using rFNA. Aspirates were suspended in a light methanol fixative solution, with $10 \%$ of each sample used to determine morphology and overall cellularity. Remaining cells were pelleted, dissolved with TRIzol, and stored at $-80^{\circ} \mathrm{C}$ until RNA was isolated using phenol-chloroform extraction and DNAse treatment. After confirmation of integrity (Agilent bioanalyzer), RNA was reverse transcribed using random primers. Samples with low RNA integrity were amplified to the point at which they could be further assayed (Systems Bioscience Inc.). Through Taqman Realtime PCR assay, we investigated the following panel of estrogen-associated genes and steroidogenic enzymes: ER- $\alpha$, ER- $\beta$, Steroid Sulfatase, Aromatase, $17 \beta$ HSD-1, and $17 \beta$ HSD-2. IGF- 1 and TGF- $\beta 1$ were also assessed, as they are known to have direct influence on tumorigenesis and relate to this pathway. These findings were then compared to pathology diagnoses. Results: rFNA from three cancer-bearing and two non-cancer-bearing mastectomy samples resulted in average cell counts of $2.63 \times 10^{6}$ and $1.55 \times 10^{5}$ cells respectively. Cytologically, all samples contained a high proportion of epithelial cells, averaging 0.75 stromal fragments per 100 epithelial cells. TRIzol RNA extraction yielded expected amounts of RNA (mean of $4.13 \mathrm{ng} / 100$ cells). ER- $\alpha$ transcripts were readily detected in ER+ tumor samples (as assessed pathologically), but not in those designated ER-. ER- $\beta$ followed a similar pattern to ER- $\alpha$. The relative expression of $17 \beta$ HSD- 1 (catalyzing the reaction from $E 1$ to $E 2$ ) was inversely related to that of its oxidative counterpart $17 \beta$ HSD-2. Although aromatase and sulfatase transcripts were expressed in positive controls (both epithelial MCF-7 and monocyte THP-1 cell lines), all samples showed very low levels, with a slightly higher relative expression of aromatase. TGF- $\beta 1$ expression was low overall, whereas IGF-1 was very highly expressed in THP-1 cell line controls, and all samples. We will continue to accrue these samples for further analysis. Conclusions: This initial experience is encouraging with regard to the ability to obtain epithelium-enriched cellular sample using rFNA, and its utility in the analysis of gene expression in high-risk normal breasts, as well as in the characterization of tumors.

Supported by the Bluhm Family Program for Breast Cancer Early Detection \& Prevention and NIH/NCI P50 CA89018.

\section{3}

Regulation of steroid sulfatase gene expression in breast cancer.

Zaichuk T, Bhandare D, Ivancic D, Khan SA. Northwestern University, Chicago, IL

Background: The importance of local estrogen production in the development of breast cancer is increasingly recognized. Estradiol (E2) is intratumorally synthesized through the aromatase and sulfatase pathways. Aromatase inhibitors are well established in breast cancer therapy, but sulfatase inhibitors are just entering the clinical arena. Progress in this area requires a better understanding of regulatory mechanisms responsible for loca sulfatase deregulation in breast cancer. The sulfatase enzyme STS (EC 3.1.6.2, aryl sulfatase C) is responsible for the hydrolysis of steroid sulfates to their unconjugated forms which can be converted to steroids with estrogenic properties to stimulate tumor growth. Results: We have conducted experiments to investigate the molecular mechanism of STS gene regulation. Our data confirm, as reported by others, that STS gene expression is induced by estradiol (E2) and 4-hydroxytamoxifen abolishes this upregulation. We also have evidence that the changes in STS expression seen with E2 exposure are mediated through the estrogen receptor (ER). Transcription start site(s) in hormone-dependent and hormone-independent cells were identified by rapid amplification of 5'-cDNA end assay (RACE) to confirm the presence of alternative promoters. In addition we have observed altered STS expression in breast cell lines treated with demethylating agent 5-aza-2' deoxycytidine (5-azaC) suggesting that epigenetic mechanisms might be involved in the regulation of STS expression.

Conclusions: Elucidation of the interaction of the ER with STS regulation may provide opportunities for the development of new combinatorial approaches to endocrine therapy with ER modulating agents and STS inhibitors. The demonstration that regulation of STS expression involves DNA methylation will lead to the development of assays to predict sensitivity to STS inhibitorbased therapy, which can be performed on small, formalin-fixed clinical samples.

Supported by the Bluhm Family Program for Breast Cancer Early Detection \& Prevention and NIH/NCI P50 CA89018.

\section{4}

Regulation of bcl-2 by the BP1 homeotic protein in breast cancer cells.

Stevenson $H, F u S$, Berg PE. George Washington University Medical Center, Washington, DC

The BP1 homeotic protein belongs to a family of transcription factors with established roles in coordination of developmental processes in many species, several of which have been described to play a role in breast cancer. We have previously shown that BP1 mRNA and protein are overexpressed in $80 \%$ of invasive ductal carcinomas. Recently, we demonstrated that MCF-7 cells generated to stably overexpress BP1 protein showed enhanced viability when challenged with TNF-alpha, an inducer of cell death. Overexpression of BP1 in these cells also resulted in increased mRNA and protein levels of bcl-2, an anti-apoptotic gene. These 
data implicate a role for BP1 as a potential modulator of cell survival. The aim of this study was to test the ability of BP1 to directly regulate transcription of bcl-2 in breast cancer cells. BP1 protein binds in vitro to a DNA consensus binding sequence located near the bcl-2 promoter region at -2539 . To test whether this binding has functional significance, transient assays were performed. A construct containing a sequence spanning the bcl-2 promoter linked to the luciferase reporter gene, LB170, was transfected into MCF-7 cell lines either constitutively expressing BP1 or containing an empty vector. Three BP1 overexpressing cell lines consistently exhibited a 4-10-fold activation of the bcl2 promoter. Using LB170 as template, site-directed mutagenesis was performed to generate a construct lacking the BP1 binding site. Deletion of this site decreased activation of the bcl-2 promoter to approximately $50 \%$ of wild-type activity. Upon mutating a $7-$ nucleotide region of the BP1 binding site, we observed loss of binding of BP1 protein to its binding site at -2539 as revealed by electrophoretic mobility shift assays. Introduction of this mutation into LB170 DNA resulted in a $40 \%$ loss of bcl-2 activation. Thus, our results demonstrate that BP1 protein modulates upregulation of bcl-2 expression through binding to the bcl-2 promoter. These data are consistent with the protective effect of constitutive BP1 in MCF-7 cells challenged with TNF-alpha. Importantly, these findings demonstrate a link between BP1 and bcl-2 gene pathways that may impart a survival advantage to breast tumor cells and lead to decreased responses to therapeutic agents in patients.

\section{5}

p53 codom 72 polymorphism and the correlation with breast cancer.

Higo PES, Gebrim LH, Vieira JO, Silva IDCG. Federal University of Sao Paulo, Sao Paulo, Brazil

p53 codom 72 polymorphism and the correlation with breast cancer.

Higo PES, Vieira JO, Gebrim LH, Silva IDCG, Laboratory of Molecular ginecology, Federal University of São Paulo, São Paulo, Brazil

Background: The p53 gene is polymorphic at amino acid 72 of the protein that it encodes. It has reported that patients with the arginine form have a higher risk of developing other forms of cancer than those with proline form. The purpose of this study was examine whether p53 Arg represent a risk factor for Brazilian woman with breast cancer.

Material and Methods: Extracting the DNA and using allelespecific polymerase chain reaction to detected the p53 codon 72 polymorphism, we tested oral swab samples from 100 women diagnosed and treated for invasive breast carcinoma and 100 healthy individuals of similar age and from the same geographical region.

Results: We found statistically significant correlation between polymorphism and breast cancer. The allele frequency of p53 Arg/ Arg was much higher than that of the of the normal samples $(61 \%$ versus $22 \%$ )

Discussion This study suggested that p53 Arg homozygosis could represent a risk factor for the tumorigenesis of the breast cancer

\section{6}

Occludin is aberrantly expressed in human breast cancer. Martin TA, Jiang WG. Wales College of Medicine, Cardiff, United Kingdom

Background: Occludin is an integral membrane protein localised at tight junctions. It bears 4 transmembrane domains in its $\mathrm{N}$ terminal, with both the $\mathrm{N}$ - and $\mathrm{C}$-termini located in the cytoplasm. The C-terminal anchors the protein to ZO- 1 . We have already shown that levels of occludin are reduced in human breast cancer tissues, with reduced localisation at the cell periphery. This study aimed to determine the changes responsible for this loss of expression and re-distribution.
Methods: 6 paired normal and breast cancer tissues and 10 breast cancer cell lines were assessed using RT-PCR and western blotting to determine aberrant forms of occludin. Methylation status of the promotor was also investigated.

Results: Tissues and breast cancer cells lines were amplified for functional regions of occludin. 6/6 tumour tissues showed truncated and/or variant signals for $\mathrm{N}$-terminal and first trans-membrane loop of occludin; 4/6 tumour tissues did not express the C-terminal region of Occludin. Paired background tissues showed similar expression profiles. None of the breast tissues showed methylation of the occludin promotor. Of the 10 human breast cancer cells lines, 3 did not express the $\mathrm{N}$-terminal, 6 expressed 2 or more variants; 3 did expressed a truncated message for the first transmembrane loop, 5 expressed the correct message, MDA-MB-231 cells did not express this region; the $\mathrm{C}$-terminal region was expressed correctly in 3 cell lines, 4 expressed variants, and 4 were missing this region. Overall, only $3 / 10$ breast cancer cell lines expressed full length occludin; interestingly, these were of the more invasive phenotype. Methylation of the promotor was not observed. Western blotting also demonstrated variants of occludin when probed with 3 antibodies specific for the $\mathrm{N}$-terminus, first membrane loop and C-terminus. These variants did not fit the expected occludin signals for changes in phosphorylation status of the protein. Immuno-staining showed similarly disparate levels of expression, with more invasive cell lines showing reduced cell junction location.

Conclusion: This study shows for the first time that occludin is differentially expressed in breast tumour tissues and in human breast cancer cell lines. The changes in occludin message indicate that variants are expressed in tumour tissue. The loss of/truncation of the N-terminus indicates reduced assembly of tight junction structure and reduced maintenance of barrier function. Loss of $\mathrm{C}$ terminal expression suggests reduced intracellular trafficking of occludin to the basolateral membrane and binding to $\mathrm{ZO}-1$, resulting in reduced tight junction anchoring, assembly and cell-cell adhesion. This has clear repercussions as to the importance of occludin in maintaining tight junction integrity in breast tissues. Such inappropriate expression may play a part in breast cancer development.

\section{7}

GRB-7 promotes HER-2/Neu mediated signaling and tumor formation in breast cancer cells.

Luoh S-W, Bai T. Portland VA Medical Center, Portland, OR. Oregon Health \& Science University, Portland, OR

Background: Amplification of a chromosomal segment from 17 q21 containing HER-2/Neu gene is present in $20-25 \%$ breast tumors. HER-2/Neu amplification portends adverse prognosis and predicts response to therapy. GRB-7, encoding a SH2 domain containing signal transduction molecule, is located in the immediate vicinity of HER-2/Neu gene. GRB-7 is amplified and over-expressed concurrently in most, if not all, of the breast tumors with HER-2/ Neu amplification. This study aimed to ascertain the functional contribution of GRB-7 in HER-2/Neu mediated signal transduction and tumor formation in breast cancer cells.

Methods: MCF-7/HER-2 cells were derived from MCF-7 cells and over-expressed HER-2/Neu. MCF-7/HER-2 cells that also stably over-expressed GRB-7 were obtained via transfection. Knock down of GRB-7 expression in breast cancer cell lines that carried naturally occurring HER-2/Neu amplification was achieved with siRNA transfection. Immuno-precipitation was performed to examine interaction between HER-2/Neu and GRB-7. The activation status of various signaling transduction molecules was studied with Western blotting with phospho-specific antibodies. The ability of GRB-7 over-expression to promote tumor growth of xenografts was measured in nude mice.

Results: Immuno-precipitation demonstrated interaction between GRB-7 and HER-2/Neu when GRB-7 was stably over-expressed in MCF-7/HER-2 cells. GRB-7 over-expression lead to increased 


\section{S118 Abstracts - Poster Session II}

tyrosine phoshporylation of the HER-2/Neu molecule. More specifically, tyrosine phosphorylation at 1248 , a major autophosphorylation site for HER-2/Neu, was increased. GRB-7 overexpression also resulted in increased phosphorylation of PLC- $\gamma$ 1. In support of the above findings, knockdown of GRB-7 expression with siRNA transfection in SKBR-3 cells lead to decreased phosphorylation for HER-2/Neu and PLC- $\gamma-1$. Phosphorylation of a major PKC substrate, MARCKS, was increased, indicating activation of PKC pathways as a result of GRB-7 over-expression in MCF-7/HER-2 cells. When injected subcutaneously into nude mice, MCF-7/HER-2 cells that over-expressed GRB-7 induced tumor xenograft formation more readily than MCF-7/HER-2 cells that expressed GFP.

Discussion: GRB-7 over-expression activates HER-2/Neu and promotes HER-2 /Neu mediated signal transduction and tumor formation in breast cancer cells. Our results suggest that GRB-7 may constitute a rational target for therapeutic intervention for breast tumors with HER-2/Neu gene amplification.

\section{8}

Clinical and pathological characterization of basal-like breast cancer.

Osborne CR, Kannan L, Ashfaq R, Ariyibi J, Frawley WH, Tripathy D. University of Texas Southwestern Medical Center, Dallas, TX

Background: Gene profiling studies have revealed multiple subtypes of breast cancer with distinct outcomes. The "basal" subtype is in part defined by hormone receptor (HR) and HER2 negativity. Early stage basal cases are associated with a worse outcome and targeted therapies are currently not available for this group.

Methods: Cases were identified from surgical and biopsy specimens demonstrating HR and HER2 negativity. Specimens were characterized by histology, grade, ploidy, and proliferative index as measured by Ki-67 staining. Patient information, including race, age at first diagnosis and dates of recurrence and death were obtained.

Results: From 1996-2004, 473 biopsies were identified consistent with a basal-like phenotype, corresponding to 366 patients; 156 $(42.6 \%)$ were Caucasian, 132 (36\%) Black, 57 (15.6\%) Hispanic, and $21(6 \%)$ other. The median age at first diagnosis of the total cohort was 50 years of age, significantly lower than the national (SEER) median age of 61years $(\mathrm{p}<.0001)$. Additionally, Hispanics presented at a younger median age (40 years) than did Caucasians or Blacks $(\mathrm{p}<0.05)$. The majority $(68 \%)$ presented with stage I or II disease. $28 \%$ of women presented with or developed metastatic disease. Visceral metastases predominated with 5 women alone having bone-only disease. At a median follow up of 2.6 years, 76 $(21 \%)$ of the women died due to breast cancer with a median age of 47 years at the time of death, markedly lower than the SEER median age of death of 69 years. Of the women who died of breast cancer, $40 \%$ presented with early stage disease. Histologic classifications were invasive ductal $(87 \%)$, high grade $(77 \%)$, aneuploid $(60 \%)$, diploid $13 \%$ and $27 \%$ other ploidy status. A strikingly high median proliferative index was observed with $51.4 \%$ Ki-67 staining. In comparison, 728 unselected breast biopsies had a median $23.0 \% \mathrm{Ki}-67$ staining $(\mathrm{p}<.0001)$.

Discussion: This study shows that the basal phenotype is associated with an early age of breast cancer onset, high chance of presentation with metastases, high proliferative index and confirms an aggressive course. Further protein and gene characterization is in progress with the intent of identifying potential therapeutic targets.

\section{9}

Influence of pico-tesla range electromagnetic fields on mammary carcinoma protein expression profiles.

Coyne CP, Siyambalapitiyage Dona WSC, Hagood G, Bell E, Lawrence M. College of Veterinary Medicine, Mississippi State University, Mississippi State, MS

Background: The potential effect of electromagnetic (EM) fields on biological systems represents a controversial and relatively under-investigated field of medical research. A large proportion of the investigations cited in the literature to date have been devoted to determining the effect of chronic or intense exposure to 50$60-\mathrm{Hz}$ frequency EM-fields with flux densities in the milli-Tesla to Tesla range. Relatively little is known about how pico-Tesla range electromagnetic fields influence the viability of neoplastic populations or modify expression profiles for mRNA sequences and cancer cell proteins

Materials and Methods: Human MCF-7 mammary carcinoma populations were exposed to pico-Tesla range electromagnetic fields (PTREMF) for 1 hour/day for 5 consecutive days. Alterations in cell viability were recognized utilizing a MTT vitality staining methods. Alterations in replicate mRNA expression profiles were delineated by genetic micro-array analyses (96 genes/platform). Differential changes in phosphoprotein and SyproRuby stained protein expression profiles in aqueous and lipid soluble fractions were detected in replicate populations by 2D-PAGE and identified using LC/MS-MS analysis.

Results: Exposure to a PTREMF schedule consistently compromised the in-vitro viability/proliferation of human MCF7 mammary carcinoma populations approximately $30 \%$ relative to negative reference controls. Micro-array and LC/MS-MS analyses identified specific mRNA sequences $(n=12)$, and proteins fractions $(n=15)$ respectively that had their expression profiles modified in PTREMF-exposed populations of mammary carcinoma.

Discussion: Several neoplastic disease biomarkers, phosphoproteins and participants in cellular apoptosis phenomenon were identified that had their expression modified in mammary carcinoma populations following PTREMF exposure. Such findings have implications pertaining to the discovery of; [i] mRNA sequences and proteins that uniquely influence mammary carcinoma viability; [ii] PTREMF parameters that enhance chemotherapeutic efficacy; and [iii] genetic and protein "targets" that can be applied as templates for the molecular design of alternative chemotherapeutic agents.

\section{0}

\section{Protein acetylation and hormone-independent breast} cancer.

Cui Y, Parra I, Chen Y, Niu A, Fuqua SAW. Baylor College of Medicine, Houston, TX

When ER $\alpha$ is bound to the antiestrogen tamoxifen, corepressors and HDAC complexes are recruited to the promoter of estrogenresponsive genes, and transcription is attenutated. It is thought that acetylation, either at the promoter or of ER $\alpha$ protein itself, is dictated by the balance of coregulatory proteins present. We have recently discovered that metastasis associated protein 2 (MTA2), which is present in distinct HDAC complexes, acts as a repressor of ER $\alpha$ action; MTA2 siRNA reverses transcriptional repression. Levels of MTA2, as measured by immunoblot analysis, are significantly higher in ERa-positive invasive breast tumors. MTA2 overexpression in T47D breast cancer cells renders them resistant to estradiol, and the growth-inhibitory effects of tamoxifen; however these cells remain sensitive to pure steroidal antiestrogens, suggesting the continued involvement of $\operatorname{ER} \alpha$ in MTA2-induced hormone independence. MTA2 directly participates in the deacetylation of $E R \alpha$ protein through its associated HDAC1 activity. In addition, we found that MTA2 overexpression dramatically upregulates insulin receptor substrate 1 (IRS-1) protein expression. IRS-1 is a major signaling effector 
of the insulin and insulin-like growth factor I receptors. MTA2 binds to IRS-1 at its amino terminus (residues 20-115), a region which harbors the pleckstrin homology domain. We also determined that IRS-1 is acetylated by p300/CBP at its carboxy-terminus, and that proteasomal-dependent IRS-1 degradation is induced by treatment with HDAC inhibitors. Therefore, the functions of both ER $\alpha$ and IRS-1 can be regulated via protein deacetylation. In conclusion, MTA2 overexpression in ER $\alpha$-positive breast cancer cells initiates hormone resistance via a novel mechanism of protein deacetylation and turnover.

\section{1}

Diet and global DNA methylation in breast cancer.

Germano PBMR, Silva AG, Madeira M, Correa IC, Pitas AMCS, Bolsoni EMM, Reis LC, Souza FG, Andreoni S, Simony RF D'Almeida V, Gebrim LH, Correa M, Jasiulionis MG. Universidade Federal de São Paulo, São Paulo, Brazil

Background: Alterations in DNA methylation profile, an important epigenetic mechanism regulating gene expression, are associated with a variety of neoplasias, including breast cancer. Recent studies in humans have correlated folate, vitamins $B_{12}$ and $\mathrm{B}_{6}$ and methionine deficiencies with higher risk of developing cancer. These nutrients are involved in the methionine metabolic pathway, which has an important role in DNA methylation. Plasma homocysteine levels, another component of the methionine cycle, may reflect a methylation imbalance.

Materials and Methods: Global DNA methylation levels were determined by a methyl acceptance assay in tumor biopsies samples from 30 breast cancer patients. Blood folate, vitamin $B_{6}$ and homocysteine levels were determined by appropriate methods. Dietary information (folate, vitamins $\mathrm{B}_{12}$ and $\mathrm{B}_{6}$ and methionine) was obtained using a food frequency questionnaire and relevant clinical data was obtained from patients charts. Pearson's correlation test and unimodal ANOVA were performed for statistical analysis.

Results: We observed an inverse correlation between plasma homocysteine and tumor DNA methylation $(\mathrm{p}<0,0001 ; \mathrm{r}=0,777)$. Tumor DNA methylation was also inversely correlated with age $(\mathrm{p}=0,006 ; \mathrm{r}=0,538)$, tumor diameter $(\mathrm{p}=0,023 ; \mathrm{r}=0,453)$ and axillary status $(\mathrm{p}=0,009)$. No significant statistical correlation was observed between tumor DNA methylation and nutritional information or vitamin blood levels.

Discussion: Tumor global DNA hypomethylation is correlated with prognostic factors associated with a poor outcome, such a positive axillary status and larger tumor diameter, which was confirmed in our study. Interestingly, homocysteine blood levels showed a strong inverse correlation with tumor DNA methylation, suggesting that homocysteine levels may be used as a surrogate marker for that epigenetic anomaly.

\section{2}

Molecular pathogenesis of breast cancer in women of African ancestry.

Ikpatt OF, Dignam J, Khramtsov A, Xu J, Dangou J, Perou C, Ndoma-Egba R, Malami S, Adelusola O, Falusi A, Olopade OI. University of Chicago, Chicago, IL; Pasteur Institute, Dakar, Senegal; University of North Carolina at Chapel Hill, Chapel Hill, $N C$; University of Calabar, Calabar, CRS, Nigeria; Obafemi Awolowo University Hospital, Ile Ife, Osun, Nigeria; Usman Danfodio Teaching Hospital, Sokoto, Nigeria; Institute of Medical Research and Training, Ibadan, Oyo, Nigeria

Purpose: Genomic analysis of breast carcinomas distinguish molecular subsets of estrogen receptor ER+/luminal A, ER+/ HER2+luminal B, ER-HER2+, and basal-like groups with clinical implications. Experimental Design: Using a panel of antibodies against ER, PR, HER1, HER2, and cytokeratin 5/6, we determine the relative frequency of the molecular subtypes in a series of invasive breast tumors from African women with early onset breast cancer. In addition, we evaluated additional molecular markers including P53, VEGF, BCLX, BCL2, Cyclin D, and Cyclin E to identify potential therapeutic targets. Result: Of the 378 cases, $73 \%$ were under age 50 years with a mean age of $43.8 \pm 11.2$ years; large tumor size (mean $4.2 \pm 1.3 \mathrm{~cm}$ ); $83 \%$ had histological grade 2 or 3 . Among the 378 invasive tumors of different histologic subtypes, $27 \%$ wereER+/luminal A, 2\%ER+/HER2+luminal B, $15 \%$ ER-HER $2+, 27 \%$ basal-like and of significance $29 \%$ were unclassifiable which suggest a distinct molecular pathogenesis of these category of breast cancers (See Table 1) Conclusion: Our results suggest that molecular portraits of breast tumors are broadly conserved between women of African and European ancestry. However the relative frequencies of the distinct subsets differ, with a majority of tumors from African women lacking the expression of important therapeutic targets like ER, HER2 and HER1 while demonstrating markers of increased angiogenesis. These findings provide further evidence that breast tumor subtypes with the worse clinical outcomes may be overrepresented in young women of African ancestry and clinical trials of novel therapeutic targets, including anti-angiogenic agents may be warranted to reduced the disparities that exist in outcomes for these patients.

Comparison between African and U.S.* Patients
Age $<50$ years

$\geq 50$ years

$\begin{array}{lllllll}\text { Molecular subsets } & \text { A } & \text { AA } & \text { C } & \text { A } & \text { AA } & \text { C } \\ \text { Her2+/ER- } & 15 & 9 & 16 & 15 & 7 & 16 \\ \text { Basel-like } & 27 & 39 & 6 & 23 & 14 & 6\end{array}$ Basal-like

Luminal A

Luminal B

Unclassified

ER/PR status

$\begin{array}{ll}27 & 39 \\ 25 & 36\end{array}$

29

$\begin{array}{ll}39 & 16 \\ 36 & 6\end{array}$

$36 \quad 51$

51
18

$23-14$

14
59
16

16

* African-American and Caucasian Pts from Carrie et al, ASCO 2004 74

\section{3}

Notch signaling is altered in breast cancer and is a potential therapeutic target.

Rizzo P, Miao H, Siziopikou K, Song LL, Bashir A, Koenerner F, Chaturvedi V, Chin JZ, Zhao H, Selvaggi S, Tonetti DA, Nickoloff $J B$, Miele L. Oncology Institute, Loyola University Chicago, Maywood, IL; University of Illinois at Chicago, Chicago, IL; Rush University Chicago, Chicago, IL; University of Wisconsin, Madison, WI; Brigham and Women's Hospital, Boston, MA

Notch signaling is deregulated in several malignancies and maintains the neoplastic phenotype in Ras-transformed human cell lines in vitro and in vivo. While Notch-1 and Notch-4 have been implicated in mammary carcinogenesis in mice, the role of Notch signaling in human breast cancer remains unclear. We studied 77 archival cases including normal breast, hyperplastic lesions, carcinomas in situ and invasive ductal and lobular breast carcinomas for Notch receptor and ligand expression. Infiltrating carcinomas co-express Notch-1 and -4 , while normal breast and hyperplastic lesions do not express Notch-4, and in situ lesions do so inconsistently. All breast cancers we studied express one or more Notch ligands. HRas induces Notch-1 and -4 . Notch- 1 induce Notch-4 in breast cancer cells. RNAi silencing of Notch-1 or Notch-4 in MDAMB231 breast cancer cells significantly inhibits matrix invasion and subsequently increases the fraction of cells in G2/M, eventually inducing death. Pharmacological interruption of Notch signaling in MDA-MB231 cells via a gamma-secretase inhibitor induces G2/ $M$ accumulation and death. Treatment with estradiol increases Notch-1 but not Notch-4 expression in estrogen receptor $\alpha(\mathrm{ER} \alpha)$ positive T47D:A18 cells. Using reporter assays we determined that in the same cell line estradiol inhibits Notch 1 trascriptional activity and antagonizes the effects of Ras on Notch-1 activity. Consistently with these data we observed that estrogen receptor $\alpha$ $(E R \alpha)$-negative cells T47D:C42 have higher Notch-1 activity than estrogen receptor $\alpha(\mathrm{ER} \alpha)$-positive cells T47D:A18. Tamoxifen and other SERMS tested do not inhibit Notch-1 dependent trascriptional activity, but rather stimulate it. This indicates that activation of Notch-1 signaling may be an undesirable effect on some SERMS, and inhibition of the Notch signaling 


\section{S120 Abstracts - Poster Session II}

pathway should make breast cancer ER $\alpha$-positive more responsive to treatment with SERMS. Consistently with our hypotheses genetic or pharmacological interruption of Notch signaling strikingly potentiated the effects of tamoxifen in ER $\alpha$-positive cells and treatment of T47D:A18 xenografts in mice with gamma-secretase inhibitors with sub-therapeutic doses of tamoxifen strongly enhances the effect of tamoxifen. Additionally, genetic or pharmacological interruption of Notch signaling strikingly potentiated the effects of paclitaxel in both ER $\alpha$-positive and ER $\alpha$-negative cells. Our data suggest that inhibition of the Notch signaling pathway with gamma-secretase inhibitors is an attractive new strategy for the treatment of either $\operatorname{ER} \alpha$ - positive or $\operatorname{ER} \alpha$ negative breast cancers in combination with different agents.

\section{4}

Activated c-Src in ductal carcinoma in situ (DCIS) correlates with high tumour grade, high proliferation and HER2 expression.

Wilson GR, Barnes N, Knox F, Cramer A, Swindell R, Kawakatsu H, Dive C, Bundred NJ. South Manchester Acute Hospitals Trust, Manchester, United Kingdom; Paterson Institute for Cancer Research, Chrisite Hospital, Manchester, United Kingdom; University of California, San Francisco, CA

Background: The non receptor tyrosine kinase $\mathrm{c}-\mathrm{Src}$ is downstream of HER2/c-erbB2 and activation of c-Src influences response to Herceptin, tumour progression and metastasis.

Aim: To determine the expression of activated c-Src in pure DCIS and determine if activated c-Src correlates with HER2 expression and clinicopathological parameters in DCIS

Method: Immunohistochemical expression of activated c-Src using Clone 28, a monoclonal antibody, was evaluated in 110 patients (median age 55 years, range 29-71 years) with 'pure' DCIS and a median follow-up of 60 months (range 10-155 months). HER2, HER4, estrogen receptor (ER) and Ki67 levels were evaluated by immuno-histochemistry. Activated c-Src staining was evaluated as 1 (weak), 2 (intermediate) and 3 (strong). A HER2/ HER4 score $\geq 2$ was considered positive.

Results: Forty (out of 67) HER2 positive tumours over-expressed activated c-Src compared with seven (out of 35) HER2 negative tumours $(\mathrm{p}<0.0005)$. Strong expression of activated $\mathrm{c}-\mathrm{Src}$ was also associated with high tumour grade $(\mathrm{p}<0.0005)$ and epithelial proliferation (measured by Ki67, $\mathrm{p}=0.015$ ) but not tumour size, ER status and HER4 expression. HER2 positive DCIS had a higher recurrence rate at 5 years $(\mathrm{p}=0.0076, \log$ rank $)$.

DCIS Characteristics Activated c-Src Score

$\begin{array}{lllll} & 1 & 2 & 3 & \mathrm{p} \text { value (Pearson } \mathrm{chi}^{2} \text { ) } \\ \text { Tumour Grade } & & & & \\ \text { Low } & 5 & 3 & 0 & \\ \text { Intermediate } & 11 & 18 & 6 & \\ \text { High } & 5 & 21 & 38 & <0.0005 \\ \text { HER2 negative } & 10 & 18 & 7 & \\ \text { HER2 positive } & 7 & 20 & 40 & <0.0005 \\ \text { Ki67 Mean Rank } & 47.5 & 45.5 & 63.5 & 0.015 \\ \text { ER negative } & 6 & 15 & 17 & \\ \text { ER positive } & 14 & 28 & 30 & 0.906\end{array}$
ER positive $\quad 14 \quad 28 \quad 30=0.906$

Table 1. Activated c-Src and DCIS characteristics. A p value $\leq 0.05$ was considere statistically significant

Conclusion. Activation of $\mathrm{c}-\mathrm{Src}$ is seen in HER2 positive, high grade DCIS lesions with a higher proliferation index.Interruption of c-Src signalling with small molecule inhibitors may be therapeutically useful.

\section{5}

The pure prolactin receptor $(\operatorname{PrlR})$ antagonist $\Delta 1-9$ G129RhPrl reduces breast cancer clonogenicity and enhances doxorubicin cytotoxicity in vitro.

Howell SJ, Anderson E, Kalirai H, Clarke RB. University of Manchester, Christie Hospital NHS Trust, Manchester, United Kingdom

Background: Prolactin ( $\mathrm{Prl})$ is mitogenic and anti-apoptotic in breast cancer cell lines, however, breast cancer therapies targeting pituitary Prl have been ineffective. Autocrine Prl production has been demonstrated in cell lines and primary breast cancers. PrlR antagonism has the capacity to block the effects of both endocrine and autocrine/paracrine Prl.

Aim: To examine the effects of the novel pure prolactin receptor (PrlR) antagonist $\Delta 1-9$ G129R-hPrl ( $\Delta 1-9)$ in 5 breast cancer cell lines in vitro.

Methods: $\Delta 1-9$ was a gift from Dr V Goffin, Necker, Paris. The Sulforhodamine B (SRB) assay was used to assess cell growth in monolayer culture. Colony forming efficiency was assessed using the soft agar assay (CFE-SA), by seeding cells at limiting density onto tissue culture plastic (CFE-P) and in suspension culture (mammosphere forming efficiency, MFE). RT-PCR was used to examine Prl mRNA expression. Dual immunofluorescence was used to identify subpopulations of cells expressing the PrlR and Prl proteins. All statistical comparisons were by unpaired Student's t-test.

Results: $\Delta 1-9$ alone had no effect on the growth in monolayer of any of the cell lines, but significantly enhanced the effects of doxorubicin (DOX) in $4 / 5$ lines, reducing cell number by $5-15 \%$ over DOX treatment alone after 10 days $(\mathrm{p}<0.05)$. DOX treatment increased Prl mRNA expression in all 5 cell lines. Pretreatment of MCF-7 cells for 2 hours with DOX $1 \mu \mathrm{M}+\Delta 1-950 \mathrm{nM}$ reduced CFE-SA by $84 \% \pm 4.0($ mean $\pm \mathrm{SD}, \mathrm{p}=0.003)$ compared to cells pretreated with DOX alone, whereas $\Delta 1-9$ pretreatment alone had no effect. In contrast, inclusion of $0.05-50 \mathrm{nM} \Delta 1-9 \mathrm{G} 129 \mathrm{R}-$ $\mathrm{hPrl}$ into the soft agar resulted in a dose dependent inhibition of MCF-7 CFE-SA. All cell lines that grew as colonies in soft agar showed dramatic reductions in CFE-SA over control with $50 \mathrm{nM}$ 11-9: MCF-7 93\% $\pm 4.0($ mean \pm SD), T47D $89 \% \pm 3.8$ and MDAMB-468 $93 \% \pm 7.0(\mathrm{p}<0.001$ for all). $\Delta 1-9$ at $50 \mathrm{nM}$ reduced MCF7 CFE-P by $87-92 \%(p<0.001)$ and MFE by $42 \%(p<0.01)$. Immunofluorescence analysis of MCF-7, MDA-MB453, MDAMB-468 and SKBR3 cell lines in monolayer showed distinct patterns of PrlR and Prl expression in subpopulations of cells. Conclusions: The autocrine prolactin induced by DOX appears to be biologically active as antagonism of its effects by $\Delta 1-9$ enhances DOX cytotoxicity. $\Delta 1-9$ is highly effective at inhibiting breast cancer cell line colony formation as a single agent as assessed by three independent assays. Prl responsiveness appears to be a crucial regulator of a sub-population of highly clonogenic cells. Targeting the PrlR to enhance the efficacy of cytotoxic therapy and to eradicate clonogens that may be responsible for disease relapse after conventional therapies holds promise in breast cancer therapy.

\section{6}

The potential of MRI relaxation times to predict biological aggressiveness of breast cancer.

Kimijima I, Yoshida S, Sato A, Tamura R. Kita-Fukushima Medical Center, Date, Japan; Kita-Fukushima Medical Center, Date, Kenya

Backgrounds: The use of magnetic resonance imaging (MRI) has been increasing in breast imaging, mainly due to its high resolution and high imaging quality. However, some parameters visible on MR images may contain information for identifying the malignant potential of breast cancer. In experimental studies using DMBA-induced rat breast cancer, we observed a positive relationship between growth rate and T1 values of tumors. In the present study, we compared longitudinal and transverse relaxation times ( $\mathrm{T} 1$ and $\mathrm{T} 2$, respectively) in MR images of invasive breast cancer with several prognostic factors, and demonstrated their potential to predict the malignant potential of breast cancer. Patients and Methods: The present study investigated 60 cases of invasive breast cancer examined by MR imaging before surgery. Pathological findings of nodal state, histological grade, ER, PR, and Her2/neu were obtained in all cases. The MRI equipment used was a $1.5 \mathrm{~T}$ superconducting MRI system. Using AQnet software, relative values of $\mathrm{T} 1$ and $\mathrm{T} 2$ were measured as follows. In $\mathrm{T} 1$ weighted images, ROIwas set for the tumor and pectoral major muscle, then averaged figures from the muscle were divided by 
those from the tumor. The values obtained were used as the "relative $\mathrm{T} 1$ value" (rT1) in the following investigation. Relative T2 values were obtained by the same method as T2 weighted images. In order to test the relationship between these figures and the state of prognostic factors, StatView software was used.

Results: Pathological diagnoses for the 60 cases included 51 cases of invasive ductal cancer, 6 of invasive lobular cancer, and 3 special types. After dividing the rT1 values into a group of values higher than the mean, and a group of values lower than the mean, higher rT1 was found to be closely related to higher grading (grade III) of tumors $(\mathrm{p}=0.039)$. However, no relationship was observed between rT2 and tumor grading. Among the other factors, a weak positive relationship was observed between lower rT1 value and ER positivity $(\mathrm{p}=0.092)$. There was no relationship between nodal status and rT1 or rT2

Conclusions: This study successfully demonstrated the prognostic value of relative relaxation time, specifically rT1 values, in predicting the biological aggressiveness of breast cancer. This finding further enhances the potential of MRI as a highly sensitive imaging tool to not only identify minor lesions such as intraductal spreading, but also to identify prognostic information. Furthermore, in consideration of its non-radioactivity, MRI is an extremely important imaging method in breast cancer practice.

\section{7}

\section{Withdrawn by author}

\section{8}

Chinese herb lycium barbarum inhibits growth of hormone responsive human breast cancer cells by down-regulating C16 $\propto$-hydroxylation pathway of estradiol metabolism. Telang NT, Li G, Sepkovic DW, Bradlow HL, Wong GYC. Strang Cancer Research Laboratory, New York, NY; Hackensack University Med. Center, UMDNJ, Hackensack, NJ

Background: Chinese herbs containing phytoestrogens have received increasing attention in the management of estrogen related health issues. The safety and relevance of such herbs for breast cancer, however, remains to be rigorously evaluated. The present study was designed to identify mechanistic leads for the efficacy of nontoxic dose of the Chinese herb Lycium barbarum (LB) on a cell culture model of hormone responsive breast cancer. Material and Methods: The ER ${ }^{+}$MCF-7 human breast carcinoma cells maintained in serum depleted medium $(0.7 \%$ serum, $<1 \mathrm{nM}$ estradiol $\left(\mathrm{E}_{2}\right)$ ) represented the model system. Growth modulation by physiological levels of $E_{2}$ and cellular metabolism of $E_{2}$ represented the endpoints for $\mathrm{E}_{2}$ responsiveness. Dose dependent growth inhibition by an aqueous extract of $\mathrm{LB}$ and its effect on $\mathrm{E}_{2}$ metabolism by GC-MS analysis represented the endpoints for efficacy.

Results: A 7 day treatment of MCF-7 cells with 1,5 and $10 \mathrm{nM} \mathrm{E}_{2}$ produced a dose dependent increase in cell number. A $48 \mathrm{hr}$ treatment with $20 \mathrm{nM} \mathrm{E}_{2}$ induced a 6.3 fold, $42.8 \%$ and $15.4 \%$ increase in formation of estrone, 2-hydroxyestrone, and 16œhydroxyestrone, respectively. A 7 day treatment with LB produced a dose dependent growth inhibition. LB at $0.5 \%$ (IC53) increased the metabolism of $\mathrm{E}_{2}$ by predominantly down-regulating the $\mathrm{C} 16 \propto-$ hydroxylation pathway. Specifically, LB treatment resulted in a 13 fold increase in the level of nonmitogenic proximate metabolite estriol $\left(\mathrm{E}_{3}\right)$.

Discussion: The unique activity of LB via preferential increase in nonmitogenic $\mathrm{E}_{3}$ identifies a novel mechanistic lead. Overall, these data validate an efficient, mechanism-based approach to screen chinese herbs for breast cancer. [Support: Daniel and Katherine Mezzalingua, William Randolph Hearst Foundation, and Horst M. Rechelbacher Foundation].

\section{9}

Haemangiogenesis and lymphangiogenesis in the primary tumor and in lymph node metastases of breast cancer: a comparative histomorphometrical study.

Van den Eynden GG, Van der Auwera I, Dirix LY, Vermeulen PB, Van Marck EA. Lab Pathology University of Antwerp/University Hospital Antwerp, Edegem; Oncology Center, General Hospital St-Augustinus, Wilrijk, Wilrijk, Antwerp, Belgium

Introduction: Breast cancer (BC) often spreads from the primary tumor (PT) to regional lymph nodes (LNs). Tumor cells in LN metastases (LNMs) may then provide a reservoir of cells leading to distant, lethal metastases. Nevertheless, recent models of BC metastasis include dissemination to distant organs both via the LNs and directly through the blood stream. Although the role of haemangiogenesis and lymphangiogenesis in the PT growth and dissemination has extensively been studied, only few data are available on their role in the growth and progression of LNMs of BC. The aim of this study was to obtain histological data on hypoxia response, haemangiogenesis and lymphangiogenesis in BC LNMs and to compare these processes in the LNMs and PT. Materials and Methods: One representative tissue block was selected of both the PT and a LNM of 55 BC patients. Immunohistochemical (IHC) staining was performed for Carbonic Anhydrase 9 (CA9), Hypoxia Inducible Factor- $1 \alpha$ (HIF-1 $\alpha)$ and DEC-1. To visualize proliferating blood and lymphatic endothelial cells an IHC doublestaining for respectively CD34/Ki-67 and for D2-40/Ki-67 was done. Blood vessel endothelial cell proliferation fraction (BVECP) (\%), lymphatic vessel endothelial cell proliferation fraction (LVECP) $(\%)$ and tumor cell proliferation fraction (TCP) (\%) of the PT and of the LN metastases were assessed at the tumor/normal tissue interface. CA9, DEC-1 and Hif- $1 \alpha$ expression in the PT and in the LN metastases were assessed. Results: Mean BVECP and TCP in the LNMs were $6.56 \%$ and $26.64 \%$, respectively. BVECP and TCP strongly correlated in LNMs $(r=0.802, p<0.001)$. Comparable results were found in the PTs. BVECP and TCP of PTs and corresponding LNMs strongly correlated (BVECP $r=0.537, p<0.001 ;$ TCP $r=0.702$, $p<0.001)$. CA9 was expressed in $18.0 \%$ and $43.4 \%$ of LNMs and PTs, respectively. Hif- $1 \alpha$ was expressed in $30.9 \%$ and $50.9 \%$ of LNMs and PTs. CA9 and Hif- $1 \alpha$ expression strongly correlated (LNMs $p<0.001$; PTs $p<0.005$ ). Mean BVECP was higher in LNMs and PTs with hypoxia $(\mathrm{p}<0.002)$. CA9 and Hif- $1 \alpha$ expression in the PT and LNMs were correlated (CA9 p $<0.001$, Hif- $1 \alpha p=0.08)$. Lymphangiogenesis assesment (LVECP) is ongoing.

Conclusions: Our data demonstrate that the growth of BC LNMs is haemangiogenesis dependent. Newly formed blood vessels in BC LNMs might be one of the routes by which haematogenous dissemination of tumor cells in BC occurs. Furthermore, the hypoxia response and angiogenesis in the PT predict the hypoxia response and angiogenesis in the LNMs. This is in contrast with our observations in liver metastases of BC of which $90 \%$ grow according to a non-angiogenic 'replacement' growth pattern. Hypoxia response and angiogenesis in $\mathrm{BC}$ metastases, and therefore the success of anti-angiogenic therapy, might therefore be sitedependent.

\section{0}

Phenotypic characterization of inflammatory breast cancers on tissue microarrays: a study of 109 cases with 25 proteins. Charafe-Jauffret E, Tarpin C, Esterni B, Bertucci F, Xerri L, Birnbaum D, Jacquemier J, Viens P. Institut Paoli Calmettes, Marseille, France

Background: Inflammatory breast carcinomas (IBC) are defined clinically and/or pathologically but less is known on their molecular characterization. We proposed here an immunophenotypic definition of IBC from a study of 109 IBC with 25 proteins, This larger study will test candidate markers from two previous smaller studies. 


\section{S122 Abstracts - Poster Session II}

Material and Methods: A tissue microarrays (TMA) was constructed from paraffin-embedded samples of a series of 109 IBC and 74 locally advanced breast cancers (LABC) used as controls. The expression of 25 proteins were tested by immunohistochemistry. Seven proteins were obtained from an "inflammatory signature "previously defined by cDNA analysis, five were from an immunophenotypic characterization (Estrogen receptor ER, E-Cadherin, ERBB2, proliferation index Mib1, sialomucin MUC1) established from a previous study, three were angiogenic factors, five were basal and luminal differentiation molecules, two were protein possibly involved in specific response to chemotherapy, and three were other "classical" proteins in breast cancers (anti-apoptotic $\mathrm{Bcl} 2$, progesterone receptor $\mathrm{PR}$, p53). The expression was compared between IBC and LABC, and in IBC group between those who presented dermal lymphatic emboli or no. Main features were noted.

Results: IBC patients are younger $(\mathrm{p}=0.01)$, higher grade tumors $\left(\mathrm{p}=10^{-10}\right)$, with more metastatic lymph nodes $\left(\mathrm{p}=10^{-7}\right)$, more peritumoral vascular emboli $\left(\mathrm{p}=10^{-8}\right)$ compared with LABC. We defined phenotypic differences between IBC and LABC. We confirmed the previous phenotypic characterization of IBC with ER, E-Cadherin, ERBB2, Mib1 and MUC1 but we did not confirm at the protein level the transcriptional signature of IBC. There was no phenotypic difference between IBC with or without dermal lymphatic emboli.

Discussion: This phenotypic characterization of 109 IBC with 25 proteins may be helpful to better define this entity. We confirmed a previous immunophenotypic signature, we did not validate at the protein level our transcriptional signature of IBC. Some of the proteins differentially expressed in IBC may be of special interest as prognostic factors or specific therapeutic targets, but still need further investigations.

\section{1}

PIK3CA mutations in breast cancer: an attractive target for small molecule inhibitors and a potential biomarker for chemoresistance.

Margeli M, Ramirez J, Taron M, Rosell R, Cirauqui B, Mendez P, Castella E, Barnadas A, Sanchez-Ronco M, Santarpia M. Catalan Inst of Oncol, H Germans Trias i Pujol, Badalona, Barcelona, Spain; H de Sant Pau, Barcelona, Spain; A University of Madrid, Madrid, Spain; H Germans Trias i Pujol, Badalona, Barcelona, Spain

\section{Background:}

Genetic alterations of PIK3CA consist exclusively of somatic missense mutations and are clustered to specific sites in the coding sequence (exons 9 and 20). Two of the most frequently altered residues, E542 and E545, are located within the helical domain (exon 9) of p110a. These residues are often substituted with lysine in tumors of colon and brain. Another targeted residue, H1047, resides in the kinase domain (exon 20) and is frequently substituted with an arginine in tumors of the breast, colon and brain. These PI3-kinase mutations - E542K, E545K and H1047R - correlate with elevated catalytic activity in in vitro kinase assays. The mutant-transformed cells show constitutive phosphorylation of Akt, of p70 S6 kinase and of 4E-binding protein 1.

Materials and Methods:

We have analyzed 35 surgically resected stage I-III sporadic primary breast tumor biopsies with a median follow-up of 33 months. The presence of the PI3-kinase mutations E542K, E545K and H1047R was assessed in extracted DNA by the 5-nuclease assay (Taqman) using the ABI Prism 7900HT Sequence Detection System (Applied Biosystems, Foster City, CA).

Results:

Mutations were found in 9/35 patients (25.7\%): 5 H1047R; 2 $\mathrm{E} 542 \mathrm{~K}$, and $2 \mathrm{E} 545 \mathrm{~K}$. There was no correlation between mutations and expression of estrogen and progesterone receptors, lymph node metastases or ERBB2 expression, confirming three previous reports (Campbell, Bachman,Levine) and in contrast with a fourth report (Saal). A significant association between PIK3CA mutations and older age was observed (Table 1).

Conclusion:

We have observed PIK3CA mutations in a large number of patients, and for the first time, have found an association with older age. No correlation was observed with pathological characteristics. The median follow-up is not long enough to determine prognostic involvement. A kinase with a cancer-specific somatic mutation is an ideal target for a small molecule inhibitor that could be developed into an effective anticancer drug. Data on more patients will be presented.

Table 1

\begin{tabular}{|c|c|c|}
\hline & $\begin{array}{l}\text { PIK3CA wild type } \\
\text { (26) } \mathrm{N}(\%)\end{array}$ & $\begin{array}{l}\text { PIK3CA Mutant } \\
\text { (9) N(\%) }\end{array}$ \\
\hline $\begin{array}{l}\text { Pathological tumor } \\
\text { size (median, range) }\end{array}$ & $1.80(1.5-3)$ & $1.50(0.7-8)$ \\
\hline Pathological stage & & \\
\hline I & $9(36)$ & $1(11.1)$ \\
\hline II & $13(52)$ & $5(55.6)$ \\
\hline III & $3(12)$ & $3(33.3)$ \\
\hline Age (mean, range) & $50.69(32-73)$ & $60.56(47-75)$ \\
\hline Estrogen receptor & & \\
\hline Positive $(0-9 \%)$ & $23(92)$ & $8(88.9)$ \\
\hline Negative $(10-100 \%)$ & $2(8)$ & $1(11.1)$ \\
\hline Progesterone receptor & & \\
\hline Positive $(0-9 \%)$ & $15(60)$ & $7(77.8)$ \\
\hline Negative $(10-100 \%)$ & $10(40)$ & $2(22.2)$ \\
\hline Lymph nodes & & \\
\hline Positive & $11(42.3)$ & $5(55.6)$ \\
\hline Negative & $15(55.7)$ & $4(44.4)$ \\
\hline ERBB2 (her2ihq) & & \\
\hline Positive & $8(33.3)$ & $1(12.5)$ \\
\hline Negative & $16(66.7)$ & $7(87.5)$ \\
\hline
\end{tabular}

\section{2}

Nectin-3: a putative tumour suppressor in human breast cancer.

Martin TA, Harrison GM, Watkins G, Lane J, Jiang WG. Wales College of Medicine, Cardiff, United Kingdom

Background: The Nectin family of integral molecules are involved in formation \& functioning of Adherens \& Tight Junctions. Aberrant expression is thought to be associated with cancer. This study aimed to ascertain the distribution and role of Nectin-3 in human breast cancer.

Methods: Breast cancer primary tumours and matched background tissue were processed for frozen sections \& RNA extraction. Nectin3 was analysed at mRNA \& protein levels using IHC \& Q-PCR. 40 human cancer cell lines were screened for expression of Nectin-3. An invasive breast cell line, MDA-MB-231 (MDA ${ }^{\mathrm{WT}}$ ) exhibiting aberrant Nectin-3 expression was chosen for introduction of the Nectin-3 gene $\left(\mathrm{MDA}^{\mathrm{N} 3}\right)$ via amplification from normal breast cDNA \& cloning into a pEF6/V5-His TOPO plasmid before electroporation. Successful expression was confirmed by RT-PCR, Western blotting \& fluorescent microscopy. Functional testing was carried out using cell invasion \& motility assays with changes in tight junction function by trans-epithelial resistance (TER). A hammerhead ribozyme transgene was generated $\left(\mathrm{MDA}^{\Delta \mathrm{N} 3}\right)$ to knockout aberrant Nectin-3 expression.

Results: IHC revealed that Nectin-3 expression showed clear changes in distribution between normal and cancerous cells. However, there was little difference in overall expression when analysed by Q-PCR. All the cancer cell lines screened showed aberrant expression for Nectin-3. Nectin-3 transformed cells $\left(\mathrm{MDA}^{\mathrm{N} 3}\right)$ showed retarded invasion, even when treated with HGF $(40 \mathrm{ng} / \mathrm{ml})$ compared to $\mathrm{MDA}^{\mathrm{WT}}$ cells $\left(\mathrm{MDA}^{\mathrm{N} 3}\right.$ untreated $16.8 \pm 4.96$ cells, HGF treated 22.6 \pm 4.33 ; MDA ${ }^{\text {WT }}$ untreated $65.6 \pm 4.93$, HGF treated $93.1 \pm 6.12$ ). Invasion was significantly different between $\mathrm{MDA}^{\mathrm{N} 3}$ and MDA ${ }^{\mathrm{WT}}$ cells $(\mathrm{p}<0.001)$ and when treated with HGF $(\mathrm{p}<0.02) . \mathrm{MDA}^{\mathrm{N} 3}$ cells were significantly less motile than MDA ${ }^{\mathrm{wT}}$ cells, irrespective of treatment with HGF (number of cells: MDA ${ }^{\mathrm{N} 3}$ $4.8 \pm 1.5$ versus $\mathrm{MDA}^{\mathrm{WT}} 21.8 \pm 2.6, \mathrm{p}<0.001$; HGF treated $\mathrm{MDA}^{\mathrm{N} 3}$ $9.6 \pm 1.9$ versus HGF treated $\left.\mathrm{MDA}^{\mathrm{WT}} 38.4 \pm 3.8, \mathrm{p}<0.001\right)$. Changes in TER were measured over $2 \mathrm{~h}$ for the $\mathrm{MDA}^{\mathrm{N} 3}$ and $\mathrm{MDA}^{\mathrm{WT}}$ cells, with the $\mathrm{MDA}^{\mathrm{N} 3}$ cells showing less change in resistance after treatment with $\mathrm{HGF}$ (Change in resistance after $2 \mathrm{~h}: \mathrm{MDA}^{\mathrm{N} 3}$ 
$57 \pm 2.5$ vs $\left.\mathrm{MDA}^{\mathrm{WT}}-98 \pm 3, \mathrm{p}<0.001\right)$. As anticipated, $\mathrm{MDA}^{\Delta \mathrm{N} 3}$ cells showed both increased invasiveness \& motility when compared to $\mathrm{MDA}^{\mathrm{WT}}$ cells (invasion: $\mathrm{MDA}^{\Delta \mathrm{N} 3}$ 77.8 \pm 4.76 , $\mathrm{p}<0.001$; motility: $\left.\mathrm{MDA}^{\Delta \mathrm{N} 3} 26.9 .8 \pm 4.76, \mathrm{p}<0.001\right)$.

Conclusion: The staining pattern in human breast cancer tissues indicated that the distribution of the molecule is more crucial than the level of expression. The introduction of Nectin-3 into human breast cancer cells results in breast cancer cells with reduced invasive phenotype and increased tight junction function; conversely, breast cancer cells with Nectin-3 knock-out showed increased invasion and motility. This, together with the reported aberrant expression of other Nectins in human cancer, indicates that Nectin-3 may be a key component in the formation of cell-cell junctions and be a putative suppressor molecule to the invasion of breast cancer cells.

\section{3}

Microarray analysis of breast tumor tissue from African American and Ugandan women show that high risk biological features are similar.

Bhatia V, Wabinga H, Baehner F, Mbidde EK, Luce JL. UCSF, San Francisco, CA; Uganda Cancer Institute, Makerere University, Kampala, Uganda

Background: We have previously shown that differences in overall survival for African American women at San Francisco General Hospital (SFGH) cannot be fully explained by differences in socioeconomic status or delivery of care. Among hormone receptor negative patients, we found that the phenotype ER-/PR-/Her2- is more frequent in young African American women and contributes to their poor survival. Furthermore, the survival advantage of hormone positivity is smaller for African American women than for all other ethnic groups. Survival for Ugandan women with breast cancer is reportedly very poor, counfounded by late stage presentation and lack of access to therapy. IHC testing is not routinely done in Uganda; therefore, it is not known what the prevalence of the ER-/PR-/Her2- phenotype is in Uganda. The distribution and interaction of ER and PR, as well as their isoforms, $\mathrm{ER} \beta, \mathrm{ER} \beta \mathrm{cx}$, and PRB, are not well characterized in non-Caucasian women, and may reveal other unique high risk biological features for both African and African American women. Methods: We have created a tissue bank of breast cancer tumor paraffin blocks from 109 patients of African American descent identified in the SFGH tumor registry and 50 Ugandan patients identified in the Kampala Cancer Registry. A tumor tissue microarray analysis ofall patients is being performed, utilizing IHC for the primary markers $\mathrm{ER} \alpha, \mathrm{ER} \beta$, and HER-2lNeu, as well as secondary markers PRA and $\mathrm{B}, \mathrm{ER} \beta \mathrm{cx}$, and AKT.Results: pending

Conclusions: The biological features of breast tumor tissue from African American and Ugandan women are similar. The high prevalence of ER-/PR-/Her2- tumors may contribute to the comparable poor survival in these groups, and is a subject for future analysis. 


\section{S124 Abstracts - Poster Session III}

3001

Risk of early relapse in post-menopausal women with early stage, estrogen receptor positive (ER+) breast cancer on tamoxifen.

McArthur HL, Olivotto I, Gelmon KA, Speers CH, Chia S, Ellard $S$, Kennecke HF. British Columbia Cancer Agency, Vancouver/ Victoria/Kelowna, BC, Canada

Background: Postmenopausal women with ER+ breast cancer benefit from an aromatase inhibitor (AI) after 2 to 3 years of tamoxifen. Upfront AI therapy, however, may be suitable for patients at risk of early relapse. The purpose of this study was to identify predictors of early relapse among postmenopausal women with ER+ breast cancer on adjuvant tamoxifen.

Methods: The British Columbia Breast Cancer Outcomes Database was used to identify 4159 women aged 50 or older, diagnosed between 1986 and 1999 with stage I-III, ER+ breast cancer who were treated with tamoxifen after adequate locoregional therapy +/- chemotherapy. A relapse was any local, regional or distant recurrence or death from breast cancer without a recorded metastasis. Kaplan-Meier estimates of relapse rates during the first 2.5 years after diagnosis were determined. The effect of prognostic variables on time to recurrence was examined by assessing the distribution of variables within three relapse categories: early (within 2.5 years of diagnosis), delayed (more than 2.5 years after diagnosis) and no documented relapse.

Results: Median age at diagnosis was 65. Median follow-up was 7.4 years. $15 \%$ of patients received adjuvant chemotherapy. Relapse rates were $7.4 \%, 14.5 \%$ and $25.9 \%$ within $2.5,5.0$ and 10.0 years after diagnosis, respectively. Predictors of early relapse were Grade III pathology, low-positive ER status and increasing lymph node involvement (Table 1). In the analysis of prognostic variables among relapse groups, neither lymphovascular invasion, age, tumor size nor administration of chemotherapy identified early vs. delayed relapses. Her2neu and progesterone receptor (PR) status will be determined for a subgroup of this population. Table 1. 2.5 year Relapse Rates.

$\begin{array}{llll}\text { Grade } & \mathbf{n} & \mathbf{2 . 5} \text { yr. Relapse Rates. (95\% C.I.) } & \begin{array}{c}\text { p value } \\ <0.001\end{array} \\ \text { I } & 544 & 1.1(0.5,2.5) & \\ \text { II } & 2135 & 5.3(4.4,6.4) & \\ \text { III } & 1242 & 13.4(11.6,15.5) & 0.005 \\ \text { ER status } & & & \\ \text { Mod/High/ }>50 \mathrm{fmol} / \mathrm{mg} & 2990 & 6.5(5.6,7.4) & \\ \text { Low } / 10-50 \mathrm{fmol} / \mathrm{mg} & 393 & 14.5(11.4,18.4) & <0.001 \\ \text { \# Positive Nodes } & & & \\ 0 & 1962 & 3.7(2.9,4.6) & \\ 1-3 & 1650 & 8.5(7.3,10.0) & \\ 4+ & 543 & 17.2(14.3,20.7) & \end{array}$

Conclusion: Postmenopausal women with ER+ breast cancer who are at high risk of early relapse while on tamoxifen can potentially be identified. Grade III pathology, positive nodal status and low ER positivity can identify patients at a higher and earlier risk of relapse. Such patients may be optimal candidates for upfront AI therapy. Conversely, sequential tamoxifen-AI therapy may be most appropriate in the absence of these higher risk factors.

\section{2}

Outcome and prognostic factors among patients with nodenegative invasive breast carcinoma that is one centimeter or less in size (stage 1; T1a,b NO M0): the University of Texas M. D. Anderson Cancer Center experience.

Hanrahan EO, Gonzalez-Angulo AM, Broglio K, Meric-Bernstam F, Cristofanilli M, Buccholz TA, Hortobagyi GN, Valero V. M.D. Anderson Cancer Center, Houston, TX

Background: The diagnosis of stage T1a,b N0 M0 breast cancer (BC) is increasing due to mammographic screening. Controversy surrounds the prognosis of these patients following locoregional therapy and the need for adjuvant systemic therapy. A number of retrospective reviews of outcome have been reported, but most have small patient numbers and/or short follow-up. The purpose of this study was to perform a retrospective analysis of outcome and prognostic factors for patients with stage T1a,b N0 M0 BC seen at M. D. Anderson Cancer Center (MDACC).

Methods: All cases of stage T1a,b N0 M0 BC seen at MDACC from 1980 through 1999 were identified in the Tumor Registry database. A retrospective chart review was performed. Patients with prior diagnosis of invasive BC were excluded. Patient, tumor and treatment characteristics were tabulated. Survival distributions were estimated by the Kaplan-Meier method. Groups were compared by the log-rank test. Available histology is currently being reviewed and more detailed information on histopathologic prognostic factors is being collected. A multivariate analysis of prognostic factors will then be performed.

Results: 517 cases of T1a,b N0 M0 BC were identified. Median age was 56 years (yrs). Most patients had T1b primaries [5.1-10 $\mathrm{mm}$ ] $(76 \%)$ and invasive ductal carcinoma $(77 \%)$, and $24 \%$ of patients had received adjuvant systemic therapy. Of those with currently available parameters, most had no lymphovascular invasion [LVI] $(n=253$ of 290), nuclear grade $2(n=276$ of 446), and estrogen receptor positive disease $(n=280$ of 363). Median follow-up was 9 yrs (range 1.8-24 yrs) for those alive at last follow-up. Estimated relapse free survival (RFS) and breast cancer specific survival (BCSS) rates respectively were: $90 \%$ and $94 \%$ at $10 \mathrm{yrs} ; 87 \%$ and $91 \%$ at $20 \mathrm{yrs}$. The only factors significantly associated with inferior RFS on univariate analysis were age $<50$ yrs at diagnosis (10-yr RFS $83 \%$ for age $<50$ yrs vs. $93 \%$ for age $>50 \mathrm{yrs}, \mathrm{p}=0.0001)$ and LVI (10-yr RFS $80 \%$ with LVI vs. $92 \%$ without LVI, $\mathrm{p}=0.01)$. There was a trend towards worse outcome for T1b versus T1a primaries (10-yr RFS $87 \%$ vs. 94\%, $\mathrm{p}=0.18$ ). LVI was the only factor significantly associated with inferior BCSS ( $80 \%$ vs. $95 \%$ at $10 \mathrm{yrs}, \mathrm{p}=0.01$ )

Conclusions: Outcome for patients with stage T1a,b N0 M0 BC managed at MDACC was very good. Patients with age $<50$ yrs at diagnosis or with LVI had significantly inferior RFS. A comprehensive analysis of prognostic factors will be available at the meeting. This may better characterize patients with stage T1a,b N0 M0 BC who are at higher risk of relapse and might benefit from systemic therapy.

\section{3}

A novel prognostic immunohistochemical biomarker panel for estrogen receptor expressing breast cancer.

Ross DT, Ring BZ, Seitz RS, Beck R, Shasteen WJ, Tarr SM, Cheang MC, Yoder BJ, Budd GT, Nielsen TO, Hicks DG, Estopinal NC. Applied Genomics Inc., Sunnyvale, CA; Applied Genomics Inc., Huntsville, AL; Cleveland Clinic Foundation, Cleveland, $\mathrm{OH}$; University of British Columbia, Vancouver, BC, Canada; Comprehensive Cancer Center of Huntsville, Huntsville, $A L$

Background: Gene expression signatures have been identified that distinguish biologically and clinically significant breast tumor diversity. We have used gene expression data to target the production of hundreds of novel antibody reagents to explore whether a panel of targeted immunohistochemistry reagents can distinguish similar tumor diversity and identify patients at increased risk of poor outcome.

Methods: Eighty novel and seven commercially available antisera were used to stain tissue arrays containing a retrospective breast cancer cohort from the Comprehensive Cancer Center of Huntsville (550 patients). Cox proportional hazard analysis was used to identify a recurrence score algorithm that uses only five antisera to predict risk of recurrence in estrogen receptor-positive, lymph node-negative patients. To validate this model and antibody panel, we then tested the prognostic association of this prospectively defined algorithm by staining two independent tissue array cohorts, with linked clinical follow-up data.

Results: In both validation cohorts, the Kaplan-Meier estimates of recurrence confirmed that the Cox model distinguished estrogen receptor-positive patients with poor outcomes. In a cohort assembled at the British Columbia Cancer Agency (440 patients total) the five antisera algorithm identified ER+ patients with a high risk of recurrence that showed an overall 5 year survival rate 
of $56 \%$ compared to $74 \%$ for moderate and $89 \%$ for good ( $\mathrm{p}=0.003$ ). In the Cleveland Clinic Foundation Cohort (292 patients total), the Cox model identified ER+ 'bad' patients with a five year recurrence rate of $51 \%$ compared to about $84 \%$ for patients classified as either moderate or good $(\mathrm{p}=0.0022)$. Although both cohorts were underpowered to test the association of the prognosticator with ER+ lymph node negative patients, using multivariable analysis the calculated risk of recurrence was independent of stage, grade and lymph node status.

Conclusion: A panel of five antibodies can significantly improve upon traditional prognosticators in predicting outcome for estrogen receptor positive breast cancer patients. Additional retrospective and prospective studies focused on early stage patients are indicated for further validation.

\section{4}

Statistical and pathway analysis of multiple prognostic gene signatures in lymph node negative (LNN) primary breast cancer.

Wang Y, Klijn J, Yu J, Zhang Y, Sieuwerts A, Berns E, Atkins D, Foekens J. A Johnson \& Johnson Company, San Diego, CA, Erasmus MC / Daniel den Hoed Cancer Center, 3000 DR, Rotterdam, Netherlands

Background: In our earlier genome-wide measurements of gene expression we have identified a 76-gene signature that predicts distant metastasis for lymph node-negative (LNN) breast cancer patients (The Lancet 365:671-679, 2005). Like previously published gene signatures, the 76-gene prognostic signature virtually lacks overlap to other signatures' gene lists. The aim of this study was to evaluate multiple gene signatures for the same questions and understand why multiple signatures differ in gene content.

Material and Methods: In order to evaluate alternative gene signatures,we repeated the gene selection and signature construction procedures used for discovery of the 76-gene signature using multiple training sets of the patients. Five-hundred training sets of $80 \mathrm{ER}+$ patients each were randomly selected from the total of $209 \mathrm{ER}+$ patients. The remaining $129 \mathrm{ER}+$ patients were served as the testing set. A signature was built from each of the training sets using Cox proportional-hazards regression. The signature was validated in the corresponding testing set. Overlaps in the gene lists of the 500 signatures were determined and compared to 500 randomly selected gene lists. Correlation of the expression patterns was evaluated between different gene signatures. Furthermore, the genes in each signature were assigned to functional classes using pathway analysis tools. Pathways that cover significant numbers of genes were selected ( $p$-value $<0.01$ ). Common pathways from the prognostic signatures were identified. The same analysis was carried out in 136 ER- patients.

Results: We produced the ROC curve on the testing set and used AUC to assess performance. The average AUC for the 500 signatures for ER+ patients is 0.66 (standard deviation: 0.05). This result indicates that the performance of the selected signature is highly stable with different sample selections. The overlap of the 500 gene signatures for ER+ patients was 2.5 -fold higher than the 500 random gene lists and 7 genes appeared in more than 200 of the signatures. Several pathways were significantly overrepresented in these prognostic signatures, suggesting that common pathways might be involved in tumor recurrence. Immune response was found in both the ER+ and ER- signatures while cell cycle, DNA replication, and DNA repair were dominantly associated with the ER+ signatures.

Discussion: Our result suggests that alternative gene signatures with similar prognostic value can be produced because many genes are significantly correlated to distant metastasis-free survival. Genes that belong to a particular signature could be substituted with other genes of similar expression patterns. Although the prognostic signatures differ in their gene lists, each and every gene signature represents several common pathways that highlight the underlying mechanisms of disease progression.

\section{5}

Basal-like breast carcinomas: clinical outcome with chemotherapy.

Banerjee SN, Reis-Filho JS, Ashley S, Steele D, Ashworth A, Lakhani S, Smith IE. Royal Marsden Hospital, London, United Kingdom; Institute of Cancer Research, London, United Kingdom; Life and Health Sciences Research Institute, University of Minho, Braga, Portugal; School of Medicine, The University of Queensland, Mayne Medical School, Herston, Queensland, Australia

Background: Grade III invasive ductal carcinomas of no special type (IDC-NST) constitute a heterogeneous group of tumours with different clinical behaviour and response to chemotherapy. It has been demonstrated that up to $25 \%$ of all grade III IDC-NST harbour a basal-like phenotype, as defined by gene expresssion profiling or immunohistochemistry for basal cytokeratins.

Patients with basal-like breast carcinomas (BLBC) are reported to have a shorter disease-free and overall survival.

Patients and methods: We performed a retrospective analysis of 50 patients with BLBC (as defined by expression of cytokeratins $5 / 6,14$ or 17) and 50 age-, nodal status- and grade-matched controls. Histological features, immunohistochemical findings for oestrogen (ER) and progesterone (PgR) receptors and HER2, clinical outcome and survival after adjuvant chemotherapy were compared between the two groups.

Results: BLBCs were more likely to be negative for ER ( $p<0.001)$, $\operatorname{PgR}(\mathrm{p}<0.001)$ and HER2 $(\mathrm{p}=0.005)$ than controls. Patients with BLBCs had a significantly higher recurrence rate $(p<0.001)$ and were associated with a significantly shorter disease-free and overall survival $(p<0.001$ and $p=0.03$, respectively). In the group of patients that received anthracycline-based adjuvant chemotherapy (BLBC $n=48$, control $n=50$ ), the disease free survival was significantly shorter in the BLBC group $(\mathrm{p}=0.01)$. Multivariate analysis demonstrated that the basal-like status was the only independent prognostic factor for disease free survival $(\mathrm{p}=0.0125)$. Discussion: BLBCs are a distinct clinical and pathological entity, characterised by high nuclear grade, lack of hormone receptors and HER 2 expression and a more aggressive clinical course. Standard adjuvant chemotherapy appears less effective in these tumours. New therapeutic approaches are indicated.

Kaplan-Meir curves for disease-free (A) and overall (B) survival - patients treated with anthracycline-based adjuvant chemotherapy
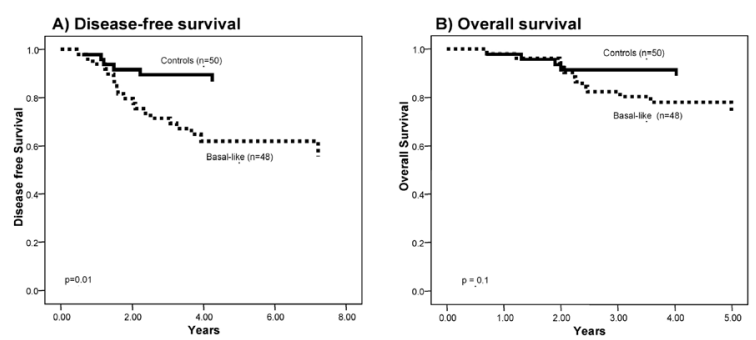

\section{6}

A prospective risk model for neutropenic complications in early-stage breast cancer patients receiving adjuvant chemotherapy.

Lyman GH, Kuderer NM, Shayne M, Dale DC, Wolff D, Culakova E, Poniewierski MS, Crawford J, for the ANC Study Group. University of Rochester School of Medicine and Dentistry, Rochester, NY; University of Washington School of Medicine, Seattle, WA; Duke University Medical Center, Durham, NC

Introduction: Myelosuppression including severe and febrile neutropenia (SFN) remains the major dose-limiting toxicity of cancer chemotherapy. Previous studies have demonstrated that 


\section{S126 Abstracts - Poster Session III}

the risk of neutropenic complications is greatest during the first cycle of chemotherapy. A prospective, nationwide study was undertaken to develop and validate risk models for SFN in patients receiving cancer chemotherapy.

Methods: Between March, 2002 and the present, more than 1,200 consecutive patients with breast cancer initiating a new chemotherapy regimen have been prospectively registered at 115 randomly selected practice sites from throughout the U.S. Data on 974 early-stage patients completing at least one cycle of a standard adjuvant regimen are available. Multivariate logistic regression models for SFN were developed based on a priori defined patient-, disease- and treatment-related variables. Model predictive test performance characteristics were estimated.

Results: Of 438 patients $(45 \%)$ experiencing one or more SFN events, $318(73 \%)$ did so in cycle 1 . Independent predictors of first cycle SFN include: $\mathrm{CAF}(\mathrm{OR}=3.0, \mathrm{P}=.067)$; $\mathrm{CEF}$ $(\mathrm{OR}=2.9, \mathrm{P}=.075)$, TAC $(\mathrm{OR}=5.5, \mathrm{P}=.007)$, docetaxel $(\mathrm{OR}=6.1$, $\mathrm{P}=.035)$, anthracycline-based chemotherapy $(\mathrm{OR}=4.09, \mathrm{P}=.023)$, diabetes $(\mathrm{OR}=1.7, \mathrm{P}=.002)$, planned $\mathrm{RDI}>85 \%(\mathrm{OR}=3.5, \mathrm{P}<.001)$. Factors associated with a decreased risk of SFN in the model included a $\mathrm{Q} 14$ day schedule $(\mathrm{P}=.004)$, glomerular filtration rate (GFR) $(\mathrm{P}<.001)$, baseline neutrophil count $(\mathrm{P}=.03)$ and prophylactic colony-stimulating factor $(\mathrm{OR}=0.37, \mathrm{P}=.044)$. Model Goodness of fit was excellent $(\mathrm{P}<.001)$ with $\mathrm{R}^{2}=0.321$ and $\mathrm{c}$ statistic $=0.753[95 \% \mathrm{CI}, 0.72-0.79]$. Model discrimination was optimized for a SFN threshold of $20 \%$ with the following performance characteristics $[ \pm 95 \% \mathrm{CL}]$ : sensitivity $=91 \%[87 \%$ $93 \%]$; specificity $=40 \%[36 \%-44 \%]$; diagnostic odds ratio $=6.4$ [4.1-9.8]; predictive value $(\mathrm{PV})+=42 \%[38 \%-46 \%], \mathrm{PV}-=90$ [86\%-93\%]. The $70 \%$ of patients with a predicted risk of SFN $>20 \%$ experience an average risk of $42 \%$ while the $30 \%$ with a predicted risk $<20 \%$ have an average risk of $10 \%$. A weighted risk score [0-100] based on the logistic regression coefficients has been developed to aid supportive care decision making.

Discussion: A risk model for early neutropenic complications in patients with ESBC receiving adjuvant chemotherapy has been developed..This model will be validated in a separate group of patients in phase II of this ongoing prospective registry study. Once validated, this model should aid the identification of high risk patients who are candidates for targeted prophylaxis with a myeloid growth factor.

\section{7}

The percentage of positive/dissected nodes is a useful prognostic indicator of postmastectomy recurrence and mortality.

Truong PT, Olivotto IA, Lee JC, Kader HA, Speers CH, Berthelet E. Vancouver Island Centre, British Columbia Cancer Agency, Victoria, BC, Canada

Objective: The AJCC staging system for breast cancer classifies nodal involvement by number (\#) of positive nodes $(\mathrm{N}+)$ but not \# of dissected nodes. This study evaluates the prognostic impact of the percentage (\%) of positive/dissected nodes in breast cancer relapse and survival.

Methods: Data were analyzed for 2713 women with pT1-4, N0-3, M0 breast cancer treated with mastectomy. Ten-yr Kaplan-Meier locoregional relapse (LRR), distant relapse (DR), and overall survival (OS) stratified by \# $\mathrm{N}+$, \# dissected nodes, and \% positive/ dissected nodes were examined. Cox regression analyses were performed with and without $\%$ positive nodes in the model. Results: Median follow-up was 7.6 yrs. 1310 patients had N0, 901 had 1-3 N+, and 502 had $\geq 4 \mathrm{~N}+$. LRR, DR, and OS correlated significantly with \# $\mathrm{N}+$ and $\% \mathrm{~N}+$ but not with \# dissected nodes. LRR were $8.7 \%, 15.8 \%$, and $19.8 \%$ in patients with $0,1-3$, and $\geq 4$ $\mathrm{N}+$ respectively, $(\mathrm{p}<0.0001)$. LRR were $13.4 \%$ and $12.3 \%$ in patients with $\leq 10$ vs. $>10$ dissected nodes $(\mathrm{p}=0.27)$. The cutoff at which the most significant differences in LRR and DR were observed was $25 \%$. On multivariate analysis, the $\% \mathrm{~N}+$ was the most significant factor for all three outcomes. Compared to N0 disease, the presence of $25-40 \% \mathrm{~N}+$ was associated with hazard ratios
(HR) of 2.18 (95\% confidence interval CI 1.24-3.86) for LRR, 3.42 (95\% CI 2.44-4.81) for DR, and 2.22 (95\% CI 1.64-3.01) for OS, all $\mathrm{p}$ values $<0.001$. Corresponding HRs with $>40 \% \mathrm{~N}+$ were 3.16 (95\% CI 2.01-4.95), 4.63 (95\% CI 3.53-6.08), and 2.90 (95\% CI 2.30-3.66).

Conclusion: The percentage of positive nodes is a highly significant prognostic factor for locoregional recurrence, distant recurrence, and survival and should be considered in staging and therapeutic decisions for women with breast cancer. Ten-year LRR, DR, and OS

$\begin{array}{lllll}\text { \# Positive Nodes } & \mathrm{N} & \text { \% LRR } & \text { \% DR } & \text { \% OS } \\ 0 & 1310 & 8.7 & 15.9 & 72.6 \\ 1-3 & 901 & 15.8 & 35.0 & 57.7 \\ >=4 & 502 & 19.8 & 55.9 & 42.1 \\ \mathrm{p} & & <0.0001 & <0.0001 & <0.0001 \\ \text { \% Positive Nodes } & & & & \\ 0 & 1310 & 8.7 & 15.9 & 72.6 \\ 1-10 & 279 & 12.5 & 29.7 & 62.2 \\ 11-15 & 187 & 12.6 & 26.0 & 62.3 \\ 16-20 & 156 & 14.9 & 33.5 & 59.4 \\ 21-25 & 103 & 11.6 & 40.7 & 56.2 \\ 26-40 & 197 & 20.9 & 45.1 & 50.4 \\ >40 & 481 & 24.2 & 58.3 & 40.1 \\ \mathrm{p} & & <0.0001 & <0.0001 & <0.0001\end{array}$



\section{8}

The prognostic impact of the axillary lymph node ratio in patients with micrometastatic node-positive breast cancer. Truong PT, Cserni G, Woodward W, Janni W, Tai P, Vlastos G, VinhHung $V$, the International Nodal Ratio Working Group. British Columbia Cancer Agency, Vancouver Island Centre, Victoria, BC, Canada; Bács-Kiskun County Hospital, Kecskemét, Hungary; University of Texas, M. D. Anderson Cancer Center, Houston, TX; Ludwig-Maximilians-Universität, München, Germany; University of Saskatchewan, Regina, SK, Canada; Geneva University Hospitals, Geneva, Switzerland; AZ-VUB, Jette, Belgium

Purpose: To evaluate survival outcomes among patients with micrometastatic nodal involvement, and compare lymph node ratio (LNR)-based classification versus $\mathrm{pN}$-derived classification. Methods: Data were analyzed for 2071 women identified by the SEER database with primary invasive carcinoma diagnosed between 1988-97 with pT1-2 breast cancer and micrometastatic involvement of the axillary nodes (largest nodal metastasis $<=2$ $\mathrm{mm}$, i.e. pN1a according to the former AJCC Cancer Staging). Primary end-points were overall survival (OS) and breast cancerspecific survival (BCSS), calculated with Kaplan-Meier product limit methods, and compared using log-rank chi-square tests. Categories of $\mathrm{pN}$-derived classification were $<=3$ and $>3$ involved nodes. Categories of LNR-based classification were $<=0.25$ and LNR $>0.25$.

Results: Median follow up time was 7 years. Median age was 56 years (range 24-97), T size $18 \mathrm{~mm}(0-50)$, number of positive nodes 1 (1-36), number nodes examined 15 (1-46). Survival differences are summarized in the Table and Figures below. Table 1: Survival by pN and by LNR

\begin{tabular}{|c|c|c|c|c|c|c|}
\hline & $\begin{array}{l}\leq 3 \mathrm{~N}+ \\
\mathrm{n}=1886\end{array}$ & $\begin{array}{l}>3 \mathrm{~N}+, \\
\mathrm{n}=185\end{array}$ & $\begin{array}{l}\mathrm{Chi}^{2} \\
(\mathrm{P})\end{array}$ & $\begin{array}{l}\mathrm{LNR} \leq 0.25, \\
\mathrm{n}=1850\end{array}$ & $\begin{array}{l}\mathrm{LNR}>0.25, \\
\mathrm{n}=221\end{array}$ & $\begin{array}{l}\mathrm{Chi}^{2} \\
(\mathrm{P})\end{array}$ \\
\hline $\begin{array}{l}10-\mathrm{yr} \\
\text { BCSS }\end{array}$ & $82.5 \%$ & $64.0 \%$ & $\begin{array}{l}43.06 \\
\left(0.0004 * 10^{-6}\right)\end{array}$ & $83.1 \%$ & $60.5 \%$ & $\begin{array}{l}53.97 \\
\left(\mathrm{P}<0.0001 * 10^{-6}\right)\end{array}$ \\
\hline
\end{tabular}
(*Note: $P$-values for LNR 200-2000 times smaller than $P$-values for " $\mathrm{pN}$ "). 
Conclusion: The absolute number of positive nodes and the ratio of positive:examined nodes are both strong prognostic factor for survival in women with micrometastic nodal involvement Compared to absolute numbers of positive nodes, the LNR provided a wider distinction between prognostic subgroups and should be considered in adjuvant therapy decisions.

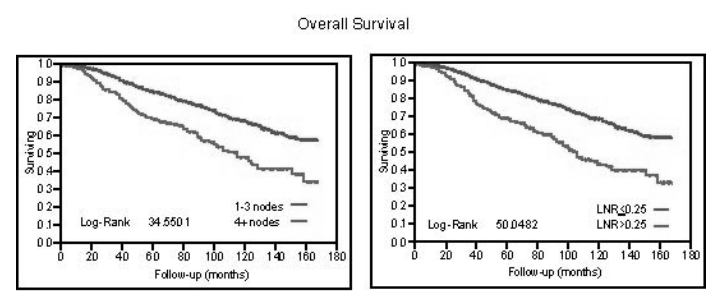

Breast cancer specific survival

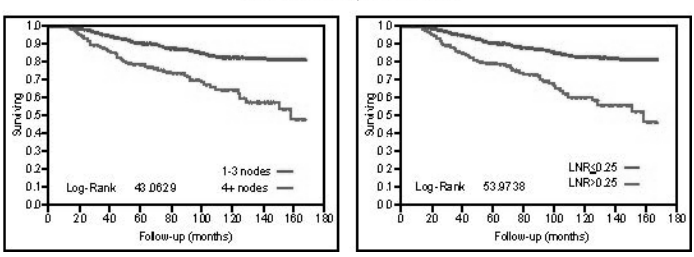

\section{9}

Ki-67/MIB-1 as prognostic marker in women with early breast cancer: a meta-analysis of published studies involving 10.958 patients.

Azambuja E, Cardoso F, Castro Jr G, Colozza M, Larsimont D, Sotiriou C, Piccart MJ, Paesmans M. Jules Bordet Institute, Brussels, Belgium; Azienda Ospedaliera San Sisto, Perugia, Italy

Background: Ki-67 or MIB-1 antibodies can evaluate the proliferative activity of breast cancer, although their use as a prognostic marker in early breast cancer is not standard in treatment decision-making. Methods: In order to better define Ki-67/MIB-1 prognostic value, we performed a systematic review of studies published in English, through Medline, that evaluated the impact of these markers by immunohistochemistry on disease free survival (DFS) in early breast cancer. Two independent reviewers extracted the data. Harzard ratio (HR) for DFS or event free (EFS) was derived and fixed-effects or random-effects models were used for meta-analysis. Results: Sixty-four studies were identified (published between 1989 and 2004) and 37 were evaluable for the meta-analysis, including 10.958 pts. Reasons for exclusion were missing data that permitted the HR calculation or no information about the DFS. In total, $42.0 \%$ of pts were considered as having tumor positive for the expression of Ki-67/MIB-1 according to the cut-offs defined by the authors. Data show that Ki-67/MIB-1 positivity is associated with higher probability of relapse, with an overall $\mathrm{HR}=1.93(95 \% \mathrm{CI} 1.75-2.13$; p value for heterogeneity 0.02 ). In the subgroup of node-negative pts (3423), the combined HR for relapse was 2.20 (95\%CI 1.78-2.72), with a borderline heterogeneity $(\mathrm{p}=0.08)$. For node-positive pts $(1430)$ only the fixed-effects model could be used, leading to an estimated of $\mathrm{HR}=1.60(95 \% \mathrm{CI} 1.36-1.88$; $\mathrm{p}$ value for heterogeneity $\mathrm{p}=0.68)$ Conclusion: Our meta-analysis suggests that Ki-67/MIB-1 positivity confers a higher risk of relapse in pts with early breast cancer. However, since this meta-analysis was not based on individual patient data, further confirmation of the independent value of $\mathrm{Ki}-67 / \mathrm{MIB}-1$ is needed.

\section{0}

Clinicopathologic significance of the basal-like subtype in breast cancer: comparison with hormone receptor and Her2/neu expressing phenotypes.

Kim MJ, Ro JY, Gong GY. Asan Medical Center; Cornell University, Methodist Hospital

Background: DNA microarray profiling studies on invasive breast carcinomas (ca) have identified distinct subtypes of tumors showing different clinical outcomes. These include luminal/ER ${ }^{+}$, normal breast-like, Her2/neu+, and basal-like types. Among of these subtypes, basal-like ca is characterized by the expression of basal markers without expression of ER or Her2/neu and known to be associated with a poor prognosis in Western countries. However, the clinicopathologic characteristics of the basal-like ca in Korean population have not been described. Design: We have examined the expression of basal (CK5 and 14) and luminal (CK8/18) cytokeratin, EGFR, c-kit, hormone receptors (HR), p53, and Her2/ neu in 776 invasive breast ca from 1993 to 1998 , using tissue microarray technique, and categorized them into five subgroups (basal-like, $\mathrm{HR}^{+}$, Her2/neu ${ }^{+}$, both $\mathrm{HR}$ and $\mathrm{Her} 2 / \mathrm{neu}^{+}$, and null subtype) based on the immunohistochemical (IHC) results. Basallike phenotype was defined as tumors expressing one or more of the basal markers without HR and Her2/neu positivity. Cases with ER and/or PR expression without Her $2 /$ neu positivity were designated as $\mathrm{HR}^{+}$phenotype. Cases with both $\mathrm{HR}$ and Her2/neu positivity were regarded as both HR and Her2/neu ${ }^{+}$subtype. Her2/ neu positivity was defined as tumors with IHC score $3^{+}$. Null phenotype was regarded as tumors all negative for HR and Her2/ neu as well as basal markers. Results: Of the 776 invasive breast ca, $98(12.6 \%)$ basal-like, $345(44.5 \%) \mathrm{HR}^{+}, 133(17.1 \%) \mathrm{Her} 2 /$ neu $^{+}, 61(7.9 \%)$ both HR and Her2/neu ${ }^{+}$, and $139(17.9 \%)$ null subtypes were included. Basal-like ca frequently coexpressed p53 $(59 / 98,60.2 \%)$. Histologically, most of the basal-like ca were invasive ductal ca, NOS $(86 / 98,87.8 \%)$ with higher nuclear and/or histologic grades, and most of metaplastic ca $(6 / 8,75.0 \%)$ were basal-like ca. Basal-like ca were associated with larger tumor size $(3.4 \mathrm{~cm})$ than $\mathrm{HR}^{+}$group $(2.8 \mathrm{~cm})(p=0.018)$. Nodal stage was significantly higher in Her $2 /$ neu $^{+}$group than basal-like subtype $(p=0.010)$. Her $2 /$ neu $^{+}$group showed higher tumor stage than basallike subtype $(p=0.045)$. Distant metastasis was most frequent in Her $2 /$ neu $^{+}$subtype $(33.8 \%)$. Basal-like subtype displayed poorer prognosis than $\mathrm{HR}^{+}$subtype $(p=0.076)$, however, Her $2 /$ neu $^{+}$subtype showed the worst survival rate $(p=0.048)$. Conclusion: Basallike breast ca appeared to be an aggressive phenotype of breast ca based on the higher histologic and/or nuclear grades as well as frequent p53 expression and tended to show worse clinical outcome compared with $\mathrm{HR}^{+}$subtype, however, this difference was not statistically significant. Instead, Her $2 / \mathrm{neu}^{+}$subtype was the worst subgroup of breast ca with poorer prognosis than basal-like subtype $(p=0.048)$. Her $2 /$ neu status appeared to be one of the most important prognostic factors of breast ca in our study, and therefore knowledge of the Her2/neu status is required in all breast ca patients irrespective of other clinicopathologic parameters.

\section{1}

Prognostic value of pathologic complete response after primary chemotherapy in patients with hormone receptorpositive breast cancer.

Guarneri V, Broglio KR, Kau S, Cristofanilli M, Buzdar AU, Valero V, Buchholz TA, Meric F, Middleton L, Hortobagyi GN, GonzalezAngulo AM. The University of Texas M.D. Anderson Cancer Center, Houston, TX

\section{Rationale}

The achievement of pathologic complete response (pCR) in breast cancer $(\mathrm{BC})$ patients treated with primary chemotherapy $(\mathrm{PC})$ is the most reliable predictor of survival. Patients with hormonal receptor (HR) positive tumors are less likely to achieve a pCR; however, the prognostic value of pCR in these patients is not well 


\section{S128 Abstracts - Poster Session III}

characterized. The aim of our analysis was to evaluate whether HR-status can influence the prognostic significance of pCR.

\section{Patient and Method}

This retrospective analysis included 1731 patients with stage I-III non-inflammatory breast cancer (BC) treated between 1988 and 2005 with primary chemotherapy (PC). Ninety-one percent of patients received anthracycline-based $\mathrm{PC}$ and $66 \%$ received additional taxane. pCR was defined as no evidence of invasive tumor in the breast and axillary lymph nodes.

\section{Results}

Median age was 49 years, (range 19-83 years). Sixty-seven percent $(\mathrm{n}=1163)$ had HR-positive tumors. pCR was observed in $225(13 \%)$ of patients, 91 of them had HR-positive tumors. A significant survival benefit for patients who achieve pCR compared with no pCR was observed regardless or HR status: the 5-year overall survival (OS) rates in the HR-positive group were $96.4 \%$ vs $84.5 \%$, respectively, $\mathrm{p}=0.04$, while the 5 -year progression-free survival (PFS) rates were $91.1 \%$ vs $65.3 \%$, respectively $(\mathrm{p}<0.0001)$. For the HR-negative group, the five-year OS rates were $83.9 \%$ vs $67.4 \%$, for $\mathrm{pCR}$ and non-pCR, respectively $(\mathrm{p}=0.003)$, and the 5year PFS rates were $83.4 \%$ vs $50.0 \%$, respectively $(\mathrm{p}<0.0001)$. After adjustment for HR status, clinical stage, and nuclear grade, patients who did not achieve a pCR had 1.68 times increased risk of death.

\section{Conclusion}

pCR is associated with better outcome regardless of HR status in $\mathrm{BC}$ patients who receive $\mathrm{PC}$.

\section{2}

\section{Breast cancer characteristics and 10 year survival in young} women.

Kaplan HG, Malmgren JA, Atwood MK. Swedish Cancer Institute, Swedish Medical Center, Seattle, WA; HealthSTAT Consulting, Inc., Seattle, WA; University of Washington, Seattle, WA

Background: Previous studies have compared prognostic factors and mortality in young women to older women who are often mammography detected (MGD) whereas young women rarely are. Given mammography screening is not recommended for women < age 40 , older women with patient detected (PtD) breast cancer are the more appropriate comparison group to assess differential mortality risk.

Materials and methods: We conducted a cohort study of women diagnosed with primary invasive breast cancer Stage I-IV from 1989-1999 followed by the institutions' breast cancer registry. Method of detection was ascertained from chart review at the time of diagnosis. We compared PtD women aged 21-39 to PtD 40-94 year olds by prognostic factors and to PtD and MGD 40-94 year old women for disease specific survival (DSS) $(n=2502)$. Results: $90 \%$ of women 21-39 were PtD ( $n=225)$ (figure 1). Compared to $\mathrm{PtD}$ women age $>=40(n=1066)$, women age $21-39$ were significantly more likely to have greater than TNM stage I, high histologic and nuclear grade, and ER negative tumors. Compared to PtD and MGD women $>=40$, women 21-39 had significantly worse DSS at both 5 and 10 years (5 year: PtD 21-39 $=81 \%$, PtD 40-94 = 90\%, MGD 40-94 = 97\%; 10 year: PtD 21$39=75 \%, \operatorname{PtD} 40-94=82 \%$, MGD $40-94=93 \% ;$ PtD $21-39$ to PtD 40-94, log rank test $=7.94, p=.005$; PtD 21-39 to MGD 4094, log rank test $=76.01, \mathrm{p}<.001$ ) (figure 2 ).

Discussion: Young women have worse prognostic factors and are at increased risk of death from breast cancer when compared to $\mathrm{PtD}$ older women. These results indicate breast cancer in young women is often a more virulent form of breast cancer but the differential risk of death is not as great as previous reports when mammography detected women were included in the comparison group.

Supported by the Kaplan Cancer Research Fund
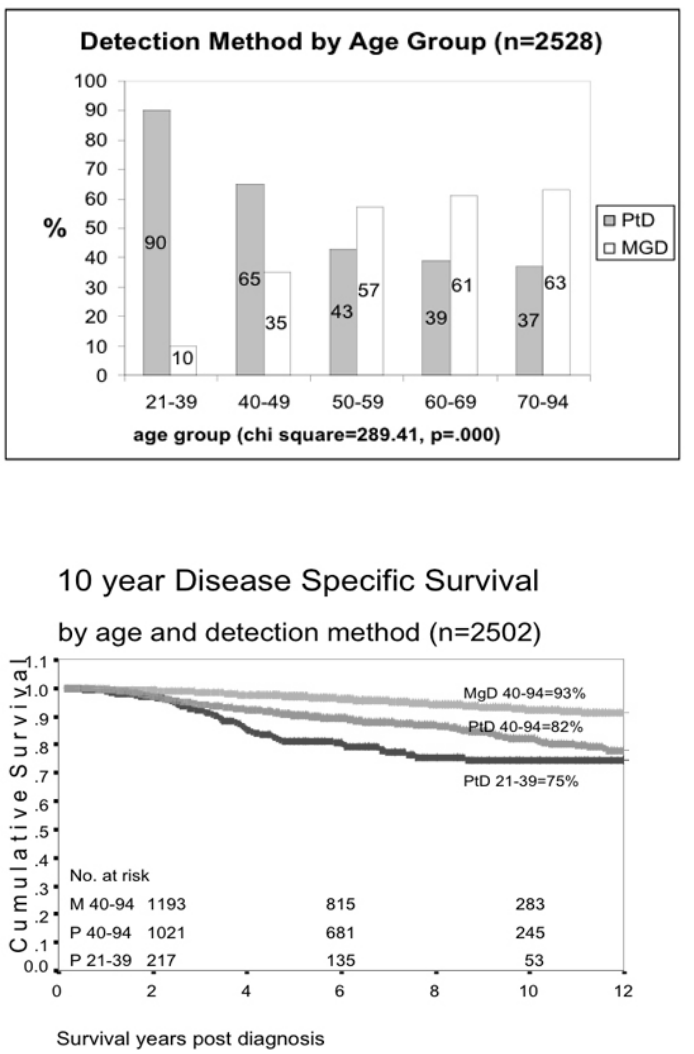

\section{3}

Prognostic significance of CDKs profiling in breast cancer. Kim SJ, Nakayama S, Miyoshi Y, Taguchi T, Tamaki Y, Matsushima T, Torikoshi Y, Tanaka S, Yoshida T, Ishihara H, Noguchi S. Graduate School of Medicine, Osaka University, Suita, Osaka, Japan; Sysmex Corporation, Kobe, Hyogo, Japan

Background: Cyclin-dependent kinases (CDKs), catalytic partners of cyclins, play a key role in cell proliferation. Recently, we have established the assay system for specific activity (SA = activity/ expression) of CDK1, 2, 4, and 6 using a very small tumor sample (> $8 \mathrm{~mm} 3)$. The aim of the present study is to evaluate the correlation of CDKs SA with tumor cell growth speed in vitro, and to assess the clinical significance of CDKs SA as a prognostic indicator.

Material and Methods: A CDK profiling system is composed of two parts; (1) analysis of CDK expression based on a modified dot blot method and (2) analysis of CDK activity based on a nonradioisotopic kinase method (Ishihara, et al: Biochim Biophys Acta, inpress). CDK1, 2, 4, and $6 \mathrm{SA}$ in human breast cancer cell lines (MCF-7, SKBR3, and MDA-MB231) and breast cancer tissues were determined by our method. Correlation between CDKs SA and growth speed was evaluated in $\mathrm{MCF}-7$ cells in vitro and in SKBR3 and MDA-MB231 xenografts in nude mice. Then, prognostic significance of CDKs SA as well as expression of p21, p27, and Ki-67 was studied in 126 primary breast cancer patients (median follow up: 45.5 months).

Results: CDK1 SA was negatively and CDK2 SA was positively associated with growth speed of MCF-7 cells in vitro and the CDK2/CDK1 ratio was found to be more accurately representative of the growth speed than S-phase fraction (flow-cytometry). This ratio was also representative of the growth speed in the xenograft models, i.e., SKBR3 tumors with a low CDK2/CDK1 ratio showed 
a low growth speed and MDA-MB231 with a high CDK2/CDK1 ratio showed a high growth speed. In 126 breast cancer patients, p21, p27, and Ki-67 expression levels had no significant correlation with 5-year DFS, whereas patients with a high CDK2/CDK1 ratio showed a significantly lower 5-year DFS than those with a low CDK2/CDK 1 ratio $(35.4 \%$ vs. $88.4 \%$, p $<0.0001)$. Especially in the node-negative subset, the difference in DFS between patients with high and low CDK2/CDK1 ratios was prominent $(41.0 \%$ vs $97.6 \%, \mathrm{p}<0.0001)$. Multivariate analyses have revealed that a high $\mathrm{CDK} 2 / \mathrm{CDK} 1$ ratio is a significant and independent prognostic factor in all patients (Hazard ratio (HR): 4.27, 95\% CI: 1.79 10.20 ) and in the node-negative subset (HR: 24.28 , 95\% CI: 3.13 188.28).

Discussion: The present study has demonstrated that the CDK2/ CDK1 ratio represents the cell growth speed very accurately, and this ratio is strongly associated with patient prognosis especially in node-negative patients. The $\mathrm{CDK} 2 / \mathrm{CDK} 1$ ratio seems to have a potential to be used as a new prognostic factor being independent of the conventional risk factors.

\section{4}

The survival analysis of immunohistochemically defined basal and luminal subtype of breast cancer.

Lee JB, Kim AR, Son GS, Bae JW, Koo BH. Korea University College of Medicine, Seoul, Republic of Korea

Background and purpose DNA microarray studies of breast cancer have identified distinct subtypes showing different survivals. The results of DNA microarray revealed the HER2 negative and estrogen receptor(ER) negative subtype, which was designated as basal or basal-like subtype. The basal subtype can't be manipulated by HER 2 monoclonal antibody and selective estrogen receptor modulator (SERM) but DNA microarray is not an easy task for the usual clinical practice. We tried to identify the new subtype by commercially available antibodies for cytokeratins (CK) and characterize the clinical outcomes statistically. Materials and Methods A retrospective analysis was conducted using medical records of 295 patients diagnosed with infiltrating ductal carcinoma of breast who underwent mastectomy at the department of surgery, Korea University Medical Center between January 1992 and September 2004. Tissue array was constructed and stained immunohistochemically by antibodies for HER2, ER, HER1, ckit and CK5/6 according to usual methods. The basal subtype was characterized by HER2 negative, ER negative and positive for one of HER1, c-kit or CK5/6. Only ER positive subtype was also designated as luminal subtype of breast cancer. The mean period of follow up was 5.71 years and the survival rates were calculated by Kaplan Meier methods. Results The percentages of each subtype of breast cancer were HER2 positive $20.7 \%$, luminal $39.7 \%$ and basal $23.7 \%$. The 5 year survival rates were HER 2 positive $80.4 \%$, luminal $86.8 \%$ and basal $73.8 \%$ but there were no statistical differences $(p=0.1274)$. The frequencies of basal and luminal subtypes were not different in the comparison of age distribution, presence of menopause, size of tumor, lymph nodes metastases and proliferation index but the basal subtype was dominant among the patients of low grade $(\mathrm{p}=0.000)$. The 5 year overall survival of basal subtype was significantly lower than luminal subtype $(\mathrm{p}=0.049)$ and the poor prognosis of basal subtype was definite in the patient of age less than 35 years old, premenopause and lymph node metastasis. Conclusions The basal subtype of breast cancer showed significantly poor prognosis and affected greatly the patients of age less than 35, premenopause and node metastasis The immunohistochemical assay for basal subtype was helpful for detection of poor prognostic patients of breast cancer.

\section{5}

Normalization of urinary $\mathrm{N}$-telopeptide levels by zoledronic acid correlates with improved survival in patients with bone metastases from breast cancer.

Lipton A, Hei YJ, Coleman RE, Major P, Smith M, Cook RJ. Milton S. Hershey Medical Center, Hershey, PA; Novartis Oncology, East Hanover, NJ; University of Sheffield, Sheffield, England, United Kingdom; Hamilton Regional Cancer Centre, Hamilton, ON, Canada; Massachusetts General Hospital, Boston, MA; University of Waterloo, Waterloo, ON, Canada

Background: The bone resorption marker N-telopeptide (NTX) provides valuable prognostic information in patients with bone metastases. Elevated baseline NTX increases the relative risk of skeletal-related events, disease progression, and death across all tumor types (Brown JE, et al. J Natl Cancer Inst. 2005;97:59-69). Material and Methods: Urinary NTX was measured at baseline and at month 3 in 328 breast cancer patients with bone metastases treated with monthly zoledronic acid 4 or $8 / 4 \mathrm{mg}$ for up to 25 months. Results: At baseline, 132 patients had a normal urinary NTX value of $\leq 64 \mathrm{nmol} / \mathrm{mmol}$ creatinine (upper limit of normal for premenopausal women) and 196 had elevated baseline NTX (> $64 \mathrm{nmol} / \mathrm{mmol}$ creatinine). At month 3, only $1 / 132(0.8 \%)$ patient with normal baseline NTX developed elevated NTX, 124/132 $(93.9 \%)$ patients still had a normal NTX (N-N group), and 7/132 (5.3\%) patients died. At month 3, 149/196 (76\%) patients who began treatment with elevated NTX had normal NTX (A-N group), $31 / 196(15.8 \%)$ patients had persistent elevation of NTX (A-A group), and $16 / 196(8.2 \%)$ patients died. The median survival was 901 days for N-N patients, 790 days for A-N patients and 446 days for A-A patients. The relative risk for survival among A-N versus A-A patients was $0.454(P=.0004)$. There was no statistically significant difference in survival between N-N and A$\mathrm{N}$ patients. Discussion: For patients with elevated baseline bone markers, zoledronic acid therapy normalized bone marker levels in the majority $(76 \%)$ of these patients after 3 months of treatment. Persistent elevation of urinary NTX during zoledronic acid treatment is associated with shorter survival.

\section{6}

Predicting relapse in estrogen receptor (ER) positive breast cancer (luminal) subgroups treated with adjuvant tamoxifen.

Loi SM, Desmedt C, Haibe-Kains B, Lallemand F, Gillett C, Tutt A, Ryder K, Ellis P, Harris A, Smeds J, Bergh J, Cardoso F, Piccart MJ, Sotiriou C. Jules Bordet Institute, Brussels, Belgium; Guy's Hospital, London, United Kingdom; Weatherall Institute of Molecular Medicine, University of Oxford, John Radcliffe Hospital, Oxford, United Kingdom; CCK Cancer Centrum Karolinska, Karolinska Institutet and Hospital, Stockholm, Sweden

Background: ER-positive breast cancers (BC) exhibit considerable clinical heterogeneity. Microarray profiling has lead to the notion of distinct molecular subgroups within ER-positive BC; these are often described as luminal subtypes (Sorlie, Sotiriou et al). The luminal subtypes seem to be directly associated with proliferative genes, with the luminal A group correlated with low grade, and the $\mathrm{B}$ and $\mathrm{C}$ groups with high grade. We sought to further define these subtypes and identify genes associated with $\mathrm{BC}$ recurrence within the subgroups of ER-positive BC. Material and Methods: We determined gene expression profiles from 168 tamoxifen-only treated ER positive early stage BC samples (training set) using Affymetrix U133 2.0 Plus Genechips. Median follow-up was 7.3 yrs. We divided these tumors into 2 groups according to their degree of proliferation. These groups, which had distinct clinical outcomes (HR:4.1, 95\% CI:2.0-8.5, p<0.001), were named low and high grade ER-positive subtypes and are molecularly consistent with the previously described luminal subtypes of Sorlie and Sotiriou et al. Genes associated with distant relapse within the subtypes were identified using Cox proportional hazards model. The independent validation set consisted of 86 ER-positive tamoxifen- 


\section{S130 Abstracts - Poster Session III}

only treated BC from a different institution. Results: For the low grade subgroup we identified 330 genes that were significantly associated with distant relapse. Here, many genes were related to immune function. In the high grade subgroup 195 genes were identified, including many that were HER-2 and ER-related. The probability of selecting these genes by chance was estimated to be $\mathrm{p}=0.01$ and 0.04 after 1000 random permutations respectively. There were only 7 genes in common. In the independent validation set, these genes could identify distinct prognostic groups within the low $(n=44)$ and high grade subtypes $(n=42)$ : low grade: HR: 3.9 (95\%CI: 0.9-19.2), $\mathrm{p}=0.06$; high grade HR: 2.7 (95\%CI:1.1-7.1), $\mathrm{p}=0.04$. We are currently validating this concept in a further 100 tumor samples. Discussion: ER-positive BC can be divided into low grade or high grade subtypes. Furthermore, different groups of genes can identify women at high risk of relapse on adjuvant tamoxifen within these ER-positive subgroups for whom other therapies could be targeted. Further investigation into the biology of these diverse gene sets could substantially aid treatment tailoring for $\mathrm{BC}$ patients.

\section{7}

Leptin receptor isoforms (OBR-L and OBR-S) expression in breast cancer and relation with clinical outcome.

Revillion F, Charlier M, Lhotellier V, Hornez L, Giard S, Baranzelli $M C$, Djiane J, Peyrat JP. Centre Oscar Lambret, Lille, France; Institut National de la Recherche Agronomique, Jouy-en-Josas, France

Background: The relationship between leptin and obesity is clearly demonstrated, and it is well established that overweight and obesity are associated with an increased risk of developing breast cancer. The human leptin receptor (OBR) belongs to the class I cytokine receptor family. Two main isoforms (OBR-L and OBR-S) resulting from an alternative splicing have been described in breast cancer (Laud et al, Mol Cell Endocr, 2002; 188:219-26). We established the relationships between these two isoforms and the clinical, pathological, and biological parameters as well as clinical outcome in breast cancer. Materials and Methods: The expression of OBR-L and OBR-S was quantified by real time RTPCR, using TaqMan fluorogenic probes, in 322 breast cancers operated on between May 1989 and December 1991 (Pawlowski et al, Clin Cancer Res, 2000; 6:4217-25). The TATA box binding protein was used to normalize OBRs expression. The human breast cancer cells SKBR3, expressing the two target genes, were chosen as calibrator sample (i.e. target expression =1). Results: All the tumors tested expressed OBR-L and OBR-S and the median value of expression was respectively 6.57 (range 0.32 to 1408) and 2.58 (range 0.02 to 20.8 ). There was a strong positive correlation between OBR-L and OBR-S $(r=0.504, \mathrm{P}<0.001)$ (Spearman test). Both isoforms negatively correlated to histoprognostic grading (HPG) $(\mathrm{r}=-0.159, \mathrm{P}=0.007$; and $\mathrm{r}=-0.219, \mathrm{P}<0.001$ respectively) and OBR-L negatively correlated to tumor size $(\mathrm{r}=-0.11, \mathrm{p}=0.05)$. In contrast, a positive correlation was observed between OBR-L and ER ( $\mathrm{r}=0.128, \mathrm{P}=0.022)$ and between OBR-S and PR $(\mathrm{r}=0.126$, $\mathrm{p}=0.024)$. Both isoforms correlated with HER3 $(\mathrm{r}=0.117, \mathrm{P}=0.036$ for OBR-L; $r=0.126, P=0.024$ for OBR-S) and HER4 $(r=0.135$, $\mathrm{P}=0.015$ for OBR-L; $\mathrm{r}=0.229, \mathrm{P}<0.001$ for OBR-S). Longer relapse-free survival was observed in patients with elevated OBR$\mathrm{S}$ expression ( ${ }^{3}$ upper quartile) $(\mathrm{P}=0.008)$. Cox univariate analyses demonstrated prognostic value of OBR-S $(\mathrm{P}=0.009$; risk ratio (RR), 0.5) besides node involvement ( $\mathrm{P}=0.035$; $\mathrm{RR}, 1.52)$ and tumor size $(\mathrm{P}=0.004$; RR, 1.69). In multivariate analyses, OBR-S maintained its prognostic value besides tumor size. Conclusion: This study demonstrates that OBR-L and OBR-S are associated with a more differentiated phenotype in breast cancer. Furthermore, OBR-S is an independent prognostic marker of better relapse-free survival. Supported by the Association pour la Recherche sur le Cancer (Grant $n^{\circ} 3522$, Villejuif, France).

\section{8}

Using AQUA ${ }^{\mathrm{TM}}$ and tissue microarrays for discovery of a minimal set of multiplexed markers to subclassify breast cancer.

Dolled-Filhart MP, Cregger M, Camp RL, Rimm DL. Yale University School of Medicine, New Haven, CT

Expression profiling using nucleic acid technologies has led to dozens of methods of subclassification of breast cancer. The ultimate goal of these assays is to better predict outcome or response to therapy. Quantitative analysis of protein expression on tissue microarrays provides a similar but parallel approach with the potential to define a smaller set of prognostic or predictive markers that can be assessed on conventional diagnostic histopathology slides. Toward that goal we have assessed 35 markers selected from expression profiling studies focusing on estrogen status. The absolute level of protein expression was assessed using the AQUA assay on a set of 250 cases of breast cancer with long term follow-up. Unsupervised hierarchical clustering of these markers revealed two markers most closely associated with estrogen receptor(ER). Univariate analysis of 5 year disease-specific survival of these two markers, GATA3 and NAT1, shows significant association with good outcome $(p=0.0011$ and $\mathrm{p}=0.0200$ respectively). These markers were combined with ER to form a three marker multiplex test. This test was then reevaluated on a cohort of 675 breast cancers. Clustering of this group subclassifies the cases into three prognostically distinct groups including a GATA3 driven subset with 5 year survival of $97 \%$, an ER and NAT1 driven subset with a 5 year survival of $83 \%$ and a triple negative driven group with a 5 year survival of $65 \%$ $(\mathrm{p}<0.0001)$. The multiplex assay divides the pathologist-scored $\mathrm{ER}+$ group into two groups with significantly unique outcome. Tests for the predictive value of the assay in hormonal therapy trials are underway.

\section{9}

Predicting prognosis in early stage primary breast cancer using a five biomarker panel and image assisted immunohistochemistry (IHC) scoring.

Ross JS, Boguniewicz AB, Ross MS, Whitehead CM, Morel D, He $Q$, Sheehan CE. Albany Medical College, Albany, NY; Tripath Oncology, Inc, Durham, NC

\section{Background}

Recent reports document a growing list of biomarkers that demonstrate varying utility in the risk stratification of earlystage breast cancer patients for disease recurrence and/or death. In the following novel image assisted IHC study, we confirm the ability of a panel of 5 biomarkers, measured individually and in combinations, to risk-stratify node negative disease and predict patient outcome.

Materials and Methods

217 formalin fixed, paraffin embedded archival specimens of node negative (T1N0, T2N0) invasive ductal breast cancer with a minimum of five years of clinical follow-up were employed in this retrospective study. Specimens were processed via standard IHC protocols on a Dako Autostainer (Dakocytomation Inc.) using antigen unmasking in a pressure cooker (Decloaker, Biocare Medical Inc) and monoclonal primary antibodies (ProEx Br, TriPath Imaging Inc.). The expression levels of the secretory leukocyte protease inhibitor $S L P I$, the transcription factor $E 2 F 1$, the oncogenes $c$-src and $p 21^{r a s}$ and the immunoproteasome gene PSMB 9 were assessed using an Interactive Histology Imaging System (IHIS) (Tripath Imaging Inc.) that quantifies subcellular staining intensity using brightfield microscopy. The IHIS system determines both the staining intensity within the appropriate subcellular compartment and the percentage of labeled cells are utilized as thresholds to quantify overexpression levels. 


\section{Results}

The performance of the biomarkers collectively and in conjunction with standard clinico-pathologic parameters was assessed by multivariate Cox proportional analysis (Table 1).

Table 1. Individual and combination biomarker analysis

$$
\text { Marker }
$$

SLPI (individual)

SLPI (individual)

Any 1 or more of 5 (SLPI, E2F1, c-src, PSMB9, 21 ,

Any 1 or more of 4(SLPI, E2F1, c-src, PSMB9)

Any 1 or more of 3(SLPI, E2F1, c-src)

1 or more of 3 (SLPI, E2F1, c-src)

with other factors (age, tumor size)

The sensitivity of the biomarker panel increased with increasing number of markers. Using Kaplan-Meier plots, the risk of recurrence or death increased from $40 \%$ to $70 \%$ when any two or more of the 5 marker panel were scored as positive $(\mathrm{p}=0.0078)$.

Discussion

This data supports the potential utility of this image-assisted IHC assay of the SLPI, E2F1, c-src, p2 $1^{\text {ras }}$ and PSMB9 biomarkers to risk stratify node negative breast cancer patients. The IHIS evaluation of this 5 biomarker panel achieved independent prognostic utility in assessing disease recurrence and predicted a significant reduction in survival rates when 2 or more of these 5 biomarkers were overexpressed. Further evaluation in larger trials of this assay appears warranted.

\section{0}

Breast cancer phenotype associated with a propensity for central nervous system (CNS) metastases.

Tham YL, Sexton K, Kramer R, Hilsenbeck S, Elledge R. Baylor College of Medicine, Houston, TX

Background: There is anecdotal evidence that the incidence of CNS metastases has increased with the advancement of systemic therapy, such as trastuzumab. However, it is unclear whether either specific tumor biological properties or systemic therapies influence the risk of CNS metastases. Furthermore, the identification of a tumor phenotype with a propensity for CNS metastases would be important for future screening or preventive strategies.

Methods: Using a database of 10782 patients that were diagnosed and treated from 1970 to 1999,2685 patients were identified who relapsed distantly. Clinical and biological features of these patients were analyzed in two groups: 1) Patients who ever had CNS metastases $(14 \%, \mathrm{n}=383)$ were compared with those who never had CNS metastases (86\%, $n=2302)$ and 2) Patients who had CNS metastases as the first site of relapse $(39 \%, \mathrm{n}=150)$ vs. those who had other sites $(61 \%, n=233)$. Survival after CNS metastasis was calculated using the Kaplan-Meier method and this was correlated with clinical and biological features of the patients.

Results: In the ever versus never analysis, factors associated with CNS metastases were young age $(\mathrm{p}<0.001)$, premenopausal status $(p=0.008), E R$ and PR negative tumor $(p<0.001)$, high S-phase $(\mathrm{p}=0.002)$, aneuploidy $(\mathrm{p}=0.02)$, and altered $\mathrm{p} 53(\mathrm{p}=0.01)$. ILC was less likely to be associated with CNS metastases $(p=0.01)$. Tumor size and lymph node status were not associated with a relative increase in risk of CNS metastases compared with other sites. Adjuvant systemic therapy also did not alter the relative risk of CNS vs. non-CNS metastases when compared with patients that did not receive therapy. Her2 positivity was not associated with CNS metastases in these patients, all of whom were treated prior to the trastuzumab era $(\mathrm{p}=0.91)$, though Her $2+$ patients were more likely to develop CNS metastases following non-CNS relapse $(\mathrm{p}=0.04)$. The biomarker profile of CNS failure as first recurrence did not otherwise differ from those with CNS metastases as subsequent recurrence. In a multivariate analysis of the above factors, ER negativity (OR 2.8, p<0.001), IDC histology (OR 2.5, $\mathrm{p}=0.02)$, and young age $(\mathrm{p}<0.001)$ were independent factors associated with any CNS metastases. The median survival after CNS metastases was 5.5 months, with $25 \%$ of the patients alive at one year and $10 \%$ at 2 years. The only factor that significantly influenced survival was Her2 status, with Her2 positive patients having a shorter survival $(\mathrm{p}=0.02)$.
Conclusion: Younger patients with hormone receptor negative tumors that are highly proliferative, genomically unstable, and p53 altered are at increased relative risk for CNS metastases. Her2 expression did not increase the relative risk of CNS metastases in the absence of trastuzumab therapy. Adjuvant therapies did not change the patterns of distant recurrence.

\section{1}

\section{Lymph node ratio as a prognostic factor in metastatic breast} cancer.

Ueno NT, Cserni G, Wallace AM, Janni W, Royce M, Nieto Y, Vinh-hung V, International Nodal Ratio Working Group. INRWG, Houston, TX; INRWG, Kecskemét, Hungary; INRWG, Albuquerque, NM; INRWG, München, Germany; INRWG, Pamplona, Spain; INRWG, Brussels, Belgium

Background: The prognostic value of pathologic lymph node status $(\mathrm{pN})$ is unclear for patients presenting with breast cancer and distant metastases at diagnosis. However, the lymph node ratio (LNR; \# of positive nodes $\div$ \# of nodes examined) can identify subgroups with distinctly different prognoses in terms of 10 -year breast cancer-specific survival rate. We compared the prognostic value of the $2002 \mathrm{pN}$ system vs. an LNR-based system in a retrospective sample of patients presenting with distant metastases.

Methods: We used the Surveillance, Epidemiology, and End Results database ( 9 registries, 2004) to identify women diagnosed from 1988 to1997 for whom pathologic nodal status was available. 1,301 cases recorded as Stage IV, 1,144 were metastatic; 66 patients with supraclavicular or internal mammary lymph node involvement were excluded, leaving 1,078 cases for analysis. Endpoints were overall survival and breast cancer-specific survival, calculated with the Kaplan-Meier product limit method; differences were evaluated with log-rank $\mathrm{Chi}^{2}$ tests. Owing to the small number of cases, $\mathrm{pN}$ and LNR were each grouped in 2 subcategories ( $\leq$ or $>3$ involved nodes for $\mathrm{pN}$ and $\leq$ or $>0.25$ for $\mathrm{LNR}$ ).

Results: At median follow-up of 6.6 years (0.6-13.6 years), median primary tumor size recorded in 907 cases was $40 \mathrm{~mm}(6-190 \mathrm{~mm})$ and $800 \mathrm{~mm}$ in 1 outlier, involved nodes was 6 (mean 7.95, range 1-55), and nodes examined was 12 (1$59)$. The type of nodal involvement was micrometastatic $(\leq 2 \mathrm{~mm})$ in 33 cases, $>2$ $\mathrm{mm}$ and/or extending beyond capsule in 391 cases $(331 \geq 20 \mathrm{~mm}$ and/or extending beyond capsule and/or fixed/matted), unspecified in 654 cases. All lymph nodes were involved in 350 patients. Differences in survival according to $\mathrm{pN}$ and LNR classifications are summarized below.

Table 1 . Survival by $\mathrm{pN}$ and by LNR

$\begin{array}{lll}10 \text {-year } & \leq 3 \mathrm{~N}+ & >3 \mathrm{~N}+ \\ \text { survival rates } & (\mathrm{n}=384) & (\mathrm{n}=694)\end{array}$

Overall

\section{$\mathrm{Chi}^{2}$}

(P)

LNR $\leq 0.25$

$(\mathrm{n}=216)$

$\begin{array}{ll}\mathrm{LNR}>0.25 & \mathrm{Chi}^{2} \\ (\mathrm{n}=862) & (\mathrm{P})\end{array}$

BC-specific $\quad 16.8 \% \quad 10.2 \%$

$(0.0254)$
11.81

(0.0006)

$30.0 \%$

$4.8 \%$

(P) 47.13

$\left(10^{-9}\right)$

54.81 $\left(10^{-9}\right)$

Conclusion: Despite the skewed distribution and severe nodal involvement, the LNR clearly identified different prognostic subgroups. Further investigations of the LNR as a prognostic factor are warranted.

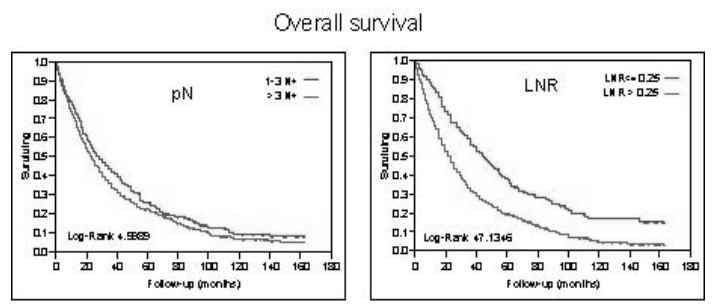

Breast cancer specific survival
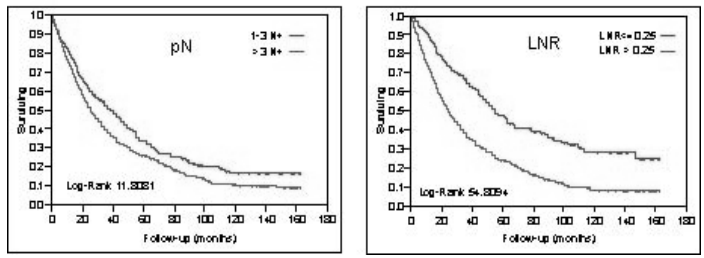


\section{S132 Abstracts - Poster Session III}

3022

Prognostic value of uPA and PAI-1 mRNA expression in primary breast cancer.

Verjat T, Lamy PJ, Grenier J, Servanton AC, Paye M, Krause A, Bachelot T, Puisieux A, Mougin B, Leissner P. BioMerieux, Marcy l Etoile, France; Centre Regional de Lutte Contre le Cancer Val d Aurelle, Montpellier, France; Centre Leon Berard, Lyon, France

Urokinase-type Plasminogen Activator (uPA) and its inhibitor, Plasminogen Activator Inhibitor type 1 (PAI-1) are the first novel tumor biomarkers to be validated, by the EORTC, at the highest level of evidence regarding their clinical utility in breast cancer. Patients with high protein levels of uPA and/or PAI-1 in their tumors have statistically significant shorter Metastasis-Free Survival (MFS) and Overall Survival (OS) than patients with low protein levels. However, the need of a minimum of 100-300 mg of frozen tissue for ELISA is often stated to be an obstacle to use these prognostic factors in routine. We therefore investigated the prognostic value of UPA and PAI-1 at the mRNA level as measured by Nucleic Acid Sequence-Based Amplification (NASBA) that needs as little as 50ng of total RNA thus allowing to analyse small earlystage tumors. First, comparison of uPA and PAI-1 NASBA results with the corresponding protein levels measured by ELISA (Femtelle kit, American Diagnostica, USA) was performed on 77 primary tumor samples. We observed that uPA and PAI-1 mRNA expression was significantly greater $(\mathrm{p}<0,0001)$ in ELISA-positive samples than in negative-group confirming the good correlation between mRNA and protein expression for both markers. Secondly, the prognostic value of uPA and PAI-1 mRNA expression was investigated in a retrospective series of 95 lymph-node- and hormone receptor-positive breast cancer tumors by means of Affymetrix Human U133 Plus 2.0 GeneChips. We demonstrated that PAI-1 mRNA expression represented a strong prognostic factor for the development of metastasis and for the overall survival in this population. Furthermore, PAI-1 but also uPA mRNA were significant prognostic factors for MFS and OS in the subgroup of the postmenopausal patients. Taken together, these results indicate that UPA and PAI-1 mRNA analysis give results as interesting as those obtained at the protein level suggesting that NASBA could be proposed as an alternative to ELISA method for the study of the uPA and PAI-1 system in human breast cancer.

\section{3}

Breast cancer of the lower inner quadrant is associated with an increased mortality risk among women with early stage disease.

Sarp S, Fioretta G, Verkooijen HM, Wespi Y, Schubert H, Bouchardy C, Vlastos G. Institute for Social and Preventive Medicine, Geneva, Switzerland; Association of Physicians of the Canton of Geneva, Geneva, Switzerland; Geneva University Hospital, Geneva, Switzerland

Introduction: Stage I (T1, N0, M0) breast cancer has an excellent prognosis, but some women still die of this disease. This could partly be explained by understaging, due to undetected lymph node involvement of the internal mammary chain. As lymph node metastases of the internal mammary chain occur more frequently among patients with cancer of the lower inner quadrant, we designed a population-based study to evaluate the impact of tumour location on breast cancer mortality risk.

Methods: We used information from the Geneva Cancer Registry to identify all 1411 women, operated for stage I breast cancer between 1986 and 2002. With multivariate Cox regression analysis we compared breast cancer mortality risks according to tumour location and adjusted for all other prognostic factors.

Results: Sixty-five patients died of breast cancer. The ten-year specific survival was $93 \%$ (95\% CI: 91-95\%). Grade, oestrogen receptor status and treatment were associated with mortality from breast cancer. After accounting for all these factors, patients with breast cancer of the lower inner quadrant $(n=103 ; 7.3 \%)$ had a more than two-fold increased risk to die of breast cancer compared to women with breast cancer of the upper outer quadrant (multiadjusted Hazard Ratio 2.5; 95\% CI 1.1-5.9). Tumour location in other quadrants was not associated with a significantly altered mortality risk

Conclusions: Patients with stage I breast cancer of the lower inner quadrant have an increased risk to die of their disease. These women might benefit from systematic staging of the internal mammary chain, in order to prevent undertreatment.

\section{4}

Risk factor analysis of early metastatic relapse for postmenopausal patients treated with tamoxifen.

Debled M, MacGrogan G, Brouste V, Mathoulin-Pélissier S, Durand M, Mauriac L. Institut Bergonié, Regional Cancer Center, Bordeaux, France

Results of ATAC and BIG 1-98 trials have showed a benefit of 5 years aromatase inhibitors over 5 years tamoxifen for estrogenreceptor-positive post-menopausal women. Three other trials have demonstrated a significant DFS benefit when switching tamoxifen for aromatase inhibitors after two or three years. According to indirect comparisons, a bigger reduction of relapse risk could be obtained using a sequential strategy. However, anastrozole prevents early relapses more efficiently than tamoxifen in the ATAC trial. The aim of this retrospective study was to identify risk factors in post-menopausal women, for relapse during the first three years of adjuvant treatment with tamoxifen.

Materials and Methods: We identified in our database postmenopausal women with an ER and/or PR positive breast cancer treated by surgery and adjuvant tamoxifen without any adjuvant chemotherapy. All the patients had at least three years follow-up. Systemic relapses occurring during these three years were considered as events. We analyzed age, histologic type, pathologic size, tumor grade, mitotic count, necrosis, peritumoral vascular emboli (PVE), ER and PR status and number of involved lymph nodes as possible prognostic factors of relapse.

Results: 715 patients who were registered between 1985 and 2000. Principal characteristics were: median age 64 y (range: 43 88); mastectomy/lumpectomy: $28 \% / 72 \%$; irradiation: $78 \%$; ductal/ lobular: $92 \% / 8 \%$; pathologic size $<2 \mathrm{~cm} / \geq 2 \mathrm{~cm}$ : $68 \% / 32 \%$; SBR grading (ductal): I/II/III: $26 \% / 52 \% / 22 \%$; mitotic count 1/2/3: $38 \%$; 40\%/22\%; necrosis: no/yes: $83 \% / 17 \%$; PVE: no/yes: $72 \% / 28 \%$; node -/+: 22\%/78\%; ER +/-: 98\%/2\%; PR +/-: 61\%/39\%.

Among this population, 38 systemic relapses occurred during the first three years (systemic relapse risk at 3 years: 5.3\%).

In an univariate analysis, significant prognostic factors were: grading $\left(\mathrm{p}=1.10^{-5}\right), \mathrm{N}+\left(\mathrm{p}=2.10^{-3}\right)$, necrosis $\left(\mathrm{p}=3.10^{-3}\right)$, mitotic count $\left(3.10^{-3}\right)$, PVE $\left(2.10^{-2}\right)$, size $\geq 2 \mathrm{~cm}(0.02)$. Negative progesterone receptor was not significant (0.07). Because of a small number of ER- tumors $(2 \%)$, this factor was not analyzed.

As only one relapse was observed in 280 node negative and/or grade I tumors $(0.3 \%)$, multivariate analysis was restricted to node positive grade II-III ductal carcinomas (378 patients): only SBR grading (III vs II) was significant (HR $3.72\left[1.79-7.73 ; \mathrm{p}<10^{-3}\right]$ ). Over-expression of Her-2/neu was detected in 6 cases of relapses $(16 \%)$. Analyses of other potential biological factors including VEGF-R2, PTEN, AIB-1 are in progress. Results will be available in December 2005.

Conclusion: Post-menopausal women treated for node positive grade III tumors with adjuvant tamoxifen without any chemotherapy have a high risk of early relapse. These women may benefit from initial treatment with an aromatase inhibitor. 


\section{5}

Four genes by RT-PCR predicts distant relapse for women given adjuvant tamoxifen.

Desmedt C, Loi SM, Haibe-Kains B, Soree A, Lallemand F, Durbecq $V$, Larsimont D, Tutt A, Ellis P, Gillett $C$, Ryder $K$, Harris A, Cardoso F, Martiat PH, Piccart MJ, Sotiriou C. Jules Bordet Institute, Brussels, Belgium; Guy's Hospital, London, United Kingdom; Weatherall Institute of Molecular Medicine, University of Oxford, John Radcliffe Hospital, Oxford, United Kingdom

Background: There have been many gene classifiers developed recently that claim to predict clinical outcome better than currently used clinical factors. Whilst microarray technology offers huge advantages in furthering our knowledge of breast cancer biology, for present-day use, clinically applicable and useful tools may need only the quantitative information that is provided by genes that are already well known to convey prognostic/predictive information in breast cancer. Material and Methods: Our aim was to assess if the results of a reverse-transcriptase-polymerasechain-reaction (RT-PCR) assay for the genes ER, PgR, HER2/Neu and Ki67 in frozen tissue could correlate with distant disease recurrence in 175 breast cancer patients from 2 institutions treated with adjuvant tamoxifen only and followed for a median of 9.4 years. All RT-PCR experiments were performed in duplicate. Results: Adequate RT-PCR profiles were obtained for 154 of 175 tumors. We constructed a score from a linear combination of the coefficients from a multivariate Cox analysis including the 4 genes (likelihood ratio test, overall $\mathrm{p}$-value $<0.001$ ) and the expression of those genes. When considering the score as a binary variable with the median as cutoff, a hazard ratio (HR) of 3.7 (95\% CI: $1.8-7.6, p<0.001$ ) was reached with $97 \%, 95 \%$ and $91 \%$ of the patients being distant metastasis free at 3,5 and 10 years in the low risk group and $88 \%, 74 \%$ and $65 \%$ in the high risk group respectively. In a Cox model that included the binary score and traditional prognostic variables (tumor size, grade, age, nodal status), the score was the only significant predictor of distant metastasis at .05 level with a HR of 2.7 (95\% CI: 1.2-6.2, $\mathrm{p}=0.019$ ) and tumor size was borderline significant $(\mathrm{p}=0.052)$. Similar HR were found when considering the score as a continuous variable both in univariate and multivariate analysis. Discussion: We are currently validating this score on a further 100 samples and comparing with RT-PCR results on corresponding paraffinembedded tumour tissue. A comparison between RT-PCR and immunohistochemistry is also ongoing. This simple test using the RT-PCR value of 4 genes could provide an immediately applicable and cheap clinical tool that can assist clinicians in discriminating high and low risk prognostic groups for ER+ women treated with tamoxifen.

\section{6}

$\mathrm{C}$-kit expression in high-risk breast cancer treated with high-dose (HD) or conventional dose-dense chemotherapy: results of multivariate analysis from the WSG-AM-01 phase III trial.

Diallo R, Ting E, Gluz O, Mohrmann S, Schuett G, Rody A, Geddert H, Schaefer KL, Gabbert HE, Nitz U, Poremba C. Institute of Pathology, Heinrich-Heine-University of Duesseldorf, Duesseldorf, Germany; University Hospital of Duesseldorf, Duesseldorf, Germany; University Hospital of Frankfurt, Frankfurt, Germany Prognostic and predictive factors identifying patient subgroups with maximal benefit from high-dose chemotherapy with peripheral blood stem cell transplantation (PBSCT) remain to be defined. The proto-oncogene c-kit (CD 117) is known to be expressed in poorly differentiated breast cancer. In this study, we analyzed the protein expression of c-kit in a high risk subgroup of breast cancer patients ( $>9$ axillary node metastases) and correlated these findings with various histopathological parameters and the expression of cytokeratin (CK) 5, estrogen receptor alpha (ER), progesterone (PR) receptor, Her-2/neu, p53 and MIB-1.
403 patients were randomly assigned to dose-dense conventional chemotherapy (four cycles of EC, followed by three cycles of CMF q2w) or to two courses of EC followed by two courses of HD chemotherapy (EC-thiotepa) with PBSCT. Treatment arms were well balanced for age, menopausal status, tumor size, grading, number of involved lymph nodes, nodal ratio and ER/PR status. C-kit, CK5, ER, PR, Her-2/neu, p53 and MIB-1 expression was evaluated immunohistochemically using tissue microarrays containing breast cancer samples from 239 patients (from whom paraffin tumor blocks were available).

Within the WSG AM01 trial, the average number of positive axillary lymph nodes was $17.6 \pm 8.0 \mathrm{SD}$. At a median follow-up of 48.6 months, there was a significant overall survival benefit for patients receiving $\mathrm{HD}(\mathrm{p}=0.00047)$. C-kit expression was found in $12 \%$ of all breast cancers and correlated with a reduced time to relapse and a poorer overall survival (OS) not only in univariate $(\mathrm{p}=0.00026)$ but also in multivariate analysis (HR for OS $=2.10$ [CI 1.09-4.07], $\mathrm{p}=0,028)$ independently of therapy, stage and nodal status. Furthermore, c-kit correlated with high grade $(\mathrm{p}=0.024), \mathrm{CK} 5+(\mathrm{p}=0.0007)$ and PR- $(\mathrm{p}=0.0092)$.

These findings underline that c-kit represents an independent prognostic marker in high risk breast cancer. Furthermore, correlation with CK5+ and PR- suggests that c-kit positive carcinomas are at least partly of basal-type. Further analysis by treatment arm will be presented.

\section{7}

Genomic alterations identified by array comparative genomic hybridization as prognostic markers in tamoxifen treated estrogen receptor positive breast cancer.

Han W, Han MR, Kang JJ, Bae JY, Lee JE, Shin HJ, Hwang KT, Hwang SE, Noh DY. Seoul National University College of Medicine, Seoul, Korea: Cancer Research Institute, Seoul National University College of Medicine, Seoul, Korea; Macrogen Inc., Seoul, Korea Considerable proportion of estrogen receptor (ER) positive breast cancer recurs in spite of tamoxifen treatment, which has been a serious clinical problem commonly encountered in the patient management. To find novel prognostic or predictive markers in this subtype of breast cancer, we performed a high-resolution array comparative genomic hybridization $(\mathrm{CGH})$ with an array of 1,440 human bacterial artificial chromosome (BAC) clones to assess copy number changes in 28 archival fresh frozen ER $(+)$ breast cancer tissues. Nine patients had distant recurrence within five years (Recur group) and 19 patients were alive without disease at least five years after diagnosis (Non-recur group). All the patients received tamoxifen as an adjuvant endocrine therapy for at least a year. The clinicopathological characteristics, such as age, tumor size, lymph node status, histologic grade, and progesterone receptor status, were comparable between the two groups. In an unsupervised clustering analysis, all samples from Recur group were clustered together with only four samples from Non-recur group clustered with the Recur group samples. We used CGH-Explorer (Lingjarde, et al.) and Analysis of Copy Error (ACE) algorithm for calling gain and loss of each BAC clone and chromosomal location. The most common regions of gain in all samples were 1q32.1, 17q23.3, $8 \mathrm{q} 24.11,17 \mathrm{q} 12-\mathrm{q} 21.1$, and $8 \mathrm{p} 11.21$; and the most common regions of loss were 6q14.1-q16.3, 11q21-q24.3 and 13q13.2-q14.3. The average frequency of copy number changes was similar between the two groups. We used two different kind of statistical methods to identify clones with significantly different copy number change between the two groups: chi-square test applied to $2 \times 2$ table and SAM analysis applied to the sliding windows of three consecutive BAC clones. As a result, the most significant chromosomal alterations found in common by the two methods were loss of $11 \mathrm{p} 15.5-\mathrm{p} 15.4,1 \mathrm{p} 36.33,11 \mathrm{q} 13.1$, and $11 \mathrm{p} 11.2$ with adjusted $p$ values $<0.01$. In conclusion, our array CGH analysis with BAC clones could detect vaious genomic alterations in ER positive breast cancers and the Recur group showed significantly different pattern of chromosomal gain or loss from Non-recur group. The interesting regions of copy loss and candidate genes are now in the stage of verification with real-time PCR and $\mathrm{LOH}$ analysis. 


\section{S134 Abstracts - Poster Session III}

\section{8}

Prognostic value of Ki-67 in lymph node-negative breast cancer and the usefulness of a combination of Ki-67 and the St. Gallen classification.

Jung SY, Han W, Park IA, Shin HJ, Lee JE, Hwang KT, Hwang SE, Noh DY. Seoul National University College of Medicine, Seoul, Korea

Purpose: To evaluate the independent prognostic value of $\mathrm{Ki}-67$ in lymph node-negative breast cancer and the usefulness of Ki-67 when it combined with St. Gallen classification as guidance of adjuvant chemotherapy for node-negative cancer.

Methods: We retrospectively reviewed the data of patients with lymph node-negative breast cancer who underwent curative surgery between Jan 1998 and Dec 2001 at our institution. We classified the patients as average or minimal risk groups according to the St. Gallen classification, combined the groups with Ki-67 expression, and compared the distant metastasis-free survival (DFS) rates. Results: A total of 543 patients were analyzed. Median follow-up was 49 months. The overall 5-year DFS rate was 91.8\%. The 5year DFS rates for patients with Ki-67-positive and negative (cutoff value: $\geq 10 \%$ ) tumors were $83.0 \%$ and $94.1 \%$, respectively $(p=0.0007)$. The 5-year DFS rates for patients with average and minimal risk group by St. Gallen classification were $89.7 \%$ and $97.2 \%$, respectively. In a Cox regression model involving potential prognostic factors (young age $(<35)$, tumor size $(>2 \mathrm{~cm})$, histologic grade, estrogen receptor, c-erbB2, chemotherapy, and hormone therapy), high Ki-67 expression could independently predict the risk of distant recurrence (odds ratio $=1.96[95 \%$ confidence interval, 1.11-3.02]). The average risk group by the St. Gallen classification was further divided into two subgroups with significantly different prognosis according to the Ki-67 expression (DFS rate: $82.7 \%$ vs. $91.9 \% ; p=0.007$ ).

Conclusion: $\mathrm{Ki}-67$ was an independent prognostic factor in lymph node-negative breast cancer and the combination of Ki-67 expression and the St. Gallen classification could provide a more useful therapeutic guideline for node-negative patients.

\section{9}

Evaluation of TGF- $\alpha$ expression and prevalence of EGFR and HER2 kinase domain mutations in breast cancer.

Konecny GE, Finn F, Seshagiri S, DeForge L, Untch M, Wang HJ, Kahlert S, Slamon DJ, Pegram MD. UCLA, Los Angeles, CA; Genentech Inc., South San Francisco; Ludwig Maximilians University, Munich, Germany

Background: EGFR is commonly expressed in breast cancer, but the therapeutic utility of targeting this receptor for breast cancer treatment is unclear. Increased expression of EGFR ligands such as TGF- $\alpha$ have been implicated in autocrine activation loops which may promote independent tumor growth. In addition, mutations in the gene encoding EGFR in non-small-cell lung cancer have been identified. These mutations confer sensitivity to EGFR inhibitors in vitro and may be associated with clinical responses to these agents. In this study we (a) examine the expression of TGF$\alpha$ and its association with EGFR in a large clinical cohort of primary breast cancer patients and (b) study the prevalence of specific EGFR and HER2 mutations in breast cancer.

Materials and Methods: TGF- $\alpha$ and EGFR expression were measured by ELISA in primary breast cancer tissue extracts from 662 patients with long term clinical follow up (median 72 months). Furthermore, we sequenced the tyrosine kinase domain of HER2 and exons 19 21 of EGFR in 100 unselected primary breast cancer patients. Results: TGF- $\alpha$ expression was detectable in $52(8 \%)$ of the 662 patients (range: $7-394 \mathrm{pg} / \mathrm{mg}$ protein). EGFR expression was detectable in $531(80 \%)$ of the 662 patients (range: $0.5-636 \mathrm{ng}$ / $\mathrm{mg}$ protein). TGF- $\alpha$ expression was significantly associated with EGFR expression $(\mathrm{p}<0.0001)$ and VEGF expression $(\mathrm{p}=0.0069)$. TGF- $\alpha$ and EGFR expression were significantly associated with a negative hormone receptor status $(\mathrm{p}<0.0001)$. EGFR expression demonstrated prognostic significance for disease-free (DFS, risk ratio (RR) 1.17, $\mathrm{p}=0.0190$ ) and overall survival (OS, RR 1.16, p $=0.0419)$ only in univariate analysis. TGF- $\alpha$ expression similarly demonstrated prognostic relevance for DFS and OS, although not statistically significant (DFS, RR $1.47, p=0.0705$, OS RR 1.49, p $=0.0826$. TGF $-\alpha$ had a discriminatory effect on patients with EGFR expressing tumors. No specific EGFR or HER2 mutations were found in the analyzed 100 breast cancer tissue lysates.

Conclusion: EGFR expression is frequent in breast cancer however only in cox univariate analysis did EGFR show prognostic significance. TGF- $\alpha$ expression is rare, but it may define a distinct subgroup regarding EGFR signaling and angiogenesis. Mutations in the kinase domains of HER2 or EGFR are unlikely to play a significant role in the pathogenesis of breast cancer.

\section{0}

Detection and prognostic significance of HER2 mRNApositive cells in the peripheral blood of patients with operable breast cancer.

Mavroudis D, Perraki M, Apostolaki S, Politaki E, Xenidis N, Manousakis E, Georgoulias V. University General Hospital, Heraklion, Crete, Greece; School of Medicine, University of Crete, Heraklion, Crete, Greece

Background: We have previously validated a nested RT-PCR assay for the detection of circulating occult tumor cells in the blood and bone marrow of patients (pts) with breast cancer (Proc ASCO 2005, abstr 668). Here we present the clinical relevance of the detection of HER2 mRNA-positive cells in the peripheral blood of pts with operable breast cancer.

Materials and Methods: $10 \mathrm{ml}$ of blood was obtained from 216 pts with stage I and II breast cancer after completion of primary surgery and before the initiation of any adjuvant systemic treatment. Peripheral blood mononuclear cells were isolated, RNA was extracted and subjected to nested RT-PCR for HER 2 mRNA as previously described. Results of the detection were analyzed in univariate and multivariate models with other known prognostic factors in relation to disease-free interval (DFI) and overall survival (OS).

Results: Patients' median age was 55 years (range 28-79), 135 $(62.5 \%)$ were postmenopausal, $67(31 \%)$ had stage I disease, 78 (36\%) had 1-3 involved axillary lymph nodes (LN) and $126(58 \%)$ had estrogen receptor (ER)-positive tumors. HER2 mRNApositive cells were detected in $76(35 \%)$ of the 216 pts and independently of known clinical and pathologic risk factors. After a median follow up period of 57 months (range 4-108), 50 (23\%) pts developed distant metastases and 30 (14\%) pts have died. Univariate analysis showed that the detection of HER2-mRNApositive cells in the blood was associated with decreased DFI $(\mathrm{p}<0.00005)$ and OS $(\mathrm{p}=0.002)$. Multivariate analysis revealed the detection of HER2-mRNA-positive cells to be an independent prognostic factor for DFI $(\mathrm{p}<0.000001)$ and OS $(\mathrm{p}=0.0026)$.

Conclusions: The detection of HER2 mRNA in the blood of patients with operable breast cancer provides important prognostic information and thus may serve as a new marker for the presence of occult tumor cells.

\section{1}

HER-2/neu is associated with axillary nodal invasion in breast cancers expressing both hormone receptors.

Neven P, Huang HJ, Drijkoningen M, Amant F, Leunen K, Berteloot $P$, Wildiers $H$, Van Limbergen E, Paridaens $R$, Christiaens $M R$ Vergote I. UZ-Leuven, Leuven, Belgium

Background: In breast cancer, overexpression of the HER2/neu receptor has been correlated with poor prognosis. We explored whether the presence of HER-2/neu, together with other biological features of the primary tumour, aids in predicting axillary nodal metastasis in operable breast cancers stratified by their steroid hormone receptor status. 
Patients and Methods: 1362 consecutive patients who underwent primary breast surgery and complete axillary clearance for an invasive breast carcinoma between Jan 2000 and Jun 2003 were examined. The study variables included the HER-2/neu and steroid receptor status, mean maximal microscopic tumor size, proportion of tumours being grade 3 and mean age at surgery. Steroid hormone receptors and HER-2/neu were measured by immunohistochemistry using respectively the $\mathrm{H}$ - and DAKO-score. A H-score of 50-300 and a DAKO-score of $2+$ and $3+$ were considered positive.

Results: Compared with HER-2/neu negative breast cancers, HER2/neu positive tumours were more likely node-positive (41.1 vs $34.2 \% ; P=0.042$ ), grade 3 (63.9 vs $33.9 \% ; P<0.001)$, not larger (27.2 vs $25.9 \mathrm{~mm} ; P=0.351)$ and women were slightly younger (55.8 vs 57.7 yrs; $P=0.027$ ). The results by oestrogen receptor (ER) -status and for ER-positive cancers by progesterone receptor (PR)-status are summarized in the table. HER-2/neu overexpression affects the lymph node status of ER-positive breast cancers only when PR is co-expressed. Again in this subgroup, HER-2/neu positive tumours were not larger $(28.4$ vs $25.5 \mathrm{~mm} ; P=0.181)$ and patients were slightly younger ( 54.7 vs $57.5 \mathrm{yrs} ; P=0.029)$. These findings were confirmed when considering only DAKO-score $3+$ cases as HER-2/neu positive.

Axillary lymph node invasion in operable breast cancers by HER-2/neu and steroid receptor expression taking tumour grade into account $(\mathrm{n}=1362)$

ER/PR status HER-2/Neu status Numbers Grade 3

$\begin{array}{lllllll} & & & & & & \\ \text { ER-Neg } & \text { Neu Neg } & 168 & 84.5 \% & 0.643 & 37.5 \% & 0.827 \\ & \text { Neu Pos } & 90 & 86.7 \% & & 38.9 \% & \\ \text { ER-Pos } & \text { Neu Neg } & 953 & 25.0 \% & <0.001 & 33.6 \% & 0.035 \\ & \text { Neu Pos } & 151 & 50.3 \% & & 42.4 \% & \\ \text { ER-Pos } & \text { Neu Neg } & 199 & 31.7 \% & 0.009 & 35.2 \% & 0.869 \\ \text { PR-Neg } & & & & & & \\ & \text { Neu Pos } & 53 & 50.9 \% & & 34.0 \% & \\ \text { ER-Pos } & \text { Neu Neg } & 754 & 23.2 \% & <0.001 & 33.3 \% & 0.007 \\ \text { PR-Pos } & & & & & & \\ & \text { Neu Pos } & 98 & 50.0 \% & & 46.9 \% & \end{array}$

Conclusion: We observed that only breast cancers positive for ER and PR may carry an elevated risk of nodal involvement if HER$2 /$ neu is expressed. This finding suggests that co-expression of both steroid hormone receptors and HER-2/neu represents a more aggressive breast cancer subtype. Our hypothesis that oestrogens more efficiently lead to regional tumour progression if the progesterone receptor is coexpressed with HER-2/neu warrants further research.

\section{2}

$\beta 1$ integrin expression is prognostic for overall and diseasefree survival in breast cancer.

Yao ES, Lee B, Chen YY, Moore DH, Chew K, Park CC. University of California, San Francisco, CA

Background: Cell-extracellular matrix (ECM) interactions are critical in maintaining normal tissue architecture and function. $\beta 1$ integrins are a major class of molecules that mediate cell-ECM interactions, and are aberrantly expressed in breast cancer.

Purpose: To investigate the role of $\beta 1$ integrin expression and its primary ligands in breast cancer prognosis.

Methods: Tumor samples from the UCSF Breast Oncology Program Tissue Bank were used to assemble Tissue MicroArray (TMA) blocks by the UCSF Tissue Core. Cores $0.6 \mathrm{~mm}$ in diameter are taken from representative tumor areas of donor paraffin blocks and then inserted into the TMA block utilizing a Beecher Instruments Tissue Arrayer. After obtaining approval from the UCSF Committee on Human Research, three separate TMA blocks were used for the present study. Clinical data was available for all 141 evaluable samples used in this study, which comprised the study population. The median age of the population was 57 years (28-86), and median follow-up time was 8.4 years. Clinical characteristics evaluated include stage, tumor size, nodes positive, grade, estrogen and progesterone receptor status and treatment (chemotherapy, radiotherapy, hormone therapy). $\beta 1$ integrin expression was determined by immunohistochemical staining. Intensity (scored 0-3) and percentage of cells positive were scored for each. In addition, extracellular fibronectin expression was detected by immunohistochemical staining. Univariate and multivariate analysis for overall survival and disease-free survival were analyzed for each variable.

Results: $\beta 1$ integrin intensity was significantly associated with decreased overall survival $(\mathrm{p}=0.03)$ and with decreased diseasefree survival $(p=0.05)$. $\beta 1$ integrin intensity was significantly correlated with extracellular fibronectin expression (Kendall's tau $\mathrm{b}=0.19, \mathrm{p}=0.03$ ). In a multivariate Cox proportional hazards model, age, number of positive nodes and $\beta 1$ integrin intensity score were significant predictors for overall survival (Table 1). $\beta 1$ integrin was also a jointly significant predictor, with TNM stage, for diseasefree survival (Hazard Ratio for $\beta 1$ intensity score 3 vs. lower scores $=2.07, \mathrm{p}=0.008$ ).

Conclusions: $\beta 1$ integrin intensity score was an independent, significant predictor of decreased overall and disease-free survival in patients with breast cancer. $\beta 1$ integrin expression was correlated with fibronectin expression in a subset of patients.

Table 1. Multivariate Cox Proportional Hazards Model

$\begin{array}{lll}\text { Factor } & \text { Hazard Ratio } & \text { p-value } \\ \text { Age } & 1.03 & 0.015 \\ \text { Positive Nodes } & 2.38 & <0.001 \\ \beta 1 \text { integrin intensity (score 3 vs. <3) } & 1.49 & 0.004\end{array}$

\section{3}

CSF1 expression signature identifies a subset of breast carcinomas and influences outcome.

West RB, Horlings H, Nuyten DSA, Subramanian S, Zhu SX, Miller $M$, Rubin BP, Nielsen TO, Gilks CB. Huntsman DG, Tibshirani R, van de Vijver $M$, van de Rijn M. Stanford University Medical Center, Stanford, CA; Netherlands Cancer Institute, Amsterdam, Netherlands; Vancouver General Hospital, Vancouver, BC, Canada

Background: We have previously shown that two different types of soft tissue tumors, solitary fibrous tumors (SFT) and desmoid type fibromatosis (DTF), are representative of different populations of fibroblastic cells in normal connective tissue and that expression of gene sets from such tumors can distinguish stromal gene expression patterns in breast carcinomas that correlate with a difference in clinical outcome (PLOS Biology, 2005). We recently identified CSF1 as a fusion partner in the chromosomal translocation found in many tenosynovial giant cell tumors (TGCT).

Materials and Methods: We compared 4 cases each of TGCT, SFT, and DTF on 42000 spot cDNA arrays. The genes specific for TGCT were used to analyze DNA microarray gene expression data set of 295 breast carcinomas with a median follow-up of 7.8 years. Results: We find that the TGCT/CSF1 expression pattern defines a group of breast carcinomas that is distinct from the groups defined by SFT and DTF and that have a poor clinical outcome. Discussion: Our data show that gene sets defined by different soft tissue tumors can be used as a genome-wide search tool to obtain information about gene expression patterns in the microenvironment of breast carcinoma, and that these distinct patterns are associated with different clinical behavior.

\section{4}

\section{Confirmation of an ER negative PR positive phenotype by} quantitative PCR.

Bloom KJ. CLARiENT Inc and University of Southern California, Los Angeles, $C A$

The ER negative PR positive phenotype is unusual, occurring in less than $5 \%$ of invasive breast carcinomas. The existence of the phenotype has been questioned with the belief that it is due to a false negative ER assay. It is generally believed that there are two estrogen receptor pathways, one nuclear and one membranous and that when the nuclear pathway is activated by estrogen, synthesis of the progesterone receptor is induced. Tamoxifen is an antagonist to the nuclear pathway and thus one would expect that it should have a reduced benefit in the ER positive PR negative 


\section{S136 Abstracts - Poster Session III}

phenotype, in which the nuclear pathway does not appear to be activated, based on the lack of PR expression. This study was performed to assess the relationship between ER mRNA and PR mRNA expression levels determined by quantitative PCR to determine if the ER negative PR positive phenotype exists at the mRNA level.

Material and Methods: Paraffin embedded tissue blocks from 247 breast cancers were examined. A single 8uM section of the paraffin block was deparaffinized and the tumor removed by macrodissection. RNA was extracted using a silica based extraction method (Pico-pure, Arcturus CA), and a single round of linear amplification performed (RiboAmp, Arcturus, CA). Relative levels of RNA expression for ER and PR were obtained using quantitative $\mathrm{PCR}$, using B-actin as a reference.

Results: One hundred fourteen breast cancers showed upregulation of PR, ninety-two of which were significantly upregulated. No tumor showing significant upregulation of PR showed significant downregulation of ER although five (5\%) tumors showed ER downregulation. Overall 9 of the 114 tumors (8\%) demonstrating some level of PR upregulation showed some level of ER downregualtion.

\begin{tabular}{|c|c|c|c|c|c|}
\hline \multicolumn{6}{|c|}{ ER vs PR mRNA expression } \\
\hline & ER Sig & ER & & & ER Sig \\
\hline PR Sig upreg & 20 & 43 & 24 & 5 & 0 \\
\hline PR Upreg & 2 & 9 & 7 & 2 & 2 \\
\hline PR Baseline & 3 & 8 & 5 & 1 & 5 \\
\hline PR Downreg & 4 & 8 & 5 & 3 & 63 \\
\hline PR Sig downreg & 2 & 0 & 0 & 0 & 27 \\
\hline
\end{tabular}

Conclusions: The ER negative PR positive phenotype was identified in approximately $8 \%$ of the examined breast cancers, based on mRNA expression levels. The significance of this phenotype, with respect to response to therapy and prognosis should be more thoroughly evaluated.

\section{5}

Disease free survival (DFS) of breast cancer patients with invasive mucinous/tubular $(\mathrm{M} / \mathrm{T})$ carcinomas vs invasive ductal/lobular $(\mathrm{D} / \mathrm{L})$ carcinomas relative to the grade of the tumor

Chalchal HI, Derakhshan M, Kazmi N, Cheshenckuk S, Tonita J, Salim M. Allan Blair Cancer Centre, Regina, SK, Canada

Background: Several large studies have shown that patients with invasive $\mathrm{M} / \mathrm{T}$ carcinomas of the breast have a good prognosis and higher DFS. However other investigators feel that grade of the tumor could be more important The objective of this study was to compare the outcomes based on histology and grade of tumor between the two groups.

Methodology: This is a retrospective case-control study.A list was generated for all women with breast cancer categorized by morphology from the provincial cancer registry. Inclusion criteria were: diagnosis between 1980 and 2002; all patients diagnosed with M/T (Group 1); and, a random selection of patients diagnosed with $\mathrm{D} / \mathrm{L}$ (Group 2). The random selection in Group 2 was to have resulted in the same number of cases as in Group 1.Grade of the tumor was identified from pathology reports based on scarf-BloomRichardson (SBR) classification.In total, 443 charts were reviewed: invasive $\mathrm{M} / \mathrm{T}$ histology $(\mathrm{N}=241)$ and invasive $\mathrm{D} / \mathrm{L}$ histology $(\mathrm{N}=203)$. A univariate analysis was done to correlate prognostic factors to the outcomes for each group and subsequent to that Kaplan-Meier survival curves were calculated DFS was calculated from time of diagnosis to date of relapse. Deaths were censored (removed from follow up for recurrence after death) with the end date of follow-up being December 31, 2003. The survival curves were in days and the log rank test was used to calculate differences in survival between groups.

Results: Both groups were similar in terms of age, menopausal status, harmone receptor expression, size of the tumor and lymph node status. In patients presenting with $\mathrm{D} / \mathrm{L}$ carcinomas, $44(33.6 \%)$ had well differentiated histology (grade 1), 55 (42.0\%) with moderate to poorly differentiated histology (grade 2 or 3 ) and 32
$(24.4 \%)$ with unknown grades.Relapses were noted in $7.2 \%$ of patients with $\mathrm{M} / \mathrm{T}$ histology as compared with $25.3 \%$ of cases with $\mathrm{D} / \mathrm{L}$ histology. Relapse was less common in the M/T group than in the $\mathrm{D} / \mathrm{L}$ group (odds ratio $=0.23 ; 95 \%$ confidence interval $0.12-0.43$, p value $<0.0001)$. Six $(2.4 \%)$ of the 241 patients diagnosed with $\mathrm{M} / \mathrm{T}$ carcinomas died from breast cancer, while 37 of $201(18.4 \%)$ of patients diagnosed with $\mathrm{D} / \mathrm{L}$ carcinomas died from breast cancer. Patients diagnosed with M/T carcinomas had a better disease-free survival rate when compared to patients with well and moderately differentiated D/L carcinomas. After 10years of follow-up, $9.6 \%$ of patients diagnosed with M/T carcinomas had relapsed as compared with $44.8 \%$ of patients with well differentiated D/L carcinomas. Patients with moderately or poorly differentiated $\mathrm{D} / \mathrm{L}$ carcinomas had a relapse rate of $40.7 \%$ at 10-years as compared with patients diagnosed with $\mathrm{M} / \mathrm{T}$ carcinomas. These differences were highly significant $(\mathrm{p}<0.0001)$. Conclusions: This study suggests that patients diagnosed with M/T carcinomas have a better DFS compared to D/L histology and grade of the tumor has no impact on the outcome.

\section{6}

Identifying univariable and multivariable correlates of HER2 amplification.

Crowe JP, Rybicki LA, Patrick RJ, Budd GT, Tubbs R, Hicks D. Cleveland Clinic Foundation, Cleveland, $\mathrm{OH}$

Introduction: The purpose of this study was to identify correlates of human epidermal growth factor (HER2) amplification.

Methods: Data were collected prospectively in our institutional review board approved patient registry for patients diagnosed with infiltrating ductal carcinoma (IDC). HER2 for all tumors was measured using fluorescence in-situ hybridization. Logistic regression analysis was used to identify multivariable correlates of HER2 amplification. A stepwise selection procedure was used; $\mathrm{P}<0.10$ was required to allow variables into the model, while $\mathrm{P}<0.05$ was required to retain a variable in the final model. Odds-ratios were adjusted for all other variables in the model. Variables analyzed included race, age at diagnosis, hormone receptor status, TNM stage, presence of angiolymphatic invasion, Scarff-BloomRichardson (SBR) grade, type of associated ductal carcinoma insitu (DCIS), if any, and percent DCIS.

Results: Data were available for 1083 patients. Univariable analysis of clinical correlates of HER2 amplification included decreasing age at diagnosis, hormone receptor negative tumors, increasing TNM stage, the presence of angiolymphatic invasion, increasing SBR, the presence of DCIS (particularly comedo), and increasing percentage of DCIS. However, the final multivariable correlates of HER2 amplification, based on 796 non-amplified tumors and 192 amplified, included only age at diagnosis, SBR, and type of DCIS

Multivariable correlates of HER2 Amplification

\begin{tabular}{|c|c|c|c|}
\hline & OR & $95 \% \mathrm{CI}$ & P-Value \\
\hline Age at Diagnosis & & & \\
\hline $\begin{array}{l}\text { Per 10-year increase } \\
\text { Scarff-Bloom-Richardson }\end{array}$ & 0.88 & $0.77-0.99$ & 0.039 \\
\hline $\begin{array}{l}\text { Per 1-point increase } \\
\text { Type DCIS }\end{array}$ & 2.34 & $1.80-3.05$ & $<0.001$ \\
\hline None/Not Comedo & 0.78 & $0.50-1.22$ & 0.28 \\
\hline Comedo/Not Comedo & 2.32 & $1.36-3.94$ & 0.002 \\
\hline Comedo blend/Not Comedo & 1.70 & $1.09-2.64$ & 0.019 \\
\hline
\end{tabular}

Conclusion: Multivariable correlates of HER2 amplification are: 1) decreasing age at diagnosis; 2) increasing SBR grade; and 3) IDC with comedo DCIS. 


\section{7}

Hepsin expression is inversely correlated with patient prognosis in human breast cancer.

Parr C, Watkins G, Jiang WG. Wales College of Medicine, Cardiff University, Cardiff, United Kingdom

Background: Hepsin belongs to the type II transmembrane serine protease (TTSP) family of proteolytic enzymes. The importance of hepsin in vivo is presently unclear; however, studies suggest that this factor may play a role in cancer invasion and metastasis. Our study examined the profile of hepsin in human breast cancer and assessed hepsin expression in relation to patient clinical parameters.

Material and Methods: Hepsin expression and distribution was assessed qualitatively through RT-PCR and Western Blotting (on a range of 25 normal and cancer cell lines); immuno-histochemically (patient samples of both normal and breast cancer tissue); and quantitatively using real-time quantitative PCR on a cohort of human breast cancer tissue $(\mathrm{n}=118)$ and background breast tissue $(\mathrm{n}=31)$.

Results: We demonstrate that hepsin expression was dramatically reduced in the breast cancer tissues compared to the normal breast tissues. Quantitative and IHC analysis of paired patient samples (normal vs. tumour) revealed a significant decrease $(\mathrm{p}=0.023)$ in hepsin expression in breast cancer tissues. In addition, examination of cell line RT-PCR data showed that hepsin was mainly expressed in the breast cancer cells of low invasive nature. Importantly, upon assessment of patient survival status, quantitative PCR demonstrated that hepsin expression was significantly decreased $(\mathrm{p}=0.001)$ in patients with an overall poor prognosis $(309 \pm 78.7$ copies/ml), compared to those with a good prognosis $(981 \pm 183$ copies $/ \mathrm{ml}$ ). Upon Q-PCR analysis of tumour grade we reveal that reduced levels of hepsin correlate with poorly differentiated breast tumours (grade 1 vs. grade 2 tumours $\mathrm{p}=0.015$; grade $1 \mathrm{vs}$. grade 3 tumours $\mathrm{p}=0.018$ ). Also, hepsin expression was dramatically reduced $(\mathrm{p}=0.041)$ in patients within the TNM-3 classification group (299 \pm 171 copies $/ \mathrm{ml}$ ), compared to the TNM-1 group (815 \pm 165 copies $/ \mathrm{ml})$.

Discussion: This is the first study to examine hepsin in human breast cancer. There are aberrant levels of hepsin in breast cancer tissues, and we report that hepsin displays prognostic value in breast cancer patients. Reduced expression levels of hepsin correlated with an overall poor prognosis for breast cancer patients.

\section{8}

The androgen receptor gene polymorphisms in human breast cancer: short CAG repeats are associated with lymph node involvement.

Betancor E, Rodriguez, FG, Gonzalez A, Cabrera A, Sanchez M, Vega V, Murias A, Bohn U, Limeres M, Pestano J, Diaz-Chico BN, Diaz-Chico JC. ICIC - Instituto Canario de Investigacion del Cancer, Las Palmas de Gran Canaria, Canary Islands, Spain; Hospital Materno-Insular and Hospital Dr Negrin, Servicio Canario de Salud, Las Palmas de Gran Canaria, Canary Islands, Spain; University of Las Palmas de GC, Las Palmas de Gran Canaria, Canary Islands, Spain

The AR gene is located at the Xq11.1-12 locus, and encode for a ligand-dependent transcription factor which is expressed in most of breast cancers (BC). In vitro studies have suggested both inhibitor and stimulator cell growth effects of androgen on BC cell lines, which are mediated by the AR. The AR gene contains a CAG repeat (polyglutamine) length polymorphism, that modulate the AR transcriptional activity. Since there are few studies about the possible role of the AR CAG repeat on $\mathrm{BC}$ progression, here we have genotyped this repeat in the tumor tissue DNA obtained from 317 consecutive $\mathrm{BC}$ specimens, and compared the obtained data with the clinical and pathological characteristics of tumors, and with the clinical outcome of patients. As controls we used DNA from blood of 242 age-matched women enrolled in the CDC study of the Canary Islands ( $>95 \%$ caucassians). The allele frequency of the CAG repeat in controls was similar to other caucassian populations. No significant differences in the allele frequencies were observed between the $\mathrm{BC}$ cases and controls. The CAG repeat was dichotomyzed by using the median of allele frequency, as follow: short (S) (<21 repeats) vs. large (L) (> 21 repeats). The SS-CAG genotype (both short alleles were compared with SL- and LL-CAG genotypes, considered altogether) did not associate with age at diagnosis, tumor size, stage or grade. However, the frequency of the SS-CAG genotype showed a significant trend to increase from negative lymph node $(28 \%)$ to $1-3$ affected nodes $(35 \%)$ to $>3$ affected nodes $(44 \%)(\mathrm{P}=0.03)$. This association was stronger in the group of postmenopausal patients $(\mathrm{P}=0.003)$. Univariate survival analysis revealed that the $\mathrm{CAG}$ polymorphism is not related with disease-free survival or overall survival during a short follow-up period (median: 51 months). In conclusion, our data suggest that short CAG repeat size in the AR gene is associated with lymph node involvement in human breast cancer.

Aknowledgements: This study was sponsored by the Fondo de Investigaciones Sanitarias (FIS-ISCiii-RTICCC C03/10; Government of Spain), and by the Fundacion Canaria de Investigacion y Salud (FUNCIS) and the Direccion General de Universidades (Government of the Canary Islands). Technical assistance of BP Diaz and JF Rivero is gratefully acnowledged.

\section{9}

The distribution of EGFR mRNA expression in 247 breast carcinomas and its relationship to ER mRNA expression. Bloom KJ. CLARiENT Inc and University of Southern California, Los Angeles, $C A$

Expression of epidermal growth factor receptor (EGFR) has been reported to be associated with poor prognosis in breast cancer. Since EGFR is expressed on virtually all epithelial cells, including breast cancer cells, negative expression indicates that the number of receptors present is below the sensitivity of the assay being used. Most prior studies used immunohistochemistry and thus were limited by pre-analytical variables as well as analytical variables such as the antibody used, the detection system and the antigen retrieval method. This study examined EGFR expression by quantitative PCR using beta-actin as the reference gene.

Material and Methods: Paraffin embedded tissue blocks from 247 breast cancers were examined. EGFR mRNA expression was performed as follows. A single 8uM section of the paraffin block was deparaffinized and the tumor removed by macrodissection. RNA was extracted using a silica based extraction method (Picopure, Arcturus CA), and a single round of linear amplification performed (RiboAmp, Arcturus, CA). Relative levels of RNA expression for EGFR and ER were obtained using quantitative PCR, using B-actin as a reference.

Results: EGFR expression levels were binned and the resulting histogram was plotted, (figure 1). The distribution was bimodal with two miniminally over-lapped normally distributed curves, one curve whose mean shows significant over-expression of EGFR mRNA and one curve whose mean shows under-expression of EGFR mRNA. Sixty of 62 tumors showing significant upregulation of EGFR mRNA showed significant downregulation of ER mRNA. However of the 42 tumors showing significant downregulation of EGFR mRNA, 9 showed significant upregulation and 3 showed significant downregulation of ER mRNA, with the remaining tumors tending toward upregualtion of ER mRNA. Of the 97 tumors showing significant downregulation of ER mRNA, 60 showed significant upregulation, 7 showed downlegulation and the remaining tumors tended toward upregulation of EGFR mRNA. Conclusions: With the advent of anti-EGFR therapies a better 


\section{S138 Abstracts - Poster Session III}

understanding of EGFR expression and how it relates to hormonal expression is essential. When EGFR mRNA is significantly upregulated, ER mRNA is almost always significantly downregulated. Further studies should be performed to clarify the interaction of these important pathways.

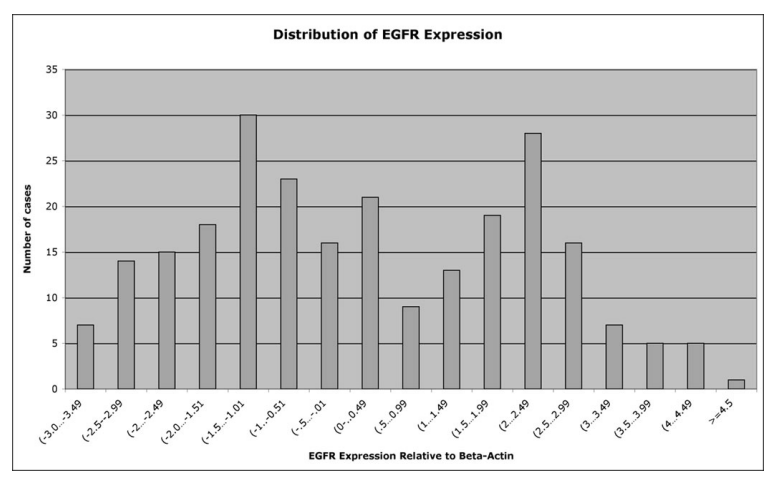

\section{0}

CX chemokine receptor $4(\mathrm{CXCR4})$ membrane staining is an independent prognostic factor in primary breast cancer. Blot E, Laberge-Le-Couteulx S, Jamali H, Guillemet $C$, Duval C, Hellot MF, Pille JY, Picquenot JM, Veyret C. Centre Henri Becquerel, Rouen, France; Faculté de Médecine-Pharmacie, Rouen, France

Background: Staining for CXCR4 was compared with usual clinically relevant prognostic factors for 10-year metastase-free survival. Patients and Methods: CXCR4 membrane staining was studied by immunochemistry in 194 primary breast cancer patients treated in 1991. Comparison was performed with age, initial TNM stage, grade and estrogen and progesterone receptors expression.

Results: Significant prognostic factors for 10-year metastase-free survival were CXCR4 membrane staining $(\mathrm{p}<0.0001)$, $\mathrm{T}$ stage $(\mathrm{p}<0.0001)$ and estrogen $(\mathrm{p}=0.03)$ and progesterone $(\mathrm{p}<0.001)$ receptors expression. $\mathrm{N}$ stage $(\mathrm{p}=0.07)$ and grade $(\mathrm{p}=0.052)$ did not reach statistical significance. Relative-risk for metastasis was significant for CXCR4 staining, $\mathrm{T}$ stage and estrogen and progesterone receptors expression.

Relative-risk for 10-year metastase-free survival

$\begin{array}{lll} & \text { Relative-risk } & 95 \% \text { confidence interval } \\ \text { CXCR4 } & 4.3 & 2.5-7.3 \\ \text { T stage } & 3.4 & 1.9-5.8 \\ \text { Estrogen receptors } & 0.5 & 0.3-0.9 \\ \text { Progesterone receptors } & 0.4 & 0.2-0.7\end{array}$

Multivariate Cox regression showed CXCR4 was a prognostic factor independent of $\mathrm{T}$ stage $(\mathrm{p}=0.0004)$ and estrogen $(\mathrm{p}=0.03)$ and progesterone $(\mathrm{p}=0.008)$ receptors expression.

Discussion: In this series, CXCR4 membrane staining is a strong independent prognostic factor in primary breast cancer patients. This result needs further confirmation in other series. Comparison with other new prognosis factors (uPA, PAI-1, microarrays) would be of interest.

\section{1}

Plakoglobin ( $\gamma$-catenin) is a prognostic marker in breast cancer.

Buehler H, Mahnke E, Duvnjak B, Schaller G. Medical Center Marienhospital Herne, Ruhr-Universitaet, Bochum, Germany; Martin-Luther Hospital, Berlin, Germany; Ruhr-Universitaet, Bochum, Germany

Background: Plakoglobin $=\gamma$-catenin is an important protein of cellular adhesion structures in epithelia. It is part of the desmosomal plaque as of the adherens junctions as well. Together, both structures account for more than $90 \%$ of total cellular adhesion. During the metastatic process cell-cell adhesion has to be broken before tumor cells are able to disseminate. Since plakoglobin is part of both important adhesive structures it might be a central candidate for downregulation during dedifferentiation and malignant transformation. In a retrospective study we have determined the plakoglobin expression in breast carcinomas and correlated it with the clinical outcome of the patients. In addition, several human breast cancer cell lines were tested for plakoglobin expression and for invasiveness in Boyden chamber experiments

Material and Methods: 86 specimens were tested for plakoglobin by means of immunohistochemistry and the expression scored separately for membrane, cytosol, and nucleus. Mean plakoglobin values were evaluated for the two groups of surviving and deceased tumor patients. The plakoglobin expression of 6 human breast cancer cell lines was determined by Western blotting and correlated with invasiveness in matrigel coated filter inserts (Boyden chambers).

Results: In a 15 years follow-up the ratio surviving/deceased was 2.2 for membrane, 1.6 for nucleus, 1.2 for cytosol, and 1.4 for overall staining. All patients with an intense staining of either membrane or nucleus are still alive, in contrast to about $40 \%$ survival for low membrane or low nuclear staining and $12 \%$ survival for low both. Similar results were obtained in vitro: the higher the expression of plakoglobin the lower the invasiveness of a cell line and vice versa.

Discussion: In conclusion, we found a close correlation of conserved plakoglobin expression in the tumor with survival over 15 years, in particular for membraneous and nuclear staining. In the nucleus plakoglobin might compete with $\beta$-catenin which acts as proliferative transcription factor in some oncogenic pathways. In cultured cancer cells we found a similar "benign" effect of plakoglobin on the aggressiveness of the tumor cell. Transfection experiments with a low expressing invasive cell line will proof the principle.

\section{2}

C-KIT expression in ductal carcinoma in situ of the breast: co-expression with HER-2/neu.

Diallo R, Rody A, Schaefer KL, Geddert H, Shroyer KR, Gabbert HE, Kaufmann M, Jackisch C, Poremba C. Institute of Pathology, University of Duesseldorf, Duesseldorf, Germany; University Hospital of Frankfurt, Frankfurt, Germany; University of Colorado at Denver and Health Sciences Center, Denver, CO; University Hospital of Marburg, Marburg, Germany

The proto-oncogene c-KIT (CD 117) is highly expressed in normal breast epithelium and is decreased in invasive breast cancer. In this study, we analyzed the protein expression and the mutational status of c-KIT in ductal carcinoma in situ (DCIS) of the breast and correlated these findings with nuclear grade, architectural pattern and with the expression of HER-2, estrogen receptoralpha (ER) and progesterone receptor (PR).

C-KIT, HER-2, ER and PR expression were analyzed immunohistochemically in 106 cases of paraffin-embedded DCIS (85 pure DCIS and 21 DCIS with concurrent carcinoma). Direct sequencing of exons 9 and 11 of the c-KIT gene was performed to analyze the hot spot mutational regions in representative cases. C-KIT expression was found in $55(52.8 \%)$ of all DCIS, correlating with high nuclear grade $(\mathrm{p}<0.0001)$, comedonecrosis $(\mathrm{p}<0.0001)$ and solid growth pattern $(\mathrm{p}=0.001)$. Furthermore, c-KIT expression was strongly associated with HER-2 positivity $(\mathrm{p}<0001)$ and was significantly lower in ER- or PR-positive cases $(p=0.001$ and $\mathrm{p}=0.006$, respectively). C-KIT expression alone or coexpression with Her-2/neu in pure DCIS did not differ significantly from DCIS with invasive component $(\mathrm{p}=0.09)$. Mutational analysis in 6 c-KIT-positive DCIS revealed no activating mutations in exons 9 or 11 .

Our findings suggest that co-expression of c-KIT and HER-2/neu may define a subgroup of poorly differentiated DCIS with decreased steroid hormone receptor expression. The meaning of c-KIT- and HER-2/neu- co- expression in this subgroup of DCIS and the 
potential relevance to progression to invasive cancer should be evaluated further.

\section{3}

Sprouty 4 expression is decreased in node-negative breast cancer and intimately related to expression of cell cycle proteins.

Faratian D, Halliday G, Kerr GR, Thomas JS, Cameron DA Harrison DJ. University of Edinburgh, Edinburgh, Scotland, United Kingdom; Weastern General Hospital, Edinburgh, Scotland, United Kingdom

Background: Sprouty proteins are endogenous inhibitors of Ras/ mitogen-activated protein kinase (Ras/MAPK) signalling, deregulation of which may be expected to exert profound effects on cell proliferation and cancer development. Using in silico interrogation of publicly available gene expression microarray data, we identified Sprouty 4 as overexpressed in populations of 'poor prognosis' breast cancers. The purpose of this study was to (i) verify the expression and prognostic significance of Sprouty 4 and other putative prognostic markers in a population of nodenegative patients with poor and good outcomes, treated with local therapy alone and (ii) investigate the association of Sprouty 4 expression with $\mathrm{G} 1 / \mathrm{S}$ phase checkpoint proteins.

Materials and Methods: 436 patients with pathologically nodenegative breast cancer were treated in Edinburgh between 19691978 without the use of adjuvant systemic therapy. We identified 56 patients who died of their breast cancer within 5 years of treatment ('poor prognosis group') and 119 who survived more than 25 years ('good prognosis group'). The histopathology of the cases was reviewed by two pathologists (DF and JST). Sprouty 4 (Ab7513, Abcam) expression was examined in full sections of normal breast and breast carcinomas by immunohistochemistry (IHC). Tissue microarrays were constructed using triplicate cores from 96 available cases, and Sprouty 4, ER, cyclin D, cyclin E, p21, p27, p53, HER2 and Ki67 status were assessed by IHC.

Results: Sprouty 4 IHC showed strong granular staining of luminal epithelial cells of normal breast ducts, and variable intensity of staining in the epithelial component of breast carcinomas. IHC was interpretable in $65 / 96$ tissue microarray cores. Sprouty 4 showed decreased expression (zero to moderate staining) in 28/65 (43\%) of cases. High cyclin E and Ki67 expression were associated with poor prognosis by univariate analysis (Chi-squared test, $\mathrm{p}<0.05$ ), whilst only size and high cyclin $\mathrm{E}$ expression were associated with poor prognosis in a multivariate analysis (logistic regression, $\mathrm{p}<0.05$ ). Low Sprouty 4 expression was associated with low p21, low p27, high cyclin E and low cyclin D expression (Chi-squared test, $\mathrm{p}<0.05$ ). In addition, low Sprouty 4 expression was associated with negative/low ER status.

Discussion: Here we have shown, for the first time, that Sprouty 4 is constitutively expressed in normal breast ducts and, contrary to gene expression data, Sprouty 4 shows decreased protein expression in a population of breast carcinomas. Cyclin $\mathrm{E}$ is confirmed as an independent prognostic factor in breast cancer. Decreased expression of Sprouty 4 is associated with a pattern of expression of cell cycle proteins regulating S-phase entry and progression, confirming a functional role in regulating cellular proliferation in breast cancer.

\section{4}

p53 protein accumulation and presence of visceral metastasis are independent prognostic factors for survival in patients with metastatic inflammatory breast carcinoma. Sezgin C, Gokmen E. Ege University School of Medicine, Bornova, Izmir, Turkey

Purpose: Inflammatory breast cancer (IBC) is known as the most aggressive form of breast cancer. Majority of patients with nonmetastatic IBC relapse despite therapy with a curative intent. It is not entirely clear whether the established prognostic markers in
non-IBC have significance in IBC as well. The aim of this study was to determine the markers of prognosis in metastatic IBC. Methods: The prognostic significance of clinical characteristics and molecular markers of the primary tumor was assessed in the 45 patients with IBC who had developed distant metastasis. ER, PR, HER2 neu, Ki67 and p53 expressions by immunohistochemistry, histological and nuclear grade, number of axillary lymph nodes involved ( $<4$ vs $\geq 4$ ), setting of chemotherapy (neoadjuvant vs adjuvant), taxane use in the adjuvant-neoadjuvant setting (taxane vs non taxane containing regimes), site of recurrence (visceral vs non-visceral) and performance status (0-1 vs 2-3) were correlated with the disease free survival (DFS), and overall survival (OS).

Results: The median follow up duration from the time of primary disease diagnosis is 78 months. The median OS measured from the diagnosis of metastatic disease is 23 months. In the univariate analysis, p53 accumulation, the presence of visceral metastasis and low performance status were predictive of poor survival (p:0.01, 0.003, and 0.02, respectively). In the multivariate analysis, accumulation of $\mathrm{p} 53$ protein and the presence of visceral metastasis were found to correlate with OS. The median OS for the 22 patients who had p53 negative tumors was 43 months. In contrast, the OS for the 23 patients with p53 positive disease was only 17 months (p:0.01). The OS for patients with visceral disease was 17 months vs 43 months for those without visceral organ involvement (p:0.003). None of the parameters analyzed was predictive of DFS.

Conclusions: In metastatic IBC, accumulation of p53 protein and presence of visceral metastasis are independent prognostic factors for OS. Survival of patients with a negative p53 immunohistochemistry stainingappears similar to those reported for non-IBC patients in the literature. Other prognostic factors established in non-IBC did not have independent significance in IBC in this study.

\section{5}

Comparison between the 5th and 6th American Joint Committee on Cancer(AJCC) staging system in 1,275 breast cancer patients.

Kang SH, Kim BS, Lee SJ, Kwun KB. Yeungnam University Medical Center, Daegu, Korea

Purpose: Since the publication of the 5th edition of the AJCC cancer staging manual in 1997 (old stage), significant developments have occurred in the field of breast cancer diagnosis and management; therefore, it was revised at 2002 (new stage). There are few reports comparing the changes in prognosis in relation to the changes in the staging system. The aims of this study were to evaluate the changes in patient distribution and prognosis according to the changes in the staging system and to elucidate the efficacy of new staging system.

Methods: The records of 1,275 patients who underwent an operation for breast cancer at Yeung-Nam University Hospital between 1987 and 2003 were reviewed. The pathological stage was assigned retrospectively according to the 5th and the 6th AJCC staging criteria. The patient distributions by stage, nodal status, 5-year relapse free survival (RFSR) and overall survival rates (OSR) were retrospectively compared.

Results: Five hundred and five of 616 stage II patients according to the 1997 classification system were also stage II according to the 6th AJCC staging system. The number of patients with stages IIA and IIB decreased from 370 and 246 (old stage) to 342 and 165 (new stage), respectively. Conversely, the number of patients with stage III increased from 158 (old stage) to 271 (new stage). The five-year RFSR for patients with stage I, IIA, IIB, and IIIA were $94.2,87.1,74.3$, and $48.8 \%$ according to the old stage $(\mathrm{p}<0.0001)$, and $95.2,87.8,81.7$, and $66.8 \%$, respectively, according to the new stage $(\mathrm{p}<0.0001)$. The five-year OSR for patients with stage I, IIA, IIB, and IIIA were 98.7, 94.3, 86.1, and $63.5 \%$ according to the old stage $(\mathrm{p}<0.0001)$, and $98.7,95.7$, 


\section{S140 Abstracts - Poster Session III}

96.5 , and $72.9 \%$, respectively, according to the new stage $(\mathrm{p}<0.0001)$. The RFSR and OSR for stage IIIC were 42.0 and $59.5 \%$, respectively. There was significant difference in the fiveyear OSR for stages IIB and IIIA $(p=0.0308$ and $p=0.0132$, respectively).

Conclusions: In our study, the 6th AJCC staging system shifted poorer prognostic cohort of each stage toward a higher stage compared to the 1997 version. Therefore, the survival rate for any one stage assigned by 2002 staging system was also improved. In conclusion, it is imperative that careful attention is devoted to this effect so that accurate conclusions regarding the efficacy of new treatment can be drawn.

\section{6}

Pretreatment plasma leptin and leptin receptor levels in metastatic breast cancer.

Leitzel K, Demers L, Ali SM, Evans DB, Lipton A. Penn Statel Hershey Medical Center, Hershey, PA; Lebanon VA Medical Center, Lebanon, PA; Novartis Pharma AG, Basel, Switzerland

Background: Leptin is a $16 \mathrm{kD}$ protein produced by adipocytes, plays a key role in weight regulation, and leptin plasma levels are increased with increasing weight. Recently serum leptin has been implicated as a regulator of bone mass. The leptin receptor (OB$\mathrm{R}$ ) is a 150-190 kD protein that binds leptin and is present in many cell types including brain, placenta, pancreas, liver, lung, and heart. Over-expression of leptin and the leptin receptor by IHC has been reported in primary breast cancer but not in normal mammary epithelial cells.

Materials and Methods: Pretreatment plasma leptin and leptin receptor were assayed in 136 patients with metastatic breast cancer enrolled in a phase III $2^{\text {nd }}$-line hormone therapy trial using the leptin and leptin receptor ELISAs from Diagnostic Systems Laboratories, Webster TX. Leptin and leptin receptor plasma levels were correlated with patient response to $2^{\text {nd }}-$ line hormone therapy.

Results: Median plasma leptin levels were $40 \mathrm{ng} / \mathrm{ml}$ (range 1.3 $330 \mathrm{ng} / \mathrm{ml}$ ), and median plasma leptin receptor levels were 30.9 $\mathrm{ng} / \mathrm{ml}$ (range $2.6-67.2 \mathrm{ng} / \mathrm{ml}$ ). The median leptin and leptin receptor levels were used as cutoff points for statistical analysis. In univariate analysis using these cutoffs, pretreatment plasma leptin levels did not significantly predict patient response to $2^{\text {nd }}$ line hormone therapy [Clinical benefit rate (CBR) or time to progression (TTP)], or overall survival. Patients with elevated plasma leptin receptor levels had lower CBR (Odds ratio 0.4, pvalue $=0.012$ ), but had no effect on TTP. Patients with elevated plasma leptin receptor levels had a significantly reduced survival (Hazard Ratio 1.9, $\mathrm{p}=.006$ ). When examined in reference to the presence of bone metastases, plasma leptin and leptin receptor levels did not significantly differ between these subgroups. Patients with elevated serum HER-2/neu levels had significantly higher leptin receptor plasma levels $(35.6 \mathrm{ng} / \mathrm{ml}$ vs. $29.2 \mathrm{ng} / \mathrm{ml})(\mathrm{p}=0.004)$, whereas plasma leptin levels were not different in patients with elevated vs. normal serum HER-2/neu levels. In multivariate analysis, plasma leptin receptor level remained a significant prognostic factor when serum HER-2/neu level was included in the analysis.Conclusion: Elevated pretreatment plasma leptin receptor predicted decreased CBR and reduced overall survival. Plasma leptin receptor levels deserve further study in metastatic breast cancer.

\section{7}

Identification of a mechanistically-defined panel of mRNA markers associated with long-term prognosis of nodenegative breast cancer.

Macina RA, Ghosh S, Doval DC, Patole K, Sridhar T, Saxena R, Segal MR, McNeil M, Vartanian S. diaDexus, Inc, South San Francisco, CA; Triesta Sciences, Bangalore, India; Rajiv Gandhi Cancer Institute and Research Center, New Delhi, India; University of California, San Francisco, $C A$

Background: Rational interrogation of the primary tumor phenotype has the potential to provide clinically useful information about its metastatic potential and the long-term clinical outcome of primary breast cancer. Previous studies have reported the utility of different RNA expression markers for this purpose. Using comprehensive mining of cDNA databases and subsequent microarray analysis, we identified a minimal subset of differentially expressed genes coding for proteins involved in different biological processes in breast cancer. To evaluate their prognostic value, we selected genes involved in cell adhesion, cell proliferation, metastasis, chemotaxis, DNA repair, immune response and apoptosis.

Materials and Methods: We performed quantitative reverse transcriptase PCR (Q-PCR) on archived formalin fixed paraffinembedded (FFPE) primary cancer tissues. We studied a total of 37 breast cancer patients, who were lymph node (LN) negative and estrogen receptor (ER) positive with a median follow up of 70 months. Thirty patients had not presented with any local recurrence or distant metastasis (disease free group, DF), while 7 patients presented with either local recurrence or distant metastasis (progressive disease group, PD). Gene expression of 12 cancer genes and 3 endogenous controls were performed by Q-PCR to identify which genes were predictive of long-term outcome.

Results: The Q-PCR expression data was analyzed by assessing differential expression (DE) between DF and PD subjects, as well as associating expression with survival. Calibration was based on the average of 3 endogenous control genes. DE was measured using two-sample t-tests. In preliminary results comparing the DF subjects to the PD subjects, significant differences are obtained for the gene encoding the chemokine receptor CCR $8(p=0.026)$ involved in chemotaxis and cell adhesion, and the gene encoding CYR61 $(p=0.04)$ involved in cell growth, proliferation and adhesion, with a borderline result for a gene involved in cell adhesion $(p=0.057)$

Discussion: All 3 genes with differential expression between the two cohorts are involved in the process of metastasis and are good candidates to predict differential outcomes. Higher levels of all three genes were found in the PD cohort. We are currently extending this analysis including additional cancer genes and endogenous controls, more patients with PD, and use of discrimination and survival analysis.

\section{8}

Cyclin E2 mRNA expression and metastasis-free survival in untreated node-negative breast cancer patients.

Schmidt M, Glawatz C, Gehrmann MC, Puhl A, von Toerne C, Steiner E, Boehm D, Koelbl H. University of Mainz, Medical School, Mainz, Germany; Bayer HealthCare AG, Levekusen, Germany; Bayer Technology Services, Leverkusen, Germany

Background: high levels of low molecular cyclin E protein have been proposed as a prognostic factor in early breast cancer Furthermore, cyclin E2 RNA levels (CCNE2) were part of two different gene expression signatures identifying node-negative patients with low risk of recurrence. We tried to corroborate the prognostic impact of CCNE2 in untreated node-negative breast cancer.

Material and Methods: we analyzed 212 fresh-frozen breast tumors. The tumors had been removed from node negative patients not treated with adjuvant systemic therapy. RNA was extracted from the tissue, amplified, biotin labeled and hybridized to HG 
U133A Affymetrix arrays. Signal intensities for CCNE2 mRNA were computed by MAS 5.0 software. The association between CCNE2 mRNA and development of metastasis was analyzed in the entire patient population as well as in subgroups stratified according to the estrogen receptor-a (ESR 1) status using univariate and multivariate Cox regression analysis.

Results: univariate Cox regression analysis showed that both CCNE2 and histological grade were significantly associated with the development of distant metastasis $(p=0.0078$ and $p=3.3 \mathrm{e}-$ $05)$. However, in multivariate analysis only histological grade remained significant $(\mathrm{p}=0.0019)$. When tumors were stratified according to estrogen receptor status, CCNE2 levels were higher in ESR1 negative $(\mathrm{n}=35)$ than in ESR1 positive $(\mathrm{n}=177)$ tumors $(p<0.0001)$. However, CCNE2 $(p=0.0069)$ was significantly associated with metastasis-free survival only in the ESR1 positive subgroup. In multivariate analysis only histological grade was independently associated with metastasis-free survival $(\mathrm{p}=0.0037)$. CCNE2 failed to show any prognostic impact in ESR1 negative patients.

Discussion: expression of CCNE2 showed a significant association with metastasis-free survival only in ESR1 positive node-negative breast cancer patients. However, in multivariate analysis only histological grade remained an independent predictor of metastasisfree survival. These results challenge earlier reports of an independent association between Cyclin E and prognosis in breast cancer.

\section{9}

Survivin is a predictor of poor outcome in breast cancer. Hinnis A, Walker RA. University of Leicester, Leicester, United Kingdom

Background: There are well recognised clinico-pathological factors that can determine outcome in breast cancer but there is a therapeutic need for subdividing patients that are within what appear to be good and poor prognostic groups. This study examined the value of cell cycle and apoptotic regulatory proteins in predicting behaviour in a poor prognostic group.

Materials and Methods: The study group comprised 165 cases, all of whom had died of breast cancer, with duration of survival from 12-127 months, median 38 months. 18 had received neoadjuvant chemotherapy, 18 adjuvant chemotherapy, 70 adjuvant chemo- and hormonal therapy, and 59 adjuvant hormonal therapy. $68 \%$ were $\mathrm{T} 2,5 \% \mathrm{~T} 3,745$ were node positive, $75 \%$ grade 3 and $51 \%$ ER positive. Immunohistochemistry was performed for proliferation (MIB1), apoptosis (M30), p53, phosphorylated p53, p21, chK2, bcl-2, bax, Survivin and XIAP. Results: High proliferation, presence of phosphorylated p53, ChK2 and Survivin correlated with grade 3 and lack of ER, whilst low proliferation, presence of p21 and bcl-2 related to better grade and presence of ER. Tumour grade correlated significantly with duration of survival for all treatment groups. Proliferation, phosphorylated p53, bcl-2, ER and Survivin were significantly related to duration of survival. Analysis in a Cox regression model showed grade $(\mathrm{p}=0.001)$ and Survivin $(\mathrm{p}=0.005)$ to be independent prognostic factors. When considered in relation to treatment received the presence of Survivin correlated with a significantly shorter duration of survival for the neoadjuvant group and the adjuvant chemo- and hormonal therapy group. ER related to longer duration of survival for the group receiving adjuvant hormonal treatment.

Discussion: Within a group of patients who have all died from breast cancer better grade, lower proliferation, presence of ER and bcl-2, and lack of Survivin all related to longer duration of survival, and the value of determining ER was demonstrated again. For those patients with shorter survival duration high grade and high proliferation were features along with phosphorylated p53 and Survivin.Of the various markers assessed the apoptosis protein Survivin proved to be an independent predictor of poor outcome, particularly for certain treatment groups, where its role as an inhibitor of apoptosis may be important.

\section{0}

Prognostic value of p53 specific mutations in low-risk HER2/neu negative primary breast cancers.

Wu L, Robin HS, Gallarda JL, Eberhardt JS, Muller WD, Sadeghi $S$, Clark RC. Roche Molecular Systems, Pleasanton, CA; Sharp Memorial Hospital, San Diego, CA; DecisionQ, Washington, DC Background: Prognostic factors are required for the evaluation of patients with small tumors and node negative disease. These patients have a good prognosis, although $30 \%$ will experience recurrent disease. In breast cancers with HER-2/neu amplification, p53 mutations are associated with poor survival. However, in the absence of HER-2 over expression, such mutations were thought to be of limited prognostic value. We examined the effect of specific p53 mutations on Stage I breast cancers that were HER-2 negative.

Patients and methods: The analysis of the p53 gene was performed using GeneChip technology. We examined 66 archival breast specimens derived from formalin fixed paraffin embedded tissue from patients with stage I tumors that were HER-2 negative by immunohistochemistry and fluorescent in-situ hybridization. The median follow-up for patients was 3.5 years. We used a Bayesian probabilistic model to identify prognostic factors that contribute to overall outcomes.

Results: Amplification and detection were achieved in 55 samples and specific p53 point mutations were detected in $36.4 \%$ of these samples. Using a Bayesian classifier, patient outcome was conditionally dependent on Estrogen/Progesterone receptor status and mutations on Exon 6. The model was validated using randomized train-and-test cross validation, and had a mean area under the curve for outcome of $63.2 \%$ and a median area under the curve of $63.5 \%$. P53 gene mutation on Exon 6 was an independent prognostic marker of death. In the overall population, a confirmed mutation increases the probability of recurrence and death from $33.0 \%$ to $52.2 \%$. Further, in a population with negative Estrogen/ Progesterone Receptor status, the presence of a mutation increases probability of death from $31.2 \%$ to $63.2 \%$.

Conclusions: Mutations of the p53 gene are the most common genetic alterations identified in breast cancers and these mutations are often associated with poor prognosis and resistance to chemotherapy and radiation. In our population, the presence of a p53 mutation in Exon 6 indicates a relative risk of death of 1.6 times the overall reference population and 2.3 times the population with a confirmed wild type Exon 6, known to be a critical site for p53 functionality. These results are preliminary and based upon a small sample size, therefore further research is necessary to determine the prognostic value of specific P53 gene mutations in Stage I and HER-2 negative breast cancer patients who may benefit from adjuvant chemotherapy.

\section{1}

Prognostic and predictive value of CK-19 mRNA-positive cells detected by real time RT-PCR in the peripheral blood of patients with axillary lymph node-negative breast cancer receiving adjuvant chemotherapy.

Xenidis N, Perraki M, Pallis A, Kalmanti L, Stathopoulou A, Lianidou E, Mavroudis D, Georgoulias V. University General Hospital of Heraklion, Heraklion, Greece; School of Medicine, University of Crete, Heraklion, Greece; University of Athens, Athens, Greece

Purpose: To investigate the predictive and prognostic value of occult CK-19 mRNA-positive cells in the peripheral blood of axillary lymph node-negative breast cancer patients. Patients and Methods: Peripheral blood was obtained from 167 patients with stage I and II (N0 by both histologic and immunohistochemical analysis) breast cancer after primary surgery and before the initiation of any systemic adjuvant therapy, and was analyzed for the presence of CK-19 mRNA-positive cells using a real time RTPCR assay. The association with known prognostic factors and 


\section{S142 Abstracts - Poster Session III}

the effect of CK-19 mRNA-positive cells on patients' prognosis was investigated. Results: CK-19 mRNA-positive cells were detected in the blood of $36(21.6 \%)$ of the 167 patients who had no axillary lymph node involvement by immunohistochemistry using anti-cytokeratin monoclonal antibodies. There was no correlation between the detection of CK-19 mRNA-positive cells in the peripheral blood and the different known pathologic and clinical prognostic factors; only overexpression of HER2 receptor (score $2+/ 3+$ ) on the tumor cells was associated with a higher incidence of CK-19 mRNA-positive cell detection in the blood ( $25 \%$ vs $12.8 \%$ for CK-19 mRNA-positive and CK-19 mRNAnegative, respectively; $\mathrm{p}=0.033$ ). Multivariate analysis revealed that the detection of CK-19 mRNA-positive cells in the peripheral blood was an independent predictive and prognostic factor for both DFI $(\mathrm{p}<0.00001)$ and overall survival $(\mathrm{p}=0.008)$. In addition, adjuvant chemotherapy combining sequential docetaxel followed by epirubicin-cyclophosphamide was also an independent predictive factor for DFI $(p=0.03)$. Conclusion: Detection of occult CK19 mRNA-positive tumor cells in the peripheral blood is an independent predictive and prognostic factor in node-negative breast cancer patients and may be used to select high risk patients for adjuvant treatment.

\section{2}

Prognostic factors predicting survival of metastatic breast cancer patients: analysis of 591 patients.

Kim SI, Jung SY, Sohn JH, Keum KC, Park BW, Lee KS. Yonsei University Medical College; Yonsei University Medical College, Seoul, Korea

Background: To identify prognostic factors for survival from first recurrence, we have analyzed retrospectively 591 recurrent breast cancer patients.

Material and Methods: Between 1980 and 1999, 2629 patients were diagnosed of breast cancer and followed at a single institution. During follow up, 591 patients experienced distant recurrence of their disease and included in this study. Variables at the time of diagnosis (age, tumor size, axillary lymph node involvement, hormone receptor status in primary tumor) and variables at the time of recurrence (disease free interval, dominant site of metastasis, number of recurrence sites) were examined to determined their relationship with overall survival from first recurrence. Survival data were analyzed using Kaplan-Meier method and Cox proportional hazards model to identify predictive variables. Results: The mean survival from first recurrence was 26.9 months (median; 15.4 months). On the univariate analysis, negative estrogen receptor status of primary tumor $(\mathrm{p}<0.0001)$, visceral recurrence $(\mathrm{p}<0.0001)$, shorter disease free interval $(<2 \mathrm{yrs}$; $\mathrm{p}<0.0001)$, number of metastatic site $(>2 ; \mathrm{p}<0.0001)$ were significantly associated with poor overall survival from first recurrence. On the multivariate analysis, negative estrogen receptor status of primary tumor $(\mathrm{p}<0.0001, \mathrm{RR} ; 1.8615)$, visceral recurrence $(\mathrm{p}=0.0046, \mathrm{RR} ; 1.4401)$, and shorter disease free interval $(\mathrm{p}=0.0001, \mathrm{RR} ; 1.6057)$ remained independently associated with poor overall survival.

Discussion: We confirm that the negative estrogen receptor status of primary tumor, visceral recurrence, and shorter length of disease free interval are independent prognostic factors of survival after first recurrence. Our retrospective review in a large series should help in designing tailored therapeutic strategies for patients with recurrent breast cancer.

\section{3}

Expression of leptin and leptin receptor in breast cancer are associated with aggressive histology, distant recurrence and survival.

Kulkarni SA, Saxena S, Bundy R, Groth J, Watroba N, Edge SE, Ambrosone CA, Geradts J. Roswell Park Cancer Institute/SUNY Buffalo, Buffalo, NY

Background: Leptin (L) is a cytokine-like hormone that was originally identified in adipocytes. At physiologic concentrations, it controls adipocyte mass and energy balance by binding to the leptin receptor (OB-R). At higher concentrations, leptin can stimulate cellular proliferation, invasion and angiogenesis. Recently, leptin and the long form of the leptin receptor were identified in normal and neoplastic breast epithelium. The clinical significance of aberrant leptin and leptin receptor in patients diagnosed with breast cancer is unclear.

Methods: The anti-leptin rabbit (A-20) and anti-leptin receptor (M-18) goat polyclonal antibodies from Santa Cruz Biotechnology were applied in indirect immunohistochemical assays. Following an antigen retrieval step, the antibodies were reacted with 5 um paraffin sections of tissue microarrays (TMAs) prepared at Roswell Park Cancer Institute. These TMAs included $1 \mathrm{~mm}$ cores of 128 evaluable invasive breast carcinomas. For leptin expression, nuclear (LN) and cytoplasmic (LC) staining was evaluated separately. For leptin receptor (LR) expression, only one overall qualitative score $(0,1+, 2+, 3+)$ was applied to each case. For analysis, 0 and +1 were considered low expression and +2 and +3 were considered high expression.The MCF-7 cell line was included as a positive control. The expression levels were correlated with a large number of clinico-pathologic, epidemiologic and biologic data.

Results: There was a positive correlation between LC and OB-R expression. LC levels were significantly higher in PR-negative tumors $(\mathrm{p}=0.01)$ and were also correlated with both local and distant recurrence $(\mathrm{p}=0.003)$. It was not associated with ER or HER2 status, lymphovascular invasion, tumor grade, DNA ploidy or nodal status. LN and OB-R levels did not correlate with any of the patho-biologic variables studied so far.

Conclusions: Overall, our data indicate that LN and LR may not be significantly associated with common clinical and pathologic variables. However, LC may prove to be an important new biomarker for breast cancer recurrence.

\section{4}

Comparison of outcomes of hormone receptor (HR) negative, and HER2 negative (triple negative, TN) to HER2+ breast cancer (BC) patients (pts): impact of HER2 status.

Man MC, Moore D, Chen YY, Rugo HS. University of California San Francisco; University of California San Francisco, San Francisco, $C A$

Background: TN and HER2+ BCs have an aggressive clinical course and poor prognosis. Evaluation of cDNA expression patterns from breast tumor tissue demonstrated that although each group has a distinct genetic profile, both groups had decreased OS compared to pts with HR+, HER2- BCs. Trastuzumab therapy has improved outcomes for pts with HER2+ BC. No studies to date have directly compared characteristics and clinical outcomes between $\mathrm{TN}$ and HER2neu positive pts.

Materials and Methods: A chart review of 102 TN and 59 HER2+ pts treated at UCSF between 2000 to present was performed. All patients had central pathology and receptor status review. Patients with borderline staining for HER2 by IHC had FISH performed for confirmation of HER2 status. Data were collected on demographic and pathologic characteristics, course of treatment, and outcomes including time to first recurrence (DFS), site of first recurrence, and OS. Pts in this database had not received adjuvant trastuzumab. Results: Initial analysis of DFS and OS was performed. Median follow up is 2.7 yrs (range $0.2-17$ ). $14 \%$ of TN vs $2 \%$ of HER2+ 
BC were African American. 64\% of pts in both groups had $\geq$ stage II disease at diagnosis (4\% stage IV). $80 \%$ of pts with TN and $63 \%$ of pts with HER2+ BC received adjuvant chemotherapy. Pts with HER2+ BC had a significantly better DFS than pts with TN disease $(\mathrm{p}=0.03)$. In addition, HER $2+$ disease was associated with a significantly improved OS $(\mathrm{p}=0.001)$. This difference was seen in the first 5 years following diagnosis.

Conclusion: HER2 modulates the outcome of BC with a positive impact on DFS and OS compared to pts with TN BC. Our analysis is ongoing, and data on an additional 100 HER2+ pts will be presented. Further subset analysis will be performed to compare the characteristics and outcomes of HER2+ cancers based on HR status in comparison to the TN population. New treatments are needed for pts with TN BC.

\section{5}

Expression of estrogen receptor and Ki-67 as prognostic factors for locoregional recurrence after breast conserving surgery.

Shin HJ, Han W, Park IA, Hwang KT, Hwang SE, Lee JE, Noh DY. Seoul National University College of Medicine, Seoul, Korea

Purpose and Background: Breast conserving surgery (BCS) is a standard operation for early breast cancer if indicated. Although local-regional recurrence (LRR) was a common serious problem after BCS, factors predicting LRR after BSC are not established yet. A number of studies have reported potential prognostic factors for LRR, such as estrogen receptor (ER), progesterone receptor (PR), nuclear grade, histologic grade, lymph node metastasis, tumor size, and young age with inconclusive result. We tried to identify the value of $\mathrm{Ki}-67$ as a new prognostic factor for LRR after BCS. Patients and Method: The study population consisted of 361 patients who underwent BCS as primary therapy in Seoul National University Hospital from Jan 1995 to Dec 2002. As an adjuvant therpy, radiation therapy was done in all patients with or without systemic therapy. Clinicopathological data were retrospectively reviewed.

Result: LRR was observed in fifteen out of 361 patients $(4.2 \%)$ during follow up period. In a univariate analysis, ER $(p=0.008)$, nuclear grade $(p=0.01)$ and Ki-67 $(p=0.002)$ were significant factors for predicting LRR. However, histologic grade, lymph node metastasis, tumor size $>2 \mathrm{~cm}$, age $>50$, positive resection margin, and extensive intraductal component $(p>0.05)$ were not significant factors. In a multivariate analysis, only high $\mathrm{Ki}-67$ expression was significant for LRR after BCS (HR=3.31; 95\% CI: 1.06-10.34). Conclusion: We suggested resection with wider margins and careful follow up for the patients without ER expression, especially with high Ki-67 expression when considering BCS.

\section{6}

Clinicopathologic characteristics and prognostic factors in 420 metastatic breast cancer patients with central nervous system metastases.

Altundag K, Bondy ML, Kau SW, Broglio K, Rivera E. The University of Texas M.D. Anderson Cancer Center, Houston, TX

Background:Breast cancer is the second most common cause of central nervous system (CNS) metastases. CNS metastases may appear either within the brain parenchyma or along the leptomeninges. As systemic therapy of metastatic breast cancer improves, management of CNS metastases becomes an increasing challenge.

Material-Methods: We retrospectively evaluated clinical datafrom 420 patients who had been diagnosed with breast cancer and CNS metastasis between 1994 and 2004 at M. D. Anderson Cancer Center. The purpose of this analysis is to describe these patients' clinicopathologic characteristics and overall survival. Overall survival (OS) was measured from the date of CNS metastasis to the date of death or last follow-up. OS was estimated by the
Kaplan-Meier method and the $\log$ rank statistic was used to compare groups.

Results: The median age at a diagnosis of breast primary was 45 (range 25 to 77). Pre- and postmenopausal patients were equally distributed. Most patients had invasive ductal histology $(91.2 \%)$, were T2 $(40.1 \%)$, N1 (59.7\%), and grade III (81.4\%) at diagnosis. Forty percent of patients had ER-positive disease, and $34 \%$ were PR-positive disease. HER-2 neu status was recorded for only 248 patients, and among these patients, 39\% had HER-2 neu positive disease. The most common sites of first metastasis were liver, bone, and lung. CNS metastasis was the site of first relapse in 53 patients (12\%). 329 patients had received neoadjuvant treatment (113 pts) and adjuvant chemotherapy (216 patients). Most of these patients $(74.4 \%)$ had received anthracycline-based regimens. $62.8 \%$ of patients had multiple parenchymal metastases, and 111 (26.4\%) had solitary metastasis. 374 patients $(89 \%)$ had only parenchymal metastases (PM), 29 patients had leptomeningeal metastases (LPM), and 17 patients had both PM and LPM. Median time to developing of CNS metastases after primary diagnosis was 31.4 months (range, 0-220 months). Median follow-up was 6 months (range 0.7 months to 95.9 months). Three hundred fifty nine patients died and the overall median survival was 6.8 months. Patients with ER-positive disease tended to have longer overall survival compared to patients with ER negative disease $(\mathrm{p}=0.003)$. Patients under age 50 years tended to have longer overall survival compared to patients over 50 years $(\mathrm{p}=0.047)$. Patients with grade III tumors or with more than 9 positive lymph nodes tended to have shorter median OS.

Conclusion: Prognosis for metastatic breast cancer patients with CNS metastases is poor. More aggressive treatment approach may be considered for patients with favorable prognostic factors such as ER-positive tumors or younger age.

\section{7}

Patterns of care in patients included in the TEAM (tamoxifen and exemestane adjuvant multicentre) trial. Differences among the participating countries.

van de Velde CJ, Jones SE, Seynaeve C, Namer M, Kieback DG, Rea DW, Dirix D, Markopoulos C, Hozumi Y, van Nes JG, Klein Kranenburg WM, Putter H. Leiden University Medical Centre, Leiden, Netherlands; US Oncology, Inc., Dallas, TX; Erasmus Medical Centre, Rotterdam, Netherlands; Centre Antoine Lacassagne, Nice, France; University Hospital Maastricht, Maastricht, Netherlands; Institute of Cancer Studies, The University of Birmingham, Birmingham, United Kingdom; St Augustinus Hospital, Wilrijk, Belgium; Euroclinic of Athens, Athens, Greece; Jichi Medical School, Tochigi, Japan

Introduction: The TEAM trial is evaluating the efficacy and safety of exemestane, alone and in sequence following tamoxifen, in the initial adjuvant treatment of postmenopausal women with early hormone sensitive breast cancer (BC). Within the TEAMpopulation, the patterns of care in the different countries were compared.

Methods: Patients (pts) were enrolled in Belgium, France, Germany, Greece, Ireland, Japan, Netherlands, UK and the USA. Postmenopausal women with hormone sensitive early BC were randomised to five years of exemestane alone or sequential therapy with tamoxifen followed by exemestane. Minor differences do exist among countries with regards to inclusion and exclusion criteria for the TEAM trial.

Results: Among pts randomised between 2001 and 2004 ( $\mathrm{n}=$ 7159), baseline-characteristics are: mean age: 64.5 years (SD 9.0); mean tumour size: $20.7 \mathrm{~mm}$ (SD 12,7); TNM stage: $62 \% \mathrm{~T} 1,34 \%$ $\mathrm{T} 2 ; 3 \% \mathrm{~T} 3 ; 1 \% \mathrm{~T} 4 ; 56 \% \mathrm{~N} 0,41 \% \mathrm{~N} 1,2 \% \mathrm{~N} 2,1 \% \mathrm{~N} 3$. There were large differences in the choice for mastectomy versus breast conserving surgery (BCS): BCS was performed in $81 \%$ of the French pts versus $39 \%$ of the Belgian pts. Generally, BCS was more often performed in T1-tumours, but differences exist: in Greece $54 \%$ of $\mathrm{T} 1$ tumours were treated by BCs versus up to $85 \%$ 


\section{S144 Abstracts-Poster Session III}

in the USA. Ninety-one percent of the pts underwent an axillary dissection, ranging from $80 \%$ in the Netherlands to $100 \%$ in Belgium and Germany. The mean number of examined lymph nodes was 13 (SD 6.3), ranging from 11 in France to 17 in Greece. There are also differences with regards to the use of adjuvant therapy prior to randomisation. Almost all pts (98\%) in the USA received chemotherapy compared to a small amount of the Dutch pts $(27 \%)$. Further analysis of these differences are ongoing. Conclusion: Major differences exist in the patterns of care of primary BC among the different TEAM-countries reflecting large global differences in the usual treatment of early hormone sensitive $\mathrm{BC}$ despite international consensus guidelines (e.g. St Gallen). These differences warrant careful further investigation, and should be taken into account considering the results of international studies.

\section{8}

\section{Benchmarking patterns of utilization among breast cancer} patients.

Schafer JM, Lee M-P, Stout KL, Nydam JE, Swisher JM, Siambekos MT, Suvari WC. Sg2, Evanston, IL

Background: Breast cancer patients utilized 17,919,088 outpatient services nationally in 2002, with the highest volumes being for chemotherapy and visits. Extreme variations in the number and types of services breast cancer patients utilize make benchmarking extremely difficult. Using a novel method of analysis to quantify patterns of utilization, breast cancer patients can be segmented into 2 unique groups: those that are actively receiving treatment (Active Phase) and those that being monitored for recurrences (Surveillance Phase). These 2 patient groups exhibit very different patterns of utilization as measured by types of services used and number of encounters with the health care system.

Methods: Patient-level data representing utilization in physician offices and hospital outpatient settings were compiled from a sampling of US institutions (2003) and analyzed using Symmetry Health Data Systems Episode Treatment Group (ETG) software. ICD-9 and CPT-4 codes were used to group breast cancer patient encounters into 8,216 distinct treatment courses. The Symmetry software defines type of cancer based on ICD-9 codes. CPT-4 codes were grouped into higher-level categories such as chemotherapy, which includes both infusions and injections.

Results: Of the total population of breast cancer patients, $77 \%$ were classified to the surveillance phase, while $23 \%$ were classified to the active phase of treatment in 2003. The average breast cancer patient experiences $17.87 \pm 0.66$ encounters/year and uses 46.74 services/year as an active patient, and $1.8 \pm 0.02$ encounters/ year and 3.17 services/year as a surveillance patient. Breast cancer patient utilization benchmarks

\begin{tabular}{|c|c|c|c|c|}
\hline Breast cancer patie & Surveillance Phase & & Active Phase & \\
\hline \multirow{3}{*}{ Service Type } & Mean \# of & $95 \%$ & Mean \# & $95 \%$ \\
\hline & Services/ & Confidence & of Services/ & Confide \\
\hline & Treatment Course \pm & Interval & Treatment Course & Interval \\
\hline Visit & 1.39 & \pm 0.024 & 8.45 & \pm 0.368 \\
\hline Mammogram & 0.313 & \pm 0.012 & 0.327 & \pm 0.028 \\
\hline Radiation & 0.027 & \pm 0.012 & 8.84 & \pm 0.782 \\
\hline Chemotherapy & 0.198 & \pm 0.034 & 19.46 & \pm 3.400 \\
\hline $\mathrm{CT}$ & 0.108 & \pm 0.016 & 1.97 & \pm 0.164 \\
\hline Ultrasound & 0.108 & \pm 0.010 & 0.407 & \pm 0.048 \\
\hline MRI & 0.027 & \pm 0.006 & 0.467 & \pm 0.088 \\
\hline
\end{tabular}

Breast cancer patients received a ratio of $2.74 \pm 0.384$

chemotherapy infusions or injections for every visit.

Conclusions: There are fewer breast cancer patients $(23 \%)$ in active phase of treatment and they are using a significantly greater number of services/patient compared to the surveillance group which makes up the majority of patients (77\%). The types of services utilized are also significantly different between the 2 groups. These data can be used to provide benchmarking for physician offices or hospitals, and can provide a framework with which to allocate health care resources.

\section{9}

Comorbidity risk model for patients with breast cancer. Braithwaite D, Ozanne E, Moore D, Belkora J, Esserman L. University of California, San Francisco, San Francisco, CA, Institute for Technology Assessment, Massachusetts General Hospital, Boston, MA

Background: While we are improving our ability to tailor estimates of disease risk, there are very few tools that allow these risks to be put in a decision-ready context where the impact of comorbidity is considered. Comorbid conditions are an important context within which breast cancer risk and treatment decisions should be examined. Several comorbidity scoring systems exist including the widely used Charlson Comorbidity Scale [1], but these provide a numerical score do not project 10 year survival and are therefore difficult to interpret.

Methods: We translated the Charlson comorbidity score into a 10 year survival prediction using a Cox proportional hazards model based on a Northern California Cancer Center database of 1200 breast cancer patients who were members of the Kaiser Permanente Medical Care Program [2]. We divided the database into training and validation samples and used the validation sample to measure the precision and accuracy of the predictions.

Results: We have created a breast cancer specific algorithm for projecting individualized 10 year estimates of survival as a function of comorbid conditions. On average, the algorithm predicted survival within $+/-5 \%$. For these data, ten year survival decreased from $70 \%$ for women with the Charlson score 0 to $65 \%$ for women with the score 1 to $41 \%$ with the score 2 and $30 \%$ with the score 3 or higher.

Conclusions: Our tool has potential to standardize the assessment of comorbidities in breast cancer patients. We are currently evaluating our prototype in a clinical setting.

1. Charlson, M., et al., Validation of a combined comorbidity index. J Clin Epidemiol, 1994. 47(11): p. 1245-51.

2. West, D.W., et al., Comorbidity and breast cancer survival: a comparison between black and white women. Ann Epidemiol, 1996. 6(5): p. 413-9.

\section{0}

Decreasing incidence of Paget's disease of the breast among American women.

Chen $C-Y$, Sun L-M, Anderson BO. University of Washington, Seattle, WA; Fred Hutchinson Cancer Research Center, Seattle, $W A$

Background: Paget's disease is an uncommon form of breast cancer, reportedly constituting $1.1 \%$ of all breast cancers in 1973 1987 from the Surveillance, Epidemiology, and End Results (SEER) Program of the National Cancer Institute, the largest populationbased cancer registry. Paget's original 1874 report describes nipple ulceration associated with an underlying breast carcinoma mass. It is now recognized that Paget's disease may 1) occur in the nipple without frank underlying cancer in the breast, and 2) be amenable to breast conserving surgery. The incidence may be changing but not reported.

Material and Methods: The study is based on 3942 cases of microscopically confirmed Paget's disease of breast reported by 1973-2002 SEER 9 Registries, Nov. 2004 with SEER*Stat software 6.1.4. Incidence rates were age-adjusted to the U.S. 2000 population. Because of small case number (about 1\%), male Paget's disease was excluded in incidence and survival statistics. Annual percent change (APC) was calculated by using the weighted least squares method. The APC of the later 15 years, 1988-2002, were compared with that of the early 15 years, 1973-1987. While the beginning year of registries about surgical types was 1983, the 5year survival rates of different surgeries were obtained by actuarial method from 1983 to 2002 . The patients who underwent partial mastectomy were compared with those who underwent total mastectomy (including simple, modified radical and radical mastectomy). 
Results: The age-adjusted incidence rate of female Paget's disease is 0.809 per 100,000 population in 2002 and the case number constituted $0.49 \%$ of all breast cancers in that year. The APC for 1988-2002 is -3.18 and was statistically significant compared with 6.21 for $1973-1987(\mathrm{p}=0.000)$. Both white and black women showed the same trends of decreasing in incidence. The median age of diagnosis was 62 during 1973-1987 and 64 during 19882002. When cases are stratified by underlying tumor, the group of Paget's disease with ductal carcinoma (invasive or in situ) showed stronger trend of decreasing in incidence (APC for 1988-2002: 3.675). By comparison, the APC of Paget's disease without ductal carcinoma was -0.231 , which showed much slower trend of decreasing. The number of patients who underwent partial mastectomy increased from $8.8 \%$ in $1983-1992$ to $21.9 \%$ in 1993-2002 with 5-year survival rates that were not worsened by the breast conserving approach $(93.4 \%$ vs. $89.4 \%, 81.1 \%, 52.2 \%$ with simple mastectomy, modified radical mastectomy and radical mastectomy respectively in 1993-2002).

Discussion: Paget's disease with underlying cancer is decreasing in incidence, while the incidence of Paget's disease without underlying cancer appears relatively stable. More patients are undergoing breast conservation therapy instead of mastectomy without worsening of outcome.

\section{1}

Breast cancer characteristics at diagnosis among ArabAmerican women compared to European- and AfricanAmerican women in the Detroit SEER registry.

Hensley Alford S, Schwartz K, Soliman A, Gruber S, Douglas JA, Johnson CC, Merajver SD. University of Michigan, Ann Arbor, MI; Karmanos Cancer Institute, Wayne State University, Detroit, MI; Henry Ford Health System, Detroit, MI

Background. Data from Arab world studies suggest that Arab women may experience a more aggressive breast cancer phenotype with an earlier age of onset than US women. One of the largest settlements of Arabs outside the Middle East is located in the Detroit metropolitan area. Detroit is a SEER reporting site and has been capturing all diagnosed incident cancers since 1973, including breast cancer.

Materials and Methods. Using the SEER registry, we identified a population-based cohort of women diagnosed with invasive primary breast cancer in Detroit between 1973 and 2003. Using a previously validated name driven algorithm, women were identified as being of Arab descent if they had an Arab first, last, or maiden name. The race of non-Arab women was taken from physician report. Women who were $<18$ at diagnosis or were not of European, African, or Arab descent were excluded. We assessed differences in the distribution of age, stage, and histology at diagnosis between Arab-American, European-American, and African-American women using $\mathrm{c}^{2}$ and $\log$-rank tests.

Results. A total of 80316 breast cancers were captured in the Detroit SEER from 1973-2003. We excluded cases due to age $(n=9)$, ethnicity $(n=1095)$, and non-breast primary histology $(n=91)$. We identified 1652 women as being of Arab descent, 13 855 women as African-American, and 63615 women as being European-American, which contributed $2 \%, 18 \%$, and $80 \%$ of the analytic sample, respectively. Analysis showed that $34 \%$ of ArabAmerican and $33 \%$ of African-American women were diagnosed before age 50 years compared to $26 \%$ of European-American women. The log-rank test comparing the relative proportions of women in each ethnic group diagnosed by decade of life was statistically significant $(\mathrm{p}=0.0001)$. Additionally, Arab-American and African-American women were more likely to be diagnosed with regional $(33 \%$ each) or distant disease $(6 \%$ and $8 \%$, respectively) than European-American women ( $c^{2}$ tests; p-values $<0.05$ ). However, Arab-American women and European-American women had similar diagnosis with typical invasive ductal/lobular carcinoma (91\% and 92\%, respectively) as compared to AfricanAmerican women $(88 \%)$, who were relatively more likely to be diagnosed with rare histologies $(\mathrm{p}<0.0001)$.
Discussion. This cohort is being further analyzed to determine whether a younger age of onset is present in certain ethnic minority groups. Overall, Arab-American women were more like EuropeanAmerican women with respect to histology and more like AfricanAmerican women with respect to stage at diagnosis. We intend to assess differences in the extent of disease and survival as well as include multivariate analysis to control for potential confounders in this cohort.

\section{2}

\section{Pregnancy after breast cancer in Western Australian} women.

Ives AD, Saunders CM, Semmens JB. The Iniversity of Western Australia, Perth, Western Australia, Australia; The University of Western Australia, Perth, Western Australia, Australia

Objectives: To establish the incidence and outcomes of pregnancy subsequent to a diagnosis of breast cancer in women aged less than 45 years within the stable population of Western Australia between 1982 and 2000.

Methods: A geographically defined population-based descriptive study. Potential cases were identified from the Western Australian Data Linkage System. Cases were validated and supplementary data obtained from hospital and clinicians records. The data were analysed to establish the pregnancy rate, management, and outcome of the breast cancer and pregnancy.

Results: Ninety eight women became pregnant at least once following a diagnosis of breast cancer. This is only $4 \%$ of young women diagnosed with breast cancer in Western Australia. More than half $(52 \%)$ the tumours of these women were greater than $20 \mathrm{~mm}$ but they were more likely to be lymph node negative (69\%). This suggests that women who go on to conceive have more localised disease and better prognosis tumours which supports the "healthy mother" effect bias. Chemotherapy was used as adjuvant therapy in $40 \%$ of women but only $5 \%$ of women were given tamoxifen. Two women received in vitro fertilisation to conceive and both are alive and well without recurrence. Median time from diagnosis to pregnancy was 18.5 months. Nearly $60 \%$ of women who had a subsequent pregnancy conceived less than two years after diagnosis. Proportionally more women had terminations of pregnancy in the first six months after breast cancer was diagnosed. As many live births occurred in women who became pregnant within two years as delayed conception for two years post diagnosis. Early conception, however, did not compromise survival. Overall five-year survival for breast cancer survivors who conceived was $93 \%$.

Conclusions: The high proportion of terminations of pregnancy in the first six months post diagnosis suggests there may be contraceptive issues for women newly diagnosed with breast cancer. Women diagnosed with breast cancer who subsequently conceived had a five-year survival of $93 \%$. Their survival was not affected by time from diagnosis to conception.

\section{3}

General population rates of selected conditions and events recorded in breast cancer hormonal therapy trials.

Kulig K, Erensen JG, Zhou Z. Pfizer Inc., New York, NY

Background: Several of the conditions or events reported in clinical trials of hormonal therapy for treatment of early breast cancer may largely overlap those expected within an age-matched, postmenopausal population of women without breast cancer. We sought to establish reference levels for these conditions and events in a cancer-free population to estimate background prevalence and shed perspective on the potentially increased burden of these conditions or events that may be associated with early breast cancer treatment.

Material and Methods: Using 2001-2002 NHANES, the nationally representative Health and Nutrition Examination Survey, we established a cohort of women aged 55 to 85 years who 


\section{S146 Abstracts - Poster Session III}

reported going through menopause and being amenorrheic for $\geq 12$ months. Women were excluded if they reported a history of at least one cancer, current use of hormone replacement therapy, or impaired kidney or liver function. Conditions of interest were determined a priori and prevalence for each was determined by self-report ("Has a doctor ever told you....") or lab measurement. Raw data were weighted to the national population according to NHANES analytic guidelines.

Results: A total of 500 of 1,123 women in our age cohort met the study inclusion/exclusion criteria. In our sample, weighted prevalences of immobility (difficulty walking without equipment) and having 2 or more comorbid conditions were $8.4 \%$ and $34.8 \%$, respectively. The table below shows results of analyses by age groups.

Weighted Prevalence of Selected Conditions and Events Among Postmenopausal Women by Age, NHANES 2001-2002

$\begin{array}{lllll}\text { Condition/Event } & \begin{array}{l}\text { Prevalence }(\%) \\ \text { in cohort }\end{array} & 55-65 \mathrm{yrs} & 66-75 \mathrm{yrs} & \mathbf{7 6 - 8 5} \mathrm{yrs}\end{array}$

Joint pain

Joint pais

Arthritis
(ever told

(ever told")

Joint pain ${ }^{1}$ without arthritis

(ever told)

Osteoporosi

(ever told)

Osteoporosis
(ever treated)

Fracture $^{2}$

due to any cause

Fracture $^{2}$

due to short fall

Dyslipidemia

(ever told)

Total cholesterol $>240 \mathrm{mg} / \mathrm{dL} \quad 28.2$

(by lab) in cohort

$\begin{array}{llll}(55-85 y r s) & 25.5 & 18.5 & 16.3\end{array}$

by lab)

Hypertension $\quad 44.8$

ever told $2+$ times)

Myocardial infarction

(ever told)

Stroke

(ever told)

$\begin{array}{lll}25.5 & 18.5 & 16.3 \\ 17.2 & 16.6 & 17.3\end{array}$

18.7

11.2

4.0

23.9

11.2

8.0

3.5

5.2

10.6

19.0

4.0

8.9

10.4

1.2

3.3

6.0

8.0

0.7

3.3

4.0

.6

15.2

14.8

10.6

10.8

8.6

8.8

15.7

14.2

14.9

5.2

1.2

1.4

2.6

0.9

1.5

27

${ }^{1}$ Joint pain/ache/stiffness/swelling in past 12 months ${ }^{2}$ Fracture of hip, wrist, or spine at age $50+$ "Ever told by a doctor or other health professional

Discussion: Differing methodologies in characterizing and measuring conditions and events in our study versus clinical trials precludes our ability to make direct comparisons; however, study results highlight that certain conditions and events investigated are not uncommon among postmenopausal women in the general population and that rates of some conditions or events may be higher than those reported in hormonal therapy trials for early breast cancer. These data, along with ongoing analyses of other population datasets, may provide useful context for conditions and events reported in breast cancer clinical trials.

\section{4}

Comparing improvements in survival for older and younger breast cancer patients.

Bhatia P, Hilsenebeck SG, Dunn JK, Klos K, Chenault C, Morrison A. Baylor College of Medicine, Houston, TX; University of Texas Health Science Center, Houston, TX

Background: Over the last 20 years, there have been substantial improvements in survival for breast cancer patients, but many of the most effective diagnostic and therapeutic tools have been aimed at or have the greatest impact in older women. Most studies on breast cancer trends do not assess whether improvements in survival rates accurately describe trends in younger patients.

Materials and Methods: Using a prospective cohort from the National Breast Cancer Tissue Resource (NBCTR) at the Breast Center at Baylor College of Medicine, we examined age group differences in survival trends over time. Diagnosis age group (less than 50 years versus at least 50 years), diagnosis period (19841990 versus 1991-1997), and their interaction term were assessed with accelerated failure-time regression models. Both the Weibull and the log-normal survival distributions were tried with similar results and only the log-normal distribution results are presented here as they fit the data better in each comparison. The parametric models were used instead of Cox proportional hazards regression because the proportional hazards assumption was violated in the analysis. The analysis was also performed on a comparable Surveillance, Epidemiology, and End Results (SEER) program dataset to assess the generalizability of the NBCTR results.

Results: The NBCTR data showed that for overall breast cancerspecific survival and disease-free survival, younger patients did worse than older patients $(\mathrm{p}<0.05)$, but the effect diminished after controlling for predictive and prognostic factors. Patients diagnosed in the earlier period did worse than patients diagnosed in the later period, even after controlling for predictive and prognostic factors $(\mathrm{p}<0.05)$. The interaction terms for overall breast cancerspecific survival and disease-free survival were not significant. In the SEER data for overall breast cancer-specific survival, younger patients did worse than older patients $(p<0.05)$, but the effect reduced after controlling for tumor size and any positive lymph nodes. Patients diagnosed in the earlier period did worse than patients diagnosed in the later period, even after controlling for predictive and prognostic factors $(\mathrm{p}<0.05)$. The interaction term was significant, which showed that younger patients did not improve in overall breast cancer-specific survival as much as older patients over time $(\mathrm{p}<0.05)$, and this effect weakened after controlling for tumor size and any positive lymph nodes.

Discussion: We found that diagnosis time period had a stronger effect than age at diagnosis on overall breast cancer-specific and disease-free survival after controlling for a number of important predictive and prognostic factors in the main analysis. While some of the results suggested that the improvements in survival over time differed by age at diagnosis, this effect weakened after accounting for tumor size and any positive lymph nodes. This analysis has shown that improvements in survival over time may not differ by diagnosis age after controlling for predictive and prognostic factors, and it is important for researchers, clinicians, and others involved in the advancement of new therapeutic and screening interventions to continue to ensure that all persons are considered in the development of these new tools.

\section{5}

Variation in breast disease co-occurrence frequencies between pre- and post-menopausal women.

Maskery S, Zhang Y, Hu H, Hooke J, Shriver CD, Liebman M. Windber Research Institute, Windber, PA; Walter Reed Army Medical Center, Washington, DC

OBJECTIVE: Menopausal status is known to significantly influence a woman's risk for developing breast cancer. The Clinical Breast Care Project (CBCP) between Windber Research Institute and Walter Reed Army Medical Center has generated a vast knowledge base of breast disease and breast cancer data in the form of a highly pathologically-annotated tissue and biospecimen repository ( $>14,000$ samples) and a database of life history data (>450 data fields) for each CBCP patient. This unique data source allows us to examine the clinical presentation of breast disease and cancer in pre- and post-menopausal women.

DESIGN: Co-occurrence frequency is assessed between clinically relevant combinations of columnar cell hyperplasia $(\mathrm{CCH})$, atypical ductal hyperplasia (ADH), ductal carcinoma in situ (DCIS), invasive ductal carcinoma (IDC), lobular carcinoma in situ (LCIS), invasive lobular carcinoma (ILC), and nodal metastases diagnoses. Consistent pathologic quality is maintained by having each case reviewed and annotated by a single pathologist who records the occurrence of any and all of 131 possible breast pathology and lymphoid diagnoses that co-occur within each patient's specimen(s). Co-occurrence frequency of diagnosis $i$ with diagnosis $j$, for a patient population with diagnosis $j$, is defined as the number of patients with diagnoses $\mathrm{i}$ and $\mathrm{j}$ divided by the number of patients with diagnosis $\mathrm{j}$. The Pearson Chi-Squared test statistic is used to assess the significance of observed variation in diagnosis co-occurrence frequency between pre-menopausal $(\mathrm{N}=452)$ and post-menopausal $(\mathrm{N}=420) \mathrm{CBCP}$ patients. 
RESULTS: No significant variation between pre- and postmenopausal women is seen in the frequency of DCIS or IDC in women with ADH, the frequency of IDC in women with DCIS, or the frequency of ILC in women with LCIS. However, nodal metastases occur in pre-menopausal women with IDC more frequently than in post-menopausal women with IDC (Table 1). Post-menopausal women with $\mathrm{CCH}$ are significantly more likely to have ADH, DCIS, and IDC than pre-menopausal women with $\mathrm{CCH}$ (Table 2). However, menopausal status does not affect the frequency of ILC or LCIS in women with $\mathrm{CCH}$.

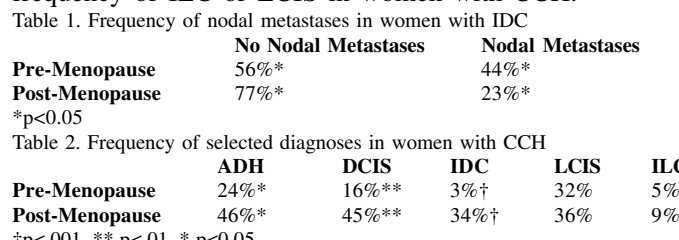
CONCLUSIONS: Co-occurrence analysis of this well characterized, highly annotated, and standardized pathologic set of breast diseases and cancers will lead to identification of complex pathologic associations between patients such that we may begin to identify differences in clinical presentation of breast cancer between different patient populations.

\section{6}

Distinct breast cancer incidence and survival patterns according to histopathology: analysis of the NCI's SEER database.

Anderson WF, Jatoi I. National Cancer Institute, Bethesda, MD; National Naval Medical Center and Uniformed Services University, Bethesda, MD

Background: We recently demonstrated that breast carcinoma overall was a mixture of early-onset and late-onset cancer populations with distinct incidence and survival patterns, according to age at onset. Briefly, early-onset tumors had a sharp 2-year hazard peak for breast cancer death, whereas late-onset lesions lacked this hazard peak.

Methods: To further explore the link between breast cancer incidence and survival, we examined age frequency distributions at diagnosis and annual hazard rates for different histopathologic types.

Results: Duct, tubular and lobular carcinomas were mixed with early-onset and late-onset breast cancer populations, irrespective of estrogen receptor (ER) expression or race. Medullary and inflammatory carcinomas demonstrated mostly early ages at onset, irrespective of ER or race. Papillary and mucinous carcinomas showed mostly late ages at onset, irrespective of ER or race. Duct and lobular carcinomas had 2-year hazard peaks for ER negative but not ER positive tumors. Approximately 4 to 6 years following breast cancer diagnosis, ER negative and positive hazard rates crossed over for duct and lobular carcinomas. Inflammatory breast carcinomas had 2-year hazard peaks for both ER negative and positive tumors with crossover at approximately 4 years. Tubular and medullary breast carcinomas lacked an obvious 2-year hazard peak or crossover. Papillary and mucinous tumors had 2-year hazard peaks for ER negative tumors without a clear crossover. Conclusion: We observed mixed incidence and survival patterns for different histopathologic types of breast carcinoma; possibly reflecting varying risk factor profiles, carcinogenic exposures, stem cells of origin, or causal pathways.

\section{7}

Incidence and risk factors for lymphedema after axillary lymphadenectomy for breast cancer.

Bergmann A, Mattos IE, Koifman RJ, Ribeiro MJP. National School of Public Health, Rio de Janeiro, Brazil; National Cancer Institute, Rio de Janeiro, Brazil

Introduction: Breast cancer is an important problem in public health due to the high incidence and mortality. According to data gathered from cancer patients' hospital charts at the INCA [National Cancer Institute], between 2000 and 2001, 50\% of breast cancer cases were diagnosed at stages III and IV. The later the diagnosis, the greater the possible treatment sequelae, among which lymphedema is the main one, constituting a primary focus of concern in the public health system. Main purpose: Determining the incidence and the factors associated with the development of lymphedema in a cohort of women subjected to lymphadenectomy for breast cancer. Method: Prospective cohort study of women surgically treated for breast cancer from August 2001 to November 2002. The follow-up prescribed a re-evaluation on the first day after surgery and at the follow-up outpatient appointments scheduled for 30 days, 6 months, 12 months, 18 months, and 24 months. All evaluations were standardized, with the use of instruments specifically created and tested for this purpose. The criterion for lymphedema diagnosis was based on Casley-Smith's proposal: measurement of upper limb circumference. Results: One thousand and four women were studied, averaging 56 years of age and with an average follow-up period of 19 months. The overall incidence of lymphedema in the 24 -month period was $17.5 \%$. On the basis of Cox multivariate analysis, the variables statistically associated with lymphedema were: axillary radiotherapy (Harzard Ratio $\mathrm{HR}=3,10$ IC 1,99-4,85), early edema (HR=2,86 IC 1,51-5,43), overweight or obesity (HR=1,89 IC $1,19-3,01)$, seroma $(\mathrm{HR}=1,75$ IC $1,11-2,76)$, number of chemotherapy cycles administered to the upper limb homolateral to the breast cancer $(\mathrm{HR}=1,19$ IC $1,08-1,32)$ and age $(\mathrm{HR}=1,02$ IC 1,01-1,04). Conclusion: The incidence of lymphedema after two-years of follow-up was high, and axillary radiotherapy was the variable wich more explained the development of lymphedema. Obese women should be encouraged to reduce weight, and the upper limb homolateral to the breast cancer should be avoided when administering chemotherapy. Protocols for post-surgical rehabilitation must be established, aiming at a better quality of life for women treated for breast cancer.

\section{8}

Trends in breast cancer incidence in Scotland: the influence of screening and deprivation.

Brown SBF, Hole DJ, Cooke TG. Glasgow Royal Infirmary, Glasgow, United Kingdom; University of Glasgow, Glasgow, United Kingdom

\section{Background:}

Examining trends in the incidence of breast cancer is of critical importance, allowing planning of health services and analysis of the influence of risk factors. Rising incidence could be associated with a change in tumour biology, ie more women getting tumours of better biological prognosis. Analysis of trends in incidence in the UK became complex with the introduction of the breast screening programme for women of 50-64 in 1988. We present epidemiological data from Scotland; with a comprehensive cancer registration programme and accurate socio-economic data Scotland is well-suited to analysis of trends in breast cancer.

Results:

Screening and breast cancer incidence Our data demonstrates the expected sharp rises in breast cancer incidence after the introduction of screening. However, rates have continued to rise rather than level off (as is expected once screening becomes established). Rises in incidence were occurring before screening and are seen in age groups above screening age, suggesting factors other than screening may be contributing. 


\section{S148 Abstracts - Poster Session III}

Deprivation and breast cancer incidence Postmenopausal breast cancer is commoner in the affluent. In the West of Scotland the gap in incidence between the most deprived and the affluent is widening. In our data, premenopausal breast cancer appears not to be influenced by deprivation but marked differences are seen in the screened age groups. The proven difference in screening uptake rates between socio-economic groups is likely to be contributing, but a gap was developing before screening was introduced. Many other factors could be contributing, including differences in reproductive patterns.

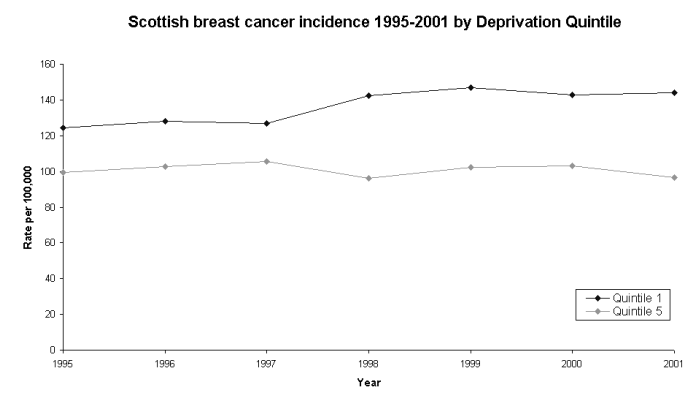

Conclusions:

The incidence of breast cancer in Scotland continues to increase. Whilst the introduction of screening produced the expected increase in incidence, there is evidence that the underlying trend has also increased, suggesting that other factors are implicated. We intend to analyse the effects of changes in uptake of screening, changes in screening methodology and changing reproductive patterns.

The gap between the deprived and affluent in breast cancer incidence is widening among post-menopausal but not premenopausal women. Differences in screening uptake are likely to be contributing but again other factors are implicated; we intend to analyse further the reasons behind the widening gap.

\section{9}

registHER: treatments and clinical outcomes from a prospective observational cohort study of patients with HER2-positive metastatic breast cancer.

Brufsky A, Rugo H, Tripathy D, Kaufman P, Mayer M, Paik S, Ulcickas-Yood M, Yardley D, Tan-Chiu E. University of Pittsburgh Cancer Center, Pittsburgh, PA; UCSF Comprehensive Cancer Center, San Francisco, CA; University of Texas Southwestern Medical Center, Dallas, TX; Dartmouth-Hitchcock Medical Center, Lebanon, NH; Patient Advocate, New York, NY; National Surgical Adjuvant Breast Bowel Project, Pittsburgh, PA; EpiSource, LLC and Yale University School of Medicine, New Haven, CT; Sarah Cannon Cancer Center, Nashville, TN; Cancer Research Network, Plantation, FL

Background: HER2 is amplified/overexpressed in $25 \%$ of patients (pts) with breast cancer and is a significant unfavorable prognostic factor for survival. Randomized clinical trials of second-line chemotherapy with or without trastuzumab, however, have been difficult to execute due to $\mathrm{pt} / \mathrm{MD}$ reluctance to randomize to chemotherapy-only treatment.

Methods: registHER is a prospective, longitudinal cohort study of pts with newly diagnosed HER2-positive metastatic breast cancer (MBC). The goal of this study is to describe treatment outcomes following standard treatments in this population. The objectives are to measure time to treatment failure, time to progression, survival, and cardiac safety. Clinicopathologic and treatment data are collected from the time of diagnosis of metastatic disease through study discontinuation or death. Eligibility criteria include: HER2-positive MBC and signed informed consent.
Results: From Dec 2003 - Mar 2005, 488 eligible pts were enrolled from 153 study sites. Baseline Characteristics $(\mathrm{n}=488)$ : Median age 55 yrs (23-92); White race $82 \%$; Female 99\%; ECOG $0 / 190 \%(n=322)$; median disease-free interval 17 months (mos) $(\mathrm{n}=485)$. Tumor Characteristics: Node+ $68 \%$; Stage IV at initial diagnosis $31 \%$; ER+/PR+ in MBC $49 \%$; sites of metastatic disease $(n=485)-$ CNS $4 \%$, visceral $58 \%$, bone $12 \%$, other $26 \%$. Prior Treatment: Neo-adjuvant $17 \%$; adjuvant $52 \%$. Cardiac dysfunction: 3 cases. The median follow-up is $6.5 \mathrm{mos} ; 15 \%(48 / 329)$ at 6 mos and $16 \%(53 / 329)$ at 12 mos experienced recurrence or death from start of first MBC therapy.

Metastatic Treatment

Trastuzumab-based regimen:

\begin{tabular}{lll}
\hline$\cdot 1^{\text {st-line }}$ & $77 \%$ & $(356 / 462)$ \\
$\cdot 2^{\text {nd }}-$-line & $82 \%$ & $(138 / 169)$ \\
Sequential Treatment: & & \\
\hline$\cdot \cdot \mathrm{H}+\mathrm{C} \rightarrow \mathrm{H}+\mathrm{C}$ & $94 \rightarrow 71$ & $(75 \%)$ \\
$\cdot \mathrm{H} \rightarrow \mathrm{H}+\mathrm{C}$ & $9 \rightarrow 8$ & $(89 \%)$ \\
$\cdot \mathrm{C} \rightarrow \mathrm{H}+\mathrm{C}$ & $39 \rightarrow 23$ & $(59 \%)$
\end{tabular}

$\cdot \mathrm{C} \rightarrow \mathrm{H}+\mathrm{C} \quad 39 \rightarrow 23 \quad$

Conclusion: This study represents the largest dataset of HER2Conclusion: This study represents the largest dataset of HER2-
positive MBC pts. A large percentage of pts had stage IV MBC at initial diagnosis. The majority of pts received a trastuzumab-based regimen as first and second-line therapy. Currently the median follow-up time is $6.5 \mathrm{mos}$ from initiation of the first metastatic treatment, with $16 \%$ having progressed at 12 mos. Updated clinical outcomes will be presented at the meeting.

\section{0}

Do changes in ER status explain improvements in survival? Henley NC, Hole DJ, Leake RE, Cooke TC. University of Glasgow, Glasgow, United Kingdom; University of Glasgow, United Kingdom Aims

Incidence of breast cancer is increasing but mortality is decreasing. We assessed whether the biology of breast cancer has changed by assessing changes in hormonal sensitivity over time.

Methods

Oestrogen receptor (ER) status was determined on patients diagnosed with primary operable breast cancer by ligand binding assay $(20 \mathrm{fmol} / \mathrm{mg}$ protein cut-off for ER positivity) between 1980-1988 and immunohistochemistry (10\% positive staining cut-off for ER positivity) between 1996-2001 in 5 specialist breast units. Demographic details were collected including deprivation category (using Carstairs scores).

Results

2423 patients were diagnosed in 1980-1988, and 3291 in 19962001. $1188(49.0 \%)$ patients in $1980-1988$ had ER positive tumours compared with $2473(77.8 \%)$ in $1996-2001{\left(\mathrm{chi}^{2}\right.}^{2}$ $\mathrm{p}<0.001)$.

On univariate analysis, older age $(\mathrm{p}<0.001)$, affluence $(\mathrm{p}<0.001)$, hospital of diagnosis $(\mathrm{p}=0.009)$ and screen-detected tumours $(\mathrm{p}<0.001)$ were significantly predictive of having an ER positive tumour. On multivariate analysis diagnosis between 1996-2001 remained significantly predictive of ER positivity $(\mathrm{p}<0.001)$ independent of age, hospital, deprivation and method of diagnosis. Older age $(\mathrm{p}<0.001)$, hospital of diagnosis $(\mathrm{p}<0.001)$, and diagnosis at breast screening $(\mathrm{p}<0.001)$ were also independently predictive of ER positivity, but deprivation was not.

\section{Conclusion}

Concordance between ligand binding assay and immunohistochemistry is estimated to be around $80-90 \%$. While part of the increase in the proportion of ER positive breast cancer may be attributed to differences in technique, part of it may be due to change in aetiology or tumour biology. The prevalence of aetiological factors for ER positive breast cancer has increased over the past 20-30 years and may account the increase in ER positive breast cancer. ER positive breast cancer has a lower incidence of early recurrence than ER negative breast cancer. In addition, ER positive tumours are sensitive to endocrine manipulation, unlike ER negative tumours. Therefore, the increase in ER positive breast cancer we have observed could account for improved breast cancer survival. 


\section{1}

The incidence and outcomes of gestational breast cancer in Western Australian women.

Ives AD, Saunders CM, Semmens JB. The University of Western Australia, Perth, Western Australia, Australia; The Iniversity of Western Australia, Perth, Western Australia, Australia

Objective: To determine the incidence, and describe the management and outcomes for all women aged less than 45 years diagnosed with gestational breast cancer (GBC) in Western Australia between 1 January 1982 and 31 December 2000.

Design: A population-based study of gestational breast cancer using data from the Western Australian Data Linkage System validated and supplemented with information from patient records. Results: GBC accounted for $6.25 \%$ of breast cancers in Western Australian women less than 45 years of age, and was a complication in 23.6 per 100,000 pregnancies. Women diagnosed with GBC ranged in age from 24 to 43 (median 34) years. The median time from onset of symptoms to diagnosis was four weeks (interquartile range 2,16$)$. More women $(72 \%)$ had mastectomy than breast conserving surgery. Chemotherapy was administered to $68 \%$ of women and hormone therapy was administered to $5 \%$. Over half of the 49 women $(55 \%)$ pregnant at diagnosis received chemotherapy; three women received chemotherapy when pregnant, 10 choose to terminate their pregnancy and 16 delayed chemotherapy until safe delivery of the fetus. Five year survival was only $73 \%$ for women with GBC when compared to other Western Australian women (between 75-85\%) diagnosed with breast cancer matched by age, year of diagnosis and disease stage.

Conclusion: The incidence of gestational breast cancer in the Western Australian population is lower than anticipated. There were no deliberate delays in diagnosis. Survival is worse than for other young women diagnosed with breast cancer even when matched by disease stage. GBC appeared to be a more aggressive disease.

\section{2}

A systematic review and descriptive analysis of inflammatory breast cancer clinical trials.

Kim TY, Lau J, Erban J. Tufts-New England Medical Center, Boston, MA; Institute for Clinical Research and Health Policy Studies, Tufts-New England Medical Center, Boston, MA

INTRODUCTION: Inflammatory Breast Cancer (IBC) comprises between $1-5 \%$ of all diagnosed breast cancers reported in the literature. IBC is the most aggressive form of breast cancer with historically poor 5-year rates of Disease Free Survival (DFS) and Overall Survival (OS). Prior to the use of systemic chemotherapy, the 5-year OS rate ranged from $0-5 \%$. No randomized controlled trial (RTC) with an IBC-only cohort has been published to date. A systematic review of the literature was conducted to assess the outcomes of various treatment modalities.

METHOD: Inclusion criteria: Prospective IBC-only cohort studies that utilize systemic chemotherapy, clear description of how the diagnosis was made, a description of patient characteristics, reporting of outcomes such as DFS, OS, Local Relapse (LR), and Distant Relapse (DR). Exclusion criteria: Evidence of metastatic disease, or prior treatment with chemotherapy. The following databases were searched: Medline, Cochrane Library, and Best Evidence.

RESULTS: Between 1966 and November 2004, 1,452 potential abstracts were identified, 82 of which were prospective clinical trials. However, only 30 of these studies met our inclusion criteria. Forty percent of the studies were done outside the United States. Patient accrual for all studies occurred between the years 1972 and 1998. The median age was 50 years (range: 25-83). Between 28$79 \%$ of patients were pre-menopausal. The percentage of patients who presented with clinical nodes ranged from $32-90 \%$. An anthracycline-based induction regimen (ABI) was used in 24 studies. Twenty-one of these studies were followed by both surgery and radiation for local control. Only three of these studies used radiation without surgery. Five studies used greater than $150 \mathrm{mg} / \mathrm{m}^{2}$ total dose of induction anthracycline (HDA). Six studies involved high dose chemotherapy with an autologous stem cell bone marrow rescue (HDC). Outcomes are shown in the table.

CONCLUSION: The introduction of systemic chemotherapy has improved the outcome for IBC patients in terms of OS. However, the response rates vary widely across the studies. Within the literature, a large degree of heterogeneity exists between patient populations, treatment modalities, and treatment schedules. Additional analysis evaluating the impact of this heterogeneity is planned. However, RCTs will be needed to resolve the discrepancies of treatment responses.

\begin{tabular}{|c|c|c|c|c|c|c|c|}
\hline \multicolumn{8}{|c|}{ Treatment Outcomes } \\
\hline & \# Patients & $\begin{array}{l}\text { 3-yr DFS } \\
(\%)\end{array}$ & $\begin{array}{l}5 \text {-yr DFS } \\
(\%)\end{array}$ & $\begin{array}{l}3 \text {-yr OS } \\
(\%)\end{array}$ & $\begin{array}{l}5 \text {-yr OS } \\
(\%)\end{array}$ & $\begin{array}{l}\mathrm{LR} \\
(\%)\end{array}$ & $\begin{array}{l}\mathrm{DR} \\
(\%)\end{array}$ \\
\hline All Trials & 1098 & $15-75$ & $11-71$ & $34-84$ & $31-75$ & $0-80$ & $20-100$ \\
\hline ABI & 928 & $15-75$ & $11-71$ & $34-84$ & $31-75$ & $0-80$ & $20-100$ \\
\hline $\begin{array}{l}\text { ABI plus } \\
\text { surgery and } \\
\text { radiation }\end{array}$ & 601 & $15-75$ & $11-71$ & $34-84$ & $31-75$ & $0-80$ & $20-100$ \\
\hline $\begin{array}{l}\text { ABI plus } \\
\text { radiation }\end{array}$ & 327 & $35-56$ & $25-42$ & $44-78$ & $32-70$ & $21-75$ & $50-79$ \\
\hline & 175 & & & & & & 100 \\
\hline IDC & 254 & 44-71 & 40-71 & $60-84$ & $44-60$ & $17-63$ & $27-83$ \\
\hline
\end{tabular}

\section{3}

Breast cancer in young women age < 36 years: a retrospective analysis of prognostic factors in 908 patients in 8 french instituitions. GETNA Group.

Pouillart P, Gligorov J, Guilhaume M, Spielmann M, Luporsi E, Rivera S, Penault-Llorca F, Aimard L, Savignoni A, Asselain B, Namer M. Institut Curie, Paris, France; Tenon Hospital, Paris, France; Institut Gustave Roussy, Villejuif, France; Alexis Vautrin, Nancy, France; Geoges Francois LeClerc, Dijon, France; Jean Perrin, Clermont Ferrand, France; Hospital Ambroise Pare, Marseille, France; Antoine LaCassagne, Nice, France

Background: Age $<35$ years is considered as a bad prognostic factor in women with breast cancer (BC).

Methods: Clinical and pathological data of 908 women $<35$ years with invasive non metastatic $\mathrm{BC}$, consecutively treated between 1990-99 in 8 french institutions were analysed. Clinical and pathological size, node involvement, histological type, SBR histological grading, hormone receptors (HR), and treatment characteristics were analysed for all patients.

Distant Recurrence Free Survival (DRFS) and overall survival (OS) were analysed using Kaplan Meier estimates and comparisons were made using the logrank test. Multivariate analyses were carried out using Cox hazards model.

Results: With a median FU of 87 months, 239 deaths, 177 locoregional and 323 distant recurrences were observed. Five and 10 years survival rates were $82.2 \%$ and $66.5 \%$. Five and 10 years DRFS rates were $67.2 \%$ and $50.8 \%$. No difference was observed according to age $(<30$ years old, $31-33$ and $34-35, \mathrm{p}=0.74)$ neither in DRFS nor in OS $(\mathrm{p}=0.99$ and $\mathrm{p}=0.74)$.

Compared to T1, T2 was associated with a RR of 1.65 [1.23$2.22]$, and T3/T4 with a RR of $2.73[1.92-3.88]$ for the OS $(\mathrm{p}<10-4)$ and $\mathrm{T} 2$ was associated with a RR of 1.57 [1.23-2.02], and T3/T4 with a RR of 2.25 [1.65-3.07] for the DRFS $(\mathrm{p}<10-4)$. Compared to negative node involvement, $\mathrm{pN} 1$ status was associated with a RR of 2.22 [1.60-3.09], and pN2 with a RR of 4.35 [3.14$6.03]$ in $\mathrm{OS}(\mathrm{p}<10-4)$ and $\mathrm{pN} 1$ nodes involved was associated with a RR of 2.64 [2.01-3.47], and 4 and more with a RR of 4.22 [3.175.62] for the DRFS $(\mathrm{p}<10-4)$.

Compared to positive HR, negative HR were respectively associated with a RR of 1.37 [1.05-1.82] ( $\mathrm{p}=0.019)$, and 1.49 [1.14-1.96] $(\mathrm{p}<10-2)$ in OS. But no difference was observed according to HR in DRFS.

Compared to grade I in SBR, grade II and III were respectively associated with a RR of 2.40 [1.35-4.27], and 2.61 [1.46-4.65] for the OS $(\mathrm{p}<10-3)$ and a RR of $1.86[1.20-2.89]$, and 1.75 $[1.12-2.72]$ in DRFS $(\mathrm{p}<10-3)$. 


\section{S150 Abstracts - Poster Session III}

After multivariate analysis, statistically significant factors influencing OS and DRFS were pTpN, SBR grade, HR status, proliferative factors and pregnancy before cancer diagnosis. Final analysis regarding the impact of treatment strategy (neoadjuvant first or mastectomy), the impact of HR status on DRFS after 5 years of treatment will be presented at the congress. Conclusions: In these retrospective analyses, the most important prognostic factor for YA with BC is tumour size followed by SBR GRADE, pN and HR status, but we find that other factors like pregnancy before cancer and tumor proliferation could impact on OS and DRFS.

\section{4}

A survey of breast cancer screening activity and beliefs among Arab women in the Detroit metropolitan area.

Schwartz KL, Shah B, Kakish M, Bartoces MG, Monsur J, Fakhouri M. Wayne State University, Detroit, MI; Arab American and Chaldean Council, Lathrup Village, MI

Background: The Detroit metropolitan area has large populations of Arab and Chaldean immigrants and descendants. Cancer statistics for this population group are not available; however, we do know that the breast cancer rates in Arab countries are as high as those of the U.S and that women in Arab countries are often diagnosed at a more advanced stage of disease. This study was conducted to determine breast screening activity and perceptions among Arab and Chaldean women in the metropolitan Detroit area, particularly perceived susceptibility to breast cancer, and benefits and barriers to mammography, clinical breast examination, and self breastexamination.

Materials and Methods: Using two different population-based telephone lists of Arab surname households, we conducted a telephone survey of women 40 years or older, who were of Arab or Chaldean descent, living in the tri-county area of Detroit. The validated questionnaire, an adapted Arabic version of the Champion's Revised Health Belief Scales, was delivered by trained tri-lingual (English, Arabic, and Chaldean) speaking female interviewers, and assessed women's knowledge and perceptions about breast cancer screening modalities: self-examination, clinical breast examination, and mammography. Descriptive statistics compare women with screening history and those without; multivariable analyses will determine predictors of breast cancer screening.

Results: 399 of $755(52.8 \%)$ eligible women completed the survey. Mean age was 53.1 years (SD 10.7). All but 5 of the women were born in a country outside the U.S., with the majority from either Iraq $(50.9 \%)$ or Lebanon $(28.6 \%)$. Sixty four percent of women reported performing breast self-exam, $70 \%$ had had a clinical breast exam, and $77 \%$ ever had a mammogram. Women that had never had a mammogram or had not had one in over 5 years were significantly less educated $(\mathrm{p}=0.008)$, less likely to be married $(\mathrm{p}=0.002)$, and less likely to have medical insurance $(\mathrm{p}<0.001)$ than women who reported a mammogram in the past 5 years. Women that had a mammogram in the past 5 years reported fear of breast cancer more often than women without a mammogram in over 5 years, being significantly more likely to agree with the statements "My chances of getting breast cancer are great" and "I am afraid to think about breast cancer". Multivariable analyses will be presented.

Discussion: A large proportion of the women who participated in the survey had received breast cancer screening; a percentage similar to all Michigan women. The results of this survey will increase our understanding of the knowledge and attitude barriers and facilitators for breast cancer screening among this immigrant group, in order that culturally sensitive interventions can be designed to further increase the number of Arab-American women who receive breast cancer screening and early detection.

\section{5}

Relationship between educational level and breast cancer. Sun W, Zhang Y, Hooke J, Brzeski $H$, Shriver CD, Liebman $M N, H u$ H. Windber Research Institute, Windber, PA; Walter Reed Army Medical Center, Washington, DC

Background: In the Clinical Breast Cancer Project (CBCP), comprehensive demographic and medical data collected from patients consisting of over 450 fields has gone through extensive QA procedures. A specific advantage of the CBCP is that military family members / patients have equal access to healthcare upon diagnosis which rules out many socio-economic factors from data interpretation. Here we present the results of a preliminary study on the demographics in relation to pathological categories and tumor stages.

Methods: Patients undergoing biopsy $(\mathrm{n}=933)$ were placed in four pathological groups: invasive carcinoma (Invasive); lobular or ductal carcinoma in situ (IS); atypical hyperplasia (Atypical); and benign. Tumor stage was determined according to AJCC standards. Analysis was done using SPSS and age of diagnosis, ethnicity, education level, and tumor stage were included in the analysis.

Results: Patients with higher education (4-year college degrees or higher, $\mathrm{n}=580)$ have fewer Invasive cases $(26.0 \%, p=0.015)$ than those with lower education (no 4-year college degree, $\mathrm{n}=$ $241 ; 34.4 \%$ ). We also observed a trend that the former population have more IS and Atypical cases than the latter. There is no difference in educational level among White, African, Asian, Hispanic and others ethnic groups $(n=595,208,52,55$, and 23 respectively; although some education data are missing). Patients with higher-stage breast cancer (II, III or IV; $\mathrm{n}=118$, mean \pm SD $=56.47 \pm 14.61, p=0.01)$ are younger than those with lowerstage cancer ( 0 or $\mathrm{I} ; \mathrm{n}=194 ; 60.53 \pm 12.64)$.

Discussion: Our observation that invasive cases are fewer in patients of higher educational levels cannot be attributed to socioeconomic factors since our patients' accessibility to healthcare is equal at time of diagnosis and is independent of educational or ethnic backgrounds. One explanation of the data is that people with a higher education are better informed and so are more likely to proactively attend for medical examinations when the disease is less severe so that the Invasive percentage is lowered. It is also possible that the higher education population has a different life style so the prevalence of the Invasive disease is lower. The finding that patients with higher-stage cancer are younger than those with lower-stage is also intriguing. The above relationships mined from the CBCP database show that careful collection, data cleansing and analysis is of significant importance in breast cancer research. Pathology (percentage within education group)

$\begin{array}{llllll}\text { Pathology (percentage within education group) } & & & \\ \text { Education } & \text { Invasive } & \text { IS } & \text { Atypical } & \text { Benign } & \text { Total } \\ \text { Lower } & 83(34.4 \%) & 18(7.5 \%) & 7(2.9 \%) & 133(55.2 \%) & 241(100.0 \%) \\ \text { Higher } & 151(26.0 \%) & 62(10.7 \%) & 33(5.7 \%) & 334(57.6 \%) & 580(100.0 \%) \\ \text { Subtotal } & 234(28.5 \%) & 80(9.7 \%) & 40(4.9 \%) & 467(56.9 \%) & 821(100.0 \%)\end{array}$
$\begin{array}{llllll}\text { Higher } & 151(26.0 \%) & 62(10.7 \%) & 33(5.7 \%) & 334(57.6 \%) & 580(100.0 \%) \\ \text { Subtotal } & 234(28.5 \%) & 80(9.7 \%) & 40(4.9 \%) & 467(56.9 \%) & 821(100.0 \%)\end{array}$ $\begin{array}{lllll}\text { * p-value } & 0.015 & 0.156 & 0.091 & 0.527\end{array}$ * Pearson Chi-Square test

\section{6}

\section{Dying with breast cancer - an audit.}

Clemons M, Simmons C, Sue J, Fralick J, Fralick M, Blair A Fitzgerald B, Zalany L, Beaudoin G, Marcus T. Sunnybrook and Women's College Health Science Centre, Toronto, ON, Canada Introduction:

Most patients dying of metastatic breast cancer (MBC) would prefer to die at home if possible. However, from the literature, there is a considerable discordance between preferred and actual location of death, with significantly less than $30 \%$ of these pts dying at home. The low incidence of home death is associated with a low rate of palliative care referral and a high rate of specialist care at the end of life. At our centre coordination of palliative care and supportive care services is facilitated by a dedicated social work (SW) team. The purpose of our study was to review the management of end of life care of MBC pts to determine if it was 
consistent with their wishes and to identify areas of improvement Methods:

Pts with MBC who died under the care of one oncology team between May 2002 and May 2005 were identified. Pt demographics, place of death, and expressed preference for place of death were recorded. Health care professionals involved with each pt were interviewed.

Results:

55 pts died during the audit period. Mean age was 57 yrs (30-84 range). Median time with metastatic disease was 32 months (range 1 week-125 months). While $70 \%$ of pts expressed that they wished to die at home, only $44 \%$ actually did. $28 \%$ died in a palliative care unit, and $28 \%$ died in an acute care setting. Overall, there was $40 \%$ discordance between desired and actual location of death amongst patients who had specified their wishes. $80 \%$ of pts were seen by SW prior to death. Health care professionals felt earlier referral to SW and earlier discussion of palliative care services may help meet pts needs.

Conclusions:

Despite the presence of a coordinating supportive care team, there remains a significant discordance between pt wishes and actual place of death. From clinical experience, while many acute hospital admissions at the end of life occur due to poor coordination of palliative resources or primary care-giver distress, earlier referral to SW may help in the coordination of resources to improve pt management.

\section{7}

Patient satisfaction in breasst cancer care - results from the patient satisfaction and quality in oncological care study (PASQOC@ 2004).

Kleeberg UR, Behrens MS, Heiden I. Hamburg Cancer Society, Hamburg, Germany; GlaxoSmithKline GmbH \& Co. KG, Munich, Germany; Picker Institute Deutschland, Hamburg, Germany

The study on Patient Satisfaction and Quality in Oncological Care (PASQOC®) 2002 was the first assessment in Germany focussing directly on patient satisfaction in oncological care. In 2004 PASQOC® was executed again, this time with an additional focus on breast cancer patients.

Objective: Compare breast cancer $(\mathrm{BCa})$ patients with other female cancer patients.

Method: To assess and observe quality of oncological ambulatory care, the formally validated questionnaire PASQOC@ was distributed to all cancer patients presenting at the investigators' practices within a defined recruiting period. Patients' inclusion criteria: German speaking, $\geq 18$ years, confirmed cancer diagnosis, physical/ mental ability to complete a self-administered questionnaire. The questionnaire is analysed by creating dichotomous 'problem scores' indicating the presence or absence of a problem with lower scores marking fewer problems (scale range: 0-100). These are summed into 13 'dimension scores', each clustering a defined set of questions. Results: The 49 practices recruited $n=2617$ women, $43.3 \%$ with breast cancer $(\mathrm{BCa})$; mean age with $\mathrm{BCa}$ : 59 years (others: 63 years; $p \leq 0.001)$. Samples did differ significantly in structure, eg. therapy goal, status of employment etc.

Women with $\mathrm{BCa}$ reported on average more problems than women with other tumours in all 13 dimensions but "communication with other patients". Differences were highly significant $(\mathrm{p} \leq 0.01)$ for patient-physician relationship (BCa: 10.6; other tumours: 8.3), communication with physicians $(21.6 ; 19.1)$, handling of side effects $(41.4 ; 36.6)$, involvement of family and friends (19.4; $15.3)$ and need for further information $(21.4 ; 18.9)$. Women with $\mathrm{BCa}$ showed particular concern in respect to information on impact on sexual life $(43.0 ; 36.6)$ as well as consideration of family situation $(21.5 ; 17.0)$. Furthermore, BCa patients reported a greater need for information on therapy related side-effects. Conclusion: Quality assurance in patient satisfaction in oncological care is of importance. The PASCOQ ${ }^{\circledR}$ questionnaire is a tool to assess not only status quo but is also feasible to detect differences in patient perception of quality of care of defined patient populations. Further analysis will focus on the explanations for those differences. Irrespective of the underlying reasons, women with $\mathrm{BCa}$ have more need for targeted care especially information. It is up to the professional carers to find ways and means to serve those needs.

\section{8}

Efficacy of internet-based education for patients with post breast therapy pain syndrome and lymphedema.

Wascher RA, Rosenbaum E, Andrews A, Manuel F, Shapiro R, Dollbaum CM. Cancer Research Center, University of Hawaii, Honolulu, HI; Stanford Hospitals and Clinics, Palo Alto, CA; Union Memorial Hospital, Baltimore, MD; University of California at San Francisco, San Francisco, CA

Background: The ability to use personal computers is an essential function in the professional and private lives of millions of people and the medical profession around the world. The impact of Post Breast Therapy Pain Syndrome (PBTPS) and Lymphedema on the ability to comfortably use a computer has received little attention in the published medical literature on complications of breast cancer therapy and illness.

PBTPS is associated with a wide variety of etiologies, symptoms, durations and severities. PBTPS is difficult to clinically define, understand, discuss, and manage. Upper extremity lymphedema is also a potentially debilitating side-effect of breast cancer therapy. PBTPS and Lymphedema remain prevalent problems now and for the foreseeable future, as an estimated $10 \%$ to $50 \%$ of breast cancer survivors who develop these complications will remain symptomatic throughout their lives.

Methods: Pilot questionnaires were developed in September 2002 to evaluate the perceived utility of information about "Post Breast Therapy Pain Syndrome", "Living with Lymphedema" on CancerSupportiveCare.com. From September 2002 through May 2005, responses were received from interested health care providers and patients in over 130 countries, including the US. Based upon current data, this website will serve an estimated 800,000 pages in 2005 (the number of website hits is not included because the term hit can be vastly misleading, e.g. 100 graphics +1 web page $=101$ hits). Specific results will be presented.

Conclusion: By participating in an on line patient education program, and preliminary therapeutic concepts, a worldwide audience of patients and health care personnel derived significant and useful information and insight into the infrequently underreported breast cancer treatment complications of PBTPS and Lymphedema. Internet-based patient and health care worker education will assist clinicians to better serve the needs of their patients, and improve the quality of their lives.

Results:

On line Questionnaires (September 2002 - May 2005)

Score $1-4(n=1529$ Responses $)$

Of the 1529 responses, 1318 were from patient and patient support teams (86\%), and 211

were from health care professionals (14\%).

Lymphedema Post Breast Total

Module Therapy Pain

$\begin{array}{llll}\text { (1) Not Helpful } & 3 \%(29) & \text { Syndrome Module } & 2 \%(11)\end{array}$

(2) Somewhat Helpful $\quad 23 \%(223) \quad 13 \%(75) \quad 19 \%(298)$

$\begin{array}{llll}\text { (3) Helpful } & 34 \%(326) & 36 \%(204) & 35 \%(530)\end{array}$

(4) Very Helpful $\quad 40 \%(378) \quad 50 \%(283) \quad 43 \%(661)$

Total Responses $\quad 956 \quad 573 \quad 1529$

* Overall $97 \%$ of the respondents felt that the educational information was somewhat-tovery helpfu 


\section{S152 Abstracts - Poster Session III}

3079

Neoadjuvant vs. adjuvant chemotherapy: young women's experiences, attitudes and information needs after diagnosis.

Berlin LM, Westphal LM, Rugo HS. Young Moms with Breast Cancer, San Jose, CA; Stanford University, Stanford, CA; University of California at San Francisco, San Francisco, CA

Background: Response to neoadjuvant chemotherapy (NCT) provides important prognostic information for patients and their physicians that may affect choice of subsequent therapy. Young women frequently have larger tumors amenable to NCT. We explored the information needs and decisions of young women after diagnosis, and the impact of chemotherapy and surgery sequence on their attitudes and subsequent decisions.

Methods and Subjects: As part of a study of information needs and decision-making in young women with breast cancer, 23 women were interviewed. Participants (pts) were chosen via theoretical sampling. Median age at diagnosis: 35 years (range 27-45), median time from diagnosis 3 years $(5$ mo- $10 \mathrm{yrs}) .65 \%$ had children at dx. $26 \%, 48 \%$ and $26 \%$ were stage I, II, III respectively. $7 / 23(30 \%)$ had NCT. Interviews were semi-structured and were audiotaped, transcribed and coded for emergent themes.

Results: All women for whom NCT was recommended agreed to NCT. Participants who had surgery first reported ongoing concern about tumor resistance to their adjuvant chemotherapy. The key reasons why women did not have NCT were (a) excisional biopsy, (b) MD did not mention, or did not recommend NCT and (c) surgeon advised excision first. The key perceived benefits of NCT were (a) ability to monitor response and change to another regimen based on response, (b) ability to start chemo quickly, and (c) reduced anxiety for responders. The key concerns about NCT were (a) would the same regimen be continued despite poor response or progression? (b) risk of metastatic spread during NCT, and (c) misinformation, (e.g., that CT does not work on the breast). Two pts who had surgery first would not have chosen NCT, but all pts would have liked information about the benefits of monitoring tumor response to CT. For most pts who had NCT, monitoring tumor response reduced anxiety and/or guided chemotherapy: two women had pCR; two received a 2 nd regimen due to +nodes at time of surgery. 2 pts who aborted NCT after 1-3 cycles for earlier surgery regretted not continuing NCT until CR.

Conclusions: Women need better information about treatment options at the time of primary diagnosis, and in particular about NCT. The majority of women with surgery first wished that their surgeon had informed them of NCT and the potential benefit of assessing chemosensitivity. Women after NCT reported finding tumor response information useful: not just those with a good response or pCR, but also two who were $\mathrm{N}+$ after NCT. Communication of treatment options and rationale for each option is important for participatory decision making and should be emphasized in MD training.

Funded by a Community-Research Collaboration (CRC) Grant of the California Breast Cancer Research Program.

\section{0}

Does inequality of access affect whether patients have breast reconstruction after mastectomy? A survey of breast care nurses in the South West region of the UK.

Scarrott S, Cassidy-Gray M, Thomas A, Mansoor I, Titcomb D, Bristol JB, Chan HY. Cheltenham General Hospital, Cheltenham, Gloucestershire, United Kingdom

Introduction

Rates of breast reconstruction vary considerably across the UK and many parts of the world. In the UK and some parts of Europe, 'oncoplastic' breast surgeons, as opposed to plastic surgeons, perform breast reconstruction for women with breast cancer. As a result, more women in the UK now have access to 'on site' reconstruction services, as their cancer surgeon also performs their reconstruction. Nevertheless, many centres still do not have 'on site' reconstruction and hence access to reconstruction is not equal for all women. In the UK, Breast Care Nurses (BCNs) perform much of the counselling with women prior to choosing reconstruction. The value of $\mathrm{BCNs}$ in helping surgeons has been presented previously (SABCS 2004 abstract 2082). As BCNs are pivotal in discussing reconstruction with women, we decided to address whether these inequalities might affect their counselling and the patients' decision.

Method

BCNs at 21 centres in the South West of the UK were surveyed by post and subsequently by telephone. Centres were asked whether they had 'in house' reconstruction and what type of surgeon performed reconstruction. They were also asked whether the access (or lack thereof) to this service coloured the discussions with patients and whether the BCNs felt that this influenced patient choice about reconstruction. Results were analysed using Statview 5.0 statistical software.

Results

$87 \%$ of centres replied to the survey (18 out of 21$)$. These individual centres treated between 110 - 430 cancers per year, with an average caseload per surgeon of almost 130 cases per year. These centres treat over $10 \%$ of all breast cancers in the UK. $50 \%$ of centres ( 9 out of 18 ) had an 'on site' reconstruction service (the 'on site' centres); centres having an "on site' service were staffed by 'oncoplastic' surgeons, whilst those centres referring elsewhere (the 'off site' centres) tended to send women to plastic surgeons at other hospitals. When asked as to whether access to reconstruction influenced their discussions with women, $67 \%$ of the 'off site' centres said it did, compared to $55 \%$ of the 'on site' centres. In reply to whether they felt that access to reconstruction influenced the final decision of the women, $67 \%$ of the 'off site' centres and $77 \%$ of the 'on site' centres felt it did. The proportion of women having reconstruction was higher in 'on site' centres compared to 'off site' centres..

Discussion

The availability of breast reconstruction has increased greatly in recent years. However, lack of access to reconstruction at a local centre may lead many women in the UK away from breast reconstruction. This study suggests that access (or lack thereof) may significantly influence patient counselling and ultimately patient choice.

\section{1}

Alamo breast cancer foundation patient advocate program. Eastman D.

Background: In 1997, the San Antonio Breast Cancer Symposium directors, Charles A. Coltman Jr., M.D. and C. Kent Osborne, M.D., requested that the Alamo Breast Cancer Foundation develop, organize and facilitate an advocate program in conjunction with the annual Symposium. The directors saw the need for an advocate program because of the increasing Symposium attendance of advocates and the absence of specific planned activities to acknowledge their presence and thier interest in breast cancer research. With the Symposium directors' encouragment and support, the first Alamo Breast Cancer Foundation Advocate Program was held in December 1998 in association with the 20th Annual San Antonio Breast Cancer Symposium.

Methods: The Alamo Breast Cancer Foundation Patient Advocate Program in conjunction with the San Antonio Breast Cancer Symposium is designed to increase the dissemination of latebreaking information on breast cancer. Advocates who apply for financial assistance from the Alamo Breast Cancer Foundation to attend the Symposium must represent an organization with a constituency. In addition, the advocate must have a basic knowledge of research either by being a Project LEAD graduate or from participation on committees, panels or review boards related to breast cancer. The funded advocates are assigned a "Hot Topic" and will go to all the sessions, talks, and poster sessions relevant to 
their particular topic. Mentor sessions are offered every evening of the Symposium to interpret in lay terms the scientific presentations of the day and to help put the information into perspective to aid in the eventual writing of "Hot Topic" reports. The mentor sessions are also open to anyone wishing to attend. The mentors consists of scientists, researchers, and clinicians highly regarded in the field of breast cancer. The "Hot Topic" reports are due one month after the Symposium is over and are compiled in a CD-ROM. This interactive CD-ROM is a complete record of meeting highlights that can be circulated by advocacy groups worldwide. In addition, The Alamo Breast Cancer Foundation Patient Advocate Program Committee selects two advocates from the participants to serve as a patient advocate on the two Symposium Case Panels. Subsequent to each Annual San Antonio Breast Cancer Symposium, the Alamo Breast Cancer Foundation holds an Annual Breast Cancer Update Forum for the San Antonio public.

Results: 240 advocates have been funded since 1998. 6 "Hot Topic" books have been printed and circulated. 7 Annual Breast Cancer Update Forums were held in San Antonio. One CD-ROM was produced.12 patient advocates have served on the Symposium Case Panels.

\section{2}

Knowledge and practice of breast-self examination in underserved population (Goiania - Brazil).

Freitas Junior R, Koifman S, Santos NRM, Nunes MOA, Melo AFB. Goias Federal University, Goiania, GO, Brazil; Oswaldo Cruz Foundation, Rio de Janeiro, RJ, Brazil; Hospital das Clinicas, Goias Federal University, Goiania, GO, Brazil

Objective: To ascertain the prevalence of women in a hospital sample in Goiânia, Brazil, who mention to know and to carry out breast-self examination (BSE), likewise the factors yielding to have the knowledge and to practice this diagnostic method. Methodology: A descriptive study was carried out aiming to identify which factors are potentially associated to BSE in a sample of 2,073 women. Data was collected using a standardized questionnaire with women's age, education level, origin, parity, civil status, income and breastfeeding antecedents. Results: 75\% of women knew BSE and 51\% practiced it. A multivariate analysis yielded the following odds ratios: BSE knowledge was 4.2 times higher among housewives than women working outside home; 2.1 times higher among those aged 30 or older, having 5 year at school or higher, 1.98 times higher among those living in the Great Goiânia, 1.4 times higher among those with 2 children or more, and 1.68 times higher among those with an income higher than 2 minimal wages. According to BSE practice, it was 1.7 times more frequently carried out among housewives and that 30 year or older, 1.8 times higher among those with more years at school and 1.2 higher among women with an income higher than 2 minimal wages. Conclusions: The majority of women reported to know BSE, and half of them, to do it. The poorest women, those with low health information and awareness about this technique usefulness to early breast cancer detection, presented high proportions of not knowing and practicing BSE.

\section{3}

Assessing the needs of women with advanced (metastatic) breast cancer.

Mayer M, Grober SE, Caplan ES. Living beyond Breast Cancer, Ardmore, $P A$

Background: As new treatments extend life, women with advanced (metastatic) breast cancer (ABC) have increased needs for information and support. The purpose of this study was to conduct an in-depth assessment of these needs and to help plan new programs and services.

Methods: Living Beyond Breast Cancer (LBBC) staff, consultants and an advisory committee developed a 64-question survey administered online and on paper to people with $\mathrm{ABC}$, focusing on valued and desired services. Online, in-person, print media, and telephone services were assessed. Data was gathered using webbased \& paper survey versions.

Results: A total of 697 people with ABC responded, 619 online; 78 on paper. Those who took the survey on paper were older, with $47 \%$ aged 60 and over, while $70 \%$ of online respondents were ages 40-59. Further differences between online and paper survey groups await analysis.

In a preliminary combined analysis of respondents, $87 \%$ were US residents, 94\% were Caucasian, and 99\% were female. Four-fifths $(86 \%)$ relied on private insurance and/or Medicare. Nearly half $(47 \%)$ were working full or part-time, with $24 \%$ on disability or unemployed. Three-quarters $(77 \%)$ had children, many still at home.

Length of time since ABC diagnosis was variable: $22 \% \geq 1$ year, $35 \%$ 1-2 years, $29 \%$ 3-5 years, $10 \%$ 6-10 years, $4 \%>10$ years. Three-quarters $(75 \%)$ were currently in treatment with active disease, with metastases to bone $(68 \%)$, liver (47\%), lungs/pleura $(37 \%)$, and CNS $(11 \%)$. One-half $(49 \%)$ received hormonal treatment for $\mathrm{ABC}, 43 \%$ chemotherapy, and $30 \%$ biological therapy, while $6 \%$ had enrolled in clinical trials. Most frequently reported current symptoms/side-effects were fatigue or weakness $(67 \%)$, cognitive problems $(60 \%)$, sexual dysfunction $(60 \%)$, disturbed sleep (56\%), hot flashes $(50 \%)$, pain (49\%), depression $(34 \%)$, and anxiety $(28 \%)$. However, $44 \%$ found maintaining daily routines and activities very easy/easy, $37 \%$ somewhat easy, and only $19 \%$ difficult/very difficult.

The desire for information and support was strong. Two-thirds $(67 \%)$ of respondents sought information on ABC at least weekly, $27 \%$ daily. Similarly, $62 \%$ sought emotional/practical support at least weekly, and $30 \%$ daily. Top ranked informational needs focus on treatment options, including clinical trials and symptoms/sideeffects management. Top ranked support needs include stress management and online and in-person support groups. Top ranked practical needs center on referrals for medical care and information with health insurance, Medicare/Medicaid and disability.

Conclusions: There is a growing need for targeted education, information and support for women with advanced (metastatic) breast cancer. This survey offers key insights into the experiences, preferences and behaviors of this underserved population and will be used both to inform program development at LBBC and to educate other health professionals in the breast cancer community. In-depth analyses will be presented at the conference.

\section{4}

Creating a DNA bank for pharmacogenomic epidemiology: the Friends for Life study.

Lemler S, Rufenbarger C, Skaar T, Murphy V, RushTaylor A, Garvey $J$, Thompson B, Christmon D, Coleman N, Rosenberg L, Schneider $B$, on Behalf of the Friends for Life Volunteers. Indiana University, Indianapolis, IN; Catherine Peachey Fund

Background: Increasing interest in genomics and pharmacogenetics has necessitated the recruitment of subjects at low risk for cancer to serve as controls. In order to make valid comparisons, large numbers of subjects with and without a personal history of cancer are required. While subjects with cancer can be recruited from clinic populations indefinitely, recruitment of controls is challenging. A research project evaluating the role of polymorphic differences in genes important in the angiogenesis pathway in breast cancer became the impetus for creating a model for addressing this challenge. 500 women with history of breast cancer and 500 controls were statistically required to address the hypothesis. We estimated total accrual would take months or years to complete with extensive financial funds. To minimize need for resources and to optimize time, an oncology fellow and research nurse from Indiana University (IU) and an advocate from the Catherine Peachey Fund, coordinated to obtain subjects for the trial in a single day. 


\section{S154 Abstracts - Poster Session III}

Methods: The study included the completion of a 5 page questionnaire (consisting of risk factors, medications, and demographic information) and collection of one $9 \mathrm{ml}$ tube of blood (for future DNA extraction and genotyping). The Catherine Peachey Fund, the Breast Cancer Research Foundation and the NIH-Pharmacogenetics Research Network supported the project; additional support was obtained from the IU General Clinical Research Center and pharmaceutical representatives. The Indianapolis Affiliate of the Susan G. Komen Foundation provided support by allowing on-site advertising for the project which would ultimately take place five blocks from the Race for the Cure. Over 160 volunteers from a variety of disciplines assisted with advertising, recruitment, consent, questionnaires and phlebotomy. Results: On Saturday, April 16, 2005, a total of 855 subjects successfully completed the study over a 5.5 hour period.Demographic information for enrollment revealed $92 \%$ of participants were Caucasian, $5 \%$ were African American, $1 \%$ were Asian, and 2\% were other. The mean age of controls was 41 and the mean age of breast cancer survivors was 52. The majority of women enrolled did not have a history of breast cancer (ratio 7 to $1)$. Recruitment to complete enrollment for breast cancer survivors continues in the clinics; 6 weeks after the event, we have enrolled a total of 350 .

Conclusion: IU has developed a model for collecting large groups of subjects for epidemiology studies in a time frame of hours rather than months or years. With detailed logistical planning and concerted effort by a committed group of volunteers, we have demonstrated that it is feasible to obtain biologic samples from a large group of breast cancer survivors and controls within several hours.

\section{5}

\section{Mucositis - an evolving problem.}

Dollbaum CM, Andrews A, Wascher RA, Rosenbaum E, Ignoffo RJ. University of California at San Francisco, San Francisco, CA; Stanford Hospitals and Clinics, Palo Alto, CA; Cancer Research Center, University of Hawaii, Honolulu, HI

Mucositis occurs when cancer treatments break down the rapidly divided epithelial cells lining the GI tract, particularly in the oral cavity, leaving the mucosal tissue open to ulceration and infection. Oral Mucositis is probably the most common, debilitating complication of cancer surgery, chemotherapy and radiation. It occurs in $20-40 \%$ of patients treated with chemotherapy alone and up to $50 \%$ of patients receiving combination radiation and chemotherapy. The consequences of mucositis can be mild requiring little intervention to severe (hypovolemia, electrolyte abnormalities, and malnutrition) that may result in fatal complications.

Taste loss tends to increase in proportion to the aggressiveness of treatment. Nausea, vomiting, diarrhea, xerostomia and oral cavity pain further impair oral intake. Thus, maintaining adequate nutrition is frequently a challenge for patients undergoing therapy. Reduction of caloric intake can lead to weight loss, loss of muscle mass and strength, as well as decreased immunocompetency. Patients with chemotherapy-associated mucositis and immunosuppression are prone to opportunistic oral and enteric infections. Breast cancer patient educators must address the risks and the under-reporting of mucositis. Delayed or reduced medical treatment doses may reduce chances for cure. The potential impact of morbidity and mortality with oral Mucositis should not be underestimated.

Methods: Based upon 2005 website activity to date, this website will serve an estimated 800,000 pages in 2005 (the number of website hits is not included because the term hit can be vastly misleading, e.g. 100 graphics +1 web page $=101$ hits $)$. A pilot questionnaire was developed in December 2004 to evaluate the perceived utility of the new education Internet site, "Mucositis Oral, Esophageal and Gastrointestinal Problems and Solutions" on CancerSupportiveCare.com. Respondents were interested patients, and health care providers from 50 USA and non USA countries. Specific results will be presented.

Conclusion: The worldwide audience of patients and health care personnel derived significant and useful clinical information and insight into Mucositis. Internet-based patient and health care worker education will assist clinicians to better serve the needs of their patients, and improve the quality of their lives.

Results: On line Questionnaire December 2004 - May 2005

(c) $14(n=144$ responaire

*111 were patients $(77 \%)$ and 33 professionals $(23 \%)$

$\begin{array}{llll}* 111 \text { were patients (77\%) and } 33 \text { professionals (23\%) } & \text { (2) Helpful } & \text { (4) Very Helpful }\end{array}$ $\begin{array}{llll}\text { (1) Not Helpful } & \text { (2) Somewhat Helpful } & \text { (3) Helpful } & \text { (4) Very Help } \\ 1(.05 \%) & 8(6 \%) & 57(39.6 \%) & 78(54.2 \%)\end{array}$



\section{6}

Emerging solutions: moving from informed consent to informed choice, an advocate collaborative model.

Devine P, Brady C. Cancer Information \& Support Network, Pleasanton, $C A$

Background: In today's clinical trial arena interest in accrual and retention is extremely high among investigators. A 2001 study by Lara et al, at U.C. Davis, reported that the consent process, with its legalistic and confusing forms, is itself a barrier to patient participation.

This work began with UCSF SPORE advocates who wrote letters for specific studies conducted at UCSF. Under the guidance of UCSF researchers Laura Esserman and Nola Hylton, Ms Devine developed an advocate component for an ACRIN MRI / CALGB correlative science clinical trial. A suite of materials were created to assist patients as they underwent the informed consent process. The study has been open for three years, accrual is close to target projections and retention is $100 \%$ three years and 177 patients later. Our goal at Cancer Information and Support Network (CISN) is to continue this work (using patient centered educational support materials to accompany the consent form) with other projects. CISN principals are now working with UCSF, ACOSOG, ACRIN, Pfizer, Genomic Health, the Colorectal Cancer Coalition, the Ovarian Cancer National Alliance, GlaxoSmithKline, the Summit on Clinical Trials and Genentech on various projects that will provide patients with better ways to understand specific clinical trials. These studies provide a bold new blueprint for advocate involvement in the informed consent process.

Hypothesis: Patient centered educational materials designed to enhance the informed consent process, may increase patient literacy, improve patient satisfaction, and advance public trust in the research enterprise, leading to responsible increased accrual and retention. This new model moves from informed consent to informed choice where patients are presented with more information and support as they undergo consent so they can truly make an informed decision.

Discussion: CISN continues to introduce the medical community to an array of issues affecting patients considering participation in clinical trials: lack of literacy about research requirements, tissue donation; understanding the informed consent process; the importance of meaningful and full disclosure to patients resulting in increased trust of the research enterprise.

CISN works closely with academic, government, other non-profits and industry researchers to help foster public awareness about the importance of medical research to daily life. We address these issues and present various strategies that might be applied to cooperative group and industry trials so as to bridge the research gap, move research forward and adopt the best course to serve the needs of the community, researchers and patients. 
3087

Differential gene expression in normal breast tissue from African American and Caucasian women.

Field LA, Love BJ, Kane J, Deyarmin B, Hooke JA, Ellsworth RE, Shriver CD. Windber Research Institute, Windber, PA; Walter Reed Army Medical Center, Washington, DC

Background: Despite lower overall incidence of breast cancer in African American women (AAW) compared to Caucasian women (CW), AAW have earlier disease onset and less favorable clinical prognosis. These differences can be partly attributed to differences in socio-economic status. However, tumors in AAW have larger size, high grade nuclear atypia, more frequent lymph node involvement, and a higher frequency of estrogen receptor negativity, suggesting that a biological component(s) may also contribute to the poorer prognosis and outcome observed in AAW. In the present study, we used microarray analysis to determine if gene expression differences exist in normal breast tissue that may predispose AAW to earlier onset and a more aggressive tumor phenotype.

Materials and Methods: Normal breast tissue (reductive mammoplasty and/or disease-free biopsy specimens) was collected from age-matched AAW $(n=25)$ and CW $(n=25)$ enrolled in the Clinical Breast Care Project. From each sample, $400 \mathrm{mg}$ of breast tissue was removed and RNA isolated using the Qiagen RNeasy Lipid Tissue Midi kit. RNA was amplified, fragmented, and hybridized to a CodeLink Human Whole Genome Bioarray representing 45,000 transcripts. Mann-Whitney testing was performed to detect differential gene expression between AAW and CW $(P<0.01)$. Differentially expressed genes were then categorized according to their gene ontology.

Results: Over 500 transcripts were differentially expressed between AAW and CW $(P<0.01)$. When the up-regulated genes in each ethnic group were mapped to their biological process ontology, genes involved in cell proliferation were found to be overrepresented in the AAW group. Specifically, although less than $0.9 \%$ of transcripts on the array represent genes involved in cell proliferation, $4.3 \%$ of genes up-regulated in AAW fell into this category compared to only $0.5 \%$ in $\mathrm{CW}(P<0.05)$. Among the genes up-regulated in the AAW group are the proto-oncogene RAF1, fibroblast growth factor 1 (FGF1), and prokineticin-1/EGVEGF, all of which have been reported to increase cell proliferation. Discussion: While poor clinical outcomes in AAW with breast cancer have often been attributed to health care disparities, the data from this study may explain why breast cancer in AAW occurs at a higher frequency in young women. The increased expression of genes involved in cellular proliferation in diseasefree tissues suggests that breast cells in AAW may be dividing more rapidly than those in $\mathrm{CW}$. This increased cellular proliferation may serve as an oncogenic stimulus and/or prematurely age the breast tissue in AAW. Efforts are currently underway to identify population-specific DNA variants in these genes that may account for the increased expression and gene expression changes in breast tumors to determine whether these changes detected in diseasefree tissue are associated with tumor development.

\section{8}

Racial disparities in the utilization of adjuvant chemotherapy and radiation therapy in elderly patients with early stage breast cancer: a population-based study. Hershman DL, McBride RB, Wang X, Grann VR, Jacobson JS, Neugut AI. Mailman School of Public Health, Columbia University, New York, NY; College of Physicians and Surgeons, Columbia University, New York, NY

Background: African American women (black women) with breast cancer have poorer survival than women of predominantly European descent (white women). The purpose of this study is to assess racial disparities in the utilization of adjuvant chemotherapy and radiation therapy in elderly patients with early stage breast cancer.
Methods: The Surveillance, Epidemiology and End ResultsMedicare database represents approximately $14 \%$ of the US population and provides clinical and demographic information on cancer patients covered by Medicare, along with health care utilization data from Medicare claims files. We analyzed the association of demographic and clinical factors with treatment among patients diagnosed from 1992 to 2000 with stage I or III breast cancer at $\geq 65$ years of age.

Results: About $15 \%$ of elderly patients with early-stage breast cancer received some form of chemotherapy within 12 months of diagnosis, and $34 \%$ received radiation therapy (89\% postlumpectomy). In a multiple logistic regression model, black patients were $25 \%$ less likely to initiate chemotherapy or to initiate radiation therapy. Black patients with hormone-sensitive tumors were less likely to receive chemotherapy $(\mathrm{HR}=0.65)$ compared to white patients with hormone-sensitive tumors. In the same model stratified by age, black patients with hormone-sensitive tumors aged 65-69 were half as likely to receive chemotherapy $(\mathrm{HR}=0.55)$. Both chemotherapy use and radiation therapy use decreased with increasing age. With patients aged 65-69 years as the reference group, the odds ratios (ORs) $(95 \% \mathrm{CI})$ of receiving chemotherapy were $0.70(0.6-0.7)$ for ages $70-74,0.40(0.3-0.4)$ for ages $75-79$, $0.10(0.1-0.1)$ for ages $80+$ years. Patients $>80$ years were less than half as likely as younger patients to receive radiation therapy. Conclusions: Despite the proven efficacy of adjuvant chemotherapy and radiation therapy, elderly black women appear to be less likely than elderly white women to receive these treatments. To reduce the burden of cancer overall, further research on the causes of this treatment disparity, and interventions to reduce it are needed.

\section{9}

Delays and receipt of adjuvant chemotherapy and radiation therapy in breast cancer patients: a population-based study. Hershman DL, Wang X, McBride RB, Jacobson JS, Grann VR, Neugut AI. Mailman School of Public Health, Columbia University, New York, NY; College of Physicians and Surgeons, Columbia University, New York, NY

Background: Delay in the diagnosis of breast cancer is associated with both poor survival and non-white race. Few studies have analyzed the determinants or effects of delay in the receipt of adjuvant therapy (chemotherapy and radiation therapy) following surgery for localized breast cancer.

Methods: The Surveillance, Epidemiology and End Results (SEER)-Medicare database, representing approximately $14 \%$ of the US population, provides clinical and demographic information on cancer patients covered by Medicare, along with health care utilization data from Medicare claims files. Among female patients in the SEER-Medicare database aged $\geq 65$ years, diagnosed in 19922000 with stage I or III breast cancer, we investigated the time intervals between breast cancer surgery and the receipt of chemotherapy or radiation therapy and the association of those intervals with survival.

Results: Among 60,756 women in our sample with stages I-III breast cancer, 9,316 (15\%) received adjuvant chemotherapy and $19,975(33 \%)$ received adjuvant radiation therapy $(17,857(89 \%)$ after lumpectomy; 2,118 (11\%) after mastectomy). Among 15\% of those who underwent adjuvant chemotherapy, the time interval from surgery to chemotherapy was $\geq 12$ weeks $(n=1411)$. While $13 \%$ were delayed $>12$ weeks in receiving their post-mastectomy RT, only $5 \%$ were delayed $>12$ weeks beyond their lumpectomy. Delayed chemotherapy was associated with increasing age, AfricanAmerican race, earlier stage, hormone receptor positive tumors, increased comorbidity, and lower grade. Delayed post-lumpectomy RT was associated with race, earlier stage, advanced stage, and increased comorbidity. Delayed radiation therapy predicted poorer survival, either post-lumpectomy (HR 1.6, 95\% CI 1.5-1.6) or post-mastectomy (Hazard Ratio 1.7, 95\% CI 1.6-1.8).. Delay in RT following chemotherapy was also associated with poorer survival 


\section{S156 Abstracts - Poster Session III}

(HR 1.9, 95\% CI 1.6-2.3), but delay in initiating chemotherapy was not (HR 1.0).

Conclusions: Although long delays ( $>12$ weeks) in receipt of adjuvant chemotherapy or radiation therapy are not very common following surgery, certain groups, notably African-Americans, those who are older, and those with comorbidities, are more likely than others to experience such delays. Although delays in the initiation of radiation may be causally linked to poor prognosis, they may also reflect uncontrolled confounding by host factors or generally inadequate medical care.

\section{0}

Impact of ethnicity on conditional survival of breast cancer patients: analysis from the SEER database.

Wang SJ, Luh JY, Fuller CD, Thomas, Jr CR. University of Texas Health Science Center, San Antonio, TX

Background: Conditional survival is a more accurate estimate of survival probability for patients who have already survived one or more years following diagnosis. The purpose of this study was to determine whether ethnicity plays a role in the 5-year conditional survival rates for breast cancer patients.

Methods: Using the Surveillance, Epidemiology, and End Results (SEER 11) database from the NCI, we analyzed 98,845 breast cancer patients diagnosed between 1988 and 1994. Patients were divided into 4 ethnic groups, White (non-Hispanic), Hispanic, African-American, Asian/Pacific Islander. Using the life table method, we computed the observed 5-year conditional survival, stratified by stage and ethnicity, for patients who had already survived up to 5 years after diagnosis.

Results: In general, five-year conditional survival rates rose most significantly for advanced stage patients (III and IV) as survival time since diagnosis increased. African-American women had the lowest survival rates at diagnosis for all stages, and the lowest conditional survival for most survival times since diagnosis. The disparity was particularly marked for stage III patients at the time of diagnosis, where African-American women had survival of $34 \%$, compared to $50-51 \%$ for the other ethnic groups. However, this difference resolved by 5 years after diagnosis, where conditional survival became comparable to that for White women $(62 \%)$. Asians/Pacific Islanders had slightly higher conditional survival than other ethnic groups for stage I $(90-94 \%)$ and stage II (81$83 \%$ ), for all time periods from 0 to 5 years after diagnosis. Conditional survival increased significantly with time for all stage IV patients, but was most pronounced for Hispanic patients, where 5 -year conditional survival rose from $17 \%$ at time of diagnosis, to $55 \%$ at 5 years after diagnosis.

Conclusion: For breast cancer patients surviving a period of time after diagnosis, 5-year conditional survival rates vary by ethnicity. Asian/Pacific Islanders with stage I and II disease had higher conditional survival than other ethnic groups. The most significant increases in conditional survival were seen for AfricanAmerican women with stage III disease, and for Hispanic women with stage IV disease. Conditional survival can provide more accurate prognostic information for breast cancer patients who have already survived several years after diagnosis. Five-Year Conditional Survival

\begin{tabular}{|c|c|c|c|c|}
\hline \multirow{2}{*}{\multicolumn{5}{|c|}{ African-American }} \\
\hline & & & & \\
\hline \multicolumn{5}{|l|}{0 yrs after Dx } \\
\hline \multicolumn{5}{|l|}{$\begin{array}{l}5 \text { yrs after Dx } \\
\text { Stage II }\end{array}$} \\
\hline \multicolumn{5}{|l|}{0 yrs after Dx } \\
\hline \multicolumn{5}{|l|}{ Stage III } \\
\hline 0 yrs after Dx & & $50 \%$ \\
\hline & \multicolumn{3}{|c|}{ Stage IV } & $70 \%$ \\
\hline 0 yrs after Dx & $16 \%$ & $17 \%$ & $12 \%$ & $16 \%$ \\
\hline 5 yrs after Dx & $38 \%$ & $55 \%$ & $44 \%$ & $48 \%$ \\
\hline
\end{tabular}

3091

Low socio-economic status African-American, Hispanic \& white women with breast cancer demonstrate similar hormone receptor status, tumor grade \& survival.

Dookeran KA, Wang Y, Ferrer K, Sekosan M, Gao X, De La Torre $R$, Diaz de Leon L, Lukaszcyk B, Roman G, Muthyala N, Rogowski WA, Zaren HA. University of Illinois at Chicago, Chicago, IL; Stroger Hospital of Cook County, Chicago, IL

Background: Compared with other races, African-American (AA) women with breast cancer are more frequently diagnosed with high grade, hormone receptor (HR) negative tumors, and have poorer survival. However, recent studies suggest that women with low socio-economic status (SES), regardless of race, demonstrate similar HR status and poor outcome. We hypothesized that low SES AA, White and Hispanic women with breast cancer, treated at a single institution, would demonstrate similar tumor biology and survival.

Materials \& Methods: Clinical-pathological features and survival were evaluated for 462 consecutive low SES women with breast cancer, diagnosed and treated at the MBCCOP, Stroger Hospital of Cook County, which treats the medically-underserved \& indigent in Chicago. Results were compared for AA, White and Hispanic women, and included adjustment for variations in age and stage. Results: There were 291 AA, 85 White and 86 Hispanic women. Significantly fewer AA $(31 \%)$ \& White $(35 \%)$ women were age < 50 years old, compared to Hispanics $(56 \%$; $<<0.01)$. No significant differences occurred between races with regards to tumor size (T3 $=12,8 \& 8 \%$ for AA, White \& Hispanic respectively), tumor grade (grade $3=52,54 \& 56 \%$ ), lymph node status (positive $=46$, $53 \& 54 \%)$, stage at diagnosis ( $>2 \mathrm{~B}=58,57 \& 58 \%)$, HR status (negative $=41,42 \& 43 \%$ ) and disease free (DFS; events $=28,27$ $\& 23 \%$ ), distant disease free (DDFS; events $=20,21 \& 19 \%$ ) or overall survival (OS; $18,17 \& 13 \%$ ). High grade tumors were significantly more likely to be HR negative $(\mathrm{p}<0.01)$ and higher stage $(\mathrm{p}<0.01)$. Multivariate analyses adjusted for age and stage, demonstrated no difference in HR status, tumor grade or survival for AA versus White or Hispanic women.

Discussion: These results indicate that underserved or low SES AA, White and Hispanic women with breast cancer, treated at a single institution, demonstrate similar survival and tumor biology, with higher frequency of both high grade and HR negative tumors. Prevalence of low SES and data heterogeneity, may be responsible for the relative excess of high grade, HR negative tumors seen in AA women in prior studies.

\section{2}

Racial/ethnic differences in delay in obtaining medical care for breast symptoms.

Friedman LC, Kalidas $M$, Elledge R, Chang J, DuLay MF, Romero C, Liscum KR. Baylor College of Medicine, Houston, TX; Baylor College of Medicine-The Methodist Hospital Breast Care Center, Houston, TX

Background: Delay in obtaining medical care for breast symptoms is associated with increased morbidity and mortality. A number of factors have been associated with delay, for example, African American or Hispanic ethnicity, younger age, lower income, less education and presence of symptoms other than breast lumps. Despite the fact that African Americans, Hispanics and the poor are more likely to delay, differences in delay among these groups has received little attention.

Material and Methods: Participants were a multiethnic sample of 97 women with breast symptoms attending an outpatient breast clinic in a public sector general hospital. Only women without diagnosed breast cancer were eligible for this study. Participants completed questionnaires measuring demographic and medical characteristics, perceived risk of developing breast cancer, degree of spirituality and barriers to obtaining medical care for breast symptoms. 
Results: Mean age was 44 years. Participants were 59\% Hispanic, $30 \%$ African-American and $11 \%$ Caucasian. Thirty-five per cent were married, $40 \%$ were employed and $74 \%$ had a high school education or less. Twenty-four per cent reported a family history of breast cancer. Forty-six per cent had delayed obtaining medical care three months or longer after having detected a breast symptom, the mean delay being nine months. Over $50 \%$ of the women perceived little or no chance of developing breast cancer despite reporting breast symptoms. Hispanics were younger, delayed longer and were less spiritual than Caucasians or African Americans ( $p$ 's < $0.05)$. Hispanics reported more barriers to seeking a medical consultation than Caucasians $(p<0.05)$. Less educated Hispanics reported more symptoms other than breast lumps than less educated African Americans or Caucasians ( $p$ 's $<0.05$ ). Hispanics reported worry about cancer being a barrier to seeking medical care more than did Caucasians $(p<0.01)$. The three racial/ethnic groups did not differ in their perceptions of risk.

Conclusion: The current study suggests that Hispanic women in public sector settings are at increased risk for late stage diagnosis of breast cancer due to delay in seeking medical consultation for breast symptoms. Low-income women with less education should be instructed about their risk of breast cancer and the importance of seeking prompt medical consultation.

\section{3}

Factors affecting breast cancer screening practices among African American women in Western New York.

Hurd TC, Chapman IR, Kelly M, Wall B, Rodgers T, Womack SD. University of Texas Health Sciences Center, San Antonio, TX; Roswell Park Cancer Institute, Buffalo, NY; State University of New York at Buffalo, Buffalo, NY

Background: African American women have lower breast cancer screening utilization rates than other populations. This study was conducted to assess correlates of screening among women who participated in a community based breast and cervical cancer education program.

Methods: The Witness Project is a community based breast cancer education program delivered by African American women. In this setting, African American women over age 18 who attended Witness Project programs gave informed consent and completed a questionnaire at the completion of the program presentation. Current and prior screening practices (breast self exam (BSE), clinical breast exam (CBE), mammography), screening barriers, knowledge of breast cancer risk factors, method of referral for screening and demographic information were queried and entered into a central data base. Uni- and multivariate analysis were performed using the SPSS statistical software package.

Results: Twenty five percent of 688 women who completed the questionnaire were under age 40 and 19\%(129) were $\geq 70$ years of age. Sixty four percent attained education beyond grade $12.58 \%$ of participants under age 40 did not perform BSE in the prior month and $37 \%$ denied having a clinical breast exam in the prior year. Conversely, over $70 \%$ of women $\geq$ age 40 had BSE and CBE. While 388/514 women who were screening eligible received a mammogram in the preceding 12 months, only $46 \%$ had yearly mammography during the preceding 5 years. Cost, insurance status and lack of a regular provider were significant barriers to screening for women who did not have mammograms. Furthermore, $28 \%$ of these women 'felt they didn't need one'. Only $7 \%$ of women cited lack of referral as a barrier. Multivariate analysis showed that women age 40-69 had significantly higher odds of having BSE, $\mathrm{CBE}$ and annual mammograms in the prior 5 years compared to women $\geq 70$ years (OR $2.26[0.96-0.39]$ vs. 0.39 [0.15$1.04] ; \mathrm{p}<0.05)$. Neither higher educational level nor knowledge of breast cancer risk factors increased the odds of having combination screening.

Discussion: Educational level and knowledge of risk factors do not increase combination breast cancer screening in this cohort. Sustained annual screening rates remain low despite the increase in reported mammography rates. Older African American women are less likely to have guideline concordant breast cancer screening when compared to younger women.

\section{4}

Racial differences do not predict response to induction chemotherapy.

Maloney N, Schneider H, Elkins D, Goffman T, Laronga C. Eastern Virginia Medical School, Norfolk, VA

Introduction: Racial disparities exist in breast cancer for a plethora of reasons. African American (AA) women typically present at a younger age with larger receptor negative tumors and increased nodal positivity. Induction chemotherapy (IC) is offered to women with large tumor or node positive disease at presentation. Our objective was to determine if any racial differences exist in response to IC between the AA and the Caucasian (C) women.

Methods: A retrospective review of prospectively gathered data on women diagnosed with locally advanced breast cancer and treated with IC was conducted at our institution. Data collected focused on tumor size at presentation based on clinical exam and/or imaging studies, pathological tumor size at surgery, calculation of response to therapy, nodal status, type of surgery performed and survival. Statistical analysis was by Chi square and paired T-tests.

Results: From 3/96 to 10/04, 66 women (33 AA, 33 C) were diagnosed with locally advanced breast cancer and treated with IC. Overall the median age was 46 years ( $\mathrm{AA}=46 \mathrm{yrs}, \mathrm{C}=47 \mathrm{yrs}$; $\mathrm{p}=0.168)$. The median tumor size was $4 \mathrm{~cm}($ range $=0-25 \mathrm{~cm})$ $(\mathrm{AA}=5.0 \mathrm{~cm}, \mathrm{C}=3.5 \mathrm{~cm} ; \mathrm{p}=0.015)$ based on initial clinical examination. Median tumor size radiographically was $2.7 \mathrm{~cm}$ (range $=0-12 \mathrm{~cm})(\mathrm{AA}=3.2 \mathrm{~cm}, \mathrm{C}=2.55 \mathrm{~cm}, \mathrm{p}=0.024)$. Median final pathological size was $2.2 \mathrm{~cm}$ (range $=0-20 \mathrm{~cm})(\mathrm{AA}=3.5 \mathrm{~cm}$, $\mathrm{C}=1.75 \mathrm{~cm}, \mathrm{p}=0.339)$. At least a partial response $(>50 \%$ reduction in clinical tumor size) was seen in 26 women $(47.3 \%)(\mathrm{AA}=9$, $\mathrm{C}=17$ ) [3AA and $1 \mathrm{C}$ had a complete pathological response]. There were no significant racial differences based on either the follow-up clinical examination after the course of IC $(\mathrm{p}=0.075)$ or based on radiographic imaging after IC $(\mathrm{p}=0.393)$. Axillary node involvement post IC occurred in $45.5 \%$ ( $\mathrm{AA}=48.5 \%, \mathrm{C}=42.4 \%$, $\mathrm{p}=0.621)$. As of $5 / 05,14(21.2 \%)$ women have died of their disease $(A A=9, C=5 ; p=0.228$.) and another $6(9.1 \%)$ women have distant metastatic disease currently $(\mathrm{AA}=4, \mathrm{C}=2 ; \mathrm{p}=0.392)$. Conclusions: African Americans present with larger breast cancers than Caucasian women. However, no racial differences could be identified in women receiving IC for their breast cancer with regards to response to therapy, lymph node involvement after IC, or survival. Better treatment strategies for locally advanced breast cancer are equally needed for both races.

\section{5}

Eligibility to the study of tamoxifen and raloxifene (STAR) by ethnicity in New Mexico (NM).

Vargas Y, Parsons A, Heurtin-Roberts S, Verschraegen C, Moser R, McCaskill-Stevens W. NCI/NIH, Bethesda, MD; UNM, Albuquerque, $N M$

Background: Preliminary results from STAR present data on Hispanics in aggregate. Results may not generalize to the many diverse ethnic groups comprising the U.S. Hispanic population. NM is 39\% Hispanic. Descendents of original Spanish settlers populate the north and Mexican immigrants populate the south. We sought to compare eligibility characteristics for STAR in northern NM according to Hispanic and non-Hispanic white ethnicity from 1999-2004. Methods: Eligibility to STAR was determined by responses to the Gail model-based risk assessment tool. Calculated risk for developing invasive breast cancer (IBC) was based upon current age, age of menarche, number of breast biopsies, age at first live birth, number of first degree relatives with IBC, and ethnicity. Eligibility required a modified Gail risk of $\geq 1.67 \%$ of IBC at five years from assessment. Ethnicity was self- 


\section{S158 Abstracts - Poster Session III}

reported. Using zip codes, residence was established to be north or south of $34.5^{\circ}$ latitude. Risk factors for Hispanics and Non-Hispanic whites were compared using $t$-test or $\chi^{2}$ analyses. Logistic regression was used to assess predictors of eligibility including interactions with ethnicity. Results: $95.5 \%(n=297)$ of respondents resided in northern NM. Eligibility differed by ethnicity $\left(\chi^{2}=21.1, \mathrm{p}<.01\right)$ with a lower proportion of Hispanics $(50.7 \%, \mathrm{n}=35)$ eligible than non-Hispanics whites $(78.9 \%, \mathrm{n}=180)$. Mean Gail risk scores differed by ethnicity $(t=2.78, \mathrm{p}<.01)$ with Hispanics having a lower mean $(2.29 \%)$ relative to non-Hispanic whites $(3.02 \%)$. No difference was detected in mean Gail risk between the ethnicities when stratified into eligible or ineligible respondents. Nor was there a difference in mean current age, age of menarche, or number of breast biopsies by ethnicity. Mean age at first live birth differed for Hispanics, 20.7 years compared to non-Hispanic whites, 23.3 years $(t=3.87, \mathrm{p}<.01)$. Hispanics had a lower proportion $(30.3 \%)$ of a maternal history of breast cancer compared to non-Hispanic whites $(54.1 \%)\left(\chi^{2}=11.5, \mathrm{p}<.01\right)$. Hispanics reported a fewer number of first degree relatives affected with $\operatorname{IBC}(0,1$, or $\geq 2)$ than non-Hispanic whites $\left(\chi^{2}=10.4, \mathrm{p}<.01\right)$. No interaction was detected between ethnicity and each of the other risk factors as they predict eligibility. Conclusions: Hispanics were less likely to be eligible to STAR than non-Hispanic whites in northern NM. Respondents differed significantly in eligibility characteristics by ethnicity and by IBC risk factors - overall Gail score, mean age at first live birth, maternal history of IBC, and number of first degree relatives. Risk factors did not predict eligibility differentially by ethnicity. Gail risk for eligible women did not differ statistically by ethnicity. Results support Gail's premise that the risk required for Hispanics to be eligible to STAR is greater relative to non-Hispanic whites.

\section{6 \\ Breast cancer treatment and survival in African Americans and Caucasians.}

Banerjee M, Schwartz K, May HC, Noone AM, Vigneau F, Simon M. University of Michigan, Ann Arbor, MI; Karmanos Cancer Institute, Wayne State University, Detroit, MI

BACKGROUND: Breast cancer (BC) is currently the most common malignancy diagnosed among women, and the second leading cause of cancer mortality in the United States. African Americans (AA) suffer disproportionately higher mortality from BC compared to Caucasian Americans (CA). Poorer survival among AA is often attributed to a more advanced stage of disease at diagnosis. However, residual disparities in BC survival remain even after adjusting for stage at diagnosis, suggesting that factors other than stage contribute to the poorer survival in AA. In recent years, a competing theory that cancer biology is different in AA compared to $\mathrm{CA}$ has gained prominence. Yet, few studies have evaluated the role of treatment aggressiveness in survival differences between $\mathrm{AA}$ and CA. This study examined if racial differences in BC survival can be partly explained by treatment differences in the two groups, using the Metropolitan Detroit SEER registry data. METHODS: Eligibility criteria for this study were: AA or CA cases diagnosed with primary invasive BC between 1988 and 1992, and living in the Detroit tri-county area at the time of diagnosis. Cases were obtained from the Detroit SEER registry and geocoded to census block group. Data were linked to 1990 Census of Population and Housing Summary Tape File $3 \mathrm{~A}$ to obtain information on socioeconomic status. Information on treatment (primary as well as adjuvant) and survival were obtained from SEER. Polytomous logistic regression was used to compare the two racial groups in terms of treatment patterns, after adjusting for age, socioeconomic status, tumor size, and number of positive lymph nodes. Cox proportional hazards model was used to compare survival in AA versus CA, after adjusting for age, socioeconomic status, tumor size, number of positive lymph nodes, and treatment received. RESULTS: A total of 9,597 BC cases diagnosed with local or regional disease were analyzed. CA comprised $82 \%$ of the cases.
Sixty-three percent of the cases were local stage, and $36 \%$ were regional stage. Eleven percent of the cases had lumpectomy only, $21 \%$ had lumpectomy with radiation, $62 \%$ had mastectomy only, and the remaining $6 \%$ had mastectomy with radiation. There was significant difference in treatment patterns between AA and CA ( $\mathrm{p}$-value=0.009), with AA receiving radiation less frequently for both local and regional stage disease. Among patients diagnosed with regional stage disease, AA had poorer survival compared to CA after adjusting for age, SES, tumor size, number of positive lymph nodes, and treatment. There were no significant differences in survival between the two races for local stage disease, after adjusting for age, SES, tumor size, number of positive lymph nodes, and treatment. CONCLUSION: Findings from this research can help objectively address the factors that contribute to the disparate mortality in AA, by targeting patient education and intervention efforts in this population.

\section{7}

Understanding racial differences in outcome from metastatic breast cancer (MBC): a pooled analysis of Cancer and Leukemia Group B (CALGB) 9342 and 9840.

Polite BN, Cirrincione C, Fleming GF, Berry DA, Seidman AD, Muss H, Norton L, Hudis C, Winer EP. University of Chicago Medical Center, Chicago, IL; Duke University Medical Center, Durham, NC; Memorial Sloan-Kettering Cancer Center, New York, NY; University of Vermont, Burlington, VT; Dana-Farber Cancer Institute, Boston, MA

Background: African American (AA) women are more likely to be diagnosed with MBC than Caucasians (C). They also have lower 5 year survival rates once diagnosed. The reasons for this survival difference are not clear. This study examines racial differences in survival and response in the setting of two large cooperative group randomized clinical trials.

Methods: The study cohort consisted of $787 \mathrm{C}(80 \%)$ and 195 AA $(20 \%)$ patients (pts) with MBC enrolled in CALGB trials 9342 (paclitaxel $175 \mathrm{mg} / \mathrm{m} 2$ v $210 \mathrm{mg} / \mathrm{m} 2$ v $250 \mathrm{mg} / \mathrm{m} 2$ q 3 weeks) and 9840 (weekly v q 3 week paclitaxel). Sixty-one pts $(6 \%)$ who were non-C and non-AA and 13 pts $(1 \%)$ with unknown ethnicity were excluded from the analyses. Overall survival (OS), response rate (RR) and time to failure (TTF) differences were examined by race. Future analyses will use statistical modeling to adjust for differences in known prognostic factors between the groups and will explore differential rates of toxicity including neutropenia.

Results: AA pts were more likely to be younger (median age 52 vs 57 ), premenopausal ( $26 \%$ vs $15 \%$ ), and have ER negative tumors $(51 \%$ vs $38 \%)$. AA women were also more likely to have had a performance status of 2 or greater (9\% vs $5 \%$ ) and to have received prior chemotherapy ( $51 \%$ vs $41 \%)$. Stratified by previous therapies, RR were $40 \%$ for AA and $35 \%$ for $\mathrm{C}$ in first line $(\mathrm{p}=0.41)$ and $20 \%$ vs $25 \%$ in second line $(\mathrm{p}=0.32)$. With 779 deaths $(166$ AA and $613 \mathrm{C}$ ), unadjusted median OS was 14.3 months (mo) for AA and 18.75 mo for $\mathrm{W}(\mathrm{p}=0.0001)$. Unadjusted median TTF was 4.9 mo for AA and 6.4 mo for $\mathrm{W}(\mathrm{p}=0.019)$.

Conclusions: Consistent with data from epidemiological studies, in this cohort, AA pts have a shorter survival for MBC than do C. The extent to which this survival disparity stems from underlying differences in measured tumor and patient specific factors will be explored further. Despite these differences, AA appear to derive equal benefit from therapy in terms of tumor response.

\section{8}

Does screening underserved/minority women for breast cancer under the age of $\mathbf{5 0}$ make a difference?

Shum M, Robles E, Kankipati S, El-Khoury M, Bodofsky E, Grana G. The Cancer Institute of New Jersey at Cooper University Hospital, Camden, NJ

Background: Although breast cancer screening rates have increased in recent years nationwide, the importance of screening 
underserved/minority women at a younger age has not been clearly reported. We initiated this study to determine the number of women under the age of 50 who were screened and diagnosed with breast cancer from our Camden County Cancer Screening Project (CCCSP) and compared these results with our institutional registry, state and national findings.

Methods: We retrospectively identified all women diagnosed with breast cancer through our screening project using the CAncer Screening Tracking System. All women screened were minority, uninsured, or living at or below $250 \%$ of the poverty line in Camden County, New Jersey. Age comparison at diagnosis was made utilizing the Cooper registry and the National Cancer Database (NCDB).

Results: A total of 3,458 unduplicated women were screened for breast cancer from 1993-2004. Sixty-three women (AfricanAmerican-17, Asian-1, Caucasian-29, Hispanic-16) were diagnosed with breast cancer. Median age of diagnosis was 50 years (range, 29-84 years). Final histology resulted in 14 cases of DCIS and 49 cases of invasive carcinoma. TNM staging revealed: $14(22.2 \%)$ with stage $0,14(22.2 \%)$ with stage I, $23(36.5 \%)$ with stage II, 11 $(17.5 \%)$ with stage III, and $1(1.6 \%)$ with stage IV. Interestingly, $31 / 63(49.2 \%)$ of the women from the CCCSP were diagnosed under the age of 50 with no known cases of BRCA $1 / 2$ mutations. Approximately $1,940 / 3,458(56.1 \%)$ of the women screened were under 50. Additionally, 11/17 (64.7\%) of our African Americans were $<50$ vs. $29.3 \%$ for the total $\mathrm{NJ}$ data, $\mathrm{t}=2.71, \mathrm{p}=.02$ and $30.4 \%$ for the total US data, $\mathrm{t}=3.02, \mathrm{p}<.01$. Series of comparisons from the CCCSP with the Cooper registry, the state and national figures are noted below.

Conclusions: Our screening project and our institutional registry had a proportionately higher percentage of women diagnosed with breast cancer $<50$ when compared to the state and the national figures. Comparing our data for African Americans vs. NJ and US (NCDB 2001) showed that our patients were younger. Further evaluation is needed to elucidate whether socioeconomic factors (i.e. nutrition, housing conditions, environmental exposures, and education) are contributing to this rise in early breast cancers in underserved/minority women.

Table 1. Summary of Patients Diagnosed with Breast Cancer Under 50

\begin{tabular}{|c|c|c|c|c|}
\hline Comparison groups & No. of Patients & $\begin{array}{l}\text { No. of } \\
\text { Patients (\%) }\end{array}$ & $\begin{array}{l}\mathrm{Z} \\
\text { score }\end{array}$ & $\begin{array}{l}\mathrm{p} \\
\text { value }\end{array}$ \\
\hline $\begin{array}{l}\text { CCCSP vs. Cooper } \\
\text { Registry }(1996-2003)\end{array}$ & $31 / 63$ vs. $192 / 645$ & 49.2 vs. 29.8 & 2.94 & $=.004$ \\
\hline $\begin{array}{l}\text { CCCSP vs. } \\
\text { NJ (2001) }\end{array}$ & $31 / 63$ vs. $1259 / 5644$ & 49.2 vs. 22.3 & 4.3 & $<.0001$ \\
\hline $\begin{array}{l}\text { CCCSP vs. } \\
\text { US (2001) }\end{array}$ & $31 / 63$ vs. $34614 / 155596$ & 49.2 vs. 22.2 & 4.28 & 01 \\
\hline $\begin{array}{l}\text { Cooper Registry vs. } \\
\text { NJ (2001) }\end{array}$ & $192 / 645$ vs. $1259 / 5644$ & 29.8 vs. 22.3 & 4.05 & $<.0001$ \\
\hline Cooper Registry vs. & $192 / 645$ vs. $34614 / 155$ & 29.8 vs. 22.2 & 3.61 & \\
\hline
\end{tabular}

$\begin{array}{lllll}\text { Cooper Registry vs. } \quad 192 / 645 \text { vs. } 34614 / 155596 & 29.8 \text { vs. } 22.2 & 3.61 & =.0004\end{array}$

US (2001)

\section{9}

Hormone replacement therapy (HRT) may not increase the incidence of breast cancer in Japan.

Saeki T, Takashima S, Takeuchi M, Sano M, Honjo H, Sonoo H, Ochiai K, Komoike Y. Saitama Medical School, Irumagun, Saitama, Japan; Shikoku Cancer Center, Matsuyama, Ehime, Japan

Background: A prospective study conducted by Woman's Health Initiatives demonstrated an increased risk of breast cancer in the United States. Other studies also supported this result and hormone replacement therapy (HRT) has been considered as one of risk factors of breast cancer. However, the incidence of breast cancer is still low in Japanese population comparing to the USA. We conducted a case-control study to clarify the relationship between HRT and breast cancer incidence in Japan.Material and Methods: 45 to 69 years aged women with histological confirmed breast cancer in 3 major cancer centers and 3 university hospitals were selected to be a case group. We sent questionale to 4500-breast cancer patients treated with those institutions by mail. In a case group, we selected patients who already had recieved treatments and we asked the history of HRT before their onset of breast cancer. On the other hand, a control group was selected with regard to hospital based and to records of screening for GI disease and respiratory disorders, and no history of previous treatment for breast cancer, gynecological and hormonal disease was essential. Control group must be 45-69 years aged healthy post-menpausal Japanese women and be no diagnosed breast cancer at this moment. Forty-five thousands Japanese women were selected by the inclusion criteria of the protochol and questionale were sent by mail. Contents of questionale included factors, which were related to breast cancer incidence. Institutional review board in each institution reviewed and our protocol was certified. Data center was located in Kitasato University and collected data were analyzed independently. For statistical analysis, SAS8 (version 8.2) was used and two statisticians evaluated the statistical results independently. Results: 5035 questionale were collected by the end of December 2004. We have sent 6282-questionale and compliance was approximately $80 \%$. We planned an interim analysis when we analyzed 2000 questionale. On December 2004, 2344 cases (1224 case and 1120 control) were analyzed. Out of 1224 persons in a case group, 46 patients $(3.8 \%)$ received HRT and 104 of $1120(9.6 \%)$ healthy women received HRT. Odds ratio was $0.374(95 \% \mathrm{CI}=0.262-0.535)$. Four of 46 patients received HRT more than 5-years, otherwise 21 of 104(20.2\%) healthy women received. There was no statistical significance in BMI, history of smoking, history of benign breast disease, age of first child, daily excise and family history between a case and a control group. Discussion: Our interim analysis of the case-control study demonstrated no correlation between HRT and breast cancer in Japanese women. These results came from interim analysis of $38 \%$ planned data set of the case-control study and we are planning to analyze 6282 questionale until the end of August 2005.

\section{0}

Cyclophosphamide and 5-fluorouracil: an alternative neoadjuvant chemotherapy for patients with stage II breast cancer in underdeveloped countries.

Vigil CE, Vigil KJ, Valdivia S, Velarde R, Vigil Sr CE. Henry Ford Hospital, Detroit, MI; Instituto de Enfermedades Neoplasicas, Lima, Peru

In underdeveloped countries, like Perú, the majority of patients cannot afford current standard recommended chemotherapeutic cancer regimens secondary to its expensive cost. Therefore, we designed a neoadjuvant chemotherapeutic protocol for the treatment of patients with stage II breast cancer with cyclophosphamide and 5 fluorouracil, affordable drugs for our population.

Material and Methods: Forty patients with stage II breast cancer received neoadjuvant chemotherapy with cyclophosphamide 1000 $\mathrm{mg} / \mathrm{m} 2 \mathrm{IV}$ and 5 -fluorouracil $1000 \mathrm{mg} / \mathrm{m} 2$ IV every 21 days for four cycles. Afterwards, lumpectomy and axillary dissection were done, followed by breast irradiation. Patients with axillary node involvement received four additional courses of the same adjuvant chemotherapeutic regimen. Overall survival rate and disease free survival rate were calculated.

Results: Thirteen of the forty patients $(32.5 \%)$ had stage IIB breast cancer. The average tumor size was $3.12 \mathrm{~cm}$ and axillary lymph node metastases were found in $42.5 \%$. The overall response rate was $60 \%$, with complete clinical response in $17.5 \%$ of cases. The pathological complete response was $5 \%$ and carcinoma in situ was found also in $5 \%$. The overall survival rate at 5 years was $77.3 \%$ and the disease free survival rate $70 \%$, similar to results reported with other standard regimens.

Conclusions: Combination of cyclophosphamide and 5fluorouracil demonstrated similar overall and disease free survival rate compared to the standard chemotherapy regimen recommended in the literature and it can be used as an alternative regimen of neoadjuvant chemotherapy treatment for patients with stage II breast cancer who cannot afford expensive chemotherapy. 
3101

A comparison of clinicopathological features and molecular markers in British and Nigerian women with breast cancer. Gukas ID, Jennings BA, Mandong BM, Girling A, Igun G, Prime W, Leinster SJ. University of East Anglia; Norfolk and Norwich University Hospital Trust, Norwich, United Kingdom; Jos University Teaching Hospital, Jos, Nigeria; Univeristy of Liverpool, Liverpool, United Kingdom

Background: Several studies have suggested that breast cancer in black women is more aggressive than in white women. This study examines the clinical stage, grade and five molecular markers in breast cancer material from Nigeria and United Kingdom to see if there are biological differences.

Methods: The histological diagnoses of 178 consecutive Nigerian patients with breast cancer and 113 consecutive British patients with breast cancer were retrieved from their hospital records. A subset of 68 age-matched Nigerian and British patients was staged and their tumours typed and graded. Immunohistochemical staining of sections from paraffin wax embedded tissues from these cases for the expression of oestrogen receptor (ER), progesterone receptor (PGR), ERBB2 (HER2/neu), P53 and cyclin D1 (CCND1) was carried out using the avidin biotin complex $(\mathrm{ABC})$ procedure. The Chi square test was used for statistical analysis.

Results: Invasive ductal carcinoma made up $92.7 \%$ of the Nigerian patients compared to $77 \%$ seen in the British patients. Significant difference in clinical stage but not tumour grades was also observed. The expression of ER and Cyclin D1 was significantly higher in the British patients than the Nigerian patients $\left(\mathrm{X}^{2}=6.0123 \mathrm{P}=\right.$ $0.0142, \mathrm{X}^{2}=3.9272 \mathrm{P}=0.0475$ respectively). Other markers showed no statistical difference.

Conclusion: The differences in prognosis of breast cancer between Nigeria and Britain may be partly explained by differences in hormone receptors and cell cycle regulation in addition to the obvious differences in stage at presentation.

\section{2}

The SNP309 HDM2 polymorphism is associated with chemoresistance and poor survival in breast cancers harboring mutations in the TP53 gene.

Staalesen V, Knappskog S, Geisler S, Baumbusch L, BørresenDale AL, Lillehaug JR, Lønning PE. University of Bergen, Bergen, Norway; Haukeland University Hospital, Bergen, Norway; The Norwegian Radiumhospital, Oslo, Norway

Background: Chemoresistance is the main obstacle to cancer cure. We previously reported mutations in the TP53 gene to be associated with resistance to doxorubicin and subsequently mitomycin treatment in breast cancer. The key role of the p53 pathway was recently substantiated by the finding of a mutation in the CHEK2 gene in one of our patients wildtype for TP53 expressing resistance to doxorubicin. Recently, a novel polymorphism (SNP309, T/G) in the HDM2 promoter was described and homozygosity for the $\mathrm{G}$ allele was associated with early cancer development as well as increased risk of development of multiple cancers in Li-Fraumeni families, and attenuated response to etoposide in cell cultures. The SNP309 promoter variant alters a transcription factor binding site, leading to increased HDM2 expression in cell lines during cellular stress.

Materials and Methods: To investigate the possibility that the SNP309 polymorphism might affect breast cancer risk, as well as response to chemotherapy, we analyzed tumor DNA from 122 patients with locally-advanced breast cancers previously evaluated for the predictive value of TP53 status to chemoresistance. In addition, we also analyzed blood DNA from 92 healthy controls. Results: We here report homozygosity for the G allele to be associated with drug resistance in patients harboring TP53 mutations affecting the $\mathrm{L} 2$ / $\mathrm{L} 3$ domains $(\mathrm{P}=0.0188)$, but not in patients wildtype for TP53
Discussion: Our observations that homozygosity for the $G$ allele of the HDM2 polymorphism was associated with drug resistance in tumors harboring TP53 mutations suggest that this allele could interact with, and amplify, the effect of TP53 mutations. This finding ties in with our recent observation with respect to the CHEK2 gene. Similar to TP53, mutations in CHEK2 is associated with the Li-Fraumeni syndrome, and we recently found a somatic mutation in this gene in one of our tumors wildtype for TP53 expressing resistance to doxorubicin treatment. As HDM2 and CHK2 are closely linked (CHK2-mediated p53 phosphorylation inhibits HDM2-p53 complex formation), a similar effect of the G allele of the SNP309 on p53 as that resulting from $\mathrm{CHK} 2$ inactivation may be hypothesized. It is therefore highly interesting to note that while CHEK2 mutations substitute for p53 defects, HDM 2 overexpression seems to cause its effect in concert with TP53 mutations, both with regard to cancer risk and treatment response.

\section{3}

Activation of nuclear factor (NF)-kB is linked to resistance to neoadjuvant chemotherapy in breast cancer patients. Montagut C, Tusquets I, Domingo-Domenech J, Corominas JM, Ferrer B, Bellosillo B, Fernandez PL, Rovira A, Suarez M, Albanell J. Hospital del Mar - IMAS, Barcelona, Spain; Hospital Clinic, Barcelona, Spain

Background: The NF-kB system is viewed as a promising anticancer target due to its role in oncogenesis and in chemoresistance. To provide further evidence on the expression/ role of NF-kB in breast cancer, we aimed here to: (1) characterize the expression and subcellular localization of $\mathrm{p} 65$ protein, the most common form of NF-kB, in normal breast, DCIS and infiltrating breast cancer, and (2) explore the value of p65 in predicting response to neoadjuvant chemotherapy in locally advanced breast cancer as well as pharmacodynamic changes in p65 expression after chemotherapy.

Patients and Methods: Normal breast, ductal breast carcinoma in situ (DCIS) and infiltrating carcinoma specimens were assayed by IHC for 065 expression. We used a semiquantitative score using p65 staining intensity and distribution to evaluate p65 cytoplasmic overexpression. The presence of any nuclear immunoreactivity was considered as positive. Since p65 activation results in nuclear translocation, nuclear p65 expression was interpreted as an activated form of NF- $\mathrm{KB}$.

Results: Normal breast showed mainly weak p65/NF- $\mathrm{KB}$ cytoplasmic staining and occasional faint nuclear staining. DCIS had strong and diffuse cytoplasmic p65NF- $\mathrm{KB}$ staining. Twelve out of $14(86 \%)$ ER-negative infiltrating breast cancers exhibited p65NF- $\mathrm{KB}$ activation (i.e. nuclear staining), whereas only 2 out of $6(33 \%)$ ER-positive specimens had p65NF- $\mathrm{KB}$ activation $(\mathrm{p}=0.037)$. We then analyzed an additional set of 54 patients with locally advanced breast cancer treated with neoadjuvant chemotherapy; a total of 37 pre- and 50 post-chemotherapy $(n=87)$ specimens were available for this study. Patients received anthracycline- and/or taxane- based chemotherapy as preoperative treatment. Nuclear staining was positive in $10 \%$ of the pretreatment biopsies $(n=4)$, and in $28 \%(n=14)$ post-therapy surgical specimens, thus suggesting that activation of NF-kB appears to be inducible upon chemotherapy exposure. Nuclear p65 staining was linked with resistance to chemotherapy while cytoplasmic p65 was not associated to response (data not shown). In patients with tumors with pre and/or post-chemotherapy nuclear staining the clinical response rate (RR) was significantly lower (37\% RR) than in patients with negative (both pre- and post-) nuclear p65 (91\% RR) $(\mathrm{p}<0.05)$. Notably, 3 patients experienced a complete pathological response and none of them had pre-treatment p65 nuclear staining.

Conclusions: These results show that activation of p65/NF-kB (i.e nuclear translocation) occurs in the transition of DCIS to infiltrating breast cancer and indicate that NF-kB activation is 
linked to resistance to neoadjuvant chemotherapy in breast cancer These findings strengthen the rationale for the association of NF$\mathrm{kB}$ inhibitors to chemotherapy to prevent or revert chemoresistance.

\section{4}

Altered prostaglandin-signalling in hormone resistant breast cancer by microarray and real time PCR validation. Scott DJ, Cummings M, Parkes AT, Poola I, Speirs V. Institute of Molecular Medicine, Epidemiology and Cancer Research, University of Leeds, Leeds, W Yorks, United Kingdom; Howard University, Washington, DC

The non-steroidal antiestrogen tamoxifen (TAM) still remains the "gold standard" treatment for hormone dependent breast cancer and provides good therapeutic activity to approximately $60-70 \%$ of all breast cancer patients with $\operatorname{ER}(\alpha)^{+}$lesions. However, following initial anti-tumour activity, resistance often develops resulting in tumour recurrence. Mechanisms associated with the acquisition of an antiestrogen-resistant phenotype are poorly understood. Due to the complexity of ER-signalling it is becoming increasingly apparent that investigation of a single or small number of genes will be insufficient to delineate the mechanisms of TAMresistance (TAM-r). An approach that reflects a broad range of changes between the sensitive and resistant phenotypes is clearly more rational. To begin to address this we have applied microarray technology to an in vitro model of TAM-r, developed in house from the breast cancer cell line MCF-7. Using Affymetrix U133A GeneChips, we have identified 131 up-regulated genes and 156 down-regulated genes whose steady state expression levels differed by at least 3-fold between TAM-r cells and their TAM-sensitive (TAM-s) controls (Scott et al., submitted). Further detailed analysis of these data revealed differential regualtion of several components of the prostaglandin-signalling pathway in TAM-r cells. We observed increased mRNA expression of phospholipase A2 group III (PLA2G3),COX-1 and EP4 and decreased mRNA expression of EP3 and hydroxyprostaglandin dehydrogenase 15-NAD $[H P G D])$, which is responsible for prostaglandin inactivation, in TAM-r cells. No changes were observed in $C O X-2, E P 1$ or EP2 expression. Our data was validated by real time PCR and Western blotting. Taken together these changes in gene expression would suggest an increase in prostaglandin production and signalling is associated with TAM-r. This is currently being validated by our group in a clinical model of TAM-r.

\section{5}

Gene expression profile of ATP binding cassette (ABC) transporter in breast cancer patient in relation to the response to neoadjuvant chemotherapy.

Park S, Shimizu C, Shimoyama T, Takeda M, Hasegawa T, Nishio $K$, Ando M, Katsumata N, Kouno T, Fujiwara Y. National Cancer Center Hospital, Tsukiji, Chuo-ku, Tokyo, Japan; National Cancer Center Research Institute, Tsukiji, Chuo-ku, Tokyo, Japan

Background:From the clinical point of view, multidrug resistance is one of the major problems in the treatment of the cancer patient. ABC (ATP binding cassette) transporter is supposed to play important roles in chemoresistance by affecting absorption, distribution, excretion of chemotherapeutic agent. In particular, ABCB1 (MDR1-PgP), ABCC1 (MRP1), and ABCG2 is well known to be related with resistance to several chemotherapeutic agent. In the present study, we analyzed the gene expression profile of breast cancer patients focusing on the relationship between $A B C$ gene expression and sensitivity to drug on the basis of microarray. Materials and methods: Using tissue microarray data of the breast cancer patients underwent neoadjuvant chemotherapy, we analyzed the expression profile of all 48 set of $\mathrm{ABC}$ transporter gene. The majority of the patients received 4 courses of CEF combination chemotherapy (Cyclophosphamide, Epirubicin, 5FU) followed by 12 courses of weekly paclitaxel. For HER-2 positive patients determined by IHC staining, the specific inhibitory antibody of HER-2 receptor, Herceptin ${ }^{\circledR}$ (Trastuzumab) was added in the course of the treatment. Every patient underwent surgery on the completion of the neoadjuvant chemotherapy and the histopathologcal study was accompanied.

Results: $29.4 \%$ of patients achieved pathologic CR. We found ABCA1, ABCA12 and ABCC5 were highly expressed in patients with residual tumor in comparison with pCR patients with statistical significance $(\mathrm{p}<0.05)$ Ongoing studies are evaluating whether theses gene are prognostic factors in breast cancer patients.

Discussion: Using the microarray data, we evaluated if there is any difference in the gene expression profile of $\mathrm{ABC}$ transporter according to the response to chemotherapy.

We found increased gene expression of several ABC transporters are associated with decreased response in the breast cancer patients who underwent neoadjuvant chemotherapy.

This study is supported by Health and Labour Science Research Grants, Research on Advanced Medical Technology, H14-Toxico007.

$\mathrm{ABC}$ transporters associated with poor response to neaodjuvant chemotherapy

\begin{tabular}{|c|c|c|c|c|c|c|c|}
\hline & Genbank & Map & Common & $\mathrm{pCR}$ & $\begin{array}{l}\text { Non- } \\
\text { pCR }\end{array}$ & Ratio & $\begin{array}{l}\mathrm{Sig} \\
\text { (2-tailed) }\end{array}$ \\
\hline 1565776_at & AL833227 & $9 \mathrm{q} 31.1$ & ABCA1 & $\begin{array}{l}0.454+/ \\
-.231\end{array}$ & $\begin{array}{l}2.010+/ \\
-1.003\end{array}$ & 4.423 & .001 \\
\hline 215465_at & AL080207 & $\begin{array}{l}\text { 2q34- } \\
\text { q35 }\end{array}$ & ABCA12 & $\begin{array}{l}0.325+1 \\
-.433\end{array}$ & $\begin{array}{l}1.651+/ \\
-.945\end{array}$ & 5.088 & .003 \\
\hline 209380_s_a & t AF146074 & $3 q 27$ & ABCC5 & $\begin{array}{l}0.697+1 \\
-.497\end{array}$ & $\begin{array}{l}1.681+/ \\
-.673\end{array}$ & 2.411 & .009 \\
\hline
\end{tabular}

\section{6}

Elevated c-met expression accompanies endocrine resistance in MCF7 breast cancer cells and promotes in vitro cell migration and invasion.

Hiscox S, Harper M, Jiang WG, McClelland R, Nicholson RI. Cardiff University, Cardiff, United Kingdom; Cardiff University Medical School, Cardiff, United Kingdom

Background: The c-met receptor is overexpressed in a number of human cancers and is strongly implicated as a mediator of tumour metastastic spread in vivo through its ability to promote cell motility and invasion. In this study, we have investigated the expression and function of the c-met/HGF pathway in fulvestrantresistant (FulR) MCF7 breast cancer cells, which display a significantly elevated motile and invasive nature in vitro compared to their wild-type counterparts.

Materials and Methods: FulR cells were derived through the continual exposure of wtMCF7 cells to fulvestrant (10-7M) for at least 18 months. This resulted in a cell line which displayed a highly invasive and motile phenotype in vitro and a higher growth rate than wild-type, endocrine-responsive MCF7 cells. Gene expression was determined by Affymetrix analysis and confirmed with RT-PCR. c-met protein expression and pathway activity under basal and hepatocyte growth factor (HGF)-stimulated conditions was determined by immunocytochemisty and Western blotting using phospho-specific antibodies. Cell invasion was determined by seeding cells onto a Matrigel-coated porous membrane in the presence or absence of HGF. After 3 days, invasive cells were fixed, stained and counted. Cellular migration was measured by seeding cells onto uncoated and fibronectin-coated membranes with or without HGF. After 24 hours culture, migratory cells were fixed, stained and counted.

Results: FulR cells had significantly elevated c-met mRNA and cell-surface protein levels compared with wtMCF7 cells. HGF treatment induced c-met autophosphorylation and activation of Src, AKT, MAPK, FAK and paxillin in a time and dose dependent manner in FulR cells together with promoting colony scattering, cellular migration and invasion. No significant effects were observed upon stimulation of wtMCF7 cells with HGF.

Discussion: Our data demonstrates that fulvestrant resistance in MCF7 cells results in significant overexpression of the c-met receptor which, upon activation, is able to greatly augment their aggressive in vitro phenotype. 


\section{S162 Abstracts - Poster Session III}

3107

A novel role for the ASK/JNK pathway in mediating Aktinduced endocrine therapy resistance.

Nielsen A, Silva JM, Friedrichs WE, Beeram M, deGraffenried LA. UT Health Science Center at San Antonio, San Antonio, TX

Several studies have now implicated aberrant activity of the Akt kinase as a significant mechanism by which breast cancer tumors are unresponsive to tamoxifen. Recent studies suggest that Aktinduced resistance is mediated through both estrogen receptordependent as well as estrogen receptor-independent mechanisms. Several studies, including our own, have demonstrated a significant role for mTOR in modulating drug sensitivity in models of Aktinduced resistance. Intriguingly, the ASK1/JNK pathway has been shown to induce apoptosis in breast cancer cells in response to tamoxifen, and in separtate studies has been shown to be suppressed by activation of the mTOR pathway. These findings, in combination with our own preliminary data, have led us to propose the following hypothesis: that Akt suppression of the ASK1/JNK pathway is a significant mechanism by which Akt confers tamoxifen resistance and that mTOR inhibitors such as rapamycin restore response to tamoxifen by relieving this suppression. In this current study, we have explored how modulation of the ASK1/JNK pathway contributes to tamoxifen resistance, and how the use of mTOR inhibitors reestablishes normal response to tamoxifen. We assessed tamoxifen response in MCF-7 breast cancer cells expressing either wild-type (control) or constitutively-active Akt (myrAkt1) and a dominant-negative ASK1 (DNASK1). We found that similar to our myrAkt1 cells, our DNASK1 cells were much more resistant to the growth inhibitory effects of tamoxifen. At the molecular level, treatment with tamoxifen resulted in phosphorylation (activation) of cJUN, in the control cells, but not in either the myrAkt1 or DNASK1 cells. Importantly, rapamycin is unable to restore tamoxifen sensitivity in our model of Akt resistance after both molecular and pharmacological inhibition of ASK1 and JNK activity. These studies have the potential for identifying and elucidating a novel mechanism by which Akt confers tamoxifen resistance and could provide the rationale for developing clinical trials investigating the efficacy of mTOR inhibitors for the treatment of hormone-resistant breast cancer.

\section{8}

Zinc-dependant stimulation of Src, EGFR and IGFR signalling pathways in tamoxifen-resistant breast cancer and the role of zinc transporters.

Taylor KM, Vichova P, Hiscox S, Nicholson RI. Cardiff University, Cardiff, UK, United Kingdom

Treatment of oestrogen receptor positive breast cancer with antioestrogens is the therapy of choice in the clinic. However, with time, these cancers can develop resistance to anti-hormone therapy leading to the subsequent re-growth of the tumour. Zinc, which is essential for normal cell growth, is present in elevated levels in breast cancer tissue and recent evidence suggests zinc can activate growth factor signalling pathways such as EGFR. We have shown that intracellular zinc concentration is elevated in our 'in house' models of tamoxifen resistance compared that observed in wildtype cells. Interestingly, affymetrix array results have demonstrated elevated levels of ZIP zinc transporter family members in these tamoxifen-resistant cells. Of particular interest is the increased expression of HKE4 (SLC39A7), a zinc transporter present on intracellular membranes and capable of elevating intracellular zinc by transporting zinc into the cytosol from intracellular stores. We have demonstrated that short term zinc treatment of Tamoxifen-resistant breast cancer cells can activate various signalling pathways that have been implicated in anti-hormone resistant proliferation. Treatment of tamoxifen-resistant breast cancer cells with $20 \mathrm{uM}$ zinc for 15 minutes clearly demonstrated a zinc-dependant activation of EGFR at tyrosine residue 845 which was reduced by both the zinc chelator TPEN and the Src kinase inhibitor SU6556. Importantly, this activation of EGFR by zinc is not only observed in the absence of EGF stimulation but is also of greater magnitude than that produced by EGF alone. Activation of EGFR was also accompanied by a parallel zinc-dependant activation of both Src kinase and IGFR. We also demonstrate downstream activation of Mapkinase by the addition of zinc. We have used fluorescent microscopy to visualise the localisation of zincactivated EGFR and Src kinase in cells, confirming plasma membrane localisation after zinc treatment and demonstrate the co-localisation of EGFR and vinculin in focal adhesions.

We have also established that longer term (6 days) zinc treatment of Tamoxifen-resistant breast cancer cells can increase cell growth threefold and invasion through Matrigel twofold. These results together suggest that increased intracellular zinc levels can help to protect cells from the effects of anti-hormones such as tamoxifen. Further investigation of any causal role of zinc transporters in this pathway may provide a useful new therapeutic target for antihormone resistant breast cancer.

\section{9}

Overexpression of c-Myc confers anti-estrogen resistance in breast cancer cells.

McNeil CM, Sergio CM, Butt AJ, Musgrove EA, Sutherland RL. Garvan Institute of Medical Research, Darlinghurst, NSW, Australia Background: It has been hypothesized that aberrant expression of cell cycle targets of estrogen action may contribute to the development of anti-estrogen resistance in breast cancer cells. We have previously demonstrated that constitutive overexpression of cyclin D1 reduces the sensitivity of MCF-7 cells to anti-estrogen treatment. Since the transcription factor c-Myc is also a central mediator of estrogen-stimulated cell cycle progression we assessed the consequences of c-Myc overexpression in MCF-7 cells on their sensitivity to anti-estrogen mediated inhibition of proliferation.

Methods: Clonal MCF-7 breast cancer cell lines were constructed with constitutive or zinc-inducible overexpression of c-Myc. Proliferation rates and cell cycle phase distribution were measured over a 48 hour time course following treatment with $0-100 \mathrm{nM}$ of the pure steroidal anti-estrogen ICI 182,780 (ICI). Protein lysates were collected for Western blotting of cell cycle regulatory proteins. Results: Two-fold elevation of c-Myc expression resulted in significantly reduced sensitivity to ICI. After 48 hours of treatment with $10 \mathrm{nM}$ ICI, the percentage of cells in S phase was 3-5 times higher in the overexpressing cells, as compared with empty vector control cells. A reduction in cyclin D1 expression was observed even in the presence of c-Myc overexpression, and despite persistent $\mathrm{Rb}$ phosphorylation.

Conclusion: These data confirm that c-Myc overexpression induces resistance to anti-estrogens. However, the anti-estrogenic response was only partially attenuated by increased c-Myc expression. Cyclin D1 was downregulated, suggesting that cyclin D1 was regulated independently of $\mathrm{c}-\mathrm{Myc}$ and that cyclin D1 downregulation might be responsible for the residual sensitivity to anti-estrogen.

\section{0}

Expression patterns of 5-fluorouracil metabolism-related genes in breast cancer using focused DNA array.

Shimada K, Kuroki S, Ohshima A, Takeda T, Shirahane K, Koga K, Tanaka M. National Hospital Organization, Kokura Hospital, Kitakyushu, Fukuoka, Japan; Graduate School of Medical Sciences, Kyushu University, Fukuoka, Japan

Backgrounds: 5-fluorouracil (5-FU) and its prodrugs are widely used for a number of breast cancer patients. However, unlike colorectal cancer, little is known about the expression of metabolic enzymes of 5-FU in breast cancer. We examined the transcriptional expression of these enzymes using newly developed DNA array. Material and Methods: Samples of breast cancer and normal 


\section{Abstracts-Poster Session III S163}

breast tissue were obtained from 21 patients with a median age of 52 years undergoing surgery. After extraction and DNace treatment, total RNA was reverse-transcribed and applied to focused DNA array (FDA, Taiho Pharmaceutical Co., Japan). This array consisting of 52 genes ( 25 genes related to 5-FU metabolism, 9 genes to DNA repair, 8 genes to drug resistance and others) was designed for minimizing background noise and cross-hybridization with other genes resulting in semiquantification with better sensitivity and specificity in a single assay.

Results: In all patients, expression of dihydropyrimidine dehydrogenase (DPD), the rate-limiting enzyme for 5-FU catabolism, was decreased in cancer tissue comparing with matched normal breast tissue $(\mathrm{P}<0.001)$. However, there was no significant difference in the expression of key enzymes in the 5-FU activation pathways such as thymidine phosphorylase (TP), uridine phosphorylase (UP) and orotate phosphoribosyltransferase (OPRT) between cancer and normal tissues. Expression ratio of each of these enzymes to DPD was significantly increased in cancer tissue $(\mathrm{P}<0.01)$. In normal tissue, expression of thymidylate synthase (TS) had positive correlations with OPRT and other enzymes which were located downstream of OPRT, whereas it had a negative correlation with TP. In cancer tissue, however, correlations between expression of TS and other anabolic enzymes were almost lost.

Conclusions: 5-FU is mainly catabolized by DPD in normal breast tissue, however, the degradation of 5-FU is decreased in cancer tissue leading to produce active forms mainly via the OPRT pathway. Because breast cancer tissue has been reported to possess higher expression of DPD protein and enzyme activity compared with normal tissue, there might be a posttranscriptional regulation in DPD expression. Correlations between expression of each anabolic enzyme were decreased in cancer tissue, therefore, comprehensive analysis of the enzymes related to 5-FU metabolism is important for an effective use of this agent for breast cancer patients.

\section{1}

Tamoxifen failure in breast cancer: use of gene expression array and immunohistochemistry tissue micro arrays to define a molecular signature of tamoxifen resistance. Bray SE, Robertson K, Vendrell J, Nguyen C, Purdie CA, Thomson $G$, Thompson AM, Cohen P. University of Dundee, Dundee, United Kingdom; University of Montpellier, Montpellier, France; University of Aix-Marseille II, Marseille, France

Background: Despite the increasing use of aromatase inhibitors, tamoxifen will remain a therapy for recurrent or advanced disease. However, the mechanisms of tamoxifen resistance remain uncertain. The aim of this study was to identify a gene signature for tamoxifen resistance and based on this signature develop an immunohistochemical approach for future clinical application.

Materials and Methods: 21 patients who had initially responded to tamoxifen then progressed requiring surgery, were divided into a training set and test set and compared with a control group of age matched female patients. cDNA mini-array gene expression was conducted on a 1034 nylon membrane human gene array. Cross analysis using several statistical methods and hierarchical cluster analysis using the Cluster ${ }^{\mathrm{TM}}$ and Treeview ${ }^{\mathrm{TM}}$ software yielded a group of genes with significantly different expression in the tamoxifen resistant cancers. Real Time Quantitative (RTQ)PCR was performed to confirm gene expression. Tissue microarrays were constructed using 6 cancer cores of each of the tamoxifen resistant or control tumours and stained with commercially available antibodies for the genes highlighted by the gene expression array and quantitative RT-PCR.

Results: 61 genes (encoding proteins of the immune system, the regulation of proliferation, apoptosis, invasion, or adhesion) discriminated the resistant cancers by hierarchical cluster analysis. Micro-array expression correlated by Spearman rank testing with RTQ-PCR for 9 key genes (and was statistically significant for 8 genes) demonstrating close correlation between the two techniques. The key genes included ERalpha, TGFBR2, IGFBP4 and STAT1.Excellent quality morphology and staining definition was achieved with antibodies for 8 of these genes and showed concordance with the RNA based techniques.

Discussion: This study has identified a gene signature set for tamoxifen resistance and suggests that immunohistochemistry could be employed on tumour cores taken from cancers undergoing endocrine therapy to identify emerging resistance and guide therapeutic decision making.

\section{2}

Therapeutic modulation of anti-estrogen resistance through histone deacetylase inhibition.

Beeram M, Russell DH, Friedrichs WE, Silva JM, deGraffenried LA. UT Health Science Center at San Antonio, San Antonio, TX Tamoxifen (TAM) is one of the most effective current therapies for breast cancer. However, only $60 \%$ of estrogen receptor expressing $(\mathrm{ER}+)$ breast cancers respond to TAM $(40 \%$ de-novo resistance). Continuous treatment with TAM beyond 5-years leads to emergence of acquired resistance in these initially-responsive cancers. A fundamental problem is the lack of understanding of events underlying the loss of responsiveness to antiestrogenic therapies. Compelling in vitro and clinical evidence suggests that one potential mechanism of resistance is through transcriptional upregulation of the Her2/neu promoter which is transactivated by ER. One-fourth of patients with ER+ breast cancers treated with TAM convert from HER-2/neu negative to positive phenotype upon disease progression. Another significant mechanism for resistance appears to be loss of ER expression. In this current study, we developed an in vitro model of tamoxifen resistance to test whether acquired HER-2/neu expression and/or loss of ER expression is a significant mechanism for mediating TAMresistance in breast cancer cells exposed to TAM. Forty-eight (48) MCF-7 breast cancer single-cell colonies were isolated, and then each of the forty-eight were separated into four (4) treatment groups exposed for four months to the following: media containing complete $10 \%$ FBS, media containing complete $10 \%$ FBS and 10 ${ }^{7} \mathrm{M}$ tamoxifen, media containing $10 \%$ charcoal-stripped media (which removes steroids, including estrogen), and media containing $10 \%$ charcoal-stripped media with $10^{-7} \mathrm{M}$ tamoxifen. 30 of 40 $(75 \%)$ clones grown in the charcoal-stripped media survived the four months, but only 21 of $48(44 \%)$ grown in complete media with tamoxifen and only 16 of $48(33 \%)$ grown in charcoalstripped media with tamoxifen survived. Intriguingly, by Western blot analysis, we observed that of the 16 clones that developed tamoxifen resistance under conditions of estrogen deprivation, 6 (38\%) demonstrated strong expression of phosphorylated (active) Her-2. All 16 clones were Her-2 negative at the start of the study. Her-2 expression strongly correlated with estrogen receptor expression. ER expression was lost in 9 of the $16(56 \%)$ resistant clones with a concomittent increase in phosphorylated $\mathrm{Rb}$ levels. Studies elucidating the trascriptional mechanisms of resistance, by co-treating the resistant clones with the HDAC inhibitor TSA, are on-going, and will be presented at this meeting. These preliminary results indicate that in vitro modeling systems can be developed to investigate the molecular changes associated with clinical outcome and serve as the platform for clinical evaluations which result in pharmacological interventions that abrogate and/or reverse the emergence of TAM- resistance. 


\section{S164 Abstracts - Poster Session III}

3113

SERM-resistant breast cancer is cross-resistant to tibolone. Osipo C, Meeke K, Cheng D, Betrucci A, Weichel A, Kloosterboer HJ, Jordan VC. Feinberg School of Medicine Northwestern University, Chicago, IL; Fox Chase Cancer Center, Philadelphia, PA; Organon, Netherlands

Background: Tibolone is a selective estrogen activity regulator that prevents bone loss without stimulating the endometrium. The current study investigates the growth properties of tibolone in four in vivo breast cancer models: selective estrogen receptor modulator (SERM)-naïve MCF-7 and T47D; and SERM-resistant, raloxifene (MCF-7RAL) and tamoxifen (MCF-7TAMLT) MCF7 xenograft models. Methods: T47D, MCF-7, MCF-7RAL, and MCF-TAMLT xenografts were implanted into either 50 or 60 ovariectomized athymic mice. Mice-bearing T47D or MCF-7 tumors were treated as follows: vehicle control, $0.30 \mathrm{~cm} 17 \mathrm{~b}$ estradiol silastic capsules (implanted intrascapularly) releasing circulating blood levels of $83-96 \mathrm{pg} / \mathrm{ml}$, estradiol plus $1.5 \mathrm{mg}$ tamoxifen (fed orally by gavage 5 days/week), $20 \mathrm{mg} / \mathrm{Kg}$ tibolone (fed orally by gavage 5 days/week), estradiol plus tibolone, or estradiol plus tamoxifen plus tibolone. Mice-bearing MCF7TAMLT or MCF-7RAL tumors were treated with vehicle control, $1.5 \mathrm{mg}$ tamoxifen, $1.5 \mathrm{mg}$ raloxifene (fed orally by gavage 5 days/ week) $0.30 \mathrm{~cm}$ estradiol capsules, or $20 \mathrm{mg} / \mathrm{Kg}$ tibolone. Tumor area was measured weekly with the use of vernier calipers and tumor cross sectional area was calculated using the following formula: [(length $\mathrm{x}$ width) x p] / 4. Results: Tibolone inhibited growth of estradiol-stimulated T47D tumors while having little effect on the combination of estradiol plus tamoxifen. Tibolone modestly, but significantly increased estradiol-stimulated growth or tamoxifen-inhibited growth of MCF-7 tumors. In addition, treatment with tibolone alone of both T47D and MCF-7 tumors did have a slight but significant growth-stimulatory effect compared to controls. However, growth of both SERM-naïve tumors with estradiol plus tamoxifen, estradiol plus tamoxifen plus tibolone, or tibolone alone was significantly decreased versus treatment with estradiol alone. In contrast, tibolone stimulated growth of both tamoxifen- and raloxifene-resistant MCF-7 tumors. Discussion: The data demonstrate that tibolone has a minor agonist effect but little effect on tamoxifen-inhibited growth of SERM-naïve breast tumors, T47D and MCF-7. Furthermore, breast tumors that are resistant to raloxifene or tamoxifen are crossresistant to tibolone. 


\section{1}

Genetic counseling and testing for hereditary breast cancer in underserved women.

Beattie MS, Lee RF, Crawford B, Komaromy M, McLennan J, Luce J, Ziegler J. University of California, San Francisco, San Francisco, $C A$

Genetic counseling and testing for heritable susceptibility to breast cancer due to mutations in BRCA genes is largely unavailable to underserved women in the USA. In 2002, the UCSF Cancer Risk Outreach Program (CROP) began at San Francisco General Hospital (SFGH). Genetic counseling and testing as well as follow up procedures and surveillance are available to high risk individuals at SFGH free of charge. This report analyzes the first 3 years of experience of genetic counselling and testing at a public hospital. Methods: Patients were recruited through clinical inservices, oncology and breast clinic consultations, community outreach and mammography screening questionnaire. Patients identified as high risk for hereditary breast and ovarian cancer were offered genetic counseling, cancer risk assessment, genetic testing (if appropriate) and follow-up care.

Results: 350 individuals have been seen for a total of 580 genetic counselling visits. Approximately half of the patients were Caucasian, 26\% Latina, 13\% Asian and 12\% African American. 72 patients were offered genetic testing, based on a prior probability of testing positive of over $10 \%$, and 2 declined. Of the 70 who tested: $48(67 \%)$ tested negative, 5 were $B R C A 1$ positive and 12 were $B R C A 2$ positive (table 1). This $2: 1$ ratio of BRCA2 to BRCA1 mutation carriers is the opposite of most genetic testing programs across the US, including the Cancer Risk Program at the UCSF Mt. Zion Comprehensive Cancer Center (CCC). 5 patients at SFGH carry a total of 14 Variants of Undetermined Significance, a slightly higher rate than most programs nationwide. Of the 17 women who tested positive, 13 have elected increased surveillance and 4 have opted for prophylactic surgery according to recommended guidelines. Although these numbers are small, this profile of risk reduction compares with the $\mathrm{CCC}$ experience.

Comparison of Individuals Receiving Genetic Testing At SFGH and UCSF's CCC

$\begin{array}{llllll} & \% \text { white } & \text { BRCA1 } & \text { BRCA2 } & \text { negative } & \text { VUS } \\ \text { SFGH }(\mathrm{n}=70) & 49 \% & 7 \% & 17 \% & 67 \% & 7 \% \\ \mathrm{MZ}(\mathrm{n}=872) & 91 \% & 14 \% & 10 \% & 70 \% & 6 \%\end{array}$

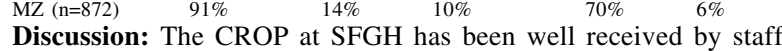
and patients. Uptake of genetic testing was high, and the percentage of patients testing positive is similar to the positive rate of the CRP in the CCC. The majority of positive results, however, had mutations in BRCA2, a surprising difference from the CRP in the CCC. It is possible that BRCA2 mutations are more common diverse populations. Future studies will examine the role of ethnic diversity and VUS as well as follow up on risk reduction strategies

\section{2}

German populations with infrequent $C H E K 2 * 1100 d e l C$ and minor associations with early-onset and familial breast cancer.

Hamann U, Rashid MU, Jakubowska A, Justenhoven C, Harth V, Pesch B, Baisch C, Pierl CB, Bruening T, Ko Y, Benner A, Wichmann $H E$, Brauch H, the GENICA Network. German Cancer Research Center, Heidelberg, Germany; Pomeranian Medical University, Szczecin, Poland; Dr. Margarete Fischer-Bosch-Institute of Clinical Pharmacology, Stuttgart, Germany; Berufsgenossenschaftliches Forschungsinstitut für Arbeitsmedizin, Ruhr University Bochum, Bochum, Germany; Johanniter Krankenhaus, Bonn, Germany; GSF-National Research Centre for Environment and Health, Institute of Epidemiology, Neuherberg, Germany

Introduction: $C H E K 2 * 1100 \mathrm{delC}$ is associated with a 2 -fold increased breast cancer risk. This was shown in a collaborative analysis of European populations, but not in other populations from Europe and the US. Accordingly, there is a need to clarify the role of $C H E K 2 * 1100$ delC in breast cancer.
Materials and Methods: We established the prevalence of CHEK2*1100delC in two German populations GENICA (Northrhine-Westphalia, $n=724$ ) and KORA (Bavaria, $n=600$ ) and in women with breast cancer. The latter included cases $(n=688)$ from the GENICA breast cancer case-control study, patients with early-onset breast cancer $(n=86)$ and patients with familial breast cancer $(n=71)$. The latter patient groups were previously investigated for $B R C A 1 / 2$-mutations and tested negative. Mutation analysis was performed by combined PCR/DHPLC methodology. Results: $C H E K 2 * 1100$ delC was found in $0.9 \%$ of GENICA controls and was absent in the KORA controls indicating a significant difference between the two populations $(\mathrm{P}=0.03)$. The frequency of $C H E K 2 * 1100$ delC in age-matched cases of the GENICA collection was $0.8 \%$ and thus not different from controls (OR 0.88 , 95\% CI $0.21-3.50$ ). In patients with early-onset disease CHEK2*1100delC was found at a frequency of $2.3 \%$ referring to an increased breast cancer risk of 2.56 (95\% CI $0.25-14.58)$. In patients with familial disease the frequency was $1.4 \%$ referring to an increased risk of 1.53 (95\% CI 0.03-12.93).

Conclusion: Our data showed variations in $C H E K 2 * 1100 \mathrm{delC}$ prevalence within German populations suggesting possible inaccuracies in breast cancer risk assessments from non populationbased studies. In patients with a high-risk profile however, CHEK $2 * 1100$ delC was indicative for this risk and highest for early-onset breast cancer.

\section{3}

Actively approaching breast cancer patients for genetic counseling during adjuvant radiotherapy: does it harm? Warlam-Rodenhuis CC, Schlich-Bakker KJ, van Echtelt J, Ausems $M G$, ten Kroode HF. University Medical Center Utrecht, Utrecht, Netherlands

\section{Background}

In a previous study we searched for factors predictive for the presence of BRCA1 and BRCA2 mutations in recently diagnosed breast cancer patients (Eur J Cancer, in press). As many as $60 \%$ of patients at risk rejected genetic counseling. Genetic counseling is increasingly offered to breast cancer patients shortly after diagnosis although little is known about its psychological impact. This was the subject of a new study.

Patients and methods

Patients referred for adjuvant radiotherapy with a first diagnosis of breast cancer and $<75$ years of age were eligible for the trial. Medical history and sociodemographic aspects were registered. Patients filled out a baseline questionnaire ('T0') before the first vist to the Department of Radiotherapy, followed by a next ('T1') 5 weeks later. By then patients had been informed on the presence or abcense of predictive factors for hereditary breast cancer, and had started radiotherapy. If predictive factors were present, compilation of a family pedigree and the option of referral to a clinical geneticist had been offered. Both at T0 and T1 general anxiety and depression were measured using the 'Hospital Anxiety and Depression Scale' and breast cancer specific distress was measured by use of the 'Impact of Event Scale'. Quality of life, coping strategy and optimism were determined as well. Results

684 patients were invited to participate. The first questionnaire was filled out by 482 patients $(70 \%)$, and both were returned by 410 patients $(60 \%) .225$ patients had at least one predictive factor for hereditary breast cancer and were offered initial counseling.

High scores of general anxiety, depression and breast cancer specific distress were noted in the group as a whole: $49 \%$ of patients showed values above the clinically important cut-off scores, at T1. Medical history (time elapsed from surgery, mastectomy versus lumpectomy, adjuvant chemotherapy before radiation, lymphe node status) was not of influence. Scores were influenced however by psychological resources: high distress was more often seen in patients with lower experienced quality of life, a lower level of 


\section{S166 Abstracts - Poster Session IV}

optimism and showing an avoiding coping system. Slightly more distress was present in patients with a low level of education and in singles.

No differences of general anxiety and depression and breast cancer specific distress were found between the patients approached for initial genetic counseling and controls. In both groups of patients comparable significant decreases in anxiety and breast cancer specific distress were seen after the start of radiotherapy.

\section{Conclusion}

Breast cancer patients can be actively approached for genetic counseling several weeks after diagnosis and surgery, without causing short term additional psycholgical burden.

\section{4}

Genetic testing for $B R C A 1$ and $B R C A 2$ mutations in the Hispanic population.

Erlichman J, Valero V, Lu K, Rivera E, Strong L, Arun B. UT MD Anderson Cancer Center, Houston

Background: Approximately $5-10 \%$ of all breast cancer is inherited. Molecular genetic testing of the BRCA1 and BRCA2 genes is now available, making it possible to identify individuals with a genetic susceptibility to breast cancer. Studies have shown that individuals from certain ethnic groups are more likely to carry a $B R C A 1$ or $B R C A 2$ mutation based on the presence of founder mutations. To date, there is no data regarding the incidence of inherited breast cancer in persons of Hispanic ancestry. This information is needed so that clinicians can provide Hispanic individuals with accurate risk estimates when evaluating their families for the likelihood of carrying a $B R C A 1$ or $B R C A 2$ mutation. Our aim in this study is to describe the prevalence of $B R C A 1$ or BRCA2 mutations in a cohort of Hispanic women who underwent genetic counseling at a single Institution.

Materials and Methods: Under an IRB approved protocol, the M.D. Anderson Clinical Cancer Genetics database was queried for Hispanic individuals who underwent genetic counseling at M.D. Anderson from 2001-present. Information regarding the number of patients who went on to have genetic testing and the genetic testing results were collected.

Results: From 2001 to present, 1055 individuals have undergone genetic counseling for inherited breast cancer at U.T. M.D. Anderson Cancer Center (UTMDACC). Of those individuals, 98 $(9 \%)$ were of Hispanic origin. After receiving genetic counseling, $47(48 \%)$ Hispanic individuals went on to have genetic testing of the $B R C A 1$ and $B R C A 2$ genes. $8(17 \%)$ were found to have a deleterious $B R C A 1$ or BRCA2 mutation, $22(47 \%)$ had uninformative negative results, $10(21 \%)$ were found to be negative for a known mutation in the family, $3(6 \%)$ were found to have a variant of uncertain significance in $B R C A 1$ or $B R C A 2,2$ were found to have a deleterious mutation and a variant of uncertain significance, and 1 was found to have two deleterious mutations (one in BRCA1 and one in BRCA2) as well as a variant of uncertain significance in BRCA2. The remaining individual's test results are still pending. Overall, 8/98 (8\%) of all Hispanic individuals who underwent genetic counseling at UTMDACC were found to carry a deleterious $B R C A 1$ or $B R C A 2$ mutation. Interestingly, 2 of these patients, with no reported Jewish ancestry, were found to carry the BRCA1 Ashkenazi Jewish 185delAG mutation.

Discussion: This is the first reported single Institution study of Hispanic individuals undergoing genetic counseling for inherited breast cancer risk. About $9 \%$ of all individuals who underwent genetic counseling at UTMDACC were individuals of Hispanic origin. After having identified these individuals through this study, next we will prospectively analyze patterns of risk perception and decision making process among Hispanic individuals who undergo genetic counseling and testing at UT MDACC.

\section{5}

Determinants in the uptake of genetic testing for BRCA1/ 2 mutations.

Fowler ES, Neese ER, Schwartzberg LS. Baptist Centers for Cancer Care, Memphis, TN; The West Clinic, Memphis, TN

Background: Disparities exist in the utilization of and access to genetics services among various groups. This study examined variations in the uptake of genetic testing for hereditary breast/ ovarian cancer among patients according to ethnicity, age, and a priori risk of a positive test result. We evaluated the uptake of genetic testing for hereditary breast/ovarian cancer in patients with breast cancer or DCIS that received comprehensive genetic counseling in a community-based setting.

Materials and Methods: Data from 307 patients with breast cancer or DCIS who had genetic counseling between January 1999March 2005 were abstracted. Data was analyzed according to the uptake of BRCA $1 / 2$ testing and was stratified by patient ethnicity, age at breast cancer diagnosis, and a priori risk of a BRCA1/2 mutation. Patients with personal and family histories suggestive of mutations in other genes were excluded from the data set. Results: $49.2 \%$ (151/307) of patients pursued BRCA1/2 testing. Differences in the uptake of genetic testing following genetic counseling were identified. 78.6\% (22/28) of Ashkenazi Jews, 49.4\% $(115 / 233)$ of Caucasians, $26.8 \%$ (11/41) of African Americans, and $60 \%(3 / 5)$ of patients who were other ethnicities (Hispanic Pacific Islander, Native American) elected to have BRCA1/2 testing. $59.3 \%(32 / 54)$ of patients diagnosed with breast cancer before age 40 pursued genetic testing, as compared to $47.0 \%(119 / 253)$ of patients diagnosed with breast cancer after age $40(\mathrm{p}=.103)$. As the a priori risks of identifying mutations increased, so did the uptake of genetic testing and the proportion of positive test results: $<10 \%$ a priori risk of mutation $-21 \%(13 / 62)$ proceeded to genetic testing, no deleterious mutations detected; $10-24 \%$ a priori risk of mutation $-53.6 \%(60 / 112)$ proceeded to genetic testing, $3.3 \%(2 / 60)$ had deleterious mutations; $25-49 \%$ a priori risk $-53.6 \%(44 / 74)$ proceeded to genetic testing, $15.9 \%(7 / 44)$ had deleterious mutations; $50-74 \%$ a priori risk $-38.6 \%(17 / 44)$ proceeded to genetic testing, $35.3 \%(6 / 17)$ had deleterious mutations; $75-100 \%$ a priori risk $-71.9 \%$ (23/32) proceeded to genetic testing, $47.8 \%(11 / 23)$ had deleterious mutations. Associations between a priori risks of a mutation, uptake of genetic testing $(\mathrm{p}=<0.001)$, and the discovery of deleterious mutations $(\mathrm{p}=<0.001)$ were statistically significant.

Discussion/Conclusions: Our findings demonstrate a higher uptake of genetic testing in the Ashkenazi Jewish population and a lower rate of uptake in the African American population. A priori risks of identifying a BRCA1/2 mutation correlate not only with a higher rate of genetic testing uptake regardless of ethnicity, but also with a higher percentage of positive test results. Ethnicity and a priori risks of BRCA1/2 mutations influence the uptake of genetic testing in patients with breast cancer.

\section{6}

Breast cancer risk management choices by women with inherited breast cancer predisposition: a preliminary analysis.

Kurian AW, Hartman AR, Mills MA, Jaffee M, Chun NM, Garber JE, Ford JM, Plevritis SK. Stanford University School of Medicine, Stanford, CA; Dana-Farber Cancer Institute, Boston, MA

Background: More than 250,000 women in the United States are estimated to have a high inherited risk of breast cancer. Genetic counseling and testing permits identification of such women; options for management of their breast cancer risk include prophylactic mastectomy (PM) or intensive screening, incorporating mammography and breast magnetic resonance imaging (MRI). Factors predicting women's choices for breast cancer risk management have not been fully characterized.

Methods: Women at high breast cancer risk, either because of a 
mutation in BRCA1/2 or another cancer susceptibility gene, or because of a greater than $10 \%$ predicted chance of BRCA mutation carriage due to family history, were evaluated in cancer genetics clinics and educated about options for breast cancer risk management, including PM or screening with annual mammography plus breast MRI. After genetic counseling and testing, they were mailed an 11-item questionnaire about their intended management of their breast cancer risk, and the Revised Impact of Event Scale (RIES), a validated measure of breastcancer related anxiety. Statistical analysis used Fisher's exact test, 2 -sided for categorical variables and t-test or Wilcoxon Rank Sum test for continuous variables.

Results: 55 women were sent a questionnaire, and 36 have responded to date, yielding a response rate of $65.5 \%$. The median age of responders was 40.5 years; $50 \%$ were mutation carriers and $50 \%$ at high risk due to family history. Thirteen $(36.1 \%$ [22.5$52.6 \%]$ ) women declared a low, $16(44.4 \%$ [29.6-60.5\%]) a moderate, and $7(19.4 \%$ [9.5-35.5\%]) a high likelihood of choosing PM. There was a non-significant trend toward increase in median RIES score from low $($ score $=18)$ to moderate $($ score $=21)$ to high ( $\mathrm{score}=25)$ PM likelihood groups $(\mathrm{p}=0.56)$; this range of scores was similar to scores previously reported in women with high breast cancer risk. Compared to moderate and low PM likelihood groups combined, the high likelihood group had a greater proportion of patients with personal cancer history (100\% vs. $44.8 \%, \mathrm{p}=0.01)$. Low PM likelihood patients had a significantly lower proportion of mutation carriers $(23.1 \%$ vs. $65.2 \%, \mathrm{p}=0.04)$ and a non-significantly higher median age ( 46 vs. 38 years, $\mathrm{p}=0.17$ ) than high and moderate likelihood groups combined.

Discussion: In a clinic-based sample of women at high inherited breast cancer risk, personal cancer history, BRCA or other highrisk mutation carriage, and higher breast cancer-related anxiety as measured by RIES, were more frequent among women likely to choose PM over intensive breast screening. Evaluation of a larger number of high-risk women is ongoing, and updated data will be presented. Follow-up questionnaire administration is planned for women who have chosen intensive breast screening, permitting identification of experiences and characteristics which predict choice of continued screening versus PM.

\section{7}

Characteristics of pre-menopausal invasive breast cancer and age-associated risk of breast cancer in BRCA1 and BRCA2 mutation carriers compared with non-carriers (BRCA0).

McLennan JL, Crawford BC, Stewart N, Mak J, Lee R, Braithwaite $D$, Esserman L, Ziegler J. UCSF Comprehensive Cancer Center, San Francisco, $C A$

Background: Published data indicate that the historical cohort of BRCA1 and BRCA2 mutation carriers have a lifetime risk of developing invasive breast cancer (IBC) by age $80 \mathrm{y}$ of up to $82 \%$. BRCA associated IBC is marked by an earlier age of onset and a characteristic pattern of histo-pathological features. It has been observed that in the general population the incidence of IBC is increasing and the age of diagnosis of breast cancer decreasing. Methods: From 1998 - 2005 we collected data on a cohort of more than 900 high-risk individuals and their families who had BRCA testing and enrolled in 20-year IRB-approved follow up study at UCSF Cancer Risk Program. To date we have identified more than 250 BRCA mutation carriers (140:110 BRCA1:BRCA2) and also collected data on an additional 460 of their family members who have also been identified as having a BRCA mutation. 359 UCSF BRCA tested women had IBC for whom histopathology and tumor markers were available (75 BRCA1, 54 BRCA2, 230 BRCA0). We also compared BRCA1 probands and BRCA1 positive family members $(n=533)$, BRCA 2 probands and BRCA2 positive family members $(n=180)$ and BRCA0 probands $(n=727)$ for age of diagnosis of IBC.
Results: High grade ER/PR/HER2 negative IBC in pre-menopausal women (age 50 or younger) is significantly associated with finding a BRCA1 mutation ( $p>0.001)$. HER2 negative IBC is significantly associated with pre-menopausal BRCA2 related IBC $(\mathrm{p}>0.001)$ but BRCA2 IBC cannot be separated from BRCA0 IBC by other distinct histo-pathological patterns. BRCA1 mutations were found exclusively in IBC cases diagnosed at $55 \mathrm{y}$ or younger. $86 \%$ of BRCA1 associated IBC is diagnosed at or before age 50y compared with $82 \%$ of BRCA2 associated IBC. In a time-to-failure logrank analysis, BRCA1 and BRCA2 carriers did not differ from one another and had a significantly earlier age of diagnosis of IBC compared to BRCA0 women $(\mathrm{p}<0.001)$. Adjustment for birth cohort, age at menarche, age of first birth, parity and Ashkenazi Jewish descent did not alter this finding.

Conclusion: Over $80 \%$ of IBC in BRCA carriers occurs in the pre-menopausal years, has an accelerated onset, and typically shows adverse characteristics. Thus, genetic counseling and BRCA testing is particularly urgent in young women at hereditary risk of IBC in order to achieve the greatest risk reduction benefit.

\section{8}

Patients' perceived breast cancer risk and psychological distress: can oncologist-based counseling achieve durable improvements?

Mertens WC, Katz D, Quinlan M, Barham R, Carr C, MakariJudson G. Baystate Regional Cancer Program, Springfield, MA

Background: Women tend to overestimate their risk of breast cancer development. While studies have evaluated formal genetic/ nurse educator-based counseling, little work has been reported on short- and long-term effects of risk counseling by oncologists.

Methods: High-risk clinic patients consented prior to the physician visit and completed the Brief Symptom Inventory-18 (BSI) and their estimates of 5-year and lifetime risk of breast cancer and $B R C A$ mutation probability before (PRE), immediately (POST) and 2 months (2 MO) after counseling. Gail model (or, for lobular carcinoma in situ [LCIS], accepted literature data) and $B R C A$ mutation estimates were shared during physician counseling. Results: 81 patients were enrolled. PRE risk perceptions were much greater than calculated estimates (mean 5-year: $33.1 \mathrm{v}$. $2.7 \%$; lifetime 48.0 v. $23.4 \%$; BRCA 41 v. $9 \%$, all $\mathrm{p}<0.0001)$. POST perceptions decreased significantly $(\mathrm{p}<0.0001)$ but continued to exceed shared calculated estimates $(5$-year mean difference $18.4 \%, \mathrm{p}<0.0001$; lifetime $11.1 \%, \mathrm{p}=0.0003$; BRCA $14.7 \%$, $\mathrm{p}<0.0001)$. POST perceptions correlated with PRE perceptions $(\mathrm{P}<0.0001)$ but not with estimates. Patient 2 MO risk perceptions tended to be greater than POST perceptions. PRE BSI T-scores were greater for anxiety $(\mathrm{ANX} ; \mathrm{p}=0.0001)$ but other indices were similar to standardized community norms; all POST indices demonstrated declines $(\mathrm{p}<0.0001)$. POST and 2 MO ANX scores were similar and both were correlated strongly with PRE ANX. Younger patients and those with LCIS demonstrated greater PRE and POST ANX scores. ANX scores correlated with PRE, POST and 2 MO risk perceptions. While changes in patient risk perceptions (5-year: $\mathrm{p}=0.005$; lifetime: $\mathrm{p}=0.032$ ) differed between physicians, similar results were not found for ANX. In multivariate analysis PRE 5-year risk perception was positively associated with PRE ANX ( $\mathrm{p}=0.0004)$, number of breast cancer-affected $1^{\circ}$ relatives $(p=0.018)$ and body-mass index (BMI; $p=0.012)$. Excess POST 5-year risk perception was associated with PRE perception $(p<0.0001)$ and counseling physician $(p=0.003)$. Lifetime perceptions yielded similar results. Increased PRE ANX was associated with younger age $(p=0.006)$, LCIS $(p=0.010)$, past psychiatric diagnosis $(\mathrm{p}=0.045)$ and increased PRE 5-year risk perception $(\mathrm{p}=0.06)$. POST ANX was associated with PRE ANX $(\mathrm{p}<0.0001)$, and recommendation for genetic counseling $(\mathrm{p}=0.073)$. Conclusions: 1) PRE risk perceptions predict those at POST/2 MO which remain several-fold greater than actual estimates; 2) increased PRE ANX is associated with younger age, LCIS, past psychiatric diagnosis and increased PRE risk perception; 3) POST 


\section{S168 Abstracts - Poster Session IV}

ANX remained strongly correlated with PRE ANX, despite improvements in scores; 4) modification of risk perception, but not ANX, differed between physicians. Counseling is effective in reducing ANX despite persistent risk perception overestimation.

\section{9}

Risk-reducing strategies in breast cancer: a decision analysis.

Chagpar AB, Studts JL, Abell T, Ruberg J, Fleming M, McMasters KM. University of Louisville, Louisville, KY; Ouray Research Consulting, Ouray, $\mathrm{CO}$

BACKGROUND: The purpose of this study was to examine the impact of ductal lavage (DL) and genetic testing (GT) on decisions regarding risk-reducing strategies (RRS) in women at high risk of developing breast cancer (BC).

METHODS: Medical students $(\mathrm{N}=155)$ were given a hypothetical scenario of a 35 year old woman at high risk for developing BC, and asked what they felt her risk would be. They were then given 3 situations, each with additional data. In part 1 , they were given the calculated Gail 5-year risk of $1.8 \%$ (lifetime risk of $40 \%$ ). In part 2, they were given the finding of atypical cells on DL and told that this may increase their risk to an uncertain degree. In part 3, they were given the finding of a BRCA1 mutation, increasing their lifetime risk of developing $\mathrm{BC}$ to $85 \%$. For each of these parts, they were asked to choose a RRS: (a) frequent surveillance (FS), (b) chemoprevention $(\mathrm{CP})$ which would decrease risk by $50 \%$, (C) bilateral prophylactic mastectomy (BPM) which would decrease risk by $95 \%$, or (d) bilateral prophylactic oopherectomy (BPO) which would decrease risk by $50 \%$ and would also reduce the risk of ovarian cancer. Statistical analyses were performed using SPSS 11.0 .

RESULTS: Students overestimated the risk of developing BC (median 5-year and lifetime perceived risk $50 \%$ and $75 \%$ respectively, $\mathrm{p}<0.001$ by one-sample t-test). Although $60 \%$ of students opted to undergo DL for risk assessment, only $42 \%$ of students changed their RRS based on the findings of the DL. Over $95 \%$ of students opted to pursue GT. When given a positive test for a mutation, $72 \%$ of students changed their original RRS based on the findings of GT. Significantly more students changed their RRS based on GT than on DL findings, $\mathrm{p}<0.001$ (likelihood ratio test).

CONCLUSIONS: Most people are likely to overestimate their actual risk of $\mathrm{BC}$. While many may opt for risk-stratification procedures, such as DL, such techniques do not significantly alter decision-making in the absence of quantitative data regarding the level of risk. Techniques such as GT, for which quantitative information exists, have a significant impact in altering decisions regarding RRS.

$\begin{array}{lllll}\text { Scenario } & \text { FS (\%) } & \text { CP (\%) } & \text { BPM (\%) } & \text { BPO (\%) } \\ \text { 1 (Gail) } & 129(82.7) & 14(9.0) & 8(5.1) & 4(2.6) \\ \text { 2 (DL) } & 75(48.1) & 59(38.1) & 16(10.3) & 5(3.2) \\ 3 \text { (GT) } & 30(19.0) & 32(20.5) & 83(53.2) & 11(7.1)\end{array}$

\section{0}

$B R C A 1$ and $B R C A 2$ mutations in a South American population.

Reyes JM, Jara L, Bustamante E, Seccia L, Rodriguez J, Bustamante M, Martinez V, Catenaccio A, Lay-Son G, Blanco R, Gonzalez-Hormazabal P. Instituto Oncologico, Clinica Las Condes, Las Condes, Santiago, Chile; Institute of Biomedical Sciences, School of Medicine, Universidad de Chile, Santiago, Chile; Corporracion Nacional del Cancer, Santiago, Chile

A sample of sixty four high-risk breast and/or ovarian cancer families from Chile, South American were screened for germline mutations in BRCA1 (MIN \# 113705) and BRCA2 (MIN \# 600185), using conformation-sensitive gel electrophoresis (CSGE) and direct sequencing. Seven families $(10.9 \%)$ were found to carry $B R C A 1$ mutations and three families $(4.7 \%)$ BRCA2 mutations. Six different pathogenic mutations were detected in $B R C A 1$, from which four had been previously reported (c.187_188delAG; c. $300 \mathrm{~T}>\mathrm{G}$, c. $34503453 \mathrm{delCAAG}$ and IVS17-1G $>$ A) and 2 were novel mutations (c.2605_2606delTT and c.4185_4188delCAAG). In $B R C A 2$, we found three different pathogenic mutations, two previously described (c.6174delT and c.6503_6504delTT) and one novel mutation (c.5667delT). Also, we identified 9 variants of unknown significance ( 5 in BRCA1 and 4 in BRCA2). These findings indicate that the Chilean population has an heterogeneous spectrum of prevalent BRCA mutations. Given the results obtained in our study the screening of the whole coding region of $B R C A 1$ and $B R C A 2$ is necessary for the molecular genetic testing of the Chilean high-risk breast/ovarian cancer patients. This is the first genetic study carried out in Chile in relation to mutations in the BRCA genes. The Chilean population has a well known admixture Amerindian-Caucasian ratio and therefore our findings have not only importance per se but they constitute the basis that will allow to give a much better and specific genetic counselling and will also be useful to support the preventive campaigns carried out in the Chilean population.

\section{1}

A strong family history of breast cancer increases the use of systemic treatment among patients with early-onset breast cancer: results from a population-based study.

Verkooijen HM, Chappuis PO, Rapiti E, Vlastos G, Fioretta $G$ Sarp S, Sappino AP, Schubert H, Bouchardy C. Institute for Social and Preventive Medicine, Geneva, Switzerland; Geneva University Hospital, Geneva, Switzerland

Background: Breast or ovarian cancer among family members increases the individuals risk to develop breast cancer. In this population-based study we evaluate the impact of a strong family history on the diagnostic and therapeutic management of women with early onset breast cancer.

Methods: With information of the Geneva cancer registry we identified all women diagnosed with breast cancer at 50 years of younger between 1990-2001. We compared patients with a highly increased familial risk to those with no affected relatives. With multivariate logistic regression analysis, we compared both groups in terms of tumour characteristics, method of detection and treatment.

Results. This study includes 58 patients with a highly increased familial risk and 575 without affected relatives. Tumours of high familial risk patients were equally often screen-detected as those of low familial risk patients. Women with a highly increased familial risk received significantly more often hormonotherapy. For lymph node negative disease, high familial risk patients were significantly more often treated with chemotherapy, hormonotherapy or both. Conclusions: This population based study shows that a strong family history of breast cancer influences the use of systemic therapy among patients with early-onset breast cancer.

\section{2}

Preliminary results of a randomized phase IIb doubleblind $2 \times 2$ trial of low-dose tamoxifen and fenretinide for breast cancer prevention.

Bonanni B, Guerrieri-Gonzaga A, Robertson C, Serrano D, Cazzaniga M, Mora S, Gulisano M, Johansson H, Galimberti V, Intra M, Latronico A, Franchi D, Pelosi G, Decensi A. European Institute of Oncology, Milan, Italy; Strathclyde University, Glasgow, United Kingdom; Ospedale San Bortolo, Vicenza, Italy

Background and Purpose: Low-dose tamoxifen and fenretinide, a vitamin A derivative, have both shown to modulate biomarkers of breast cancerogenesis in premenopausal women. In the present study we are investigating whether the combination of the two drugs have a synergistic effect on putative surrogate biomarkers of breast cancerogenesis in premenopausal women at increased risk for breast cancer. Additionally, we are interested in studying the safety and the endometrial effects of the drug combination. 
Patients and Methods: Between October 1998 and April 2002, 235 women were randomly assigned in a double-blind 4-arm trial to tamoxifen $5 \mathrm{mg}$ /day, fenretinide $200 \mathrm{mg}$ /day, both agents, or placebo for 2 years. All subjects are being followed for three additional years. The primary endpoints were the changes in circulating insulin-like growth factor-I (IGF-I) and computerized mammographic percent density.

Results: Subjects were included because of a previously excised DCIS (57\%), LCIS (13\%), micro-invasive breast cancer $(7 \%)$, or a 5 -year Gail risk $>1.3 \%(23 \%)$. There was a $15 \%$ reduction on IGF-I levels on tamoxifen, as early as after 6 months of treatment, while the reduction on fenretinide was about $2 \%$. Recruitment was stopped earlier, based on the lack of a synergistic interaction of the two drugs on plasma IGF-I levels. After a median follow-up of 40 months, 35 subjects dropped the study for refusal $(n=19)$ or adverse events $(n=16)$. So far, 24 primary or recurrent breast cancers have been observed, with no difference among arms. Of the three serious adverse events, one stage-I endometrial cancer occurred in the fenretinide arm, one optic nerve ischemia and one deep venous thrombosis occurred in the tamoxifen arm. There was no increased endometrial thickness and no difference in endometrial polyps among the four arms.

Conclusions: The combination of low-dose tamoxifen and fenretinide is safe and well tolerated, but is not synergistic in lowering circulating IGF-I levels. Low-dose tamoxifen does significantly reduces IGF-I levels and does not affect endometrial proliferation. Mammographic percent density is currently under evaluation and updated results will be presented at the conference.

\section{3}

Celecoxib downregulats estrogen receptor expression in breast tissue of women at increased risk for developing breast cancer.

Arun B, Valero V, Hornbeak J, Gong Y, Broglio K, Logan C, Browne D, Hortobagyi G, Sneige N. The University of Texas MD Anderson Cancer Center, Houston, TX; BMO, Houston, TX; Houston, TX; NCI, Bethesda, MD

Background: Shortterm phase II chemoprevention trials offer a convenient model to screen potential chemopreventive agents and to identify surrogate endpoint biomarkers. One of the potential agents is the selective cyclooxygenase- 2 inhibitor, celecoxib, which has antiproliferative, antiangiogenesis and apoptosis inducing properties. In this prospective study, we aimed to evaluate changes in proliferation and apoptosis induced by celecoxib in breast tissue of high risk women. Here, we report changes in estrogen receptor (ER) expression and proliferation index.

Methods: 32 patients (pts) are enrolled into the study who underwent baseline fine needle aspiration (FNA) and started celecoxib at a dose of $400 \mathrm{mg}$ BID. So far, 26 pts underwent a repeat FNA after 6 months of therapy and data is available on 30 paired FNA samples (including bilateral FNAs). Median age: $51 \mathrm{yrs}$ (range: 39-71 yrs). Risk factors include: Gail risk $>1.67 \%(\mathrm{n}=9)$, lobular carcinoma insitu (LCIS) $(n=6)$, atypical hyperplasia $(\mathrm{AH})$ $(n=) 8$, previous history of contralateral breast cancer $(n=3)$. For ER and Ki-67 testing, thin preparations slides were incubated with primary mouse monoclonal antibody 6F11 against the ER (Novacastra/Vector Laboratories, Burlingame, CA) at a dilution of 1:50 for 30 minutes and mouse monoclonal antibody, clone MIB-1 (Dako), respectively. The EnVision+ method was employed on Dako Autostainer instrument. Appropriate negative and positive controls were included. At least 100 epithelial cells were evaluated per slide. Immunoreactivity for each marker was scored as the percentage of positive nuclei.

Difference in ER and Ki-67 levels before and after treatment was assessed using a Wilcoxon signed rank test.

Results: The average pre- and postreatment ER expression was $45 \%(0-100)$ and $27.4(0-100)$, respectively. The difference in ER levels was statistically significant $(\mathrm{p}=0.04)$. The average Ki67 pre-and postreatment levels were $1.8 \%$ (range: $0-10 \%$ ) and 1.2
$\%$ (range: 0-5\%), respectively. The median difference in Ki-67 levels was not statistically significant $(\mathrm{p}=0.63)$.

Conclusions: We have found a significant downregulation of ER expression with 6 months celecoxib treatment in breast epithelium of women who are at increased risk to develop breast cancer. Since ER expression is a marker of proliferation, this finding confirms celecoxibs antiproliferative properties. Currently, we have not observed a change in $\mathrm{Ki}-67$; this could be partly due to the small number of samples and the fact that Ki-67 is low in normal epithelium. Further analysis and correlation with other proliferation (COX-2, EGFR) and apoptosis markers (Bcl-2) are currently going on.

\section{4}

Chemopreventive efficacy of new RXR specific retinoids against mammary cancers and correlations with shortterm biomarkers.

Christov K, Muccio D, Brouillette W, Atigadda R, Desphande A, Bland $K$, Beenken $S$, Grubbs $C$, Lubet R. University of Illinois at Chicago, Chicago, IL; University of Alabama at Birmingham, Birmingham, AL; National Cancer Institute, Bethesda, MD

A series of structurally varied RXR agonists that were synthesized based on computer fitting to the RXR receptors were evaluated for their long term chemopreventive efficacy in the methylnitrosourea (MNU)-induced ER+ rat mammary cancer model. To predict their efficacy and toxicity, agents were given in the diet for 7 days and their ability to modulate proliferation and apoptosis in small mammary cancers and their effect on serum triglycerides levels were measured. Synthesized rexinoids (RA-IV10A, AM3-2, UAB-20, RA-IV-69A, and UAB-30) plus the rexinoid targretin and 9-cis-retinoic acid (9-cis-RA) were administered in the diet. Targretin and RA-IV-10A decreased cancer multiplicity by $75-85 \%$; UAB-30 and 9 -cis-RA decreased multiplicity by $45-$ $60 \%$, while a low dose of Targretin, and UAB-20 and AMD3-2 decreased multiplicity $<35 \%$. RA-IV-69A had no effect on the number of cancers. A correlation was observed between the longterm chemopreventive efficacy of these agents and their ability to decrease cell proliferation in mammary cancers after shortterm treatment. However, only the highly effective agents (RAIV-10A and targretin, $150 \mathrm{mg} / \mathrm{kg}$ diet) significantly increased apoptosis. Although most of the effective rexinoid treatments increased serum triglycerides levels $2.5-4.0$ times, one moderately effective chemopreventive agent (UAB-30) had minimal effects on serum triglycerides levels. Thus, these short-term in vivo methods could predict both chemopreventive efficacy and toxicity of new rexinoids.

\section{5}

\section{Reproducibility of ductal lavage findings in high-risk} women.

Bhandare DJ, Nayar R, Masood S, Bryk M, Cohn R, Hou N, Rademaker A, Khan SA. Northwestern University Feinberg School of Medicine, Chicago, IL; University of Florida College of Medicine, Jacksonville, FL

Background: Ductal lavage (DL) is a minimally invasive technique that allows repeat sampling of ductal epithelium. We are conducting a Phase II trial, wherein high-risk women may opt for Tamoxifen (TAM), or decline it, following an entry DL procedure. We present data from the non-intervention arm of our study, to assess the reproducibility of cannulation, cell yield and cytological diagnosis from DL of the same duct at two time-points.

Methods: Consenting women undergo DL; the samples are alcohol-fixed and centrifuged to separate the cells from the supernatant. The first $1 / 4$ sample of cells is used to prepare a Thinprep, Papanicoloau-stained slide for cyto-morphology evaluation. The other aliquots are assayed for biomarker studies. A repeat lavage six months later is analyzed similarly. Cytodiagnosis on the same set of samples is compared between two experienced 


\section{S170 Abstracts - Poster Session IV}

cytopathologists (RN and SM) to assess interobserver agreement. Results: Of the 104 women (mean age 52 years, mean Gail score $2.6 \%$ ) who have had a follow-up DL, 65 are from the nonintervention (No TAM) group. Of the 179 ducts lavaged at baseline, successful recannulation of the same duct/s could be accomplished on 159 ducts $(88 \%)$. Epithelial cells sufficient for analysis $(>100)$ could be obtained in 42/63 $(67 \%)$ women (kappa=0.3) and 76/159 $(47 \%)$ ducts $(\mathrm{kappa}=0.2)$ at both time points. Overall, the cytological diagnosis at first lavage was reproducible in $29 / 63$ $(46 \%)$ women $(\mathrm{kappa}=0.2)$ and $75 / 159(47 \%)$ ducts $(\mathrm{kappa}=0.14)$ at second lavage. The breakdown by cytodiagnosis is shown in Table 1.Interobserver variability for cytodiagnosis between two observers (RN and SM) showed good agreement with kappa index of 0.56 (by duct) and 0.68 (by woman). Variability in diagnosis was seen either in the "benign" or "mild atypia" category.

Conclusion: We were able to successfully resample at least one duct in all but one woman. Sufficient cells for analysis can be procured at repeat lavage in two-thirds of women. The value of cytologic atypia as a reproducible biomarker is limited. As more women return, we will evaluate reproducibility of estrogen response biomarkers in this cohort of subjects.

Supported by the Bluhm Family Program for Breast Cancer Early Detection \& Prevention and NIH/NCI P50 CA89018.

Table 1

$\begin{array}{lll}\text { Concordant cytology at 1st and 2nd lavage } & \text { By woman } & \text { By duct } \\ \text { ICMD } & 4 / 8(50 \%) & 21 / 40(52.5 \%) \\ \text { Benign } & 17 / 35(48.6 \%) & 50 / 96(52.1 \%) \\ \text { Mild atypia } & 8 / 20(40 \%) & 4 / 23(17.4 \%) \\ \text { Severe atypia } & 0 / 0(0 \%) & 0 / 0(0 \%)\end{array}$

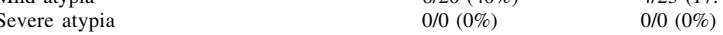

ICMD: Insufficient cells for morphologic diagnosis

\section{6}

Bone turnover by osteocalcin and risks of breast cancer and fracture: a prospective study.

Cummings SR, Blackwell T. California Pacific Medical Center Research Institute, San Francisco, CA; University of California, San Francisco, San Francisco, $C A$

Background: Osteocalcin is a protein secreted by osteoblasts and is used to assess bone remodeling. Osteoblasts are sensitive to the effects of E2. Women with little or no estradiol (E2) tend to have high rates of bone remodeling and increased levels of osteocalcin (OC). Women with little or no E2 also have a substantially decreased risk of breast cancer. E2 is also synthesized by aromatase in both osteoblasts and breast tissue. We used the placebo group of the Multiple Outcomes of Raloxifene (MORE) trial to test the hypothesis that women with high $\mathrm{OC}$ levels have a decreased risk of breast cancer. We compared this association to the relationship of $\mathrm{OC}$ to risk of fracture.

Methods: OC was measured at baseline (CIS Biointernational) in 913 postmenopausal women (mean age 67.5 years) with low BMD or osteoporosis. Serum E2 was measured by a double-antibody method (Covance). Incident breast cancer was confirmed by histopathology reports. Incident non-spine fractures were confirmed by radiographs and incident vertebral fractures by semiquantitative grading and morphometry of baseline and followup spine radiographs.

Results: After adjustment for age, OC level had no relationship to risk of non-spine $(\mathrm{RH}=1.10 ; 95 \% \mathrm{CI} 0.88-1.38)$ or vertebral fracture $(\mathrm{RR}=1.13$; 95\% CI 0.86-1.47). However, twelve incident breast cancer cases were confirmed during the 4-year trial. And after adjustment for age, women with high OC (>28 g/L) had a lower risk (no cases) of breast cancer than did women with lower OC levels ( $\mathrm{P}$ for trend $=0.027$; Figure). Adjustment for baseline E2 did not attenuate this relationship.

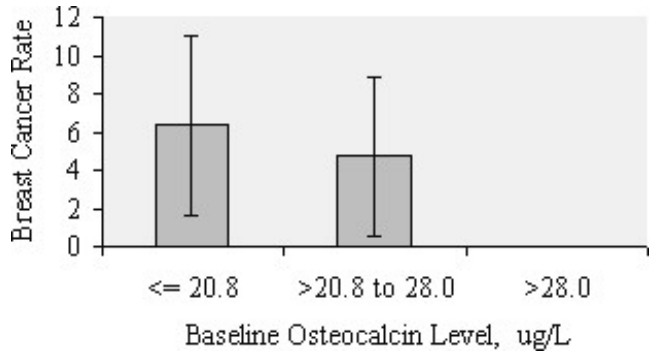

Conclusion: If confirmed by larger studies, OC may be a better marker of breast cancer than fracture risk.

\section{7}

Chemopreventive effects of the EGFr inhibitor Iressa in the methylnitrosourea (MNU) - induced model of mammary carcinogenesis.

Grubbs C, Christov K, You M, Wang Y, Steele V, Juliana M, Lubet R. University of Alabama at Birmingham, Birmingham, AL; University of Illinois at Chicago, Chicago, IL; Washington University, St. Louis, MO; National Cancer Institute, Bethesda, $M D$

The efficacy of the EGFr inhibitor Iressa to prevent mammary cancers was determined in female Sprague-Dawley rats administered MNU. In this model, the mammary cancers are estrogen receptor positive, and approximately $50 \%$ of the cancers have mutations in the HaRas oncogene. The rats were given a single dose of MNU ( $75 \mathrm{mg} / \mathrm{kg} \mathrm{BW}$ ), IV via the jugular vein, at 50 days of age. Beginning five days later and continuing until the end of the study, Iressa was administered by gavage, 6x/week. The vehicle for Iressa was ethanol: polyethylene glycol $400(10: 90 \mathrm{v} / \mathrm{v})$. A low dose $(10 \mathrm{mg} /$ $\mathrm{kg} \mathrm{BW/day)} \mathrm{of} \mathrm{Iressa} \mathrm{was} \mathrm{given} \mathrm{until} \mathrm{the} \mathrm{end} \mathrm{of} \mathrm{the} \mathrm{experiment,}$ while a high dose $(20 \mathrm{mg} / \mathrm{kg} \mathrm{BW} /$ day $)$ was given only until 82 days after MNU (11 weeks of treatment) due to clinical signs of toxicity. At 82 days post MNU, control rats had 2.5 mammary tumors/rat, while rats receiving either the high or low doses of Iressa had 0.3 mammary tumors/rat $(88 \% \downarrow)$. At the end of the study (126 days after MNU), MNU-treated only rats had 5.5 mammary cancers/ rat while Iressa (low dose) treated rats exhibited only 0.6 cancers/ rat $(89 \% \downarrow)$. Rats receiving the high dose for a limited time showed only a $58 \%$ decrease in cancer multiplicity. Treatment for 11 weeks, therefore, did not stop the appearance of cancers once treatment was discontinued. Thus, Iressa was an effective agent in this model despite the fact that it was similarly expressed (RTPCR) in both normal mammary epithelium and in cancers. Additional data examining Iressa's therapeutic effects in this model will also be presented.

\section{8}

Breast endoscopy in the evaluation of individuals in a highrisk breast cancer clinic.

Ley M, Frank D, Davis J, Degan J, Lacovara J, Waer A, Kim C. University of Arizona, Arizona Cancer Center, Tucson, AZ; ; University of Arizona

Background: Current models of breast cancer risk assessment are limited. Previous studies show that cytologic and karyometric analyses of ductal lavage fluid can assist in the risk stratification of high risk individuals. Breast endoscopy is a minimally-invasive procedure that allows direct visualization of breast ducts with access to terminal ductal lobular units and has the potential for high cellular yield using intraductal brushings. We report our experience with breast endoscopy in evaluating patients enrolled in a high risk clinic.

Methods: Of the 91 patients followed in the High Risk Breast Cancer Clinic from $11 / 2003$ to $5 / 2005,22$ patients had either 
spontaneous (11) or elicited nipple discharge (11). High risk criteria included family history, 5-year risk Gail score $\geq 1.7$, personal history of breast cancer or spontaneous nipple discharge. All patients had normal screening mammograms. Information was collected prospectively on patient demographics, visual endoscopic findings, distance travelled by endoscope, patient comfort and complications. Cytology and karyometry of intraductal brushings were performed.

Results: All 22 patients with fluid-yielding ducts underwent 29 breast endoscopies (7-multiple) and intraductal brushings. The average distance traveled with the endoscope was $4.5 \mathrm{~cm}$ (range 2$8 \mathrm{~cm}$ ). Cellular yield was adequate in 23/29 (79\%) of intraductal brushings, which is improved from our previously reported catheterbased ductal lavages $(66 \%)$. Results are shown figure 1 . Intraductal lesions were found in $8 / 15$ endoscopies performed for spontaneous nipple discharge. Subsequent surgical excisions revealed 7 papillomas and 1 DCIS. All patients who had elicited nipple discharge had normal endoscopic findings with benign/ normal cytology (7), mild atypia (4) and insufficient cells (3). All patients tolerated the procedure without discomfort or complications. Karyometric analyses showed quantitative differences in nuclear abnormality between normal controls and patients with atypia or DCIS.

Discussion: Breast endoscopy is safe, feasible and well tolerated in individuals at higher risk of breast cancer. This minimallyinvasive procedure may be used as an adjunct to risk stratification in these patients. We are currently exploring various biomarkers in intraductal brushings to further improve risk stratification and evaluate efficacy of chemoprevention agents.

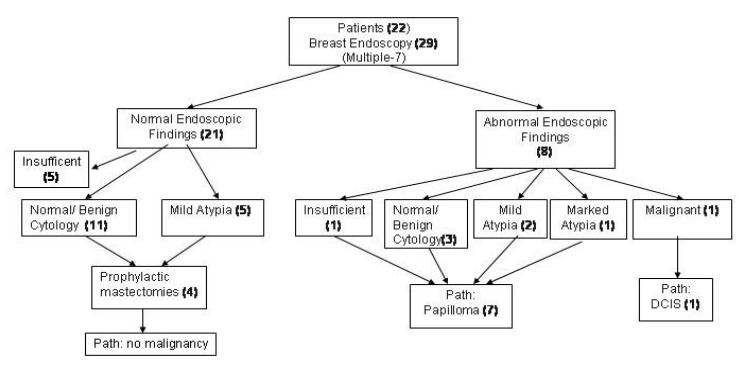

\section{9}

Chemopreventive effects of the statins, lipitor (Atorvastatin) and lovastatin, in the methylnitrosourea (MNU) induced model of mammary carcinogenesis.

Lubet R, Grubbs C, Steele V, Eto I, Juliana M, Kopelovich L. National Cancer Institute, Bethesda, MD; University of Alabama at Birmingham, Birmingham, $A L$

The statins have proven to be highly effective in lowering cholesterol by inhibiting HMGCoA reductase. More recently, there has been a limited amount of epidemiologic data showing that the use of statins may decrease the incidence of certain types of cancer (e.g., colon). The abilities of Lipitor and Lovastatin, either administered as single agents or in combination with suboptimal doses of the SERM tamoxifen or the RXR agonist Targretin, were evaluated for prevention of ER positive mammary cancers in the rat mammary model. Female Sprague-Dawley rats were administered MNU (50 mg/kg BW) at 50 days of age and the chemopreventive agents beginning five days later. Lipitor (500 $\mathrm{mg} / \mathrm{kg}$ diet) alone did not significantly affect cancer incidence or multiplicity. Suboptimal doses of tamoxifen $(0.4 \mathrm{mg} / \mathrm{kg}$ diet $)$ or Targretin $(80 \mathrm{mg} / \mathrm{kg}$ diet $)$ reduced cancer multiplicity from 4.60 (control) to 3.75 and 1.13 , respectively. Combining Lipitor with either of these two effective agents minimally changed their efficacy. Although this dose of Lipitor did not decrease serum triglycerides levels in control rats, it significantly decreased triglycerides levels which had been increased in Targretin-treated rats. Experiments performed with a second statin, Lovastatin (500 mg/kg diet), in the same model system yielded similar results; specifically, a) limited activity when administered alone; b) no obvious synergy with suboptimal doses of tamoxifen or Targertin; and c) an ability to decrease the Targretin induced increase in serum triglycerides. Thus, the statins had minimal activity in a rat model of mammary cancer in which roughly half of the cancers are mutated at the HaRas locus, and which has previously been shown to respond to hormonal therapies that are significant in human (e.g., SERMS, aromatase inhibitors, and pregnancy).

\section{0}

Curcumin induces cell cycle arrest and apoptosis in an in vitro model for hormonally non-responsive ductal carcinoma in situ..

Crawford CV, Thakur S, Kim D, Osborne MP, Katdare M. Weill Medical College of Cornell University, New York, NY; Strang Cancer Prevention Center, New York, NY

Background: The overexpression of oncogene HER-2/neu and $\mathrm{ER}^{-} / \mathrm{PR}^{-}$are markers for poor prognosis in Ductal Carcinoma in situ (DCIS). Despite intensive management, post-operative survival and remission are challenged by dose limiting side effects of therapy. Nontoxic phytochemicals are known to reduce tumor incidence, and we have shown cytostatic arrest of growth and induction of apoptosis in an in vitro murine model for breast cancer by curcumin. Present experiments were designed to identify its preventive mechanism in an in vitro model for human comedo DCIS.

Materials and Methods: The preclinical model for DCIS, represented by HER-2/neu transfected 184B5/HER cells, exhibits hyperproliferation, high anchorage independent growth and tumorigenecity compared to the immortalized, non-transformed 184B5 breast epithelial cells. Normal or transformed cells in log phase were exposed to $0,10,20,40$ and $60 \mathrm{uM}$ CUR for $72 \mathrm{hr}$ and analyzed for growth response, viable cell counts, cell cycle distribution and apoptosis. cDNA libraries were constructed using $5 \mathrm{ug}$ of total RNA from cells of the 0uM and 20uM CUR treatment groups at $24 \mathrm{hr}$. Biotin-labeled RNA was transcribed from the cDNA and hybridized to human genome microarrays. Genes that showed more than 1.5 fold changes in expression with $\mathrm{p}<0.05$ were filtered by GeneSpring ${ }^{\mathrm{TM}}$ and DAVID ${ }^{\mathrm{TM}}$. Select cell cycle and apoptosis related genes from this list were then verified by western blot.

Results: 184B5/HER cells exhibited a dose dependent sensitivity to CUR compared to 184B5 cells. The response of 20uM CUR exposure to $184 \mathrm{~B} 5 / \mathrm{HER}$ cells was observed within $12 \mathrm{hr}$ as cytostatic growth arrest, decreased $\mathrm{G}_{0} / \mathrm{G}_{1}: \mathrm{S}+\mathrm{G}_{2} / \mathrm{M}$ ratio and induction of apoptosis which peaked at $24 \mathrm{hr}(\sim 45 \pm 0.7 \%$ inhibition and $\sim 40 \pm 0.5 \%$ apoptosis) and persisted for $72 \mathrm{hr}$. Microarray analysis of 184B5/HER cells exposed to $20 \mathrm{uM}$ of CUR for $24 \mathrm{hr}$ revealed 380 downregulated genes and 177 upregulated. Amongst the downregulated genes, 12 were specific to $S+G_{2} / M$ phases: cyclin A1 (-2.79), cyclin A2 (-3.60), cyclin B1(-3.45), cyclin B2 (3.89), CDK1 (3.96), CDK 2 (-1.69), Dbf4 (-2.56), Wee (-1.6), Cdc25C $(-3.80)$, Chk1 (-2.58), BubR1 (-2.82) and PTTG (-2.77). HDAC6 was the only gene upregulated $(+7.65)$ in this group. Apoptosis specific survivin $(-3.28)$ was also modulated. Western blots of cyclin A1, cyclin B2, CDK1 and CDK2 correlated with the microarray data.

Discussion: Our results confirm the preventive efficacy of CUR in 184B5/HER cells, via cytostatic arrest in $\mathrm{S}+\mathrm{G}_{2} / \mathrm{M}$ phases of cell cycle and induction of apoptosis. The modulation in $\mathrm{G}_{0} / \mathrm{G}_{1}: \mathrm{S}+\mathrm{G}_{2} / \mathrm{M}$ ratio and apoptosis was dose-dependent and correlates with the altered transcription and expression of genes in proliferative phases. Theeffects of CUR on this DCIS model were not observed under identical conditions in nontumorigenic cells, suggesting the chemopreventive potential of CUR for breast cancer is worthy of further investigation. 


\section{S172 Abstracts - Poster Session IV}

4021

Effect of estrogen deprivation on proliferation marker Ki67 and minichromosome maintenance protein-2 (Mcm-2) in normal postmenopausal breast tissue: potential biomarkers for chemoprevention.

Kendall AH, Williams GH, Stoeber K, Salter J, Dowsett M. Royal Marsden Hospital, London, United Kingdom; Wolfson Institute for Biomedical Research, University College London, London, United Kingdom

Background: In a previously reported pilot prevention study we examined changes in proliferation marker Ki67 in normal breast tissue from 30 postmenopausal women exposed to the aromatase inhibitor letrozole for 3 months [1]. Pre-treatment Ki67 levels were low (mean $1.28 \%$ (95\% CI 1.0-1.65)) and although this was reduced post treatment the change was not statistically significant (mean $0.99 \%(95 \%$ CI $0.59-1.66) ; \mathrm{p}=0.65) . \mathrm{Mcm}-2$ is a licensing factor for DNA replication. Mcm-2 expression is elevated above Ki67 levels in breast malignancy [2]. This study investigated whether Mcm-2 was changed to a greater degree than Ki67 in normal postmenopausal breast tissue exposed to letrozole and might therefore be a potential marker for chemoprevention.

Materials and Methods: Immunohistochemical staining for $\mathrm{Mcm}-2$ was performed on archival paraffin embedded $14 \mathrm{G}$ corecut biopsies from 20 paired specimens available from the initial study. A median of 2362 (1032 - 4104) luminal epithelial cells were scored for Mcm-2 with results expressed as a percentage of cells stained. Paucity of cellular material limited the planned 3000 cell count.

Results: There was no evidence of a correlation between $\mathrm{Mcm}$ 2 and Ki67 pre-treatment (Rs $0.31,95 \% \mathrm{CI}$ : -0.16 to 0.67 ) or post-treatment (Rs $0.27,95 \% \mathrm{CI}:-0.21$ to 0.64 ) although the point estimates indicate it is not possible to rule out weak correlations $(\mathrm{Rs}=$ Spearman Rank Correlation coefficient). Of the 20 paired samples that were re-evaluated mean Ki67 expression fell by $8.2 \%$ (95\%CI: $41 \%$ less to $42 \%$ greater, $\mathrm{p}=\mathrm{ns}$ ), mean values falling from 1.47 to 1.35 , after 3 months of letrozole therapy. Mean Mcm-2 expression fell by $24.2 \%$ (95\% CI: $66 \%$ less to $70 \%$ greater, $\mathrm{p}=\mathrm{ns}$ ), mean values falling from 1.55 to 1.20 . Mcm-2 expression was not significantly higher than Ki67 in this study population, $\mathrm{Mcm}-2$ values being on average $10 \%$ lower $(95 \% \mathrm{CI}$ : $42 \%$ lower to $39 \%$ higher). However, there was a suggestion that the change in Mcm-2 levels correlated with that of Ki67 (Rs $0.43,95 \%$ CI: -0.03 to $0.74, p=0.06$ ).

Conclusions: $\mathrm{Mcm}-2$ expression can be determined in archival paraffin embedded tissue and shows expression levels similar to that of Ki67. The lack of significant change of either of these markers after 3 months of letrozole suggests that they have little utility as biomarkers for chemoprevention. We are currently assessing genome wide mRNA changes in these tissues to determine if such markers exist in normal postmenopausal breast tissue. References:

1. Harper-Wynne $\mathrm{C}$ et al. Cancer Epidem, Biomarkers and Prevention. Vol 11 614-621 2002

2. Gonzalez MA et al. Journal of Clinical Oncology Vol 21 No23 4306-4313 2003

\section{2}

Association of RARß2, ER, BRCA and p16 promoter methylation with cytologic atypia in random periareolar fine needle aspiration (RPFNA) breast tissue of asymptomatic women at high risk for breast cancer.

Seo PH, Bean GR, Baker Jr. JC, Scott JV, Rasheed K, Yee LD, Troch MM, Case N, Bowie ML, Marcom PK, Kimler BF, Zalles CM, Sloane R, Fabian CJ, Seewaldt VL. Duke University Medical Center, Durham, NC; Ohio State University Medical Center Columbus, OH; University of Kansas Medical Center, Kansas City, $K S$

Background: DNA methylation of tumor suppressor genes may be a marker of early breast carcinogenesis. Previously we have shown that hypermethylation of RAR $\beta 2$ promoter in breast tissue of asymptomatic high-risk women was associated with mammary cytologic atypia, an independent marker of breast cancer risk. This study reports on the association of RAR $\beta 2$, ER, BRCA and p16 promoter methylation with cytologic atypia.

Methods: RPFNA is a research technique that obtains a representative sampling of the whole-breast. Women at high-risk had a 5 -year Gail risk $\geq 1.7 \%$, prior atypical hyperplasia, LCIS or DCIS or known BRCA1/2 mutation. A dedicated pathologist determined cell count and atypia (Masood cytology index). Methylation-specific PCR was performed for RAR $\beta 2$ at two regions (M3 and M4), ER, BRCA and p16. Wilcoxon Rank Sum determined the association of methylation status with Masood index. CochranMantel-Haenszel (CMH) trend test determined the association of methylation status with stratified Masood index of normal (6$10)$, proliferative (11-14), hyperplasia (15-17) and suspicious for cancer (18+). Spearman correlation (rho) determined relationship of cell count with Masood index.

Results: 95 RPFNA breast tissue samples were obtained from 66 asymptomatic high-risk women (mean 46.1 years (range 25-64)) Masood indices and cell counts ranged from 8-19 and $<10-10000$ respectively.

Methylation Analyses

\begin{tabular}{|c|c|c|c|c|c|}
\hline Gene & $\begin{array}{l}\text { Methylation, \% } \\
\text { (methylated/ } \\
\text { total samples) }\end{array}$ & $\begin{array}{l}\text { Unmethylated } \\
\text { Masood } \\
\text { index (mean) }\end{array}$ & $\begin{array}{l}\text { Methylated } \\
\text { Masood } \\
\text { index (mean) }\end{array}$ & $\begin{array}{l}\text { Wilcoxon } \\
\text { p-value }\end{array}$ & $\begin{array}{l}\text { CMH } \\
\text { p-valu }\end{array}$ \\
\hline $\begin{array}{l}\text { RARß2 } \\
\text { (M3) }\end{array}$ & $62.7(47 / 75)$ & 11.8 & 13.1 & 0.03 & 005 \\
\hline $\begin{array}{l}\text { RAR } \beta 2 \\
\text { (M4) }\end{array}$ & $25.3(19 / 75)$ & 12.0 & 14.0 & 0.005 & 0.001 \\
\hline $\mathrm{ER}$ & $22.4(17 /$ & 12.4 & 12.5 & 0.53 & \\
\hline $\mathrm{RC} A$ & $13.5(12 / 89)$ & 12.5 & 12.4 & 0.42 & \\
\hline 16 & $10.5(9 / 86)$ & 12.3 & 13.0 & 0.85 & \\
\hline
\end{tabular}

56 RPFNA samples $(58.9 \%)$ had all 5 methylation sites analyzed. $9 / 56$ samples $(16.1 \%)$ had 3 or more methylated sites. Masood index for samples with 0-2 methylated sites (mean 12.2) compared to 3 or more methylated sites (mean 13.5) were similar $(\mathrm{p}=0.36$ ). Cell count was correlated with Masood score (rho $=0.69, \mathrm{p}<0.0001)$. Conclusions: Our preliminary results show that RAR $\beta 2$ hypermethylation and cell count in RPFNA breast tissue continue to be significantly associated with cytologic atypia. Although ER, BRCA, p16 or multiple gene methylations did not confer an association, completion of methylation analyses for all 5 sites in all samples may disclose additional methylation patterns.

\section{3}

Effect of raloxifene on invasive breast cancer incidence in postmenopausal women stratified by body mass index (< 25 and $\geq 25 \mathrm{~kg} / \mathrm{m}^{2}$.

Cauley J, Disch D, Dowsett S, Mershon J. University of Pittsburgh, Pittsburgh, PA; Eli Lilly and Company, Indianapolis, IN

Background: The Continuing Outcomes Relevant to Evista ${ }^{\circledR}$ (CORE) trial was a double-blind, placebo-controlled, 4-year followup to the 4-year Multiple Outcomes of Raloxifene Evaluation (MORE) trial. The purpose of CORE was to examine the effects of raloxifene on invasive breast cancer incidence. Raloxifene was associated with a 59\% reduction in invasive breast cancer incidence 
versus placebo.Since obesity has been associated with an increased risk of breast cancer, the present pre-specified secondary analysis compared the effect of raloxifene with placebo on invasive breast cancer incidence over 8 years in postmenopausal women with osteoporosis, grouped by BMI $\left(<25\right.$ and $\left.\geq 25 \mathrm{~kg} / \mathrm{m}^{2}\right)$. A BMI $\geq 25$ $\mathrm{kg} / \mathrm{m}^{2}$ is considered overweight, and was close to the median for this population $\left(\right.$ median $=24.8 \mathrm{~kg} / \mathrm{m}^{2}$ ).

Methods: Of the 7705 postmenopausal women enrolled in MORE, 4011 continued in CORE. Those women randomized to raloxifene 60 or $120 \mathrm{mg} / \mathrm{d}$ in MORE were assigned to raloxifene $60 \mathrm{mg} / \mathrm{d}$ in CORE; those randomized to placebo in MORE received placebo in CORE. BMI was calculated using MORE baseline data. Time to first invasive breast cancer was analyzed using Cox proportional hazard models.

Results: In the placebo group, invasive breast cancer incidence was numerically greater in women with BMI $\geq 25 \mathrm{~kg} / \mathrm{m}^{2}$ versus those with BMI $<25 \mathrm{~kg} / \mathrm{m}^{2}$, but this difference was not statistically significant (hazard ratio [HR] $1.29,95 \%$ confidence interval [CI] 0.77-2.17; $\mathrm{p}=0.33$ ). The effect of raloxifene on breast cancer incidence is shown in the table.

Conclusion: In this population of postmenopausal women with osteoporosis, the incidence of invasive breast cancer did not differ between those women with BMI $<25$ versus $\geq 25 \mathrm{~kg} / \mathrm{m}^{2}$. Raloxifene significantly reduced the incidence of invasive breast cancer in both groups, and the magnitude of its effect was not dependent upon BMI group. Raloxifene is indicated for osteoporosis prevention and treatment in postmenopausal women.

Breast cancer incidence in postmenopausal women grouped by BMI Number of cases $(\%) \quad$ Raloxifene vs Placebo Placebo Raloxifene HR $(95 \% \mathrm{CI})$ Absolute risk reduction $(\mathrm{N}=2575) \quad(\mathrm{N}=5128)$

$\begin{array}{llll}\mathrm{BMI}<25 \mathrm{~kg} / \mathrm{m}^{2} & (\mathrm{~N}=2575) & (\mathrm{N}=5128) \\ 26(1.95) & 16(0.59) & 0.29\end{array}$ (cases/10,000 woman-yrs)

$(\mathrm{N}=4035)$

$\mathrm{BMI} \geq ; 25 \mathrm{~kg} / \mathrm{m}^{2} \quad 32(2.58)-24(0.99)$

$(\mathrm{N}=3668)$

Therapy by BMI interaction not significant $(\mathrm{p}=0.58)$

\section{4}

Identification of genes modulated by LGD1069, a rexinoid that prevents mammary tumorigenesis.

Li Y, Kim H, Uray I, Bissonnette R, Lamph W, Johnson K, Brown P. Baylor College of Medicine, Houston, TX; Ligand Pharmaceuticals, Inc, San Diego, CA; National Cancer Institute, National Institutes of Health, Bethesda, MD

Background: Retinoids are natural and synthetic vitamin A analogues that have been shown to prevent breast cancer in animal models. LGD1069, an RXR-selective retinoid (rexinoid), inhibits the growth of normal breast cells and suppresses the development of ER-negative mammary tumors in mice with reduced toxicity. However, the mechanism by which this rexinoid suppresses carcinogenesis is not fully understood. We hypothesized that LGD1069 exerts its chemopreventive effects by modulating the expression of growth regulatory proteins in normal breast cells. Material and Methods: By performing cDNA microarray profiling, we compared the gene expression patterns between normal human mammary epithelial cells treated with vehicle and LGD1069. Genes found to be regulated by LGD1069 were validated by quantitative real time RT-PCR. To determine which retinoid receptor plays role in the regulation, we also tested the response of these genes to other pathway-selective retinoids such as 9cRA, LG100268 and TTNPB. The regulation of selected growth control proteins was further characterized by western blot analysis and luciferase reporter assays. Sequential deletion analysis was then conducted to map the response elements in the promoter of the selected retinoid responsive genes.

Results: We identified the set of genes that are modulated by LGD1069 treatment in HMECs. These genes includes short-chain dehydrogenase/reductase 1 (SDR1), involucrin (IVL), differentiated embryonic chondrocyte 2 (DEC2), retinoic acid-induced 3 (RAI3), cyclooxygenase-2 (COX-2) and cyclin D1. Most of these genes were also regulated by 9cRA and TTNPB, and not by LG100268, suggesting that the modulation of gene expression occurs primarily through the RAR signaling pathway. We also observed that LGD1069 repressed the expression of cyclin D1 protein and induced a G1 cell cycle block. Therefore, we next investigated whether LGD1069 suppressed the activation of the cyclin D1 promoter. Our studies showed that LGD1069 inhibited the transcription of cyclin D1 promoter reporter constructs after 12 hours of treatment. The response elements of this repression were found to be within $-254 \mathrm{bp}$ of the proximal promoter.

Conclusion: These results suggest that LGD1069 prevents mammary tumorigenesis in part by modulating the expression of growth control proteins including cyclin D1 and COX-2. Our studies also suggest that LGD1069 modulates the expression of many genes through RAR signaling pathways. By elucidating the mechanism by which rexinoids prevent cancer, it will be possible to develop more effective and less toxic drugs for the prevention of breast cancer.

\section{5}

Activation of ATM and p53 in mammary gland epithelial cells as a possible breast cancer prevention model.

Loehberg CR, Thompson T, Kastan MB, Conneely OM, Medina D, O'Malley BW. Baylor College of Medicine, Houston, TX; St. Jude Children's Research Hospital, Memphis, TN

Background: Breast cancer remains the major cancer among women in the United States with more than 200,000 new cases annually. The use of possible breast cancer preventive agents to complement existing therapies has the potential to improve breast cancer treatment. Quinoline sulfonamide family members like chloroquine or quinidine have shown effects of reduced cell proliferation, differentiation and apoptosis. We considered the anti-malarial drug chloroquine to be an interesting candidate as a possible cancer preventive agent.

Materials and Methods: Cell culture: non-tumorigenic mammary gland epithelial cell line MCF10A, Methods: Immunoblotting, siRNA technology, cell growth assays, flow cytometry

Results: Chloroquine, a known chromatin-modifying agent, inhibits cell proliferation and activates the tumor-suppressor protein p53 in the human mammary gland epithelial cell line MCF10A. Using p53 and phospho-specific antibodies we could demonstrate a significant up-regulation of both total p53 and its activated form phospho-p53-Ser ${ }^{15}$. The phosphorylation at $\operatorname{Ser}^{15}$ appeared specific since no phosphorylation at $\operatorname{Ser}^{6,9,20,37,46}$ was detected in Western blot experiments. In order to assess the involvement of protein kinases we utilized antibodies against the Chk1 and Chk2 protein kinases and could not detect up-regulation. In contrast, we were able to demonstrate activation of the ATM protein kinase, a central player of cell cycle regulation and apoptosis. To further confirm this data we used ATM-siRNA and showed both a down-regulation of ATM and p53 phosphorylation at $\mathrm{Ser}^{15}$. Moreover the tumor-suppressor protein $\mathrm{p} 21$, a cell cycle inhibitor and downstream target gene of p53, was up-regulated. To determine the cellular effects of cholorquine treatment, we performed cell growth assays and flow cytometry and showed reduced proliferation and a G0/G1 cell cycle arrest after chloroquine. Only at high doses was apoptosis detected. Using Histone 3/4 and $\mathrm{H} 2 \mathrm{AX}$ antibodies we demonstrated that neither DNA damage (no $\mathrm{H} 2 \mathrm{AX}$ phosphorylation) nor Histone $3 / 4$ hyperacetylation is required to activate the ATM-p53-p21 molecular pathway with choloroquine.

Discussion: Our results reveal that the chromatin-modifying agent chloroquine activates ATM, p53 and p21 without detectable DNA damage and causes G0/G1 cell cycle arrest in a non-tumorigenic mammary gland epithelial cell line. Chloroquine is known to alter chromatin structures in the absence of DNA breaks. The pharmacokinetic properties of this quinoline sulfonamide are well characterized by excellent oral bioavailability, extensive tissue penetration, low protein binding and a long half-life. Our results indicate that the drug could have a preventative application for tumorigenesis. 


\section{S174 Abstracts - Poster Session IV}

4026

Induction of apoptosis in the absence of p53: implications for chemoprevention for ER-negative breast cancer.

Lee MH, Ganai S, Barnard Z, Mason HS, Arenas RB. Pioneer Valley Life Sciences Institute, Springfield, MA; Baystate Medical Center, Springfield, MA; University of Massachusetts, Amherst, $M A$

Mutations of p53 cause an imbalance of regulatory controls leading to breast cancer and downregulate the expression of estrogen and progesterone receptors, hence complicating cancer treatment. High levels of estrogen, 12-lipoxygenase (12-LOX), oncogenic Ras proteins, and cyclooxygenase-2 (COX-2) have been associated with cancer by increasing cell proliferation while decreasing programmed cell death or apoptosis. Prior studies reveal an inverse relationship between COX-2 and p53 expression. We are evaluating chemopreventive agents that target estrogen receptor (ER) negative breast cancer utilizing a p53 mutated mouse model. Overproduction of estrogen and prostaglandins has been associated with ER-negative breast cancer in these mice. The evolution of ER-negative breast cancer from ER-positive breast tissue may involve pathways mediated by aromatase and later by COX-2. We hypothesize that inhibition of COX-2 and aromatase leads to an increase in apoptosis providing protection against ER-negative breast cancer. Fourth mammary glands of 8-week old wildtype and p53-null females were sustained in tissue culture for four days in the presence or absence of estrogen and progesterone. Several agents were tested for their potential chemopreventive properties: COX-2 and 12-LOX inhibitors, selective estrogen receptor modulator (SERM), aromatase inhibitor, farnesyltransferase (Ras) inhibitor, or a control medium. On the fourth day, the mammary glands were irradiated to induce DNA damage and mimic tumor development. The glands were then harvested and apoptosis was quantified by fluorescent TUNEL. Our results show that an increase in apoptosis by Tamoxifen, the COX-2 inhibitor NS-398, as well as farnesylthiosalicylic acid, requires the presence of hormones but is independent of p53 status $(\mathrm{p}<0.05)$. The 12-LOX inhibitor Baicalein increases apoptosis only in p53-null mammary glands $(\mathrm{p}<0.05)$. The most effective chemoprotection is from a combination of NS-398 with a phytochemical compound, Rhodiola, known to suppress tumor growth $(\mathrm{p}<0.05)$. In conclusion, mammary gland apoptosis in p53 mutated mice may be influenced by the inhibition of several important pathways implicated in breast cancer. Agents influencing this increase in apoptosis may serve as chemopreventive agents for ER-negative breast cancer.

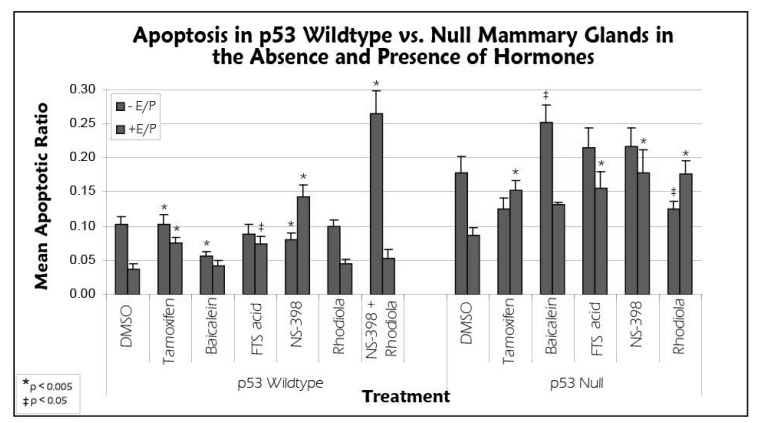

4027

Expression of prostaglandin $\mathrm{E}_{2}$ receptor, $\mathbf{E P}_{1}$, in breast cancer.

Morimiya A, Mehrotra S, Konger R, Badve S. Indiana University, Indianapolis, IN

Background: Cyclooxygenases (COX) enzymes in conjunction with prostaglandin $\mathrm{E}\left(\mathrm{PGE}_{2}\right)$ synthases (mPGES) are involved in the biosynthesis of $\mathrm{PGE}_{2}$. COX enzymes play an important role in carcinogenesis and increased expression has been reported in cancers arising at a number of different sites. Most, if not all of these actions are thought to be mediated by prostaglandin $\mathrm{E}\left(\mathrm{PGE}_{2}\right)$. The actions of $\mathrm{PGE}_{2}$ are mediated via four main prostanoid receptors, designated $\mathrm{EP}_{1}, \mathrm{EP}_{2}, \mathrm{EP}_{3}$ and $\mathrm{EP}_{4}$ based on their different pharmacological properties and secondary messenger pathways. Of these $\mathrm{EP}_{3}$ and $\mathrm{EP}_{4}$ are ubiquitous, whereas the expression of $\mathrm{EP} 1 \& \mathrm{EP}_{2}$ is cell dependent. Recently, expression of $\mathrm{EP}_{1}$ rat mammary gland has been reported in rat mammary gland and inhibition of this receptor has been documented to have chemopreventive effect in this animal model. More recently, $\mathrm{EP}_{1}$ has also been shown to decrease the incidence of colon cancer in mouse models. In this study analyze the expression of $\mathrm{EP}_{1}$ in normal and malignant breast tissues and correlate it with the expression of COX-2 and mPGES-1.

Material and Methods: Expression of $\mathrm{EP}_{1}$ was analyzed in breast (benign and cancer) cell lines (MCF-10A, MCF-7, MDA-MB231, Hs578T, MDA-MB-468, ZR-75-1, T47D, SK-BR-3, DU4475) by reverse-transcriptase PCR and by Western Blot analyses. These cell line data was compared with expression of COX-2 and mPGES. In addition, expression was analyzed by immunohistochemistry (anti-EP $\mathrm{E}_{1}$ antibody from Cayman) in normal breast tissues and in 90 cases of breast cancer. Peptide blocking was performed to verify specificity of staining. Semiquantitative analysis of the staining was performed. The data were compared with patient age, tumor size, lymph node positive status, ER, PR, Her-2 (IHC), COX-2 and mPGES-1 expression status. Results: $\mathrm{EP}_{1}$ expression was detected in breast cell lines by WB and RT-PCR and was up-regulated in human breast cancer by IHC. Cytoplasmic expression of $\mathrm{EP}_{1}$ was seen in 70 of 89 cases $(78 \%)$ and expression was nuclear in 36 cases $(40 \%)$. Nuclear $\mathrm{EP}_{1}$ expression correlated with lymph node metastasis, however, EP expression did not correlate with expression of COX-2 or mPGES1 or with hormone receptor status.

Conclusions: Expression of $\mathrm{EP}_{1}$ is frequently up-regulated in human breast cancers and. Further experiments are being carried out to analyze the effects of blocking of these receptors using specific and non-specific antagonist in relation to tumor growth and apoptosis and to assess the feasibility of using $\mathrm{EP}_{1}$ antagonists as chemopreventive agents in human breast cancer.

\section{8}

Counceling and care combined with breast self examination training as motivation strategy for breast cancer awareness and participation in breast cancer screening programs.

Artmann A, Heyne M, Ruessmann B, Hammes A, Kiechle $M$, Harbeck N. Technical University of Munich, Klinikum Rechts der Isar, Germany

Objectives: In Germany, participation in gynecologic cancer screening is only about $30 \%$, and about $32 \%$ in the Bavarian breast cancer screening. Therefore, we evaluated the impact of counceling together with confidence in breast self examination (BSE) after structured BSE training withon breast cancer awareness, acceptance of screening offer, and actual participation rate.

Method: Since 2003, 154 women (mean age 35 y; range 19-65 y; $59 \% \geq 40 \mathrm{y})$ got intensive breast cancer counceling and were professionally trained in MammaCare ${ }^{\mathrm{TM}} \mathrm{BSE}$ ( 3 hours, 4 trainees); $41 \%$ had positive breast cancer family history. In their first beginner's course, trainees got general BSE information, covering breast anatomy, periodical and permanent breast tissue changes, breast symptoms, cancer and breast cancer screening, and breast cancer therapy. Participants practised BSE, after they learned on tactually accurate silicone breast models, that include simulated lumps in order to discriminate normal nodularity from lumps. Finally, trainees got information about visual inspection. After 3 months, rescreening or supervision sessions included BSE evaluation and instruction in presence of a professional took place. In a model exam, number of detected lumps, false positive and negative findings were documented. In breast exams, 
performance technique and breast tissue coverage were assessed Again, importance of screening programs was reinforced. At both initial sessions and after 12 months, questionnaires on BSE practice, experience, and compliance, cancer worry, healthcare behaviour, changes in lifestyle, acceptance and participation at cancer screening programs were evaluated.

Results: Breast cancer worry, anxiety, and lack of information were the main reasons for program participation. Within 3 months after the base course, mean decrease of breast cancer worry was about $96 \%$. Participation in gynecologic cancer screening and screening mammography ( $\geq 40 \mathrm{y}$ ) more than doubled ( $94 \%$ and $86 \%$ ). Even after 12 months, these numbers remain consistent. $78 \%$ of participants practice BSE monthly, and $46 \%$ reported changes in lifestyle regarding nutrition and obesity.

Rationale: Our approach emphasizes importance of self confidence and awareness for participation in cancer screening also in women with breast cancer family history. Counceling, BSE reevaluation and reinforcement are correlated with decreased breast cancer worry and anxiety, a main barrier against participation in breast cancer and gynecologic cancer screening.

\section{9}

Anticarcinogenic effects of citrus auraptene on rat breast cancer.

Kleiner HE, Campbell CT, Prince M, Robertson TA, Krishnan P, Li $B D, C h u$ QD. Louisiana State University Health Sciences Center, Shreveport, $L A$

Background: Auraptene is a simple coumarin possessing a geranyloxyl side chain and is abundant in citrus fruit. It has been shown to block carcinogenesis in rat colon and oral cancers, and mouse skin cancer. However, its effectiveness in blocking mammary cancer has not been fully investigated.

Material and Methods: Female Sprague-Dawley rats (8 rats per group) were fed Teklad mesh diet with or without auraptene (200 $\mathrm{ppm}$ ). At day 50, rats were treated with $\mathrm{N}$-methylnitrosourea (MNU) $(50 \mathrm{mg} / \mathrm{kg}$, i.p.) or saline. At 19 weeks after MNU, rats were euthanized and all tumors were counted during necropsy. To evaluate the effects of auraptene on cancer development, auraptene was tested on MCF-7 cells and MDA-MB-231 human breast cancer cell lines.

Results: All rats fed with Teklad diet and MNU developed mammary tumors (average $3.13 \pm 1.55$ tumors/rat). No tumors were observed in the control group. In rats fed Teklad with auraptene $(200 \mathrm{ppm})$, there was a statistically significant $(\mathrm{P}<$ 0.05 , t-test) reduction in tumor incidence by $25 \%$. Furthermore, the diet was well tolerated since there were no significant changes in body weight nor overt signs of toxicity observed in the treatment groups. In MCF-7 cells, auraptene inhibited cell viability (measured by trypan blue uptake) by $59 \%, 19 \%$ and $8 \%$ at $6 \mathrm{~h}$; and by $93 \%$, $17 \%$, and $5 \%$ at $24 \mathrm{~h}$ at $200 \mu \mathrm{M}, 50 \mu \mathrm{M}$ and $25 \mu \mathrm{M}$, respectively. In MDA-MB-231 cells, auraptene inhibited cell viability at $24 \mathrm{~h}$ by $77 \%, 61 \%$, and $30 \%$ at $200 \mu \mathrm{M}, 50 \mu \mathrm{M}$ and $25 \mu \mathrm{M}$, respectively. Interestingly, auraptene had no effect on MDA-MB-231 cell viability at $6 \mathrm{~h}$. Auraptene blocked ornithine decarboxylase activity in MCF-7 cells by $83 \%$ and $39 \%$ at $200 \mu \mathrm{M}$ and $50 \mu \mathrm{M}$, respectively. Finally, auraptene blocked invasion of MDA-MB-231 cells into Matrigel (a basement membrane substance) by $46 \%$ at $50 \mu \mathrm{M}$ in vitro.Conclusion: These preliminary results suggest that auraptene may have promising chemopreventive effects on breast cancer.

\section{0}

A case-control study evaluating the association of purposeful physical activity, body fat distribution and steroid hormones on pre-menopausal breast cancer risk. Kumar NB, Riccardi D, Cantor A, Dalton K, Allen K. H. Lee Moffitt Cancer Center \& Research Inst, Tampa, FL

BACKGROUND:

The objective of this case-control study was to investigate the relationship between purposeful physical activity, body fat distribution, body mass index and steroid hormones. These factors are known to be implicated in modulating breast cancer risk in premenopausal women.

\section{METHODS:}

One hundred and twelve newly diagnosed, pre-menopausal breast cancer patients and 106 age matched pre-menopausal disease-free controls were admitted to the study. Information regarding personal, medical, hormonal and reproductive history, smoking and alcohol use, physical activity history and anthropometric measurements was obtained. Serum samples for steroid hormone assays were collected and analyzed.

\section{RESULTS:}

Disease-free pre-menopausal controls had a significantly higher physical activity index (PAI) $(\mathrm{P}=<0.05)$, however, significantly higher weight $(\mathrm{P}=<0.05)$, body mass index $(\mathrm{P}=0.01)$, waist $(\mathrm{P}=<0.005)$, hip $(\mathrm{P}=<0.05)$ circumferences, wasit:hip ratios $(\mathrm{P}=<0.05)$ and serum total estradiol levels $(<0.0005)$ were observed in cancer cases. The final model using stepwise logistic regression analysis indicates that the variables that significantly predicted breast cancer risk were waist:hip ratio $(\mathrm{OR}=1.11 \mathrm{p}=<0.005)$ and serum total estradiol levels $(\mathrm{OR}=1.03 \mathrm{p}=<0.0001)$.

CONCLUSION: Our study provides some evidence that purposeful physical activity may reduce upper body fat distribution associated with adult weight gain. This may be a result of alterations in the steroid hormone pathway such as reduced estradiol levels. This demonstrates the potential mechanism through which increased physical activity can reduce the risk for breast cancer in pre-menopausal women.

\section{1}

The controversy of annual mammographic screening (AMS) for 40 to 69y-o women of Brazilian cohort of 10.000 underserved women.

Caleffi M, Duarte Filho D, Skoniesky G, Bedin Jr A, Zignani JM, Antunes LP, Dias EC, Ashton-Prolla P, Weber B, Kivitz P, Graudenz MS, Pohlmann PR. Hospital Moinhos de Vento, Porto Alegre, RS, Brazil

Introduction: Porto Alegre has the highest breast cancer (BC) incidence and mortality in the country, being the main general cause of death among 25-49y-o women. Use of AMS for women in their 40s is controversial, due to the lower frequency of the disease at this age group and to the higher density of their breasts. The NMPOA cohort included patients over $40 \mathrm{y}-\mathrm{o}$ for screening. Radiological findings at one year of the cohort were analyzed. Material and Methods: From Mar/04 to Apr/05, of 3200 women, a subgroup of 1330 within 40-69y of age were asymptomatic and selected for AMS. Age stratification for the present analysis: 40$49 y-o \quad(n=690) ; 50-59 y-o \quad(n=423) ; 60-69 y-o \quad(n=217)$. BI-RADS Classification of Mammography was used. Results: Age at menarche, number of children, menopausal status, tabacco use, previous breast biopsy, hormonal replacement therapy (HRT) and familial BC history were balanced among the groups. BI-RADS zero was found in $2.3 \%$ of patients, soon recalled for new imaging evaluation. So far 4 cases of cancer were detected: One $48 \mathrm{y}-\mathrm{o}$ pat (GIII DCIS) and 3 cases at the 50's age group ( $\mathrm{T} 1_{\text {mic }} \mathrm{NOM} 0$, GIII DCIS and T2NOM0). Three of the 4 cancer cases were initially classified as BI-RADS zero. BI-RADS I was present in $84.9 \%$, $71.4 \%$ and $68.7 \%$ of the 40 's, 50's and 60's age groups, respectively $(\mathrm{p}<0.001)$. Breast density was affected by age, number of children, 


\section{S176 Abstracts - Poster Session IV}

HRT and menopausal status. 'Fatty' or 'almost fatty' breast cathegories for the 40's, 50's and 60's age groups were $45.3 \%$, $65.1 \%$ and $76.9 \%$, respectively $(\mathrm{p}<0.001)$. Conclusion: Numbers are still small for definitive conclusions, but accrual rates exceed expectation for an underserved community in Latin America. BIRADS zero were found to shelter relevant conditions, emphasizing the need for an organized program for recall. All early diagnosed cases were potentially agressive, indicating the benefit of AMS to communities often presenting as stage III/IV disease. Costeffectiveness is a major issue to evaluate the intervention in the 40 to $49 y-o$ group.

\section{2}

Tubular carcinoma: outcomes analysis of favorable breast cancer treated with breast conserving therapy.

Perkins GH, Middleton LP, Tran RT, Garcia SM, Buchholz TA. The University of Texas M D Anderson Cancer Center, Houston, TX

Purpose: To evaluate outcomes data for patients with tubular carcinoma treated with breast conserving therapy.

Methods: The features of 293 pathologically reviewed patients with a diagnosis of tubular carcinoma were compared with respect to bct, axillary management, sytemic therapy, and percentage of tubular formation. OS, DMFS, DFS, and Local-regional control were also compared. Kaplan Meier statistics were utilized.

Results: Median age at diagnosis was 55 (range 33-81years). Median follow-up was 95 months (range 3-284). $14 \%$ had + lymph nodes. $20 \%$ had multifocal and or multicentric presentation after workup. 5 and 10 year OS, LRC,DMFS, and DFS were as follows: $96 \%$ $93 \% ; 98 \% / 96 \% ; 99 \% / 95 \% ; 97 \% / 93 \%$. For patients treated with BCT 5/10 year OS vs mastectomy was $98 \% / 95 \%$ vs $98 \% / 89 \%$ $(\mathrm{p}=.07)$. LRC was $99 \% / 98 \%$ vs $98 \% / 94 \%(\mathrm{p}=.8)$. OS and LRC were not significantly different at 5 and 10 years for BCT patients not treated with xrt who had negative margins (93/93 vs 97/97; 99/96 vs 100/100). Similarly patients undergoing ALND had rates of OS and LRC that were not siginificantly different at 5 and 10 year interval (98/92 vs $92 / 92$ and $99 / 96$ vs $100 / 100(p=.3$ and .6 respectively)

Conclusions: This large retrospective analysis demonstrates equivalent efficacy in carefull selected patients undergoing BCT with a diagnosis of tubular carcinoma even when xrt is omitted. It is noted however that $20 \%$ of patients had mutifocal or multicentric presentation. In this study the axilla was effectively managed with and without ALND although $15 \%$ of patients had psotive nodal presentation. Consensus criteria tubular carcinoma (70\% + tubules) yields excellent outcome when managed in the context of the multidisciplinary team. Individualized therapy is an appropriate standard to insure high quality of care.

\section{3}

Decision-making process for early-stage breast cancer is surgeon driven.

Nkoy FL, Rees W, Sause W, Hammond E, Pinto K, Rowe K. Intermountain Health Care (IHC), SLC, UT

Background: Breast Conserving Surgery (BCS) has become the standard of care for early stage breast cancer and is considered as one of the quality indicators of a breast program practice. Several studies have reported that BCS is still under utilized, mostly, because of patient's choice. However, surgeons' decision-making process has not been emphasized. Based upon an overall baseline frequency of $55 \%$ of BCS in 2001, the Intermountain Health Care (IHC) oncology clinical program developed a quality of care initiative to increase the use of BCS for women with early stage breast cancer treated at IHC facilities. This initiative resulted in a significant increase in the frequency of BCS to $67 \%$ overall, 2 year after implementation of data feedback to surgeons. The objective of this study was to evaluate the difference in clinical factors that affected the use of BCS before and after implementation of data feedback.
Methods: We extracted cancer registry data of 3236 women with early-stage breast cancer who received BCS at IHC facilities between 1999-2004. We conducted a retrospective study. Multiple logistic regression was used to generate odds ratios (ORs) and $95 \%$ Confidence Intervals (CIs) to determine change in clinical factors associated with increase in the frequency of BCS after implementation of data feedback.

Results: Before the implementation of data feedback (years 1999$2001)$, the ORs were respectively: age (OR=0.98; 95\% CI, 0.97 0.99), number of nodes positive ( $\mathrm{OR}=0.68 ; 95 \% \mathrm{CI}, 0.50-0.93$ ), tumor size $(\mathrm{OR}=0.97$; 95\% CI, 0.96-0.98) and grade $(\mathrm{OR}=0.83$; 95\% CI, 0.73-0.96) and stage $(\mathrm{OR}=0.86 ; 95 \% \mathrm{CI}, 0.69-1.08)$ After implementation of data feedback (years 2002-2004), the ORs were: age $(\mathrm{OR}=0.98 ; 95 \% \mathrm{CI}, 0.97-0.99)$, number of node positive $(\mathrm{OR}=0.76 ; 95 \% \mathrm{CI}, 0.53-1.09)$, tumor size $(\mathrm{OR}=0.99$; 95\% CI, 0.99-1.0) and grade $(\mathrm{OR}=0.85 ; 95 \% \mathrm{CI}, 0.75-1.0)$ and stage $(\mathrm{OR}=0.53 ; 95 \% \mathrm{CI}, 0.41-0.69)$.

Conclusions: Before implementation of data feedback the clinical factors that affected the surgeon's decision-making process for BCS were age, number of nodes positive, tumor size and grade. After implementation of data feedback, we found that the following clinical factors, number of nodes positive, tumor size and grade, were no longer influencing the surgeon's decision-making for BCS. However, an increase in patient age and stage decreased the chance of having a BCS. The data demonstrated that surgical decisionmaking process for early stage breast cancer is very much surgeon' driven and that any strategy to increase the frequency of BCS should also emphasize widespread education to surgeons.

\section{4}

Adjuvant chemotherapy in stage II node positive male breast cancer.

Walshe JM, Vatas U, Berman AW, Steinberg SM, Llppman ME, Anderson WF, Swain SM. Cancer Therapeutics Branch; Biostatistics and Data Management Section, National Cancer Institute, NIH, Bethesda, MD; Univ of Michigan, Ann Arbor, MI; Division of Cancer Epidemiology \& Genetics, National Cancer Institute, NIH, Bethesda, $M D$

Background: Male breast cancer (MBC) is a rare disease, which accounts for an annual estimate of $0.2 \%$ of all cancers and $0.1 \%$ of all cancer deaths in men in the US, with approximately 1,690 new breast cancer cases and 460 breast cancer - specific deaths among men per year. We present the long-term follow-up of a prospective study of MBC with node positive disease treated with adjuvant chemotherapy.

Material and Methods: Between 1974 and 1988, men with Stage II node positive disease were entered on study MB82. Following mastectomy, patients were treated with 12 cycles of CMF therapy. The treatment protocol utilized intravenous cyclophosphamide $500 \mathrm{mg} / \mathrm{m}^{2}, 5$-fluorouracil $600 \mathrm{mg} / \mathrm{mg}^{2}$ and methotrexate $60 \mathrm{mg} / \mathrm{m}^{2}$ all given on day 1 and 8 of a 28 -day cycle for one year. Three patients received tamoxifen therapy.

Results: Thirty one patients were enrolled on study with a median age of $61 \mathrm{yrs}$ at diagnosis $(38-74 \mathrm{yrs})$. Twenty-three patients (74\%) had 1-3 positive axillary lymph nodes while 8 patients $(26 \%)$ had 4 or more positive nodes. Estrogen receptor status was determined in 23 patients $(74 \%)$; positive in 22 patients and negative in one patient. Progesterone receptor status was determined in 19 patients $(61 \%)$; positive in 17 patients and negative in two patients. Median potential follow-up for all patients is 22.0 years with a median survival of 15.2 years. Twenty patients have died, one from a treatment-related complication (GI hemorrhage), six patients from recurrent breast cancer, three from other cancers (prostate, esophageal, and lung cancer), 2 from non-cancer related causes, and 8 unknown. Eleven patients remain alive at a median of 17.9 yrs. The survival probability at 10 years is $64.0 \%$ (95\% CI: 46.2 to $75.8 \%)$, at 15 -years is $50.5 \%$ (95\% CI: 33.6 to $67.3 \%$ ) and at 20 years is $45.4 \%$ (95\% CI: 28.6 to $63.5 \%$ ). In 1988 , the NCI's SEER program began to collect 
information regarding tumor size and nodal status for $n=2,258$ male breast cancer cases and specifically $n=810$ known node positive male breast cancer cases. Notably, the 10 -year cumulative relative survival rate for men with node-positive breast cancer was $57.9 \%$, consistent with MB82.

Discussion: We present the long-term results of a prospective study of node positive MBC. By comparing our results with the population-based SEER-program, it is difficult to draw definitive conclusions regarding the benefit of adjuvant CMF in the MB82 study. Trials using different chemotherapeutic combinations and/ or hormonal therapies possibly should be considered for this mostly hormone receptor positive type of breast cancer.

\section{5}

Long-term risk of cardiovascular disease in 10-year survivors of breast cancer.

Hooning MJ, Botma A, Aleman BM, Klijn JG, van Leeuwen FE. Netherlands Cancer Institute, Amsterdam, Netherlands; Erasmus MC, Daniel den Hoed Cancer Center, Rotterdam, Netherlands

Purpose: To assess cardiac risk according to radiation field in breast cancer patients, accounting for cardiac risk factors.

Patients and methods: We studied incidence of cardiovascular disease $(C V D)$ in a group of 10 -year survivors $(n=4368)$ who were treated in the Netherlands Cancer Institute and the Daniel den Hoed Cancer Center for early breast cancer between 1970 and 1987. Follow-up was for $98 \%$ complete until January 2000. Treatment-specific incidence of CVD was evaluated by calculating standardized incidence ratios (SIRs) based on comparison with general population rates and by using Cox proportional hazards regression.

Results: After a median follow-up of 18 years 942 cardiovascular events (acute myocardial infarction (MI), angina pectoris and congestive heart failure) were observed resulting in a SIR of 1.3 (95\% CI: 1.2-1.4) and an absolute excess risk of 63/10,000 personyears. For the treatment period 1970-79, radiotherapy (RT) on the internal mammary chain (IMC) was associated with an increased risk of MI both for patients with left- and right-sided tumors in comparison with non-irradiated patients; hazard ratio (HR), 2.2; 95\% CI: 1.3-3.7, and 2.9; 95\% CI: 1.7-5.1, respectively, while for the treatment period 1980-86, these risks had declined to 0.8 (95\% CI: $0.4-1.6)$ and 0.9 (95\% CI: $0.5-1.7)$, respectively. Patients irradiated on the left chest wall experienced a significantly increased risk of $\mathrm{MI}$ as compared to those treated with surgery only in both treatment periods (HR, 2.8; 95\% CI: $1.4-5.5$, and $3.7 ; 95 \% \mathrm{CI}: 1.2-11.5$, respectively). RT on the right chest wall showed a non-significantly 1.5 -fold increased risk of MI for the period 1970-79, while from 1980 on, no MIs occurred in this treatment group. RT on the breast only, applied from 1980 on, was not associated with an increased risk of MI, with HRs of 0.7 (95\% CI: 0.3-1.6) for left-sided, and 0.9 (95\% CI: 0.4-2.2) for right-sided tumors. Hypertension, smoking, diabetes mellitus and hypercholesterolemia acted as independent risk factors for MI, with HRs of $2.0(95 \%$ CI: $1.5-2.7), 2.1(95 \%$ CI: $1.5-2.7), 1.3(95 \%$ CI: 0.9-1.8) and 3.0(95\% CI: 2.2-4.1), respectively. Analysis on the combined effects of smoking and RT revealed a more than additive effect on MI, with a HR of 3.0; 95\% CI: 2.0-4.5 (HR for irradiated non-smokers, 1.3; HR for non-irradiated smokers, 1.4). Conclusions: Radiotherapy after 1979 is not associated with increased MI risk, with the only exception for radiation to the left chest wall. The combination of smoking and RT appears to exert a greater than additive effect on MI risk.
4036

Stroke rates and risk factors in patients treated with radiation therapy for early stage breast cancer.

Jagsi R, Griffith KA, Koelling T, Roberts R, Pierce LJ. University of Michigan, Ann Arbor, MI; Massachusetts General Hospital (Visiting Researcher, $U$ of Michigan), Boston, MA

INTRO: Radiation therapy (RT) increases risk of stroke in head \& neck cancer patients. Meta-analyses show increased vascular mortality in patients receiving RT for breast cancer (BC). A recent study reveals increased stroke incidence in Swedish BC patients. We examine whether the common technique of supraclavicular RT (SCRT) is associated with stroke in BC patients.

METHODS: 867 consecutive patients with Stage I/II BC were treated with breast-conserving surgery \& RT at U of Michigan Hospital from 1983-2000. 841 had records sufficient to determine incidence of cerebrovascular accident (CVA) or transient ischemic attack (TIA) in follow-up. Observed rates of CVAs (excluding \& including TIA) were compared to expected age, gender, \& racespecific rates calculated from the National Hospital Discharge Surveys to obtain standardized incidence ratios (SIRs). Relationships between potential risk factors and actuarial rate of first CVA were analyzed. Characteristics found on univariate analysis to be at least marginally associated with time to stroke $(\mathrm{p}<0.1)$ were included in a multivariate Cox model, along with potential 2-way interactions. Factors were removed stepwise until only characteristics significant at the 0.05 level remained.

RESULTS: 15 cases were excluded because they received RT to the neck for other causes. Median follow-up was 6.8 years (range 0.120.3). This yielded 6164 person-years of observation. Median age was 55.6 (range 21.5-88.4). At time of BC diagnosis, 317 patients had a history of hypertension, 58 diabetes, 302 smoking, 211 hypercholesterolemia, 14 previous stroke, 84 coronary artery disease (CAD), and 15 atrial fibrillation (AF). 373 received adjuvant tamoxifen, and 222 SCRT.

21 patients $(2.5 \%)$ had at least one CVA in follow-up; $36(4.4 \%)$ had at least one CVA/TIA. The SIR of CVA was 1.67 (95\% CI $1.08-2.14)$. The SIR of CVA/TIA was $1.56(1.13-2.11)$.

On univariate analysis, factors significantly associated with actuarial of first CVA included hypertension $(\mathrm{p}=0.004)$, age $(\mathrm{p}<0.001), \operatorname{CAD}(\mathrm{p}=0.002), \operatorname{AF}(\mathrm{p}=0.01)$, and $\operatorname{SCRT}(\mathrm{p}=0.03)$. Factors associated with CVA/TIA were hypertension $(p<0.001)$, $\operatorname{CAD}(p=0.002)$, and age $(p<0.001)$, with $\operatorname{SCRT}(p=0.09)$ and $\mathrm{AF}(\mathrm{p}=0.06)$ trending towards significance. Tamoxifen use alone was not significant $(\mathrm{p}=0.26)$, but tamoxifen combined with baseline hypertension did lead to increased risk of CVA/TIA $(\mathrm{p}<0.001)$. On multivariate analysis, only age $(\mathrm{p}<0.001)$ and hypertension $(\mathrm{p}=0.005)$ remained significant predictors of CVA/ TIA. Age was the only significant predictor of CVA alone $(\mathrm{p}<0.001)$. CONCLUSION: This study suggests that BC survivors have an elevated risk of stroke compared to the general population. While recent studies have raised concerns that SCRT may lead to increased strokes in BC patients, this study reveals no significant association between SCRT and stroke, after controlling for other risk factors.

\section{7}

Inverse-planned, dynamic, multi-field, intensity modulated radiation therapy (IMRT) for left sided breast cancer: comparison to best standard technique.

Olivotto IA, Beckham W, Popescu C, Patenaude V, Wai ES, Cao F. Vancouver Island Centre, BC Cancer Agency, Victoria, BC, Canada

Background: Delivering radiation therapy (RT) to the left breast plus internal mammary nodes (IMNs) without excessive dose to the heart is a challenge. The purpose of this study was to determine if dynamic, multi-field, inverse-planned IMRT would improve conformity and reduce dose to the heart and lungs without an excessive increase in healthy tissue dose, compared to best standard plans, when treating women with left-sided breast cancer with the IMNs included in the $95 \%$ planning target volume (PTV). 


\section{S178 Abstracts - Poster Session IV}

Material and Methods: PTVs (breast plus IMNs), heart, lungs, body and medial right breast for 30 randomly selected patients after lumpectomy for left-sided breast cancer were contoured. IMRT was a class solution employing 11 equally-spaced beams oriented through a 190 degree sector angle around the left thorax. Dose-volume histograms (DVHs) were derived for IMRT and best standard plans (modified wide tangent or direct internal mammary techniques). Conformity Index (CI = Volume PTV divided by the volume receiving $>95 \%$ ), Homogeneity Index $(\mathrm{HI}=\%$ PTV $>95 \%$ and $<105 \%$ ) and doses to normal tissues were compared. The proportion of patients benefiting at various thresholds for improved cardiac dose were assessed.

Results: IMRT vs best standard plans improved mean values of CI $(0.892$ vs 0.559$)$, V30-heart $(0.45 \%$ vs $6.59 \%)$ and V20-left lung $(12.8 \%$ vs $20.6 \%)$. HI was improved with IMRT $(0.97$ vs 0.73 ). All differences were significant (paired t-test, $\mathrm{p}<0.001$ ). Mean Healthy Tissue dose (whole body minus PTV) was 5.2Gy vs 5.3Gy $(\mathrm{p}=0.46)$. The improvement in heart V30 dose was positively correlated with maximum heart depth in the best standard plan $\left(\mathrm{R}^{2}=0.76\right)$. Changing from standard planning to IMRT when the maximum heart depth was $2.3 \mathrm{~cm}$ reduced heart $\mathrm{V} 30$ by $10 \%$. To reduce V30 by $10 \%$ would require IMRT for approximately $20 \%$ of our randomly selected patients.

Discussion: Dynamic, inverse-planned, IMRT significantly improved conformity by decreasing dose to heart and ipsilateral lung with minimal increase in mean healthy tissue dose. The maximum heart depth in the best standard plan is useful to select patients likely to benefit from conformal IMRT. If a goal for heart dose improvement is established then it is possible to calculate the proportion of patients requiring IMRT.

Supported by a grant from the Canadian Breast Cancer Foundation, BC/Yukon Chapter

\section{8}

One year analysis of cosmesis and treatment efficacy by the American Society of Breast Surgeons (ASBS) MammoSite breast brachytherapy registry trial in patients treated with accelerated partial breast irradiation (APBI). Vicini FA, Beitsch P, Quiet CA, Keleher A, Garcia D, Snider H, Gittleman M, Zannis V, Kuerer H, Whitacre E, Whitworth P, Fine $R$, Haffty B. William Beaumont Hospital, Royal Oak, MI; Dallas Breast Center, Dallas, TX; Arizona Oncology, Phoenix, AZ; Western PA Hospital, Pittsburgh, PA; St.Louis Cancer and Breast CTR, St. Loius, MO; Baptist Medical Center, Montgomery, AL; Sacred Heart Hospital, Allentown, PA; MDACC, Houston, TX; The Breast Ctr of Southern Arizona, Tuscon, AZ; The Breast Ctr, Marietta, GA; Yale, New Haven, CT

Purpose: This report presents data on cosmesis and overall treatment efficacy with a minimum of one year follow-up for patients treated on the ASBS MammoSite Registry trial.

Materials and Methods: Since closure of the ASBS sponsored Registry Trial in November 2004, a total of 1550 patients have been treated with the MammoSite device. Follow-up data on cosmesis and efficacy have continuously been recorded to examine changes in these endpoints over time. A total of 488 patients treated with APBI have been followed $\geq 12$ months, $211 \geq 18$ months and $83 \geq 24$ months. These patients constitute the study population.

Results: A total of $5 / 488$ patients $(1 \%)$ have experienced a local failure $(13,13,16,22$ and 26 months after APBI) for a 2-yr actuarial rate of $2 \%$ (None of the 83 patients followed $\geq 24$ months developed a local recurrence). No clinical, technical or pathologic variable was associated with the development of a local recurrence. The $\%$ of patients with good/excellent cosmetic results at $6,12,18$ and 24 months were as follows: 93.9, 92.4, 90.5 , and $92.8(\mathrm{p}=\mathrm{NS})$. (The rate of good/excellent cosmetic results in the 83 patients followed $\geq 24$ months was $94 \%$ at 12 months and $92.8 \%$ at 24 months $(\mathrm{p}=0.7))$. At 12 months $(\mathrm{n}=488$ patients), factors associated with good/excellent cosmetic results included increasing median skin spacing $(\mathrm{p}=0.016)$ and smaller bra size $(\mathrm{p}=0.0016)$. Skin spacing $(\geq 7 \mathrm{~mm})$ and the lack of developing an infection were borderline significant $(\mathrm{p}=0.082$ and 0.081$)$. Conclusion: Treatment efficacy and cosmesis with a minimum of 1 or 2 years of follow-up after treatment with APBI using the MammoSite device are excellent and appear comparable to those reported with standard whole breast RT. Additional follow-up will be needed to establish the stability of these findings with time.

\section{9}

$A T M$ sequence variants as predictors for adverse radiation responses in breast cancer patients.

Ho AY, Atencio DP, Fan G, Green S, Formenti SC, Haffty BG, Bernstein JL, Stock RG, Cesaretti JA, Rosenstein BS. Mount Sina School of Medicine, New York, NY; NYU School of Medicine, New York, NY; Yale University School of Medicine, New Haven, CT; Memorial Sloan-Kettering Cancer Center, New York, NY

Objective: To examine whether sequence variants in the ATM gene predict for the development of late radiation-induced adverse effects resulting from external beam radiation therapy for breast cancer.

Methods: 107 patients with a minimum of a 2-year follow-up underwent breast-conserving surgery and standard adjuvant radiation therapy for either DCIS or early stage breast cancer at three tertiary referral centers in the United States between 1990 to 2003. These patients were screened for DNA sequence variations in all 62 coding exons of the ATM gene. DNA was isolated from blood lymphocytes and each coding exon amplified using PCR. Genetic variants were identified using denaturing high performance liquid chromatography (DHPLC). The clinical course of each genetically characterized patient was obtained from a database of patients treated and examined during follow-up visits. The RTOG/ EORTC late morbidity scoring schemes for skin and subcutaneous normal tissues were applied to quantify radiation-induced effects The chi-squared test was used to compare groups with respect to categorical endpoints (e.g. radiation-induced late effects).

Results: 34 of the 107 screened patients were found to carry ATM sequence alterations located within exons, or in short intronic regions flanking each exon that encompass putative splice sites. For this group, 77\% (26/34) exhibited at least one form of adverse response. In contrast, of the 73 patients who did not harbor an ATM sequence variation, $51 \%$ (37/73) manifested radiation-induced adverse responses $(p=0.02$, two-sided). Nine of the patients in this study specifically possessed the $\mathrm{G} \rightarrow \mathrm{A}$ transition polymorphism at nucleotide 5557, which results in substitution of asparagine for aspartic acid at position 1853 of the ATM protein. For this group, $100 \%(9 / 9)$ exhibited an adverse response. In contrast, of the 98 patients who did not have this polymorphism, 55\% (54/98) manifested a late response ( $\mathrm{p}=0.02$, two-sided).

Conclusions: Possession of sequence variants in the ATM gene predict for the development of late adverse radiotherapy responses among breast cancer patients treated with adjuvant radiation therapy. In particular, the $5557 \mathrm{G} \rightarrow \mathrm{A}$ polymorphism is associated with the development of adverse late responses. The number of patients without ATM sequence variants who nevertheless developed late normal tissue effects suggests that variants in radiation response genes other than $A T M$ may also play a role conferring radiosensitivity, and could therefore serve as additional predictors of adverse radiation effects. 
4040

Improved survival, quality of life (QOL), and qualityadjusted survival (QAS) in breast cancer patients treated with efaproxiral (EFAPROXYN ${ }^{\mathrm{TM}}$ ) + whole brain radiation therapy (WBRT) for brain metastases.

Scott C, Suh J, Stea B, Nabid A, Hackman J. CBS Squared; Cleveland Clinic Hospital; $U$ of AZ Health Sciences Center; Centre Hospitalier $U$ de Sherbrooke; Allos Therapeutics

Background: Approx. 25\% of breast cancer patients will develop brain metastases. The effectiveness of WBRT as primary therapy for brain metastases is limited by tissue hypoxia, which has been shown to cause radioresistance in solid tumors. Efaproxiral is a novel therapeutic agent that sensitizes radiation by acting as an allosteric modifier of hemoglobin, facilitating $\mathrm{O}_{2}$ release \& decreasing tissue hypoxia. Although survival is the primary endpoint of many therapeutic regimens in oncology, maintaining a good QOL is also important, as there are usually adverse events associated w/brain therapy, primary tumor therapy, \& symptoms of each disease site.

Methods: A randomized, open label Phase 3 study was conducted comparing efaproxiral combined $\mathrm{w} / \mathrm{WBRT} \&$ supplemental $\mathrm{O}_{2}$ to WBRT \& supplemental $\mathrm{O}_{2}$ alone in patients w/newly diagnosed brain metastases from various solid tumors (the REACH study). Patients $w / K P S \geq 70$, at least one measurable lesion, \& no prior WBRT or stereotactic radiotherapy were eligible. QOL was assessed prior to initiation of WBRT \& periodically in follow up using the Spitzer Quality of Life Index (SQLI). QAS was modeled using the method of Willan et al. (2003), which involved multiplying QOL \& survival estimates at periodic intervals then computing the area under the curve (AUC). Analysis was performed on all eligible patients w/a pre-treatment SQLI score \& on the subgroups of these patients w/NSCLC or breast cancer primary site.

Results: A total of 500 patients were eligible \& had a pre-treatment SQLI score; of these, 282 patients had NSCLC primary \& 106 patients had breast cancer primary. SQLI was a statistically significant prognostic factor $(\mathrm{p}<0.001)$, w/higher baseline SQLI scores associated w/better survival outcome. No difference was observed in Median Survival Time (MST), QAS, or QOL between treatment groups in the overall group or the subgroup of patients w/NSCLC primary. However, there was an increase in survival for efaproxiral-arm patients w/breast cancer, which was accompanied by a highly statistically significant improvement in both QAS \& QOL (see Table 1).

Table 1

$\begin{array}{llll}\text { Parameter } & \text { Txt Arm } & \text { Summary Statistic } & \text { P-Value (Method) } \\ \text { Survival } & \text { Efaproxiral } & 9.00 \mathrm{mo} & 0.004 \text { (Log-rank) } \\ \text { (MST) } & \text { Control } & 4.47 \mathrm{mo} & \\ \text { QAS } & \text { Efaproxiral } & 75.1 \mathrm{SQLI}-\mathrm{mo} & <0.001 \text { (Willan) } \\ \text { (Mean AUC) } & \text { Control } & 43.6 \mathrm{SQLL}-\mathrm{mo} & \\ \text { SQLI } & \text { Control - } & -0.12 \mathrm{SQLI} / \mathrm{mo} & <0.001 \text { (GEE) }\end{array}$

$\begin{array}{llll}\text { SQLI } & \text { Control - } & -0.12 \mathrm{SQLI} / \mathrm{mo} & <0.001 \text { (GEE) }\end{array}$

Conclusion: Survival, QOL, \& QAS were all improved in breast cancer patients w/brain metastases receiving efaproxiral \& WBRT compared to those receiving WBRT alone. The survival benefit realized for the breast cancer patients was not clinically compromised by a decline in QOL.

\section{1}

Radiation therapy and cardiac toxicity in breast cancer patients 65 years and older: a population-based study.

Doyle JJ, Neugut AI, McBride RB, Jacobson JS, Grann VR, Hershman DL. Mailman School of Public Health, Columbia University, New York, NY; College of Physicians and Surgeons, Columbia University, New York, NY

Purpose: Among high-risk patients with early-stage breast cancer, the benefit of adjuvant radiation therapy (RT) may be counterbalanced by an elevated risk of cardiac toxicity. Patients receiving $\mathrm{RT}$ on the left side, patients with pre-existing heart disease (HD), and the elderly may be especially vulnerable. We studied the cardiac effects of RT in a population-based sample of breast cancer patients aged $\geq 65$ years with long-term follow-up. Patients and Methods: In the Surveillance, Epidemiology and End Results (SEER)-Medicare database, we analyzed treatments and outcomes among women $\geq 65$ years of age diagnosed with stage I -III breast cancer 1/1/92-12/31/99. A multiple logistic regression model was used to control for known predictors of receiving radiation, baseline HD, surgery type and chemotherapy use. Cox proportional hazards models and propensity analysis were used to estimate the risk of myocardial infarction (MI), congestive heart failure (CHF), and HD in the five years following diagnosis

Results: Of 31,748 women with stage I-III breast cancer. 11,429 (36\%) had breast-conserving surgery (BCS), and 19,906 (63\%) had a mastectomy. Overall, $14,461(46 \%)$ received RT, but of the BCS patients, 8,396 (73\%) received RT. RT use was associated with BCS, younger age, fewer comorbidities, hormone receptor negativity, multiple primaries, white race, non-rural residence, chemotherapy use and advanced disease. Pre-existing HD did not influence receipt of radiation therapy. Among RT patients, leftsided radiation therapy (LSRT) was associated with a $25 \%$ increase in the hazard rate of $\mathrm{MI}(\mathrm{HR}=1.26 ; 95 \%$ CI (1.05-1.49)) but not with other cardiac outcomes. The RT-associated cumulative risk of MI increased over time (Figure 1).

Conclusion: In this cohort of elderly patients, a previous diagnosis of HD was not associated with RT use. Although patients who received LSRT had a higher risk of MI than those who received right sided RT, this risk was not amplified in patients that had prior chemotherapy compared to those who did not. In addition, RT did not increase the risk of CHF. This analysis highlights the need for cardiac surveillance among high-risk patients and emphasizes the need for new treatment approaches that prolong survival while minimizing adverse effects.

Figure 1. Cumulative incidence of MI by year since

breast cancer diagnosis

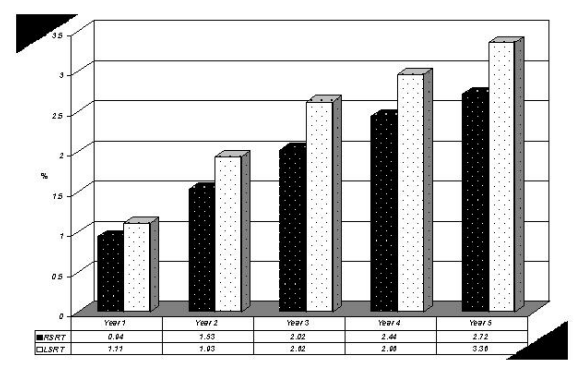

\section{2}

Accelerated partial breast irradiation compared to whole breast radiotherapy: the potential for reduced contralateral breast dose and heart dose.

Ben-David MA, Marsh RB, Moran JM, Balter JM, Hayman JA, Griffith KA, Pierce LJ. University of Michigan Medical School, Ann Arbor, MI; University of Michigan, Ann Arbor, MI

Background: While most studies do not show an increase in longterm radiation-associated complications in patients treated with conservative surgery and radiotherapy (RT) compared to surgery alone, other studies do suggest an increase in complications, including cardiac toxicity and increased contralateral breast (CB) cancers, in women treated with breast RT. Therefore, techniques that can reduce or eliminate the dose to the $\mathrm{CB}$ and heart would have the potential for improving overall outcome and survival. For these reasons, we evaluated the potential of accelerated partial breast irradiation (APBI) combined with breath hold $(\mathrm{BH})$ to deliver less dose to the $\mathrm{CB}$ and heart when compared with whole breast radiotherapy (WBRT). 


\section{S180 Abstracts - Poster Session IV}

Methods: Following IRB approval, 10 patients diagnosed with stage 0/I BC have been enrolled in a Phase I-II study of APBI using intensity modulated radiotherapy (IMRT) in the Radiation Oncology Department of the University of Michigan School of Medicine. Following lumpectomy, patients were treated twice daily for 5 days to $38.5 \mathrm{~Gy}$. All patients underwent a CT scan using an Automated Breathing Control (ABC) device and a scan at free breathing (FB) prior to treatment. Patients were treated using the $\mathrm{ABC}$ device with a $\mathrm{BH}$ at $65-80 \%$ inhale state to maximize the heart-chest wall distance. A WBRT plan using the FB scan was also generated for each patient using two opposed tangent fields. Doses to the $\mathrm{CB}$ and heart were calculated using a convolution/ superposition algorithm for both techniques and compared. Heart doses were evaluated only for the 5 patients who were treated to the left breast.

Results: As shown in the table there was no difference between the two techniques in the mean dose to the whole heart. However, the mean dose to $20 \%$ of the heart volume (V20) was significantly higher with the WBRT technique $(\mathrm{p}=0.008)$, suggesting a higher dose to the anterior portion of the heart, containing the left anterior descending artery and left ventricle. For the CB, the mean average dose was not different between the techniques, but there was a highly significant difference between the V10 $(\mathrm{p}=0.0006)$ and the V20 $(\mathrm{p}=0.02)$ of the CB, consistent with a higher (medial) breast dose for the WBRT technique.

Conclusions: Our data suggest that heart dose and CB dose are reduced when the patient is treated with APBI using IMRT with $\mathrm{BH}$ compared with WBRT in a FB state. These results support the need to accrue to randomized trials for long term outcomes of patients treated with APBI vs. WBRT.

\begin{tabular}{|c|c|c|c|c|c|c|}
\hline \multicolumn{3}{|c|}{ Mean Heart dose (\%) } & \multirow{2}{*}{$\begin{array}{l}\mathrm{p}- \\
\text { value }\end{array}$} & \multicolumn{2}{|c|}{ Mean CB Dose (\%) } & \multirow{2}{*}{$\begin{array}{l}\text { p- } \\
\text { value }\end{array}$} \\
\hline & APBI & WBRT & & APBI & WBRT & \\
\hline erage & 0.5 & 2.35 & .13 & 0.33 & 0.49 & .4 \\
\hline V10 & 2.6 & 4.75 & .086 & 1.17 & 2.6 & .0006 \\
\hline V20 & 1.95 & 3.25 & .008 & 1.17 & 1.9 & .025 \\
\hline
\end{tabular}

V10 is 10\% of the structure volume; V20 is $20 \%$ of the structure volume.

\section{3}

A phase I dose escalation trial of gemcitabine with radiotherapy for breast cancer in the treatment of chest wall recurrences.

Lin A, Hayman JA, Schipper MJ, Schott AF, Shewach DS, Pierce LJ. University of Michigan, Ann Arbor, MI

Background: The standard treatment for an isolated local or local-regional failure after mastectomy is radiotherapy (RT), with a preceding surgical resection when feasible. However, rates of durable local control following RT salvage average only approximately $50 \%$. We previously established that the maximum tolerated dose of gemcitabine with concurrent RT for chest wall disease was $300 \mathrm{mg} / \mathrm{m}^{2} /$ week. We now present our final results in the 12 patients enrolled on our phase I study.

Materials and Methods: After obtaining Institutional Review Board approval, all patients with unresectable and resectable localregional recurrence of breast cancer following mastectomy seen at the University of Michigan Breast Care Clinic who signed informed consent were eligible to participate in this phase I trial. Gemcitabine was given at $300 \mathrm{mg} / \mathrm{m}^{2} /$ week. RT was delivered initially to the chest wall and supraclavicular fossa to a total of 50 Gy in 2 Gy fractions. If the axillary and/or internal mammary lymph nodes were clinically involved, these nodal sites were included in the initial treatment volume. Additional boosts of 10 to $20 \mathrm{~Gy}$ were given to the areas of re-excision or to remaining gross disease. Endpoints were local-regional control, progressionfree, and overall survival by resection status.

Results: Of the total 12 patients enrolled, 0/12 patients experienced a local-regional re-recurrence after treatment as first failure or as any failure (median $\mathrm{F} / \mathrm{U}$ of 31.5 months, range 1.1 68.9). With a median F/U of 61.8 months (range $1.1-68.9$ ) progression-free survival was $50 \%$, and overall survival was $69 \%$

in the 7 patients with unresectable disease. Of the 5 patients who had resectable disease, with a median F/U of 5.9 months (range 3.5 -9.1), both progression-free survival and overall survival were $80 \%$. There was no statistically significant difference in progressionfree survival $(\mathrm{p}=0.94)$ or overall survival $(\mathrm{p}=0.85)$ by resectability status.

Discussion: Patients with resected or unresected chest wall recurrences treated concurrently with gemcitabine and RT appear to have excellent rates of local-regional control. While we will continue to follow these patients over time to assure sustained local control, these preliminary results are encouraging given the baseline high rates of local failure previously observed with RT alone. A phase II trial with concurrent gemcitabine and RT is warranted.

\section{4}

Targeted intraoperative radiotherapy (TARGIT) as a boost yields very low recurrence rates.

Vaidya JS, Baum M, Tobias JS, Wenz F, Massarut S, Hilaris BS, Houghton J, Murphy O, Saunders C, Corica T, Harrisson E, Keshtgar M, Douek M, Sainsbury R, Kraus-Tiefenbacher U, Melchart F, Joseph D. University of Dundee and Ninewells Hospital, Dundee, United Kingdom; University College London, United Kingdom; University of Mannheim, Mannheim, Germany; CRO, Aviano, Italy; Our Lady of Mercy New York Medical College; Sir Charles Gairdner Hospital, Perth, Australia

The value of tumour bed boost after breast conserving surgery has been well demonstrated, especially in those with higher risks of local recurrence. However, accurate targeting of this boost is difficult and the risk of a 'geographical miss' is estimated to occur in $50 \%$ to $80 \%$ of cases, substantially contributing to local recurrence.

Beginning in 1998, we have been treating patients of early breast cancer suitable for breast conserving surgery with TARGeted Intraoperative radioTherapy (TARGIT) using the Intrabeam ${ }^{\mathrm{TM}}$ system. This was a pilot series to test the feasibility and safety of the new approach as a prelude to the randomised trial which would test if intraoperative radiotherapy would alone be sufficient for local control in selected patients.

This series now includes patients from the UK, USA, Italy, Germany and Australia. Patients suitable for breast conserving surgery were given intraoperative radiotherapy at the time of surgery, using the Intrabeam ${ }^{\mathrm{TM}}$ system, delivering $20 \mathrm{~Gy}$ to the surface of the tumour bed, followed external beam radiotherapy (EBRT) as per local guidelines, but excluding the boost.

324 patients have been treated. The median follow up is 26 months (longest 77 months). The treatment is well tolerated and the local recurrence rate is very low (table).

These data suggest that TARGIT + EBRT results in an extremely low local recurrence rate and the time is ripe for a randomised trial to test whether the conventional external boost should be replaced by Targit, especially in high risk women. We are planning to commence this study to run in parallel with the ongoing TARGIT trial. For young high risk patients $n=476$ will be well powered to detect a difference between $2 \%$ and $8 \%$. Table 1

\begin{tabular}{|c|c|c|c|}
\hline & $\begin{array}{l}\text { Number } \\
\text { of cases }\end{array}$ & $\begin{array}{l}\text { Follow up time } \\
\text { in months: Median } \\
\text { (Range) }\end{array}$ & $\begin{array}{l}\text { Local Recurrence as first event after } \\
\text { Surgery + TARGIT + EBRT }\end{array}$ \\
\hline ndon & 23 & $64(55-77)$ & $\begin{array}{l}1 \text { new primary outside the index } \\
\text { quadrant at } 42 \text { months }\end{array}$ \\
\hline w York & 57 & $44(30-60)$ & $\begin{array}{l}1 \text { focus of DCIS in the index quadrant } \\
\text { at } 30 \text { months }\end{array}$ \\
\hline Mannheim & 85 & $16(0-35)$ & $\begin{array}{l}1 \text { diffuse recurrence including skin at } \\
10 \text { months-died soon after }\end{array}$ \\
\hline Aviano & 119 & $16(6-30)$ & $\begin{array}{l}1 \text { diffuse recurrence at } 10 \text { months in a } \\
\text { patient with multiple positive margins } \\
\text { and positive nodes who refused a } \\
\text { mastectomy }\end{array}$ \\
\hline & 40 & $24(2-44)$ & 0 \\
\hline & 4 & $3(4-8)$ & 0 \\
\hline L & 328 & 26 months & 4 recurrences/new primaries \\
\hline
\end{tabular}




\section{5}

Breast magnetic resonance imaging (MRI) enhancement beyond the tumor margin: implications for radiation therapy.

Rembert JL, Klifa C, Lu Y, Gibbs J, Hylton N, Park C. University of California, San Francisco, San Francisco, CA

Background: Radiation therapy (RT) is used after lumpectomy for breast cancer to decrease the risk of local recurrence. However, the optimal volume for treatment is not well characterized. Contrast-enhanced breast MRI is often used as a diagnostic tool based on signal enhancement characteristics of extravasated gadolinium-based contrast. Signal enhancement ratios (SER), which reflect the physiologic blood flow in the breast, can be quantified on a voxel-by-voxel basis within the 3-dimensional architectural information provided by one pre-contrast, one post-contrast at 2.5 minutes and one late post-contrast at 6 minutes MRI scans. Purpose: To determine if breast MRI signal enhancement ratios (SER) could be used to characterize stromal tissue beyond the tumor margin in patients with invasive breast cancer before and after neoadjuvant chemotherapy.

Methods: We included contrast-enhanced fat-suppressed breast MRI data from 11 patients with invasive breast cancer taken before and after one cycle of neoadjuvant chemotherapy. Volumetric SER maps were generated using an institutionally developed, validated, computer-based algorithm. On one sagittal slice representing the tumor, five circular regions of interest (ROI's), $5 \mathrm{~mm}$ in diameter each, were drawn to extend radially out from the tumor. The first ROI was completely placed within enhancing tumor while the $2^{\text {nd }}-5^{\text {th }}$ ROI's extended into fibroglandular stroma. We used fat-suppressed MRIs where the signal intensity in regions of fat appears nearly as dark as the image background, and therefore regions of fat were not included in ROIs calculations. Two unique ROI sets were obtained on each pre and post-chemotherapy scan provided adequate non-tumor fibroglandular tissue was present. A mixed random effects model was used to fit the data by quadratic curves of the distance from tumor before and after chemotherapy as the fixed effect, patients as the random effects, and SER as the dependent variable. F-test was used to assess the significance of the distance from tumor as well as the effects of chemotherapy. A 5\% statistical significant level was used.

Results: The mixed random effects model showed a significant quadratic relationship between the distance from the tumor and SER. The average vertex of this curve reached an inflection point at approximately $1.25 \mathrm{~cm}$ from the margin of the tumor. Chemotherapy shifted the curve downwards significantly $(\mathrm{p}=0.02)$, but had no effect on the overall shape of the curve.

Conclusions: Physiologic information from breast MRI may reflect stromal abnormalities beyond the tumor margin. Volumetric SER may be a useful tool in defining the optimal volume for breast RT.

\section{6}

Risk of internal mammary recurrence after mastectomy in absence of internal mammary chain radiation therapy. A retrospective study.

Lerouge D, Levy C, Ollivier JM, Switsers O, Vie B, Delozier T. Centre Francois Baclesse, Caen, France

Purpose

Many controversies remain about the role of internal mammary lymph node (IMLN) radiation therapy for breast cancer, without evidence for real benefit in term of loco-regional recurrence or survival.

In order to evaluate the risk of recurrence in IMLN, and to determine possible risk factors, we retrospectively study a population of 1353 women, treated by mastectomy, eventually associated by chest wall radiotherapy, but without IMLN radiation therapy.
Material and methods

From 1985, ILMN irradiation was excluded of local treatment after breast surgery. After mastectomy, post operative radiation therapy (50 Gy) was limited to the chest wall (+/- supra-clavicular area) in case of uncomplete resection and/or extensive axillary involvement.

Between 1985 and 1996, this protocol was applied to 1353 women (mean age 55 years). Clinical characteristics: $13 \% \mathrm{~T} 1,50 \% \mathrm{~T} 2$, $37 \%$ T3-T4. Inner or central tumor: $46,3 \%$, external $53,7 \%$.pN negative $=39 \%$, pN1 $1-3=34 \%, \mathrm{~N}+>3=27 \%$.

$52 \%$ of these patients received chest wall radiotherapy, $42,4 \%$ adjuvant chemotherapy and for $65,6 \%$ of the population an adjuvant hormonal therapy was administered.

Results

The 5-yrs rate of internal mammary nodes recurrence is $2 \%$.

No statistically significant difference in IMNL recurrence rate was observed according to clinical features (age, hormonal status, tumor size, tumor location), histological features (axillary involvement vs not, grade, hormonal receptors, histological type) or adjuvant treatment (chemo and/or hormonal therapy vs not). The largest rate of IMLN recurrence was observed in the subgroup of $\mathrm{N}+>9(8,3 \%)$. The number of axillary positive nodes $(\mathrm{N}+1-3$, $\mathrm{N}+4-9, \mathrm{~N}+>9)$ is the most important parameter, but the difference remains under statistical value $(\mathrm{p}=0.06)$. Inner/central tumors experienced more IMLN recurrence $(1,08 \%)$ than external tumors $(0,3 \%)$, but this rate remains low and the difference is not statistically significant $(\mathrm{p}=0.2)$.

In addition, historical comparison with 1226 patients treated with IMLN radiation after mastectomy (+/- chest wall irradiation) from 1973 to 1984 was made. In this group, no internal mammary nodes recurrence was observed. This difference in IMLN recurrence did not affect the survival: the 5 and 10 years overall survival is higher in the NO- IMLN-radiation group (respectively 79 and 62 $\%$ versus 73 and $58 \%)(\mathrm{p}<0.005)$.

Conclusions

IMLN recurrences remain very rare, therefore the benefit of ILMN radiation therapy must be discussed. Waiting for results of ongoing randomised trials, retrospective evaluation of no-IMLN treated patients give us interesting data about ILMN recurrence risk. Even in the subgroups for which the radiation therapy is often proposed (inner/central tumor location, axillary nodes involvement), the recurrence rate remains low and the reduction of this small incidence by radiation is eventually without effect on survival.

The "pertinent" indications of ILMN radiation therapy remain to define.

\section{7}

Frequency of asymptomatic brain metastases in Her-2 positive breast cancer patients.

Niwinska A, Tacikowska M, Pienkowski T, Lemanska I, BauerKosinska B, Glogowska I, Rudnicka H. Memorial Cancer Center and Institute, Warsaw, Poland

Introduction: Clinically evident brain metastases are observed in $10-16 \%$ of breast cancer patients (pts). In HER-2 positive breast cancer the percentage is much higher and makes up $30-48 \%$. Since trastuzumab has been introduce in the treatment of breast cancer, that's brain metastases are the direct cause of death, specially in pts with clinical response in viscera. This is the reason of performing screened magnetic resonance imaging (MR) of the brain in pts with disseminated disease without neurological symptoms in order to early detection and irradiation of brain metastases.

Aim: The aim of the study was to evaluate the frequency of asymptomatic brain metastases in HER-2 positive breast cancer pts and to establish the extent of regression after radiotherapy. Material nad Methods: Screened MR of the brain was performed in 32 HER-2 positive breast cancer pts currently treated in Breast Cancer Clinic with trastuzumab and chemotherapy because of visceral metastases and/ or locoregional failure. In those pts in 


\section{S182 Abstracts - Poster Session IV}

whom asymptomatic brain metastases were detected irradiation to the brain $30 \mathrm{~Gy}$ in 10 fraction was undertaken. Than, control MR was performed 3 months after radiotherapy in order to assess the extent of regression of metastases.

Results: In 11 (34\%) pts asymptomatic brain metastases were detected: in 5- solitary, in 6 - numerous. Pts with brain metastases were younger (51 vs 54 years), with shorter DFS ( 25 vs 32 months) and more often with distant than with locoregional failure but differences were not statistically significant. Median time from recurrence to brain metastases was 15 months. In 10 pts radiotherapy of brain was undertaken. In control MR, performed 3 months after radiotherapy, 3 complete and 7 partial regressions were stated.

Conclusion: Higher than expected percentage of asymptomatic brain metastases was detected in HER-2 positive breast cancer pts. Good radiological response in all pts was achieved. It seems, that it is reasonable to introduce MR screening of the brain in HER-2 positive breast cancer pts with disseminated disease for early detection and irradiation of brain metastases before neurological signs and symptoms appear. Longer follow-up is necessary in order to evaluate risk reduction of neurological symptoms and the cause of death of pts

\section{8}

Over expression of apoptotic markers - p53 and bcl-xl is associated with axillary recurrence following radiotherapy in breast cancer patients.

Jameel JK, Garimella V, Long E, Beavis A, Drew PJ, Cawkwell L. Postgraduate Medical Institute, University of Hull, Castle Hill Hospital, Cottingham, East Yorkshire, United Kingdom; Hull \& East Yorkshire Hospitals NHS Trust, Hull, East Yorkshire, United Kingdom

\section{Introduction}

Management of the node-positive axilla from carcinoma of the breast remains controversial, axillary radiotherapy and axillary clearance being the two options. Specific molecular markers in axilla and primary tumour that mediate radioresistance could influence the choice of treatment.

\section{Aim}

Toassess the expression of apoptosis proteins as markers for axillary recurrence following axillary radiotherapy.

\section{Methods}

Ten patients who developed axillary recurrence following axillary radiotherapy were identified and were compared with 10 matched controls who remained disease free 5 years post-treatment. All patients underwent a wide local excision (WLE)/mastectomy followed by radiotherapy to the breast/chest wall and axilla under a similar regime. Immunohistochemical analysis was performed on primary tumour, axillary node samples for $\mathrm{p} 53$, anti-apoptotic markers (bcl-2, bcl-xl, mcl-1) and pro-apoptotic markers (bad, bak, bax). Over expression was recorded in cases where a clonal pattern of nuclear staining was seen in $>10 \%$ of malignant cells for $\mathrm{p} 53$ and anti-apoptotic markers, while loss of expression was recorded when there was absence of staining in $>50 \%$ of malignant cells for the pro-apoptotic markers. Scoring was done by 2 independent observers.

Results

In 5 out of the 10 cases, the primary tumour was positive for $\mathrm{p} 53$ as opposed to none in the controls, the difference being statistically significant $(\mathrm{p}=0.016$, Fisher's exact test). A statistically significant difference was also found in the expression of bcl-xl between the axillary samples of cases and controls $(\mathrm{p}=0.035$, Fisher's exact test). None of the other markers were significantly different between the 2 groups.

Conclusion

p53 mutation in the primary tumour is a significant risk factor for axillary recurrence following axillary radiotherapy. Overexpression of bcl-xl in the axillary sample may also contibute to radioresistance by failing to initiate an appropriate apoptotic response in cells with radiation induced damage.

\section{9}

Improved survival after radiotherapy for brain metastases in patients with HER2 positive breast tumors.

Maur M, Frassoldati A, Piacentini F, Ramundo D, Sabbatini $R$, Giovannelli S, Ficarra G, Bertolini F, Falchi AM, Conte PF. University of Modena and Reggio Emilia, Modena, Italy

Background: A high incidence of brain metastases (BM) has been reported in patients with HER2 positive breast tumors. This could be the combined result of more aggressive tumor biology and better control of systemic disease with trastuzumab. In order to define how HER2 status affect the CNS involvement and the response to radiotherapy we conducted a retrospective chart review of patients (pts) with BM.

Patients and methods: Data from 53 consecutive patients with $\mathrm{BM}$ from $\mathrm{BC}$ were retrieved. Median age at CNS progression was 56 years (range 33 to 76 ); $38 / 53$ pts $(71 \%)$ had two or more CNS metastases ( 23 brain, 6 cerebellum, 14 brain/cerebellum, 3 brain/ cerebellum/leptomeningeal), $43 / 53 \mathrm{pts}(81 \%)$ had multiple extra cranial metastases. Median time to developing CNS mts after primary diagnosis was 50 months (range 32 to 236). Forty-one pts $(77 \%)$ had received prior chemotherapy (37/53 antracyclinebased, 21/53 taxane-based). The tumor biological characteristics were as follows: high grade $27 / 53(51 \%)$, high proliferative rate (MIB-1 > 20\%) 33/53 (62\%), ER positive 23/53 (43\%), PgR positive $12 / 53(22 \%)$. Twenty-five $(47 \%)$ were HER2 positive. Three patients only underwent to brain metastasectomy. Fortynine pts were treated with whole brain radiotherapy (WBR) plus prednisolone (28 pts $30 \mathrm{~Gy} / 10$ fractions, 21 pts $20 \mathrm{~Gy} / 5$ fractions) and 4 pts had received stereotassic radiosurgery (SRS). At the time of diagnosis of BM $16 / 53(30 \%)$ were on treatment with trastuzumab.

Results: No significant correlation between site of CNS relapse and tumor histology $(\mathrm{p}=0.877)$, grading $(\mathrm{p}=0.495)$, HER2 status $(\mathrm{p}=0.127)$, ER status $(\mathrm{p}=0.499), \operatorname{PgR}$ status $(\mathrm{p}=0.152)$ anthracycline based $(\mathrm{p}=0.998)$ or taxane-based chemotherapy ( $p=0.756)$ was observed. The response status after radiotherapy was: 1 complete response (CR), 20 (57\%) partial response (PR), $11(31 \%)$ stable disease (SD), $3(8.5 \%)$ progression disease (PD) response was not assessed in 18 pts. No difference between type of response to radiotherapy and histology $(\mathrm{p}=0.681)$, grading $(\mathrm{p}=0.183)$, HER2 status $(\mathrm{p}=0.844)$, CNS metastatic site $(\mathrm{p}=0.116)$, number of CNS mts $(p=0.677)$ and trastuzumab-therapy $(p=0.389)$ was observed. A significant better response was observed with high dose (30 Gy/10 fractions) of WBR $(p=0.01)$. So far $38 / 53(72 \%)$ died for disease progression, $13 / 53(25 \%)$ are alive with disease. Median survival of all pts was 9 mos. Significant predictors for better overall survival were: HER 2 status (positive 21 mos vs negative 3 mos, $p=0.005)$, age $(<55$ years 10 mos vs $>55$ years $3 \operatorname{mos}, p=0.007$ ) and among HER2 positive patients continuous treatment with trastuzumab (yes 21 mos vs no 5 mos, $\mathrm{p}=0.026$ ). Conclusions: breast cancer patients with HER2 positive BM experience a more long survival when treated with radiotherapy and trastuzumab.

\section{0}

Efficacy of accelerated partial breast irradiation (APBI) as a neoadjuvant treatment for patients with breast cancer: a pilot study.

Sato K, Uematsu M, Saito T, Hiraide H. National Defense Medical College, Namiki, Tokorozawa, Saitama, Japan; Keio University School of Medicine, Shinanomachi, Shinjuku-ku, Tokyo, Japan, Saitama Red Cross Hospital, Kami-ochiai, Chuo-ku, Saitama, Japan

Background: Breast conserving treatment (BCT) consists of breast-conserving surgery and followed by whole-breast irradiation (WBI). Accelerated partial breast irradiation (APBI) is being considered as a possible alternative to WBI. Neoadjuvant APBI might provide more benefit than postsurgical APBI because tumor downstaging will enhance the likelihood of BCT. 
Method: APBI was delivered as 50 Gy in 5 fractions over 5 days before surgery for patients with breast cancer of 3-4 cm diameter. Patients with $3 \mathrm{~cm}$ or less tumor were deemed to be candidates for breast-conserving surgery.

Results: Between September 1998 and August 1999, 12 women were enrolled. The mean tumor diameter and volume were reduced from 3.4 to $1.8 \mathrm{~cm}$ (reduction rate: $47 \%$ ) and from 8.1 to $2.2 \mathrm{~cm}^{3}$ (reduction rate: $71 \%$ ), respectively. The mean pathologic tumor size was $1.5 \mathrm{~cm}$, and a complete pathologic response was found in one patient $(8 \%)$. All patients were eligible for breast-conserving surgery. Noipsilateral breast recurrences have been observed to date.

Conclusion: This is the first report of neoadjuvant APBI for relatively large breast cancers. Although the number of participants was small, these results would encourage the development of clinical trials exploring the efficacy of neoadjuvant APBI. Clinical response to neoadjuvant APBI

\begin{tabular}{|c|c|c|c|c|}
\hline & \multicolumn{2}{|l|}{ No. of patients } & $\%$ \\
\hline \multicolumn{2}{|l|}{ CR } & 0 & & 0 \\
\hline \multicolumn{2}{|l|}{ PR } & 11 & & 91.7 \\
\hline \multicolumn{2}{|l|}{ SD } & 1 & & 8.3 \\
\hline \multicolumn{2}{|l|}{ PD } & 0 & & 0 \\
\hline \multicolumn{2}{|c|}{ Response rate (95\%C.I.) } & 11 & & $91.7(56-80)$ \\
\hline \multicolumn{5}{|c|}{ Pathological response to neoadjuvant APBI } \\
\hline & \multicolumn{2}{|c|}{ No. of patients } & $\%$ & \\
\hline Grade 0 & \multirow{2}{*}{\multicolumn{2}{|c|}{$\begin{array}{l}0 \\
2\end{array}$}} & \multicolumn{2}{|l|}{0} \\
\hline Grade 1a & \multirow{2}{*}{\multicolumn{2}{|c|}{$\begin{array}{l}2 \\
6\end{array}$}} & \multicolumn{2}{|l|}{16.7} \\
\hline Grade $1 \mathrm{~b}$ & & & \multicolumn{2}{|l|}{50} \\
\hline Grade 2 & \multicolumn{2}{|l|}{3} & \multirow{2}{*}{\multicolumn{2}{|c|}{$\begin{array}{l}25 \\
83\end{array}$}} \\
\hline Grade 3 (pCR) & \multicolumn{2}{|l|}{1} & & \\
\hline
\end{tabular}

\section{1}

Mammosite brachytherapy: predictive factors for complications and cosmesis.

McLaughlin M, Isreal P, Fine R, Corgan K, Robbins A, Hughes L, Haile K, Vanipalli J, Pope K. North Georgia Radiation Therapy, Marietta, GA; Wellstar Kennestone Hospital, Marietta, GA

BACKGROUND: This study reviewed factors that predicted cosmesis and complications in women treated with Mammosite based partial breast irradiation.

MATERIAL/METHODS: Eighty-one patients (T1No-64; T2N08; CIS-9] underwent lumpectomy. This was followed by Mammosite partial breast irradiation. CT was used for dosimetric planning.

RESULTS: CT showed the minimum skin spacing to be $5-6 \mathrm{~mm}$ in $19,7-8 \mathrm{~mm}$ in 54 and greater than $9 \mathrm{~mm}$ in 8 patients. Four patients were explanted because of inadequate skin spacing, one patient because of extensive pain secondary to balloon inflation and one from suboptimal conformance of the surgical cavity to the Mammosite balloon. Fifty-two patients had no-to-mild skin reactions, 21 developed moderate skin reactions and 8 developed desquamation. Predictive factors include balloon-to-skin spacing, balloon volume, post-radiotherapy exposure to adriamycin-based chemotherapy, infection and body position of the patient during treatment (sitting vs. supine). Nineteen patients developed an infection. Large balloon volume was predictive for infection $(>60$ cc). Patients' perception of cosmesis was good-to-excellent in 64; Skin reaction, infection and the amount of breast tissue removed were predictive of the patients' perception.

DISCUSSION: Mammosite accelerated partial breast irradiation is a safe method for treating early stage breast cancer and CIS. The factors that predict suboptimal outcomes include, small balloonto-skin distance (5-6 mm], adriamycin based chemotherapy, balloon volume $>60 \mathrm{cc}$ and infections. Patients with small balloonto-skin distance should be aware of the potential poorer cosmesis. All patients should be evaluated by a Medical Oncologist. If adriamycin is recommended, this should be delivered at least 6-8 weeks post-irradiation to reduce radiation recall. If a breast infection develops, chemotherapy should not be delivered until the infection has resolved. If the balloon volume is $>60 \mathrm{cc}$, the patient should be placed on prophylactic antibiotics.

\section{2}

Fatty acid synthase (FAS)-catalyzed endogenous fatty acid metabolism regulates Her-2/neu (erbB-2) oncogene expression via malonyl-coenzyme-a-dependent expression of the Ets protein polyomavirus enhancer activator 3 (PEA3), a transcriptional repressor of Her-2/neu promoter activity in cancer cells.

Menendez JA, Papadimitropoulou A, Vellon L, Colomer R, Lupu R. Evanston Northwestern Healthcare, Evanston, IL; Northwestern University Feinberg School of Medicine, Chicago, IL; Institut Catala Oncologia, Hospital Universitari Dr. Josep Trueta, Girona, Catalonia, Spain

We recently revealed that FAS-catalyzed endogenous fatty acid metabolism is a novel regulator of Her-2/neu oncogene in cancer cells (Menendez et al. PNAS USA. 2004; 101:10715-20). Her-2/ $n e u$-overexpressing tumor cells exhibited noteworthy reductions of Her-2/neu protein and Her-2/neu mRNA following pharmacological inhibition of FAS activity with $\mathrm{C} 75$, a novel small-compound targeting the $\beta$-ketoacyl synthase partial activity of FAS. We here addressed the ultimate molecular mechanism linking tumor cells' response to FAS inhibition and Her-2/neu gene expression. Transient transfection experiments demonstrated that pharmacological FAS blockade specifically repressed Her-2/ neu promoter activity, while concomitantly induced the upregulation of the Ets protein PEA3 (a transcriptional repressor of Her-2/neu promoter activity) in cancer cells naturally exhibiting Her-2/neu gene amplification but not in cancer cells expressing low to undetectable Her-2/neu. Indeed, an intact PEA3 DNAbinding site at the wild-type Her-2/neu promoter was essential for C75-induced Her-2/neu gene repression as either a Her-2/neu promoter bearing a PEA3 site-mutated sequence or a full-length Her-2/neu cDNA controlled by a SV40 viral promoter were not subject to negative regulation by $\mathrm{C} 75$. Importantly, these effects were recapitulated by siRNA-induced inhibition of FAS gene expression, thus demonstrating that C75 exerts its anti-Her-2/ $n e u$ effects through its FAS target. If palmitate starvation mediated the regulatory effects of $\mathrm{C} 75$ on the transcriptional activity of Her-2/neu gene, then any other FA synthesis inhibitor should produce similar effects. Bezafibrate, known to block the activity of the rate-limiting enzyme of FA synthesis Acetyl-CoA Carboxylase, failed to regulate either Her-2/neu promoter activity or PEA3 expression. Interestingly, exogenous supplementation with the FAS substrate Malonyl-CoA dramatically decreased Her2/neu promoter activity while concomitantly promoting PEA3 accumulation, thus mimicking the regulatory actions of C75induced inhibition of FAS activity on Her-2/neu gene expression. Considering difference in the site of action of $\mathrm{C} 75$ and bezafibrate along FA synthesis pathway, these findings strongly suggest that Malonyl-CoA -but not FA starvation- not only represents a previously unrecognized signal of fuel availability able to trigger repression of Her-2/neu gene expression via the Ets protein PEA3 but further support the notion of FAS-dependent de novo FA biogenesis as a valuable molecular target in the management of Her-2/neu-overexpressing carcinomas.

\section{3}

Epigenetic alteration of a protein tyrosine phosphatase and its role in tamoxifen-resistance in breast cancer.

Ramaswamy B, Motiwala T, Kutay H, Majumder S, Shapiro CL, Jacob ST. Ohio State University, Columbus, $\mathrm{OH}$

Background: Protein tyrosine phosphatases (PTPs) such as PTPL1, PTPG, and LAR are induced by tamoxifen (TAM) and the resulting increase in PTP activity is important for its antiapoptotic effects. [Friess G etal.Crit rev Onc Hem. 2004]. Moreover, in vitro and in vivo studies show that high tyrosine kinase activity in breast tumors may result in tamoxifen resistance, suggesting that PTP activity may be reduced under these conditions. We have shown that the gene for receptor-type protein tyrosine 


\section{S184 Abstracts - Poster Session IV}

phosphatase type $\mathrm{O}(P T P R O)$ is suppressed by methylation in primary rat hepatocellular carcinoma [Motiwala $T$ et al. Oncogene 2003], and in several human primary tumors including chronic lymphocytic leukemia (CLL), hepatocellular carcinomas, and lung cancer. We have further shown the growth suppressing potential of PTPRO in lung cancer [Motiwala T etal. PNAS 2005]. Additionally, PTPRO is localized to chromosome region $12 \mathrm{p} 12.3$, a region characterized by loss of heterozygosity in several tumor types, a hallmark of classical tumor suppressors. We hypothesized that PTPRO may function as a tumor suppressor in normal breast and is epigenetically silenced in breast cancer which may contribute to tamoxifen resistance. Further, this suppression may be hormonally mediated.

Results:

Using RT-PCR, we found that normal human mammary epithelial cell (HMEC), 48R and 184 express PTPRO. We demonstrate that the PTPRO promoter is unmethylated in these cells using combined bisulfite restriction analysis (COBRA) and sequencing.In estrogen receptor (ER)+ MCF-7 and ER- MB231 cell lines, PTPRO is suppressed and its promoter is densely methylated (COBRA and bisulfite sequencing). Moreover, treatment of MCF-7 and MB231 cell lines with $1 \mu \mathrm{M}$ and $2.5 \mu \mathrm{M}$ of demethylating agent, 5-azadeoxycytidine (Decitabine) for 72 and 96 hours, respectively, resulted in re-expression of PTPRO.Treatment of MCF-7 and MB231 cells grown in phenol-red free media with $50 \mathrm{nM}$ of TAM for 48 and 72 hours resulted in up-regulation of PTPRO in ER+ MCF-7 cells but not in ER- MB231 cells.

In our pilot study of primary breast tumors, we have thus far analyzed 9 tumor samples and three normal breast tissue samples by methylation-specific PCR (MS-PCR) and found that the PTPRO promoter is methylated in all the tumor samples and unmethylated in all the normal breast tissue samples.

Conclusions: These results show that PTPRO promoter is methylated in human breast cancer and not in normal breast tissue; $P T P R O$ can be re-expressed by decitabine in both ER negative and positive cell lines, and PTPRO is induced by anti-estrogens in ER+ MCF-7 cells. Ongoing studies are evaluating whether PTPRO exhibits growth suppressive and/or pro-apoptotic effects in breast cancer and its induction is crucial for the anti-tumor effect of TAM. Methylation and suppression of PTPRO could be a predictive marker of response to TAM and a molecular target for epigenetic therapy.

\section{4}

EPLIN, epithelial protein lost in neoplasm, is aberrantly expressed in human breast cancer and is related to clinical outcomes.

Jiang WG, Martin TA, Douglas-Jones A, Mansel RE. School of Medicine, Wales College of Medicine, Cardiff University, Cardiff, Wales, United Kingdom; Cardiff University, Cardiff, Wales, United Kingdom

Introduction

EPLIN, epithelial protein lost in neoplasm, is a protein that has been found to be reduced or lost after cellular transformation. It is also reduced in cancer cells, such as oral cancer cells. However, the role of the molecule in human cancers, including breast cancer has not been investigated. The current study examined the expression and levels of expression of EPLIN in a cohort of human breast cancer tissues and analysed its correlation with the clinical outcomes

Methods.

Invasive breast tumours $(\mathrm{n}=120)$ and normal mammary tissues $(n=32)$ were used. A panel of human breast cancer, fibroblast and endothelial cell lines were also used. EPLIN transcript was assessed qualitatively and quantitatively using conventional and real-time quantitative PCR, respectively. Methylation of the EPLIN gene promoter was investigated using methylation specific PCR (MSP). The levels of the EPLIN transcript was analysed against the clinical and pathological information. Median follow up for the current cohort was 120 months.
Results.

Breast cancer cell lines had detectable EPLIN transcript, but at reduced level. Fibroblast cell line had virtually no detectable EPLIN. Breast cancer tissues generally displayed a low level of EPLIN, compared with normal tissues. Grade 2 and grade 3 tumour had significantly lower levels of EPLIN compared with grade 1 breast tumours $(p=0.047$ and $p=0.046$ vs grade 1 , respectively). Significantly lower levels of EPLIN was seen in TNM4 tumours (3.1 \pm 1.5 copies/50ng RNA in TNM4 tumours vs $30.5 \pm 8.7$ in TNM1 tumours). When the Nottingham Prognostic Index was used as a prognosis indicator, patients who had poor prognosis had a significantly lower levels of the EPLIN transcript compared with those with good prognosis $(2.73 \pm 0.8$ in patients with poor prognostic index vs $32.8 \pm 10$ in patients with good prognostic index, $\mathrm{p}=0.0081$ ). Over a median 10 year follow up, patients who developed local recurrence and who died of breast cancer had significantly lower levels of EPLIN compared with those who remained disease free $(\mathrm{p}=0.0003$ and $\mathrm{p}=0.0008$, respectively). Kaplan-Meier survival analysis has shown that patients with high levels of EPLIN transcript had longer survival than those with low levels (median survival 141.6 months vs 135.4 months, respectively, $\mathrm{p}=0.064)$. Methylation specific PCR had shown presence of hypermethylation of the EPLIN promoter in breast tumour tissues. Hypermethylation of the EPLIN promoter was also frequently seen in breast cancer cell lines.

It is concluded that expression of EPLIN in breast cancer is downregulated in breast cancer cells and tissues. A potential mechanism of the aberrant expression is via the EPLIN promoter hypermethylation. The levels of EPLIN transcripts are linked to the clinical outcomes in patients with breast cancer.

\section{5}

$B R C A 1$ promoter methylation confers sensitivity to cisplatin in vitro.

Nanda R, Dignam JJ, Collins C, Xu J, Dolan ME, Olopade OI. University of Chicago, Chicago, $I L$

Background: Women with BRCA1 mutations are more likely to have breast cancers that are hormone receptor and HER2/neu negative. We have previously demonstrated that $B R C A 1$ promoter methylation occurs to some degree in $20-30 \%$ of all sporadic tumors, and up to $50 \%$ of high-grade hormone receptor negative tumors, making it much more common than germline mutation (Wei et. al., in press). Given the role of BRCA1 in DNA repair, it is likely that cells deficient in BRCA1 secondary to promoter methylation will have increased sensitivity to DNA damaging agents, as has previously been demonstrated in cells deficient in BRCA1 secondary to mutation. The role of BRCA1 methylation in determining chemosensitivity is not yet known.

Methods: Using an in vitro model, the relative sensitivity of BRCA1 methylated, mutated and competent cells was determined in four representative breast cancer cell lines: UACC-3199 (methylated BRCA1), HCC-1937 (mutated BRCA1), MCF-7 (wildtype BRCA1, ER positive) and MDA-MB-231 (wildtype BRCA1, ER negative). Exponentially growing cells were treated with doses of cisplatin between $0.25 \mu \mathrm{M}$ and $350 \mu \mathrm{M}$. Cells were harvested 96 hours after drug exposure and stained with Annexin-V and DAPI. Cell survival and apoptosis were determined by flow cytometry using FACS DiVa. FlowJo FACS analysis software (version 6.1.1) was used to generate percent apoptotic and live cells. $\mathrm{IC}_{50}$ values and $95 \%$ confidence intervals were calculated from dose response curves. Results: The $\mathrm{IC}_{50}$ values for the UACC-3199 and HCC-1937 cells were $12.2 \mu \mathrm{M}$ (95\% CI 9.49-14.88) and $60.3 \mu \mathrm{M}(95 \%$ CI 40.45 94.63), respectively. The $\mathrm{IC}_{50}$ values for MCF-7 and MDA-MB231 cells were not reached, even at a dose of $350 \mu \mathrm{M}$. Peak percentage of apoptotic cells observed for the UACC-3199 was $38 \%$ at a cisplatin concentration of $50 \mu \mathrm{M}$. Peak percentage of apoptotic cells observed for the HCC-1937, MCF-7 and MDAMB-231 cells were 20\%, $18.7 \%$ and $20 \%$ at cisplatin concentrations of $100 \mu \mathrm{M}, 350 \mu \mathrm{M}$, and $350 \mu \mathrm{M}$, respectively. 
Discussion: Previous studies have demonstrated that cells deficient in $B R C A 1$ secondary to mutation are more sensitive to cisplatin than $B R C A 1$ competent cells. We have demonstrated for the first time that cells deficient in BRCAl secondary to promoter methylation are also highly sensitive to cisplatin. As varying degrees of $B R C A 1$ methylation occurs in a significant proportion of high-grade hormone receptor negative tumors, it represents a potential therapeutic target in the treatment of a subset of sporadic breast cancers.

\section{6}

ER status and age-at-diagnosis determine frequency and structural severity of breast cancer p53 mutations.

Fedele V, Roydasgupta R, Tommasi S, Paradiso A, Albertson D, Benz C. University of California, San Francisco, CA; National Cancer Institute-Bari, Bari, Italy; Buck Institute for Age Research, Novato, CA

Breast cancer markers thought to refect genomic instability (e.g. abnormal p53, high nuclear grade, aneuploidy) show strong inverse associations with patient age-at-diagnosis, while estrogen receptor (ER) overexpression shows a strong positive association with aging. As well, breast cancer p53 immunopositivity correlates imperfectly with p53 DNA mutation status and both correlate negatively with ER overexpression. Thus, the present study was undertaken to compare the relationship between ER status, ageat-diagnosis, frequency and type of p53 mutations from a cryobank of 111 primary breast cancer cases recently diagnosed and treated at NCI-Bari, subdivided into younger ( $\mathrm{Y} \leq 45 \mathrm{y} ; \mathrm{n}=52 ; 44 \%$ ERnegative) and older ( $\mathrm{O} \geq 70 \mathrm{y} ; \mathrm{n}=59 ; 15 \%$ ER-negative $)$ age cohorts. Overall, we identified DNA coding mutations within p53 exons 5-8 (p53mut) in 20 cases (18\%), consistent with the reported p53 mutation rate for breast cancers worldwide (www-p53.iarc.fr). ER-positive breast cancers showed a p53mut rate of only $6 \%$, while ER-negative cancers showed a p53mut rate of $46 \%$ $(\mathrm{p}<0.0001)$. When controlled for ER status, age cohorts showed no significant differences in p53mut rates. Breast cancer p53 mutations resulted from base transitions $(11 / 20)$, transversions $(8 / 20)$ and an in-frame micro-deletion (1/20), producing missense amino acid substitutions (17/20) and nonsense protein truncations $(2 / 20)$. Half of these p53 DNA mutations resulted in structurally more severe changes in $\mathrm{p} 53$ protein primary sequence, characterized by protein truncations or amino acid polarity and H-bond changes within evolutionarily conserved regions of the p53 DNA-binding domain. Among all cases, $90 \%$ of these more severe changes occurred in $\mathrm{Y}$ cohort tumors $(\mathrm{p}=0.007)$; among ER-negative cases, $100 \%$ of these more severe changes occurred in Y cohort tumors $(\mathrm{p}=0.015)$. Array-based comparative genomic hybridization (array CGH) showed significantly more genome copy number gains/losses in p53mut vs. p53wt cases, and in ER-negative vs. ER-positive cases, but not in $\mathrm{Y}$ vs. O cases controlled for ER status. Altogether, these findings indicate that ER status rather than age-at-diagnosis associates with breast cancer p53mut frequency and genomic instability. In contrast, age-at-diagnosis may associate with the functional consequences of p53 DNA mutations since, when controlled for ER status, younger age appears associated with more severe changes in p53 primary structure.

\section{7}

The human p53 gene encodes nine p53 protein isoforms that can modulate p53 tumour suppressor activity.

Bourdon JCR, Murray-Zmijewski F, McDowell H, Thompson A, Lane DP. University of Dundee, Dundee, Scotland, United Kingdom The p53 gene is central to tumorigenesis and response to therapy in breast cancer. However, unlike most epithelial cancers, p53 mutation is much less common than expected in breast cancer. The recently discovered p53-related genes, p73 and p63, express multiple splice variants and amino-terminally truncated forms initiated from an alternative promoter in intron-3. To date, no such complexity has been described for the p53 gene. In this study, we show that human p53 gene expresses multiple splice variants and contains an internal promoter. Therefore, p53 gene has a similar gene organization than p63 and p73 and can encode for at least nine p53 protein isoforms.

The conservation of the internal promoter in the p53 gene from drosophila to man suggests an essential role for the p53 isoforms and reveals an unforeseen complex regulation conserved through evolution.

p53 isoforms are expressed in multiple normal human tissues. One isoform can act in a dominant-negative manner towards wild-type p53 for its function in transcription and apoptosis, revealing a new mechanism by which p53 can be inactivated. This mechanism would not be detected by the current sequencing and immunohistological methods used to determine p53 status of human cancers.

Some p53 isoforms are differentially expressed in breast cancer where they can act to modulate the p53 activity threshold and could therefore influence the susceptibility to cancer development and response to therapy.

\section{8}

mda-7: a remedy for oncogene addiction in breast cancer? Chada S, Mhashilkar A, Liu Y, Bocangel D, Zheng M, Ramesh R, Meyn R, Hunt K. Introgen Therapeutics Inc., Houston, TX; UTMD Anderson Cancer Center, Houston, TX

Background: The concept of oncogene addiction has been proposed as a mechanism for breast cancer growth and proliferation supporting the rationale for development of molecularly targeted therapies. It is clear that acquisition of genetic mutations results in dysregulation of oncogenic signaling pathways in tumor cells, and recent studies have indicated that persistence of these dysregulated oncogenes is essential for maintaining the tumorigenic phenotype. We evaluated the role of $m d a-7$ gene transfer in oncogene-addicted breast cancer cells. Current therapies used in the treatment of breast cancer are limited by systemic toxicity, by rapid drug metabolism and by intrinsic and acquired drug resistance. We have previously shown that transfer of the melanoma differentiation-associated gene-7 ( $m d a-7)$ elicits growth inhibition and apoptosis in various tumor types when delivered by adenoviral mediated gene transfer (Ad-mda7). In the current study, we evaluated the role of Ad-mda7 as a tool to inhibit the growth of oncogene addicted breast cancer cells. Methods: We evaluated the effects of Ad-mda7 alone and in combination with other therapeutics against a panel of nine breast cancer cell lines and their normal counterparts. These therapeutics exhibit diverse modes of action, including formation of bulky adducts, inhibition of DNA replication (Adriamycin, XRT), damage to microtubules (Taxotere), non-steroidal estrogen antagonists (Tamoxifen), or HER-2/neu receptor blockade (Herceptin). We analyzed growth inhibition, G2/M cell cycle arrest, and apoptosis induction by Admda7 and combination therapy. Results: In vitro, Ad-mda7 inhibited growth and induced cell cycle arrest and apoptosis in all breast tumor lines, but not in normal mammary epithelial cells. In vivo, Ad-mda7-induced p53-independent tumor growth inhibition in multiple breast cancer xenograft models $(p<0.004)$. We then evaluated the activity of Ad-mda7 in combination with other agents commonly used to treat breast cancer. Treated with Tamoxifen, Taxotere, Adriamycin or radiation, MDA-7-expressing cells displayed additive or synergistic cytotoxicity. Increased rates of apoptosis correlated with decreased BCL-2 expression and BAX up-regulation in breast cancer cell lines. In vivo, animals that received Ad-mda7 in combination with XRT had a significant reduction of tumor growth $(\mathrm{p}<0.002)$. Conclusions: This is the first report of the synergistic effects of Ad-mda7 combined with chemotherapy or radiotherapy on human breast carcinoma cells. These data suggest that mda-7 gene transfer can overcome the oncogene addiction observed in breast cancer. 
4059

Brg1, a chromatin remodeling gene, is suppressed in ERnegative breast cancer in human.

Pan M. Kaiser Permanente Medical Center, Santa Clara, CA

BACKGROUND: $B r g 1$ is an ATP-dependent chromatin remodeling gene of SWI/SNF complex, and is a candidate tumor suppressor gene. In $\mathrm{Brgl}^{+/-}$mouse heterozygotes, 15\% developed epithelial carcinomas. Mutations of $\mathrm{Brg} 1$ gene have been identified in multiple human cancer cell lines. Brg1 interacts with BRCA1 as well as Rb (retinoblastoma gene) protein in mammalian cells and a dominantnegative Brgl mutant abrogates p53-stimulated BRCA1 transcription, suggesting that $B r g l$ participates in tumor suppression pathways. This study aimed to investigate expression of $\mathrm{Brg} 1$ gene in human breast cancer.

METHODS AND MATERIALS: Paraffin blocks of 104 cases of invasive breast cancer were retrieved, sectioned and immunohistochemically stained with a polyclonal antibody against human $\mathrm{Brg} 1$ (J1). H\&E staining was performed as well on all cases. The level of Brg1 expression was determined as percentage of cells stained and intensity of staining (on a scale of 1 to 3 ). The histologic characteristics of cases were retrieved from computerized records.

RESULTS: Brg1 is expressed in the nucleus of normal human breast ductal epithelial cells with 80 to $100 \%$ cells stained with intensity of 2 to 3 , while normal myoepithelial cells did not show detectable staining. In 104 cases of invasive breast cancer studied, 80 were ER-positive, 24 were ER-negative, and 20 were HER2 over-expressed. In ER-positive cases, Brg1 staining was detected in a median of $95 \%$ of carcinoma cells with intensity of 2 to 3. In contrast, in ER-negative tumors, Brg1 staining was detected in a median of $60 \%$ of carcinoma cells with intensity of 1 to 2 . Among 22 cases that $\mathrm{Brg} 1$ expression was suppressed (detected in less than $50 \%$ of carcinoma cells), 10 were ER-negative ( $42 \%$ of all ER-negative cases), 12 were ER-positive (15\% of all ER-positive cases), which is statistically significant $(\mathrm{p}<0.01)$. Expression of $\operatorname{Brg} 1$ also appeared to be suppressed in poorly differentiated tumors with high proliferation rate. Of 22 cases with suppressed expression of Brg1, 7 were HER2/NEU over-expressed (or amplified). However, no statistically significant relationship with regard to HER2/NEU status was observed.

CONCLUSION: Expression of ATP-dependent chromatin remodeling gene $\mathrm{Brg} \mathrm{l}$ appears suppressed in ER-negative and poorly differentiated invasive breast cancer in human. This is consistent with the previous observation that $B r g l$ is candidate tumor suppressor gene and may be a useful marker in breast cancer in human.

\section{0}

Notch ligands and receptors are co-expressed at high levels in a subset of breast tumors with poor prognosis pathological features.

Reedijk M, Odorcic S, Chang L, Zhang H, Egan SE. The Hospital for Sick Children, Toronto, ON, Canada; Princess Margaret Hospital, The University Health Network, Toronto, ON, Canada

Background: Notch receptors are powerful regulators of cell fate specification, stem cell self-renewal, proliferation and apoptosis. Aberrant Notch activation has been implicated in the formation of a number of malignancies including T-cell acute lymphocytic leukemia. The mouse mammary tumor virus causes breast cancer in mice through activation of the Notch4 gene.

Materials and Methods: To test if Notch signaling plays a role in human breast cancer we used mRNA in situ hybridization to analyze expression of Notch receptors (Notch1, 2, 3, 4), ligands (Jagged1, Jagged2, Dl11, Dl13, Dl14) and Fringes (LFng, MFng, RFng) in this disease.

Results: We surveyed approximately 25 invasive carcinomas for most genes, as well as several carcinomas in situ (CIS). 5/25 tumors for which we have data on most receptors and ligands expressed high levels of one or more of Notch 1, 3 or 4 genes. In each case, the tumor also expressed high levels of one or more Notch ligand, and in three of these tumors the Radical Fringe gene was highly expressed. Interestingly, all of these tumors were high grade, estrogen receptor and progesterone receptor negative tumors that had spread to the ipsilateral axillary lymph nodes (node status was not determined in one of the five tumors), suggesting that high level co-expression of Notch receptor, ligands (and perhaps Fringes) is associated with poor prognosis pathological features in breast cancer. Furthermore, all tumors displaying high-level Notch ligand and receptor co-expression were of the basal (CK5/17 positive) subtype. In contrast to the selective high-level coexpression of Notch1, Notch3 or Notch4 with Notch ligand mRNA in a subset of tumors, Notch 2 was highly expressed in 19 of 22 tumors tested, and in most cases without co-expression of a Notch ligand gene. Finally, several Notch receptors and ligands were highly expressed in tumor-associated blood vessels.

Discussion: MMTV is known to cause breast cancer in mice through activation of Notch4. The findings in the current study highlight a potential role for activation of several different Notch receptors and ligands in a subset of aggressive human breast cancer.

\section{1}

Pattern of expression of genes linked to epigenetic silencing in human breast cancer.

Munot K, Bell SM, Horgan K, Lane S, Quirke P, Speirs V. Institute of Molecular Medicine Epidemiology and Cancer Research, University of Leeds, Leeds, W Yorks, United Kingdom

Epigenetic mechanisms such as DNA methylation are now recognised to play an important role in neoplasia. The aim of this study was to determine the pattern of expression of multiple key cancer genes that are known to undergo epigenetic inactivation by promoter hypermethylation in breast cancer. These included the tumour suppressor gene p16, estrogen receptor (ER) - $\alpha$, and $\beta$, progesterone receptor (PR) and the DNA repair genes hMLH1 and MGMT. Their expression was determined using immunohistochemistry in a panel of 200 breast cancers. The majority of breast cancers showed loss of expression of at least one gene $(n=157,78 \%)$, while $23 / 200(11.5 \%)$ showed loss of expression of at least 3 genes. More specifically, loss of expression of MGMT, ER $\alpha, E R \beta, P R$ and p16 was observed in $19 \%, 24 \%$, $13 \%, 40 \%$ and $50 \%$ of cases, respectively, while hMLH1 expression remained constitutive. A strong correlation was seen between highgrade tumours and loss of expression of ER $\alpha, \mathrm{ER} \beta$ and PR (all $P<$ $0.0001)$ and MGMT $(P=0.04)$, while loss of expression of p16 was associated with low/intermediate-grade tumours $(P<0.001)$. In addition, methylation-specific PCR was performed in a subset of 20 cancers to confirm the role of DNA methylation in the loss of expression of MGMT and a significant association was observed $(P<0.001)$. In conclusion we have observed methylation-linked silencing of several key breast cancer genes in a cohort of high grade breast tumours. These have potential as new targets for therapeutic strategies based on epigenetic intervention.

\section{2}

Genomic alterations in axillary lymph node metastases are associated with clinical outcomes in patients with breast cancer.

Becker TE, Ellsworth RE, Ellsworth DL, Deyarmin B, Hooke JA, Shriver CD. Walter Reed Army Medical Center, Washington, DC Windber Research Institute, Windber, PA

]BACKGROUND Metastatic breast carcinomas exhibit patterns of genomic alterations that differ from those in the primary tumors. Effectiveness of treatment regimens based on histologic or genetic features of primary tumors may thus be inadequate for treating metastatic disease, which may contribute to the poor clinical outcome of patients with metastatic breast cancer. We analyzed allelic imbalance (AI) in primary breast carcinomas and 
corresponding lymph node metastases to examine relationships between levels of genomic instability in primary and metastatic axillary lymph node tumors and clinical outcomes defined by recurrence and survival.

METHODS DNA was extracted from pure populations of tumor cells obtained by laser microdissection of primary breast and corresponding metastatic axillary lymph node tumors from 50 patients enrolled in the Clinical Breast Care Project. Referent DNA for each patient was obtained from blood or disease-free skin samples. A panel of 52 microsatellite markers from 26 chromosomal regions commonly altered in breast cancer was used to assess AI, which was determined by a peak height ratio of $\leq 0.35$ between tumor and referent alleles. Fisher's exact test (2-sided) and Student's t-tests were used to test for significant differences in levels of AI between patient groups defined by clinical outcome. Patient subsets included poor clinical outcome $(n=25)$ consisting of those who were alive with disease (AWD) from recurrence or dead of disease (DOD) and good clinical outcome $(n=25)$ consisting of those who had no evidence of disease (NED).

RESULTS Median follow-up for all patients is 29 months. Median time lapse from diagnosis to recurrence in the AWD subset is 17 months and median survival after diagnosis in the DOD subset is 27 months. Patients with poor clinical outcomes showed significantly more AI in their metastatic axillary lymph node tumors $(32 \%)$ than patients with good clinical outcomes $(20 \%$; $\mathrm{P}<0.001)$. Compared to patients with a good prognosis (NED), patients with a poor prognosis (AWD and DOD) showed significantly higher levels of AI in their metastatic tumors at chromosomal regions 10q23.31-q23.33 and 17p13.1 $(\mathrm{P}<0.001)$, which contain the tumor suppressor genes for PTEN and p53, respectively. Conversely, patterns of AI in primary breast tumors did not differ significantly between patients with poor versus good clinical outcomes.

CONCLUSIONS Genomic changes in metastatic breast carcinomas may have greater utility in identifying patients at risk for poor clinical outcomes than information derived from primary tumors. Molecular characterization of metastatic tumors may identify novel therapeutic targets for effective treatment of metastatic disease that are not revealed in the primary breast carcinomas.

\section{3}

Manipulation of expression of MMP-14 and its impact on the invasivess and progression of breast cancer cells.

Jiang WG, Davies G, Martin TA, Parr C, Mason MD, Mansel RE. School of Medicine, Wales College of Medicine, Cardiff University, Cardiff, Wales, United Kingdom

Introduction. MMP-14, otherwise known as MT1-MMP (membrane type-1 matrix metalloproteinase) is a proteolytic enzyme known to be involved in degradating extracellular matrix and assist progression of cancer invasion and progression. The current study investigated the impact of targeting the expression of MMP-14 in breast cancer and its clinical relevance.

Methods. Human breast cancer cell line MDA MB 231 was used in genetic manipulation studies. Expression of MMP-14 in the breast cancer cell line was targeted by way of retroviral ribozyme transgene. The in vitro invasion, growth and cell migration were determined on cell lines transfected with either the transgene or control plasmid. Protein and message levels of MMP14 in a cohort of human breast cancer were also assessed using immunohistochemistry and real time quantitative analysis, and correlated with clinical and pathological information of the patients

Results. Retroviral ribozyme transgene to human MMP-14 successfully knocked down the levels of MMP-14 mRNA from MDA MB 231 cells, which otherwise strongly expressed MMP14. Reduction of MMP-14 from the breast cancer cells had resulted in significant reduction of the in vitro invasiveness and loss of response to an invasion stimulus, HGF (hepatocyte growth factor), compared with transfection control and wild type cells. The invasion indices for MMP-14 knockdown cells were 13 \pm 3.1 (without HGF) and 16.4 \pm 2.3 (with HGF, p=0.14), and the indices for transfection control cells $25.3 \pm 4.3$ (without HGF) and $40.4 \pm 4.1$ with HGF, $p=0.0049$ ). Transfection with the transgenes did not change the rate of cell growth. In clinical breast cancer, MMP-14 staining was both membranous and cytoplasmic. Tumours cells displayed stronger staining compared with normal mammary epithelial cells. Tumour tissues had a marginal higher levels of the MMP14 transcript $(8.6 \pm 1.9)$, compared with normal tissues $(4.7 \pm 1.4), p=0.13$. No significant difference was observed between node positive and node negative tumours $(9.0 \pm 2.2$ vs $8.7 \pm 3.1$, $\mathrm{p}=0.24)$. Marginal higher levels of the MMP14 transcript were seen in tumours which developed metastasis and local recurrence. However, tumours from patients who died of breast cancer related causes had significantly higher levels of the transcript, compared with tumours from patients who remained disease free, 10 years after initial surgery $(12.2 \pm 2.5$ vs $6.3 \pm 1.2, \mathrm{p}=0.0091)$.

Conclusion. MMP-14 is a proteolytic enzyme that is pivotal in controlling the invasiveness of breast cancer cells. It is highly expressed in aggressive breast tumours and is associated with clinical outcome. The enzyme is a potential therapeutic target in breast cancer.

\section{4}

Osteopontin expression increases lymphatic metastasis of breast cancer: experimental and clinical studies.

Vantyghem SA, Allan AL, George R, Lee MW, Hodgson $N$, Engel CJ, Holliday R, Girvan D, Scott L, Al-Katib W, Stitt L, Yeatman TJ, Chambers AF, Tuck AB. London Regional Cancer Program, London, ON, Canada; London Health Sciences Centre, London, ON, Canada; H. Lee Moffitt Cancer Center and Research Institute University of South Florida, Tampa, FL

Background: Although a primary route of breast cancer metastasis is believed to be via lymphatics, the molecular factors involved are poorly understood.

Design: To identify candidate genes involved in lymphatic metastasis, we performed gene expression profiling of breast cancer cell lines of high (468LN) vs. low (MDA-MB-468) metastatic ability specifically to lymph nodes. One of the genes most highly overexpressed $(42 x)$ in the lymph node metastatic line was the secreted protein, osteopontin (OPN). The significance of this gene to lymphatic metastasis was assessed both experimentally, by transfection into weakly metastatic MDA-MB-468 cells, and clinically, by analysis of OPN expression (by immunohistochemistry) in a group of patients undergoing sentinel lymph node biopsy.

Results: High-level expression of OPN in 468LN cells was validated by Western blotting. Transfection of OPN into MDAMB-468 cells resulted in increased lymphatic invasion, regional lymph node metastases and micrometastases to lung after mammary fat pad injection in nude mice. In a group of 108 patients undergoing sentinel lymph node biopsy for breast cancer, OPN levels were significantly higher in the lymph node metastases of lymph node positive patients, than in the primary tumors $(\mathrm{p}<0.001)$.

Conclusion: OPN overexpression is a key molecular event involved in lymphatic metastasis of breast cancer. 


\section{S188 Abstracts - Poster Session IV}

\section{5}

\section{Withdrawn by Author}

\section{6}

Tumour-associated tenascin-C isoforms promote breast cancer cell invasion and proliferation.

Alcock RA, Holliday DL, Shaw JA, Walker RA, Pringle JH, Jones $J L$. University of Leicester, Leicester, United Kingdom; Institute of Cancer, Cancer Research UK Clincial Centre, Charterhouse Square, London, United Kingdom

Interactions with the extracellular matrix (ECM) control many aspects of cell function, therefore changes in tumour-associated ECM may be expected to influence tumour cell behaviour. One consistent change in breast cancer is the up-regulation of the extracellular matrix glycoprotein Tenascin-C (TN). TN exists as multiple isoforms generated through alternative splicing and invitro studies suggest that these isoforms have different effects on cell adhesion, migration and proliferation. We have identified a switch in isoform profile in malignant compared to normal and benign breast tissue, with expression of two isoforms, one containing exon 16 (TN16), the other containing exons 14 plus 16 (TN14/ 16 ), in addition to the normal adult truncated TN (tTN) in the majority of invasive carcinomas and a proportion of DCIS.

The aim of this study was to investigate the hypothesis that TN14 and TN14/16 promote breast cancer progression either via direct interactions with tumour cells or indirectly through modifying fibroblast function.

Flag-tagged clones of a series of TN isoforms were generated including adult tTN, TN16, TN14/16 and the unspliced, full-length LTN, and transiently expressed in breast cancer cells (MCF-7, T47D, MDA MB 468 and MDA MB 231) and in primary normal breast fibroblasts. The effect of over-expression of individual isoforms on tumour cell invasion and proliferation was analysed using transwell Matrigel invasion assays and incorporation of BrdU, respectively, and their ability to influence expression of members of the Matrix Metalloproteinase (MMP) family was analysed by RT-PCR, ELISA and zymography.

Over-expression of TN16 and TN14/16 in breast cancer cells led to significantly higher levels of tumour invasion compared to tTN, LTN, vector-only and non-transfected controls. A similar effect on tumour cell proliferation was also demonstrated. The ability of conditioned media (CM) from transfected and nontransfected normal breast fibroblasts to promote tumour cell invasion was also measured and demonstrated significantly higher invasion in the presence of CM from TN16 and TN14/16 transfected cells. In both tumour cells and fibroblasts, all TN isoforms were found to up-regulate MMP gene expression and MMP release, and invasion was inhibited in the presence of an MMP inhibitor.

In conclusion, TN16 and TN14/16 specifically enhance breast cancer cell invasion and proliferation which is in part MMPmediated, though other isoform-specific mechanisms are implicated. The largely tumour-specific nature of these isoforms make them potential therapeutic targets.

\section{7}

The CxCR4 mRNA and/or protein expression in breast cancer tissue does not always correlate with cancer metastasis.

Koyama Y, Valera V, Kaneko K, Kanbayashi C, Hatakeyama K. Niigata University Graduate School of Medical \& Dental Sciences, Niigata, Japan

Background: Cancer metastasis is a major prognostic factor for breast cancer patients. Recent findings suggest that the chemokine receptor CxCR4, expressed on breast cancer cells, may have an association with breast cancer metastases. The aim of the present study was to examine both CxCR4 mRNA and protein expression in the clinical specimens of primary breast cancer, and to explore whether CxCR4 expression in breast cancer correlate with cancer metastasis and other conventional clinicopathological parameters. Materials and methods: Fresh tissue samples were obtained from 55 breast cancer patients undergoing mastectomy or breast conserving surgery. Total RNAs were isolated from 55 surgical specimens of breast cancer tissue and 16 non-cancer breast tissue. The relative mRNA abundance of CxCR4 was measured by real time reverse transcription-PCR analysis based on TaqMan method, and the results were standardized with b-globin mRNA expression. The CxCR4 protein expression was examined by immunohistochemistry of paraffin-embedded sections of corresponding patients by using anti-human CxCR4 antibody (R\&D). The intensity of CxCR4 staining was classified into 3 categories; i) negative-, ii) weakly- and iii) strongly-staining. Statistical analyses were performed using Mann-Whitney test and Kruskal-Wallis test, and the statistical significance was defined as $\mathrm{p}<0.05$.

Results: CxCR4 mRNA expression was significantly higher in breast cancer tissues compared to non-cancer tissues $(\mathrm{p}<0.01)$. However neither mRNA nor protein expression of CxCR4 correlated with any clinicopathological factors such as lymph node status, lymphatic invasion, venous invasion, hormone status, distant metastasis or tumor stage. Furthermore, there was no correlation between CxCR4 protein and mRNA expression.

Conclusions: These results suggest that CxCR4mRNA expressions, significantly up-regulated in tumor specimens compared with noncancer breast tissue, might have an association with carcinogenesis in breast cancer. However, because the metastasis will be formed not only by chemokine receptor but also its ligand at site, it seems to be difficult to predict cancer metastasis only by examination of the expression of CxCR4 mRNA and/or protein.

\section{8}

Targeting Rho-C by way of ribozyme transgene in human breast cancer cells and its impact on cancer invasion.

Lane J, Martin TA, Jiang WG. Wales College of Medicine, Cardiff University, Cardiff, Wales, United Kingdom

Background: The Rho-GTPases have been shown to play a key role in transformation, transcription and cell motility. In particular, we have shown that expression of the family member Rho-C is significantly raised in breast tumour tissue with this increase being linked to axillary node involvement and poor prognosis. This study aimed to examine whether targeting Rho-C using retroviral ribozyme transgenes would have an impact on the invasiveness of breast cancer cells.

Material and Methods: A panel of hammerhead ribozymes that specifically targeted human RHO-C were generated using touchdown PCR. Transgenes were generated using these ribozymes and a tetracycline regulated retroviral vector. Breast cancer cell line, MDA-MB-231, was transduced with either retroviral Rho-C transgene, or control retroviral transgene. Stably transfected cells MDA-MB-231 $1^{\text {DRHO-C }}$, MDA-MB-231 $1^{\text {RevTRE }}$ were tested for their invasiveness and migratory properties in vitro using MDA-MB$231^{\mathrm{WT}}$ as control. Statistical analysis was carried out using MannWhitney $U$ test and significant difference was taken at $p<0.05$. Results: MDAMB 231 ${ }^{\mathrm{wT}}$ cells expressed high levels of Rho-C.Of the ribozyme transgenes constructed, all were active. The expression of Rho-C in MDA MB 231 cells was successfully eliminated by the retroviral hammerhead ribozyme transgene for Rho-C as revealed by RT-PCR. TransfectedMDA-MB-231 cells had significantly reduced invasiveness into Matrigel when compared with MDA-MB-231 $1^{\text {wT }}$ cells and MDA-MB-231 ${ }^{\text {pRevTRE }}$ (mean \pm SEM $13.4 \pm 1.68$ vs $26.2 \pm 6.16$ vs $25.2 \pm 4.25$ respectively, $\mathrm{p}<0.005)$. An even greater reduction in invasiveness was shown by MDA-MB-231 ${ }^{\text {DRHO-C }}$ cells in response to hepatocyte growth factor when compared with MDA-MB-231 ${ }^{\text {wT }}$ cells and MDA-MB$231^{\text {pRevTRE }}(11.8 \pm 2.16$ vs $56.75 \pm 8.75$ vs $40.0 \pm 4.08$ respectively, $\mathrm{p}<0.004)$. Transfection of MDA MB 231 cells with either 
ribozyme transgenes or control vectors did not affect the growth of the cells.

Conclusions: The expression ofRho-C, which is aberrantly expressed in breast tumours, was successfully knocked out in MDAMB-231 breast cancer cells by utilising hammerhead ribozyme transgenes. These transfectedMDA-MB-231 ${ }^{\text {DRHO-C }}$ cells showed a dramatic decrease in their in vitro invasiveness. This study suggests that targeting Rho- $\mathrm{C}$ may have important therapeutic implications in breast cancer.

\section{9}

The use of DNA microarray to determine potential pathways of tumor cell metastasis.

Moulder SL, Enkemann S, Dupont E, Riker A, Furman B, Carter WB, Hoover S, Cox C, Eschrich SA, Yeatman T, Diaz N. H.Lee Moffitt Cancer Center and Research Institute, Tampa, FL

Background: Metastatic disease and chemoresistance are the two principal causes of breast cancer mortality. This project was designed to examine functional genomic differences between matched primary and metastatic tumors that could possibly lead to novel therapeutic targets.

Methods: After obtaining informed consent, tissue was harvested from treatment naïve breast cancer patients undergoing biopsy or definitive surgical resection of an invasive breast primary tumor (PT) and ipsilateral axillary lymph nodes metastasis (LNM). Two to four core-shaped fragments of tissue from PT and LNM $>0.5$ $\mathrm{cm}$ were snap-frozen in liquid nitrogen. Frozen sections were used to confirm the presence of tumor then non-tumor tissue was grossly microdissected from the tumor block. Microarray analysis of PT and LNM was performed using standard techniques with the Affymetrix HG-U133 Plus 2.0 GeneChip ${ }^{\mathrm{TM}}$ array. Expression profiles from matched pairs of PT and LNM were compared using a matched pair analysis in the Affymetrix Microarray suite software as previously published. Genes of interest were selected if changes were present in at least 8 out of 10 lymph node/primary tumor pairs regardless of the magnitude of change in gene expression. Results: One hundred and twenty two genes were identified. Genes with $>3$ fold change in expression in $\geq 9$ matched pair samples are listed in table below.

Discussion: Genetic differences can be detected in tumor sample obtained from a breast primary and lymph node metastasis. Interesting observations include a decrease in MMP7 and an increase in complement component 7 in 10/10 samples analyzed. Although all visible lymphoid tissue was removed from the LNM, many genes with prominent changes were lymphatic in origin and likely represent the presence of lymphoid cells. These data are promising in that they validate the detection of changes not only in tumor cells, but in the microenvironment as well. Microarray analysis of lymphatic tissue microdissected from non-involved nodes is currently being performed to utilize a subtraction approach and remove lymphoid confounders.

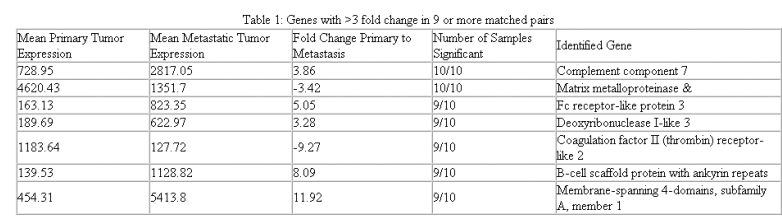

\section{0}

The role of angiotensin II in integrin mediated breast cancer cell metastasis.

Puddefoot JR, Udeozo U, Vinson GP. Quen Mary, University of London, London, United Kingdom

Background: Because breast cancer remains the most common cause of cancer death in women, there is a continuing need not only to further characterise the processes of cancer progression, but also to improve accuracy of prognostic markers. Breast epithelial cells express components of the renin angiotensin system (RAS) and studies suggest that these may be altered in disease progression. In addition altered integrin expression correlates with lymph node metastasis. The aim of this study was to investigate the relationship between Angiotensin II (Ang II) and integrins in breast tissue and, in particular, their role in breast cancer cell metastasis.

Materials and Methods: Cells were cultured in serum free medium in the presence or absence of Angiotensin II (AII). These cells were harvested and then used for cell adhesion to 96 well plates coated with extracellular matrix proteins collagen, fibronectin and laminin or invasion assays through membranes with an $8 \mathrm{uM}$ pore which have been coated with the same extracellular matrix proteins. In addition these cells were utilised to provide RNA for RTPCR analysis of integrin a3 and b1 or protein for western blot analysis.

Results: Using in vitro assays, AII $\left(10^{-6} \mathrm{M}\right)$ treated MCF-7 breast cancer cells both reduced adhesion to extracellular matrix proteins collagen, fibronectin and laminin coated wells $(\mathrm{p}<0.001)$. and reduced invasion through collagen, fibronectin and laminin coated membranes $(p<0.001)$. This action was inhibited by co-treatment with the angiotensin type 1 receptor (AT1R) antagonist DUP753 $\left(10^{-5} \mathrm{M}\right),(\mathrm{p}<0.001)$. The addition of the angiotensin type 2 receptor antagonist PD123319 $\left(10^{-5} \mathrm{M}\right)$ to AII treated cells had no significant effect. Addition of the tripeptide RGD $(150 \mathrm{mg}$ / well), which antagonises integrin binding, to matrix proteins also inhibited adhesion and invasion in the same manner as AII but the two effects were not additive. Semi-quantitative RT-PCR and western blotting revealed that cells treated with AII $\left(10^{-6} \mathrm{M}\right)$ expressed lower levels of both integrin a 3 and b1.

Discussion: These data suggest that AII reduces cell adhesion and invasion through the type 1 receptor and that this effect may be due to reduced expression of integrins, in particular a 3 and b1. These processes all appear to be mediated via the AT1 receptor. It is therefore possible that breast tumours become metastatic partly through changes in AII availability.

Regulation of AII expression and components of the local RAS may be important in disease progression and altered expression of these factors may convey information on prognosis of the disease.

\section{1}

Gene profile of fibroblasts from involved and uninvolved lymph nodes from breast cancer patients and influence of malignant cancer cells on their gene expression.

Santos RPC, Rozenchan PB, Katayama MLH, Brentani HP, Carraro DM, Patrao DFC, Mota LDC, Bastos EP, Lyra EC, Goes JCGS, Brentani MM, Koike Folgueira MAA. Faculdade de Medicina da Universidade de Sao Paulo, Sao Paulo, Brazil; Instituto Ludwig de Pesquisa Sobre o Cancer, Sao Paulo, Brazil; Instituto Brasileiro de Controle do Cancer, Sao Paulo, Brazil

Background: Some carcinoma cells may attach and grow in the lymph node of breast cancer (BC) patients, in contrast to others, that never establish regional metastases. Such behavior may depend on the epithelial cells themselves, as well as on microenvironment characteristics. Soluble factors produced by fibroblasts from lymph nodes may influence the epithelial cells, which, on the other hand, may exert similar effects on fibroblasts. Our aim was to characterize fibroblasts obtained from involved and uninvolved lymph nodes BC patients, to evaluate whether there were differences in their proliferation rate and gene expression. Another aim was to determine the influence from malignant (MDA MB-231) or non malignant (MCF10A) mammary epithelial cells in the gene expression of these fibroblasts.

Material and methods: Primary cultures of fibroblasts from lymph node samples ( 3 involved and 3 uninvolved) from 6 differents BC patients were established and the expression of vimentin and smooth muscle actin, confirmed the stromal origin of these cultured cells. Co-cultures of MCF10A and MDA MB 231 


\section{S190 Abstracts - Poster Session IV}

cells and fibroblasts from lymph nodes, physically separated by a porous membrane, which allow the passage of soluble factors, were carried out for $72 \mathrm{~h}$. Total RNAs from cells were isolated and two-round RNA amplification procedure using a template-switching primer was carried out. Gene profile of fibroblasts, upon co-culture or not, was analyzed on a c-DNA microarray glass slides containg 4,608 spotted sequences. Genes satisfying a $\mathrm{p}<0.01, \mathrm{FDR}<0.01$ and at least a two fold variation, were considered differentially expressed.

Results: There was no statistical difference in the proliferation rate from fibroblasts obtained from involved and from uninvolved lymph nodes and only $0.28 \%$ of the genes were differentially expressed between them. Fibroblasts co-cultured with mammary epithelial cells, had $2.2-7.8 \%$ trancripts modulated. Several genes expressed by the fibroblasts were commonly modulated by malignant as well as non-malignant mammary cells. Other genes were exclusively regulated upon co-culture with a specific cell lineage, and MDA MB-231 cells modulated 1\% genes expressed by fibroblasts from uninvolved nodes and other $1 \%$ genes of fibroblasts from involved lymph nodes.

Discussion: Fibroblasts obtained from involved or uninvolved lymph nodes from BC patients present a similar gene expression profile. Genes exclusively differentially expressed by fibroblasts of involved or uninvolved lymph nodes upon co-culture with transformed MDA-MB231 cells may be implicated in the development of regional metastases in breast cancer.

\section{2}

Enhanced growth of KGF-transfected human breast cancer cells in a mouse xenograft model.

Zang XP, Howard EW, Jupe ER, Manjeshwar S, Pento JT. University of Oklahoma HSC, Oklahoma City, OK

Background: Previously, we reported that keratinocyte growth factor (KGF) produced a rapid increase in the motility of ERpositive breast cancer cells. Others have demonstrated that KGF treatment in rodent species produces rapid mammary ductal hyperplasia. Epithelial cells do not produce KGF; thus, in the present study we stably transfected MCF-7 cells with a KGF expressing vector and compared the motility and morphology of transfected, non-transfected and empty vector cells. In addition, the growth of KGF-transfected human breast cancer cells was examined in a mouse xenograft model.

Methods: A KGF-cDNA vector was transfected into $\mathrm{MCF}-7 / \beta$ cells (MCF-7 cells stably transfected with $\beta$-gal) and two stable clones (T8 and T9) were identified. Western blotting and ELISA were used to confirm the expression of KGF in the transfected cells and the secretion of KGF into 24 hour conditioned media from these transfected clones. We compared the motility of parental and KGF-transfected MCF-7 cells using a cell culture-wounding model which examined cell migration over a period of 1-3 days. Viable MCF-7 cells $\left(5 \times 10^{6}\right)$ transfected with KGF vector or empty vector, were embedded into $0.2 \mathrm{ml}$ Matrigel and implanted into female nude mice at 6 weeks of age that had been pre-implanted with an estrogen pellet, and randomly placed into three groups. Animal weights and tumor volumes were measured twice weekly for four weeks and the animals were then euthanized and primary tumor, lung and liver tissue were removed and $\beta$-gal assayed to quantify MCF-7 cells

Results: Western blots demonstrated that the expression of KGF in both $\mathrm{T} 8$ and $\mathrm{T} 9$ cell lines and in conditioned media from these cells was higher than the parental and MCF-7/ $\beta$ (control) cell lines. The cell proliferation and migration distance was significantly greater for both KGF-transfected MCF-7 cell lines than the control cell lines. In addition, changes in motile morphology were observed in both the T8 and T9 cell lines when compared to the control cell lines. In the mouse xenografts, tumor size was 3-4 fold greater for the KGF-transfected MCF-7 cell lines than the EV-transfected cell line. Thus, autocrine production of KGF in the KGF-transfected MCF-7 cells enhanced cell migration and migration-related morphology in culture and enhanced the growth and metastasis of KGF-transfected human breast cancer cells in the xenograft model. Discussion: KGF-transfected MCF-7 cells displayed a much greater motility than non-transfected cells, confirming our previously observed enhancement of motility by KGF. Additionally, enhanced tumor growth and metastasis of KGF-transfected cancer cells was observed in a mouse xenograft model. This model will be useful for elucidating the mechanism of KGF-mediated cell motility and to identify potential therapeutic agents to prevent KGFmediated metastatic progression. Supported in part by grants from NCI (CA-89740), DOD (DAMD17-01-1-0591) and from the OU Cancer Center ACS Inst. Award.

\section{3}

Increased expression of CD44 in visceral metastases of breast cancer.

Cabioglu N, Sahin AA, Guray M, Islam $R$, Morandi P, MericBernstam F, Hortobagyi GN, Cristofanilli M. MD Anderson Cancer Center, Houston, TX

Background: CD44, a widely expressed extracellular matrix glycoprotein, plays a major role in cell-cell adhesion, lymphocyte homing, and tumor metastasis. Recent studies have shown that high expression of CD44 in certain types of tumors is associated with the hematogenic spread of cancer cells. We therefore evaluated the CD44 expression in matched primary and metastatic breast cancers, and associated tumor infiltrating lymphocytes (TIL) to determine whether this marker was preferentially expressed in any organ-specific metastases.

Methods: CD44 expression levels were evaluated using paraffinembedded tissue sections of matched primary and metastatic breast cancers by immunohistochemical staining. Sections were incubated with a primary antibody for CD44 (clone SFF-2, Chemicon International, Temecula, CA) following heat-induced antigen retrieval using a standard immunoperoxidase assay with diaminobenzidine chromogen. CD44 staining was evaluated in tumor cells and in tumor infilrating lymphocytes independently. In both tumor cells and lymphocytes, any disctinct cytoplasmic staining in more than $5 \%$ of the cells were considered to be positive. Missing cases were excluded from the statistical analysis for each parameter.

Results: Archival tissue material obtained from 33 tumors by either diagnostic biopsy or surgical resection of their metastatic site along with their corresponding primary tumors were evaluated. The metastatic sites included: bone $(n=11)$, brain $(n=14)$, lung $(n=5)$, and other visceral organs including liver/omentum $(n=3)$ CD44 was expressed in $21 \%$ of in primary tumors $(6 / 29)$, and in $40 \%$ of metastatic tumors (12/30). Expression of CD44 in primary tumors did not correlate with the occurrence of visceral or bone metastases $(5 / 19$ vs $1 / 10$, respectively; $p=0.633)$. However, CD44 was more likely expressed in visceral metastases, as detected in $61.5 \%$ of brain metastases $(8 / 13)$ and $80 \%$ of lung metastases and in none of the bone metastases $(60 \%$ of all visceral metastases vs $0 \%$ of bone metastases, $\mathrm{p}=0.002$ ). Presence of CD44-positive TIL was significantly associated with the expression of CD44 in both primary and metastatic tumors $(\mathrm{p}=0.008$ and $\mathrm{p}=0.004$, respectively). Furthermore, patients with HER2-neu positivity (3+ by immunohistochemistry) were more likely found to have CD44-positive metastatic tumors (HER2-neu-positive, 6/7 vs HER2-neu-negative, 6/21; $\mathrm{p}=0.023$ ).

Conclusions: These results indicate that CD44 was differentially expressed in metastatic sites suggesting that particularly CD44 can contribute to the homing of breast cancer cells to the visceral organs such as brain and lung. More studies are needed to validate the clinical implications of anti-CD44 targeted therapies in patients with visceral organ metastases. 


\section{4}

Women with breast cancer heterozyous for $\mathrm{CC}$ chemokine receptor5 $\Delta 32(\Delta 32 / \mathrm{WT})$ may have a greater tendency for metastatic pleural effusion than those with wild type CCR5 (WT/WT).

Kaplan MH, Dosik MH, Lu R, Wang XP. North Shore University Hospital, Manhasset, NY; Stony Brook University, Stony Brook, $N Y$

RANTES is the natural ligand for CCR5. It is expressed in breast cancer cells. Antagonists of RANTES inhibit breast cancer (BCa) tumor progression in the murine model. Polymorphisms in CCR5 notably CCR $5 \Delta 32$ occur in $5-15 \%$ of people. We evaluated patients(pt) with $\mathrm{BCa}$ plerual effusion (PE) to determine the incidence CCR $5 \Delta 32$ and to study the different expression of RANTES, MMP2,MMP9, IFN $i g$ and TNFa using real time PCR(RT-QPCR) in PE effusions and PE derived cell lines.

Method: Cells from BCa PE were harvested. RNA was extracted and tested for expression of RANTES MMP2, MMP9, TNFa and IFN $\gamma$ using RT-QPCR. DNA was extracted from either PBMCs or PE cells and tested for CCR5 and CCR5 32 using standard PCR technology

Results: In BCa pts. 11/97 (11/3\%)[PBMCs] in contrast to 5/ $13(38.5 \%)$ pts with BCa PE were heterozygous for CCR5 $\Delta 32$. RT-QPCR revealed that RANTES expression in $\triangle 32 / \mathrm{WT}(\mathrm{n}=3)$ vs WT/WT $(\mathrm{n}=5)$ was decreased $(0.23 \mathrm{vs} 1)$, while MMP2 and MMP9 expression was significantly increased in $\triangle 32 / \mathrm{WT}$ vs WT/ WT 4737:1; and 23:1 respectively. TNFa gene expression was decreased $0.67: 1$ in $\Delta 32 / \mathrm{WT}$ vs WT/WT while there was no detectable IFN $\gamma$ in all 8 tested samples and or in $\mathrm{K} 151(\Delta 32 / \mathrm{WT})$, K259(WT/WT) primary cell lines derived from PEs. K234( $\Delta 32 /$ WT) cell line showed some inducible IFN $\gamma$ expression. RANTES gene expression became down regulated when primary PE cells were induced to become breast cancer cel lines. Two cell lines from $\triangle 32 /$ WT PEs and one form WT/WT showed such downregulation of RANTES.

Conclusion: $\triangle 32 /$ WT PE cells and cell lines show reduced RANTES expression relative to WT/WT. MMP2 and MMP9 in contrast are overexpressed while $\Delta 32 / \mathrm{WT}$ underexpressed TNFa and showed no IFN $\gamma$ production. Patients with $\Delta 32 / \mathrm{WT}$ may also have a marked decrease in the natural receptor for RANTES notable CCR5. Thedifferent expression of these cytokines and chemokines and chemokine receptors may indicate a greater potential for metastases in $\Delta 32 / \mathrm{WT}$ patients.

\section{5}

Identification of estrogen regulated metastasis-associated genes using hormone-responsive bone metastases models. Simons LA, Thurn KE, Satcher RL, Levenson AS. Northwestern University Feinberg School of Medicine, Chicago, IL

Introduction: Bone is one of the most frequent sites for metastasis in breast cancer patients. Interestingly, it has been shown that patients with ER-positive tumors have had bone metastases three times more often than patients with ER-negative tumors. However, the role of estrogens (E2) in progression of breast cancer bone metastases is largely unknown partially because there are very few ER-positive in vitro and in vivo models of breast cancer bone metastases. Results: To study complex molecular mechanisms responsible for bone metastases we have established an in vitro hormone-responsive bone metastases model, which consists of ER $(\alpha$ or $\beta$ )-positive metastatic breast cancer cells and ER ( $\alpha$ or $\beta$ )-positive osteoblasts. Using bi-compartmental co-culture system we examined expression of E2-regulated metastasis-associated genes involved in "vicious cycle" in co-cultured breast cancer (MDA-ER $\alpha$ or MDA-ER $\beta$ ) and bone cells stably expressing ER (U2OS-ER $\alpha$ or U2OS-ER $\beta$ ). We found that E2 down-regulates uPA expression in both breast cancer and bone cells alone, however co-culturing increases expression of uPA by bone cells. In contrast, expression of IGFBPs $(1 \& 3)$ was increased in the presence of E2 in co-cultured cancer cells. More interestingly, the levels of IGFBPs were dramatically increased in co-cultured MDA-ER $\beta$ cells compared with co-cultured MDA-ER $\alpha$. These results suggest that increased levels of inhibitory IGFBPs might block the activity of IGFs, which have strong mitogenic and antiapoptotic effects on breast cancer cells. Together with down-regulation of uPA, which plays role in several aspects of bone resorption, including osteoclast formation, mineral dissolution and degradation of the organic matrix, these data imply possible favorable effects of E2 via ER $\alpha$ and in higher degree via ER $\beta$ in the pathogenesis of breast cancer bone metastases. In addition, experiments are in progress to determine the role of ER $\alpha / E R \beta$ in the development of osteoblastic/ osteolytic bone metastases using an in vivo mouse intracardiac model. For this, breast cancer cells expressing either ER $\alpha$ or ER $\beta$ were inoculated into the left ventricle of 4-6 week-old mice. Radiography, bone histology and histomorphometric analysis are in the process for the evaluation of the phenotype of the bone metastases. Conclusions: Our data demonstrate that the transcriptional effects of E2 via ER $\alpha$ and ER $\beta$ are distinct in cocultured breast cancer and bone cells indicating possible unique biological roles of each isotype in the development and progression of bone metastases. Identification of critical metastasis-associated genes and respective roles of ER $\alpha$ and ER $\beta$ in response to E2 will suggest possible new strategies of hormonal therapy in advanced metastatic disease. Supported by the Susan G. Komen Breast Cancer Foundation grant to ASL.

\section{6}

Expression of secretory leukocyte protease inhibitor in human breast carcinoma.

Yoshida S, Sugino T, Yasuda M, Hiroya S, Ohtake T, Takenoshita S, Suzuki T. Fukushima University School of Medicine, Fukushimashi, Fukushima-ken, Japan

Introduction: Secretory leukocyte protease inhibitor (SLPI), a molecule sized $12 \mathrm{kDa}$, is a member of serine protease inhibitor (SPI) family and important protective component of secretory fluids at sites of degenerative and inflammatory disease. SLPI is also expressed in various human cancers, like lung, breast, cervical, head and neck cancers. Recently SLPI expression level some cancers is reported to be correlated with tumor aggressiveness and metastasis. The aim of this study is to investigate the relationship between SLPI expression and clinicopathological factors of human breast cancers.

Materials and Methods: 46 patients of invasive ductal carcinoma and 25 cases of carcinoma in situ were retrieved from breast cancer list of Second Department of Surgery, Fukushima University School of Medicine, Fukushima, Japan. Immunohistochemistry with anti-SLPI antibody was performed for formalin fixed specimens of the patient carcinoma tissue. Intensively expressed cases compared with the normal grand are judged as positive.

Result: The age distribution of patients was 25 to 89 year-old (median 51.7 year-old). Follow up time ranged 0.03 to 12 years (median, 8.3). In invasive ductal carcinoma cases, 15 cases were recurrent, and 11 cases were dead on disease. SLPI positivity in carcinoma in situ (all of 25 cases, $100 \%$ ) was significantly higher than invasive ductal carcinoma ( 26 of 46 cases, $63 \%$, $\mathrm{p}=0.002$ ). In invasive ductal carcinomas, there were significant differences between SLPI expression and recurrence (23 of 31 cases without recurrence, $74 \%$ vs 6 of 15 cases with recurrence, $40 \%: p=0.025$ ) and overall survival (23 of 31 alive cases, $71 \%$ vs 4 of 11 cases dead on disease, $36 \%$ : $\mathrm{p}=.038$ ). SLPI expression had no significant correlation with the receptors for estrogen (28 of 35 positive cases, $71 \%$ vs 16 of 25 negative cases, $64 \%$ : $\mathrm{P}=0.167$, unknown in 11 cases), and progesterone ( 13 of 20 positive cases, $65 \%$ vs 31 of 40 of negative cases, $77 \%$ : $\mathrm{p}=0.302$, unknown in 11 cases) and, in invasive ductal carcinoma, lymph node metastasis (15 of 26 positive cases, $58 \%$ vs 13 of 19 cases, $68 \%$ : $\mathrm{p}=0.462$, unknown in one cases). 


\section{S192 Abstracts - Poster Session IV}

Conclusion: In contrast to other types of cancers, breast cancers showed reverse correlation of SLPI expression with cancer progression including invasiveness and prognosis. These results suggest that SLPI expression can be a favorable prognostic factor in breast cancers.

\section{7}

Epidermal growth factor induces the IGF signaling protein insulin receptor substrate-2 via the JNK/AP-1 pathway and NF-kB transcription factor in breast cancer cells. Cui X, Kim H, Kuiatse I, Lee AV. Baylor College of Medicine, Houston, TX

Both epidermal growth factor (EGF) and the insulin-like growth factors (IGFs) are critically involved in cell proliferation, survival, and malignant transformation. Aberrant activation of these two signaling pathways is commonly observed in solid human tumors. Understanding how they cross-talk with each other to regulate cancer development and progression is important for developing effective therapies against aggressive breast cancer, in which these two pathways frequently play a dominant role. In this study, we found that EGF remarkably induces expression of a major IGF signaling component, insulin receptor substrate-2 (IRS-2), in all EGFR positive breast cancer cells. This EGF effect, which can be blocked by common EGFR tyrosine kinase inhibitors, is via a transcriptional mechanism. Using small molecule signaling inhibitors, we found that JNK specifically mediated the EGF regulation of IRS-2. This is confirmed by ectopic expression of dominant active and constitutively active mutants of JNK and its upstream kinase MEKK1. In addition, blockade of AP-1 function suppressed the IRS-2 transcription induced by EGF, suggesting that the MEKK1/JNK/AP-1 pathway mediates the EGF effect. Surprisingly, we also found that inhibition of NF-kB transcription factor abolished the IRS-2 transcription by EGF. In line with the increase of total IRS-2 levels, EGF treatment prior to IGF-I stimulation resulted in higher tyrosine-phosphorylated IRS-2 levels, increased binding of IRS-2 to the PI3K regulatory subunit p85, and correspondingly enhanced ERK and Akt activation, as compared with IGF-I-only conditions. Moreover, EGF pretreatment enhanced the tyrosine phosphorylation of IRS-2 and its downstream signaling elicited by integrin engagement. Using IRS-2 siRNA, we found that repressing IRS-2 expression remarkably reduced the EGF-induced cell motility and invasion to the level under non-EGF conditions, suggesting that increased IRS-2 mediates the EGF effect on breast cancer cell migration. Taken together, our data suggest that EGF can interact with IGF signaling by upregulating IRS-2 through integration of JNK/AP-1 and NF-kB signaling. This modulation of IRS-2 reveals a novel level of crosstalk between EGF and the IGFs, and may provide implications in the efficacy of therapeutic targeting EGFR in breast tumors. As JNK/AP-1 and NF-kB are highly activated in aggressive breast cancer, our work may also provide support to establish IRS-2 as a useful marker for aggressive breast cancer.

\section{8}

Autophophorylation of the hepatocyte growth factor receptor, cMET in human breast cancer.

Jiang WG, Davies G, Watkins G, Mason MD, Mansel RE. School of Medicine, Wales College of Medicine, Cardiff University, Cardiff, Wales, United Kingdom

Introduction. Hepatocyte growth factor (HGF) is a cytokine that has direct effect on cancer cells and on endothelial cells, via its receptor, cMET. The action of $\mathrm{HGF}$ on these respective cells results in stimulation of invasion and progression of breast cancer cells and induction of angiogenesis in tumours. The HGF receptor has been reported to be highly expressed in cancer cells in a number of tumour types. The current study examined the coexpression of HGF and its receptor proteins, and most importantly the activation status of the HGF receptor, its autophosphorylation within mammary tissues.
Methods. Fresh frozen human mammary tissues were used in the current study. Consecutive frozen section from tissues were stained with ant-HGF antibody, anti-cMET and anti-Phospho-cMET antibodies. The staining patterns of the cytokine, it's its receptor and the activated receptor (phosphorylated on tyrosine residual) were assessed and analysed using computerised imaging analysis. Results. The HGF receptor, cMET, was strongly stained in both normal mammary epithelial cells and in breast cancer cells, together with vascular endothelial cells. Breast tumours cells had a higher level of staining of cMET $(0.105 \pm 0.03)$, compared with normal epithelial cells $(0.067 \pm 0.030, \mathrm{p}=0.014)$. In both normal and tumour cells, cMET was primarily membranous staining, but cytoplasmic staining was also seen. The most striking difference between normal and tumour tissues was the differential presence of autophosphorylated cMET in tissues. In normal tissues, there was virtually no to very low levels of autophosphorylated cMET protein detected $(0.023 \pm 0.017)$, despite high levels of cMET. However, significantly high levels of phosphorylated cMET were seen in tumour cells $(0.072 \pm 0.018, \mathrm{p}<0.0001$ vs normal epithelial cells). In addition, vascular endothelial cells in tumour tissues stained strongly for both cMET and phosphorylated cMET. Vessels in normal mammary tissues were otherwise shown to have only very weak staining of phosphorylated cMET. Normal mammary tissues stained very little HGF, which was largely confined to stromal fibroblasts. In contrast, cancer cells in mammary tissues, together with tumour associated stromal cells had marked stronger staining.

Conclusion. Auto-phosphorylation of the HGF receptor is frequently present in human breast cancer. This is likely the result of the ligand, HGF, expressed in both autocrine (in breast cancer cells) and paracrine (stromla fibroblasts) fashions. This has important implications in understanding the biology of the stromal-tumour interactions and the role of HGF in progression and angiogenesis in breast cancer.

\section{9}

Results of BCIRG 103: a presurgical study to evaluate molecular alterations that occur in human breast cancer tissue after short-term exposure to gefitinib.

Finn RS, Wilson CA, Dering J, Ginther C, Cook AM, Glaspy P, Venkatesen N, Raab G, Pawlicki M, Gerber B, Pinter T, Eiermann $W$, von Minckwitz G, Mackey J, Reese D, Kiger C, French T, Barrett I, Chang KM, South M, Slamon DJ. Geffen School of Medicine at UCLA, Los Angeles, CA; Frauenklink von Roten Kreuz, Munich, Germany; Maria Sklodowska-Curie Memorial Cancer Institute, Krakow, Poland; Frauenklink der LMU, Munich, Germany; Petz Aladar County Hospital, Gyor, Hungary; Frauenklinik von Roten Kreuz, Munich, Germany; JW Goethe-Universitats-Frauenklinik, Frankfurt, Germany; Cross Cancer Institute, Edmonton, Canada TORI, Los Angeles; CIRG, Edmonton, Canada; AstraZeneca, Manchester, United Kingdom

Gefitinib (IRESSA) is a small molecule inhibitor of the epidermal growth factor receptor tyrosine kinase (EGFR-TK), which has been approved for the treatment of advanced non-small cell lung cancer (NSCLC) in patients who have previously received chemotherapy. Recently, mutations in the EGFR-TK have been described that may predict for response to gefitinib in NSCLC. These mutations have not been identified in breast cancer to date. Numerous pre-clinical studies have suggested that gefitinib may play a role in the treatment of breast cancer. However, Phase II studies of single agent gefitinib have yet to show significant clinical benefit. To determine the potential role of gefitinib in human breast cancer we performed a comprehensive translational science program. We first determined gefitinib sensitivity in vitro in $>40$ human breast cancer cell lines. Basal expression profiles (Agilent microarrays) were generated for all of these cell lines and, at this time, potential predictive markers for response and resistance in a subset of cell lines have been identified. In addition, 16 cell lines have been treated with gefitinib, and pre-and post-treatment 
expression profiles obtained. In parallel, a presurgical clinical study (BCIRG 103) was conducted at multiple centers in the United States, Canada, Australia, and Europe. BCIRG 103 enrolled 59 women with primary breast cancer. Frozen tumor core biopsies were obtained at baseline and RNA was isolated. Patients then received gefitinib $250 \mathrm{mg}$ orally each day until definitive surgery (minimum 14 days). At the time of surgery, frozen tissue was obtained for RNA isolation. In addition, immunohistochemistry (IHC) was performed on the pre-and post-treatment samples, for downstream effectors of the EGFR pathway, Ki67, and ER/PR status. 43 matched pre-and post-treatment tumor samples were evaluable for microarray and IHC analysis. As in the in vitro studies, subsets of tumors that have gene expression changes in key growth regulatory pathways have been identified. Detailed data analysis is ongoing and will be presented at the meeting. IRESSA is a trademark of the AstraZeneca group of companies

\section{0}

Gefitinib has a low clinical benefit rate in advanced breast cancer patients.

Francis P, Green M, Gebski V, Harvey V, Karapetis C, Chan A, Snyder R, Forbes J. Australian New Zealand Breast Cancer Trials Group (ANZ BCTG), Newcastle, NSW, Australia

Background: In vitro studies in estrogen receptor (ER) positive breast cancer cells with acquired hormone resistance show a switch to epidermal growth factor receptor (EGFR) signalling pathways compared with the parental hormone sensitive cells. Breast cancer cells show an inverse correlation between ER and EGFR, thus ER negative breast cancers are more likely to express EGFR. Gefitinib is an orally active inhibitor of EGFR-tyrosine kinase.

Materials and Methods: This phase II trial of gefitinib ('Iressa') was designed to assess the efficacy and safety of single agent gefitinib $500 \mathrm{mg}$ once daily in two separate parallel groups of advanced breast cancer patients: (i) Hormone resistant: defined as hormone receptor positive disease progressing after both tamoxifen and an aromatase inhbitor and (ii) Hormone receptor negative breast cancer. It was planned to enrol 45 patients in each group. Eligibility required measurable disease and allowed only one prior chemotherapy regimen for advanced disease. The primary end point was the clinical benefit rate (Complete Response [CR] + Partial Response [PR] + Stable Disease at 24 weeks) in each patient group. Tumor samples from primary or relapsed disease were tested for EGFR expression using the DakoCytomation pharmDx kit to assess the potential correlation with disease control by gefitinib.

Results: Sixty-six patients entered the study with a mean age of 58 years. Among 40 patients with acquired hormone resistance, one patient $(2.5 \%, 95 \% \mathrm{CI} 0.1-13.2 \%)$ achieved SD with treatment for 28 weeks. Among 25 treated patients with hormone receptor negative disease, two patients $(8 \%, 95 \%$ CI0.9-26.1\%) achieved SD with treatment for 24 and 40 weeks. The patient treated for 24 weeks ceased gefitinib due to skin rash. At this dose of gefitinib, $85 \%$ patients experienced skin rash (>grade 1 in $43 \%$ ). No patient in either group achieved CR or PR. Most patients had progression at the first assessment at 8 weeks. In view of the absence of responses and low clinical benefit rate, the trial was prematurely closed to further enrolment. Tumor samples from 46 patients are undergoing central testing for EGFR expression.

Discussion: Previous preliminary reports (Proc ASCO 2003: abstracts \# 23 Robertson JF et al, \# 24 Baselga J et al) suggested some activity of gefitinib in advanced breast cancer. This study of gefitinib in advanced breast cancer patients who were not heavily pretreated, did not produce any responses and was associated with a low clinical benefit rate.

\section{1}

Mammary specific overexpression of insulin receptor substrate-1 (IRS-1) or IRS-2 in mice results in tumorgenesis and metastasis.

Dearth RK, Cui X, Kim HJ, Lazard Z, Lawrence N, Kuiatse I, Britton O, Mohsin S, Hadsell DL, Lee AV. Baylor College of Medicine, Houston, TX; Children's Nutrition Research Center, Houston, TX

Numerous cell culture, animal, and clinical studies support the importance of locally produced IGF-I acting in an autocrine/ paracrine manner to initiate/propagate breast cancer development and survival. Importantly, critical IGF-I/IGFR down stream signaling proteins, the insulin receptor substrates (IRSs) have recently been implicated in playing a role in breast cancer cell proliferation and metastasis. Both IRS-1 and IRS-2 are expressed in breast cancer cells and we have previously shown that over expression of IRS-1 reduces the survival rate in ER-positive breast cancer patients. However, little is known about disease-free IRS signaling proteins with regards to the role they may have in mammary tumorgenesis. Therefore, we assessed the ability of forced overexpression of IRS-1 or IRS- 2 to cause a disruption in the IRS signaling cascade resulting in mammary hyperplasia or tumorgenesis. To facilitate this study we developed novel transgenic mice that overexpress HA-tagged human IRS -1 or -2 specifically in the mammary gland using the mouse mammary tumor virus (MMTV) promoter. IRS-1 or -2 were specifically shown to be overexpressed in only the mammary gland by western blot and PCR analysis. Overexpression of IRS-1 or -2 had little affect on normal ductal development, pregnancy, or lactation. However, multi-parous female MMTV-IRS-1 and IRS-2 mice developed mammary tumors, mainly consisting of adenocarcinomas and adenosquamous carcinomas. Median time to tumor formation was $\sim 68$ weeks and $\sim 100$ weeks in MMTV-IRS-2 and MMTV-IRS-1 respectively. Virgin MMTV-IRS-2 female mice developed hyperplasia at 24 weeks of age which were pronounced at 52 weeks of age, but didn't begin to develop tumors until $72 \mathrm{wks}$ of age, a significant delay compared to the multi-parous female mice. Interestingly, MMTV-IRS-2 tumors metastasized to the lungs. MMTV-IRS-1 and IRS-2 tumors showed complex histology consisting of adenocarcinomas with alveolar differentiation and milk secretion, squamous metaplasia, and myoepithial differentiation. These histological features have recently been ascribed to tumors arising from alterations in the wnt $/ \beta$-catenin signaling pathway. Consistent with this, we found increased $\beta$ catenin levels in IRS-2 tumors compared to adjacent mammary glands. In addition, MMTV IRS-2 tumors had increased p-Akt and p-ERK. These results are the first to show that altered IRS production results in mammary tumorgenesis; thus implicating critical IGF-I down-stream IRS signaling proteins as major candidates in propagating breast cancer.

\section{2}

The ROCK Inhibitor Y-27632 supresses the effect of HGF in human breast cancer cells.

Lane J, Martin TA, Jiang WG. Wales College of Medicine, Cardiff University, Heath Park, Cardiff, United Kingdom

Background: Rho-associated serine-threonine protein kinases (ROCKs) are key factors in regulation of motility \& invasion of breast cancer cells. They function as downstream effectors of the Rho-GTPase signalling pathway \& are associated with tumour progression by regulation of actin cytoskeletal reorganisation \& formation of focal adhesions. Rho-GTPases are also involved in tight junction (TJ) regulation. This study investigated the effect of inhibiting ROCK function on distribution of TJ proteins in relation to motility \& invasion in invasive \& less invasive breast cancer cell lines.

Methods: MDA-MB-231 \& MCF-7 breast cancer cell lines were assessed. Functional assays were performed - invasion, Cytodex- 


\section{S194 Abstracts - Poster Session IV}

2-bead motility \& trans-epithelial resistance (TER) - using wild type cells. Cells were treated with HGF $(25 \mathrm{ng} / \mathrm{ml})$, ROCK inhibitor Y-27632 $\left(10^{-6} \mathrm{~mm}\right)$ or HGF\&Y-27632. MDA-MB-231 \& MCF-7 cells were treated with HGF or Y-27632 or both \& immunostained for either ZO-1, occludin or the linker molecule, ezrin. Results: As expected both cell types treated with HGF showed a significant increase in invasion compared with untreated cells $(\mathrm{p}<0.001)$. The addition of ROCK inhibitor to the assay caused a significant decrease in invasion $(\mathrm{p}<0.002)$. Cells treated with a combination of HGF/Y27632 also showed a significant decrease in invasivion compared with wild type \& with HGF treated cells $(\mathrm{p}<0.005)$. Motility of both cell types increased significantly with addition of HGF $(\mathrm{p}<0.001)$ as expected but the effect of HGF was negated on the addition of HGF/Y27632 with motility greatly reduced in these cells $(\mathrm{p}<0.002)$. MDA-MB-231 cells exhibited reduced TER when treated with $\mathrm{HGF}$, as expected. However, addition of ROCK inhibitor reduced this effect.

Immuno-fluorescent staining for the TJ proteins ZO-1 \& occludin together with ezrin showed an overall increase in staining with cells more tightly packed together when treated with Y-27632 \& with $\mathrm{HGH} / \mathrm{Y}-27632$ combination than untreated cells or cells treated with HGF alone. Staining of ZO-1 was more intense in MCF-7 than in MDA-MB-231 cells with edge staining of occludin and ezrin seen in the MCF-7 cell line. Membrane ruffling was observed in the MCF-7 HGF treated cells with lamellopodia formation \& separation of individual cells. Conversely, no membrane ruffling was seen in MCF-7 cells treated with the ROCK inhibitor or with HGF/Y27632 combination.

Conclusion: The effect of HGF on motility \& invasion of cells is well documented but this study shows the effect of the ROCK inhibitor Y-27632 on HGF activity within breast cancer cell lines. ROCK inhibitor decreased motility \& invasive action of HGF in both invasive MDA-MB-231 \& MCF-7 breast cancer cells. Staining of junctional \& cytoskeletal linker molecules showed a stronger concentration of occludin \& ezrin at TJ regions of the MCF-7 cells when the cells were treated with ROCK inhibitor and with HGF/Y-27632 combination, suggesting a role for ROCK in the signalling pathway for $\mathrm{TJ}$ regulation.

\section{3}

Human epidermal growth factor receptor 1 (EGFR) expression was not associated with gene amplification but intimately associated with HER2 gene amplification and protein expression in tissue microarray of clinical breast cancers.

Park K, Kim H, Lim S, Kwak K, Han S. Inje University Sanggye Paik Hospital, Seoul, Korea

Background: Introduction of anti-epidermal growth factor receptor 1 (EGFR) biologic therapeutics for numerous human malignant diseases mandates the appropriate understanding on the biologic properties of EGFR. We performed the current study to investigate the frequency and clinical implication of EGFR gene amplification and protein expression in breast cancer.

Methods: EGFR gene amplification was assayed by fluorescence in situ hybridization (FISH) and protein expression was assayed by immunohistochemistry (IHC) on tissue microarray (TMA) of 165 non-selected invasive breast cancer.

Results: The EGFR was expressed in 34 (20.6\%) of 165 studied invasive breast cancers, whereas EGFR gene was amplified in 13 $(7.9 \%)$ by FISH. The EGFR protein was expressed in $5(38.5 \%)$ of 13 EGFR amplified tumors, whereas it was expressed in $29(19.1 \%)$ of 152 EGFR non-amplified tumors. The EGFR protein expression was increased in EGFR amplified tumors but the difference was not statistically significant. EGFR protein was expressed in $33.3 \%$ of HER2 amplified tumors whereas it was expressed in only $16.3 \%$ of HER2 non-amplified tumors. EGFR expression was significantly increased in HER2 amplified breast cancer. The finding was similar when EGFR expression was analyzed according to HER2 protein expression. During the median follow-up period of 56 months (range: 13-80 months), 41 patients $(24.8 \%)$ had recurrent disease and 26 patients $(15.7 \%)$ died due to recurrent breast cancer. EGFR expression was a significant prognostic factor for the disease free and overall survival of the patients together with lymph node metastasis and Ki67 labeling index in univariate survival analysis but lymph node metastasis was an only significant prognostic factor in multivariate analysis.

Conclusions: EGFR expression was independent of EGFR gene amplification and was intimately associated with HER2 amplification and overexpression. Low frequency of EGFR gene amplification hampers its clinical utility as a tool to identify proper patient population for the specific treatment. In contrast, EGFR protein expression seems to have a role as a useful predictive factor if it is rationally integrated with other biologic predictive factors.

\section{4}

Combination approach using RAD001 plus or minus tamoxifen or letrozole. A preclinical model of the treatment of endocrine-resistant breast tumours.

Farmer I, Evans DB, Lane HA, Lykkesfeldt AE, Dowsett M, Martin L-A. Breakthrough Breast Cancer Research Centre, London, United Kingdom; Novartis Pharma AG, Basel, Switzerland; Institute of Cancer Biology, Danish Cancer Society, Copenhagen, Denmark

Background: Estrogens exert their effects by binding to the estrogen receptor (ER), which in turn interacts with estrogen response elements (ERE) on target genes controlling proliferation and cell survival. This knowledge has been exploited clinically by the development of endocrine agents that perturb the steroid hormone environment either by blocking E2 biosynthesis or competing with E2 for the ER. Despite the success of current endocrine agents the majority of women eventually relapse whilst maintaining functional steroid receptors. Cross-talk between receptor tyrosine kinase (RTK) and ER signaling pathways may contribute to endocrine-resistance by sensitizing breast tumour cells to estrogens or by circumventing the need for hormone. Based on this evidence, one strategy to improve the efficacy of current endocrine agents as well as delaying the onset of resistance is to target the ER and pertinent signal transduction pathways concomitantly. One obvious choice is mTOR which regulates cell cycle progression, by enhancing translation initiation and/or the stability of cell cycle regulatory proteins such as D-type cyclins In the following study we investigated the use of RAD001 (everolimus), a specific inhibitor of mTOR in combination with tamoxifen or letrozole on a panel of human breast cancer cell lines modelling endocrine-sensitive and -resistant disease.

Materials and Methods: Tamoxifen-resistant $\left(\operatorname{Tam}^{\mathrm{R}}\right)$ and longterm estrogen-deprived cells (LTED) were generated from the parental cell line MCF7. In essence Tam ${ }^{\mathrm{R}}$ cells were selected after long-term culture in $2 \%$ FBS containing $10^{-6} \mathrm{M}$ tamoxifen and were compared in all assays to their parental line cultured similarly but in the absence of tamoxifen (2\% FBS MCF7). The MCF7 Arom-1 cell line was engineered to constitutively express aromatase under control of the CMV promoter. The effect of RAD001 alone or in combination with tamoxifen or letrozole was assessed in proliferation and ER $\alpha$-mediated transcription assays. Inhibition of mTOR signalling in response to RAD001 was analysed by immunoblotting.

Results: The LTED and $\operatorname{Tam}^{\mathrm{R}}$ cell lines (both previously shown to have enhanced pMAPK and pAKT activity respectively) revealed enhanced expression of proteins downstream of mTOR compared to their parental cell lines. Treatment of the target cell lines shown in table 1, with increasing concentrations of RAD001 resulted in a dose-dependent decrease in both proliferation and $\mathrm{ER} \alpha$-mediated transcription together with a concomitant decrease in phosphorylated p70S6 and S6. The Tam ${ }^{\mathrm{R}}$ cells were exquisitely sensitive to the anti-proliferative effects of RAD001 but no additive effect was noted with the addition of tamoxifen as expected. However, treatment of the $2 \%$ FBS MCF7 cells with 
RAD001 in combination with $10^{-6} \mathrm{M}$ tamoxifen resulted in a c.10fold shift in sensitivity to RAD001. Similarly treatment of the Arom-1 cells with letrozole $\left(10^{-7} \mathrm{M}\right)$ in combination with a suboptimal dose of RAD001 resulted in a further $50 \%$ reduction in proliferation compared to letrozole alone. CELL LINE

wt-MCF7 (10\% FBS)

LTED

$2 \%$ FBS MCF7 $\left(\right.$ Tam $^{\mathrm{R}}$ parental cell line)

Tam

RAD001 IC50

c. $0.7 \mathrm{nM}$

$5.0 \mathrm{nM}$

$8.0 \mathrm{nM}$

$<0.1 \mathrm{nM}$

Arom-1 (in the presence of $5 \times 10^{-9} \mathrm{M}$ androstenedione) $0.2 \mathrm{nM}$

Discussion: These data provide evidence that combinations of RAD001 with tamoxifen or letrozole may provide enhanced antitumour activity in endocrine-resistant disease and may be applicable in the treatment of primary disease by delaying the onset of resistance.

\section{5}

The effect of silencing the insulin-like growth factor receptor on tamoxifen sensitive and tamoxifen resistant breast cancer cells.

McVittie CJ, Khalaf S, Ogunkolade BW, Bustin SA, Jenkins PJ, Carpenter R. St Bartholomew's Hospital, London, United Kingdom; Bart's and the London, London, United Kingdom

Background: The growth hormone/insulin-like growth factor I (GH/IGF-I) axis has been shown to be important in the pathogenesis of breast cancer and IGF-I is a known proliferative and antiapoptotic agent in breast cancer cells. Increased IGF-I signaling through the IGF-I receptor (IGF-IR), has been postulated to play a role in the development of tamoxifen resistance in breast cancers. Aims: To investigate the importance of IGF-I signaling in tamoxifen resistant (TR) and wild-type (WT) MCF-7 breast cancer cells by using small interfering RNA (siRNA) to cause transcriptional silencing of the IGF-IR and investigate the effect this has on cell proliferation.

Methods: WT MCF-7 breast cancer cells have previously been obtained from ATCC and we have developed a TR cell line from this parent cell line. WT and TR cells $\left(10^{4}\right.$ cells/well $)$ were cultured in serum-free medium alone (media only) or media + Oligofectamine (mock-transfected) or media + oligofectamine + 200nM siRNA specific to the IGF-IR (siRNA-transfected). Cell proliferation was assessed at 48 and 72 hours using the colorimetric MTS assay. IGF-IR silencing was confirmed by extracting RNA from the transfected cells and performing quantitative real time PCR to look at expression levels of IGF-IR mRNA at 72 hours after transfection. These experiments have been repeated in triplicate. Results: Cell number as percentage of media only in the WT and TR cells at 48 and 72 hours after mock or siRNA transfection (mean of 3 experiments $+/$ - SEM).

$\begin{array}{lllll} & \text { WT } & & \text { TR } & \\ 48 \mathrm{hrs} & \text { mock } & \text { siRNA } & \text { mock } & \text { siRNA } \\ 72 \mathrm{hrs} & 86.7+/-3.6 & 51.9+/-2.2 & 86.8+/-2.9 & 92.2+/-0.7 \\ \text { Wre } & 83.4+/-0.9 & 37.1+/-2.6 & 88.6+/-3.4 & 84.4+/-3.9\end{array}$

WT cells transfected with siRNA showed significantly decreased proliferation compared to siRNA-transfected TR cells $(\mathrm{P}<0.005)$. However no difference was seen in cell proliferation in the mocktransfected cells between the 2 cell lines.

IGF-IR mRNA copy number as percentage of media only IGF-IR copy number in the WT and TR cells at 72 hours after transfection (mean of 3 experiments $+/$ - SEM).

$$
\begin{array}{llll}
\text { WT } & & \text { TR } & \\
\text { Mock } & \text { siRNA } & \text { Mock } & \text { siRNA } \\
94.4+/-3.6 & 1.51+/-0.9 & 88.5+/-11.8 & 1.06+/-0.7 \\
\text { r } & &
\end{array}
$$

$\begin{array}{llllr}72 \mathrm{hrs} & 94.4+/-3.6 & 1.51+/-0.9 & 88.5+/-11.8 & 1.06+/-0.7\end{array}$ expression level in the siRNA transfected cells of both cell lines but no significant decrease of IGF-IR expression level in the mocktransfected cells.

Conclusions: The decreased proliferation of WT cells in response to siRNA against IGF-IR confirms the importance of IGF-I as a proliferative agent in breast cancer. The lack of similar response in the tamoxifen resistant cells suggests that disruption of the normal GH/IGF-I signaling pathway might be important in the development of tamoxifen resistance.

\section{6}

Does HER2 positive breast cancer have a prelediction to metastasise to the brain?

Paterson C, McIntyre A, Canney PA. Beatson Oncology Centre, Western Infirmary, Glasgow, United Kingdom

Background: There have now been several reports of an increased rate of central nervous system (CNS) relapse in patients with metastatic HER2 positive tumours treated with Trastuzemab. However in one report CNS metastases occurred as frequently in patients with HER2 positive tumours but who had not been exposed to Trastuzemab [1], suggesting that CNS disease in these patients may not just be an effect of better control of systemic metastatic disease leading to longer survival. To investigate this further we have examined the rate of HER2 positivity in a sequential cohort of patients treated for brain metastases from breast cancer.

Material and Methods: Between April 2003 and October 2004 a cohort of 60 patients with a diagnosis of breast cancer who were treated with palliative radiotherapy for brain metastases were identified from the radiotherapy bookings system. A further 9 patients were excluded due other primary tumours. HER2 and ER status were obtained from the patient's case records.

Results: $34 / 60(57 \%)$ patients had HER2 positive breast cancers and 26/60 (43\%) were HER2 negative. Of the patients with HER2 positive tumours $14(41 \%)$ had not received Trastuzemab before developing their brain metastases. $13 / 34$ patients $(38 \%)$ with HER2 positive brain metastases were also ER positive, and 10/26 of patients with HER2 negative tumours $(38 \%)$ were ER positive.

Discussion: The reported rate of HER2 positivity in the general population of breast cancer patients is between $20 \%-25 \%$, less than half the rate in this series of patients with brain metastases. In contrast the rate of ER positivity in this group of patients was lower than expected and not related to the HER2 status. These results suggest that the high rate of brain metastases in HER2 positive patients is an intrinsic feature of the disease not just an effect of better control of systemic metastases by Trastuzemab. 1. Lai et al. Cancer. 101(4):810-6, 2004.

\section{7}

Inhibition of PCDGF/GP88 expression by SiRNA restores tamoxifen responsiveness in tamoxifen resistant breast cancer cells.

Tian C, Serrero G. A\&G Pharmaceutical Inc., Columbia, MD

Tamoxifen therapy is widely used for the treatment of breast cancer. The inhibitory effect of tamoxifen is observed almost exclusively in breast tumors that are estrogen receptor positive $\left(E R^{+}\right)$, since estrogen is the major growth stimulator for these types of tumors. However, after prolonged anti-estrogen hormonal therapy, breast cancer often progresses from an estrogen sensitive to insensitive state. Constitutive overexpression of autocrine growth factor is one possible mechanism of tamoxifen resistance. PCDGF/GP88 (PC-Cell Derived Growth Factor, also known as progranulin) is an $88 \mathrm{kDa}$ autocrine growth factor, shown to play a critical role in breast tumorigenesis. GP88 is expressed in human $\mathrm{BC}$ tumors in a positive correlation with their tumorigenicity. In estrogen receptor positive $\left(\mathrm{ER}^{+}\right)$cells, GP88 expression is low and is stimulated by estradiol whereas in ER negative cells, it is constitutively overexpressed. Inhibition of GP88 expression by antisense transfection in ER negative breast carcinoma leads to inhibition of breast tumor incidence and growth in nude mice. In addition to stimulating proliferation, GP88 increased survival, inhibited apoptosis, stimulated migration, matrix metallo-protease activities and angiogenesis. Pathological studies have shown that GP88 is expressed in $80 \%$ of human invasive ductal carcinomas and correlates with expression of markers of poor prognosis whereas normal tissues and benign breast lesions are negative. We have shown that in $\mathrm{ER}^{+}$cells, GP88 mediates estrogen mitogenic activity. Increased GP88 expression rendered $\mathrm{ER}^{+} \mathrm{MCF}-7$ cells tamoxifen resistant while they remained estrogen receptor positive. 


\section{S196 Abstracts - Poster Session IV}

GP88 overexpressing cells were able to proliferate in the absence of estrogen and in the presence of tamoxifen, both in vitro and in vivo. More importantly, tumor growth of the overexpressing cells was significantly increased when the mice were treated with tamoxifen. Conversely, tamoxifen resistant variants of MCF-7 displayed a 10 to 20 -fold increase in GP88 level suggesting a strong correlation between tamoxifen resistance and GP88 expression in human breast cancer cells.

Based on this data, we investigated whether inhibition of GP88 expression by Si RNA in tamoxifen resistant breast cancer cells would restore cellular responsiveness to tamoxifen treatment. We show here that administration of GP88 SiRNA restored the ability of tamoxifen to inhibit cell proliferation in vitro and stimulate apoptosis in a dose dependent fashion. In contrast, treatment of the cells with unrelated Si RNA, used as negative control, had no effect. These data as well as in vivo mouse xenograft studies will be presented here. These results demonstrate the important role of GP88 expression in the development of tamoxifen resistant breast cancer and suggest that GP88 is a suitable molecular therapeutic target for endocrine therapy resistant breast cancer.

\section{8}

The intrinsic effects of IGFBP-3 on the survival of human breast epithelial cells involve the sphingolipid 'rheostat'. Perks CM, Holly JM, Carter JV, Winters ZE. University of Bristol, Bristol, South-West, United Kingdom

Background: We have shown previously that IGFBP-3 is a growth inhibitor for breast cancer cells and enhances their sensitivity to radio- and chemotherapy induced apoptosis, but has the opposite effects in normal breast epithelial cells. In addition, these effects of IGFBP-3 are reversed by activation of fibronectin receptors. The balance of sphingolipid metabolite second-messengers, ceramide (which can induce apoptosis) and sphingosine-1phosphate (S-1P) (which can promote survival), plays a critical role in controlling cell growth and apoptosis. These can be interconverted by the action of ceramide synthase(CS) and sphingosine kinase(SK), which therefore form a sphingolipid 'rheostat'.

Aims: We investigated whether the enzymes controlling this sphingolipid rheostat are involved in IGFBP-3 effects on breast cancer cell survival in normal MCF10A breast epithelial cells and in Hs578T breast cancer cells.

Methods: Cells were dosed with C2-ceramide $(14 \mathrm{mM})$ or antimycin A with or without IGFBP-3 $(100 \mathrm{ng} / \mathrm{ml})$ in the presence or absence of inhibitors of a) $\mathrm{SK}(\mathrm{DMS}, 0.5 \mathrm{mM})$ b) $\mathrm{CS}$ (fumonisin $\mathrm{B} 1, \mathrm{FUM}, 1 \mathrm{mM}$ ) and c) blocking antibody to ceramide (anti-CER). Cell death was assessed by Trypan blue cell counting and apoptosis confirmed using flow cytometry. Cell surface ceramide was detected using flow cytometry with an antibody to ceramide.

Results: In Hs578T cells, we found that inhibiting the production of S-1P with DMS accentuated the ability of $100 \mathrm{ng} / \mathrm{ml}$ IGFBP-3 to promote apoptosis (apoptosis:-IGFBP-3 without DMS $=137 \%$; with $\mathrm{DMS}=220 \%$ ). Conversely inhibiting the endogenous production of ceramide with FUM reversed the action of IGFBP3 , such that it then acted as a survival factor (apoptosis:-IGFBP3 without $\mathrm{FUM}=137 \%$; with $\mathrm{FUM}=68.4 \%$ ). With apoptosis induced by antimycin A, IGFBP-3 significantly $(\mathrm{p}<0.05)$ increased the level of ceramide on the cell surface, which was blocked in the presence of FUM. In addition, the ability of IGFBP-3 to enhance antimycin A-induced apoptosis was also switched in the presence of anti-CER, such that again IGFBP-3 acted as a survival factor (apoptosis:-IGFBP-3 without anti-CER $=172 \%$; with anti$\mathrm{CER}=62.3 \%$ ). Conversely, on fibronectin, the ability of IGFBP-3 to confer cell survival in the presence of DMS was switched, such that IGFBP-3 then accentuated apoptosis (apoptosis:-IGFBP-3 without DMS=74\%; with $\mathrm{DMS}=120 \%$ ).

Interestingly, in the normal MCF-10A cells, where IGFBP-3 acts as a survival factor against $\mathrm{C} 2$-ceramide $(\mathrm{p}<0.05)$, DMS was without effect.

Summary \& Conclusion: These data indicate that in cancer cells, the ability of IGFBP-3 to accentuate cell death is dependent upon endogenous production of ceramide, but limited by enhanced generation of S-1P, whereas on fibronectin the effects of IGFBP 3 are reversed. These results suggest that IGFBP-3 affects cell survival in cancer cells, but not in normal cells, by modulating the sphingolipid 'rheostat'.

\section{9}

EGFR is necessary but not sufficient for YB-1-mediated EGF independence.

Pang $B$, Wu R, Chen YQ, Berquin IM. Wake Forest University Health Sciences, Winston-Salem, NC

Background: Y-box binding-protein 1 (YB-1) is a multifunctional regulator of gene expression belonging to the cold-shock domain family of proteins. Increased expression and nuclear localization of YB-1 has been linked to poor patient outcome in breast cancer and several other cancer types. YB-1 overexpression in human mammary epithelial cells leads to epidermal growth factor independence (EGFi) and increased EGFR levels. Induction of EGFi may be relevant to the poor prognosis of breast cancer patients with increased YB-1 levels, but the mechanism is unclear. Materials and Methods: Chromatin immunoprecipitation (ChIP) was used to determine if YB-1 could bind to the EGFR gene in intact human mammary epithelial cells. Tetracycline-inducible EGFR-overexpressing cell clones were used to determine if EGFR overexpression was sufficient to activate receptor phosphorylation and EGFi.

Results: Using ChIP, we found that YB-1 bound to a downstream enhancer of the EGFR gene. Although tetracycline-induced EGFR overexpression was sufficient to trigger EGFR phosphorylation at several auto-phosphorylation sites, it was not sufficient for EGFi. However, EGFR kinase inhibitors prevented EGF-independent proliferation of YB-1-overexpressing cells.

Discussion: We confirmed that YB-1 binds to an enhancer region located within intron 1 . YB-1 has previously been shown to bind naked DNA from this region, but binding within the natural cromatin context in live human mammary epithelial cells had not been demonstrated. Our results suggest that YB-1 mediates EGFR transcription, which contributes to EGFR activation and EGFi. However, EGFR overexpression appears to be insufficient for EGFi. Therefore, additional targets of YB-1 may be involved in this phenotype.

\section{0}

Estrogen receptor alpha modulates TGF-beta signaling independent from its activation status.

Buck MB, Laukemann S, Peusser T, Knabbe C. Institute of Clinical Pharmacology, Stuttgart, Germany; Robert Bosch Hospital, Stuttgart, Germany

Background: Transforming Growth Factor beta (TGF $\beta$ ) is a hormonally regulated multifunctional growth factor in breast cancer. It is a potent growth inhibitor of breast cancer cells in early tumor stages, in later stages however it appears to exhibit pro-metastatic activity. Previous results of a clinical study from our group provide evidence, that loss of estrogen receptor (ER) expression is involved in the modification of TGF $\beta$ effects on tumor progression (Clin Cancer Res 2004, 10:491). The aim of this study was to further characterize the influcence of ER expression on TGF $\beta$ signal transduction.

Material and Methods: ER $\alpha$ was transiently transfected into MDA435 ER negative breast cancer cells. The TGF $\beta$ sensitive reporter plasmid p3TP-lux was used as an end point marker of TGF $\beta$ signal transduction. Re-expressed ER $\alpha$ was either fully activated by addition of estradiol or completely blocked by addition of the antiestrogen fulvestrant. Overexpression of Smad3, Smad4, c-jun or c-fos was used to further characterize the influence of specific pathways.

Results: Expression of ER $\alpha$ significantly attenuated TGF $\beta$ dependent induction of p3TP-lux. The effect was independent 
from ER $\alpha$ activation status. Expression of Smad3 and c-fos strongly enhanced basal and TGF $\beta$ induction of the reporter in absence of $\mathrm{ER} \alpha$. This effect was abrogated by co-expression of $\mathrm{ER} \alpha$, again independent from its activation status. Smad4 and c-jun had no effect.

Discussion: It has been suggested that Smad3 and MAPK signaling are required for pro-metastatic effects of TGF $\beta$ in late stage breast cancer. Our results show that enhanced TGF $\beta$ signaling induced by $\mathrm{Smad} 3$ and $\mathrm{c}-\mathrm{fos}$ is attenuated by $\mathrm{ER} \alpha$. ER $\alpha$ is known to bind AP1 (c-jun/c-fos) as well as Smads. As the effect of ER was independent from its activation status, direct binding of ER $\alpha$ to $c$-fos and Smad3 is a likely mechanism for the observed effects, preventing activation Smad or c-fos dependent TGF $\beta$ sensitive promotors. In conclusion, our results suggest that in breast cancer cells ER counteracts pro-metastatic effects of TGF $\beta$.

\section{1}

Long term culture of MCF-7 breast cancer cells with small interfering RNA to the insulin-like growth factor receptor causes decreased cell proliferation.

McVittie CJ, Khalaf S, Ogunkolade BW, Bustin SA, Jenkins PJ, Carpenter R. St Bartholomew's Hospital, London, United Kingdom; Barts and the London, London, United Kingdom

Introduction: The Growth hormone/Insulin-like growth factor I (GH/IGF-I) axis has been implicated in the pathogenesis of breast cancer and development of tamoxifen resistance. We have previously used small interfering RNA (siRNA) for short term silencing of the IGF-I receptor (IGF-IR) in MCF-7 breast cancer cells.

Aims: To investigate the use of siRNA to cause long term silencing of IGF-IR.

Methods: MCF-7 cells were cultured in phenol red-free medium (RPMI 1640) with $10 \%$ fetal calf serum (FCS). We used a specific siRNA duplex designed to target IGF-IR mRNA. MCF-7 cells $\left(10^{4}\right.$ cells/well) were washed and cultured in serum-free medium alone (un-transfected) or transfected with Oligofectamine alone (mocktransfected), or with Oligofectamine plus 200nM siRNA (siRNAtransfected). Every six days, cells were re-transfected with siRNA in the same manner. Every three days, cell proliferation was assessed using the colorimetric MTS assay, cells were lysed and RNA extracted for quantitative real time PCR for IGF-IR and c-myc mRNA. The expression level of c-myc mRNA was quantified to demonstrate that the siRNA was specific for IGF-IR.

Results: Mean cell proliferationas percentage of un-transfected (media only) cells. Mean of three experiments +/- SEM. 3 days 6 days 9 days 12 days 15 days $\begin{array}{llllll}\text { mock transfected } & 74.3+/-0.2 & 77.6+/-2.4 & 67.9+/-2.3 & 74.9+/-2.3 & 65.0+/-3.9\end{array}$


$* \mathrm{p}<0.0001$

There is a significant decrease in cell proliferation in the siRNA transfected cells compared to media only but no significan difference in cell proliferation in the mock-transfected cells cultured with transfection agent only.

Real-time RT-PCR confirmed that in the siRNA-transfected cells there was a significant decrease in IGF-IR mRNA levels compared to un-transfected cells, but no effect on c-myc mRNA levels. In the mock-transfected cells there was no significant difference in IGF-IR or c-myc mRNA expression levels compared to untransfected cells.

mRNA copy number expressed as a percentage of un-transfected cells +/- SD

$\begin{array}{llllll} & \text { Day } 3 & \text { Day } 6 & \text { Day } 9 & \text { Day } 12 & \text { Day } 15 \\ \text { mock IGF-IR } & 114.8+13.8 & 109.3+1-10.1 & 121.5+111.5 & 82.6+t-1.0 & 95.9+t-14.2\end{array}$

$\begin{array}{lllllll}\text { mock IGF-IR } & 114.8+/-13.8 & 109.3+/-10.1 & 121.5+/-11.5 & 82.6+/-1.0 & 95.9+/-14.2\end{array}$

$\begin{array}{llllll}\text { mock c-myc } & 90.7+/-22.6 & 83.9+/-5.7 & 121.9+/-22.2 & 88.6+/-11.2 & 86.7+/-9.4\end{array}$

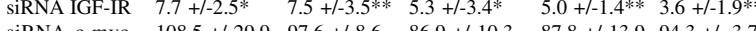

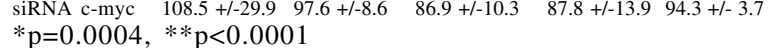

Conclusions: Repeated transfection of MCF-7 cells with IGF-IR siRNA every six days enables prolonged IGF-IR knock down and a sustained decrease in cell proliferation. This anti-proliferative effect of IGF-IR siRNA is confirmed by the decrease in IGF-IR mRNA expression in siRNA-transfected cells.

\section{2}

Blockade of p38 and JNK kinases inhibits the growth of normal and malignant breast cells.

Krisko T I, DuPre E N, Kim H, Brown P H. Baylor College of Medicine, Houston, TX

Purpose: Signal transduction networks, and particularly MAPK pathways, transduce signals from peptide and steroid hormones that control gene regulation and cell growth. Several kinases in these pathways have been found to be overexpressed or deregulated in cancer cells. Previous studies have shown that the MAPkinases ERK, p38, and JNK are highly expressed in aggressive, invasive breast cancers, and that increased levels of activated MAPKs are markers of poor prognosis. In this study we investigated whether blockade of these signaling kinases will decrease the growth of normal and malignant breast cells. Such studies will determine which of these signaling molecules are most appropriate as targets for the therapy of breast cancer.

Materials and Methods: Normal breast cells (HMEC) and malignant breast cancer cell lines (MDA-MB-468, MDA-MB$361)$ were treated with specific small-molecule inhibitors of either p38 (SB203580) or JNK (AZ11551384). The biochemical activity of the inhibitors was confirmed by western blot analysis using antibodies specific for the phosphorylated forms of substrates of these kinases (JNK: p-cJun; p38: p-MAPKAPK-2). The rate of growth of the cells was measured using a standard proliferation assay (MTS assay).

Results: Treatment with the p38 inhibitor $\left(10^{-5} \mathrm{M}\right)$ completely blocked p38 activity in all three cell lines, as demonstrated by western blot analysis measuring the phosphorylation of the p38 substrate MAPKAPK-2. Growth assays revealed that the p38 inhibitor caused a significant decrease of growth in both HMEC $\left(\mathrm{p}<0.0001, \mathrm{ED}_{50}=5 \times 10^{-6} \mathrm{M}\right)$ and MDA-MB-468 $(\mathrm{p}<0.0001$, $\mathrm{ED}_{50}=10^{-6} \mathrm{M}$ ) cell lines, as compared to vehicle treatment. However, MDA-MB-361 cells demonstrated no inhibition of growth $\left(\mathrm{ED}_{50}>10^{-5} \mathrm{M}\right)$. Treatment with the JNK inhibitor $\left(10^{-4} \mathrm{M}\right)$ demonstrated complete blockade of JNK activity in MDA-MB468 cells, and a partial blockade in both HMEC and MDA-MB361 cells as determined by measuring levels of p-cJun, a substrate of JNK, using western blot analysis. Growth assays revealed a statistically significant inhibition of cell growth in MDA-MB-468 $(\mathrm{p}=0.02)$, HMEC $(\mathrm{p}=0.02)$, and MDA-MB-361 $(\mathrm{p}<0.0002)$ cell lines, as compared to vehicle. The resulting $\mathrm{ED}_{50}$ for all three cell lines was $5 \times 10^{-5} \mathrm{M}$. We are currently investigating the effect of specific knockdown of JNK and p38 isoforms (JNK 1,2,3 and p38 $\alpha, \beta \gamma \delta)$ using siRNA.

Conclusion: These results suggest that small-molecule inhibitors successfully block p38 and JNK activity in both normal and malignant breast cells. In addition, this blockade leads to an inhibition of both normal and malignant breast cell proliferation. The greater sensitivity of MDA-MB-361 cells to the JNK inhibitor suggests dominance of the JNK pathway over the p38 pathway in this cell line. Taken together, these results provide the foundation for testing specific signal transduction inhibitors for the treatment of breast cancer.

\section{3}

Anti-idiotype antibody vaccine therapy for HER2/Neu overexpressing breast cancer.

Nahleh ZA, Mohanty K, Pal S, Mallick P, Saha A, Chatterjee SK, Jazieh A, Foon KA, Bhattacharya-Chatterjee M. University of Cincinnati, Cincinnati, OH; University of Pittsburg, Pittsburg, PA

Background: Amplification of HER2/neu is associated with poor prognosis in breast cancer. HER2/Neu proto-oncogene is a suitable target for cancer immunotherapy. However, HER2 /neu is a nonmutated self protein, and immune tolerance commonly develops. In our attempts to circumvent immune tolerance to HER2/neu, our goal is to apply an anti-idiotype (Id) based vaccine approach for the treatment of HER2/Neu positive breast cancer. Our strategy is active specific immunotherapy in which patients immunized 


\section{S198 Abstracts - Poster Session IV}

with an anti-Id antibody mimicking HER2/Neu will generate sustained high titer HER2/Neu specific antibodies.

Methods: We have developed and characterized one such anti-Id, designated 6D12(IgG1, k), which mimics a specific epitope of HER2/Neu and can be used as a surrogate antigen for HER2/Neu. The anti-Id 6D12 (Ab2) was raised by immunization against the anti HER2/Neu murine monoclonal antibody 4D5 (Ab1). Immunization of allogeneic C57BL/6 mice and rabbits with 6D12 induced anti-HER2/Neu specific antibodies that reacted with antigen positive SKBR3 cells by ELISA and FACS analysis. The immune sera inhibited binding between $\mathrm{Ab} 1$ and $\mathrm{Ab} 2$ and vice versa (binding of $\mathrm{Ab} 2$ to $\mathrm{Ab} 1)$ indicating that it was a true anti-anti-Id (Ab3) antibody. The Ab3 sera, or purified Ab3, demonstrated strong reactivity with EL4 cells transfected with HER2/Neu gene, but no reactivity at all with parental EL4 cells by FACS analysis showing specificity of the binding. In in vitro culture, immune sera killed HER2/Neu positive tumor cells by antibody dependent cellular cytotoxicity (ADCC). Mice immunized with 6D12 were protected against a challenge with lethal doses of EL4-HER, whereas no protection was observed when $6 \mathrm{D} 12$ vaccinated mice were challenged with HER2 negative EL4 cells ; also no protection was observed when mice were vaccinated with an unrelated anti-Id antibody and challenged with EL4-HERcells.

Conclusion: These data suggest that the anti-Id 6D12 vaccine can induce protective HER2/Neu specific antitumor immunity in mice and would be potentially useful for the treatment of patients with HER2/Neu positive tumors. A phase I clinical trial in breast cancer patients is being planned. Supported by the NIH Grant 1RO1 CA 91878.

\section{4}

Enhanced HER2/neu specific T-cell immunity in vitro by HER2/neu Ii-key modified "agonist" class II peptides in breast cancer patients.

Murray JL, Kawano K, Efferson C, Babiera G, Meric-Bernstam $F$, Ibrahim N, Kallinteris NL, Humphreys RE, Von Hofe E. M.D. Anderson Cancer Center, Houston, TX; Antigen Express, Inc., Worchester, MA

Research objectives:

The purpose of this laboratory research study was to determine whether novel "hybrid" Ii-Key HER2/neu specific MHC class II peptides were capable of generating greater T-cell immunity compared to unmodified peptides when tested in vitro using peripheral blood mononuclear cells (PBMC) from breast cancer (BC) patients.

Results :

PBMC from 13 BC patients (4 HER2+, 9 HER2-) and 6 normal donors were incubated with individual Ii-Key peptides (AE37,38,39,47,48) or unmodified peptides G89 and AE36. IiKey peptides differed from unmodified peptides in that they contained a specific amino acid sequence [LMRK("Ii-key")] coupled to the N-terminus of each class II epitope to allow for prolonged contact and "charging" of the MHC class II molecule. Following 6 days of incubation gamma interferon (IFN $\gamma$ ) secretion in $\mathrm{pg} / \mathrm{ml}$ and the number of IFN $\gamma$ producing lymphocytes was measured using ELISA and ELISPOT, respectively. Results were expressed as a stimulation index (S.I.) calculated as: $\mathrm{pg} / \mathrm{ml}$ IFN $\gamma$ or spot number IFN $\gamma$ producing cells from PBMC incubated with peptide(s) $\div$ IFN $\gamma$ produced by PBMC incubated without peptide. S.I. $\geq 2$ were considered significant.

Greater IFN $\gamma$ production as assessed by both ELISA and ELISPOT respectively, occurred following 96 hours of incubation compared to 48 or 72 hours. The frequency of positive responses (S.I. $\geq 2$ ) was greatest for Ii-Key peptides AE37, 39 and 47, was significantly greater for HER2+ patients compared to HER2- patients $(\mathrm{p}<0.04)$, and was significantly greater for Ii-Key peptide AE37 (78\%) compared to all other peptides combined $(24 \%$; $<<0.0001)$. Median S.I. was also significantly greater for AE37 (3.0) compared to combined median for other peptides $(1.2 ; \mathrm{p}<0.04)$. A combination of either Ii-Key peptide AE37 or AE47 and class I HER2 peptide, E75, induced greater numbers of CD8+ E75+ effector T-cells than each individual peptide alone. The absolute number of CD8+ Tcells induced was inversely associated with the number of CD4+CD25+ regulatory T-cells. These data may have relevance with respect to the design of more immunogenic peptide vaccines and suggest that certain epitopes may have agonist or inhibitory effects depending on the ratio of CD8+ effector/ CD4+CD25+ regulatory $\mathrm{T}$-cell subsets.

\section{5}

\section{CpG DNA augments dendritic cell-based therapy of breast} cancer.

Baar J, Cai O, Kublo L. University of Pittsburgh Cancer Institute, Pittsburgh, $P A$

Dendritic cells (DC) are potent antigen-presenting cells whose cytotoxic T-cell priming function is enhanced by CpG DNA. To establish a rationale for breast cancer therapy using tumor lysateloaded DCs with CpG DNA, 4 groups of 5 BALB/c mice were inoculated in their right flanks with $5 \times 10^{4}$ syngeneic TS/A mammary tumor cells, which were allowed to grow until they were palpable $\left(\sim 1 \mathrm{~mm}^{2}\right)$. Mice were then vaccinated subcutaneously twice, 7 days apart, in their left flanks with either (a) PBS, (b) TS/A lysateloaded DCs alone, (c) CpG DNA alone, or (d) DCs + CpG DNA. The combination of DCs + CpG DNA was more effective in mediating the regression of the established TS/A tumor than either PBS, DCs, or CpG DNA alone. Also, surviving mice successfully withstood a rechallenge with fresh TS/A tumor cells, indicating the generation of antitumor immune memory. We also show that the intratumoral injection of DCs + CpG DNA is better than DCs alone in slowing the outgrowth of an established TS/A tumor in $\mathrm{BALB} / \mathrm{c}$ mice. Based on these results, there is a compelling rationale for DC-based therapy of breast cancer using CpG DNA to augment DC function.

\section{6}

Cellular immunotherapy in late stage breast cancer patients with reactivated autologous memory T-cells derived from bone marrow.

Schuetz F, Ehlert K, Schneeweiss A, Schirrmacher V, Diel IJ, Sohn $C$, Beckhove P. University of Heidelberg, Medical School, Heidelberg, Germany; German Cancer Research Center Heidelberg, Germany

Tumorspecific Memory T-cells (MTC) can be found in the bone marrow (BM) in the majority of primary and metastatic breast cancer (BC) patients by using ELISpot-analysis. Upon specific restimulation with tumourantigen-pulsed dendritic cells (DC) those autologous T-cells exert specific effector functions like IFN-gamma or perforin production and specific cytotoxicity. Furthermore we have shown in NOD/Scid-mice that reactivated MTC are able to infiltrate autologous and heterologous tumor tissue, proliferate and kill tumor cells by induction of apoptosis, leading to a marked or complete tumor rejection within 21 days after transfer (Nature Med, 2001). Endocrine and cytostatic cancer therapies only have a limited influence on the frequency of tumorspecific MTC in BM of BC patients. In a phase-I trial 11 patients with metastatic BC (inclusion criteria) were treated with autologous reactivated MTC of BM. Primary objective were feasbility, and toxicity, secondary were clinical response, and immunomonitoring. After testing patient's BM for presence of tumorspecific MTC those cells were reactivated by incubating them in vitro with autologous DC pulsed MCF-7 lysate for 12 days. Reactivated T-cells and pulsed DCs were injected once intravenously. Follow Ups were done after 7, $14,21,28$, and 120 days. Study design was feasible in every way. There were no side effects found during and after T-cell injection. There was a partial response in 3 of 5 measurable patients. In 5 Patients - who received a maximum of reactivated T-cells- we were still able to find these cells 7 days after vaccination. We 
conclude that cellular immunotherapy with autologous reactivated MTC is an new way of BC treatment. We thus prepare a phase-II trial in metastatic and primary $\mathrm{BC}$ patients.

\section{7}

Whole cell autologous/allogeneic vaccine induces an immune response to specific antigens in breast cancer patients.

Head JF, Fort KA, Hsu K, Elliott RL. Mastology Research Institute, Elliott-Elliott-Head Breast Cancer Research and Treatment Center, Baton Rouge, LA

Introduction: Immune responses to tumor-associated antigens have been correlated with longer diseases-free and overall survival in breast cancer patients. The purpose of this study was to boost immune response to tumor-associated antigens and other specific cancer antigens with a mixed autologous/allogeneic breast cancer vaccine in patients that were found to be immune depressed. Methods: Immune responses for 41 patients were measured with a lymphocyte blastogenesis assay (LBA) before and after the vaccination series. The components of the vaccine are as follows: patients' own breast tumor cells $\left(10^{6}\right.$ cells when available $)$ allogeneic cell line (10 $\mathrm{MCF}-7$ cells), CA 15-3 (1,000 IU), CA 125 (1,000 IU), CEA (2ug), PSA (50ug), IL-2 (2x10 $10^{4}$ IU), GMCSF $(16.7 \mathrm{ug})$. The standard vaccine series was a subcuticular injection on weeks $0,1,2,6,10,14$ in alternating femoral triangles. A significant response was defined as an LBA response ratio of $>1.5$.

Results: The average response for all the antigens after the vaccination series was $38 \%$. Specifically, $56.2 \%$ of the patients responded to their own tumor cells, $31.7 \%$ responded to the allogeneic cell line, $43.6 \%$ responded to CA $15-3,35.1 \%$ to CEA and $35.9 \%$ to CA 125 . Also, $31.7 \%$ of the patients responded to antigen, $14.6 \%$ to 2 antigens, $19.5 \%$ to 3 antigens, $7.3 \%$ to 4 antigens, $2.4 \%$ to 5 antigens, and only $24.4 \%$ of the patients responded to 0 antigens.

Discussion: The breast cancer vaccine was most successful at boosting the patients' response to their own tumor cells, suggesting that the autologous cells are the most antigenic. CA 15-3 was the most antigenic protein antigen. There was no general antigen response pattern for the patients, indicating that response to one antigen is independent of response to another antigen. Continued follow-up will be needed to determine the effect of the vaccine on the survival of these patients.

\section{8}

Evaluation of foxp3 expression in sentinel nodes in breast cancer patients.

Matsuura K, Yamaguchi Y, Osaki A, Ueno H, Ohara M, Arihiro K. Research Institute for Radiation Biology and Medicine, Hiroshima University, Hiroshima, Japan; Hiroshima University, Hiroshima, Japan

Background: Detection of sentinel nodes (SNs) and their clinical significance have been established. Recent advances in molecular immunology have enabled us to analyze precise immune responses. In the present study, we attempted to clarify regulatory $\mathrm{T}$ (T-reg)cell responses in $\mathrm{SNs}$ in patients with breast cancer.

Method: SNs and non-SNs were identified by a radio-guided method and a blue dye-guided method in 88 consecutive patients with clinically N0 breast cancer. The SNs and non-SNs were immediately cut into two pieces, one half of which were subjected to histological analysis, while the other half were frozen for mRNA analysis. Total RNA was extracted from SNs and non-SNs, and the expression of foxp3, which is the master regulatory gene for developmental differentiation of Treg, was evaluated using quantitative real-time RT-PCR. Moreover, the immunological status of the SNs was further analyzed with regard to micrometastasis, which was identified as microscopically negative but positive by RT-PCR specific for mammaglobin.
Results: Out of 88 patients, $28(31.8 \%)$ had positive metastasis in SNs (pNO(mol+): 11, pN1: 14, pN2: 3). Among 60 metastasisnegative patients, RT-PCR analysis revealed that no significant differences were indicated in the expression level of Foxp3 mRNA when compared between SNs and non-SNs. Next, the immunological parameters were compared between 60 metastasis-negative and 28 metastasis-positive SNs. The metastasis-positive SNs showed significantly higher expression of Foxp3 mRNA than the metastasis-negative SNs(p=0.0008). Moreover, the expression level of Foxp3 mRNA was significantly higher in SNs than in non$\mathrm{SNs}(\mathrm{p}=0.0367)$, when compared between SNs and non-SNs in 28 metastasis-positive patients.

Conclusion: The regulatory $\mathrm{T}$ cell responses are triggered and may suppress anti-tumor immune responses in SNs, once the metastasis is occurred in SNs in patients with breast cancer.

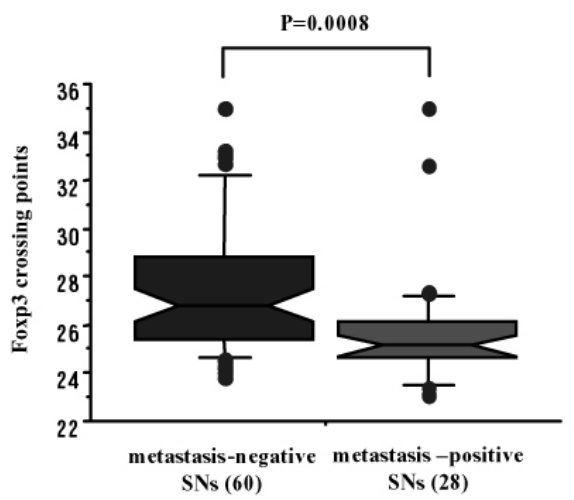

\section{9}

Synthetic peptide vaccine candidates and their matching profile with the proteome.

Mittelman A, Ashok BT, Kanduc D, Tiwari RK. New York Medical College, Valhalla, NY; University of Bari, Bari, Italy

HER-2/neu is an overexpressed oncoprotein that is a target of immunotherapy in breast cancer. Since multiple antigenic epitopes to a single protein can be generated and the patients' response to these antigens is also not against a single epitope, it is imperative to generate synthetic peptides that can be used in combination as multivalent immunogens. To this end, some current approaches that may yield dividends are (i) reverse immunology which involves screening of immunogenic epitopes in a protein that is least represented in the proteome (ii) clinical screening of large number of peptides that are both B and T cell activators. We have identified eight different peptides from a synthetic phage display peptide library, LX-8 consisting of 12-mer peptides by panning the library against an antibody (c-erbB-2 Ab-2; Clone 9G6.10) that recognizes the extra-cellular domain of the HER-2/neu protein. Three different peptides were injected in mice that resulted in peptide specific immune response with only a minimal degree of crossreactivity. We used the sequences to search the human and mouse proteome data bases for matches. The immunogenicity potency of the peptides was calculated and the peptides could be categorized in descending order of potency. The peptide sequences were reduced to five-mer sequences and number of matches to human and mouse proteome determined using combinations of several data base searches. We also calculated the MHC peptide matches using the epitope prediction program SYFPEITHI and determined the peptide ligation strength to different MHC alleles. Our methodology may be able to predict the most optimized immunogenic peptides that will help in analyzing the data obtained by either protein sequence analyses or peptide library searches for multivalent peptide antigens against clinically relevant proteins. 
4100

An important role for AIB1 phosphorylation in mediating growth factor signaling dependent estrogen agonist activity of tamoxifen in breast cancer cells.

Shou J, Choudhury P, Chamness G, Osborne K, Schiff R. Baylor College of Medicine, Houston, TX

The nuclear receptor coactivator AIB1 is the most important member of the p160 protein family for breast cancer development and progression. Overexpression of AIB1 reduces tamoxifen's antagonistic activity in cultured breast cancer cells, and breast tumors in patients overexpressing both AIB 1 and HER2/neu (HER2) are more resistant to tamoxifen than tumors with only one of these factors elevated. Therefore we hypothesized that signaling from high HER2 leads to phosphorylation and activation of AIB1, which may then contribute to development of tamoxifen resistance by increasing its antagonist activity on estrogen receptor (ER) and stimulating tumor growth. In this study, using ERdependent transcription assays with ERE-luciferase constructs, we found that AIB1 significantly increased tamoxifen's agonist activity in HER2-overexpressing MCF7/HER2-18 breast cancer cells compared to parental MCF-7 cells. Downregulating AIB1 with specific siRNA markedly reduced tamoxifen's agonist activity in this assay. Analyzing the AIB1 sequence, we identified several potential phosphorylation sites including a specific serine located between the nuclear receptor and the CBP interaction domains of AIB1, which can be phosphorylated by Akt in in vitro kinase assays. Antibody generated to an AIB1 peptide containing this specific phospho-serine recognized an IGF-1, heregulin, and Aktinduced phosphorylated form of AIB1 in vivo, including in breast cancer cells. Mutating this serine to glutamic acid to mimic phosphorylation greatly increased ER-dependent gene transcriptional activity, while substitution by alanine $(\mathrm{S}>\mathrm{A})$ at this site, which doesn't change AIB1's cellular distribution, greatly reduced AIB1 coactivation of both ER and androgen receptor dependent but not progesterone receptor dependent gene transcription. Constitutively active Akt1 further increased activity of wt AIB1 but not the S>A mutant. This specific phosphorylation may mediate p300's enhancement of ER-dependent transcription, since the $\mathrm{S}>\mathrm{A}$ mutation at this site significantly attenuated this activity. AIB1-induced tamoxifen agonist activity seems to be largely dependent on this specific phosphorylation, since the $\mathrm{S}>\mathrm{A}$ mutation almost completely diminished tamoxifen-induced ERdependent gene transcriptional activity, while the mutation with glutamic acid dramatically increased tamoxifen's agonist activity. Thus, this serine phosphorylation site appears important for AIB1 function and may link tamoxifen's agonist activity on the nuclear receptor pathway to growth factor pathways that activate Akt. Our data thus offer a mechanistic explanation for our previous clinical observation that high levels of both HER2 and AIB1 are required for tamoxifen resistance in breast cancer, suggesting that we might impede the clinical onset of tamoxifen resistance by blocking signaling from HER2 to AIB1.

\section{1}

Gene expression changes during acquired resistance to letrozole; a preclinical model of post-menopausal breast cancer.

Macpherson NA, Moore S, Brodie A, Thiantanawat A, Jelovac D, Nelson CC. BC Cancer Agency, Victoria, BC, Canada; Vancouver General Hospital, Vancouver, BC, Canada; University of Maryland, Baltimore, $M D$

\section{Background:}

Most metastatic breast cancers initially respond to hormonal treatment but all become resistant to these treatments over time. The genetic events that occur during acquired resistance are unknown. To examine the gene expression changes during acquired hormonal resistance, we used a model that mimics ER positive breast cancers in the post-menopausal setting with the tumors responsive to both Tamoxifen (TAM) and aromatase inhibitors. Tumors were analyzed with high density cDNA microarrays to identify genes associated with Letrozole (LET) resistance. Methods:

Aromatase-transfected MCF-7Ca human breast cancer cells were grown as tumor xenografts in female ovariectomized athymic nude mice in which an androstenedione supplement was converted to estrogen to stimulate tumor growth. When tumor volume was approximately $300 \mathrm{~mm}^{3}$, the animals were grouped (4 groups, each with $\mathrm{n}=20$ ) for continued supplementation with androstenedione $(\triangle 4 \mathrm{~A})$ only (control), LET (an aromatase inhibitor) $10 \mu \mathrm{g} / \mathrm{day}+\Delta 4 \mathrm{~A}$, TAM $100 \mu \mathrm{g} / \mathrm{day}+\Delta 4 \mathrm{~A}$, or vehicle. Tumors were then retrieved at various time points during the development of hormone resistance. Tumor RNA samples were compared to reference RNA from Stratagene and incubated with 14K microarrays (Array-Ready Oligo Set, Qiagen). Expression results were analyzed with Genespring 6.1 (Silicon Genetics).

\section{Results:}

We have identified 16 LET-resistant associated genes that are over- or under-expressed by at least 2 -fold and significant by ANOVA, after controlling for genes associated with house-keeping function (vehicle and short term control), proliferation (freely growing tumors without anti-estrogens), and LET inducible genes. They include; PELP1 a modulator of non-genomic activity of the estrogen receptor, POU2F2 a transcription factor, and hydroxyacyl dehydrogenase a gene involved in fatty acid metabolism.

\section{Conclusions:}

A number of LET- acquired resistance-associated genes have been identified. These are different than the TAM-resistance genes we identified in earlier work.Patient biopsies are currently being collected and analyzed to validate these observations.

\section{2}

Raloxifene effectively inhibits the growth of tamoxifen resistant T47D:A18/PKC $\alpha$ tumor.

Zhang Y, Zhao H, Tonetti DA. University of Illinois at Chicago, Chicago, IL

Background: Tamoxifen (TAM) is approved as a chemopreventive for breast cancer in women at high risk for developing the disease. Our laboratory previously reported that overexpression of protein kinase C alpha $(\mathrm{PKC} \alpha)$ in T47D:A18 breast cancer cells (T47D:A18/PKC $\alpha$ ) resulted in hormoneindependent, TAM-resistant growth both in vivo and in vitro (Chisamore MJ et. al.,2001, Clin Cancer Res. 7(10):3156-65). By comparing $\mathrm{PKC} \alpha$ expression in biopsies from patients exhibiting disease recurrence with patients remaining disease-free following TAM treatment, overexpression of $\mathrm{PKC} \alpha$ was found to correlate with TAM resistance (Tonetti DA, et al, 2003 Br. J. Cancer 88: 1400-1402). Furthermore, PKC $\alpha$ upregulation was evident in the primary tumor at diagnosis suggesting the alteration is likely an early event. In this study we investigated the susceptibility of T47D:A18/PKC $\alpha$ cells and tumors to raloxifene(RAL). RAL is a selective estrogen receptor modulator (SERM) and is currently being compared with TAM as a chemopreventive in the STAR trial.

Material and Methods: The growth rate of T47D:A18/ PKC $\alpha$ cells in the presence of RAL, 4-hydroxytamoxifen, and 17 $\beta$ estradiol (E2) was monitored by proliferation assay. T47D:A18/ PKC $\alpha$ tumors were established by injection of cells into ovariectomized athymic mice and divided into three treatment groups: TAM $(1.5 \mathrm{mg} / \mathrm{day}), \mathrm{RAL}(0.5 \mathrm{mg} / \mathrm{day})$, and RAL $(1.5 \mathrm{mg} /$ day). In a separate experiment, preexisting long- term TAMtreated (5 years) T47D:A18/ PKC $\alpha$ tumors were passaged to 20 mice and were randomized to either RAL or TAM treatment. All drugs were administrated p.o. and tumor cross-sectional areas were measured weekly. The expression levels of total Akt, phosphoAkt, HER2/neu, phospho-HER2/neu in differentially treated tumors were detected by western blot. 
Results: Cell proliferation assays indicate that neither RAL nor TAM inhibits T47D:A18/ PKC $\alpha$ cell growth in vitro. However, T47D:A18/ PKC $\alpha$ tumors were growth inhibited by RAL but not TAM. Furthermore, the inhibitory effect of RAL is dose dependent. RAL inhibited the growth of the pre-existing long-term TAMtreated tumors. There were no significant differences in the levels of total Akt, phospho-Akt, total HER2/neu nor phospho-HER2/ neu comparing TAM and RAL-treated tumors.

Discussion: TAM prevention trials achieved an overall 49\% decrease in the development of disease. We observed that RAL can inhibit the growth of T47D:A18/ PKC $\alpha$ tumors whereas TAM fails to do so. Initial mechanistic studies show that both AKT and HER2 expression levels are similar in both RAL and TAM treated tumors, indicating that the AKT and HER2/neu signaling pathways may not be involved. Although our mouse model is not a cancer prevention model, our studies suggest that RAL may be more beneficial as a chemopreventive than TAM in those patients that may harbor pre-existing cellular changes involving PKC $\alpha$ upregulation. Although RAL is a failed breast cancer therapeutic, it may be effective in pre-selected patients with $\mathrm{PKC} \alpha$ overexpressing tumors.

\section{3}

The phytoestrogen resveratrol acts opposite of estrogen to inhibit migration and differentially signal to the actin cytoskeleton of metastatic breast cancer cells.

Azios $N$, Krishnamoorthy L, Harris $M$, Cubano $L$ Dharmawardhane S. University of Texas at Austin, Austin, TX; Universidad Central del Caribe, Bayamon, Puerto Rico

Background: Resveratrol, a phytoestrogen from grapes and red wine, binds estrogen receptors (ER) $\alpha$ and $\beta$ to exert both estrogenic and antiestrogenic effects. Resveratrol is a potential cancer preventive due to its antioxidant, antiproliferative, and proapoptotic properties, yet the effects of resveratrol on metastatic breast cancer are relatively unknown. Metastasis is initiated by cell migration, which is regulated by Rho GTPases like $\mathrm{Rac}$ and Cdc42. To evaluate the role of resveratrol on breast cancer cell migration, we investigated the effects of resveratrol on the actin cytoskeleton and Rac1 and Cdc42 activity in a metastatic human breast cancer cell line.

Materials and Methods: Directed cell migration was determined using transwell assays where cells migrated for $8 \mathrm{hrs}$ in response to estradiol (E2), epidermal growth factor (EGF), resveratrol (Res), or combinations of Res/E2 or Res/EGF. The effects of E2, EGF, Res, Res/E2, or Res/EGF on the actin cytoskeleton was determined by treating cells with these compounds for $10 \mathrm{~min}$ and staining with rhodamine phalloidin. To test the hypothesis that Res and E2 signal to Rac or $\mathrm{Cdc} 42$ to modulate the actin cytoskeleton, we created MDA-MB-231 cells $(E R \alpha-/ \beta+)$ stably expressing dominant negative Rac1(T17N) or Cdc42(T17N). These cell lines were treated with Res, E2, or EGF for 10 min and stained with rhodamine phalloidin. Rac1 or Cdc42 activity in response to Res was determined by pulling-down the active GTP-Rac1 or GTP-Cdc42 with GST-Rac/Cdc42-GTP binding domain conjugated to glutathione-sepharose beads and probing with anti-Rac or antiCdc42 antibodies.

Results: We recently reported that Res significantly decreases directed cell migration at $8 \mathrm{hrs,}$, while E2 or EGF significantly increases cell migration. Res can maintain a significant inhibition of migration even in the presence of E2 or EGF. We hypothesize that the inhibitory action of Res on cell migration may depend on it's induction of sustained global actin structures called filopodia. E2 or EGF induced lamellipodia, actin structures known to promote cell migration. Stable expression of Rac1(T17N) did not affect Res-induced filopodia extension, though Res did induce Rac activity at 5-30 min. E2 or EGF did not induce lamellipodia in cells expressing Rac1(T17N) indicating that E2 and EGF signal via Rac to promote cell migration. Res was partially effective in filopodia extension in cells stably expressing Cdc42(T17N), but did not affect $\mathrm{Cdc} 42$ activity at 5-30 min.
Discussion: These data indicate novel Rac1- and Cdc42dependent and independent signaling pathways for resveratrolmediated modulation of the actin cytoskeleton leading to persistent filopodia extension and decreased cell migration. Therefore, resveratrol may act as an antiestrogen and novel chemopreventive for breast cancer metastasis.

\section{4}

Comparison of effects of 4-hydroxy-tamoxifen and trilostane on oestrogen-regulated gene expression in MCF7 cells: up-regulation of oestrogen receptor beta.

Barker S, Malouitre SD, Glover HR, Puddefoot JR, Vinson GP. Queen Mary, University of London, London, United Kingdom

Background: Acquired resistance to tamoxifen treatment of breast cancer is a major concern. Tamoxifen is a selective estrogen receptor modulator (SERM) acting to competively block binding of oestrogen to the oestrogen receptor (ER). Trilostane (Modrenal ${ }^{\mathrm{TM}}$ ) is a non-competitive inhibitor of ER alpha function that has shown clinical benefit in patients with advanced postmenopausal breast cancer after relapse on tamoxifen. The different modes of action of tamoxifen and trilostane suggests that their effects on gene expression within breast tumours will also be different. The aim of this study was to compare the effects of tamoxifen and trilostane on gene expression in MCF-7 breast cancer cells using cDNA microarrays.

Materials and Methods: RNA was prepared from cells cultured in phenol red free medium containing charcoal-stripped foetal bovine serum (FBS). Cells were treated with $10 \mathrm{nM}$ 17-beta oestradiol alone or together with 4-hydroxy tamoxifen $(1 \mu \mathrm{M})$ or trilostane $(10 \mu \mathrm{M})$ for 72 hours. Fluorescently labelled cDNAs were synthesised from the RNA and hybridised to 20000 gene human microarrays. Real-time RT-PCR was then used to confirm the changes observed for selected genes of interest. In addition, experiments using trilostane treated rats were used to follow these effects in vivo, using both RT-PCR and immunoblotting of rat tissue homogenates.

Results: We observed a striking difference in the changes in gene transcription resulting from treatment with tamoxifen versus trilostane. Transcription of genes involved in cell cycle regulation and cell adhesion and matrix formation was affected by both tamoxifen and trilostane, however, in most cases these were not the same genes. Of particular interest was a selective up-regulation of ER beta by trilostane. Another key gene affected was the multidrug resistance gene (ABCG2); down-regulated by trilostane but not by tamoxifen. As ER beta has an important role to play in regulation of ER-dependent gene transcription, the regulation of this gene by trilostane was investigated in vivo. Specifically it was found that ER beta was up-regulated in the uterus of trilostane treated rats at the level of mRNA and protein expression.

Discussion: This data shows that 4-hydroxy tamoxifen and trilostane regulate the expression of different sets of genes and some if these changes may account for the reported efficacy of trilostane after patients have become resistant to tamoxifen treatment. An increase in ER beta would have a suppressive effect on oestrogen-mediated tumour growth through both ERE and AP1-dependent (growth factor driven) cell survival pathways. A reduction in the multidrug transporter ABCG2, known to be highly expressed in breast tumour stem cell populations, suggests a possible mechanism by which trilostane can show consistent efficacy after development of acquired endocrine resistance. 


\section{S202 Abstracts - Poster Session IV}

\section{5}

Glyceollins (I-III), novel anti-estrogenic phytochemicals isolated from soy.

Zimmermann MC, Salvo VA, Boue SM, Fonseca JP, Elliot S, Dugan CM, Zhu Y, Corbitt C, Collins-Burow BM, Weldon CB, Curiel TJ, Shih BY, Carter-Wientjes C, Wood C, Clarkson TB, Erhardt P, McLachlan JA, Cleveland TE, Beckman BS, Burow ME. Tulane University, New Orleans, LA; Tulane Cancer Center, New Orleans, LA; The Center for Bioenvironmental Research, New Orleans, LA; Tulane University Health Science Center, New Orleans, LA; Southern Regional Research Center, USDA, New Orleans, LA; University of Louisville, Louisville, KY; Wake Forest University School of Medicine, Winston-Salem, NC; University of Toledo, Medical College of Ohio, Toledo, $\mathrm{OH}$

Background: Members of the flavonoid family of phytochemicals, particularly those derived from soy, have received attention regarding their estrogenic activity as well as their effects on human health and disease. We have identified the isoflavonoid glyceollins I, II and III in soy plants grown under stressed conditions which exhibit marked anti-estrogenic effects on ER function. Here we examine the ability of the glyceollins to suppress the tumorigenesis of ER-positive estrogen-dependent breast cancer cells and inhibiting ER-dependent gene expression.

Materials and Methods: The effects of glyceollins (I-III) on gene expression were determined by ERE-luciferase and RT-PCR assays. ER-dependent cancer cell lines were transfected with an ERE-Luc plasmid, treated with glyceollins in the presence and absence of estrogen stimulation, and harvested for luciferase activity. The cells were also analyzed for the expression of PgR and SDF1 genes after glyceollin treatment with and without estrogen stimulation. Ovariectomized female mice were injected into the mammary fat with breast cancer cells and treated with glyceollin subcutaneously for 20 days.

Results: We have established the ability of glyceollins to significantly suppress basal and estrogen-stimulated tumor growth in animal models. We further demonstrate that the effects of glyceollins on suppression of tumor growth correlate with inhibition of estrogen stimulated gene expression and suppression of EREreporter gene activation.

Discussion: Our results establish the in vivo suppression of estrogendependent and independent tumor growth by glyceollins (I-III) while also providing critical information for the understanding and treatment of breast cancer. The glyceollins may represent important components of a soy-based diet in terms of chemoprevention and in the treatment of tamoxifen resistant breast cancer.

\section{6}

Down regulation of p42/44 MAPK and pAKT in response to neo-adjuvant tamoxifen or anastrozole (IMPACT) in ER positive breast cancer.

Salter J, A'Hern R, Smith IE, Dowsett M. Royal Marsden Hospital, London, United Kingdom

Background: Numerous signal transduction inhibitors are now under development for breast cancer treatment, frequently in combination with endocrine therapy. Studies have suggested that these combinations not only improve the efficacy of endocrine agents in the advanced disease setting but may also delay the onset of resistance. Hence assessment of the activation state of downstream signaling partners such as p42/44 MAPK and pAKT is an important aspect of their evaluation. To date few studies have investigated the effect of endocrine agents on these major signal transduction pathways. We have therefore assessed the effect of tamoxifen and the aromatase inhibitor anastrozole on p42/44 MAPK and pAKT in the neoadjuvant IMPACT study.

Materials \& Methods: Post menopausal patients (28) with ER positive breast cancer from the neo-adjuvant tamoxifen vs anastrozole vs combination trial (IMPACT) were immunohistochemically assessed for p42/44 MAPK (Cell signalling) and pAKT(Cell signalling) pre-and 3-months post therapy. Samples were scored using the Allred score (values 0-8) Results: Analysis of patient samples pre- and post-treatment resulted in a significant decrease in p42/44 MAPK and pAKT signalling irrespective of the agent used (Table 1). There was a trend for anastrozole to be more effective than tamoxifen at inhibiting pAKT expression.

Table 1. Overall analysis of the effect of tamoxifen or anastrozole on p42/44 MAPK or PAKT expression

OVERALL (p42/44 MAPK)

OVERALL (pAKT)

Baseline proportion $=64.3 \%(44.06-81.4) \quad$ Baseline proportion $=60.7 \%(40.58-78.5)$ 3 Months proportion $=21.4 \%(8.3-41) \quad 3$ Months proportion $=10.7 \%(2.27-28.2)$ p-value $=0.006$ p-value $=<0.001$

Conclusion: Tamoxifen and anastrozole both down-regulate the expression of p42/44 MAPK and pAKT (generally considered key components of the cell proliferation and survival pathways) and may form a significant component of the endocrine response mechanism. This observation could also provide important information when considering the impact of signal transduction inhibitors in combination with endocrine therapies for the development of optimal treatment regimes.

\section{7}

Macrophage colony-stimulating factor (CSF-1) overexpression leads to mammary tumorigenesis: induction of CSF-1 receptor, c-fms, by steroid hormones. Kirma NB, Liu Y, Nair HB, Tekmal RR. University of Texas Health Science Center at San Antonio, San Antonio, TX

In addition to its essential role in normal mammary development during lactation, the macrophage colony stimulating factor (CSF1) is a cytokine that has been also implicated in breast cancer. Lack of CSF-1 signaling in mice, either due to deficiency in CSF1 expression (CSF-1 ${ }^{\text {op/op }}$ ) or disruption of the CSF-1 receptor (c$\mathrm{fms}$ ), leads to defects in lactation. On the other hand, elevated levels of both CSF-1 and c-fms have been detected in breast cancer. The concomitant expression of CSF-1 and its receptor in breast cancer cells has been demonstrated to correlate with high grade and metastatic breast cancer. Although breast cancer cells have been shown to express CSF-1 and its receptor c-fms, another source of CSF-1 in mammary tumors is from infiltrating macrophages, which may interact with tumor cells in a paracrine fashion, leading to tumor cell migration and metastasis. To study the role of CSF-1 in mammary carcinogenesis, we developed a transgenic mammary mouse model that over-expresses CSF- 1 under the control of the MMTV promoter. These mice overexpress CSF-1 specifically in the mammary glands and show extensive precancerous lesions (hyperplasia and dysplasia) that are aggravated by pregnancy and develop into palpable tumors in aged mice. Our data also show infiltration of macrophages in tumors of MMTV-CSF-1 mice. This infiltration contributes to the pool of CSF-1 present in the microenvironment of the glands. The mammary glands of MMTV-CSF-1 mice exhibit increased levels of c-fms, suggesting that CSF-1 may enhance its signaling through a positive feedback loop. The levels of estrogen and progesterone receptors (ER and PR) are also increased in these mice raising the possibility that these steroid receptors may mediate induction of c-fms expression in these mice. Interestingly, our preliminary data show that $\mathrm{c}-\mathrm{fms}$ expression is elevated in aromatase transgenic mice, which maintain elevated estrogen levels in mammary glands due to local aromatase over-expression. Furthermore, estrogen and progesterone treatment of human breast cancer cell lines resulted in increased c-fms expression and induction of mouse and human c-fms promoter activity, as determined by the luciferase reporter assay. Combined, the data suggest that estrogen and progesterone may mediate induction of c-fms by its ligand CSF-1. These data have implications in understanding the cross-talk between CSF-1 signaling and that of steroid receptors as well as in the development of breast cancer therapies that target CSF-1 signaling. 


\section{8}

Lipid profile and homocysteine levels in postmenopausal women with early breast cancer at low risk treated for two years with exemestane: follow-up results of a randomized, placebo-controlled study.

Lønning PE, Geisler J, Krag L, Ottestad L, Risberg T, Hagen AI, Schlichting E, DiSalle E, Polli A, Paolini J. Haukeland University Hospital, Bergen, Norway; Central Hospital of Rogaland, Stavanger, Norway; The Norwegian Radiumhospital, Oslo, Norway; University Hospital of Northern Norway, Troms $\phi$, Norway; St. Olavs Hospital, Trondheim, Norway; Ullevål University Hospital, Oslo, Norway; Pharmacia Italia S.p.A. / Pfizer Group, Milan, Nerviano, Italy

Background: Estrogens favorably modify the lipid profile in postmenopausal women. Aromatase inhibitors markedly reduce estrogen levels. We reported the effects of 2 years of treatment with exemestane (Aromasin ${ }^{\circledR}$ ), a steroidal aromatase inactivator, on plasma levels of total cholesterol, HDL-cholesterol, LDLcholesterol, triglycerides, apoliporotein A1, lipoprotein A, apolipoprotein B and serum homocysteine (Lønning et al., J Clin Oncol 2005, in press). During treatment, lipid profile was similar in exemestane and placebo patients, except for a modest reduction in HDL-cholesterol and apolipoprotein A1; homocysteine levels slightly increased. No change was observed in coagulation parameters.

Methods: Randomized, double-blind study evaluating the effect of exemestane on bone metabolism, endocrinological and metabolic parameters in 147 patients randomized to exemestane $(25 \mathrm{mg} /$ day p.o.) or placebo for 2 years, with a 1-year follow-up. We report here the results of the follow-up period for the lipid profile and homocysteine levels, assessed at month 27,30 and 36, corresponding to 3,6 and 12 months after treatment discontinuation.

Results: 147 pts have been enrolled, 73 on exemestane and 74 on placebo. Follow-up results are available for approximately 4555 patients per group. Preliminary results show that the slight decrease in HDL-cholesterol and apolipoprotein A1 caused by two years of exemestane treatment disappeared shortly after treatment discontinuation. Homocysteine levels remain slightly increased during the entire follow-up period in both treatment arms. Similar levels were observed during follow-up in the two treatment groups for all the assessed parameters. Final results will be presented. Discussion: The very minor changes in the circulating levels of HDL-cholesterol and apolipoprotein A1 observed after two years of exemestane treatment disappeared shortly after treatment discontinuation. The slight increase over time of homocysteine levels in both groups is consistent with the reported increase during aging (Nygard et al., JAMA 1995; 274:1526). We conclude that the effects of exemestane therapy on lipids are mostly reversible within three months after treatment withdrawal. This suggests exemestane adjuvant therapy should not have long term detrimental effects on lipid profile.

\section{9}

Aromtase X HER-2/Neu double transgenic mice: effect of local estrogen on mammary development and carcinogenesis.

Tekmal RR, Perla RP, Nair HB, Liu Y-G, Kirma NB. University of Texas Health Science Center at San Antonio, San Antonio, TX

A majority of breast cancers are hormone-responsive and will require estrogen for growth, and respond to hormonal therapy that blocks estrogen receptor action. Breast tumors lacking estrogen receptor fail to respond to antiestrogen therapy yet require estrogen for tumor initiation. To address directlythe importance of breast tissue aromatase in initiation and progression of breast cancer, we have generated aromatase transgenic mice (MMTV-aromatase) and shown that elevated estrogen levels due to aromatase overexpression resulted in the induction of hyperplastic and dysplastic lesions and they are persistent even without circulating estrogens. Aromatase transgenic mice form ER-positive mammary tumors when exposed to DMBA within four to five months. To our knowledge, this is the first in vivo model that clearly demonstrated the direct involvement of breast tissue aromatase/ estrogen in tumorigenesis. To address the importance of synergistic role of estrogen with oncogenes and their receptors we have crossed MMTV-aromatase with MMTV-neu mice. Presence of continuous local estrogen results in down regulation of ER, PR and a number of growth factors in double transgenic mice. Unlike previous studies, continuous estrogenic stimulation in double transgenic mice at prepubertal stage results in reduced tumor incidence or no tumor formation even at one year of age. Presence of high levels of local estrogen production during the mammary development (at prepubertal stage) and before the initiation of tumor formation by HER-2/neu appears to have a protective effect on the tumor formation in double transgenic animals. Ongoing studies are focused on determining tumor incidence, estrogen receptor status after blocking local estrogen beginning with 5 weeks of age with letrozole as well as molecular changes during various stages of development. These studies provide interesting in vivo observations that aid in understanding the biology of breast cancer and in developing potential therapeutic and prevention strategies. Supported by NIH/ NCI grant CA75018.

\section{0}

Total body aromatization is strongly correlated to plasma leptin levels in postmenopausal breast cancer patients.

Geisler J, Haynes B, Ekse D, Dowsett M, Lonning PE. Haukeland University Hospital, Bergen, Norway; Royal Marsden Hospital, London, United Kingdom

Background: Obesity as well as elevated plasma estrogen levels are well-established risk factors for breast cancer development in postmenopausal women. However, the link between obesity and elevated plasma estrogens is still uncertain. Leptin, encoded by the $o b$ gene, has recently been shown to influence on aromatase expression in vitro. Thus, we intended to evaluate the influence of plasma leptin levels in postmenopausal breast cancer patients on basal levels of total body aromatization in vivo.

Materials and Methods: 22 postmenopausal women with metastatic breast cancer, previously participating in tracer studies for the measurement of "total body aromatization" (TBA) in vivo were available. Total body aromatization was calculated following an intravenous double-tracer $\left({ }^{3} \mathrm{H} /{ }^{14} \mathrm{C}\right)$ bolus injection in HPLC-purified urinary estrogen fractions. Plasma leptin levels were measured using a commercial kit provided by Diagnostic Systems Laboratories, Webster, TX, USA. Plasma estrogen levels (estrone, estradiol, and estrone sulfate) were measured by highly sensitive radioimmunoassays established in our laboratory.

Results: Plasma leptin levels varied from 1,83 to $95,51 \mathrm{ng} / \mathrm{ml}$. Values for total body aromatization varied from $1,46 \%$ to $4,72 \%$. All plasma estrogens were in the normal range expected for postmenopausal women. We found a significant correlation between pre-treatment leptin levels and total body aromatization $(\mathrm{p}=$ 0.01 ; Spearman). In addition, plasma leptin levels correlated to plasma levels of estrone $(p=0.009)$, estradiol $(p=0.007)$, and estrone sulfate $(p=0.01)$. In contrast, basal levels of TBA did not correlate to body mass index (BMI).

Discussion: Our results show that plasma levels of leptin are strongly correlated to basal levels of total body aromatization in postmenopausal women with metastatic breast cancer. In vitro findings by Catalano et al. suggest that leptin enhances aromatization by interaction with the promoters II and I.3. Our findings may also provide an explanation for the association between breast cancer outcome and diet intervention (Chlebowski et al. ASCO abstract \# 10, 2005). 


\section{S204 Abstracts - Poster Session IV}

4111

Effects of aromatase inhibitors on human osteoblast cells: a possible androgenic bone protective effects induced by exemestane.

Miki Y, Suzuki T, Igarashi K, Kanno J, Sasano H. Tohoku University Graduate School of Medicine, Sendai, Japan; National Institute of Health Sciences, Biological Safety Research Center, Tokyo, Japan

Background: Effects of aromatase inhibitors (AIs) on human skeletal system could become clinically very important due to their increasing use as an adjuvant therapy in postmenopausal patients. However, possible effects of AIs on human bone cells have been largely unknown. We studied effects of AIs the steroidal AI, exemestane (EX), the non-steroidal Aromatase Inhibitor I [AI-I; 4-(Imidazolylmethyl)-1-nitro-9H-9-xanthenone; Calbio] and aminoglutethimide (AG; Sigma-Aldrich) on osteoblast cells.

Materials \& Methods: We employed the human osteoblast cell line, hFOB (ATCC) which expressed estrogen receptor (ER) $\beta$ and androgen receptor (AR) as in human osteoblasts. We first examined effect of $100 \mathrm{pM}-1 \mu \mathrm{M}$ of estradiol (E2), 5. $\alpha$-DHT (DHT), EX, AI-I, and AG treatments in hFOB cells using cell proliferation assays (WST-8). We examined whether these effects were mediated through steroid receptors using corresponding blockers to ER [ICI182,780 (ICI)], to AR [flutamide (FL)], or to progesterone receptor [RU38,486 (RU)] as pretreatment. We subsequently screened E2, DHT, and EX responsive genes using an mRNA microarray analysis in these cells for further characterization.

Results: There was a significant increase in the number of the cells after $72 \mathrm{~h}$ treatment with E2 and DHT ( $\geq 10 \mathrm{nM})$ and EX $(\geq 100 \mathrm{nM})$. FL pre-treatment partially inhibited this effect of EX but no inhibition was seen with ICI or RU pre-treatment. AI-I exerted no effects on cell proliferation treated for 72 hours. AG diminished the number of the cells. In microarray analysis, gene expression profile patterns after treatment with EX resembled patterns seen with DHT but not with E2 treatment.

Discussion: Steroidal Aromatase inhibitor, EX stimulated hFOB cell proliferation via both AR dependent and independent pathway. Upregulation by EX of specific genes in hFOB cells will be discussed in relation to cell proliferation and osteoblast differentiation.

\section{2}

Effect of nomegestrol acetate on aromatase activity in MCF-7aro breast cancer cells.

Chetrite G, Shields-Botella J, Postruznik D, Pasqualini JR. Institut de Puériculture et de Périnatalogie, Paris, France; Laboratoires Merck-Théramex, Monaco, Monaco

Background: The progestin nomegestrol acetate (NOMAC), a 17a-hydroxy-nor-progesterone derivative (17a-acetoxy-6methyl-19-nor-4,6-pregnadiene-3,20-dione, the active substance in Lutenyl $($ ) is largely used as an oral contraceptive and in the treatment of menopausal complaints. In previous studies in this laboratory we demonstrated that NOMAC is an anti-sulfatase agent in hormone-dependent MCF-7 and T-47D breast cancer cells. In the present study, we explore the effect of NOMAC on the aromatase activity in a stable aromatase-expressing estrogen receptor-positive human breast cancer cell line: the MCF-7aro. Materials and Methods: The MCF-7aro cell line was a gift from Dr S. Chen (Beckman Research Institute, Duarte, U.S.A). For experiments, the cells were stripped of endogenous steroids and incubated with physiological concentrations of $[3 \mathrm{H}]$-testosterone $(5 \times 10-9 \mathrm{M})$ alone or in the presence of NOMAC $(5 \times 10-5 \mathrm{M}$ and $5 \times 10-6 \mathrm{M})$ for $24 \mathrm{~h}$ at $37^{\circ} \mathrm{C}$. The cellular radioactivity uptake was determined in the ethanolic supernatant and the DNA content in the remaining pellet. $[3 \mathrm{H}]-\mathrm{E} 2,[3 \mathrm{H}]-$ estrone $(\mathrm{E} 1)$ and $[3 \mathrm{H}]-$ testosterone were characterized by thin layer chromatography and quantified using the corresponding standard.

Results: It was observed that aromatase activity is present at a high level in MCF-7aro cells, since the concentration of [3H]-E2 found was $5.78 \pm 0.55 \mathrm{pmol} / \mathrm{mg}$ DNA in the non-treated cells NOMAC, at the concentrations of $5 \times 10-5 \mathrm{M}$ and $5 \times 10-6 \mathrm{M}$ significantly inhibits this conversion by $42 \%$ and $27 \%$, respectively. Conclusion: The MCF-7aro cell line shows a high detectable aromatase activity and NOMAC can act as an anti-aromatase agent by inhibiting this activity. This is an important new effect of this progestin, as it was previously demonstrated that NOMAC is also an anti-sulfatase agent. This dual effect of NOMAC can provide attractive possibilities for clinical trials.

\section{3}

Estradiol is an anti-aromatase agent in human breast cancer cells.

Pasqualini JR, Chetrite G. Institut de Puériculture et de Périnatalogie, Paris, France

Background: Estradiol (E2) is an important risk factor in the development and progression of breast cancer. However, a « direct effect » of E2 in breast cancerization has not yet been demonstrated. Breast cancer cells possess all the enzymes [sulfatase, aromatase, 17ß-hydroxysteroid dehydrogenase (17ß-HSD)] for the local bioformation of E2. In the last years many studies have shown that treatment of patients with breast cancer using antiaromatase agents has beneficial therapeutic effect. In the present study, we explore the effect of E2 on the aromatase activity in a hormone-dependent breast cancer cell line which overexpressed the aromatase gene: the MCF-7aro cell

Materials and Methods: The MCF-7aro cell line was a gift from Dr S. Chen (Beckman Research Institute, Duarte, U.S.A). For experiments, the cells were stripped of endogenous steroids and incubated with physiological concentrations of $[3 \mathrm{H}]$-testosterone $(5 \times 10-9 \mathrm{M})$ alone or in the presence of E2 $(5 \times 10-5-5 \times 10-7-$ $5 \times 10-9 \mathrm{M})$ for $24 \mathrm{~h}$ at $37^{\circ} \mathrm{C}$. The cellular radioactivity uptake was determined in the ethanolic supernatant and the DNA content in the remaining pellet. $[3 \mathrm{H}]-\mathrm{E} 2,[3 \mathrm{H}]$-estrone $(\mathrm{E} 1)$ and $[3 \mathrm{H}]$ testosterone were characterized by thin layer chromatography and quantified using the corresponding standard.

Results: It was observed that $[3 \mathrm{H}]$-testosterone is converted mainly into $[3 \mathrm{H}]-\mathrm{E} 2$, and not to E1, which suggests no oxidative $17 \mathrm{~B}$ HSD activity in these experimental conditions. The aromatase activity, corresponding to the conversion of $[3 \mathrm{H}]$-testosterone to $[3 \mathrm{H}]-\mathrm{E} 2$ after $24 \mathrm{~h}$, is relatively high, since the concentration of E2 was $2.25 \pm 0.15 \mathrm{pmol} / \mathrm{mg}$ DNA in the non-treated cells. E2 inhibits this conversion by $73 \%, 54 \%$ and $20 \%$ at the concentrations of $5 \times 10-5 \mathrm{M}, 5 \times 10-7 \mathrm{M}$ and $5 \times 10-9 \mathrm{M}$, respectively. Conclusion: E2 has a paradoxical effect by significantly inhibiting the aromatase activity in MCF-7aro cells. In a previous study, we have shown that E2 can also exert a potent anti-sulfatase activity in two cell lines: MCF-7 and T-47D, where the aromatase activity is very low or non-detectable. The dual inhibition of the sulfatase and aromatase activities, two crucial enzymes for the biosynthesis of E2, by E2 itself in breast cancer add interesting and attractive information for the use of estrogen treatments. 


\section{1}

MRI surveillance downstages invasive cancer (IC) to DCIS in women at high risk for hereditary breast cancer. Warner E, Causer PA, Hill KA, Ramsay E, Jong RA, Wong JW, Wright FC, Detzler G, Glazier J, Murray C, Muldoon J, Messner SJ, Eisen A, Rosen B, Verity L, Chung A, Yaffe MJ, Narod SA, Plewes DB. Sunnybrook \& Women's College Health Sciences Centre, Toronto, ON, Canada; University of Toronto, Toronto, ON, Canada; Sunnybrook \& Women's College Health Sciences Centre, Canada; Sunnybrook \& Women's College Health Sciences Center, Canada; Sunnybrook \& Women's College Health Sciences Centre

Background: In 2 multicenter surveillance studies of women at high risk for hereditary breast cancer (Kriege et al. NEJM 351:427,2004; Leach et al. Lancet 365:1769,2005) MRI was twice as sensitive as mammography (M) for IC but $\mathrm{M}$ was much more sensitive for DCIS. However, we found MRI superior to M for both IC and DCIS (ASCO 2004, \#9500). It might be argued that MRI-only detected cases of DCIS are clinically irrelevant either because they may never progress to invasion or because they may eventually be detected by $\mathrm{M}$ prior to invasion.

Methods: In November, 1997 we began a surveillance study of annual MRI, $M$ and ultrasound for women ages 25 to 65 at high risk for hereditary breast cancer. All cases of DCIS \pm microinvasion and IC in our study were analyzed in 2 time frames: before (period A) and after (period B) July, 2001 when a radiologist (PC) with special training in MRI joined the study. In period A, 225 women had a total of 487 rounds of screening, and in period B 396 women (247 new patients) had 877 rounds of screening.

Results: In period A there were 16 cases of DCIS or IC detected (3.3\% of screens) compared to 27 cases $(3.1 \%$ of screens) for period B. Of the 16 cases in period A, 2 (12\%) were DCIS compared to $12(44 \%)$ of the 27 cases in period $B(p=0.04)$ of which 3 had microinvasion. Both DCIS cases in period A were detected by M only. All 12 DCIS cases in period B were detected by MRI but only $1(8 \%)$ by M. No cases of DCIS were detected by ultrasound. These differences could not be explained by age, mutation status, previous M, or year of screening. Sensitivity of MRI vs. M for invasive cancer was $79 \%$ vs. $43 \%$ in period A, but $93 \%$ vs. $13 \%$ in period B. Discussion: In view of the similar total case detection rate in both periods, it is unlikely that the additional cases of DCIS detected in period B (1.4\% vs. $0.4 \%)$ are incidental findings, particularly since 3 had already progressed to microinvasion. The lower IC detection rate in period B (1.7\% vs. $2.9 \%)$ suggests downstaging of IC to DCIS by earlier detection with MRI. The $100 \%$ detection rate of DCIS by MRI in period B challenges the need for M in addition to MRI for hereditary cancer surveillance in highly experienced centers.

\section{2}

Clinical guidelines for early detection of tumor response to neoadjuvant chemotherapy for breast cancer using contrast-enhanced MRI.

Loo CE, Schlief AT, vd Vijver MJ, Muller SH, Rodenhuis S, Gilhuijs KG. The Netherlands Cancer Institute, Amsterdam, Plesmanlaan, Netherlands

Background: Contrast-enhanced (CE) MRI has been shown useful to assess response of locally advanced breast cancer after completion of neoadjuvant chemotherapy. However if signs of unfavorable response are visible early after the start of neoadjuvant chemotherapy, the treatment may be changed accordingly, thus improving survival of the patient.

Purpose:The aim of our study was to establish clinical guidelines for the early detection of unfavorable response to neoadjuvant chemotherapy of locally advanced breast cancer.

Methods:Fifty-four patients (24-66 years) with locally advanced breast cancer $(>3 \mathrm{~cm}$ and/or lymph node positive) were consecutively included between September 2000 and September 2004. Tumors (45 IDC, 9 ILC) were examined with CE MRI prior and after 2 (of 6) courses neoadjuvant chemotherapy. A combined MRI protocol was employed: fast dynamic imaging in the first 45 $\mathrm{s}$ after contrast injection (Turbo-FLASH) followed by dynamic imaging in 5 consecutive series at $90 \mathrm{~s}$ intervals (FLASH-3D). MRI findings were assessed by dedicated breast radiologists and correlated with postoperative pathology findings.

Multivariate logistic regression with double cross-validation and ROC analysis was employed to identify temporal and morphological characteristics of contrast uptake that are predictive of unfavorable outcome with regard to tumor response after the second course of chemotherapy.

Results:Postoperative pathology showed unfavorable response (presence of residual disease after 6 courses of chemotherapy) in $39(72 \%)$ of 54 patients.

After 2 courses of chemotherapy imminent unfavorable response was best indicated by the change of largest washout diameter on the second MR examination relative to the first $(\mathrm{Az}=0.73)$.

Reduction of the largest washout diameter less than $25 \%$ yielded 95\% specificity to identify unfavorable response.

This operating point was selected as a clinical guideline for a new randomized prospective phase 2 study (tailored preoperative chemotherapy).

Conclusions: Insufficient change of largest washout diameter is the most predictive MRI characteristic for tumor response during chemotherapy and may be used as a clinical guideline for early detection of unfavorable response.

\section{3}

Correlating breast cancer grade and hypoxia status with MRI features.

Ah-See M, Makris A, Taylor NJ, Stirling JJ, Daley FM, Richman P, Harris A, d'Arcy J, Collins D, Padhani AR. Mount Vernon Cancer Centre, Northwood, Middlesex, United Kingdom; Weatherall Institute, John Radcliffe Hospital, Oxford, Oxfordshire, United Kingdom

Background: Tumour grade and oxygenation are important prognostic features in breast cancer. The purpose of the current study is to see whether Blood oxygenation level dependent (BOLD) or dynamic contrast enhanced MRI (DCE-MRI) are predictive of tumour grade and hypoxia status of breast cancers.

Methods: 32 untreated breast cancer patients with invasive ductal cancer were studied. A standard series of $\mathrm{T}_{2}{ }^{*}$-weighted images with different echo-times were used to quantify the BOLD signal (intrinsic susceptibility - $\mathrm{R}_{2}{ }^{*}$ ). The DCE-MRI scans were performed using Gd-DTPA as the contrast agent and sequences that directly measured or were sensitive to blood flow, blood volume and microvessel permeability. Whole tumour measurements of maximum amplitude of enhancement and wash-out gradient together with transfer constant ( $\mathrm{K}^{\text {trans; }}$ previously called permeability surface area product), lesion leakage space $\left(\mathrm{v}_{\mathrm{e}}\right)$, relative blood volume (rBV) and flow (rBF) were obtained. Tumours were graded according to the Bloom-Richardson system on core biopsies or surgical specimens. Low $(n=1)$ and moderate grade tumours $(n=15)$ were grouped as not high-grade. Immunohistochemical staining to assess the oxygenation status of breast cancer was done on the pre-treatment diagnostic corebiopsy samples using the carbonic anhydrase-IX (CA-IX) mouse monoclonal antibody. CA-IX immunostaining was quantified in carcinoma cells as either positive or negative. Univariate and multivariate analyses dividing morphology (size), BOLD-MRI and DCE-MRI kinetics were performed. For assessment of $\mathrm{R}_{2}{ }^{*}$, only patients with solid masses $(n=23)$ were included. Multivariate analysis of the most significant univariate variables was done. The statistical significance for the 2-tailed Mann-Whitney U-test was set at a p-value of $<0.01$.

Results: Univariate analysis showed significant positive MRI correlates of tumour grade (maximal amplitude, $\mathrm{P}=0.006$; washout gradient, $\mathrm{p}=0.01 ; \mathrm{rBV} / \mathrm{rBF} ; \mathrm{p}=0.001$ ) and inverse correlation with $\mathrm{R}_{2}{ }^{*}(\mathrm{p}<0.001)$. Multivariate analysis showed that maximum 


\section{S206 Abstracts - Poster Session V}

amplitude was the dominant explanatory variable. The only MRI correlate of tumour CA-IX staining was $\mathrm{rBV} / \mathrm{rBF}$ with positively staining tumours having higher $\mathrm{rBV} / \mathrm{rBF} ; \mathrm{p}=0.001$ ).

Conclusions: There is a strong relationship between breast cancer blood volume/flow and tumour grade. The inverse correlation between blood volume/flow and our marker of tumour hypoxia (CA-IX) was unexpected. However the paradox of large blood volume and concomitant tumour hypoxia is well recognized in the literature. BOLD-MRI does not reflect on tumour hypoxia status in breast cancers as detected by CA-IX.

\section{4}

Observer variability in dynamic contrast-enhanced MRI when used for prediction of response to neoadjuvant chemotherapy in primary breast cancer.

Beresford MJ, Makris A, Taylor NJ, Stirling JJ, Ah-See M, d'Arcy JA, Collins D, Padhani AR. Mount Vernon Hospital, Northwood, Middlesex, United Kingdom

Background: Dynamic contrast MRI (DCE-MRI) can be used to assess breast cancer microvasculature in response to neoadjuvant chemotherapy. We have previously shown that changes in $\mathrm{T}_{1}$ weighted DCE-MRI kinetic parameters after 2 cycles of chemotherapy (5-FU, epirubicin and cyclophosphamide) were able to predict pathological response following 6 cycles. Tumour size failed to predict for eventual pathological response, but changes in median transfer constant $\left(\mathrm{K}^{\text {trans }}\right)$ predicted response with a sensitivity of $100 \%$ and specificity of $72 \%$. For this technique to be useful in practice, it is necessary to confirm the repeatability of the definition of tumour regions of interest (ROI) by observers.

Methods: 30 untreated women with primary breast cancers were studied. $\mathrm{T}_{1}$ weighted DCE-MRI studies were acquired before and after administration of $0.1 \mathrm{mmol} / \mathrm{kg}$ of Gd-DTPA with 40 time points over $8 \mathrm{~min}$, through the centre of the tumour. Two observers (a - a radiologist with 7 years of DCE-MRI experience and $\mathbf{b}$ - an oncologist with no prior DCE-MRI experience) independently outlined ROIs on the same image slice of each tumour on five separate occasions (giving comparisons of ROIs defined 2 months apart, 2 weeks apart, 1 day apart and on the same day). For homogeneous and well-defined lesions the entire lesion was outlined around its outer border. For infiltrating lesions the dominant enhancing nodule was outlined. Parameters including ROI size, $\mathrm{K}^{\text {trans }}$, leakage space, rate constant and area under the Gd-DTPA concentration curve at 90 seconds were calculated. Descriptive and Bland-Altman reproducibility statistics were applied.

Results: For the non-expert observer the reproducibility of ROIs improved as the time interval reduced. The coefficient of variance (wCV) for lesion size at 2 months, 2 weeks, 1 day and same day intervals was $11.6 \%, 10.7 \%, 4.8 \%$ and $2.6 \%$ respectively. The variability in kinetic parameters also reduced ( $\mathrm{K}^{\text {trans }}$ wCV: $8.9 \%$, $9.7 \%, 6.7 \%$ and $3.2 \%$ ). For the expert observer, values were more consistent, but again showed improvement when regions were drawn on the same day (size wCV: $7.5 \%, 6.2 \%, 7.1 \%$ and $3.7 \%$; $\mathrm{K}^{\text {trans }} \mathrm{wCV}: 5.4 \%, 5.3 \%, 5.6 \%$ and $4.5 \%$ ). Inter-observer variability was calculated for regions defined on different days (wCV size: $10.5 \%$; $\mathrm{K}^{\text {trans: }} 7.4 \%$ ) and on the same day (wCV size: $7.1 \%$; $\mathrm{K}^{\text {trans: }}$ $6.0 \%)$.

Conclusions: Longer intervals between ROI definition result in greater variability. Inter-observer variability was no worse than intra-observer variability for regions defined on different days, but did not improve as much for regions defined on the same day. If DCE-MRI is to be used as a method of monitoring treatment response, the same observer should outline pre- and post-treatment ROIs at the same sitting. For the most important vascular parameter $\left(\mathrm{K}^{\text {trans }}\right)$ the observer variability is approximately $5 \%$ which should be taken into account when setting thresholds for judging response.

\section{5}

Mammographic breast density as a predictor for local recurrence after breast conserving surgery and radiotherapy.

Park C, Rembert J, Chew K, Moore D, Kerlikowske K. University of California, San Francisco, CA

Introduction: Mammographic breast density (MGD) has been shown to be an independent risk factor for breast cancer, and also to correlate with the risk for local recurrence (LR) following treatment for ductal carcinoma in situ (DCIS). However, the role of MGD as a prognostic factor following breast-conserving surgery (BCS) and radiation therapy (RT) for invasive cancer is not known. Purpose: To investigate the role of MGD as a risk factor for LR in patients with invasive breast cancer who have undergone BCS and RT.

Methods: A retrospective analysis was performed among 139 women who presented to UCSF or California Pacific Medical Center for primary AJCC Stage I-II breast cancer diagnosed between 1982-1999, who had BCS and RT, and mammographic density reading prior to or at the time of breast cancer diagnosis. Median follow-up was 7.4 years (range 2.1-16.3 years). Mammographic breast density was previously quantified using a validated computerbased threshold. The craniocaudal view was digitized using a Lumisys LumiScan 200 radiographic films digitizer (Kodak,Inc). The mammographic image was divided into a distribution of gray values using a computer-automated system, with darker regions representing adipose tissue and lighter regions representing dense tissue. The percentage of dense tissue in the breast was determined by dividing the number of pixels outlined in the dense regions by the total area of the breast.

A multivariate cox proportional hazards model was used to analyze factors for their association with local recurrence. Factors included in the analysis were patient age, tumor size, number of nodes positive $(0,1-3, \geq 4)$, tumor grade, estrogen receptor status, progesterone receptor status, surgery, chemotherapy, hormone therapy, body mass index (BMI, $\mathrm{kg} / \mathrm{m} 2$ ) and MGD (quartiles).

Results: Within the follow-up period, there were 18 local recurrences (LR), 18 distant recurrences (DM) and 7 contralateral breast cancers $(\mathrm{CBC})$. The site of first failure was LR in 18, DM in 16 and $\mathrm{CBC}$ in 7 . In the multivariate logistic regression model, MGD was the most important independent predictor of local recurrence with a hazard ratio (HR) of 2.60 (95\% confidence interval=1.35-4.99). In addition, BMI was also significantly associated with LR and progesterone receptor expression was associated with a lower risk for LR (Table 1). Table 1. Multivariate Model

Variable

$\begin{array}{lll}\text { Progesterone Receptor } & 0.19 & 0.037(0.04-0.91) \\ \text { BMI } & 1.31 & 0.001(1.11-1.55)\end{array}$

Conclusions: MGD was the most important factor in predicting for local recurrence after BCS and RT. Progesterone receptor expression and BMI were additional factors associated with LR. These findings suggest that a subset of women with high MGD may need more aggressive local treatment. Further studies are needed to determine how MGD, BMI and progesterone receptor may be acting in concert to modify risk for LR.

\section{6}

Effect of 4-hydroxytamoxifen gel treatment on breast density and safety in premenopausal women.

Harvey JA, McTiernan A, LeNestour E. UVA Health System, Charlottesville, VA; Fred Hutchinson Cancer Research Ctr, Seattle, WA; Besins International, Paris, France

Background: Breast density is a significant risk factor for breast cancer. Tamoxifen reduces breast density, but time to response may be slow, acute adverse effects (AE) decrease compliance, and long-term use increases health risks. The study's goal was to determine the effect of 4-OHT gel on breast density and assess 
tolerability in healthy premenopausal women. 4-OHT is a potent antiestrogen delivered percutaneously, thus avoiding $1^{\text {st }}$-pass liver metabolism. Materials and Methods: Otherwise healthy premenopausal women (18-45 yrs) with $50-80 \%$ breast density $(n=61)$ and $>80 \%$ breast density $(n=19)$ were enrolled in a stratified manner to this randomized, double-blind, phase 2 study of 2-mg/ day 4-OHT gel vs placebo. Primary efficacy endpoint was $>10 \%$ decrease in breast density relative to placebo (responder), based on digitized analysis at 6 mo. Secondary endpoints included treatment effect at $4 \mathrm{mo}$ and several safety/tolerability parameters. Paired mammograms from each participant were digitized at $100 \mu \mathrm{mm}$ pixel size with 14 -bit precision and read by blinded investigator. All mammograms were performed at the same day of menstrual cycle as baseline mammogram \pm 7 days. Breast density was assessed using left craniocaudal (CC) view or with right $\mathrm{CC}$ view if left positioning between $\mathrm{CC}$ views was noticeably different. Results:

$\geq 10 \%$ Reduction in Breast Density After 6 \& 4 Months of 4-OHT Gel (Efficacy Evaluable Population) in $50-80 \%$ group at 4 mo. However, multivariate logistic regression with treatment group as independent variable showed pts in 50$80 \%$ group treated with 4-OHT had 8.6 times higher likelihood of being responders at 6 mo than placebo pts (CI, 1.07-69.5) and that women $<40$ yrs had 7.1 times higher likelihood of success than women $>40$ yrs (CI, 0.93-54.5). No drug-related serious adverse event occurred in any treatment group. There were no significant clinically relevant changes in hot flash episodes and no menstrual cycle disruption following exposure to 4-OHT. Discussion: The study suggests transdermal 4-OHT may have some effect on breast density. However, a cleaner effect of 4OHT gel on breast density may have been obscured by age, which in a logistic regression model showed large effect on treatment outcome. A larger, longer trial assessing efficacy of 4-OHT gel on breast density is warranted because (1) duration of follow-up may have been too short; (2) dose may have been too low; and (3) safe and tolerable options for chemoprevention remain an important need. 4-OHT gel was safe and tolerable, consistent with a highly favorable safety/tolerability profile seen in a previously reported cyclic mastalgia trial.

\section{7}

Baseline radiological staging in primary breast cancer: impact of an educational intervention on adherence to published guidelines.

McWhirter E, Yogendran G, Fralick $J$, Sue J, Fralick M, Wright $F$, Dranitsaris G, Clemons M. Sunnybrook and Women's Health Sciences Centre, Toronto, ON, Canada

Background: The purpose of baseline radiological staging in breast cancer patients is to rule out distant disease. We have previously reviewed the use of radiological staging at our institution, in comparison to those recommended by the Cancer Care Ontario Practice Guidelines Initiative (CCOPGI). These guidelines recommend no radiological staging for pathological Stage I; bone scan for Stage II; bone scan, chest x-ray (CXR), and abdominal ultrasound (US) for Stage III. The results showed that from January 2000 to December 2002, a high proportion of the 135 patients analyzed underwent unnecessary investigations.

Objectives: To implement an educational intervention for the staging guidelines, and then re-assess the extent of radiological investigations.

Methods: In January 2003, multidisciplinary educational rounds were held, highlighting the CCOPGI guidelines in the context of the staging investigations taking place at our institution. Subsequent to this, the staging guidelines were included in the Clinical Practice Guidelines of the Breast Disease Site Group, Toronto-Sunnybrook
Regional Cancer Centre (TSRCC). By retrospective chart review of a random sample of patients, $(\mathrm{N}=132)$, we have now analyzed the staging investigations for a similar group of patients from January 2003 to April 2005, to explore the effects of these educational interventions on actual practice.

Results: For patients with Stage I breast cancer, there was a significant decrease $(\mathrm{p}<0.004)$ in each type of investigation: $37 \%$ of patients had a CXR (a 2-fold decrease); $23 \%$ of patients had a bone scan (2.5-fold decrease) and $14 \%$ of patients underwent abdominal US (4-fold decrease). For patients in Stage II, there was no significant change in the proportion of patients undergoing radiologic investigations, with approximately $50 \%$ of patients having CXR's and bone scans, and $40 \%$ of patients having an abdominal US. For patients with Stage III disease, there was a nonsignificant trend towards appropriately receiving all 3 investigations, with $65 \%-75 \%$ of patients undergoing imaging.

Conclusions: Our results demonstrate that prior to the educational interventions many patients with early breast cancer were undergoing inappropriate radiological staging. Since 2003 however, for Stage I patients there has been a significant improvement in adherence with the guidelines, and a nonsignificant trend towards improvement in Stage III patients. We hypothesize that our educational intervention had a positive impact on improving the utilization of baseline radiological staging in patients with primary breast cancer. Staging in accordance with these guidelines may have both an economic and psychological impact.

\section{8}

\section{Discomfort and pain during mammography.}

Freitas Junior R, Fiori WF, Ramos FJF, Godinho E, Rahal RMS, Oliveira JG. Hospital Araujo Jorge, Goias Anticancer Association, Goiania, GO, Brazil; Clinica ARO, Goiania, GO, Brazil; Goias Federal University, Goiania, GO, Brazil

Introduction: Mammography is the most important method for early detection of breast cancer. However, patients frequently complain of discomfort and pain. Objective: Evaluating how often discomfort and pain are felt during a mammography and identifying factors that may be associated to these complaints. Methods: Prospective study including 2,164 patients recruited from the public $(996)$ and private $(1,168)$ health services. After the imaging procedure, patients quantified the pain using a linear analogical scale. Discomfort was qualitatively evaluated through multivariate analysis. Results: Discomfort was reported by $90 \%$ of the patients, and of these women, $12 \%$ rated the sensation as intense or intolerable. Only $2 \%$ of the women in the study group did not feel any pain during the procedure. Factors associated to the pain were: patient age, use of birth control methods (BCM), previous mastalgia and patients from the private health sector. Discomfort was independently associated to the service where the procedure was performed $(\mathrm{OR}=2.50 \mathrm{IC} 1.64-5.17)$ and to previous mastalgia (OR $=3.15$ IC 1.96-7.12). When asked about a repeat mammography, $98 \%$ of the patients said they would comply. Conclusion: Young women (<50 years), BCM users, mastalgia patients and women who were using the services of a private clinic felt more intense pain and discomfort during the mammography.

\section{9}

Estrogen receptor alpha gene polymorphisms and mammographic density in postmenopausal women without hormonal therapy.

Kemp C, Ramos EHM, Silva IDCG, Chambo D, Nogueira de Souza NC. EPM-UNIFESP, São Paulo, SP, Brazil

Background: Genes that encode proteins involved at biosynthesis, action and metabolism of sexual steroids are polymorphic. This condition represents individual responses to sexual hormones that could explain individual variations in mammographic density. The present research intends to verify the eventual association between 


\section{S208 Abstracts - Poster Session V}

polymorphisms Hae III and Msp I, from estrogen receptor alpha gene, and mammographic density in postmenopausal women. Material and Methods: The study included 115 postmenopausal women not in use of hormonal therapy and also without clinical or mammographic breast lesions. All of them underwent bilateral mammography and radiology density was determined by two independent observers, considering the ACR-BIRADS ${ }^{\circledR} 2003$ classification of mammographic patterns. In order to obtain a numerical value for breast density, and knowing that left breast is more affected by cancer, mammographic images from left medium lateral oblique incidences were captured and digitalized through a CX312. T scanner (Radiographic Digital Imaging, Compton, CA, USA). Density was calculated using the gray scale histogram from software adobe Photoshop 7.0. Oral swabs were obtained to extract DNA, following the Kit GFXÒ from Amersham-Pharmacia protocol to oral cells. After DNA extraction, PCR-RFLP (Polymerase Chain Reaction - Restriction Fragment Length Polymorphism) was performed to analyze the presence of polymorphisms in Intron 1 from estrogen receptor (HaeIII e MspI).

Results: Alpha estrogen receptor HaeIII (heterozygous - 29.6\%; mutated $-7.8 \%$; normal $-62.6 \%$ ) and alpha estrogen receptor MspI (heterozygous - 47\%; mutated - 36.5\%; normal $16.5 \%$ ).After variables analysis (age, menopausal age, parity, smoker, breast feeding, age of first delivery), we found no significant association of mammographic density with the assessed polymorphisms. Only age at menarche and Body Mass Index (BMI) showed significant association independent of the observer classification, once they agreed in their results.

Discussion: There was not found significant association when analyzing polymorphisms and the most part of variables, probably due to the sample size. More researches are needed to find out a reliable relationship between receptor estrogen alpha gene polymorphisms and mammographic density.

\section{0}

Significant improvement in the diagnosis of breast lesion by means of real-time elastographie.

Thomas A, Fischer $T$, Kristiansen $G$, Lichtenegger $W$, Kuemmel $S$. University of Berlin, Charité, CCM, Berlin, Germany; Institut of Pathology, University of Berlin, Charité, CCM, Berlin, Germany

Background: Real-time elastography was carried out in 108 candidate patients with histologically confirmed findings as a new, non invasive method for the diagnosis of mammary carcinoma. The goal of the study consisted of testing the suitability of the method for tumour diagnosis in clinical practice.

Materials and Methods: Differences between healthy and tumour tissue were visualised by measurements of elasticity, based on the correlation between tissue properties and elasticity modulus. The study contained 108 female potential breast cancer patients with histologically confirmed focal signs ( 58 benign, 50 malignant) in the age range of 16 to 84 years old. Evaluation was made with the 3D Finite Element method (Hitachi Eub 8500) and was colour coded and superimposed on the ultrasound scan in brightness mode (B-mode). The results were compared with the data of previous ultrasound investigations and histology, and were statistically assessed with the aid of matrices and ROC curves. A second examiner was employed, in order to evaluate the objectivity of the method. Results: The study showed that the correspondence between elastography and ultrasound in the BIRADS classification of mammary carcinoma was good. Assessment in McNemar's Test gave a weighted kappa of $0.5565-0.7751$. Benign tissues were recognised with certainty, although malignant findings resulted in significant differences compared to the histological results which were moreover dependent on the examiner $(\mathrm{p}=0.008 / 0.012)$ Overall, elastography possesses a sensitivity of $91 \%$ and a specificity of $83 \%$. ROC curve results gave a sensitivity of elastography from BIRADS 3 and more advanced stages of $92 \%$, compared to the B-mode scan of $98 \%$. The sensitivity is at $53 \%$ compared with the B-mode of $47 \%$.
Conclusion: The conclusion is measurement of tissue elasticity by means of realtime elastography combined with the familiar B image improves significant diagnosis of breast lesions. Additiona the method can be integrated easily into daily clinical practise.

\section{1}

Menstrual-cycle dependence of breast parenchyma elasticity determined by realtime sonoelastography: finding the optimal time for examination.

Wojcinski S, di Liberto A, Cassel M, Ertan AK, Schmidt W. University of Saarland, Homburg, Germany

Background: Realtime sonoelastography of the breast is a promising diagnostic method that enables a highly accurate estimation of the tissue elasticity distribution. Like colour Doppler, sonoelastography can be performed with conventional ultrasound probes and does not require additional instruments. The examination results are represented in colour in addition to the conventional B-mode image. With the additional information, lesions can be classified with higher accuracy than with conventional ultrasound, and even lesions invisible on B-mode images can be detected. It is yet unclear, which time is the best during the menstrual cycle to perform elastography. The aim of this study was to examine the changes in breast tissue elasticity during the menstrual cycle using realtime sonoelastography.

Materials and Methods: 23 healthy volunteers (age 18-33, median 22) without breast disease and without history of lactation were examined once a week during 2 menstrual cycles resulting in a total of 184 measurements. Group $1(n=11)$ was without any hormonal treatment and had a regular cycle, group $2(n=12)$ took contraceptive medication. Examinations were performed with the sonoelastography module that can be integrated into the platform of the HITACHI EUB-8500 system. Each elastographic image was acquired at a defined breast segment using the HITACHI EUP-L53L long-linear probe $(92 \mathrm{~mm}, 10 \mathrm{Mhz}$, with adapted waterbag). The elasticity of the skin, fibroglandular tissue and fatty tissue was analyzed and the median values of elasticity over the menstrual cycle were determined.

Results: All volunteers presented a repeating pattern concerning the parenchyma elasticity during 2 cycles. Generally parenchyma was softer in group 1 than in group $2(p=0.02)$. Group 1 showed continuously decreasing parenchyma elasticity during the menstrual cycle with relatively soft parenchyma during the follicular phase and harder during the luteal phase $(\mathrm{p}=0.0002)$ Group 2 presented constant values during the 3 weeks of hormonal intake and significantly softer parenchyma only during the menstrual phase $(p=0.001)$. The elasticity of fatty tissue was independent of contraceptive medication and menstrual cyclicity. The skin showed significant different elasticity distribution in the two groups. Women taking hormones presented a homogenous elasticity whereas women without hormonal treatment had an irregular distribution of skin elasticity $(\mathrm{p}=0.002)$.

Discussion: Previous studies using MRI and clinical examination have already demonstrated the menstrual-cycle dependence of breast parenchyma elasticity. These changes can also be demonstrated with the use of the new method of realtime sonoelastography. Regarding elastography as a tool to find and evaluate breast lesions, the best time to perform the examination seems to be during the menstrual phase, because malignant breast lesions present as hard tissue and therefore can be better located in the relatively soft surrounding fibroglandular tissue. 
5012

Clinicopathological and radiological characteristics of screening ultrasound-detected breast cancers with negative mammography findings.

Hwang SE, Han WS, Cho N, Park IA, Hwang KT, Lee JE, Shin HJ, Kim SW, Moon WK, Noh DY. Seoul National University Hospital, Seoul, Korea

Purpose: Mammographically dense breast tissue can be a cause of false-negative findings on mammography. This study aimed to evaluate radiological and clinicopathological features of screening ultrasound (US)-detected breast cancers.

Material and methods: For last five years, 23,129 women at average or high risk of breast cancer with dense breasts underwent supplemental screening US in addition to mammography. Thirtytwo surgically proven cancers from different individuals (aged 3665 ; mean 46.6 years) were identified by US alone and were not seen on mammography, even in the retrospective review. Eighty consecutive screening mammography-detected cancers and 80 biopsy-proven nonpalpable benign masses were selected for a control group. Two experienced radiologists blindly analyzed US images of these 192 lesions without mammographic information and provided final consensus assessment according to the ACR BIRADS US lexicon.

Results: Significant differences between US and mammographically detected cancers were found for the following US findings: shape (oval or round $31.3 \%$ vs $10 \%$, irregular $64.7 \%$ vs $90 \% ; p=0.007$ ), margin (circumscribed $21.9 \%$ vs $3.8 \%$, spiculated $0 \%$ vs $18.8 \% ; p=0.006$ ), boundary (abrupt interface $87.5 \%$ vs $52.5 \%$, echogenic halo $12.5 \%$ vs $47.5 \%$; $p=0.001$ ), posterior acoustic features (no posterior echo $59.4 \%$ vs $52.5 \%$, shadowing $15.6 \%$ vs $30.0 \%$; $p=0.008$ ), and final assessment (category $4 \mathrm{a}: 31.3 \%$ vs $8.8 \%$, category $4 \mathrm{~b}: 25.0 \%$ vs $22.5 \%$, category $4 \mathrm{c}: 31.3 \%$ vs $28.8 \%$, category $5: 3.1 \%$ vs $37.5 \%$; $p=0.001$ ). Screening US-detected cancer was smaller (mean $1.34 \mathrm{~cm}$ vs $2.27 \mathrm{~cm} ; p<0.001)$, often stage I invasive carcinomas $(68.8 \%$ vs $43.8 \% ; p=0.008$ ), and lower histologic grade (grade $1: 39.1 \%$ vs $3.8 \%$, grade $2: 43.5 \%$ vs $65.4 \%$, grade $3: 17.4 \%$ vs $30.8 \%$; $p<0.001$ ) than mammographically detected cancer. However, there was no statistically significant difference between the two groups for nodenegativity and proportion of in situ cancer. In immunohistochemical staining, the US-detected cancer showed lower ER expression (50\% vs $73.1 \% ; p=0.023$ ) and lower c-erbB2 expression ( $30.0 \%$ vs $55.1 \%$; $p=0.019)$. Regarding operation method, breast conserving surgery was performed more frequently for US-detected cancer ( $68.8 \%$ vs $52.5 \%$; $p=0.015)$ Conclusion: US-detected breast cancer was often an oval or round mass without boundary echo and posterior acoustic change. The majority of screening US detected cancer was stage I invasive carcinomas. The advantage of screening breast sonography in the population of women with dense breast was a potential to detect small breast cancers that are not found on mammography or clinical breast examination and to increase the breast conservation rate. The use of US as an adjunct to screening mammography in women with increased risk of breast cancer and dense breasts may be especially beneficial.

\section{3}

Is ultrasound useful in the management of patients with ductal carcinoma in situ?

Zager JS, Al-Refaie WB, Hunt KK, Khakpour N, Kuerer HM, Lin E, Yen T, Stephens T, Feig BW, Ames FC, Singletary SE, Ross MI, Babiera GV. MD Anderson Cancer Center, Houston, TX

Background: Mammography (MMG) is the gold standard for screening and detection of ductal carcinoma in-situ (DCIS) of the breast.Recently, ultrasound (US) technology has improved making it a reliable tool. We sought to elucidate the role of US in the management of patients (pts) with DCIS by determining 1) the accuracy of US in estimating pathologic tumor size (PATH) compared to MMG and 2) the ability of US to detect foci of invasive disease in the breast or metastatic disease in the axilla. Methods: Following institutional review board approval, 248 pts were identified who received treatment at our institution from 1999 to 2004 after a diagnosis of DCIS by core $(n=200)$ or excisional $(\mathrm{n}=48$ ) biopsy (bx) for diagnosis. Data analysis was performed on 172 pts who had identifiable lesions visualized on US. Of these 172 pts, 135 (68\%) had an US of the ipsilateral nodal basins as well. Clinicopathologic (demographics, nuclear grade, receptor status, final pathologic diagnosis, tumor size and nodal status), and radiologic (size of the lesion on US and MMG, and axillary US findings) variables were evaluated. Statistical analysis was performed using chi square, linear regression models, and Fisher's exact test. Results: The mean size of the lesions on US, MMG and PATH were $1.6,2.9$, and $2.5 \mathrm{~cm}$, respectively. Overall, there was a stronger correlation between MMG size and PATH than US size and PATH, $r^{2}=0.73$ and 0.44 , respectively. Of the 172 pts with identifiable lesion(s) on US, $28(16 \%)$ were diagnosed by excisional bx and $144(84 \%)$ were diagnosed by core bx. There was no significant association between US size and PATH for either method of diagnosis. US upstaged 7 (4\%) of the 172 pts by identifying invasive disease. Of the 49 pts who had axillary US and FNA of a suspicious node, final surgical treatment was changed in $2(4 \%)$ of the 49 pts due to findings of axillary nodal metastasis. On univariate analysis, there was no significant association between US findings and PATH, nuclear grade, or findings of invasive disease final PATH. Analysis of the relationship between tumor size on US and PATH stratified by age groups (age $\leq 50$ or $>50$ ) revealed a significant association for those pts $>50 \mathrm{y}(\mathrm{p}<0.006)$, whereas MMG size significantly correlated with PATH for both age groups $(\mathrm{p}<0.001)$.

Conclusions: $M M G$ is the gold standard in the screening and detection of DCIS. Overall, MMG correlated better with final PATH than did US. There appears to be minimal benefit in using US along with MMG to detect additional disease in the breast or nodal basins for pts with DCIS. US did not outperform MMG for younger pts with dense breasts ( $\leq 50$ years old). Cost-benefit analyses are needed to determine the overall usefulness of US in the preoperative assessment of pts with DCIS.

\section{4}

Preoperative FDG-PET/CT can change the tumour stage in locally advanced breast cancer.

Segaert I, Neven P, Ceyssens S, Amant F, Berteloot P, Leunen K, Smeets A, Wildiers H, Paridaens R, Vergote I, Christiaens MR. UZLeuven, Leuven, Belgium

Background: The feasibility and accuracy of FDG-PET in breast cancer has been demonstrated in a recently published meta-analyses (Breast Cancer Res Treat 2005;90:105). However, the clinical interpretation of FDG-PET can be difficult because (1) anatomical localisation of FDG uptake is not easy and (2) normal physiological accumulation of FDG can be misinterpreted as a pathologic area. The functional anatomic fusion imaging with FDG-PET/CT has the potential to improve this interpretation. Only a few studies have been conducted on the potential role of FDG-PET/CT in breast cancer patients. We compared conventional preoperative staging and FDG-PET/CT in women with a locally advanced breast cancer.

Materials and methods: Single institution prospective study of selected patients with a biopsy proven breast cancer stage $\geq$ IIB (revised AJCC) between July 2003 and April 2005. All patients underwent conventional staging with biochemistry, chest X-ray, bone scanning and liver ultrasound followed by FDG-PET/CT. We examined whether FDG-PET/CT identified metastatic disease better than conventional imaging and how often patients were classified as metastatic on the basis of PET-CT only.

Results: A total of 75 patients matched the inclusion criteria. 14 women underwent primary surgery with classical axillary clearance, 37 neoadjuvant therapy and 24 women were considered metastatic. Two patients had a FDG-PET/CT negative breast tumour. Eight 


\section{S210 Abstracts - Poster Session V}

patients out of the 14 with primary axillary clearance were lymph node positive. In this group, clinical examination together with axillary ultrasonography had a higher positive predictive value (6/ 8) than FDG-PET/CT (5/8). Twenty four patients had distant metastases according to the revised AJCC. In 19 patients this diagnosis was based on conventional staging. In one of these patients the tumour was negative on FDG-PET/CT. In all other 18 cases, FDG-PET/CT was also positive. FDG-PET/CT did find another metastatic localisation as compared with conventional imaging in 13 of the 19, mainly in mediastinal nodes (8), lung (5), pleura (1), kidney (1) and bone (1); another primary tumour (GIST) was detected in 1 case. In 5 other patients FDG-PET/CT did localise at least one metastatic deposit not diagnosed with conventional imaging: mediastinal lymph nodes (4), lung (1), pleural metastasis (1), and bone metastases (1). If all women would have had CT scanning for conventional imaging 2 with a positive FGD-PET would be missed; both with positive lymph nodes in the mediastinum.

Conclusion:In our series FDG-PET/CT did change staging and therapy in $5 / 75$ patients with a locally advanced breast cancer. The use of a FDG-PET/CT may identify extended disease earlier than conventional imaging methods and thus influence treatment decisions. FDG-PET/CT can influence the planning of treatment at staging in patients with locally advanced breast cancer.

\section{5}

\section{Evaluation of 18-FDG PET in initinal staging of the axilla} in breast cancer.

Jeong J, Lee S, Yoon S, Lee I, Ryu Y, Jung W, Lee H. Ongdong Severance Hospital, Yonsei University College of Medicine, Seoul, Republic of Korea

Background: Although sentinel lymph node biopsy(SLNB) has increased in frequency as an alternative procedure, axillary lymph node dissection(ALND) is still preformed in most women with invasive breast cancer. ALND has well known complication like lymphedema and other upper extremity discomforts. SLNB is an effective and accurate method and has become the standard care for evaluating the axillary lymph nodes in breast cancer patients. However, for successful SLNB, the surgeon should be sufficiently trained before practice. ${ }^{18} \mathrm{~F}$-fluorodeoxyglucose-positron emission tomography (FDG-PET) is a noninvasive imaging modality that can detect malignant lymph node. We evaluated the accuracy of FDG-PET as a method for axillary lymph node staging by comparision with the pathologic findings of ALND and SLNB.

Material and Methods: Between March 2004 and April 2005 , 79 breast cancer patients were entered into this study. FDG-PET was performed within 3 days before surgery. PET scanning was carried using the $10 \mathrm{mCi}(370 \mathrm{MBq})$ FDG. Patients fasted for at least 6 hours before PET scanning and their serum glucose level was controlled below $115 \mathrm{mg} / \mathrm{dl}$. Visual analyses of attenuationcorrected PET images were compared with histopathologic findings.

Results: PET correctly diagnosed axillary metastasis in 65 of the 79 cases; three false- positive and eleven false-positive results were found. The overall sensitivity, specificity and accuracy of PET for axillary metastasis were $68 \%, 93 \%$ and $82 \%$, respectively. After surgery, 34(43.0\%) of the 79 cases showed axillary lymph node metastasis. Seventeen out of the 34 cases were belonged to $\mathrm{N} 1 \mathrm{a}, 12$ cases were $\mathrm{N} 2 \mathrm{a}$ and 5 were $\mathrm{N} 3 \mathrm{a}$. The detection rate of axillary metastasis by PET was $80 \%(4 / 5)$ in N3a group, $75 \%(9 /$ 12) in N2a group and $59 \%(10 / 17)$ group. The less the number of axillary node metastasis is, the lower the detection rate is $(\mathrm{p}<0.05)$. As the axillary node metastasis cases were grouped according to the biggest metastasis size, 6 cases were belonged to $\leq 0.5 \mathrm{~cm}, 11$ cases were belonged to bigger than $0.5 \mathrm{~cm}$ and none bigger than $1.5 \mathrm{~cm}$, and 4 cases were belonged to $>1.5 \mathrm{~cm}$ (Metastasis size was measured in 21 cases). When the metastasis size was $\leq 0.5 \mathrm{~cm}$, the detection rate was $33.3 \%(2 / 6)$, in bigger than $0.5 \mathrm{~cm}$ and none bigger than $1.5 \mathrm{~cm}$ group, the detection rate was $72.7 \%(8 / 11)$, and
$75 \%(3 / 4)$ in bigger than $1.5 \mathrm{~cm}$ group. Metastasis size is also significantly related to the detection rate $(\mathrm{p}<0.05)$. Extra noda extension was found in 14cases and thirteen out of 14 (93\%) cases were detected by PET.

Discussion: PET showed relatively good overall diagnostic accuracy in the detection of axillary metastases( $82 \%)$. In case of small number of metastasis and small size of metastasis, false negative rate was high. However, because of relatively high specificity and positive predictive value, omitting SLNB and forging ALND may be considered in positive axillary metastasis cases detected by PET.

\section{6}

Cone beam breast CT - a feasibility study with surgical mastectomy specimens.

Yang WT, Shaw CC, Chen L, Altunbas C, Wang T, Lai CJ, Cheenu $K$, Tu SJ, Liu X, Whitman GJ. The University of Texas M. D. Anderson Cancer Center, Houston, TX

Background: X-ray mammography has been an important tool in the screening, diagnosis and management of breast cancers. However, the effectiveness of mammography, conventional or digital, has been compromised by the overlapping of cancers with breast anatomy in the projection views. Tomosynthesis imaging may partially overcome this limitation but its image quality suffers from a crude depth resolution and associated artifacts. Cone beam CT technique, on the other hand, can provide true 3-D breast images with isotropic resolution $(140 \mu \mathrm{m}$ or smaller) and no reconstruction artifacts. We have constructed a flat panel detector based cone beam CT system to investigate the feasibility of using it for dedicated breast imaging.

Materials and Methods: The experimental system consists of a general radiography tube pointing at a $30 \times 40 \mathrm{~cm}^{2}$ a-Si/CsI flat panel detector (Paxscan 4030CB, Varian Medical Systems, Salt Lake City, UT). A motor driven rotation stage is used to hold and rotate the specimen to simulate dedicated breast CT imaging in which the patient would lie on a table in supine position with one breast drawn downward through an opening to allow the x-ray tube and detector to rotate around and scan the breast beneath the table. The scans are performed at $50-80 \mathrm{kVp}$ with a voxel size of 140 or $300 \mu \mathrm{m}$. The dose level is estimated to be $1.5-1.8 \mathrm{cGy}$ at the isocenter, corresponding to 2.5-3 times of the mean glandular dose limit ( $0.6 \mathrm{cGy})$ for two view mammograms of a $5 \mathrm{~cm}$ thick compressed breast.

Results: The mean scanning time is 12 seconds for low resolution (binning) mode which is adequate for visualizing tissue structures, and 48 seconds for high-resolution (non-binning) mode necessary for visualizing small calcifications. Artifacts encountered from high density metallic tumor marker coils are successfully removed or reduced by post-processing techniques without compromising tissue detail. Structured noise is minimal due to absence of overlapping. Breast anatomy is well resolved on all images as skin, adipose and glandular regions. Image noise is visible but low as compared to the tissue contrast. Clear visualization of $250 \mu \mathrm{m}$ or larger calcifications is successfully demonstrated. The detection of cancers is based on morphological assessment of tissue structures that is improved compared to mammography due to lack of overlapping. Cancer is visualized as an area of architectural distortion, an irregular spiculated mass with associated microcalcifications, or an irregular mass with overlying skin thickening.

Discussion: Cone beam breast images demonstrate exceptional tissue contrast that tomographic images of the breast can provide, and can potentially reduce exam time with comparable radiation dose and eliminate the need for compression and additional workup views that is routine with mammography. 
5017

A chart review of method of detection of contralateral breast cancers in two different age cohorts of patients.

Robinson AG, Speers C, Olivotto I, Chia S. British Columbia Cancer Agency, Vancouver, BC, Canada

Background: Screening for a contralateral breast cancer after an initial primary breast cancer diagnosis typically consists of annual mammography and physician physical exams at 6 monthly intervals. Mammography is known to be less sensitive in younger women with denser breasts. Recent studies have demonstrated MRI to be superior to mammography as primary screening in patients at high risk for breast cancer (BRCA $1 / 2$ carriers or those with a strong family history). It is unknown at this time if mammography screening for contralateral breast cancer works equally well in younger patients as compared to older cohorts. Methods: Patients with a contralateral breast cancer diagnosed between 1985 and 2004 following a prior diagnosis of a stage I-II breast cancer were identified from the BCCA Breast Cancer Outcomes Unit database. Patients were divided into two age cohorts based on the age at which they developed their primary cancer: $<40$ y (Group A) and 55-60y (Group B). Information regarding characteristics of the initial and contralateral tumours was recorded, as well as method of detection of the contralateral breast cancer. Chi square and student t-test were used for between group comparisons.

Results: Out of 240 patients identified, we have currently collected full data on 140 patients. Younger patients (age $<40$ years) were significantly less likely to have their contralateral breast cancer detected by screening mammography compared with the older cohort $(20 \%$ vs $60 \%, \mathrm{p}<0.001)$. The contralateral breast cancers diagnosed in younger patients were more likely to be ER negative (63\% vs. $30 \%, \mathrm{p}=0.002)$, grade 3 (64\% vs. $37 \%, \mathrm{p}=0.002)$, and trended towards being larger in size. Conversely, tumours detected by mammography were more likely to be of a lower grade, ER positive, and smaller in size.

Conclusions: Older patients are much more likely to have a contralateral breast cancer detected by mammography, while younger patients are more likely to present with physical exam abnormalities or with symptoms. A one size-fits all approach to detection of a contralateral breast cancer may not be justified, particularly for younger patients. Full data and statistical analysis will be obtained prior to presentation.

\section{8}

Local recurrence rates in screen detected breast cancers from 1996-1997.

MacNeill FA. East of England Screening Quality Assurance Reference Centre, Cambridge, United Kingdom

Background: Recurrence rates, a surrogate measure of surgical and adjuvant therapy are not routinely monitored in the UK national screening programme (NHSBSP), yet increasingly women are encouraged to seek out performance figures when choosing providers. For a screened population with early disease the combination of very low local recurrence rates and small numbers limits meaningful interpretation of individual institutional data. A collaborative approach may be the answer.

Methods: In 1996-7 the East of England region NHSBSP screened 110,000 women between 50-65yrs. All resulting cancers were identified from the regional NHSBSP data base. Each screening unit then retrieved pathology, therapy and relapse data from clinical records. Missing data was actively recovered and regional cancer/ death registers interrogated.

Results: 709 NHSBSP cancers were identified from 11 units (range 21-116) of which 563 were available for analysis from 10 units: one unit was unable to participate. $123(22 \%)$ cancers were in-situ (30\% were high grade, mean size 16mm) and $427(76 \%)$ invasive of which $60 \%$ were good or excellent prognosis using the Nottingham Prognostic Index. Age at diagnosis 58yrs. Mean time to recurrence 4.2 years (62yrs). Median follow-up 6years. All relapses for in-situ disease occurred following breast conservation (BCT):70\% recurred as invasive disease but none were node positive on relapse. High grade DCIS accounted for $30 \%$ of the total but $50 \%$ of the relapses. Margins were originally reported as clear in $90 \%$ of in-situ relapse.

$\begin{array}{llllll} & \text { BCT } & \text { Radiotherapy } & \text { Tamoxifen } & \text { Local relapse } & \text { Death } \\ \text { Insitu } & 79 \% & 29 \% & 54 \% & 9 \% & 0 \\ \text { Invasive } & 70 \% & 82 \% & 85 \% & 2 \% & 7 \%\end{array}$

In total $12 \%$ of woman died: $7 \%$ from breast cancer (BC) and $5 \%$ from other causes, No woman with DCIS or local relapse has died from BC. Time from distant relapse to death was 12 months.

Discussion: Our data collection was rigorous and deaths confirmed using well validated national cancer registers. Local recurrence rates for both in-situ and invasive disease are substantially below those published. Time from distant relapse to death is shorter than published. Regional collaboration has allowed us to collect meaningful data on local and distant relapse rates in a highly selected good prognostic group. Our units now have performance data available for public consultation.

\section{9}

An analysis of breast cancer recurrences for screen detected and symptomatic breast cancers diagnosed in the West Midlands in 1996 and 1997.

Lawrence G, Pritchard MG, Kearins O, Casey M. West Midlands Cancer Intelligence Unit, Birmingham, United Kingdom; Royal Wolverhampton Hospital NHS Trust, Wolverhampton, United Kingdom

Aim: To use routine cancer registration data to generate recurrence data for women diagnosed with screen detected or symptomatic breast cancer in the West Midlands region in 1996 and 1997. To compare the levels of ascertainment and data completeness achieved by passive (registration) and active (notes review) follow up.

Method: Over 4000 breast cancers are diagnosed annually in the West Midlands. Cancer registration data are obtained from routine clinical information sent to the West Midlands Cancer Intelligence Unit by pathology and radiotherapy departments. Recurrences in screen detected and symptomatic breast cancers diagnosed in 1996 and 1997 were identified from the cancer registration database. Recurrences occurring before December 2002 were included giving a median follow up of 70 months. For one hospital trust, an audit of the data available in the original patient notes was also undertaken in order to compare the levels of ascertainment and data completeness achieved by passive (cancer registration) and active (patient notes review) follow up.

Results: 6823 cancers (983 screen detected and 5840 symptomatic) were included. Median age at diagnosis was 57 for screen detected cases and 65 for symptomatic cases. To reduce the effect of the higher age at diagnosis among the symptomatically diagnosed cohort, 983 patients were sampled in a pseudo-random manner using random number tables to give a group of symptomatic patients with an equal median age and variance of age at diagnosis as the screen detected patients. There were $28(2.8 \%)$ local or nodal recurrences in the screen detected arm compared with 64 $(6.5 \%)$ in the symptomatic arm and $50(5.1 \%)$ and $152(15.5 \%)$ distant recurrences respectively. 37 women with a screen detected cancer died of their cancer during the study period compared with 129 symptomatic patients. The incidence of local recurrence decreased with increased margin size, distant metastases were more prevalent in the positive lymph node patients and recurrences increased with increasing grade. All types of recurrence increased with Nottingham Prognostic Index score. However, 92 cases in the Poor Prognostic Group did not have a recurrence. These cases had extensive radiotherapy (89\%) and chemotherapy (48\%). Conversely, 19 cases in the Excellent or Good Prognostic Group developed distant metastases and 10 died from breast cancer. These cases had poor nodal ascertainment $(22 \%$ had $<4$ nodes examined) and only $11 \%$ had chemotherapy. Active follow up identified 1 less recurrence and 6 fewer deaths than passive follow up. 


\section{S212 Abstracts - Poster Session V}

Cancer registries can provide accurate information on the incidence of recurrence in patients with breast cancer. Despite improvements in the management of the disease, there remains a significant difference in survival of women with a screen detected and symptomatic breast cancer independent of age at diagnosis.

\section{0}

Mammographic breast density, dense area and breast area by phase in the menstrual cycle.

Buist DSM, Aiello EJ, Miglioretti D, Mahoney L, White E. Group Health Cooperative, Seattle, WA; University of Washington, Seattle, WA

Background: For women under 50 years old, the question of screening efficacy has been controversial, in part because mammographic breast density is significantly higher in premenopausal women. Three small studies suggest that mammographic breast density may be lower in the follicular phase (days 1-14) of the menstrual cycle compared to the luteal phase (days 15-30), which may be influenced by lower circulating progesterone levels in the follicular phase.

Objective: To examine if percent breast density, breast area or dense area (all measured continuously) are greater in the luteal compared to the follicular phase of the menstrual cycle.

Methods: We identified 211 premenopausal women who met our eligibility criteria and had 2 mammograms within 9-18 months of one another, with 1 mammogram taken during days 9-14 and 1 mammogram taken during days 22-35 of the menstrual cycle. All women were members of a breast cancer screening program at Group Health Cooperative, an integrated health plan in western Washington State. We included women who were having regular periods ( $<35$ day cycles) and were $<55$ years at both mammograms. We excluded women who had previous breast cancer, bilateral biopsies, breast augmentation/reduction, or who used hormone therapy, raloxifene, tamoxifen, or oral contraceptives. We used Cumulus software developed at the University of Toronto to measure percent breast density, breast area, and dense area on the craniocaudal view of the left breast. We used linear regression, fitted with generalized estimating equations accounting for clustering within women, to test for change in densities from the follicular to luteal phase adjusting for age and body mass index (BMI) at each exam, time between exams and parity.

Results: Women were on average 45.6 years (standard deviation [SD] 4.1) and were normal weight (BMI 25.5 (6.0)). The mean (SD) percent breast density was $36.1 \%$ (21.3) in the follicular phase and $37.1 \%$ (21.6) in the luteal phase. Percent breast density decreased with age and BMI and increased with parity. Dense area decreased with BMI, increased with parity and had no association with age. Breast area decreased with age and parity and increased with BMI

Increase in breast density measures $(95 \% \mathrm{CI})$ from follicular to luteal phase

$\begin{array}{llc} & \text { Density increases* } & \text { p-value } \\ \text { Mammographic breast density (\%) } & 0.94(-0.47-2.36) & 0.19 \\ \text { Dense area (1,000 pixels) } & 19.3(-3.1-41.7) & 0.09 \\ \text { Breast area (1,000 pixels) } & 21.1(-9.8-52.1) & 0.18 \\ \text { *Adjusted for age and BMI at each exam, time between exams \& parity }\end{array}$

*Adjusted for age and BMI at each exam, time between exams \& parity

Conclusions: There are small but not clinically meaningful increases in percent breast density, dense area and breast area in the luteal phase of the menstrual cycle. However, there are other factors that may differ by menstrual cycle phase that we were not able to assess (e.g., breast compression), which may ultimately influence mammographic sensitivity by menstrual cycle phase.

\section{1}

Association of travel distance to mammography and breast cancer tumor size at diagnosis.

Schroen AT, Lohr ME. University of Virginia, Charlottesville, VA

Background: Access to screening mammography facilitates breast cancer early detection. We hypothesize that shorter travel distance to mammography is associated with smaller tumor size at diagnosis.
Methods: Data on all incident, female invasive breast cancer patients diagnosed in Virginia between 2000-01 was collected from the state cancer registry. Data included patient age at diagnosis, race, tumor size $(\mathrm{cm})$ and AJCC stage. Travel distance to the nearest mammography facility was calculated for each patient using ArcGIS 9.0 geographical software $(<=2 \mathrm{~km},>2-5 \mathrm{~km},>5$ $10 \mathrm{~km},>10-15 \mathrm{~km},>15-25 \mathrm{~km},>25 \mathrm{~km})$. Socioeconomic status was approximated by mean per capita income (PCI) by patient census tract from the 2000 U.S. Census $(<\$ 15 \mathrm{~K}, \$ 15<20 \mathrm{~K}, \$ 20<25 \mathrm{~K}$, $\$ 25-35 \mathrm{~K}, \$>35 \mathrm{~K})$. The outcome of interest was tumor size at diagnosis in relation to driving distance to nearest mammography facility, adjusting for patient age, race, and PCI.

Results: Of 9,482 eligible cases, 7,767 invasive cancer cases had known tumor size under $10 \mathrm{~cm}$. Mean tumor size was $2.1 \mathrm{~cm}$ (SD 1.6) with larger tumors more common in women $<40$ years of age, of non-white race, and living in census tracts with lower PCI $(<\$ 20,000)$. Mean distance to mammography was $9.1 \mathrm{~km}$, with $18 \%$ of women living $>15 \mathrm{~km}$ from the nearest mammography facility. Tumor size for screening-age women $(40+)$ varied minimally with travel distance to mammography $(2.1 \mathrm{~cm}$ at $<=2 \mathrm{~km}$; $2.0 \mathrm{~cm}$ at $>2-5 \mathrm{~km} ; 2.1 \mathrm{~cm}$ at $>5-10 \mathrm{~km} ; 2.0 \mathrm{~cm}$ at $>10-15 \mathrm{~km} ; 2.3 \mathrm{~cm}$ at $>15-25 \mathrm{~km} ; 2.1 \mathrm{~cm}$ at $>25 \mathrm{~km}$ ). In multivariate analysis, distance to mammography was not significant in relation to tumor size, adjusting for patient age, race, and PCI.

Discussion: Travel distance to mammography did not have a clinically significant impact on tumor size at diagnosis. Altering geographic access to mammography is unlikely to translate into earlier detection of breast cancer unless other access barriers are addressed simultaneously.

\section{2}

Resource and service implications of a screening clinic for women at increased breast cancer risk from a family history. Gui GPH, Kadayaprath G, Darhouse N, Ward A, A'Hern R, Self J, Eeles R. Royal Marsden NHS Foundation Trust, London, United Kingdom; Institute of Cancer Genetics, Institute of Cancer Research, London, United Kingdom

\section{Introduction}

The value of screening women at increased breast cancer risk from a family history remains controversial. Despite this, individual breast units in the United Kingdom are expected to offer screening to such women $<50$ years of age outside the auspices of the national programme. Little is known about recall rates, false negative outcomes and the impact on clinical service.

\section{Methods}

Screening consisted of annual clinical examination and mammography from the age of 35 years. The active audit period ran for four months and each patient was followed through a further screening cycle.

\section{Results}

1132 patients attended for their routine incident screen. 137 women were classified to be at high-risk (lifetime risk $\geq 25 \%$ ), 803 at moderate risk (lifetime risk $<16 \%$ ) and 192 at standard risk. Seven cancers were diagnosed during the 4 month study period at their incident screen. During follow-up, a further 10 patients were diagnosed with cancer ( 2 interval and 8 at the next screen). The total cancer incidence rate was $17 / 1132(1.5 \%) .13$ patients had invasive cancer and 4 ductal carcinoma in-situ. The median invasive tumour size was 15 (range 7-28) mm. 10/13 (76.9\%) invasive cancers were $\leq 20 \mathrm{~mm}$ and $2 / 13$ patients $(15.4 \%)$ were lymph node positive. The sensitivity and specificity of mammography was $85.7 \%$ and $98.8 \%$, leading to 20.3 radiology recalls per 1000 patients over the four month active audit period. The benign to malignant surgery ratio was $8: 17(0.5 \%)$.

\section{Conclusion}

Early breast cancer detection rates in family history breast clinics are comparable to that of older women attending the national screening programme. 


\section{3}

Diffuse optical spectroscopy: a novel laser-based approach for breast cancer diagnosis and screening in young women. Shah NS, Cerussi AE, Hsiang D, Yu H, Su M, Nalcioglu O, Tromberg BJ. Beckman Laser Institute, University of California, Irvine, Irvine, CA; University of California, Irvine Medical Center, Orange, CA; University of California, Irvine, Irvine, CA

Background: Diffuse Optical Spectroscopy (DOS) is a noninvasive, non-ionizing technique that quantitatively determines concentrations of biological components of breast tissue in vivo. DOS uses near-infrared light to quantify concentrations of deoxyhemoglobin (Hb-R), oxy-hemoglobin $\left(\mathrm{Hb}-\mathrm{O}_{2}\right)$, lipid and water which are related to several disease processes in the breast including angiogenesis, necrosis and increased metabolism and cellularity. Because DOS focuses on tissue function rather than structure it is not impeded by radiographic density. Thus DOS techniques may be suitable for screening and characterization of lesions in young women with dense breasts, a population where current radiographic techniques, such as X-ray mammography, have limitations.

Materials and Methods: A DOS instrument was used to determine a full near-infrared scattering and absorption spectra (600-1000nm) in 58 subjects (18 to 81 y.o) with malignant lesions. DOS-derived parameters were compared to the healthy contralateral breast in the same subject as a control. A Tissue Optical Index (TOI $=[\mathrm{Hb}-$ $\mathrm{R}][$ Water]/[Lipid]) was developed as a contrast function that relates to tissue metabolism. DOS results were validated using dynamic contrast-enhanced magnetic resonance imaging (DCE-MRI)

Results: DOS results for the subjects were segregated into five age groups: $<30,30-39,40-49,50-59$ and $>59$. The contralateral breast shows a strong age dependence on physiological parameters with a 6-fold difference in TOI between the $<30$ and $>59$ age group. Malignant tumor tissue shows an average of higher THC, water and scattering and lower lipid and $\mathrm{StO} 2$ than normal tissue $(\mathrm{p}<0.0001)$. Women $30-50$ y.o. $(\mathrm{n}=25)$ showed 3:1 contrast in TOI between normal and tumor tissue $(\mathrm{p}<0.0001)$. Co-localization with DCE-MRI shows increased THC in regions with increased contrast-enhancement and significant TOI contrast corresponding to MRI morphological information

Discussion: DOS can quantitatively characterize malignant lesions in vivo. In addition DOS can distinguish tumor tissue in pre-menopausal women with significant contrast. Thus DOS may be suitable as an adjunct to current techniques for screening in young women with high breast density.

\section{4}

Role of fine needle aspiration cytology as an adjunct to core biopsy in the diagnosis of screen-detected breast carcinoma.

Lieske B, Ravichandran D, Wright D. Bedfordshire and Hertfordshire Breast Screening Unit and Luton \& Dunstable Breast Unit, Luton, Bedfordshire, United Kingdom

Introduction: Core biopsy $(\mathrm{CB})$ has now largely replaced fine needle aspiration cytology (FNAC) in the preoperative assessment of breast cancer. We studied the contribution of FNAC, when done as an adjunct to $\mathrm{CB}$, to the pre-operative diagnosis in screendetected breast carcinoma.

Materials \& Methods: Data was prospectively collected for all women who attended the Bedfordshire and Hertfordshire Breast Screening Unit in England during 4 consecutive screening years (April 1999 - March 2003). During this period most women who attended for assessment of a screen-detected lesion had both FNAC and $\mathrm{CB}$ performed of the lesion. All women who had both tests performed and subsequently had malignancy confirmed by open biopsy were reviewed.

Results: During the 4-year period 150,840 women were screened, 2,994 were recalled for assessment of a screen-detected lesion and 843 cancers (DCIS or invasive) were diagnosed. In 771 cancers both FNAC \& CB were performed at assessment. Malignancy was subsequently confirmed by histological examination after open biopsy in all cases.

Cytology (C) and histology (B) results of the 771 cases

Unsatisfactory/ Benign Benign but Suspicious of Malignant Total Normal tissue (B2) of uncertain Malignancy (B5) $\begin{array}{lll}\text { only (B1) } & \begin{array}{l}\text { of uncertain Malignal } \\ \text { malignant }\end{array} & \text { (B4) }\end{array}$

$\begin{array}{lllllll}\text { potential (B3) } & & \\ \text { Unsatisfactory } & 5 & 2 & 4 & 6 & 44 & 61\end{array}$

(C1)

Benign (C2) 5

Atypia probably 0

benign (C3)

Suspicious of 8

Malignancy

(C4)

37

$7 \quad 18 \quad 12$

12

36

$\begin{array}{ll}36 & 78 \\ 17 & 29\end{array}$

78
29

$\begin{array}{lllll}3 & 7 & 19 & 68 & 105\end{array}$

FNAC missed the diagnosis (C2 or less) in 139 patients $(18 \%)$ and was inadequate $(\mathrm{C} 1)$ in $8 \%$. Most cytology failures occurred with lesions presenting as microcalcifications (25\% were $\mathrm{C} 1$ or $\mathrm{C} 2$ ). $\mathrm{CB}$ was $\mathrm{B} 2$ or less in in 54 patients $(7 \%)$. CB correctly diagnosed (B3 or above) $86 \%$ of the cancers missed by FNAC and FNAC diagnosed (C3 or above) $65 \%$ of those missed by CB. 19 cancers $(2.6 \%)$ were missed by both in the initial assessment and were picked up by subsequent assessment $(n=8)$ or open biopsy.

Conclusion: $\mathrm{CB}$ is better than FNAC at preoperative diagnosis of screen-detected breast cancer as it missed fewer cancers. However, FNAC is a useful adjunct as two-thirds of those cancers missed by $\mathrm{CB}$ were picked up by concurrent FNAC.

\section{5}

Molecular profiling of human breast cancer with serum mass spectrum data.

Zhang Y, Zhu L, Ru Q, Brzeski H, Liebman MN, Hooke J, Shriver CD. Windber Research Institute, Windber, PA; Walter Reed Army Medcical Center, Washington, DC

Background: Mass spectrum (MS) analysis identifies peptides by mass/charge ratio $(\mathrm{M} / \mathrm{Z})$ and is semi-quantitative. Sera from breast cancer patients enrolled in the Clinical Breast Care Project have been systematically analyzed by MS. In this abstract, we report results of artificial neural network (ANN) analysis of the serum MS profile to classify the pathological category of breast cancer patients

Methods: Sera from 120 breast disease patients in 6 pathological categories: breast carcinoma invasive (49), lobular/ductal carcinoma in situ (13), atypical hyperplasia (13), benign neoplastic (11), benign non-neoplastic (24) and normal (10) were digested with trypsin and loaded to a BioBasic SCX column (Thermo Electron, Co.). Peptides eluted from the column with a $100 \mathrm{mM} \mathrm{NH}_{4} \mathrm{Cl}$ salt step was further separated on a BioBasic-18 reverse phase column (Thermo Electron, Co.) and analyzed by mass spectrometry. The maximum peptide abundance from the full MS scan over the entire retention time was extracted for each $\mathrm{M} / \mathrm{Z}$ (rounded to 0 decimal points) after normalization. Samples were randomly split into modeling $(\sim 65 \%)$ and test $(\sim 35 \%)$ data set. With the modeling data, ten M/Zs were selected for each pathological category using top signal-to-noise ratios and an ANN model was trained using Clementine (SPSS, Inc.) and evaluated with the test data. The process was repeated to build multiple models.

Results: Twelve ANN models were built and involved $347 \mathrm{M} / \mathrm{Zs}$. The overall accuracy of prediction (identification of class) on the test data was $77.8 \%$. Accuracy of individual models ranged from $70.6 \%$ to $82.4 \%$. The ANN models performed best on invasive carcinoma (212 predictions, 94\% accurate) followed by benign non-neoplastic $(96,81.3 \%)$, normal $(38,79.0 \%)$, benign neoplastic $(51,66.7 \%)$, atypical hyperplasia $(44,50.0 \%)$ and lobular/ductal carcinoma in situ $(60,41.7 \%)$.

Discussion: Our results show that serum MS profile has potential for dis-criminating various types of breast diseases, including cancer, but more work is needed to make them more robust. It can potentially be used to assist physicians on breast cancer diagnosis. 


\section{S214 Abstracts - Poster Session V}

5026

A phase II, randomized, placebo-controlled trial of the safety and efficacy of dexmethylphenidate (d-MPH) as a treatment for fatigue and "chemobrain" in adult cancer patients.

Fleishman S, Lower E, Zeldis J, Faleck H, Manning D. Beth Israel Cancer Center, New York, NY; University of Cincinnati Medical Center, Cincinnati, OH; Celgene Corporation, Summit, NJ

Background: This study investigated the safety and efficacy of d-MPH (Focalinä) in the treatment of persistent fatigue and cognitive impairment ("chemobrain") after chemotherapy in nonanemic breast cancer patients. Methods: Breast cancer patients (excluding those with primary or metastatic brain tumors) treated with $\geq 4$ cycles of cytotoxic chemotherapy (completed $\geq 2$ months prior to entry) were eligible. Patients completing the single-blind placebo period with no improvement in disease status were randomized to the 8-week double-blind phase. Dosing (d-MPH or placebo) was adjusted from $10 \mathrm{mg} /$ day to a maximum of $50 \mathrm{mg} /$ day, based on clinical criteria. The optimal dose was maintained $\geq 2$ weeks. Efficacy endpoints were change from Baseline using last observation carried forward in the Functional Assessment of Chronic Illness Therapy-Fatigue Subscale (FACIT-F) Total Score (primary endpoint) and High Sensitivity Cognitive Screen (HSCS) Overall Total and Subscale Scores (secondary endpoint). The planned accrual was 160 patients to obtain 120 completed patients, based on a comparison of FACIT-F scores in the 2 groups, assuming a 2 -sided test with Type 1 error rate of 0.05 , providing $80 \%$ power to detect a $15 \%$ difference with a standard deviation of 10.5 . Results: In total, 152 cancer patients were randomized with a majority $(\mathrm{n}=110)$ being breast cancer patients (placebo: $\mathrm{n}=54$; $\mathrm{d}$ MPH: $n=56$ ). In this breast cancer subset, significant improvement in the FACIT-F Total Score (Weeks 2, 3, 4, 5, 6, 7, and 8; $\mathrm{p}<0.05$ ) was observed in the d-MPH group versus placebo. The change from Baseline in cognitive assessments did not reach a level of significance. Mean highest dose of d-MPH was $27.8 \mathrm{mg} / \mathrm{day}$. Common adverse events (AEs) were headache (d-MPH: 42.9\%; placebo: $40.7 \%$ ), dry mouth (d-MPH: $28.6 \%$; placebo: $11.1 \%$ ) and nausea (d-MPH: $28.6 \%$; placebo: $7.4 \%$ ), and were mostly mild to moderate. Hot flashes were not exacerbated with d-MPH. The incidence of insomnia in d-MPH-treated patients was not significantly different from placebo-treated patients. Eight d-MPH treated patients were discontinued due to AEs. No deaths were reported. One placebo-treated patient reported a serious AE. Conclusions: Dexmethylphenidate was well-tolerated and significantly more effective than placebo for improving fatigue after chemotherapy in breast cancer patients. While positive trends in cognitive assessments were identified, a larger study of appropriate power will be needed to draw conclusions. For breast cancer patients with fatigue after chemotherapy, dexmethylphenidate therapy should be strongly considered.

\section{7}

Anemia is a common and neglected complication of adjuvant chemotherapy for early stage breast cancer. Goldrick AJ, Olivotto IA, Alexander C, Speers CH, Barnett J, Allan S. British Columbia Cancer Agency, Victoria and Vancouver, $B C$, Canada

Background: Chemotherapy related anemia [Hemoglobin $(\mathrm{Hb})<100 \mathrm{~g} / \mathrm{L}]$ adversely affects quality of life. The purpose of this study was to define the frequency and severity of anemia associated with adjuvant chemotherapy and whether corrective interventions were undertaken

Methods: British Columbia (BC), Canada has a universal access health care system where all antineoplastic drugs (but not support medications) are supplied free of charge to patients with cancer through the BC Cancer Agency (BCCA). Among 933 patients receiving breast cancer adjuvant chemotherapy at four BCCA clinics in 2002 or 2003, a retrospective chart review was conducted of a $50 \%$ random sample of those receiving $\mathrm{AC}$ (doxorubicin and cyclophosphamide) and all patients receiving other chemotherapy combinations. In total, 702 patients were studied. Chemotherapy was $\mathrm{CEF}(\mathrm{C}$, epirubicin and 5 fluorouracil) $\mathrm{n}=325(46 \%), \mathrm{AC} \mathrm{n}=228$ $(32.5 \%)$, AC-T (AC followed by paclitaxel) $\mathrm{n}=55(8 \%)$, CAF $\mathrm{n}=48(7 \%)$, oral CMF $\mathrm{n}=31(4 \%)$ and FEC100 $\mathrm{n}=17(2 \%)$. The dates of the first $\mathrm{Hb}$ in the ranges $110-119,100-109,90-99$ and $<90 \mathrm{~g} / \mathrm{L}$ and any discussion about or delivery of interventions for anemia (transfusion or epoetin alfa) were recorded.

Results: Median age was 53 and varied by chemotherapy type. $12 \%$ of subjects had a $\mathrm{Hb}<120 \mathrm{~g} / \mathrm{L}$ prior to starting chemotherapy. Overall, the proportion of subjects with at least one $\mathrm{Hb}<120$ was $78 \%,<110$ was $54 \%,<100$ was $31 \%$ and $<90$ was $14 \%$. $\mathrm{Hb}<100 \mathrm{~g} /$ $\mathrm{L}$ occurred in $54 \%, 27 \%, 12 \%$ and $5 \%$ of women using CEF, AC$\mathrm{T}, \mathrm{FEC} 100$ and $\mathrm{AC}$, respectively. Intervention rates increased as $\mathrm{Hb}$ declined. Interventions based on $\mathrm{Hb}$ value are summarized in the Table.

Interventions for Anemia by $\mathrm{Hb}$ value

$\mathrm{Hb}(\mathrm{g} / \mathrm{L}) \quad \mathrm{N}$ Anemia Discussed Transfuse only EPO only Both Transfuse

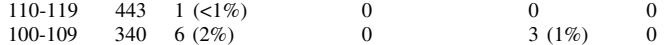

$\begin{array}{llllll}100-109 & 340 & 6(2 \%) & 0 & 3(1 \%) & 0 \\ 90-99 & 190 & 28(15 \%) & 0 & 10(5 \%) & 2(1 \%)\end{array}$

$\begin{array}{llllll}90-99 & 190 & 28(15 \%) & 0 & 10(5 \%) & 2(1 \%) \\ <90 & 99 & 49(49 \%) & 23(23 \%) & 11(11 \%) & 8(8 \%)\end{array}$

Conclusions: Anemia was relatively common and varied with chemotherapy type. Documentation of a discussion of anemia occured in a minority of patients with a $\mathrm{Hb}$ of $90-99 \mathrm{~g} / \mathrm{L}$ and only half of patients with $\mathrm{Hb}<90 \mathrm{~g} / \mathrm{L}$. Intervention rates were relatively low at $\mathrm{Hb}$ values where randomized trials have shown that intervention can improve quality of life.

\section{8}

Greater area under the hemoglobin change curve is associated with improved outcomes in breast cancer patients receiving epoetin alfa for chemotherapy-related anemia. Lefebvre P, Duh MS, McKenzie RS, Piech CT. Groupe d'Analyse, Ltée, Montréal, QC, Canada; Analysis Group, Inc., Boston, MA Ortho Biotech Clinical Affairs, LLC, Bridgewater, NJ

Background: Several measures have been used to assess the efficacy of erythropoietic agents in patients with chemotherapyrelated anemia (CRA). Previous research has shown that area under the 16-week hemoglobin $(\mathrm{Hb})$ change curve $\left(\mathrm{Hb} \mathrm{AUC}_{16}\right)$ is a more sensitive and comprehensive efficacy measure compared to traditional single time-point or threshold-based measurements, such as hematopoietic response. This subgroup analysis of breast cancer patients with CRA evaluates the clinical significance of higher $\mathrm{Hb} \mathrm{AUC}_{16}$ values in this unique population.

Methods: Data from three large multicenter EPO clinical trials were evaluated (EPO 1: N=378; EPO 2: N=541; EPO 3: N=117). In EPO 1, patients received 10,000 Units three-times-weekly (TIW) with potential escalation to 20,000 Units TIW. In EPO and EPO 3, patients received 40,000 Units once weekly (QW) with potential escalation to 60,000 Units QW. Inclusion criteria for this analysis were breast cancer patients, with a baseline $\mathrm{Hb} \leq$ $11 \mathrm{~g} / \mathrm{dL}$, and receipt of chemotherapy with or without radiotherapy. $\mathrm{Hb} \mathrm{AUC}_{16}$ was calculated using sequential trapezoidal methodology based on the $\mathrm{Hb}$ changes over 16 weeks of treatment and was stratified into quartiles to assess correlation with clinical and drug utilization outcomes. Trend tests were performed to determine if the following outcomes had significant linear trends across the $\mathrm{Hb}$ $\mathrm{AUC}_{16}$ quartiles: proportion of patients transfused, time to hematopoietic response ( $\mathrm{Hb}$ rise $\geq 2 \mathrm{~g} / \mathrm{dL}$ over baseline or $\mathrm{Hb} \geq 12$ $\mathrm{g} / \mathrm{dL}$ during study), EPO utilization, and QOL score changes measured by the Linear Analogue Scale Assessment (LASA) and the Functional Assessment of Cancer Therapy subscales for anemia (FACT-An) and fatigue (FACT-F) parameters.

Results: Greater $\mathrm{Hb} \mathrm{AUC}_{16}$ values had a strong linear association with decreasing proportion of patients transfused $(\mathrm{p}<.001)$, decreasing time to hematopoietic response $(\mathrm{p}<.0001)$, decreasing average weekly EPO dose $(\mathrm{p}<.0001)$, and increasing QOL improvements $(\mathrm{p}<.05)$. 
Discussion: In breast cancer patients, greater $\mathrm{Hb} \mathrm{AUC}_{16}$ values were associated with significant improvement in clinical outcomes, including percentage of patients transfused, time to hematopoietic response, QOL improvements, and EPO utilization. $\mathrm{Hb} \mathrm{AUC}_{16}$ is an objective and comprehensive metric that summarizes hematologic response over the course of treatment and is associated with clinical benefits in breast cancer patients receiving epoetin alfa therapy.

\section{9}

Acute and delayed chemotherapy-induced nausea and vomiting and its impact on quality of life in patients with breast cancer in community practice settings.

Cunningham RS, Hu HX, Chen Y-T. The Cancer Institute of New Jercey, New Brunswick, NJ; Merck \& Co., Inc, West Point, PA

Objective. Chemotherapy-induced nausea and vomiting (CINV) is an important, but often underestimated consequence in cancer patients receiving chemotherapy. We examined the occurrence of acute (on the day of chemotherapy) and delayed (days 2-5 post chemotherapy) CINV during the first cycle of chemotherapy and its impact on quality of life in breast cancer patients.

Methods. Adult patients were recruited from community-based medical oncology practices and were eligible to participate in the study if they had highly or moderately emetogenic chemotherapy planned for at least two cycles with at least 6 days between cycles. Information on demographics, prior experience and risk factors for nausea and vomiting were obtained by patient self-report at baseline. Data on cancer type and past and current chemotherapy/ anti-emetic regimen were reported by treating physicians prior to each chemotherapy cycle. Incidence of acute and delayed nausea and vomiting and their impact on quality of life (QoL) were reported by patients via the interactive voice response (IVR) system on days 2 and 5 post treatment. QoL was assessed using Functional Living Index - Emesis.

Results. A total of 461 breast cancer patients were enrolled; the mean age was 54.4 (SD 10.6) years, $78 \%$ were Caucasian, and $15 \%$ had prior chemotherapy experience. The most common chemotherapy regimens were cyclophosphamide $(52 \%)$ and doxorubicin $(45 \%)$, All patients but $3(99 \%)$ received antiemetics on the day of chemotherapy and $95 \%$ were prescribed antiemetics post chemotherapy. The most commonly used antiemetic regimens were dexamethasone $(74 \%)$ and palonosetron $(34 \%)$ on the day of chemotherapy and compazine (41\%), ondansetron $(20 \%)$, granisetron $(19 \%)$, and dexametheseon $(18 \%)$ post chemotherapy. After the first cycle of chemotherapy, the incidence of acute and delayed nausea was $53 \%$ and $66 \%$; the frequency of acute and delayed vomiting was $48 \%$ and $45 \%$. Overall, delayed CINV had greater impact on patients QoL compared to acute CINV. Furthermore, nausea appeared to have greater impact on worsened quality of life than vomiting.

Conclusion. Despite anti-emetic treatment, nausea and vomiting, both acute and delayed, were frequent in breast cancer patients post-chemotherapy. Delayed nausea had the greatest impact on quality of life. There is room for improvement in the management of nausea and vomiting in breast cancer patients receiving chemotherapy.

\section{0}

A randomised controlled trial to assess the efficacy of Maharishi Amrit Kalash - an ayurvedic herbal compound in ameliorating toxicity of cancer chemotherapy in women with breast cancer.

Srivastava A, Seenu V, Saxena A, Dixit S, Parshad R, Taranikanti $V$, Misra MC. All India Institute of Medical Sciences, New Delhi, Delhi, India

Background: Anorexia, Nausea, Vomiting, Stomatitis, diarrhea, weight loss and alopecia are common side-effects of cytotoxic chemotherapy. Some of these side effects are related to free oxygen radical release and can be reduced by antioxidants. Maharishi Amrit Kalash (MAK) is an ayurvedic compound containing many herbs rich in antioxidants.

Aim: Aim of the present study was to evaluate the effectiveness of MAK in controlling toxicity of chemotherapy.

Materials and Methods: Design: Open 2 arms randomized controlled clinical trial.

We recruited 214 patients with breast carcinoma receiving cyclophosphamide, methotrexate and 5- flourouracil (CMF) or cyclophosphamide, adriamycine, and 5-flourouracil (CAF), adjuvant or neo-adjuvant chemotherapy. The toxicity of chemotherapy was assessed according to WHO criteria. Statistical analysis was carried out on Epi-info 6 and STATA-7.

Result: There was significant reduction in following toxicities in MAK group: Poor performance status was prevented with Prevented Fraction $(\mathrm{PF})=60.6 \%(95 \%$ confidence interval 22.1 to 80.1 ). Vomiting was prevented with $\mathrm{PF}=40.3 \%$, (95\% confidence interval 15.1 to 58.1 ). Anorexia was reduced with $\mathrm{PF}=35.6 \%$. (95\% confidence interval 17.6 to 49.7 ). No improvement occurred in stomatitis, diarrhea, alopecia and leucopenia.

Discussion: MAK was beneficial in reducing vomiting, anorexia and improving general well being of patients receiving chemotherapy. We suggest its use along with cytotoxic chemotherapy to reduce the above side-effects.

\section{1}

First and subsequent cycle pegfilgrastim results in low rates of neutropenic events in patients receiving myelosuppressive chemotherapy.

Rader ME, Breyer W, Luedke S, Truscinski D, Ding B, Dansey $R$ Ozer H. Nyack Hospital, Nyack, NY; Cancer Center, Provo, UT; Cancer \& Breast Institute, St Louis, MO; Amgen Inc., Thousand Oaks, CA; U of Oklahoma, Cancer Center, Oklahoma City, OK

Background: Patients (pts) with early-stage breast cancer often receive reduced chemotherapy (CT) dose intensity when treated with adjuvant CT (Lyman 2003), potentially compromising longterm survival (Bonadonna 1995). Neutropenia is the major doselimiting toxicity of CT. First and subsequent cycle pegfilgrastim has been shown to dramatically reduce febrile neutropenia in cycle $1(11 \%$ vs $<1 \%)$ and overall $(17 \%$ vs $<1 \%$; p $<0.001)$ for pts receiving $\mathrm{CT}$ with a moderate risk of febrile neutropenia compared with placebo (Vogel 2005). We have undertaken a prospective, community-based study to determine if real-world pts supported by pegfilgrastim from cycle 1 receiving commonly used myelosuppressive CT regimens experience a similarly low incidence of neutropenic events.

Methods: This open-label, single-arm study has enrolled 2252 pts (1008 breast cancer) at 319 sites. Pts $\geq 18$ yrs with cancers other than leukemia or MDS were eligible, including pts with major comorbid illnesses not generally eligible for clinical trials. Key exclusions were weekly CT and concurrent radiotherapy (RT). Pts received pegfilgrastim $6 \mathrm{mg}$ approximately 24 hours after CT in each cycle for up to 8 cycles of any myelosuppressive CT. Endpoints included neutropenic complications and CT dose reductions and delays. Point estimates and 95\% confidence limits (CL) are provided.

Results: Cycle 1 and 2 data are available from 444 pts with breast cancer at 162 sites. The mean (SD) age was 53.9 years (11.3). $92 \%$ of pts had earlier-stage (I, II, or III) disease, $12 \%$ received prior $\mathrm{CT}, 7 \%$ received prior $\mathrm{RT}$, and $16 \%$ had significant comorbidities. $56 \%$ of pts received one of 4 standard regimens containing doxorubicin and cyclophosphamide (AC): AC every 21 days $(n=70)$; AC every 14 days $(n=78)$; AC followed by paclitaxel every 14 days $(n=76)$; and docetaxel with AC (TAC; $n=25)$. Most of the remaining pts received either an anthracycline- or taxanebased regimen. $10 \%$ of pts experienced serious adverse events, which were consistent with those generally observed in pts receiving myelosuppressive CT. 


$\begin{array}{ll}\begin{array}{l}\text { Hospitalization related to neutropenia (including febrile neutropenia) } \\ \text { in cycle } 1\end{array} & \begin{array}{l}\mathrm{N}=444 \\ \%(95 \% \mathrm{CL}) \\ 1(<1,3)\end{array} \\ \begin{array}{l}\text { Febrile neutropenia (ANC }<0.5 \times 10^{9} / \mathrm{L} \text { and temperature } \geq 38.2^{\circ} \mathrm{C} \text { ) } \\ \text { cycle } 1\end{array} & 3(1,5) \\ \begin{array}{l}\text { Neutropenia-related IV antibiotic use in cycle } 1 \\ \text { Neutropenia-related CT dose reductions in cycle } 2^{\mathrm{a}}\end{array} & 1(<1,3) \\ \begin{array}{l}\text { Neutropenia-related CT dose delays in cycle } 2^{\mathrm{a}} \\ { }^{2} \text { physician reported }\end{array} & 2(1,3) \\ \end{array}$

Conclusions: Patients with breast cancer in a real-world community setting, treated with myelosuppressive CT (regardless of specific regimen) supported by pegfilgrastim, experienced a low incidence of neutropenic events in cycle 1 similar to data reported by Vogel and colleagues.

\section{2}

Synchronicity: evaluating darbepoetin alfa administered at $300 \mathrm{mcg}$ every three weeks to treat chemotherapyinduced anemia in breast cancer patients.

Silberstein P, Boccia R, Liu D, Tchekmedyian S, Holladay C, Tomita D, Rossi G, Otterson GA. Creighton University, Omaha, NE; Center for Cancer and Blood Disorders, Bethesda, MD; New York Medical College, Valhalla, NY; Pacific Shores Medical Group, Huntington Beach, CA; Charleston Cancer Center, Charleston, SC; Amgen Inc., Thousand Oaks, CA; Ohio State University, Columbus, $\mathrm{OH}$

Background: Breast cancer therapies are highly myelosuppressive (Cristofanilli et al, 2004) and can result in anemia and reduced quality of life (Groopman and Itri, 1999). Darbepoetin alfa (DA) can effectively treat chemotherapy-induced anemia in breast cancer patients (pts) (Schwartzberg et al, 2004). Due to its extended serum half-life, DA can be given at extended intervals. This offers the possibility for DA therapy to be synchronized with a conventional chemotherapy schedule (often every 3 weeks [Q3W]).

Methods: This 16-week, open label, single-arm study evaluated DA $300 \mathrm{mcg}$ Q3W in achieving and maintaining hemoglobin $(\mathrm{Hb})$ in a target range of 11 to $13 \mathrm{~g} / \mathrm{dL}$ (consistent with evidence based guidelines) in anemic pts $(\mathrm{Hb}<11 \mathrm{~g} / \mathrm{dL})$ undergoing chemotherapy. Secondary endpoints included transfusion requirements, incidence of a hematopoietic response, and the mean changes in $\mathrm{Hb}$ and FACT-F scores from baseline (BL) at the end of study (EOS). The analysis was stratified by $\mathrm{BL} \mathrm{Hb}(<10 \mathrm{~g} / \mathrm{dL}$ or $\geq 10 \mathrm{~g} / \mathrm{dL})$.

Results: Data from the breast cancer pt subset are presented $(\mathrm{n}=$ 354; $29 \%$ of all pts). DA $300 \mathrm{mcg}$ Q3W effectively alleviated anemia (see table). More pts with $\mathrm{BL} \mathrm{Hb} \geq 10 \mathrm{~g} / \mathrm{dL}$ reached target $\mathrm{Hb}$ and achieved a hematopoietic response than pts with $\mathrm{BL} \mathrm{Hb}<$ $10 \mathrm{~g} / \mathrm{dL}$; pts with $\mathrm{BL} \mathrm{Hb} \geq 10 \mathrm{~g} / \mathrm{dL}$ also required fewer transfusions. $\mathrm{Hb}$ increases correlated with clinically significant improvements in quality of life as measured by the FACT-F scale. The mean $(95 \% \mathrm{CL})$ change in FACT-F scores for all patients at EOS was 6.3 $(4.7,7.9)$ from a mean $(95 \%$ CL) BL FACT-F score of 27.9 (26.5, 29.2). Safety results were consistent with those reported for this pt population in other DA studies.

Discussion: DA $300 \mathrm{mcg}$ Q3W effectively achieved and maintained $\mathrm{Hb}$ in the target range. The possibility of increased convenience created by synchronizing DA therapy with common chemotherapy regimens may be important for breast cancer pts who are often younger than pts with other tumor types, more likely to be working, and are often primary caregivers for their families (Ganz et al, 2004).

Mean (SD) BL $\mathrm{Hb}(\mathrm{g} / \mathrm{dL})$

Kaplan-Meier \% of pts (95\% CL) achieving target $\mathrm{Hb}$ (11 to $13 \mathrm{~g} / \mathrm{dL})$

Mean (SD) Hb after achieving target $(\mathrm{g} / \mathrm{dL})$ Kaplan-Meier \% of pts $(95 \% \mathrm{CL})$ requiring transfusions (week 1 to EOS

Kaplan-Meier \% of pts (95\% CL) achieving a hematopoietic response (week 1 to EOS)

$\begin{array}{ll}\begin{array}{l}\mathrm{BL} \mathrm{Hb}<10 \mathrm{~g} / \mathrm{dL} \\ (\mathrm{n}=104)\end{array} & \begin{array}{l}\mathrm{BL} \mathrm{Hb} \geq 10 \mathrm{~g} / \mathrm{dL} \\ (\mathrm{n}=229)\end{array} \\ 9.4(0.5) & 10.6(0.4) \\ 80(71,89) & 92(88,95) \\ & \\ 11.6(0.8) & 11.6(0.8) \\ 25(16,34) & 10(6,14) \\ 72(62,82) & 74(68,80)\end{array}$

\section{3}

Darbepoetin alfa administered once every three weeks is effective for treating chemotherapy-induced anemia.

Canon J-L, Bodoky G, Mateos MV, Bastit L, Ferreira I, Amado R, Vansteenkiste J. Centre Hospitalier Notre Dame et Reine Fabiola, Charleroi, Belgium; Szt. Laszlo Hospital, Budapest, Hungary; University of Salamanca Hospital Clinic, Salamanca, Spain; Centre Frederic Joliot, Rouen, France; Amgen Inc., Thousand Oaks, CA; University Hospital Gasthuisberg, Leuven, Netherlands Background: Chemotherapy-induced anemia (CIA) increases the risk of red blood cell transfusions and debilitating fatigue. Darbepoetin alfa (Aranesp ${ }^{\circledR}$; DA) is licensed in Europe for treatment of CIA using every-three-week (Q3W) or weekly $(\mathrm{QW})$ administration. The DA Q3W schedule is of particular interest as it can be synchronized with most chemotherapy regimens, resulting in fewer clinic visits and increased convenience for patients (pts). This study evaluated the comparability (non-inferiority) of DA $500 \mathrm{mcg}$ Q3W with DA $2.25 \mathrm{mcg} / \mathrm{kg}$ QW with respect to efficacy and safety.

Methods: This was a randomized, double-blind, double-dummy, active-controlled phase 3, multicenter study. Eligibility criteria included $\geq 18$ years of age, anemia (hemoglobin $[\mathrm{Hb}]<11 \mathrm{~g} / \mathrm{dL}$ ), diagnosis of hematologic malignancies and solid tumors, and $\geq 12$ weeks planned chemotherapy. Pts were randomized $1: 1$ to either a fixed dose of DA $500 \mathrm{mcg}$ Q3W or DA $2.25 \mathrm{mcg} / \mathrm{kg}$ QW for up to 15 weeks. The primary endpoint was the incidence of transfusions from week 5 to end of treatment period (EOTP). Non-inferiority for the primary endpoint was determined if the upper limit of the $95 \%$ confidence interval (CI) of the difference in transfusions between groups did not exceed a $12.5 \%$ margin based on previous placebo-controlled studies of DA $2.25 \mathrm{mcg} / \mathrm{kg}$ QW. Secondary endpoints included the proportion of pts achieving target $\mathrm{Hb}$ level $(\geq 11 \mathrm{~g} / \mathrm{dL}$; not to exceed $13 \mathrm{~g} / \mathrm{dL})$, the change in FACT-F scores at EOTP, and safety.

Results: 705 pts were randomized in this study (353 in the Q3W arm; 352 in the QW arm). Of these, 54\% were women and 112 (16\%) patients had breast cancer. Of all pts, 672 were analyzed for the primary endpoint. The unadjusted Kaplan-Meier percentage (95\% CI) of all pts requiring transfusions from week 5 to EOTP was $23 \%$ (19 to 28 ) and $30 \%$ ( 25 to 35 ) for the Q3W and QW groups, respectively (difference: -6.8 percentage points [-13.6 to $0.1])$. Transfusion results were consistent when adjusted for stratification factors. The percentage $(95 \% \mathrm{CI})$ of all pts achieving target $\mathrm{Hb}$ during the entire study was $84 \%$ ( 81 to 88 ) in the Q3W arm and $77 \%$ ( 72 to 81 ) in the QW arm. The mean difference $(95 \% \mathrm{CI})$ between groups in change in FACT-Fatigue scores at EOTP between groups was 0.75 ( -0.97 to 2.46$)$. The safety profile was similar between the two treatment groups. Results specific to the breast cancer subgroup will be presented.

Conclusions: The fixed $500 \mathrm{mcg}$ DA dose regimen was comparable to the weight-based $2.25 \mathrm{mcg} / \mathrm{kg}$ QW regimen as the upper limit of the $\mathrm{CI}$ of the transfusion incidence fell substantially below the pre-determined non-inferiority margin. These results demonstrate effective anemia management with less frequent dosing of DA.

\section{4}

Comparison of outcomes in patients receiving standard community care while enrolled on a nationwide registry with those enrolled in a prospective nationwide communitybased clinical trial.

Lyman GH, Rader M, Wolff D, Culakova E, Ding B, Dansey R, Ozer H. University of Rochester, School of Medicine, Rochester, NY; Nyack Hospital, Nyack, NY; Amgen Inc., Thousand Oaks, CA; University of Oklahoma, Oklahoma City, OK

Background: The Awareness of Neutropenia in Chemotherapy (ANC) Study Group recently established a prospective registry of cancer patients (pts) receiving systemic chemotherapy (CT) in 
over 100 community practices to study the incidence of and associated risk factors for neutropenic complications. FIRST, a phase 4 community-based study, evaluated the impact of first and subsequent cycle pegfilgrastim protection on neutropenic events in pts with similar characteristics to those enrolled in the Registry. In order to test the feasibility of comparing the outcomes of these 2 pt cohorts, data from breast cancer pts receiving doxorubicin and cyclophosphamide (AC) CT every 3 weeks (Q3W) were examined in each population.

Methods: Both studies comprised adult cancer pts starting a new CT regimen across all tumor types (except leukemia and MDS), including pts with most major co-morbidities and performance status. Registry pts received supportive care including CSFs under conditions of standard community care. FIRST pts received pegfilgrastim $6 \mathrm{mg}$ approximately 24 hours after each cycle for up to 8 cycles of any myelosuppressive chemotherapy. Both studies evaluated neutropenic complications. Point estimates and 95\% confidence limits are provided.

Results: The Registry has enrolled more than 4326 pts at over 100 sites; of these, 387 are breast cancer pts receiving AC Q3W. The FIRST study has completed enrollment of 2252 pts at 319 sites. Interim data from 874 pts are available; of these 70 are breast cancer pts receiving standard AC Q3W. Demographics are shown (table). 39\% Registry pts received a myeloid growth factor either proactively or reactively in the first cycle of CT, compared with $100 \%$ of pts on the FIRST study. The incidence of neutropenia in the first cycle was $60 \%(55,65)$ in Registry pts and $31 \%(21$, $44)$ in FIRST pts. The incidence of febrile neutropenia (FN) in the first cycle was $8 \%(6,11)$ in Registry pts and $4 \%(1,12)$ in FIRST pts.

Age (years)
$<65$
$\geq 65$
Disease Stage
I/II
III
IV
ER/PR Positive
Baseline BSA $\left(\mathrm{m}^{2}\right)$
$\leq 2$
$>2$
Baseline ECOG Performance Status
0
1
$\geq 2$
Vascular Disease
Diabetes
Pulmonary Disease
Prior Chemotherapy

FIRST Study (\%) $\quad$ ANC Registry (\%)

$77 \quad 88$

$23-12$

$80 \quad 83$

$14+14$

$\begin{array}{ll}4 \\ 69 & 63\end{array}$

69
89

$29-11$

$83-80$

14

4

1

Conclusions: The comparison of these specific pt groups appears to be feasible. Although $39 \%$ of Registry pts received some form of first cycle CSF support, consistent first cycle use in the FIRST study resulted in a lower FN rate. More detailed analyses of other pt cohorts and regimens are planned. The ability to compare pt outcomes from an observational registry with an interventional clinical trial may provide useful information regarding the impact of growth factor use on neutropenic complications in community practice.

\section{5}

Darbepoetin alfa administered once every three weeks either synchronously or asynchronously with every-threeweek chemotherapy improves anemia in breast cancer patients.

Glaspy J, Henry D, Patel R, Tchekmedyian NS, Berg R, Hendricks L, Rossi G. UCLA School of Medicine, Los Angeles, CA; Joan Karnell Cancer Center, Philadelphia, PA; Comprehensive Blood and Cancer Center, Bakersfield, CA; Pacific Shores Medical Group, Long Beach, CA; Amgen Inc., Thousand Oaks, CA

Background: Breast cancer patients undergoing chemotherapy often develop anemia that is associated with an increased risk of red blood cell (RBC) transfusions and debilitating fatigue.
Chemotherapy-induced anemia can be effectively treated with darbepoetin alfa. Because of its prolonged half-life, darbepoetin alfa can be administered on an every-three-week (Q3W) schedule, which is compatible with most chemotherapy regimens.

Methods: This randomized, multicenter, open-label study focuses on the efficacy of darbepoetin alfa $6.75 \mathrm{mcg} / \mathrm{kg}$ Q3W administered with Q3W chemotherapy in cancer patients with anemia (hemoglobin $[\mathrm{Hb}] \geq 9$ and $\leq 11 \mathrm{~g} / \mathrm{dL}$ ). This analysis compares response to Q3W darbepoetin alfa therapy in patients with breast cancer compared with all patients enrolled in the study. Patients were randomized 1:1 to receive darbepoetin alfa for 16 weeks on either an asynchronous schedule (begin chemotherapy day 15) or a synchronous schedule (begin chemotherapy day 1 ). The primary endpoint of mean change in $\mathrm{Hb}$ from baseline after 6 weeks of therapy was chosen to prevent confounding effects of chemotherapy delays, patient attrition, and differential dose escalation. Secondary endpoints (measured over the entire 16 weeks of treatment) included the incidence of RBC transfusion, incidence of hematopoietic response and time to hematopoietic response. For the incidence endpoints, percentage with the event and time to event were estimated using Kaplan-Meier methodology. Results: Of the 81 randomized patients in this study, $32(40 \%)$ patients had breast cancer (asynchronous, $n=20$; synchronous, $n$ $=12$ ). Regardless of synchronous or asynchronous timing, robust increases in $\mathrm{Hb}$ were observed, with mean $\mathrm{Hb}$ reaching the 11 to $13 \mathrm{~g} / \mathrm{dL}$ target range within 4 weeks. For patients with an $\mathrm{Hb}$ evaluation after 6 weeks of treatment, the mean (95\% confidence interval $[\mathrm{CI}])$ change in $\mathrm{Hb}$ was $1.2(0.8$ to 1.5$) \mathrm{g} / \mathrm{dL}$ and $1.0(0.7$ to 1.3$) \mathrm{g} / \mathrm{dL}$ among breast cancer and all patients, respectively. The percentage $(95 \% \mathrm{CI})$ of patients who received an RBC transfusion was $9 \%$ (0 to 20) (breast cancer) and 28\% (18 to 39) (all patients). The percentage $(95 \% \mathrm{CI})$ of patients achieving a hematopoietic response $(\geq 2 \mathrm{~g} / \mathrm{dL} \mathrm{Hb}$ increase from baseline or $\mathrm{Hb}$ $\geq 12 \mathrm{~g} / \mathrm{dL}$ ) was $78 \%$ (62 to 94 ) (breast cancer) and $74 \%$ (61 to 87 ) (all patients). Median (95\% CI) time to hematopoietic response was 43 ( 29 to 58 ) days (breast cancer) and 49 (36 to 58) days (all patients).

Conclusions: These results indicate that Q3W administration of darbepoetin alfa is effective in treating chemotherapy-induced anemia in breast cancer patients and may allow for once-percycle dosing with added convenience for patients and their caregivers.

\section{6}

Cost-utility evaluation of adjuvant hormonal options in postmenopausal women with breast cancer: tamoxifen vs. anastrazole vs. tamoxifen then exemestane.

Skedgel C, Rayson D, Dewar R, Younis T. Dalhousie University, Halifax, NS, Canada; Queen Elizabeth Health Sciences Centre, Halifax, NS, Canada; Cancer Care Nova Scotia, Halifax, NS, Canada

BACKGROUND: Based on the ATAC and IES trials, adjuvant Anastrazole (ANA) for 5 years or Tamoxifen followed by Exemestane (TAM-EX) for 2.5 years each have become acceptable alternatives to Tamoxifen (TAM) for 5 years in postmenopausal women with hormone receptor positive breast cancer. As these newer options are associated with higher drug costs, a cost-utility evaluation was undertaken to compare the relative costeffectiveness (CE) of ANA and TAM-EX relative to TAM alone in terms of cost per quality-adjusted life year (QALY) gained. METHODS: A Markov model was developed to calculate incremental costs and QALYs in a hypothetical cohort of 1,000 postmenopausal women with early-stage breast cancer. The model was constructed based on monthly probabilities of cancer recurrence and general mortality rates for women aged 60-80, taken from Statistics Canada life tables. The baseline rate of cancer recurrence with TAM and treatment benefits associated with ANA and TAM-EX were derived from the ATAC and IES trials. Unit costs of drug treatment were based on 2005 average Canadian 


\section{S218 Abstracts - Poster Session V}

wholesale prices. Other costs, event rates and health state utilities were taken from a review of the literature. The primary analysis assumed local recurrences increased the risk of a subsequent distant recurrence and treatment benefit was modeled to persist for 5 years beyond adjuvant treatment. After 10 years of treatment benefit, hazard ratios for recurrent cancer events with ANA and TAM-EX relative to TAM were set to 1.0. Adverse side effects were not included in the primary analysis. The analysis took a direct payer perspective and adopted a 20-year time horizon to reflect life expectancies. Costs and outcomes were discounted at $3 \%$. Costs are reported in 2005 Canadian dollars $(\mathrm{CDN} \$ 1.00=\mathrm{US} \$ 0.82)$

RESULTS: Both ANA and TAM-EX were associated with QALY gains relative to TAM alone. Per 1,000 patients treated, ANA resulted in an incremental gain of 364 QALYs relative to TAM alone, while TAM-EX had an incremental gain of 334 QALYs relative to TAM alone. Incremental costs, including hormonal treatment and cancer recurrences, were $\$ 7.7$ million with ANA and $\$ 3.4$ million with TAM-EX per 1,000 treated, relative to TAM. The CE of ANA relative to TAM alone was $\$ 21,098$ per QALY gained, while TAM-EX relative to TAM alone was $\$ 10,305$ per QALY gained. The CE of ANA relative to TAM-EX was $\$ 138,838$ per QALY gained. These relative rankings were robust and were not affected by changes in rates of cancer recurrence. A complete sensitivity analysis will be presented.

CONCLUSIONS: Relative to TAM alone, both ANA and TAMEX were cost-effective, with incremental cost-effectiveness ratios well below $\$ 50,000$ per QALY gained. TAM-EX appears to the preferred option as the cost-effectiveness of ANA relative to TAM-EX was unfavourable.

\section{$\mathbf{5 0 3 7}$}

Cost-effectiveness of switching to exemestane following two-to-three years of therapy with tamoxifen in postmenopausal women with primary breast cancer.

Thompson D, Taylor DCA, Montoya EL, Winer E, Weinstein MC. INNOVUS Research, Inc., Medford, MA; Harvard School of Public Health, Boston, MA; Dana Farber Cancer Institute, Boston, MA

Objective: Although a 5-year course of tamoxifen has been the standard adjuvant therapy for postmenopausal women with primary breast cancer, data from the Intergroup Exemestane Study suggest that switching to the aromatase inhibitor, exemestane, after 2-3 years prolongs disease-free survival versus continuing tamoxifen therapy. We sought to evaluate the cost-effectiveness of this management strategy from a U.S. perspective.

Methods: A Markov model with a 10-year time horizon for recurrence and a lifetime horizon for survival and costs was developed to predict patients' transitions across various health states based on treatment strategy (continuing tamoxifen versus switching to exemestane), breast cancer recurrence status (none, local, contralateral, distant), and other related health events (osteoporosis, endometrial cancer, death). Recurrence was estimated using data from the Intergroup Exemestane Study, which directly compared the two treatment strategies over a 4-year period of follow-up; the 4-year data were extrapolated by conservatively assuming equivalent hazards between treatment strategies in years 5-10 (i.e., no difference in recurrence risk). Similarly assumptions were made to extrapolate hazards for osteoporosis and endometrial cancer in years 5-10. Survival and lifetime medical-care costs by type of recurrence were estimated using SEER-Medicare data. Health state utilities were obtained from the published literature. The model was used to estimate direct costs (in 2004 U.S. dollars, discounted at 3\% per annum), life expectancy, quality adjusted life years (QALYs), and incremental cost-effectiveness. Deterministic and probabilistic sensitivity analyses were performed to assess uncertainty in model results.

Results: Switching to exemestane was associated with increased recurrence-free survival (11.12 vs. 10.58 years), QALYs (8.45 vs. $8.23)$, and net costs of cancer care $(\$ 17,168$ per patient vs.
$\$ 13,588$ ) over the lifetime versus continuing tamoxifen therapy. The incremental cost-effectiveness ratio (ICER) of exemestane was $\$ 16,000$ per QALY gained $(95 \% \mathrm{CI}$ : $\$ 7,600$ to $\$ 53,800$ ). One-way sensitivity analyses showed model results were robust to plausible variations in recurrence rates, costs, and utilities, with ICERs ranging from $\$ 8,500$ to $\$ 40,600$ per QALY gained. Probabilistic sensitivity analyses indicated that there was a $70.2 \%$ probability that switching to exemestane is a cost-effective treatment strategy at a $\$ 20,000 /$ QALY threshold, and a $96.9 \%$ probability at a $\$ 50,000 / \mathrm{QALY}$ threshold.

Conclusions: Switching postmenopausal early breast cancer patients to exemestane after 2-3 years of tamoxifen appears to be a cost-effective treatment strategy at currently accepted thresholds.

\section{8}

Cost-effectiveness of adjuvant chemotherapy for node + breast cancer: modeling the downstream effects of adjuvant TAC vs FAC: docetaxel ( $T$ ), adriamycin (A), cyclophosphamide (C) compared to 5-fluorouracil (F) A C. Au HJ, Golmohammadi K, Chia S, Verma $S$, Younis T, Chin $C$, Jacobs P. Cross Cancer Institute, Edmonton, AB, Canada; Institute of Health Economics, Edmonton, AB, Canada; Vancouver Cancer Centre, Vancouver, BC, Canada; Ottawa Hospital Integrated Cancer Care Program, Ottawa, ON, Canada; QEII Health Sciences Centre, Halifax, NS, Canada; Aventis Pharma Inc., Montreal, QC, Canada; University of Alberta, Edmonton, AB, Canada

Background: BCIRG 001 investigated TAC vs FAC adjuvant chemotherapy for women with node positive breast cancer demonstrating prolonged disease-free and overall survival for TAC. TAC though is associated with increased acute toxicity and initial chemotherapy drug costs. However, with reduced disease recurrence, downstream cancer-related symptoms, treatment toxicity, and treatment costs may be decreased with TAC. Treatment regimens used in disease recurrence are influenced by the initial adjuvant chemotherapy choice and the time to recurrence from the adjuvant setting. This study evaluates the overall quality-adjusted survival and cost-effectiveness of adjuvant TAC vs FAC chemotherapy, taking downstream decisions and events into account, including the later choices of palliative chemotherapy with taxanes. Methods: A Markov model was developed to project outcomes over a 5-year time horizon for a hypothetical cohort of women with unilateral node positive breast cancer who are eligible for adjuvant anthracycline chemotherapy. The perspective is that of a Canadian health care government payer. Data input included clinical and resource utilization data collected prospectively as part of BCIRG 001, including rate of recurrence based on Her2 status and within or after 1-year of adjuvant therapy. Treatment decisions and outcomes with disease recurrence are based on a systematic literature review with validity reviewed by a national panel of breast cancer oncologists. Unit costs were obtained from Alberta provincial cost list. Utility scores were derived from the literature based on standard gamble ratings. Costs were discounted at $5 \%$ per annum. Incremental cost-effectiveness (ICE) in cost per quality-adjusted life-years (QALYs) gained for TAC vs. FAC was calculated. Sensitivity analyses being completed include the use of prophylactic G-CSF for prevention of febrile neutropenia with TAC. Results: For 1000 women with node positive breast cancer the model showed that TAC would lead to a gain of 276 QALYs (246 LYs) at an additional cost of \$6.7Million compared to FAC over a 5-year time horizon. The ICE of TAC vs. FAC was $\$ 24,304$ per QALY gained. Sensitivity analyses will be reported. Conclusion: For women with node positive breast cancer, TAC improves disease-free and overall survival compared to FAC and, by commonly accepted standards, is a cost-effective adjuvant chemotherapy. 


\section{9}

Economic evaluation of sequential capecitabine $(X)$ and taxanes vs. the combinations in patients (pts) with advanced/ metastatic breast cancer (MBC): a Mexican Oncology Study Group (MOSG) Trial.

Reynoso N, Torrecillas L, Soto C, Reyes S, Perez-Michel L, Ramirez, $M$, Cervantes $G$, Benitez $H$, Delgadillo $F$, Talavera J. Centro de Investigacion en Ciencias Medicas UAEM, Toluca, Mexico; ISSSTE Centro Medico 20 de Noviembre, Mexico City, Mexico; IMSS, Mexicali, Mexico; IMSS, San Luis Potosi, Mexico; IMSS, Cd. Obregon, Mexico; IMSS, Chihuahua, Mexico; IMSS, Guadalajara, Mexico; ISSSTE, Guadalajara, Mexico; IMSS Siglo XXI, Mexico City, Mexico

Background: Adding X (Xeloda ${ }^{\circledR}$ ) to docetaxel (T) extends overall survival, time to progression and response rate beyond $\mathrm{T}$ alone. Sequential single-agent therapy could offer convenience benefits and may be more appropriate than combination chemotherapy for some pts. In the MOSG trial, pts with anthracycline-pretreated MBC received 3-weekly cycles of one of the following: $\mathrm{X} \rightarrow$ TorP (X $1250 \mathrm{mg} / \mathrm{m}^{2}$ bid $\mathrm{d} 1-14$, followed after progression by $\mathrm{T} 100$ $\mathrm{mg} / \mathrm{m}^{2}$ or paclitaxel $[\mathrm{P}] 175 \mathrm{mg} / \mathrm{m}^{2}$ day 1 ; XP (X $825 \mathrm{mg} / \mathrm{m}^{2}$ bid days $1-14+\mathrm{P} 175 \mathrm{mg} / \mathrm{m}^{2}$ day 1$)$ or XT (X $825 \mathrm{mg} / \mathrm{m}^{2}$ bid days $1-$ $14+\mathrm{T} 75 \mathrm{mg} / \mathrm{m}^{2}$ day 1 ). We conducted a separate analysis of cost effectiveness to determine the cost per quality-adjusted life-year (QALY) in each group. Materials and Methods: A costeffectiveness analysis was performed on the MOSG trial data using the Mexican Health Social-Security Institute (IMSS) economic/ health parameters; the perspective was of healthcare systems. Clinical data from the trial showed similar overall survival for the 3 arms. In our analysis, we used the actual overall survival data in each treatment arm in the MOSG trial (31, 29, and 34 months). To determine cost effectiveness (mean cost/QALY), we considered direct treatment costs and costs involved in managing toxicities. The resources needed to handle each grade of toxicity and the number of lost days of productivity due to toxicity were estimated by an expert panel of breast cancer specialists; the cost of each treatment administration during the first 8 cycles was obtained from an electronic public source of costs/expenses (Portal de transparencia IMSS, 2004). QALYs were determined using internationally validated utility scores and the overall survival for each arm in the study. Being an international standard currency, US dollars were used in this analysis. Results: Mean cost per QALY (US dollars) and Incremental Cost-Effectiveness Ratio (ICER) of $\mathrm{X} \rightarrow$ TorP vs. $\mathrm{XP}$ and $\mathrm{XT}$ vs. $\mathrm{X} \rightarrow$ TorP are shown in the table.

\begin{tabular}{lllll}
$\begin{array}{l}\text { Treatment } \\
\text { regimen }\end{array}$ & $\begin{array}{l}\text { Cost of treatment } \\
\text { and follow up }\end{array}$ & QALY & $\begin{array}{l}\text { Mean cost/ } \\
\text { QALY }\end{array}$ & ICER \\
$\mathrm{X} \rightarrow$ TorP & $\$ 4,781.42$ & 1.84 & $\$ 2,598.59$ & \\
$\mathrm{XP}$ & $\$ 6,176.63$ & 1.66 & $\$ 3,720.86$ & $\begin{array}{l}\text { Dominant* } \\
\mathrm{XT}\end{array}$ \\
\hline
\end{tabular}

*Less expensive and more effective $1.95-\$ 5,664,29$

Conclusion: Sequential $X \rightarrow$ TorP therapy produced a $43 \%$ cost saving per QALY compared with XP, and a $118 \%$ cost saving per QALY compared with XT. These findings indicate that sequential $\mathrm{X} \rightarrow$ TorP therapy is dominant (less expensive and more effective) compared with XP and is more cost effective than XT.

\section{0}

Clinical and cost-effectiveness implications of the adjuvant transtuzumab in HER2+ breast cancer trials.

Hillner BE. Virginia Commonwealth Univ., Richmond, VA

Earlier in 2005, benefits were reported from adding trastuzumab (T) to adjuvant chemotherapy to women with HER $2+$ breast cancer (BCa). The recurrence free survival (RFS) was reduced $>50 \%$ at 2-3 yrs appropriately leading to stopping these trials. With time, substantial benefits in RFS and overall survival (OS) are anticipated. This good news comes with unprecedented cost consequences. One yr of $\mathrm{T}$ costs about $\$ 60,000$ and varies minimally between countries. This upfront cost must be balanced against the anticipated long-term benefits. Herein, we have modified previously developed simulations of the long-term cost and benefits of adjuvant therapies to address this question.

Method: A Markov model compared cohorts of 50 y.o. women as if they entered the above trials. Adverse events and direct U.S. healthcare costs considered were $\mathrm{BCa}$ systemic relapse and death, congestive heart failure (CHF), and non-BCa death. The $\mathrm{T}$ cohort had a $52 \%$ reduction in RFS for 5 yrs. After 5 yrs, the relative efficacy declined such that the absolute benefit in RFS remained nearly constant (EBCTCG overview, Lancet 2005). Due to late use of $\mathrm{T}$, the non- $\mathrm{T}$ cohort had a greater survival after recurrence. The model was run with and w/out the T-cohort having a $4 \% \mathrm{CHF}$ incidence with a $20 \%$ annual mortality. Costs for $\mathrm{T}$ and its delivery were based on Medicare reimbursements and for metastatic disease and $\mathrm{CHF}$ from the literature.

Results: The table shows the projected RFS and OS at 3, 10 and 20 yrs. The RFS benefit plateaus at $\sim 12 \%$ after 5 yrs. The OS benefit steadily increases and approximates the RFS benefit at 20 yrs. By $13 \mathrm{yrs}$, the increase in OS exceeds one yr. The costs difference gradually narrows since the non- $\mathrm{T}$ cohort has greater $\mathrm{BCa}$ recurrence costs. At $20 \mathrm{yrs}, 30 \%$ of the $\mathrm{T}$ associated costs are offset. The CEA ratios varied dramatically with changes in time horizon and crossed thresholds of $\$ 100,000$ and $\$ 50,000$ per life year (LY) at $\sim 10$ yrs and $\sim 16$ yrs. If the hazard ratio with $\mathrm{T}$ were 0.6 (vs. 0.48), the CEA ratio at 20 yrs would be $\$ 101,000$ per LY. Including $\mathrm{CHF}$ increased the CEA ratios about $25 \%$.

Conclusion: The cost of adjuvant $\mathrm{T}$ are substantial and only modestly offset by reduced $\mathrm{BCa}$ recurrences. Using assumptions consistent with other studies of the duration of benefit from adjuvant $\mathrm{Rx}$ and the declining $\mathrm{BCa}$ recurrence risk, the projected benefits and CEA ratios for adjuvant $\mathrm{T}$ is consistent with other accepted Rxs.

$\begin{array}{llll} & \text { Chemo+T } & \text { Chemo w/out T } & \text { Difference } \\ \text { RFS (\%) @ 3, 10, 20 yrs } & 90.0,73.2,57.8 & 81.2,59.6,44.8 & 8.8,13.6,13.1 \\ \text { OS }(\%) @ 3,10,20 \mathrm{yrs} & 93.8,75.9,59.3 & 90.6,64.5,46.5 & 3.5,11.3,12.8 \\ \text { Costs* @ 3,10, 20 yrs } & 67150,75430, & 7610,25450, & 59530,49980, \\ & 81300 & 32750 & 48560 \\ \text { Survival Gain* (yrs)* } & & & 0.03,0.48,1.13 \\ \text { @ 3,10, 20 yrs } & & & \$ 1.8 \text { million, } \\ \text { Cost per LY* @ 3,10, 20 yrs } & & & \$ 102400, \$ 39600 \\ \text { no CHF } & & \$ 2.5 \text { million, } \\ \text { Cost per LY* @ 3,10, 20 yrs } & & & \$ 137000, \$ 51300 \\ \text { w/CHF }\end{array}$

*Discounted at $3 \%$ per yr

\section{1}

Cost-evaluation of second generation adjuvant chemotherapy options in breast cancer.

Al-Shehri A, Skedgel C, Rayson D, Sellon M, Younis T. Queen Elizabeth II Health Sciences Centre, Halifax, NS, Canada

Introduction: A number of adjuvant chemotherapy regimens have become standard treatment options for many patients with early stage breast cancer. Three second-generation anthracyclinebased regimens commonly employed in Canada include: $\mathrm{CEF}$ [cyclophosphamide (C) - epirubicin (E) - 5-flurouracil (F)], FEC 100, and AC-T [adriamycin (A) - C followed by taxol (T)]. These regimens are assumed to be equally efficacious although randomized comparative data is lacking. MA 21 , a recently completed three arm trial, directly compared $\mathrm{CEF}$ and $\mathrm{AC}-\mathrm{T}$, but efficacy results are not yet available. Assuming comparable survival among these accepted regimens, an economic evaluation may be helpful in selecting a preferred option. Methods: A cost minimization analysis was performed for CEF (6 cycles), FEC 100 (6 cycles), and AC-T (8 cycles). We examined the direct costs of chemotherapy drug acquisition, supportive medications, laboratory investigations, and health resources utilization for a standard course of these three regimens. We also included the costs of febrile neutropenia (FN) management and secondary G-CSF use based on reported incidence, and local practice. Indirect patients costs including travel and employment loss were also estimated based on average provincial wages and participation rates. This analysis was performed in Canadian dollars $(\mathrm{Cdn} \$)$ at the Nova Scotia 


\section{S220 Abstracts - Poster Session V}

Cancer Center, and assumes complete drug delivery. Sensitivity analyses were performed. A cost-effectiveness (CE) model estimated the required lower risk of cancer recurrence associated with the costly regimen to be cost effective at commonly accepted $\mathrm{CE}$ threshold. Results: The CEF regimen was associated with higher direct costs compared to FEC 100 or AC-T regimens (Table I). The total direct costs for uncomplicated chemotherapy delivery for standard courses of treatments were $\$ 7470, \$ 5995$, and $\$ 5853$ for the CEF, FEC 100, and AC-T regimens, respectively. Of these costs, $72 \%$ were for chemotherapy drug acquisition on average. The estimated additional cost of FN management and other indirect costs further increased the incremental cost associated with the $\mathrm{CEF}$ regimen. Estimated costs of FN management and secondary G-CSF use in the different regimens accounted for $5 \%-37 \%$ of the total direct costs of therapy. Indirect patient related costs amounted to $13 \%$ of the overall combined costs. Sensitivity analyses will be presented. For CEF to be a CE option at 5 year follow-up, a $29 \%$ relative benefit of CEF compared to AC-T is required. Conclusions: The $\mathrm{CEF}$ regimen is associated with higher direct and indirect costs compared to the FEC 100 or AC-T regimens. Unless the recently completed MA 21 trial reports a significant benefit in favor of CEF, other second generation regimens, such as FEC 100 or AC-T, are likely to be preferred. Table I

$\begin{array}{llll}\text { Costs } & \text { CEF } & \text { FEC } 100 & \text { AC-T } \\ \text { Direct } & 11328 & 6276 & 6660 \\ \text { Indirect } & 1771 & 830 & 1118 \\ \text { Combined } & 13099 & 7106 & 7778 \\ \text { All dollars figures rounded, in Cdn\$. } & & \end{array}$

\section{2}

Predictive value of health economic models: similarity in lifetime results using three-year versus five-year observations from the ATAC Trial.

Verma S, Rocchi A. The Ottawa Hospital Regional Cancer Centre, Ottawa, ON, Canada; Axia Research, Hamilton, ON, Canada

Background: Compared to tamoxifen, anastrozole (Arimidex) has demonstrated a reduced risk of recurrence in post-menopausal, hormone receptor positive $(\mathrm{HR}+)$ women with early breast cancer over five years in the ATAC trial (Arimidex, Tamoxifen Alone or in Combination). We originally conducted a health economic analysis using three-year data and have now finalized the analysis using recently released completed-treatment (CT) five-year data. Methods: A Markov model extrapolated trial results over a lifetime horizon for the typical ATAC trial patient. Data from the HR+ subset of the ATAC trial were used to determine rates of recurrence, death and adverse events for 3 years (original) or 5 years (CT). Tamoxifen recurrences were based on the 1998 EBCTCG overview; recurrences for anastrozole were $82 \%$ (original) and $83 \%$ (CT) of tamoxifen rates (based on the hazard ratio of disease-free survival from the ATAC trial). Anastrozole benefit was assumed to be constant and to last for 10 years; tamoxifen benefit was assigned for 15 years.

Results: The three-year analysis predicted an incremental difference of $7.6 \%$ in the total recurrence rate and $3.2 \%$ in the breast cancer mortality rate; the $\mathrm{CT}$ analysis predicted a $5.7 \%$ difference in total recurrences, and a $2.8 \%$ difference in breast cancer mortality. The number of locoregional recurrences and contralateral cancers predicted originally were very similar to the recurrences observed in years four and five of the ATAC trial; distant recurrences were less frequently observed than predicted. Minor differences were noted in the predictions of tolerability, adverse events and mortality. There was only a small difference in the cumulative number of lives saved; thus, the cost-utility ratio was stable at CDN\$26K/QALY (three-year analysis) and CDN\$28K/QALY (CT analysis). In the five-year CT model, the range of possible cost-utility results was much narrower in the sensitivity analysis, since the extent and duration of anastrozole benefit were proven to be consistent and durable.

Conclusions: Three year observations were highly predictive in determining economic conclusions regarding the use of anastrozole in place of tamoxifen in the treatment of postmenopausal women with $\mathrm{HR}+$ breast cancer.

\section{3}

Physician-based active cost management of gynecologicaloncological therapies reducing pharmaceutical costs by $83.4 \%$ in two years without leaving standard of care. Jacobs VR, Thoedtmann J, Euler U, Niemeyer M, Paepke S, Fischer T, Harbeck N, Kiechle M. Technical University Munich, Munich, Germany

Objective: Performance of chemo therapy is expensive and can cause the financial ruin for any clinic if not performed cos covering. Expensive innovative chemo drugs, increasing financial pressure of limitation of ressources with growing physicians' responsibility for accurate coding is contributing to the problem. In the following we report about a successful concept of a physician-based active cost management for gynecologicaloncological therapies in a German university OB/GYN clinic.

Methods: Primary target is identifying not cost covering oncological therapies and assignment to a cost covering reimbursement without reducing standard of oncological care. The model contains four steps: 1. financial as-is analysis, 2. precalculation of standardized pharmaceutical cost, 3. a case-bycase management with cost optimizing individual decision and 4 postcalculation of actual patient-individual pharmaceutical cost and correction of potential reimbursement mistakes.

Results: Over 4.000 oncological cycles were individually analyzed within a two year project. Depending on several factors for each patient a cost covering pathway was defined. Within two years the cost for oncological pharmaceuticals were so reduced by $778.339 \cdot(-83.4 \%)$, but neither the number of chemo cycles performed was reduced nor innovative pharmaceuticals substituted with older and cheaper therapies. Further reasons for a financial deficit were identified and eliminated.

Conclusion: In contrast to previously published cost efficiency analysis this is the first cost reimbursement analysis by physicians. With this model oncological therapies on a maximum care level can be performed cost covering so far even in a university clinic without leaving the standard of care. Although developed for optimization of reimbursement in Germany this model is applicable anywhere chemos are performed.

Decrease of oncological pharmaceutical cost from 2002-2004 in Euro [•] and percen $[\%]$.

$\begin{array}{llllll}\text { Year } & \begin{array}{l}\text { Chemo } \\ \text { drugs }[\bullet]\end{array} & \begin{array}{l}\text { Yearly } \\ \text { Reduction [\%] }\end{array} & \begin{array}{l}\text { Bisphosphonates } \\ {[\bullet \cdot}\end{array} & \begin{array}{l}\text { All Oncological } \\ \text { drugs }[\bullet]\end{array} & \begin{array}{l}\text { Yearly } \\ \text { Reductio } \\ {[\%]}\end{array} \\ 2002 & 891.309,- & & & & \\ 2003 & 368.101,- & -58.7 & 81.982,- & 933.291,- & \\ 2004 & 105.333,- & -71.4 & 49.619,- & 450.932,- & -51.7 \\ \Sigma & -785.976,- & -88.2 & & 154.952,- & -65.6\end{array}$

\section{4}

Cost-effectiveness of nanoparticle albumin-bound paclitaxel versus docetaxel in the treatment of metastatic breast cancer.

Gradishar W, Vishalpura T, Franklin M, Bramley T. Northwestern University Feinberg School of Medicine, Chicago, IL; Applied Health Outcomes, Palm Harbor, FL

Background: An albumin-bound, solvent-free nanoparticle formulation of paclitaxel was recently approved for the treatment of metastatic breast cancer (MBC). Patients receiving nanoparticle, albumin-bound (NAB) paclitaxel have demonstrated higher response rates, lower neutropenia rates (despite higher doses infused over shorter periods of time), longer time to tumor progression, and an absence of severe hypersensitivity reactions when compared to patients receiving Cremophor-based paclitaxel in the treatment of MBC (Gradishar 2005 in press). Like NAB-paclitaxel, docetaxel has also demonstrated superior clinical outcomes as compared to Cremophor-based paclitaxel (Ravdin 2003). However, docetaxel has also been associated with hematologic toxicities and a high 
incidence of febrile neutropenia, often requiring support with granulocyte colony stimulating factor. The purpose of this study was to compare the clinical and economic outcomes of NABpaclitaxel to docetaxel.

Material and Methods: A decision analytic model was developed to evaluate the economic impact and clinical outcomes in the treatment of MBC with NAB-paclitaxel and docetaxel from a payer perspective. The total cost per patient, cost per progression-free survival, and cost per responder are reported. Utilization costs considered were medical and pharmacy costs associated with a full course of chemotherapy, pretreatment medication costs, drug administration times, and costs for management of toxicities associated with each agent. Clinical inputs for dosing schedules and toxicity frequencies were derived from Phase III clinical trials (Gradishar 2005 in press, Ravdin 2003). Drug costs were based on average wholesale prices. Other unit costs were obtained from published reimbursement rates. Patients receiving docetaxel were assumed to receive first and subsequent cycle use of pegfilgrastim to prevent the occurrence of febrile neutropenia as demonstrated in a recent Phase III trial and received dexamethasone to prevent hypersensitivity reactions (Vogel 2005). Usage of pegfilgrasitm in patients receiving NABpaclitaxel was obtained from Phase III data. These patients did not require premedication to prevent hypersensitivity reactions as NAB-paclitaxel is solvent-free.

Results: Total costs per patient were $\$ 28,854$ for NAB-paclitaxel and $\$ 39,568$ for docetaxel. The cost per month of progressionfree survival as well as the cost per responder was lower for NABpaclitaxel than docetaxel $(\$ 5,702$ versus $\$ 6,942$; and $\$ 87,436$ versus $\$ 106,941$, respectively).

Discussion: Both NAB-paclitaxel and docetaxel have demonstrated superior response rates as compared to conventional paclitaxel; however, docetaxel has higher total costs when compared to NAB-paclitaxel. NAB-paclitaxel is a cost-effective novel treatment option for patients with MBC.

\section{5}

Microarray-based comparative genomic hybridisation (aCGH) analysis of breast cancer patients receiving neoadjuvant chemotherapy: analysis of tumour subtypes and chemotherapy-related molecular genetic changes.

Pierga J-Y, Reis-Filho JS, Cleator SJ, Dexter T, MacKay A, Jones $R$, Ashworth A, Smith IE, Powles T, Dowsett M. Breakthrough Breast Cancer Research Centre, The Institute of Cancer Research, London, United Kingdom; Royal Marsden Hospital, London, United Kingdom; Institut Curie, Paris, France

Background: Several studies have shown that gene expression profiling may be useful to predict response to neoadjuvant chemotherapy (CT) in breast cancer (BC) patients. Although changes in gene expression during neoadjuvant $\mathrm{CT}$ have been reported, little is known on chemotherapy-related genomic alterations. We analysed the molecular genetic changes in paired breast cancer samples before, during and after a neoadjuvant combination of doxorubicin-cyclophosphamide (AC).

Methods: Microdissected frozen breast core biopsies from 44 patients were obtained before CT (pre). In 17 patients, frozen samples were obtained 3 weeks after the first course of CT (D21) and in 21 patients, paraffin embedded surgical specimens were obtained after 4 to 6 cycles. Surgical specimens in pathological complete and good clinical responders were not available. aCGH was performed using the $5.8 \mathrm{~K}$ Breakthrough Breast Cancer Research Centre microarray platform, containing 5620 bacterial artificial chromosome clones (BACs) spaced at $<1 \mathrm{Mb}$ intervals throughout the genome. Data were analysed using S-Plus and a modified version of the aCGH package built on R. BACs were classified as gains, losses, or no-change according to their smoothed $\log 2$ ratio values. Thresholded data for each BAC were also used for categorical analysis using a Fishers exact test adjusted for multiple-testing with a permutation correction based on the false discovery rate.
Results: Subgroup analysis of 44 pre treatment biopsies showed that 5q11.2 and 16q23-q24 losses, 7q32-q36 and 2p25 gains were more frequently associated with oestrogen receptor negativity, 16q21-q22.1 losses with lobular carcinoma, 5q33.3-q4 and 18p11.31 losses, 6p25.1-p25.2 and Xp11.4 gains with HER2 amplification on 17q11.2-12. The comparison of the pretreatment, the D21 biopsies and the tumor excised after CT did not reveal significant differences in DNA profile. Unsupervised hierarchical clustering analysis based upon genetic alterations on all chromosomes showed that all pre and D21 post biopsies clustered together ( $\mathrm{N}=17$ cases). In 12 cases, three samples were available for the same patient (pre, D21 and at surgery), all clustering together. All but two surgical samples clustered with the respective pre CT sample.

Conclusions: Specific chemotherapy-driven genomic changes were not detected following 3 weeks or even 4 months of treatment. The hypothesis of resistance to neoadjuvant CT related to early induced gene amplifications or losses is not supported by our results.

\section{6}

Predictive gene signatures for response to neoadjuvant TAC-chemotherapy from expression profiling.

Rody A, Karn T, Munnes M, von Minckwitz G, Loibl S, Gaetje R, Solbach C, Holtrich U, Kaufmann M. J.W.Goethe-University, Frankfurt, Germany; Bayer Healthcare AG, Leverkusen, Germany; German Breast Group, Neu-Isenburg, Germany

Background: Neoadjuvant chemotherapy of breast cancer provides a unique opportunity to directly monitor and excactly assess response to treatment. We previously demonstrated the feasibility of performing gene expression profiling on pretherapeutic material in this setting in order to identify predictive gene signatures to guide the selection of the individual therapy.

Material and Methods: Pretherapeutic core biopsies from patients undergoing neoadjuvant docetaxel, adriamycin, cyclophosphamide (TAC) chemotherapy within the GEPARTRIOtrial were fresh frozen. Samples were classified according to standard pathology including ER, PR and HER2 IHC/FISH and amount of cancer cells. Only biopsies containing more than $80 \%$ tumor cells were considered further. RNA was isolated and expression profiling performed using Affymetrix HG-U133 Arrays (22,500 genes). Expressionist software package (GeneData, Basel) was used for subsequent bioinformatic analyses.

Results: Sufficient amounts of RNA for microarray analysis were isolated from two thirds of the biopsies and high quality data were obtained for 70 samples. In addition, for a subset of patients expression profiles of residual tumor at time of surgery were aquired. For signature identification consecutive samples were splitted into training $(n=50)$ and test-cohort $(n=20)$ based on date of surgery. Unsupervised clustering of samples broadly revealed a correlation with hormone receptor status. More than $90 \%$ concordance was observed when data from immunohistochemical analyses and corresponding mRNA expression as measured by microarrays were compared. Several described prognostic marker sets from microarray studies yielded no straight correlation with response to preoperative systemic therapy. Therefore, 50 samples were used in a supervised class prediction approach utilizing paired statistical tests and principle component analysis to identify a predictive gene signature for complete remission. This analysis resulted in a marker set encompassing 90 genes allowing the identification of all cases of stable and progressive diseases as well as the discrimination of all eight pathologic complete remissions. This gene signature was used in a KNN-cross-validation approach and subsequently verified on 20 additional independent samples. Interestingly, ESR1 status as well as PGR status did not seem to play a dominant role in the final signature while genes from the HER2 locus on chromosome $17 \mathrm{q}$ were highly expressed among many of the samples with pathologic complete remission. 


\section{S222 Abstracts - Poster Session V}

Discussion: Our analysis revealed an informative gene set correlated with treatment outcome to neoadjuvant chemotherapy with TAC. The gene signature was verified in a training/test cohort setting. Genes identified in this study do represent cell cycle regulation as well as cell signaling.

\section{7}

Preoperative doxorubicin / cyclophosphamide followed by docetaxel (AC-Doc) versus dose-dense doxorubicin and docetaxel (Adoc) as preoperative treatment in operable breast cancer: first analysis of the event-free survival of the GeparDuo-Study.

Raab G, Kaufmann M, Schuette M, Hilfrich J, Blohmer JU, Gerber $B$, Costa SD, Eidtmann H, Eiermann W, Lampe D, Jackisch $C, d u$ Bois A, von Minckwitz G. Marien Hosp., Stuttgart, Germany; Univ. Hosp., Frankfurt, Germany; Bethesda Hosp., Essen, Germany; Henriettenstift, Hannover, Germany; St. Gertrauden Hosp., Berlin, Germany; Univ. Hosp., Rostock, Germany; Univ. Hosp., Magdeburg, Germany; Univ. Hosp., Kiel, Germany; Rot-Kreuz Hosp., Munich, Germany; Hosp., Weissenfels, Germany; Univ. Hosp., Marburg, Germany; Horst-Schmidt-Kliniken, Wiesbaden, Germany; German Breast Group, Neu-Isenburg, Germany

Background: Sequential AC-DOC is more effective than dosedense ADOC as preoperative treatment at inducing pathologic complete response for patients with operable breast cancer. Whether this advantage translates into improved survival rates needs to be shown.

Methods: This phase III study investigated 913 women with untreated operable breast cancer (T2-3, N0-2, M0) randomized to receive either doxorubicin $50 \mathrm{mg} / \mathrm{m} 2$ plus docetaxel $75 \mathrm{mg} / \mathrm{m} 2$ every 14 days for four cycles with G-CSF support (ADOC; $n=455$ ) or doxorubicin $60 \mathrm{mg} / \mathrm{m} 2$ plus cyclophosphamide $600 \mathrm{mg} / \mathrm{m} 2$ every 21 days followed by docetaxel $100 \mathrm{mg} / \mathrm{m} 2$ every 21 days for four cycles each (AC DOC; $n=458$ ). The primary endpoint was the incidence of pathologic complete (invasive and non-invasive) response (pCR) in the breast and axillary nodes (von Minckwitz et al., J Clin Oncol 2005). We report here on disease-free (e.g. intrabreast, local, regional, and distant) and overall survival rates as one of the secondary endpoints. Analysis is planned after 226 events resulting from an expected median event-free survival at five years of $65 \%$ in the ADOC and $73.4 \%$ in the AC-DOC group (relative risk reduction $24 \%$ ).

Results: Both groups were well balanced for conventional prognostic factors at randomization: Median age: 51 (24-77) years, median clinical tumor size 40 (10-160) $\mathrm{mm}, \mathrm{cN}+40.1 \%$, ER +: $67.4 \%$, PR+: $58.5 \%$. A pCR was achieved with ADOC in $7.0 \%$ and AC-DOC in $14.3 \%(\mathrm{p}<0.001)$. At the analysis after a median follow-up of 30 months, 177 patients with events including 84 deaths and 154 local recurrences or metastases have been reported. Conclusion: An updated follow-up with a medium survival of approx. 40 months and more than $>226$ events will enable the first planned analysis of event-free survival and will be presented at the SABCS 2005 .

\section{8}

Operable breast cancer: preliminary results of a phase II, double blind, placebo controlled, randomized trial of preoperative chemotherapy $+/$ - gefitinib with biomarkers evaluation.

Guarneri V, Frassoldati A, Ficarra G, Giovannelli S, Borghi F, Puglisi F, Mansutti M, Andreetta C, Banna G, Masci G, Santoro A Boni C, Bisagni G, Michelotti A, Crispino S, Conte PF. Modena University Hospital, Modena, Italy; Modena University Hospital, Modena; Udine University Hospital; Istituto Clinico Humanitas, Rozzano; Arcispedale Santa Maria Nuova, Reggio Emilia; S Chiara University Hospital, Pisa; USL7, Siena

\section{Introduction:}

EGFR is expressed in $14-80 \%$ of breast cancers (BC). The activity and safety of TKIs in earlier stages and in combination with chemotherapy has yet to be characterized. To evaluate the in vivo interaction between gefitinib and its target in patients (pts) with operable $\mathrm{BC}$, we designed this phase II randomized trial of preoperative chemotherapy +/- gefitinib. Secondary aims: evaluation of biomarker modulation at baseline and at surgery, percentage of pathologic complete response (pCR), and toxicity. Patients and Methods:

After core biopsy, pts with stage IIB-IIIA BC were randomized to receive:

epirubicin (E) $90 \mathrm{mg} / \mathrm{m}^{2}$ iv and paclitaxel (T) $175 \mathrm{mg} / \mathrm{m}^{2}$ iv on day 1 plus: gefitinib $250 \mathrm{mg}$ daily from day 5 to 16 (Arm A), gefitinib $250 \mathrm{mg}$ daily from day 1 to 21 (Arm B), or placebo (Arm C). Four courses were administered every 3 wks, and then pts underwent surgery. The following parameters were evaluated at baseline, and on the specimens of definitive surgery: pMAPKinase, EGFR/aEGFR expression, Ki67, apoptotic index (TUNEL test), and VEGF-R (Flk1) expression.

\section{Results:}

So far $40 / 90$ planned pts have been entered; thirty-three pts have received at least one course of treatment and are evaluable for toxicity. Median age was 50 years (range:34-66); $85 \%$ of pts had stage IIA-IIB disease. A total of 104 courses were administered; treatment was generally well tolerated. Two pts experienced febrile neutropenia. Seven pts discontinued treatment: 2 due to progressive disease, 1 died for a car accident, and 4 due to toxicity (cutaneous: 1 , severe mood alteration:1, grade 4 hepato-biliary toxicity: 1; grade 3 hypertransaminasemia:1). Twenty-one pts completed treatment plan and underwent surgery; 7 pts $(33 \%)$ received breast conservative surgery. A pCR was observed in 2 pts $(9,5 \%)$.

Median expression at baseline and after therapy were respectively: Ki67: $33,3 \%$ (range3-90\%) and 17,5\% (range: $1-80)(\mathrm{p}=0.039)$; EGFr: $8,2 \%(0-80 \%)$ and $0,5 \%(0-4 \%)$; pMAPK: $13,8 \%(0-65)$ and $8,3 \%(0-70)$, VEGFR positivity $54 \%$ and $23,5 \%$.

Conclusions:

Despite the low number of pts, the inclusion of gefitinib in a preoperative chemotherapy program is feasible, and the toxicity profile of this combination is not dissimilar to that reported for gefitinib or for the ET combination alone. By preliminary assessment, the expression of all the evaluated biomarkers tended to be lower after treatment, despite this reduction is significant for Ki67 only. Complete analysis including biomarker evaluation will be available at the time of the meeting. 


\section{9}

Prospective data of additional patients treated with neoadjuvant therapy with paclitaxel followed by FEC chemotherapy with trastuzumab in HER-2 positive operable breast cancer, and an update of initial study population.

Buzdar AU, Valero V, Ibrahim $N$, Francis D, Theriault RL, Green M, Hunt K, Sahin A, Buchholz T, Hortobagyi GN. The University of Texas M.D. Anderson Cancer Center, Houston, TX

Purpose: The initial data of our prospective trial of concomitant chemotherapy \pm trastuzumab were published (JCO 23:3676-3685; 2005). An additional 23 patients were treated with chemo $+\mathrm{H}$ on this study after closure of the control arm. An update on efficacy and safety on all patients is included here.

Patients and Methods: After modification of study (closure of control arm) an additional 23 pts were treated with chemo+H (1 pt after initiation of therapy withdrew her consent). Median age 51 (range 21-70). Tumor size was $T_{1}(3 \mathrm{pts}), \mathrm{T}_{2}(14 \mathrm{pts})$, and $\mathrm{T}_{3}$ (5 pts). Nine pts had clinically negative axilla, and 13 pts had $\mathrm{N}_{1}$ (confirmed by FNA). Safety and efficacy results of initial 43 patients have been updated.

Results: Of 22 pts, the $2^{\text {nd }}$ cohort, 12 patients $(54.5 \%)$ had pathological complete remission (pCR; in breast \& nodes). In 4 pts, (18.2\%) the residual tumor in the breast consisted of presence of scattered single tumor cells in the tumor bed and/or the tumor volume $\leq 2 \mathrm{~mm}$. In $4 \mathrm{pts}$, residual disease in the breast was $>0.2 \mathrm{~mm}$ $1.1 \mathrm{~cm}$, and additional two pts had pCR in breast, but had residual disease in a node measuring $0.2 \mathrm{~mm}$ and $0.5 \mathrm{~cm}$. A $>10 \%$ decrease in left ventricular ejection fraction was observed in 6 pts. Of the initial 45 patients, with a median follow-up of 32 months (range 20-48 months), 1 patient in the control group had disease recurrence. All patients treated with chemo+H have remained free of disease without any clinical cardiac dysfunction.

Conclusion: Additional data support the initial observations that this approach can result in high pCR in patients with HER-2 positive breast cancer. With additional follow-up of initial study population, the efficacy and safety data remain unchanged.

\section{0}

Pathological complete response with neoadjuvant docetaxel, carboplatin and trastuzumab in HER2-positive, locally advanced breast cancer on behalf of the GETN(A) Group.

Coudert B, Largillier R, Chollet P, Camponne M, Coeffic D, Priou $F$, Gligorov J, Martin X, Trillet Lenoir V, Weber B, Arnould L, Bleuse JP, Vasseur B, Serin D, Namer M. CAC GF Leclerc, Dijon, France; CAC A Lacassagne, Nice, France; CAC J Perrin, Clermont Ferrand, France; CAC R Gauducheau, Nantes, France; Clinique du Mail, Grenoble, France; CH Les Oudairies, La Roche sur Yon, France; Hopital Tenon, Paris, France; Clinique Ste Marie, Chalon sur Saone, France; Institut St Catherine, Avignon, France; Sanofi Aventis, Paris, France; Roche, Neuilly, France; CHU Lyon Sud, Lyon, France; CAC A Vautrin, Nancy, France

Background: The study assessed the complete pathological response (Sataloff or Chevallier scales) to neoadjuvant docetaxel (T), carboplatin (C) and trastuzumab (H) in HER2-positive (immunochemistry [IHC] 3+), locally-advanced breast cancer patients (pts).

Materials and methods: Six TCH cycles were scheduled with three-weekly T $\left(75 \mathrm{mg} / \mathrm{m}^{2}\right)$ and C (AUC 6) and weekly $\mathrm{H}(4 \mathrm{mg} / \mathrm{kg}$ loading dose then $2 \mathrm{mg} / \mathrm{kg} /$ week for 17 weeks). Safety (WHO criteria), objective response (OR; RECIST criteria) and rate of breast-conserving surgery were secondary endpoints. All breast cancers were IHC scored; final centralized IHC and fluorescence in-situ hybridization (FISH) determination is ongoing.

Results: From January 2003 until December 2004, 70 pts were enrolled. Preliminary data are available for 44 pts: mean age 48 years [24-66]; 16 (36\%) post menopausal; mean clinical tumor size $40 \mathrm{~mm}$ [18-90]. All pts had an normal initial cardiac evaluation before entry. Some pts stopped treatment prematurely during cycles $1-5$. Clinical and radiological response $(n=30)$ was complete in 10 pts $(33.3 \%)$, partial in $18(60 \%)$, stable in $2(6.7 \%)$. Surgery was conservative in 23 patients $(92 \%)$ and mastectomy in $2(8 \%)$. Pathological tumour Sataloff classification $(\mathrm{n}=23)$ was T-A in 11 patients $(47.8 \%)$, T-B in 7 (30.4\%), T-C in $4(17.4 \%)$, T-D in 1 $(4.3 \%)$. Pathological node Sataloff classification was N-A in 6 patients $(26.1 \%), \mathrm{N}-\mathrm{B}$ in $7(30.4 \%), \mathrm{N}-\mathrm{C}$ in $8(34.8 \%), \mathrm{N}-\mathrm{D}$ in 2 (8.7\%).Pathological Chevallier classification was grade 1 in 5 patients $(21.7 \%)$, grade 2 in $4(17.4 \%)$, grade 3 in $11(47.8 \%)$, grade 4 in $3(13 \%)$. Preliminary centralized IHC testing on 45 cases showed that 5 tumours $(11 \%)$ were in fact HER2-1+, while 3 (6.5\%) were HER2-2+ and $37(82.5 \%)$ were HER2-3+

Conclusions: In HER 2 positive $(3+)$ locally advanced breast cancer patients, targeted primary chemotherapy with Trastuzumab, Docetaxel and Carboplatine was active and promising, achieving high histological complete response without significant toxicity. Final results on all patients and according to centralized IHC and FISH determination will be presented

Acknowledgements are due to P Attali, P Caille, S Detry (GETN(A) and OSMO)for their permanent assistance to the study

Supported by Sanofi Aventis Laboratories and Roche Laboratories

\section{1}

Prospective randomized comparison of neoadjuvant / primary systemic therapy (PST) with dose-dense sequential epirubicin (E)/ paclitaxel (P) chemotherapy versus standard dose therapy regimen in patients with breast cancer (bc), multicentre study of the AGO, Germany): subgroup analysis of inflammatory bc.

Ditsch N, Bauerfeind I, Kahlert St, Lenhard MS, Himsl I, Untch M. Ludwig-Maximilians.University, Grosshadern, Munich, Bavaria, Germany

Introduction: Inflammatory breast cancer is a rare rapidly progressive disease; prognosis remains poor despite improved primary systemic therapy (PST). Mastectomy is still the current standard of surgical therapy. This analysis was designed to compare response rates, frequency of breast conserving surgery (BCS) and side effects of Epirubicin/Paclitaxel as either a dose-dense sequential regimen $(\mathrm{Arm} A)$ or as standard chemotherapy (Arm B) in a subgroup of patients with inflammatory breast cancer.

Patients and methods: In 679 breast cancer patients diagnosed between 1998 and 2002, 101 patients presented with inflammatory type. Patients were randomized to receive $3 \mathrm{xE} 150 \mathrm{mg} / \mathrm{m} 2$ followed by $3 \times T 250 \mathrm{mg} / \mathrm{m} 2 \mathrm{q} 2 \mathrm{w}$ with G-CSF (Filgrastim) support $(5 \mathrm{mg} / \mathrm{kg} /$ d, d3-10) (Arm A) or 4xET 90/175 mg/m2 q3w (Arm B) as preoperative therapy. All patients received 3xCMF q4w (500/40/ $6000 \mathrm{mg} / \mathrm{m} 2 \mathrm{~d} 1+8)$ after surgery; locoregional radiotherapy was also mandatory. All $\mathrm{HR}+$ pts received adjuvant endocrine treatment.Results: Data are available for 93 (A $n=42, B n=51)$ patients with inflammatory disease. All patients were scheduled for mastectomy before starting PST, however in $23 \%$ of patients BCS was performed. BCS was possible after PST in $12 / 36$ patients with a tumor-size ranging from 3 to $7.9 \mathrm{~cm}$. Clinical downstaging regarding tumor size was achieved in 37 patients and for nodal status in 23 patients. Pathologic complete response rate was in favour of the dose dense arm (21\% vs $12 \%)$. Conclusion and discussion: Even in inflammatory disease the rate of mastectomy could be reduced after PST. Pathologic response showed a benefit in favour of the dose-dense sequential Arm A, but patients with inflammatory breast cancer have a poor prognosis independent of $\mathrm{pcR}$ rate in both arms at the time of this analysis. The side effects were tolerable with no clinical relevant cardiac, hematolgic and nonhematologic toxicities. 
5052

Mature results from a randomized phase III trial of docetaxel/capecitabine (TX) vs. doxorubicin/ cyclophosphamide (AC) as primary chemotherapy for patients (pts) with stage II/III breast cancer (BC).

Lee KS, Lee ES, Kwon YM, Nam BH, Kwon HS, Chung KW, Kang HS, Kim EA, Kim SW, Ro J. National Cancer Center, Goyang, Republic of Korea

Background: Use of $\mathrm{T}$ in the preoperative setting increases clinical and pathologic response. The oral fluoropyrimidine $\mathrm{X}$ (Xeloda) is effective and well tolerated as single-agent therapy in pts with metastatic $\mathrm{BC}$ and adding $\mathrm{X}$ to $\mathrm{T}$ improves survival, TTP and response rates vs. $\mathrm{T}$ alone. We compared the efficacy and safety of TX vs. AC as primary chemotherapy for stage II/III BC. Materials and Methods: Eligible pts had positive axillary lymph nodes by PET or ultrasound-guided fine-needle aspiration (FNA), adequate organ and hematological profiles and good PS (ECOG 0/ 1). No prior hormonal, chemotherapy, radiotherapy or surgery was permitted. Pts were stratified according to age ( $\leq 50$ years vs. $>50$ years), ER status (+ve vs. $-v e$ ), and stage (II vs. III). They were randomized to preoperative TX $\left(\mathrm{T} 75 \mathrm{mg} / \mathrm{m}^{2}\right.$ i.v. $\mathrm{d} 1+\mathrm{X}$ $1000 \mathrm{mg} / \mathrm{m}^{2}$ twice daily d1-14) or AC (A $60 \mathrm{mg} / \mathrm{m}^{2}$ i.v. d $1+$ C 600 $\mathrm{mg} / \mathrm{m}^{2}$ i.v. d1), $\mathrm{q} 3$ wks $\mathrm{x} 4$. Following surgery, pts crossed over to receive the other treatment with further radiotherapy \pm tamoxifen as required. Assessment for clinical response was by ultrasound at baseline and after the 2nd and 4th cycles. Results: 209 pts were enrolled between Aug02 and Apr05. Age, ECOG PS, stage, and hormone receptor status were balanced in each arm. 191 pts (96 on TX; 95 on AC) had undergone surgery by Apr05 and 18 pts are still receiving preoperative chemotherapy. Safety is currently evaluable in the 202 pts who have completed at least 2 cycles of preoperative chemotherapy. Compared with $\mathrm{AC}$, TX led to increased clinical response rate $(93 \%$ vs. $79 \%, \mathrm{p}=0.0058)$, and pathological complete response (pCR) in primary tumors (23\% vs. $8 \%, \mathrm{p}=0.0059)$ and lymph nodes $(33 \%$ vs. $22 \%, \mathrm{p}=0.08)$. pCRs in primary tumors were observed regardless of stage, ER/PR and HER2 status. Significantly more lymph node pCRs were seen in ER/PR-ve pts in the AC group. More pts on TX benefited from primary tumor shrinkage (52\% vs. $47 \%$ ) and lymph node shrinkage $(100 \%$ vs. $50 \%)$. A higher breast-conservation rate $(\mathrm{p}=0.0001)$ was possible in pts with stage II disease $(90 \%$ on TX vs. $78 \%$ on AC) compared with stage III ( $32 \%$ on TX vs. $40 \%$ on AC). TX caused less nausea and vomiting but more myalgia, skin and nail toxicities than AC. The most common grade $3 / 4$ adverse events (TX vs. AC) were neutropenia ( $72 \%$ vs. $85 \%)$, vomiting (5\% vs. $25 \%)$, hand-foot syndrome (22\% vs. $0 \%)$, stomatitis $(10 \%$ vs. $0 \%$ ) and desquamation (5\% vs. $0 \%$ ). Discussion: In stage II/III $\mathrm{BC}, \mathrm{TX}$ significantly increased clinical and pathological response compared with AC. TX and AC resulted in high breast-conservation rates in pts with stage II disease. A non-anthracycline-based regimen consisting of TX proved effective as primary therapy in early stage breast cancer. QoL data using the EORTC QLQ-BR23/C30 questionnaire will be presented at the meeting.

Supported by NCC grant-0210150, Sanofi-Aventis and Roche Korea.

\section{3}

Evaluation of the effect of neoadjuvant chemotherapy on tumour microvessel density (MVD), pericyte coverage index (PCI) \& vascular endothelial growth factor (VEGF) in primary breast cancer.

Ah-See MW, Harris AL, Burcombe RJ, Fox SB, Richman PI, Daley FM, Padhani AR, Bentzen SM, Makris A. Mount Vernon Hospital, Northwood, Middlesex, United Kingdom; John Radcliffe Hospital, Oxford, Headington, United Kingdom

Background: Angiogenesis is critical for the growth \& metastasis of breast tumours \& can be quantified using MVD. Pericyte recruitment to the tumour microvasculature is thought to reflect vessel maturation \& thus PCI provides a qualitative measure of tumour angiogenesis. VEGF is the key angiogenic factor driving neovascularisation within breast cancers. Here we assess the effect of neoadjuvant chemotherapy (NAC) on MVD, PCI \& VEGF expression in primary breast cancer (PBC).

Methods: Paired pre- \& post-treatment pathological specimens (diagnostic core biopsy \& definitive surgical resection specimen) from 80 women with PBC (median age 47 years; range $29-70$ ) who received 5-fluorouracil, epirubicin \& cyclophosphamide (FEC) NAC were analysed for MVD \& PCI. Immunohistochemical doublestaining was performed using the panendothelial marker, CD34, \& alpha-smooth muscle actin ( $\alpha$-SMA). MVD \& PCI were scored from random fields (median 9; range 2-31) at x200 magnification or, in the case of small samples $(\mathrm{n}=20)$, from all fields (median 2; range 1-12). Individual microvessels (CD34 positive) were counted per field \& MVD expressed per $\mathrm{mm}^{2}$. PCI was scored as the number of CD34 \& $\alpha$-SMA positive vessels \& expressed as a percentage of all CD34 positive vessels within the field. VEGF expression was evaluable on samples from 48 of the women \& was analysed using the anti-VEGF monoclonal antibody, VEGF AB-7. The intensity of VEGF staining was scored as: negative $=0$, weak $=1$, moderate $=2$, strong $=3$. The percentage of cells staining was scored as: $0 \%=0$, $<5 \%=1,5-20 \%=2,20-50 \%=3,>50 \%=4$. A VEGF immunoreactive score (IRS) was calculated as the product of the intensity of staining \& the percentage of cells staining. Change in median MVD, PCI \& VEGF IRS following NAC was evaluated using the Wilcoxon's signed ranks test.

Results: The median (interquartile range) pre-NAC MVD, PCI \& VEGF IRS values were $76.4 / \mathrm{mm}^{2}\left(46.5-106.6 / \mathrm{mm}^{2}\right), 17.3 \%(6.6$ $-30.4 \%) \& 6(4-9)$ respectively \& the post-NAC values were $72.2 / \mathrm{mm}^{2}\left(50-100 / \mathrm{mm}^{2}\right), 25.5 \%(18.2-43.3 \%) \& 4(3-6)$ respectively. There was no significant difference between the pre$\&$ post-NAC MVD values $(\mathrm{p}=0.48)$, however, there was a significant increase in PCI $(\mathrm{p}<0.0001)$ \& a significant reduction in VEGF IRS following NAC $(\mathrm{p}<0.005)$.

Conclusions: The MVD of breast tumours following FEC NAC is not significantly different to that in the pre-NAC diagnostic core biopsy. A significant increase in the PCI \& a significant reduction in VEGF expression occurs following NAC.This suggests a differential effect of NAC on the tumour microvasculature according to functional status, with a reduction in the proportion of "immature" blood vessels. This effect may be mediated by VEGF.

\section{4}

Frequent pathologic complete responses seen with neoadjuvant q4week carboplatin and weekly paclitaxel \pm weekly trastuzumab in resectable and locally advanced breast cancer: a Brown University Oncology Group (BrUOG) Study.

Fenton MA, Ries LM, Strenger R, Dizon DS, Legare RD, Joseph PJ, Theall KP, Graves TA, Gass JS, Sikov WM, Brown University Oncology Group. Rhode Island Hospital, Providence, RI; Women and Infants Hospital of Rhode Island, Providence, RI; The Miriam Hospital, Providence, RI; Memorial Hospital of Rhode Island, Pawtucket, RI

Background: Achievement of pathologic complete response (pCR) with neoadjuvant chemotherapy correlates with improved disease-free survival in patients (pts) with resectable breast cancer. Weekly paclitaxel (P) enhances the pCR rate compared to q3week P (M Green, ASCO 2002). Based on data in advanced disease, we performed a phase II study to assess the addition of carboplatin $(\mathrm{Cb})$ to neoadjuvant weekly P in HER2- pts and weekly P with trastuzumab $(\mathrm{H})$ in HER2+ pts.

Methods: Pts were stratified by resectability (stage IIA-IIIA vs. stage IIIB-C) and HER2 status (defined by FISH). Pretreatment pathologic evaluation of suspicious lymph nodes (LN) was encouraged. Pts received Cb AUC $6 \mathrm{q} 4 \mathrm{wks}$ and P $80 \mathrm{mg} / \mathrm{m}^{2}$ weekly x 16 wks, with weekly H 2 mg/kg in HER2+ patients, followed by 
surgery with axillary LN sampling (except in pts with (-) sentinel LNs pre-chemo). Post-op therapy was left to the discretion of the treating physicians. The study was designed to detect a pCR rate of $>25 \%$ in at least 40 resectable pts.

Results: 55 patients (43 with resectable disease) were enrolled in 18 months. Median age 54 (31-74). Pts received median 16/16 weekly treatments. Doses were held in 13 pts for neutropenia $(\mathrm{ANC}<800)$ and in 3 pts for grade 3 thrombocytopenia. Serious adverse events were limited to one pt each with pulmonary embolus, syncope, port infection, and dehydration. No episodes of febrile neutropenia were reported. Grade 2 (4 pts) or 3 (1 pt) neuropathy was uncommon. Other grade 3 toxicities were rare.

Overall the pCR rate was $45 \%(24 / 53,95 \%$ CI 32-60\%); HER2+ pts were more likely to achieve a pCR $(78 \%)$ than HER2- pts $(29 \%)$. The pCR rate in resectable pts was $43 \%(18 / 42,95 \%$ CI $28-59 \%$ ). pCRs by strata are tabulated below:

Factor pCR rate

Resectable vs. unresectable

Resectable node-negative vs. positive

HER2+ vs. HER2-

ER+ vs. ER-

HER2+: ER+ vs. ER-

HER2-: ER+ vs. ER-

Two pts were inevaluable due to early termination of treatment. pCRs include 6 pts with scattered residual tumor cells or a micrometastasis in a single lymph node.

Conclusion: This carboplatin/weekly $\mathrm{P} \pm \mathrm{H}$ neoadjuvant regimen was very well tolerated and demonstrates significant activity, particularly in HER2+ and ER-/HER2- pts, despite the omission of an anthracycline. We conclude that this regimen merits further study in the neoadjuvant setting.

\section{$\mathbf{5 0 5 5}$}

A phase II randomized study to compare the neoadjuvant administration of docetaxel and vinorelbine or docetaxel followed by adriamycin and cytoxan with all chemotherapy administered in a dose dense fashion to women with stage II and stage III breast cancer.

Limentani SA, Brufsky AM, Rubin P, Lambert-Falls R, Carroll M. Blumenthal Cancer Ctr, Charlotte, NC; Magee Women's Hospital, Pittsburgh, PA; Moses Cone Reg Cancer Ctr, Greensboro, NC; S Carolina Onc Assoc, Columbia, SC

We have previously demonstrated that a combination of docetaxel (D) $\left(60 \mathrm{mg} / \mathrm{m}^{2}\right)$ and vinorelbine (V) $\left(45 \mathrm{mg} / \mathrm{m}^{2}\right)$ administered every two weeks for 6 cycles to women with breast cancer in a neoadjuvant fashion results in a pathologic complete response rate (pCR) of $27 \%$. However, the incidence of fever and neutropenia $(\mathrm{F} / \mathrm{N})$ was unacceptably high $(22 \%)$ in spite of the use of prophylactic filgrastim and quinolones. We reasoned that a decrease in the dose of $\mathrm{V}\left(30 \mathrm{mg} / \mathrm{m}^{2}\right)$ would result in a lower incidence of $\mathrm{F} /$ N. Furthermore, the incorporation of doxorubicin $\left(60 \mathrm{mg} / \mathrm{m}^{2}\right)$ and cyclophosphamide $\left(600 \mathrm{mg} / \mathrm{m}^{2}\right)$ (AC) administered every two weeks for 4 cycles following the completion of TN would result in an increased pCR rate ( $\operatorname{arm} 1)$. Based on the Norton-Simon hypothesis we also evaluated the administration of D $\left(75 \mathrm{mg} / \mathrm{m}^{2}\right)$ for 6 cycles followed by AC administered every two weeks for 4 cycles (arm 2). One hundred and six patients (pts) (arm $1=51$, arm $2=55$ ) have been enrolled with a planned accrual of 70 pts per arm. Arm 1, 35 pts stage II, 16 pts stage III, arm 2, 39 pts stage II, 16 pts stage III. 341 cycles have been administered on arm 1 and 332 cycles on arm 2 . Grade $3 / 4$ toxicities include mucositis: $\operatorname{arm} 1=2$, arm $2=0$, fatigue: $\operatorname{arm} 1=3$, arm $2=2$, epiphora: $\operatorname{arm} 1=0$, arm $2=1$, hand foot syndrome (HFS): arm 1 $=2$, $\operatorname{arm} 2=2$, Diarrhea: arm $1=1$, arm $2=3$, pulmonary: arm 1 $=0$, $\operatorname{arm} 2=2$, fever and neutropenia: $\operatorname{arm} 1=3$, arm $2=1$. Dose modifications have been performed in 13 pts on arm 1 and 15 pts on arm 2. Four pts in arm 1 had dose reductions of AC, two pts in arm 2 had dose reductions of AC. Five pts have had chemotherapy stopped prematurely because of toxicity, two from arm 1 and three from arm 2. Clinical partial responses have been seen in 10/ $29(34 \%)$ pts on arm 1 and 11/34 (32\%) pts on arm 2, complete response $17 / 29(58 \%)$ pts arm 1 and 18/34 (53\%) pts arm 2, stable disease $2 / 29(7 \%)$ arm 1, 4/29 (12\%) arm 2, progressive disease in $1 / 34(3 \%)$ on arm 2 . Overall response rate $93 \%$ on arm 1 and $85 \%$ on arm 2. pCR has been seen in 7/26 (27\%) pts on arm 1 and $9 / 27(33 \%)$ pts on arm 2 . In pts with hormone receptor negative disease 4/11 (36\%) pts have had a pCR on arm 1 and 6/ $8(75 \%)$ pts have had a pCR on arm 2. In summary, chemotherapy has been well tolerated by most pts irrespective of the arm upon which they have been treated. Two early concerns, F/N on arm 1 and HFS on arm 2 have been infrequent occurrences. Although preliminary, both clinical and pathologic response rates are encouraging. The findings in hormone receptor negative disease support the contention that these pts have a better response to neoadjuvant chemotherapy.

\section{6}

High pathological complete remission rates with paclitaxel and carboplatin \pm trastuzumab $(\mathrm{TC} \pm \mathrm{H})$ following dose dense doxorubicin and cyclophosphamide (AC) supported by GM-CSF in breast cancer-a phase II study.

Mehta RS, Schubbert T, Hsiang D, Butler J, Baick C, Su M-Y. University of California, Irvine, Orange, $C A$

Background: We reported an 87\% (CI .47-.99) pathological complete remission (pCR) with $\mathrm{AC}$, TCH administered sequentially with relative cardiac safety in eight consecutive breast cancer (BC) patients (SABC 2004). Tolerability data of the sequential $\mathrm{AC}, \mathrm{TC}+\mathrm{H}$ in a follow up phase II setting demonstrated the safety of this outpatient regimen (ASCO 2005). We report here the final outcome analysis of the first 21 patients who received a maximum of 4 cycles of dose dense AC supported by GM-CSF. Two weeks following AC, 13 Her-2 negative patients received 2-4 cycles of TC (6-12 weekly doses), and $8 \mathrm{Her}-2$ positive (IHC3+/and or FISH positive) patients received 3-4 cycles of TCH (12-16 weeks of trastuzumab), respectively. Twelve patients were hormone receptor positive. An additional 20 patients have completed 1-4 cycles of AC. Ten of these patients are candidates for TCH following AC. Results: Of > 140 AC cycles supported by GM-CSF, only 1 cycle was associated with neutropenic fever. Two additional neutropenic febrile episodes developed in the few cycles supported by G-CSF or pegfilgrastim. A pCR rate of $50 \%$ (95\% CI $0.29-0.76$ ) by NSABP criteria was achieved in the first 20 assessable patients with stage II-IV breast cancer. Lymph node negativity rate was $65 \%$ at final surgery. On subset analysis, 5 of $7(71 \%)$ Her-2 positive, and 5 of $13(38 \%)$ Her-2 negative patients achieved pCR. Three additional patients had rare cells, and a fourth had a $1.5 \mathrm{~mm}$ residual cancer, therefore, $70 \%$ of patients achieved a $\mathrm{T} 0 / \mathrm{T} 1 \mathrm{mic} / \mathrm{T} 1 \mathrm{a}$ status in a heterogeneous BC population. One additional stage IV patient with Her-2 positive inflammatory breast cancer not included in the analysis died of septic shock following $\mathrm{TCH}$. She had no evidence of breast cancer but had undiagnosed cirrhosis at autopsy. Following TCH, there was no clinical cardiac dysfunction or $\mathrm{EF}<55 \%$ by Echo, and only 1 patient had $>15 \%$ reduction from the baseline EF. Conclusion: A 50\% pCR and a $65 \%$ lymph node negative rate, and a $70 \%$ T0/T1mic/T1a status is one of the highest reported for a heterogeneous BC population. An impressive pCR rate in the Her- 2 positive BC subset not only validates our 8 patient pilot data but mirrors the remarkable disease free survival improvement observed in the adjuvant setting with sequential anthracycline, trastuzumab based regimens. Extrapolating from NSABP neoadjuvant studies, each $10 \%$ increment in pCR should yield $2-3 \%$ increment in survival. Minimum anthracylines may be important in achieving a high pCR rate as the studies of neoadjuvant taxane, platinum, and trastuzumab based regimens have yielded low pCR rates. Moreover, this study suggests trials of shorter duration trastuzumab (12-16 weeks) versus longer duration of trastuzumab are warranted. 
$\mathbf{5 0 5 7}$

Semi-quantitative gene expression profiling for therapy prediction in a breast cancer neoadjuvant therapy study applying docetaxel/epirubicin/cyclophosphamide.

Schlotter CM, Vogt U, Tidow N, Kemming D, Bosse U, Bonk $U$, Ergoenc Y, Adiguezel H, Egbert M, Brandt BH. Clinical Centre, Ibbenbueren; European Laboratory Association, Ibbenbueren; GeneSys Lab, Muenster; Institute of Tumor Biology, University Medical Center, Hamburg; Institute of Pathology, Osnabrueck; Institute of Pathology, Bremen; St. Anna Hospital, Herne; Institute of Tumor Biology, University Medical Centre, Hamburg

More than 28000 curated human genes can be analyzed semiquantitatively using a new chemiluminescent detection technology and 60mer oligonucleotides on a Human Genome Survey Microarray (HGSM, Applied Biosytems). Our results demonstrate a low rate of false-positives $(1.2 \%)$, a high specificity and quantification accuracy of HGSM system. Comparison of data from HGSM and RT-PCR obtained on mRNA from fresh frozen tissue resulted a Pearson-correlation of 0.92 to 0.63 for the breast cancer genes, e.g. EGFR, HER2, estrogen receptor a (ESR1), progesterone receptor (PGR), urokinase-type plasminogen activator (PLAU, uPA), and plasminogen activator inhibitor-1 (PAI-1).

HGSM expression profiling was performed on biopsy samplesfrom a setting of patients under neoadjuvant treatment. The protocol for a phase II study was elaborated for the treatment of breast cancer patients suffering from a primary tumor $>1,5 \mathrm{~cm}$ or inflammatory breast cancer with Docetaxel/Epirubicin/ Cyclophosphamide (TEC) prior to surgical treatment. The study was approved by the local ethical committee and 40 patients will be included into the study after written informed consent. Twenty two patients have been already included in the ongoing study. In this prospective study a biopsy from the tumor is taken before chemotherapy. Therefore, success of treatment is detectable directly at the operated residual tumor. First expression profiling results are obtainable showing that a subset of 43 genes indicates patients with complete remission (CR, no detectable tumor at end of chemotherapy), partial remission (PR) and progressive disease (PD). Remarkable, that the expression profile clearly separated $\mathrm{CR}$ and PD tumors whereas PR tumors presented with a closer relationship to $\mathrm{PD}$ tumors than to $\mathrm{CR}$ tumors but displayed small specific subprofiles. A comparable separation of the groups could not achieved by established tumor markers, e.g. ER, PgR, HER2, uPA etc. which are measured simultaneously on the HGSM.

In Conclusions, HGSM semi-quantitative expression profiling is promising to have the potential to figure out genes that are related to cancer progression and chemotherapy resistance, especially in primary systemic chemotherapy.

\section{8}

Multicenter study of nonpegylated liposomal doxorubicin and docetaxel as neoadjuvant treatment in patients with stage II - III breast cancer.

Modolell A, Mayordomo J, Garcia JM, Machengs I, Alvarez I, Palombo H, Yubero A, Murillo L, Belon J, Andres R, Burillo M, Lambea J, Centelles M, Tres A. I Corachan, Barcelona; H Clinico, Zaragoza; P Miramar, Palma; H Sagrado Corazon, Barcelona; H S Jorge, Huesca; Cl Remedio, Barcelona; H Obispo Polanco, Teruel; H R Sofia, Tudela; H Virgen de las Nieves, Granada, Spain

Background: Non-pegylated liposomal doxorubicin (Myocet)(M) and docetaxel $(\mathrm{T})$ are active agents for patients with breast cancer. $M$ has been shown to be as effective as doxorubicin at the same dose while reducing the cardiotoxicity. This study was designed to evaluate clinical and pathological response rates (RR) and toxicity after induction chemotherapy with $\mathrm{D}$ plus $\mathrm{M}$ in patients with breast cancer. Patients and Methods: Patients with histological confirmation of breast cancer (stage II-III), age $>18$ years, left ventricular ejection fraction $>45 \%$ and adequate bone marrow, renal and hepatic function were included in the study. Prior systemic therapy, radiotherapy or surgery for breast cancer were not allowed. Treatment: D $\left(75 \mathrm{mg} / \mathrm{m}^{2}\right)$ iv and $\mathrm{M}\left(75 \mathrm{mg} / \mathrm{m}^{2}\right)$ iv, both on day 1 every 21 days for 4 courses, followed by surgery. Results: Fifty patients have been enrolled. Median age was 52 years (28-76) ECOG PS was 0 in $88 \%$ of patients and 1 in $12 \% .56 \%$ of patients were premenopausal. TNM category of the primary tumor was $\mathrm{T} 1$ in 1 pts $(2 \%)$; T2 in $20(40 \%)$; T3 in $10(20 \%)$ and T4 in 19 $(38 \%)$. In addition, 13 pts $(26 \%)$ had palpable regional lymph nodes. Receptor status was ER+PR+ in $46 \%$ of pts; ER+PR- in $14 \%$; ER+PR unknown in $2 \%$; ER-PR+ in $2 \%$ and ER-PR- in $36 \%$. Patients received a total of 188 courses (median 4, range 2-4). Median relative dose intensity was $99 \%$ for both D and M. Fortyone pts have been evaluated for clinical response ( 9 treatment ongoing): 5 achieved CR $(12.2 \%), 26$ PR $(63.4 \%), 9$ SD $(22.0 \%)$ and $1 \mathrm{PD}(2.4 \%)$, for a clinical RR of $75.6 \%$ (95\% CI: 62.5 $88.7 \%$ ). Surgery was performed in 40 patients (1 pending): 6 $(15.0 \%)$ achieved pathological CR, $25(62.5 \%)$ pPR, $9(22.5 \%)$ pSD resulting in a pathological RR of $77.5 \%$ (95\% CI: 64.6$90.4 \%$ ). Median disease-free and overall survival have not been reached. Grade III/IV toxicities per course were: neutropenia $(4.8 \%)$, thrombocytopenia $(1.1 \%)$, anemia $(0.5 \%)$, febrile neutropenia $(3.7 \%)$ and asthenia $(2.1 \%)$. Conclusion: 4 courses of $\mathrm{D}$ and $\mathrm{M}$ every 21 days is an active and well tolerated induction treatment for patients with stage II and III breast cancer.

\section{9}

Dose-dense taxotere $(T)$ and adriamycin/cyclophosphamide (AC) as neoadyuvant treatment in locally advanced breast cancer (LABC).

García-Mata J, Calvo L, García-Palomo A, Mel JR, Almanza MC, Ramos M, de Paz L. H. Santa María Nai, Ourense, Spain; H. Juan Canalejo, A Coruña, Spain; H. de León, León, Spain; H. Xeral Calde, Lugo, Spain; Clínica Povisa, Vigo, Spain; Centro Oncológico, A Coruña, Spain; H. Arquitecto Marcide, Ferrol, Spain

Background: Systemic and local therapy is the standard care in the management of LABC. DD chemotherapy has shown improvement in clinical outcomes for BC. This study was designed to evaluate the efficacy of DD therapy with $\mathrm{T} \times 4$ followed by AC $\mathrm{x}$ 4. Main objective is clinical response rate and pathological complete response.

Patients and methods: Women with histological confirmation of LABC, ECOG PS $\leq 2$, age $\geq 18$ years and adequate bone marrow, hepatic, renal and cardiac functions were included. Prior systemic therapy and radiotherapy were not allowed. Neoadyuvant treatment: $\mathrm{T} 100 \mathrm{mg} / \mathrm{m}^{2}$ iv and prophylactic G-CSF, every 2 weeks x 4 cycles followed by A $60 \mathrm{mg} / \mathrm{m}^{2}$ iv and C $600 \mathrm{mg} / \mathrm{m}^{2}$ iv, every 2 weeks x 4 cycles. Response was evaluated every 4 cyclesaccording to RECIST criteria.

Results: Up to date, 54 patients (pt) were enrolled, with a median age of 49 years (31-80), ECOG PS was 0/1 96.1/3.9\%. Breast locations were: left $48.1 \%$, right $48.1 \%$ and both $3.7 \% .27 \mathrm{pt}$ $(57,5 \%)$ presented stage III breast cancer. Forty pt $(74.1 \%)$ had infiltrating ductal carcinoma. Menopausal status was: premenopausal $55.6 \%$, postmenopausal $42.6 \%$ and perimenopausal $1.9 \%$. Hormonal receptor status was positive in $66.7 \%$ of pt (RE+ $62.8 \%$ and $\mathrm{RP}+51.0 \%$ ) and $14 \mathrm{pt}$ of 39 with available data had Her-2 overexpression. Up to date, $53 \mathrm{pt}$ have received $\mathrm{T}$ and 51 AC. A total of 211 cycles of T (median 4), and 203 of AC (median 4) were administered. Median relative dose intensity was $100 \%$ for $\mathrm{T}$ and $96 \%$ for both $\mathrm{A}$ and C. Of 49 evaluated pt for efficacy, 12 achieved CR, $28 \mathrm{PR}, 7 \mathrm{SD}$ and $2 \mathrm{PD}$, resulting in an ORR of $81.6 \%$ (95\% CI: $70.8 \%, 92.5 \%)$. Surgery was performed in $50 \mathrm{pt}$ 6 of them achieved pCR (12\%; 95\%CI: $3.0 \%, 21.0 \%), 28$ pPR, 13 $\mathrm{R}$ minor and $3 \mathrm{SD}$, and $20(51.3 \%)$ were free of malignant cells in the nodes. The median number of positive nodes was $1(0-21)$. Breast conservative surgery rate was $36 \%$. During $\mathrm{T}$ treatment, main grade III/IV toxicity per $\mathrm{p}$ was skin toxicity $(17.0 \%)$, 
neutropenia $(3.8 \%)$, asthenia $(3.8 \%)$ and hepatotoxicity $(3.8 \%)$; during AC treatment was neutropenia (19.6\%), leucopenia $(5.9 \%)$, amenorrhoea $(9.8 \%)$ and stomatitis $(3.9 \%)$. Main grade I/II toxicity during $\mathrm{T}$ treatment was asthenia $(66.0 \%)$, nauseas $(43.4 \%)$, skin toxicity $(37.7 \%)$, diarrhoea $(37.7 \%)$ and stomatitis $(35.8 \%)$; during AC treatment was asthenia $(62.7 \%)$, nauseas $(49.0 \%)$, skin toxicity $(35.3 \%)$, vomiting $(33.3 \%)$, anaemia $(31.4 \%)$ and stomatitis $(31.4 \%)$.

Conclusion: This scheme of DD neoadyuvant chemotherapy is an active regimen, even in a particular high risk cohort of LABC p $(57.5 \%$ stage III), with a manageable toxicity profile.

\section{0}

Neoadjuvant capecitabine chemoradiation (X-RT) for patients (pts) with locally advanced breast cancer (LABC) failing anthracycline-based neoadjuvant therapy: findings from a prospective phase II trial.

Gaui M, Amorim G, Pereira G, Moreira D, Djahjah C, Spector $N$. Instituto Nacional do Cancer, Rio de Janeiro, Brazil

Background: In Brazil, LABC remains a serious heath problem and represents approximately $30 \%$ of all newly diagnosed breast cancer pts. Anthracycline-based neoadjuvant therapy is a standard treatment, but approximately $30 \%$ of pts do not respond. For these refractory pts, there is no standard approach. Retrospective data from our institution indicate that, despite receiving RT, the majority of pts still progress: only $60 \%$ became operable and the majority of pts still have gross residual disease; 4 pts have minimal residual disease $(9 \%)$ with only 1 pathologic complete response (pCR, 4\%). $\mathrm{X}$ is highly active and well tolerated as a single agent and extends survival, time to progression and response rates when added to docetaxel in metastatic breast cancer. Because $X$ is a potent radiosensitizer, and it has been proven effective and well tolerated in chemoradiation for locally advanced rectal cancer, we studied the concomitant use of RT and X in pts with LABC. Materials and Methods: Eligible pts had inoperable LABC refractory to FAC, ECOG PS 0-2 and adequate bone marrow, renal and hepatic functions. Pts received RT $50 \mathrm{cGy} / \mathrm{d}$ plus X $850 \mathrm{mg} / \mathrm{m}^{2}$ bid orally on d1-14. Pts underwent surgery, if appropriate, after completion of neoadjuvant therapy. Pts with hormone receptorpositive tumors received tamoxifen after surgery. Results: We enrolled a total of 30 pts. Baseline characteristics were as follows: median age 47 years (range 26-70); median tumor size (afte anthracyclines) $80 \mathrm{~cm}^{2}$ (range $36-357 \mathrm{~cm}^{2}$ ); inflammatory carcinoma (21\%); hormone receptor positive tumor (ER $37.5 \%$, PR 41\%): 12 pts were HER2 $2+$ or $3+(50 \%)$. Two pts were excluded from the analysis as they were protocol violators (they received an inadequate dose of $\mathrm{X}$ ). Treatment with X-RT rendered 23 of the 28 evaluable pts $(82 \%)$ operable. Four pts did not undergo surgery because of disease progression. After surgery, histology reports showed pCR in 3 pts $(11 \%)$ and minimal residual disease in 4 pts $(14 \%)$. A median residual tumor size of $11 \mathrm{~cm}^{2}$ (range $0-72$ $\mathrm{cm}^{2}$ ) and a median number of 2 positive nodes were observed Treatment was well tolerated. The most common (all grade) adverse events were nausea/vomiting, diarrhea and mucositis. There were no grade 3/4 adverse events. Discussion: Our data indicate that neoadjuvant X-RT is feasible, well tolerated and effective in pts with LABC refractory to FAC, rendering pts eligible for surgery. These findings suggest that a randomized study should be performed to compare RT vs. X-RT.

\section{1}

The farnesyl transferase (FTase) inhibitor (FTI) tipifarnib inhibits FTase in vivo and enhances the efficacy of neoadjuvant dose-dense doxorubicin-cyclophosphamide (AC) in patients with locally advanced breast cancer (LABC).

Moulder SL, Sparano JA, Kazi A, Wright J, Munster PN, Vahdat L, Minton S, Hershman D, Diaz N, Malafa M, Riker A, Lee D, Pellegrino C, Li T, Negassa A, Sebti S. H. Lee Moffitt Cancer Center and Research Institute, Tampa, FL; New York Phase II Consortium (N01-CM-57018), New York, NY

Background: Ras protein overexpression has been associated with a poor prognosis in breast cancer. Combination of $\mathrm{AC}$ with agents inhibiting the Ras pathway and downstream elements augment the effects of AC in vitro.

Materials and Methods: Patients with stage IIB-IIIC breast cancer received up to 4 cycles of neoadjuvant $\mathrm{AC}(\mathrm{A}=60 \mathrm{mg} / \mathrm{m} 2$, $\mathrm{C}=600 \mathrm{mg} / \mathrm{m} 2)$ IV q 2 weeks with G-CSF $(5 \mathrm{mcg} / \mathrm{kg}$ days $2-13)$ plus tipifarnib 200mg BID PO on days 2-7 of each cycle, followed by definitive surgery. The primary endpoint was pathologic complete response (pCR) in the breast (defined as no invasive cancer). Enzymatic assays measuring FTase activity and western blotting for signaling proteins (pSTAT3, pERK, pAKT, p27, Bcl-xL, and Bax) were performed on optional tumor biopsies obtained before starting therapy and 2 hours after the last dose of tipifarnib in 5 evaluable patients.

Results: 21 eligible patients enrolled on the $1^{\text {st }}$ stage of the phase II trial and initiated treatment; accrual of 29 additional patients to the $2^{\text {nd }}$ stage is ongoing. $7 / 21$ patients $(33 \% ; 95 \%$ C.I. $15 \%, 55 \%)$ treated in the $1^{\text {st }}$ stage had a pCR in the breast (including 5/12 ER and/or PR+ cases [42\%] and 2/9 ER/PR negative cases [22\%]). 5 patients $(24 \% ; 95 \%$ C.I. $8 \%, 47 \%)$ had pCR in the breast and lymph nodes. Comparing post vs. pre-treatment specimens in 5 evaluable patients, the median decrease in FTase enzyme activity was $100 \%$ (range $55 \%, 100 \%$ ), 4/5 exhibited decreased p-STAT-3, and there were variable effects on other proteins. 1 patient who underwent serial biopsies had a pCR in the breast (FTase decreased 91\% and p-STAT-3 decreased).

Discussion: Tipifarnib inhibits FTase activity in human breast cancer in vivo, and is associated with downregulation of p-STAT3 (which may potentiate apoptosis). The $33 \%$ pCR rate in the breast ( $42 \%$ for ER-positive cases) in LABC exceeds the pCR rate of about $13 \%$ in non-LABC ( $6 \%$ for ER-positive disease) expected after 4 cycles of non dose-dense AC (J Clin Oncol 2003; 21: 4165 4174), suggesting that tipifarnib may overcome mechanisms of resistance to AC, particularly in patients with ER-positive disease. Further studies of this combination are warranted.

\section{2}

Neoadjuvant dose dense chemotherapy (NDDC) with sequential doxorubicin/cyclophosphamide (AC) followed by taxane yields high pathologic complete response (pCR) rate in stage II/III breast cancer.

Schwartzberg LS, Kanter LR, Huang R, Tauer KW, Somer BR. The West Clinic, Memphis, TN; Accelerated Community Oncology Research Network, Memphis, TN

Background: Adjuvant dose dense AC followed by paclitaxel delivered at 14 day intervals improves disease free survival and overall survival compared to standard 21 day schedules of the same drugs and doses. We reasoned that NDDC could increase responses before definitive surgery and improve outcome.

Methods: From 1/03 to 12/04, consecutive patients (pts) with large primary $(\mathrm{T}>3 \mathrm{~cm})$ or locally advanced non-metastatic breast cancer were treated in a community-based cancer clinic with sequential AC $60 / 600 \mathrm{mg} / \mathrm{m}^{2}$ x 4 cycles followed by paclitaxel 175 $\mathrm{mg} / \mathrm{m}^{2}(\mathrm{~N}=34)$ or docetaxel $90-100 \mathrm{mg} / \mathrm{m}^{2}$ x 4 cycles $(\mathrm{N}=8)$ every 14 days with pegfilgrastim support. Pts were evaluated pre and post NDDC by clinical and imaging measurements (mammography 


\section{S228 Abstracts - Poster Session V}

$+/$ - ultrasound) and pathologically after partial mastectomy or total mastectomy and SLNB and/or ALND. pCR was defined as no invasive tumor in both the breast and LNs by H\&E. Results: A total of 42 pts were treated, 35 with infiltrating ductal, 6 infiltrating lobular, 1 unknown histology; Grade: 19 Grade 3, 11 grade 2, 1 grade 1, 10 not reported; $18 \mathrm{ER}+, 12 \mathrm{PR}+; 8$ Her2+; Clinical Stage: 6 IIA, 12 IIB, 10 IIIA, 5 IIIB, 9 IIIC. Mean size of primary tumor was $5.9 \mathrm{~cm}$ by clinical exam, $4.0 \mathrm{~cm}$ by imaging and $26 \mathrm{pts}$ had clinically + LNs. NDDC was well tolerated, with majority of patients receiving full dose intensity on schedule. After NDDC, 19/42 (49\%) achieved clinical (c)CR, 18/42 (46\%) achieved cPR, and 2 had stable disease. Mean size of the primary tumor after chemotherapy was $1.0 \mathrm{~cm}$ by clinical exam and $1.2 \mathrm{~cm}$ by imaging. Four pts did not go to surgery: 1 developed brain metastases, 2 refused, 1 lost to follow-up, all with cIIIC disease pre chemotherapy. Of the 38 evaluable post surgery pts, $14(38 \%)$ had pCR in breast and LNs, $22(58 \%)$ had pPR and $2(5 \%)$ had no response. pCR occured in $6 / 20(30 \%)$ pts with cStage III vs. $8 / 18(44 \%)$ pts with cStage II disease. 10/16 (62.5\%) with cCR demonstrated pCR vs. $3 / 18(16.7 \%)$ with cPR. There was a significant association between hormone receptor (HR) status and pCR: $52.4 \%$ of HR- vs. $17.6 \%$ of $\mathrm{HR}+(\mathrm{p}=0.036)$. No significant association with $\mathrm{pCR}$ was seen for tumor histology $(\mathrm{p}=1.0)$, tumor grade $(\mathrm{p}=0.59)$, or Her2 status $(\mathrm{p}=0.33)$.

Conclusions: NDDC is associated with a high pCR rate in breast and LNs, even in locally advanced cancer, and is completed safely and more rapidly compared to standard sequential neoadjuvant therapy. HR negative tumors are significantly more likely to achieve pCR to NDDC. Triple negative breast cancers (ER-PR-Her2-) are likely to benefit most from this approach.

\section{3}

Response to primary chemotherapy in breast carcinoma depends on histological tumor type: a study on 860 patients from one institution.

Tubiana-Hulin MJ, Stevens DM, Guinebretiere JMR, Bouita L, Lasry S, Cohen-Solal C, Cherel P, Rouesse J. Centre Rene Huguenin, Saint Cloud, France

Background: The poor responsiveness of invasive lobular breast carcinoma to chemotherapy has been recently described. We studied in our data-base the impact of primary chemotherapy on response and outcome in operable invasive lobular breast carcinoma (ILC) compared to invasive ductal breast carcinoma (IDC).

Patients and Methods: We extracted from the data base all operable breast cancer patients entirely diagnosed, treated, and followed in our institution from 1990 to 2002 and who received a combined strategy including neoadjuvant chemotherapy, adapted surgery, radiotherapy and adjuvant hormonal treatment in case of hormonal receptors positivity. They were selected on histological type: pure invasive lobular $(\mathrm{n}=118,14 \%)$ or pure invasive ductal carcinomas $(n=742,86 \%)$. Different neo-adjuvant chemotherapy protocols were successively used: all were anthracyclin-containing regimens, $16 \%$ ILC and $12 \%$ IDC received also taxanes. Median follow-up was 65 months for ILC, and 58 months for IDC.

Results: The median age was 53 years for ILC and 49,6 years for IDC [ $\mathrm{p}=0.0002]$.ILC presented with larger tumors (T3: $38,1 \%$ vs $21,4 \%$, T2: $45,9 \%$ vs $54,3 \%$ p $<0.0007)$, more N0 nodal status $(55,9 \%$ vs $43,3 \% \mathrm{p}=0.007)$, less inflammatory tumors $(5.9 \%$ vs $11.8 \% \mathrm{p}=0.01$ ), more hormonal receptor positivity ( $89 \%$ vs 60 $\%$, with entirely receptor negative tumors 4 times less frequent compared to IDC, $\mathrm{p}=0.0001$ ), lower histological grade (low nuclear grade [MSBR1] 92,9\% vs 61,7\%, $\mathrm{p}<0.0001)$.

Final surgery was a mastectomy in $70 \%$ of patients with ILC (of whom $34 \%$ were reoperated after initial partial mastectomy) and in $52 \%$ of IDC after $9 \%$ of reoperation $(p=0.0004)$

A complete pathologic response (pCR) without invasive lesion was achieved in $1 \%$ of ILC and $9 \%$ of IDC ( $\mathrm{p}=0.002)$. At axillary level, nodes were found microscopically negative in $25 \%$ of ILC and $37 \%$ of IDC patients. The median number of involved nodes was 4,4 for ILC and 4,2 for IDC.

The outcome at 60 months, was significantly better for disease free survival (DFS) and overall survival (OS) for ILC: DFS was $76.5 \%$ (CI95\% [66.2-84.4]) vs 60.8\%(CI95\% [56.6-64.8]); OS was $91.7 \%$ (CI95\% [83.7-96]) vs 79.3\% (CI95\% [75.6-82.6]) Conclusions: In our study, ILC breast tumor appeared to be less responsive to chemotherapy however these patients presented a better outcome than those with IDC. While expecting new informations on intimate biological features of ILC that could improve treatment, we consider that neoadjuvant endocrine therapy in hormonal receptors positive ILC may be a more adapted approach than neoadjuvant chemotherapy.

\section{4}

Quality of life during three-weekly versus weekly neoadjuvant docetaxel: a randomised trial.

Walker LG, Eremin JM, Vassanasiri W, Walker MB, El-Sheemy M, Jibril JA, Valerio D, Cowley $G$, Clarke D, Kamal M, Thorpe G, Beer J, Wiseman J, Eremin O. Oncology Health Centres and Institute of Rehabilitation, University of Hull, Kingston upon Hull, United Kingdom; Lincoln County Hospital, Lincoln, United Kingdom

Background: We have previously shown that neoadjuvant docetaxel (D) following anthracycline-based chemotherapy improves clinical and pathological responses and 3-year survival in women with large or locally advanced breast cancer. The aim of this study was to compare the effects on quality of life (QoL) of weekly versus 3-weekly sequential neoadjuvant D.

Material and Methods: Eighty-nine women with large $(>3 \mathrm{~cm})$ or locally advanced $\left(\mathrm{T}_{3}, \mathrm{~T}_{4}, \mathrm{~T}_{\mathrm{X}} \mathrm{N}_{2}\right)$ breast carcinoma (median age 50, range 27-72 years) received four cycles of neoadjuvant doxorubicin $60 \mathrm{mg} / \mathrm{m}^{2}$ and cyclophosphamide $600 \mathrm{mg} / \mathrm{m}^{2}$ at 3 week intervals. They were then randomised to four cycles of D $100 \mathrm{mg} / \mathrm{m}^{2}$ at 3 -week intervals, or to 12 cycles of D $33 \mathrm{mg} / \mathrm{m}^{2}$ at weekly intervals with a 2 -week break between cycles 6 and 7 . QoL, mood and coping were assessed serially during chemotherapy and at follow up (FU) 3 weeks after the final cycle. The primary outcome measure was the Trial Outcome Index (TOI) of the Functional Assessment of Cancer Therapy (breast cancer version) (FACT-B) at FU.

Results: The TOI for the two regimens at FU did not differ significantly (ANCOVA $\mathrm{F}=0.03, \mathrm{p}=0.86$ ), and between-group analysis of the FACT-B subscales (physical, social, emotional and functional well-being; additional concerns) also failed to reveal significant differences. No differences were found at FU using the Rotterdam Symptom Checklist (RSCL) (psychological symptoms $\mathrm{F}=2.057, \mathrm{p}=0.15$; physical symptoms $\mathrm{F}=0.335, \mathrm{p}=0.57)$ or Hospital Anxiety and Depression Scale total scores $(F=1.943$, $\mathrm{p}=0.16$ ). However, during treatment, women on weekly D reported significantly less distress at all time points assessed, and significantly less tiredness, unhappiness, vomiting, diarrhoea, constipation, nail problems, pain and neuropathy during at least one assessment. Women on 3-weekly D reported more energy before the final cycle.

Discussion: D regimens given weekly or every 3 weeks are similar in terms of generic measures of QoL (FACT-B, RSCL) at FU. However, during treatment, weekly D appears to have fewer/less distressing side effects. As the two groups did not differ in terms of clinical response (complete, partial, minimal, no response, progression $)\left(\chi^{2}=3.117, \mathrm{p}=0.54\right)$ or pathological response $(1-5$ scale $)\left(\chi^{2}=2.811, \mathrm{p}=0.59\right)$, the fewer/less distressing side effects associated with weekly D treatment do not come at the expense of response. Weekly D utilises more staff time and hospital resources, and some women may prefer treatment every 3 weeks. Where resources permit, women should be offered the choice of weekly D. 


\section{5}

The changes of histologic and biologic markers induced by neoadjuvant chemotherapy in locally advanced breast cancer.

Choi UJ, Lee KM. Wonkwang University School of Medicine, Iksan, Jeongbuk, Korea

Background: Neoadjuvant chemotherapy (NCT) has become the standard treatment of locally advanced breast cancer. The postoperatively adjuvant systemic treatment is based on the status of histological and biological markers of either the pre-NCT or post-NCT. There have been several reports which show the expression of some of those markers (e.g. bcl-2 and Ki67) changed after NCT. The aim of this study is toinvestigate the effect of NCT on the ecpression of histological and biological markers of breast cancer.

Material and Methods: We analyzed paired pre- and post-NCT tumor specimens from 27 patients with stage IIIa or IIIb breast cancer. All patients received 2 to 4 cycles of anthracyclinecontaining NCT. Over 6 pieces of pre-NCT tumor specimens were taken by $14 \mathrm{G}$ core needle from multiple sites of a tumor and post-NCT specimens were taken at the time of operation. Tumor histologic grade and immunohistochemical expression of estrogen receptor (ER), progesterone receptor (PR), c-erbB2, p53, Ki-67, $\mathrm{CD} 31$, p-glycoprotein and cathepsin-D were analyzed in paired pre- and post-NCT tumor specimens from 24 patients, excluded 3 patients with complete response to NCT.

Results: After NCT, partial response was seen in 14 patients and stable disease in 10 patients. Sixteen patients (66.7\%) had significant changes in more than one parameter. ER/PR were changed from positive to negative in 5 patients; c-erbB2 was changed in 3 patients; p53 in 1 patient; Ki-67 in 4 patients; CD31 in 4 patients; p-glycoprotein in 3 patients; cathepsin-D in 2 patients and histologic grade in 2 patients. In 9 patients (37.5\%), significant changes were observed in the parameters which can influence the selection of postoperative systemic therapy (i.e. histologic grade, ER, PR and c-erbB2). Discussion: The specimens for histologic and biologic markers of a tumor should be taken before NCT because NCT can have influencing factors on the expression of prognostic parameters of locally advanced breast cancers, which subsequently may influence the prediction and the decision-making of adjuvant systemic treatment.

\section{6}

Doxorubicin and cyclophosphamide followed by weekly docetaxel (AC-T) as neoadjuvant chemotherapy in operable breast cancer patients: GEICAM 2002-03 Study.

Estévez LG, Adrover E, Barnadas A, Cuevas JM, Seguí MA. On Behalf of the Spanish Breast Cancer Research Group (GEICAM), San Sebastián de los Reyes, Madrid, Spain

Objective: to assess the safety and efficacy of AC-T as neoadjuvant chemotherapy (NC) in operable breast cancer patients (pts). Methods: Eligible pts had pathologically confirmed measurable stage II or IIIA untreated breast cancer. Doxorubicin (A) $60 \mathrm{mg} / \mathrm{m}^{2}$ and cyclophosphamide $600 \mathrm{mg} / \mathrm{m}^{2}$ were given on day 1 every 3 weeks (wks) for 4 cycles (Cy); docetaxel $36 \mathrm{mg} / \mathrm{m}^{2}$ was given intravenously once a wk for 6 wks followed by a $2 \mathrm{wk}$ break then 6 more wks of treatment ( 12 doses in a 14-wk period). After all chemotherapy was completed, clinical responses were assessed. After surgery, pathological responses were evaluated using the Miller \& Payne scoring scale (MPSS). Results: 63 pts have been enrolled. Median age was 48.5 years (range 25.5-80.4) and median tumour size $5 \mathrm{~cm}$ (range, 1.5-12.5). Five pts (8\%) presented with stage IIIA disease and 58 pts (92\%) with stage II; 36 pts $(57 \%)$ were premenopausal; 32 pts $(51 \%)$ had histological grade 2-3 tumours; and $8(12.7 \%)$ were ER-PgR-negative. Median number (nr) of administered AC and T cycles was 4 and 2 (range 1-2) respectively. Objective clinical response rate was $89 \%$ (95\% CI: 81.3-96.7) with 28 (44\%) complete responses and $28(44 \%)$ partial responses. $43 \mathrm{pt}(68 \%)$ underwent conservative surgery, $10 \mathrm{pts}$ (15.8\% [95\% CI: 6.8-24.8]) achieved a pathological complete response in breast (Grade 5 in MPSS). 32 pt (51\%) were nodenegative after surgery. Main grade (G) 3/4 toxicities during AC treatment: leucopenia was present in 3 pts $(4.8 \%)$ and $12 \mathrm{Cy}$ $(4.8 \%)$; neutropenia in 10 pts $(15.8 \%)$ and 14 Cy $(5.5 \%)$, febrile neutropenia in 3 pts $(4.7 \%)$ and 4 Cy $(1.6 \%)$. Main toxicity during $\mathrm{T}$ treatment: $\mathrm{G} 2 / 3$ onycolysis was present in $26 \mathrm{pt}(41.3 \%)$ and $93 \mathrm{cy}(52 \%), \mathrm{G} 2$ rash in $7 \mathrm{pts}(11 \%)$ and $11 \mathrm{Cy}(17.5 \%)$, and $\mathrm{G} 3$ asthenia in 4 pts $(6.3 \%)$ and $8 \mathrm{Cy}(4.5 \%) .1$ patient $(1.6 \%)$ experienced symptomatic cardiac heart failure. $7 \mathrm{pt}(11 \%)$ withdrew treatment due to toxicity. Conclusions: Weekly docetaxel following four cycles of $\mathrm{AC}$ is an effective and feasible regimen in operable breast cancer.

\section{7}

Dynamic infrared imaging - a real-time, non-invasive tool for monitoring tumor response to neoadjuvant therapy for breast cancer.

Fanning S, Andresen S, Silverman P, Hicks D, Budd GT, Moore $H$, Crowe J, Weng DE. Cleveland Clinic Foundation, Cleveland, $\mathrm{OH}$; Case Western Reserve University, Cleveland, $\mathrm{OH}$

Strategies to improve the efficacy of neoadjuvant chemotherapy for breast cancer have primarily focused on the development of more potent chemotherapy/endocrine regimens. Another important strategy is to develop improved methods for monitoring tumor response to treatment during therapy, with the option to[MD1] change primary treatment regimens when response is inadequate.

Current means of assessing therapy effectiveness include serial measurements by physical exam, radiographic methods (ultrasound, mammography, magnetic resonance imaging (MRI), positron emission tomography (PET)), or repeated biopsies. Reasons of expense, time, or patient risk make repeated assessments using these methods impractical.

A new, innovative approach for imaging tumor response to therapy involves the use of dynamic infrared imaging. DIRI ${ }^{\circledR}$ couples a highly sensitive NASA/JPL-developed quantum well infrared photon (QWIP) sensor, which detects photon emission in the 810 micron wave-length, with proprietary software programs to analyze the emission patterns over time. Twenty second scans are obtained at 100 frames/second (max. 400 frames/second) with each frame comprised of $256 \times 256$ pixels. Temperature changes can be detected with a sensitivity of $0.009^{\circ} \mathrm{C}$.

The technology is particularly suited to the pathophysiology of cancer cells. Neoplastic cellular production of interstitial nitric oxide (NO) results in increased capillary blood flow. When this effect approaches the skin surface, the minute changes in temperature secondary to increased blood flow can be detected. Anti-tumor therapies of either chemo/hormonal therapy-induced cell death or anti-angiogenic therapies can result in decreased peri-tumoral capillary blood flow. The resulting changes in temperature can be detected through dynamic infrared imaging, providing a non-invasive, easily repeatable tool for real-time clinical assessment that can provide serial objective measurements of the effectiveness of ongoing neoadjuvant therapy.

This paper will outline the preliminary findings of a study utilizing DIRI $^{\circledast}$ sequentially over the course of treatment to assess the effectiveness of neoadjuvant therapies for breast cancer compared to standard imaging techniques (mammogram, ultrasound, dynamic contrast-enhanced MRI), and to the pathological assessment of tumor response at the time of surgical treatment. [MD1] 


\section{8}

Recurrence rates after dynamic contrast enhancedmagnetic resonance image guided planning for breast conserving surgery following neoadjuvant chemotherapy for breast cancer.

Garimella V, Qutob O, Iwuagwu O, Mahapatra TK, McManus $P$, Fox JN, Long ED, Lowry M, Chaturvedi A, Turnbull LW, Drew PJ. University of Hull, Hull, East Yorkshire, United Kingdom; Hull and East Yorkshire Hospitals NHS Trust, Hull, East Yorkshire, United Kingdom; Hull and East Yorkshire NHS Trust, Hull, East Yorkshire, United Kingdom

Background: Neoadjuvant therapy results in a significant increase in breast conserving surgery. However, traditional imaging methods are unable to accurately predict the extent of viable residual disease leading to uncertainty in surgical planning and some previous studies have shown a disproportionately high incidence of locoregional recurrence. Dynamic Contrast Enhanced-MRI (DCEMRI) has been shown to provide a potentially more accurate prediction of residual disease.

Aims: To assess the incidence of locoregional recurrence in patients treated with breast conserving surgery planned using DCE-MRI after neoadjuvant chemotherapy and to identify factors implicated in local and overall recurrence.

Methods: Patients undergoing neoadjuvant chemotherapy for breast cancer in our unit are staged with a DCE-MRI of the breast performed at $1.5 \mathrm{~T}$ before, during and after treatment and the final result used to plan surgery. The clinicopathological details of these patients were obtained from a prospectively collected database.

Results: 204 patients with breast cancer were treated with neoadjuvant chemotherapy between 1996 and April 2005. 18 of these patients had distant metastases at the time of initial diagnosis and so were excluded from the present study. Following neoadjuvant chemotherapy, 186 patients underwent surgical treatment. Of these, 68 patients had breast-conserving surgery. At a median follow up of 30 months (range 5.6 - 72 months) 21 patients in this group developed subsequent recurrence $(21 / 68-30 \%)$ of whom $7(7 / 68-10 \%)$ had locoregional recurrence, 5 had local recurrence (5/68-7\%), and $17(17 / 68-25 \%)$ had distant recurrence. Two of the 17 patients with distant recurrences also had loco regional recurrence. Logistic regression analysis revealed only vascular invasion of the tumour to be significantly associated with overall recurrence. None of the pathological factors (ER, PR status, vascular invasion, lymph node metastases, pathological complete response to neo adjuvant chemotherapy) showed a significant association with locoregional recurrence.

Conclusion: In this high risk group a local recurrence rate of $7 \%$ at nine years is comparable to patients treated with breast conserving therapy for early breast cancer. Breast conserving surgery with DCE-MRI planning after neoadjuvant chemotherapy provides an acceptable level of local recurrence without the need for mastectomy. The planned UK NEOCOMICE study will provide the further data required to confirm these results.

\section{9}

Impact of pre-operative three different regimens on breastconservation surgery (BCS) and pathological complete response rates (pCR) in locally advanced breast cancer (LABC) in Pakistani patients.

Lal AM, Alidina AG, Khan SM, Valimohd AT, Vaziri IA. AKU, Khi, Sind, Pakistan

Background: LABC accounts for 28\% (n 350) of all breast cancer cases (1370 patients) treated at our AKUH over the last 15 years. This is sharp comparison to the US data (only 3-6\% of all cases).Pre-operative chemotherapy PC) given in LABC impacts type of surgery and survival.

Methods: One hundred and seventy cases receiving PC were evaluated. Patients receiving TAC chemotherapy (n 60) were evaluated in a prospective Phase II study (2003- ongoing), compared with FAC/AC or CMF regimens given from 1998-2005, the data of which were extracted for BCa Tumor registry. End points included RR; evaluate pCR and BCS. Women were eligible if they were; histological confirmed invasive infiltrating carcinoma, stage III A-C, as per AJCC (6 $6^{\text {th }}$ edition), PS 0-I.

After 3-4 cycles of chemotherapy, definitive surgery was performed. Type of surgery depended upon the response rates and the patients' desire. Balance to complete a total of 4-6 cycles of chemotherapy was given in the adjuvant setting. Adjuvant hormone therapy was given for receptor positive cases.

Results: Demographics, response rates, BCS and toxicities are reported in table below:

Conclusions:

Preoperative TAC chemotherapy leads to impressively higher response rates, pathological complete response rates and probability of BCS, than when compared with FAC/AC chemotherapy or CMF chemotherapy, given in the same setting. Where as survival data of patients with TAC is not available, we feel that this will be superior to AC/FAC or CMF, given higher pathological complete response rates.

\begin{tabular}{|c|c|c|c|c|c|c|}
\hline Demographics, 1 & spon & & & & & \\
\hline & & & $p v$ & & & 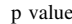 \\
\hline & $\mathrm{N}=60$ & $\mathrm{~N}=88(\%)$ & & & $\mathrm{N}=22(\%)$ & \\
\hline lean Age & $46 \pm 8.5$ & $49 \pm$ & 0.045 & $5 \pm$ & $51 \pm$ & 25 \\
\hline em & $(42 \%)$ & $30(34 \mathrm{r}-\mathrm{s}$ & 0.3. & & & 664 \\
\hline T3 & 3 & & 0.8 & & & \\
\hline T4 & $15(25 \%)$ & $30(34 \%)$ & 0.237 & $(25 \%)$ & $\%)$ & 834 \\
\hline nfla & $10(17 \%)$ & $08(09 \%)$ & 0.166 & $10(17 \%)$ & $04(18 \%)$ & 0.871 \\
\hline $\begin{array}{l}\text { Lymphadeno- } \\
\text { pathy }\end{array}$ & $28(47 \%)$ & $30(34 \%)$ & 0.123 & $28(47 \%)$ & $09(40 \%)$ & 0. \\
\hline Grade III & $25(41$ & $35(4$ & 0.026 & $\cos 2$ & 6) & 0.664 \\
\hline irades II or I. & $35(5$ & $53(6$ & 0.81 & $5(5$ & $4(03 \%)$ & 0.664 \\
\hline $\mathrm{R} / \mathrm{P}$ & $38 \mathrm{8}-2$ & & 0.540 & c) & $12(55 \%)$ & 0.469 \\
\hline DRR & $56(93 \%)$ & $70(80 \%)$ & 0.020 & $6(93 \%)$ & $14(64 \%)$ & 0.001 \\
\hline & $8(30 \%)$ & $11(13 \%)$ & 0.008 & $18(30 \%)$ & $01(4.5 \%)$ & 0.002 \\
\hline (Brea & & & & & & \\
\hline $\begin{array}{l}\text { pCR } \\
\text { (Bre: }\end{array}$ & $17(28 \%)$ & $09(09 \%)$ & 0.002 & $17(28 \%)$ & $00(00 \%)$ & 0.005 \\
\hline Grad & $25(41 \%)$ & $09(10 \%)$ & $<0.001$ & $25(41 \%)$ & $02(09 \%)$ & 0.005 \\
\hline & & & & & & \\
\hline $\begin{array}{l}\text { Mucositis } \\
\text { BCS }\end{array}$ & $\begin{array}{l}30(50 \%) \\
18(30 \%)\end{array}$ & $\begin{array}{l}16(18 \%) \\
07(08 \%)\end{array}$ & $<0.001$ & $18(30 \%)$ & $05(23 \%)$ & 0.026 \\
\hline
\end{tabular}

\section{0}

Preliminary results of a phase II study of neoadjuvant treatment with docetaxel (T), doxorubicin (A) and capecitabine $(X)$ in locally advanced or inflammatory breast cancer.

Pérez-Manga G, Méndez M, Palomero MI, Quibén R, Belón J. Hospital Gregorio Marañon, Madrid, Spain; Hospital de Móstoles, Madrid, Spain; Hospital Virgen de las Nieves, Granada, Spain

Background: Previous studies suggest that combined treatment of chemotherapy + surgery + radiotherapy has a high survival rate in patients with locally advanced or inflammatory breast cancer. Primary objective was evaluate response rate. Secondary objectives were time to progression and toxicity profile of neoadjuvant chemotherapy T, A and X in patients with locally advanced or inflammatory breast cancer.

Patients and methods: Eligibility criteria: Patients with histological confirmation of locally advanced or inflammatory breast cancer, ECOG PS $\leq 2$, age $\leq 75$ years and LVEF $>$ $50 \%$,adequate bone marrow, renal and hepatic function. Prior systemic therapy, surgery or radiotherapy for breast cancer was not allowed. Patients with invasive bilateral breast cancer were not included. Treatment: T $\left(30 \mathrm{mg} / \mathrm{m}^{2}\right)$ iv day 1,8 and 15 , A (50 $\left.\mathrm{mg} / \mathrm{m}^{2}\right)$ iv day 1 and $X\left(1500 \mathrm{mg} / \mathrm{m}^{2}\right.$ o.d. $)$ days $1-14$, in a 4 weeks course. This scheme was repeated up to 4 cycles followed by surgery. According to investigator criteria patients receive a maximum of six cycles. Radiotherapy and hormonal treatment are allowed depending on molecular markers. Expression of markers was performed by inmunohistochemistry before chemotherapy. Results: thirty-four patients were included in this interim analysis, 
with a median age of 48 years (25-68). The ECOG PS was 0 in $31.3 \%$ and 1 in $68.8 \%$ of patients. Hormonal receptor status was $\mathrm{ER}+30 \%, \mathrm{PR}+42 \%$ and $\mathrm{C}$-erb2+ $50 \%$. Primary tumour sites were breast: left $(\mathrm{n}=18)$ and right $(\mathrm{n}=16)$. A total of 118 cycles (median 3.5, range 1-4) were administered. Median relative dose intensity was $87 \%$ for T, $91 \%$ for A and $92 \%$ for X. Thirteen patients are still undergoing treatment; of 29 evaluable patients for efficacy, 9 achieved CR, 19 PR and 1 PD resulting in an ORR of $96.6 \%$ (CI 95\%: 90-100). Surgery was performed in 25 patients: three $(12.0 \%)$ of them achieved pathological CR and one additional patient had non invasive carcinoma. All patients were evaluable for toxicity. Grade III/IV toxicity per patient was neutropenia (70.6\%), leucopenia $(50.0 \%)$, febrile neutropenia $(8.8 \%)$; diarrhea $(11.8 \%)$, mucositis (11.8\%), nausea/vomiting (5.9\%), dysgeusia (2.9\%) and asthenia (2.9\%). Median follow up time was 5.7 months.

Conclusions: T, A and X every 28 days administered during 4 cycles as neoadjuvant chemotherapy in locally advanced or inflammatory breast cancer is an active and well tolerated regimen.

\section{1}

Neoadjuvant chemotherapy for invasive lobular carcinomas of the breast: a poorer response rate but not a worse prognosis than invasive ductal carcinoma.

Vincent-Salomon A, Pierga J-Y, Gautier C, Sigal-Zafrani B, Freneaux P, Lae M, Rosty C, Asselain B, Salmon R, Sastre-Garau $X$. Institut Curie, Paris, France

Background: Invasive Lobular Carcinomas (ILC) at initial presentation are larger tumors, with a low proliferative rate and higher hormonal receptors positivity compared to invasive ductal carcinomas (IDC), characteristics known to be negative predictive factors for response to neoadjuvant chemotherapy. Our aim was to retrospectively analyze the overall response rate of the ILC to neoadjuvant chemotherapy and compared it to those of ductal carcinomas (IDC).

Material and methods: We selected from our database, patients with T2T3 $(<7 \mathrm{~cm})$ N0-N1a N1b ductal or lobular unilateral breast carcinoma, treated with neoadjuvant chemotherapy (4 cycles of anthracyclines-based chemotherapy) from 1990 to 1999. All slides of lobular carcinomas were retrospectively reviewed. The Ecadherin expression was assessed by immunohistochemistry. We retrospectively analyzed, the clinical and pathological response rates to chemotherapy of the lobular compared to the ductal carcinomas. We also determined the conservative treatment and the survival rates (overall survival OS, disease-free DFS and metastasis-free MFS) for patients in each group.

Results: 802 patients were studied (median follow-up: 109 months), 86 (11\%) with an ILC and 716 with an IDC. All ILCs except 3 were E-cadherin negative. The pathological characteristics showed that ILC, when compared to IDC, were more frequently grade I (39\%versus $12 \%, p<0.0001)$, ER positive $(77 \%$ versus $64 \%, p=0.02)$ and PR positive $(75 \%$ versus $61 \%, p=0.02)$. A conservative surgery was possible for $53 \%$ of the ILC and for $64 \%$ of the IDC $(p=0.04)$. Pathological response (tumor and nodes) was available for 584 patients (532 IDC, 52 ILC) and showed that only one patient with ILC presented a complete pathological response contrasting with to 32 complete pathological response in the IDC group. DFS, MFS and OS were identical within the two groups of patients.

Conclusion: We showed that after neoadjuvant chemotherapy, a conservative treatment was less frequently possible for ILC than for IDC and that complete pathological response to neoadjuvant chemotherapy was very rarely observed in ILC. But patients with ILC presented the same outcome than patients with IDC. This poor response to neoadjuvant chemotherapy can be related to the biological characteristics of ILC. As one of the major goal of neoadjuvant chemotherapy is to increase breast conservative surgery, the ILC patients are not good candidates for this treatment.

\section{2}

Neoadjuvant, biweekly, dose-dense chemotherapy with epirubicin and cyclophoshamid followed by docetaxel in primary breast cancer.

Cramer EM, Moers C, Zarghooni V, Bosse K, Mallmann P, Warm M. Faculty of Medicine, University of Cologne, Cologne, Germany

Background: Primary chemotherapy is established in the treatment of local advanced breast cancer. Two important benefits are an increasing rate of breast conserving surgery and the chance to detect the clinical responders during the chemotherapy. Given good results with dose-dense chemotherapy in the adjuvant setting we tested the benefit of this approach in a primary chemotherapy protocol.

Material and Methods: This clinical trial (01/2003-05/2005) enroled81 females (age range 28-65 years) with advanced breast cancer (sonographic average tumor size: $32 \mathrm{~mm}$ ). The patients received four courses of epirubicin $(90 \mathrm{mg} / \mathrm{m} 2)$ and cyclophosphamide $(600 \mathrm{mg} / \mathrm{m} 2)$ followed by four courses of docetaxel $(75 \mathrm{mg} / \mathrm{m} 2,100 \mathrm{mg} / \mathrm{m} 2)$ every two weeks. During pretesting 19 patients were treated with docetaxel $100 \mathrm{mg} / \mathrm{m} 2$ in the beginning. Among this group 10 required a reduction to $75 \mathrm{mg} /$ $\mathrm{m} 2$ due to a hand-foot-skin reaction grade 3 . This was the reason to reduce docetaxel to $75 \mathrm{mg} / \mathrm{m} 2$ for the following patients. During the first four cycles a support with pegfilgrastim was performed to reduce the risk of neutropenic complications. Every two cycles a clinical and sonographical examination was performed to determine tumor response. Clinical and pathological response, toxicity and the rate of breast conserving surgerywas evaluated.

Results: Pathological complete remission of the invasive tumors was observed in 20 patients (25\%), sonographic partial remission in 32 patients $(40 \%)$ minimal response in 16 patients $(20 \%)$, a stable disease in 11 patients $(13,75 \%)$ and disease progression in 1 patient $(1,25 \%)$. Two patients developed neutropenic fever and stopped the chemotherapy after the $5^{\text {th }}$ and $6^{\text {th }}$ cycle, respectively. One patient died after the $8^{\text {th }}$ cycle in neutropenic sepsis. During this trial the main sideeffect of docetaxel was a hand-foot skin reaction.

Discussion: This neoadjuvant dose-dense chemotherapy regime seems to be a potent therapy in the treatment of primary breast cancer - although the number of patients in this trial is still small. Support with pegfilgrastim results in low rates of neutropenic complications. Using Docetaxel with $75 \mathrm{mg} / \mathrm{m} 2$ instead of $100 \mathrm{mg} /$ $\mathrm{m} 2$ the chemotherapy is in general well tolerated. Our results warrant further investigation.

\section{3}

Neoadjuvant dose dense chemotherapy alternating gemcitabine (G) + docetaxel (D) and vinorelbine (V) + epirubicin (E) in locally advanced non inflammatory breast carcinoma (LABC): a phase II study.

Levy E, Jenabian A, Scotte F, Lecuru F, Lefrere-Belda MA, Hoffman H, Eme D, Rideller K, Medioni J, Andrieu JM. Georges Pompidou European Hospital, Paris, France

Purpose : These four drugs resulted in the highest response rates (RR) in breast cancer treatment. Since pathological complete response (pRC) after primary chemotherapy is the best prognostic factor, search for combination allowing high pRC is relevant. This study was designed to evaluate $\mathrm{pRC}$ rates with this dose dense alternating multidrug regimen in non inflammatory locally advanced breast cancer.

Method: 62 women with $\mathrm{LABC}$ more than $3 \mathrm{~cm}$ with adequate liver, renal, cardiac and haematological function were included. Treatment: G $1000 \mathrm{mg} / \mathrm{m}^{2}+\mathrm{T} 75 \mathrm{mg} / \mathrm{m}^{2} \mathrm{D} 1$ and D15, V $25 \mathrm{mg} / \mathrm{m}^{2}$ + E $100 \mathrm{mg} / \mathrm{m}^{2} \mathrm{D} 29$ and D43. Tumor assessment was planned on day 56. In case of objective response, two additional cycles with G+T D57 and E+N D71 were prescribed. Surgery was planned 4 weeks after the last cycle. Post operative radiotherapy was prescribed according to guidelines. All patients with RE+ tumor were treated with adjuvant hormonotherapy. 


\section{S232 Abstracts - Poster Session V}

Patient characteristics: 62 pts were included, 56 evaluable. Reasons for exclusion were anaphylaxis (4), patient decision (1), metastatic disease (1). Median age was 49 years. TNM: 1 T1, 44 T2, 6 T3, 5 T4. 31 N0, $22 \mathrm{~N} 1,2 \mathrm{~N} 2,1 \mathrm{~N} 3$. SBR grade I: 8 pts, II: 32, III: 16 . R0+: 24 pts (43\%).Clinical and radiological median size were 43 and $24 \mathrm{~mm}$ respectively.

Results: 43 pts $(76 \%)$ achieved 6 cycles. 13 pts underwent surgery after 4 cycles because of no or minor response, or patient decision. Toxicity: grade 4: 11 neutropenia (19\%) (1 febrile). Grade 3: 21 neutropenia (37\%), 1 Gemcitabine induced pneumopathy, 4 anaphylaxis related to docetaxel, 1 acute cardiac failure. No toxic death was observed.

Response: Clinical and radiological objective RR were $96 \%$ and $91 \%$ respectively. Despite this size reduction rates, only $50 \%$ of pts underwent breast conservative surgery, with lymph node dissection. The great number of radical surgery is in part explained by the high number of central tumors in our series.

Pathological results: Pathological median tumor size was $13 \mathrm{~mm}$. $15 \mathrm{pts}(27 \%)$ were free of infiltrating residual carcinoma [1 CR (19.6\%), 4 intraductal carcinoma (7\%)]. 1 CR with node positive, 10 residual tumor $<5 \mathrm{~mm}, 31$ significant residual tumor. According to the classification of Chevallier, we observed 12 grade $1(21 \%)$, 4 grade $2(7 \%), 9$ grade $3(16 \%), 33$ grade $4(56 \%)$.

The Median of follow up was 13 months. 4 pts relapsed (metastase: 3, local: 1).

Conclusion: this regimen combining four major drugs in breast carcinoma exhibit a high pathological complete response rates, with no major complication.

\section{4}

Sequential FEC100 and taxotere as a neoadjuvant treatment for operable breast cancer.

Servent V, Baranzelli MC, Deschildre L, Chauvet MP, Giard S, Belkacemi Y, Fournier C, Bonneterre J. Centre Oscar Lambret, Lille, France

Neoadjuvant chemotherapy is proposed in all the patients in whom a total mastectomy should be performed due to the tumor size. We report the results of the sequential treatment: 4 cycles of FEC100 followed by 4 cycles of Taxotere.

Patients and Methods: Between October 2003 and May 2005 , 54 patients treated in a single institution were included in the study ; 2 of them had a bilateral breast cancer. The patients with inflammatory, locally advanced or metastatic breast cancer were excluded. The regimen included 4 cycles of FEC 100, then 4 cycles of Taxotere at the dose of $100 \mathrm{mg} / \mathrm{m} 2$, all given every 3 weeks. The rationale for using 8 cycles was based on the results of the NSABP B27 and Aberdeen studies.

Results: Patients median age was 47.8 years $(31-66) ; 30 \%$ were premenopausal ; the median size of the tumor was $5 \mathrm{~cm}(2-11)$; 28 patients had clinical axillary nodes ; 48 tumors were ductular, 5 lobular, 1 medullary, 1 mucinous and 1 undifferenciated . 61, \% were estradiol receptor positive $(\mathrm{ER}+), 59 \%$ progesterone receptor positive $(\operatorname{PgR}+) .16 \%$ were HER $2+++(n=38)$. All the patients had a metallic clip in their tumor to allow adequate localization for surgery even in case of complete clinical response(CCR). The treatment was done according to the protocol in $65 \%$ of the patients. No febrilee aplasia has been observed. After 4 courses, the CCR rate was $29 \%$, the partial response(PR) rate $35 \%$. No patients had progressive disease (PD). The echographic figures were the following, CR: $10 \%$, PR: $56 \%$. After 8 courses the CCR rate was $51 \%$, the PR rate $20 \%$, the echographic CR rate was $30 \%$, PR rate $36 \%$. $64 \%$ patients had a tumorectomy, 36\% a mastectomy which can be considered as a failure of the treatment. $25 \%$ of the patients experienced a pathological complete response

Conclusions: The sequential regimen is feasible and effective in patients who had to be treated by total mastectomy. The predictive factors of response will be presented.

\section{5}

Monitoring early treatment response of breast cancer to neoadjuvant chemotherapy using MR spectroscopy. Su MY, Baik HM, Yu H, Mehta RS, Nalcioglu O. University of California, Irvine, CA; UCIMC, Orange, $C A$

Introduction: MR spectroscopy has been proven helpful in improving specificity in diagnosis of breast cancer, also the Choline peak is known to be sensitive to chemotherapy. The single-voxel technique can be easily implemented, but it is not optimal for studies of large heterogeneous lesions. In this study we investigated the reduction in Choline peak in patients receiving neoadjuvant chemotherapy using single voxel (SV) and chemical shift imaging (CSI) techniques.

Materials and Methods: Fourteen patients (31 to 57 years old) with biopsy proven breast cancer who elected to receive neoadjuvant chemotherapy were studied, 7 patients with single voxel technique $(2 \times 2 \times 2 \mathrm{~cm}$ voxel size $)$, and 7 patients with chemical-shift imaging ( $8 \times 8$ grids, each grid $1 \times 1 \times 1.5 \mathrm{~cm})$. Two studies were performed, the baseline before chemotherapy and the F/U after 1-2 cycles AC treatment. Dynamic contrast enhanced MRI was first performed, and the single voxel or the CSI grid was placed on the enhanced tissues. In CSI, a region of interest consisting of $2 \times 2$ grids from the area showing the highest Cho was chosen, and a mean Cho peak value was measured. If the patient continued to receive 4 cycles $\mathrm{AC}$, another $\mathrm{F} / \mathrm{U}$ was performed at that time.

Results: All 7 patients studied using the SV technique showed Cho reduction (33 to 99\%) after 1-2 cycles AC. Of these, 5 patients did not show a substantial size reduction at that time. Among the 7 patients studied with CSI, the Cho reduction was found in 5 patients but not from the two diagnosed with inflammatory breast cancer. Despite the elevated Cho, these 2 patients were responders after 4 cycles AC. Excluding these 2, 8 of remaining 12 patients completed 4 cycles AC. Of them, 7 were responders and one was a nonresponder. In this patient, a $72 \%$ reduction in Cho was found after 1 cycle $\mathrm{AC}$ which was not predictive of final response. The reduction of Cho (from $100 \%$ in the baseline study) for all patients are shown in Figure 1.

Discussion: The results indicated that Cho was sensitive to $\mathrm{AC}$ treatment in ductal or lobular cancer but not in inflammatory cancer. The percentage reduction in Cho was much higher than the percentage size reduction after 1-2 cycles AC, and in $7 / 8$ patients the Cho reduction was correlated with further size reduction after 4 cycles AC. More data are needed to establish its early predictive value for final outcome.

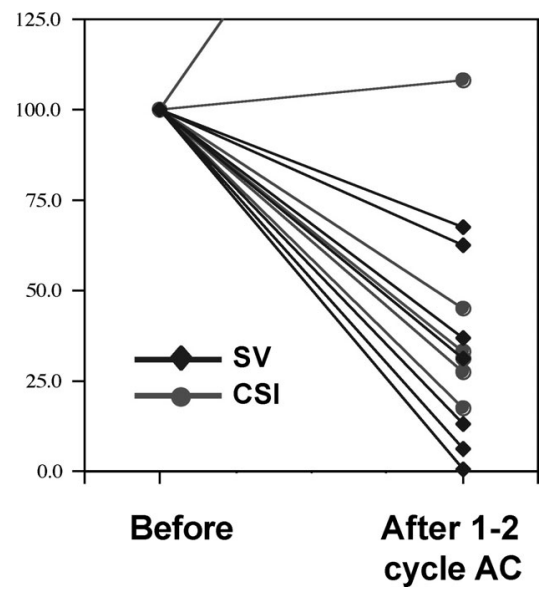




\section{6}

Skeletal effect of exemestane in the Intergroup Exemestane Study (IES) - 2 year bone mineral density (BMD) and bone biomarker data.

Coleman RE, Banks LM, Girgis SI, Vrdoljak E, Fox J, Porter LS, Snowdon CF, Hall E, Bliss JM, Coombes RC. Yorkshire Cancer Research Centre, Weston Park Hospital, Sheffield, United Kingdom; Imperial College, London, United Kingdom; Clinical Hospital Split, Split, Croatia; Castle Hill Hospital, Cottingham, United Kingdom; Institute of Cancer Research. Sutton, United Kingdom; On Behalf of the Intergroup Exemestane Study (IES) Background: It is known that Tamoxifen (T) preserves bone in postmenopausal women but aromatase inhibitors (AI) accelerate bone loss and increase the fracture risk. Pre-treatment with T, coupled with possible anabolic effects of the steroidal AI exemestane (E), would be expected to cause fewer adverse effects on bone than 5 years of unopposed AI use.

Methods: 4724 postmenopausal women with early breast cancer, disease-free following 2-3 yrs $\mathrm{T}$, were randomised to further $\mathrm{T}$ or E to complete 5 yrs adjuvant therapy. 206 of the IES patients (100E, 106T) without osteoporosis or osteoporotic fracture took part in a detailed bone sub-protocol. BMD was assessed by dualenergy x-ray absorptiometry of the lumbar spine and hip at prerandomisation, 6, 12, $24 \mathrm{mths}$, end of treatment (EOT) and annually following treatment completion. Biochemical markers of bone resorption (urinary NTX and DPD, serum CTX), and formation (BAP, osteocalcin and PICP) were collected before randomisation, and then at 3, 6, 9, 12, 18, 24, 30 mths, EOT and annually following treatment completion. The $12 \mathrm{mth}$ BMD and bone marker data are shown here but 24 mth data will also be available for presentation.

Results:

At randomisation patient demographics, BMD and bone markers in the $\mathrm{T}$ and $\mathrm{E}$ groups were comparable. Bone marker measurements showed increased bone turnover in the $\mathrm{E}$ group with significant increases in both bone resorption and formation at all time points after randomisation $(\mathrm{p}=<0.001)$. At $12 \mathrm{mths}$ there was a significant negative correlation between BMD and all bone markers $(\mathrm{p}=<0.001)$ except PICP vs total hip $(\mathrm{p}=0.033)$. Changes at 12 mths from baseline in BMD and bone markers were:

$\begin{array}{llll} & \text { Exemestane } & \text { Tamoxifen } & \text { E v T } \\ \text { L Spine BMD* } & -3.2 \%(-4.0 \text { to }-2.5) & -0.2 \%(-0.9 \text { to } 0.5) & \mathrm{p}=<0.001 \\ \text { Total hip BMD* } & -2.1 \%(-2.7 \text { to }-1.6) & -0.6 \%(-1.1 \text { to }-0.03) & \mathrm{p}=<0.001 \\ \text { Serum CTX\# } & 137 \%(55.3 \text { to } 204.8) & -9 \%(-31.5 \text { to } 24.4) & \mathrm{p}=<0.001 \\ \text { Urinary NTX\# } & 71 \%(34.5 \text { to } 129.7) & -7 \%(-15.0 \text { to } 26.9) & \mathrm{p}=<0.001 \\ \text { Serum BAP\# } & 44 \%(22.7 \text { to } 75.4) & -0 \%(-8.8 \text { to } 11.2) & \mathrm{p}=<0.001 \\ \text { Serum PICP\# } & 24 \%(9.8 \text { to } 51.2) & -0 \%(-13.5 \text { to } 14.4) & \mathrm{p}=<0.001 \\ \text { * mean and 95\% confidence intervals \# median and interquartile ranges }\end{array}$

mean and $95 \%$ confidence intervals \# median and interquartile ranges

Discussion:

In contrast to patients remaining on $\mathrm{T}$, those switching to $\mathrm{E}$ had significant BMD loss. Whilst this is consistent with changes seen with other AIs, we are uncertain whether the observed effect in the IES is due to T withdrawal, E treatment or both. The 2-year follow-up data should help us elucidate this.

\section{7}

Withdrawn by author

\section{8}

Inhibition of steroid sulfatase by 667 COUMATE (STX64): a new treatment paradigm for breast cancer.

Stanway S, Purohit A, Woo LW, Wilson R, Sufi S, Dobbs N, Vigushin D, Stanczyk FZ, Potter BV, Reed MJ, Coombes RC. Imperial College, London, United Kingdom; University of Bath, Bath, United Kingdom; Belfast City Hospital Tower, Belfast, United Kingdom; Cancer Research UK, London, United Kingdom; USC Keck School of Medicine, Womens and Childrens Hospital, Los Angeles, $C A$

\section{Background}

The development of potent steroid sulfatase (STS) inhibitors represents a new approach to the treatment of postmenopausal (PM) women with hormone-dependent breast cancer. STS inhibitors block the formation of estrone (E1) from estrone sulfate (E1S) but also inhibit the formation of androstenediol (Adiol), a steroid with potent estrogenic properties, which originates from dehydroepiandrosterone sulfate (DHEAS).

Patients and Methods

PM with ER+ metastatic breast cancer were recruited for this Phase I study. All had received at least two previous lines of endocrine therapy and all but one had received prior chemotherapy. STX64 was administered as an initial dose (5mg or $20 \mathrm{mg}$ p.o.) followed one week later by 3 two weekly cycles with dosing for 5 days followed by 9 days off treatment. Nine patients have been treated at the $5 \mathrm{mg}$ dose and 5 at the $20 \mathrm{mg}$ dose. Blood samples were collected for the assessment of STS activity in peripheral blood lymphocytes (PBLs) and steroid concentrations. For some patients core biopsies of tumor samples were also taken before and during therapy.

\section{Results}

After 5 doses of STX64 at the 5mg and 20mg doses STS activity in PBLs was inhibited by $98 \%$ (IQR 95-99\%) and 97\% (IQR 96$99 \%$ ) respectively. Overall, tumor STS activity was inhibited by > $90 \%$. Inhibition of STS activity was accompanied by significant increases in the ratios of DHEAS: DHEA and E1S: E1 and significant decreases in serum concentrations of estradiol and Adiol. Serum concentrations of androstenedione (A) and testosterone (T) decreased by up to $86 \%$ and $82 \%$ respectively. Four out of twelve evaluable patients, who had all progressed whilst on aromatase inhibitor therapy, were considered by the treating investigators as having stable disease.

Conclusions

Inhibition of STS was associated with expected decreases in serum concentrations of estradiol and Adiol, but the decreases in A and T were not anticipated. This finding suggests that in PM women the major part of A originates from peripheral conversion from DHEAS rather than by direct secretion from the adrenal cortex as was previously thought to occur. Thus, inhibition of STS not only blocks the production of Adiol, but also that of the major substrates (A and T) for the synthesis of estrogens in peripheral tissues. Only minor adverse events have been reported and the disease stabilisation ( $>6$ months) reported in 3 patients suggest a significant clinical potential for this new therapeutic approach.

\section{9}

Rosiglitazone sensitizes breast cancer cells to early apoptosis and synergizes with roscovitine to inhibit cellular proliferation.

Mody M, Dharker N, McCaffrey TA, Yang Z, Pumfery AM, Glickman TS, Pinzone JJ. The George Washington University, Washington, $D C$

Peroxisome proliferator-activated receptor $\gamma$ (PPAR $\gamma$ ), a member of the nuclear hormone receptor superfamily, is widely expressed and has multiple ligands including rosiglitazone (rosi). Ligand binding induces heterodimerization with retinoid-X-receptor $\alpha$ $(\operatorname{RXR} \alpha)$, and the resultant complex transcriptionally regulates genes important for development and cellular growth and metabolism. PPAR $\gamma$ agonists decrease cellular proliferation and 


\section{S234 Abstracts - Poster Session V}

induce apoptosis of various tumor types including breast cancer cells. In this study we investigated the mechanism of rosi-induced apoptosis of MDA-MB-231 (MDA) human breast cancer cells. We first determined a rosi dose that inhibits MDA cells in vitro. In humans, an $8 \mathrm{mg}$ rosi dose leads to a plasma concentration of about $500 \mathrm{ng} / \mathrm{mL}$ (equivalent to $1.4 \mu \mathrm{M}$ ), while in a rodent tumor model, a dose of $150 \mathrm{mg} / \mathrm{kg} / \mathrm{day}$ was used for up to $4 \mathrm{wks}$ with significant tumor shrinkage but no apparent adverse effects. ${ }^{1}$ We found no growth inhibition with $1.4 \mu \mathrm{M}$ rosi; however, growth inhibition of MDA cells did occur in a dose-dependent manner at 50 and $100 \mathrm{mM}$. We then used a PPAR $\gamma$ response element-driven luciferase reporter to demonstrate transcriptional activation as early as $1 \mathrm{hr}$ after addition of $100 \mathrm{mM}$ rosi to MDA cells. Based on this, MDA cells were treated with $100 \mathrm{mM}$ rosi for $4 \mathrm{hrs}$ and gene expression changes determined using Affymetrix microarrays which indicated increased expression of p21 (1.6 fold, p<0.05), p53 (2.3 fold, $\mathrm{p}<0.02)$, and $\mathrm{Bax}(1.5$ fold, $\mathrm{p}<0.05)$; confirmatory Western analysis was performed. With early up-regulation of Bax and p53, we predicted that rosi would quickly sensitize MDA cells to apoptosis. MDA cells were treated for $24 \mathrm{hrs}$ with $100 \mathrm{mM}$ rosi and then either $\mathrm{CH} 11$ (trimerizes Fas) or tumor necrosis factor- $\alpha$ $(\mathrm{TNF} \alpha)$ was added and cellular proliferation was measured $24 \mathrm{hrs}$ later. ${ }^{2,3}$ Rosi $+\mathrm{CH} 11$ and rosi + TNF $\alpha$ inhibited cellular proliferation by $42 \%$ and $45 \%$ respectively, compared to CH11 $4 \%$, TNF $\alpha 8 \%$, and rosi $17 \%$. With the early increase of p21 and p53 we hypothesized that rosi would synergize with a CDK inhibitor (roscovitine) to decrease cellular proliferation. MDA cells were cultured in the presence of rosi + roscovitine for $96 \mathrm{hrs}$; this combination synergistically decreased cellular proliferation compared to either agent alone (rosi $21 \%$, roscovitine $45 \%$, rosi + roscovitine $90 \%$ ). We conclude: 1 . microarray analysis is an important tool for predicting synergistic drug activity, 2 . sensitization to apoptosis can be achieved with a high dose, short duration treatment with rosiglitazone followed by either $\mathrm{CH} 11$ or $\mathrm{TNF} \alpha$, 3. synergistic inhibition of cellular growth can be achieved with rosiglitazone + roscovitine.

\section{0}

Molecular changes in response to pre-operative endocrine therapy.

Richer JK, Harvell DME, Spoelstra NS, Singh M, Elias AD, Horwitz KB. University of Colorado Health Sciences Center, Aurora, CO

Background. Preoperative hormonal therapy in patients with locally advanced, ER+, breast cancers increases the frequency of breast conserving surgery without adversely affecting event-free and overall survival. Aromatase inhibitors and tamoxifen are effective for preoperative use. Known predictors of responsiveness include small tumor size, early stage, and presence of estrogen (ER) and progesterone receptors (PR). However, despite predictors, at least $30 \%$ of receptor positive tumors do not respond to hormone treatments. We postulated that specific genes in the expression profile of breast cancers can be used to predict response to preoperative endocrine therapy.

Methods. Paired pre- and post-treatment tumor specimens were obtained from patients with locally advanced, ER+ and/or PR+ breast cancers enrolled in a clinical trial evaluating the effectiveness of preoperative exemestane with or without tamoxifen. The tumors were analyzed by expression profiling using an Affymetrix platform. Robust statistical analyses identified 187 putative E-regulated genes involved in tumor growth or regression. To confirm the gene assignments, human breast cancer cells were grown as estrogen dependent xenografts in ovariectomized nude mice. Sets of mice received no estradiol $(\mathrm{C})$ for 8 weeks, estradiol for 8 weeks $(+\mathrm{E})$, or E for 7 weeks followed by 1 week of E withdrawal (Ewd). Six independent tumors per group were expression profiled.

Results. Paired biopsies of tumors and uninvolved, adjacent normal breast tissue from 5 patients have been analyzed and the results compared to data from the xenograft models. At least 18 genes have been identified that were consistently altered by estrogen blockade therapy in the clinical trial, and estrogen regulated in the xenograft model. Additionally, 90 genes changed in response to neoadjuvant endocrine therapy that have been previously identified as "ER identifier genes".

Conclusions. Using dynamic, rather than static profiling studies, we have now determined which genes, among putative "ER identifier genes" are actually involved in E signaling and E-dependent tumor growth and regression. These genes and their protein products have potential as future therapeutic targets.

The first two authors contributed equally to these studies.

\section{1}

Synergistic interaction between recombinant human insulin-like growth factor-binding protein 3 (rhIGFBP-3) and letrozole in estrogen positive breast cancer.

Alami N, Banerjee K, Page V, Brossard M, Shiry L, Brodie A, Leyland-Jones B. McGill University, Montreal, QC, Canada; Insmed Inc., Richmond, VA; University of Maryland, Baltimore, $M D$

Background: Progression of hormone-sensitive breast cancer is a result of stimulation by estrogen acting through the estrogen receptor (ER),thereby regulating the transcription of several target genes and growth factors.Accumulating evidence for cross-talk between estrogen and insulin-like growth factor (IGF) system has been reported.IGF receptor-mediated signaling is modulated by IGF-binding proteins (IGFBPs 1-6) which regulate IGF bioavailability. IGFBP-3 is the highest affinity carrier protein for IGFs. IGFBP-3 inhibits cell proliferation largely through sequestering circulating IGFs and preventing their interaction with IGF receptors. IGFBP-3 has also apoptotic effects independent of IGF-binding.Both IGFs and estrogen act as mitogens promoting cell proliferation in breast carcinomas.Currently, the use of letrozole, a non-steroidal aromatase inhibitor that blocks estrogen synthesis, has proved to be a significant improvement in postmenopausal hormone-dependent breast cancer treatment.This study was specifically designed to explore the ability of rhIGFBP3 to enhance the letrozole efficacy, previously demonstrated by Brodie et al. in a postmenopausal cancer model.

Material and Methods: Estrogen-dependent human breast cancer cells stably transfected with aromatase,MCF-7Ca,were used. Cells were treated with rhIGFBP-3, at concentrations: 0.02 to $200 \mu \mathrm{g}$ / $\mathrm{ml}$, either alone or in combination with $1 \mu \mathrm{M}$ letrozole, in the presence of $1 \mathrm{nM}$ androstenedione. Their in vitro effects were assessed by MTT assay following 6 days exposure.

Results: Treatment with rhBP-3, as single agent, inhibited the AD-induced growth of MCF-7 Ca cells in a dose-dependent manner. The IC50 obtained was $90 \mu \mathrm{g} / \mathrm{ml}$. Letrozole alone reduced cell proliferation by $50 \%$ at concentrations $1-5 \mu \mathrm{M}$. The combination of various concentrations of rhBP-3 with a constant dose of letrozole elicited a strong dose-dependent enhancement of letrozole activity in MCF-7Ca cells. Synergistic interactions $(\mathrm{CI}<1)$ were observed with all the rhBP-3 doses, as evaluated by the combination index-isobologram method(Chou and Talalay). Preliminary observations in the MCF-7 Ca xenograft model using rhBP-3 and letrozole, either alone or in combination, are consistent with our in vitro results.

Discussion: rhIGFBP-3 displayed synergistic interactions with letrozole in the MCF-7 Ca model. Our findings provide further evidence that co-targeting IGF and ER may have important clinical therapeutic implications in breast cancer. Our previous work examining rhBP-3 downstream signaling effects in ER+ and ERmodels, differences in IGFI-dependent and -independent p-MAPK signaling were observed. Ongoing work is directed towards correlating rhBP-3 and letrozole effects on IGFR and ER signaling pathways in the MCF-7Ca model, both in vitro and in vivo. 


\section{2}

A role for aromatase inhibition in the treatment of estrogen receptor- $\alpha$ negative breast carcinoma.

Brandy KP, Maier KG, Lemke SM, O'Donnell RW, Landas SK, Gatto LA, Kort KC. SUNY Upstate Medical University, Syracuse, NY; SUNY Geneseo, Geneseo, NY; SUNY Cortland, Cortland, NY

Background: Despite improvements in early detection and therapy of invasive breast cancer, nearly $30 \%$ of women develop metastatic disease. Matrix metalloproteinases (MMP) are necessary for many of the cellular events associated with metastases. Previous studies have shown that MMP-2 and MMP-9 are overexpressed in invasive breast cancers and their inhibition may be an early therapeutic option. Further, the use of aromatase inhibitors have shown success in postmenopausal women with estrogen receptor positive (ER+) breast cancer. Aromatase activity is detectable in both ER+ and ER- breast tumors. We hypothesized that the use of the MMP inhibitor (COL-3) alone or with the aromatase inhibitor (letrozole) would result in decreased tumor growth and metastasis in ER- breast cancer.

Methods: MDA-MB-435 cells were incubated for 48 hrs. in 4 treatment groups: Vehicle, letrozole (LET), COL-3, both LET and COL-3. Proliferation/cytotoxicity was quantitated in vitro by the CyQuant cell proliferation assay. In our postmenopausal in vivo model, nude ovariectomized mice were implanted with $17 \beta$ estradiol slow releasing pellets 3 days prior to injection of $10^{6}$ MDA-MB-435 ER- breast cancer cells. Mice were gavaged daily for 8 weeks with one of four treatments; Vehicle $(1 \%$ carboxymethyl cellulose, $\mathrm{n}=4)$, LET $(1 \mathrm{mg} / \mathrm{kg}, \mathrm{n}=5)$, COL-3 (30mg/ $\mathrm{kg}, \mathrm{n}=5)$, both LET and COL-3 $(\mathrm{n}=5)$. Tumor volume was estimated weekly as: $V=\left(w^{2} \times 1\right) / 2$. At necropsy organs were histologically assessed for metastases.

Results: Both in vitro and in vivo, the administration of LET led to decreased cellular growth $(\mathrm{p}<.05)$, tumor volume $(\mathrm{p}<.05)$ and metastases. COL-3 alone had no significant effect, whereas the combination of COL-3 and LET led to fewer metastasis and decreased tumor volume.

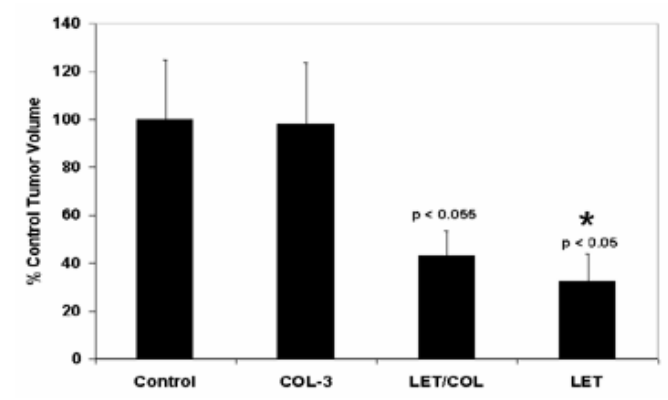

Metastatic pulmonary lesions were observed in $100 \%$ of the controls, $75 \%$ of the COL-3 mice, $25 \%$ of the LET group and $0 \%$ of the combination of COL-3 and LET mice.

Discussion: The use of an aromatase inhibitor in an ER- breast cancer cell line significantly reduced tumor cell growth both in vitro and in vivo. Further, there was a marked reduction in the development of metastases when LET was used with a MMP inhibitor. These data indicate that aromatase inhibition may have clinical efficacy in the treatment of breast cancer regardless of estrogen receptor status.
5083

Inhibition of $E R \alpha$ and PI3K/Akt pathways improve sensitivity of long term estrogen deprived breast cancer cells to antiestrogens.

Sabnis GJ, Jelovac D, Long BJ, Brodie AM. University of Maryland, Baltimore, Baltimore, $M D$

Estrogens play an important role in development and progression of breast cancer. Aromatase inhibitors (AIs) that block the synthesis of estrogen are proving to be superior to antiestrogens (AEs) and may replace tamoxifen as first line treatment for postmenopausal ER positive breast cancer patients. Thus, the potential for developing subsequent resistance to estrogen deprivation is a major concern. In order to study the effects of long term estrogen deprivation on breast cancer, we have developed a long term estrogen deprived cell line, UMB-1Ca. These cells were derived from ER positive human breast cancer cells stably transfected with the aromatase gene (MCF-7Ca), and cultured in steroid depleted medium for 8 months until they had acquired the ability to proliferate. Estradiol and aromatase substrate androstenedione $\left(\Delta^{4} \mathrm{~A}\right)$ did not stimulate the growth of UMB-1Ca cells. As we previously reported UMB-1Ca cells showed an increase in ER $\alpha$, and HER-2 compared to parental MCF-7Ca. Activation of $\mathrm{PI}_{3} \mathrm{~K}$ pathway as seen by increased expression of phospho-Akt was shown by western immunoblotting and in vitro protein kinase assay. UMB-1Ca growth was partially inhibited by AE fulvestrant and a higher dose of AI letrozole, but completely resistant to AIs anastrazole, exemestane, formestane and AE tamoxifen. When $\mathrm{PI}_{3} \mathrm{~K}$ pathway was blocked by wortmannin proliferation of UMB$1 \mathrm{Ca}$ cells was markedly inhibited, whereas no effects of this agent were seen in parental MCF-7Ca cells. However, when treatment of UMB-1Ca cells was combined with $\mathrm{PI}_{3} \mathrm{~K}$ inhibitor wortmannin, the anti-proliferative effects of tamoxifen and anastrazole were restored $(p<0.005)$. To determine whether sensitivity to AE ans AIs can be regained in tumor xenografts, we innoculated UMB$1 \mathrm{Ca}$ cells into overiectomized athymic female nude mice. Animals were divided into two groups and injected sc with either vehicle or $\Delta^{4} \mathrm{~A}$. Tumors grew equally well with and without $\Delta^{4} \mathrm{~A}$ indicating that these cells have developed ability to proliferate in estrogen deprived conditions. Twelve weeks after innoculation animals were divided into six groups and injected with vehicle, tamoxifen $(100 \mu \mathrm{g} /$ mouse/day-sc), wortmannin $(0.35 \mathrm{mg} / \mathrm{kg} / \mathrm{day}-\mathrm{ip}-2 \mathbf{X}$ weekly), fulvestrant ( $1 \mathrm{mg} / \mathrm{mouse} / \mathrm{day})$, tamoxifen plus wortmannin, fulvestrant plus wortmannin. Tamoxifen was not effective in suppressing tumor growth. The combination of wortmannin with tamoxifen or fulvestrant was better than either one alone. However, combination of wortmannin plus fulvestrant was the most effective treatment. The treatment of tumors with wortmannin alone and in combination was associated with downregulation of phosphoAkt as seen by western immunoblotting. After 120 days of treatment, this combination had maintained tumor regression to $30 \%$ of their starting volume.

These results suggest that blocking both pathways ER and growth factor receptor could provide better control over tumor growth of long term estrogen deprived human breast cancers.

\section{4}

Randomized pre-operative study of $750 \mathrm{mg}$ of fulvestrant and $20 \mathrm{mg}$ tamoxifen in premenopausal women with estrogen receptor-positive breast cancer.

Young O, Renshaw L, White S, Macaskill EJ, Cameron D, Thomas $J$, Faratian D, Dixon JM. Western General Hospital, Edinburgh, Scotland, United Kingdom

Introduction: Fulvestrant is a pure antioestrogen that has been shown to be as effective as anastrozole in postmenopausal women with hormone receptor-positive breast cancer who have progressed or recurred on tamoxifen. A small pre-operative pilot study of fulvestrant at a dose of $250 \mathrm{mg}$ showed no significant effect on breast cancers in premenopausal women. The aim of this study 


\section{S236 Abstracts - Poster Session V}

was to investigate the effects of fulvestrant $(\mathrm{F})$ at a dose of 750 $\mathrm{mg}$ and compare its effects with tamoxifen $(\mathrm{T})$ in a pre-operative study in premenopausal women.

Materials and Methods: 60 premenopausal women with operable, invasive estrogen receptor (ER)-positive breast cancer have been randomized to receive either:-

$750 \mathrm{mg}$ of $\mathrm{F}$ (given as 3 separate intramuscular, $5 \mathrm{ml}$ injections) or $20 \mathrm{mg}$ of oral $\mathrm{T}$ both started 14-16 days before surgery.

Breast cancer tissue is being assessed before and after treatment for ER, progesterone receptor (PgR), HER2, and proliferation (Ki67) by immunohistochemistry with FISH for HER 2+. ER and $\mathrm{PgR}$ are given as Allred scores and proliferation as \% Ki67 positive cells. Results are presented as means (SEM); analysis is by paired t test.

54 have completed the study (29T, 25F): and complete histology data and data on tolerability, side effect profile and pain scores during injections are available on all 54.).

Results: ER expression fell significantly with $\mathrm{F}$ from a mean Allred score of $7.15(0.25)$ to $4.38(0.61), \mathrm{p}<0.0001$. The fall with $\mathrm{T}$ from $7.21(0.19)$ to $4.14(0.98)$ was also significant, $\mathrm{p}<0.0001$. The fall in ER was significantly greater for $\mathrm{F}$ than $\mathrm{T}$, $\mathrm{p}=0.02$.

PgR expression fell significantly with $F$ from a score of 6.11 $(0.47)$ to $4.0(0.63), p=0.002$. The change with $\mathrm{T}$ from 6.34 (0.31) to 5.39 (0.53) was not significant, $\mathrm{p}=0.06$. The fall in $\mathrm{PgR}$ was significantly greater for $\mathrm{F}$ than $\mathrm{T}, \mathrm{p}=0.02$.

Proliferation $\mathrm{F}$ reduced the mean $\%$ of $\mathrm{Ki} 67$ positive cells from 14.29 (1.55) to $8.18(1.55), \mathrm{p}<0.0001$, a $48 \%$ median reduction. $\mathrm{T}$ reduced proliferation from $12.36(1.71)$ to $4.12(0.98)$, a $71 \%$ median reduction, $\mathrm{p}<0.0001$. Direct comparison of $\mathrm{F}$ and $\mathrm{T}$ showed no significant difference, $\mathrm{p}=0.06$.

HER2: $5 / 25 \mathrm{~F}$ patients were HER $2+$ as were $2 / 29 \mathrm{~T}$ patients. All these 7 patients had a reduction in tumour cell proliferation. Average pain per injection was $1.6 / 10$. Swelling (12\%), bruising $(16 \%)$, and skin sensitivity $(12 \%)$ were also reported at injection sites with F. Side effects with T included light headedness $(10 \%)$ and hot flushes $(14 \%)$. With $\mathrm{F}$ hot flushes $(16 \%)$, loose stools (12\%) and headache (28) were reported. All were grade 1 or 2 . No patient contacted staff due to adverse events, before routine review. Conclusions: In premenopausal women $750 \mathrm{mg}$ fulvestrant is well tolerated and significantly reduces ER and PgR expression to a greater degree than tamoxifen. Fulvestrant and tamoxifen both produce reductions in proliferation in ER+ breast cancers. Fulvestrant reduces proliferation in both HER2+ and Her2- tumors. Fulvestrant is biologically active in premenopausal women.

\section{5}

Regulation of aromatase expression in the breast by LRH1: a new potential target for breast cancer therapy. Simpson ER, McDonnell DP, Kovacic A, Clyne CD, Safi R. Prince Henry's Institute of Medical Research, Clayton, Victoria, Australia; Duke University Medical Center, Durham, NC

Aromatase inhibitors are replacing Tamoxifen as the breast cancer therapy of choice for postmenopausal women in the first line, adjuvant and neoadjuvant settings. However, these compounds have side effects such as bone loss and arthralgia due to the fact that they inhibit the catalytic activity of aromatase. Consequently they inhibit the enzyme in a global fashion, not only in breast but in other tissues where estrogen action is beneficial such as bone, vasculature and brain. Ideally we wish to inhibit aromatase specifically in the breast and leave other sites of synthesis such as bone and brain protected. This is theoretically possible because in the post-menopausal woman, aromatase expression in a tumorbearing breast is regulated by the proximal promoter II which is activated by tumor-derived factors such as prostaglandins and inhibited by $\mathrm{COX} 2$ inhibitors. In the breast this promoter uniquely utilizes the monomeric orphan nuclear receptor LRH-1 as an obligatory basal enhancer. In the present studies we have shown that LRH-1 activation of aromatase promoter II in breast preadipocytes utilizes PGC1a but not a related gene product, PGC1b, as coactivator. This interaction is inhibited by a sub-class of LXXLL containing peptides. The same sub-class of peptides also inhibits the ability of PGC1a to coactivate RXRa. We have previously shown that RXR and PPARg agonists inhibit aromatase expression from promoter II in primary human preadipocytes via an indirect mechanism not involving binding of either RXR or PPARg to the aromatase promoter. Based on the present results, we conclude that these ligands inhibit aromatase expression by activating RXR and PPARg respectively. The activated receptors compete with LRH-1 for coactivators such as PGC1a, and thus inhibit LRH-1-induced local aromatase expression and estrogen production within breast tissue. RXR ligands are promising molecules for both chemoprevention and therapy of a number of cancers. In particular, 9-cis retinoic acid and RXR-selective ligands are efficacious in preventing breast cancer in experimental animal models. We suggest that the action of these factors may be to inhibit LRH-1 transcriptional activity, thus blocking aromatase expression and local estrogen production within the breast. However, the greatest efficacy in terms of breast-specific inhibition of aromatase would likely be achieved by antagonists/inverse agonists of LRH-1. When such compounds are developed they may prove highly effective as the next generation of endocrine therapeutic agents for breast cancer.

\section{6}

Relationship between CYP2D6 and SULT1A1 genotypes and serum concentrations of tamoxifen and its metabolites during steady state treatment in breast cancer patients. Gjerde J, Hauglid M, Breilid H, Lundgren S, Varhaug JE, Kisanga ER, Mellgren G, Steen VM, Lien EA. Haukeland University Hospital, Norway; Institute of Medicine, University of Bergen, Norway; University of Bergen; St. Olavs Hospital Trondheim University Hospital; Haukeland University Hospital

Background: The metabolism of tamoxifen (tam) shows considerable inter-individual variation in man. The drug is normally hydroxylated by CYP2D6 to the potent metabolites $4 \mathrm{OH}$ tamoxifen (4OHtam) and 4OH-N-demethyltamoxifen (4OHNDtam). The CYP2D6 activity shows a polymorphic distribution that divides populations into poor (PM), extensive (EM) and ultrarapid (UM) metabolizers. The hydroxylated compounds are conjugated by a sulfotransferase (SULT1A1) which has a polymorphic distribution as well. We therefore aimed at examining the relationship between CYP2D6 and SULT1A1 genotypes and serum concentrations of tam and its metabolites in breast cancer patients during steady state tam treatment.

Material and Methods: A total of 153 patients with tamoxifentreated (20 mg daily) breast cancer were enrolled in the study. The concentrations of tam, 4OHtam, 4OHNDtam, Ndemethyltamoxifen (NDtam), N-dedimethyltamoxifen (NDDtam), and tamoxifen-N-oxide (tamNox) in serum were measured by a liquid chromatography-tandem mass spectrometry method. CYP2D6 (CYP2D6*3, CYP2D6*4, CYP2D6*5, CYP2D6* and CYP2D6*2X2) and SULT1A1 (SULT1A1*2) polymorphisms were determined by long-PCR- and multiplex-PCR-based methods and PCR-RFLP assays. The Jonckheere-Terpstra test was used to compare the mean tamoxifen and metabolite levels and ratios over the four genotype groups. Mann-Whitney test was used for comparison between groups. All statistical tests were two-sided. Results: The median (range) of tam, 4OHtam, 4OHNDtam, NDtam, NDDtam, and tamNox concentrations (ng/ml) were 102 (27 - 302), 6.2 (1.7 - 17.2), 55.2 (24.3 - 184.8), 255 (90.1 - 691), $40(11-93)$ and $10.6(2.7-38)$ respectively. The levels of 4OHNDtam and NDtam were significantly associated with the CYP2D6 genotype distribution (PM, n=12; heterozygous EM, $\mathrm{n}=50 ; \mathrm{EM}, \mathrm{n}=87 ; \mathrm{UM}, \mathrm{n}=4)(\mathrm{p}<0.005)$, whereas the levels of tam, 4OHtam, NDDtam and tamNox were not. In the total patient group no differences in tam or metabolite concentrations between those with the SULT1A1 [*1/*1] alleles and those with the 
SULT1A1 [*1/*2] alleles were observed. However, in the postmenopausal subgroup $(\mathrm{n}=120)$ tam as well as 4OHNDtam were lower in those with the SULT1A1[ $* 1 / * 1](\mathrm{n}=56)$ alleles compared to those with the SULT1A1 $[* 1 / * 2](\mathrm{n}=64)$ alleles $(97$ vs $111 \mathrm{ng} / \mathrm{ml}(\mathrm{p}=0.04)$ and $52 \mathrm{vs} 61 \mathrm{ng} / \mathrm{ml}(\mathrm{p}=0.007)$ respectively). Conclusion: The metabolism of tamoxifen is clearly influenced by both CYP2D6 and SULT1A1 polymorphisms. This effect may in part explain the inter-individual variation in serum concentrations of tamoxifen and its metabolites observed during steady state tamoxifen treatment.

\section{7}

A randomised, blinded, phase II study of tipifarnib (Zarnestra ${ }^{\circledR}$ ) combined with letrozole in the treatment of advanced breast cancer after antiestrogen therapy.

Johnston SRD, Semiglazov V, Manikhas G, Spaeth D, Romieu G, Dodwell D, Wardley A, Neven P, Bessems A, Ma Y-W, Howes AJ, on Behalf of the R115777 INT-22 Investigators. Royal Marsden Hospital, London, United Kingdom; Petrov Research Institute of Oncology, St Petersburg, Russian Federation; City Oncology Dispensary, St Petersburg, Russian Federation; Centre Alexis Vautrin, Nancy, France; Centre Val D'Aurelle, Montpellier, France; Cookridge Hospital, Leeds, United Kingdom; Christie Hospital, Manchester, United Kingdom; Universitair Ziekenhuis Gasthuisberg, Leuven, Belgium; Johnson \& Johnson PRD, Raritan, NJ

Background: Tipifarnib, an orally administered farnesyltransferase inhibitor (FTI), has shown activity as a single agent in a previous phase II study in advanced breast cancer. Several groups have reported, in pre-clinical models, an additive or synergistic effect on inhibition of breast cancer cell growth when FTIs were combined with endocrine therapies. This trial was designed to explore whether tipifarnib could enhance the response rate to an aromatase inhibitor.

Methods: 121 postmenopausal patients (median age 61 years, range 31-82) with advanced ER+ve breast cancer that had progressed after tamoxifen were randomised (2:1) to placebo+letrozole $(L ; n=40)$ or tipifarnib+letrozole $(T+L ; n=81)$. Tamoxifen had been adjuvant therapy in $70 \%$ patients, and firstline therapy for advanced disease in $30 \%$. The dominant site of metastasis was visceral in $57 \%$, soft tissue in $36 \%$, bone in $7 \%$ patients. Tipifarnib/placebo was administered at a dose of $300 \mathrm{mg}$ bid for 21 of 28 days, and letrozole at $2.5 \mathrm{mg}$ daily. The primary objective was to estimate the objective response rate, with secondary endpoints of duration of response, time to treatment failure, clinical benefit rate, overall survival and safety profile. Results: Objective response rate was $38 \%(95 \%$ CI; $23 \%, 55 \%)$ for the L-group, and $26 \%(95 \% \mathrm{CI} ; 16 \%, 37 \%)$ for the T+Lgroup. The median duration of objective response was similar (479 days vs. 443 days). An equal proportion of patients had stable disease for $>24$ weeks ( $23 \%$ in both groups), giving clinical benefit rates of $62 \%(95 \%$ CI $45 \%, 77 \%)$ and $49 \%(95 \%$ CI $37 \%$, $61 \%$ ), respectively. There was no difference in time to disease progression or overall survival, and 30 patients remain on treatment. Grade $3 / 4$ adverse events were recorded in $30 \%$ of Lpatients and $45 \%$ of $\mathrm{T}+\mathrm{L}$-patients, the difference being mainly related to asymptomatic neutropenia observed in 15/81 (19\%) tipifarnib treated patients. The most common adverse events were fatigue, nausea and diarrhoea.

Discussion: While this trial has shown no improvement in response rate for the addition of tipifarnib to letrozole, it was not powered to detect any impact on time to disease progression. Further clinical trials are in progress to determine whether tipifarnib can enhance the benefit of endocrine therapy in advanced breast cancer.

\section{8}

Changes in estrogen binding to ER during endocrine therapy measured by serial [F-18]-fluoroestradiol positron emission tomography (FES PET).

Linden HM, Link JM, Stekhova S, Livingston RB, Gralow JR, Ellis GK, Schubert EK, Peterson LM, Krohn KA, Mankoff DA. University of Washington/Seattle Cancer Care Alliance, Seattle, WA; University of Washington, Seattle, WA

Introduction: Endocrine therapy is targeted to the Estrogen Receptor (ER). Agents such as tamoxifen (TAM) and fulvestrant (FUL) antagonize estrogen binding to ER, while aromatase inhibitors (AIs) lower estrogen levels. Treatment therefore changes estrogen binding to ER and may result in an increase or decrease in ER expression. Since FES PET measures regional in vivo estrogen binding to ER at all tumor sites, we used serial FES PET to measure in vivo pharmacokinetics of estrogen binding to ER as a pharmacodynamic effect of endocrine therapy of metastatic breast cancer.

Methods: We performed serial FES PET in patients with Stage IV breast cancer undergoing treatment with TAM $(n=2)$, AIs $(n=14)$, and FUL $(\mathrm{n}=5)$. Patients were imaged a median of 29 days (range 8 to 97 days) after starting treatment. Estrogen binding at tumor sites was measured as the average FES standardized uptake value (SUV) of up to the 3 most prominent tumor sites included in dynamic imaging 30 to 60 minutes after injection. Changes in whole-body FES PET images were also evaluated qualitatively.

Results: FES uptake declined for most patients (mean $-22 \%$, range $-66 \%$ to $+38 \%$ ). The decline in FES SUV was greater for antagonists (TAM or FUL, mean $-42 \%$ ) versus AI (mean -11\%) (p $<.05$ ). In patients on AIs, responding tumors showed an average decline in FES uptake, while non-responders had no change ( $\mathrm{p}=.06)$. In patients treated with antagonists (TAM or FUL), there were no objective responses seen, although some had disease stabilization. The decline if FES uptake was greater in TAM versus FUL treated patients, but not statistically significant. Post-treatment qualitative FES uptake showed complete blockade with TAM, but incomplete blockade with FUL in 4 of 5 patients, despite complete blockade of uterine uptake.

Conclusions: Serial FES PET measures changes in ER estrogen binding during endocrine therapy. For AIs, response is associated a small early decline in estrogen binding, possibly reflecting response. ER antagonists lead to a larger decrease in estrogen binding. Unlike TAM, FUL appears to incompletely block estrogen binding in tumor sites. Further study is needed to elucidate the mechanisms underlying these changes and the ability of serial FES PET to predict response to endocrine therapy.

(Supported by CA42045 and CA72064)

\section{9}

Modeling for cost-effective strategies in adjuvant hormonal therapy for postmenopausal women with breast cancer: upfront aromatase inhibitors vs sequential tamoxifenaromatase inhibitors.

Younis T, Rayson D, Dewar R, Skedgel C. Queen Elizabeth II Health Sciences Centre, Halifax, NS, Canada

Background: Aromatase inhibitors (AI) have become standard adjuvant options for postmenopausal (PM) women with hormone receptor positive $(\mathrm{HR}+)$ breast cancer. The higher upfront drug costs associated with AI may be offset by lower downstream costs of recurrent breast cancer due to the disease free survival benefit observed in randomized clinical trials. For the first five years of therapy, Tamoxifen (TAM) with a crossover to AI (TAM-AI) and upfront AI are both cost-effective (CE) alternatives to TAM alone. Modeling for the cost-effectiveness of TAM-AI versus upfront AI, however, may help in selecting a preferred CE strategy. Methods: A Markov model was developed to project 5 to 20 year benefit and cost outcomes for a hypothetical cohort of 60 year old PM women with HR+ early stage breast cancer undergoing 


\section{S238 Abstracts - Poster Session V}

adjuvant hormonal therapy. Baseline estimates of events for TAM alone were derived from reported recurrence rates and life tables, with survival modeling for recurrences. Unit costs and utility scores were derived from the literature, and costs of adverse events were not included in the primary analysis. Hormonal treatments costs were based on average wholesale prices $(\mathrm{Cdn} \$)$ in Canada in 2005. Sequential TAM-AI and upfront AI were examined relative to TAM alone across a wide range of hazard ratio (HR) benefits, including those reported in the different trials. A carry over benefit for 5 years beyond AI therapy was assumed. Cumulative costs, life year gains (LYG), quality adjusted LYG (QALYG), and incremental $\mathrm{CE}$ ratios (ICER) were calculated across a wide range of efficacy HR to predict a preferred CE strategy at commonly accepted ICER thresholds. The analysis took a direct payer perspective. Both costs and benefits were discounted at 3\%. Results: Predictions of the preferred CE strategy are generated, with two way sensitivity analyses, across a wide range of efficacy HR. Based on the HR reported in the AI trials, the model predicts a superior $\mathrm{CE}$ for sequential TAM-AI compared to upfront AI over a 20 year horizon. Based on the ARNO and ATAC studies, however, upfront AI appears to be the preferred $\mathrm{CE}$ strategy for patients with estrogen receptor positive $(\mathrm{ER}+) /$ progesterone receptor negative (PR-) breast cancer. A complete sensitivity analysis will be presented, with subset analyses for node positive and negative patients. Conclusions: Sequential TAM-AI is the preferred CE adjuvant strategy compared to upfront $\mathrm{AI}$ in $\mathrm{PM}$ women with $\mathrm{HR}+$ breast cancer. For ER+/PR- breast cancer, however, upfront AI appears to be the preferred CE strategy. This model predicts the preferred CE strategies at commonly accepted CE thresholds across a wide range of efficacy HR, and baseline recurrence risks. Modeling for CE strategies may help select a preferred adjuvant hormonal therapy until evidence from direct comparative randomized studies is available.

\section{0}

Metabolism of the aromatase inhibitor drug letrozole by the human hepatic cytochrome $\mathbf{P 4 5 0}$ enzyme system.

Desta Z, Ward BA, Flockhart DA. Indiana University School of Medicine, Indianapolis, IN

BACKGROUND/AIMS: We used human liver microsomes (HLMs) to identify the CYP isoforms involved in letrozole metabolism. Letrozole, a potent inhibitor of aromatase (a ratelimiting enzyme in the biosynthesis of estrogens), is increasingly used to treat women with breast cancer. Although letrozole is cleared by metabolism via human hepatic cytochrome P450 (CYP) enzymes, the specific isoforms involved have not been fully clarified.

METHODS: Initial experiments were performed in human liver microsomal preparations to define linear conditions for time of incubation and microsomal protein concentration. Letrozole $(10 \mu \mathrm{M})$ was incubated for 0 to $90 \mathrm{~min}$ at $37^{\circ} \mathrm{C}$ in HLMs (0 to $2 \mathrm{mg}$ protein $/ \mathrm{ml}$ ) and a NADP-generating system. Negative control experiments included no cofactor, no microsomal protein and no substrate. Subsequent incubation studies to determine kinetic, inhibition and correlation analysis were performed by incubating letrozole in HLMs $(0.5 \mathrm{mg}$ protein $/ \mathrm{ml})$ at $37^{\circ} \mathrm{C}$ for $30 \mathrm{~min}$.

RESULTS: HPLC chromatograms of microsomal incubates of letrozole showed one major metabolite that was consistent with 4,4'-methanol-bisbenzonitrile (MI). The formation of this metabolite showed sigmoidal kinetics: apparent $\mathrm{K}_{\mathrm{m}}, 38.4 \mu \mathrm{M}$; $\mathrm{V}_{\max }, 14.4 \mathrm{pmol} / \mathrm{min} / \mathrm{mg}$ protein; and Hill coefficient, 1.75 . MI formation from letrozole $(10 \mu \mathrm{M})$ correlated significantly with the activity of CYP3A (Spearman's $r=0.67 ; p=0.039$ ) and CYP2B6 $(r=0.68 ; p=0.035)$. Of the CYP isoform specific inhibitors, CYP3A inhibitors potently inhibited letrozole metabolism: troleandomycin $(50 \mu \mathrm{M})$, ritonavir $(1 \mu \mathrm{M})$ and ketoconazole $(1 \mu \mathrm{M})$ by $100 \%$ (complete inhibition), $83.8 \%$ and $61.3 \%$ respectively. Pilocarpine $(50 \mu \mathrm{M}$; CYP2A6 inhibitor) also showed moderate inhibition (by $46.7 \%$ ). The $\mathrm{IC}_{50}$ s for the inhibition of MI from letrozole $(10 \mu \mathrm{M})$ by ritonavir, troleandomycin, ketoconazole and pilocarpine were $0.3,0.5,0.4$ and $25 \mu \mathrm{M}$ respectively

CONCLUSIONS: Our in vitro data implicate CYP3A as a major catalyst of letrozole metabolism, with some contribution of CYP2A6. Genetic polymorphisms in CYP3A and CYP2A6 and drug interactions that potently induce or inhibit these enzymes may influence letrozole clearance and clinical response.

\section{1}

A phase I, open-label, non-randomized, dose-finding safety, tolerance, and pharmacokinetic study of TAS-108 administered orally in postmenopausal female patients with breast carcinoma following standard endocrine therapies.

Noguchi S, Saeki T, Aogi K, Inaji H, Tabei T, Ikeda T. Osaka University Medical School, Suita, Osaka, Japan; National Shikoku Cancer Center Hospital, Matsuyama, Ehime, Japan; Osaka Medical Center for Cancer and Cardiovascular Diseases, Higashinari-ku, Osaka, Japan; Saitama Cancer Center Hospital, Kitaadachi-gun, Saitama, Japan; Keio University School of Medicine, Shinjyuku-ku, Tokyo, Japan

Background: TAS -108 is a novel steroidal anti-estrogen compound that has a strong binding affinity to the estrogen receptor and, in preclinical studies, has antitumor activity against tamoxifenresistant breast cancer cell lines. Its molecular mechanisms of actions are different from those of tamoxifen and fulvestrant. TAS-108 showed an agonist activity in the bone and cardiovascular systems, and did not show any agonistic effect on the endometrium in preclinical study. A Phase I (open-label and ascending singledose) study for TAS-108 was conducted at the doses 40,80 , or $120 \mathrm{mg}$ in healthy Japanese volunteers. It had good safety profile with no severe adverse effects (AEs). The drug has linear pharmacokinetics. The objective of the present study was to investigate the dose-finding safety and tolerance and to document any antitumor activity observed with TAS-108 in Japanese postmenopausal breast cancer patients who had progressed on the standard endocrine therapies.

Methods: TAS-108 was administered orally at $40 \mathrm{mg} /$ day with planned escalations to 80 and $120 \mathrm{mg}$ after 14 days observation at each dose level. If there were no study drug-related (possibly, probably or definitely related) serious AEs in the 5 pts at that dose level, then pts were enrolled at the next level. Safety was assessed with NCI-CTC (v2.0) and efficacy was with RECIST

Results and Discussion: Total 16 pts were enrolled, and 15 pts were eligible. Fifteen (15/15) pts experienced 122 AEs. Of these, there were 4 pts with AEs of Grade $(\mathrm{G}) 1,8$ with G2, and 3 with G3. Eight pts, one in the $40 \mathrm{mg}$ dose group, 3 in the $80 \mathrm{mg}$ dose group, and 4 in the $120 \mathrm{mg}$, experienced 19 study drug-related AEs. Of these, there were 6 pts with AEs of G1, and 2 pts with G2. The most frequent study drug-related AEs were ALT increase 3(3/15), hot flush 2(2/15), and arthralgia 2(2/15). Study drug-related G2 AEs were T-cho increase, sweaty, and arthralgia (1 pt each). Endometrial hypertrophy was experienced in one pt $(80 \mathrm{mg}$ dose group), but there were no notable change from baseline in the endometrial thickness in the other pts. There were $2 \mathrm{PR}, 3 \mathrm{SD}$ for at least 24 weeks, $6 \mathrm{SD}$ and $3 \mathrm{PD}$. The objective response rate (ORR) was $13.3 \%(2 / 15)$ and clinical benefit $(\mathrm{CR}+\mathrm{PR}+\mathrm{SD}$ for at least 24 weeks) was $33.3 \%(5 / 15)$. Eleven pts had received 3 or more prior endocrine therapies and 8 pts had received 2 or more prior chemotherapies. These data suggest that TAS-108 will be effective and tolerable in the treatment of postmenopausal breast cancer patients. 
5092

Similar time to response between fulvestrant and anastrozole: comparison from two phase III trials. Pippen J. Baylor Sammons Cancer Center \& US Oncology Research, Dallas

Background: Fulvestrant is administered as a sustained-release intramuscular (IM) injection and takes between 3 to 6 months to reach steady-state levels, which is in contrast to some tablet therapies that take only a few days. This has led to speculation amongst some physicians that this pharmacokinetic difference may equate to a delayed time to response (TTR) with fulvestrant compared with other treatments such as the aromatase inhibitors. Materials and Methods: TTR data were collected from two International Phase III trials (0020 and 0021) of fulvestrant 250 $\mathrm{mg} / \mathrm{month}$ (IM injection) versus anastrozole $1 \mathrm{mg} /$ day (orally) in the treatment of postmenopausal women with advanced breast cancer who had recurred or progressed on prior tamoxifen therapy. Trial data were analyzed individually and collectively to determine median TTR with each treatment. Median TTR was calculated from randomization to the observation of an objective response (complete or partial response).

Results: In the combined analysis, objective responses (OR) were observed in 82 patients $(19.2 \%)$ in the fulvestrant group and 70 patients $(16.5 \%)$ in the anastrozole group. Clinical benefit (OR + stable disease $\geq 24$ weeks) rates were $43.5 \%(n=186)$ and $40.9 \%$ $(\mathrm{n}=173)$ in the two groups, respectively. The time taken to achieve an objective response was similar with fulvestrant and anastrozole in both individual and combined analyses (Table). Median TTR with fulvestrant was close to 3 months in each case and almost identical to that of anastrozole, but values ranged between 0.933.1 months overall, suggesting that an objective response may still occur after a long period of stable disease with fulvestrant treatment.

Discussion: Median TTR was similar between fulvestrant and anastrozole, despite differences in their mode of administration and subsequent pharmacokinetics. These data suggest that patients without rapidly progressive disease should be kept on endocrine treatment for at least 3 months to allow a response to be achieved prior to considering changing treatments. Furthermore, objective responses may occur following a long period of stable disease during fulvestrant treatment.

Data source Median TTR (months) Range (months)

Trial 0020

Fulvestrant $250 \mathrm{mg} /$ month $(\mathrm{n}=46) \quad 3.15 \quad 0.9-24.9$

Anastrozole $1 \mathrm{mg} / \mathrm{day}(\mathrm{n}=36) \quad 3.10 \quad 0.7-9.4$

Trial 0021

Fulvestrant $250 \mathrm{mg} /$ month $(\mathrm{n}=36) \quad 3.02 \quad 0.9-33.1$

Anastrozole $1 \mathrm{mg} /$ day $(\mathrm{n}=34) \quad 2.96 \quad 0.8-20.2$

Combined data (Trials 0020 and 0021)

Fulvestrant $250 \mathrm{mg} / \mathrm{month}(\mathrm{n}=82) \quad 3.10 \quad 0.9-33.1$

Anastrozole $1 \mathrm{mg} /$ day $(\mathrm{n}=70) \quad 2.99 \quad 0.7-20.2$

\section{3}

Ovarian histopathology in premenopausal patients with breast cancer receiving gonadotropin-releasing hormone(GnRH) agonist and/or cytotoxic chemotherapy.

Sato N, Sano M, Kaneko K, Kanbayashi C, Honmma K. Niigata Cancer Center Hospital, Niigata, Japan

Introduction:Chemotherapy-related amenorrhea is the most frequent long-term toxicity from adjuvant chemotherapy for earlystage breast cancer. Induction of gonadal quiescence using GnRH agonists during chemotherapy has shown promise in reducing rates of amenorrhea in patients with lymphoma. In the metastatic setting, we performed surgical oophorectomy after efficacy of ovarian function suppression has been confirmed by GnRH agonist for premenopausal patients with positive hormone receptors.

Purpose:The purpose of this study is to examine histological influence of chemotherapy and/or GnRH agonist on breast carcinoma patient's ovary.

Materials and Methods:Records of twenty-five patients undergoing oophorectomy as endocrine therapy for metastatic breast cancer from January 1995 to May 2005 were evaluated. The median of age was 44 years old (range 34 to 52 years old). The patients were classified into two groups; control group $(\mathrm{N}=16)$ without chemotherapy, and Chemotherapy and GnRH agonist (Cx_GnRHa) group (N=9) receiving both chemotherapy and GnRH agonist. Four patients received standard doxorubicin and cyclophosphamide (CPA) for four cycles, two received CAF for six cycles, two received CAF followed by high-dose chemotherapy and autologous peripheral blood stem cell transplantation, and one received FAM (5Fu, CPA, Mitomycin C). The average dose of CPA given before oophorectomy was $15.3 \mathrm{~g}$ (range $1.4 \mathrm{~g}$ to 40.6 g). Gosereline was given in a dose of $3.75 \mathrm{mg}$ IM and repeated every four weeks until completion of chemotherapy. Cx_GnRHa group was compared with control group with regard to gonadal histology. Ovarian damage was evaluated histologically by absence of ovarian follicles.

Results: Impaired ovarian maturation was found 50\% (8 out of 16 pts) in control group, compared with $89 \%$ ( 8 out of 9 patients) in Cx_GnRHa group $(\mathrm{p}=0.0518)$. The average number of total ovarian follicles in control group was 19 compared with 4 in Cx_GnRHa group $(\mathrm{p}=0.0161)$.

Conclusion: Ovarian damage was confirmed in premenopausal patients with metastatic breast cancer after chemotherapy with $\mathrm{GnRH}$ agonist. From these results, it is suggested that patient age, cumulative dose and the specific agent used should be taken into considerations to interpret possible effect of GnRH agonist on preservation of ovarian function.

\section{4}

Side effect profile of anastrozole compared with tamoxifen in Japanese women: findings from N-SAS BC03 Trial.

Aihara T, Nishiuchi H, Takatsuka Y, Ohashi Y. Kansai Rosai Hospital, Amagasaki, Hyogo, Japan; University of Tokyo, Bunkyoku, Hongo, Tokyo, Japan

Serective aromatase inhibitors now serve as treatment of choice for hormone responsive postmenopausal early breast cancer. The difference in the toxicity profile between aromatase inhibitors and tamoxifen has been noted. Tamoxifen was associated with a higher incidence of gynecological symptoms and venous thrombosis than aromatase inhibitors, while musculoskeltal disorders and fractures were more common with aromatase inhibitors (Lancet 2005; 365: 60-62. N Engl J Med 2004;350:108192.). These data are derived from the clinical trials conducted in the Western countries. The ethnic difference may exist in terms of the toxicity profile, however few data concerning the difference in the toxicity profile between aromatase inhibitors and tamoxifen among Asian women is available. Hence we investigated the adverse events among Japanese women who participated in Phase III Randomized Adjuvant Study of Tamoxifen Alone Versus Sequential Tamoxifen and Anastrozole in Hormone-Responsive Postmenopausal Breast Cancer Patients (N-SAS BC 03 trial). The worst toxicity grade after randomization of fifteen predefined adverse events were compared between anastrozole arm $(n=277)$ and tamoxifen arm $(n=279)$ using Cochran-Mantel-Haenszel test stratified with the toxicity grade at baseline. $\mathrm{p}<0.05$ was considered as statistically significant. The toxicity was graded according to the NCI-CTC ver2.0.

No significant difference was observed in any of the predefined adverse events, but marginally significant difference was observed in hot flushes and vaginal discharge in favor of anastrozole which was similar to the above studies. Further follow-up will reveal the similarity and difference in the toxicity profile of aromatase inhibitors between Western and Asian population. 


\begin{tabular}{|c|c|c|c|c|c|c|}
\hline \multirow[t]{2}{*}{ Adverse event } & \multicolumn{2}{|l|}{ At baseline } & \multicolumn{2}{|c|}{ After randomization } & \multirow{2}{*}{$\begin{array}{l}\text { CMH statistical } \\
\text { amount } \\
\text { (ANOVA) }\end{array}$} & \multirow{2}{*}{$\mathrm{p}$ value } \\
\hline & $\begin{array}{l}\mathrm{A}(\mathrm{n},[\%]) \\
\mathrm{n}=277\end{array}$ & $\begin{array}{l}\mathrm{T}(\mathrm{n},[\%]) \\
\mathrm{n}=279\end{array}$ & $\begin{array}{l}\mathrm{A}(\mathrm{n},[\%]) \\
\mathrm{n}=277\end{array}$ & $\begin{array}{l}\mathrm{T}(\mathrm{n},[\%]) \\
\mathrm{n}=279\end{array}$ & & \\
\hline Hot flushes & $78(28)$ & $71(25)$ & $106(38)$ & $107(38)$ & 2.43 & 0.12 \\
\hline nausea & $3(1.1)$ & $4(1.4)$ & $17(6.1)$ & $13(4.7)$ & 0.02 & 0.89 \\
\hline appetite loss & $3(1.1)$ & $4(1.4)$ & $8(2.9)$ & $12(4.3)$ & 0.04 & 0.84 \\
\hline fatigue & $33(12)$ & $28(10)$ & $70(25)$ & $57(20)$ & 0.00 & 0.99 \\
\hline mood alteration & $18(6.5)$ & $12(4.3)$ & $35(13)$ & $23(8.3)$ & 0.66 & 0.42 \\
\hline headache & $16(5.8)$ & $16(5.8)$ & $47(17)$ & $35(13)$ & 0.03 & 0.86 \\
\hline arthralgia & $37(13)$ & $26(9.4)$ & $105(38)$ & $56(20)$ & 0.28 & 0.60 \\
\hline $\begin{array}{l}\text { white blood } \\
\text { cell count }\end{array}$ & $21(7.6)$ & $23(8.3)$ & $53(19)$ & $47(17)$ & 0.19 & 0.66 \\
\hline liver function & $29(10)$ & $23(8.3)$ & $79(29)$ & $51(18)$ & 0.02 & 0.90 \\
\hline thrombosis & & 0 & 0 & 0 & - & \\
\hline vaginal & $4(1.4)$ & $5(1.8)$ & $16(5.8)$ & $12(4.3)$ & 0.00 & 0.99 \\
\hline $\begin{array}{l}\text { bleeding } \\
\text { vaginal } \\
\text { discharge }\end{array}$ & $50(18)$ & $44(16)$ & $64(23)$ & $62(22)$ & 3.47 & 0.06 \\
\hline cardiovascular & $2(0.72)$ & $1(0.36)$ & $3(1.1)$ & $2(0.72)$ & 0.98 & 0.32 \\
\hline $\begin{array}{l}\text { second } \\
\text { malignancy }\end{array}$ & 0 & 0 & $1(0.36)$ & $2(0.72)$ & & \\
\hline contra-lateral & 0 & 0 & 0 & $1(0.36)$ & - & - \\
\hline
\end{tabular}

\section{5}

Celecoxib anti-aromatase neoadjuvant (CAAN) Trial for locally advanced breast cancer.

Chow LWC, Toi M. University of Hong Kong Medical Centre, Hong Kong, Hksar, Hong Kong; Tokyo Metropolitan Komagome Hospital, Tokyo, Japan

Background: Anti-aromatase therapy is important in the treatment of breast cancer in postmenopausal women. Cyclooxygenase-2 (COX-2) inhibitors have been shown to be effective in chemoprevention in animal and clinical studies.

Patients and Methods: A proof of principle study was performed to investigate the efficacy of combing anti-aromatase therapy (exemestane) and COX-2 inhibitors neoadjuvantly in 82 postmenopausal patients with histologically confirmed invasive hormone-sensitive breast cancers. 30 patients were randomly assigned to receive exemestane $25 \mathrm{mg}$ daily and celecoxib $400 \mathrm{mg}$ twice daily (group A), 24 patients to receive exemestane $25 \mathrm{mg}$ daily (group B) and 28 patients to receive letrozole $2.5 \mathrm{mg}$ daily (group C).

Results: All groups showed clinical response (62\% for group A, $55 \%$ for group B and $60.7 \%$ for group C) and decrease in tumor area $(61.8 \%$ for group A, $58.1 \%$ for group B and $55.7 \%$ for group C). However, out of the 5 patients with complete clinical response, 3 were observed from group A. Of the 58 patients operated, there were 2 patients with pathologic complete response and both were observed in group C. The mean microscopic size of the tumor was $2.57 \mathrm{~cm}$ for group A, $3.05 \mathrm{~cm}$ for group B and $2.02 \mathrm{~cm}$ for group C. The differences were only statistically significant when group $\mathrm{C}$ was compared with group $B(p=0.031)$. The serial changes in tumor area were shown in (figure1).Conclusion: Anti-aromatase therapy is effective in the treatment of breast cancer and may be safely used preoperatively. The addition of COX-2 inhibitors may provide additional benefit.

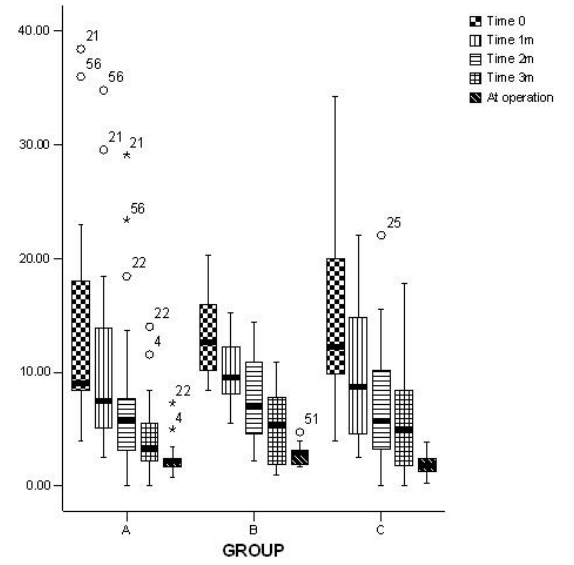

\section{6}

Female sexual dysfunction and changes in hormonal levels in patients with early breast cancer on anti-estrogen therapy.

Amsterdam AD, Wheler J, Hudis C, Krychman ML. Memorial Sloan-Kettering Cancer Center, New York, NY

Objective: To determine if differences exist between breast cancer patients on tamoxifen or aromatase inhibitors or no treatment with respect to female sexual dysfunction (FSD) and estrogen and testosterone levels.

Methods: A retrospective review was performed on 119 patients with early breast cancer who attended the Sexual Health Program at Memorial Sloan-Kettering Cancer Center. Patients were seen from March 2003 through December 2004 and were evaluated by a sexual medicine gynecologist.

Results: Of the 119 breast cancer patients, $21(18 \%)$ received tamoxifen, $26(22 \%)$ an aromatase inhibitor and $72(61 \%)$ did not receive any hormonal therapy for their disease. The majority of patients were menopausal at initial consultation and FSD symptoms were seen most commonly in the aromatase inhibition group.

Tamoxifen Aromatase Inhibitors No Hormonal Therapy

$\begin{array}{llll}\text { Total Patients } & 21(18 \%) & 26(22 \%) & 72(61 \%)\end{array}$

$\begin{array}{llll}\text { Menopausal } & 19(90 \%) & 26(100 \%) & 62(86 \%)\end{array}$

Vaginal Dryness $\quad 13(62 \%) \quad 22(85 \%) \quad 56(78 \%)$

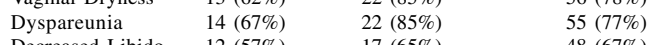

Decreased Libido $12(57 \%) \quad 17(65 \%) \quad 48(67 \%)$

Using Pearson's Chi-Square test, no significant difference was seen between the groups with respect to menopausal status or reported symptoms of FSD. When evaluating continuous variables with ANOVA, a significant difference in estradiol levels $(\mathrm{p}=0.021)$ and sex hormone binding globulin $(\mathrm{p}=0.007)$ was noted between the 3 groups. Only minor differences were seen when evaluating testosterone levels $(p=0.169)$ and age $(p=0.055)$.

Conclusion: Breast cancer patients treated with tamoxifen or an aromatase inhibitor frequently report symptoms of FSD. The results of this study fail to demonstrate a significant difference among treatment groups in terms of symptoms of FSD, suggesting that other factors, in addition to hormone levels, contribute to development of these symptoms. Further studies are warranted in larger groups of patients to confirm these findings.

\section{7}

Primary hormone therapy in locally advanced breast cancer.

Buhari SA, Cheung Kl, Robertson JFK. Nottingham Breast Institute, Nottingham City Hospital, Nottingham, United Kingdom

Background

In 1989 , our institute started a prospective randomized trial comparing multimodality therapy (neoadjuvant chemotherapy, Patey mastectomy, postoperative radiotherapy and adjuvant home therapy) versus initial hormone therapy for the treatment of locally advanced breast cancer. Early and medium-term result showed no statistically significant differences in the rates of survival, metastasis and uncontrolled locoregional disease. The number of therapies required for the initial hormone arm was less (3.6 versus 4.9). On subgroup analysis, estrogen positive subgroup showed better initial objective response rate (80\% versus $36 \%$ ). We concluded that initial hormone therapy might be a reasonable option in managing locally advanced breast cancer, especially for estrogen receptor positive tumours.

Material and Method

To validate these results, we recruited 81 patients presenting with locally advanced breast cancer, between 1997 and 2004. All had estrogen receptor positive tumours and treated initially with hormone therapy. They were followed up for a mean duration of 32 months.

Results

Overall objective response at 6 months was $96.8 \%$ and at 24 months was $69.2 \%$. Among the responders, $25 \%$ developed local recurrence or progression with a mean time of 21.4 months. The 
mean number of therapies at 2 years was 1.4 . There was no locoregional failure. On subgroup analysis, neither did initial response at 6 months nor the tumour grade predict the development of local recurrence or progression. Overall survival at 2 years is $95 \%$ and at 5 years $75 \%$.

\section{Discussion}

Initial hormone treatment is an option in the treatment of locally advanced breast cancers, which are estrogen receptor positive. Being a predictor for response, estrogen receptor status should be used in patient selection for this therapy. Our results validate the results of earlier trial, with comparable outcome measures.

\section{8}

Tipifarnib with tamoxifen as a rescue for tamoxifen acquired clinical resistance for metastatic ER and/or PgR positive breast cancer after releapse under tamoxifen. Preliminary results.

Dalenc F, Lacroix-Tikri M, Mourey L, Debled M, Gladieff L, Tilkin AF, Faye JC, Seronie-Vivien S, Roché H. Claudius Regaud Institute, Toulouse, France; Bergonié Institute, Bordeaux, France

Background: tipifarnib (t), a farnesyltransferase inhibitor (FTI), has a modest antitumor activity in heavily pretreated patients (pts) with metastatic breast cancer (MBC). Given preclinical experiments, combining FTIs and tamoxifen (T) is a promising clinically approach. Specially FTIs could regenerate T responsiveness in de-novo resistant or acquired resistant disease. In this phase II, we evaluate safety and activity of $\mathrm{T}+\mathrm{t}$. The pharmacokinetics of drugs and serum predictors biomarkers of responsivness or resistance were also assessed.

Methods: Postmenopausal pts with measurable, ER and/or PgR expression MBC were enrolled. All disease were in progression on $\mathrm{T}$ therapy. There were no limitations regarding prior chemotherapy or hormonotherapy regimens. Initially pts were treated with $t$ at $300 \mathrm{mg}$ p.o twice daily for 21 day of 28 days + T $20 \mathrm{mg}$ once daily. Pts were reassessed every 4 weeks with toxicity assessment, physical exam and metabolic panel. Tumor assessment was were done every 8 weeks (RECIST).

Results: To date, 20/40 pts were accrued and 19 assessed. 1 pt presented a cutaneous rash and was rapidly ruled out. The majority have visceral metastases (16) and 3 have only bone metastases. 2 were treated with aromatase inhibitor before $\mathrm{T}$. The median age was 63 [39-72] years. The median time of progression on $\mathrm{T}$ was 30.5 months [9-60]. Toxicity: at $300 \mathrm{mg}$ p.o twice daily, 7/12 pts required dose reduction due to toxicities: grade 3-4 neutropenia (2), grade 3 thrombopenia (2), grade 3 mucositis (1), venous thrombosis (2) and grade 3 neurotoxicity (1). Then t doses were decreased to $200 \mathrm{mg}$ p.o twice daily and well tolerated (no further dose reduction was necessary). Efficacy: 8 pts were still on treatment. 11 were rouled out: 9 for progressive disease $(4,2,2,1$ respectively at 2, 4 and 6 and 8 months) and 2 for toxicity (neurotoxicity and venous thrombosis). There were 1 partial response, 6 and 4 stable disease $\geq 4$ and 6 months respectively (18 months +). The last 2 pts included are in stable disease at 2 months. Pharmacokinetics and predictors biomarkers will be evaluated. Conclusion: $t$ (200 mg p.o twice daily) + $\mathrm{T}$ was well tolerated. Preliminary efficacy data are encouraging.

\section{9}

Tolerance for adjuvant letrozole in daily practice. Fontaine C, Vandenbossche K, Dewaele A, Verfaillie G, Collen K, Neyns B, Schallier D, Vermeij J, Bourgain C, De Grève J. AZ-VUB, Brussels, Belgium

Recent results from randomized clinical trials (RCT) have demonstrated a superiority of adjuvant aromatase inhibitors (AI) over tamoxifen in relapse free survival, administered either immediately postoperatively (anastrazole and letrozole) or in cross-over setting in patients on tamoxifen (exemestane) or in extended setting after 5 years of tamoxifen (letrozole), challenging the historical standard tamoxifen. AI's were associated with fewer gynaecological side-effects and vascular events than tamoxifen, but athralgia and bone demineralization are increased. As a result of these studies, adjuvant AI was introduced in daily clinical practice in a general population that does not necessarily match the RCT inclusion criteria. Post registration observational studies might therefore provide complementary information to RCT.

We have evaluated retrospectively the short-term outcome and tolerance of adjuvant letrozole in such a setting.

Hundred and twelve consecutive patients were included of which 81 received adjuvant letrozole as a first line hormonal treatment, while 31 patients were crossed over from tamoxifen to letrozole. Median age was 57yrs (37-85y) years. Pre- or postoperative chemotherapy preceded hormonal treatment in $88 / 110$ pts. The breast cancers were ER+/PR+ in $81 \%, \mathrm{ER}+/ \mathrm{PR}$ - in $11 \%$, ER-/PR+ in $6 \%, \mathrm{ER}+/ \mathrm{PR}$ unknown in $2 \%$. Median time on letrozole was 6.5 mth (1wk-24 mth). Main toxicities were arthralgia (33\%), hot flushes $(27 \%)$ and increased fatigue $(8 \%)$; one patient developed arterial hypertension and another patient diarrhoea G3 under letrozole. The proportion of patients without any subjective toxicity was only $33 \%$. Sixteen of the $112(14 \%)$ of the patients discontinued the adjuvant therapy with letrozole (after a median duration of treatment of 4.5 months $(1 \mathrm{wk}-7 \mathrm{mth})$ ), because of athralgia $\mathrm{G} 1+2$ in $7(50 \%)$ pts (sometimes debilitating), mood disturbances in 2, and gastrointestinal toxicity G2, arterial hypertension, fatigue and hair loss G1, headache, diarrhoea G3 in one pt each and PD in 2 pts. The PD patients received chemotherapy, 13 patients were switched to tamoxifen with excellent tolerance and 1 patient refused further endocrine therapy. Conclusion: This retrospective analysis suggests that possibly threefold more patients than observed in RCT's withdraw from adjuvant $\mathrm{AI}$ due to tolerance issues, including previously unreported toxicities. Such a discrepancy might be explained by different patient selection and by the absence of the coaching effect derived from a trial context. Until more data on potential patient enrichment criteria and survival data for AI adjuvant treatment vs tamoxifen adjuvant treatment become available, it appears reasonable to either start patients with lower risk profiles on adjuvant tamoxifen or to switch back to tamoxifen whenever tolerance for AI interferes with quality of life.

\section{0}

Aromatase inhibitors (AIs) are unlikely to improve overall survival in postmenopausal women with stage $I$ breast cancer.

Diab S. Rocky Mountain Cancer Centers, Aurora, CO; The Women's Breast Center-Aurora Medical Center

Objective: To determine causes of mortality in breast cancer patients 50 and older with stage I disease. Method: 88542 patients with stage I invasive breast cancer diagnosed between 1973 and 2002 were analyzed in the SEER database. Results: As shown, overall survival (OS), but not breast cancer specific survival (BCSS), decreased with advancing age indicating that the majority of patients are not dying from breast cancer. Cardiac and stroke were major causes of mortality with increasing significance in older patients.

\begin{tabular}{|ccccccccl|}
\hline Age & $\mathrm{N}$ & $\begin{array}{c}10 \mathrm{y} \\
\text { OS }\end{array}$ & $\begin{array}{c}10 \mathrm{y} \\
\mathrm{BCSS}\end{array}$ & $\begin{array}{l}\text { Cardiac } \\
\text { mortality }\end{array}$ & $\begin{array}{c}\text { Stroke } \\
\text { mortality } \\
\%\end{array}$ & $\begin{array}{l}\text { Breast } \\
\text { Cincer } \\
\text { mortality } \\
\%\end{array}$ & $\begin{array}{l}\text { All Ca } \\
\text { mortality } \\
\%\end{array}$ \\
\hline $50-54$ & 11,38 & 85. & $97.3 \%$ & 8.2 & 1.6 & 54.3 & 74 \\
\hline $55-59$ & 11,83 & 80. & $97.4 \%$ & 12.8 & 2.6 & 43 & 65.7 \\
$60-64$ & 12,89 & 74. & $97.6 \%$ & 14.3 & 3.7 & 31.5 & 58.2 \\
\hline $65-69$ & 14,51 & 65. & $97.7 \%$ & 19.3 & 5.6 & 23.5 & 48.9 \\
\hline $70-74$ & 14,41 & 54. & $97.1 \%$ & 26.9 & 6.4 & 18.4 & 37.3 \\
\hline $75-79$ & 12,13 & 42. & $96.7 \%$ & 29.7 & 8.9 & 13.4 & 29.8 \\
\hline $80-84$ & 7,343 & 27. & $96.0 \%$ & 32.1 & 11.2 & 11.6 & 24.9 \\
\hline $85+$ & 4,018 & 12 & $94.3 \%$ & 39.3 & 10 & 10.7 & 18.4 \\
\hline
\end{tabular}




\section{S242 Abstracts - Poster Session V}

Conclusion: Since 10 year breast cancer specific survival is already very high without the use of aromatase inhibitors and since the majority of patients are either alive or are dying from non-breast cancer, it is unlikely that AIs would improve overall survival. Since increasing vascular events might be associated with lowering estrogen levels, a negative impact of AIs on overall survival in early stage patients should be carefully evaluated.

\section{1}

\section{Standardization of estrogen and progesterone receptor} assay values.

Chapman JW, Jasani B, Ibrahim M, Miller K, Murray D, Hewlet $B$, Daidone $M G$, Allred C, Hammond E, Li D, Sweep F, O'Malley FP, Kelly J, Goss P. National Cancer Institute of Canada, Kingston, ON, Canada; UK-NEQAS, United Kingdom; University of Toronto, Canada; Milan, Italy; Baylor Breast Center, TX; Intermountain Health Care and University of Utah; Radboud University Nijmegen Medical Center, Netherlands; BC Cancer Agency, Canada; Harvard University

Background: The increasing use of aromatase inhibitors, requires a decision about likely responsiveness to such breast cancer treatment. Estrogen receptor (ER) and progesterone receptor (PR) are currently assessed most frequently with immunohistochemical (IHC) methods.

Materials and Methods: We will review a variety of laboratory control processes to show the rationale for an adjunct to good laboratory control. ER and PR may be standardized with the conversion to continuous $\mathrm{Z}$-scores, like bone mineral density (BMD). We will then examine support for the routine use of continuous $\mathrm{Z}$-scores to obtain more uniform clinically relevant cut-points.

Results: Decades of world-wide laboratory control work will be reviewed to demonstrate that inter-laboratory comparability of hormonal assay results is still problematic with varying methods for assessment and the classification of tumors as being ER-positive or -negative based on a variety of different cut-points. However, IHC assessment yields a continuous quantity (i.e. percent positive stain), so a quality control program could be developed which externally records the results of a particular laboratory's assessments for a common set of tumor materials. Providing a laboratory meets adequate scientific practice levels, the laboratory-specific mean and standard deviation for test assessments could be utilized to standardize routine clinical assessments. The standardization process could be implemented with as few as 10 assessments per year to improve inter-laboratory comparability; the same quality control data could be used to follow long term performance of a particular laboratory, i.e. intra-laboratory coefficient of variation. Records for multiple years of similarly good quality control work would further improve the laboratory-specific adjustments. ER and PR in standardized units would be applicable across a number of assessment platforms to investigate more generalizable associations with clinical outcome(s).

Discussion: An international consortium is proposing an analogous strategy to BMD for ER and PR of laboratory standardization to $\mathrm{Z}$-scores. The adjunct of statistical standardization to a quality control program would benefit both research and clinical practice.

\section{2}

Inhibition of MAPK restores anti-estrogen response in vitro and $E R \alpha$ expression in breast tumors.

Bayliss JM, Hilger AM, Murthy S, Diehl KM, El-Ashry D. University of Michigan, Ann Arbor, MI

Breast cancer presents as estrogen receptor $(\mathrm{ER} \alpha)$ positive, or negative. $E R \alpha$ - tumors have a poor prognosis, are resistant to hormonal therapies, and frequently show overexpression, amplification, and/or hyperactivation of growth factor receptors, such as the erbB family. Using MCF-7 breast cancer cell line models that mimic this elevated growth factor signaling by EGFR and erbB-2, we have previously shown that hyperactivation of downstream MAPK results in the reversible loss of ER $\alpha$ expression, and that in addition to the direct effect of MAPK on ER $\alpha$, indirect activation of NFkB by MAPK also plays a role. The primary mechanism underlying this MAPK-induced downregulation of ER $\alpha$ involves targeting ER $\alpha$ for proteasomal degradation as inhibition of the ubiquitin-proteasome pathway restores $\mathrm{ER} \alpha$ expression to levels similar to that with inhibition of MAPK activity. Here, we set out to determine if inihibition of MAPK activity in established $E R \alpha$ - breast cancer cell lines could restore ER $\alpha$ expression and further, if this re-expressed ER $\alpha$ could restore antiestrogen response. MAPK inhibition via treatment with U0126 in the low $\mathrm{ER} \alpha+\mathrm{BT} 474$ breast cancer cell line and in $2 \mathrm{ER} \alpha$ - breast cancer cell lines, SUM 149 and SUM 229, resulted in increased or reexpressed ER $\alpha$ protein, respectively. To ascertain that this reexpressed ER $\alpha$ could restore anti-estrogen sensitivity, growth assays analyzing the effects of 4-hydroxy-tamoxifen (4HT) and the pure antiestrogen ICI 182,780 (faslodex) at $10-7 \mathrm{M}$ alone, $5 \mu \mathrm{M}$ U0126 alone, or the combination of 4HT or ICI and U0126 on cell proliferation were performed. BT474 and ER $\alpha$ - SUM 149 and 229 cells were resistant to both 4HT and ICI. While having little or no growth inhibitory effects on its own, $5 \mu \mathrm{M}$ U016 restored the growth inhibitory effects of both 4HT and ICI in both BT474 and ER $\alpha$ - SUM 229 cells, but not in SUM 149 cells. To determine if these in vitro cell line results would extrapolate to a real breast tumor situation, ER $\alpha$ - tumor specimens were obtained from the Tissue Procurement Core. Tumors were minced and divided evenly into a baseline sample and into tissue culture dishes containing medium alone, or supplemented with $10 \mu \mathrm{M}$ U0126 or vehicle control DMSO. The minced tumor specimens in medium plus or minus U0126 were incubated at $37 \mathrm{oC} / 5 \% \mathrm{CO} 2$ for 20 hours. RNA was prepared from all treatment groups and analyzed for $\mathrm{ER} \alpha$ mRNA level by qRT-PCR. Of the 12 tumors received to date, 6 displayed increased ER $\alpha$ mRNA levels after treatment with U0126. Collectively, these data are supportive of our hypothesis that there exists a population of ER $\alpha$ - tumors where upregulated growth factor signaling is directly involved in the generation of the ER $\alpha$ phenotype by repressing ER $\alpha$ expression and that further, this reversible downregulation may be targeted clinically such that this repression can be reversed by inhibiting signaling through MAPK, resulting in re-expression of $\mathrm{ER} \alpha$ and restoration of antiestrogen sensitivity.

\section{3}

Estrogen-induced suppression of gene expression: mechanisms of down-regulation.

Cuba VL, DeNardo DG, Hilsenbeck SG, Brown PH. Baylor College of Medicine, Houston, TX

Background: Estrogen $\left(\mathrm{E}_{2}\right)$, a critical mitogen for breast cancer cells, modulates gene expression by interaction with the estrogen receptors $(E R \alpha+\beta)$. Previous microarray experiments have shown that over two-thirds of the genes modulated by estrogen are downregulated. We have investigated the mechanisms by which estrogen down-regulates gene expression to better understand the role of estrogen in breast cancer development and progression.

Hypothesis: We hypothesized that estrogen down-regulates gene expression either directly through immediate effects on ERdependent genes or indirectly through regulation of expression of other transcriptional regulators such as transcription factors, coactivators, and co-repressors.

Methods: In this study we identified a set of estrogen downregulated genes using Affymetrix array analysis of RNA from vehicle- or estrogen-treated MCF7 cells. Affymetrix array data was compared using dChip analysis software. Genes that were present and varied by $\geq 1$.2-fold were selected for further study. Selected genes were analyzed by Q-RT-PCR to determine whether they were $E_{2}$-down-regulated in a panel of ER+ and ER-breast cancer cell lines. The kinetics of down-regulation was then measured over 48 hours. $\mathrm{E}_{2}$-responsive regions within the promoter were 
mapped by cloning promoter fragments upstream of the transcriptional start site into a luciferase vector. Luciferase activity was measured using the Dual- Luciferase Reporter Assay.

Results: Of 12,000 gene transcripts, at least 120 genes were found to be statistically down-regulated by estrogen $(\mathrm{p}<0.05)$. Of these genes, twenty were further analyzed in MCF7 cells using RTPCR to determine if they were down-regulated by $\mathrm{E}_{2}$. Eleven genes were confirmed to be down regulated within 24 hours using Q-RTPCR analysis. These genes were categorized into different subsets based on the kinetics of down-regulation: those that were downregulated early (1-6 hours after treatment; JunB, Btg2, Cathepsin $\mathrm{H}$, RAI3, CD24, TGF- $\beta 1$ ) and those that were down-regulated late (12-24 hours after treatment; NPIP, SSM4, LXR- $\beta$, Brd2, Brd3). The kinetics of down-regulation was also observed in T47D, MDAMB-231, and MDA-MB-468 breast cancer cells. Ten of these genes were modulated only in ER-positive breast cancer cells suggesting that the observed down-regulation is ER dependent. We are currently mapping the $E_{2}$-responsive region within the promoter of these genes, and are investigating whether $E_{2}$ affects the occupancy of ER, other transcription factors, and co-regulators on these genes' promoters. The $\mathrm{E}_{2}$-responsive region of $\mathrm{Btg} 2$ is within the first 500 bases upstream of the start site as determined by luciferase assays. These results suggest that $\mathrm{E}_{2}$-treatment reduces expression of cell cycle regulators (Btg2), growth inhibitory transcription factors (JunB), and anti-proliferative factors (TGF$\beta 1$ ). This $E_{2}$-induced down regulation of gene expression may be critical for the basic biology of breast cancer.

\section{4}

Loss of estrogen receptor (ER) expression in MCF-7 cells following long-term exposure to fulvestrant.

Giles M, Fiegl H, Widschwendter M, Gee J, Wakeling A, Nicholson R. Cardiff University, United Kingdom; University Hospital, Austria; AstraZeneca Pharmaceuticals, United Kingdom

Background: The pure antiestrogen fulvestrant is registered for use in breast cancer patients previously treated with partial agonists like tamoxifen. Thus, as the mechanisms of resistance to fulvestrant must differ from those to tamoxifen, we studied development of resistance to fulvestrant in $\mathrm{ER} \alpha+\mathrm{MCF}-7$ human breast cancer cells exposed to the drug for short ( $\sim 6$ months) and long ( 24 months) time periods.

Material and Methods: MCF-7 cells were exposed continuously to fulvestrant $(10-7 \mathrm{M})$ for at least 6 months at which time the proliferation rate recovered to that of the parental cells. Continuing exposure to fulvestrant generated a cell line which grew faster than the wild-type cells. Cells exposed to fulvestrant for 6 or 24 months were characterized for ER and PS2 gene promoter methylation status, mRNA and protein levels by qRTPCR, Southern/Western blotting and MethyLight assays. The promotors of these genes were examined for chromatin modifications associated with transcriptional activity using ChIP. Results: Fulvestrant initially inhibits the growth of MCF-7 cells but after 6 months growth resumed at a rate equal to that of the parental cells. ER $\alpha$ protein levels in these cells were extremely low, but were restored to near normal levels 2 months after removal of fulvestrant. Restoration of functional ER signalling after fulvestrant withdrawal was demonstrated by estradiol growth stimulation and regulation of PS2. This is consistent with clinical experience which showed that patients who respond to fulvestrant and then relapse can benefit from further endocrine therapy. In contrast, continued exposure of the cells to the drug for a further 18 months produced an ER $\alpha$-negative phenotype that was not reversible upon drug withdrawal. Gene dosage and rearrangement studies confirmed the ER gene was not deleted and lacked major somatic modifications in these cells. A MethyLight assay showed very low level methylation of the ER promoter compared with MDA 231 cells in which the gene is fully methylated and not expressed. The ER $\alpha$-negative phenotype of the long-term fulvestrant treated cells was not reversed by methylation (DNMT) inhibitors alone or in combination with an HDAC inhibitor. Subsequent ChIP studies indicated, that members of the Polycomb group of transcriptional repressor complexes may have initiated and maintained transcriptional silencing of the ER $\alpha$ gene.

Conclusions: The development of resistance to fulvestrant after short term in vitro exposure resulted in a reduction of ER mRNA and functional protein that was reversible on removal of fulvestrant. The development of resistance following in vitro longterm drug treatment may be associated with ER $\alpha$ gene silencing. The clinical significance of these findings is unknown. Knowledge of the silencing mechanism may ultimately allow $\mathrm{ER} \alpha$ to be reexpressed, with the potential re-establishment of endocrine response.

\section{5}

\section{Scaffold attachment factor B1 (SAFB1) - an estrogen} receptor $\alpha$ corepressor.

Meyer R, Dobrzycka KM, Ivanova M, Jiang J, Kang K, Oesterreich S. Baylor College of Medicine, Houston, TX

Background: The estrogen receptor $\alpha(\mathrm{ER} \alpha)$ plays a critical role in the development and progression of estrogen-dependent breast cancer. $\mathrm{ER} \alpha$ activity is regulated by a variety of coactivators and corepressors, as well as through interactions with several other signaling pathways involved in the development and progression of breast cancer. The Scaffold attachment factor B1 (SAFB1) was cloned and defined as ER $\alpha$ corepressor in our laboratory. Its chromosomal locus 19p13.3 shows one of the highest rates of loss of heterozygosity ( $\mathrm{LOH}$ ) described so far in breast cancer. SAFB1 mutations have been found in breast cancer specimens that are not present in normal tissues. SAFB1 is a strong growth inhibitor, and a lost or reduced expression in breast cancer is correlated with a shorter overall survival. We are now asking the question which genes are controlled by the SAFB1/ER $\alpha$ complex, and whether the loss of this regulation contributes to breast tumor genesis.

Material and Methods:We have generated a SAFB1 knockout mouse which display pleiotropic phenotypes, and use mouse embryonic fibroblasts (MEF) from this model for the analysis of SAFB1's role in transcriptional repression. We reintroduce SAFB1 and mutants in which functional domains have been deleted (SAFBox, RRM, or repression domain) into the knockout MEFs to study mechanisms of altered gene regulation. To analyze the estrogen regulation by SAFB1 in human cells, we use human breast cancer cell lines deficient in SAFB1 by using RNAi technique.

Results: Comparing SAFB $1^{+/+}$and $\mathrm{SAFB} 1^{-/-} \mathrm{MEFs}$ we observed significant differences in ER $\alpha$ activity. Consistent with our previous observation that overexpression of SAFB1 results in a dosedependent repression of $\mathrm{ER} \alpha$ transcriptional activity, SAFB 1 deletion resulted in 2-3-fold increased ER $\alpha$ activity. Furthermore, the antagonistic activity of tamoxifen was decreased in the SAFB11- MEFs as compared to SAFB $1^{+/+}$. Using specific siRNA we decrease SAFB1 expression in human breast cancer cell lines to analyze the transcriptional ER $\alpha$ activity under various conditions, and measure the expression of endogens ER $\alpha$ regulated genes.

Discussion: Our preliminary data show that the corepressor SAFB1 plays a critical role in regulating ER $\alpha$ activity. The transfection of SAFB1-deletion proteins will allow us to study separate functions of different domains and their involvement in regulation of endogens gene expressions. The depletion of SAFB1 in human breast cells results in increased transcriptional activity of $\mathrm{ER} \alpha$, ultimately leading to increased breast tumor genesis.

\section{6}

Thyroid hormone may induce breast cancer progression via interactions with the estrogen receptor.

Thor A, Liu B, Ordonez-Ercan D, Edgerton S. OUHSC, Oklahoma City, $O K$

Background: Approximately $50 \%$ of breast cancer patients have been shown to have overt or sub-clinical thyroid disease. Estrogen 


\section{S244 Abstracts - Poster Session V}

receptors (ER) and thyroid hormone receptors (THR) belong to the same nuclear receptor superfamily and demonstrate structural similiarities. Binding of ER by thyroid hormones $(\mathrm{TH})$ has been demonstrated. We hypothesize that TH may promote cellular proliferation and disease progression, in ER positive breast cancer patients.

Materials and Methods: We examined the clinical records of 808 lymph node negative (LN-) breast cancer patients, median follow up 10.2 yrs, for thyroid disease and or TH supplementation, as well as other clinical and histologic factors. Archival fixed breast cancers from these same patients were stained for ERa and proliferation associated antigens. In vitro cell growth was measured by a Cell Titer $96^{\mathrm{TM}} \mathrm{AQ}$ non-radioactive cell proliferation kit Results: LN-, ER+ breast cancer patients who received thyroid hormone replacement therapy had a mean the disease free interval (DFI) of 68 months $(n=28)$, as compared to untreated LN-, ER+ patients (DFS 158 mo., $\mathrm{n}=431 ; \mathrm{p}<0.0001$ ). The disease specific overall survival (DSS) for these same TH treated patients was also significantly shorter, with a mean of 80 as compared to 211 months $(\mathrm{p}=0.0004)$. Similar interactions with TH were not observed in LN-, ER- breast cancer patients $(n=349)$. For breast cancer patients treated with tamoxifen $(n=107)$, those also receiving TH therapy $(n=6)$ had the shortest DFI (mean 40 months) as compared to tamoxifen alone (mean 93 months, $\mathrm{n}=101$; $\mathrm{p}=0.0003$ ). We have observed similar interactions using in vitro models of breast cancer. The ER+ cell lines MCF-7 and T47D show enhanced cell proliferation with estrogen, T3 or T4 while the pure estrogen receptor antagonist ICI 182,780, inhibits cell proliferation. ICI 182,780 abrogates growth promotion induced by estrogen, T3 or T4 when co-administered in vitro. Similar interactions were not detectable in the ER- cell lines SKBR3 or MDA-MB-468.

Conclusions: These clinical and pre-clinical data suggest thyroid hormone may induce breast cancer cell proliferation and disease progression. The mechanism of this induction likely involves ER, as it is not identified in ER- cancer patients or cell lines. This research is generously supported by a grant from the Mary Kay Ash Foundation.

\section{7}

Day of surgery affects estrogen receptor test results in women with breast cancer.

Nkoy FL, Hammond E, Rees W, Sause W, Pinto K, Rowe $K$. Intermountain Health Care (IHC), Salt Lake City, UT

Background:Estrogen (ER) and Progesterone (PgR) Receptor tests are used to select breast cancer patients who would benefit from adjuvant endocrine therapy. Recent reports have indicated that tumors may be falsely classified as negative due to specimen processing considerations. LDS Hospital (LDSH) in SLC, Utah serves as the reference laboratory for ER and PgR tests ordered from IHC facilities located, in some cases, many miles away from SLC. A standardized, automated test method is routinely used at LDSH lab. However, variation in specimen handling or delay in specimen processing at sending facilities may affect test results. In this study, we evaluated the association between ER negative test results and the day surgery was performed. We hypothesized that specimens removed at the end of the week would have high ER negative test results. To our knowledge, no study has ever looked at the impact of the day of surgery on ER and PgR test results.

Methods: We extracted cancer registry data of 5028 women with breast cancer who received surgery at IHC facilities, and were tested for ER between 1997-2003. We conducted a cross-sectional study. We calculated the prevalence of ER negative test results associated with the day of the week the surgery was performed. Trend test was used for significance. For each IHC facility, we compared the prevalence of ER negative test results between Group A (specimens removed between Sunday and Thursday) and Group B (specimens removed on Friday and Saturday). Chi-Square tests were used to evaluate whether ER negative test results were significantly different between the groups.

Results: The prevalence of ER negative tests by the day of the week were: Sunday (19\%), Monday (18\%), Tuesday $(21 \%)$, Wednesday (22\%), Thursday (21\%), Friday (24\%) and Saturday (27\%), $\mathrm{p}=0.020$. The overall prevalence of ER negative test results was $20 \%$ for Group A vs. $24 \%$ for Group B, p=0.030. Except for LDSH (20\% vs. $18 \%$ ), the reference lab, the respective prevalence of ER negative test results for each facility was consistently higher for Group B: AFH (26\% vs. 39\%), AVH $(20 \%$ vs. $26 \%), \mathrm{CWH}(24 \%$ vs. $26 \%)$, DXH (23\% vs. $30 \%)$, MKH (15\% vs. $29 \%)$ and UVRMC ( $23 \%$ vs. $25 \%)$. Both groups were similar in regard to age distribution.

Conclusion:For facilities sending specimens to the reference lab,we found a significant association between ER negativity and the day surgery was performed. Specimens removed at the end of the week have the highest ER negative test results. Since many if not most pathology laboratories do not process routine specimens on the weekends, specimens removed Friday or Saturday are likely to remain fresh at refrigerator temperatures or be fixed for prolonged intervals in buffered formalin. These conditions are likely to result in false negative results. We recommend further study since many healthcare facilities across the United States use reference laboratories for special tests.

\section{8}

Role of estrogen receptor $\alpha$ and corepressors in estrogenmediated repression of genes.

Zubairy S, Wilscher E, Oesterreich S. Baylor College of Medicine, Houston, TX

The estrogen receptor $\alpha(\mathrm{ER} \alpha)$ is a ligand-dependent transcription factor that when bound to estrogen can regulate the transcription of a large number of genes. $\mathrm{ER} \alpha$ is also regulated through its interaction with cofactors which can either enhance (coactivators) or repress (corepressors) its activity. Although the role of estrogenmediated activation of genes is well established, the relevance of repression of genes is only beginning to be appreciated. Large scale expression analysis has revealed that more genes are repressed than are activated following estrogen treatment. Our hypothesis is that $\mathbf{E R} \alpha$-corepressor complexes are critically involved in estrogen-mediated down-regulation of genes. We have performed a meta-analysis of estrogen-mediated down-regulated genes on published studies and have generated a table of 236 genes that are significantly repressed by estrogen. We find several genes like Chemokine receptor 4 (CXCR4), Cyclin G2 (CCNG2), Nmyc down-regulated gene 1 (NDRG1), Claudin 4 (CLDN4), B cell linker (BLNK), and Kruppel like factor 6 (KLF6) that are clearly important in human breast cancer. Additionally, we have analyzed various transcription factor binding sites in the promoters of these genes including ERE, AP-1 and SP-1. One gene that is of interest is CXCR4 because of its recently reported role in growth and metastasis of breast cancer cells. Real time quantitative PCR has been performed to confirm down-regulation of CXCR4. Interestingly, CXCR4 has 1 AP-1 site and 9 SP-1 sites in its promoter. Further analysis of the functional transcription factor binding sites is ongoing to determine whether and which $\operatorname{ER} \alpha$ corepressor complexes are recruited to the promoter regions of these genes, and how they may function.

\section{9}

High ER $\beta$ expression is associated with improved survival on tamoxifen in breast cancer.

Witton CJ, Tovey SM, Cooke TG, Dunne B, Bartlett JM. University of Glasgow, Glasgow, United Kingdom; DakoCytomation A/S, Copenhagen, Denmark

Background: ER $\alpha$ expression in breast tumors is used clinically to predict response to hormonal therapies. The role of ER $\beta$ is not fully established in this setting with conflicting data about whether 
expression predicts response to hormonal therapies and whether it is an independent prognostic factor.

Materials and Methods: We examined carcinoma tissue from $389 \mathrm{ER} \alpha$ positive primary breast tumors from patients treated with Tamoxifen for a median 5 years. Median follow up was 7 years and median tumor size $20 \mathrm{~mm}$ in diameter. There were 186 node negative and 170 node positive patients and 86/181/103 grade $1 / 2 / 3$ tumors. The tumor specimens were obtained from the archive and tissue microarrays (TMA) were constructed in triplicate. Ethical approval was obtained from the GRI Ethics committee. ER $\beta$ monoclonal antibody (Abcam) was used at 1/200 $\mathrm{g} / \mathrm{ml}$ and a Streptavidin-Biotin kit for detection (Biogenex, CA). Antigen retrieval was carried out by heating for 5 minutes under pressure in a microwave in citrate buffer. The ER $\beta$ staining was assessed using a weighted histoscore.

Results: Staining was observed in both the nucleus and cytoplasm of tumor cells and also in the nucleus of surrounding stromal cells. For ER $\alpha$ positive cases 379 (97.4\%) showed some ER $\beta$ staining in the nucleus, and $266(68.4 \%)$ showed some staining in the cytoplasm. Nuclear staining had higher median (120 vs. 50, interquartile range 100-160 vs. 0-100). Expression was separated into "high" (198/389) and "low" expression (190/389) around the median expression value before further analysis. High ER $\beta$ expression was associated with decreased chance of recurrence while taking Tamoxifen $(\mathrm{p}=0.0241)$ but not decreased overall survival $(\mathrm{p}=0.065)$. This was not independent of nodes, grade and size of tumor by multiple regression analysis PgR and HER1-3 were also not independent in this analysis. High ER $\beta$ expression correlated with negative human epidermal growth factor receptors (HER) 1-3 ( $\mathrm{p}=0.0054$, CHI-squared) and with positive progesterone receptor $(\mathrm{PgR}, \mathrm{p}=0.0081, \mathrm{CHI}-\mathrm{squared})$. There was no significant correlation of ER $\beta$ with grade, size or nodal status.

Discussion: Despite the strong correlations, ER $\beta$ is not likely to be acting as a surrogate for PgR or HER1-3, as both HER positive ER $\beta$ positive and PgR positive ER $\beta$ negative tumors were observed (see table). In keeping with previous studies our data suggests that reduced ER $\beta$ expression may predict de novo resistance to Tamoxifen, as it appears to be a predictor of response to Tamoxifen in $\mathrm{ER} \alpha$ positive tumors.

Relationship Between ER $\beta$ and other receptor

$\begin{array}{llll} & \text { ER } \beta \text { low } & \text { ER } \beta \text { high } & \text { p-value (Chi-squared) } \\ \text { PgR positive } & 97 / 187 & 134 / 194 & 0.0081 \\ \text { PgR negative } & 90 / 187 & 60 / 194 & \\ \text { HER1-3 positive } & 65 / 173 & 37 / 179 & 0.0067 \\ \text { HER } 1-3 \text { negative } & 108 / 173 & 142 / 179 & \end{array}$

HER 1-3 negative $\quad 108 / 173-142 / 179$

\section{0}

Loss of heterozygosity at $\mathbf{1 4 q}$ does not correlate with estrogen receptor $\beta$ negative breast cancer.

Parker MD, Hanby AM, Bell SM, Speirs V. Institute of Molecular Medicine, Epidemiology and Cancer Research, University of Leeds, Leeds, W Yorks, United Kingdom

Estrogen receptor $\beta(E R \beta)$ is expressed abundantly in normal mammary gland but its expression is lost or reduced in some breast tumours. In recent years, epigenetic modification has emerged as an important regulatory event associated with transcriptional silencing. There is mounting evidence that this is the case in breast cancer with loss of expression of ER $\beta$ due, in some cases, to methylation of its promoter. Rather surprisingly, no study has considered genetic mechanisms, despite the fact that cytogenetic analysis has revealed deletions of $14 \mathrm{q}$ in in situ breast cancer $(1,2)$. This is relevant as ER $\beta$ maps to $14 q 22-24$. Thus in addition to the epigenetic mechanism detailed above, allelic loss of ER $\beta$ could also contribute to its loss of expression in some breast cancers and consequently, be an important early event in breast carcinogenesis. The aim of this study was to investigate if loss of heterozygosity (LOH) commonly contributes to loss of ER $\beta$ expression in breast tumours. Following ethical approval, cases were selected from the Leeds Breast Tissue Bank. Prior to freezing, samples were harvested by a specialised breast histopathologist (AMH) who ensured separate selection and segregation of tumour / normal pairs for each banked case and examined frozen sections to ensure the banked samples contained representative amounts of either tumour or normal tissue $(>80 \%)$. The selected cases corresponded to those which had previously been analysed immunohistochemically for ER $\beta$ expression in other studies by our group. The cohort consisted of 5 grade I, 12 grade II and 10 grade 3 tumours (age range 30-93 years). Seventeen were lymph node positive and 10 were node negative. Immunohistochemical analysis of ER $\beta$ was conducted using previously published protocols. DNA was isolated from 27 paired primary breast tumour and adjacent normal tissue specimens. LOH was determined using four polymorphic markers spanning chromosome 14q22-24 and included D14S1026, AL359235, D14S63 and AL122035. Allele ratios of tumour and normal samples were calculated for informative cases from the peak heights obtained from the electrophoretograms and a tumour/normal ratio calculated. A value of $<0.5$ indicated $\mathrm{LOH}$. $\mathrm{LOH}$ was correlated to immunohistochemical expression of ER $\beta$. LOH was detected in $21 \%$ of cases in a region immediately adjacent to the location of $\operatorname{ER} \beta$ but not within the ER $\beta$ region itself. No correlation between $\mathrm{LOH}$ and loss of expression of ER $\beta$ by immunohistochemistry was observed. Thus, the loss of expression of ER $\beta$ observed in some breast cancers does not appear to be a mutational event in most cases and is most likely to be in association with epigenetic inactivation such as methylation, as reported in other studies.

1. Burki NG et al., Int J Cancer 88: 607-13, 2000

2. James LA et al., Oncogene 14: 1059-65, 1997

\section{1}

Expression of estrogen receptor $\beta$ variant mRNA in primary breast cancer - a potential role in predicting hormonal responsiveness.

Vinayagam R, Davies MPA, Sibson DR, Holcombe C. Royal Liverpool University Hospital, Liverpool, Merseyside, United Kingdom; Clatterbridge Cancer Research Trust, Bebington, Wirral, United Kingdom

Background: Estrogen receptor alpha $(E R \alpha)$ is an accepted marker for response to hormonal therapy, but may fail to accurately predict outcome. The role of estrogen receptor beta $(\operatorname{ER} \beta)$ and its variants in breast cancer is poorly understood. Published studies are conflicting, partly due to different case selection and study methods.

Materials and Methods: We quantitatively measured mRNA of ER $\beta 1$ (wild-type), C-terminal splice variants (ER $\beta 2 / E R \beta c x, E R \beta 5)$ and exon deletion variants $(\operatorname{ER} \beta \Delta 5, \operatorname{ER} \beta \Delta 3)$ in 100 primary breast cancers [70 ER $\alpha$ positive $(\mathrm{ER} \alpha+)$ and $30 \mathrm{ER} \alpha$ negative $(E R \alpha-)]$ from postmenopausal women treated with surgery and adjuvant endocrine therapy, but not chemotherapy. ER $\beta$ qRTPCR results were related to clinical and histopathological variables and to outcome [breast cancer relapse (BCR) or breast cancer survival (BCS), median follow-up $>5$ years].

Results: In ER $\alpha+$ cases ER $\beta 2$ was expressed at the highest level followed by ER $\beta 5$ then ER $\beta 1$, but in ER $\alpha$ - cases ER $\beta 5$ was highest followed by ER $\beta 2$ then ER $\beta 1$. ER $\beta \Delta 5$ was only detected in 20 cancers, 17 of which were ER $\alpha$ - and 14 of which were high grade; $\operatorname{ER} \beta \Delta 3$ was only detected in 3 cases. Mean ER $\beta 1$ levels were significantly higher in ER $\alpha+$ cases than ER $\alpha$ - cases, but mean $E R \beta 5$ and $E R \beta \Delta 5$ were significantly higher in $E R \alpha$ - than $E R \alpha+$ cases $(\mathrm{T}$-test all $\mathrm{P}<0.003)$. All $\mathrm{C}$-terminal $\mathrm{ER} \beta$ variant levels were higher in low grade tumors; but only ER $\beta 5$ was significantly higher in low grade tumors within the $\mathrm{ER} \alpha+$ subgroup.

Outcome analysis was limited to $62 \mathrm{ER} \alpha+$ cases receiving tamoxifen. High ER $\beta 2$ levels were most closely associated with good outcome; in a ER $\beta 2$-high group $(E R \beta 2>2400$ copies/ $\mu$ g total RNA, $n=30)$ the 5 year cumulative relapse-free population was $81 \%$, compared to $55 \%$ in the ER $\beta 2$-low group $(n=32)$; Log-Rank $\mathrm{BCR} \mathrm{P}=0.0095$, BCS $\mathrm{P}=0.010$. In multivariate analysis, high $\mathrm{ER} \beta 2$ was significantly associated with reduced $\mathrm{BCR}$ independent of grade, size or nodal status (Cox $\mathrm{P}=0.04)$.

In node negative cases $(n=33)$, using a lower cut-off $(E R \beta 2>1100$ copies/ $\mu$ g total RNA), ER $\beta 2$ was significantly associated with better 


\section{S246 Abstracts - Poster Session V}

outcome; the 5 year cumulative relapse-free population was $96 \%$ in the ER $\beta 2$-high group, compared to $55 \%$ in the ER $\beta 2$-low group; Log Rank BCR P=0.0005, BCS P<0.00005.

Discussion: Differential expression of ER $\beta$ variants was seen in relation to $\mathrm{ER} \alpha$ status and tumor grade. Using a treatment-specific adjuvant tamoxifen cohort, high ER $\beta 2$ mRNA levels were significantly associated with favorable outcome. Notably, in node negative breast cancers, low ER $\beta 2$ identified a poorly performing sub-group. Our results indicate that specific ER $\beta$ splice variants may be useful predictive markers and are potentially important in determining response to endocrine therapy. These results need to be validated in larger cohorts of patients.

\section{2}

Estrogen $\left(\mathbf{E}_{2}\right)$ / anti-estrogen driven estrogen receptor (ER) transcription complex assembly in resistant human breast cancer cell lines.

Naughton C, Kuske B, MacLeod K, Langdon SP, Smyth JF, Cameron DA. University of Edinburgh, Edinburgh, United Kingdom

Transcriptional activation by $\mathrm{ER} \alpha$ is a complex and multistep process influenced by coactivator and corepressor proteins (cofactors) that can either positively or negatively modulate ER $\alpha$ mediated transcriptional activity. Deviations from this process due to alterations in either the levels or activity of ER $\alpha$ cofactors have been proposed mechanisms for the development of endocrine resistance in human breast cancer.

To examine this hypothesis further, we have investigated transcription complex assembly at the $\mathrm{pS} 2$ promoter in a panel of human breast cancer variants derived from hormone sensitive MCF-7 cells. MCF-7/LCC1 cells have become $\mathrm{E}_{2}$ independent with respect to growth, whereas MCF-7/LCC9 cells have in addition acquired resistance to anti-estrogens. RT-PCR analysis demonstrated that pS2 expression increased more than 100-fold in MCF-7 cells following $\mathrm{E}_{2}$ treatment for $48 \mathrm{~h}$, whereas Tamoxifen (Tam) treatment resulted in a less than 3 -fold increase. In contrast, LCC1 and LCC9 cells have high basal expression of pS2 (levels comparable with $\mathrm{E}_{2}$-stimulated $\mathrm{MCF}-7$ cells) with only minor changes being observed following either $\mathrm{E}_{2}$ or Tam treatment in LCC 1 cells (2-5 fold) or LCC9 cells (2-3 fold). In addition, LCC1 cell lines displayed elevated protein levels for both ER (4-6 fold) and the coactivator SRC-1 (>2 fold) whereas expression levels in LCC9 cells were comparable to MCF-7 cells.

Chromatin immunoprecipitation (ChIP) was used to compare factors recruited over a $90 \mathrm{~min}$ time course to the $\mathrm{pS} 2$ promoter in response to $\mathrm{E}_{2}\left(10^{-9} \mathrm{M}\right)$ or Tam $\left(10^{-6} \mathrm{M}\right)$ treatment, in each cell line. ChIP analysis demonstrated that the coactivators AIB1 and SRC-1 form part of the ER transcription complex assembled at the $\mathrm{pS} 2$ promoter in MCF-7 cells in response to $\mathrm{E}_{2}$, whereas Tam caused recruitment of the corepressors NCoR and SMRT. The ER transcription complex formed in LCC1 and LCC9 cells differs from that seen in MCF-7 cells in terms of $\mathrm{H} 4$ acetylation, ER $\alpha$ recruitment and cofactor binding. Specifically, the $\mathrm{E}_{2}$ driven recruitment of AIB 1 and SRC-1 was greatly increased in both LCC1 and LCC9 cells, despite $\mathrm{E}_{2}$ having little or no effect on growth in these cell lines. However, in LCC1 and LCC9 cell lines, Tam did not recruit either NCoR or SMRT to the pS2 promoter consistent with the observation that Tam causes only minimal growth retardation in LCC1 cells and no effect on growth in LCC9 cells. In conclusion, these data support the hypothesis that changes in cofactor recruitment to the ER transcription complex may be related to endocrine resistance and these observations are being explored further using RNAi technology.

\section{3}

ER- $\alpha 36$, a novel variant of estrogen receptor- $\alpha$, mediates membrane-initiated mitogenic estrogen signaling in ERnegative breast cancer cells.

Shen P, Zhang X-T, Loggie BW, Wang Z-Y. Creighton University Medical School, Omaha, NE; First Affiliated Hospital, Medical College, Zhejiang University, Hangzhou, Zhejiang, China

Clinically, breast cancers are classified as either ER- $\alpha$ positive or as ER- $\alpha$ negative breast cancer. It is well known that breast tumors with an ER- $\alpha$ positive phenotype are more differentiated and have lower metastasis potential than ER- $\alpha$-negative tumors. Therefore, the absence of ER- $\alpha$ is correlated with a worse prognosis in terms of disease-free survival and overall survival.

We recently identified and cloned a novel variant of ER- $\alpha$ with a predicted molecular weight of $35.7 \mathrm{kDa}$. The transcript of this ER- $\alpha$ variant is initiated from a previously unidentified promoter in the first intron of the original ER- $\alpha$ gene. This ER- $\alpha$ variant differs from the original ER- $\alpha$ by lacking both transcriptional activation domains (AF-1 and AF-2) but retaining the dimerization, DNA-binding and partial ligand-binding domains. In transient transfection assays, this ER- $\alpha$ variant exhibited no intrinsic transcriptional activity but strongly inhibited ligand-dependent and -independent transactivation activities mediated by the original ER- $\alpha$ and ER- $\beta$. Immunohistochemistry analysis using a specific antibody against this ER- $\alpha$ variant revealed that 21 of 35 cases $(60 \%)$ breast cancer specimens examined express this ER- $\alpha$ variant on the plasma membrane and cytoplasm, and 11 out of 14 ER-negative breast caner specimens also express this ER- $\alpha$ variant. Western blot analysis of proteins prepared from normal mammary epithelial cells and established breast cancer cell lines demonstrated a single protein band with $35-\mathrm{kDa}$ molecular weight in most of breast cancer cells but not in normal mammary epithelial cells. Interestingly, ER- $\alpha 36$ is highly expressed in MDA-MB-231 and MDA-MB-436 cells, two well-known ER- $\alpha$ negative breast cancer cell lines, and also expressed in ER- $\alpha$ positive breast cancer cells such as MCF7, T47D and H3396. RT-PCR analysis further demonstrated that this ER- $\alpha$ variant has an inverse expression pattern of the original ER- $\alpha$ in established breast cancer cells. Immunofluorescence microscope analysis showed that this ER- $\alpha$ variant is expressed on the plasma membrane and in the cytoplasm and nucleus of MDA-MB-231 cells. In MDA-MB-231 cells, 17 estradiol (E2 $\beta)$ treatment activated a membrane-initiated effect of estrogen signaling by activating the mitogen-activated protein kinase (MAPK) pathway that led to an increase of cell proliferation and foci formation on soft agar. Antiestrogens such as tamoxifen, 4-hydroxtamoxifen and ICI 182,780 at $10 \mathrm{nM}$ strongly activated the MAPK pathway and stimulated cell growth. However, antiestrogens at higher concentrations $(>5 \mathrm{mM}$ ) arrested cell growth and induced apoptotic cell death. Our findings thus demonstrate a novel ER- $\alpha$ variant that mediates membrane-initiated mitogenic estrogen signaling in ER-negative breast cancer cells, and suggest that aberrant expression of this ER- $\alpha$ variant contributes to development of ER-negative human breast cancer.

\section{4}

Differential overexpressions of EGFR, c-erbB-2, and IGF1R in histological types, nuclear grades, and hormone receptors status of breast carcinoma.

Ueda S, Tsuda H, Sato K, Takeuchi H, Shigekawa T, Mochizuki H. National Defense Medical College, Tokorozawa, Saitama, Japan Although IGF1R and EGFR overexpressions are reported to occur in breast cancer, their pathological significance is still unclear. We examined IGF1R, EGFR, and c-erbB-2 overexpressions immunohistochemically in 150 cases of surgically resected breast cancer and their correlation with the histological type and grade and ER and/or PgR subgroups of primary tumor. To facilitate the analysis, we constructed a tissue microarray comprising $2-\mathrm{mm}$ diameter tissues cored from the representative tissue block of 
each tumor. IGF1R, EGFR, and c-erbB-2 overexpressions were detected in $70(47 \%), 12(8 \%)$, and $23(15 \%)$, respectively. The EGFR was more frequent in the IDCs of solid-tubular type than in other histological types $(\mathrm{P}<0.05)$, and the c-erbB2 was more frequent in DCIS in the group of IDC. On the contrary, the IGF1R was comprehensively overexpressed in the groups of both IDC and DCIS. The EGFR was significantly correlated with nuclear grade $3(\mathrm{P}=0.0005)$, lymph node matastasis $(\mathrm{P}=0.007)$, and tumor size $(\mathrm{P}=0.014)$. The IGF1R was more frequent with nuclear grade $2(\mathrm{P}=0.017)$, while the c-erbB-2 was not correlated with nuclear grades. The correlations with tumor size, lymph node status were not observed for c-erbB-2 and IGF1R. In cases of ER negative and $\mathrm{PgR}$ negative status, the EGFR and c-erbB2 were significantly detected in $12(92 \%)(\mathrm{P}<0.0001)$ and $16(64 \%)(\mathrm{P}=0.0003)$, respectively, while in the cases of ER positive and $\mathrm{PgR}$ positive status, the IGF1R was detected in $41(59 \%)(\mathrm{P}=0.0005)$. The EGFR appeared to be an indicator of breast cancer groups with high-grade or lymph node metastasis. Both EGFR and c-erbB2 appeared to be independent from hormone receptors status, while the IGF1R appeared to depend on hormone receptors status. 


\section{S248 Abstracts - Poster Session VI}

6001

Method of cooking and risk of breast cancer in the Philippines.

Kotsopoulos J, Liede A, De Leon Matsuda ML, Sun P, Narod SA. Sunnybrook and Women's College Hospital, Toronto, ON, Canada; University of Toronto, Toronto, ON, Canada; College of Medicine and Philippine General Hospital, University of the Philippines, Manila, Philippines

Background: Evidence from epidemiological studies suggests that environmental exposures, including lifestyle and dietary factors, play an important role in the etiology of breast cancer. Among Asian countries, the highest age-standardized rates have been reported for the Philippines. The influence of diet and nutrition as possible contributors to these high rates has not been of intense research. Recent epidemiological studies have suggested a relationship between methods of food preparation and the risk of breast cancer. Other studies suggest that dietary intake of added fats and oils from both animal and vegetable sources may also influence the risk of cancer. We examined the possible role of current and adolescent cooking methods and the risk of breast cancer in a case-control study conducted in Manila, Philippines. Materials and Methods: Eligible subjects were women undergoing evaluation at the Philippine General Hospital, Manila for a breast complaint (mass, pain, or nipple discharge). All of the women completed a risk factor questionnaire by personal interview with a research assistant prior to the determination of their case or control status. Information regarding current, as well as usual method of cooking in the household at 12 years of age was obtained. Unconditional logistic regression was used to examine the association between various methods of cooking and the risk of breast cancer. Adjusted odds ratios (OR) and $95 \%$ confidence intervals (CI) are reported.

Results: Boiling food in coconut milk was associated with a significantly increased risk of breast cancer $(\mathrm{OR}=2.2 ; 95 \% \mathrm{CI}$ 1.3-3.8). There were positive associations between boiling food in coconut milk currently $(\mathrm{OR}=1.9 ; 95 \% \mathrm{CI} 1.0-3.3)$, and at 12 years of age $(\mathrm{OR}=2.9 ; 95 \% \mathrm{CI} 1.6-5.5)$, and the risk of breast cancer. A positive association between frying food and breast cancer risk was restricted to women whose household fried food at 12 years of age $(\mathrm{OR}=1.89$; 95\% CI 1.1-3.4).

Discussion: The results of this study suggest that various cooking methods during adolescence (rather than in adulthood) have a substantial influence on the risk of breast cancer, though these findings need to be confirmed. The high content of saturated fat and calories in coconut products, as well as the mutagenic compounds generated from high-temperature cooking, may underlie the increased risks. Primary prevention initiatives that promote healthy lifestyle practices may help decrease the high rates of breast cancer reported for this population of women.

\section{2}

A single gene biomarker identifies undifferentiated breast cancers associated with short duration of breastfeeding. Symmans WF, Fiterman DJ, Anderson SK, Ayers $M$, Rouzier $R$, Dunmire V, Stec J, Valero V, Sneige N, Albarracin C, Wu Y, Ross JS, Wagner $P$, Theriault $R L$, Arun B, Kuerer H, Hess K, Zhang W, Hortobagyi GN, Pusztai L. M.D. Anderson Cancer Center, Houston, TX; Millennium Pharmaceuticals, Inc, Cambridge, MA; Albany Medical College, Albany, NY

Background. The pathogenesis of breast cancers that do not express estrogen receptors or Her-2/neu receptors (ER-/HER2- phenotype) is incompletely understood. We initially observed markedly elevated gene expression of gamma-aminobutyric acid type A (GABAA) receptor pi subunit (GABApi, GABRP) restricted to ER-/HER2- breast cancers in a pilot analysis of cDNA microarrays. Other evidence indicates that GABApi expression is related to endocrine changes during pregnancy and parturition.

Materials and Methods. Transcriptional profiles (TxPs) were obtained from 82 primary invasive breast cancers using oligonucleotide microarrays. Real time reverse transcription polymerase chain reaction (RT-PCR) was used to measure GABApi gene expression in a separate cohort of 121 invasive breast cancers. GABApi gene expression values from TxP and RT-PCR were compared with combined ER and HER2 status and clinicopathologic characteristics in 203 patients.

Results. Elevated GABApi gene expression was identified in $16 \%$ of breast cancers (13/82 TxP, 20/121 RT-PCR), including $60 \%$ of ER-/HER2- breast cancers (13/21 TxP, 18/31 RT-PCR), $60 \%$ of breast cancers in the basal-like genomic category (13/22 TxP), and $72 \%$ of tumors that are both ER-/HER2- and basal-like (13/18 TxP). Genes co-expressed with GABApi in the TxPs are associated with undifferentiated cells. In a multivariate linear regression analysis of main effects, GABApi gene expression was associated with ER-/HER2- phenotype $(\mathrm{p}<0.0001)$, younger age at diagnosis $(\mathrm{p}=0.0003)$, and shorter lifetime duration of breastfeeding $(<=6$ months $)$ in all women $(\mathrm{p}=0.017)$ and specifically in parous women $(p=0.013)$. In a two-way interaction analysis GABApi expression was positively associated with the combination of ER/HER2- phenotype and high grade $(\mathrm{p}=0.002)$, and with the combination of Hispanic ethnicity and high grade $(p=0.036)$. Discussion. GABApi gene expression defines an undifferentiated form of breast cancer that is significantly associated with shorter lifetime history of breastfeeding and with high-grade breast cancer in Hispanic women. This suggests that prolonged breastfeeding is protective from future development of an undifferentiated and estrogen-independent form of breast cancer.

\section{3}

Past exogenous hormone use and current endogenous sex hormone status in postmenopausal women in the EPICNorfolk population cohort.

Chan MF, Khaw KT, on Behalf of EPIC-Norfolk Collaborators, University of Cambridge. Institute of Public Health, University of Cambridge

High endogenous sex hormones are implicated in breast cancer risk. Use of exogenous hormones in the form of oral contraeptives (OC) and hormone replacement therapy (HRT) are also associated with disease risk.

In 1,983 postmenopausal women aged 55 to 81 years not currently on hormones in the EPIC-Norfolk population-based study, we examined the association between past OC and HRT use and circulating endogenous levels of estrogens, androgens and SHBG. In multiple linear regression analyses, past OC and HRT use was independently associated with lower 17-OHprogesterone and testosterone levels, age-matched, and then after adjusting for age, body mass index, parity, ages at menarche and menopause, alcohol and smoking status, and physical activity. Past OC use was also associated with reduced androstenedione and SHBG levels compared to never-OC use, and past HRT with lower testosterone/SHBG ratio compared to never-HRT. In multivariate analysis, both OC and HRT use had independent effects on current testosterone levels.

Conclusion:

Past exogenous hormone use is associated with differences in currrent endogenous hormone levels in postmenopausal women not apparently explained by known confounding factors. This raises questions about long-term and lifelong physiological effects of exogenous hormone use in earlier life. 
Geometric mean and 95\% confidence interval of endogenous hormones and SHBG levels among postmenopausal women by past OC and HRT use Oral contraceptive Hormone replacement therapy Ever use Never use $p$ value Ever use Never use $p$ value

\begin{tabular}{|c|c|c|c|c|c|c|}
\hline Estradiol (pmol/L) & $\begin{array}{l}15.99 \\
(14.95 \\
-17.12)\end{array}$ & $\begin{array}{l}16.61 \\
(15.78 \\
-17.57)\end{array}$ & 0.23 & $\begin{array}{l}16.02 \\
(14.81 \\
-17.34)\end{array}$ & $\begin{array}{l}16.54 \\
(15.71 \\
-17.41)\end{array}$ & 0.41 \\
\hline Estrone (pmol/L) & $\begin{array}{l}71.02 \\
(65.89 \\
-79.12)\end{array}$ & $\begin{array}{l}75.87 \\
(71.24 \\
-76.63)\end{array}$ & 0.09 & $\begin{array}{l}72.46 \\
(66.42 \\
-80.72)\end{array}$ & $\begin{array}{l}74.44 \\
(70.32 \\
-79.28)\end{array}$ & 0.49 \\
\hline $\begin{array}{l}17 \mathrm{OH} \\
\text { Progesterone } \\
(\mathrm{nmol} / \mathrm{L})\end{array}$ & $\begin{array}{l}1.05 \\
(0.99 \\
-1.11)\end{array}$ & $\begin{array}{l}1.11 \\
(1.06 \\
-1.16)\end{array}$ & 0.04 & $\begin{array}{l}1.01 \\
(0.94 \\
-1.08)\end{array}$ & $\begin{array}{l}1.11 \\
(1.06 \\
-1.16)\end{array}$ & 0.003 \\
\hline $\begin{array}{l}\text { Androstenedione } \\
(\mathrm{nmol} / \mathrm{L})\end{array}$ & $\begin{array}{l}2.88 \\
(2.68 \\
-3.09)\end{array}$ & $\begin{array}{l}3.24 \\
(3.06 \\
-3.43)\end{array}$ & 0.001 & $\begin{array}{l}3.01 \\
(2.78 \\
-3.27)\end{array}$ & $\begin{array}{l}3.15 \\
(2.97 \\
-3.33)\end{array}$ & 0.28 \\
\hline $\begin{array}{l}\text { Testosterone } \\
(\mathrm{nmol} / \mathrm{L})\end{array}$ & $\begin{array}{l}0.68 \\
(0.64 \\
-0.73)\end{array}$ & $\begin{array}{l}0.76 \\
(0.72 \\
-0.81)\end{array}$ & 0.002 & $\begin{array}{l}0.68 \\
(0.63 \\
-0.73)\end{array}$ & $\begin{array}{l}0.75 \\
(0.71 \\
-0.79)\end{array}$ & 0.009 \\
\hline SHBG (nmol/L) & $\begin{array}{l}41.34 \\
(39.25 \\
-43.551)\end{array}$ & $\begin{array}{l}44.30 \\
(42.48 \\
-46.15)\end{array}$ & 0.007 & $\begin{array}{l}44.12 \\
(41.51 \\
-46.90)\end{array}$ & $\begin{array}{l}43.21 \\
(41.51 \\
-44.93)\end{array}$ & 0.47 \\
\hline $\begin{array}{l}\text { Estradiol/SHBG } \\
\text { ratio }(/ 1000)\end{array}$ & $\begin{array}{l}0.39 \\
(0.36 \\
-0.42)\end{array}$ & $\begin{array}{l}0.38 \\
(0.35 \\
-0.40)\end{array}$ & 0.49 & $\begin{array}{l}0.36 \\
(0.33 \\
-0.40)\end{array}$ & $\begin{array}{l}0.38 \\
(0.36 \\
-0.41)\end{array}$ & 0.26 \\
\hline $\begin{array}{l}\text { Testosterone/ } \\
\text { SHBG ratio }\end{array}$ & $\begin{array}{l}0.016 \\
(0.015 \\
-0.018)\end{array}$ & $\begin{array}{l}0.017 \\
(0.016 \\
-0.018)\end{array}$ & 0.026 & $\begin{array}{l}0.015 \\
(0.014 \\
-0.017)\end{array}$ & $\begin{array}{l}0.017 \\
(0.016 \\
-0.018)\end{array}$ & 0.012 \\
\hline
\end{tabular}
smoking status, teetotaller status, physical activity

\section{4}

Antidepressants and breast cancer risk: casual link or no cause for concern?

Masry P, George R, Jackman M, Thain D, Walker R, Warner J, Wintonic A, Melinyshyn S, Sunderland C. Queen's University, Kingston, ON, Canada; Hotel Dieu Hospital, Kingston, ON, Canada

Background: There has been debate about antidepressant medications and the development of breast cancer in women. Several studies suggest antidepressants as potential initiators or promoters, while others have supported no correlation. These medications are increasingly being prescribed among women for the management of menopausal symptoms, as well as for depressive illness. As such, it is important to shed light on antidepressant (AD) culpability as a risk factor for breast cancer development. This prospective study extends our previous report from 2003 at the San Antonio Breast Cancer Symposium.

Methods: A prospective cohort study was initiated at a regional breast assessment program accruing 1591 patients referred for investigation of an abnormal mammogram or clinical breast finding. Data included demographic information, antidepressant use, Gail scores, menopausal status, hormonal therapy and family history. Biopsy results, imaging reports, receptor status and staging information were collected on follow up. Nonparametric data was analyzed with the Chi-square test and parametric data with the Student's t-test. All patients were followed to a diagnosis of cancer or the confirmation of benign disease.

Results: Of 1591 women, 595 were found to have invasive cancer or DCIS. $27.2 \%$ of all women referred were current or previous users of AD. Among those found to have breast cancer $27.1 \%$ were AD users, compared to $27.3 \%$ in those with benign disease; no difference $(\mathrm{p}=0.960)$. AD class (selective antidepressants versus tricyclic antidepressants - no patient reported MAOI use) could not be correlated with the diagnosis of cancer, nor did antidepressant use or class of antidepressant used relate to the receptor status of those found to have breast cancer.

Conclusions: A high proportion of women referred for breast assessment were or had been prescribed antidepressant medications (27.2\%). There was no correlation between the use of antidepressants, or any class of $\mathrm{AD}$ and the diagnosis of breast cancer. Similarly, AD use did not influence the receptor status among women found to have a cancer.

\section{5}

Pilot study of changes in mammographic density in women treated with letrozole or placebo on NCIC CTG MA17.

Vachon CM, Ingle JN, Scott CG, Olson JE, Goss PE. Mayo Clinic College of Medicine, Mayo Clinic, Rochester, MN; Harvard Medical School, Boston, MA

Background: Mammographic density in healthy women has been associated with breast cancer risk. It is also known to be reduced by the anti-estrogen tamoxifen and to increase in women on hormone or estrogen replacement therapy. Changes in mammographic density in women on aromatase inhibitors (AI) could be a marker of efficacy and a surrogate of response to treatment or a preventative effect. To examine mammographic density in response to AI therapy, we examined the influence of letrozole (LET) on mammographic density in a subset of women enrolled on the NCIC CTG MA-17 clinical trial.

Methods: MA-17 randomized 5187 postmenopausal women to receive LET or placebo (PLAC) after 5 years of tamoxifen. Women enrolled at Princess Margaret Hospital or the Mayo Clinic were eligible for this study. Eligible participants had one intact non-cancerous breast, a mammogram available before discontinuing TAM and at least one mammogram post randomization to LET or PLAC. Percent mammographic density $(\%)$ and absolute density $\left(\mathrm{cm}^{2}\right)$ were estimated on the craniocaudal views of the noncancerous breast using the Cumulus program developed at the University of Toronto. Age, weight and height at each mammogram, tumor stage and nodal involvement were abstracted from medical records. Change in mammographic density over time was compared between the LET and PLAC groups using a mixed model repeated measures approach adjusting for the abstracted variables.

Results: 57 women randomized to LET and 48 to PLAC were eligible for this pilot study. $17 \%$ of women had two mammograms available for review; $67 \%$ had three mammograms and $16 \%$, four or more. Mean age, weight, height, body mass index (BMI), percent and absolute density at first mammogram (while on TAM prior to entry on MA.17) were similar between the LET and PLAC groups. Adjusted for age, BMI, tumor stage and nodal status, there was a greater decrease in percent density per year for women on LET (0.55 per year) vs. women on PLAC (-0.07 per year), but this difference was not statistically significant $(\mathrm{p}=0.33)$. Similar, but more pronounced differences were seen for absolute density; women on LET experienced a $-0.29 \mathrm{~cm}^{2}$ decrease in absolute density per year while women on PLAC experienced a $0.10 \mathrm{~cm}^{2}$ increase per year $(p=0.10)$. There was no evidence to suggest that these associations differed by categories of BMI or age.

Conclusion: Women transitioning from TAM to LET in this pilot study experienced greater decreases in mammographic density than TAM to PLAC, supporting the hypothesis that LET decreases mammographic density. The decreases observed did not achieve statistical significance, likely because of the small sample size, and a larger study examining the AI and mammographic density association is being conducted.

\section{6}

Influence of family history on breast cancer risk in women with biopsy-confirmed benign breast disease: results from the Nurses' Health study.

Collins LC, Baer HJ, Tamimi RM, Connolly JL, Colditz GA, Schnitt SJ. Beth Israel Deaconess Medical Center and Harvard Medical School; Brigham and Women's Hospital; Harvard School of Public Health; Harvard Center for Cancer Prevention, Boston, MA

Background: Prior clinical and epidemiologic studies have demonstrated an association between histologic category of benign breast disease (BBD) and risk of subsequent cancer. However, the influence of a positive family history of breast cancer on breast cancer risk among women with biopsy-confirmed BBD is less certain. 


\section{S250 Abstracts - Poster Session VI}

Methods: To address this issue, we conducted a case-control study of benign breast disease and breast cancer risk nested within the Nurses' Health Study and the Nurses' Health Study II. Cases were women with breast cancer who had a previous confirmed benign breast biopsy $(n=353)$. Controls were women who also had a previous biopsy-confirmed diagnosis of benign breast disease, but who were free from breast cancer at the time the corresponding case was diagnosed $(n=1495)$. Controls were matched to cases on year of birth and year of benign breast biopsy. Histologic sections of the benign breast biopsies were reviewed and categorized as showing either non-proliferative lesions, proliferative lesions without atypia, or atypical hyperplasia (AH).

Results: Among all women with BBD, those with a family history of breast cancer in a first-degree relative (mother or sister) had an increased breast cancer risk when compared with women without a family history (multivariate O.R. 1.58; 95\% CI, 1.14-2.19). Compared to women with non-proliferative lesions and no family history, women with proliferative lesions without atypia and a positive family history had a slightly higher breast cancer risk (multivariate O.R. 2.68; 95\% CI, 1.67-4.29) than those without a family history (multivariate O.R. 1.55, 95\% CI, 1.14-2.12), and this difference approached statistical significance $(p=0.06)$. In contrast, a family history of breast cancer did not significantly increase the risk among women with $\mathrm{AH}$. The multivariate O.R. for the development of breast cancer was 4.55 (95\% CI, 3.046.83) for women with $\mathrm{AH}$ and no family history and 5.50 (95\% CI, 2.76-10.95) for those with $\mathrm{AH}$ and a positive family history $(\mathrm{p}=0.64)$. Moreover, among women with $\mathrm{AH}$, those with a family history were at only a non-significant $14 \%$ greater risk compared to those with no family history.

Conclusions: We conclude that in this case-control study, a family history of breast cancer in a first-degree relative slightly increased the breast cancer risk among women with proliferative lesions without atypia, but did not further increase the risk among those with atypical hyperplasia.

\section{7}

Ultra-sensitive GC/Tandem mass spectrometry assay for estradiol measurements in post-menopausal women.

Santen RJ, Demers LM, Ohorodnik SK, Settlege JA, Langecker P, Wang S. University of Virginia, Charlottesville, VA; Penn State, Hershey, PA; Taylor Technologies, Princeton, NJ; Intarcia Therapeutics, Emeryville, $C A$

Pooled data from 9 separate studies (JNCI 94:606-16, 2002) reported that a single plasma estradiol (E2) level predicted the risk of developing breast cancer over the ensuing years (2.0 to 12.1 years median) in postmenopausal ( $\mathbf{p m})$ women. A notable aspect of the pooled analysis was that the median E2 levels from the 9 studies ranged from a high of $40 \mathrm{pg} / \mathrm{ml}$ to a low of $6.3 \mathrm{pg} / \mathrm{ml}$. Such variations in the normal ranges of E2 in pm women conclusively demonstrate that currently available E2 assays for post-menopausal women are insufficiently sensitive and specific to reproducibly measure actual circulating E2 levels. A critical need is to develop new, valid, ultra-sensitive assays of E2 to predict who will develop breast cancer.

The current study examined an ultra-sensitive, gas chromatographic, triple derivative, tandem mass spectrometry assay (GC/MS) for use in pm women. Validation included assessment of precision, recovery and sensitivity as well as correlation with biologic parameters (i.e BMI and \% suppression of plasma E2 with aromatase inhibitors).

The sensitivity of the GC/MS assay is $0.6 \mathrm{pg} / \mathrm{ml}$ ( $1 \mathrm{ml}$ sample). Precision for between assay measurements at levels of $0.8,5$, and $20 \mathrm{pg} / \mathrm{ml}$ were $8 \%, 6 \%$ and $6 \%$ respectively (within assay). Recoveries of added E2 in samples with varying levels of E2 were $105 \%, 96 \%$ and $102 \%$ respectively and linearity of recovery of added E2 was $\mathrm{r}=0.9977$.

Basal levels of E2 in 30 normal postmenopausal women were $7.26 \pm 4.82 \mathrm{pg} / \mathrm{ml}(\mathrm{SD})$. With the GC/MS assay and $11.9 \pm 12.0 \mathrm{pg} /$ $\mathrm{ml}(\mathrm{SD})$ with a previously characterized radioimmunoassay. For
55 women with breast cancer the mean level of E2 with the GC/ MS assay was $5.88 \pm 3.43(\mathrm{SD}) \mathrm{pg} / \mathrm{ml}$. Correlation of the GC/MS assay with BMI was $r=0.674$ versus a range of $r=0.14$ to 0.574 with 7 different RIA methods.

Both RIA and GC/MS assays were used to assess the levels of E2 during administration of the aromatase inhibitor atamestane, plus the antiestrogen toremiphene or the aromatase inhibitor letrozole alone. No differences were detected between groups and accordingly, data were pooled. Mean levels for the women on aromatase inhibitors were less than $0.6 \mathrm{pg} / \mathrm{ml}$ when measured by GC/MS (119 of 120 samples undetectable) and by RIA, mean levels were 8.8 $\mathrm{pg} / \mathrm{ml}$. The degree of suppression with aromatase inhibitors was $89 \%$ if assessed by GC/MS and only $49 \%$ by RIA. Using the "gold standard" isotope kinetic method, the reported level of suppression is $97-99 \%$ \% for third generation aromatase inhibitors which correlates best with the GC/MS. Taken together, these data suggest that the GC/MS assay is a superior method for analysis of E2 in pm women and should now be used in a prospective study to predict the risk of breast cancer.

\section{8}

Unilateral congenetial breast abnormalities and laterality of breast cancer.

Olsson HL, Luts L, Anderson H. University Hospital, Lund, Sweden Background:

Congenital abnormalities have in some instances been related to cancer risk such as double ureters and lack of testicular descent (chryptorchism). In the present study unilateral congenital breast abnormalities have been related to which side the breast cancer presents.

Material and Methods: Consecutive women with breast cancer $(n=1578)$ at the Department of Oncology, University Hospital, Lund, Sweden were questionned and examined about congenital breast abnormalities. Unilateral abnormalies were related to the laterality of the breast cancer.

Results: Twelve women displayed a unilateral congenital nipple retraction, confirmed by clinical investigation at breast cancer diagnosis. In all cases the woman underlined that the inverted nipple had been present since birth/childhood. In three cases a unilateral breast hypoplasia were present. Extra mammary tissue (breasts) were found in 5 cases. Presence of extra nipples was not assessed.

Among the cases with inverted nipples, the tumor developed in all cases on the inverted nipple side, 12/12, $\left(\mathrm{p}=0.5^{12}=0.00024\right)$. Also among the women with hypoplasia, the tumor developed on the same side, while there was no relationship between extra breast tissue and breast cancer laterality.

Discussion: The findings suggest that breast tumors more often develop in a breast that either is hypoplastic or has a congenitally inverted nipple. The reason could be that the breast fails to differentiate leaving a larger proportion of epithelial stem cells or progenitor cells prone to carcinogenesis. Patho-anatomic investigations to elucidate this are underway.

\section{9}

The relationship between serum cholesterol level and axillary lymph node statu in breast cancer patients. Utkan G, Onur H, Akbulut H, Yalcin B, Buyukcelik A, Tek I, Doruk H, Dogan M, Demirkazik A, Icli F. Ankara University School of Medicine, Ankara, Turkey

BACKGROUND: Estrogen is known to decrease total cholesterol and low density lipoprotein levels whereas it increases high density lipoprotein level. The aim of the study is evaluation of the association between serum total cholesterol level, tumor size and axillary status.

MATERIAL and METHOD: In this retrospective study, 150 patients who underwent breast cancer surgery and adjuvant chemotherapy were evaluated for axillary lymph node status, tumor size and serum total cholesterol level. Measurement of 
serum total cholesterol level within 3 months before or after cancer surgery was accepted as reference value. Body mass index (BMI) was calculated for all patients. None of them had hypothyroidism, hyperthyroidism, diabetes mellitus and alcohol abuse. Level above $200 \mathrm{mg} / \mathrm{dL}$ for serum total cholesterol was defined as hypercholesterolemia.

RESULTS: Characteristics of patients are listed in Table 1. BMI was found significantly associated with age, menopausal status and total cholesterol level $(\mathrm{p}=0,0001, \mathrm{p}=0,012, \mathrm{p}=0,038$; respectively). There was no correlation between serum total cholesterol level and number of resected axillary lymph nodes $(p=0,069)$. Number of positive axillary lymph nodes was inversely correlated with serum total cholesterol level ( $\mathrm{r}:-0,189, \mathrm{p}=0,022)$. Serum total cholesterol level was determined as an independent prognostic factor for evaluating number of positive axillary lymph nodes in multivariate analysis $(\mathrm{p}=0,01)$. The relationship between high serum total cholesterol level and number of positive axillary lymph nodes is shown in Table $2(\mathrm{p}=0,05)$.

CONCLUSIONS: Despite small number of patients in this study, we found an inverse correlation between serum total cholesterol level and number of positive axillary lymph nodes. The effect of BMI in breast cancer is known. But relation with total cholesterol level, axillary involvement and the effect on survive, should experienced by large number of studies. Table 1; Characteristics of patients (median values) Age (year)

umor size $(\mathrm{cm})$

Total number of resected axillary lymph nodes

Number of positive axillary lymp nodes

BMI $(\mathrm{kg} / \mathrm{m} 2)$

Serum total cholesterol level $(\mathrm{mg} / \mathrm{dL})$

Premenopausal / postmenopausal $(\%)$

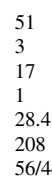

Table 2; The relationship between serum total cholesterol level and number of positive xillary lymph nodes. AXILLARY LYPMH

72,2

38,5

\section{0}

Association of manganese superoxide dismutase (MnSOD) gene polymorphism and breast cancer in males and females. Bica CG, Silva LLM, Toscani NV, Da Cruz, IBM, Graudenz MS. FFFCMPA, Porto Alegre, Rio Grande do Sul, Brazil

Background: One of the several metabolic pathways involved in breast carcinogenesis is the human polymorphism $A A$ in the mitochondrial targeting sequence Val16Ala of the manganese superoxide dismutase $(M n S O D)$ gene, which has previously been associated with an increased risk of breast cancer in females. Since there's no previous report on the MnSOD polymorphism in males with breast cancer, the objective of this study is to analyse the $M n S O D$ polymorphism in a population of male breast cancer from the southernmost state of Brazil, compared to healthy controls and to female breast cancer.

Methodology: A case-control study of 100 patients affected by breast cancer (11 men and 89 women) and 370 healthy ageadjusted data-base controls (153 men and 217 women) was performed. DNA was extracted from peripheral blood and paraffinembedded tumoral tissue and $M n S O D$ polymorphism was determined by PCR-RFLP techniques using restriction enzyme Hae III. Chi-square test was used to compare the MnSOD frequencies distribution.

Results: $M n S O D$ genotypes and allele frequencies for all patients with breast cancer were $\mathrm{AA}=15 \%, \mathrm{AV}=56 \%$ and $\mathrm{VV}=29 \%$. Either male or female patients with breast cancer presented significantly higher $A A$ frequencies compared to controls $(\mathrm{p}=0,035)$, suggesting a strong association of this genotype with breast cancer. A 2.15fold (95\% CI 1.393-4.541) risk of breast cancer was found among individuals carrying the $M n S O D A A$ allele-containing genotypes compared with the $M n S O D V V$ genotype.Discussion: These results confirm the already established association of the MnSOD AA genotype with female breast cancer and further indicates a similar frequency distribution and increased risk in the male population. Our study supports the idea that although gender differences may influence breast carcinogenesis through different pathways, $M n S O D$ polymorphism seems to share the same role in both genders.

\section{1}

Ductal carcinoma in situ and risk factors for breast cancer: can we target individuals for surveillance?

Saettler ER, George R, Thain D, Walker R, Warner J, Wintonic A, Melinyshyn S, Sunderland C. Queen's University, Kingston, ON, Canada; Hotel Dieu Hospital, Kingston, ON, Canada

Background: Ductal carcinoma in situ (DCIS) is recognized as a precursor to breast cancer. Overall 10 year survival rates after treatment approaches $97 \%$. The purpose of this study was to investigate the risk factors associated with a presentation of DCIS, to more effectively identify people for surveillance strategies.

Methods: New referrals with a breast complaint (abnormal imaging, symptom or finding) were administered a pre-assessment questionnaire. Patients were asked age, reproductive/menstrual history, medications, hormonal use, previous breast health and detailed personal/family histories were obtained. Gail scores were calculated. Patients were followed to a diagnosis of benign, malignant or in situ disease. $\mathrm{N}=1223$

Results: Of 1223 patients $753(61.5 \%)$ had benign and 470 (38.5\%) a malignant diagnosis. DCIS accounted for $16 \%$ of the latter group. There was no age difference between people with DCIS and infiltrating cancer (mean ages 58 and 57), but noncancer patients were significantly younger (mean age 49.7, $\mathrm{p}=0.001) .52 \%$ of DCIS patients had elevated Gail scores $(>1.67$ as per NSABP P.1 prevention trial), compared to $41 \%$ of the invasive and only $27 \%$ of the benign groups $(\mathrm{OR}=3.05, \mathrm{p}=0.0001)$. Also significantly associated with a diagnosis of DCIS were prior breast biopsies $(51 \%$ of DCIS group, $\mathrm{OR}=3.15, \mathrm{p}=0.005)$, family history in first-degree relatives (35\% of DCIS group, OR $=1.77$, $\mathrm{p}=0.002)$, and prior breast cancer $(\mathrm{p}=0.001)$.

Conclusions: Careful assessment of individual risk factors, including Gail scores, prior biopsies and significant family history, identified the majority of DCIS patients in this series as having been at risk for breast cancer. While completely sporadic cases occur, this series challenges the notion that a majority of cases will have no identifiable risk factors.

\section{2}

Morphological and immunohistochemical aspects of the breast tissue in postmenopausal women before and after hormone replacement therapy.

Elias S, Dardes RC, Baracat EC, Logullo AF, Kemp C. Federal University of São Paulo, São Paulo, Brazil

Background: Estrogen replacement therapy isolated or combined with progestin is still a controversial issue and most studies associate with increased risk of breast cancer after hormone replacement therapy for over 5 years. However, despite this important evidence, not much is known about the mechanisms by which hormones act on normal breast epithelium. In this study breast tissue of postmenopausal women was analyzed before and after 6 months of continuous combined estrogen-progestin replacement therapy. Material and Methods: The normal breast tissue (48 samples) was obtained from the upper outer left quadrant, through a percutaneous large-core breast biopsy. Epithelial density and nuclear volume on hematoxylin-eosin stained plates were evaluated for the morphological study. Morphometry was graphically analyzed with the use of IMAGELAB 2000 software, after acquisition of a microscopic image by the VIDCAP 32 system. In addition, we evaluated the epithelial proliferative activity through the monoclonal antibody $\mathrm{Ki}-67$, the expression of the estrogen and progestin receptors and the stroma, using CD-34 antibody, an angiogenic marker. Results: After 6 months of estrogen-progestin 


\section{S252 Abstracts - Poster Session VI}

replacement therapy, there was a significant increase in nuclear volume, in late postmenopausal women. There was no difference in epithelial density, neither in Ki-67 labelling index and CD34 marker. Additionally, estrogen and progestin receptors did not change with the treatment. Discussion: As a conclusion, estrogenprogestin combined replacement therapy for 6 months induced an enhanced in nuclear volume of breast epithelial cells, suggesting an increase in their metabolic activity. However, it is important to emphasis that this finding was observed only in late postmenopausal women. The increased nuclear volume could precede others events that confirm the stimulation of cellular proliferation by these hormones. Certainly, factors such as duration of treatment, type of hormone therapy, the timing of hormone initiation, the treatment regimen used and individual characteristics interfere directly in the response of the breast epithelium and stroma to hormonal therapy.

\section{3}

Transfer of lipids to HDL in patients with breast cancer. Grazianni SR, Hegg $R$, Morikawa A, Puk CG, Vinagre $C G$, Maranhao RC. Heart Institute-USP, Sao Paulo, Brazil; University of Sao Paulo, Sao Paulo, Brazil

Background: Neoplastic diseases are often accompained by changes on lipid metabolism, such as alterations in the plasma concentration of lipoproteins. Lipoproteins are constantly being remodeled, and transfer proteins such CETP and PLTP shift cholesterol esters (CE), phospholipids (PL) and triglycerides (TG) from one to other lipoprotein class. Free cholesterol (FC) can freely diffuse from the lipoprotein particle although PLTP may accelerate its transfer. The characterization of these changes is relevant for the understanding of some pathophysiological mechanisms of cancer. In this study, we use a simple method of measuring the transfer rates from an artificial lipoprotein model to HDL in subjects with or without breast cancer (BC).

Material and Methods: Twenty five BC patients aged 58 2 years and 14 paired controls were studied. Blood samples were collected and plasma aliquots $(200 \mathrm{~m} \mathrm{~L})$ were incubated with an artificial nanoemulsion labeled with ${ }^{3} \mathrm{H}-\mathrm{TG}$ and ${ }^{14} \mathrm{C}-\mathrm{FC}$ or ${ }^{3} \mathrm{H}-\mathrm{CE}$ and ${ }^{14} \mathrm{C}$-PL. After precipitation of nanoemulsion and apoBcontaining lipoproteins, the supernatant containing HDL was counted for radioactivity. Total and HDL cholesterol, and triglycerides levels were determined through the enzime colorimetric method. LDL and VLDL cholesterol were calculated by the Friedewald formula.

Results: The BC group shows lower levels of total, LDL and HDL cholesterol, and triglycerides when compaired to the control group $(\mathrm{p}<0,05)$. However, the transfer of PL, TG, FC from the nanoemulsion to HDL were greater in $\mathrm{BC}$ group when compaired to control group $(\mathrm{p}<0,01)$.

Discussion:

Hypocholesterolemia due to low LDL as well as low HDL levels were rather commom findings in $\mathrm{BC}$ group patients. Those results are possibly related to the increased need of lipids for synthesis of new membranes required by the cell proliferation. Transfer of nanoemulsion lipids to HDL were increased in BC, except $\mathrm{CE}$. Further studies concerning elevated lipids transfer rates in $\mathrm{BC}$ patients will be evaluated in the future.

\section{4}

Risk factors in breast cancer, a myth - an Indian experience. Pant CS, Tandon A. Col Pant's Imaging Centre, New Delhi, Delhi, India

\section{OBJECTIVE:}

An array of breast cancer risk factors have been established over the years, which include age of patient, family history, parity, age at first childbirth, no breast feeding, smoking, non-vegetarian diet and Hormone Replacement Therapy. Considering these factors Indian women would fall in low risk group as most women here have an early marriage, early childbirth, breast feed for more than six months, are vegetarians and non smokers. Surprisingly, though, the incidence of breast cancer is moderately high in Indian population. Hence, this study was conducted to determine the validity of established breast cancer risk factors in Indian population. MATERIALS \& METHODS:

We retrospectively reviewed 449 cases of breast cancer ( 240 freshly diagnosed \&159 on follow up) for the presence on absence of risk factors. Additional, 200 cases with benign breast disease were taken as control. The risk factors included in the study were age, parity, age at first childbirth, duration of breast feeding, smoking, non vegetarian diet, family history \& Hormone replacement therapy. A univariate \& multivariate statistical analysis was then performed on data from both study groups.

RESULTS:

Only $5.8 \%$ of Indian women with breast cancer were childless and $13.2 \%$ had their first child after 30 years. On the contrary $86.8 \%$ had their first child before 30 yrs with as many as $13 \%$ having had it before 20 years of age. Age at first childbirth was, thus, not significantly associated with breast cancer ( $p$ value 0.457 ). Lack of breast feeding again was not statistically a significant risk factor. About $80 \%$ of women had breast fed their babies with as high as 40 $\%$ having breast fed for about one year. A large number of women with breast cancer were vegetarians $(61.7 \%)$ and non smoker (95.1\%). Hormone replacement therapy (HRT) again was not statistically significant risk factor ( $\mathrm{p}$ value 0.537 ), only $8 \%$ of cancer group had taken HRT.

Age of the patient ( $\mathrm{p}$ value 0.000 ) and family history ( $\mathrm{p}$ value .007) came up as the only two significant risk factors. The risk of breast of breast cancer was nearly two times greater in women over $50 \mathrm{yrs}$ in comparison to those $<35 \mathrm{yrs}$ (ODDS ratio 1.86, 95 $\%$ confidence interval (CI) $0.879-3.957$ ). Women with family history had 1.8 times more risk of breast cancer (ODDS ratio $1.78,48,95 \%$ CI $1.126-2.712$ )

CONCLUSION:

In Indian population, except for patient age and family history none of the other established risk factors had any positive association with breast cancer. Hence, we conclude that all these risk factors are a myth.

\section{5}

The effect of the oral contraceptive pill on prognosis and survival in women with breast cancer.

Clarke E, Haji A, Kalimuddin S, Hajduga V, Bates T. William Harvey Hospital, Ashford, Kent, United Kingdom

Aim

To determine whether the oral contraceptive pill (OCP) has an effect on the prognosis, age of diagnosis and survival in women with breast cancer.

\section{Methods}

The hospital cancer database was analysed to identify women who had been diagnosed with breast cancer between 1990 and 1999 1116 women were identified and divided into two groups, never users of the OCP (Group 1, $n=665$ ), and current or previous users of the OCP (Group II, $n=423$ ). Tumour prognostic factors were compared for both groups using non parametric t tests. Five year Breast cancer specific survival (BCS), Disease Free Survival (DFS) and Overall Survival (OS) were compared between the two groups using Kaplan-Meir Survival analyses.

Results

We identified 665 women in Group 1 and 423 in Group II. There were more patients in Group II with Grade III tumours when compared with Group $1(\mathrm{p}=0.02)$. Evaluation of the other prognostic factors revealed no significant difference between the two groups. There was a significant correlation between the age of first starting the pill and the age of diagnosis of breast cancer $(\mathrm{p}=<0.01)$, with age of first pregnancy not acting as a counfounding factor $(\mathrm{p}=0.63)$. There were no significant differences in BCS $(p=0.57)$ and DFS $(p=0.97)$, however overall survival was improved in the "ever users" of the OCP compared with "never users" $(\mathrm{p}=<$ $0.01)$. 


\section{Conclusion}

Use of the OCP is not associated with a worse prognosis and survival in breast cancer and may lead to less clinically advanced disease. However, we observed that the earlier the pill was started, the earlier the age of diagnosis of breast cancer.

\section{6}

Prediction of axillary sentinel node status: study of a large single institution series of breast cancer patients.

Zurrida S. European Institute of Oncology, Milan, Italy

Background: Sentinel node biopsy (SNB) has emerged as a powerful predictor of axillary status and can spare axillary dissection when the sentinel nodes (SN) are disease free. Identification of reliable predictors of SN metastases would enable selection of patients for SNB, sparing those at very low risk of axillary involvement.

Materials and Methods: We examined clinical and pathologic characteristics in 4351 consecutive patients with primary invasive breast cancer who had SNB from 1996 to 2003 at the European Institute of Oncology. Mean age was 54.7 years, range: 24-85. Logistic regression was used to assess relations between characteristics and presence of SN metastases. Variables significantly associated with SN involvement by univariate analysis were included in a multivariate model.

Results: SN metastases were found in 1446 (33.2\%) patients. The SN(s) were the only involved axillary nodes in $766(57.3 \%)$ By multivariate analysis, presence of $\mathrm{SN}$ metastases was directly associated with tumor above $1 \mathrm{~cm}(\mathrm{P}<0.0001)$, multifocality $(\mathrm{P}<0.0001)$ and presence of perivascular invasion $(\mathrm{PVI})$ $(\mathrm{P}<0.0001)$, and inversely associated with favorable histotypes $(\mathrm{P}=0.0007)$ and lack of progesterone receptors $(\mathrm{P}=0.004)$. PVI was the most powerful predictor of $\mathrm{SN}$ metastases with odds ratio of $5.26(95 \%$ CI $4.44-6.23)$

When patients were stratified according by a predictive model of features associated with SN status (tumor size, histotype type, focality and presence of PVI) lowest risk of SN metastases (10.1\%) was in patients with favorable histology, tumors up to $1 \mathrm{~cm}$, without PVI ( $\mathrm{n}=178,4 \%$ of population); highest risk $(77.2 \%)$ was in those with tumors $>2 \mathrm{~cm}$ and PVI ( $\mathrm{n}=250,5.7 \%$ of population); all other combinations had intermediate risk of SN involvement. Discussion: Tumor size and PVI emerged as the most powerful independent predictors of SNN metastases. However no combination of features identified patients with risk of SN metastases below $10 \%$, we therefore conclude that SNB should continue to be offered to all eligible patients.

\section{7}

Telomere DNA content and allelic imbalance predict disease-free survival and define field cancerization in histologically normal tissue adjacent to breast tumors.

Heaphy CM, Bisoffi M, Fordyce CA, Haaland-Pullus CM, Hines WC, Joste NE, Mangalik A, Griffith JK. University of New Mexico, Albuquerque, NM; University of California at San Francisco, San Francisco, $C A$

Purpose: Cancer arises from mutations that promote the selection of cells with increasingly malignant phenotypes. Previous studies show genomic instability is a driving force behind this process. One mechanism leading to genomic instability is loss of telomere function. Telomeres are specialized nucleoprotein complexes that protect the ends of chromosomes from degradation and end-toend fusion. Genomic instability has been shown to occur in histologically normal tissue adjacent to breast tumors. The purpose of this study was to identify fields of histologically normal, yet genetically unstable cells within breast tissues. We measured telomere DNA content (TC) and allelic imbalance (AI) at defined distances from breast tumor margins, and tested the hypothesis that TC correlates with breast cancer progression.

Methods: The present study included three independent cohorts of breast tissues. The first cohort consisted of normal, disease- free breast tissue obtained from reduction mammoplasties $(n=20)$. The second cohort consisted of archival breast tumors $(n=38)$ and their matched tumor adjacent histologically normal tissues. The third cohort consisted of breast tumors $(\mathrm{n}=11)$ with matched histologically normal tissues excised at $1 \mathrm{~cm}$ and $5 \mathrm{~cm}$ from the tumor margins. TC was measured by chemiluminescence hybridization and AI was determined by multiplex PCR analysis of 16 microsatellite loci. Survival curves were generated by Kaplan/ Meier Log Rank analysis. Associations between TC, AI and tissue site were analyzed by Wilcoxon/Kruskal Wallis Rank Sums test. Results: The distributions of TC and AI in tumor adjacent histologically normal tissues resembled that of their matched tumors, rather than the normal, disease-free breast tissues. TC was associated in tumors with disease recurrence within 84 months of surgery $(p=0.012)$ and with time of disease-free survival $(p=0.017)$. TC was also associated with recurrence and time of disease-free survival in tumor adjacent histologically normal tissues $(\mathrm{p}=0.025$ and $\mathrm{p}=0.006$ ). Tissues from the third cohort showed TC and AI differed as a function of distance from the tumor margin $(\mathrm{p}=0.0003$ and $\mathrm{p}=0.0066$, respectively).

Conclusions: Our study shows that TC is a prognostic marker of disease recurrence in breast cancer. In addition, our data indicate that telomere attrition occurs early in fields of breast tissues, including histologically normal areas; and leads to genomic instability, which represents a fertile ground for the malignant transformation. The finding that markers of genomic instability occur in fields of histologically normal tissues is of practical importance, as it has implications for the definition of appropriate tumor margins and the assessment of recurrence risk factors in the context of breast-sparing surgery.

\section{8}

Validation of reference genes for relative real time PCR to study hormone-dependent gene expression in breast cancer biopsies.

Larionov AA, Dixon JM, Krause A, Evans DB, Miller WR. WGH, Edinburgh, United Kingdom; Novartis Pharma AG, Basel, Switzerland

Background: Relative gene expression measurement by realtime quantitative PCR (qPCR) is widely used in breast cancer research and may soon come into clinical practice. Because of the relative nature of the quantitation, appropriate selection of reference genes is essential for qPCR interpretation and reproducibility. So far there have been no reports directly addressing stability of expression of different reference genes in breast cancer biopsies during hormonal treatment. In the present study the stability of 10 potential reference genes was compared in ER+ve breast cancer biopsies before and after neoadjuvant treatment with the aromatase inhibitor letrozole.

Methods: The potential reference genes were selected using microarray data along with literature searches. Stability of their expression was then validated using $\mathrm{qPCR}$. The microarray data were based on patients receiving neoadjuvant letrozole (Miller 2005). The genes were ranked by a stability score accounting for both (i) overall coefficient of variation and (ii) individual variation before and after treatment. Five genes technically optimal for qPCR detection (consistently annotated gene structure, no pseudogenes, no alternative splicing etc) were selected among the most stably expressed ones. Five other candidate reference genes were added from the literature: (i) three common reference genes: ACTB, GAPDH and TBP (TBP was selected due to the high stability rank in the microarrays) and (ii) two other genes that have been specifically recommended for use in breast cancers: MRPL19 and PUM1 (Szabo 2004). qPCR validation of candidate reference genes was performed using a separate group of 19 patients. Stability of gene expression in qPCR was estimated by two different methods (Vandesompele 2002, Szabo 2004).

Results: Both methods placed the genes in the following order according to the stability of their expression (from most stable to the least stable): KIAA0674, TBP, PUM1, FLJ10385, SNX11, 


\section{S254 Abstracts - Poster Session VI}

MRPL19, GAPDH and ACTB. Due to sub-optimal performance in qPCR, MSH3 and MYL4 were excluded from assessment. Discussion and Conclusions: There is no universal reference gene that is stably expressed in all experimental systems. Instead, reference genes should be validated for each experimental system individually. Ideally an average of 2 or 3 carefully validated genes should be used to normalize expression of target genes in qPCR (Vandesompele 2002). Our results show that in breast cancer biopsies ACTB and GAPDH have the less stable expression among all studied potential reference genes. It confirms that these genes traditionally used as positive controls in qualitative studies may not be optimal as references for quantitative measurements. The most stable expression was observed for KIAA0674, TBP and PUM1. The geometric average of these genes may be recommended for normalization in $\mathrm{qPCR}$ to study hormonedependent gene expression in breast cancer biopsies in the neoadjuvant setting.

\section{9}

Molecular risk estimation and adjuvant chemotherapy in node-negative breast cancer patients - a status report of the prospective clinical trial NNBC 3-Europe.

Herbst F, Paepke D, Gauger K, Gaskill N, Sweep F, Meisner C, Schmitt $M$, Jaenicke $F$, Thomssen $C$, Harbeck $N$. Universitaetsklinikum Hamburg-Eppendorf, Hamburg, Germany; Technische Universitaet Muenchen, Muenchen, Germany; University Hospital Nijmegen, Nijmegen, Netherlands; Institute fuer Medizinische Datenverarbeitung, Universitaet Tuebingen, Tuebingen, Germany; Martin-Luther-Universitaet Halle, Halle, Germany

Background: Risk assessment in node negative breast cancer patients by the use of the invasion markers urokinase-type plasminogen activator (uPA) and its inhibitor PAI-1 has been demonstrated in several single studies and a large meta analysis. Patients with low uPA and/or PAI-1 tumor levels have an excellent 5 -year overall survival ( $>95 \%$ ) even without any adjuvant therapy. The use of these molecular markers have shown to spare adjuvant chemotherapy in app. one half of all node-negative breast cancer patients. Whereas patients with an intermediate grade tumor can easily be differentiated in low and high risk. In addition, patients with high uPA and/or PAI-1 levels seem to have an enhanced benefit from adjuvant chemotherapy. The NNBC-3-Europe trial seeks to answer two questions:

1) Is risk assessment by the molecular markers uPA/PAI-1 superior to that by clinico-pathological factors with regard to identification of low-risk patients?

2) Is adjuvant chemotherapy using an anthracycline-taxane containing sequence (FEC-Docetaxel) superior to standard FEC in high-risk patients?

Methods: In the NNBC 3-Europe trial, participating centres opt to either perform risk estimation by clinico-pathological factors or by the invasion markers. Low-risk patients will be then observed without adjuvant chemotherapy. High-risk patients are randomised to adjuvant chemotherapy (FEC-100*6 versus FEC-100*3 followed by Docetaxel-100*3). Patients with steroid hormone receptor positive tumors receive an endocrine therapy.

Results: Of the first 312 patients ( 22 centers) in the study arm with the biological risk assessment, 33 had a grade 1 tumors, and 110 had grade 3 tumors. Among grade 2 tumors $(n=169), 64$ had low levels of uPA (med. 0,9ng/mg protein) and PAI-1 (med. 7,9ng/ $\mathrm{mg}$ ); 105 patients presented with elevated values: uPA (med. 3,8 $\mathrm{ng} / \mathrm{mg}$ ) and PAI-1 (med. 21ng/mg). Grade 3 tumors showed uPA at $2,9 \mathrm{ng} / \mathrm{mg}$ and PAI-1 at 20,4ng/mg (med.). Overall, 97 (31\%) of the patients were allocated to the low-risk group.

Conclusion: An adjuvant chemotherapy trial based on uPA/PAI-1 determination in the primary tumor is feasible in a multicenter setting. Applying these molecular markers for risk assessment for almost on third of the patients an adjuvant chemotherapy could be spared. The patient distribution shows to be in line with the expected distribution. The study is planned to recruit 5.700 patients. This study is performed in association with the EORTC Receptor and Biomarker Group and the German AGO Breast Group.

\section{0}

Repeatability and sources of uncertainty in relative real time PCR gene expression measurements in breast cancer biopsies.

Larionov AA, Dixon JM, White S, Anderson TJ, Miller WR. WGH, Edinburgh, United Kingdom

Background: Relative real time PCR is widely used in breast cancer research and potentially may be used for molecular tumour profiling in clinic. At the same time there is lack of publications addressing repeatability of the PCR results in breast cancer biopsies. In present study we evaluated intra-laboratory repeatability of PCR measurements for Cyclin B1 (CB1) and Mammaglobin 1 (MGB1) in core biopsies of breast tumours

Materials and Methods: Paired biopsies were taken from 9 breast tumours. After RNA extraction two separate reverse transcriptions have been performed for each biopsy. Two separate PCRs were run then on each of cDNAs. Therefore 4 measurements were taken for each biopsy ( 8 measurements for each tumor). Coefficients of repeatability $(\mathrm{p}=0.95)$ were calculated according to Bland and Altman (1986). Relative input of sampling, reverse transcription and PCR into results uncertainty was estimated using the analysis of components of variance.

Results: Results are summarised in the figure below (grey and white bars represent PCR measurements on different biopsies). Relative coefficients of repeatability for CB1 and MGB1 were 2.2 times and 15 times correspondingly. Exclusion of the most obvious outliers (circled on the figure) dramatically improved the coefficients of repeatability (to 1.3 and 3.1 times correspondingly). The components of variance analysis showed that just $1 \%$ of the total variance was introduced by PCR, $4 \%$ was introduced by reverse transcription and $10 \%$ was introduced by sampling. $85 \%$ of observed variation reflected true differences between tumours.

Discussion and Conclusions: Currently real time PCR is the most precise method of gene expression measurement. However, the pre-PCR factors (first of all - tumour heterogeneity) may introduce uncertainty in gene expression measurements in breast biopsies. In research studies this uncertainty may be overcome by accumulating appropriate sample size. This can not be applied for individual interpretation of real time PCR measurements for potential clinical purposes. In this case the repeatability coefficients can be applied. For breast cancer biopsies they are gene specific and should be based on a validating series of double biopsies taken from the same tumours. To improve the reliability of measurements the additional criteria for outliner detection may be considered (e.g. stability of reference genes expression or routine use of double biopsies).

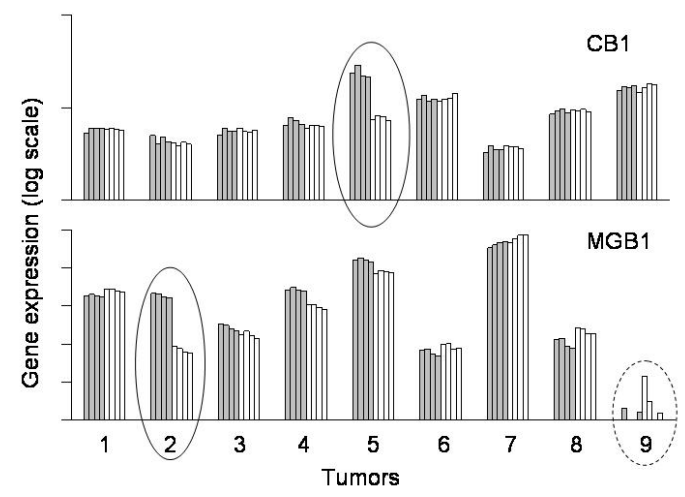




\section{1}

Identification of predictive biomarker panels by computational modeling of treatment responses in breast cancer patients.

Samadzadeh LK, Lett SG, Stella G, Nagle RB, Grogan TM, Beresford PJ, Pestano GA. Ventana Medical Systems Inc., Tucson, AZ; The BioAnalytics Group Inc., Princeton, NJ; University of Arizona Cancer Center, Tucson, AZ

Background: The epidermal endothelial growth factors (EGF) are highly potent growth promoting proteins with effects that include the regulation of normal physiologic processes. However, these factors also promote solid tumor growth and hematological malignancies. The diversity of the families of ligands and receptors and resulting outcomes from EGF signaling have, in part, contributed to the difficulties in identifying robust prognostic and diagnostic candidate biomarkers for targeted therapies. In this report, we have applied computational methods including, high throughput logistic regression models, to determine panels of markers that predict the most likely patient outcomes after treatment with Herceptin ${ }^{\oplus}$.

Materials and Methods: Multi-tissue arrays with 147 evaluable patient samples previously treated with Herceptin ${ }^{\circledR}$ were utilized for these analyses. Molecular biomarkers hypothesized to be expressed in response to the EGF ligands were assessed by immunohistochemistry (IHC). The factors utilized in the development of the computational models included age and pathology reviewed expression of nine markers. Actual survival within this patient group was $41.49 \%$ based on status at last check. We trained the logistic regression model on this data, and compared predicted probabilities of survival with actual outcomes.

Results: We first determined threshold probabilities to separate the patients into two groups. The group above the threshold probability of $45 \%$ was likely to survive post Herceptin ${ }^{\circledast}$ treatment. Patients in the group below this cut-off were unlikely to survive. We were then able to reduce the model to determine panels of markers that may be used to increase the survival responses without excluding a significant number of known survivors. We identified at least one subset panel of markers that may increase the response rate from $41.67 \%$ to $74.07 \%$. Using this panel for stratification would result in the loss of $4.7 \%$ of the patient population actually known to survive.

Discussion: Using logistic regression models to analyze IHC derived tissue microarray data we were able to determine marker panels that were significant in the prediction of survival for patients treated with Herceptin ${ }^{\circledast}$. These methods may be extended for general use in patient stratification for other targeted therapies.

\section{2}

A new rabbit monoclonal antibody (4B5) for the immunohistochemical (IHC) determination of the HER2 status in breast cancer: comparison with CB11, fluorescence in situ hybridization (FISH) and interobserver variability.

Hicks DG, Prescott N, Tarr S, Pettay J, Laniauskas S, Swain E, Grogan T, Roche P, Powell W, Tubbs R, Hartke M. Cleveland Clinic Foundation, Cleveland, OH; Ventana Medical Systems Inc., Tucson, AZ

Background: The two methodologies in current clinical use to assess HER2 status in breast cancer are FISH to evaluate HER2 gene amplification and IHC to detect protein over-expression. While most HER2 gene/protein studies have shown good concordance, a consistent finding has been that from 3\% to $15 \%$ of breast cancers over-express HER2 protein without evidence for gene amplification. The clinical importance of accurate determination of the HER2 status has significant implications for the selection of the most appropriate patients for Trastuzumab ${ }^{\mathrm{TM}}$ therapy. Rabbit monoclonal antibody technology (RMoAb) provides for high-quality IHC reagents with improved sensitivity and specificity. We report here our preliminary experience with a new RmoAb, 4B5, for HER2 IHC.

Materials and Methods: A synthetic peptide from the carboxyterminal domain of the HER2 protein was used to generte a new RMoAb, 4B5, for the evaluation of HER2 status in 201 wellcharacterized breast cancer cases. Staining for 4B5 was performed on a BenchMark XT ${ }^{\circledast}$ automated stainer (Ventana Medical Systems, Inc., Tucson, Az) and scored in a blinded fashion by 3 pathologists (0-3+), for comparison with CB11 staining results (Pathway ${ }^{\circledR}$ ), FISH (PathVysion ${ }^{\mathrm{TM}}$ ), and determination of interobserver reproducibility.

Results: Of the 201 non-consecutive breast cancer cases, 94 were HER2 non-amplified (HER2/CEP17<2), 90 were HER2 amplified (HER2/CEP17>2.3), 10 were low-level amplified (HER2/CEP17=2-2.3). Six cases could not be evaluated due to lack of invasive tumor. Staining results for 4B5 were highly comparable to those obtained for CB-11, and 4B5 demonstrated sharper membrane staining with less cytoplasmic background. Among the HER2 non-amplified cases, 93\% (87/94) were scored as negative with 4B5 $(0-1+)$ with 7 discordant cases $(6$ cases $-2+$, and 1 case - 3+). Among the HER2 amplified breast cancers, $90 \%$ $(81 / 90)$ were scored as $2+$ or $3+$ for $4 \mathrm{~B} 5$ with 9 discordant cases $(5$ cases - 0 , and 4 cases - 1+). 60\% (6/10) of HER2 low-level amplified cases were scored as $2+$ or $3+$ while $40 \%$ were negative $(0-1+)$. Using FISH as the reference standard, the sensitivity for 4B5 was $90 \%(\mathrm{CI}=81.9 \%-95.3 \%)$, specificity was $92.6 \%(\mathrm{CI}=85.3 \%$ $97 \%$ ), and there was very good interobserver agreement for 4B5 interpretation (Kappa 0.831-0.932).

Conclusions: Using FISH as the reference standard, RMoAb 4B5 provides excellent sensitivity, specificity, and interobserver reproducibility for the detection of $H E R 2$ status in breast cancer.

\section{3}

Improvements of breast cancer cure fractions in surveillance, epidemiology, and end results (SEER) estimated using CanSurv software.

Lee S-J, Royce ME, Wallace AM, Chapman JW, Tai P. University of New Mexico Cancer Research and Treatment Center, Albuquerque, NM; National Cancer Institute of Canada-Clinical Trials Group, Queen's University, Kingston, ON, Canada; University of Saskatchewan, Allan Blair Cancer Center, Regina, SK, Canada

Background: Population trends in SEER data provide an assessment of breast cancer survival experience over three decades. We hypothesized that a parametric Mixture Cure Model, on population-based grouped data, might produce results that differ from those obtained with the standard Cox Model.

Materials and Methods: Patients diagnosed with breast cancer were abstracted from SEER-9 registries from 1973-2002 to study the cause-specific survival. All stages and ages from the same time periods were compared. The cure fractions were estimated using the Log-logistic Mixture Cure Model and breast cancer specific survival was estimated using the Cox Model in the CanSurv software: http://srab.cancer.gov/cansurv/.

Results: Breast cancer cure fraction by Log-logistic Model and breast cancer specific survival by Cox Model are presented in Tables 1 and 2, respectively.

Table 1: Breast cancer cure fraction by Log-logistic Model

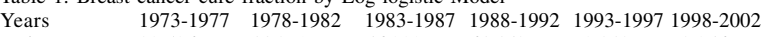
$\begin{array}{lllllll}\text { Patients } & 39,596 & 44,371 & 56,200 & 64,458 & 70,843 & 78,056\end{array}$ $\begin{array}{lllllll}\text { Cure fraction } & 0.415 & 0.444 & 0.511 & 0.609 & 0.633 & \text { NA }\end{array}$ NA, not available because there is no convergence in parameters.

Table 2: Breast cancer specific survival by Cox Model

$\begin{array}{lllllll}\text { Year } & 1973-1977 & 1978-1982 & 1983-1987 & 1988-1992 & 1993-1997 & 1998-2002 \\ 5 & 0.750 & 0.764 & 0.802 & 0.846 & 0.863 & 0.874 \\ 10 & 0.639 & 0.649 & 0.703 & 0.771 & 0.794 & \text { NA } \\ 15 & 0.580 & 0.590 & 0.649 & 0.722 & \text { NA } & \text { NA } \\ 20 & 0.545 & 0.556 & 0.614 & \text { NA } & \text { NA } & \text { NA } \\ 25 & 0.520 & 0.529 & \text { NA } & \text { NA } & \text { NA } & \text { NA } \\ 30 & 0.499 & \text { NA } & \text { NA } & \text { NA } & \text { NA } & \text { NA }\end{array}$

Discussion: There has been a consistent increase in breast cancer specific survival over the past three decades. Longer follow-up time is needed to accurately apply parametric Mixture Cure Models. 


\section{S256 Abstracts - Poster Session VI}

6024

Factors predicting the axillary lymph node status in women with an ER-positive breast cancer are age-dependent.

Neven P, Huang HJ, Drijkoningen M, Amant F, Leunen K, Berteloot $P$, Wildiers $H$, Van Limbergen E, Paridaens $R$, Christiaens MR, Vergote I. University Hospitals Leuven, Leuven, Belgium; Chang Gung Memorial Hospital, Taoyuan, Taiwan

Background: Axillary lymph node status (ALNS) is an important prognostic factor in breast cancer. We examined whether classical tumour predictors for lymph node status differ by age.

Patients and Methods: The ALNS of all consecutive patients with a primary operable invasive ER-positive breast cancer between January 2000 and July 2003. I In this period ALNS was always based on complete axillary clearance; axillary staging with the sentinel node procedure was performed in selected patients from July 2003 onwards. The ALNS was correlated with clinicopathological factors in multivariate analysis for the overall population $(n=1104)$ and for the age groups $\leq 50(n=328)$ and $>50$ years $(n=776)$. We considered the following tumour variables to predict ALNS: maximal microscopic tumour size and grade, PRand HER-2/neu status. PR and HER-2/neu were measured by immunohistochemistry using respectively the $\mathrm{H}$ - and DAKO-score. A H-score from 50-300 and a DAKO-score of 2+ and 3+ were considered positive.

Results: Only tumour size $(>20 \mathrm{~mm}$ vs $\leq 20 \mathrm{~mm} ; \mathrm{P}<0.001)$ and grade $(3$ vs $1-2 ; \mathrm{P}=0.008)$ were independent predictors for ALNS in the overall group. The prognostic factors differed for women $\leq$ and $>50$ years of age. In the younger age group, a large tumour size and a negative PR were predictors whereas in the elder age group only a large tumour size was predictive. Near significance was reached for a positive HER-2/neu status and high tumour grade respectively in younger and elder women.

Multivariate analyses of variables predicting ALNS

\begin{tabular}{lllllll} 
& All & \multicolumn{3}{c}{$\leq 50$ years of age } & \multicolumn{2}{l}{$>$ 50 years of age } \\
Variables & OR $(95 \%$ CI) & P & OR $(95 \%)$ & P & OR $(95 \%$ CI $)$ & $P$ \\
PR (- vs +$)$ & - & 0.826 & $2.6(1.3-5.4)$ & 0.010 & - & 0.508 \\
Grade $(3$ vs $1-2)$ & $1.5(1.1-2.0)$ & 0.008 & - & 0.214 & $1.4(0.9-1.9)$ & 0.060 \\
Size $(>20$ vs $\leq 20 \mathrm{~mm})$ & $3.9(3.0-5.1)$ & $<0.001$ & $6.3(3.8-10.3)<0.001$ & $3.5(2.6-4.8)$ & $<0.00$
\end{tabular}

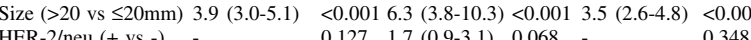
Conclusion: In women with an ER-positive breast cancer, tumour size is an independent predictor for ALNS in either age group. Other predictors for the lymph node status like tumour grade, a negative PR and HER-2/neu overexpression differ by age.

\section{5}

Lymph node ratio (LNR) is better survival predictor than conventional nodal categories: a surveillance, epidemiology, and end results (SEER) database analysis for node-positive breast cancer (BC).

Royce ME, Lee S-J, Wallace AM, Woodward WA, Ueno NT, VinhHung $V$, the International Nodal Ratio Working Group. University of New Mexico Cancer Research and Treatment Center, Albuquerque, NM; U.T. M.D. Anderson Cancer Center, Houston, TX; U.T. M. D. Anderson Cancer Center, Houston, TX; AZ-VUB, Jette, Belgium; Spain, Belgium, USA

Background: The current AJCC staging introduced pathologic nodal stage $(\mathrm{pN})$ to reflect the prognostic impact of increasing absolute number of positive lymph nodes (LN). However, LNR (\# LN positive/ \# LN examined) may have greater prognostic value than absolute number of positive nodes. Previous studies of LNR have been on relatively homogeneous single institution data or large population data with restrictive selection. This study investigates LNR- vs. pN-based classification performance, without adjustment, among heterogeneous cases of node-positive BC. Materials and Methods: Except for histologic confirmation and regional nodal examination, unselected data for women diagnosed in 1988-1997 with primary invasive node-positive BC were abstracted from the SEER 9-registries (2004). Three LNR categories were defined, low LNR $\leq 0.25$, intermediate LNR $>0.25$ -0.75 , and high LNR $>0.75$. Performance was evaluated between prognostic groups using LNR- vs. pN-categories (AJCC $6^{\text {th }}$ ed) Comparison was performed in all cases and in subgroups according to stage by AJCC $3^{\text {rd }}$ ed. The end-point is breast cancer specific survival (BSS) using the Kaplan-Meier method and log rank test. Results: 37,015 cases were available. Median follow-up was 94 months, age 58 years, tumor size $24 \mathrm{~mm}$, number involved nodes 3 , nodes examined 15. Global 10-year BSS was $65.7 \%(95 \%$ confidence interval 65.1-66.3). Performance by pN- vs. LNRcategories by stage is given in Table 1. 2,061 cases of unknown stage were not analyzed.

Table 1. Performance on 10-year BSS (\%) by pN- vs. LNR-categories by stage Table 1. Performance on 10-year BSS (\%) by pN- vs. LNR-categories by stage
AJCC3 $\begin{array}{llll}\text { All stages } & \text { Stage II } & \text { Stage III } & \text { Stage } \\ 37,015 & 27,525 & 6,128 & 1,301\end{array}$

10-year BSS by pN pN1 76.1 $\begin{array}{ll}\mathrm{pN} 2 & 56.9 \\ \mathrm{pN} 3 & 38.1\end{array}$ $\mathrm{pN} \chi^{2} \quad 3539.1$ Low LNR 77.3 Mid LNR $\quad 56.0$ High LNR 33.0

10-year BSS by LNR LNR $\chi^{2} \quad 4783.2$

$\begin{array}{lll}78.6 & 63.3 & 16.7\end{array}$ $\begin{array}{lll}78.6 & 63.3 & 16.7 \\ 41.7 & 47.2 & 14.0\end{array}$ $\begin{array}{lll}44.9 & 33.9 & 13.5 \\ 1755.7 & 338.8 & 6.5\end{array}$ $\begin{array}{lll}1755.7 & 338.8 & 6.5\end{array}$ $\begin{array}{lll}78.7 & 67.0 & 28.9\end{array}$ $\begin{array}{lll}60.9 & 47.0 & 14.7\end{array}$ $\begin{array}{lll}41.8 & 27.7 & 9.2 \\ 1946.9 & 600.0 & 82.0\end{array}$ The larger $\chi^{2}$ values correspond to better separation. $\chi^{2}$ statistic are given rather than $\mathrm{p}$ values which are exceedingly small. For instance, $\mathrm{p}$-value by $\mathrm{pN}=0.0388$ for stage IV vs. $<0.1 \times 10^{-10}$ by LNR for the same stage.

Discussion: LNR showed wider prognostic separation compared to $\mathrm{pN}$ for all stages including previously stage IV. Further investigation of the prognostic advantage of LNR over absolute number of nodes from randomized data sets is warranted.

\section{6}

Flourescence in situ hybridization (FISH) as the primary methodology for the assessment of $H E R 2$ status in adenocarcinoma of the breast: a single institution experience.

Tubbs R, Hicks DG, Downs-Kelly E, Pettay J, Hartke M, Myles J, Budd GT, Crowe JP. Cleveland Clinic Foundation, Cleveland, $\mathrm{OH}$

Background: Diagnostic assays for HER2 expression in breast cancer independently guide therapeutic decisions as to the suitability for trastuzumab targeted treatment. Despite the importance in determining patient management, consensus on testing methodologies for HER2 assessment is lacking. Retrospective clinical studies have suggested that FISH for HER2 gene amplification is superior in predicting a benefit from trastuzumab compared with immunohistochemistry for HER2 protein expression, and has lead to an increasing demand for primary FISH testing in the clinical setting. However, direct reagent cost, the need for specialized equipment, and a lack of familiarity with the technical aspects needed to perform and interpret FISH assay results have limited implementation within the greater laboratory community.

Materials and Methods: FISH (PathVysion HER2 DNA Probe Kit, Vysis, Downer's Grove, IL) is the primary method for determining HER2 status of breast carcinomas at our institution. We report here our experience with FISH testing in 727 consecutive cases of breast cancer, for the calender year 2004 .

Results: $81.6 \%(593 / 727)$ of breast cancer cases were not amplified for HER2 (HER2/CEP17-0.8-1.9), while $18.4 \%$ (134/ 727) of cases were HER2 amplified (HER2/CEP17>2.0). Among the HER2 amplified cases, 3.3\% (24/727) were low-level amplified (HER2/CEP17 ratio2.0-2.3). Genotypic heterogeneity, with $<50 \%$ of tumor cells demonstrating HER2 gene amplification was observed in $5.5 \%(40 / 727)$ of cases, and was reported as such. HER 2 monoallelic deletion $(H E R 2 / C E P 17<0.7)$ was demonstrated in $1.9 \%(14 / 727)$ of cases while $C E P 17$ monosomy $(C E P 17-<1.4$ in $>90 \%$ of tumor cells), eusomy (CEP17-1.4-2.1), and polysomy $(C E P 17->2.1)$ was seen in $5.2 \%(38 / 727), 64 \%(468 / 727)$, and $35.4 \%(257 / 727)$ respectively. Polysomy if defined as CEP17 spot count 3.0 or greater, was observed in $8.0 \%$ (58/727); among this group of polysomic cases, $5.1 \%$ (37/727) were not HER2 amplified, $0.6 \%$ (4/727) were low level amplified for HER2 (HER2/ CEP17 ratio $2.0-2.3$ ), and $2.3 \%$ (17/727) were HER2 amplified. 
Conclusions: FISH for the assessment of HER2 status in breast cancer is quantitative, specific, and a better predictor of Trastuzumab response in retrospective reports. The additional time and direct laboratory expense involved in FISH testing, although an important consideration, needs to be carefully weighed against the cost of inappropriate classification and potential inappropriate treatment of patients. The clinical significance of low level gene amplification, aneusomy, monosomic states for chromosome 17, HER2 allelic deletion, and genotypic heterogeneity encountered with FISH assays for HER2 is unclear at this time and warrants further study.

\section{7}

Newly established ELISA suitable for evaluation of HER2 antibodies in sera of patients with primary or advanced breast cancer, or benign or premalignant breast lesions. Willems A, Harbeck $N$, Henrichs $C$, Kiechle M, Peschel C, Bernhard H, Schmitt M. Technical University of Munich, Klinikum Rechts der Isar, Germany

Purpose: HER2, a growth factor receptor, is overexpressed in tumor cells of $25-30 \%$ of patients with invasive breast cancer. Herceptin ${ }^{\mathrm{TM}}$, a humanized monoclonal mouse antibody to HER2, reduces tumor growth in HER2 overexpressing tumors. Considering that the extracellular domain (ECD) of HER2 is shed into serum as part of its degradation process, a so-called "shed antigen", it would be of considerable clinical interest to evaluate whether an autologous antibody reaction triggered by this shed ECD is detectable. To pursue this idea, we set up an ELISA to test for active HER2 antibodies and screened prospectively collected sera from patients with newly diagnosed breast cancer or benign breast disease.

Patients and methods: HER2 antibody detection in serum was done by ELISA. Target antigen is the recombinant ECD attached to a microtiter plate to which serum is added to screen for putative human antibodies to HER2 ECD. As a secondary antibody, we introduced peroxidase-labeled anti-human IgG. Herceptin ${ }^{\mathrm{TM}}$ spiked serum served as "positive" control, and serum of healthy female donors not treated with Herceptin ${ }^{\mathrm{TM}}$ as "negative" control. Lowes detectable concentration of Herceptin ${ }^{\mathrm{TM}}$ was $10 \mathrm{ng} / \mathrm{ml}$. In serum of patients under Herceptin ${ }^{\mathrm{TM}}$ treatment, the antibody was detectable up to a dilution of 1:160,000. We screened sera of 173 patients, 132 of whom had newly diagnosed breast cancer, and 41 $(23.7 \%)$ had non- malignant breast disease. HER2 status of tumor tissues was determined by HercepTest ${ }^{\mathrm{TM}}$ with $33(25 \%)$ of the malignant tumors being HER2 $3+(25 \%)$.

Results: Although HER2 antibodies in serum from patients treated with Herceptin ${ }^{\mathrm{TM}}$ were detectable up to a dilution of $1: 160,000$, by our test, in sera of patients with newly diagnosed breast cancer (even at a low serum dilution of 1:10), a specific HER2neu antibody reaction was not detected.

Conclusion: We could not detect a preexisting antibody response against HER2/neu in patients with breast cancer or benign breast tumors. The failure to detect HER2-reactive antibodies in patients with HER2-overexpressing breast cancer is in contrast to previous data derived from an ELISA using a lysate of HER2-overexpressing human breast cancer cells (Disis et al. J Clin Oncol 1997). This discrepancy can be explained by the hypothesis that naturally occurring anti-HER2 antibodies may not crossreact with the recombinant ECD used in our ELISA. Therefore, the serum samples are currently being reevaluated for the presence of HER2-directed antibodies using a lysate-based ELISA. Moreover, this newly developed assay can also be used for monitoring of Herceptin ${ }^{\mathrm{TM}}$ levels in body fluids.

\section{8}

Automation of preanalytical components and image quantification of direct dual label fluorescence in situ hybridization (FISH) for HER2 gene amplification.

Tubbs R, Pettay J, Swain E, Roche P, Powell W, Hicks D, Grogan T. Cleveland Clinic \& the Cleveland Clinic Lerner College of Medicine, Cleveland, OH; Ventana Medical Systems International, Tucson, AZ

Determination of $H E R 2$ status by Fluorescence in situ hybridization (FISH) correlates well with response to targeted therapy and prognosis. However, the preanalytical and quantification aspects of the procedure may be challenging for some laboratories. We examined the feasibility of automating these components of the FISH assay.

Material and Methods: A tissue microarray (TMA) and a series of whole sections of breast carcinomas were used for this study. The TMA constructed contained 118 consecutive wellcharacterized primary invasive breast cancers diagnosed at the Cleveland Clinic Foundation between 1995 and 1996 and consisted of $8 \times 12$ arrays of $1.5 \mathrm{~mm}$ tissue cores from archived formalinfixed paraffin-embedded surgical blocks. Two separate tissue cores of invasive carcinoma represented each surgical case in the TMA. Each separate tissue core was made anonymous and assigned a unique TMA location number, which was subsequently linked to an IRB approved database containing corresponding 5-year clinical follow up data. An automated in situ workstation (Discovery $\mathrm{XT}^{\mathrm{TM}}$; Ventana Medical Systems, Tucson) was used to automate a programmed overnight start, on line baking, deparaffinization, cell conditioning, protease digestion, and prehybridization buffer washing. Probe/target codenaturation/hybridization and stringency washing were done off line using a directly labeled CEP17 SpectumGreen $^{\mathrm{TM}}$ and HER2 SpectrumOrange ${ }^{\mathrm{TM}}$ probe set (Abbott Vysis; Downers Grove). The HER2 and CEP17 spot counts were quantified, and the HER2/CEP17 ratio calculated, via ISIS and Metaphor TM analysis on a MetaCyte4 imaging workstation (Metasystems; Belmont, Ma). Results were benchmarked against manual counts for whole sections, and bright field in situ hybridization \{silver in situ hybridization (SISH) $\}$ and CB 11 immunohistochemistry for the TMA.

Results: Automated FISH results using whole sections well correlated well with manual results $H E R 2$ spot count correlation coefficient $\mathrm{r}=0.87 ; \mathrm{p}<0.0001 ; H E R 2 / \mathrm{CEP} 17$ ratio correlation coefficient $\mathrm{r}=0.82 ; \mathrm{p}=0.0002$ ). Correlations between automated and manual FISH results for the TMA were also excellent (automated FISH ratio versus SISH one-way ANOVA $\mathrm{p}<0.001$ ). Disease free survival was significantly shorter $(\mathrm{p}<0.001)$ for the HER2 amplified cases evaluated by automated FISH of the TMA. Discussion: Automation of the laborious preanalytical and image quantification components of FISH using directly labeled probes is feasible. Operational gains and enhanced consistency are inherent in this automated approach to HER2 FISH clinical testing.

\section{9}

Blood oxygenation level dependent (BOLD) contrast MRI for early evaluation of breast cancer chemotherapy.

Jiang L, McColl R, Weatherall P, Tripathy D, Mason RP. UT Southwestern Medical Center at Dallas, Dallas, TX

Background: Tumor microcirculation and oxygenation play critical roles in tumor growth and responsiveness to cytotoxic treatment and might provide prognostic indicators for therapy. Deoxyhemoglobin $\left(\mathrm{dHbO}_{2}\right)$ can serve as an endogenous contrast agent. Interventions improving tumor oxygenation, which convert $\mathrm{dHbO}_{2}$ to $\mathrm{HbO}_{2}$ produces a BOLD signal gain, and this may complement conventional MRI.

Material and Methods: Seven patients with locally advanced breast cancer received doxorubicin and cyclophosphamide (AC) for four cycles every two or 3 weeks. Prior to start of chemotherapy and after 1 and 4 cycles, MRI was performed on a $1.5 \mathrm{~T}$ scanner. 


\section{S258 Abstracts - Poster Session VI}

For the BOLD study, patients breathed room air for $45 \mathrm{sec}$, then oxygen for $6 \mathrm{~min}$ and finally room air again. The imaging parameters were TR/TE $(500 / 41.4 \mathrm{~ms})$ and matrix $(256 \times 256)$. During a standard MRI study, the patient breathed room air and received gadolinium.

Results: ${ }^{1} \mathrm{H}$ MRI showed BOLD contrast enhancing regions in all patients with a typical signal change of $\sim 3 \%$. The relative signal gain during DCE was much greater. Both responses decreased with chemotherapy. However, it was notable that two patients with an exceptionally high BOLD-effect $(>10 \%)$ achieved a pathological response after chemotherapy.

Discussion: While these data are preliminary, it appears that BOLD MRI may add value to the prognostic capability of imaging. Moreover, BOLD is non-invasive and we now routinely achieve artifact-free results.

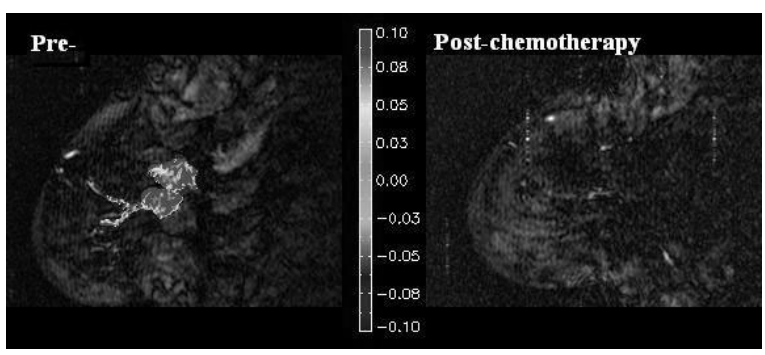

6030

Multicenter, phase IV randomized study to assess efficacy of continuous versus alternate administration of pamidronate to breast cancer patients with symptomatic bone metastasis: GEICAM/2000-01 Trial.

Ruiz-Borrego M, Lluch A, Martín M, Calvo L, Bayo J, Ramos M, Adrover E, Franquesa R, Rodríguez-Lescure A, Barnadas A. On Behalf of the Spanish Breast Cancer Research Group (GEICAM), San Sebastián de los Reyes, Madrid, Spain

Background: Pamidronate (PMT) is effective in reducing skeletal related events (SRE) in breast cancer (BC) patients (pt) with bone metastasis (BM). Its best way of administration and optimum treatment duration are still to be determined. Objective: evaluate the efficacy of continuous administration ( $\operatorname{arm~A)}$ vs. alternate administration ( $\operatorname{arm} \mathrm{B}$ ) of PMT to delay time to first SRE in BC pt presenting with symptomatic BM. Methods: pt aged $>18$, ECOG performance status $\geq 2$, adequate renal function, and $\mathrm{BC}$ symptomatic BM were eligible. BM was defined as presence of 3 or more hot spots (HS) in skeletal scintigraphy (SS), or any number of HS in SS if osteolytic, osteoblastic or mixed bone lesions determined by radiography, or 2 or less HS in SS if magnetic resonance or CT scan confirmation of BM. Symptomatic BM was defined as pain associated to SS HS, or SRE (pathological fractures or spine cord compression or radiation bone treatment or tumour induced hypercalcemia), or treatment with analgesia due to bone pain. Pt were allowed up to 1 previous chemotherapy and 2 previous hormone therapy lines for metastatic disease. Antineoplastic therapy could be changed at any time during the study. Eligible pt were stratified (isolated bone metastasis or associated to node or skin lesions vs. bone metastasis associated to visceral disease) and randomized to receive 2 hour-iv. PMT $90 \mathrm{mg}$ every 3-4 weeks for 18 months (arm A) or iv. PMT $90 \mathrm{mg}$ every 3-4 weeks for 6 months, followed by a 6 months rest, and a new 6 months ontreatment period (arm B). Quality of Life (QoL) was measured with SF-36 questionnaire. Study complied with GCP/ICH with $100 \%$ source data verification. Results: 152 pt were enrolled, 80 $(52.6 \%)$ in $\operatorname{arm~A,~and~} 72(47.4 \%)$ in arm B. Main pt characteristics were balanced between arms (Table I). Median number of BM sites and foci were 2.9 and 6 ( $\operatorname{arm~A})$ vs. 3 and 6.6 ( $\mathrm{arm} \mathrm{B})$. Median time of study participation was 13.3 (arm A) and 13.9 months (arm B).
Median time to first SRE was 7.9 vs. 10.2 months in A and B treatment arms, respectively $(\mathrm{p}=0.339$, Mann-Whitney $U$ test $)$ There were $33(22 \%)$ SRE in arm A vs. 20 (13\%) in arm B $(\mathrm{p}=0.086) .9(11 \%) \mathrm{pt}$ achieved a partial response while in study in $\operatorname{arm~A,~vs.~} 11(15 \%)$ in arm B. Analysis of treatment-related pain and QoL items showed no difference between arms. Conclusion: no differences in time to first SRE have been found between continuous or alternate administration of PMT. Table I

Age (Median)

Visceral disease $(\%)$

Previous SRE $(\%)$

Previous chemotherapy $(\%)$

Previous hormone therapy

Previous radiotherapy

$\begin{array}{ll}\text { Arm A } & \text { Arm B } \\ 58 & 61 \\ 25 \% & 28 \% \\ 46 \% & 37.5 \% \\ 62.5 \% & 72 \% \\ 66 \% & 75 \% \\ 57.5 \% & 47 \%\end{array}$

\section{1}

Accurate tumor response assessment in bone-only metastatic breast cancer by comprehensive imaging and by new response criteria.

Hamaoka T, Costelloe CM, Madewell JE, Islam R, Rondon G, Ayers GD, Champlin RE, Berry DA, Hortobagyi GN, Ueno NT. St Luke's International Hospital, Tokyo, Japan; University of Texas M. D. Anderson Cancer Center, Houston, TX

Background: Accurate assessment of bone metastases is necessary to improve prognostication to ensure appropriate treatmen decisions. Attempts to assess such responses using criteria from the UICC and the WHO have not been satisfactory; these criteria are based only on radiography (XR) and skeletal scintigraphy (SS) and have led to bone metastasis being considered unmeasurable disease. We recently proposed new imaging criteria based on CT to assess bone response (JCO 22:2942, 2004). Here we describe a retrospective review of images from patients with bone metastases to evaluate (a) the accuracy of the new MDA criteria vs the WHO criteria and (b) the accuracy of each imaging modality for assessing bone response.

Methods: Two sets of response criteria, MDA and WHO, were used to compare progression-free and overall survival (PFS, OS) of patients with bone-only metastatic breast cancer who responded or did not respond to treatment (chemotherapy or hormonal therapy). Sensitivity and specificity were also compared against clinical evidence of response (symptoms, tumor markers, imaging) as an internal control. Images were reviewed by 2 musculoskeletal radiologists at baseline and early (2-6 mo) and late (11-13 mo) after treatment. Responses were ranked as complete, partial, stable, or progressive disease. Independent diagnostic images (CT vs SS) were also compared, but too few independent XRs and MRIs were available for comparative analysis.

Results: Forty-one patients had sufficient image sets for analysis. Patients who showed a response early in treatment (according to the MDA criteria) had better PFS and OS (25.8 mo and $71.6 \mathrm{mo})$ than nonresponders $(9.2$ mo $[P=0.014]$ and $38.7 \mathrm{mo})$. The WHO criteria did not show differences in PFS or OS. The MDA criteria were also more sensitive $(87 \%$; $95 \%$ CI $60 \%-98 \%$; $P=0.07)$ at detecting true response than the WHO $(47 \%$; $95 \%$ CI $21 \%$ $73 \%$ ). CT tended to separate responders from nonresponders in PFS (24.0 mo vs $15.3 \mathrm{mo}$ ) and in OS (65.0 mo vs $37.8 \mathrm{mo})$. SS did not distinguish responders vs nonresponders in PFS and OS. CT was more sensitive $(69 \% ; 95 \%$ CI $38 \%-91 \% ; P=0.07)$ than SS (36\%; 95\% CI 13\%-65\%) for detecting response. Conclusions: The new MDA criteria, which include findings from CT scanning, are better than the WHO criteria for assessing bone metastasis. Prospective studies are warranted to test whether use of the CTinclusive MDA criteria improves the ability to detect and quantify responses in bone metastasis. 
6032

Efficacy and safety of systemic samarium 153 therapy in metastatic breast cancer patients with widespread bone metastases.

Lacko A, Pajak K, Kolodziejczyk A, Zebrowski J, Garncarek A, Filipczyk-Cisarz E. Wroclaw Medical University, Wroclaw, Poland; Lower Silesian Oncology Center, Wroclaw, Poland; IV Military Hospital, Wroclaw, Poland

Background: Bone metastases are present in approximately $75 \%$ of breast cancer patients, therefore bones are the most frequent localization of metastases and the only site of metastatic spread in many patients. The commonly used treatment options for bone pain palliation include: external beam radiotherapy, bisphosphonate therapy and systemic radionuclides. The aim of this study was to assess the efficacy and safety of samarium 153 $\left({ }^{153} \mathrm{Sm}\right)$ in breast cancer patients with widespread bone metastases. Materials and Methods: We analysed $100{ }^{153}$ Smadministrations at a dose $1.0 \mathrm{mCi} / \mathrm{kg}$ in 70 metastatic breast cancer patients with bone metastases (median age, 57 years; range: 23-75). Fifty five (79\%) patients had bone only disease, while in $15(21 \%)$ presence of metastases to other organs was confirmed. Fourty (57\%) patients were treated with external beam radiotherapy before radionuclide therapy with median of $13.5 \%$ irradiated bone marrow (range: 3 $45 \%)$. Twenty two $(31 \%)$ patients received more than $1{ }^{153} \mathrm{Sm}$ treatment. All patients were monitored with CBC every 2 weeks, until the resolution of acute hematologic toxicities. Efficacy of treatment was assessed by VAS (Visual Analogue Scale) performed before treatment, and at every follow up visit. We also analyzed the impact of the previous systemic radionuclide treatment and radiotherapy on the bone marrow supression.

Results: $93 \%$ of patientshad partial to complete relief of pain.The primary hematologic toxicities consisted of: generally mild leucopenia seen in $73 \%$ of cases (grade III in 7\%) and thrombocytopenia in $78 \%$ of cases (grade III and IV in $8 \%$ of pts) with nadirs at 4 and 5 weeks respectively. Grade IV thrombocytopenia was observed only in 2 patients, however it was asymptomatic. All hematologic toxicities resolved in 8 weeks. Correlation was not found between neither previous systemic radionuclide treatment nor radiotherapy with bone marrow supression.

Conclusion: Clinical reports regarding application of ${ }^{153} \mathrm{Sm}$ in breast cancer are limited to several studies performed in patients with variety of tumors, with poor breast cancer patients representation. We demonstrated that treatment with ${ }^{153} \mathrm{Sm}$ was generally well tolerated with mild, short-term, asymptomatic bone marrow supression. Repeated administration of ${ }^{15} \mathrm{Sm}$ and previous radiotherapy did not effect toxicity of treatment. Results of this study indicate that in metastatic breast cancer patients systemic ${ }^{153} \mathrm{Sm}$ is safe and provides effective paliation.

Key words: metastatic breast cancer, bone metastases, samarium 153

\section{3}

Non-inferiority of oral ibandronate to intravenous zoledronic acid for reducing markers of bone turnover in metastatic breast cancer patients.

Lichinitser MR, Coleman RE, Tjulandin SA, Bergström B, Body JJ. RAMS, Moscow, Russian Federation; Cancer Research Centre, Weston Park Hospital, Sheffield, United Kingdom; Hoffmann-La Roche Inc., Nutley, NJ; Institut Jules Bordet, Université Libre de Bruxelles, Brussels, Belgium

Background: Bisphosphonates are the standard of care for breast cancer patients with bone metastases. Oral bisphosphonates enable at-home treatment, which is more convenient for patients. Ibandronate is a single-nitrogen bisphosphonate available in intravenous and oral formulations with a similar efficacy for the treatment and prevention of skeletal-related events (SREs). There is increasing data suggesting that levels of bone turnover markers predict the incidence of SREs in patients with metastatic bone disease. In this study, oral ibandronate was compared with intravenous zoledronic acid for effects on bone turnover markers. Methods: In a head-to-head, multicenter, randomized, open-label, parallel-group trial, breast cancer patients with advanced disease and at least one confirmed osteolytic or mixed bone lesion received 12 weeks of treatment with oral ibandronate $50 \mathrm{mg}$ daily $(\mathrm{n}=128)$ or intravenous zoledronic acid $4 \mathrm{mg}$ infused over 15 minutes every 4 weeks $(n=126)$. The primary endpoint was the mean percentage change in serum cross-linked C-terminal telopeptide of type I collagen (S-CTX) levels at the end of the study. Other assessments included urinary CTX (U-CTX), and serum levels of bone specific alkaline phosphatase (BAP), amino-terminal procollagen propeptides of type I collagen (P1NP), and osteocalcin (OC). Results: Treatment with ibandronate or zoledronic acid was associated with comparable reductions in all bone turnover markers at study endpoint (Table 1). Conclusion: In this study, oral ibandronate was statistically non-inferior to intravenous zoledronic acid for inhibiting bone resorption, as demonstrated by comparable effects on S-CTX and U-CTX. Both agents also reduced serum markers of bone formation (BAP, P1NP and OC) to a similar extent. Overall, a convenient oral ibandronate dose of $50 \mathrm{mg} /$ day is as effective as intravenous zoledronic acid in suppressing bone turnover markers, suggesting comparable efficacy for the prevention of SREs. Head-to-head studies comparing SRE rates are warranted to confirm results.

Table 1. Mean (CI) percentage change from baseline in bone turnover markers.

$\begin{array}{llllll} & \text { S-CTX* } & \text { U-CTX } & \text { BAP } & \text { P1NP } & \text { OC } \\ \text { Ibandronate } & -76 & -76 & -37 & -47 & -35 \\ & (-81 \text { to }-71) & (-83 \text { to }-69) & (-43 \text { to }-30) & (-55 \text { to }-40) & (-39 \text { to }-30) \\ \text { Zoledronic acid } & -73 & -82 & -26 & -39 & -26 \\ & (-81 \text { to }-65) & (-87 \text { to }-77) & (-43 \text { to }-8) & (-52 \text { to }-26) & (-43 \text { to }-8)\end{array}$
*Baseline S-CTX levels in the treatment groups were ibandronate $0.65 \mathrm{ng} / \mathrm{ml}$ and zoledronic acid $0.70 \mathrm{ng} / \mathrm{ml}$.

\section{4}

Intravenous ibandronate 15-minute infusion followed by daily oral ibandronate for metastatic bone disease: bone marker data.

Bergström B, Lichinitser MR, Andreeva N, Budde M, Body JJ. Hoffman-La Roche Inc., Nutley, NJ; NN Blokhin Russian Cancer Research Center, Moscow, Russian Federation; Semashko Central Clinical Hospital, Moscow, Russian Federation; F. Hoffmann LaRoche AG, Basel, Switzerland; Institut Jules Bordet, Université Libre de Bruxelles, Brussels, Belgium

Background: Bone turnover markers in serum or urine are prognostic indicators of skeletal complications in patients with metastatic bone disease. Current guidelines suggest that all patients with metastatic breast cancer should receive continuous bisphosphonate treatment from initial diagnosis. Ibandronate is a single-nitrogen, non-cyclic bisphosphonate available in intravenous and oral formulations. In phase III trials of breast cancer patients, both formulations decreased the incidence of skeletal-related events and reduced metastatic bone pain scores. This 12-week trial examined changes in bone turnover markers following a single rapid infusion of intravenous ibandronate followed by daily oral ibandronate. Methods: Patients $(n=39)$ with breast cancer or advanced multiple myeloma and $\geq 1$ confirmed lytic or mixed bone lesion received a single 15-minute infusion of intravenous ibandronate $6 \mathrm{mg}$ immediately followed on Day 2 by 12 weeks of oral ibandronate $50 \mathrm{mg}$ once daily. Serum levels of cross-linked C-terminal telopeptide of type I collagen in serum (S-CTX) were measured at various timepoints to indicate bone resorption. Bone formation was assessed by measuring serum bone specific alkaline phosphatase (BAP), amino-terminal procollagen propeptide of type I collagen (P1NP), and osteocalcin (OC). Safety monitoring included adverse event reporting, serum chemistry, and urinalysis. Results: Treatment with intravenous ibandronate followed by oral ibandronate was associated with a rapid decrease in S-CTX levels of $77 \%$ from baseline within 2 weeks of treatment, and this was maintained throughout the 12 - 


\section{S260 Abstracts - Poster Session VI}

week trial. At study endpoint, levels of BAP, P1NP, and OC had decreased by $27 \%, 42 \%$, and $24 \%$, respectively, from baseline. The treatment schedule was well tolerated with few adverse events. Conclusions: A rapid 15-minute infusion of intravenous ibandronate $6 \mathrm{mg}$ followed by daily oral ibandronate $50 \mathrm{mg}$ was associated with a marked decrease in bone turnover markers with no safety concerns. This further confirms the efficacy of ibandronate for metastatic bone disease observed in phase III trials. The novel treatment regimen described here is undergoing further assessment.

\section{5}

Safety of oral ibandronate and intravenous zoledronic acid in breast cancer patients with metastatic bone disease.

Body JJ, Lichinitser MR, Tjulandin SA, Coleman RE, Bergström B. Institut Jules Bordet, Université Libre de Bruxelles, Brussels, Belgium; NN Blokhin Russian Cancer Research Center, Moscow, Russian Federation; Cancer Research Centre, Weston Park Hospital, Sheffield, United Kingdom; Hoffman-La Roche, Inc., Nutley, NJ

Background: Ibandronate is a single-nitrogen, non-cyclic bisphosphonate with proven efficacy for the treatment and prevention of skeletal-related events. In phase III trials of breast cancer patients, both oral and intravenous formulations of ibandronate were well tolerated and had safety profiles comparable to placebo. Here, we report comparative safety data from a headto-head trial of oral ibandronate and intravenous zoledronic acid. Methods: In an open-label, multicenter, parallel-group study, breast cancer patients with at least one confirmed osteolytic or mixed bone lesion were randomly assigned to receive oral ibandronate $50 \mathrm{mg} /$ day $(\mathrm{n}=137)$ or intravenous zoledronic acid $4 \mathrm{mg}$ via 15 -minute infusion every 4 weeks $(n=137)$ for 12 weeks. All adverse events (AEs) were recorded throughout the study. Results: In general, both bisphosphonates were well tolerated. However, a higher proportion of patients in the zoledronic acid group experienced AEs ( $76 \%$ versus $65 \%$ in the ibandronate group). In particular, there was a higher incidence of AEs during the first 3 days of the study for zoledronic acid than ibandronate $(47 \%$ versus $8 \%$ ). This was composed predominantly of acute-phase response events, including pyrexia, chills, flu-like illness, arthralgia, and myalgia, that were probably or possibly treatment-related (41\% of the zoledronic acid group versus $5 \%$ of the ibandronate group). Throughout the entire study, a higher proportion of patients reported bone pain in the zoledronic acid group than the ibandronate group ( $21 \%$ versus $12 \%)$, although the incidence of gastrointestinal (GI) AEs was slightly lower for zoledronic acid ( $18 \%$ compared with $23 \%$ for ibandronate). The incidence of serious AEs (zoledronic acid $8.0 \%$; ibandronate $5.8 \%$ ) and withdrawals (zoledronic acid $5.1 \%$; ibandronate $2.9 \%$ ) was lower for ibandronate. Conclusion: In this first direct comparative trial of third-generation bisphosphonates, more AEs were experienced by patients treated with intravenous zoledronic acid than oral ibandronate. In particular, a high proportion of the zoledronic acid group reported events associated with an acutephase response following initial treatment, a known side-effect with a disproportionate risk among intravenous bisphosphonates. The frequency of GI AEs was only slightly higher for oral ibandronate than intravenous zoledronic acid. Oral ibandronate represents an effective and well-tolerated treatment for metastatic bone disease with apparent AE advantages over intravenous zoledronic acid.

\section{6}

Fractures negatively affect survival in patients with bone metastases from breast cancer.

Hei YJ, Saad F, Coleman RE, Chen YM. Novartis Oncology, East Hanover, NJ; Hôpital Notre-Dame, Montreal, QC, Canada; Weston Park Hospital, Cancer Research Centre, Sheffield, United Kingdom Background: Patients with advanced breast cancer are at high risk of developing multiple skeletal complications, including pathologic fractures, which contribute to the poor prognosis for these patients. To assess the effect of fractures on survival in patients with bone metastases from breast cancer, we conducted a retrospective analysis of time to death for patients enrolled in a large, randomized, controlled trial (Rosen LS, et al. Cancer. 2003;98:1735-1744) based on whether they experienced a pathologic fracture on study. Material and Methods: A Cox regression model using fractures as a time-dependent variable was performed in the subset of patients with bone metastases from breast cancer $(\mathrm{N}=1,130)$ who received 4 or $8 / 4 \mathrm{mg}$ zoledronic acid or pamidronate every 3 to 4 weeks for up to 24 months. Treatment was also included in the model. Time to death was defined as the time from randomization to the final visit (month 25). Patients were censored at the final visit if death was not observed by end of study. Data from the full 25 months of followup were included in the analyses and all analyses were performed on the safety-evaluable population. Results: Patients who experienced a pathologic fracture on study had a significantly worse survival outcome compared with patients who did not experience a fracture. Overall, $35 \%$ of patients experienced a fracture on study, and these patients had a significantly increased risk for death (hazard ratio $=1.586 ; 95 \%$ confidence interval $=$ 1.145 to $2.197 ; P=.006$ ) compared with patients who did not experience a pathologic fracture. Conclusions: Pathologic fractures appear to be an independent adverse prognostic factor for survival in patients with bone metastases from breast cancer. Therefore, preventing pathologic fractures may provide a survival advantage.

\section{7}

Efficacy and safety of intravenous ibandronate $6 \mathrm{mg}$ infused over 15 minutes: results from a 2 -year study of breast cancer patients with metastatic bone disease.

Heras P, Hatzopoulos A, Mitsibounas D. General Hospital of Nafplio, Nafplio, Greece; Hellenic Medical Society for the Study of Psychosomatic Disorders, Athens, Greece

Background: Metastatic bone disease is associated with various skeletal-related events (SREs), including pathological fracture, spinal cord compression, and radiotherapy or surgery to bone. Ibandronate is a single-nitrogen, non-cyclic bisphosphonate with proven efficacy for decreasing the incidence of SREs. In this study, a randomized, placebo-controlled trial was performed to evaluate the efficacy and safety of ibandronate infused over 15 minutes in a cohort of breast cancer patients with metastatic bone disease. Methods: Patients received intravenous ibandronate $6 \mathrm{mg}$ or placebo via a 15 -minute infusion every 4 weeks for 24 months. Study endpoints included the proportion of patients who developed SREs and time to first event. Results: In a group of 150 women with breast cancer and bone metastases, intravenous ibandronate significantly reduced the proportion of patients who experienced an SRE compared with placebo ( $38 \%$ versus $49 \%$; $\mathrm{p}=0.028$ ). Time to first SRE was also delayed significantly (median 459 versus 306 days; $\mathrm{p}=0.008$ ). In a multiple-event analysis, ibandronate reduced the risk of developing an SRE by $32 \%$ (hazard ratio $=0.69 ; 95 \%$ confidence interval $0.42-0.79 ; p=0.003$ ). In general, ibandronate was well tolerated, with a renal adverse event profile comparable to placebo and no clinically-relevant changes in serum creatinine levels. Conclusions: These data demonstrate the efficacy and safety of 15-minute infusions of ibandronate. Compared with placebo, ibandronate reduced the proportion of patients who 
experienced an SRE, and decreased the median time to first SRE and the SRE risk. There was no evidence of renal toxicity. Ibandronate is a safe and effective treatment for preventing the complications of metastatic bone disease in breast cancer patients.

\section{8}

Changes in tumor metabolism and local bone turnover in patients treated for bone-dominant metastatic breast cancer measured by fluorodeoxyglucose (FDG) and fluoride positron emission tomography (PET).

Gralow JR, Brenner W, Linden HM, Livingston RB, Ellis GK, Schubert EK, Peterson LM, Muzi M, Mankoff DA. University of Washington/Seattle Cancer Care Alliance, Seattle, WA; University of Washington, Seattle, WA; University Medical Center HamburgEppendorf, Hamburg, Germany

Purpose: Following response of bone-dominant metastatic breast cancer poses a significant clinical challenge. Standard imaging studies such as bone scan and MRI rely on changes in surrounding bone to detect tumor sites and therefore often do not reflect tumor response to treatment. We have previously shown that serial FDG PET, which measures tumor glucose metabolism, accurately depicts bone metastasis response to therapy. In this study we investigated the quantitative relationship between tumor metabolism, using FDG PET and adjacent bone turnover, using fluoride PET.

Methods: Patients with bone-dominant metastatic breast cancer underwent FDG PET and dynamic fluoride PET prior to treatment and again post-treatment with either endocrine therapy $(\mathrm{N}=6)$ or chemotherapy $(\mathrm{N}=3)$. FDG images were analyzed quantitatively using the standardized uptake value (SUV). Fluoride images were analyzed using SUV and by detailed kinetic analysis of dynamic images. Whole-body survey images for both tracers were reviewed qualitatively.

Results: As expected, tumor metabolism and local bone turnover, represented by FDG and fluoride SUV respectively, did not correlate, suggesting that two different processes were being measured. Patients with lytic metastases had low fluoride uptake and had high FDG uptake, while some patients with sclerotic metastasis had high fluoride uptake and had low FDG uptake, often close to normal bone background. Patients with disease progression after therapy showed increases in both FDG and fluoride post-treatment. Responding patients tended to have a decline in FDG uptake, but some responders had an increase in fluoride uptake, likely indicating local bone healing in response to tumor regression, akin to a bone scan "flare". Kinetic analysis of fluoride images showed that changes in both fluoride delivery and retention contributed to changes in fluoride uptake, indicating that changes in both vascularity and new bone formation contribute to changes in fluoride uptake post-therapy.

Conclusions: Serial imaging of both tumor metabolism and local bone turnover using FDG and fluoride PET provides insights into the response of breast cancer bone metastases to therapy and may help guide treatment of bone-dominant disease.

Supported by CA72064

\section{9}

Lobular carcinoma in situ (LCIS). Discovery modalities, treatments and long term outcome. Analysis of 183 cases. Cutuli B, Levi C, Lemanski C, Brunaud C, Giard S, Quetin P, Cohen-Solal Le-Nir C, De Lafontan B, Meunier A, Fay R. Polyclinique de Courlancy, Reims, France; French Cancer Centers Breast Group, Paris, France; Centre d'Investigation Clinique, Toul, France

\section{BACKGROUND}

Recent studies have suggested that LCIS was a precursor of subsequent in situ or invasive breast cancer (IBC); its treatment remains very debated and our study evaluated a cohort of patients (with LCIS) treated by three different options.

\section{MATERIAL AND METHODS}

A retrospective multicentric study was performed in 8 French Cancer Centers to collect all pure LCIS treated from 1985 to 2000 (excluding patients with previous or synchronous DCIS or IBC). 183 cases were evaluable.

\section{RESULTS}

Median age was 49 years (32-79). Overall median follow up was 10 years. Family history of BC and previous benign breast disease were found in $49(27 \%)$ and $39(21 \%)$ patients. $76(42 \%)$ women were post menopausal, and 16 of them had taken HRT prior to diagnosis.

LCIS was discovered by mammography in $116(63 \%)$ cases and by clinical symptoms in $57(31 \%)$ cases. Incidental finding was noted in 10 cases $(6 \%)$.

Conservative surgery alone (CS), CS with radiotherapy (CS+RT) and mastectomy (M) were performed in $135(74 \%), 30(16.4 \%)$ and $18(9.6 \%)$ of the cases. Multiple foci of LCIS were found in 81 $(44 \%)$ cases. Associated epithelial atypical hyperplasia $(\mathrm{AH})$, lobular AH and sclerosing adenosis were found in 57 (31\%), 67 $(37 \%)$ and $55(30 \%)$ cases. Among the 30 patients who underwent RT, median dose to whole breast was $50 \mathrm{~Gy}$, with a 10-Gy boost in 21 cases. 22 women underwent Tamoxifen. Cancer-related events are shown in the Table.

Among the 135 patients in the CS group, LR rates at 5, 8 and 10 years were $13 \%, 19 \%$ and $24 \%$. 14 out of 24 (58\%) LR were invasive, with 10 lobular and 4 ductal carcinomas.

No clinical or pathological LR risk factors were found. Among the 9 contralateral BC, 6 were invasive. Globally, $172 / 183$ patients $(94 \%)$ are still alive, $3(1.6 \%)$ are evolutive and $8(4.4 \%)$ died (one of IBC, 4 of second cancer and 3 of intercurrent disease). CONCLUSIONS

LCIS is not always an "indolent" disease and, in several cases, it looks like DCIS, but with a longer relapse length.

More aggressive subtypes have not yet been clearly identified. Both mastectomy or CS+RT might be seen as possible options instead of simple lumpectomy.

Cancer-related events

\section{Median F.U. (y)}

Local recurrence (LR) In situ LR

Invasive LR

Median delay to LR (y)

Axillary recurrence

Contralateral BC

Metastases

Second cancer

$\begin{array}{ll}\text { CS (135) } & \text { CS+RT (30) } \\ 9.1 & 12.1 \\ & \\ 10 & 0 \\ 14 & 1 \\ 4.4 & 15 \\ 2 & 0 \\ 7 & 2 \\ 2 & 0 \\ 5 & 2\end{array}$

\section{M (18)}

0

0

\section{0}

Role of sentinel lymph node biopsy in screen detected ductal carcinoma in situ: analysis of $\mathbf{5 8 7}$ cases.

Goyal A, Douglas-Jones A, Stevens G, Monypenny I, Sweetland $H$, Mansel R. Cardiff University, Cardiff; Breast Test Wales, Cardiff, United Kingdom

\section{Background}

The role of sentinel lymph node biopsy(SLNB) in patients with a core needle-biopsy diagnosis of ductal carcinoma in situ(DCIS) has been intensely debated. Core needle-biopsy has an inherent sampling error leading to histologic underestimation of invasive disease. If SLNB is not performed at the time of the definitive operative procedure, patients found to have an invasive cancer, will require a second operative procedure.

The study was designed to determine whether the risk of finding invasive disease on final pathology evaluation in patients with an initial diagnosis of DCIS was sufficiently high to justify the use of SLNB. In addition, we evaluated the factors that may predict preoperatively which patients with DCIS will be upstaged to invasive cancer at the time of definitive surgery.

Methods

We identified 587 women with an initial core needle-biopsy diagnosis of DCIS in the prospective Breast Test Wales(BTW) database from 1990 through 2005. A variety of clinical, 


\section{S262 Abstracts - Poster Session VI}

mammographic and histologic features were identified and correlated with the presence of invasion at excision.

\section{Results}

Median age of patients at the time of diagnosis was 58 years(range 41 to 83 years). 201 patients( $36 \%$ ) were treated by mastectomy and $354(64 \%)$ by breast conservation surgery.

220 of 587 patients $(38 \%)$ were found to have invasive disease on final pathology. The rate of upstaging was related to the presence of a clinically palpable mass and size of the mass $(\mathrm{p}<0.001$, MannWhitney test); mammographic presence of a mass and size of the mass $(\mathrm{p}<0.001$, Mann-Whitney test); presence of microinvasion on core biopsy $(p=0.005$, chi-square test). Multivariate analysis revealed that clinical size of mass and mammographic size of mass were independent predictors of invasive carcinoma on final pathology $(p=0.047$ and $p<0.001$ respectively $)$. Age, grade of DCIS, and presence of comedonecrosis did not help in distinguishing between patients with DCIS and those upstaged to invasive carcinoma at definitive surgery.

Axillary nodal staging(four node sampling or clearance) was done at the time of surgery in 269 of 342 patients(79\%) with available information. Axillary nodal metastases were found in 35 of 269 patients(13\%). All 35 patients had invasive carcinoma on final pathology.

Conclusion

In patients with a pre-operative diagnosis of DCIS, presence of a palpable mass or mammographic mass increases the risk for invasion at definitive surgery. Even though moderate discriminatory power is obtained using these variables, it is not possible to identify a subgroup in which SLNB can be safely omitted. $38 \%$ of patients with an initial diagnosis of DCIS will be found to have invasive carcinoma on final pathology and thus need second surgery for nodal staging. SLNB is difficult after lumpectomy and impossible after a mastectomy. Given the low morbidity associated with SLNB, this procedure should be considered for all patients with an initial diagnosis of DCIS.

\section{1}

Effects of letrozole and anastrozole on ductal carcinoma in situ (DCIS): results from a randomised trial.

Faratian D, White S, Murray J, Renshaw L, Young O, Macaskill EJ, Evans DB, Cameron D, Miller WR, Dixon JM. Western General Hospital, Edinburgh, Scotland, United Kingdom; Novartis Pharma AG, Basel, Switzerland

\section{Introduction}

A number of ongoing clinical studies are investigating the effectiveness of aromatase inhibitors in patients with DCIS. To date there have been no studies looking at the biological effects of aromatase inhibitors on DCIS. The aim of this study was to investigate the effects of letrozole and anastrozole on cell proliferation in patients with DCIS.

\section{Materials and methods}

206 postmenopausal women with 209 invasive estrogen receptor (ER) positive breast cancers were enrolled into a randomised preoperative trial of 14 days treatment with either $2.5 \mathrm{mg}$ of letrozole or $1 \mathrm{mg}$ of anastrozole. A review of initial core biopsies at diagnosis and excision specimens at surgery identified 27 patients with 28 pairs of samples [15 who received anastrozole (A) and 13 letrozole (L)] with sufficient ER positive invasive cancer and DCIS for analysis. Assessment included ER, progesterone receptor (PgR), HER2, and proliferation (Ki67) by immunohistochemistry with FISH for HER 2+. ER and PgR were scored by Allred scores and proliferation scored as \% Ki67 positive cells. Results are presented as means (SEM); analysis is by paired t tests and Pearson's correlation.

\section{Results:}

Invasive cancers: Proliferation

A reduced tumour cell proliferation from baseline in 14/15 cancers from a mean of $9.33(2.31)$ to $1.43(0.46), \mathrm{p}=0.001$ - median and mean reduction $78 \%(58-91)$ and $71.1 \%(8.7)$ from baseline.
$\mathbf{L}$ reduced proliferation from baseline in all 13 cancers from a mean of $7.46(1.52)$ to $0.96(0.39), p=0.001$ - median $85 \%$ (6694) mean $78.8 \%$ (6.6) reductions from baseline.

DCIS: Proliferation

A reduced proliferation in DCIS from 10.1 (3.0) to 4.24 (1.52), $\mathrm{p}=0.058$, by a median of $57 \%(-68-89)$ : mean fall was $24.4 \%$ (31.8).

$\mathbf{L}$ reduced proliferation from 11.8 (2.34) to1.86 (0.76), $\mathrm{p}<0.001$ by a median of $83 \%(68-92)$ and a mean of $77 \%(6.9)$.

Summary of Changes in Proliferation in DCIS

Drug Increase No change Reduction Median \% reduction from

baseline $10-37(-66-89)$

$\begin{array}{lllll}\text { Anastrozole } & 2 & 3 & 10 & 57(-66-89) \\ \text { Letrozole } & 0 & 0 & 13 & 83(68-92)\end{array}$

There was a significant correlation between the magnitude of change in cell proliferation between invasive cancers and DCIS in same patient for $\mathrm{L}, \mathrm{p}=0.026$, but not for $\mathrm{A}, \mathrm{p}=0.72$.

DCIS: PgR

PgR fell with A from a mean score of $4.8(0.72)$ to $3.20(0.83)$, $\mathrm{p}=0.03$ and with $\mathrm{L}$ from $5.2(0.76)$ to $3.46(0.89), \mathrm{p}=0.038$

HER2

A; 3 invasive cancers and 4 DCIS were HER $2+$. The 3 invasive cancers and $3 / 4$ DCIS had a reduction in cell proliferation with A L: 1 invasive and 1 DCIS was HER $2+$ both had a fall in cell proliferation with $\mathrm{L}$.

Conclusions:

DCIS has a similar rate of cell proliferation to invasive cancer. In DCIS, Letrozole significantly reduced proliferation and $\mathrm{PgR}$ expression; Anastrozole significantly reduced PGR expression but the fall in proliferation did not reach significance possibly due to the small sample size. Letrozole should be further evaluated in DCIS.

\section{2}

Changes in DCIS features and treatment over a 20-year period. Analysis of 2512 patients.

Cutuli B, Lemanski C, Cohen-Solal Le-Nir C, Fourquet A, De Lafontan B, Fay R, Jourdan R. Polyclinique de Courlancy, Reims, France; Centre Val d'Aurelle, Montpellier, France; Centre Rene Huguenin, Saint Cloud, France; Institut Curie, Paris, France; Centre Claudius Regaud, Toulouse, France; Centre d'Investigation Clinique, Toul, France; Astra Zeneca, Rueil, France

\section{BACKGROUD:}

DCIS frequency has increased from $3-4 \%$ in the 80 s to $15-20 \%$ in recent years. Several changes occurred during this period in clinicoradiological features as well as in treatment modalities.

\section{MATERIAL AND METHODS}

A prospective national survey (NS) on pure DCIS was conducted in France from March 2003 to April 2004 on 1289 patients. Results were compared to those of 1223 patients previously treated in 9 French Cancer Centers from 1985 to 1996 (French Study). Treatments included conservative surgery alone (CS), conservative surgery with radiotherapy (CS+RT) and mastectomy (M).

\section{RESULTS}

Median age was 52 versus 56 years in NS and French study, respectively. Similarly, family history of breast cancer was reported in $30 \%$ versus $23 \%$ of the patients. Radiological/pathological features and treatments are compared in the table.

Endocrine therapy was used only in the NS in 170 (13.2\%) patients. Several inter-regional differences were observed in the NS regarding mastectomy rates (from $22.6 \%$ to $39 \%$ ), RT use (from $81 \%$ to $96 \%$ ) and endocrine therapy (from $6 \%$ to $34 \%$ ).

\section{CONCLUSIONS}

The most important changes in both studies were the $22 \%$ absolute increase in MD tumors, the $12 \%$ increase in RT after CS and, more particularly, the $41 \%$ decrease in axillary dissection, whereas median tumor size and mastectomy rate remained identical. The NS results are globally in accordance with the French DCIS guidelines recently published (www.fnclcc.fr). 
Comparison between NS and French Study NS (2003-2004) French Study (1985-1996)

$\begin{array}{lll}\text { Mammographically detected (MD) } & 1128(87.6 \%) & 802(65.6 \%) \\ \text { Comedo subtype (CS and CS+RT) } & 156 / 767(20.3 \%) & 274 / 865(31.7 \%)\end{array}$ Comedo subtype (CS$$
\text { CS }
$$$$
\text { CS+RT }
$$

Treatment

Treat

CS+RT

$\mathrm{M}$

Axillary dissection

Sentinel node biopsy
6

난

\section{$99(7.7 \%)$}

$797(61.8 \%)$

$393(30.5 \%)$

$133(10.3 \%)$

$274(21.3 \%)$

$265(21.7 \%)$

$600(49 \%)$

$358(29.3 \%$

$627(51.3 \%)$ $\mathrm{p}$

$<0.0001$

$<0.0001$

NS

$<0.0001$

$<0.000$

$<0.000$

\section{3}

LIBERATE Trial: a safety study of tibolone in breast cancer surgery patients - design and baseline data.

Foidart JM, Bundred NJ, Kenemans P, Kubista E, von Schoultz B, Sismondi P, Vassilopoulou-Sellin R. Univ of Liege, Liege, Belgium, Univ of Manchester, Manchester, United Kingdom; Free Univ, Amsterdam, Netherlands; Medical Univ, Vienna, Austria; Karolinska Inst, Stockholm, Sweden; Univ of Turin, Turin, Italy, Anderson Cancer Center, Univ of Texas, Houston

Background/Objectives: Hormone therapy is contraindicated in women with a history of breast cancer. A pilot study has shown that tibolone relieves vasomotor symptoms in patients receiving tamoxifen after breast cancer surgery. Studies have also shown that tibolone does not stimulate breast tissue, prevents osteoporosis and might therefore be a promising agent to treat vasomotor symptoms in these women. LIBERATE was designed as a randomized, double-blind 5-year trial to evaluate that tibolone 2.5 $\mathrm{mg} /$ day $\left(\right.$ Livial $^{\circledR}$ ) is non-inferior to placebo regarding breast cancer recurrence in women with vasomotor symptoms who have been surgically treated for primary breast cancer within the last 5 years Secondary objectives are overall survival as well as effects on vasomotor symptoms, BMD and health-related QoL.

Methods: Patients were eligible when they had histologically confirmed and surgically treated invasive breast carcinoma (T1-3, N0-2, M0). In non-hysterectomized women, entry required norma thickness of endometrium as judged by transvaginal ultrasound, defined as absence of endometrial polyps in tamoxifen users and double-layer thickness $\leq 4 \mathrm{~mm}$ or $4-8 \mathrm{~mm}$ (when inactive/atrophic) in non-tamoxifen users. The primary end-point (confirmed by blinded adjudication) is breast cancer recurrence, including contralateral. Yearly BMD will be assessed in a subset of patients. The primary analysis will be performed mid 2007, with a followup analysis on all data in 2009.

Baseline data: Recruitment started in July 2002 and was completed in December 2004. 3149 patients were randomized at 245 centers in 31 countries worldwide. Based on the data in May 2005 , the mean age at randomization was 53 years, the mean body mass index 27 , and the mean time since surgery 2.1 years. The mean daily number of hot flushes and sweating episodes was 7 and 6 , respectively. A pathological tumor size of $>2.0 \mathrm{~cm}(\mathrm{~T} 2 / 3)$ was originally reported for $48 \%$ of the patients and a node positive status $(\mathrm{N} 1 / 2)$ for $58 \%$. Of the $78 \%$ patients with a known receptor status, $79 \%$ were $\mathrm{ER}+, 66 \%$ were $\mathrm{PR}+$, and $61 \%$ were both $\mathrm{ER}+$ and $\mathrm{PR}+.74 \%$ received tamoxifen and $9 \%$ aromatase inhibitors Regular unblinded safety reviews performed so far by an independent DSMB have led to recommendations to continue without modification.

Discussion: Tibolone has been shown to relieve vasomotor symptoms after breast cancer surgery. Several trials investigating the effects of $\mathrm{E}(\mathrm{P}) \mathrm{T}$ on breast cancer risk (e.g. HABITS) were stopped prematurely. The LIBERATE trial remains the largest and only ongoing, well-controlled study in this field investigating breast safety.

\section{4}

Vaginal estrogens appear to be contraindicated in postmenopausal women on adjuvant aromatase inhibitors. Kendall AH, Dowsett M, Folkerd EJ, Smith IE. Royal Marsden Hospital, London, United Kingdom

Background: Atrophic vaginitis is a significant problem in approximately $40 \%$ of postmenopausal women. Associated dryness, pain, urinary incontinence and dysparenuia are consistently associated with marked deterioration in quality of life scores [1]. Postmenopausal women with breast cancer being treated with aromatase inhibitors (AI) can experience a worsening of these symptoms due to profound estradiol suppression [2]. As more women are treated with adjuvant AIs physicians are increasingly asked to advise on vaginal estrogen therapy. Vagifem vaginal tablet is commonly used due to good compliance and efficacy in treating atrophic vaginitis and is perceived to result in a low systemic absorption of estradiol [3].

Materials and Methods: We are monitoring the oestradiol levels in 6 women with symptomatic vaginitis who wished to commence Vagifem whilst concurrently on an AI for adjuvant therapy. Vagifem $25 \mathrm{mcg}$ was prescribed as per manufacturer's recommendations; administered daily for 2 weeks then twice per week as a maintenance therapy. Estradiol in serum was measured by radioimmunoassay, after ether extraction, using an assay sensitised to quantify the low levels of estradiol found in postmenopausal women [4]. Levels were measured at baseline, Day 14 and Day 28. Currently results are available from the first 4 women and are reported below. Table1: Estradiol levels in women on Vagifem and AI therapy

Patient Concurrent AI Estradiol level on Vagifem (pmol/L)

$\begin{array}{lllll} & & \text { Baseline } & \text { Day } 14 & \text { Day } 28 \\ 1 & \text { Letrozole } & <3.0 & 220 & 40 \\ 2 & \text { Letrozole } & <3.0 & 232 & 31 \\ 3 & \text { Letrozole } & 3.5 & 77 & 16 \\ 4 & \text { Anastrozole } & <3.0 & 46 & 2.4 \dagger\end{array}$

†Pt. 4 had experienced a 10 day break from Vagifem prior to this measurement

Discussion: Estradiol levels so far analysed in these women using Vagifem are around and above those usually seen in the postmenopausal state (mean 19pmol/L) [5] and greatly exceed those in women on an AI. Thus our initial experience in this group raises concerns over the anti-breast cancer efficacy of such a combination because of raised systemic estradiol levels to a degree which reverses the activity of aromatase inhibitors. Physicians should be advised to avoid this treatment combination and recommend non-hormonal preparations.

1.Ganz, P.A. et al. J Natl Cancer Inst, 2000. 92(13): p. 1054-64.

2.Morales, L. et al. Anticancer Drugs, 2004. 15(8): p. 753-60.

3.Suckling, J. et al. Cochrane Database Syst Rev, 2003(4): p. CD001500.

4.Dowsett M. et al. Cancer Res 1987; 47:1957-1961

5.Dunning A.M. et al. JNCI Vol 96 No. 122001 p.936-945

\section{5}

Menopausal hormone therapy after breast cancer - why are the results so different?

von Schoultz E. Karolinska Institute, Stockholm, Sweden

Background: In 2003/2004 two randomized trials of menopausal hormone therapy in breast cancer survivors were stopped and showed significantly different results. The risk of recurrence in the HABITS-study was HR 3.3, CI $1.5-7.4$ and in the Stockholm trial 0.8 , CI $0.4-1.9(\mathrm{p}=0.02)$.

Material and Methods: Available patient data from the Stockholm trial were analyzed and compared with findings reported from the HABITS. The number of women with follow-up was 345 in HABITS and 359 in the Stockholm study. Median follow-up was 2.1 and 4.1 years respectively.

Results: Among the 175 women allocated to hormone therapy in the Stockholm trial, the median age was 56.9 years, time from diagnosis to randomization 1.3 years, $16 \%$ were node positive, 65 $\%$ were ER-positive, $76 \%$ had used hormones prior to diagnosis and $52 \%$ were on adjuvant tamoxifen. The corresponding figures 


\section{S264 Abstracts - Poster Session VI}

for the 174 women on hormone therapy in the HABITS study were 55.5 years, 2.6 years, $26 \% ; 56 \% ; 52 \%$ and $21 \%$ respectively. The protocol recommendations on hormonal treatment were different. In the Stockholm material perimenopausal women were started on cyclic EPT $(22 \%)$ and postmenopausal women on a spacing out regimen where progestogen was only given every third month $(50 \%)$. After progestogen addition there was one week off treatment. In the HABITS protocol, treatment was given according to standard local practice. Perimenopausal women started on sequential EPT (26\%) and postmenopausal women were recommended continuous combined EPT (46\%).

Discussion: The management of menopausal symptoms in breast cancer survivors remains an unsolved clinical problem of growing importance. The findings that in the Stockholm material, fewer patients were node positive and more women were on adjuvant tamoxifen, could be one explanation for the different results. It could also be that doses of estrogen and progestogen and treatment regimens may be associated with the recurrence of breast cancer. The possibility that estrogen alone or with a minimum of progestogen may have a favorable risk/benefit balance needs further elucidation.

\section{6}

The effects of natural progesterone and medroxyprogesterone acetate on risk markers for breast cancer in the normal postmenopausal breast.

Wood CE, Register TC, Lees CJ, Cline JM. Wake Forest University School of Medicine, Winston-Salem, NC

Background: Recent evidence indicates that the addition of the synthetic progestin medroxyprogesterone acetate (MPA) to postmenopausal estrogen therapy significantly increases the risk of breast cancer. A major question in women's health at this time is whether this adverse effect is specific to MPA or characteristic of all progestogens. Natural progesterone (P4) has attracted recent attention as a "bioidentical" hormone alternative to synthetic progestin compounds, although the effects of $\mathrm{P} 4$ on breast cancer risk are currently unknown.

Material and Methods: In this project we used a postmenopausal primate model to compare the effects of MPA and P4 when given with oral estradiol (E2) on risk biomarkers for breast cancer. Twenty-five ovariectomized adult female cynomolgus macaques were divided into social groups and rotated randomly through the following 4 treatments (expressed as equivalent doses for women): (1) placebo; (2) E2 (1 mg/day); (3) E2 + micronized P4 (200 mg/ day); and (4) E2 + MPA (2.5 mg/day). Treatments were administered orally, and all animals were individually dosed. Hormone treatments lasted two months and were separated by a one-month wash-out period. Breast biopsies were taken at the end of each treatment and uterine area was measured by ultrasound. This interim report includes data from 2 of the 4 treatment cycles. Results: Compared to placebo, E2+MPA resulted in significantly greater breast epithelial area and proliferation (Ki67 expression) in lobular and ductal epithelium $(\mathrm{p}<0.05$ for all), while $\mathrm{E} 2+\mathrm{P} 4 \mathrm{did}$ not significantly increase any of these parameters. Expression of progesterone receptor in ductal epithelium was also significantly higher following E2+MPA $(\mathrm{p}<0.05)$ but not $\mathrm{E} 2+\mathrm{P} 4$ treatment compared to placebo. Uterine area and vaginal maturation were greater in $\mathrm{E} 2, \mathrm{E} 2+\mathrm{P} 4$, and $\mathrm{E} 2+\mathrm{MPA}$ groups versus placebo $(\mathrm{p}<0.0001$ for all)

Discussion: These preliminary findings suggest that natural progesterone has a more favorable effect on biomarkers of breast cancer risk than the synthetic progestin MPA.

\section{7}

Role of hormonal replacement therapy(HRT) on clinical characteristics tumors histo-pronostic factors and survival of patients with breast cancer.

Czernichow C, This P, Asselain B, Savignoni A, Salmon RJ. Institut Curie, Paris, France

The role played by HRT in the pathogenesis of breast cancer has been demonstrated by recent studies. Using the Institut Curie database, we compared the clinical characteristics,tumors histopronostic factors and patient survival according to the presence or absence of HRT.

6,766 post-menopausal women were enteredinto the data-base between 1988 and 1999; 1,492(22\%) had taken HRT for more than 6 months. The mode of discovery,age at diagnosis, preoperative and post-operative clinical and laboratory characteristics of the cancer were collected for all patients(BMI,TNM,SBR grade,Hormonal Receptors,Mitotic Index).The type of treatment,local recurrence rate,metastasis,recurrence-free survival and overall survival were compared between the two populations. Mammographic detection was more frequent in patients receiving HRT and the age at diagnosis was lower than that of patients not taking HRT $(\mathrm{p}<10-4)$. Cancers detected in women receiving HRT were smallers and had a less aggressive biological profile; there were more lobular cancers and the conservative management rate was higher $(\mathrm{p}<10-4)$. The number of local recurrences was identical in the two groups but metastasis-free survival and overall survival were better in patients receiving HRT.

HRT remained an independant prognostic factor on multivariateanalysis with a mean follow-up of 97 months.

As the increasing incidence of breast cancerin western countries also affects pre-menopausal women,HRT alone cannot account for the increasing incidence of breast cancer

\section{8}

Tibolone and its metabolites inhibit invasion of human mammary carcinoma cells in vitro.

Depypere HT, Bracke ME, Vanhoecke BW, Kloosterboer HJ. State Universty, De Pintelaan 185, Ghent, East Flanders, Belgium; Organon, Oss, Netherlands

Tibolone is a synthetic compound that has been very successfully used to alleviate climacteric symptoms. In many European countries it is the number one selling product. After oral administration, tibolone is converted into 3 alfa $\mathrm{OH}$ and 3 Beta $\mathrm{OH}$ tibolone and a small amount of delta 4 tibolone and 3 alfa $\mathrm{OH}$ sulfate. To explore the effect of tibolone and its metabolites breast cancer cells we performed invasion assays. One assay for invasion was based on the in vitro confrontation between cancer cell aggregates and embryonic chick heart fragments in organ culture. The second invasion assay comprised the scoring of the number of cancer cells penetrating into collagen type I gel.

Cultures with $100 \mu \mathrm{M}$ tibolone, 3 alfa $\mathrm{OH}$ tibolone, 3 Beta $\mathrm{OH}$ tibolone and delta 4 tibolone inhibited invasion of MCF 7/6 cells completely. However, $10 \mu \mathrm{M}$ was not active. A significant antiinvasive effect of $100 \mu \mathrm{M}$ tibolone and 3 alfa $\mathrm{OH}$ tibolone on the invasion of T47-D cells was observed.

Invasion of extracellular matrix requires MMP activity. MMP-9 gelatinase activty was reduced in the supernatant of cells treated with tibolone, 3 alfa $\mathrm{OH}$ tibolone and delta 4 tibolone.

These results add valid information on the influence of tibolone and its metabolites on breast cancer behavior. 


\section{9}

Hormone replacement therapy in women with breast cancer. A survey of patient's attitudes.

Turner LE, Bundred NJ. South Manchester University Hospital, Manchester, United Kingdom

Background: Menopausal symptoms such as hot flushes, night sweats and osteoporosis lead to considerable morbidity in the Western World. Women with breast cancer often develop an early menopause due to treatment effects such as chemotherapy, oophorectomy, hormonal drugs and / or the abrupt discontinuation of hormone replacement therapy (HRT). HRT is effective in relieving menopausal symptoms but its use is generally discouraged in women with breast cancer.

Methods: A case controlled survey was conducted to examine the incidence and severity of menopausal symptoms and to identify what factors predicted HRT use in postmenopausal women with breast cancer compared to a control group. Self-completed questionnaires, including Spielberger's (1977) State / Trait Anxiety Inventory (STAI), were distributed to women who had been diagnosed with breast cancer within the past five years attending the South Manchester University Hospital breast out-patient clinics. Questionnaires were mailed to 300 women (control) whose previous routine mammogram screening results were normal. Hopwood's (2001) Body Image Scale questionnaire was also given to women with breast cancer.

Results: Incidence and severity of menopausal symptoms were greater in 146 women with breast cancer, particularly those on adjuvant therapy or after chemotherapy compared to 133 controls $(\mathrm{p}<0.05)$. Psychosocial problems such as depression, state anxiety and loss of sexual interest were correlated with women treated for breast cancer $(\mathrm{p}<0.05)$. Factors associated with HRT use were the need for effective treatment of symptoms (positive correlation, $\mathrm{p}=0.01$ ) and women with breast cancer (negative association, $\mathrm{p}=0.03$ ). A negative linear relationship existed between Body Image Score and the time following treatment $(\mathrm{p}=<0.05)$, likewise with age $(\mathrm{p}=<0.05)$.

Discussion: For women with breast cancer the menopause experience has a huge impact on quality of life both in physical and psychosocial ways. Screening such symptoms using tools like the STAI is imperative to address the needs of women with breast cancer. Hence appropriate services and comprehensive treatments can be directed throughout their care. The perception of need and a history of breast cancer are the main predictive factors associated with HRT use.

\section{0}

The sentinel lymph node biopsy in male breast cancer: the European Institute of Oncology experience.

Chagas ERM, Gentilini O, Intra M, Silva L, Luini A. European Institute of Oncology, Milan, Italy

Background: Male breast cancer comprises approximately $1 \%$ of all cases of breast carcinoma It is a rare disease, and for this reason, the treatment standards for male breast carcinoma have traditionally been extrapolated from those established for women. This study was undertaken to ascertain the outcomes of male breast carcinoma patients who recived treatment at European Institute of Oncology in Milan with sentinel lymph node (SLN) biopsy.

Materials and Methods: We reviewed our database to identify males who underwent SLN biopsy for breast cancer between 1999 and 2005. SNL biopsy was performed in thirty-two male patients. Pre-operative diagnosis of cancer was documented by fine-needle aspiration cytological examination or core-biopsy in 19 patients. The other 13 patients had previously been admitted with excisional biopsy. Lymphoscintigraphy was performed one day before surgery by injecting colloid particles of human serum albumin labeled with freshly eluted ${ }^{99 \mathrm{~m}} \mathrm{Tc}(12 \mathrm{MBq})$, in a volume of $0.2 \mathrm{~mL}$. The lymphoscintigraphy was successful in 32 patients. The sentinel lymph nodes were processed in the following manner: briefly, each sentinel node was measured and cut along its entire longitudinal axis into sections of $50 \mu \mathrm{m}$ intervals thickness, amounting to around 60 sections per lymph node (30 sections per half lymph node). One section of each pair was stained with haematoxylineosin. All patients had normal bone scans, chest X-rays and liver ultrasound.

Results: The average ages was 58 years (range 33-80). Tumor type distribution was twenty-four invasive ductal carcinomas, four intracystic papillary carcinomas and four extensive DCIS. Pathological $\mathrm{T}$ stage presentation was: twenty-eight $\mathrm{T} 1$ and four T2. Tumor grades were: $35 \%$ low, $50 \%$ intermediate and 15\% high. Only in four cases was there lymphovascular invasion. Tumors were ER positive in $97 \%$ of cases. A mean number of 1,5 SLN were identified. No patients with internal mammary lymphatic drainage were identified. Twenty-six patients had negative SLN(s), six patients had positive SLN. Modified radical mastectomy was realized in six. Four men were treated with chemotherapy adjuvant, twenty-five men received adjuvant hormonal. Radiotherapy was realized in 14 patients. Thirty-one patients were followed up wevery 2.3 years.

Discussion: The optimal management of breast cancer in men is as yet unknown because the rarity of the disease precludes large randomized trials. SLN biopsy in male patients with early stage breast cancers is comparable to its use in women. It seems to be a simple and realiable method for stanging the axilla accurately, avoiding the complications of axillary dissection plus having the secondary benefit of cost reduction.

\section{1}

Selective inhibition of ADAM metalloproteases blocks Her-2 extracellular domain (ECD) cleavage and potentiates trastuzumab in blocking the growth of Her-2 overexpressing breast cancer cells.

Liu $X$, Wang $Q$, Yang $G$, Covington $M$, Marando C, Fridman $J$, Caulder E, Zhuo J, Li Y, Yao W, Vaddi K, Newton R, Friedman S, Scherle P. Incyte Corporation, Wilmington, DE

Her-2, a member of ErbB family of receptor tyrosine kinases, is overexpressed in significant portions of human breast $(20 \sim 30 \%)$, non-small cell lung $(20 \sim 60 \%)$, ovarian $(10 \sim 30 \%)$ and gastric (15 25\%) cancer patients. In breast cancer, Her-2 overexpression is associated with poor clinical outcome in patients with lymph node positive disease. The humanized monoclonal antibody, trastuzumab, which is directed against the extracellular domain (ECD) of Her-2, has proven to be an effective therapy for Her-2 positive metastatic patients, suggesting that Her-2 is a critical driver of tumor growth in this patient population. In Her-2 overexpressing cells, the ECD is frequently cleaved, rendering the remaining transmembrane portion of Her-2 (p95) constitutively active. In breast cancer patients, the presence of p95 has been shown to correlate with increased metastasis and decreased survival, suggesting that signaling via p95 is clinically relevant and may represent an attractive target for therapeutic intervention. It was previously reported that Her-2 cleavage is inhibited by matrix metalloprotease inhibitors. Data from our laboratories demonstrate that this cleavage is mediated by a subset of the ADAM metalloprotease family members in vitro. To test the role of ADAM metalloproteases in regulating the growth of tumor cells that overexpress Her-2, we have identified a series of potent, selective, orally active small molecule inhibitors of ADAM metalloproteases exemplified by INCB003619. INCB003619 effectively blocks Her-2 ECD shedding $\left(\mathrm{IC}_{50}\right.$ within nanomolar range) and potentiates the antiproliferative activity of trastuzumab in Her-2 overexpressing breast cancer cell lines in vitro. Biochemical data further suggest that the potentiating effect is mediated by enhanced inhibition of ERK and AKT activation. In addition, INCB003619, in combination with trastuzumab, enhances the pro-apoptotic and antiproliferative activities of the chemotherapeutic agent, paclitaxel, and the EGFR tyrosine kinase 


\section{S266 Abstracts - Poster Session VI}

inhibitor, gefitinib. Consistent with these in vitro findings, INCB003619 also enhances the antitumor effect of trastuzumab in the xenograft tumor model derived from the Her-2 overexpressing BT-474 breast cancer cell line. Together, these findings suggest that the selective inhibition of ADAM metalloproteases may represent a novel and effective approach for treating Her-2 overexpressing breast cancer patients when combined with trastuzumab and other cytotoxic or biological antitumor agents.

\section{2}

4-OHT gel demonstrates potent clinical antiestrogenic activity in the breast: implications for treating benign breast pain and reducing cancer risk.

Mansel RE, O'Connell K. University of Wales College of Medicine, Cardiff, Wales, United Kingdom; Columbia Univ Medical Ctr, New York, NY

Background: Tamoxifen is indicated for breast cancer prevention but has not achieved widespread use due to side effects. Tamoxifen has also been shown to alleviate cyclic mastalgia, but acute adverse effects (eg, hot flushes) and long-term risks (eg, endometrial cancer, cardiovascular risk) preclude widespread use. 4-Hydroxytamoxifen (4-OHT), a highly potent metabolite of tamoxifen that is absorbed through the skin, is currently under investigation for the treatment of cyclic mastalgia. The goal of this study was to determine the efficacy, safety, and tolerability of 4-OHT gel in cyclic mastalgia. Material and Methods: Premenopausal women were randomized to receive 2-mg $(n=43)$ or 4-mg $(n=46) 4-O H T$ gel, or placebo $(\mathrm{n}=41)$. Efficacy assessments included change from baseline in the average of the 7 worst Visual Analogue Scale (VAS) scores; physician's clinical evaluation of pain, tenderness, and nodularity; and patient's global assessment of pain. Results: After 4 cycles of treatment, 4-mg 4-OHT resulted in a significant improvement in mean VAS scores $(-32.1$, vs -19.3 with placebo; $P=0.034)$. Mean VAS scores with 4-mg 4-OHT decreased from 73.3 at baseline to 52.8 (cycle 1), 37.6 (cycle 2), 30.6 (cycle 3), and 30.6 (cycle 4). With placebo, mean VAS scores decreased from 69.6 at baseline to 54.0 (cycle 1), 48.6 (cycle 2), 42.1, and 42.2. A significant placebo effect was observed at cycle 1 , but from cycles 2-4 a clear separation in 4-OHT vs placebo emerged. Significant improvements with 4-mg 4-OHT versus placebo were observed in physician's assessments of pain $(P=0.010)$, tenderness $(P=0.012)$, and nodularity $(P=0.017)$, as well as patient assessment of pain $(P=$ 0.022 ). For all 4 parameters, the rating of "very much improved" was consistently higher in the 4-mg 4-OHT group.

Percentage of Patients Rating Parameter as "Very Much Improved" After 4 Cycles of

Treatment

Pain (physician assessed)

Nodularity (physician assessed)

Pain (patient assessed)

4-mg 4-OHT $(n=40) \quad$ Placebo $(n=36)$

$\%(\mathrm{n})$

32.5 (13)

$27.5(11)$

$15.0(6)$
$35.0(14)$

$\%(\mathrm{n})$

$8.3(3)$

$8.3(3)$

$2.8(1)$
$11.1(4)$

No drug-related severe adverse event (SAE) occurred in any treatment group. There were no significant changes in progesterone or estradiol plasma concentrations and no evidence of menstrual cycle disruption following exposure to 4-OHT. Discussion: Following 4 months of daily 4-OHT treatment, the symptoms of cyclic mastalgia significantly improved as measured across both physician- and patient-rated scales. 4-OHT appears to offer a safe and tolerable treatment of cyclic mastalgia, providing breast surgeons, gynecologists, and breast physicians with a treatment option for patients presenting with benign breast pain, but also the potential for a new prevention strategy.

\section{3}

The effects of relaxation guided imagery on natural killer (NK) cell and cytokine IL-2 induced NK cytotoxicity in breast cancer patients.

Lengacher CA, Bennett M, Gonzalez L, Cox C, Cantor A, Djeu J, Carter WB, Buck H, Yang CY. University of South Florida, Tampa, FL; H. Lee Moffitt Cancer Center \& Research Institute, Tampa, FL; Indiana State University, Terre Haute, IN

Background: Psychoneuroimmunology is an evolving science, concerned with bidirectional interactions between behavioral, neural, endocrine and immune system interactions. The use of relaxation-guided imagery has great potential to reduce stress and improve immune function for patients with breast cancer. To date, limited data exist that objectively measure these outcomes in patients using relaxation-guided imagery. We hypothesized that application of relaxation-guided imagery in breast cancer patients would improve immune function, and tested immune function using NK cell cytotoxicity.

Methods: This pilot study used a randomly assigned pre-test, post-test experimental design with 28 breast cancer patients, aged 25-75, with the diagnosis of stage I or stage II breast cancer. The experimental group received relaxation-guided imagery, and the control group received standard care. The effects of guided imagery on immune function was measured by NK cell cytotoxicity and IL-2 activation of NK cell cytotoxicity prior to surgery and four weeks post surgery. Peripheral blood mononuclear cells were serially diluted to achieve effector cell: target cell concentrations of 100:1, 50:1, 25:1 and 12.5:1. NK activity was measured using a 15 hour incubation, chromium-release assay. Cytotoxicity of NK cells was measured against chromium labeled K-562 (human leukemia) target cells. IL-2 was used to enhance reactivity of patient NK cells. After incubation, cytotoxicity was measured through the release of radioactive chromium, detected using standard gamma counter protocol. Student's t-test was used to statistically evaluate the two groups.

Results: Relaxation guided imagery significantly enhanced NK cytotoxicity and IL-2 activated NK cytotoxicity at 4 weeks post surgery. Increased NK cytotoxicity for the guided imagery group was significant at 100:1, 50:1, and 25:1 dilutions $(\mathrm{p}<.01$ at 100:1 and $50: 1 ; \mathrm{p}<.05$ at $25: 1)$, and increased IL-2 activated NK cytotoxicity ( $p<0.01$ at 100:1, 50:1, and 25:1, and $\mathrm{p}<0.05$ at 12.5:1). No differences were identified in the pre-treated groups. Discussion: Relaxation-guided imagery enhanced NK cytotoxicity and IL-2 activated NK cytotoxicity in post operative breast cancer patients. These findings suggest that a relaxation intervention such as guided imagery could have a profound effect on immune function. Use of alternative therapies such as guided imagery could be an effective intervention in clinic practice to improve outcomes by enhancing immune function, and additional studies to support this hypothesis are warranted.

* This study was funded by the American Cancer Society

\section{4}

Decision criteria for adjuvant chemotherapy or hormonal therapy in node negative breast cancer: results of a french oncologist survey.

Cowen D, Gligorov J, Pignon T, Padovani L. Hôpital Timone, Marseille, France; Hôpital Tenon, Paris, France

Between oct. 2004 and feb. 2005, we mailed a questionnaire to 59 French oncologists selected for their experience in the field of breast cancer (written or oral communication, congress lectures), as to identify factors associated with chemotherapy prescription over hormonal therapy alone or no adjuvant treatment. The oncologists were also asked to answer 3 clinical cases with increasing risks of recurrence and death due to cancer, which had been calculated according to the website www.adjuvantonline.com. Benefits of associating chemotherapy and hormonal therapy over hormonal therapy alone were calculated for cases 1, 2 and 3 and 
were respectively $0.8 \%, 1.8 \%$ and $1.5 \%$ for absolute 10 -year survival, and $4.7 \%, 3.4 \%$ and $3.8 \%$ for 10 -y recurrence risk. Results: participation was $68 \%$, with $80 \%$ male and $20 \%$ female Mean age was 49 years. Medical practice was public for $63 \%$ of participants and private for $37 \%$, and experience in the field of breast cancer was superior to 10 years in $75 \%$ of cases. According to oncologists, the factors associated with a chemotherapy prescription were age, size and grade (100\% for each), hormonal receptor status $(95 \%)$, micro-metastasis in sentinel node ( $\mathrm{SN})$ $(60 \%)$, cerb-2 status $(38 \%)$, Ki-67 value $(36 \%)$, PAI-1 $(23 \%)$ and tumor location in the inner quadrants $(10 \%)$. However, maximum age for chemotherapy prescription was $65,70,75$, and 80 years for $10 \%, 25 \%, 50 \%$ and $15 \%$ of answers. Age under 35 was a sufficient criteria for giving chemotherapy in $56 \%$ of cases while $35 \%$ required an extra risk factor, and $9 \%$ two more factors. Giving chemotherapy to patients above 70 years of age was acceptable only if there were 1,2 or 3 additional risk factors respectively in $20 \%, 40 \%$ and $25 \%$ of answers. Seemingly, the minimal size required for prescribing chemotherapy was $5 \mathrm{~mm}, 10$ $\mathrm{mm}, 15 \mathrm{~mm}$, and $20 \mathrm{~mm}$ respectively for $8 \%, 25 \%, 32 \%$ and $35 \%$ of answers. Also, while $60 \%$ would prescribe a chemotherapy in case of a micrometastasis in a SN, among these $37 \%$ would do so for cells only visible with IHC staining. Finally, for clinical cases 1,2 and 3, chemotherapy was prescribed in $82 \%, 55 \%$ and $50 \%$ of answers, although in case 1 the absolute 10 year survival was $96 \%$ with no further treatment. Chemotherapy prescription was not related to the benefit over hormonal therapy or over no treatment, in terms of absolute survival, or recurrence risk. Detailed analysis will be presented.

Conclusion: among experts in the field, there are very wide differences in the risk factors necessary for prescribing adjuvant treatments in node negative breast cancer patients. Our study underlines the necessity of evidence based decision making.

\section{5}

Premature menopause following chemotherapy for early stage breast cancer: long-term results from IBCSG trials V and VI.

Gelber S, Partridge A, Gelber RD, Castiglione-Gertsch M, Goldhirsch A, Winer E. DFCI, Boston, MA; University of Bern, Bern, Switzerland; European Institute of Oncology, Milan, Italy

Background: The likelihood of premature menopause has not been thoroughly explored in women who remain premenopausa following completion of adjuvant chemotherapy for breast cancer. Material and Methods: We evaluated the age of menopause in women with early stage breast cancer who remained premenopausa following adjuvant chemotherapy using data from the International Breast Cancer Study Group (IBCSG) Trials V and VI. From 19811985, Trial V enrolled 1407 eligible premenopausal women randomized by nodal status: 692 with $\mathrm{N}$ - disease received either no systemic therapy (No CT) or CMFx1 perioperatively (PeCT); 715 with $\mathrm{N}+$ disease received either CMFx6 postoperatively (CMFx6), or PeCT + CMFx6. Median follow up is 19 years. Tria VI enrolled 1475 eligible women from 1986-1993 and randomized to a $2 \times 2$ factorial design evaluating 3 versus 6 initial cycles of CMF and the efficacy of an additional 3 delayed cycles of CMF. The median follow up is 13 years. From Trial VI we included only the 375 women randomized to receive 6 initial cycles of CMF

Results: We excluded women who reported no menses during 12 24 months after randomization $(\mathrm{N}=934)$, history of hysterectomy $(\mathrm{N}=16)$ or bilateral oophorectomy $(\mathrm{N}=8)$, or missing $12-24$ month menses data $(\mathrm{N}=57)$, creating a cohort of 767 women in the following age at diagnosis groups: $<30$ years $(\mathrm{N}=26), 30-34$ years $(\mathrm{N}=89), 35-39$ years $(\mathrm{N}=186), 40-44$ years $(\mathrm{N}=237)$ and 45 and over $(\mathrm{N}=229)$. 540 women had received No CT or PeCT (mean age $=42$ years); 227 had received CMFx6 or PeCT+CMFx6 (mean age $=39$ years). Using a Cox proportional hazards model, censoring at recurrence, new primary or death, we found that CMF (6 or 7 cycles $)(\mathrm{HR}=2.03, \mathrm{p}<0.0001)$ and temporary amenorrhea $(\mathrm{HR}=$
$1.96, \mathrm{p}<0.0001)$ were associated with premature menopause. Age at diagnosis $(\mathrm{HR}=0.84, \mathrm{p}<0.0001)$ appears to be confounded by competing risks, such as an increased risk of recurrence for younger women and more frequent amenorrhea for older premenopausal women. Using a logistic regression model for subjects alive and disease free at 5 years $(\mathrm{N}=478)$ and 10 years $(\mathrm{N}=309)$, the table below predicts the percent of women in menopause by age at diagnosis and treatment.

Discussion: Women who remain premenopausal after 6 or 7 cycles of CMF have a higher likelihood of going through menopause at an earlier age than women who received 0 or 1 cycle. Temporary cessation of menses appears to be a marker for earlier onset of menopause. These findings may assist in making reproductive decisions after a diagnosis of breast cancer. Women in Menopause by 5 and 10 years $(\%)$ * By 5 Years $(\%)$

\begin{tabular}{|c|c|c|c|c|}
\hline \multirow[b]{2}{*}{ Age at Diagnosis } & \multicolumn{2}{|c|}{ By 5 Years $(\%)$} & \multicolumn{2}{|c|}{ By 10 Years (\%) } \\
\hline & $\begin{array}{l}\text { No CT or } \\
\text { PeCT }\end{array}$ & CMFx6 +/- PeCT & $\begin{array}{l}\text { No CT or } \\
\text { PeCT }\end{array}$ & CMFx6 +/- PeCT \\
\hline 25 & 9 & 15 & 29 & 68 \\
\hline 30 & 20 & 35 & 51 & 83 \\
\hline 35 & 37 & 62 & 72 & 92 \\
\hline 40 & 58 & 83 & 86 & 96 \\
\hline 45 & 77 & 93 & 94 & 98 \\
\hline
\end{tabular}

\section{6}

The evaluation of the clinical effectiveness of telemedicine in breast cancer multidisciplinary decision making: TELEMAM, a cluster randomised trial.

Kunkler IH, Fielding RG, Brebner J, Prescott RJ, Maclean JR, Chetty $U$, Bowman A, Neades $G$, Lee R, Smith M, Dixon JM, Swann S, Macnab M, Cairns J, Gardner T, Lee M. Edinburgh University, Edinburgh, United Kingdom

Background: In Scotland regional managed clinical networks of cancer professionals have been adopted as the administrative framework to provide equity of access to high standards of cancer care regardless of domicile. Telemedicine (TM) provides a tool for linking multidisciplinary team meetings (MDTM) between peripheral cancer units (PCU) and cancer centres (CC) for clinical decision making without the need for oncologists to travel from the CC to PCUs. There is limited information on the clinical effectiveness of TM to support joint decision making on the management of breast cancer between CCs and PCUs.

Aims and methods: We report the primary clinical outcome measure of the first randomised trial (TELEMAM) evaluating the clinical effectiveness of telemedicine for breast cancer MDTMs. The weekly MDTMs for the discussion of new or recurrent breast cancer cases at two PCUs (Dumfries, Fife), were randomised to standard 'face-to-face' (S) or to TM delivered meetings linked to the Edinburgh Cancer Centre. Imaging +/- pathology was remotely displayed from PCUs to the CC. Randomisation was in 4 week blocks over 1 year with 2:1 weighting in favour of TM. The primary endpoint was satisfaction of breast MDT members with mode of meeting delivery. Satisfaction of the MDT members was recorded per patient discussion on a standardised proforma assessing consensus on management, confidence in and appropriate sharing of the decision.

Audio, video and image quality were noted.

Results: Data was collected on 76 meetings involving 473 patient discussions, 28 standard (12 Dumfries, 16 Fife) and 48 TM delivered meetings (24 Dumfries, 24 Fife). Meetings in the two arms had a similar balance of new, re-staging and postoperative adjuvant patients. Participants' satisfaction that consensus as to the next steps in caring for the patient was reached by all involved, confidence that the decision reached was in the best interests of the patient, and feeling that the discussion was appropriately shared were similar in both arms of the trial (Table).While there was a tendency for better outcomes in the standard arm, these were not clinically important.

Conclusions: The clinical effectiveness of TM as a mode of breast MDT meeting delivery is similar to standard 'face to face' meetings.It facilitates involvement of a regional network of cancer 


\section{S268 Abstracts - Poster Session VI}

professionals in decisions on patient management irrespective of distance.

\begin{tabular}{|c|c|c|c|c|c|c|}
\hline & \multicolumn{2}{|c|}{ Consensus } & \multicolumn{2}{|c|}{ Confidence } & \multicolumn{2}{|l|}{ Shared } \\
\hline & $\mathrm{S}$ & TM & $\mathrm{S}$ & $\mathrm{TM}$ & & TM \\
\hline Strongly agree & $280(22)$ & $370(14)$ & $274(22)$ & $383(14)$ & $272(22)$ & $356(13)$ \\
\hline Agree & $959(76)$ & $2193(80)$ & $950(75)$ & 2193(80) & $947(75)$ & $2179(80)$ \\
\hline Neutral/undecided & $30(2)$ & $140(5)$ & $35(3)$ & 141(5) & $34(3)$ & $135(5)$ \\
\hline Strongly disagree & 2(1) & $34(1)$ & $2(1)$ & $11(1)$ & $6(1)$ & $45(2)$ \\
\hline Strongly disagree & $0(0)$ & $10(1)$ & $0(0)$ & $8(1)$ & $0(0)$ & $14(1)$ \\
\hline
\end{tabular}

6057

Fatigue, weight gain, lethargy and amenorrhea in breast cancer patients on chemotherapy: is subclinical hypothyroidism the culprit?

Kumar NB, Allen K, Riccardi D, Bercu B, Cantor A, Minton S, Balducci L, Jacobsen P. H. Lee Moffitt Cancer Center \& Research Inst, Tampa, FL; University of South Florida, Tampa, FL

BACKGROUND: The purpose of this study was to prospectively observe the relative contribution of each viable mechanism such as hyperphagia, physical activity, body composition, steroid hormonal and thyroid function, fatigue scores on changes in body weight in breast cancer patients, receiving adjuvant chemotherapy. METHODS: This was a prospective observational research design where 198 consecutive breast cancer patients receiving adjuvant chemotherapy were monitored from start to end and 6 months post therapy on changes in anthropometics, fatigue, nutritional intake, physical activity, thyroid and steroid hormones. RESULTS: We observed a weight gain over $>5 \mathrm{lbs}$ in $22.2 \%$ of this patient population with a significant and progressive gain of $6.7 \mathrm{lbs}$ $(\mathrm{P}<0.0001)$ at six months. Ninety four percent of all patients reported fatigue and $56 \%$ of patients reported lowered physical activity. A significant reduction in serum free and total estradiol $(\mathrm{P}<0.0001)$ was observed indicative of reduction in ovarian function with $86 \%$ amenorrehic at the end of treatment. A significant reduction in mean serum triiodothyronine uptake levels $(\mathrm{P}<0.05)$, in addition to a significant increase in TBG $(\mathrm{P}<0.0001)$ from baseline to end of chemotherapy, was observed. In addition 20$25 \%$ of this patient group was already diagnosed with clinical hypothyroidism at diagnosis and treated. Changes in fatigue frequency and serum sex-hormone binding globulin (SHBG) were variables significantly predictive of weight gain $(\mathrm{P}<0.0001)$.

CONCLUSIONS: Cytotoxic agents may influence thyroid function in breast cancer patients contributing to and progressively worsening symptoms such as weight gain, amenorrhea, fatigue and lowered physical activity in this population. The present study indicates the value of screening breast cancer patients for thyroid function at diagnosis or pre-treatment.

\section{8}

The Toyota production system applied to breast cancer care.

Wechter DG, Dubuque DP, Jacobs AD. Virginia Mason Medical Center, Seattle, WA; The Cancer Institute, Virginia Mason Medical Center, Seattle, WA

Background: In 2002, Virginia Mason Medical Center first applied the key principles of the Toyota Production System to health care delivery. These are takt time, the amount of time required to meet daily patient demand; one piece flow, providing patient service in a continuous flow without waits; pull, providing service when and how desired by the patient; and standard work for all providers.

Materials and Methods: A value stream map outlined the steps a breast cancer patient needed to take from diagnosis to followup. Our goals were to reduce the time from diagnosis to first step in treatment (lead time), standardize pretreatment evaluation and post-treatment follow-up, develop patient education tools, and create a standard intake form. A multidisciplinary team of providers participated in one week of daily intensive process improvement activities called a Rapid Process Improvement Workshop (RPIW) in which new ideas were tested and refined.

Results: Lead time was reduced from a mode of 21 to 10.5 days by providing consultations with all providers in one day when desired by the patient, shifting consultations for in situ carcinoma from medical oncologists to nurse practitioners, creating schedule hold times, eliminating some appointments with medical oncologists by developing follow-up guidelines, and by standardizing pretreatment studies and imaging through the introduction of teamwide decision tools. Pretreatment evaluation and follow-up guidelines were based on National Comprehensive Cancer Network (NCCN) recommendations. Our website was updated and we designed a Personal Care Journal which included each patient's reports, standard educational materials, and a 5 year follow-up calendar. A single health history intake form was created incorporating data needed for all providers so the patient would not need to fill out a different form for each consultation.

Discussion: Although manufacturing principles may seem far removed from the daily practice of medicine, we found that the same concepts yielding defect-free efficient production of automobiles with great customer satisfaction can be applied to the complex steps involved in the delivery of breast cancer care. Application of the Toyota Production System concepts improved a process involving many providers by reducing or eliminating wasteful steps rather than increasing the speed of any one task or adding new resources. Variation and inefficiency were reduced resulting in an improvement in quality and service.

\section{9}

Correlation between preference for adjuvant therapy prior to surgery and actual choice of therapy.

Fama T, Wood ME, Muss HB. University of Vermont, Burlington, $V T$

Background: Several studies have shown that women would choose adjuvant therapy for a small gain in survival. This study examines patient pretreatment preferences for hormonal and chemotherapy prior to breast cancer surgery and compares these preferences with actual choices.

Methods: All women with invasive or noninvasive breast cancer with clinically negative nodes seen at Fletcher Allen Health Care were eligible and offered study participation. After informed consent and prior to definitive surgery women completed a measure of psychological distress (the impact of events scale) and were asked to choose preference for therapy (no therapy, hormonal or chemotherapy or both) in response to three clinical scenarios. The scenarios provided precise risk, benefit (using ADJUVANT!, a web-based tool) and side effect information with low (10\%), moderate $(25 \%)$ or high risk $(44 \%)$ risk of death from breast cancer at 10 years. Presented here are the women with ER+ invasive cancer and risk of recurrence matching one of the three scenarios. Statistical methods were based on contingency table approaches and the calculation of p-values using Fishers Exact Tests as implemented with SAS.

Results: 69 women were enrolled from 2/02-4/05, with a mean age of 56 (range $36-89$ ), $24 \%$ over age $65,52 \%$ were low, $7 \%$ moderate and $12 \%$ high risk of recurrence. $42.7 \%$ of women saw a medical oncologist as part of their pre-surgical evaluation. Prior to surgery $56 \%$ of women chose both chemo and hormonal therapy regardless of risk of recurrence. Only $38 \%$ made the same choice after surgery as before surgery. No variable correlated with treatment preference prior to surgery, however, women with greater education were more likely to choose no therapy in the low recurrence risk scenario $(\mathrm{p}=0.15)$. Age, insurance status, psychological distress, risk and seeing a medical oncologist prior to surgery (but not pretreatment therapy preference) was significantly correlated with actual choice of therapy in univariate analysis $(\mathrm{p}<0.05)$. A logistic regression analysis revealed that greater risk, younger age and more intrusive thoughts were most significantly correlated with more aggressive treatment choice $(\mathrm{p}<0.01)$. 
Discussion: This study is among the first to correlate pretreatment preference for therapy with the actual therapy chosen and received. Although, there was not a correlation between pre surgical preference for adjuvant therapy and actual choice; level of risk, psychological distress and age do correlate with the actual choices that women make. It is therefore important to address psychological distress and provide the most accurate assessment of risk to women making decisions for adjuvant therapy for breast cancer.

\section{0}

One year outcomes of an early identification and intervention model to reduce upper extremity morbidity related to breast cancer treatment.

Gergich NL, Pfalzer LA, McGarvey CL, Augustine EA, Springer B Gerber LH, Soballe PW. National Naval Medical Center, Bethesda, MD; National Institutes of Health, Bethesda, MD; University of Michigan-Flint Campus, Flint, MI; Walter Reed Army Medical Center, Washington, DC

Background: It is widely accepted that early detection and management of impairments and limb dysfunction after breast cancer treatment contribute to more successful functional outcomes. Health care providers should be encouraged to preemptively assess for upper extremity (UE) morbidities after breast cancer treatment including; shoulder dysfunction, scarring and skin changes, pain, fatigue and lymphedema. This can be accomplished by adopting cost-effective models for early identification of impairments and providing intervention while the functional limitations are minimal, thereby preventing long term loss of function.

Materials and Methods: A prospective, observational study $(n=159)$ with one year follow-up assessed the effects of an early identification and intervention model used on women after breast cancer treatment. Measurement of UE morbidities, impairments and disability after cancer treatments were taken, e.g. quality of life as measured by the MOS SF 36, active range of motion, strength, lymphedema as measured by the optoelectronic volumeter (Perometer $\left.{ }^{\circledR}\right)$, and self-reported physical activity disability. Individuals were screened prior to surgical treatment and followed-up at approximately two to four weeks postoperatively and at three month intervals thereafter, up to 18 months.

Results: A small group of women demonstrated UE impairments (AROM, strength) prior to breast cancer treatment (5 to $8 \%$ ). The incidence of UE impairments at one year after treatment ranged from $3-8 \%$. The incidence of lymphedema within the first year of treatment ranged from 5-9\% using $150 \mathrm{ml}$ volume change from baseline as the criteria for lymphedema. QOL at one year after treatment showed that mental and physical function were similar (mean of 47 vs.45) and generally high but mental function had twice as much variability (Standard deviation of 9 vs.18).

Discussion: Incidence of UE morbidity after breast cancer treatment has been documented in the literature as high as $50 \%$ with lymphedema incidence reported on average at $33 \%$. This study clearly demonstrates the potential for substantial reduction in UE dysfunction related to breast cancer treatment when using an early identification and intervention model. Many morbidities such as pain, reduced range of motion, decreased strength and subclinical lymphedema were detected early and managed with minimal, cost-effective intervention. Additional research is needed to assess ways of maintaining this cost effective model of care in the long-term.

\section{1}

Longitudinal patterns of weight gain after breast cancer diagnosis: observations beyond the first year.

Makari-Judson G, Judson CH, Barham RB, Mertens WC. Baystate Medical Center, Springfield, MA

Background: Weight gain after a breast cancer diagnosis has been reported, but few have reported weight gain patterns and associations beyond the first year.

Purpose: To determine the durability of weight changes observed one year after diagnosis, and to identify groups with differing weight gain risks two and three years after initial diagnosis.

Methods: Retrospectively-identified breast cancer patients (stage I-IIIB) were evaluated for parameters including weight at diagnosis and one, two and three years later, height, body mass index (BMI), age, menopausal and change in menopausal status, as well as therapy and pathologic stage. Regression models identified significant independent predictors of weight change. Recursive partitioning analysis (RPA) was employed to divide the dataset into relevant and significant groups.

Results: Regression models/RPA demonstrated that weight gain at one year $(\mathrm{n}=185$; mean $1.5 \mathrm{~kg}$; $95 \%$ confidence interval [CI] $0.9,2.3$ ) was associated with younger age, adjuvant chemotherapy, and lower BMI (Proc ASCO 2003;22:726). Weight change at two years was greater than at year one (mean $2.7 \mathrm{~kg}$; 95\% CI 1.9, 3.6). Univariate associations with year two weight gain were year one weight gain $(\mathrm{p}<0.0001)$, younger age $(\mathrm{p}<0.0001)$, adjuvant chemotherapy $(\mathrm{p}<0.0001)$, adjuvant anthracycline therapy $(90 \%$ of regimens, $p<0.0001)$, and lower BMI $(p=0.05)$. Stepwise multivariate analysis revealed year two weight change from baseline was associated with weight change at year one $(\mathrm{p}<0.0001)$, adjuvant chemotherapy $(p=0.012)$ and younger age $(p=0.049)$. RPA for weight change at year two identified four groups (age $\geq 56, \mathrm{BMI} \geq$ $25.6 \mathrm{~kg} / \mathrm{m}^{2}$ [mean change $-2.2 \mathrm{~kg}$ ]; age $<56$ without adjuvant anthracycline therapy [mean $1.4 \mathrm{~kg}$ ]; age $\geq 56$, BMI $<25.6$ [mean $2.6 \mathrm{~kg}$ ]; and age $<56$ treated with anthracyclines [mean $5.2 \mathrm{~kg}$ ]). Weight change from year two to year three was not significant ( $\mathrm{n}=150$ mean change $0.3 \mathrm{~kg}, 95 \% \mathrm{CI}-0.3,0.9, \mathrm{p}=0.86$ ), and was not associated with any variable in univariate analysis. Patients with RPA-derived factors associated with mean weight loss at year one (age $\geq 59, \mathrm{BMI} \geq 30$ ) continued to weight less at year three than at baseline. Repeated measures model for weight change over three years from diagnosis revealed weight gain for age $<59$ $(\mathrm{p}<0.0001), \quad \mathrm{BMI}<30 \quad(\mathrm{p}=0.0007)$, anthracycline therapy $(\mathrm{p}=0.0028)$, as well as the product of age $<59$ and $\mathrm{BMI}<30$ $(\mathrm{p}=0.009)$; the model for weight change over 2 years was similar. Conclusions: Weight gain in early-stage breast cancer patients continues two years after diagnosis, with no further significant change at three years. Those gaining weight at one year (younger patients and those receiving adjuvant chemotherapy) tended to gain further weight, while those tending to lose at year one (older, obese women) remained stable. Weight changes are not a shortterm phenomenon, and persist three years beyond diagnosis. Longer observation periods are needed to determine the full extent of the change and the effectiveness of interventions.

\section{2}

Meta-analysis examining the efficacy of serotonin selective reuptake inhibitors in the treatment of women with hot flashes.

Mukherjee SD, Al-Sagheir A, Levine M. Juravinski Cancer Centre, Hamilton, ON, Canada

Background: Hot flashes can be particularly troublesome in postmenopausal women as well as those who are on medications such as Tamoxifen or aromatase inhibitors for breast cancer treatment. Patients with chemotherapy-induced menopause may also develop hot flashes that can impact on their quality of life. Serotonin selective reuptake inhibitors (SSRI's) have been studied to determine if they reduce the frequency or severity of hot flashes. 


\section{S270 Abstracts - Poster Session VI}

Objective: To provide a systematic review of the published literature considering all randomized controlled trials (RCT's) evaluating SSRI use in women experiencing hot flashes.

Methods of Review: Five medical literature databases were searched to identify all potential randomized placebo-controlled trials evaluating SSRI's in women with hot flashes. The methodological quality of the RCT's was assessed. The results of all studies that met our inclusion criteria were compiled and systematically reviewed. The primary outcomes for the pooled analyses were the number of patients who had a $50 \%$ decrease in hot flash frequency or hot flash score. Other outcome measures included absolute reductions in hot flash frequency and hot flash score, and the number of withdrawals in the treatment and placebo arms.

Results: A total of 7 RCT's met the study inclusion criteria. An odds ratio of $0.59(95 \%$ confidence interval $0.38,0.93)$ favoured treatment with SSRI's for the primary outcome of a fifty percent decrease in hot flash frequency or score. Pooled analyses also favoured treatment with SSRI's for the outcome measures of absolute reduction in hot flash frequency (weighted mean difference $0.91,95 \%$ CI 0.48 to 1.34 ) and hot flash score (weighted mean difference $2.48,95 \%$ CI 0.51 to 4.44 ). Pooling of studies with greater than $50 \%$ breast cancer patients suggested that SSRI's were efficacious in both women with breast cancer and those without breast cancer. Studies involving a treatment duration of 4-8 weeks showed a significant benefit for SSRI's, while pooling of 2 studies with data for 3 months of treatment showed no benefit of SSRI's in reducing hot flashes, although this latter analysis was underpowered. Overall, SSRI's were well tolerated with only minor side effects reported.

Conclusions: SSRI's reduce the number and severity of hot flashes in women with and without breast cancer. Whether or not the treatment effect lasts more than 2 months requires further studies to answer this question.

\section{3}

Time to progression as a surrogate endpoint of clinical benefit in the taxanes and aromatase inhibitors decade: "El Álamo" project.

De la Haba J, Aranda E, Lluch A, Llombart A, Martín M, Alba E, Munárriz B, Balil A, Ramos M, Martínez del Prado P. On Behalf of the Spanish Breast Cancer Research Group (GEICAM), San Sebastián de los Reyes, Madrid, Spain

Background: retrospective studies have shown an improvement in overall survival of metastatic breast cancer (MBC) patients (pts) during the last decades, which seems to be related to the availability of new drugs for the standard daily care of pts (Giordano, S.H., et al., Is breast cancer survival improving? Cancer, 2004. 100(1): p. 44-52.). However, other factors, such as the improvement of supportive cancer care might be influencing the positive outcomes shown in this analysis. We consider time to progression (TTP) as an adequate endpoint to predict clinical benefit in MBC. Its relationship to standard administration of new therapies is examined. Objectives: to analyze a 10 year- time course of TTP vs. therapeutic measures adopted as first-line (FL) standard of treatment for MBC pts. Methods: El Álamo project is a retrospective analysis of 15381 pts diagnosed of $\mathrm{BC}$ between 1990 and 1997 across 43 of the main Spanish hospitals. For the present analysis three cohorts have been considered: Álamo I (AI) consisted of pts diagnosed with MBC between 1990 and 1993; Álamo II (AII) consisted of pts diagnosed between 1994 and 1997; Álamo III (AIII) consisted of pts diagnosed between 1998 and 2001. 158 items per pt were recorded, including demographic, therapeutic and outcome data. TTP has been analysed by means of contingency tables and Kaplan-Meier log-rank test. Inferences has been analysed with $c^{2}$ and log-rank tests. Results: baseline pts characteristics in the three cohorts are well-balanced regarding age, visceral disease, number of metastatic sites, tumor grade and hormonal receptor status. Median TTP in first vs. second vs. third pts cohorts are: 9.44 vs. 12.8 vs. 15.92 months. Both the second (1994-1997) and the third (1998-2000) cohorts of pts show a significant improvement in median TTP $(\mathrm{p}<0.001)$ when compared to first cohort (1990-1993). Standard therapeutic management of MBC pts has been compared for all three cohorts. The most relevant findings are the increase in the standard administration of aromatase inhibitors and taxanes as FL treatment. Percentage of pt who received aromatase inhibitors in each cohort was $2.7 \%$ (AI) vs. $16.2 \%$ (AII) vs. $49.4 \%$ (AIII) (p<0.001). Percentage of pt who received taxanes in each cohort was $1.1 \%$ (AI) vs. $13.9 \%$ (AII) vs. $30.2 \%$ (AIII) (p<0.001). Conclusion: Spanish population of MBC pts have experienced an important improvement in TTP since 1990. This better outcome could be related to standard administration of new FL therapies, such as aromatase inhibitors and taxanes.

\section{4}

The effect of a pilot exercise intervention on bone remodeling and body composition in breast cancer survivors.

Knobf MT, Insogna K, Fennie K, Thompson AS, DiPietro L. Yale University, New Haven, CT

Significance: Postmenopausal breast cancer survivors are at risk for bone loss, accelerated bone loss has been reported with chemotherapy-induced menopause and weight gain over time is well documented and associated with increased health risks. Purpose: The purpose of this pilot study was to assess feasibility and to evaluate the effect of a weight loaded exercise intervention on primary outcomes: bone remodeling, weight and body composition, and secondary outcomes: physical functioning, general health, physical and psychological symptom distress. This analysis will report on the primary outcomes.

Methods: A one group pre and post test design was used to test a 3 times per week, 16-24 week supervised brisk treadmill walking exercise intervention. Target heart rates (HR) were individually calculated and HR recorded q 5 minutes during the 45 minute sessions. A waist belt was progressively loaded with $1 \mathrm{lb}$ to $5 \mathrm{lbs}$ weeks 1-5 and then maintained at weeks 5-24. Women who experienced chemotherapy induced menopause, or were within 2 years of natural menopause or discontinued hormone replacement therapy and within 2 years of completing breast cancer therapy were eligible. Bone remodeling was measured by serum biomarkers, specifically N-terminal propeptides of type I collagen (NTX) and serum osteocalcin. DEXA scans measured body composition, specifically lean muscle mass and \% fat mass. Data were collected at baseline, 16 and 24 weeks.

Findings: The sample consisted of 26 subjects, the majority of whom were married, well educated, employed with a mean age of 51.3 yrs $(\mathrm{SD}=6.2)$. Sixty-five percent completed adjuvant chemotherapy; $35 \%$ were on Tamoxifen and $27 \%$ on an Aromatase Inhibitor. The intervention was feasible demonstrated by high adherence rates $(\mathrm{M}=88.2 \% \mathrm{SD}=6.8)$. There was no significant difference in serum osteocalcin or serum NTX over time or by adjuvant hormone therapy. Mean weight at baseline was 156.8 $(+21.3)$ and $155.1(+20.1)$ at 24 weeks. Lean muscle mass did not differ over time $(\mathrm{p}=.08)$. There was no significant difference in $\%$ fat mass for the group as a whole but there was an interaction effect for hormone treatment over time $(p=.04)$.

Conclusions: The intervention was feasible, women maintained their weight, lean muscle mass and \% fat mass although small increases in $\%$ fat mass were observed for women on hormone therapy over time. These results support the design of a larger adequately powered randomized control group study. 


\section{5}

Acute and delayed nausea still a considerable problem in adjuvant breast cancer chemotherapy.

Malmström A, Norberg B, Börjeson S, Hursti T, Sundqvist M, Peterson C, Andersson B, Jungå A-S, Ljung U. Linköping University Hospital, Sweden; Jönköping County Hospital, Sweden; Linköping University, Sweden; Uppsala University, Sweden; Kalmar County Hospital, Sweden

Background: In adjuvant breast cancer chemotherapy thecurrent use of combinations of $5 \mathrm{HT}_{3}$-blocking agents and corticosteroids has been a major advance in controlling chemotherapy induced nausea and vomiting (CINV). This improvement has mainly been noted for acute symptoms - within the first 24 hour period after delivery of chemotherapy. Less attention has been paid to the problem of delayed CINV which also seems to be less affected by current antiemetic treatments. In order to evaluate the extent and to explore predictive parameters of acute and delayed nausea we conducted this study in three out-patient chemotherapy units within the South-East Health Care Region in Sweden. This study provides unique data from the patients entire treatment period of 7 cycles of chemotherapy.

Methods: Between November 2000 and January 2003 all breast cancer patients who fulfilled the inclusion criteria (adjuvant chemotherapy, ability to communicate in Swedish) were offered to participate in the study. 126 patients accepted. All had been diagnosed and surgically treated according to a regional management program. Therapy consisted of 7 cycles of FEC(5fluorouracil, epirubicin, cyclophosphamide) in $83 \%$ of patients and iv CMF (cyclophosphamide, methotrexate, 5-fluorouracil) in $17 \%$. To prevent acute CINV patients received antiemetics comprising a $5 \mathrm{HT}_{3}$ receptor antagonist and a corticosteroid and to prevent delayed symptoms a $5 \mathrm{HT}_{3}$ receptor antagonist combined with corticosteroid/metoklopramide was generally prescribed. A questionnaire was collected before the first chemotherapy cycle with report on baseline data regarding probable och possible predictors for CINV. Also the HAD and LSQ questionnaires were collected. Nausea (none mild moderate severe) and vomiting (no of episodes) was reported in a patient diary day 1-10 of each cycle in total 70 days.

Results: Mean number of days with nausea of any degree was 26 during the 70-day observation period. Only $2(2 \%)$ patients reported no nausea at all. Sixteen $(13 \%)$ patients reported more than 40 days with nausea. Mean number of days with vomiting was 4 during the same 70 -day period, with 55 (44\%) reporting no vomiting at all. Fourteen $(11 \%)$ patients reported more than 7 days of vomiting. Over $50 \%$ of patients experienced nausea during days $1,2,3$ and 4 when reports from all 7 cycles are combined, with a maximum of $61 \%$ having mild, moderate or severe nausea on day 4.

Conclusion: Acute and especially delayed CINV still constitutes a considerable problem in adjuvant breast cancer chemotherapy in spite of modern antiemetic prophylaxis. There is clearly still room for further improvement.

\section{6}

Breast cancer and HIV.

Hurley J, DeCesare T, Gomez-Fernandez C, Powell J. Jackson Memorial Hostpital, Miami, FL; University of Miami/Sylvester Cancer Center, Maimi, FL

Background:Breast cancer is the most common malignancy in women in the United States and the second most common cause of female cancer deaths. Cancers such as Kaposi Sarcoma and Non Hodgkins Lymphoma frequently occur in patients with Human Deficiency Virus (HIV) infection but breast cancer has seldom been reported. The fastest growing group of newly infected HIV patients are women. Breast cancer and HIV can occur in the same patient and little is known about the proper treatment of these patients.Thirty three patients with both Breast Cancer and HIV infection seen at the University of Miami/Jackson Memorial Hospital between January 1988 to May 2005 were retrospectively analyzed.

Clinical Characteristics:All stages of breast cancer were seen: ductal carcinoma in situ (2 patients), stage I (3 patient), stage II (12 patients), stage III (13 patients), and stage IV (3 patients). 16 $(53 \%)$ of the tumors had estrogen receptors. Five of the 20 patients who underwent axillary lymph node dissection had abnormal lymph node findings, including 3 with follicular hyperplasia and 2 with caseating granulomas.

Patient Characteristics:mean age 44 (range31-62), premenopausal $80 \%$, Black $70 \%$, White $30 \%$, Latin $18 \%$, nonHispanic white $12 \%$, African American 58\%, Caribbean Islander $12 \%$

Results:Of the 30 patients who presented with local disease, 15 have died: 5 of breast cancer, 7 of acquired immunodeficiency syndrome, 1 of cardiac arrest, and 2 died of unknown causes. Ten of $21(48 \%)$ patients remain free of disease $>5$ years and 3 of 11 (27\%) patients are alive $>10$ years. Thirteen patients have been treated with either neoadjuvant or adjuvant chemotherapy. Of those 13 patients, 7 had complications such as herpes zoster, candida esophagitis, neutropenic fever and ARDS.

Conclusion:Women with HIV and breast cancer can have prolonged survival from their breast cancer. They should undergo stage appropriate surgery. They do not tolerate chemotherapy as well as immunocompetent patients. Despite treatment with prophylactic medications and growth factor support, they are prone to complications and frequently need to have their chemotherapy doses adjusted. Firstline therapy with hormonal manipulations should be seriously considered as adjuvant therapy in this heavily ER positive group.

\section{7}

The impact of paclitaxel on menstrual function.

Oktay K, Libertella N, Oktem O, Beck L, Cil A. Weill Medical College of Cornell University, New York, NY; Fertile Hope, New York, NY

Background: Breast cancer is the most common malignancy in reproductive age women. Chemotherapy regimens commonly include cyclophosphamide, which has a well documented negative impact on fertility $(1,2)$. Previous studies suggested that doxorubicin+cyclophosphamide (AC) results in lower rates of postchemotherapy amenorrhea when compared to cyclophosphamide+methotrexate+5-FU (CMF) $(3,4)$. Recent adjuvant and neo-adjuvant chemotherapy regimens have incorporated taxanes in to the treatment of early stage breast cancer, however, much less is known about the effects of these agents on ovarian function. Our goal was to determine whether the addition of paclitaxel to $\mathrm{AC}(\mathrm{AC}+\mathrm{T})$ results in a higher incidence of post-chemotherapy amenorrhea, compared to AC alone.

Design: Prospective observational study

Methods: Between the years 2000-2005, 273 breast cancer patients who were counseled for fertility preservation were also asked to participate in a follow up study. All patients were asked to keep a record of their menstruation during and after chemotherapy treatment. From these patients, we identified 44 women with clinical breast cancer stage I-IIIA, who received either AC+T $(n=28)$ or $\mathrm{AC}(n=17)$, and who had at least one year of follow up after the initiation of chemotherapy. We then compared the menstrual history of women who received $\mathrm{AC}+\mathrm{T}$ with those who received AC only.

Results: The mean length of follow up was 30 months with a range of 12 to 70 months. The patients who received $\mathrm{AC}+\mathrm{T}$ were younger than those receiving $\mathrm{AC}(34.0 \pm 1.0$ vs. $37.2 \pm 1.0, \mathrm{p}=0.03)$. Of those who received AC+T, all but one $(27 / 28,96 \%)$ lost periods during chemotherapy; $48 \%(13 / 27)$ recovered after a mean $7.1 \pm 1.4$ months. Of the women who received AC, 14/17 (82\%) ceased menstruation during chemotherapy but $64 \%(9 / 14)$ regained after a mean $6.7 \pm 0.9$ months. Despite their younger age, a higher 


\section{S272 Abstracts - Poster Session VI}

percentage of patients receiving $\mathrm{AC}+\mathrm{T}$ experienced persistent amenorrhea 6 months beyond postchemotherapy $(14 / 28 ; 50 \%)$ compared to AC $(5 / 17,29 \%)(\mathrm{P}=0.03)$. Of the patients who developed persistent amenorrhea, the percentage of patients receiving tamoxifen was similar $(\mathrm{AC}$ vs. $\mathrm{AC}+\mathrm{T}, 80 \%$ vs. $85 \%$, $\mathrm{p}>0.05)$. A logistic regression analysis was performed to control for differences in age and length of follow up. On logistic regression, the odds ratio for developing persistent amenorrhea after $\mathrm{AC}+\mathrm{T}$ was 3.9 (95\% C.I. 0.85-17.7) compared to AC alone.

Conclusions: Our findings suggest that paclitaxel may adversely affect ovarian function. Young women with breast cancer should be counseled regarding the possibly increased likelihood of ovarian failure and infertility when paclitaxel is added to the $\mathrm{AC}$ regimen. References:

1. Sonmezer \& Oktay. Hum Reprod Update 2004; 10:251-266. 2.Oktay et al. J Clin Oncol. April 11, 2005 (Epub ahead of print). 3.Goodwin et al. J Clin Oncol. 1999; 17:2365-2370.

4.Bines J et al. J Clin Oncol 1996; 14:1718-1729.

\section{8}

Attitudes and management approaches of physicians who care for women with DCIS.

Partridge AH, Winer JP, Sampson E, Blood E, Dees C, Emmons $K$, Winer EP. Dana-Farber Cancer Institute, Boston, MA; Brigham and Women's Hospital, Boston, MA; University of North Carolina, Chapel Hill, NC

Physicians' attitudes about DCIS may vary, and this variability may impact on patient care, patient risk perceptions and satisfaction with care. We sought to assess attitudes and management approaches of those physicians identified as providing care to women in our ongoing cohort study of women with DCIS. Methods: Physicians identified by our DCIS study participants were invited to participate in a one-time mailed survey. A financial incentive of $\$ 10$ was sent with the survey, and repeat fax, email, or phone reminders were used to enhance response rate. Results: 208 physicians were sent the survey. 158 responded to the survey $(76 \%), 41$ did not respond, and 9 surveys were returned to sender. Of the responders, 7 indicated that they did not believe the survey was applicable to them; 151 completed the survey. The average age of respondents was 49 years (range 32-75). 53\% were male, and $71 \%$ had been in practice for over 10 years. Subspecialties were as follows: surgical specialty $35 \%$; medical oncology $29 \%$; radiation oncology $16 \%$; ob/gyn $5 \%$; internal medicine/primary care $7 \%$; other $8 \%$. Most physicians $(64 \%)$ saw $<5$ patients with DCIS per month, and $28 \%$ reported at least 60 percent of their patients have breast cancer (including DCIS). Physicians were asked to rate the general risk associated with DCIS for a patient's overall long-term health, on a scale of $1-5(1=$ not at all risky, $5=$ extremely risky). Physicians' responses included: $1(9 \%), 2$ $(54 \%), 3(27 \%), 4(9 \%), 5(0 \%)$, blank (1\%). Physicians demonstrated wide variability with regard to management approaches when responding to clinical vignettes. For a healthy 45 year-old women with high grade ER+ DCIS who needs further surgery for positive margins, $23 \%$ would recommend a lymph node evaluation, $66 \%$ would not, and $11 \%$ would recommend it only if the patient undergoes a mastectomy rather than re-excision. If this woman underwent a mastectomy and only had DCIS, 70\% of respondents would recommend tamoxifen therapy, and 29 percent would not; if she were 76 years old, $50 \%$ would recommend tamoxifen after mastectomy for DCIS, and $48 \%$ would not. Additional scenarios and analyses will be presented. Conclusions: There is substantial variation among physicians regarding perceptions and management approaches for women with DCIS. Gaining a better understanding of physician views may help to facilitate the development of interventions to improve the decision-making process and risk perceptions for women newly diagnosed with DCIS.

\section{9}

When less is more? Follow up strategies for patients with breast cancer.

Sheiner J, Fitzgerald B, Blair A, Callaghan W, Clemons M. Toronto Sunnybrook Regional Cancer Centre, Toronto, ON, Canada

Background: The prevalence of breast cancer (BC) continues to rise, due in part to the aging population \& also improvements in screening \& treatment. This, coupled with rapid changes in adjuvant endocrine strategies has generated increasing clinic workloads for oncologists. Early breast cancer patients are being followed for longer periods of time \& require ongoing surveillance for complications of estrogen suppression. Strategies are therefore required to enable the most efficient utilization of scarce oncologist resources.

Materials and Methods: A prospective program utilizing evidenced-based guidelines was developed. The goal was to transfer eligible patients from our medical oncology practice to ongoing follow up by their family physicians (FP) soon after completion of adjuvant chemo/radiotherapy or initiation of adjuvant endocrine therapy. A patient information package was provided at time of transfer, followed by a mailing of follow-up guidelines to the FP. Results: Since April 2005, 110 pts have been assessed for transfer back to the FP. $83 \%$ of pts were hormone receptor positive; $58 \%$ were being followed by another oncology discipline (of these pts $18 \%$ were being followed by surgical oncology, $40 \%<$ INS cite $=$ mailto: default $\quad$ dateTime $=2005-05-31$ T10:19 $>$ by $<$ < INS $>$ radiation oncology, \& $36 \%$ by both). $93 \%$ of pts had a FP. $42 \%$ of all pts seen were considered suitable for transfer to the FP. $58 \%$ were deemed unsuitable for transfer, mainly due to clinical trial enrollment $(51 \%)$, planned changes in endocrine therapy $(25 \%), \&$ the development of new symptoms (1\%).

Discussion: An evidence-based program for breast cancer patients to facilitate transfer of care to the FP is presented. $42 \%$ of the 110 patients assessed were suitable for transfer back to their FPx. This offers another strategy to improve workload volumes \& thus enable the medical oncologist to direct care to where it is most needed. It also allows the development of effective follow up guidelines for both the patient $\&$ the FP that take into account rapidly evolving changes in $\mathrm{BC}$ management.

\section{0}

The adherence of practice guidelines in the assessment of bone health in women with chemotherapy-induced amenorrhea.

Tham YL, Sexton K, Kramer R, Weiss H, Grollman J, Minnix J, Friedman LC. Baylor College of Medicine, Houston, TX

Background: Twenty-five per cent of invasive breast cancers occur in premenopausal women, most of whom receive adjuvant chemotherapy. Women who develop chemotherapy-induced amenorrhea are at risk for developing osteoporosis. For this reason, in 2003, ASCO issued guidelines recommending that physicians regularly assess the bone health of these women.

Methods: We surveyed women who were $<50$ years of age and premenopausal at initiation of chemotherapy and identified those who developed permanent amenorrhea. The women were recruited from a dedicated breast clinic and the Young Survival Coalition. The performance of recommended screening and preventive measures for osteoporosis was assessed.

Results: Two hundred and twenty eligible women completed the survey. Eighty-nine had permanent amenorrhea (40\%); 64 were $\leq$ 40 years of age and $25>40$ years old. Forty-nine were on tamoxifen and seven on an aromatase inhibitor. Only 55\% had discussed bone health with their health care providers. Age at diagnosis, race and use of tamoxifen were not associated with this discussion. Regular exercise was recommended to $72 \%$ of the women, calcium/vitamin D supplement to $57 \%$ and bone mineral density (BMD) testing to $40 \%$. Approximately one-half of the women regularly exercised and took a calcium/vitamin D supplement; however, over $40 \%$ of the latter took less than the recommended dose of the supplement 
(1000-1500mg/day) for prevention of osteoporosis. Thirty-two per cent of the women reported having had BMD testing. Women 40 years of age or younger were less likely to undergo BMD testing $(25 \%)$ than women over 40 years of age $(48 \%)(\mathrm{p}=0.04)$. Conclusion: For nearly one half of patients, physicians did not adhere to the published guidelines for assessing bone health after chemotherapy induced amenorrhea. Oncologists should more uniformly encourage maintenance and assessment of bone health, especially in women 40 years old or younger, who are less likely to take advantage of BMD testing.

\section{1}

A prospective longitudinal study of the impact of adjuvant chemotherapy for breast cancer (BC) on older patients' functional status and quality of life.

Hurria A, Hurria A, Panageas K, Zuckerman E, Fornier M, D'Andrea G, Dang C, Moasser M, Robson M, Seidman A, Currie $V$, Vanpoznak $C$, Theodoulou $M$, Norton L, Atienza $M$, Hudis $C$. Memorial Sloan-Kettering Cancer Center, New York, NY; Suny Upstate, Syracuse, NY; University of California San Francisco, San Francisco, $C A$

Background: Older patients are less likely to receive adjuvant chemotherapy than younger patients. Fear of toxicity and its associated impact on functional status and quality of life may factor into decision-making. This prospective study examined the toxicity experienced by a cohort of older patients receiving adjuvant chemotherapy for $\mathrm{BC}$ and the longitudinal impact on functional status and quality of life (QOL).

Methods: Fifty patients $>$ age 65 with primary invasive $\mathrm{BC}$ enrolled in an IRB-approved protocol. A geriatric assessment consisting of measurements of functional status [activities of daily living (ADL), instrumental activities of daily living (IADL), KPS], comorbidity (Charlson), mood (Geriatric Depression Scale), nutritional status (BMI) and quality of life (FACT-B) was performed at the following time points: pre-chemotherapy, end-ofchemotherapy, and 6 months later. Inclusion criteria were age $\geq$ 65 , stage I-III BC, and receipt of adjuvant chemotherapy at MSKCC [CMF (cyclophosphamide $600 \mathrm{mg} / \mathrm{m} 2 \mathrm{IV}$, methotrexate $40 \mathrm{mg} / \mathrm{m} 2 \mathrm{IV}, 5$-fluorouracil $600 \mathrm{mg} / \mathrm{m} 2 \mathrm{IV} \mathrm{q} 3$ wks $\times$ 8) or an anthracycline-based regimen: AC (doxorubicin $60 \mathrm{mg} / \mathrm{m} 2$, cyclophosphamide $600 \mathrm{mg} / \mathrm{m} 2$ q3 wks $\mathrm{x} 4$ ), $\mathrm{AC} \rightarrow \mathrm{T}$ (AC followed by Paclitaxel $175 \mathrm{mg} / \mathrm{m} 2$ IV q 3 wks $x$ 4), or $\mathrm{AC} \rightarrow \mathrm{TH}(\mathrm{AC} \rightarrow \mathrm{T}$ followed by trastuzumab x 52 weeks on another study)] with dose modifications per cause.

Results: 50 patients (mean age 68, range 65-84) enrolled in the protocol, of which 49 are evaluable. Staging was: I (35\%), IIA (49\%), IIB (14\%), IIIA (2\%). Comorbidity, measured by AgeAdjusted Charlson Comorbidity Scale was low: score $2(43 \%), 3$ $(33 \%), 4(12 \%), 5(8 \%), 6(4 \%) .53 \%(26)$ had any grade 3 or 4 toxicity: $31 \%$ (15) hematologic toxicity, $27 \% \quad$ (13) nonhematologic. Despite this toxicity, there was no significant longitudinal change in functional status as measured by ADL ( $p=$ $0.64)$ or IADL $(p=0.42)$, Charlson Comorbidity score $(p=0.95)$, Geriatric Depression Scale $(\mathrm{p}=0.56)$, BMI $(\mathrm{p}=0.95)$, or QOL as measured by FACT B $(\mathrm{p}=0.49)$. Patients had a decrease in KPS immediately post-chemotherapy $(\mathrm{p}=0.02)$ but recovered to baseline functioning by 6 months post-chemotherapy.

Discussion: Despite toxicity from adjuvant chemotherapy, older patients maintained their functional status and quality of life from pre-chemotherapy to 6 months post-chemotherapy. Subtle changes in higher order functioning may be missed by these traditional geriatric assessment scales.

\section{2}

Overestimation of risk among women with DCIS: longitudinal results from a cohort study.

Partridge AH, Adloff K, Blood E, Dees C, Kaelin C, Weeks J, Emmons K, Winer EP. Dana-Farber Cancer Institute, Boston, MA; Brigham and Women's Hospital, Boston, MA; University of North Carolina, Chapel Hill, NC

DCIS is a complex clinical entity with a variable natural history, but a favorable overall prognosis. Limited data suggest that women with DCIS may overestimate the risk of disease recurrence. Methods: Women newly diagnosed with DCIS in Massachusetts and North Carolina were asked to participate in a longitudinal study of risk perceptions, psychosocial factors and health behaviors. Questionnaires were administered at baseline, 9 and 18 months. Results: 499 women with DCIS (64\% of eligible participants) completed baseline surveys. Median age 53 years (range 26-90); $86 \% \leq 65$ years old; $94 \%$ white; $62 \%$ graduated college; $68 \%$ married/partnered; $44 \%$ working full-time. $7 \%$ of women recalled significant anxiety, and $3 \%$ depression in the month prior to diagnosis using the Hospitalized Anxiety and Depression Scale (HADS). The median Revised Impact of Event Scale (RIES) score at baseline was 12.9 (range 0-58), indicating a low-moderate level of DCIS-related anxiety. Respondents were queried about their future risks.

$\%$ women indicating a "moderate or greater" likelihood of specific events are shown below:

DCIS in next 5 years

DCIS in lifetime

Invasive disease in next 5 years

Invasive disease in lifetime

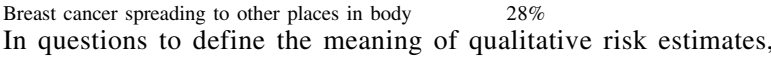
"moderate or greater" was associated with a perceived $30-40 \%$ absolute risk; "unlikely or very unlikely" was associated with a 4$5 \%$ risk. A multivariate model revealed that baseline anxiety, assessed by the HADS and RIES, was associated with elevated perceptions of risk of distant disease. Non-significant factors included age, race, education, marital status, employment, financial status, comorbidity, treatment, and satisfaction with treatment. To date, follow-up data are available from 215 women (complete data will be available for presentation). At $18-\operatorname{mos}, 24 \%$ believed there was a moderate or greater chance that DCIS would spread to other places. Some patients' perception of risk increased over time, and others' decreased, without a consistent trend in either direction (McNemar's Test p-value=0.79). Baseline factors associated with elevated perception of risk of distant disease at 18-months were: non-white race, < full-time employment, lack of satisfaction with treatment and tamoxifen use. Conclusions: A substantial proportion of women with newly diagnosed DCIS harbor grossly inaccurate perceptions of the breast cancer risks they face and these persist over time. Future research should assess the impact of altered risk perceptions on decision-making and psychosocial outcomes. Clinicians caring for women with DCIS should be aware of these inaccurate perceptions. (Supported by the Dana-Farber/Harvard Cancer Center SPORE in Breast Cancer 5 P50 CA89393-03)

\section{3}

Post-decision regret following breast reconstruction among women with breast cancer.

Sherman KA, Sheehan JC, Lam T, Boyages J, Zibdeh S. Macquarie University, Sydney, New South Wales, Australia; New South Wales Breast Cancer Institute, Westmead, NSW, Australia

Background Whether or not to undergo reconstructive surgery is a difficult decision faced by many women following mastectomy for breast cancer. Prior studies indicate that regret following a medical decision may be attributed to inadequate preparatory information, as well as psychosocial factors such as body image disturbance and emotional distress. However, with a lack of theoretically informed studies, little is known of the factors 


\section{S274 Abstracts - Poster Session VI}

associated with decision regret among these women. Adopting the theoretical framework of the Monitoring Process Model (S.M. Miller), the current study assessed the association of dissatisfaction with information, negative changes in body image, disease specificand general-distress with post-decision regret.

Methods Women diagnosed with breast cancer who had undergone immediate or delayed breast reconstructive surgery following mastectomy at the New South Wales Breast Cancer Institute were invited to participate in the study. With an uptake rate of $52 \%$, 123 consenting participants completed a questionnaire consisting of validated scales including the Decision Regret Scale, Body Image Scale, Impact of Events Scale (disease-specific distress) and the Depression, Anxiety and Stress Scales (general distress). Dissatisfaction with information was assessed with a series of researcher-developed items based on prior research. The potential moderating effect of coping style (i.e., high versus low monitoring) was assessed by the Monitor Blunter Style Scale. Demographic and medical history characteristics, social support and current mood state were assessed and treated as potential covariates.

Results Decision regret was found in $47.1 \%$ of participants. Dissatisfaction with preparatory information at some level was reported by $36.6 \%$ of participants. The majority of participants reported minimal negative changes in body image, disease-specific and general distress. Bivariate analyses indicated that decision regret was associated with body image disturbance, disease-specific distress, dissatisfaction with information, and general distress. Controlling for mood state and time since last reconstructive procedure, multinominal logistic regression analyses showed that: increases in body image disturbance $(\mathrm{OR}=1.13, \mathrm{p}=.04)$ and anxiety $(\mathrm{OR}=1.25, \mathrm{p}=.03)$, and decreases in depression $(\mathrm{OR}=.80, \mathrm{p}=.01)$ were associated with increased likelihood of a participant experiencing regret. In addition, monitoring coping style significantly moderated the association between anxiety and regret $(\mathrm{OR}=.91, \mathrm{p}=.01)$, such that low monitors who were more anxious had a greater likelihood of experiencing regret.

Conclusions These results provide theoretically-guided data regarding decision outcomes among breast cancer patients undergoing reconstructive surgery. The association between body image disturbance and regret reinforces the necessity of actively informing and educating women about realistic outcome expectations in terms of aesthetic appearance. The finding that anxiety and low monitoring coping style were associated with increased likelihood of regret suggests the need for interventions tailored to individual coping style that are designed to enhance coping responses of women undergoing breast reconstruction.

\section{4}

Memory impairments with anastrozole versus tamoxifen therapy in women with early stage breast cancer. Bender CM, Sereika SM, Ryan CM, Casillo FE, Vogel VG, Berga SL, Cohen SM, Rastogi P, Brufsky AM. University of Pittsburgh, Pittsburgh, PA; Emory University, Atlanta, GA

Background and Purpose: Cognitive impairments have been associated with adjuvant hormonal therapy in women with breast cancer. These impairments may include deficits in attention, memory and psychomotor efficiency and may be related to the effects of hormonal therapy on hormone levels. Estradiol levels are significantly lower in women with breast cancer who receive anastrozole compared to women who receive tamoxifen. The purpose of this pilot study was to compare cognitive function in women with early stage breast cancer who were receiving tamoxifen versus anastrozole therapy.

Methods: Cognitive function was assessed with a battery of measures evaluating attention, learning and memory, mental efficiency, visuospatial ability, and psychomotor efficiency in women with stage I and II breast cancer who had received a minimum of three months of tamoxifen or anastrozole therapy. Depression was measured with the Beck Depression Inventory-II, anxiety was measured with the Profile of Mood States (POMS) Tension/Anxiety subscale, and fatigue was measured with the POMS
Fatigue/Inertia subscale. Data were analyzed using hierarchical linear regression.

Results: Results suggest that, after controlling for age, education level, time on hormonal therapy, depression, anxiety, and fatigue, women who received anastrozole $(n=15)$ had significantly more severe impairment than women who received tamoxifen $(n=16)$ in: 1) visual learning and memory as measured by the Rey Complex Figure Test in the immediate $(\mathrm{p}=.006)$ and delayed $(\mathrm{p}=.011)$ recall conditions and 2) verbal learning and memory as measured by the Rey Auditory Verbal Learning Test Total $(\mathrm{p}<.001)$ and delayed recall $(\mathrm{p}=.002)$ scores, and the Rivermead Story Recall in the immediate $(\mathrm{p}=.040)$ condition and marginally significantly worse performance in the delayed recall condition of the Rivermead Story Recall $(\mathrm{p}=.069)$.

Conclusions: These results suggest that women who receive anastrozole therapy experience more severe impairment in cognitive function than women who receive tamoxifen therapy. Cognitive impairment may be limited to the domains of verbal and visual learning and memory. Further evaluation of cognitive function and the potential relationship between scores on cognitive function measures and hormone levels is needed in this population to facilitate education of women who take anastrozole and the development of interventions to prevent or compensate for such cognitive impairments.

\section{5}

Distress in a nationwide cohort study of Danish women treated for locoregional invasive breast cancer. Prevalence and associations with histopathological variables, type of treatment and social relations.

Christensen S, Zachariae R, Jensen AB, Moller S, Ravnsbak J, Vath M, Maase HVD. Aarhus University Hospital, Aarhus Denmark; Rigshospitalet, Copenhagen, Denmark; Aarhus University, Aarhus, Denmark

Background: Breast cancer is one of the leading causes of cancerrelated death and is generally found to be associated with significant psychological morbidity. There is, however, considerable betweenstudy variation, which could be explained by selection bias, zerotime bias as well as potential buffering psychosocial factors e.g. social support. A large nationwide study is needed to clarify these issues. Materials and methods: As a part of an ongoing nationwide prospective study of psychosocial factors and survival of breast cancer patients, baseline data were analyzed for the 3400 women included in the study (response rate: 68\%). Eligible patients were identified by DBCG and the surgical departments in Denmark and were all treated for locoregional invasive breast cancer between Oct., 2001 to March, 2004. Approx. 12-16 weeks post-surgery a questionnaire was mailed out including measures of depressive symptoms (BDI-II), avoidance and intrusive thoughts about cancer (IES), social support (SSQT), social constraints (SC), SF-36 Physical Function (PF) and Sleep Quality (SQ). Clinical data were obtained from the DBCG registry. Results: Participants were younger than non-participants (median 55.7 yrs. vs. 58.0 yrs; range: 23-70 yrs). Participation was not influenced by histopathological variables or adjuvant treatment when accounting for age in a logistic regression. Prevalence of moderate to severe depression was $8.6 \%$, and $7.3 \%$ had symptoms indicating possible PTSD (high avoidance and high intrusion). In univariate analyses significant higher BDI-II scores were found for women receiving chemotherapy and/or with positive axillary node status whereas higher scores on IES were found in case of radiotherapy and/or positive axillary node status. Controlling for treatment and histopatological variables in a hierarchical logistic regression, moderate to severe depression was significantly positively associated with SC (OR: 1.08), and IES (OR: 1.07), and inversely associated with being married (OR: 0.57), age (OR: 0.97), SSQT (OR: 0.98), and SQ (OR: 0.50). Neither histopathological variables nor type of treatment were associated with depression. In a similar analysis high avoidance/intrusion was positively associated with BDI-II (OR: 1.11), and SC (OR: 1.04), and inversely associated 
with chemotherapy (OR: 0.53), PF (OR: 0.94), and SQ (OR 0.76). Discussion: The cohort was nationally representative with respect to both histopathological variables and type of treatment but non-participants were slightly older. Being married, good sleep quality, physical function, and social support were inversely associated with distress, while experienced constraints from others in talking about their cancer was associated with increased distress.

\section{6}

Pre-surgical screening for emotional distress and psychiatric co-morbidity among women with newly diagnosed early stage breast cancer.

Moore CP, Kearing S, Collins ED, Hegel MT, Ahles TA, Gillock KL, Riggs RL, Clay KF. Dartmouth Hitchcock Medical Center Dartmouth Medical School

Background: Emotional distress is prevalent among breast cancer patients but few studies have documented this among women who are recently diagnosed. Screening tools are available but underutilized due to time and resource constraints. We developed the Dartmouth Computer-Based Screening Tool (DCST) to screen newly diagnosed breast cancer patients for distress and psychiatric co-morbidity prior to their surgical consultation. This web-based questionnaire identifies patients meeting a threshold for intervention (having a positive score on one or more screening elements) and instantly generates an email alert to specially trained social workers. Social workers personally assess and triage patients as needed.

Methods: All women presenting with newly diagnosed early stage breast cancer complete the DCST prior to their surgical consultation. The tool records demographics and health history. It also screens for distress (Distress Thermometer); PTSD (PC PTSD questionnaire); depression, panic and anxiety (subsets of the Patient Health Questionnaire); general mental functioning (SF-8), history of depression, medication usage, and past mental hospital admission. Those who screen positive for distress or other psychiatric disorders are contacted by a social worker.

Results: Since its launch in March of 2004, 134 patients have completed the DCST. Most were white/non-Hispanic $(97 \%)$ married $(62 \%)$, employed $(59 \%)$, and educated beyond a high school degree $(74 \%)$. Their mean age was 59 . Nearly half of patients $(49 \%, n=66)$ scored positive on one or more of the mental health screening components. Elevated distress was reported by $42 \%(n=56)$. The most commonly reported sources of distress were uncertainty about long term outcome, treatments, chance of complications, and chances of success, as well as emotional factors such as worry, nervousness, and fears. Additional results follow:

DCST Mental Health Screening Results (N=134)

Screening Tool (Scoring Rang)

Distress Therm (Scoring Range)

PHQ: Depression Screen $(0-27)$

PHQ - Anxiety Disorder (0-14)

PHQ - Panic Disorder (1-10)

PC-PTSD (0-4)

History of depression

Current medication usage

History of medication usage

History of mental hospital admission $\mathrm{N} / \mathrm{A}$

Positive Score Threshold
$>5.0$
$>10$
$>7$
10
$>1$
N/A
N/A
N/A
N/A

N (\%) Positive

$56(42 \%)$

$12(9 \%)$

$7(5 \%)$

$7(5 \%)$

$17(13 \%)$

$28(21 \%)$

$31(23 \%)$

$51(38 \%)$

$8(6 \%)$

Conclusions: A substantial number of women with newly diagnosed breast cancer were found to have levels of distress and/or psychiatric disorders that met our thresholds for intervention by a social worker. The prevalence of distress in this pre-surgical sample suggests a need for periodic re-screening and follow-up over the course of ongoing breast cancer care.
6077

Oncology rehabilitation improves patient physical function and emotional health.

Smith KY, Rodgers RG. Cancer Association of Anderson, Anderson, SC; AnMed Health, Anderson, SC

Background: Women diagnosed with breast cancer tend to reduce physical activity, which can have a negative impact on both survival and general health due to increase in body weight, a known risk factor for poorer prognosis. Women who are obese at the time of diagnosis experience the greatest decline in activity. Many studies have documented the value of support groups of cancer survivors to their emotional health. Addressing both psychosocial and fitness needs in a comprehensive oncology rehabilitation program is an important supplement to treatment for breast cancer.

Materials and method: Twenty-seven breast cancer patients ranging from stage I to IV, either in active treatment or within a year of completion, participated in an eight-week general oncology rehabilitation program at Anderson Area Medical Center between September 2003 and December 2004. Each received a full scholarship from the Cancer Association of Anderson funded by the Lance Armstrong Foundation. Patients met at the hospital's LifeChoice gym twice a week for two hours of exercise, instruction in nutrition, management of stress and depression and other topics designed to give them a sense of control and guide lifestyle changes. Participants could join a wellness program upon completion of Onc Rehab.

Results: Participants answered pre and post-completion questionnaires, showing dramatic improvements in physical functioning levels (81 percent), mental health scores (72 percent), and Beck depression scores (72 percent) and a 95 percent improvement in knowledge about cancer. Twenty-two of the 27 patients completed all 16 sessions, and 19 of these opted for an additional month of wellness training. Three of the 27 continue wellness to the present. One graduate completed two tri-athlons and one marathon in the year following treatment. Three of the 27 patients died, but one had dropped out after one session and another contracted a second primary cancer of the stomach. In written comments, patients give oncology rehab high marks for both making them feel stronger and, as one patient put it, making her feel "less isolated and more in control."

Discussion: The combination of exercise, instruction and cameraderie with other survivors gave participants more stamina, an improved sense of well-being and a group of "fellow travelers" with whom they could share their fears, frustrations and successes. A supervised oncology rehab program, with physician approval, helps many people bridge the gap from patient to survivor.

\section{8}

Determinants of presentation delay in locally advanced breast cancer.

Kerr-Cresswell DM, Fitzgerald B, Fergus K, Gould J, Clemons MJ. Toronto Sunnybrook Regional Cancer Center, Toronto, ON, Canada

Background: While there have been marked improvements in the prognosis of women with early breast cancer, these gains have not been echoed to the same degree in patients with locally advanced breast cancer (LABC). Accounting for 10 to $30 \%$ of all new primary breast cancers, 5-year survival for LABC remains poor at around $55 \%$. Research suggests that many women with LABC have delayed presentation of symptomatic breast cancer, with up to $30 \%$ waiting at least 3 months before presenting to a health care provider. Delays may be associated with more advanced lesions and lower survival rates. The characteristics of these patients and reasons for their delaying behaviour are poorly understood. Methods: From January 2002 to June 2005, all new patients referred to our dedicated LABC clinic had data collected asking what date she discovered her breast cancer symptom, the type of symptom, her appraisal of that symptom, and the date of initial presentation to a health care provider. Sociodemographic data were also collected. 


\section{S276 Abstracts - General Sessions}

Results: 102 patients were referred with LABC. 99\% were female. $74 \%$ were Caucasian, $11 \%$ Asian, and $9 \%$ Black. Median age at presentation was 51 years (range 27-83). 55\% were married. For those who identified their initial symptom, it was describes as follows: painless breast lump (59\%), axillary mass $(9 \%)$, breast erythema $(9 \%)$, nipple inversion $(4 \%)$, or other symptom $(19 \%)$. In these patients, median time from symptom discovery to presentation to health care provider was 3 months (range 0-416 weeks). Factors that negatively affected a timely diagnosis were: mistaken attribution of symptom as benign process, fear of cancer, belief that breast cancer was unlikely in the absence of a positive family history, belief that it is better "not to know", decision to pursue complementary therapies first, concern about significant other's ability to cope, and competing life demands.

Conclusions: Late-stage presentation of breast cancer is associated with poor survival. 50\% of newly diagnosed LABC patients in this study waited over three months before presenting to a health care provider with their breast cancer symptoms. Further research is necessary to identify the complex social and psychological factors involved in a woman's decision to delay presentation as it relates to breast symptoms. Understanding the barriers these women face in accessing the health care system will be important in the development of an effective, targeted health intervention program to ultimately improve their survival.

\section{9}

The role of fatigue in mediating "chemo fog" in breast cancer patients.

Awad N, Collins B, Dent S, MacKenzie J, Bielajew C, Stewart A. University of Ottawa, Ottawa, ON, Canada; Ottawa Hospital, Ottawa, ON, Canada; Ottawa Hospital Regional Cancer Centre, Ottawa, ON, Canada

Background: Previous studies show that up to $75 \%$ of breast cancer patients show signs of cognitive decline during or shortly after chemotherapy treatment. Patients refer to this as "chemo fog". There is recent evidence to suggest that fatigue may be an important contributory factor to chemo fog. The purpose of this study was to determine if changes in fatigue over the course of adjuvant therapy predicted cognitive changes over the same interval, and if fatigue was related to declining hemoglobin $(\mathrm{Hg})$ in the chemotherapy patients.

Material and Methods: Eighty-eight post-menopausal women with early stage breast cancer from an ongoing prospective study underwent a comprehensive neuropsychological test battery and completed the Profile of Mood States (POMS) prior to commencement of adjuvant chemotherapy (mostly FEC, FAC, or AC) or hormonal therapy (tamoxifen or arimidex), and again within an average of one month of completing chemotherapy (or at an equivalent time point for patients receiving hormonal treatment). The POMS includes a fatigue subscale. Linear regression analysis was used to determine if change in fatigue predicted neuropsychological performance at second testing, after controlling for baseline test performance. Correlations between change in fatigue and change in $\mathrm{Hg}$ were calculated for 34 chemotherapy treated patients for whom $\mathrm{Hg}$ values were available. Results: Changes in fatigue from first to second testing session were found to strongly predict changes on a measure of working memory and processing speed (Paced Auditory Serial Addition Test, $b=-.20, p=.006)$, such that greater increases in fatigue were associated with poorer performance. Change in fatigue correlated significantly with changes in $\mathrm{Hg}$ level from pre- to post-treatment in a subset of 34 of the chemotherapy-treated patients $(r=-.37$; $p=.03)$.

Discussion: These findings suggest that fatigue is a significant contributor to "chemo fog" and that fatigue in some patients may be related to declining $\mathrm{Hg}$. This suggests that maintenance of optimum $\mathrm{Hg}$ levels may help prevent "chemo fog".

\section{0}

What do patients bring to the consultation? Professional and social support in breast cancer: the role of childhood abuse.

Clark LK, Holcombe C, Hill J, Krespi R, Fisher J, Downey H, Salmon P. The University of Liverpool, Liverpool, Merseyside, United Kingdom; Royal Liverpool University Hospital, Liverpool, Merseyside, United Kingdom; Royal Liverpool Childrens Hospital (Alder Hey), Liverpool, Merseyside, United Kingdom

Background: The importance of support in breast cancer patients has been stressed and emphasis is placed on enhancing the skills of professional carers. Little attention has been given to what the patient brings to the consultation. Research has shown that a history of low maternal care in childhood influences women's perception of professional support. We tested whether the preexisting factors of social support and a history of childhood abuse influence breast cancer patients' perception of professional support.

Materials and Methods: Female patients $(\mathrm{N}=360$, mean $=58$ years) participated in a two-phase study. At phase 1, patients completed self-report questionnaires within 2 weeks of operation. Measures of social and professional support and recall of childhood abuse were taken. 350 patients provided sufficient data for analysis. Results: Patients with more current social support rated their medical interactions as more supportive than those with less $(\mathrm{r}=.282, \mathrm{p}<.001)$. A history of physical abuse reduced ratings of social $(\mathrm{r}=-163, \mathrm{p}<.005)$ and professional $(\mathrm{r}=-246, \mathrm{p}<.001)$ support. Emotional abuse reduced perceived professional support ( $\mathrm{r}=-.150$, $\mathrm{p}<.001)$ only. Covariance structure modelling fitted the data well (Comparative Fit Index $=0.97$, Root Mean Square Error of Approximation index $=0.05$ )

Discussion: Breast cancer patients with good support experience their professional interactions more positively than those with less. Moreover, sufferers of childhood abuse report less social and professional support. Therefore the perceived support that patients gain from medical interactions may not be attributable to the skills of professional carers, but to a patients' personal history. Clinicians should be aware of the impact childhood abuse may have on their relationships with patients.

\section{1}

Using interleukin-6 and hypothalamus-pituitary-adrenal (HPA) axis function as potential diagnostic markers in the assessment of depression in patients with advanced breast cancer.

Jehn CF, Kuehnhardt D, Bartholomae A, Pfeiffer S, Schmid P. Possinger K, Flath BC. Charite Berlin Mitte, Berlin, Germany

Background: The diagnosis of depression in cancer patients is difficult because symptoms of depression are often similar to those of cancer or its treatment. Immune activation and dysregulation of the hypothalamic-pituitary-adrenal (HPA) axis have been implicated in the pathophysiology of depression. The objective of this study was to evaluate IL-6 and HPA function as screening tools for depression in pts with breast cancer.

Methods: 63 patients with metastatic breast cancer were assessed by the Hospital Anxiety and Depression Scale (HADS) for depression and diagnoses was established according to the DSM-IV criteria. A level of $\geq 11$ was considered significant on the HADS-D axes for depression. Plasma concentrations of IL-6 were measured in addition to cortisol levels (at $8 \mathrm{AM}$ and $8 \mathrm{PM}$ ). As a measure of the circadian function of the HPA axis, the relative diurnal variation of cortisol (cortisol VAR), was calculated. In the statistical analysis the Mann-Whitney test and the receiver operating characteristic (ROC) analysis were applied.

Results: There was no significant difference in mean age and Karnofsky-index between breast cancer pts with depression $(\mathrm{n}=22)$ and breast cancer pts without depression $(n=41)$. There was a significant difference in median plasma concentration of IL-6 between pts with depression and without depression (19,6 vs. 2,8 
$\mathrm{pg} / \mathrm{ml} ; \mathrm{p}<0,001)$. Plasma cortisol concentrations at $8 \mathrm{PM}$ were significant higher in depression. The relative cortisol VAR $(17,5$ vs. $56,2 \%$ respectively; $p=0,001)$ was significantly decreased in pts with depression compared to the pts without depression, demonstrating a disturbed circadian function of the HPA axis. IL6 concentrations yielded as a predictor for the presence of depression at a cutoff value of $10,6 \mathrm{pg} / \mathrm{ml}$ a sensitivity of $82 \%$ and a specificity of $83 \%$ (AUC $=0,86 ; 95 \%$ CI $0,76-0,96)$, whereas cortisol VAR showed a sensitivity of $85 \%$ and a specificity of $75 \%$ (AUC $=0,77 ; 95 \%$ CI $0,59-0,95$ ) at a cutoff value of $34,7 \%$.

Conclusions: Depression and increased plasma IL-6 concentrations are strongly associated in pts with breast cancer. Pts with depression show a dysfunction of the HPA-axis, characterized by increased cortisol evening levels and a decreased diurnal variation of cortisol. The high sensitivity and specificity of these parameters for the presence of depression at the respective cutoff values make IL-6 and cortisol VAR helpful tools in the diagnosis of depression in pts with breast cancer.

\section{2}

Using the Brief Symptom Inventory-18 to screen patients referred to high-breast cancer risk assessment clinic: patient factors associated with "caseness" before and after counseling.

Katz, D, Makari-Judson G, Barham R, Carr C, Quinlan M, Mertens WC. Baystate Regional Cancer Program, Springfield, MA

Background: Women have been shown to exhibit high levels of stress prior to high-risk breast cancer assessment and genetic counseling. The Brief Symptom Inventory-18 (BSI) is an assessment tool assessing three dimensions (anxiety [ANX], depression [DEP] and somatization $[\mathrm{SOM}]$ ) as well as a general symptom index (GSI) that can be completed easily by patients in a clinical setting.

Methods: High-risk clinic patients consented prior to the physician visit and completed the BSI and their estimates of 5year/lifetime breast cancer risk and $B R C A$ mutation probability before (PRE), immediately (POST) and 2 months (2 MO) after counseling. Excessive distress ("Caseness") was defined as community-based T-scores $\geq 63$ on GSI or on at least two dimensions

Results: "Caseness" definition was met in 13 of 81 enrolled cases prior to counseling (16\%); all met the criteria based on GSI; while $11(85 \%)$ did so for ANX. PRE caseness patients had a past diagnosis of a psychiatric disorder $(\mathrm{p}=0.0006)$ and of lobular carcinoma in situ (LCIS; 31 v. 6\%, $\mathrm{p}=0.02)$, and tended to be younger (39.9v. 45.6 years, $\mathrm{p}=0.09$ ) and non-white $(31 v .11 \%, \mathrm{p}=0.08)$. PRE caseness subjects reported higher PRE breast cancer risk perceptions (5-year: 46.3 v. $31.3 \%, \mathrm{p}=0.046$; lifetime 66.2 v. $45.8 \%, \mathrm{p}=0.029$ ), but not of BRCA mutation ( $\mathrm{p}=0.17$ ) than others. After counseling, seven patients exhibited caseness $(9 \%, \mathrm{p}<0.0001)$; similar results were found at $2 \mathrm{MO}$. Univariate associations with POST caseness included past psychiatric diagnosis (31 v. $4.5 \%$ of non-caseness patients, $\mathrm{p}=0.012)$, non-white race $(27 v .6 \%, \mathrm{p}=0.05)$, younger age at first live birth $(19.2$ v. $24.7 \mathrm{yr}, \mathrm{p}=0.05)$ and LCIS (43 v. 7\%, $\mathrm{p}=0.02)$. POST caseness patients had greater excess risk perceptions after counseling than others (5-year: 38.2 v. $17.1 \%$, $\mathrm{p}=0.015$; lifetime: 32.6 v. $8.1 \%, \mathrm{p}=0.02)$. PRE caseness was associated in multivariate analysis with past psychiatric diagnosis $(\mathrm{p}=0.0004)$ and LCIS $(\mathrm{p}=0.020)$, as was POST caseness $(\mathrm{p}=0.010$ and $\mathrm{p}=0.018$, respectively).

Conclusions: BSI "caseness" appears to be an effective screen for excessive distress in this setting. Physician counseling reduces the number of patients exhibiting disproportionate symptoms, but those demonstrating POST caseness continue to vastly overestimate their risk. Counseling does not appear to result in patients exhibiting "caseness" if they had not demonstrated "caseness" prior to the intervention. Those with past psychiatric diagnoses and/or LCIS are prone to high BSI scores and are candidates for more intensive education and support.

\section{3}

Pre-chemotherapy assessment of cognitive function using functional magnetic brain imaging in women with breast cancer.

Cimprich B, Hayes DF, Therrien B, Reuter-Lorenz P, Noll D, Normolle D, Welsh R, Clark PM, Vincent C, Nelson J. University of Michigan, Ann Arbor, MI; School of Medicine; ; Biomedical Engineering

Background: Cognitive impairment or 'chemo brain' is recognized as a distressing side effect of adjuvant chemotherapy for breast cancer. Despite the reported frequency of cognitive deficits associated with chemotherapy, the underlying brain mechanisms are not well understood. Basic cognitive processes, attention and working memory, are prerequisites for effective functioning in daily life and have been shown to be affected by the diagnosis of breast cancer. The purpose of this study was to determine prechemotherapy cognitive responses using functional magnetic resonance imaging (fMRI) in women with early stage breast cancer as a basis for future research.

Methods: Ten women (31-61 yrs. of age) with a primary diagnosis of Stage I or II breast cancer were tested pre-chemotherapy with an established attention and working memory task (Verbal Working Memory Task) during fMRI, and 9 healthy female controls (31 64 yrs. of age) were tested after a negative screening mammogram. Accuracy of responses and reaction times were analyzed, and fMRI image analyses were performed using the SPM99 analysis package.

Results: The breast cancer group was significantly $(\mathrm{p}<.05)$ less accurate and showed slower reaction times on behavioral measures in the more demanding task conditions. On image analysis, a comparison of high vs. low demand conditions showed differences in brain activation patterns between the breast cancer and control groups (using a statistical threshold of $\mathrm{p}<.01$ ). Controls showed expected activation in the anterior cingulate in the medial frontal cortex (MFC) in Brodmann's area (BA) 32 and 6. In contrast, patients showed activation not only in the MFC but also in the left and right inferior frontal gyri (BA 44, 45, and 47), left and right insula (BA 10), and left parietal (BA 7) and right parietal areas (BA 7 and 40).

Discussion: The findings showed poorer behavioral performance on an attention and working memory task in a group of women with early stage breast cancer prior to any adjuvant chemotherapy. In order to perform the more demanding task, these patients showed bilateral brain activation with recruitment of additional components of the attention/working memory circuitry in both hemispheres. The behavioral and imaging findings in this study suggest slowed responses and compromise in attention and working memory systems in middle age women with breast cancer prior to any adjuvant chemotherapy and provide baseline data for future studies of the cognitive impact of chemotherapy.

\section{4}

A quantitative study of tumor response and progressionfree survival as surrogate endpoints for overall survival in first-line treatment of metastatic breast cancer.

Burzykowski T, Piccart MJ, Sledge G, Carmichael J, Luck HJ, Mackey JR, Nabholtz JM, Paridaens R, Biganzoli L, Jassem J, Blohmer JU, Bontenbal M, Bonneterre J, Chan S, Atalay G, Therasse P, Buyse M. Limburgs Universitair Centrum, Diepenbeek, Belgium; Institut Jules Bordet, Brussels, Belgium; IDDI, Brussels, Belgium

Background: The traditional endpoint to assess the efficacy of chemotherapies for metastatic breast cancer is overall survival (OS), but this endpoint can only be observed after prolonged follow-up. Moreover, with the number of active compounds available in this disease, any potential effect of first-line therapies on OS may be confounded by the effects of second-line therapies. It is therefore of interest to investigate whether tumor response or progression-free survival (PFS) could replace OS as the primary 


\section{S278 Abstracts - Poster Session VI}

endpoint in randomized trials for patients with metastatic breast cancer.

Methods: Individual patient data were collected on 4,256 patients in 12 randomized trials comparing an anthracycline (alone or in combination) with a taxane (alone or in combination with an anthracycline). Tumor response was assessed using WHO criteria. Progression-free survival was calculated from date of randomization to progression or death from any cause. Overall survival was calculated from date of randomization to death from any cause. Surrogacy was assessed through the correlation between the endpoints as well as the correlation between the treatment effects on the endpoints. Correlation coefficients were estimated along with their $95 \%$ confidence interval (CI).

Results: Median follow-up of alive patients was 41 months, median OS 20 months, median PFS 7 months. Tumor response was strongly associated with PFS (survival odds ratio $=5.8,95 \% \mathrm{CI}=5.0-6.5$ ) and with $\mathrm{OS}$ (survival odds ratio=3.0, 95\% CI=2.6-3.3). The correlation coefficient between response log odds ratios and PFS $\log$ hazard ratios was $0.97(95 \% \mathrm{CI}=0.74-1.21)$. The correlation coefficient between response log odds ratios and OS log hazard ratios was $0.56(95 \% \mathrm{CI}=-0.33-1.44)$. The rank correlation between PFS and OS was 0.695 (95\% CI=0.693-0.696). The correlation between the log hazard ratios for PFS and OS was $0.44(95 \% \mathrm{CI}=$ $0.41-1.30$ )

Conclusions: Tumor response is predictive of longer PFS and longer OS. Treatment effects on response are strongly correlated with treatment effects on PFS but not on OS. PFS is poorly correlated with OS, and treatment effects on PFS are poorly correlated with treatment effects on OS. These results indicate that tumor response is an acceptable surrogate for PFS but no endpoint is a good surrogate for OS in these trials. Associations between treatment effects are not precisely estimated despite the relatively large sample sizes.

\section{5}

Chemotherapy and cardiotoxicity in older breast cancer patients: a polulation-based study.

Doyle JJ, Neugut AI, Jacobson JJ, Grann VR, Hershman DL. Mailman School of Public Health, Columbia University, New York, NY; College of Physicians and Surgeons, Columbia University, New York, NY

Purpose: Adjuvant chemotherapy, especially when it includes anthracyclines, is known to cause acute and chronic cardiotoxicity in breast cancer patients. We studied the cardiac effects of chemotherapy in a population-based sample of breast cancer patients aged $\geq 65$ years with long-term follow-up.

Patients and Methods: In the Surveillance, Epidemiology and End Results (SEER)-Medicare database, we analyzed treatments and outcomes in the first five years after diagnosis among women $\geq 65$ years of age diagnosed with stage I - III breast cancer 1/1/92$12 / 31 / 99$. Propensity scores were used to control for known predictors of receiving chemotherapy and baseline heart disease, and Cox proportional hazards models were used to estimate the risks of cardiomyopathy $(\mathrm{CM})$, congestive heart failure $(\mathrm{CHF})$ and heart disease (HD) following chemotherapy.

Results: Of 31,748 women with stage I-III breast cancer, 5,575 (18\%) received some form of chemotherapy. Chemotherapy use was associated with younger age, fewer comorbidities, hormone receptor negativity, multiple primaries, and more advanced disease. Patients who received chemotherapy were less likely than other patients to have pre-existing HD (45\% vs $55 \%, \mathrm{p}<0.001)$. The hazard ratios for $\mathrm{CM}, \mathrm{CHF}$, and $\mathrm{HD}$ for patients treated with doxorubicin compared to patients who received no chemotherapy were 2.48 (95\% CI 2.10-2.93), 1.38 (95\% CI 1.25-1.52), and 1.35 (95\% CI 1.26-1.44), respectively. The incidence of cardiotoxicity among patients who received doxorubicin compared to untreated patients was highest within the first year but remained elevated five years after diagnosis (figure 1).

Conclusions: Elderly patients with pre-existing heart disease were less likely to receive adjuvant chemotherapy. Even when baseline cardiac disease was taken into account, patients who received chemotherapy, especially with anthracyclines, were more than twice as likely as other patients to develop cardiomyopathy in the five years after diagnosis. As the number of long-term survivors increases, new approaches will be needed to extend survival while minimizing the short- and long-term adverse effects of treatment.

Figure 1. Cumulative incidence of cardiomyopathy by year since breast cancer diagnosis

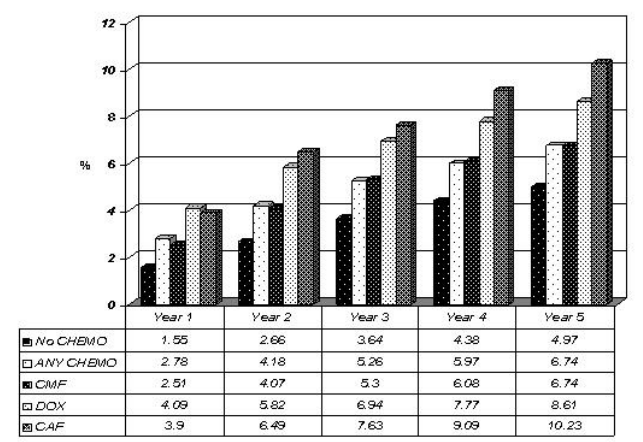

6086

Effects of taxanes alone or in combination with anthracyclines on tumor response, progression-free survival and overall survival in first-line chemotherapy of patients with metastatic breast cancer: an analysis of 4,256 patients randomized in 12 trials.

Piccart MJ, Burzykowski T, Sledge G, Carmichael J, Luck HJ Mackey JR, Nabholtz. JM, Paridaens R, Biganzoli L, Jassem J, Blohmer JU, Bontenbal M, Bonneterre J, Chan S, Atalay G, Therasse P, Buyse M. Institut Jules Bordet, Brussels, Belgium; Limburgs Univsersitair Centrum, Diepenbeek, Belgium; IDDI, Brussels, Belgium

Background: Taxanes ( $\mathrm{T}$, paclitaxel or docetaxel), in view of their partial lack of cross resistance with anthracyclines (A, doxorubicin or epirubicin), generated great enthusiasm in the 1990's for the treatment of breast cancer. Taxanes were sequenced or combined with anthracyclines and compared with standard regimens for first-line treatment of advanced disease. Randomized trials, however, have shown inconsistent results, particularly in terms of survival, which was rarely improved. This prompted the current meta-analysis of individual patient data from all relevant trials, in order to reliably detect any advantages of taxanes in terms of tumor response, progression-free survival (PFS) and overall survival (OS) in first-line treatment of patients with metastatic breast cancer.

Methods: Between December 2002 and May 2005, individual patient data were collected on 9 randomized combination trials comparing $\mathrm{A}+\mathrm{T}(+$ cyclophosphamide in 1 trial $)$ with $\mathrm{A}+$ cyclophosphamide (+ 5-fluorouracil in 4 trials), and on 3 single agent trials comparing $\mathrm{T}$ (paclitaxel in 2 trials) with $\mathrm{A}$. Combination trials included 3,337 patients, single agent trials 919 patients. Tumor response was assessed using WHO criteria. Progressionfree survival was calculated from date of randomization to progression or death from any cause.

Results: Median follow-up of alive patients was 41 months, median OS 20 months, median PFS 7 months. In single agent trials, overall response rates were $33 \%$ ( $4 \%$ complete) in the $\mathrm{T}$ arms and $38 \%$ (6\% complete) in the $\mathrm{A}$ arms $(\mathrm{P}=0.08)$. The hazard ratios for $\mathrm{T}$ compared with A were 1.19 (CI 1.04 - 1.36, $\mathrm{P}=0.01$ ) for PFS and 1.01 (CI $0.88-1.16, \mathrm{P}=0.90$ ) for $\mathrm{OS}$. In combination trials, 
response rates were $56 \%$ (10\% complete) in T-based combinations and $45 \%(6 \%$ complete $)$ in control arms $(\mathrm{P}<0.001)$. The hazard ratios for T-based combinations compared with control arms were 0.93 (CI $0.87-1.00, \mathrm{P}=0.06$ ) for PFS and 0.95 (CI $0.88-1.03$, $\mathrm{P}=0.23$ ) for $\mathrm{OS}$.

Conclusions: Single agent A was significantly better than single agent $\mathrm{T}$ in terms of PFS, marginally better in terms of response rate but not different in terms of OS. T-based combinations were significantly better than A-based combinations in terms of response rates, marginally better in terms of PFS but not different in terms of OS.

\section{7}

A phase III randomized trial of doxorubicin (A) and docetaxel (D) versus doxorubicin and paclitaxel $(P)$ in metastatic breast cancer - preliminary results of the Erasme 3 study.

Cassier PA, Chabaud S, Freyer G, Peaud PY, Tigaud JD, Cure H, Orfeuvre H, Salles B, Martin C, Jacquin JP, Agostini C, Bachelo T. Centre Leon Berard, Lyon, France; Centre Hospitalier Lyon Sud, Lyon, France; Centre Hospitalier, Valence, France; Hopital Edouard Herriot, Lyon, France; Centre Jean Perrin, ClermontFerrand, France; Centre Hospitalier, Bourg-en-Bresse, France; Centre Hospitalier, Chalon-sur-Saone, France; Centre Hospitalier, Annecy, France; Clinique de la Digonniere, St Etienne, France; Centre Hospitalier, Chambery, France

Background: In first line metastatic breast cancer,bothpaclitaxe doxorubicin (PA) and docetaxel doxorubicin (DA) combinations have been shown to be superior to treatment without taxane. The aim of this study was to compare those two combinations. As systemic therapy for breast cancer in this setting remains largely palliative, quality of life (QOL) is therefore an essential aspect of treatment and was chosen as the primary end-point of this study. Material and Methods: Primary endpoint was the overall QOL measured by EORTC QLQ-C30 scale after 4 courses. The planned sample size was 204 pts based on a minimum expected difference of 10 points in global QOL with $5 \% \alpha$ error and $90 \%$ power. Secondary aims were to compare toxicity, overall survival (OS), progression free survival (PFS) and all the sub scores of quality of life after 8 and 12 courses. Primary endpoint was compared between groups using wilcoxon rank test on relative variation from baseline. Survival distributions were estimated using the Kaplan-Meier method, and compared using the Log Rank test (LR).

Results: Between March 2000 and April 2004, 210 pts (median age 57 range [32-79]) were randomized, 103 pts (49\%) were assigned to PA group and $107(51 \%)$ to PD group. Patient characteristics were well balanced between the groups. After 4 and 8 courses of therapy, global QOL scores between groups or when compared to baseline scores did not differ significantly. Relative variation in QOL after 4 courses decreased in PA group while it was stable in DA group for physical, cognitive, or fatigue sub scores. Concerning diarrhoea sub score, absolute variation is also in favour of DA group. Response rate was $40 \%$ and $42 \%$ for DA and PA respectively. After a 24.8 [22.8-26.8] median follow-up median PFS was 8.7 months [CI95\% 8.1-9.3] and 8.0 [CI95\% 7.0-9.0] in groups DA and PA respectively $(\mathrm{LR}=0.96)$. Median survival were 22.6 months [CI95\% 16.7-28.4] and 24.1 [CI95\% 20.5-27.7] for DA and PA groups ( $L R=0.17$ ). Neuropathy (grade 3-4) occurred more frequently in PA group

Conclusion: In this studypaclitaxel or docetaxel combined with adriamycin were equivalent in terms of global QOL scores and efficacy.

\section{8}

Timing of initiation of adjuvant chemotherapy for early breast cancer does not influence disease-free survival. A Spanish Breast Cancer Research Group (GEICAM) analysis.

Jara C, Ruiz A, Martín M, Antón A, Munárriz B, Plazaola A, Cerrato L, Martínez del Prado P, Alba E, Fernández-Aramburo A. On Behalf of the Spanish Breast Cancer Research Group (GEICAM), San Sebastián de los Reyes, Madrid, Spain

Objective: the proper time for initiation of adjuvant chemotherapy (ACT) of breast cancer (BC) is not well established. A better outcome has been suggested for an early initiation of ACT. Methods: we investigated the relationship between moment of initiation of ACT and prognosis for early BC from GEICAM's centralized database (El Âlamo). Cox proportional hazards regression model was used to test the independent effect of timing of chemotherapy (TCT) after adjusting for prognostic covariables. 2782 patients (pts) diagnosed with stage I-II BC between 1990 to 1997, and who had received ACT, were selected. Pts who were treated with neoadjuvant or high-dose CT were excluded. Factors considered to potentially have an influence on disease-free survival (DFS), were: time between breast surgery and beginning of chemotherapy (TCT)(categorized as less of 3 weeks, 3 to 6 weeks, 6 to 9 weeks and more than 9 weeks), and tumour size, vascular/ lymphatic permeation, histopathologic grade, number of axillary nodes involved, hormonal receptor status (positive vs. negative), age and chemotherapy scheme (categorized as CMF, antracyclines/ taxanes, others). Results: median follow-up was 74 months. TCT does not influence DFS $(\mathrm{p}=0.68)$. Cox multiple regression analysis shows that variables influencing DFS are tumour size, number of positive nodes, age, vessel invasion, hormonal receptors status, tumour grade and scheme of chemotherapy (Table I). Conclusion: we have been unable to identify any significant benefit for DFS from an early starting or a deleterious effect of delaying chemotherapy after surgery either overall or in any subset of patients.

Table I

Variable

$1.25(1.08-1.45)$

Gi

$0.0467-1.25(1.00-1.56)$

$0.0096 \quad 1.37(1.08-1.73)$

0 nodes

$1-3$ nodes

1-3 nodes

$4-9$ nodes

$<0.00001 \quad 2.73(2.20-3.38)$

$<0.00001 \quad 4.08(3.21-5.18)$

2.1 $3.0 \mathrm{~cm}$

$3.1-4.0 \mathrm{~cm}$

$4.1-5.0 \mathrm{~cm}$

$>5 \mathrm{~cm}$

Age (years)

$<35$

$35-50$

$51-70$

$>70$

Chemotherapy Schem

Antracyclines/taxanes

CMF

0.000

.29(1.12-1.49)

$0.0265 \quad 1.22(1.02-1.44)$

$0.0145 \quad 1.29(1.05-1.59)$

$0.0079 \quad 1.45(1.10-1.91)$

$0.0001 \quad 1.61(1.27-2.04)$

$<0.00001 \quad 1.89(1.44-2.51)$

$0.6080 \quad 1.04(0.89-1.20)$

$0.0131 \quad 1.41(1.07-1.84)$

$0.0001 \quad 1.15(0.69-1.93)$

$0.0811 \quad 1.59(0.94-2.68)$ 
6089

A multicenter phase III trial comparing docetaxel plus epirubicin versus docetaxel plus capecitabine as first line treatment in patients with locally advanced and metastatic breast cancer. Preliminary report.

Mavroudis D, Boukovinas I, Ardavanis A, Syrigos K, Kouroussis CH, Kakolyris S, Malamos N, Athanasiadis A, Varthalitis I, Potamianou A, Georgoulias V. Hellenic Oncology Research Group, Heraklion, Greece

Background: Docetaxel plus Epirubicin (DE) is an effective regimen in first-line treatment of advanced breast cancer (ABC). Docetaxel plus Capecitabine (DC) is an effective treatment in anthracycline-pretreated ABC. In this multicenter phase III study we compared the efficacy and tolerability of the two regimens as front-line treatment in patients (pts) with $\mathrm{ABC}$.

Patients and Treatment: Untreated pts with $\mathrm{ABC}$, measurable disease, good performance status (PS 0-2) and organ function (including cardiac) were randomized to receive either epirubicin $75 \mathrm{mg} / \mathrm{m}^{2}$ plus docetaxel $75 \mathrm{mg} / \mathrm{m}^{2}$ (DE) on day 1 or docetaxel 75 $\mathrm{mg} / \mathrm{m}^{2}$ on day 1 plus capecitabine $950 \mathrm{mg} / \mathrm{m}^{2}$ orally twice daily on days 1-14 (DC) in cycles every 21 days. Pts who had received anthracycline-based adjuvant chemotherapy more than one year before were allowed to participate. The primary end point of the study was to compare the time to disease progression (TTP).

Results: A total of 196 pts were randomized to DE ( $\mathrm{n}=98)$ and DC $(n=98)$. All pts were evaluable for toxicity and $86 \mathrm{DE}$ and 84 DC pts for response. Nine (DE) vs 8 (DC) pts were premenopausal, 13 vs 15 pts had stage IIIB disease and 3 pts on each arm had PS 2. Thirty-three DE and $37 \mathrm{DC}$ pts had previously received adjuvant anthracycline-based treatment. We observed $12(14 \%)$ vs $7(8 \%)$ complete responses and $34(40 \%)$ vs $32(38 \%)$ partial responses for an overall response rate of $53.5 \%$ vs $46.4 \%(\mathrm{p}=0.3)$ in DE vs DC pts, respectively. The median duration of response was 13 vs 13.5 months $(\mathrm{p}=0.9)$ and the median TTP 11.8 vs 10.9 months $(\mathrm{p}=0.6)$ for DE and DC pts, respectively. A total of $534 \mathrm{DE}$ and 492 DC cycles were administered with 2 toxic deaths due to sepsis both on the DE regimen. Severe toxicity included grade 4 neutropenia $42 \%$ vs $28 \%(p=0.08)$, febrile neutropenia $10 \%$ vs $5 \%(\mathrm{p}=0.07)$, diarrhea $3 \%$ vs $0 \%(\mathrm{p}=0.03)$ for $\mathrm{DE}$ and $\mathrm{DC} \mathrm{pts}$, respectively.

Conclusions: In this preliminary analysis the DE and DC regimens showed similar activity but the DC regimen was associated with less severe toxicity. Updated results will be presented at the meeting.

\section{0}

Pegylated liposomal doxorubicin in previously treated patients with metastatic breast cancer- a large multicenter phase II trial.

Al-Batran SE, Bischoff J, von Minckwitz G, Atmaca A, Kleeberg U, Meuthen I, Morack G, Lerbs W, Hecker D, Jager E. Krankenhaus Nordwest, Frankfurt, Germany; Klinik Bad Trissl, Oberaudorf, Gabon; Universitaets-Frauenklinik, Frankfurt, Finland; Heamatologisch-Onkologische Praxis Altona, Hamburg, Germany; Krankenhaus Holweide, Köln, Germany; Klinikum Berlin-Buch, Berlin, Germany; Essex Pharma, Munich, Germany; Essex Pharma, Munich, Switzerland

Background: This study was designed to evaluate the safety and the clinical benefit of Pegylated liposomal doxorubicin (PLD) in an anthracycline and taxan pretreated patient population with metastatic breast cancer (MBC). Patients and Methods: 101 female patients with MBC were enrolled at 25 German centers. Patients received intravenous PLD $50 \mathrm{mg} / \mathrm{m}^{2}$ every four weeks (one cycle), and were evaluated for toxicity prior to each treatment, and for response every two cycles. Results: 99 of 101 patients were evaluable for the safety analysis and 98 for response. The median age was 60 years (range 31-79) and the median Karnofsky performance status was 90 (range 60-100). All patients were previously treated with chemotherapy (53\% of patients had $\geq 3$ chemotherapies), and $80 \%$ of patients had a prior exposure to an anthracycline. The clinical benefit response (objective response + stable disease) was $41 \%$. Median time to progression and overall survival were 3.6 and 10.2 months, respectively. The median response duration was 11.8 months, and the median time to progression in patients with stable disease was 8.8 months. NCICTC grade 3-4 toxicities were neutropenia in $17(17.7 \%)$ patients followed by stomatitis in $14(14.2 \%)$ and PPE in 7 (7.1\%) patients. Conclusions: PLD is safe and active in patients with MBC who had received multiple prior chemotherapies including anthracyclines and taxans.

\section{1}

Results of a phase II trial of combination therapy with oral capecitabine and weekly paclitaxel for metastatic breast cancer: preliminary results in taxane pretreated women. Blum JL, Dees EC, Asmar L, Vukelja S, McMahon R, Amare M, Gill D, Ilegbodu D, Boehm KA, O'Shaughnessy J. US Oncology Research, Inc., Houston, TX; Baylor-Charles A. Sammons Cancer Center, Dallas, TX; Texas Oncology, P.A., Dallas, TX; The University of North Carolina at Chapel Hill, Chapel Hill, NC

Background: There is evidence of synergy between the taxanes and capecitabine (C). This trial was designed to determine the efficacy of weekly paclitaxel (P) plus $\mathrm{C}$ in subjects with metastatic breast cancer who have previously received taxane on an every 3week schedule.

Subjects and Methods: Subjects had histologically proven breast cancer, with measurable metastatic disease by RECIST. Exclusion criteria included prior weekly taxanes or any prior $\mathrm{C}$ or infusional 5-FU. Participants received C $825 \mathrm{mg} / \mathrm{m}^{2} /$ dose PO BID (1650 mg/ $\mathrm{m}^{2} /$ day) for Days $1-14$ followed by 1 week of rest. P $80 \mathrm{mg} / \mathrm{m}^{2}$ was administered IV weekly on Days 1 and 8 followed by 1 week of rest. Cycles were repeated every 3 weeks.

Results: Fifty-three (53) eligible taxane pretreated women were enrolled; 30 subjects $(57 \%)$ were either ER or PR positive. Metastatic sites included: soft tissue $(58 \%)$, viscera $(51 \%)$, liver $(34 \%)$, and bone (26\%). To date, 30 patients $(57 \%)$ are evaluable for response. Complete responses were achieved in 7 patients (23\%) and partial responses in 12 patients $(40 \%)$, for an overall response rate of $63 \%$. An additional $20 \%$ had stable disease; $17 \%$ have progressed. The median duration of response for $\mathrm{CR}+\mathrm{PR}$ was 8.8 months (range, 2.4-18.5). Grade 4 treatment-related adverse events were minimal and limited to neutropenia $(n=2)$. Grade 3 treatment-related adverse events were limited to hand and foot syndrome $(n=7)$, neutropenia $(n=4)$, and fatigue $(n=2)$.

Conclusions: We have previously shown that weekly PC is an active regimen in taxane-naïve women with MBC. Weekly PC appears highly active and well tolerated in taxane-pretreated patients. The results of all 53 patients will be presented.

Supported by Roche Laboratories, Inc., Nutley, NJ

\section{2}

Phase II trial of gemcitabine plus carboplatin (plus trastuzumab in HER2+ patients) in metastatic breast cancer patients.

Loesch DM, Asmar L, McIntyre KJ, Doane LL, McKittrick RJ, Monticelli MA, Paul D, Vukelja SJ, Zhan F, Boehm KA O'Shaughnessy J. US Oncology Research, Inc., Houston, TX, Central Indiana Cancer Centers, Indianapolis, IN; Texas Oncology, P.A., Dallas, TX; Kansas City Cancer Centers, Overland Park, KS, Kansas City Cancer Centers, Kansas City, KS; Williamette Valley Cancer Center, Springfield, OR; Rocky Mountain Cancer Centers, Denver, CO; Tyler Cancer Center, Tyler, TX; Baylor-Charles A. Sammons Cancer Center, Dallas, TX

Background: Gemcitabine (G) and carboplatin (C) have significant preclinical synergy, and both provide synergistic antitumor activity in combination with trastuzumab $(\mathrm{H})$. Presently, no Phase II data exist for $\mathrm{G}+\mathrm{C}$ in $\mathrm{MBC}$ patients. This multicenter 
Phase II trial studied the efficacy and safety of biweekly $\mathrm{G}+\mathrm{C} \pm \mathrm{H}$ in MBC patients.

Patients and Methods: Patients were stratified into 3 groups; Group 1: HER2+; Group 2: HER2- (taxane naïve); and Group 3: HER2- (prior taxane). Included were: women $\geq 18$ years of age, ECOG 0-2, with measurable MBC, defined by RECIST either HER2or HER2 (3+) by IHC or FISH+, and normal organ functions; prior radiation completed $\geq 3$ weeks prior to study entry.

Treatment: All cycles were 14 days for all groups of patients, Day $1 \mathrm{G} 1500 \mathrm{mg} / \mathrm{m}^{2}$ followed by C $\mathrm{AUC}=2.5$. For Group 1 , treatment also included $\mathrm{H} 8 \mathrm{mg} / \mathrm{kg}$ Cycle 1 , followed by $4 \mathrm{mg} / \mathrm{kg}$ for Cycles 2-9, followed by $6 \mathrm{mg} / \mathrm{kg}$ for Cycles $10+$.

Results: 40, 51, and 49 patients have been enrolled and 36, 48, and 41 patients were treated in Groups 1,2, and 3, respectively. The table below summarizes responses and toxicities of these patients:

\begin{tabular}{llll} 
Eligible patients & \multicolumn{3}{c}{ Number and percentage (\%) of patients } \\
Treated w $1 \geq 1$ dose & 36 & 51 & 49 \\
Evaluable patients & 18 & 48 & 41 \\
Complete response & $1(6)$ & 35 & 25 \\
Partial response & $10(56)$ & 9 & 0 \\
Stable disease & $6(32)$ & $16(46)$ & $8(32)$ \\
Progressive disease & $1(6)$ & $10(28)$ & $9(36)$ \\
Median number of cycles & 8 & 7 & 3 \\
Alopecia (Grade 2) & $0 \%$ & $4.2 \%$ & $4.9 \%$ \\
Neutropenia (Grade 3) & $28 \%$ & $38 \%$ & $24 \%$ \\
Neutropenia (Grade 4) & $8 \%$ & $13 \%$ & $22 \%$ \\
Thrombocytopenia (Grade 4) & $3 \%$ & $4 \%$ & $2 \%$
\end{tabular}

Conclusions: $\mathrm{G}+\mathrm{C}+\mathrm{H}$ is active in HER2+ patients with metastatic breast cancer. Biweekly $\mathrm{G}+\mathrm{C}$ is active in HER2- MBC patients Prior taxane therapy does not seem to affect the response rate. $\mathrm{G}+\mathrm{C} \pm \mathrm{H}$ is associated with a low frequency of toxicity: neutropenia $(<50 \%)$ and anemia $(<15 \%)$. Alopecia was infrequent; Grade 2 $(<5 \%)$. Additional data will be provided.

Supported by Eli Lilly and Company, Indianapolis, IN.

\section{3}

The impact of educational attainment on initial doses of breast cancer adjuvant chemotherapy.

Griggs JJ, Sorbero MS, Culakova E, Lyman GH. University of Rochester, Rochester, NY; RAND Corporation, Pittsburgh, PA

Objective: The purpose of this study was to examine the impact of educational attainment, a proxy for socioeconomic status (SES), on initial chemotherapy doses in the adjuvant treatment of breast cancer. Initial chemotherapy dose reductions represent intentional physician prescribing decisions. Methods: Initial (first cycle) breast cancer adjuvant chemotherapy doses were prospectively collected from the records of 764 patients treated between March 2002 and September 2004 in 91 practices. For each subject, the ratio of the actual dose to the expected dose (using actual height, weight, and standard published doses) was calculated for individual drugs and then averaged for the regimen. Bivariate analyses were used to assess the association between first cycle dose reduction (defined as a $10 \%$ reduction below published doses using actual body weight). Chi-squared tests were used to assess for significance. Logistic regression models were used to study the impact of educational attainment on the use of first cycle dose reduction, controlling for regimen, comorbidity, body mass index (BMI), race, age, and treating practice. Practice level random effects were also included. Robust standard errors were used to account for the correlation between multiple patients receiving care from the same practice. Results: The delivery of reduced doses below $90 \%$ of the calculated dose was observed in 150 (19.6\%) of the sample. Among subjects with less than a high school education, 33\% received a first cycle dose reduction compared to $14 \%$ among those with at least a high school degree $(\mathrm{p}=0.002)$. First cycle dose reduction was also significantly associated with increasing body mass index $(\mathrm{p}<0.0001)$. These results were confirmed in multivariate analyses (educational attainment, $\mathrm{p}=0.03$ and increasing BMI, $\mathrm{p}<0.0001)$. Conclusions: The disparity in breast cancer outcomes according to SES may be in part the result of suboptimal chemotherapy doses in the adjuvant treatment of breast cancer. Efforts to address such prescribing patterns may help reduce SES disparities in breast cancer survival.

\section{4}

CHAT - an open-label, randomized phase II study of trastuzumab plus docetaxel with or without capecitabine in patients with advanced and/or metastatic, HER2-positive breast cancer: second interim safety analysis.

Wardley A, Antón-Torres A, Otero Reyes D, Jassem J, Toache LMZ, Alcedo JC, Bell R. Christie Hospital, Manchester, United Kingdom; Hospital Universitario Miguel Servet, Zaragoza, Spain; Hospital CIMA, San Jose, Costa Rica; Akademia Medyczna, Gdansk, Poland; Hospital Rosevelt, Guatemala, Guatemala; Instituto Oncológico Nacional, Panama, Panama; Andrew Love Cancer Centre, Geelong, Victoria, Australia

Background: The CHAT trial compares trastuzumab $(\mathrm{H} ; 8 \mathrm{mg} /$ $\mathrm{kg}$ loading dose and $6 \mathrm{mg} / \mathrm{kg}$ q3w) plus docetaxel (T; q3w $75 \mathrm{mg} / \mathrm{m}^{2}$ in the three-drug and $100 \mathrm{mg} / \mathrm{m}^{2}$ in the two-drug arm) with or without capecitabine (X; $950 \mathrm{mg} / \mathrm{m}^{2}$ BID) in patients (pts) with advanced or metastatic HER2-positive breast cancer. A higher than expected incidence of complicated neutropenia $(\mathrm{CN} ; 32 \%$ overall) led to temporary suspension of recruitment. After a thorough review, the independent Data Safety Monitoring Board recommended continuation of the trial four months later. Stricter entry criteria were used; only pts with ECOG 0-1 were enrolled while pts with dyspnea and on chronic concomitant steroids were excluded. All episodes of febrile neutropenia, neutropenic infection or neutropenic sepsis were considered as $\mathrm{CN}$.

Methods: Data from 110 pts (who received at least one cycle of study drug) are presented. Pts received a median of $8 \mathrm{H}$ doses. Whilst median number or cycles were 6 and 7 respectively, cumulative T dose was higher with HT than HTX (median 1,050mg vs $732 \mathrm{mg}$ ). HTX pts received a median of 6 cycles of X. There were no significant differences in baseline characteristics. Blood counts were obtained precycle and on days 8 and 15 of cycle 1 . Results: Leukopenia and neutropenia were the most significant hematological abnormalities. Grade 3/4 neutropenia occurred in $52 \%$ of pts in the HTX arm and $76 \%$ in the HT arm. Overall incidence of $\mathrm{CN}$ was lower $(26 \%)$ than in the first safety analysis, $29 \%$ in the HT arm and $24 \%$ in the HTX arm. CN generally occurred in the first cycle of HT and in later cycles of HTX treatment. The overall incidence of symptomatic congestive heart failure is $2 \%$ (one pt in each treatment arm), which is within the expected range for pts receiving $\mathrm{H}$ plus chemotherapy in recent trials (3-4\%). Discussion: $\mathrm{T}$ is a myelosuppressive drug, associated with a significant level of grade $3 / 4$ neutropenia and $\mathrm{CN}$ in a small but significant minority of pts. The overall incidence of $\mathrm{CN}$ in this study at end of June 2004 is $24 \%$ (31/131 pts), which is comparable to that seen in the M77001 and SO14999 trials (20\% and $19 \%$, respectively). No other new safety concerns have emerged to date.

\section{5}

Who profits most from a guideline basedTreatment for advanced breast cancer?

Dieing A, Possinger K, Schmid P, Regierer AC, Schulz CO, Wolters R, Wischnewsky MB. Charité, Camöus Mitte, Humboldt University, Berlin, Germany; University of Bremen, Bremen, Germany

BACKGROUND: The purpose of this work was to test, whether a guideline-based treatment leads to a better outcome (objective response (ORR), time to progression (TTP) and overall survival $(\mathrm{OS})$ ) for advanced breast cancer patients. Background is the actual german national guideline 2004, which includes the results of more than 20 other guidelines from various countries. The purpose of this work was to evaluate whether guideline-based treatment for metastatic breast cancer is associated with better outcome. 


\section{S282 Abstracts - Poster Session VI}

METHODS: 120 patients with ABC were consecutively enrolled to an open study. They were treated between 1991 and 2004 with the respective valid standard therapies. Patients characteristics were: age: median 50.0 y.; (; premenopausal: 53.3\%; ER / PgR: positive $64.2 \%$, negative $23.3 \%$, erB2 positive: $24.2 \%$. Dominant visceral metastases had $47.5 \%$ of the patients at first diagnosis of metastases. We used a prognostic score (PPS) for ABC-pts based on the 3 clinical parameters dominant site of metastases (DSM), receptor status (RS), and disease free interval (DFI) (Possinger 1984). Patients can be classified as low (PPS $£ 7$ ) and high-risk (PPS $>7$ ). In the study cohort, $58.3 \%$ of the pts were PPS-low risk. First line cytostatic treatment was checked for accordance to the current guidelines.

RESULTS: $26.7 \%$ of the treatments were in accordance with the actual guidelines. Main reasons for guideline inconsistency were that many patients were treated before the introduction of substances, which are recommended in the current guidelines, e.g. taxanes. The groups (guideline-compliant treatment or not) were compared referring to ORR, TTP and OS.

Median overall survival (=OS) of all patients was 43 months, ORR in first line therapy was $30.8 \%$. Considering the entire cohort, there was no difference in outcome of the 1st line therapy or overall survival with respect to guideline compliance. However, accordance to the current guideline compliance was relevant in subgroups: Whereas in high-risk-patients guideline-compliant treatment was associated with significant longer TTP and OS, there were no relevant differences in patients in the low-risk group. Results are summarized in table 1 .

CONCLUSIONS: This open study shows that high-risk patients profit most from a guideline based treatment for advanced breast cancer. In contrast to this, an evidence-based guideline-oriented treatment for low-risk pts does not lead to a significant better outcome (ORR, TTP, OS).

reatment results of 1st line cytostatic therapy (median values) and guideline compliance

all patients guideline-complint

ORR (months)

TTP (days)

OS (months)

high risk patients

high risk patients (days)

TTP (days)

OS (months)

TTP (days)$$
31.2
$$$$
254
$$

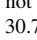

30.7

210

41

48

180

20

240

210

\section{6}

Characterization of anti-fatty acid synthase expression in normal breast and breast cancer.

Jensen KC, Montgomery K, West RB, van de Rijn JM. Stanford University Medical Center, Stanford, CA

Background: Expression of fatty acid synthase has been reported in many different tumors. In gene microarray studies of breast carcinoma, a fatty acid synthase gene (FASn) co-clustered with cytokeratins 5 and 17 and other genes that defined the basal-like subset of breast cancers.

Materials and Methods: A rabbit polyclonal antiserum (S143) to a synthetic peptide of the fatty acid synthase (FASn) gene was developed. Various tissue microarray and whole tissue sections were stained with the S143 antiserum. The tissue microarrays included breast cancer ( 979 cases), other tumors ( 259 cases), normal breast (15 cases) and various fetal tissues (90 cases). The breast cancer tissue microarray included clinical outcome data, with a mean follow-up of over 17 years. Whole tissue sections consisted of benign and malignant tissue from breast resection specimens. Results: The S143 antiserum was expressed in a wide range of normal and pathologic tissues, but showed a restricted pattern of expression in normal breast with reactivity in a small subset of basal and suprabasal cells. Dual staining experiments revealed that the subpopulation of cells labeling with S143 did not coexpress cytokeratins $5 / 6$ or $\mathrm{p} 63$, but did coexpress e-cadherin. In addition to staining the subset of basal cells, the antiserum diffusely decorated epithelial cells with apocrine differentiation (including a case of carcinoma with apocrine differentiation), and stained 3 of 5 cases of columnar alteration with prominent apical snouts and secretions (CAPSS) and 5 of 5 cases of flat epithelial atypia. Despite it association with basal keratins in gene array studies, S143 protein expression did not correlate significantly with clinical outcome. Conclusions: We describe a novel antiserum that highlights only a subset of basal and suprabasal cells in normal breast ducts and we show by dual expression studies that this subset of cells are different from myoepithelial and basal cytokeratin-positive cells. Interestingly, studies by others postulate that stem cells for normal breast may reside in a subpopulation of basal cells. Further studies are needed to determine whether S143-positive cells contain a breast stem cell. In addition, S143 expression is described in apocrine metaplasia, CAPSS and flat epithelial atypia, suggesting that this antiserum may be useful in diagnosing these lesions.

\section{7}

DD-M111/ hAG-2 is highly expressed in ductal and lobular breast cancer.

Naar EM, Macina RA, Vartanian S, Simon I, Liu SH, Shroyer KR. University of Colorado Health Sciences Center, Aurora, CO diaDexus Inc., South San Francisco, CA

Background: DD-M111 is a secreted protein of 175 aa known as hAG-2 that in Xenopus laevis is known to be expressed during embryologic development and may play a role as a differentiation factor. We identified DD-M111 by cDNA library analysis as a novel gene over-expressed in breast cancer compared to normal breast or other benign somatic tissues. The over-expression of DD-M111 mRNA was verified by microarray and real-time quantitative RT-PCR with microarray results showing up-regulation in more than $50 \%$ of early stage breast cancers. In the current study, we investigated the expression of DD-M111 at the protein level in benign, premalignant, and malignant breast lesions, as a potential diagnostic marker of breast cancer.

Materials and Methods: Archival formalin-fixed tissue blocks from 52 breast cancer cases were evaluated for DD-M111 expression by an indirect immunoperoxidase method using a mouse monoclonal antibody and heat antigen retrieval in citrate buffer (pH 6.0). The specificity of this antibody was confirmed by Western Blot of supernatant from T47 breast cancer cell lines, and by substitution of the primary antibody with subclass-matched non-immune mouse immunoglobulin in immunohistochemical assays. The proportion of DD-M111 positive cells and the intensity of staining $(0-3+)$ were compared with histologic type, grade, stage, hormone receptor status, and Her-2 neu status.

Results: DD-M111 was exclusively detected in the cytoplasm of epithelial tissue components and was detected in 38/46 (82.6\%) ductal carcinomas and in 5/5 (100\%) lobular carcinomas. Among positive cancer cases, $32 / 43(74.4 \%)$ tumors showed staining in greater than $10 \%$ of cells (median $80 \%$ ), with a median staining intensity of 1.5. The expression of DD-M111 in breast cancers did not appear to be correlated with hormone receptor status, Her-2 neu status, or with other clinicopathologic variables. DDM111 was also detected in 22/43 (51\%) of in situ carcinomas (DCIS/LCIS), (median $40 \%$ positive cells) with a median stain intensity of 1 . Most normal or benign proliferative lesions were negative for DD-M111 although high levels of expression (1.5 intensity in at least $50 \%$ of cells) was noted $4 / 8$ fibrocystic lesions adjacent to breast cancers.

Discussion: The high level of DD-M111 overexpression in most invasive breast cancers, independent of tumor grade or stage, suggests that this protein may play a critical role in breast carcinogenesis and could be a useful diagnostic marker for breast cancer. In contrast to results utilizing mRNA profiling (1), however, DD-M111 protein expression showed no correlation with estrogen receptor status in breast tumors.

(1) Fletcher GC, Patel S, Tyson K, Adam PJ, Schenker M, Loader JA, et al. hAG-2 and hAG-3, human homologues of genes involved in differentiation, are associated with oestrogen receptor-positive breast tumours and interact with metastasis gene $\mathrm{C} 4.4 \mathrm{a}$ and dystroglycan. Br J Cancer. 2003 88:579-85. 


\section{Abstracts-Poster Session VI S283}

\section{8}

Increased tartrate-resistant acid phosphatase (Trap) expression in breast cancer, patients' sera and cell lines. Honig A, Rieger L, Kapp M, Krockenberger M, Dietl J, Kammerer U. University of Wuerzburg, Wuerzburg, Germany

Introduction:TRAP5b was investigated as a marker of bone disease in breast cancer (BC) patients with and without bone metastases. Surprisingly, even patients with exclusively visceral metastases showed increased TRAP5b serum values. This observation led to the hypothesis, that it is not only the osteoclast but also the tumor cell, that secrets TRAP. In order to elucidate this phenomenon we investigated a broad range of primary and commercially available BC cell lines as well as benign cell lines with regard to TRAP expression using ELISA, immunocytology and RT-PCR techniques. In addition, samples of benign tissue and breast cancer at different stages of disease were analyzed for TRAPexpression by immunohistochemistry.

Results: By ELISA, we found high concentrations of TRAP in the supernatant of primary BC cell cultures. In commercially available BC cell lines, the levels of TRAP 5b were quite low, comparable to the low concentrations detected in benign cell cultures. Interestingly long term culture seems to affect TRAP expression as its expression decreases with the time of in vitro culture and only traces can be detected in some long-term established BC cell lines. By RT-PCR and immunocytology we could confirm that tumor cells express and secrete TRAP. By immunohistochemistry we found a high expression of TRAP in malign tissue whereas only very little expression was found in normal breast tissue of the corresponding patient.

Conclusion: TRAP expression was restricted to cancer cells in breast tissue. Increased serum levels of TRAP are not specific for bone metastases but rather show an increase of tumor cell mass. TRAP might therefore serve as a potential target for future treatment of breast cancer.

\section{9}

Withdrawn by Author

\section{0}

The loss of 14-3-3 sigma $(\sigma)$ protein expression in invasive adenocarcinoma of the breast is associated with promoter hypermethylation and a more favorable clinical outcome. Yang B, Yoder BJ, Roma AA, Wang L, Tarr S, Laniauskas S, Tso E, Choueiri T, Budd GT, Crowe JP, Hicks DG. Cleveland Clinic Foundation, Cleveland, $\mathrm{OH}$

Background: The $14-3-3 \sigma$ protein is a p53-regulated G2/M inhibitor, which plays a role in numerous signaling pathways involved in cell cycle control, DNA repair and cell survival. Recent reports have demonstrated a loss of 14-3-3 $\sigma$ expression early in the development of many breast cancers through epigenetic hypermethylation of the gene promoter. Furthermore, study in colorectal cancers showed that loss of $14-3-3 \sigma$ is associated with chemosensitivity and better prognosis. However, the prognostic

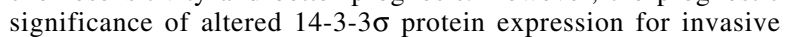
breast cancer remains unclear. Therefore, we have examined the relationship between 14-3-3 $\sigma$ expression, promoter methylation and established clinical and pathologic features in breast cancer. Materials and Methods: Tissue microarrays were constructed containing 332 primary invasive breast cancers with 5-year clinical follow up. Immunohistochemistry (IHC) for 14-3-3 $\sigma$ (1:100 dilution, LabVision, Fremont $\mathrm{Ca}$ ) was qualitatively scored on a 0 $2+$ scale, and compared with established prognostic and predictive factors. In addition, a subset of these cases was examined for hypermethylation of the 14-3-3 $\sigma$ promoter by RTPCR, as a possible mechanismcontributing to loss of 14-3-3 $\sigma$ expression.

Results: $14-3-3 \sigma$ expression was seen in $16 \%(53 / 332)$ of breast tumors $(2+-3+)$, while the remaining $84 \%$ (279/332) of cases were negative $(0-1+)$. There was no significant association between the expression of $14-3-3 \sigma$ and age, ER, PR, HER2, grade, nodal status or clinical stage $(\mathrm{p}>0.05)$. However, there was a significantly shorter mean disease free survival $(\mathrm{p}=0.001)$ and a trend toward shorter mean overall survival $(\mathrm{p}=0.1)$ for tumors expressing 14$3-3 \sigma(2-3+)$. For 10 negative and 10 positive $14-3-3 \sigma$ cases by IHC, there was a significant correlation between loss of immunoreactivity and promoter methylation of the $14-3-3 \sigma$ gene $(\mathrm{p}<0.05)$.

Conclusions: The loss of $14-3-3 \sigma$ expression through promoter methylation appears to be an early event in breast cancer development leading some to speculate that this protein functions as a tumor suppressor in breast carcinogenesis. However, the results reported here suggest that expression of $14-3-3 \sigma$ in the context of an established malignancy may contribute to a more aggressive clinical course for breast cancer. Given that $14-3-3 \sigma$ is an antiapoptotic protein, as characterized in other tumors, our study suggests that silencing expression of $14-3-3 \sigma$ through promoter hypermethylation may be associated with a better prognosis. Further study of the biologic and clinical significance of these findings, with emphasis on the potential role for this protein in predicting response to adjuvant therapies, is warranted.

\section{1}

Growth regulation is altered in cancer-containing breasts. Walker RA, Rodrigues CM, Gordon-Weeks A, Luckett JC, Jones JL. University of Leicester, Leicester, United Kingdom; Queen Marys School of Medicine and Dentistry, London, United Kingdom

Background: We have previously identified that non-involved tissue from cancer-containing breasts has lower apoptosis than age-matched normal breast, plus changes in EGFR expression. Many factors regulate apoptosis and proliferation and myoepithelial cells have been shown to have an important role. This study has compared apoptotic and myoepithelial proteins in normal tissue from cancer-containg breasts (NTCCB) and age matched controls, and the in vitro effect of myoepithelial cells from both groups on proliferation/apoptosis of breast cancer cells. Materials and Methods: Tissue from 58 NTCCB (taken at least $4 \mathrm{cms}$ away from the cancer) and 61 age- matched controls were examined using immunohistochemistry for bcl-2, bax, caspase 3 , FGF2, p63, 14-3-3 $\sigma$ with proliferation index (PI) and apoptotic index (AI) determined using Ki67 and M30, respectively. Myoepithelial cells were isolated from 6 controls (reduction mammoplasty) and 3 NTCCB, conditioned media prepared and its effects on PI and AI of MCF-7 and T47-D cells determined. All cultures were for $24 \mathrm{hr}$ and in duplicate.

Results: There was a significantly lower AI in NTCCB than controls but PIs were similar. Expression of bcl-2 and FGF2 was significantly greater in NTCCB, with lesser differences for bax and $\mathrm{p} 63$. Conditioned media from myoepithelial cells from normal caused a decrease in PI and increase in AI but that from NTCCB increased PI and decreased AI of T47-D cells. The effects on MCF-7 cells were less significant.

Discussion: Lower levels of apoptosis have been identified again but in a different cohort of NTCCB, along with higher expression of the anti-apoptotic protein bcl-2. FGF2, which is important in growth regulation, has been found at a higher level in myoepithelial cells in NTCCB. Preliminary in vitro studies indicate that the tumour suppressor effect of myoepithelial cells is modified in cancer-containing breasts. This, and the changes in apoptosis identified in tissues, could result in an impairment in removing cells that have undergone DNA damage and enhance cancer development. It also implies that there are widespread changes in breasts in which a cancer develops. 


\section{S284 Abstracts - Poster Session VI}

6102

Tumour necrosis factor-a converting enzyme (TACE) promotes apoptosis in breast cancers by cleaving HER4. Kirkegaard T, Naresh A, Tovey SM, Dunne B, Jones FE, Bartlett $J M S$. Endocrine Cancer Group, Glasgow Royal Infirmary, Glasgow, United Kingdom; Glasgow Royal Infirmary, Glasgow, United Kingdom; Tulane University Health Sciences Center, New Orleans, $L A$

Background: HER4 is associated with improved outcome in breast cancer patients ${ }^{1}$. Proteolytic processing of HER4 by tumour necrosis factor-a converting enzyme (TACE) and presenilindependent g-secretase, releases the intracellular domain (4ICD) of HER4. 4ICD harbours a BCL-2 homology 3 (BH3)-domain and can therefore induce apoptosis of breast cancer cells ${ }^{2}$.

Material and Methods: TACE and HER4 expression was determined by immunohistochemistry in 413 breast carcinomas. HER4 expression was determined using 2 antibodies raised against either an intracellular epitope (aa 1249-1264; clone HFR-1) or against an extracellular fragment (clone designation H4.77.16) both from Neomarkers. Apoptotic activity was measured by TUNEL assay. Statistics were performed using SPSS. Correlations were calculated using the Spearman rank test and patient survival assessed using Kaplan-Meier plots with log-rank testing.

Results: Positive cytoplasmic TACE expression was seen in 213/ $413(51.6 \%)$ breast carcinomas, mainly in tumour with high membrane ( $<0.001$ for both HER4 antibodies) or intracellular (4IED) ( $\mathrm{p}=0.015$ and $\mathrm{p}=0.003$ for HFR-1 and H4.77.16, respectively) HER4 expression. Positive TACE expression was also seen in tumours with high nuclear HER4 expression when the HFR-1 HER4 antibody ( $\mathrm{p}=0.028$ ), and not the H4.77.16 HER4 antibody ( $\mathrm{p}=0.197)$, was used. Apoptotic activity was noted in $156 / 398$ (39.2\%) breast carcinomas, mainly in tumours with high intracellular (4ICD) HER4 expression $(\mathrm{p}=0.024)$, but not in tumours with high membrane ( $\mathrm{p}=0.727)$ HER4 expression. No impact of tumour TACE expression and apoptotic activity on patient survival was observed.

Discussion: The association between HER4 and improved patient outcome has so far been unexplained. Recent data, however, shows that HER4 expression is associated with decreased proliferation and that proteolytic released HER4 (4ICD) is linked to apoptosis ${ }^{2}$ in breast cancer cells. Here we further demonstrate that TACE expression is associated with increased levels of intracellular HER4 (4ICD) and that intracellular HER4 is linked to apoptosis. However, more studies need to be performed to further investigate the role of HER4 and TACE in mediating apoptosis of breast cancers cells. 1: Witton et al., J Pathol 2003;200:290-97

2: Vidal et al., J Biol Chem 2005; 208:19777-833:

3: Tovey SM et al., Breast Cancer Res 2004;6:R246-51

\section{3}

Inhibition of BRCC36 enhances apoptosis by disrupting BRCA1 phosphorylation in breast cancer cells exposed to ionizing radiation.

Arciero CA, Chen X, Godwin AK. Fox Chase Cancer Center, Philadelphia, $P A$

We have previously reported the identification and characterization of a novel BRCA1 and BRCA2 interacting protein complex, BRCC (Dong et al., Molecular Cell, 2003). One protein in this multiprotein complex, referred to as BRCC 36 , was found to directly interact with BRCA1. It was demonstrated that BRCC 36 has an important role in regulating the ubiquitin E3 ligase activity of BRCC and that it is overexpressed in the majority of breast cancer cell lines $(\sim 75 \%)$ and clinical breast tumors $(\sim 60 \%)$ evaluated when compared with normal counterparts. Moreover, when evaluated using laser capture microdissection, $100 \%$ of the invasive mammary ductal carcinomas examined showed elevated levels of BRCC36 mRNA relative to the normal ductal epithelium. To further elucidate the functional consequence of BRCC 36 over expression in breast cancer, we performed in vitro silencing studies using small interfering RNAs (siRNA) targeting BRCC36 in MCF7 cell line, a breast cancer cell line which constitutively expresses high levels of BRCC36. There was no significant difference in non-specific cell killing of either BRCC36 siRNA nor control siRNA treated cells. Since BRCC36 directly interacts with BRCA1 and previous studies indicated that the BRCA1 protein is activated via the ATM/CHK2 signaling pathway following the exposure of cells to DNA damaging agents such as irradiation, we sought to determine if BRCC36 may be important in this response. Therefore, siRNA-transfected MCF-7 cells were exposed to ionizing radiation and examined for DNA damage-induced cell killing. When combined with BRCC36 abrogation, ionizing radiation exposure lead to an increase in apoptotic cells $(45.9 \% \pm$ $4.3 \%$ vs. $34.9 \% \pm 1.9 \%)(\mathrm{p}<0.05)$ and a lower fraction of viable cells $(50.9 \% \pm 5.8 \%$ vs. $58.4 \% \pm 5.7 \%)$ when compared to the siRNA control group. Furthermore, immunoblot analysis showed that abrogation of BRCC36 had no effect on the expression of p21, p53 and ATM following IR exposure, but disrupted IR-induced BRCA1 phosphorylation. These results suggest that downregulation of BRCC36 expression impairs the DNA repair pathway activated in response to IR via BRCA1 and appears to sensitize breast cancer cells to IR-induced apoptosis. Therefore, BRCC36 may be a therapeutic target for the management of radiation resistant breast tumors. This work was supported in part by an AACR Anna Barker postdoctoral fellowship for basic research, the Eileen Stein-Jacoby Fund, and a grant from the DOD, DAMD17-03-1-0707.

\section{4}

Therapeutic potential of antisense $\mathrm{Bcl}-2$ as a chemosensitizer for patients with breast cancer.

Kim R, Emi M, Tanabe K. Research Institute for Radiation Biology and Medicine, Hiroshima University, Hiroshima, Japan

Purpose: Bcl-2 confers resistance to apoptosis, thereby reducing the effectiveness of chemotherapy. We performeda preclinical evaluation of antisense (AS) Bcl-2 as an enhancer of the chemotherapeutic effect in the treatmentof breast cancer. Methods: AS Bcl-2 was used with 18-mer phosphorothiated oligonucleotides inthe MDA-MB-231, BT-474, and ZR-75-1 breast cancer cell lines. Drug sensitivity in vitro was evaluated by the MTT assay, and antitumor effect in vivo was evaluated by the nude mouse xenograft. Apoptosis was determined with TUNEL assay. AS Bcl-2 in vitro was treated with lipofectin, whereas it was administered intraperitoneally at a dose of $5 \mathrm{mg} / \mathrm{kg}$ for 6 consecutive days twice in q2wks in vivo. Anticancer drugs were administered intraperitoneally four times in qwk. Results:Bcl-2 was downregulated to $60 \%$ ofinitialvalueafter the treatment with $1.0 \mu \mathrm{M}$ of AS Bcl-2 compared to the controls of random and mismatched ODNs. Drug sensitivity to doxorubicin (DOX), paclitaxel (TXL), and docetaxel (TXT) was increased three- to ten-fold when usedin combination with AS $B c l$-2, which was determined with $\mathrm{IC}_{50}$ values in comparison withthe control. Increased drug sensitivity was associated with apoptosis, increasing in Bax, Poly (ADP-ribose) polymerase and decreasing in phosphorylated Akt. Theantitumor effect of DOX and taxanes in vivo was significantly enhanced in combination with AS Bcl-2 $(P<0.05$, ANOVA with Fisher's LSD test). Downregulation of Bcl2 was observed at day 4 after the treatment with AS Bcl-2. AS Bcl2 ODNs induced splenomegaly in association with increased serum IL-12 and expression of CD80, CD83, CD86, and CD27, which was attenuated by methylation of the $\mathrm{CpG}$ motifs of AS $\mathrm{Bcl}-2$, however, methylated $\mathrm{CpG}$ failed to negate the increased antitumor effect of AS Bcl-2. Conclusions:Combination treatment with AS $B c l-2$ and anticancer drugs, including DOX and taxanes, may be a new strategy for enhancing the chemotherapeutic effect in the treatment of breast cancer. 


\section{5}

Bystander activity of Ad-mda7: human MDA-7 protein kills breast cancer cells via an IL-20 receptor-dependent pathway.

Zheng M, Bocangel D, Menander K, Hunt K, Chada S. Introgen Therapeutics Inc., Houston, TX; UTMD Anderson Cancer Center, Houston, TX

The melanoma differentiation-associated gene-7 (mda-7/IL24) is a unique member of the IL-10 family of cytokines, with ubiquitous tumor cell proapoptotic activity. Transduction of tumor or normal cells with an Adenoviral vector encoding the mda-7 gene (Admda7) results in selective killing of tumor cells, with no effect on normal cells. However, both tumor and normal cells express high levels of MDA-7 protein after Ad-mda7 treatment and secrete glycosylated MDA-7 protein. Recent data indicate that secreted MDA-7 protein functions as both, a pro-Th1 cytokine and a potent antiangiogenic molecule. MDA-7 protein binds two distinct type II cytokine heterodimeric receptor complexes: IL-20R1/IL$20 R 2$ (type 1 IL-20R) and IL-22R1/IL-20R2 (type 2 IL-20R). In this study we analyzed the activity of glycosylated secreted MDA7 against human breast cancer cells. MDA-7 protein induced phosphorylation and nuclear translocation of STAT3 in breast tumor cells. MDA-7 protein also induced dose-dependent cell death in breast tumor cells, mediated via apoptosis. Antibodies against MDA-7 and the IL-20R1 receptor subunit were effective in blocking cell killing suggesting that the bystander apoptotic effect of MDA-7 is effected through type I IL-20R complexes. These results define a tumor-selective cytotoxic bystander role for secreted MDA-7 protein and identify a novel receptor-mediated death pathway in breast cancer cells.

\section{6}

The tumour-suppressor function of breast myoepithelial cells is mediated in part through regulation of S100A9. Mulligan KT, Wang H, Shaw JA, Hart IR, Jones JL. Institute of Cancer, Cancer Research UK Clinical Centre, Charterhouse Square, London, United Kingdom; University of Leicester, Leicester, United Kingdom

Cell-matrix interactions are known to be important in the control of many cellular functions including proliferation, apoptosis and tissue-specific gene expression. In normal breast, myoepithelial cells (MEC) form the major interface of the epithelial compartment with the extracellular matrix, however, this interface is disrupted with the development of invasive carcinoma.

We previously have demonstrated that primary MEC derived from normal breast exert a broad tumour-suppressor effect, reducing breast cancer cell proliferation and invasion and enhancing apoptosis. To address the mechanisms involved, we have performed cDNA microarray analysis on T47-D tumour cells co-cultured with MEC and compared the expression pattern to that obtained from T47-D cells grown alone. A number of potential tumoursuppressor genes were up-regulated in co-cultured T47-D cells including the calcium-binding protein S100A9 which showed an approximately 30 -fold increase in the presence of MEC. S100A9 has been implicated in the control of cell growth, and therefore was a potential mediator of the MEC-induced reduction in proliferation. To investigate whether the MEC-mediated reduction in proliferation is mediated via S100A9, co-cultured T47-D cells were transfected with S100A9 siRNA. In the presence of S100A9 knockdown there was significant abrogation of MEC-mediated suppression of proliferation compared to control cells. In conclusion, we demonstrate that normal breast MEC exert a broad tumour-suppressor role and that the suppression of breast cancer cell proliferation is mediated at least in part through the regulation of S100A9. Dissecting the molecular mechanisms involved in MEC-mediated tumour-suppression may help identify new prognostic markers and potential therapeutic targets.

\section{7}

Evidence that PI3K/Akt pathway is involved in the short non genomic autocrine loop between $17-\beta$ estradiol and aromatase activity.

Catalano S, Barone I, Giordano C, Rizza P, Gu G, Mastroianni $F$, Bonofiglio D, Ando'S. Faculty of Pharmacy, Rende, CS, Italy

Background: Estrogens are strongly associated with breast cancer development and tumor growth in both premenopausal and postmenopausal women. The intratumoral conversion of androgens to estrogens by aromatase within the breast may be an important mechanism through which 17- $\beta$ estradiol (E2) stimulates hormone-dependent breast cancer growth. The expression of aromatase in breast cancer tissue has been demonstrated by immunocytochemistry, RT-PCR and enzymatic activity. It has been shown how E2 may regulate aromatase activity in other vertebrates. The aim of the present study was to evaluate if E2/ER can modulate this enzymatic activity in human breast cancer cells.

Material and Method: In MCF-7 cells we examined, by the tritiated water release assay using $0.5 \mu \mathrm{M}[1 \beta 3 \mathrm{H}]$ androst-4-ene3-17 dione as substrate, aromatase activity in the presence or absence of E2, ICI 182,780, inhibitors or dominant-negative of MAPK and PI3K/Akt pathway and PTPase inhibitor. Western Blotting and immunoprecipitation assay were performed to evaluate Akt activation and phosphorylation status of aromatase protein upon E2 treatment.

Results: An increase of aromatase activity in MCF-7 cells, upon short exposure to E2 100nM, was observed without any change in the enzyme expression, whereas the addition of ICI $1 \mu \mathrm{M}$ reversed E2-induction (control=15.3 $\pm 1.2 ; \mathrm{E} 2=36.4 \pm 1.9 ; \mathrm{E} 2+\mathrm{ICI}=13.5 \pm 1.1$ $\mathrm{fmol} / \mathrm{h} / \mathrm{mg}$ protein). The above reported effect was also reproduced in MCF-7 cells overexpressing aromatase ectopically. When we attempted to evaluate how an important pathway of cell survival, like PI3K/Akt, may influence aromatase activity, we revealed that either LY $29400210 \mu \mathrm{M}$ or a dominant-negative of Akt ectopically expressed in MCF-7 abrogated the E2-induction. In the presence of constitutively active Akt we observed an increase in E2-stimulated aromatase activity. In ER-negative SKBR-3 cells, an up-regulatory effect of aromatase activity was induced by E2 only in the cells transfected with ER $\alpha$, but not with ER $\beta$. Finally, in the presence of sodium orthovanadate $10 \mu \mathrm{M}$, a PTPase inhibitor, an increase of aromatase activity was noticeable, addressing how changes in phosphorylation status may influence aromatase activity. Discussion: It is well known that aromatase is regulated at the transcriptional level through the alternative use of tissue specific promoters, while there are a few studies regarding post-translational regulation of aromatase activity. Our results for the first time demonstrated that $\mathrm{E} 2 / \mathrm{ER} \alpha$ up-regulates aromatase activity via interaction with the PI3K/Akt pathway. The phosphorylation processes of the aromatase protein sound to play a key role in the rapid changes in its enzymatic activity. All these data suggest the existence of a non genomic autocrine loop between E2 and aromatase activity in breast cancer cells.

\section{8}

(18)F flurothymidine (FLT) for imaging of tumor cell proliferation; an in vitro-study for monitoring chemoendocrine treatment in breast cancer cells.

Fersis N, Jusufoska A, Gargya B, Rupp C, Wallwiener D, Dittmann H. University of Heidelberg, Heidelberg, Germany; University of Tuebingen, Tuebingen, Germany

Objectives: F- FLT-PET is a promising tool for imaging primary breast cancer and metastases. Studies are needed to evaluate the clinical usefulness of FLT-PET for monitoring tumor response of neoadjuvant treated patients. Aim of the study was to evaluate whether FLT detects permutation of tumor cell proliferation as induced by chemo-endocrine treatment. 


\section{S286 Abstracts - Poster Session VI}

Methods: MCF-7 breast cancer cells were treated with chemotherapeutic agents Doxetaxel (TAX) and Adriamycin (ADR) or with the anti-estrogen Tamoxifen (TAM) and Faslodex (FAS). Cellular F-18-FLT uptake was estimated after 3, 5, or 7 days of treatment with anti-estrogenes or 4 hours, 1, 3 and 5 days after chemotherapy. Incorporation of H-3 thymidine and the fraction of S-phase cells were measured in comparison at the respective time points. Using colony formation assay and Probit/ logit fit the inhibitory concentrations (IC 25-95) of the chemotherapeutic drugs were estimated. Analysis of variance (ANOVA) was employed for statistical analysis.

Results: Cellular uptake of FLT was correlated to the proliferation inhibition mediated both by the chemotherapeutic agents (TAX and ADR), as well by the endocrine treatment with (TAM, and FAS). At high doses of chemotherapy (IC 95) the reduction of proliferation resulted in a reduction of FLT-uptake as early as $4 \mathrm{~h}$ after treatment. Overall, the reduction of FLT accumulation was greater in cell cultures treated with ADR than at the corresponding IC of TAX. Anti-hormone treatment showed also a significantly reduction of FLT accumulation. For both treatment modalities, cellular accumulation of FLT was strongly correlated to that of $\mathrm{H}$ 3- Thymidine (ADR, TAX: $r=0.91$; FAS: $r=0.92$; TAM: $r=0.88$ ). Conclusion: FLT uptake is strongly correlated to the results of classic in vitro-tests for tumor cell (MCF-7) proliferation. F-18FLT appears to be suitable for monitoring preoperative treatment of breast cancer with PET.

\section{9}

The role of the JNK signaling pathway in breast cancer cell lines.

Xue Y, Jordan CV. Fox Chase Cancer Center, Philadelphia, PA

Background: The c-Jun N-terminal kinase/stress-activated protein kinase (JNK/SAPK) pathway is activated by numerous cellular stresses. Although it has been implicated in mediating apoptosis and growth factor signaling, its role in regulating cell growth is not yet clear. In the present study we investigated the role of the JNK signaling pathway in cell growth of a panel of breast cancer cell lines: the MCF-7 WS8, 2A and 5C cells. The WS8 cell line, a clone of the MCF-7 cells, grows in response to estrogen, and this estrogendependent growth is inhibited by antiestrogens such as 4hydroxytamxifen and fulvestrant. The $2 \mathrm{~A}$ and $5 \mathrm{C}$ cell lines were derived from the parental WS 8 cells following long term estrogen deprivation, and became estrogen-independent for growth. The 2A cells express two forms of the estrogen receptor (ER), a wildtype $\mathrm{ER}^{66}$ and a mutant ER ${ }^{77}$ (Pink et al., Cancer Res. 55, 2583-2590, 1995), while the 5C cells only express wildtype ER. Recent studies in our laboratory demonstrate that estradiol treatment dramatically reduces the growth of $5 \mathrm{C}$ cells which is associated with the induction of apoptosis (Lewis et al., J. Steroid Biochem. Mol. Biol. 94,131141, 2005)

Material and Methods: The pharmacological JNK inhibitor, SP600125 was used to inhibit JNK activity. DNA quantitation assay was used to determine the growth of all three cell lines following SP600125 or estradiol and SP600125 treatment. Propidium iodine staining of cellular DNA was used to analyze cell cycle changes following SP600125 or estradiol and SP600125 treatment in these three cell lines.

Results: DNA quantitation assay results showed that SP600125, at concentrations as low as $5 \mathrm{mM}$, reduced proliferation of these three breast cancer cell lines in a dose - dependent manner. Significant inhibition of cell growth by $20 \mathrm{mM}$ SP600125 was observed starting at day four of treatment in the presence or absence of estradiol. Flow cytometry results showed that $20 \mathrm{mM}$ SP600125 treatment caused $\mathrm{G}_{2} / \mathrm{M}$ arrest of all three cell lines.

Discussion: Taken together, these results indicate that JNK signaling is required for the growth of WS8, 2A and 5C cells possibly through regulation of cell cycle at $\mathrm{G}_{2} / \mathrm{M}$, regardless of estrogen-dependent or estrogen-independent growth.

\section{0}

The selectivity of Ras signaling in tumor formation.

Cheng C-M, Onken B, Philips M, Chang EC. Baylor College of Medicine, Houston, TX; New York University School of Medicine, New York, $N Y$

The Ras G-protein signaling pathways are very complex in humans. There are four Ras proteins. The N-termini of these Ras protein are over $90 \%$ identical in primary sequences, which include the effector-binding domains, and in vitro they interact with many effectors with nearly the same efficiency. However, how a given Ras protein selectively activates a particular effector in the cell to induce tumor formation is poorly understood. One leading model suggests that the C-termini of Ras proteins undergo specific posttranslational modifications, e.g., lipidation, and that such modifications allow Ras to localize and signal from at least two distinct compartments: the plasma membrane and the endomembrane.

To unambiguously test this model, we have turned to the fission yeast Schizosaccharomyces pombe, which has only one Ras protein, but it is still capable of controlling two highly conserved pathways. Our data show that $S$. pombe Ras selectively activates a MAP kinase pathway to mediate pheromone signaling at the plasma membrane, while it activates $\mathrm{Cdc} 42$ at the endomembrane to control cell polarity and mitosis. Ras also appears to act via Cdc42 to transform mammalian cells, and $\mathrm{Cdc} 42$ can be found at the endomembrane. We thus investigated whether in mammalian cells Ras can also selectively activate $\mathrm{Cdc} 42$ at the endomembrane, and whether this interaction is important in tumor formation. We have transformed fibroblasts with endomembrane-restricted Ras and are currently testing whether such transformation can be blocked by $\mathrm{Cdc} 42$ inactivation. However, although the signaling of Ras proteins has been extensively studied in fibroblasts, Ras signaling in epithelial cells, from which most tumor cells arise, remains to be explored. While activating Ras mutations are not common among human breast tumors, breast tumors that lose the estrogen receptor are adapted to receive growth signals from receptor tyrosine kinase pathways, which frequently act via Ras. Therefore, to determine whether compartmentalized Ras signaling may play a role in breast tumorigenesis, we have examined Ras localization in MCF-7 cells and found that as in fibroblasts, Ras is concentrated in both the plasma membrane and the endomembrane. We are currently investigating whether endomembrane restricted Ras and/or Cdc42 can transform MCF10A nonmalignant breast cells.

\section{1}

Non-transformed basal (cytokeratin $5 / 14$ postitive) breast cells migrate in matrigel by collective cell migration.

Clare SE, Kolanko P, Blosser R, Xiao H, Badve S, Herbert B. Indiana University School of Medicine, Indianapolis, IN

Background Cytokeratin 5 and 14 positive breast cells are referred to as basal cells because of their location abutting the basement membrane of the duct. Boecker et al have proposed that CK 5/14 positive breast cells are progenitor cells able to differentiate into luminal or myoepithelial cells. Sorlie and colleagues identified the basal-like as one of five subtypes of breast cancer. These cells are ER, PR and Her-2 negative. The basal-like gene expression was correlated with decreased survival. Additionally, tumors from women with BRCA 1 meditations are characterized by a basal epithelial phenotype in that they frequently over-express cytokeratin 5/6 and are cytokeratin $8 / 18$ negative.

Cells migrateeither as single cells or, as groups of cells, sheets or strands of multiple cells that are motile yet connected to one another by cell-cell junctions. This latter mechanism of cell migration is referred to as collective cell migration. It is seen, for example, in keratinocytes migrating across a provisional wound matrix, and in human cancer explants invading 3D collagen matrices. 
Hypothesis We hypothesized that if CK 5/14 cells are the breast progenitor cell, these cells should be able to form a breast duct/ acinus structure if cultured in an appropriate environment.

Methods We developed a horizontal culture system consisting of three concentric rings of Matrigel in a $35 \mathrm{~mm}$ tissue culture dish. The inner most ring, $8 \mathrm{~mm}$ in diameter, and outermost ring, 10 $\mathrm{mm}$ in width, were made with Matrigel with phenol red. The middle ring, $7 \mathrm{~mm}$ in width, was fashioned using Matrigel without phenol red; this color difference enabled the observation of invasion as there initially are no cells within the ring without phenol red. CK 5/14 positive, CK 8/18/19 negative human breast cells immortalized with telomerase were grown in a single focal plane in the inner or outer ring.

Results Cells coalesced to form duct and acinar structures by 4 days after commencing culture. They invaded the Matrigel without Phenol Red and this was captured on time-lapse video microscopy. The cells move by collective cell movement. Additionally, there are individual cells which act as scouts. Migration ceases at 8-10 days after initiation of culture. Switching from commercially available media, MEGM (Cambrex) to a supplemented H-14 media (Bissell) resulted in structures showing squamous features with pilar differentiation.

Discussion Based on the similarities between collective cell migration and the pushing margins of BRCA1 positive lesions, the basal cell phenotype of most BRCA1 lesions and the fact that metaplastic (squamous) tumors are CK 5/14 positive and triple negative, we hypothesize that these lesions arise from a transformed CK $5 / 14$ precursor cell. 


\section{S288 San Antonio Breast Cancer Symposium - Author Index for Abstracts}

\begin{tabular}{|c|c|c|c|c|c|c|c|}
\hline Abell, T & 4009 & Anderson, D & 1119 & Awad, N & 6079 & Barton, JH & 2076 \\
\hline Abetz, L & 2040,2047 & Anderson, E & 2105 & Axelrod, DM & 404 & Baselga, J & 305,1068 \\
\hline Abi Raad, R & 1021 & Anderson, $\mathrm{H}$ & 2057,6008 & Axelson, D & 1038 & Bashir, A & 2103 \\
\hline Abraham, BK & 33 & Anderson, $\mathrm{K}$ & 306 & Ayers, GD & 6031 & Basso, A & 206 \\
\hline Abrams, J & 41 & Anderson, RA & 2043 & Ayers, $\mathrm{M}$ & 6002 & Bastit, L & 5033 \\
\hline Abu-Khalaf, M & 2074 & Anderson, S & 20 & Azambuja, E & 3009 & Bastos, EP & 4071 \\
\hline Adams, BJ & 1066 & Anderson, SK & 308,6002 & Azarbayejani, A & 1042 & Bates, T & 6015 \\
\hline Adelusola, O & 2102 & Anderson, TJ & 31,6020 & Azios, $\mathrm{N}$ & 4103 & Bathen, $\mathrm{T}$ & 1038 \\
\hline Adiguezel, H & 5057 & Anderson, WF & 3066,4034 & Aziz, MS & 404 & Batist, G & 2089 \\
\hline Adloff, K & 6072 & Andersson, B & 6065 & & & Bauerfeind, I & 5051 \\
\hline Adrover, E & 5066,6030 & Andersson, M & 2051,2057 & & & Bauer-Kosinska, & 4047 \\
\hline Afanasjev, B & 1070 & Ando, M 1008, 1041, & 1055,1115 & Baar, J & 4095 & Baum, CM & 1066 \\
\hline Aft, RL & 1022 & & 3105 & Babiera, G & 2082, 4094 & Baum, M & 4044 \\
\hline Agostini, C & 6087 & Ando', S & 6107 & Babiera, GV & 402,5013 & Baumbusch, L & 3102 \\
\hline Agrawal, A & 1065 & Andre, $\mathrm{F}$ & 1028,2024 & Bachelle, F & 1013 & Bautz, W & 2017 \\
\hline A'Hern, R & $409,4106,5022$ & Andreetta, C & 5048 & Bachelot, $\mathrm{T}$ & $1051,3022,6087$ & Bayliss, JM & 5102 \\
\hline Ahles, TA & 6076 & Andreeva, $\mathrm{N}$ & 6034 & Bachman, BA & 408 & Bayo, J & 6030 \\
\hline Ahlgren, J & 2051,2057 & Andreoni, S & 2101 & Bacus, $\mathrm{S}$ & 211 & Beam, CA & 1044 \\
\hline Ahmad, NM & 1071 & Andres, R & 5058 & Badorf, A & 1067 & Bean, GR & 4022 \\
\hline Ahmed, $\mathrm{N}$ & 210 & Andresen, S & 5067 & Badve, S & $1103,4027,6111$ & Bear, $\mathrm{H}$ & 20 \\
\hline Ahomadegbe, JC & 1028 & Andrews, A & 3078,3085 & Bae, JW & 3014 & Beattie, M & 102 \\
\hline Ah-See, M & $1058,5003,5004$ & Andrieu, JM & 5073 & Bae, JY & 202,3027 & Beattie, MS & 109,4001 \\
\hline Ah-See, MW & 1101,5053 & Ang, $\mathrm{P}$ & 1089 & Baehner, F & $1049,2020,2113$ & Beaudoin, G & 3076 \\
\hline Aiello, EJ & 5020 & Ang, PC & 1071 & Baer, HJ & 27,6006 & Beavis, A & 4048 \\
\hline Aihara, $\mathrm{T}$ & 2044,5094 & Angerer, J & 28 & Bafaloukos, D & 2070 & Becette, V & 1040 \\
\hline Aimard, L & 3073 & Antón, A & 6088 & Bagatelle, R & 1095 & Beck, L & 6067 \\
\hline Akashi-Tanaka, S & 1008,1115 & Antón-Torres, A & 6094 & Baggerly, K & 2002 & Beck, R & 3003 \\
\hline Akbulut, $\mathrm{H}$ & 6009 & Anthony, S & 40 & Bai, T & 2097 & Becker, $\mathrm{T}$ & 1061 \\
\hline Akel, NS & 42 & Antoine, EC & 2036 & Baick, C & 5056 & Becker, TE & 4062 \\
\hline Alami, N & 1074,5081 & Antoine, $\mathrm{M}$ & 2016 & Baiget, M & 103 & Beckham, W & 4037 \\
\hline Alanko, T & 2 & Antunes, LP & 4031 & Baik, HM & 5075 & Beckhove, $\mathrm{P}$ & 4096 \\
\hline Alba, E & $39,6063,6088$ & Aogi, K & 5091 & Baildam, AD & 2014 & Beckman, BS & 4105 \\
\hline Albanell, J & 3103 & Apostolaki, S & 3030 & Baisch, C & 4002 & Beckmann, MW & 2017 \\
\hline Albarracin, C & 6002 & Appleyard, MV & 1086 & Baker, J & 310 & Bedin Jr, A & 4031 \\
\hline Al-Batran, SE & 6090 & Aranda, E & 6063 & Baker Jr., JC & 4022 & Bee, $\mathrm{V}$ & 1,1045 \\
\hline Albertson, D & 4056 & Aravantinos, G & 2070 & $\mathrm{Bal}, \mathrm{J}$ & 1089 & Beenken, $\mathrm{S}$ & 4014 \\
\hline Alcedo, JC & 6094 & Aravind, $\mathrm{R}$ & 2055 & Balducci, L & 6057 & Beer, J & 5064 \\
\hline Alcock, RA & 4066 & Arbuckle, R & 2040,2047 & Balil, A & 6063 & Beeram, M 111 & $7,2034,3107,3112$ \\
\hline Aleman, BM & 4035 & Arciero, CA & 6103 & Balkan, M & 1005 & Beerblock, K & 2016 \\
\hline Alexander, C & 5027 & Ardavanis, A & 6089 & Balleyguier, C & 2024 & Beex, LVA & 28 \\
\hline Ali, AB & 105 & Arenas, RB & 4026 & Balslev, E & 1048 & Behranwala, K & 409 \\
\hline Ali, SM & $1032,2006,3046$ & Arihiro, K & 4098 & Balter, JM & 4042 & Behrens, MS & 3077 \\
\hline Alidina, AG & 5069 & Ariyibi, J & 2098 & Banerjee, K & 1074,5081 & Beitsch, P & 4038 \\
\hline Al-Katib, W & 4064 & Arnold, $\mathrm{K}$ & 2035 & Banerjee, $\mathrm{M}$ & 3096 & Belkaccmi, Y & 1013 \\
\hline Allan, AL & 4064 & Arnould, L & 1059,5050 & Banerjee, SN & 3005 & Belkacemi, Y & 5074 \\
\hline Allan, S & 5027 & Arpino, G & 9 & Banerji, M & 40 & Belkora, J & 3059 \\
\hline Allen, C & 1015 & Arriagada, $\mathrm{R}$ & 1028 & Bangemann, $\mathrm{N}$ & 2033 & Bell, E & 2099 \\
\hline Allen, $\mathrm{K}$ & 4030,6057 & Artmann, A & 4028 & Bani, MR & 2017 & Bell, R & 6094 \\
\hline Allevi, G & 1031 & Arun, B & $0,308,4004$ & Banks, LM & 5076 & Bell, SM & 4061,5110 \\
\hline Allouache, D & 1081 & & 4013,6002 & Banna, G & 5048 & Bello, CL & 1094 \\
\hline Allred, C & 5101 & Asgeirsson, KS & 1015 & Bannon, E & 2006 & Bellosillo, B & 3103 \\
\hline Allred, DC & $24,311,1113$ & Ashfaq, R & 2098 & Bansal, S & 33 & Belón, J & 5058,5070 \\
\hline Allred, N & 21 & Ashikaga, T & 20 & Baracat, EC & 6012 & Bendahl, P-O & 35 \\
\hline Almanza, MC & 5059 & Ashley, S & 1009,3005 & Baranzelli, MC & $1013,3017,5074$ & Ben-David, MA & 4042 \\
\hline Almokadem, S & 2006 & Ashok, BT & 4099 & Barghout, V & 2040,2047 & Bender, CM & 6074 \\
\hline Alonso, MC & 103 & Ashton-Prolla, P & 4031 & & 2054,2058 & Bendre, MS & 42 \\
\hline Al-Refaie, WB & 5013 & Ashworth, A & 1029,1106 & Barham, R & 4008,6082 & Benitez, $\mathrm{H}$ & 5039 \\
\hline Al-Sagheir, A & 6062 & 1107,1110 & $, 3005,5045$ & Barham, RB & 6061 & Benner, A & 307,4002 \\
\hline Al-Shehri, A & 5041 & Asmar, L & , 6091, 6092 & Barker, S & 4104 & Bennett, M & 6053 \\
\hline Altunbas, C & 5016 & Asola, $\mathrm{R}$ & 2 & Barlow, W & 1035 & Benoy, IH & 204, 2091 \\
\hline Altundag, K & 3056 & Assadourian, S & 1084 & Barnadas, A & $2111,5066,6030$ & Benson, JR & 1009 \\
\hline Alvarez, I & 5058 & Asselain, B & 2071, 3073, & Barnard, Z & 4026 & Bentzen, SM & 1101,5053 \\
\hline Al-Zaid, M & 207 & & 5071,6047 & Barnes, $\mathrm{N}$ & 1050,2104 & Benz, C & 4056 \\
\hline Amado, $\mathrm{R}$ & 5033 & Astakhov, V & 1070 & Barnett, J & 5027 & Bercu, B & 6057 \\
\hline Amakrane, $\mathrm{M}$ & 301 & ATAC Trialists' Group & 2056 & Barone, I & 6107 & Beresford, MJ & 1058,5004 \\
\hline Amant, F & $3031,5014,6024$ & Atalay, G & 6084,6086 & Barr, H & 1012 & Beresford, PJ & 6021 \\
\hline Amare, $\mathrm{M}$ & 40,6091 & Atencio, DP & 4039 & Barr, L & 2014 & Berg, K & 1117 \\
\hline Ambro, S & 2073 & Athanasiadis, A & 6089 & Barranger, $\mathrm{E}$ & 2016 & Berg, PE & 2094 \\
\hline Ambrosone, CA & 3053 & Atienza, M & 6071 & Barreton, G & 28 & Berg, R & 5035 \\
\hline Ames, FC & $402,2082,5013$ & Atigadda, R & 4014 & Barrett, I & 4079 & Berga, SL & 6074 \\
\hline Amiconi, G & 2053 & Atkins, D & 28,3004 & Barrier, RC & 1027 & Berger, $\mathrm{M}$ & 1071 \\
\hline Amin, $\mathrm{A}$ & 104 & Atmaca, A & 6090 & Barrios, $\mathrm{CH}$ & 1080 & Bergh, J & $37,301,302,1040$ \\
\hline Amin, $\mathrm{R}$ & 1052 & Atwood, MK & 2010,3012 & Barry, TS & 2023 & & $2051,2057,3016$ \\
\hline Amorim, $\mathrm{G}$ & 5060 & $\mathrm{Au}, \mathrm{A}$ & 1047,2020 & Bartels, CCM & 107 & Bergmann, A & 3067 \\
\hline Amsterdam, AD & 5096 & $\mathrm{Au}, \mathrm{HJ}$ & 5038 & Barthelmes, L & 1003 & Bergström, B & $6033,6034,6035$ \\
\hline Anand, A & 2001 & Augustine, EA & 6060 & Bartholomae, A & 6081 & Berlin, LM & 3079 \\
\hline ANC Study Group & 3006 & Ausems, MG & 4003 & Bartlett, JM & 2003, 5109 & Berman, AW & 4034 \\
\hline Anders, CK & 1027 & Austrian Breast and $\mathrm{Cc}$ & lorectal & Bartlett, JMS & 6102 & Bernhard, H & 6027 \\
\hline Anderson, BO & 3060 & Cancer Study Group & 8 & Bartoces, MG & 3074 & Bernik, $S$ & 404 \\
\hline
\end{tabular}


San Antonio Breast Cancer Symposium - Author Index for Abstracts

\begin{tabular}{|c|c|c|}
\hline Berns, E & 303,3004 & Bonnefoi, $\mathrm{H}$ \\
\hline Berns, EMJJ & 30 & Bonnetain, F \\
\hline Berns, EMJ & 28 & Bonneterre, J \\
\hline Bernstein, JL & 103,4039 & \\
\hline Bernstein, L & 1045 & Bono, $\mathrm{P}$ \\
\hline Berquin, IM & 4089 & Bonofiglio, D \\
\hline Berriolo-Riedinge & 1059 & Bonomi, R \\
\hline Berruti, A & 1031 & Bontenbal, M \\
\hline Berry, D & 41 & Bookman, MA \\
\hline Berry, DA & 3097,6031 & Boolbol, SK \\
\hline Berteloot, P & $3031,5014,6024$ & Booser, DJ \\
\hline Berthelet, E & 3007 & Booster, D \\
\hline Bertolini, F & 4049 & Bordelon, JH \\
\hline Bertucci, F & 1051,2110 & Borg, A \\
\hline Bessems, A & 5087 & Borgen, E \\
\hline Betancor, E & 3038 & Borges, V \\
\hline Betrucci, A & 3113 & Borghi, F \\
\hline Bhandare, D & 2093 & Borie, $\mathrm{N}$ \\
\hline Bhandare, DJ & 2092,4015 & Börjeson, S \\
\hline Bhar, P & 2073 & Børresen-Dale, AL \\
\hline Bhatia, P & 3064 & Bos, $\mathrm{R}$ \\
\hline Bhatia, V & 2113 & Bosse, K \\
\hline Bhattacharya-Cha & tterjee, $\mathrm{M}$ & Bosse, U \\
\hline Bica, CG & 6010 & Botma, A \\
\hline Bicaku, E & 1083 & Bottini, A \\
\hline Bielajew, C & 6079 & Bouchardy, C \\
\hline Biganzoli, L & 6084,6086 & Boue, SM \\
\hline Bigio, IJ & 1014 & Bouita, L \\
\hline Bijker, $\mathrm{N}$ & 7 & Boukovinas, I \\
\hline Bines, J & 1080 & Bourdon, JCR \\
\hline Birnbaum, D & 1051,2110 & Bourgain, C \\
\hline Bisagni, G & 5048 & Bouvet, M \\
\hline Bischoff, J & 6090 & Bowie, ML \\
\hline Bisoffi, M & 6017 & Bowman, A \\
\hline Bissonnette, $\mathrm{R}$ & 4024 & Bown, SG \\
\hline Blackwell, KL & 1027 & Boyages, J \\
\hline Blackwell, T & 4016 & Boynton, G \\
\hline Blair, A & 3076,6069 & Bracke, ME \\
\hline Blanchett, DG & 2046 & Bradlow, HL \\
\hline Blanco, G & 2 & Brady, C \\
\hline Blanco, R & 4010 & Brain, E \\
\hline Bland, K & 4014 & Braithwaite, D \\
\hline Bleuse, JP & 5050 & Bramley, T \\
\hline Bliss, JM & 5076 & Branco, LGP \\
\hline Blixt, O & 2008 & Brandt, BH \\
\hline Block, H & 1095 & Brandy, KP \\
\hline \multirow[t]{2}{*}{ Blohmer, JU } & $38,1023,5047$, & Brauch, H \\
\hline & 6084,6086 & Braun, $\mathrm{S}$ \\
\hline Blom, JC & 107 & Bray, SE \\
\hline Blomqvist, $\mathrm{C}$ & 2051, 2057 & Braye, $\mathrm{S}$ \\
\hline Blood, E & 6068,6072 & Breault, L \\
\hline Bloom, KJ & $1039,3034,3039$ & Brebner, J \\
\hline Blosser, R & 6111 & Breilid, H \\
\hline Blot, E & 1040,3040 & Brekelmans, CTM \\
\hline Blum, JL & $40,2039,6091$ & Brennan, $\mathrm{K}$ \\
\hline Bocangel, D & $2087,4058,6105$ & Brenner, W \\
\hline Boccardo, F & 18 & Brentani, HP \\
\hline Boccia, R & 5032 & Brentani, MM \\
\hline Bodofsky, E & 3098 & Breyer, W \\
\hline Bodoky, G & 5033 & Briasoulis, E \\
\hline Body, JJ & $6033,6034,6035$ & Briggs, G \\
\hline Boecher, O & 1017 & Bristol, JB \\
\hline Boehm, D & 3048 & Britton, O \\
\hline Boehm, KA & 6091,6092 & Brizzi, MP \\
\hline Bogaerts, J & $7,301,1040$ & Brodie, A \\
\hline Bogdanova, $\mathrm{N}$ & 1070 & Brodie, AM \\
\hline Boguniewicz, AB & 3019 & Brogi, E \\
\hline Bohn, U & 3038 & Broglio, $\mathrm{K}$ \\
\hline Boichot, C & 1059 & \\
\hline Bolsoni, EMM & 2101 & Broglio, KR \\
\hline Bolton, MG & 1070 & Brooks, R \\
\hline Bonanni, B & 4012 & Brors, B \\
\hline Bonardi, S & 1031 & Brossard, $\mathrm{M}$ \\
\hline Bonaventura, M & 1005 & Brossart, $\mathrm{P}$ \\
\hline Bondi, SM & 1047 & Brouillette, W \\
\hline Bondy, ML & 3056 & Brouste, V \\
\hline Boni, C & 5048 & Brown, A \\
\hline Boni, J & 1068 & Brown, JH \\
\hline Bonk, U & 5057 & Brown, $\mathrm{P}$ \\
\hline
\end{tabular}

\begin{tabular}{|c|c|c|c|c|}
\hline 1040 & Brown, PH & 4092,5103 & Camponne, $\mathrm{M}$ & 505 \\
\hline 2071 & Brown, $\mathrm{R}$ & 44 & Candeloro, $\mathrm{G}$ & 2053 \\
\hline 1013, 5074, & Brown, SBF & 3068 & Canney, PA & 4086 \\
\hline 6084,6086 & Brown University & Oncology Group & Canon, J-L & 503 \\
\hline 2 & & 5054 & Cantor, A & $4030,6053,605$ \\
\hline 6107 & Browne, D & 4013 & Cantrell, J & 203 \\
\hline 1009 & Brown-Shimer, S & 1032 & $\mathrm{Cao}, \mathrm{F}$ & 403 \\
\hline 6084,6086 & Bruening, $\mathrm{T}$ & 4002 & Capelli, C & 20 \\
\hline 12,2061 & Brufsky, A & 3069 & Caplan, ES & 308 \\
\hline 2027 & Brufsky, AM & $1089,5055,6074$ & Caravelli, JF & 203 \\
\hline 308 & Brunaud, $\mathrm{C}$ & 6039 & Cardoso, F & $37,301,30$ \\
\hline 1062 & Brunel, E & 1084 & & $3009,3016,302$ \\
\hline 40 & Brunner, $\mathrm{N}$ & 1033 & Carey, LA & 1047,105 \\
\hline 35 & Brunotte, $\mathrm{F}$ & 1059 & Carlo, VP & $202-r a r a r a$ \\
\hline 1016 & Bryant, J & 29,46 & Carlson, RW & 206 \\
\hline 209,2001 & Bryant, $\mathrm{K}$ & 1054 & Carmichael, J & 6084,608 \\
\hline 5048 & Bryk, M & 4015 & Carney, W & 103 \\
\hline 1051 & Brzeski, H & $1061,3075,5025$ & Carpenter, PM & 105 \\
\hline 6065 & Buccholz, TA & 3002 & Carpenter, $\mathrm{R}$ & 4085,409 \\
\hline 3102 & Buchholz, T & 5049 & Carr, C & 4008,608 \\
\hline 1096 & Buchholz, TA & $402,3011,4032$ & Carraro, DM & 407 \\
\hline 5072 & Buchmann, B & 1072 & Carroll, M & 505 \\
\hline 5057 & Buck, H & 6053 & Carter, G & 111 \\
\hline 4035 & Buck, MB & 4090 & Carter, JV & 408 \\
\hline 1031 & Budd, GT & $6,3003,3036$ & Carter, WB & $1083,4069,605$ \\
\hline 3023,4011 & & $5067,6026,6100$ & Carter-Wientjes, C & 410 \\
\hline 4105 & Budde, $\mathrm{M}$ & 6034 & Cartin, BJ & 201 \\
\hline 5063 & Budman, DR & 1075 & Carver, A & \\
\hline 6089 & Buehler, $\mathrm{H}$ & 3041 & Case, $\mathrm{N}$ & 402 \\
\hline 4057 & Bueno de Mesquit & $\mathrm{a}, \mathrm{JM}$ & Casey, M & 501 \\
\hline 5099 & Buhari, SA & 5097 & Casey, TM & \\
\hline 207 & Bühl & 1023 & lo, FE & 607 \\
\hline 4022 & DSM & 5020 & Cassel, M & 501 \\
\hline 6056 & Bundred, NJ & $25,1050,2014$ & Cassidy-Gray, M & 308 \\
\hline 1014 & & $2104,6043,6049$ & Cassier, PA & 608 \\
\hline 6073 & Bundy, R & 3053 & Castella, E & 211 \\
\hline 47 & Bunn, J & 208 & Castiglione-Gertsch & $\mathrm{h}, \mathrm{M}$ \\
\hline 6048 & Bunnell, CA & 4 & Castro Jr, G & 300 \\
\hline 2108 & Burcombe, RJ & 1101,5053 & Catalano, S & 610 \\
\hline 3086 & Burillo, M & 5058 & Catenaccio, A & 401 \\
\hline 2071 & Burkhart, DJ & 1093 & Caulder, E & 1082,605 \\
\hline 3059,4007 & Burn & 2003 & Cauley, J & 402 \\
\hline 5044 & Buro & 4105 & PA & 500 \\
\hline 1080 & Burr & 2076 & $\mathrm{Cat}$ & 105 \\
\hline 5057 & II, HA & 1073 & Cawl & 404 \\
\hline 5082 & Burst & 1066,4 & ga, $\mathrm{M}$ & 401 \\
\hline 33,4002 & Burtness, B & 2074 & Cazzaniga, ME & 206 \\
\hline 5,1016 & Burzykowski, T & 6084,6086 & Centelles, M & 505 \\
\hline 3111 & Bustamante, E & 4010 & Cerrato, $\mathrm{L}$ & 608 \\
\hline 44 & Bustamante, M & 4010 & Cerussi, AE & 1034,502 \\
\hline 47 & Bustin, SA & 4085,4091 & Cervantes, $\mathrm{G}$ & 503 \\
\hline 6056 & Butler, J & 5056 & Cesaretti, JA & 403 \\
\hline 5086 & Butt, AJ & 3109 & Cesta, A & 205 \\
\hline 107 & Buxton, MB & 1047 & Ceugnart, J & 101 \\
\hline 25 & Buyse, $\mathrm{M}$ & $1069,1,37,301$, & Ceyssens, S & 501 \\
\hline 6038 & & $302,6084,6086$ & , S & 608 \\
\hline 4071 & selik, A & 6009 & Chada, S & $2087,4058,610$ \\
\hline 4071 & Buzd & 1087 & Chagas, ERM & 605 \\
\hline 5031 & Buzdar, AU & 3011,5049 & ar, $\mathrm{AB}$ & 400 \\
\hline 2070 & Byakhov, M & 1070 & Chal & 303 \\
\hline 1014 & Byrne, G & 2014 & Chambers, AF & 406 \\
\hline 3080 & & & Chambo, D & 500 \\
\hline 2090,4081 & & & Chamness, G & 410 \\
\hline 1031 & Cabioglu, $\mathrm{N}$ & 4073 & Champlin, RE & 603 \\
\hline 4101,5081 & Cabrera, A & 3038 & Chan, A & 1084,4080 \\
\hline 5083 & Cai, Q & 4095 & Chan, HY & 308 \\
\hline 2030 & Cairns, J & 6056 & Chan, L & 202 \\
\hline 1037, 3002, & Calabro, A & 1075 & Chan, $\mathrm{M}$ & \\
\hline 3056,4013 & Caleffi, M & 4031 & Chan, MF & 600 \\
\hline 3011 & Callaghan, W & 6069 & Chan, S & $1068,6084,608$ \\
\hline 2039 & Calvo, L & $39,5059,6030$ & Chandrawansa, $\mathrm{K}$ & 106 \\
\hline 307 & Camara, O & 1064 & Chang, EC & 611 \\
\hline 5081 & Came & $40,5084,6041$ & Chang, J & 309 \\
\hline 1085 & Cameron, DA & $2043,3043,5112$ & Chang, JC & 9,30 \\
\hline 4014 & Camp, RL & 3018 & Chang, J-M & 107 \\
\hline 3024 & Campbell, CT & 4029 & Chang, KM & 407 \\
\hline 20 & Campbell, M & 1079 & Chang, L & 406 \\
\hline 407 & Campo, L & 1031 & Chap, L & 106 \\
\hline 4024 & Campone, $\mathrm{M}$ & 1040,1068 & Chapman, C & 101 \\
\hline
\end{tabular}




\section{S290 San Antonio Breast Cancer Symposium - Author Index for Abstracts}

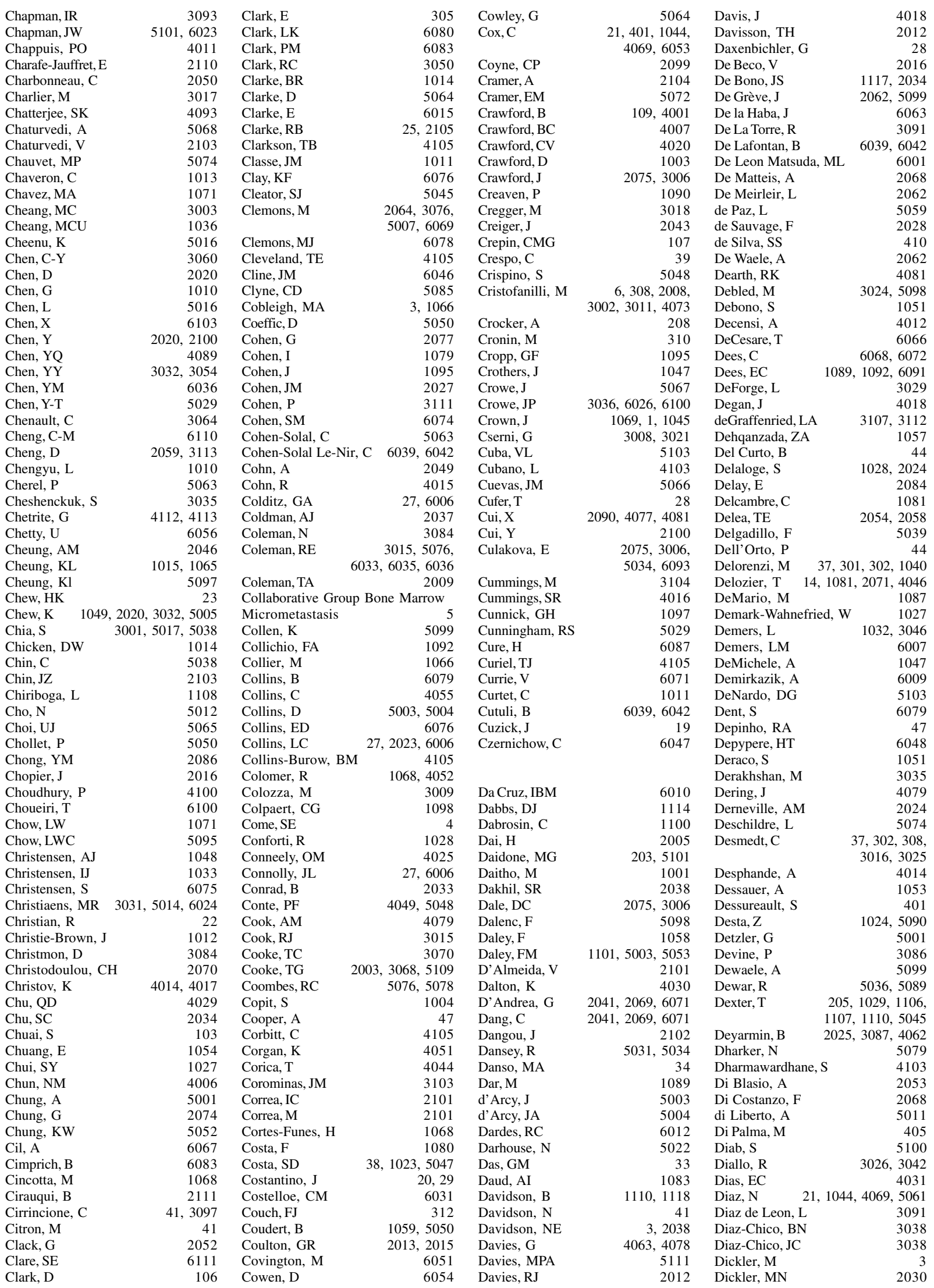


San Antonio Breast Cancer Symposium - Author Index for Abstracts

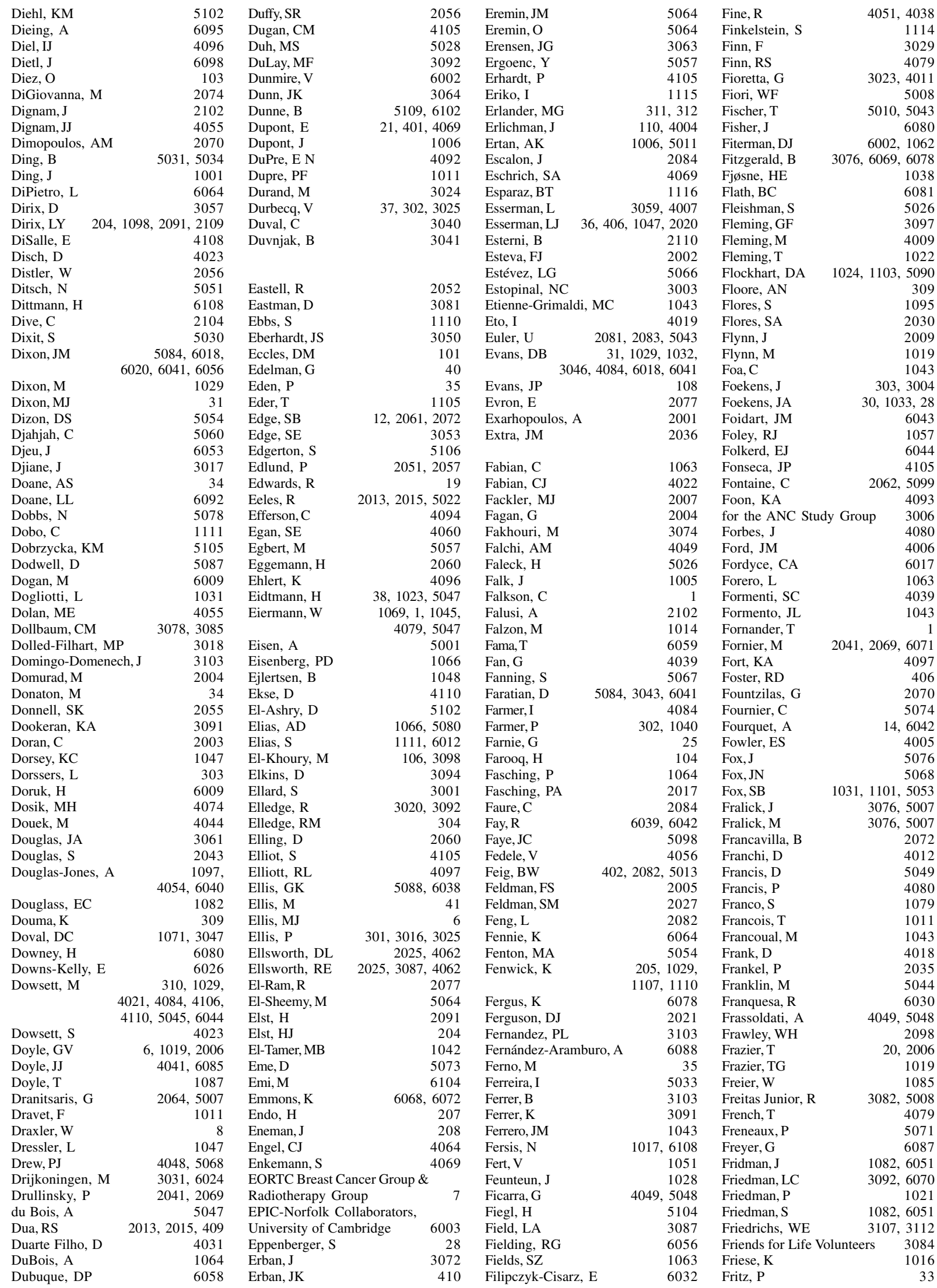




\section{S292 San Antonio Breast Cancer Symposium - Author Index for Abstracts}

\begin{tabular}{|c|c|c|c|c|c|c|c|}
\hline $\mathrm{Fu}, \mathrm{S}$ & 2094 & Gianni, L & 305 & Grana, G & 106,3098 & Hannah, AL & 1095 \\
\hline Fujii, $\mathrm{H}$ & 1007 & 1013, 3017, & , 5074, 6039 & Grann, VR 308 & $888,3089,4041,6085$ & Hannon, RA & 2052 \\
\hline \multirow[t]{2}{*}{ Fujiwara, Y } & 1008,1041 & Gibbs, J & 4045 & Graudenz, MS & 4031,6010 & Hanrahan, EO & 3002 \\
\hline & $1055,1115,3105$ & Gil, M & 1068 & Graves, TA & 5054 & Hansbury, M & 1082 \\
\hline Fukutomi, T & 1008,1115 & Giles, M & 5104 & Gray, E & 2055 & Haqq, CM & 1047 \\
\hline Fuller, CD & 3090 & Gilewski, T & 2041,2069 & Gray, JW & 1047 & Harbeck, $\mathrm{N}$ & $53,4028,5043$, \\
\hline Fumoleau, P & $1059,1068,2071$ & Gilhuijs, KG & 5002 & Graziani, SR & 1091 & & 6019,6027 \\
\hline Fuqua, SAW & 2100 & Gilks, CB & 3033 & Grazianni, SR & 6013 & Harden, AT & 1047 \\
\hline \multirow[t]{2}{*}{ Furman, B } & 4069 & Gill, D & 6091 & Green, $\mathrm{M}$ & 4080,5049 & Hardisson, D & 1106,1107 \\
\hline & & Gillett, C & 3016,3025 & Green, $\mathrm{S}$ & 4039 & Harlow, S & 20,208 \\
\hline Gabbert, HE & 3026,3042 & Gillock, KL & 6076 & Greijer, AE & 1096 & Harper, M & 3106 \\
\hline Gadd, M & 22 & Ginot, A & 1043 & Greil, R & 13 & Harrell, JC & 32,209 \\
\hline Gaddy, D & 42 & Ginther, C & 4079 & Greimel, A & 1112 & Harrington, $\mathrm{N}$ & 1121 \\
\hline Gaetje, R & 5046 & Gioioso, C & 1021 & Grellard, JM & 1081 & Harris, A & $301,302,1058$, \\
\hline Gahir, J & 205,1110 & Giordano, C & 6107 & Grenier, J & 3022 & & $16,3025,5003$ \\
\hline Galbraith, S & 305 & Giovannelli, S & 4049,5048 & Greshock, J & 1060 & Harris, AL & $031,1101,5053$ \\
\hline Galimberti, V & 4012 & Girgis, SI & 5076 & Gribbestad, IS & 1038 & Harris, J & 22 \\
\hline Gallarda, JL & 3050 & Girling, A & 3101 & Griffith, JK & 6017 & Harris, KA & 1057 \\
\hline Gan, C & 1099 & Girvan, D & 4064 & Griffith, KA & $1046,4036,4042$ & Harris, LN & 1021 \\
\hline Ganai, S & 4026 & Gitsch, G & 1064 & Griggs, JJ & 6093 & Harris, M & 4103 \\
\hline Gao, $\mathrm{X}$ & 1030,3091 & Gittleman, M & 4038 & Grigoriadis, A & 205 & Harrison, DJ & 3043 \\
\hline Garbay, JR & 1028,2024 & Gjerde, J & 5086 & Grober, SE & 3083 & Harrison, G & 1099 \\
\hline Garbay, J-R & 405 & Gladieff, L & 5098 & Grogan, $\mathrm{T}$ & 6022,6028 & Harrison, GM & 2112 \\
\hline Garber, JE & 4006 & Glas, A & 301 & Grogan, TM & 6021 & Harrison, $\mathrm{M}$ & 304 \\
\hline García-Mata, J & 5059 & Glas, AM & 309 & Grollman, J & 6070 & Harrison, RH & 1077 \\
\hline García-Palomo, A & 5059 & Glaspy, J & 5035 & Gross, $\mathrm{S}$ & 1019 & Harrisson, E & 4044 \\
\hline Garcia, D & 4038 & Glaspy, P & 4079 & Groth, J & 3053 & Hart, IR & 6106 \\
\hline Garcia, JM & 5058 & Glawatz, C & 3048 & Grove, DI & 1109 & Harth, V & 4002 \\
\hline Garcia, MV & 209 & Glazier, J & 5001 & Grubbs, C & $4014,4017,4019$ & Hartke, M & 6022,6026 \\
\hline Garcia, SM & 4032 & Glickman, TS & 5079 & Gruber, $\mathrm{S}$ & 3061 & Hartman, AR & 4006 \\
\hline Gardner, $\mathrm{T}$ & 6056 & Gligorov, J 2016, 3073, & , 5050, 6054 & Gruetzmann, R & 1053 & Hartmann, A & 1053 \\
\hline Gargya, B & 6108 & Glogowska, I & 4047 & Gruvberger-Saa & al, SK & Hartmann, O & 1053 \\
\hline Gariboldi, M & 203 & Glover, HR & 4104 & Gryaznov, SM & 1076 & Harvell, DME & 5080 \\
\hline Garimella, V & 4048,5068 & Gluz, O & 2063,3026 & $\mathrm{Gu}, \mathrm{G}$ & 6107 & Harvey, D & 23 \\
\hline Garncarek, A & 6032 & Gnant, $\mathrm{M}$ & 13,18 & Guarneri, V & 3011,5048 & Harvey, HA & 2006 \\
\hline Garvey, J & 3084 & Gnant, MFX & 8 & Guerrieri-Gonza & zaga, A & Harvey, JA & 5006 \\
\hline Gaskill, N & 6019 & Godinho, E & 5008 & Gui, GPH & $409,2013,2015,5022$ & Harvey, V & 4080 \\
\hline Gasparini, G & 2032 & Godwin, AK & 6103 & Guilhaume, M & 3073 & Hasegawa, T & 1055,3105 \\
\hline Gass, JS & 5054 & Goes, JCGS & 4071 & Guillemet, C & 3040 & Hatakeyama, K & 4067 \\
\hline Gatto, LA & 5082 & Goetz, MP & 312 & Guinebretiere, J & 5063 & Hatzis, C & 308 \\
\hline Gauger, K & 6019 & Goffman, $\mathrm{T}$ & 3094 & Gukas, ID & 3101 & Hatzopoulos, A & 6037 \\
\hline Gaui, M & 5060 & Gogas, $\mathrm{H}$ & 2070 & Gulisano, M & 4012 & Hauglid, M & 5086 \\
\hline Gautier, C & 5071 & Gokmen, E & 3044 & Gunnarsdottir, & 2051, 2057 & Hauser, N & 2065 \\
\hline Gebrim, LH & 2095,2101 & Gold, DL & 306,308 & Guray, M & 4073 & Hausmaninger, $\mathrm{H}$ & 8 \\
\hline Gebski, V & 4080 & Gold, E & 1054 & Gutierrez, MC & 9,304 & Hawke, D & 2002 \\
\hline Geddert, $\mathrm{H}$ & 3026,3042 & Goldfrank, DJ & 103 & Gutman, F & 2016 & Hawkins, MJ & 2073 \\
\hline Gee, J & 5104 & Goldhirsch, A & 6055 & Gutteridge, E & 1065 & Hayashi, T & 1074 \\
\hline Gehrke, R & 1053 & Goldrick, A & 2037 & & & Hayden, J & 1024 \\
\hline Gehrmann, MC & 3048 & Goldrick, AJ & 5027 & Haagensen, DE & 1113 & Hayes, DF & $6,1024,1035$, \\
\hline Geiger, X & 2019 & Goldstein, LC & 1035,1036 & Haaland-Pullus, & $\mathrm{s}, \mathrm{CM}$ & & 1046,6083 \\
\hline Geisler, J & 4108,4110 & Golmohammadi, K & 5038 & Habin, $\mathrm{K}$ & 22 & Hayman, JA & 4042,4043 \\
\hline Geisler, S & 3102 & Golouh, R & 28,1053 & Hackett, JR & 310 & Haynes, B & 4110 \\
\hline Gelber, RD & 6055 & Golubeva, O & 2005 & Hackman, J & 4040 & $\mathrm{He}, \mathrm{PQ}$ & 2066 \\
\hline Gelber, S & 6055 & Gomes, CA & 1080 & Hadsell, DL & 4081 & $\mathrm{He}, \mathrm{Q}$ & 3019 \\
\hline Gelman, R & 4 & Gomez, HL & 1071 & Haffty, B & 4038 & Head, JF & 4097 \\
\hline Gelmon, KA & 2037, 3001 & Gomez, KF & 1097 & Haffty, BG & 4039 & Heaphy, CM & 6017 \\
\hline Gendler, LS & 1042 & Gomez-Fernandez, C & 6066 & Hagen, AI & 4108 & Hecker, D & 6090 \\
\hline Generali, D & 1031 & Gong, GY & 3010 & Hagood, G & 2099 & Heckman, C & 1061 \\
\hline Genève, J & 1051,2071 & Gong, Y & 308,4013 & Hahn, M & 307 & Hegel, MT & 6076 \\
\hline GENICA Network & 4002 & Gonsch, T & 2033 & Haibe-Kains, B & B $37,302,3016,3025$ & Hegg, R & 1091,6013 \\
\hline Gentilini, O & 6050 & Gonzalez, A & 3038 & Haile, $\mathrm{K}$ & 4051 & Hei, YJ & 3015,6036 \\
\hline \multirow[t]{2}{*}{ George, $\mathrm{R}$} & 2041, 2069, 4064, & Gonzalez, L & 6053 & Hait, WN & 1078 & Heiden, I & 3077 \\
\hline & 6004,6011 & Gonzalez-Angulo, AM & 402,2088 , & Hajduga, V & 6015 & Heinrich, G & 1023 \\
\hline George, TK & 40 & & 3002,3011 & Haji, A & 6015 & Heinrigs, M & 1016 \\
\hline George, WD & 2003 & Gonzalez-Hormazabal, $\mathrm{P}$ & 4010 & Halgunset, J & 1038 & Heiskala, M & 1063 \\
\hline Georgoulias, V & $3030,3051,6089$ & Gordon, MS & 1095 & Hall, E & 5076 & Hellot, MF & 3040 \\
\hline Geppert, R & 1052,2060 & Gordon-Weeks, A & 6101 & Halliday, G & 3043 & Hendricks, L & 5035 \\
\hline Geradts, J & 3053 & Goss, $\mathrm{P}$ & 5101 & Hamann, $\mathrm{U}$ & 104,4002 & Henley, NC & 2003,3070 \\
\hline Gerald, WL & 34 & Goss, PE 16, 17, 2042, & , 2046, 6005 & Hamaoka, T & 6031 & Hennessy, BT & 1037,2088 \\
\hline \multirow[t]{2}{*}{ Gerber, B } & $38,1016,1023$ & Gottschalk, S & 210 & Hamer, P & 1032 & Henrichs, C & 6027 \\
\hline & 4079,5047 & Gould, J & 6078 & Hammes, A & 4028 & Henry, D & 5035 \\
\hline LH & 6060 & Gown, AM & 1036,2023 & Hammond, E & $4033,5101,5107$ & Henschke, P & 1052 \\
\hline Gergich, NL & 6060 & Goyal, A & 6040 & Hampton, G & 31 & Hensley Alford, S & 3061 \\
\hline Gerlo, E & 2062 & Goyens, P & 2062 & Han, MR & 3027 & HERA Study Team & 11 \\
\hline Germano, PBMR & 2101 & Gradishar, W & 41,5044 & Han, S & 4083 & Heras, $\mathrm{P}$ & 6037 \\
\hline Gersh, BJ & 2038 & Graham II, ML & 108 & Han, W & $202,3027,3028,3055$ & Herbert, B & 1076,6111 \\
\hline Gerty, S & 101 & Grahek, D & 2016 & Han, WS & 5012 & Herbst, F & 6019 \\
\hline Geyer, CE & 46 & Gralow, J & 3 & Hanby, AM & 5110 & Herman, M & 1019 \\
\hline Ghosh, S & 3047 & Gralow, JR 1018, 1035, & 5088,6038 & Handl-Zeller, E & 8 & Hermitte, F & 1051 \\
\hline
\end{tabular}


San Antonio Breast Cancer Symposium - Author Index for Abstracts

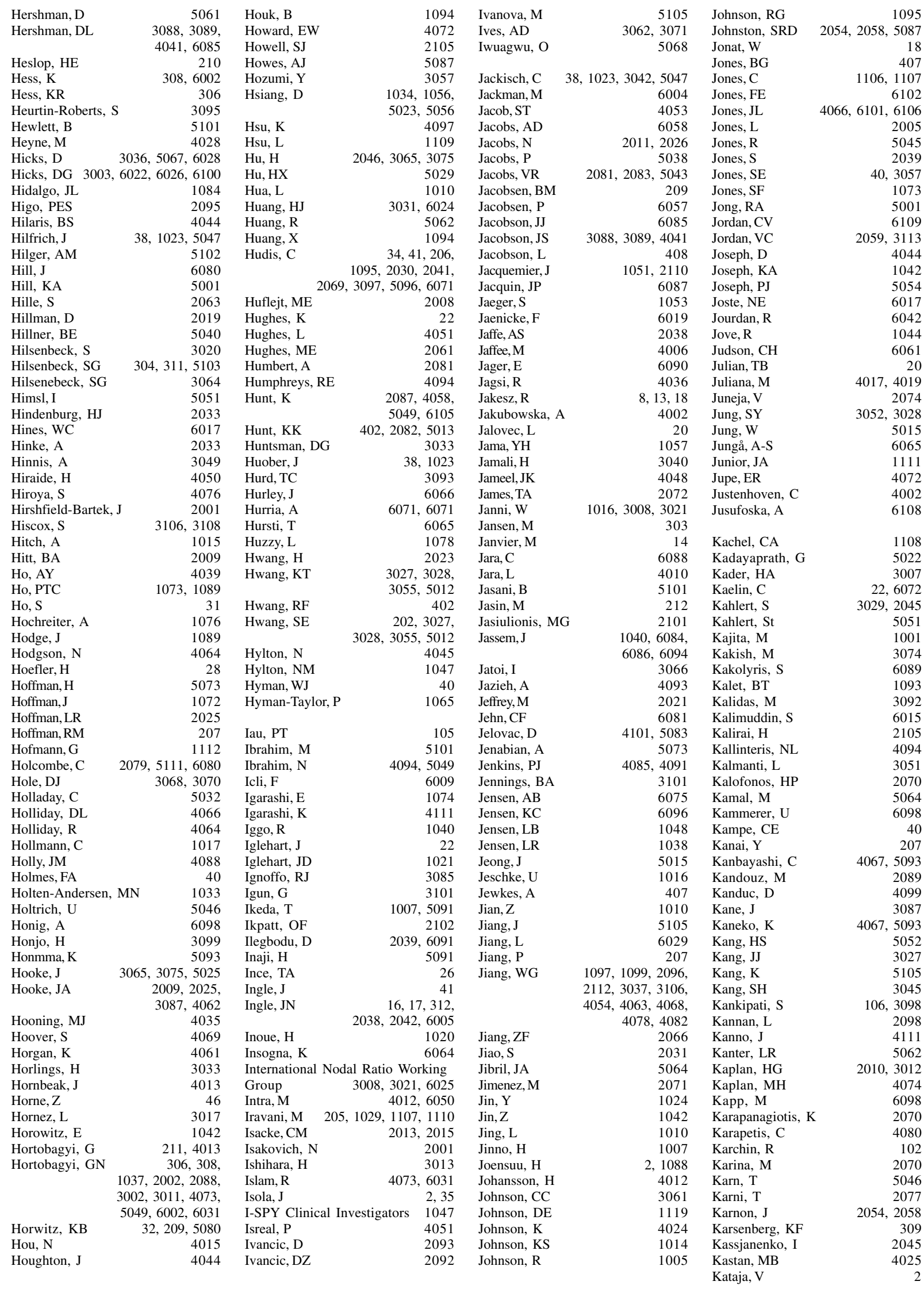




\section{S294 San Antonio Breast Cancer Symposium - Author Index for Abstracts}

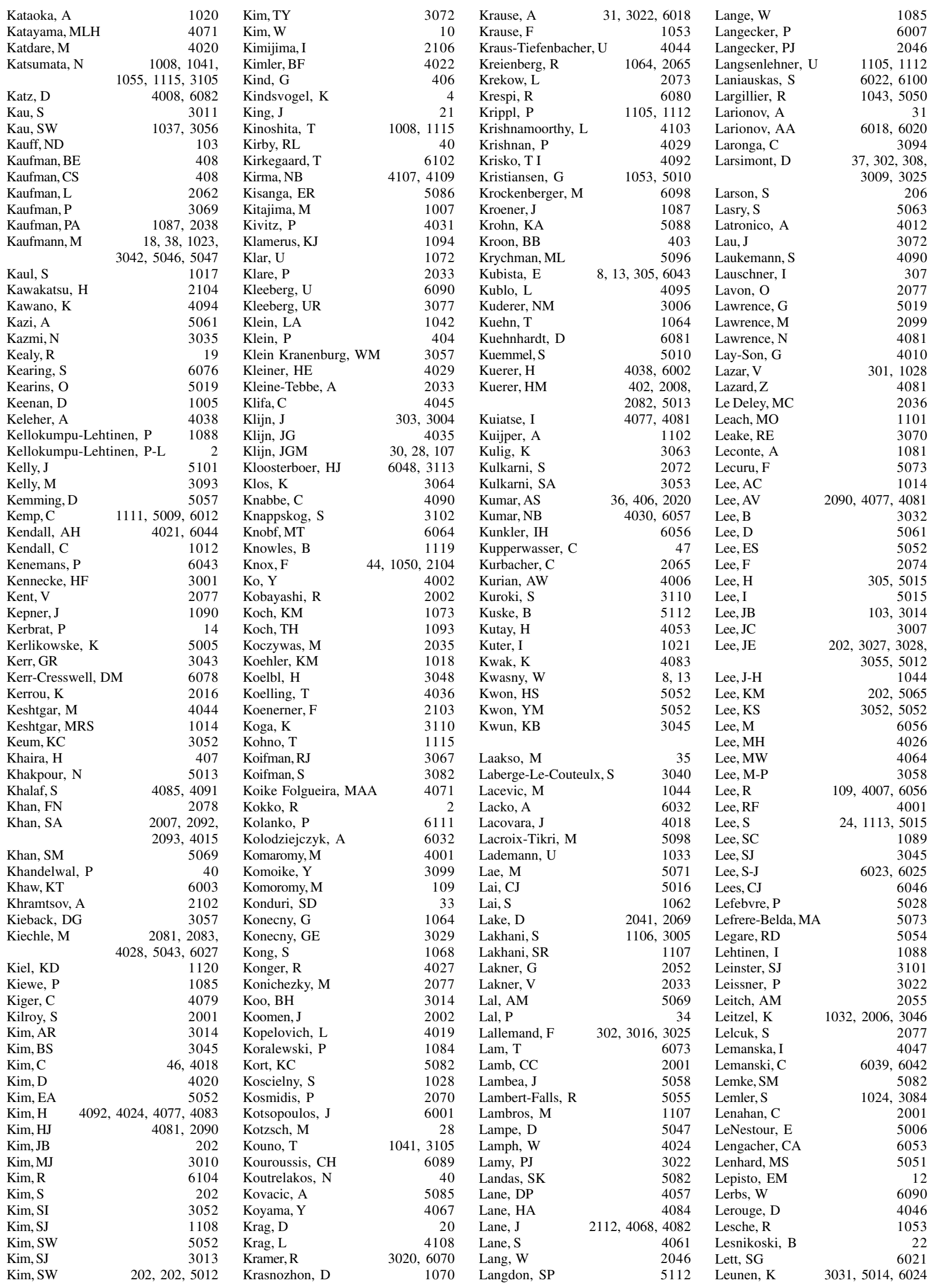




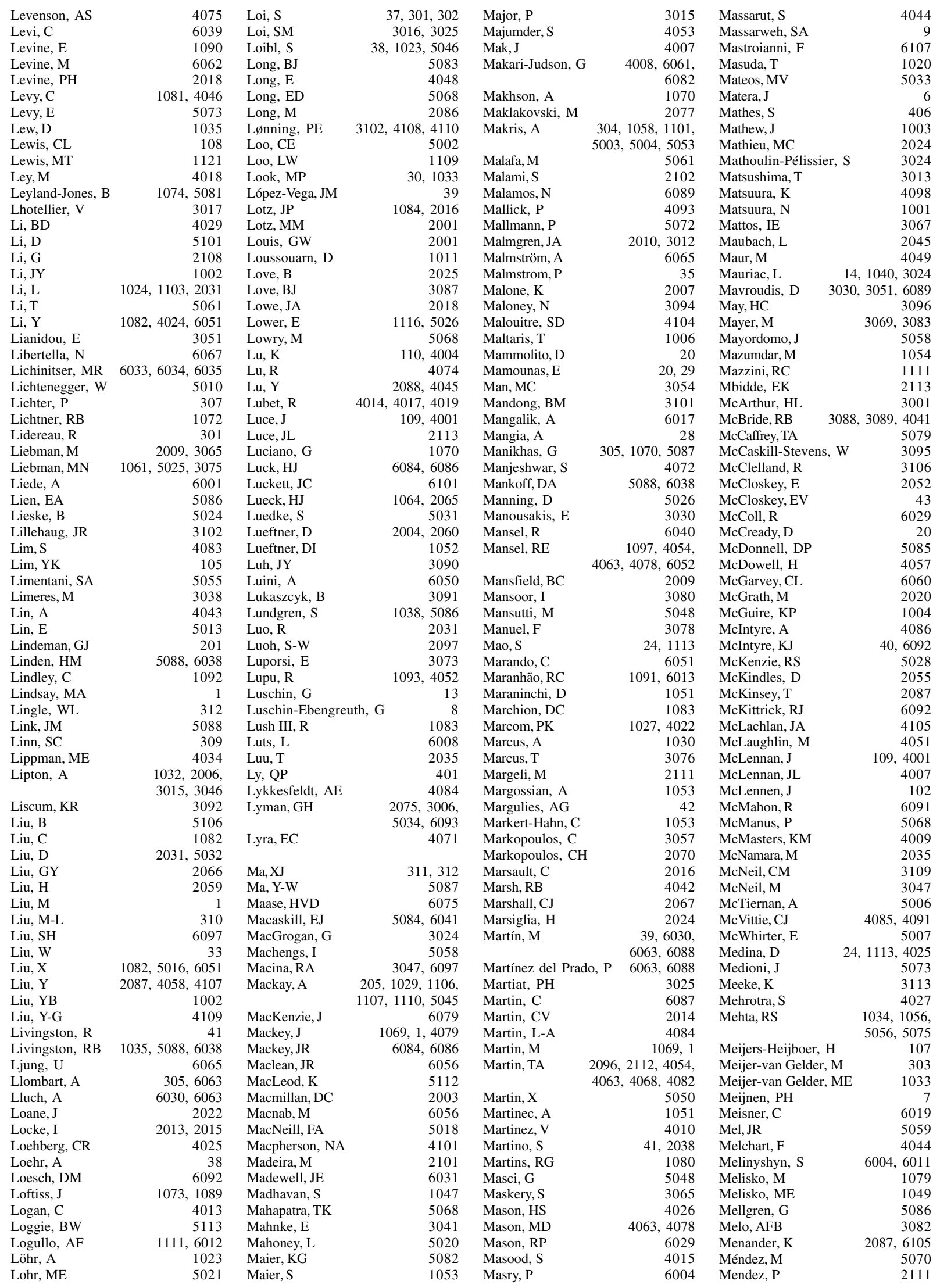




\section{S296 San Antonio Breast Cancer Symposium - Author Index for Abstracts}

\begin{tabular}{|c|c|c|c|c|c|c|c|}
\hline Menendez, JA & 1093,4052 & Moon, WK & 5012 & Nakabayashi, K & 1001 & Oberg, J & 22 \\
\hline Meneses, N & 1063 & Moore, A & 1054 & Nakayama, S & 3013 & Ochiai, K & 3099 \\
\hline Menke-Pluymers, $\mathrm{N}$ & 107 & Moore, $\mathrm{CP}$ & 6076 & Nalcioglu, O & $1056,5023,5075$ & O'Connell, $\mathrm{K}$ & 6052 \\
\hline Mennel, RG & 40 & Moore, D & 5005,1049 & $\mathrm{Nam}, \mathrm{BH}$ & 5052 & O'Connell, $\mathrm{P}$ & 304 \\
\hline Merajver, SD & 3061 & & 3054,3059 & Namer, $\mathrm{M}$ & 1043, 2036, & O'Connor, T & 1090 \\
\hline Meric, F & 3011 & Moore, DH & 36,3032 & & $3057,3073,5050$ & O'Donnell, RW & 5082 \\
\hline \multirow[t]{2}{*}{ Meric-Bernstam, $\mathrm{F}$} & 110,402 , & Moore, E & 1070 & Nanda, R & 4055 & Odorcic, $\mathrm{S}$ & 4060 \\
\hline & $3002,4073,4094$ & Moore, $\mathrm{H}$ & 5067 & Naqvi, B & 104 & Oehlschlegel, C & 44 \\
\hline Mershon, J & 4023 & Moore, L & 1068 & Naresh, A & 6102 & Oesterreich, S & 5105,5108 \\
\hline Mertens, WC & $4008,6061,6082$ & Moore, S & 4101 & Narod, SA & 5001,6001 & Offit, K & 103 \\
\hline Messner, SJ & 5001 & Moossa, AR & 207 & Naughton, C & 5112 & Ognerubov, $\mathrm{N}$ & 1070 \\
\hline Meulemans, A & 2062 & Mora, S & 4012 & Naughton, M & 1022 & Ogunkolade, BW & 4085,4091 \\
\hline Meunier, A & 2084,6039 & Morack, G & 6090 & Naume, B & 1016 & O'Hare, M & 205 \\
\hline Meurer, J & 2045 & Moraes, R & 1121 & Nayak, BK & 33 & Ohara, M & 4098 \\
\hline Meuthen, I & 6090 & Moran, JM & 4042 & Nayak, M & 1078 & Ohashi, Y & 2044,5094 \\
\hline Meyer, R & 5105 & Morandi, P & 4073 & Nayar, R & 2007,4015 & Ohno, S & 1020 \\
\hline Meyer, WG & 40 & Moreira, D & 5060 & Ndoma-Egba, R & 2102 & Ohorodnik, SK & 6007 \\
\hline Meyn, R & 4058 & Morel, D & 3019 & Neades, G & 6056 & Ohshima, A & 3110 \\
\hline Mhashilkar, A & 2087,4058 & Morgan, R & 2035 & Neal, CL & 1109 & Ohsumi, S & 2044 \\
\hline Miao, $\mathrm{H}$ & 2103 & Morgenstern, S & 2077 & Nebbia, JF & 1043 & Ohtake, T & 4076 \\
\hline Michelotti, A & 5048 & Mori, M & 1020 & Neckers, L & 206 & Oktay, K & 6067 \\
\hline Michiels, S & 1028 & Morikawa, A & 6013 & Neese, ER & 4005 & Oktem, O & 6067 \\
\hline Middleton, L & 3011 & Morimiya, A & 4027 & Negassa, A & 5061 & Oldenburg, HS & 403 \\
\hline Middleton, LP & 4032 & Morris, C & 1030 & Negron, AG & 40 & Oliveira, JG & 5008 \\
\hline Miele, L & 2103 & Morrison, A & 3064 & Nelson, CC & 4101 & Olivotto, I & 3001,5017 \\
\hline Miglioretti, D & 5020 & Moser, R & 3095 & Nelson, J & 6083 & Olivotto, IA & 2037, 3007, \\
\hline Miki, Y & 4111 & Moses, MA & 2001 & Neminathan, S & 1003 & & 4037,5027 \\
\hline Milani, M & 1031 & Mota, LDC & 4071 & Nesland, JM & 1016 & Ollivier, JM & 4046 \\
\hline Milano, G & 1043 & Motiwala, T & 4053 & Neugut, AI & 3088, 3089, & Olopade, OI & 2102,4055 \\
\hline Miller, B & 20 & Mougin, B & 3022 & & 4041,6085 & Olson, JE & 6005 \\
\hline Miller, K & 1089,5101 & Moulder, SL & 4069,5061 & Neven, $\mathrm{P}$ & 3031, 5014, & Olsson, HL & 6008 \\
\hline Miller, KD & 3,1066 & Mourey, L & 5098 & & 5087,6024 & Olszewski, WP & 44 \\
\hline Miller, M & 3033 & Mouridsen, $\mathrm{H}$ & 1048,2057 & Newstat, B & 1071 & O'Malley, BW & 4025 \\
\hline Miller, MC & $6,1019,2006$ & Mouridsen, HT & 1033,2051 & Newton, $\mathrm{R}$ & 1082,6051 & O'Malley, FP & 5101 \\
\hline \multirow[t]{2}{*}{ Miller, WR } & $31,1029,6018$, & Moynahan, M & 2041, 2069 & Neyns, B & 5099 & O’Neal, KC & 36 \\
\hline & 6020,6041 & Moynahan, ME & 212 & $\mathrm{Ng}, \mathrm{C}$ & 1089 & O'Neill, A & 22 \\
\hline Mills, GB & 2088 & $\mathrm{Mu}, \mathrm{H}$ & 1092 & Ngo, T & 1021 & O'Neill, MA & 1086 \\
\hline Mills, MA & 4006 & Muccio, D & 4014 & Nguyen, A & 1024 & Onken, B & 6110 \\
\hline Mimori, $\mathrm{K}$ & 1020 & Mueller, V & 1053 & Nguyen, C & 3111 & Onur, H & 6009 \\
\hline Minami, CA & 36 & Mukai, M & 1007 & Nibbe, AM & 312 & Oratz, R & 2049 \\
\hline Minnard, E & 1119 & Mukherjee, SD & 6062 & Nicholson, R & 5104 & Ordonez-Ercan, D & 5106 \\
\hline Minnix, J & 6070 & Muldoon, J & 5001 & Nicholson, RI & 3106,3108 & O’Regan, RM & 1030 \\
\hline Minton, S & 5061,6057 & Mull, S & 2039 & Nickoloff, JB & 2103 & Orfeuvre, $\mathrm{H}$ & 6087 \\
\hline Minton, SE & 1044,1083 & Muller, SH & 5002 & Niederle, $\mathrm{N}$ & 1085 & Orosz, Z & 44 \\
\hline Misra, MC & 5030 & Muller, WD & 3050 & Nielsen, A & 3107 & O'Rourke, P & 2034 \\
\hline Mita, A & 1117,2034 & Mulligan, KT & 6106 & Nielsen, DL & 1048 & Osaki, A & 4098 \\
\hline Mita, MM & 1117,2034 & Munárriz, B & $39,6063,6088$ & Nielsen, KV & 1048 & Osborn, G & 2085 \\
\hline Mitashok, I & 1070 & Munnes, M & 5046 & Nielsen, TO & $1036,3003,3033$ & Osborne, CK & $9,304,311$ \\
\hline Mitsibounas, D & 6037 & Munot, K & 4061 & Niemeyer, M & 2081, 5043 & Osborne, CR & 2098 \\
\hline Mittelman, A & 4099 & Munster, PN & $1044,1083,5061$ & Nieto, Y & 3021 & Osborne, $\mathrm{K}$ & 4100 \\
\hline Mittlboeck, M & 13 & Murias, A & 3038 & Nieweg, OE & 403 & Osborne, M & 1054 \\
\hline Mittmann, N & 2050 & Murillo, L & 5058 & Niland, JC & 12,2061 & Osborne, MP & 4020 \\
\hline Miyakawa, K & 1115 & Muro-Cacho, CA & 1044 & Nilsson, UW & 1100 & O'Shaughnessy, J & 1063, 2039, \\
\hline Miyamoto, A & 2052 & Murphy, O & 4044 & Nimmrich, I & 1053 & & 2073, 6091, 6092 \\
\hline Miyoshi, Y & 3013 & Murphy, V & 3084 & Nishio, K & $1041,1055,3105$ & O'Shaughnessy, JA & 40 \\
\hline Moasser, M & 6071 & Murray, C & 5001 & Nishiuchi, H & 2044, 5094 & Oshima, CT & 1111 \\
\hline Mochizuki, H & 5114 & Murray, D & 5101 & Nitz, U & $2063,2065,3026$ & Osipo, C & 2059,3113 \\
\hline Modi, S & 206,1095 & Murray, J & 31,6041 & Niu, A & 2100 & Ostler, P & 304 \\
\hline Modolell, A & 5058 & Murray, JL & 4094 & Niwinska, A & 4047 & Otero Reyes, D & 6094 \\
\hline Modrusan, Z & 2028 & Murray, KE & 1086 & Nkoy, FL & 4033,5107 & Otomo, Y & 1001 \\
\hline Mody, M & 5079 & Murray-Zmijewski, $\mathrm{F}$ & 4057 & Noble, JL & 2013, 2015 & Otterson, GA & 5032 \\
\hline Moebus, V & 1064,2065 & Murthy, S & 5102 & Noguchi, S & 3013,5091 & Ottesen, RA & 12,2061 \\
\hline Moers, C & 5072 & Musgrove, EA & 3109 & Nogueira de Souza, & 5009 & Ottestad, L & 4108 \\
\hline Mohanty, K & 4093 & Muss, $\mathrm{H}$ & $41,208,3097$ & Noh, DY & 202, 3027, & Overmoyer, B & 1073 \\
\hline Mohrmann, S & 2063,3026 & Muss, HB & 6059 & & $3028,3055,5012$ & Ozanne, E & 3059 \\
\hline Mohsin, S & 4081 & Mustacchi, G & 2068 & Noll, D & 6083 & Ozer, H & 5031,5034 \\
\hline Mohsin, SK & $9,24,1113$ & Muthyala, N & 3091 & Noone, AM & 3096 & & \\
\hline Moinon, E & 405 & Muzi, M & 6038 & Norberg, B & 6065 & Padhani, AR & 1101, 5003, \\
\hline Mokbel, K & 1097 & Myers, M & 21 & Normolle, D & 6083 & & 5004,5053 \\
\hline \multirow[t]{2}{*}{ Møller, S } & 1048, 2051, & Myles, J & 6026 & Norton, L & 41, 206, 2030, & Padovani, L & 6054 \\
\hline & 2057,6075 & & & 2041,2 & $2069,3097,6071$ & Paepke, D & 2081, 6019 \\
\hline Monsur, J & 3074 & Naar, EM & 6097 & Novelli, M & 1014 & Paepke, S & $2081,2083,5043$ \\
\hline Montagut, $\mathrm{C}$ & 3103 & Nabholtz, JM & 6084,6086 & Noyes, RD & 20 & Paesmans, M & 3009 \\
\hline Montgomery, K & 6096 & Nabid, A & 4040 & Ntukidem, NI & 1024 & Page, V & 1074,5081 \\
\hline Monticelli, MA & 6092 & Nag, S & 1071 & Nugent, JE & 40 & Paik, S & $29,46,3069$ \\
\hline Montoya, EL & 5037 & Nagle, RB & 6021 & Nunes, MOA & 3082 & Pajak, K & 6032 \\
\hline Montravers, F & 2016 & Nahleh, ZA & 4093 & Nuyten, DSA & 3033 & Pakesch, B & 8 \\
\hline Monypenny, I & 6040 & Naik, $\mathrm{R}$ & 1054 & Nydam, JE & 3058 & $\mathrm{Pal}, \mathrm{S}$ & 4093 \\
\hline Monypenny, IJ & 2085 & Nair, HB & 4107, 4109 & & & Palacios, J & 1106,1107 \\
\hline
\end{tabular}


San Antonio Breast Cancer Symposium - Author Index for Abstracts

\begin{tabular}{|c|c|c|c|c|c|c|c|}
\hline Pallis, A & 3051 & Pesch, B & 4002 & Powles, TJ & 43 & Reese, D & 4079 \\
\hline Palmer, MJ & 16 & Peschel, C & 6027 & Pratt, J & 1070 & Regan, M & 44 \\
\hline Palomares, MR & 1018 & Pestano, GA & 6021 & Praz, V & 302 & Regierer, AC & 6095 \\
\hline Palombo, $\mathrm{H}$ & 5058 & Pestano, J & 3038 & Preiss, J & 1085 & Register, TC & 6046 \\
\hline Palomero, MI & 5070 & Peterse, JL & $7,309,403$ & Prescott, $\mathrm{N}$ & 6022 & Reid, JF & 203 \\
\hline Palwai, NR & 1077 & Peterson, C & 35,6065 & Prescott, RJ & 6056 & Reintgen, D & 401 \\
\hline Pan, $\mathrm{H}$ & 2031 & Peterson, LM & 5088,6038 & Press, M & 1 & Reis, LC & 2101 \\
\hline Pan, M & 4059 & Petit, T & 14,1040 & Press, MF & 1045 & Reis-Filho, J & 205,1106 \\
\hline Panageas, $\mathrm{K}$ & 2030, 2041, & Petricoin, EF & 1047 & Prime, W & 3101 & Reis-Filho, JS & 1107, 1110, \\
\hline & 2069,6071 & Pettay, J & $6022,6026,6028$ & Prince, $\mathrm{M}$ & 4029 & & 3005,5045 \\
\hline Pang, B & 4089 & Peusser, $\mathrm{T}$ & 4090 & Pringle, JH & 4066 & Rembert, J & 5005 \\
\hline Pant, CS & 6014 & Peyrat, JP & 3017 & Priou, $\mathrm{F}$ & 5050 & Rembert, JL & 4045 \\
\hline Pantel, K & 5,1016 & Pfalzer, LA & 6060 & Pritchard, MG & 5019 & Remblier, C & 2036 \\
\hline Paolini, J & 4108 & Pfeiffer, S & 6081 & Pronzato, $\mathrm{P}$ & 2068 & Renee, $\mathrm{N}$ & 1043 \\
\hline Papadimitriou, $\mathrm{CH}$ & 2070 & Philips, M & 6110 & Provencher, L & 1069 & Renner, W & 1112 \\
\hline Papadimitropoulou & 4052 & Phillips, N & 2037 & Puddefoot, JR & 4070,4104 & Renshaw, L & $31,5084,6041$ \\
\hline Papadopoulos, $\mathrm{T}$ & 2017 & Piacentini, F & 4049 & Puglisi, F & 5048 & Repollet, M & 2006 \\
\hline Papakostas, P & 2070 & Piccart, M & $37,302,1040,1089$ & Puhl, A & 3048 & Rescigno, J & 404 \\
\hline Papo, NL & 2054,2058 & Piccart, MJ & $301,308,3009$, & Puisieux, A & 3022 & Reuben, JM & 2008 \\
\hline Pappo, I & 2077 & 3016 & $6,3025,6084,6086$ & Puk, CG & 6013 & Reuter-Lorenz, P & 6083 \\
\hline Paradiso, A & $28,1053,4056$ & Pickard, CDO & 1014 & Pule, M & 210 & Revillion, F & 3017 \\
\hline Paridaens, R & 3031,5014 , & Picone, O & 405 & Pumfery, AM & 5079 & Rey, A & 405 \\
\hline & $6024,6084,6086$ & Picquenot, JM & 3040 & Purdie, CA & 3111 & Reyes, JM & 4010 \\
\hline Park, BW & 3052 & Piech, CT & 5028 & Purohit, A & 5078 & Reyes, S & 5039 \\
\hline Park, C & 5005,4045 & Pienkowski, T 1 & $1069,1,1045,4047$ & Pusztai, L & $306,308,1062,6002$ & Reynolds, C & 312 \\
\hline Park, CC & 3032 & Pierce, K & 1032 & Putter, H & 3057 & Reynoso, N & 5039 \\
\hline Park, IA & $3028,3055,5012$ & Pierce, LJ & $4036,4042,4043$ & & & Rhei, E & 22 \\
\hline Park, J & 2030 & Pierga, J-Y & 5045,5071 & Qi, S & 2046 & Ribeiro, MJP & 3067 \\
\hline Park, K & 4083 & Pierl, CB & 4002 & Querci della Rove & vere, G & Riccardi, D & 4030,6057 \\
\hline Park, S & 3105 & Pierotti, MA & 203 & Quetin, P & 6039 & Ricart, A & 1117 \\
\hline Parker, LM & 4 & Piersma, D & 30 & Quibén, R & 5070 & Richards, DA & 40 \\
\hline Parker, MD & 5110 & Pignon, $\mathrm{T}$ & 6054 & Quiet, CA & 4038 & Richardson, A & 47 \\
\hline Parker-Johnson, K & 1119 & Pille, JY & 3040 & Quinlan, M & 4008,6082 & Richer, JK & 5080 \\
\hline Parkes, AT & 3104 & Pinter, $\mathrm{T}$ & 1,4079 & Quirke, P & 4061 & Richman, $\mathrm{P}$ & 1058,5003 \\
\hline Parr, C & $1099,3037,4063$ & Pinto, $\mathrm{K}$ & 4033,5107 & Qutob, O & 5068 & Richman, PI & 1101,5053 \\
\hline Parra, I & 2100 & Pinzone, JJ & 5079 & & & Rideller, K & 5073 \\
\hline Parshad, R & 5030 & Pioud, R & 1011 & R115777 INT-22 & 2 Investigators 5087 & Riedinger, JM & 1059 \\
\hline Parsons, A & 3095 & Pippen, J & 2039,5092 & Raab, G & $38,1023,4079,5047$ & Riegel, AC & 404 \\
\hline Partridge, A & 6055 & Pippen, JE & 40 & Raban, N & 1081 & Rieger, L & 6098 \\
\hline Partridge, $\mathrm{AH}$ & $4,6068,6072$ & Pires, LA & 1091 & Rack, B & 1016 & Ries, LM & 5054 \\
\hline Pasqualini, JR & 4112,4113 & Pitas, AMCS & 2101 & Rademaker, A & 4015 & Riggs, RL & 6076 \\
\hline Patel, R & 5035 & Pithavala, YK & 1067 & Rader, M & 5034 & Riker, A & $21,4069,5061$ \\
\hline Patenaude, V & 4037 & Pivot, $\mathrm{X}$ & 1084 & Rader, ME & 5031 & Rimawi, MF & 9 \\
\hline Paterson, AHG & 43 & Plattner, B & 2081,2083 & Raefsky, E & 2076 & Rimm, DL & 3018 \\
\hline Paterson, C & 4086 & Plaut, K & 208 & Ragaz, J & 2029 & Rimouche, $\mathrm{S}$ & 1050 \\
\hline Patnaik, A & 1117,2034 & Plazaola, A & 6088 & Rahal, RMS & 5008 & Ring, BZ & 3003 \\
\hline Patole, K & 3047 & Plevritis, SK & 4006 & Rajasekaran, AK & 33 & Risberg, $\mathrm{T}$ & 4108 \\
\hline Patrao, DFC & 4071 & Plewes, DB & 5001 & Rajasekaran, SA & 33 & Risebrough, NA & 2050 \\
\hline Patrick, RJ & 3036 & Poetter, R & 8 & Ramaswamy, B & 4053 & Ritstier, K & 303 \\
\hline Pau, D & 2036 & Pohlmann, PR & 4031 & Ramazeilles, C & 1084 & Riva, A & 1069,1 \\
\hline Paul, D & 2049,6092 & Politaki, E & 3030 & Ramesh, R & 4058 & Rivera, E & 3056,4004 \\
\hline Paul, E & 1073 & Polite, BN & 3097 & Ramirez, J & 2111 & Rivera, $\mathrm{R}$ & 1063 \\
\hline Pawlicki, M & $1069,1,4079$ & Polli, A & 4108 & Ramirez, M & 5039 & Rivera, S & 3073 \\
\hline Paye, M & 3022 & Pols, HAP & 30 & Ramon y Cajal, T & 103 & Rizza, P & 6107 \\
\hline Peacock, NW & 1073,2076 & Pongracz, K & 1076 & Ramos, D & 21 & Rizzo, P & 2103 \\
\hline Peaud, PY & 6087 & Poniewierski, M & 2075 & Ramos, EHM & 5009 & Ro, J & 5052 \\
\hline Pectasides, D & 2070 & Poniewierski, MS & 3006 & Ramos, FJF & 5008 & Ro, JY & 3010 \\
\hline Pegram, M & 1,1045 & Ponniah, S & 1057 & Ramos, M & $5059,6030,6063$ & Robbins, A & 4051 \\
\hline Pegram, MD & 1073,3029 & Ponti, D & 203 & Ramsay, E & 5001 & Robert, N & $1,1045,2073$ \\
\hline Pellegrino, C & 5061 & Poola, I & 3104 & Ramundo, D & 4049 & Roberts, L & 1021 \\
\hline Pelosi, G & 4012 & Pope, K & 4051 & Rao, CS & 1019 & Roberts, R & 4036 \\
\hline Penault-Llorca, F & 3073 & Popescu, C & 4037 & Rao, R & 2082 & Robertson, C & 4012 \\
\hline Peng, Y & 1114 & Porcu, L & 2068 & Rapiti, E & 4011 & Robertson, JFR & 1015,1065 \\
\hline Pento, JT & 1077,4072 & Poremba, C & 3026,3042 & Rasheed, K & 4022 & Robertson, JFK & 5097 \\
\hline Peoples, GE & 1057 & Pories, SE & 2001 & Rashid, MU & 104,4002 & Robertson, K & 3111 \\
\hline Pereira, G & 5060 & Portengen, $\mathrm{H}$ & 303 & Rastogi, P & 6074 & Robertson, TA & 4029 \\
\hline Perez, A & 1079 & Porter, LS & 5076 & Ratnayake, M & 210 & Robidoux, A & 20 \\
\hline Perez, E & 41,1087 & Porter, PL & 1035,1109 & Ravichandran, D & 5024 & Robin, HS & 3050 \\
\hline Perez, EA & $3,312,2019,2038$ & Possinger, K & $1052,1085,2045$ & Ravnsbæk, J & 6075 & Robinson, AG & 5017 \\
\hline Pérez-Manga, G & 5070 & & $2060,6081,6095$ & Rayson, D & $5036,5041,5089$ & Robinson, M & 47 \\
\hline Perez-Michel, L & 5039 & Postruznik, D & 4112 & Raza, S & 2001 & Robinson, $\mathrm{P}$ & 1087 \\
\hline Perkins, GH & 4032 & Potamianou, A & 6089 & Rea, DW & 3057 & Robles, E & 3098 \\
\hline Perks, CM & 4088 & Potter, BV & 5078 & Rea, S & 2053 & Robson, M & $2041,2069,6071$ \\
\hline Perla, RP & 4109 & Pouillart, P & 3073 & Rebbeck, T & 1060 & Robson, ME & 103 \\
\hline Perol, D & 2084 & Poulsen, TS & 1048 & Recchia, F & 2053 & Rocchi, A & 5042 \\
\hline Perou, C & 1047,2102 & Powell, J & 6066 & Reddy, SG & 1120 & Roché, H & $1068,2071,5098$ \\
\hline Perraki, M & 3030,3051 & Powell, S & 22 & Reed, MJ & 5078 & Roche, $\mathrm{P}$ & 6022,6028 \\
\hline Perrin, D & 42 & Powell, W & 6022,6028 & Reedijk, M & 4060 & Rodeheffer, RJ & 2038 \\
\hline Perry, PM & 2021 & Powles, $\mathrm{T}$ & 5045 & Rees, W & 4033,5107 & Rodenhuis, S & 309,5002 \\
\hline
\end{tabular}




\section{S298 San Antonio Breast Cancer Symposium - Author Index for Abstracts}

\begin{tabular}{|c|c|c|c|c|c|c|c|}
\hline Rodgers, RG & 6077 & Saeki, T & 3099,5091 & Schittulli, F & 28 & Servent, V & 5074 \\
\hline Rodgers, $\mathrm{T}$ & 3093 & Saettler, ER & 6011 & Schlich-Bakker, K & 4003 & Seshagiri, S & 3029 \\
\hline Rodríguez, CA & 39 & Safi, R & 5085 & Schlichting, E & 4108 & Sestak, I & 19 \\
\hline Rodríguez-Lescure & 39,6030 & Sagan, C & 1011 & Schlief, AT & 5002 & Settlege, JA & 6007 \\
\hline Rodrigues, CM & 6101 & Saggio, G & 2053 & Schlotter, CM & 5057 & Sexton, K & 3020,6070 \\
\hline Rodrigues, DG & 1091 & Saghatchian-d'Assi & ignies, M 301, & Schmalfeldt, B & 2081 & Seynaeve, C & 107,3057 \\
\hline Rodriguez, FG & 3038 & & 1028 & Schmid, M & 8 & Sezgin, $\mathrm{C}$ & 3044 \\
\hline Rodriguez, J & 4010 & Saha, A & 4093 & Schmid, P 1085, & $2045,6081,6095$ & Sgroi, DC & 311,312 \\
\hline Rody, A & $3026,3042,5046$ & Sahasrabudhe, $\mathrm{N}$ & 2014 & Schmidt, M & 3048 & Shackleton, M & 201 \\
\hline Rogowski, WA & 3091 & Sahin, A & 1037,5049 & Schmidt, R & 2081 & Shah, B & 3074 \\
\hline Rom, J & 1017 & Sahin, AA & 4073 & Schmidt, W & 1006,5011 & Shah, D & 2086 \\
\hline Roma, AA & 6100 & Sainsbury, R & 4044 & Schmitt, F & 1106,1107 & Shah, N & 1034,1078 \\
\hline Roman, G & 3091 & Saito, $\mathrm{T}$ & 4050 & Schmitt, $M$ & $28,6019,6027$ & Shah, NS & 5023 \\
\hline Romer, MU & 1033 & Sakemura, N & 1115 & Schnabel, FR & 1042 & Shak, S & 29,310 \\
\hline Romero, C & 3092 & Saleh, M & 1069 & Schneeweiss, A & $307,1017,4096$ & Shakoori, AR & 104 \\
\hline Romieu, G & 5087 & Salem, C & 2016 & Schneider, B & 3084 & Shao, ZM & 2066 \\
\hline Ronczka, A & 305 & Sali, A & 102 & Schneider, BP & 1103 & Shapiro, CL & 4053 \\
\hline Rondon, G & 6031 & Salim, M & 3035 & Schneider, H & 3094 & Shapiro, G & 1063 \\
\hline Rooney, CM & 210 & Salles, B & 6087 & Schnitt, SJ & $27,2023,6006$ & Shapiro, $\mathrm{R}$ & 3078 \\
\hline Rosell, R & 2111 & Salmon, $\mathrm{P}$ & 6080 & Scholz, C & 1016 & Sharma, AK & 2086 \\
\hline Rosen, B & 5001 & Salmon, R & 5071 & Schott, A & 1024 & Shasteen, WJ & 3003 \\
\hline Rosen, N & 206,1095 & Salmon, RJ & 6047 & Schott, AF & $1046,2061,4043$ & Shaw, CC & 5016 \\
\hline Rosenbaum, E & 3078,3085 & Salter, J & $310,4021,4106$ & Schroen, AT & 5021 & Shaw, HS & 1027 \\
\hline Rosenberg, A & 1004 & Salvo, VA & 4105 & Schrohl, AS & 1033 & Shaw, JA & 4066,6106 \\
\hline Rosenberg, L & 3084 & Samadzadeh, LK & 6021 & Schubbert, T & 1056,5056 & Shaw, LE & 2008 \\
\hline Rosenstein, BS & 4039 & Sammon, A & 1012 & Schubert, EK & 5088,6038 & Shayne, M & 2075,3006 \\
\hline Ross, DT & 3003 & Samonigg, $\mathrm{H}$ & $13,1105,1112$ & Schubert, H & 3023,4011 & Sheehan, CE & 3019 \\
\hline \multirow[t]{2}{*}{ Ross, JS } & $306,308,1053$ & Sampson, E & 6068 & Schuett, G & 2063,3026 & Sheehan, JC & 6073 \\
\hline & 3019,6002 & Samuelkutty, S & 2063 & Schuette, M & 5047 & Sheiner, J & 6069 \\
\hline Ross, MI & $402,2082,5013$ & Sanchez, M & 3038 & Schuetz, F & 307,4096 & Shen, $\mathrm{P}$ & 5113 \\
\hline Ross, MS & 3019 & Sanchez-Ronco, M & 2111 & Schulz, CO & 6095 & Shen, ZZ & 2066 \\
\hline Rossi, G & 5032,5035 & Sandbach, J & 40 & Schulz-Wendtland, & 2017 & Shenkier, TN & 3 \\
\hline Rosty, C & 5071 & Sandbank, J & 2077 & Schumer, S & 2001 & Shepherd, LE & 16 \\
\hline Rouanet, P & 1040 & Sano, M & 3099,5093 & Schuster, GT & 1018 & Sherman, KA & 6073 \\
\hline Rouesse, J & 5063 & Santarpia, M & 2111 & Schwartsmann, G & 1084 & Shewach, DS & 4043 \\
\hline Rouzier, R & 2024,6002 & Santen, RJ & 6007 & Schwartz, K & 3061,3096 & Shields-Botella, J & 4112 \\
\hline Rovira, A & 3103 & Santoro, A & 5048 & Schwartz, KL & 3074 & Shien, $\mathrm{T}$ & 1118 \\
\hline Rowe, K & 4033,5107 & Santos, NRM & 3082 & Schwartzberg, LS & 4005,5062 & Shiftan, T & 1 \\
\hline Rowinsky, EK & 1117,2034 & Santos, RPC & 4071 & Schwarz-Boeger, L & 2081 & Shigekawa, $\mathrm{T}$ & 5114 \\
\hline Roy, R & 2001 & Sappino, AP & 4011 & Schwede, W & 1072 & Shih, BY & 4105 \\
\hline Royce, M & 3021 & Sarapa, N & 1094 & Schwope, I & 1053 & Shim, V & 36 \\
\hline Royce, ME & 6023,6025 & Sarp, $\mathrm{S}$ & 3023,4011 & Scott, C & 4040 & Shimada, K & 3110 \\
\hline Roydasgupta, R & 4056 & Sarrio, D & 1106,1107 & Scott, CG & 6005 & Shimizu, C & 1008, 1041, \\
\hline Rozenchan, PB & 4071 & Sartorius, CA & 32 & Scott, DJ & 3104 & & $1055,1115,3105$ \\
\hline $\mathrm{Ru}, \mathrm{Q}$ & $2011,2026,5025$ & Sasano, H & 4111 & Scott, JV & 4022 & Shimoyama, $\mathrm{T}$ & $1041,1055,3105$ \\
\hline Rubagotti, A & 18 & Sastre-Garau, X & 5071 & Scott, L & 4064 & Shimozuma, K & 2044 \\
\hline Ruberg, J & 4009 & Satcher, RL & 4075 & Scott, V & 1028 & Shin, HJ & $202,3027,3028$, \\
\hline Rubin, BP & 3033 & Sato, A & 2106 & Scotte, F & 5073 & & 3055,5012 \\
\hline Rubin, $\mathrm{P}$ & 5055 & Sato, K & 4050,5114 & Sebti, S & 5061 & Shipley, DL & 2076 \\
\hline Rudnicka, H & 4047 & Sato, N & 5093 & Seccia, L & 4010 & Shirahane, K & 3110 \\
\hline Ruessmann, B & 4028 & Saunders, C & 4044 & Sedlacek, S & 2049 & Shiry, L & 5081 \\
\hline Rufenbarger, C & 3084 & Saunders, CM & 3062,3071 & Sedlmayer, F & 8 & Shou, J & 4100 \\
\hline Rugo, $\mathrm{H}$ & $1079,2030,3069$ & Sause, W & 4033,5107 & Seelig, S & 1045 & Shriver, CD & $1057,1061,2009$, \\
\hline \multirow[t]{2}{*}{ Rugo, HS } & $1049,1066,1067$ & Sauter, G & 1045,1069 & Seenu, V & 5030 & & $2025,2026,3065$, \\
\hline & 3054,3079 & Savage, K & 1107 & Seewaldt, VL & 4022 & 3087 & , 4062, 5025, 3075 \\
\hline Ruhmland, B & 2033 & Savignoni, A & 3073,6047 & Segaert, I & 5014 & Shriver, D & 2011 \\
\hline Ruiz, A & 39,6088 & Savin, MA & 40 & Segal, MR & 3047 & Shroyer, KR & 3042,6097 \\
\hline Ruiz-Borrego, M & 39,6030 & Saxena, A & 5030 & Seguí, MA & 5066 & Shulemovich, E & 212 \\
\hline Rupp, C & 6108 & Saxena, R & 3047 & Segura, C & 2016 & Shum, M & 106,3098 \\
\hline RushTaylor, A & 3084 & Saxena, S & 3053 & Sehdev, S & 1069 & Siambekos, MT & 3058 \\
\hline Russell, C & 2035 & Scarrott, S & 3080 & Seidman, A & $2041,2069,6071$ & Sibson, DR & 5111 \\
\hline Russell, DH & 3112 & Scarth, H & 20 & Seidman, AD & 3097 & Siegel, DA & 2018 \\
\hline Rustum, Y & 1090 & Schaefer, KL & 3026,3042 & Seitz, RS & 3003 & Sieling, BA & 1019 \\
\hline Rutgers, E & 301 & Schafer, JM & 3058 & Sekosan, M & 3091 & Sieuwerts, A & 303,3004 \\
\hline Rutgers, EJ & 403 & Schaller, G & 2033, 3041 & Self, J & 5022 & Sieuwerts, AM & 28 \\
\hline Rutgers, EJTh & 309 & Schallier, D & 5099 & Selle, F & 2016 & Sigal-Zafrani, B & 5071 \\
\hline Ruxer, RL & 40 & Scheib, RG & 2001 & Sellon, M & 5041 & Sikov, WM & 5054 \\
\hline Ryan, CM & 6074 & Scher, $\mathrm{H}$ & 206 & Selvaggi, S & 2103 & Silberman, J & 2011,2026 \\
\hline Ryan, PD & 4 & Scherle, $\mathrm{P}$ & 1082,6051 & Semiglazov, V & $1069,1070,5087$ & Silberman, SL & 1063 \\
\hline Rybicki, LA & 3036 & Schickling, $\mathrm{O}$ & 38 & Semmens, JB & 3062,3071 & Silberstein, $\mathrm{P}$ & 5032 \\
\hline Ryder, K & 3016,3025 & Schiff, R & 9,4100 & Seo, $\mathrm{PH}$ & 4022 & Silva, AG & 2101 \\
\hline \multirow[t]{2}{*}{ Ryu, Y } & 5015 & Schildhauer, S & 2060 & Sepkovic, DW & 2108 & Silva, IDCG & 2095,5009 \\
\hline & & Schilling, E & 2007 & Sereika, SM & 6074 & Silva, JM & 3107,3112 \\
\hline Saad, F & 6036 & Schilling, EM & 2092 & Sergio, CM & 3109 & Silva, L & 6050 \\
\hline Saal, LH & 35 & Schilsky, R & 41 & Serin, D & 2071,5050 & Silva, LLM & 6010 \\
\hline Sabath, DE & 1018 & Schindlbeck, C & 1016 & Seronie-Vivien, S & 5098 & Silverman, $\mathrm{P}$ & $1073,1087,5067$ \\
\hline Sabbatini, R & 4049 & Schipper, MJ & 4043 & Serrano, D & 4012 & Simmonds, PD & 101 \\
\hline Sabnis, GJ & 5083 & Schippinger, W & 1085 & Serrero, G & $10,2005,4087$ & Simmons, C & 3076 \\
\hline Sadeghi, S & 3050 & Schirrmacher, V & 4096 & Servanton, AC & 3022 & Simmons, $\mathrm{R}$ & 1054 \\
\hline
\end{tabular}


San Antonio Breast Cancer Symposium - Author Index for Abstracts






\section{S300 San Antonio Breast Cancer Symposium - Author Index for Abstracts}

\begin{tabular}{|c|c|c|c|c|c|c|c|}
\hline Tornos, C & 212 & Van 't Veer, L & 301 & Vijayaganesh, T & 407 & Watson, D & 29 \\
\hline Torosian, $\mathrm{K}$ & 2062 & Van 't Veer, LJ & 309 & Villalobos, I & 1045 & Watson, M & 1022 \\
\hline Torrecillas, L & 5039 & Van Dam, FSAM & 309 & Vinagre, CG & 6013 & Weatherall, $\mathrm{P}$ & 6029 \\
\hline Torres, D & 104 & Van Dam, $\mathrm{P}$ & $204,1098,2091$ & Vinayagam, $\mathrm{R}$ & 5111 & Weaver, D & 20,208 \\
\hline Toscani, NV & 6010 & van de Rijn, JM & 6096 & Vincent, C & 6083 & Weber, B & $14,205,1106$, \\
\hline Toubeau, M & 1059 & van de Rijn, M & 3033 & Vincent, $\mathrm{M}$ & 2064 & & $1107,4031,5050$ \\
\hline Tousimis, E & 1054 & van de Velde, CJ & 3057 & Vincent, S & 47 & Weber, BL & 1060 \\
\hline Touzery, C & 1059 & Van de Velde, $\mathrm{H}$ & 1085 & Vincent-Salomon, & 2036,5071 & Weber, J & 2033 \\
\hline Tovey, SM & 5109,6102 & van de Vijver, M & 3033 & Vinh-Hung, V & $3008,3021,6025$ & Wechter, DG & 6058 \\
\hline Traina, TA & 2030 & Van De Vijver, MJ & 309 & Vinson, GP & 4070,4104 & Wedam, SB & 2028 \\
\hline Tran, RT & 4032 & Van den Eynden, $\mathrm{G}$ & 204, 1098, & Vishalpura, T & 5044 & Weeks, J & 6072 \\
\hline Treaba, DO & 1035,1036 & & 2091,2109 & Visscher, DW & 312 & Weeks, JC & 12,2061 \\
\hline Treilleux, I & 1051 & Van den Ouweland, & d, AMW & Visvader, JE & 201 & Weichel, A & 3113 \\
\hline Tres, A & 5058 & Van der Auwera, I & 204, 1098, & Vlastos, G & $3008,3023,4011$ & Weilbaecher, K & 1022 \\
\hline Trillet Lenoir, V & 5050 & & 2091,2109 & Vleugel, MM & 1096 & Weinberg, RA & 26 \\
\hline \multirow[t]{2}{*}{ Tripathy, D } & 1079, 2055, & van der Groep, P & 1102 & Vogel, C & 1079 & Weinstein, MC & 5037 \\
\hline & $2098,3069,6029$ & van der Wall, E & 1096,1102 & Vogel, V & 1118,6074 & Weiss, $\mathrm{H}$ & 1113,6070 \\
\hline Troch, MM & 4022 & van Diest, PJ & 1096,1102 & Vogel-Ziebolz, S & 1053 & Weitzer, W & 1105 \\
\hline Tromberg, BJ & 1034,5023 & van Echtelt, J & 4003 & Vogl, FD & 5 & Welch, RA & 1027 \\
\hline Troob, SH & 404 & Van Harten, WH & 309 & Vogt, U & 5057 & Welchel, AK & 2059 \\
\hline Troso-Sandoval, T & 2041,2069 & Van Laere, SJ & 204, 1098, 2091 & Von Hofe, E & 4094 & Weldon, CB & 4105 \\
\hline Trudeau, M & 2050 & van Leeuwen, FE & 4035 & Von Kemp, K & 2062 & Welsh, R & 6083 \\
\hline Truong, PT & 3007,3008 & Van Limbergen, E & 3031,6024 & Von Minckwitz, G & $1069,38,1023$ & Weng, DE & 5067 \\
\hline Truscinski, D & 5031 & Van Marck, EA & 204, 1098, & & 4079,5046 & Wenkel, E & 2017 \\
\hline Tsavdaridis, D & 2070 & & 2091,2109 & & 5047,6090 & Wenz, F & 4044 \\
\hline Tschaika, M & 2045 & van Nes, JG & 3057 & von Schoultz, B & 6043 & Wernecke, K & 2060 \\
\hline Tsimelzon, A & $24,304,1113$ & van Rijk, MC & 403 & von Schoultz, E & 6045 & ecke, KD & 1052 \\
\hline Tso, E & 6100 & van Staveren, I & 303 & von Toerne, C & 3048 & $\mathrm{Y}$ & 3023 \\
\hline Tsuda, $\mathrm{H}$ & 5114 & Van Tinteren, $\mathrm{H}$ & 309 & Vrcel, V & 21 & Wes & 3033,6096 \\
\hline Tsuji, K & 207 & Vandenberghe, $\mathrm{M}$ & 204 & Vrdoljak, E & 5076 & Westphal, LM & 3079 \\
\hline Tsujimoto, M & 1001 & Vandenbossche, $\mathrm{K}$ & 5099 & Vtoraya, $\mathrm{O}$ & 1070 & Wewer, U & 2001 \\
\hline $\mathrm{Tu}, \mathrm{D}$ & $16,17,2042$ & Vanel, D & 2024 & Vukelja, S & 6091 & Wheler, J & 5096 \\
\hline $\mathrm{Tu}, \mathrm{SJ}$ & 5016 & Janhoecke, BW & 6048 & Vukelja, SJ & $40,2039,6092$ & Whitacre, E & 4038 \\
\hline \multirow[t]{2}{*}{ Tubbs, $\mathrm{R}$} & 3036,6022 , & Vanipalli, J & 4051 & Vuskovic, M & 2008 & White, E & 5020 \\
\hline & 6026,6028 & VanPoznak, C & $2041,2069,6071$ & & & White, J & 208 \\
\hline Tubiana-Hulin, M & 1040 & Vansteenkiste, J & 5033 & Wabinga, $\mathrm{H}$ & 2113 & White, L & 21,401 \\
\hline Tubiana-Hulin, MJ & 5063 & Vantyghem, SA & 4064 & Wackers, $\mathrm{F}$ & 2074 & White, RH & 23 \\
\hline Tuck, AB & 4064 & Vargas, Y & 3095 & Wade, JL & 1116 & White, S & $, 5084,6020,6041$ \\
\hline Tulusan, AH & 2083 & Varhaug, JE & 5086 & Waer, A & 4018 & Whitehead, CM & 3019 \\
\hline Turnbull, LW & 5068 & an, $\mathrm{S}$ & 3047,6097 & Wagner, $\mathrm{P}$ & 6002 & Whitman, GJ & 5016 \\
\hline Turner, JE & 1092 & Varthalitis, I & 6089 & Wai, ES & 4037 & Whitworth, P & 4038 \\
\hline Turner, LE & 6049 & Vassal, G & 1028 & Waintraub, S & 1087 & Wichmann, HE & 4002 \\
\hline Tursz, T & 1028 & Vassanasiri, W & 5064 & Wakeling, A & 5104 & Wickerham, DL & 29,46 \\
\hline Tusquets, I & 3103 & Vasseur, B & 2036,5050 & Walker, JR & 31 & Wickerman, L & 1118 \\
\hline \multirow[t]{2}{*}{ Tutt, A } & 3016,3025 & Vassiljev, L & 2045 & Walker, LG & 2067,5064 & Widschwendter, M & 5104 \\
\hline & & Vassilopoulou-Sell & 6043 & Walker, MB & 5064 & Wiedswang, G & 1016 \\
\hline Uchida, Y & 1020 & Vatas, U & 4034 & Walker, R & 6004,6011 & Wigfield, S & 1031 \\
\hline Udeozo, U & 4070 & Vaziri, IA & 5069 & Walker, RA & $3049,4066,6101$ & Wight, E & 28 \\
\hline Ueda, S & 5114 & vd Vijver, MJ & 5002 & Walko, CM & 1092 & Wijayanayagam, A & 406 \\
\hline Uematsu, M & 4050 & tega, V & 3038 & Wall, B & 3093 & Wildiers, $\mathrm{H}$ & $3031,5014,6024$ \\
\hline Ueno, $\mathrm{H}$ & 4098 & larde, $\mathrm{R}$ & 3100 & Wallace, AM & $6023,6025,3021$ & Willems, A & 6027 \\
\hline Ueno, NT & $3021,6025,6031$ & ellon, L & 1093,4052 & Wallwiener, D & 2045,6108 & ams, D & 1089 \\
\hline Uitterlinden, AG & 30 & Vendrell, J & 3111 & Walshe, JM & 4034 & Williams, GH & 4021 \\
\hline Ulcickas-Yood, M & 3069 & Venkatesen, $\mathrm{N}$ & 4079 & Wang, $\mathrm{H}$ & 6106 & Williams, M & 2067 \\
\hline \multirow[t]{2}{*}{ Untch, M } & 1064, 2045, 2065, & Verfaillie, $\mathrm{G}$ & 5099 & Wang, HJ & 3029 & Wilscher, E & 5108 \\
\hline & 3029,5051 & Vergote, I & $3031,5014,6024$ & Wang, L & 1002,6100 & Wilson, CA & 4079 \\
\hline Uray, I & 4024 & Verhoef-Post, M & 30 & Wang, M & 3 & Wilson, GR & 1050,2104 \\
\hline Urruticoechea, A & 1029 & Verity, L & 5001 & Wang, Q & 6051 & Wilson, IB & 410 \\
\hline Utkan, G & 6009 & erjat, $\mathrm{T}$ & 3022 & Wang, S & 6007 & Wilson, R & 5078 \\
\hline Utriainen, $\mathrm{T}$ & 2 & Verkooijen, HM & 3023,4011 & Wang, SJ & 3090 & Winer, E & $22,41,5037,6055$ \\
\hline Uyei, A & 110 & Verma, S & $2064,5038,5042$ & Wang, SM & 2066 & Winer, EP & 4, 3097, \\
\hline \multirow[t]{2}{*}{ Uzan, S } & 2016 & Vermeij, J & 5099 & Wang, T & 5016 & & 6068,6072 \\
\hline & & Vermeulen, PB & 204, 1098, & Wang, X & 3088,3089 & Winer, JP & 6068 \\
\hline Væth, M & 6075 & & 2091, 2109 & Wang, XP & 4074 & Winters, ZE & 4088 \\
\hline Vachon, CM & 6005 & M & 1089 & Wang, Y & $, 3004,3091,4017$ & Wintonic, A & 6004,6011 \\
\hline Vaddi, $\mathrm{K}$ & 1082,6051 & Verschraegen, C & 3095 & Wang, YS & 1002 & Wirapati, P & 37,302 \\
\hline Vahdat, L & $1063,1054,5061$ & Veyret, C & $14,1081,3040$ & Wang, Z-Y & 5113 & Wirk, B & 2019 \\
\hline Vaidya, JS & 4044 & Viale, G & $301,302,44$ & Ward, A & 409,5022 & Wischnewsky, MB & 6095 \\
\hline Vaillant, F & 201 & ichova, $\mathrm{P}$ & 3108 & Ward, BA & 5090 & Wiseman, $\mathrm{J}$ & 5064 \\
\hline Valdes, EK & 2027 & Vicini, FA & 4038 & Wardley, A & $6094,1089,5087$ & Witton, CJ & 5109 \\
\hline Valdivia, S & 3100 & Vie, B & 4046 & Warlam-Rodenhuis & 4003 & Wojcinski, S & 1006,5011 \\
\hline Valera, V & 4067 & Vieira, JO & 2095 & Warm, M & 5072 & Wolff, AC & 1066 \\
\hline Valerio, D & 5064 & Vielh, P & 2024 & Warnat, P & 307 & Wolff, D & $2075,3006,5034$ \\
\hline \multirow[t]{3}{*}{ Valero, $\mathrm{V}$} & 1, 306, 308, 1037, & Viens, $\mathrm{P}$ & $1051,1084,2110$ & Warner, E & 5001 & Wolmark, N & $20,29,46$ \\
\hline & 2088, 3002, 3011, & Vigil, CE & 3100 & Warner, J & 6004,6011 & Wolters, R & 6095 \\
\hline & $4013,5049,6002$ & Vigil, KJ & 3100 & Wascher, RA & 3078,3085 & Wolverton, D & 406 \\
\hline Valgeirsson, $\mathrm{H}$ & 205 & Vigil Sr, CE & 3100 & Watkins, G & 1097, 2112, & Womack, SD & 3093 \\
\hline Valimohd, AT & 5069 & Vigneau, F & 3096 & & 3037,4078 & Wong, GYC & 2108 \\
\hline Vallejo, CE & 404 & Vigushin, D & 5078 & Watroba, $\mathrm{N}$ & 2072,3053 & Wong, JW & 5001 \\
\hline
\end{tabular}


San Antonio Breast Cancer Symposium - Author Index for Abstracts

$\begin{array}{lrl}\text { Woo, LW } & 5078 & \text { Yalcin, B } \\ \text { Wood, C } & 4105 & \text { Yamaguchi, H } \\ \text { Wood, CE } & 6046 & \text { Yamaguchi, Y } \\ \text { Wood, ME } & 6059 & \text { Yamashita, K } \\ \text { Woodward, W } & 3008 & \text { Yamauchi, K } \\ \text { Woodward, WA } & 6025 & \text { Yang, B } \\ \text { Wright, D } & 5024 & \text { Yang, CY } \\ \text { Wright, F } & 5007 & \text { Yang, G } \\ \text { Wright, FC } & 5001 & \text { Yang, M } \\ \text { Wright, J } & 5061 & \text { Yang, SX } \\ \text { Wu, L } & 3050 & \text { Yang, WT } \\ \text { Wu, M } & 47 & \text { Yang, Y } \\ \text { Wu, R } & 4089 & \text { Yang, Z } \\ \text { Wu, Y } & 6002 & \text { Yao, ES } \\ \text { Wun, T } & 23 & \text { Yao, W } \\ \text { Wurtz, SO } & 1033 & \text { Yarden, O } \\ & & \text { Yardley, D } \\ \text { Xenidis, N } & & \text { Yardley, DA } \\ \text { Xerri, L } & 3051 & \text { Yasuda, M } \\ \text { Xiao, H } & 2110 & \text { Yaziji, H } \\ \text { Xiaoxin, J } & 6111 & \text { Yaand } \\ \text { Xiong, W } & 1010 & \text { Yeatman, T } \\ \text { Xu, H } & 1104 & \text { Yeatman, TJ } \\ \text { Xu, J } & 2008 & \text { Yee, BH } \\ \text { Xu, L } & 4055 & \text { Yee, D } \\ \text { Xue, Y } & 2102, & \text { Yee, LD } \\ \text { Yaffe, MJ } & 6109 & \text { Yeh, BM } \\ & \text { Yeh, I-T } \\ & 5001 & \text { Yen, T }\end{array}$

\begin{tabular}{|c|c|c|}
\hline 6009 & Yeoh, S & 1089 \\
\hline 1020 & Yezhelyev, M & 1030 \\
\hline 4098 & $\mathrm{Yi}, \mathrm{M}$ & 402 \\
\hline 207 & Yiangou, $\mathrm{C}$ & 2021 \\
\hline 207 & Yip, PF & 2009 \\
\hline 6100 & Ylagan, L & 1022 \\
\hline 6053 & Yoder, BJ & 3003,6100 \\
\hline 6051 & Yogendran, G & 5007 \\
\hline 207 & Yongqiao, Z & 1010 \\
\hline 2028 & Yoon, S & 5015 \\
\hline 5016 & Yoshida, S & 2106,4076 \\
\hline 1061 & Yoshida, $\mathrm{T}$ & 3013 \\
\hline 5079 & You, M & 4017 \\
\hline 3032 & Young, HA & 2018 \\
\hline 1082,6051 & Young, O & 1029 , \\
\hline 2077 & & 5084,6041 \\
\hline 3069 & Younger, J & 22 \\
\hline 2076 & Younis, $\mathrm{T}$ & 5036, 5038, \\
\hline 4076 & & 5041,5089 \\
\hline 2023 & $\mathrm{Yu}, \mathrm{H}$ & $1056,5023,5075$ \\
\hline 4069 & $\mathrm{Yu}, \mathrm{J}$ & 3004 \\
\hline 4064 & $\mathrm{Yu}, \mathrm{JM}$ & 1002 \\
\hline 2001 & Yubero, A & 5058 \\
\hline 304 & & \\
\hline 4022 & Zachariae, $\mathrm{R}$ & 6075 \\
\hline 2030 & Zager, JS & 5013 \\
\hline 1035 & Zaichuk, T & 2092, 2093 \\
\hline \multirow[t]{43}{*}{5013} & Zaidi, A & 104 \\
\hline & Zalany, L & 3076 \\
\hline & Zalles, CM & 4022 \\
\hline & Zang, XP & 1077,4072 \\
\hline & Zannis, V & 4038 \\
\hline & Zapparoli, GV & 1108 \\
\hline & Zaren, HA & 3091 \\
\hline & Zarghooni, V & 5072 \\
\hline & Zebrowski, J & 6032 \\
\hline & Zeldis, J & 5026 \\
\hline & Zhan, F & 6092 \\
\hline & Zhang, B & 2002,2066 \\
\hline & Zhang, H & 4060 \\
\hline & Zhang, L & 34 \\
\hline & Zhang, W & 6002 \\
\hline & Zhang, X & 1087,1121 \\
\hline & Zhang, X-T & 5113 \\
\hline & Zhang, Y & $\begin{array}{r}3004,3065,3075, \\
4102,5025\end{array}$ \\
\hline & Zhao, H & $2002,2103,4102$ \\
\hline & Zhao, J & 2089 \\
\hline & Zhao, T & 1002 \\
\hline & Zheng, M & $2087,4058,6105$ \\
\hline & Zhou, BB & 1082 \\
\hline & Zhou, H & 23 \\
\hline & Zhou, JY & 1045 \\
\hline & Zhou, Z & 3063 \\
\hline & Zhu, J & 2031 \\
\hline & Zhu, L & $2011,2026,5025$ \\
\hline & Zhu, SX & 3033 \\
\hline & Zhu, Y & 4105 \\
\hline & Zhuo, J & 6051 \\
\hline & Zibdeh, S & 6073 \\
\hline & Ziegler, J & $109,4001,4007$ \\
\hline & Zieglschmid, V & 1017 \\
\hline & Zignani, JM & 4031 \\
\hline & Zimmermann, MC & 4105 \\
\hline & Zito, AF & 28 \\
\hline & Zubairy, S & 5108 \\
\hline & Zuckerman, E & 6071 \\
\hline & Zuna, I & 38 \\
\hline & Zurakowski, D & 2001 \\
\hline & Zurrida, S & 6016 \\
\hline & Zwiefel, K & 2063 \\
\hline
\end{tabular}

